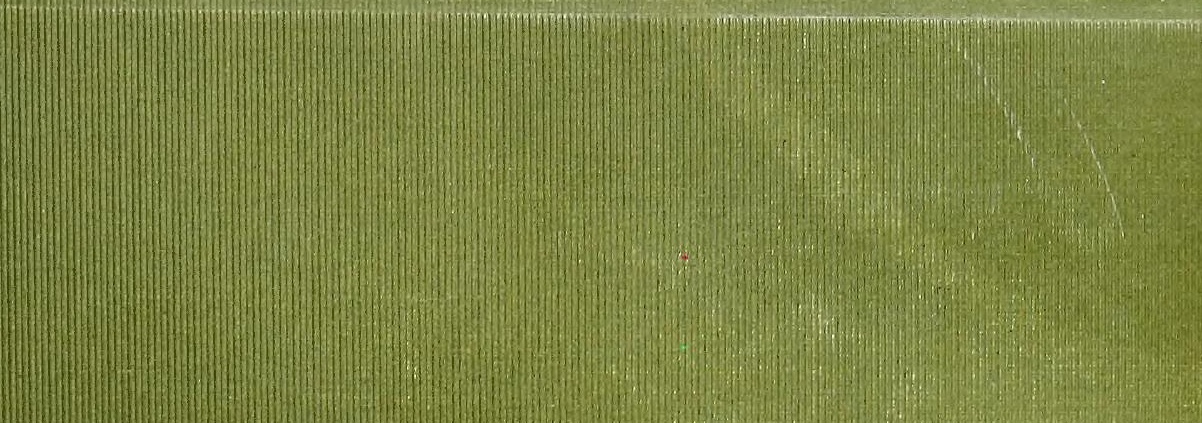

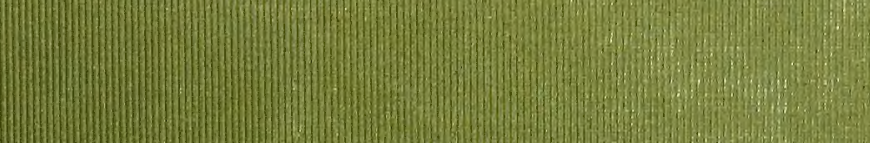

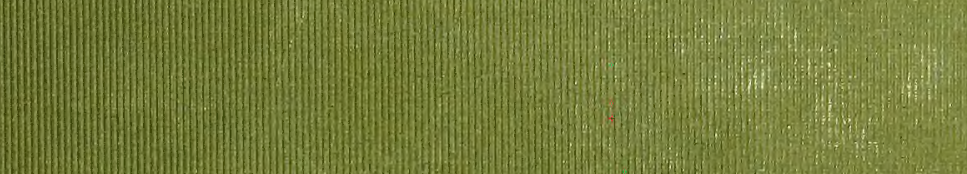

(2)

(n)

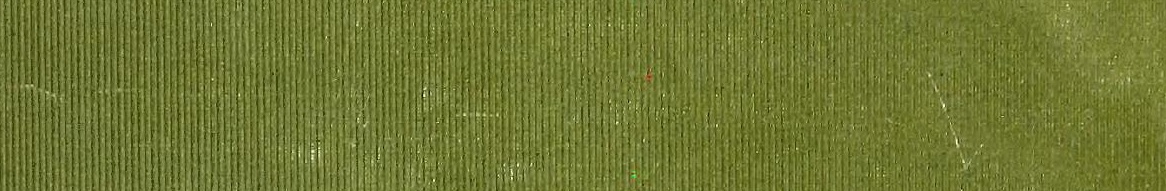

W.

m.

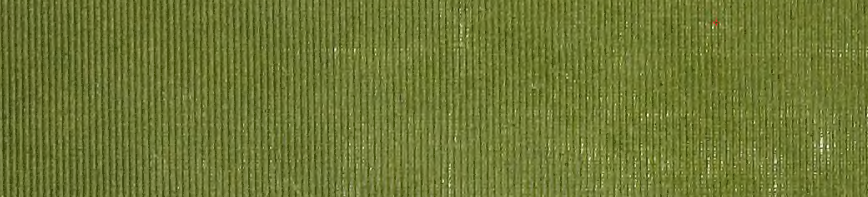

(n)

W.

Hen

SW

W.

(n)

m

(I)

(2. (I)

Wham 


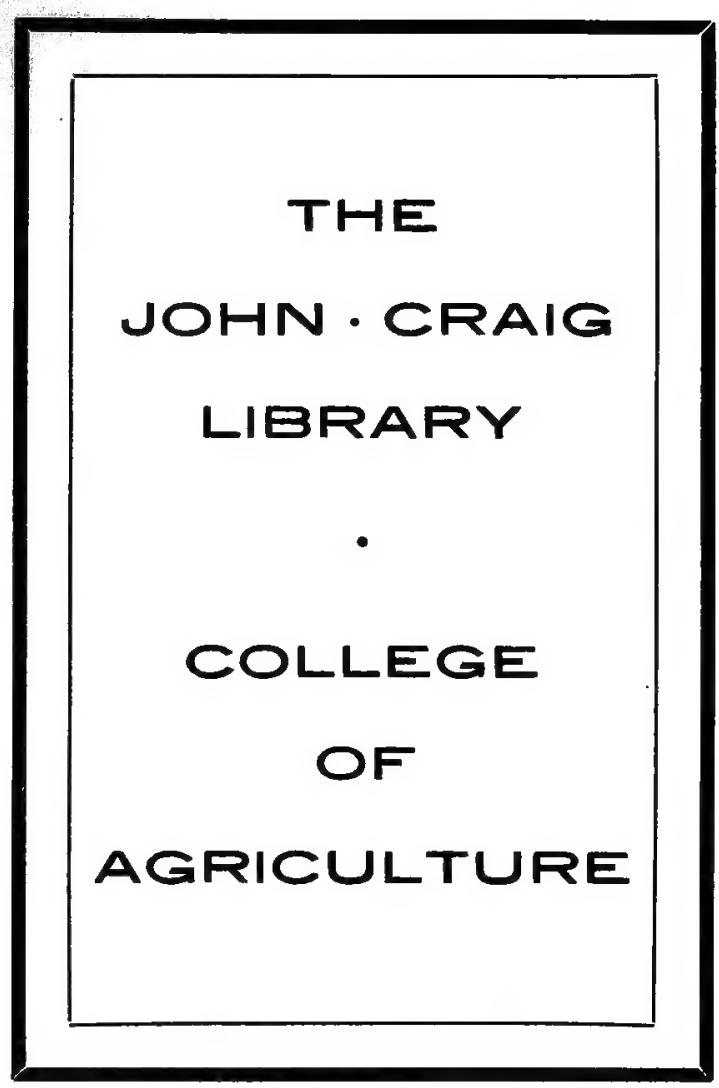


RS 164.K Cornell University Library

A text-book of botany and pharmacognosy,

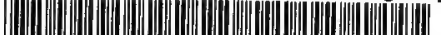

31924003469362 


\section{Cornell University Library}

The original of this book is in the Cornell University Library.

There are no known copyright restrictions in the United States on the use of the text. 



The work is illustrated throughout, and the student is advised to consult the illustrations freely, not only on account of their value in elucidating the descriptions, but also because the legends contain information which in some instances supplements that given in the text.

It should be stated that a large proportion of the illustrations are reproductions of photographs and drawings made by the author, and that in all cases where illustrations are borrowed, credit is given each author in connection with the reproduction.

One of the most difficult questions which arises in writing a work of this kind is that relating to nomenclature. Owing to the desirability of maintaining a stable nomenclature, particularly for medicinal plants, the author has adopted a rather conservative course and has been largely guided by Engler \& Prantl and Index Kewensis, or, in the case of plants growing in the United States, the names given in Britton's Flora may have been employed.

Among the works consulted by the author, and of which special mention should be made, are the following: Organography of Plants by $\mathrm{K}$. Goebel (English translation by Isaac Bayley Balfour); The Physiology of Plants by W. Pfeffer (second revised English edition by Alfred J. Ewart); Die Heilpflanzen by Georg Dragendorff; The Volatile Oils by Gildemeister \& Hoffmann (English translation by Edward Kremers); Die PflanzenAlkaloide by Jul. Wilh. Brühl, E. Hjelt and O. Aschan.

Grateful acknowledgment is also made to the following publishers for permission to reproduce illustrations from the works mentioned. Withelm Engelmann, of Leipzig: Die naturlichen Pflanzen-familien by Engler \& Prantl. Gebrüder Borntraeger, of Berlin: Handbuch der systematische Botanik by E. Warming. Weidmannsche Buchhandlung, of Berlin: Wissenschaftliche Drogenkunde by Arthur Meyer. Gustav Fischer, of Jena: Lehrbuch der Botanik by Strasburger, Noll, Schenck and Schimper.

The author desires fully to acknowledge the services of Miss Florence Yaple, without whose painstaking and constant assistance during the course of revision, this book could not have appeared in its present enlarged form.

H. K.

April, 1907. 


\section{CONTENTS.}

\section{PART I.-BOTANY.}

CHAPTER I.-PRINCIPAL GROUPS OF PLANTS.

INTRODUCTORY

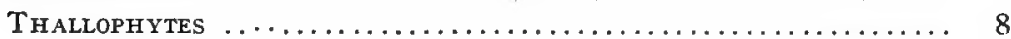

Algæ ...................................... 8

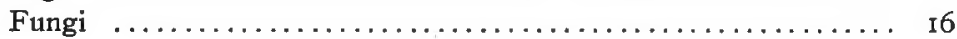

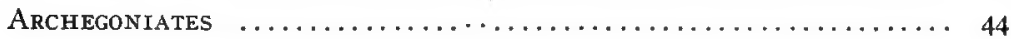

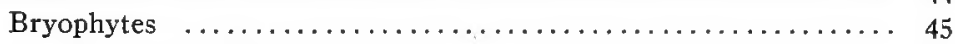

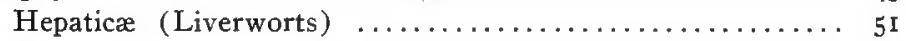

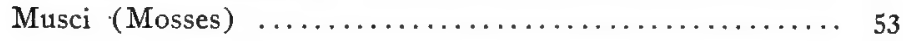

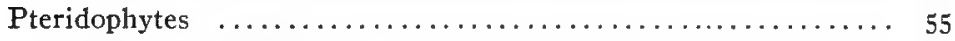

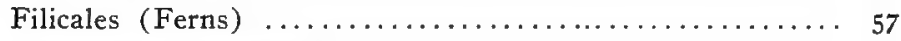

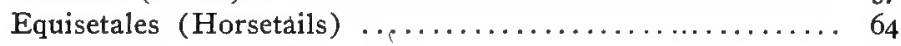

Lycopodiales (Club Mosses) ..................... 66

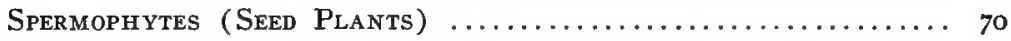

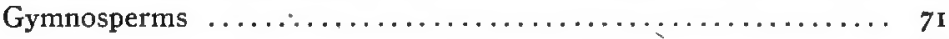

Angiosperms $\ldots \ldots \ldots \ldots \ldots \ldots \ldots \ldots \ldots \ldots \ldots \ldots \ldots \ldots \ldots \ldots, 8 \mathrm{r}$

CHAPTER II.-OUTER MORPHOLOGY OF ANGIOSPERMS.

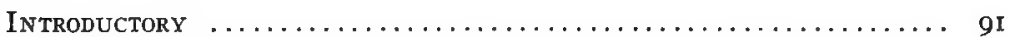

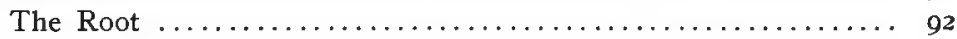

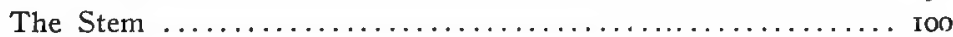

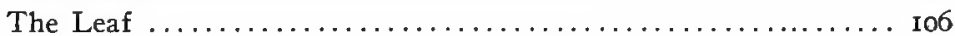

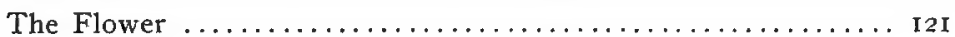

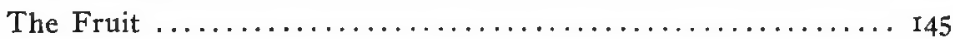

The Seed $\ldots \ldots \ldots \ldots \ldots \ldots \ldots \ldots \ldots \ldots \ldots \ldots \ldots \ldots \ldots \ldots \ldots \ldots \ldots \ldots \ldots \ldots$

CHAPTER III.-INNER MORPHOLOGY OF THE HIGHER PLANTS.

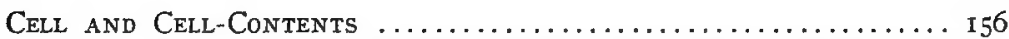

The Cell Wall $\ldots \ldots \ldots \ldots \ldots \ldots \ldots \ldots \ldots \ldots \ldots \ldots \ldots \ldots \ldots \ldots \ldots \ldots \ldots \ldots \ldots \ldots$

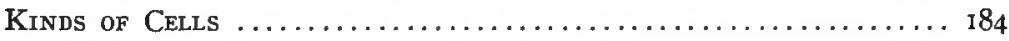

Inner Structure of Members or Organs ................ 197

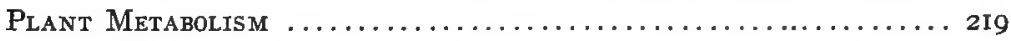




\section{CHAPTER IV.-CLASSIFICATION OF ANGIOSPERMS} YIELDING VEGETABLE' DRUGS.

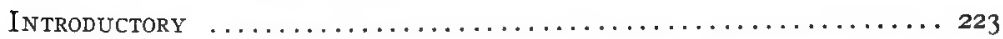

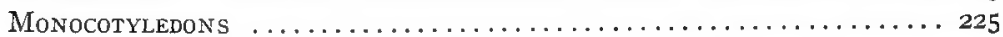

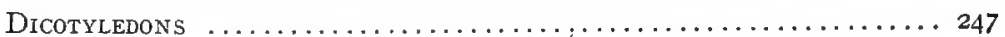

Archichlamydeæ or Choripetalæ .................... 247

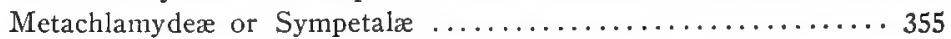

CHAPTER V.-CULTIVATION OF MEDICINAL PLANTS.

Propagation

The Collection, Curing and Yield of Drugs $\ldots \ldots \ldots \ldots \ldots \ldots \ldots . \ldots 6$

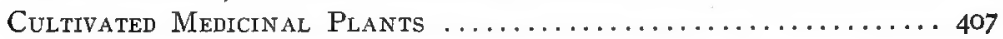

\section{PART II.-PHARMACOGNOSY.}

CHAPTER I.-CRUDE DRUGS.

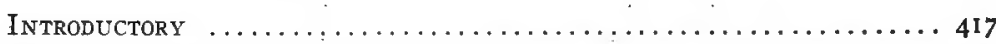

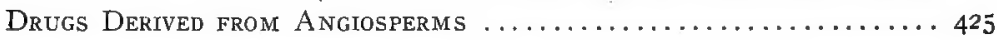

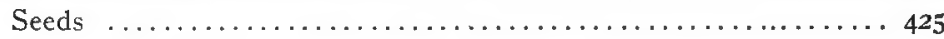

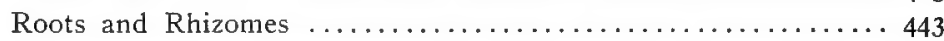

Barks, Woods and Pith ............................. 5I

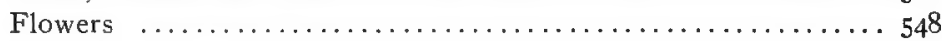

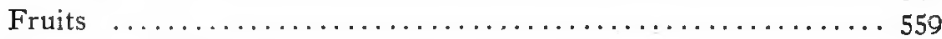

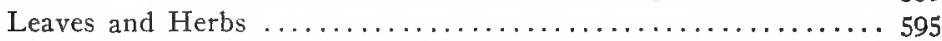

Exudations, Milk Juices and other Plant Substances ......... 640

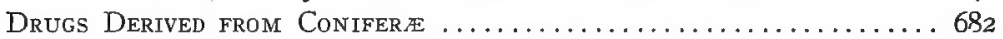

Drugs Derived from Thallophytes and Archegoniates .........6 684

CHAPTER II.-POWDERED DRUGS AND FOODS.

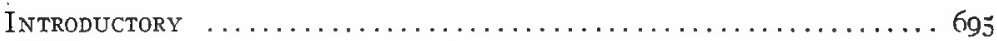

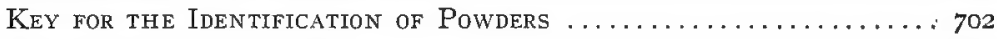

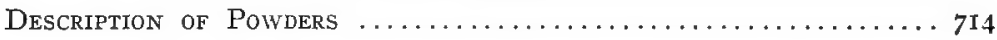

PART III.-REAGENTS AND MICROSCOPICAL TECHNIQUE.

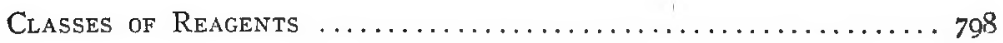

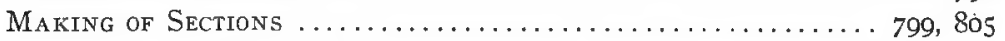

FORMULE FOR REAGENTS ........................... $800^{\circ}$

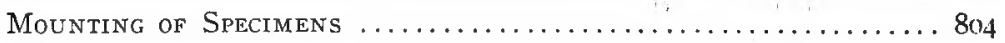

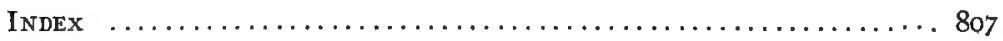




\title{
Botany and Pharmacognosy.
}

\author{
PART I.-BOTANY.
}

\author{
CHAPTER I. \\ PRINCIPAL GROUPS OF PLANTS.
}

INTRODUCTORY.

There are four main lines of botanical work recognized at present,-namely, Morphology, Histology, Physiology, and Ecology. Morphology, which is sometimes referred to as Outer Morphology, is the study of the external forms of organs and the relation of these to their functions. Histology, which is sometimes defined as Inner Morphology, has to do with the minute inner structure of organs. PHysrology may be defined as the study which considers the life processes and the conditions which influence these. ECology is the study of the adaptation of plants and their parts to external conditions. It is important to bear in mind, however, that these several departments are more or less interdependent, and that one of them cannot be intelligently considered without encroaching on the territory of the others. For instance, as Goebel states, we cannot understand the relation of the external forms of organs without reference to their functions. In other words, form and function have a direct relation; one influences the other. So, too, in the study, of ecology we study the influence of external conditions on plants and these, as indicated above, have a direct influence on - physiological processes, and thus the study of ecology merges into the study of physiology on the one hand and into morphology on the other.

While this book will deal chiefly with the structure of plants and their parts, still it will be necessary occasionally to refer to some of the characters of plants which properly belong to other departments of botanical study. 
Basis of Plant Structure.-In order to understand the significance and relation of the various parts of plants it is necessary to know something of their functions and habits of life as well as of their internal structure.

If we make a section of a plant and examine it by means of the microscope, the cut surface presents the appearance of a network indicating that the tissue is made up of small compartments or chambers. One of these compartments together with its contents constitutes the structure known as the CELL (see Frontispiece).

The cell contents vary greatly in appearance and composition, but in all active or living cells there is always present the substance known as PROTOPLASM. The protoplasm is the basis of all plant structures whether they belong to the lowest or highest forms; for by its aid or from it all parts of the plant are developed. Even the cell wall is a product of protoplasmic activity. The protoplasmic content of the cell consists of several intimately related but more or less distinct portions,-namely, a somewhat thin, semi-liquid, granular portion known as the CYTOPLASM; a more or less spherical body embedded in the cytoplasm called the NUCLEUS; and frequently, but not always, certain small bodies which are more or less variable in shape called PLASTIDS, these being also embedded in the cytoplasm (see Frontispiece). The cytoplasm and nucleus are sometimes considered together as a unit, which is known as the Protoplast. A fuller discussion of the differentiated portions of the protoplasm will be found in Chapter III. (See page I 56.)

The lowest organisms, as the slime molds, do not have an enclosing membrane but consist of a naked mass of protoplasm. With this exception plants have an outer wall or membrane. They may consist of a single cell, as in the Bacteria, or a chain of cells, as in the filamentous Algre, or a mass of cells, as in the majority of plants, and are accordingly designated as unicellular or multicellular. The cell wall is composed for the most part of cellulose, but may be modified in various ways.

The names which are used in describing plants have been derived for the most part from studies of the higher plants, they having exclusively attracted the attention of botanists at first. 
But with the light which has been thrown on the relationship of the higher and lower groups of plants by the more recent study of the lower forms the older terminology has been somewhat modified. Thus, for example, we speak of the root and shoot, with its leaves, as the vegetative organs of the higher plants, and in describing the corresponding organs (where they exist) in the lower plants, we either apply these terms directly, or indirectly by saying that the latter are root-like, stem-like, etc. On the other hand, we now speak of the sexual organs of the higher plants as antheridia and oögonia (or archegonia) instead of classifying them roughly as stamens and pistils, the latter names being retained but with a different signification.

Factors Influencing Growth.-Plants have certain inherent or inherited tendencies or characters which make up the inner constitution, and this can not be modified by external agencies except within more or less narrow limits. Depending upon this character we find plants as different in kind as the apple tree and pine growing under precisely the same conditions. In other words, the character of the structure is determined in the main by the nature of the organism. It is true that an apple tree may grow better in one locality than another, but it is still an apple tree whether it be dwarfed or attain to the full measure of its growth. These slight changes in the character are known as accidental variations. Frequently they are the result of temporary conditions and are not repeated in the succeeding generation. On the other hand, if the special conditions remain these individual variations may be repeated in generation after generation and finally become permanent characters.

The gradual change in the structure and nature of organisms which takes place through long periods of time is spoken of as EVolution. In some cases specific changes in the characters of plants arise rather suddenly without any known cause and such changes are spoken of as saltations or MUTATIONS.

The factors essential for growth in all cases are food, water and a certain temperature. Among the food elements we may mention as of chief importance, carbon, hydrogen, oxygen and nitrogen. Some of the other elements are also essential to most plants although they occur in relatively small proportion in the 
plant, as potassium, magnesium, phosphorus, sulphur, iron and calcium. The latter element does not seem to be necessary to the normal development of some of the Fungi and certain Algæ.

Water permeates all parts of the plant and when the cells are in the normal turgescent state it contains more than half its weight of water. When the supply of water falls below the normal the plants begin to droop and finally die. The need of plants varies greatly in this particular; some are aquatic in their habits and live wholly in the water; others can live only on the land; and still others are adapted to desert regions.

The degree of temperature necessary for growth varies within certain limits for each kind of plant, but as is stated by Pfeffer, the greatest extremes are shown by Fungi, Bacteria and the lower Alga. Generally speaking the most favorable temperature for growth is between $24^{\circ}$ and $34^{\circ} \mathrm{C}$.

Besides the factors enumerated there are other factors which influence growth. They include light (p. 106), gravity (p. 94), mechanical agencies, etc., and are sometimes spoken of as external stimuli.

It is difficult to separate those factors which act solely as external stimuli from those which are essential to the normal growth of the plant and which may be considered as physiological factors. For example, light under certain conditions may be regarded as in the nature of an external stimulus and not essential to the growth of the plant; while in other cases it has a direct influence on normal growth and is essential to the life of the plant, as in all plants or parts of plants where photosynthesis (p. Iog) takes place.

In addition to the essential food elements, there are many substances which affect the growth of plants which may be grouped as chemical stimuli, such as $(a)$ the substances secreted by gall-forming insects, $(b)$ in a certain measure some of the substances produced by Fungi, (c) and numerous substances not found as normal constituents of the plant. Depending upon the amount of the substance present and the conditions under which it is supplied, the substance may act as a poison and injure the plant, or it may accelerate growth, or cause abnormal developments. 
This subject has an important bearing on the physiological testing of drugs. Kobert states that in determining the qualities of a new chemical, preliminary experiments should be conducted on lower plants and animals before trying it on man. Of the plants which have been used in the testing of poisons the following may be mentioned: Oscillaria, Spirulina, Nostoc, Zygnema, Spirogyra, Saccharomyces, Mucor, Elodea, Lemna, Pistia, Potamogeton, Myriophyllum, Ceratophyllum, Tradescantia, seedlings of grasses, lupine, bean, pea, corn, etc.

Plant Organs.-Depending upon the fact that the plant requires nourishment for its growth and development and that it has also to carry on the work of reproduction or propagation, -i.e., the production of new plants, - we distinguish between vegetative or nutritive organs and propagative or reproductive organs. The vegetative organs, such as the root, stem and leaves in higher plants, manufacture the food necessary for the life of the plant, while certain other more or less specialized organs or cells carry on the work of reproduction.

In the lower plants, however, the whole structure is much simpler, and in some instances a cell which performs the work of a nutritive cell at one stage may become a reproductive cell at another, or, as in the case of the unicellular Alga, all the various functions of the plant may be carried on by a single cell.

Generally speaking, there are two principal ways in which plants are multiplied or reproduced: ( I) By CELL DIvision or cell fission, and (2) by the formation of special cells known as SPORES. In cell division (Fig. 94) the nucleus and cytoplasm of a cell divide to form two new cells or protoplasts, which become distinct by the formation of a wall or cell-plate between the two halves. All growth in plants is dependent upon this method, and in growing parts the cells are said to be in a state of division. Owing to the plasticity of the plant organism, detached portions will often grow and give rise to new plants, as in the case of cuttings. Growth here as in the parent plant is accompanied by cell division. In some of the lower Algæ (Fig. 6) cell division is the only method of propagation, and as only the ordinary vegetative or nutritive cells of the plant are involved in the process it is sometimes spoken of as vegetative multiplication. 
In both lower and higher plants, with the exceptions just noted, reproduction is also carried on by means of spores.

Depending upon their origin two classes of spores are distinguished, namely, $(a)$ asexual spores, and $(b)$ sexual spores. In the production of asexual spores the contents of a certain cell

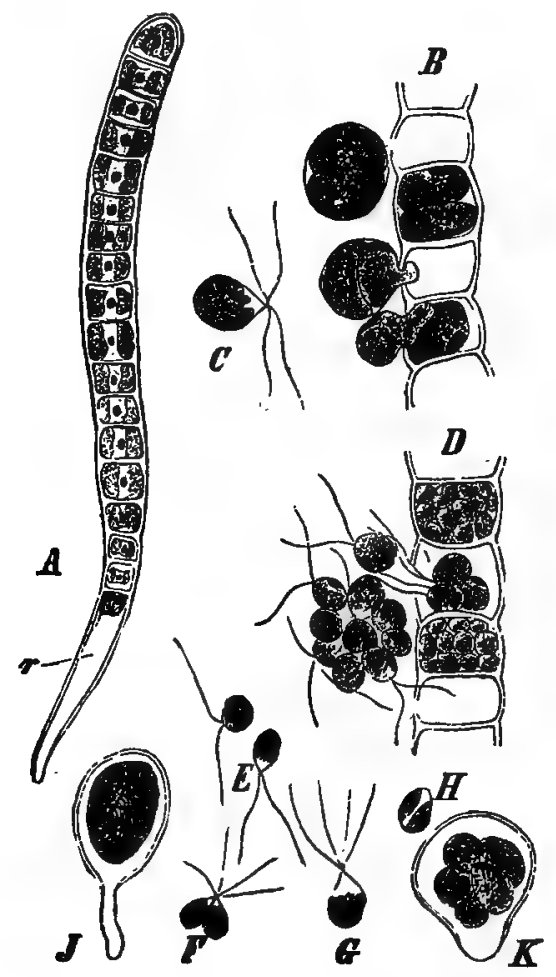

FiG. 5. Ulothrix zonata. A, young filament with rhizoid cell (r); B, piece of filament showing escape of swarm spores; C, a swarm spore or zoöspore with 4 cilia; $D$, biciliate gametes escaping from a filament; E, F, G, sthowing different stages of union of two gametes; H. young zygote or zygospore in which the cilia have been absorbed; J, I-celled plant developed from zygote; $K_{r}$ young plant organizing zoőspores.-After Dodel-Port.

called a mother cell or SPORANGIUM break up into a number of new cells sometimes called daughter cells, which escape through the cell wall. In the lower plants, particularly those growing in water or in moist places, these cells are provided with short 
thread-like appendages known as cilia, which enable them to move about in the water. They are known as zoöspoREs or swarm spores (Fig. 5, B, C), and each individual zoöspore is able to produce a new plant.

The number of zoöspores formed in a sporangium is ustually 2 to 8 , as in Ulothrix, but the number may be larger. The method of cell formation which gives rise to zoöspores is sometimes spoken of as INTERNAL DIVISION from the fact that they arise within the old cell and retain no relation to the old wall as is the case in cell fission. The zoöspores are at first naked protoplasts, but later, on coming to rest, may form a wall. Sexual spores, on the other hand, are formed by the union of two cells known as GAMETES. When the gametes are similar the resulting spore is known as a ZYGospore or zygote (Fig. $5, E, F, G$ ). When the gametes are unlike, the spore produced by their union is known as an oöspoRE. In the latter case one of the gametes is larger than the other, is less active, and is spoken of as the female gamete, oösphere, or egg (Figs. II, I2). The other more active cell is known as the male gamete, antherozoid or sperm (Fig. $34, I I I)$. The cell giving rise to the oösphere is known as the oögonium (Figs. 8, I I, I2), while the one in which the antherozoid or sperm originates is called the antheridium (Figs. 8, I I, I2, 34).

\section{PLANT GROUPS.}

Probably the most conspicuous feature of the plant world to the casual observer is the great number and diversity of forms. It was formerly the custom to devote attention chiefly to the more prominent groups of plants, or those that produce seeds, but more recently the results of the studies on the less prominent groups, as ferns, mosses, etc., have modified our views and made it imperative that the botanist have a general knowledge at least of all the great groups of plants.

The most general classification of plants is that which divides them into three great groups,--namely, (I) Thallophytes (Thallophyta), (2) Archegoniates (Archegoniatæ), and (3) Spermophytes (Spermophyta). 


\section{THALLOPHYTES.}

The Thallophytes include the lowest orders of plants,i.e., those simplest in form and structure. They are supposed also to represent more or less primitive types. In these plants the plant body does not show a differentiation into root, 'stem and leaf, as in the higher plants, and is termed a THALLUs. The thallus may branch in various ways, but the structure remains more or less uniform throughout. It should be understood, however, that even in this group of plants certain cells or groups of cells may become specialized, i.c., set apart for a particular function, as, for example, the reproductive cells. The Thallophytes vary in size and general appearance from minute unicellular organisms and those which are filamentous and delicately branched to large leaf-like organisms many feet in length (Figs. 6, 9, 13).

The Thallophytes are divided into the two groups of plants known as (1) Algæ and (2) Fungi. The Algæ produce chloroplasts, and hence are capable of manufacturing food from the inorganic substances air and water (see page Iọ8), which fact constitutes a fundamental difference between them and the Fungi.

ALGE.

Algæ are also characterized by their habit of living in water or in moist places, and they are sometimes classified as "fresh water alga" and "salt water algæ" (Fig. 9). In the first group are included the common pond-scums and certain forms living on trees, moist rocks, fences and elsewhere, and in the second group the sea-weeds.

In addition to the chlorophyll (see page 159) of the chloroplasts other color substances are found in Algx, which mask the green color to a considerable extent. ' On the basis of their color Algæ are stubdivided into (I) Blue-green Algæ or Cyanophyceæ, (2) Green Algæ or Chlorophyceæ, (3) Brown Algæe or Phæophyceæ, and (4) Red Algæ or Rhodophyceæ. While no attempt will be made to consider these groups in detail, it should be stated that they not only vary in color, but they also vary greatly in structure and general appearance. A few type forms will be considered in order to illustrate their habits of life. 
Pleurococcus.-One of the commonest of the Green Algæ as well as one of the simplest is Pleurococcus (Pleurococcus vulgaris) (Fig. 6). It occurs as a green coating, in both winter and summer on the moist bark of trees, moist ground, and stone walls, and is a component of some lichens. The plant is one-celled, more or less spherical, and at one stage contains a number of chlorophyll grains which finally unite to form a single plate which lies against the wall and is known as a chromatoPHORE. Besides it contains a considerable amount of oil. An allied species (Plcurococcus viridis) contains the sugar erythrite. The plant usually reproduces by simple division, that is, one cell or plant divides to form two. The division may continue by the production of another cross wall, so that four cells result. Under favorable conditions, division may take place by the formation

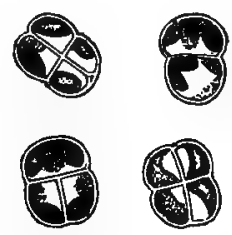

Fig. 6. Pleurococcus vulgaris. Different stages of division of the cell.-After Wille.

of still another wall at right angles to the other two. In this way two, four and finally eight individuals arise which adhere more, or less to one another, thus forming colonies. The number of individuals in a colony depends' upon the number of individuals in the colony when division begins and the extent to which division is carried. Thus if there were four cells in a colony to begin with and division took place in three planes, there would be thirty-two cells in the colony at the end of the period. .. Spirogyra.-Another one of the common Green Algæ is Spiragyta (Fig. 7), one of the pond-scums, which forms floating green masses on ponds and shallow water in the spring. The plant-body consists of a chain of cylindrical cells forming long threads or filaments. The transverse walls are sometimes peculiarly thickened. The chromatophores occur in one or more spiral bands (Fig. 7, II), which extend from one end of the cell to the 
other. In these bands are embedded proteid bodies known as pyrenoids. The nucleus lies in the center of the cell and is connected with the cytoplasmic layer lining the walls of the cell by delicate threads of cytoplasm.

Spirogyra may be propagated vegetatively by one or more cells of a filament breaking off and forming new individuals by cell division. The plant is also reproduced by means of zygo-
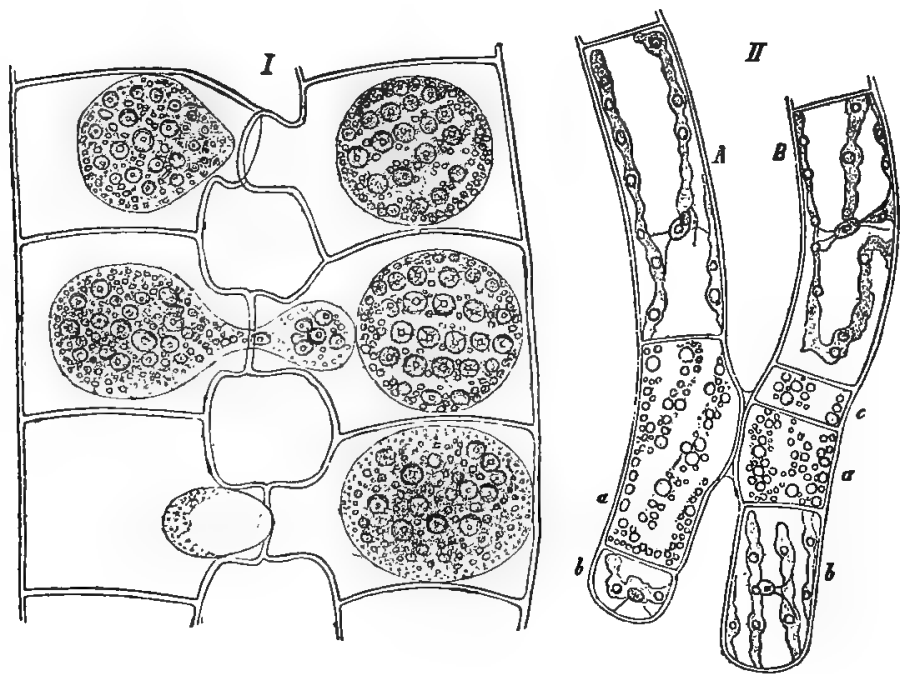

FIG. 7. II. Spirogyra stictica, showing parts of two filaments with band-like chromatophores (chloroplasts), in which are embedded spherical pyrehoids. Nuclei are shown in some of the cells with delicate threads of cytoplasm radiating from them. Two of the cells $(a, a$,$) of the adjoining filaments (A, B) are beginning conjugation. I, S. Hecriana,$ showing different stages of conjugation. In the upper cells, the contents have rounded off previous to the rupture of the adjoining walls of the two filaments. The two middle cells show the contents passing from one cell into the opposite cell. In the lower cell to the right the zygospore is shown.-After De Bary.

spores, as follows: The cells of two adjoining filaments each send out processes (Fig: $7, I I, a, a$ ), which meet; the end walls are absorbed, forming a tube through which the contents from one cell pass over into the other (Fig. $7, I$ ); the contents of the two cells then fuse, after which the mass becomes surrounded by a cellulose wall. The spore thus formed may remain dormant over winter, and the following spring germinate and form a new Spyrogyra filament or plant. This method of reproduction is known 
as conjugation, and the zygospore is called a resting spore. It should be explained that certain cells, as well as spores, may lie dormant for a period, as during the winter season or at other times, when the conditions are unfavorable to growth, and then renew their activities, these being known as " resting cells."

Vaucheria (Fig. 8) is another common green alga which may also be selected as showing the habits of this group of plants. The plant has a branching thallus and lives in shallow

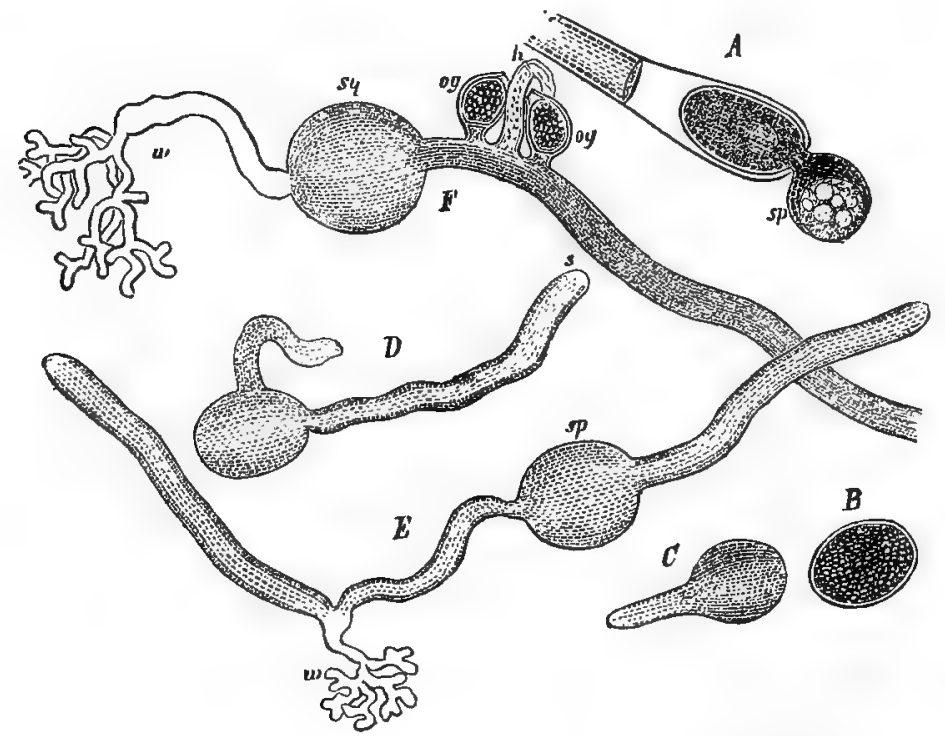

Fig. 8. Vaucheria sessilis. A, sporangium from which the multiciliate zoŏspore is escaping; B, resting zoöspore; C, D, germinating zoöspores with growing point (s); E, plant showing root-like organ of attachment $(w)$, spore from which the plant is developing (sp), F, showing in addition two ooggonia (og) and an antheridium (h).-After Sachs.

water or on moist earth, being attached to the substratum by means of delicate root-like processes sometimes spoken of as rhizoids (Fig. 8, $w$ ). In the thin layer of protoplasm lying near the wall are numerous nuclei and small oval chromatophores. Numerous oil globules are also found in the protoplasm, and calcium oxalate crystals may occur in the cell-sap.

Vaucheria furnishes an example of a plant whose interior is not segmented by cell walls. In other words, the cavity within the outer or enclosing membrane is continuous, and such a plant 
is said to be cœnocytic, i.c., like a syphon. But it should be borne in mind that the plant contains a great many nuclei, and as we have seen (page 2) a nucleus with its associated cytoplasm constitutes a unit of work. Hence such a plant as Vaucheria is in a certain sense equivalent to a plant having as many uninucleate cells as it has nuclei. It would probably be better to call such a plant multinucleate rather than unicellular.

Reproduction by means of asexual spores is brought about as follows (Fig. 8, A) : A cross wall is formed near the end of one of the branches, the end portion constituting a sporangium. The contents, including numerous nuclei group themselves into one large zoöspore, which escapes through an opening in the sporangial wall, and after swimming about for a time comes to rest and germinates, giving rise to a new plant (Fig. 8, C, D). This large zoöspore is multinucleate and multiciliate, there being two cilia for each nucleus, and by some botanists is considered to be an aggregation of numerous biciliate zoöspores. It is also of interest to note that the zoöspores of Vaucheria appear to arise by a grouping of the cytoplasm and the nuclei already existing in the sporangium rather than by repeated divisions of a single nuclets.

Another method of reproduction in Vaucheria (Fig. 8, F) is that by means of oöspores, or spores formed by the union of egg and sperm cells. Two special branches are formed on the thallus as short side shoots. One of these branches, known as the oögonium (Fig. 8,og), is somewhat egg-shaped and separated from the thallus by means of a cross wall. It contains a great many chromatophores and considerable oil, and has a comparatively thick wall. The apex is somewhat beaked and contains colorless protoplasm. The second branch, which is known as an antheridium (Fig. 8, h), is smaller, somewhat cylindrical and curved towards the oögonium. It is also cut off from the thallus by means of a cross wall. The antheridium contains very little chlorophyll, but a great many sperm cells. These are oval or egg-shaped and have two cilia, one at each end. The sperms escape from the apex of the antheridium and enter an opening at the apex of the ooggonium, one of them uniting with the egg: cell, which then develops a thick membrane, the resulting oöspore being a resting spore. 
Diatoms constitute a large group of unicellular plants, occurring in both fresh and salt waters. They form the plankton or floating microscopic life found in oceans and lakes, which is the

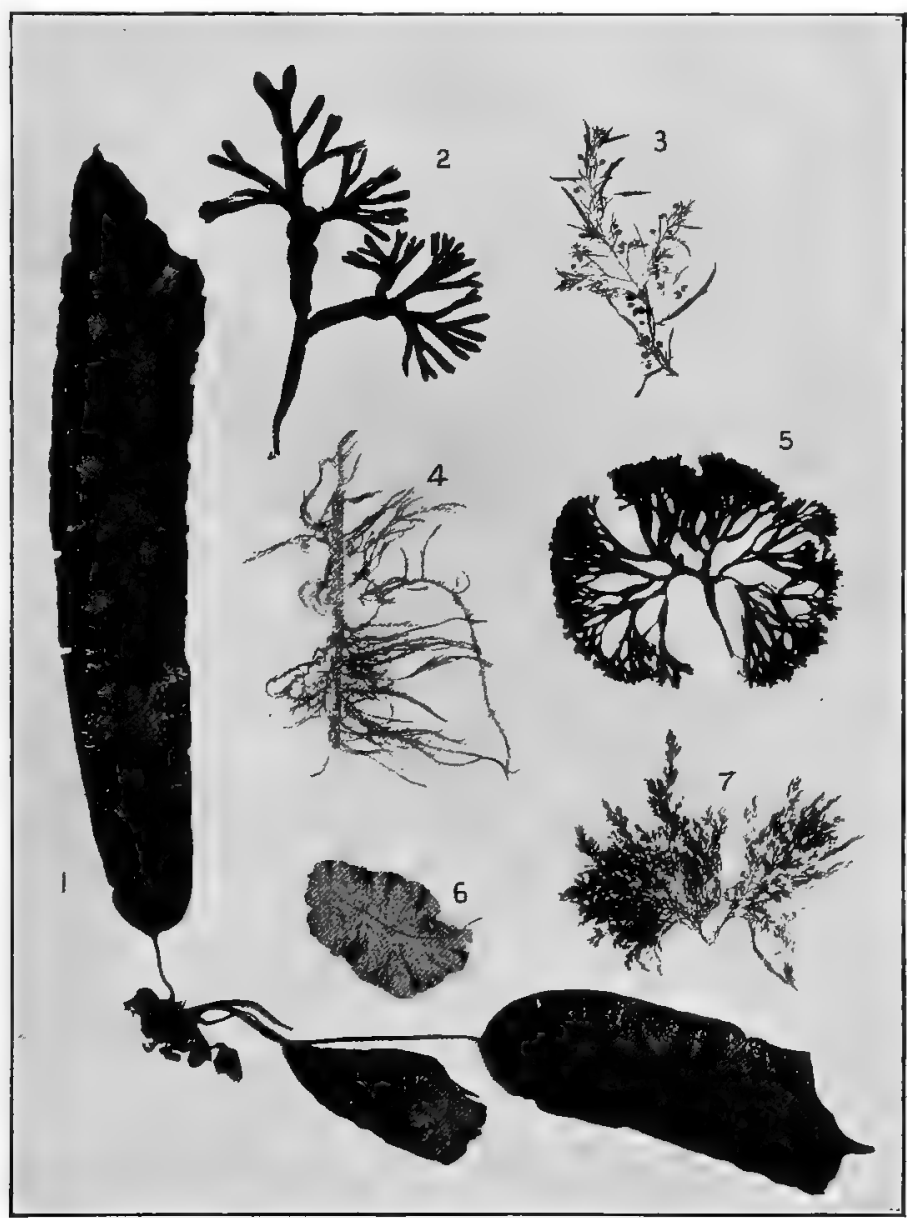

FIG. 9. Some common marine algæ. r, Laminaria, showing portions of three leaflike thalli and holdfast; 2 , dichotomously branching thallus of Fucus; 3. Sargassum, or "gulf weed," showing a thallus resembling a leafy branch, with swollen, berry-like air bladders, which act as floats; 4, Dasya, a delicate branching filamentous seaweed, attached to a blade of eel-grass; 5, dichotomously branching thallus of Chondrus, or Irish moss; 6, Leaf-like thallus of Grinnellia; 7, densely, but delicately branched thallus of Polysiphowia. I, 2, 3 are Brown Algæ and 4, 5, 6, 7 are Red Algæ. 
source of food of small animal forms inhabiting these waters. One of the distinguishing characters of the group is that the cell wall is incrusted with silica. For this reason they are practically indestructible and form marls and strata in the earth. They occur either singly or grouped in bands or chains. They are very variable in shape, being boat-shaped,

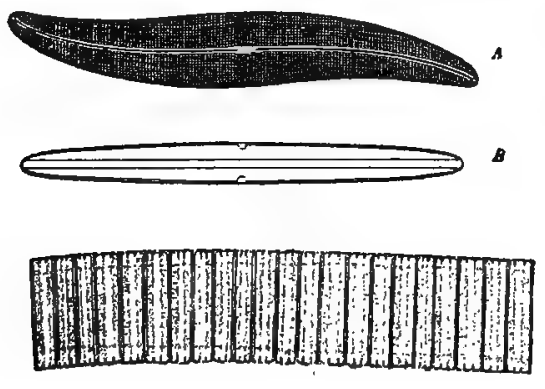

$\boldsymbol{\varepsilon}$

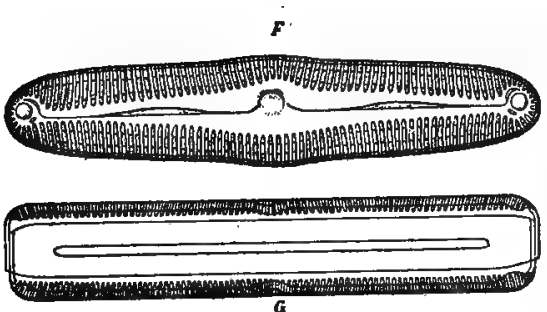

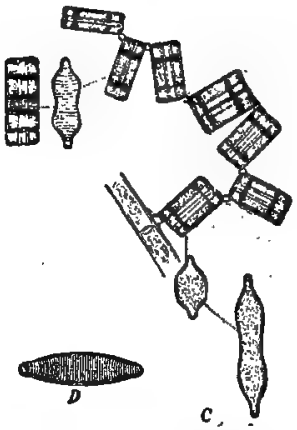

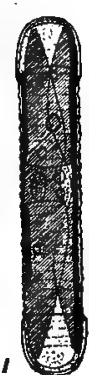

Frg. 1o. Diatoms: A, Pleurosigma attenuatum as seen from above; B, Pleurosigma balticum as seen from the girdle side; C, D, E, Fragilaria virescens showing colonies attached to an alga in $C$, a view of a single diatom from above at $D$, and a chain of diatoms viewed from the girdle side at E; F, G, two views of Navicula viridis; $H$, I, the formation of auxospores in Navicula firma, $H$ showing the exit of the protoplasts and the throwing off of the original valves.-A, B, D, after Van Heurck; C, E, after W. Smith: F-I, after Pfitzer.

ellipsoidal, spherical, or peculiarly curved in some forms. They are either free or attached to a substratum, as stones, water plants, etc., those which are free having an active movement (Fig. I0).

The cell-wall of Diatoms practically consists of two halves, one fitting over the other like the lid of a box. These are known as "valves" or "theca." The manner in which the two valves 
are joined results in the formation of a "girdle" or "pleura." The girdle is provided with a series of pores connecting with canals at either end and in the middle, through which food from without is supplied to the protoplast. The valves are very often beautifully marked by a series of parallel cross lines, dots, circles, or polygons, which are characteristic of the different groups. Some forms are used in testing the definition of objectives, as Pleurosigma angulatum, in which the lines are one-half micron wide (Fig. Io, $A$ ). ${ }^{1}$

In the Diatoms the protoplasm lies as a thin layer close to the wall surrounding a large central vacuole. The nucleus is surrounded by a relatively dense mass of cytoplasm, and occurs in definite positions according to the species. The chromatophores frequently occur in plates which are typical for certain species. They are sometimes greenish-yellow, the color being generally masked by the presence of a brown substance known as diatomin. They frequently contain pyrenoids, which are sometimes associated with granules of starch.

Reproduction takes place by simple division or fission, the two valves separating and a new valve forming on each half to replace the old one. In each case the valve formed fits into the old one and hence in the case of the smaller valve the new cell or plant becomes smaller than the parent plant, the walls not being able to expand on account of the siliceous composition. In this way the cells of one series gradually become smaller and smaller until a certain minimum is reached, when the plant rejuvenates itself by the production of spores (auxospores). These are formed in two ways: In one case the valves separate from each other, the protoplast escapes, grows larger and develops a new wall; in the other case, of which there are several types, two individuals come together, and envelop themselves in a mucilaginous covering. They then throw off their siliceous walls and the protoplasts unite to form a zygospore which grows until it is three times the original size, after which it develops a new wall, the larger valve forming first (Fig. Io, $H, I$ ).

Economic Uses of Algæ.-Diatomaceous earth, which is

2 The micron $(\mu)$ is the $\frac{1}{1000}$ of a millimeter. 
made up of the valves of diatoms, is used chiefly as an absorbent agent for storing nitroglycerin, as in the production of dynamite. Being a non-conductor of heat the material also finds use in the manufacture of the so-called isolation plates for machinery. Another use is as a tooth powder. Among the Chinese and Laplanders diatomaceots earth has also been used as an edible earth known as " mountain meal " or " bread-stone." It has been used in India as a rubefacient.

Many of the Algæ are of tuse as food, of which the following may be mentioned: Vaucheria fastigiata, Griffithsia coralina, Ceramium Loureirii, Chondrus crispus (Fig. 9), Gigartina mamillosa (Fig. 278a), Gelidium cartilagineum, Gelidium crinale (yielding agar-agar), Rhodymenia palmata (yielding dulce), and several species of Gracilaria (which also yield agar-agar).

Some of the sea-weeds are used in the production of iodine, as Durvilläa utilis, Ascophyllum nodosum, Fucus vesiculosus (Fig. 9, illus. 2), Sargassum linifolium, Laminaria saccharina, Laminaria digitata, Alaria esculenta, Rhodymenia palmata, Phyllophora membranifolia, Macrocystis pyrifera, and Fastigiaria furcellata.

A number of the Algre are also used in medicine, particularly for phthisis, as Fucus cartilagineus, Stilophora rhizodes and Dictyopteris polypodioides. Alaria esculenta and Laminaria digitata are used in the making of bougies and tents used in surgery. Owing to the toughness of some of the Algæ on drying, the material is used in the manufacture of various articles, as handles for tools from the thick stem of Lessonia fucescens, fishing lines from Chordaria filum, etc.

\section{FUNGI.}

The Fungi form a large group of plants which do not produce chloroplasts or any bodies having a similar function. They have not the power of carbon dioxide assimilation, that is, unlike the Algæ they are unable to manufacture food materials, such as carbohydrates (starches, sugars, etc.), from carbon dioxide and water. Hence they are dependent upon previously formed food products, and may derive their food from living plants or animals, when they are known as PARASITES, or from decaying animal 
or vegetable matter, when they are known as SAPROPHYTES. The living plant or animal attacked by a fungus is known as the host.

Fungi are especially characterized by the habit of arising from spores and of producing thread-like cells the growing point of which is at the apex. These threads are known as HYPHe (singular hypha). They branch and become interwoven, forming a mass or mat known as the mycelium (Fig. I3). The mycelium constitutes the plant body proper, and absorbs the food material from the substratum, which it ramifies, often causing decay. The mycelium is frequently not visible, and the presence of the fungus is not recognized until the so-called fruit bodies are developed, as sometimes seen in the case of moldy oranges, mildewed linen, and as illustrated by the common mushroom. The mycelium has a cellulose wall which in some cases is modified to chitin, a nitrogenous substance related to animal cellulose and found in crabs and other lower animals. The protoplasm either occurs in a more or less delicate form lining the hyphæ and enclosing large vacuoles, or is comparatively dense enclosing numerous small vacuoles. Many fungi contain color substances which are dissolved in the cell-sap and are of a quite brilliant hue. One of the most interesting classes of substances produced by fungi is that of the ferments, including the oxidizing ferment allied to laccase. They contain also amido-substances related to lecithin; fats; carbohydrates, as trehalose and mannitol; organic acids, as oxalic, tartaric, malic, etc.; and calcium oxalate may be present in some cases.

Reproduction in the Fungi is chiefly by means of asexual spores, which arise in two ways. In the one case they are developed in a special cell or sporangium at the end of a mycelial thread and are known as ENDOSPOREs. In the other case they arise on special hyphæ, or directly from the mycelium and are known as EXOSPORES or conidia. There are also several modifications of these two types of spores, which may be referred to later.

Groups of Fungi.-There are two principal groups of Fungi, namely, (I) the Phycomycetes, or Alga-fungi, so called because they show a resemblance to certain of the Algæ, and (2) the Eumycetes, or true Fungi. The Eumycetes have two subdivisions, namely, (I) Ascomycetes and (2) Basidiomycetes. 
The Ascomycetes are distinguished by having a sporangium of a definite shape and size, which is called an Ascus, and which contains a definite number of spores, which is two or some multiple thereof. The Basidiomycetes are the most highly developed Fungi, producing large fruit bodies, such as are seen in mushrooms, toadstools and puffballs. They are characterized by producing spores (basidiospores) on special hyphæ. The spores are ustrally four in number and the spore-producing organ is known as a B.LSIDIUII,

PHYCOMYCETES: ALGA-FUNGI.-The plant body of the Phycomycetes consists of a mycelium which is unsegmented, more or less thread-like and sometimes considerably branched. Reproduction takes place by means of several kinds of spores, and by reason of the production of two kinds of sexual spores they are subdivided into two important groups. These are (I) the Oömycetes which produce oöspores, and (2) the Zygomycetes which produce zygospores.

Saprolegnia.-Probably one of the best representatives of the Oömycetes is the group of water molds known as Saprolegnia, which are aquatic in their habits and are both parasitic and saprophytic, occurring on living fish, insects, crayfish and decaying plants and animals as well. The plant body consists of a mycelium which may be simple or branched, sometimes forming a dense mass (Fig. I I, $A$ ). Like the alga Vaucheria, it produces both swarm spores (zoöspores) and oöspores. The swarm spores (Fig. II $B, C$ ) are produced in sporangia formed by the production of a partition wall at the end of a hypha. The sporangia are either cylindrical or spherical, and contain numerous zoöspores which have two cilia at one end. These spores are peculiar in that after their escape from the sporangium they swim about, then come to rest and take on a wall, after which resting period they develop two cilia on the side, again move about, and germinate when they find a suitable host.

The oögonia and antheridia (Fig. I I, D-F) are also formed at the ends of hyphr. The oögonia are usually spherical and the wall contains a number of small pores. The contents which are at first more or less uniform, later develop egg-cells, of which there may be as many as fifty in a single oögonium. The anthe- 
ridium is more or less cylindrical and contains a somewhat uniform mass of protoplasm. The antheridium bends toward the oögonium and comes in contact with it, but apparently does not in all cases penetrate it. Nevertheless the egg-cells develop walls and become resting oöspores.

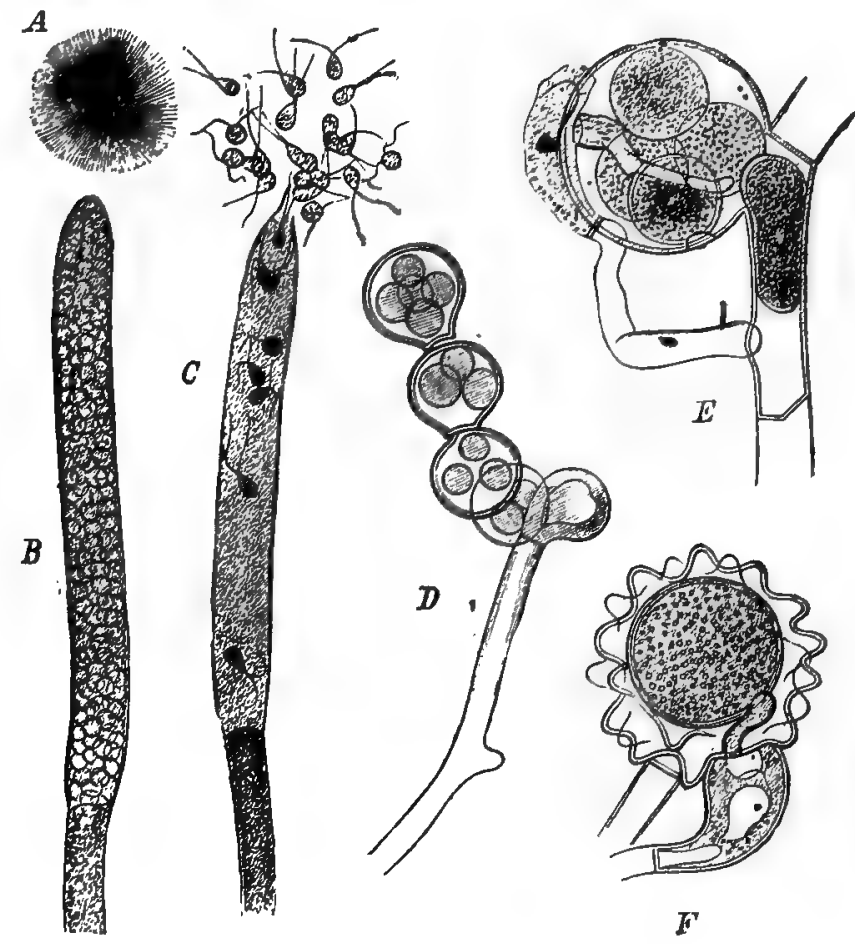

Frg. Ix. Species of Saprolegnia. A, mycelium growing out from and surrounding a dead house-fly in a water culture; B, C, sporangia with biciliate swarm spores; D, a number of ooggonia containing oóspheres; $\mathrm{E}, \mathrm{F}$, oögonia and antheridia, in $\mathrm{F}$ the tube of the antheridium having penetrated the oogonium, - A-C, after Thuret; $\mathrm{D}-\mathrm{F}$, after De Bary.

In Peronospora, one of the Oömycetes, the antheridium (Fig. I2, n) develops a tube which pierces the wall of the oögonium (Fig. I2, o) ; the contents unite with the egg-cell, after which a heavy membrane develops forming an oöspore which germinates when it finds a suitable host. The plants belonging to Peronospora as well as related genera are destruc- 
tive to many cultivated plants, constituting mildews or blights, as those occurring on the leaves of hyoscyamus, tobacco, anthemis, matricaria, aconite, grape vine, lima bean, potato, etc. The group has received the name "downy mildews" because of the
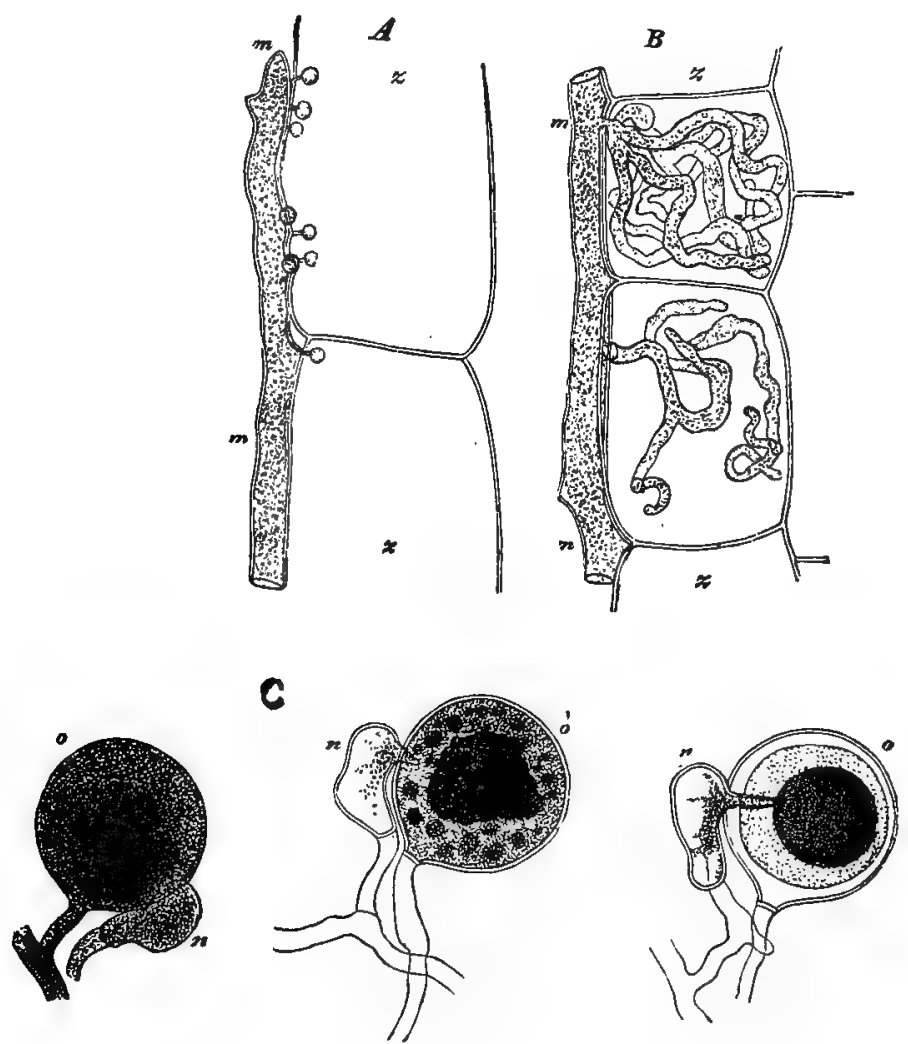

Fig. I2. A, Cystopus candidus; B, Peronospora calotheca. Mycelia (m) with hausstoria penetrating cells (z) of hosts. C; Oöspore formation in Peronospora: o, oogonium; $\mathrm{n}$, antheridium. At the left the antheridium is in contact with oögonium; the next stage shows the antheridium penetrating ooggonium and discharging its contents; at the right the resulting oöspore is shown.-After De Bary.

fact that the conidiophores rise to the surface of the leaves where the spores are discharged, forming powdery patches.

Black Mold.-A common example of the Zygomycetes is furnished by the "black mold," Mucor mucedo. The mycelium of this plant is cœnocytic, thread-like, very much branched, 
and profusely developed much like that of Phycomyces nitens (Fig. I3, B). This mold is widely distributed, causing trouble in the spoiling of many sugar- and starch-containing substances in the household, including preserves, syrups, fruits, etc. In

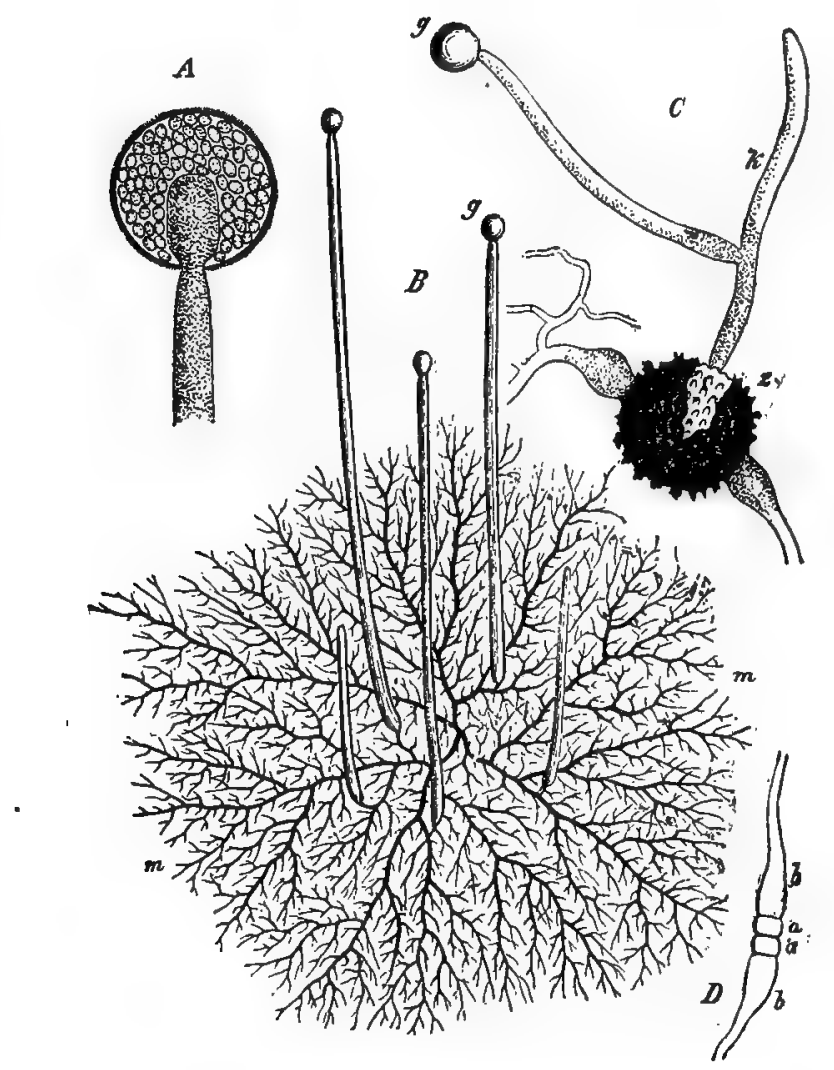

FIG. 13. B, richly branching mycelium (m) of the mold Phycomyces nitens show. ing upright hyphr bearing sporangia (g). A, C, D, the common black mold Mucor mucedo. A, sporangium with columella; C, germination of zygospore $(z)$, with formation of hypha (k), and sporangium (g); D, earliest stages in the development of a zygospore the hyphal branches (b) showing adjoining ends (a) cut off by cross walls.-After Sachs.

fact, a number of species of Mucor have the power of inducing alcoholic fermentation in glucose-containing solutions. They are also commonly found in many aqueous solutions of inorganic chemicals as well as organic substances. Asexual spores are 
formed at the ends of hyphæ which rise into the air. The sporangia are spherical and are cut off from the hypha by means of a transverse wall which projects upward into the sporangium and which is technically known as the columella (Fig. I3, $A$ ). The contents by simultaneous division form numerous one-celled spores, which are discharged by the bursting of the sporangium wall and distributed by air-currents or the wind. As the name

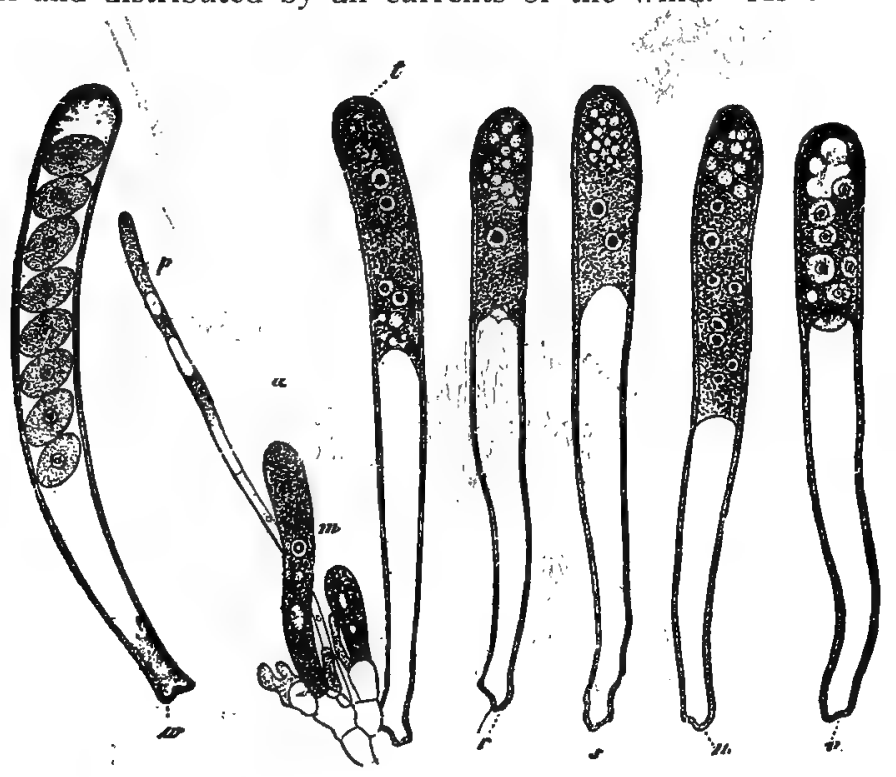

FIG. I4. Peziza confluens showing stages in the development of ascospores. In the youngest asci $(m, r)$ there is only one nucleus; this divides into two ( $\mathrm{s}$ ); the division is repeated, so that there are 4 nuclei in $(t)$ and 8 in (n). These surround themselves with protoplasm and a cell wall $(\mathrm{v}, \mathrm{w})$ but the protoplasm of the mother cell or ascus is not entirely used up.-After De Bary.

of the group to. which this plant belongs indicates, it also produces zygospores (Fig. I3, D). These are formed by hyphal branches which ascend from the substratum. The ends of two branches come together, a transverse wall is formed in each branch, the walls in contact are absorbed, the contents unite, and a spore is formed with three membranes, two belonging to the spore proper and the third being formed by the united hyphæ. As would be expected, these spores are quite resistant, being able 
to withstand unfavorable conditions, and germinate (Fig. 13,C) only after a period of rest.

EUMYCETES: TRUE FUNGI.-AsCOMYCETES.-The Ascomycetes are distinguished for the most part, like the other higher Fungi, in having a septate mycelium, i.e., one cellular in structure, and in producing asci (sacs), which latter are formed at the ends of the branches of the mycelia. Two main sub-groups are recognized, the one producing an indefinite number of spores in asci which are not well developed, and known as the Hemiascr; the other producing a definite number of spores, which number is
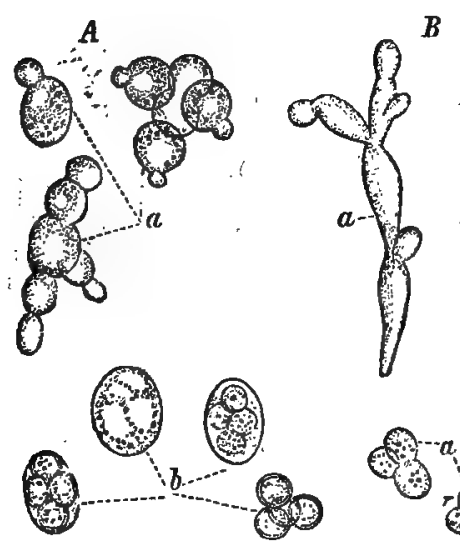

$B$

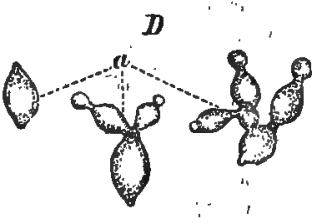
S. Pastorianus; C S S glomeratus. D S Piculatus: A, S. cerevisice or beer yeast; B, budding; $b$, formation of ascospores.-After Reesz.

characteristic for each species, in a well-developed ascus, and known as the EUASCI. In the latter group the spores arise by successive divisions of the primary nucleus into two, as shown in Peziza confluens (Fig. 14).

Yeasts.-The simplest of the Ascomycetes is the subgroup known as the Saccharomyces, or Yeasts. The Yeasts do not produce a mycelium, but the plant body consists of a single cell, or a chain of cells, and multiplies by a peculiar process known as' "yeast budding" (Fig. I5, a). From either end of the cell a wart-like process develops, which enlarges until about the size of the original cell, from which it is then separated by the forma- 
tion of a transverse wall. The cells are spherical, ellipsoidal, or egg-shaped, and in some cases somewhat elongated and hyphalike. In the protoplasm are one or more large vacuoles. In certain of the cells, which may be considered to be asci, two to eight spherical or ellipsoidal spores are produced (Fig. I6). There are a number of different species of Yeasts, some of which
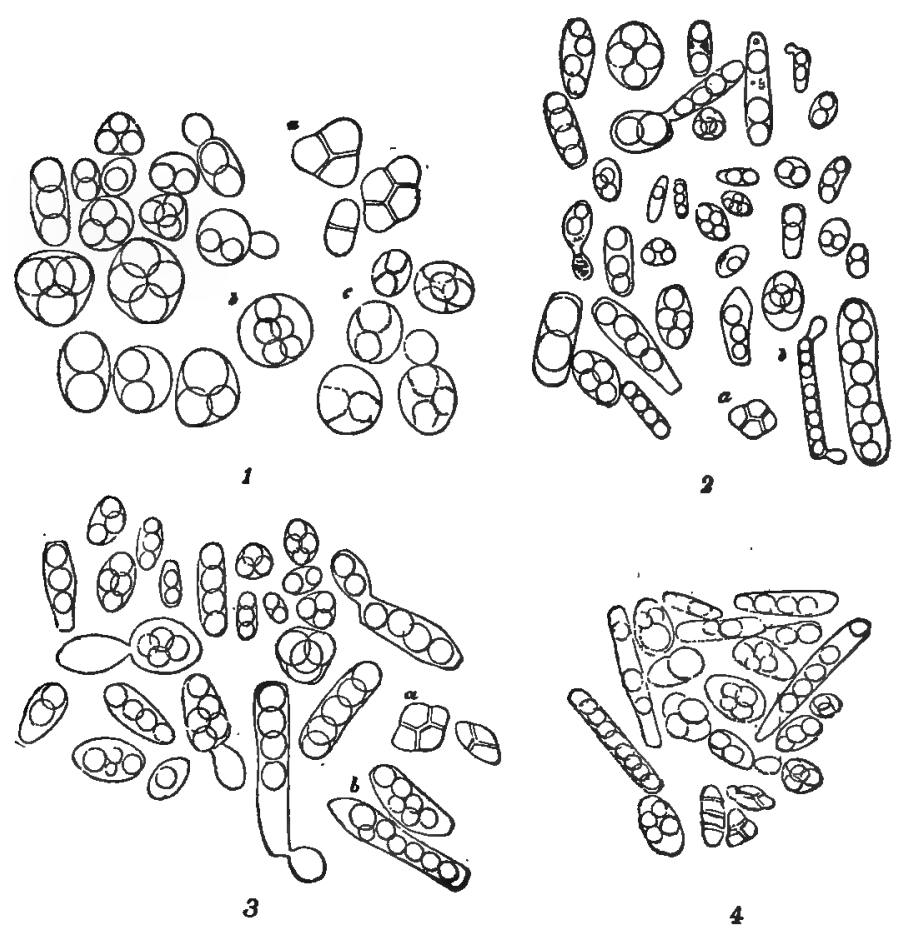

Fig. 16. Fornuation of ascospores in a number of different species of Yeasts. 1. Saccharomyces cerevisic; 2, S. Pastorianus; 3, S. intermedius; 4, S. validus. -After Hansen.

are cultivated; and these latter are of great economic importance on account of their property of inducing alcoholic fermentation. They are also of use in the making of bread, changing the carbohydrates in part into carbon dioxide and alcohol, both of which are driven off in the baking. Yeasts are always present in air and water and these constitute the so-called "wild yeasts," some 
of which cause considerable trouble in the fermentation and other industries because of the objectionable products which they form.

Green and Yellow Mildews.-To the Ascomycetes also belong the green and yellow Mildews, Penicillium and Asper-
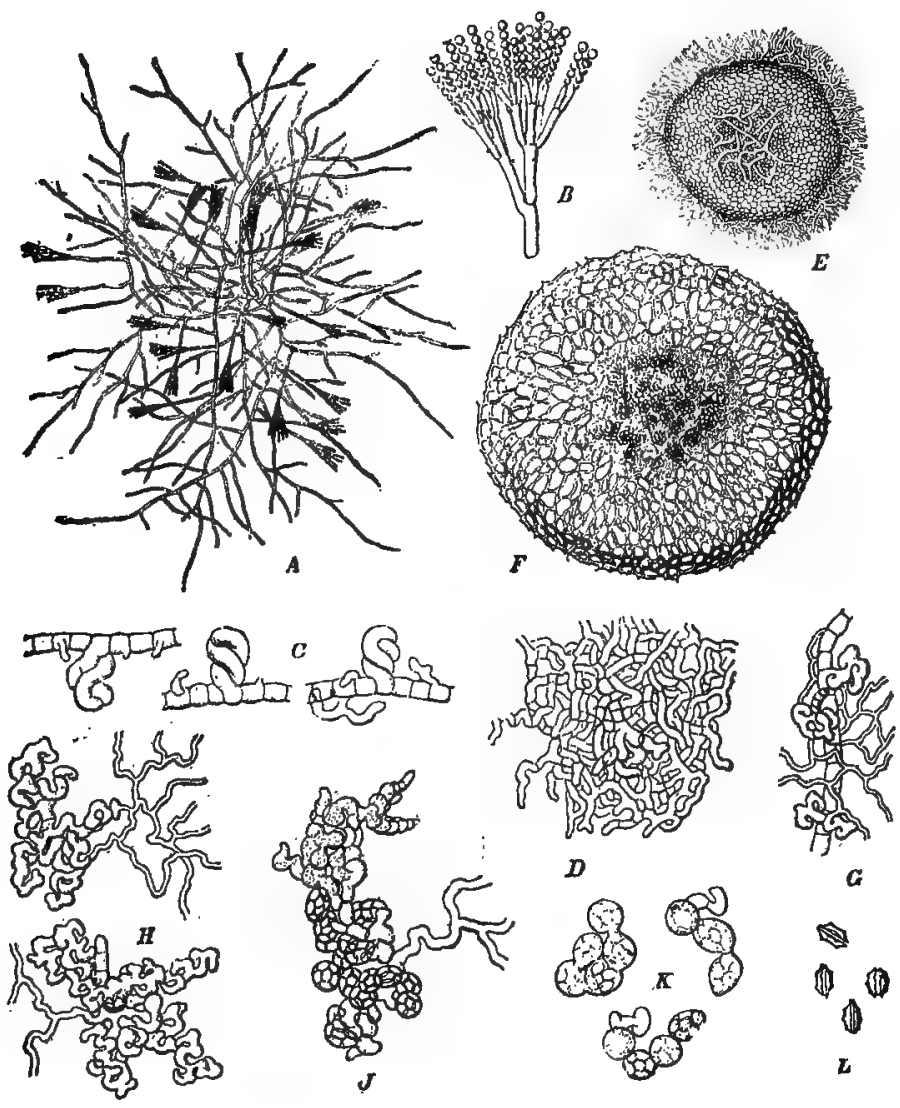

FIG. 17. Penicillium, a green mildew. A, richly branching mycelium with conidiophores; B, enlarged view of conidiophore showing chains of conidia; C, D, E, F, successive stages in the development of a perithecium; $G, H, J$, development of asci; $K$, groups of asci containing from 4 to 8 ascospores; $L$, ascospores seen from the side and showing characteristic markings. $\rightarrow$ After Brefeld.

gillus, so common in the household, the dairy, and the granary. These plants produce profusely branching mycelia which form patches upon or just under the surface of the materials upon 
which they grow. These areas become soft and spongy and are always white at first. After a time hyphal branches, which are more or less flask-shaped, rise above the substratum, and by a process of division at the end of the branch, or conidiophore, a spore called a conidiospore is formed (Fig. I7, $A$; Fig. I8, $A$ ). The process of division at the end of the conidiophore continues

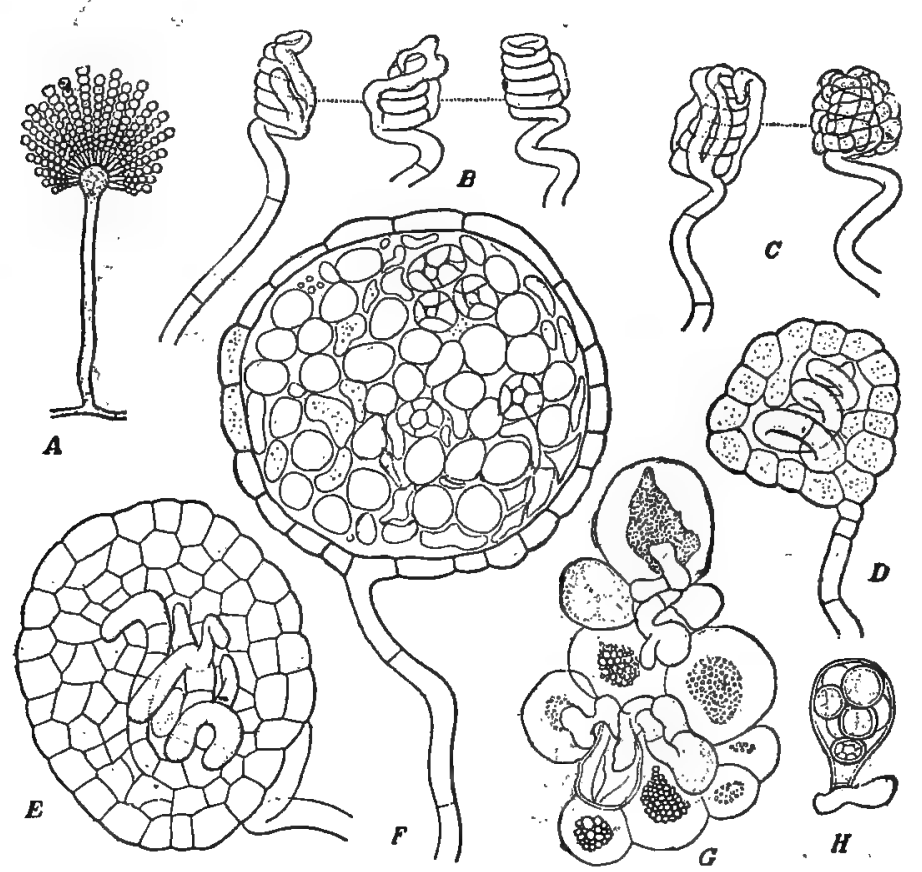

FIG. I8. Aspergillus, a yellow mildew. A, conidiophore with enlarged, more or less spherical end, from which the fan-like series of chains of conidia arise; B-E, successive stages in the development of perithecium; $F$, section through a nearly ripe perithecium; $\mathrm{G}$, groups of young asci; H, a ripe ascus with 8 spores.-A, after Kny; B-H, after De Bary.

from below until a chain of conidiospores is formed. The conidiophore frequently branches, so that a fan-like series or group of conidia or conidiospores is produced (Fig. I7, $B$; Fig. 18, $A$ ). The conidia are usually some shade of green, but finally they may become more or less brown. They are thin-walled, quite small, and so light that they float freely in the air. If a colony is inhaled it gives the sensation commonly called the "smell of mold." 
They are capable of germinating on almost everything, as old shoes, old paper, as well as on bread and other articles of the household, and are commonly found on " moldy drugs," in a nimber of pharmaceutical preparations, as syrups and infusions, and even in solutions of inorganic as well as organic chemicals.

Aspergillus (Fig. I8) is distinguished from Penicillium (Fig. I7) by the: fact that the upper end of the hyphal branch or conidiophore is somewhat enlarged and more or less spherical.

In addition to the conidiospores these fungi sometimes produce in the fall of the year, particularly when grown upon bread, asci fruits (Fig. $17, C-F$, Fig. I8, $B-E$ ). In this case two fertile initial hypha wind themselves around each other, after which they become surrounded with sterile branches which form a kind of loose tissue, more or less cellular in structure, that finally develops into a yellowish leathery wall. This body, which may be regarded as a closed ascocarp, is known as a perithecium (Fig. I7, F; Fig. $18, F)$. As a result of the conjugation of the fertile cells, asci (Fig. I $7, G, H, J$; Fig. I8, $G, H$ ) develop within the perithecium, which are more or less spherical or ellipsoidal and contain from four to eight spores (ascospores) (Fig. I7, $K$; Fig. I8, $H$ ). After maturity the cellular tissue around the asci dries up and disintegrates, the walls of the asci dissolve, and the ascospores are liberated from the perithecium by slight pressure. "The spores lie over winter and then germinate, producing a mycelium from which conidia first develop and afterwards the perithecia, thus repeating the life history of the plant.

Ergot.-Another Ascomycete of special interest is the fungus known as ergot (Claviceps purpurea). The spores of this fungus germinate on the flowers of certain grasses. The mycelium penetrates the walls of the ovary, absorbing the nutriment. After a time the mycelium develops on the surface, and from this short conidiophores arise bearing small ovoid conidia (conidiospores) (Fig. I9, $A$ ). The mycelium secretes a sweet fluid, the so-called honey dew which attracts insects, and thus the conidia are carried to other plants. As the conidia are capable of immediate germination the so-called "ergot disease" rapidly spreads during the flowering season of the host plants. After the formation of conidia ceases, the mycelium forms a dense mass which is 
surrounded by a dark layer, and this, if developed upon rye, constitutes the ergot grains (Fig. 19, B) used in medicine, these grains being a number of times larger than the rye grains which
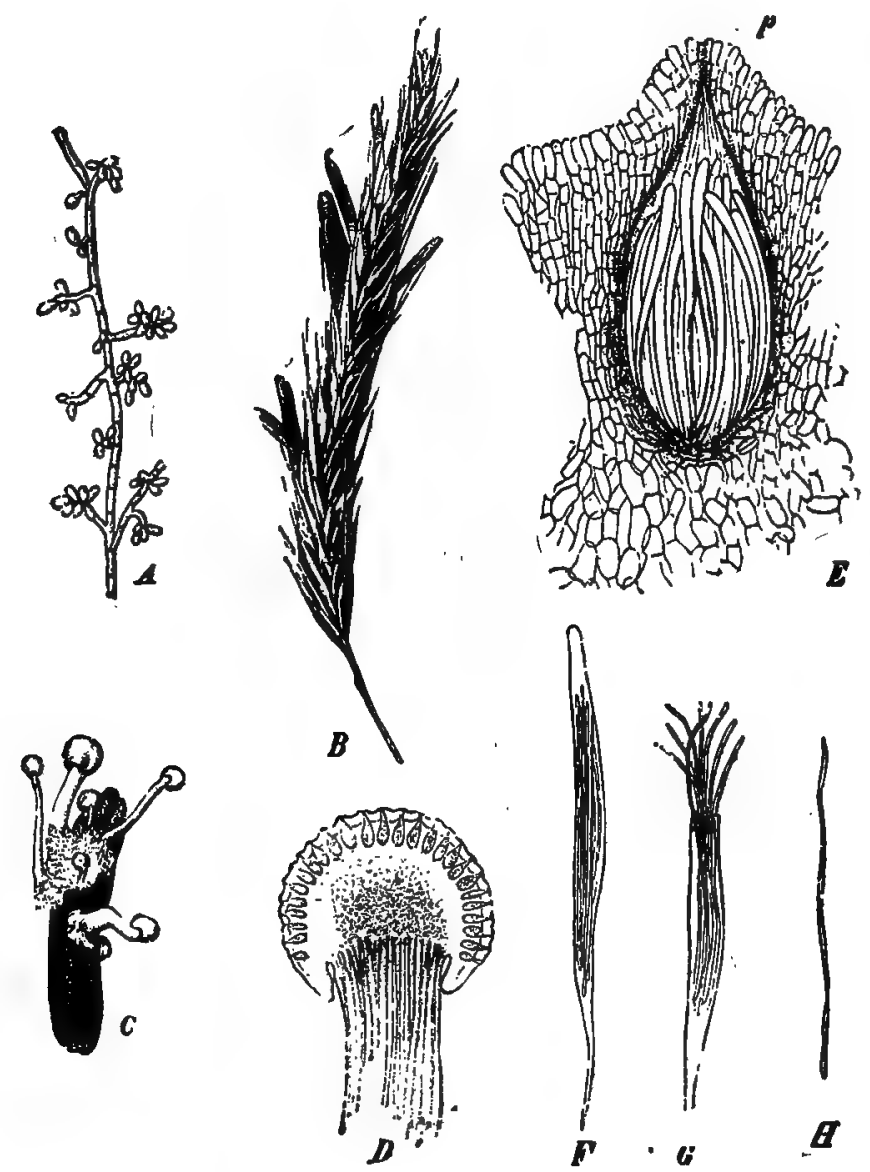

FIG. Ig. Claviceps purpurea. A, mycelium developing conidia; B, an ear of rye with a number of ripe sclerotia replacing grains of rye, and known as ergot; C, sclerotium developing spherical fruit bodies; $D$, fruit body in longitudinal section showing numerous flask-shaped perithecia at the periphery; $E_{2}$ enlarged perithecium with numerous cylindrical asci; $F$, closed ascus with 8 ascospores; $G$, discharge of ascospores; $H$, single threadlike ascospore.-A, after Brefeld; B, after Schenck; C-H, after Tulasne.

they replace. The mycelial tissues connected with the host plant die, and the ergot drops to the ground. At this stage the ergot 
mass is more or less cellular in structure and is known as the SCLEROTIUM. It is quite resistant and usually remains dormant until the following spring when the grasses are in flower again. The sclerotium then shows signs of renewed activity by the development of small, reddish, spherical bodies with a fair-sized stalk (Fig. 19, C). Within the periphery of these spherical heads
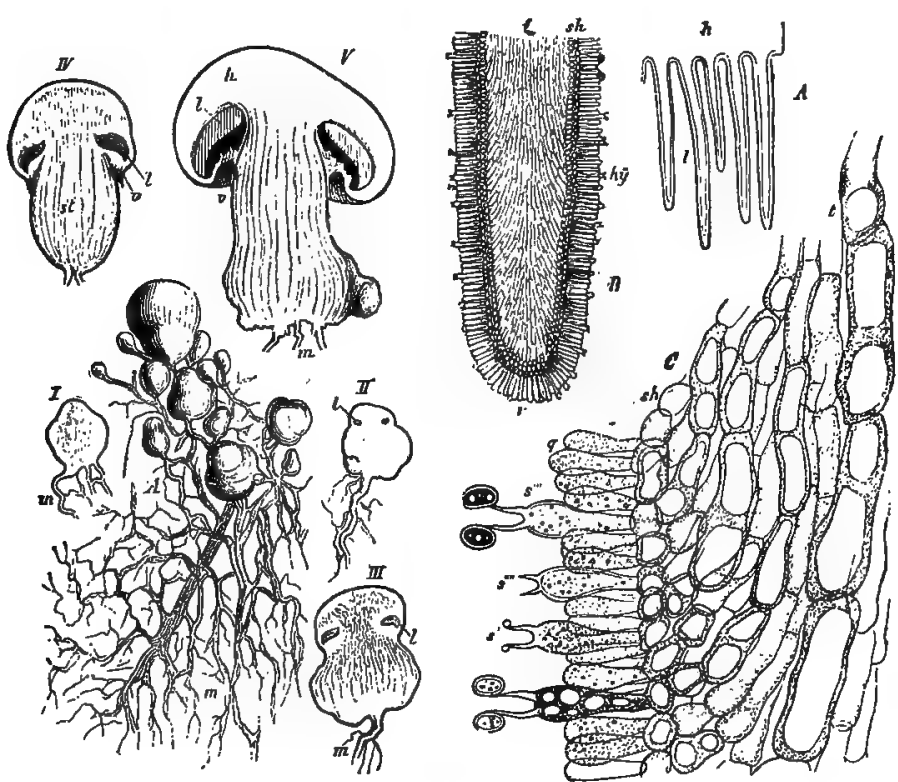

FIG. 20. Agaricus campestris, the common edible mushroom, showing at $\mathrm{A}$ on the left mycelium (m) and development of buttons or young mushrooms; I to $V$, longitudinal sections showing successive stages in development of fruit body; m, mycelium; st, stipe; 1 , portion between veil (v) and spore-bearing portion ( $h$ ).

The illustration to the right $(A, B, C)$ shows the structure of the hymenium in different degrees of magnification: A, section through portion of pilets showing five of the gills $B$, section of a gill somewhat magnified; $C$, section of gill still more magnified and showing sterile cells or paraphyses (q), and the fertile cells or basidia (s), from each of which arise two basidiospores.-After Sachs.

are produced flask-shaped perithecia or ascocarps (Fig. I9, D) containing numerous cylindrical asci (Fig. I9, E), each of which contains eight spores (Fig. I9, $F$ ) ; the latter are one-celled, hyaline and thread-like (Fig. 19, $H$ ). These spores are carried by the wind to the flowers of certain of the grasses, as already stated, and the life history or cycle of growth begins again. 

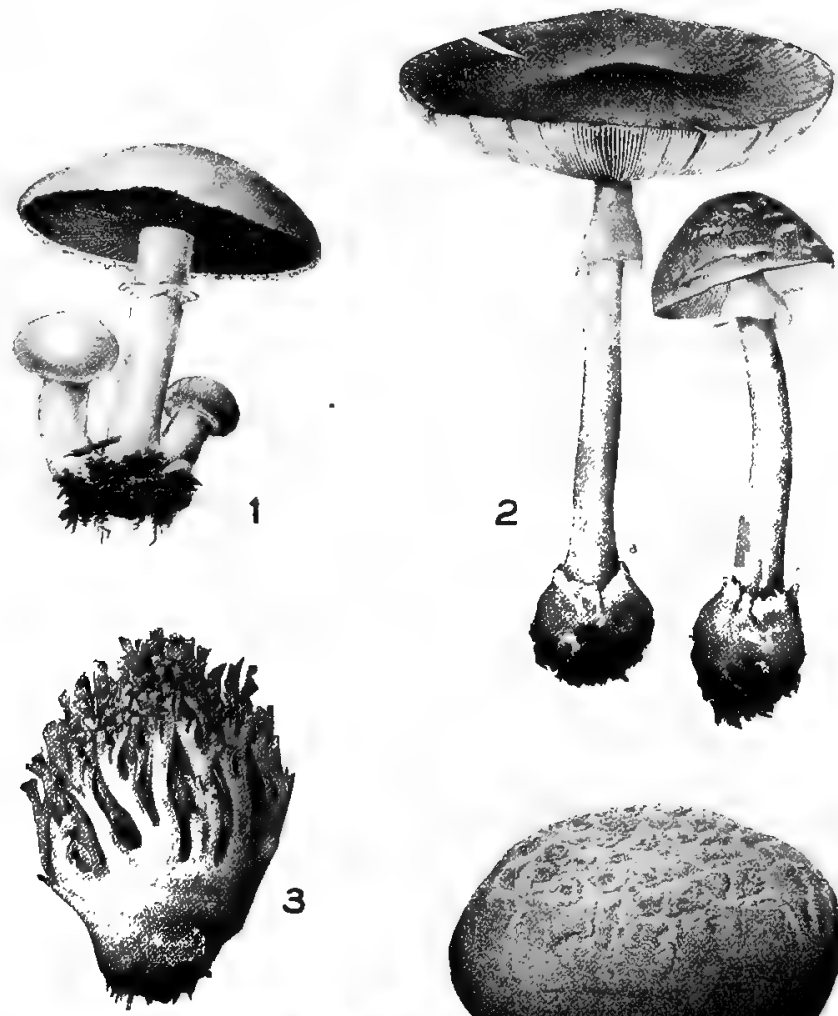

3
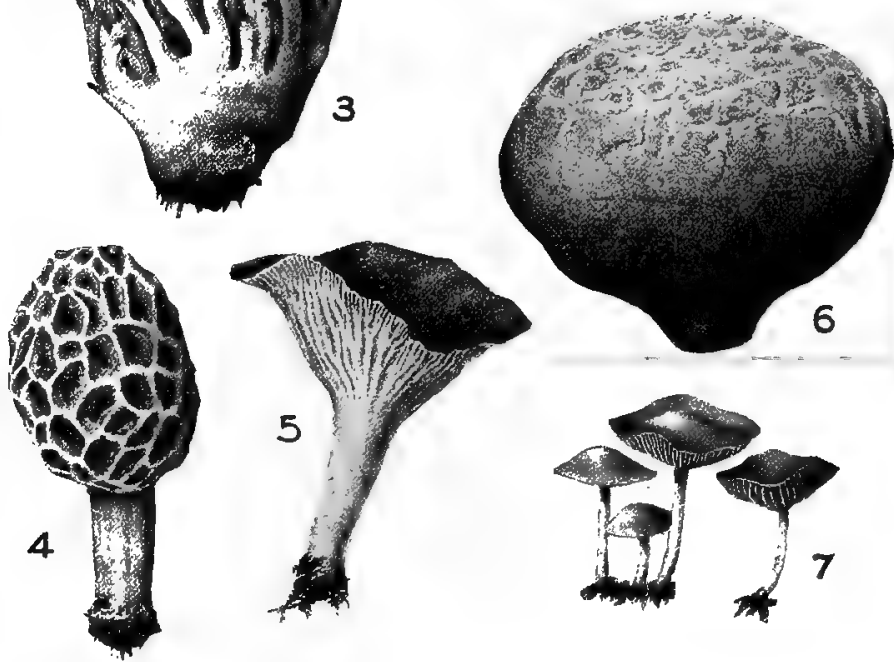

FIG. $2 \mathrm{x}$. Some common edible mushrooms and a common poisonous one. The following are edible: 1 , Common Field mushroom (Agaricus campestris); 3 , Clavaria flava. young plant; 6, Puffball (Lycoperdon cyathiforme); 4, Morel (Morchella esculenta); 5. Chanterelle (Cantharellus cibarius); 7, Fairy-ring Fungus (Marasmius oreades).

Only one poisonous species is shown, namely, 2, the deadly Agaric (Amanita phalloides). -Adapted from Farlow. 
Basidiomycetes.-The Basidiomycetes are the most highly organized of the Fungi. The mycelium consists of white branching threads and is usually concealed in the substratum. In the cultivation of the edible mushrooms propagation is by means of the mycelium which is known commercially as "spawn." It is recognized, however, that mushrooms can not be propagated in this way exclusively for more than two or three years. The mycelium is really the plant body, and the part which rises above the surface and is commonly regarded as the toadstool or mushroom (Figs. 20 and $2 \mathrm{I}$ ) is a fruit branch, or spore-producing organ. When these branches first make their appearance they are in the form of small solid bodies known as "buttons" (Fig. 20, I-V). As growth proceeds these bodies differentiate into a stalk-like portion known as the stipe (Fig. 20, st), which is directly connected with the mycelium, and an umbrella-like portion borne at the sumnit of the stalk, called a pileus, which at first is closed down over the stalk, but later expands or opens more or less widely according to the species. On the under surface of the pileus, known as the hymenium, the spores are borne (Fig. 20, $A, B, C)$. In some cases the under surface is composed of a series of narrow, radiating, knife-like plates, or gills, as in the common edible mushroom Agaricus. On the surface of the gills the basidia or spore-bearing organs arise. The basidia are somewhat swollen terminal cells of the closely arranged hyphæ composing the gills, which bear a group of spores on short stalks (Fig. 20, C). Both the basidia and spores (basidiospores) are of a characteristic size and number for the different species.

In some of the other members of the group the gills are replaced by pores, as in the "pore-fungi," which are parasites on trees and destructive to timber. In still other cases the under surface is furnished with teeth, as in the "teeth-bearing Fungi," some of which, as Hydnum repandum, form the "fairy-rings" in the woods. The latter are also formed by Marasmius oreades (Fig. 2I, illus. 7), in which the gills are comparatively few and bulge out at the middle.

One or two types will be considered, namely, the common edible mushroom and two of the poisonous group, Amanita. 
Edible Fungi.-Agaricus campestris (common mushroom) (Fig. 2I, illus. I) is practically the only edible species cultivated in this country. The plant grows wild in open grassy fields during August and September. It is not found in the mountains to any extent, and is never found in the woods or on trees or fallen trunks. The color of the stipe and the upper surface of the pileus varies from whitish to a clrab color, but the color of the gills is at first pinkish and then of a brownish-purple, which is an important character, the color being due to the spores. The stipe is cylindrical and solid, and a little more than half way up is furnished with a membranous band known as the ring. There are no appendages at the base of the stipe, which appears to rise directly out of the ground. Before the pileus is fully expanded a veil extends from its border to the stipe, which when ruptured leaves a portion attached to the stipe, and it is this which constitutes the ring. The ring shrinks more or less in older specimens but usually leaves a mark indicating where it has been formed.

Poisonous Fungi.-There are two of the poisonous group of fungi which are very common and which have some resemblance to the edible mushroom just described, namely, the fly agaric (Amanita muscaria) and the deadly agaric (Amanita phatloides) (Fig. 2I, illus. 2). The fly agaric, while more abundant in some localities than the common edible mushroom, is seldom found in grassy pastures, but more generally in poor soil, especially in groves of coniferous trees. It occurs singly and not in groups. The gills are always white; the stipe is white, hollow and provided with a ring at the top, and the base is bulbous, having fringy scales at the lower part. The pileus is yellow or orange and sometimes reddish; the surface is smooth, with prominent, angular; warty scales, which can be easily scraped off.

The deadly agaric (Fig. 2I, illus. 2) somewhat resembles the fly agaric and also differs from the common mushroom in not ustually growing in pastures. It occurs singly but not in groups, in woods and borders of fields. The gills and stipe are white, the latter, when young, having a number of mycelial threads running through it. The base is quite bulbous, the upper part of the bulb having a sac-like membrane called the volva. The pileus may vary from any shade of dull yellow to olive, although some- 
times it is shiny and white. While it does not possess the warty scales found in the fly agaric, it has occasionally a few membranous patches.

Identification of Edible Fungi.-Various rules have been given for distinguishing the edible from the non-edible fungi, many of which are practically worthless, but the following ${ }^{2}$ which have been formulated by Frofessor William G. Farlow, are well worthy the attention of the amateur collector:

"I. Avoid fungi when in the button or unexpanded stage; also those in which the flesh has begun to decay, even if only slightly.

" 2. Avoid all fungi which have stalks with a swollen base surrounded by a sac-like or scaly envelope, especially if the gills are white.

"3. Avoid fungi having a milky juice, unless the milk is reddish.

"4. Avoid fungi in which the cap, or pileus, is thin in proportion to the gills, and in which the gills are nearly all of equal length, especially if the pileus is bright colored.

" 5. Avoid all tube-bearing fungi in which the flesh changes color when cut or broken or where the mouths of the tubes are reddish, and in the case of other tube-bearing fungi experiment with caution.

"6. Fungi which have a sort of spider web or flocculent ring round the upper part of the stalk should in general be avoided.

"Rules I, 2, and 5 may for the beginner be regarded as absolute, with the exception to rule 2, Amanita ccesarea, the gills of which are yellow. Rules 3,4 , and 6 have more numerous exceptions, but these rules should be followed in all cases, unless the collector is content to experiment first with very small quantities and learn the practical result."

Economic Uses of Fungi.-A large number of the Fungi, particularly of the Basidiomycetes, are used for food. There are, however, only a few of these which enter the market. These are derived chiefly from Agaricus campestris (Fig. 21, illus. I) and Agaricus arvensis, although some other species of Agaricus

1 Yearbook of United States Department of Agriculture I897. 
as well as Morchella esculenta (Fig. 21, illus. 4) furnish excellent products and are cultivated to a limited extent. The "truffles" of the market are tuber-like masses formed under ground, which consist of the ascocarps of certain Tuberacex, one of the subgroups of the Ascomycetes, and which are used as a condiment and sometimes roasted like potatoes. Tuckahoe or "Indian bread" is also produced under ground and consists apparently of the fungus Pachyma Cocos and the roots of Liquidambar, the tissues of which have been changed into a compound resembling pectic acid by the fungus. Quite a number of Fungi have been used in medicine, as Claviceps purpurea (Fig. I9), Polyporus officinalis and other species, and various species of Lycoperdon. A number of species are used in making surgeon's agaric (Fungus chirurgorum) formerly used as a hemostatic, including Lycoperdon bovista and Polyporus fomentarius. Many of them yield very toxic principles, as (I) several species of Amanita which contain muscarine or an allied alkaloid; (2) Lactarius piperatus and others which yield highly poisonous resinous principles. Other uses of Fungi have been mentioned under the several groups.

USTILAGINEA and UREDINEA. - There are two groups of Fungi of considerable economic interest which by some writers are classed by themselves, and by others placed with the Basidiomycetes. These are the Ustilagineæ, or Smut Fungi, and the Uredineæ, or Rust Fungi.

The Smut Fungi are parasitic on higher plants. The mycelium penetrates the tissues of the host, but does not seem to cause either disease or malformation of the plant. Injury to the host results only after the development of resting spores. The mycelia are hyaline, more or less branched, and finally become septate. They send short branches, called haustoria, into the cells of the host, from which they obtain nourishment. Eventually the mycelium becomes much branched, compact and more or less gelatinous through a transformation of the hyphal walls, forming gall-like swellings or blisters on the host. Spores are formed within this gelatinous mass at the ends of the branches of the mycelium. At a later stage the smut loses its gelatinous character, the mass breaks up, and the spores are freed and distributed as a dry, dusty powder. The spores (primary conidia) 
are somewhat spherical or ellipsoidal, and are generally separate, but are sometimes united into a mass forming the so-called "spore balls." These are resting spores and upon germination (Fig. 23) produce a promycelium or basidium which becomes septate and from each cell of which conidia called sporidia arise. The sporidia are formed in succession one after another and the process continues for 'some time. On germination they bud like

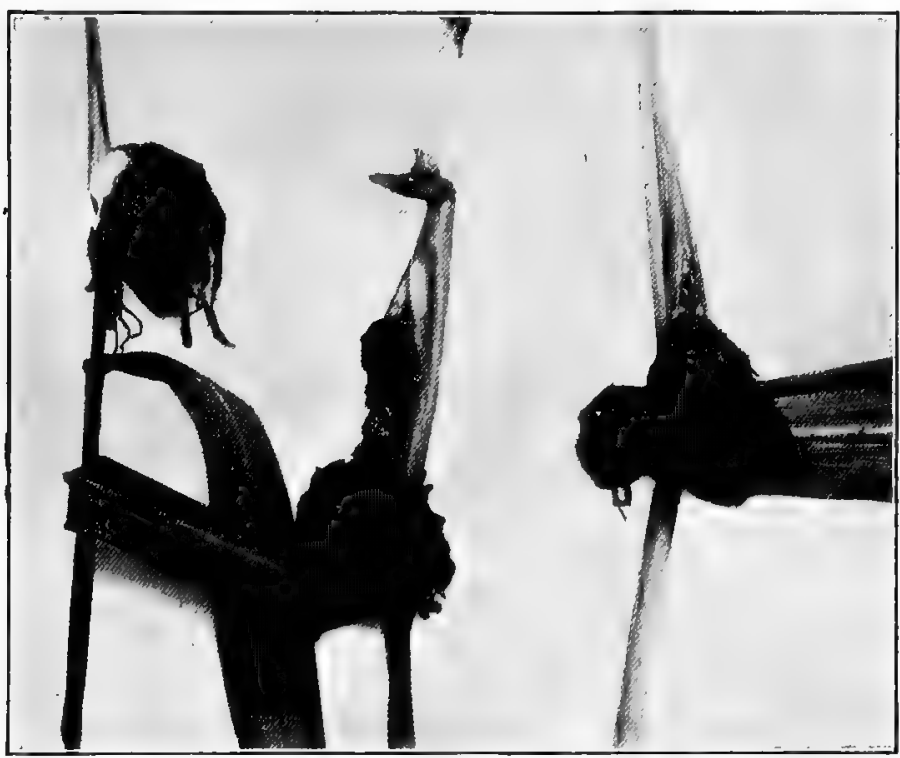

Frg. 22. Corn smut (Ustilago Maydis) showing several gall-like masses of smut full of spores.

yeast, forming new conidia, or when nutrition is not abundant they may form a mycelium, which is usually the case when they germinate on a host plant.

Corn Smut.-One of the Smut Fungi, namely, Ustilago Maydis, which develops on Indian corn (Fig. 22), is used in medicine. It forms rather large gall-like masses on all parts of the plant, including the root, stem and leaves, and both staminate and pistillate flowers. The spores (Fig. 23) are at first a dark olivegreen, but on maturity are dark brown. They are sub-spherical, have prominent spines, and vary from 8 to 15 microns in diameter. 
They do not germinate at once, but on keeping them for six months to a year they germinate readily on a culture medium of potato, and retain their power of germination for years.

Rust Fungi.-The Rust Fungi are parasitic on higher plants and produce a thread-like, branching, cellular mycelium, which develops in the tissues of the host. They differ especially
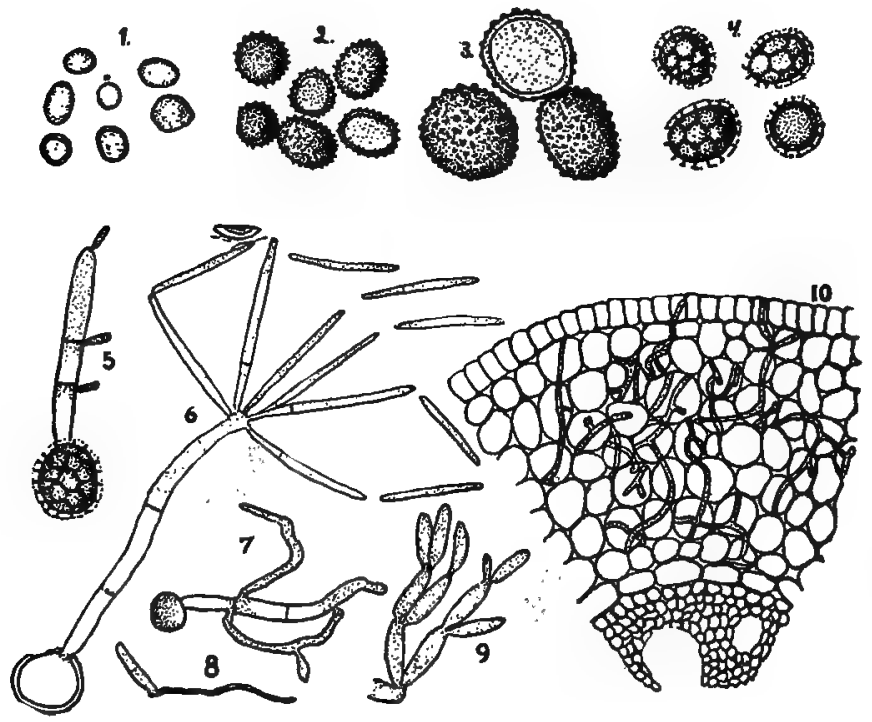

FIG. 23. Spores of various Smuts. I, Ustilago longissima growing on the reed meadowgrass (Panicularia americana); 2, Ustilago Maydis from Indian corn (Zea Mays); 3, Ustilago Oxalidis on the yellow wood-sorrel (Oxalis stricta); 4 , Ustilago utriculosa on the Pennsylvania persicaria (Polygonum pennsylvanicum).

Germination of spores of Smuts. 5, Ustilago utriculosa, in water, showing promycelium and sporidia; 6, Doassansia opaca from the broad-leaved arrow-head (Sagittaria latifolia) in water, showing promycelium, sporidia, and secondary sporidia which are falling off; 7, Ustilago avene from oat (Avena sativa) in horse dung, showing promycelium, and lateral "infection threads" or hyphæ; 8 , germination of a sporidium of Ustilago Sorghi into an infection thread; 9 , small portion of a group of sporidia developed from promycelium of Tolyposporium eriocauli in potato agar; ro, cross section of epicotyl of broomcorn infected by Ustilago Sorghi showing mycelium ramifying through parenchyma cells of the cortex.-After Clinton.

from the other Fungi in producing resting spores known as TELEutospores. These spores consist of one or more cells surrounded by a thick black wall, and they produce the "black rust" seen on foliage at the end of the season. 
Wheat Rust.-The most important member of the Rust Fungi is Puccinia, of which there are a large number of species that are destructive to economic plants as wheat, plum, cherry, red currant, etc. The one whose life history has been best

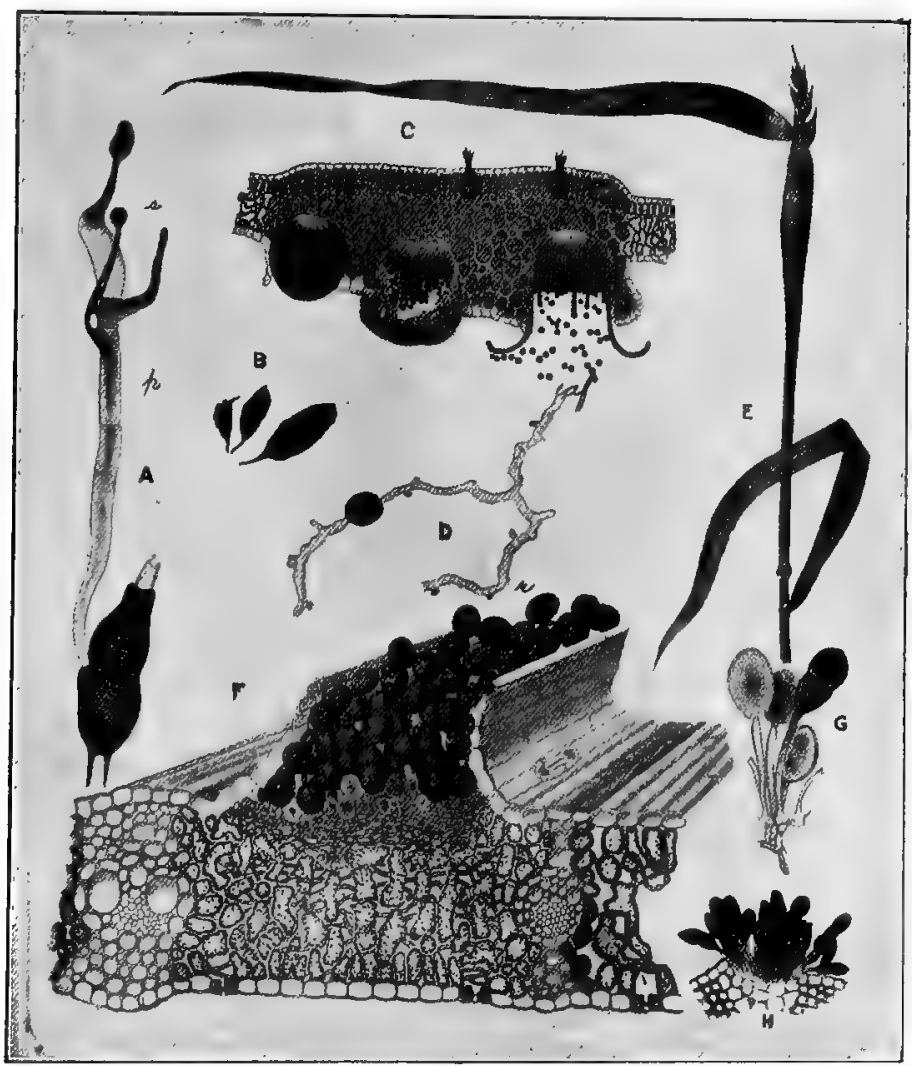

Fig. 24. Wheat rust (Puccinia graminis). A, teleutospore or winter spore germinating and giving rise to a promycelium ( $p$ ) and sporidia (s); $B$, a few leaves of barberry attacked by sporidia which give rise to the æcidia; $C$, transverse section through barberry leaf showing three cup-like receptacles (xcidia) on the lower surface of the leaf containing perpendicular rows of conidia (acidiospores); D, germinating recidiospore on wheat; $\mathrm{E}$, wheat plant attacked by æcidiospores as shown by the elongated biotches on the leaves; $F$, cross section of leaf of wheat showing on the upper surface the rust spores which are breaking through the epidermal layer (r); G, summer spores (uredospores); H, teleutospores or winter spores formed on wheat leaf.-After Dodel-Port.

studied is the wheat rust (Puccinia graminis), which requires two different plants to complete its life history, namely, wheat 
and barberry. The teleutospores or "winter spores" (Fig. 24, $H$ ), as they are called, because of their carrying the life of the plant over the winter season, consist of two cells. These spores persist on the leaves and stems of wheat over winter and in the spring they germinate (Fig. 24, $A$ ). From each cell a mycelium (promycelium or basidium) consisting of two to four cells arises (Fig. 24, $A, p$ ), and from the tip of each branch of the promycelium a spore known as a sporidium develops (Fig. 24, $A, s$ ). The sporidia are scattered by the wind and when they fall on the barberry leaves (Fig. 24, B) they germinate, producing a dense mass or mycelium which penetrates into the tissues of the host.

Sooner or later, just within the undersurface of the leaf, there is formed a more or less spherical, dense mass, which grows outward, breaking through the surface, forming a cup-like receptacle known as an æcidium (Fig. 24, C). The æcidia or cluster cups, are orange or yellow and are filled with perpendicular rows or chains of spores which arise from the basidium-like mycelium below. The spores, which have received the name AcIDIOSPOREs, are somewhat spherical or polyhedral, and contain a reddishyellow oil. They are scattered by the wind and falling upon the wheat plant (Fig. 24, E) germinate immediately, forming a dense mycelium. At first it produces what is known as a "summer spore," or UREDOSPORE (Fig. 24, G), giving rise to the reddishbrown spots and stripes on the leaves and stalks of the wheat plant. The uredospores are one-celled, and are carried by the wind to other wheat plants, thus rapidly spreading the disease.

The uredospores arise in much the same way as the teleutospores (Fig. 24,H) which form brown patches later in the season, and which have been already considered. The teleutospores last over winter on the old wheat plant, and in the spring begin again the life cycle of the rust. The plant which results from the germination of a teleutospore gives rise to sporidia which are carried to the barberry leaves where acidiospores are produced. The latter are then carried to growing wheat, forming first uredospores and later teleutospores. It should be remembered that these are all asexual spores. In regions where there are no barberry plants to act as host the acidiospore stage is omitted. 


\section{LICHENS.}

General Characters.-The Lichens are a peculiar group of plants in that an individual lichen consists of both an alga called a GONIDIUM and a fungus. These are so intimately associated that they appear to be mutually beneficial, and such a relation is known as symbiosis (Fig. 25). The Algæ which may be thus associated in the Lichens are those members of the Blue and Green Algæ which grow in damp places, as Pleurococcus, Nostoc, Lyng-

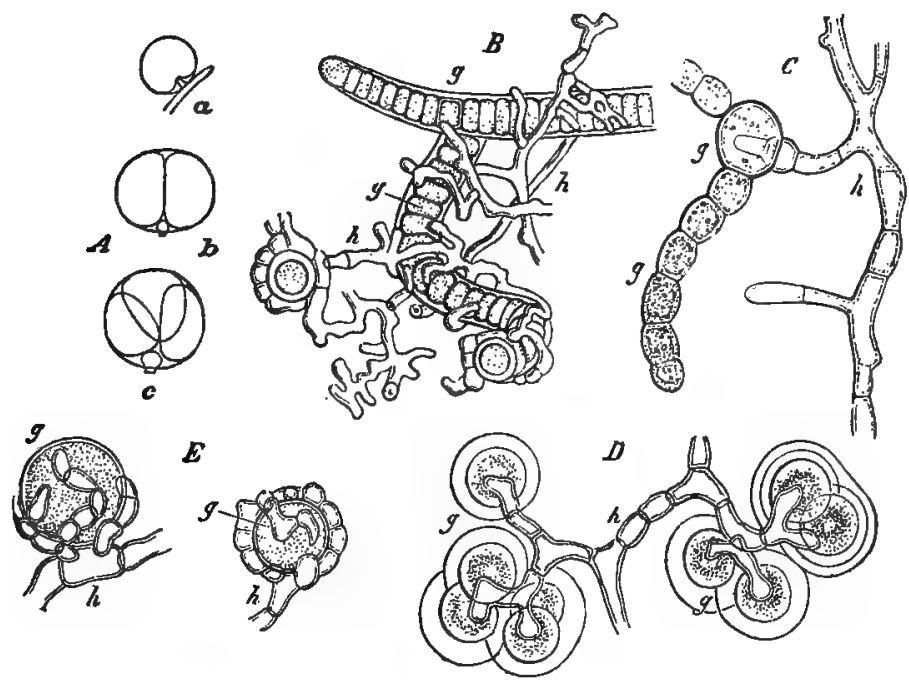

Fig. 25. Lichens showing manner of union of algæ or gonidia (g) and hyphæ (h) of Fungi. A, Pleurococcus, showing the manner in which hyphæ penetrate the cell and influence cell division; B, Scytonema, an alga surrounded by richly branching hyphæ; $C$, chain of Nostoc showing hypha of fungus penetrating a large cell known as a heterocyst; D, fungal hyphæ have penetrated the celis of Glococapsa a blue-green, unicellular alga: E, Chlorococcum, a reddish or yellowish alga found in Cladonia furcata, the cells of which are surrounded by the short hyphæ of the fungus.- $A$, after Hedlund; $B-E$, after Bornet.

bya, etc. (Fig. 25). The Fungi which occur in this relation belong both to the Ascomycetes and Basidiomycetes and it is on the characters of the fruit bodies of these particular Fungi that the main divisions of Lichens are based. The Fungi, however, are not known to exist independently of the Algæ with which they are associated, that is, the mycelia of the fungi will not live for any length of time unless they come in contact with a suitable 
alga. In its development the fungus forms a mycelium which encloses the alga, the growth of which latter is not hindered. The two organisms then continue to grow simultaneously forming lichen patches. A section of a lichen shows a differentiation into several parts, namely, a more or less compact row of cells on both surfaces forming two epidermal layers; and an inner portion made up of the hyphal tissue of the fungus in which the alga is embedded either in a single layer or throughout the mycelium. The mode of growth and branching is influenced largely by the fungus, although in some cases the alga may exert the most influence. In some cases the lichen consists of a thallus which is irregular in outline, growth taking place at no definite point, and in other cases branches which are more or less regular are formed, growth taking place at the apex.

Groups of Lichens.-According to the manner of growth and the manner of attachment to the substratum three principal groups (Fig. 26) of lichens are distinguished: namely, (I) Crustaceous Lichens, where the thallus adheres closely to the stones and barks of trees and practically can not be removed without injury; (2) Foliose Lichens, or those which are more or less flattened, somewhat leaf-like and attached at different points; (3) Fruticose Lichens, or those which are attached at a particular part of the thallus, and form diffusely branching clumps. To this latter group belongs Cetraria islandica or Iceland moss (Fig. 26, illus. 5) which is used in medicine, Usnea barbata and the redfruiting Cladonias which are so common (Fig. 26, illus. 2).

Reproduction in the Lichens takes place in several ways. In all of them there is a vegetative mode by means of what are known as SOREDIA. These are small spherical bodies consisting of a group of algal cells, which are surrounded by a mass of hyphæe, and which when cut off from the main body are able to grow. Lichens also produce spores of a number of kinds. In the largest group, the one to which Cetraria (Fig. 26, illus. 5) belongs, the spores are found in special spherical receptacles, known as PYcNIDIA, which are formed on the teeth of the margin of the thallus. The spores arise from the ends of hyphæ at the base of the pycnidia and are in the nature of conidiospores. To these spores the name PYCNOCONIDiA has been applied. Cetraria also pro- 
duces, like many other Lichens, disk-like or cup-shaped bodies at various places on the surface of the thallus, which are known as APOTHECIA and which may be regarded as exposed or open ascocarps. The inner surface of the apothecia is lined with a number of asci as well as sterile cells, the former giving rise to ascospores.

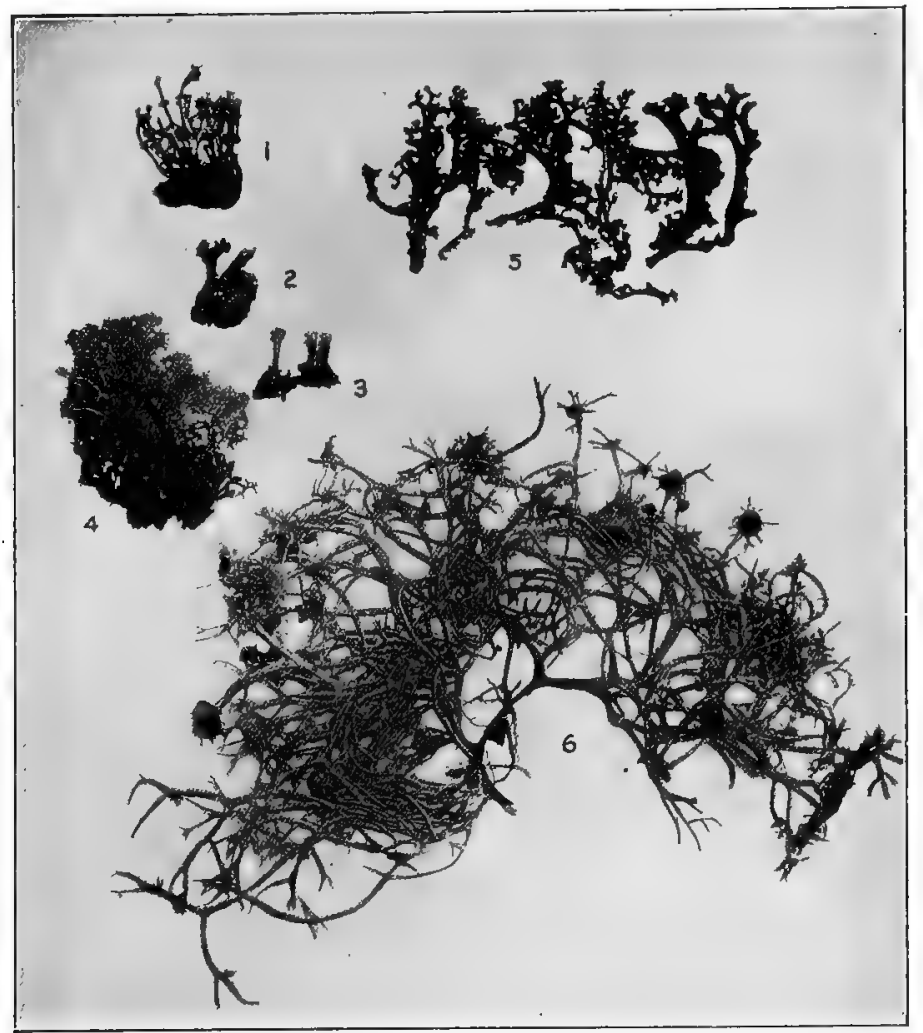

Frg. 26. Different types of Lichens. I, Cladonia gracilis var. verticillata showing long, slender, upright thalli or podetia; 2, Cladonia cornucopioides, the disk at the summit of a podetium being bright scarlet; 3. Cladonia fimbriata with long, slender podetia; 4, Cladonia rangiferina a very abundant, wiry, fruticose Lichen; 5, Cetraria islandica; 6, a specimen of Evernia vulpina found growing on Pinus Lambertiana in California, known as the Wolf's moss, and showing the large, disk-like, terminal apothecia bearing thalloid filaments.

Economic Uses of Lichens.-A number of the Lichens are used in medicine, as several species of Cetraria, Pertusaria communis, Physcia parietina, Sticta pulmonacea, Evernia furfuracea. 
Some of those used in medicine, are also used as foods on account of the gelatinous carbohydrate lichenin which they contain. Besides those given the following may be mentioned: Cladonia rangiferina (reindeer moss), Lecanora esculcnta (supposed to be the manna of the Israelites. The Lichens are, however, chiefly of interest because of the coloring principles which they contain. Roccella tinctoria, Lecanora tartarea, and other species of Lecanora, yield upon fermentation the dyes orcein and LITMUs, the latter of which finds such general use as an indicator in volumetric analysis. Cudbear, a purplish-red powder, is prepared by treating the same lichens with ammonia water; while in the preparation of orchil, a purplish-red pasty mass, sulphuric acid and salt are subsequently added. A number of species contain a yellow coloring principle, as Zeora sulphurea, Zeora sordida, Lecidea geographica and Opegrapha epigaea.

\section{BACTERIA.}

The Bacteria, or Fission Fungi, occupy rather an anomalous position, some writers classifying them with Fungi and some with Algæ. They are I-celled plants, microscopic in size, and of various shape. The contents consist of protoplasm and a central body in some cases, which is looked upon as a rudimentary nucleus. They are more or less colorless, but sometimes produce a distinct pigment called bacteriopurpurin which is rose-red or violet, and occasionally a chlorophyll-green color substance. They are capable of multiplying by division in one, two, or three directions, and under favorable conditions increase very rapidly in number. The wall is more or less albuminous in character, in this respect resembling the wall of the animal cell, and is provided with one to many cilia, or flagella, the number and position of which have been used as a basis of classification. Sometimes the walls of the cells become mucilaginous, so that the bacteria hold together forming a mass known as a zoöglœa. Bacteria may form resting spores which arise in two ways. In one case the contents round off and take on a membrane forming a so-called ENDOSPORE; in the other case the plant body is transformed directly into a spore known as an ARTHROSPORE, as in some of the Blue- 
green Alga. This body is not strictly a spore but is in the nature of a resting cell (Fig. 26a).

Occurrence.-Bacteria occur everywhere in nature, and play a most important part in decay and putrefaction in that they change dead animal and plant tissues back again into simple inorganic substances, as carbon dioxide, water, ammonia, etc. They
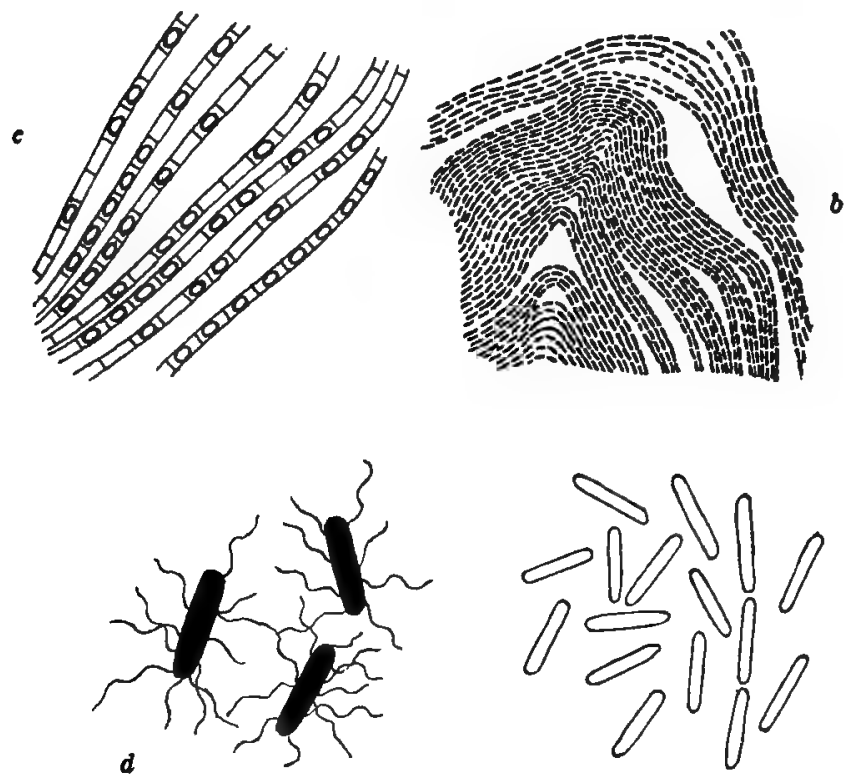

$a$

FIG. 26a. Bacillus subtilis (hay bacillus). a, Small rod-like organisms such as are found in an infusion of hay, or botillon; b, zoögloea or mass of bacilli forming the "skin " on the surface of infusions; $c$, chains of organisms forming spores; $d$, individual bacilli showing flagella, which are only seen after staining.-After Migula.

serve a useful purpose in many technical operations, as in the making of cheese, acetic acid, fermentation of tobacco, curing of vanilla and many vegetable drugs, and in soil nitrification, helping to change ammonia into nitrates- - one of the sources of the nitrogen used by plants (see page 98). Many of them are diseaseproducing, or pathogenic, and are the cause of a number of infectious diseases in man and the lower animals, and plants as well. They are injurious in two ways, in one case they consume the 
tissues of the host, as in tuberculosis, and in the other they produce powerful poisonous substances, or toxins, as in diphtheria.

Classes of Bacteria.-In order to study Bacteria they are grown upon nutrient media, such as sterile bouillon, potato, milk, etc. They are divided into a number of classes, depending for the most part on the shape of the cell: (I) The Sphærobacteria, or Cocci, are those whose cells are spherical or spheroid, and in which division takes place in one, two or three directions of space. Very few of the group are provided with cilia. According to the number of cells in a colony they are distinguished as Micrococci, Diplococci, etc. (2) Bacteria proper are elongated, rod-shaped organisms in which division occurs in only one direction, namely, transversely to the long axis, and only after a preliminary elongation of the bacterium. The Bacteria are subdivided into two important groups, namely, Bacterium and Bacillus. The Bacilli are motile organisms and produce endospores (Fig. 26a), whereas the Bacteria are non-motile and do not usually produce endospores. (3) Spiral bacteria constitute the third principal group and are characterized by the cells being spirally coiled. Division is in only one direction. These bacteria are usually motile, and seldom produce endospores. (4) There is another important group which includes the Sulphur Bacteria, of which the most common one is Beggiatoa. These occur in long threads, and move in an undulating manner much like Oscillaria, one of the Blue-green Algæ. They are found in sulphur waters, as in sulphur springs, and contain sulphur granules.

\section{ARCHEGONIATES.}

The two main features which distinguish the Archegoniates from the Thallophytes are the structure of the sexual organs and the distinct manner in which the peculiar phases known as alternation of generations is shown. The antheridium or male sexual organ is a well differentiated multicellular body which is either sunk in the adjacent tissues of the plant or is provided with a stalk. Within it are organized the sperms or spermatozoids, which are ciliate and swim freely in water. Corresponding to the oögonium of the Thallophytes is the ARCHEGonium or female sexual organ 
which gives name to the group. The archegonium is a flaskshaped cellular body consisting of a basal portion or venter, which contains a single egg, and a neck through which the sperms enter (Figs. 32, 34).

In the life history of this group of plants there are two generations or phases of development. During one stage the archegonium and antheridium are developed and this is known as the sexual generation, and as these organs give rise to gametes or sexual cells it is also spoken of as the GAMETOPHYTE. By the union of the sex cells (sperm and egg) an oöspore is formed which germinates at once within the archegonium. That portion of the plant which develops from the oöspore gives rise to asexual spores and hence this phase is called the asexual generation. It is also spoken of as the sporophyTe from the fact that it gives rise to spores. These spores are in the nature of resting spores and do not germinate on the plant as does the oöspore. They are distributed and on germination give rise to the gametophyte stage.

In some of the Archegoniates these two phases are combined in one plant as in the Bryophytes, whereas in other members of the group the two phases are represented by two distinct plants, that is, the gametophyte and sporophyte become independent of each other, as in the Ferns.

The following table shows the main divisions and subdivisions of the Archegoniates:

$$
\text { Archegoniates }\left\{\begin{array}{l}
\text { Bryophytes..... }\left\{\begin{array}{l}
\text { Hepatica (Liverworts). } \\
\text { Musci (Mosses). }
\end{array}\right. \\
\text { Pteridophytes... }\left\{\begin{array}{l}
\text { Filicales (Ferns). } \\
\text { Equisetales (Horsetails). } \\
\text { Lycopodiales (Club Mosses). }
\end{array}\right.
\end{array}\right.
$$

BRYOPHYTES.

The structure of the sexual organs in the Liverworts (Fig. 27) and Mosses (Fig. 32) is essentially the same, but the vegetative organs are more or less dissimilar. In the Liverworts the plant 
body or thallus lies more or less close to the substratum or rises somewhat obliquely, whereas in the Mosses the part we designate as the plant is in all cases an upright leafy branch. The moss plant is said to have a radial structure from the fact that the leaves radiate from a central axis, while in the Liverworts the thallus is dorsiventral, that is, as a result of its habits of growth, it is characterized by having a distinct upper and lower surface.

The Life History of this group of plants may probably be best illustrated by following that of a moss plant. Beginning with the germination of an asexual spore which is microscopic in

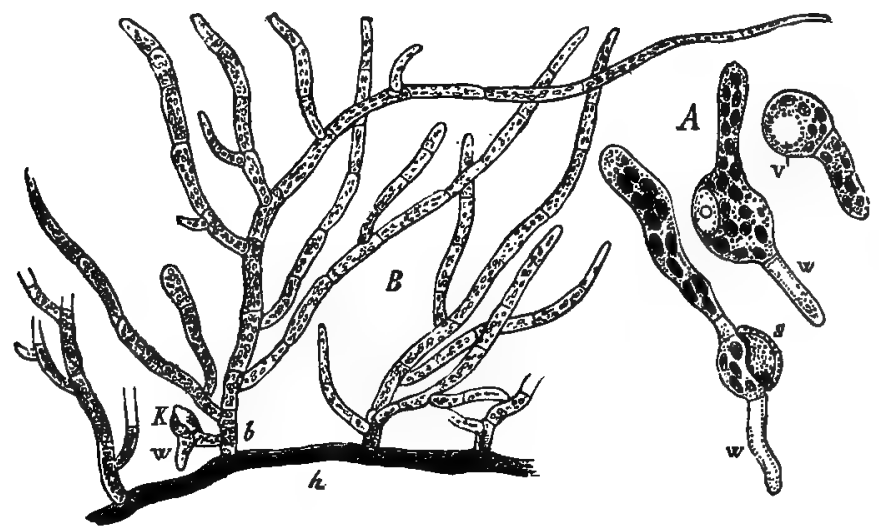

Fig. 27. A common moss (Funaria). A, germinating spores: v, vacuole; w, roothair; $\mathbf{s}$, exospore. $B$, protonema about three weeks after germination: $h$, procumbent primary shoot; $b$, ascending branch of limited growth; $K$, bud or rudiment of a leaf-bearing axis with root-hair (w).--After Sachs.

size and which germinates on damp earth, there is produced an alga-like body consisting of branching septate filaments, which is known as the protonema, or prothallus (Fig. 27). The Protonema lies close to the surface of the ground and is more or less inconspicuous except for the green color. From the lower portion thread-like processes, or rhizoids consisting of a row of cells, are developed, which penetrate the ground. Sooner or later lateral buds arise from some of the lower cells. Growth continues from an apical cell which divides and gives rise to cells that differentiate into stem and leaves, forming an upright branch, which constitutes the structure commonly regarded as the "moss-plant" 
(Fig. 28, $A$ ). The leaf-bearing axis varies considerably in size, in some cases it is but a millimeter high whereas in some species, as Polytrichum (Fig. 28), it may be several hundred millimeters

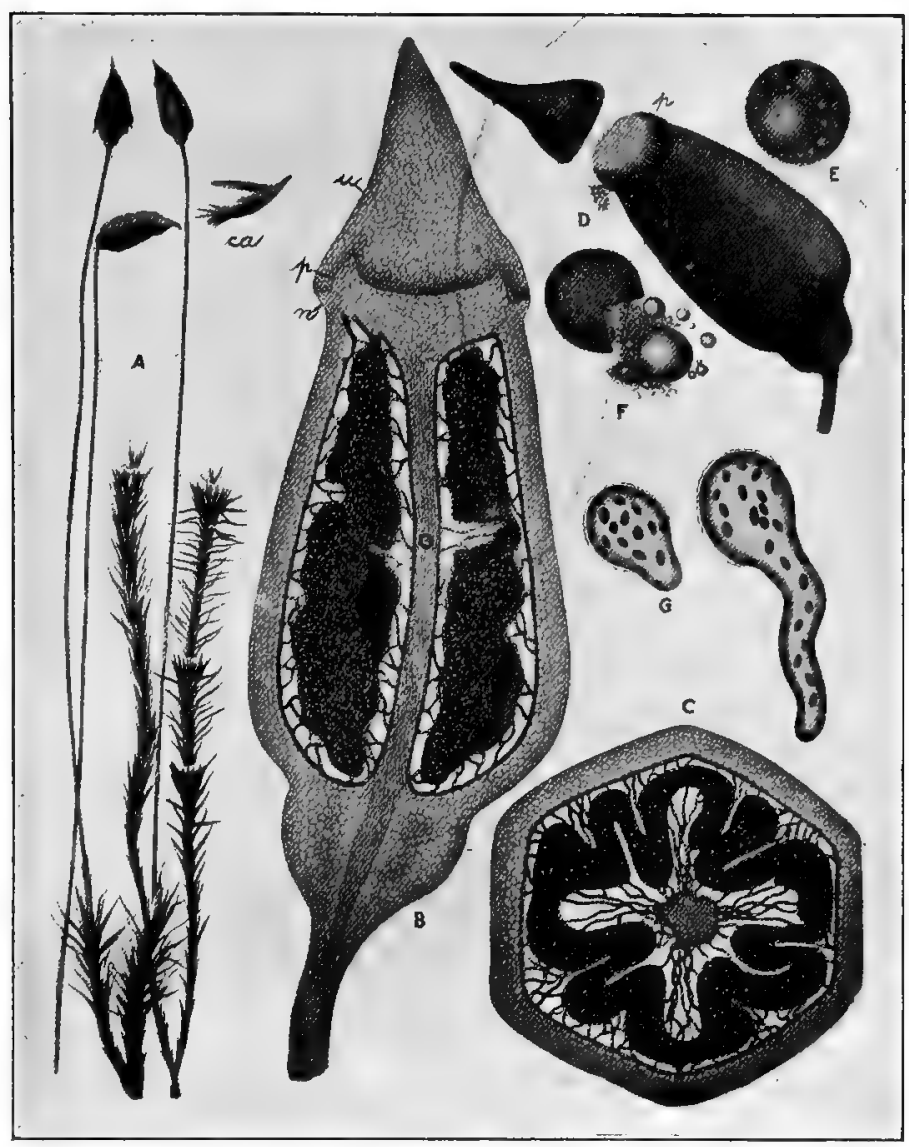

Frg. 28. A common moss (Polytrichum gracile). A, showing leafy branches (gametophores) two of which bear sporogonia, a detached sporogonium (sporophyte) with sporan. gium from which the calyptra (ca) has been detached. B, longitudinal section through a nearly ripe sporangium showing columella (o), the elongated area of sporogenous tissue (archesporium) on either side, annulus (n), peristome (p), lid or operculum (u); C, transverse section of sporangium showing columella in center and dark layer of sporogenous tissue (archesporium); D, ripe sporangium (capsule) showing the escape of spores after detachment of lid; $E$, ripe spore containing large oil globules; F, ruptured spore showing separated protoplasm and oil globules; $G$, two germinating spores i 4 days after being sown, showing beginning of protonema in which are a number of ellipsoidal chloroplasts. -After Dodel.Port. 
in height. At the tip of the branch the antheridium (Fig. 32, $A$ ) and archegonium (Fig. 32, $B$ ) are formed. These organs are developed in among the leaves and certain hairy processes, known as paraphyses (Fig. 32, p). They may both occur at the end of one branch (Fig. 32, C) or they may occur on separate branches (Fig. 32, D), when the plants are said to be monœcious, whereas when these organs occur on separate plants (Fig. 32, $A, B$ ) the plants are called diocious. In the case of dicecious plants the plant bearing the antheridium is frequently smaller and less complex than the one producing the archegonium. As already stated the archegonium produces the egg-cell or female gamete (egg) and the antheridium, the sperm cell or male gamete (sperm).

The sperms in the Bryophytes are more or less filiform and are provided with a pair of cilia at one end. The antheridia owing to the peculiar mucilaginous character of the cells only open when there is an abundance of moisture, when the sperms are discharged and move about in the water, some being carried to the archegonium, which likewise opens only in the presence of moisture. With the transferral of the sperms to the archegonium and the union of one of these with the egg which remains stationary, the work of the gametophyte may be said to be completed. The act of union of the egg and sperm is known as FERTILIZATION, and when this is effected the next phase of the life history begins.

The egg after fertilization divides and re-divides within the archegonium which becomes somewhat extended until finally it is ruptured. The dividing cells differentiate into a stalk and a spore case or sporangium which is borne at the summit, the whole structure being known as the SPOROGONIUM (Fig. 28). The base of the stalk is embedded in the apex of the moss plant, and is known as the foot, it being in the nature of a haustorium or nourishing organ. As the sporogonium develops and rises upward it carries with it the ruptured archegonium which forms a kind of covering over the top, called the calyptra (Fig. 28, ca). At first the sporangium is more or less uniform but eventually differentiates into two kinds of tissues, the one being sterile and the other fertile (producing spores), which latter is known as the ARCHESPORIUM (Fig. 28, 
$B, C)$. The fertile tissue in both the Liverworts and Mosses is variously disposed; sometimes it forms a single area and is dome shaped, spherical, or in the form of a half sphere. In other cases it is separated into two areas by sterile tissue. The sterile tissue which extends up into the dome-shaped archesporium, or which in other cases separates the fertile tissue into two parts, is known as the columella (Fig. 28, $B, C$ ). The sporangium in the mosses is capsule-like and the spores are distributed in three ways: (I) In some cases the capsule does not open, but when it decays the spores are liberated. (2) In other cases the capsule dehisces longitudinally in dry weather and thus the spores are freed. (3) There is a third method in which the capsule is provided with a lid or operculum which comes off and permits the spores to escape, this being the most common method for the escape of the spores (Fig. 28, D). In the latter instance the mouth of the capsule is usually marked by one or two series of cells, constituting the PERISTOME, which are teethlike and characteristic for some of the groups of mosses. These teeth bend inward or outward according to the degree of moisture and assist in regulating the dispersal of the spores. In the sphagnum mosses there is no peristome, but, owing to unequal tension of the lid and capsule on drying, the lid is thrown off, and the spores are sometimes discharged with considerable force and sent to quite a distance (as much as Io centimeters), in this way insuring their dispersal.

The spores (Fig. 28, E) vary in diameter from ro to 20 microns, being sometimes larger. They occur in groups of four in a mother-cell, and the spore-group is known as a tetrad, which is characteristic for the Bryophytes and the higher groups of plants. The spores therefore vary in shape from spherical tetrahedrons to more or less spherical bodies, depending upon the degree of separation. The contents are rich in protoplasm and oil (Fig. 28, F). The wall consists of two layers, the outer of which is either yellowish or brown and is usually finely sculptured. At the time of germination the outer wall is thrown off, and the protonema develops (Fig. 28, G). The spores may germinate almost immediately, or only after a considerable period. These spores are asexual and each one is capable of giving rise to a 
new plant. With the formation and dispersal of the spores the work of this generation terminates, and this phase is called the sporophyte or asexual generation, from the fact that it produces spores.

Having thus followed the stages of development in the lifehistory of a moss, we see that it is composed of the following

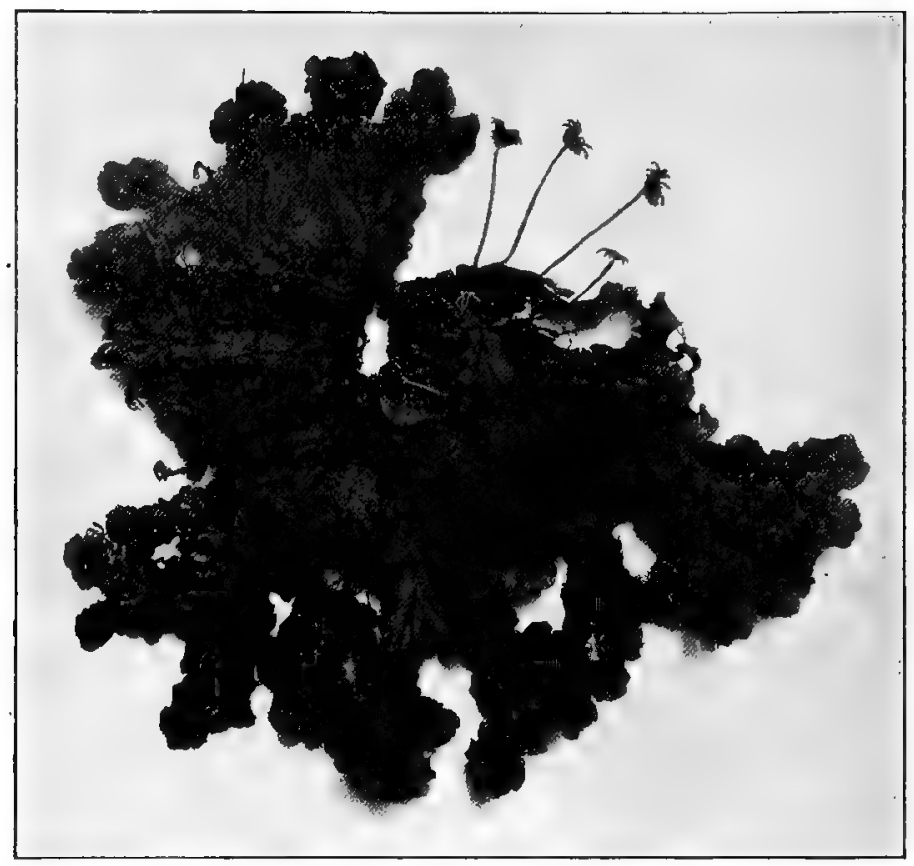

FIG. 29. Dichotomously branching thallus of the common liverwort (Marchantia polymorpha) showing rather faintly near some of the margins the cup-like depressions in which gemmæ are borne, and several archegoniophores at the upper part.

parts: (I) The alga-like protonema; (2) the leafy branch which gives rise to an oöspore (sexual spore), and (3) the sporogonium which produces asexual spores. The leafy branch is sometimes spoken of as the gametophore (gamete-bearer), and it and the protonema together constitute the gametophyte or sexual generation, while the sporogonium represents the sporophyte or asexual generation. 
The protonema sooner or later dies off in most plants, but in other cases it persists, forming a conspicuous portion of the gametophyte.

\section{HEPATIC无.}

General Structure.-The Hepaticæ or Liverworts (Fig. 29) are usually found in moist situations. The protonema formed on germination of a spore is filiform, and the plant body which develops from it consists of a flat, dichotomously-
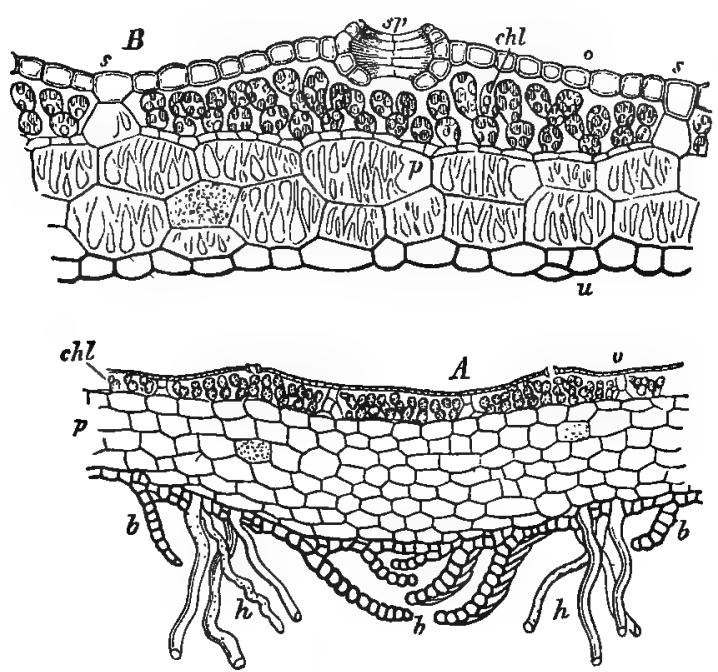

Fig. 30. Transverse section through the thallus of Marchantia polymorpha. A, middle portion with scales (b) and rhizoids (h) on the under side; $B$, margin of the thallus more highly magnified, showing colorless reticulately thickened parenchyma (p), epidermis of the upper side (o), cells containing chlorophyll (chl), air pore (sp), lower epidermis (u). -After Goebel.

branching thallus, or it may in some of the higher forms differentiate into a leafy branch as in the leafy liverworts. The thallus, owing to its position, has an upper and an under surface which are somewhat different, as in Marchantia (Fig. 29), hence it is said to be Dorsiventral. From the lower colorless surface unicellular rhizoids arise (Fig. $30, h$ ): The upper surface consists of several layers of cells containing chlorophyll which give the green color to the plant. 
Vegetative propagation may ensue by the lower portion of a branch dying and the upper portion continuing as an independent plant. Or special shoots known as GEMM either on the margin of the thallus or in peculiar cupules, which when detached by rain or other means, are capable of growing and producing a new plant.

In addition the thallus body produces both antheridia and archegonia (Fig. 29) which may rise on special stalks above the surface. After fertilization of the egg-cell which completes the work of the sexual generation or gametophyte, the sporophyte develops producing a sporogonium consisting of a short stalk which is embedded in the tissues of the gametophyte, and a capsule (sporangium). The latter at maturity dehisces or splits and sets free the spores, which are assisted in their ejection by spirally banded cells called "elaters" (Fig. $3 \mathrm{r}, C-F$ ). The spores on germination give rise to a protonema which then develops a thallus bearing the sexual organs. As in the mosses the sporogonium represents the asexual generation known as the sporophyte.

Liverwort Groups.-There are three important groups of Liverworts: (I) The marchantia group (Fig. 29) in which the thallus is differentiated into several layers and so somewhat thickened. Another character is the diversity in form of the sexual organs which range from those which are quite simple to those which are highly differentiated. In Riccia the sexual organs are embedded on the dorsal (upper) side of the thallus, while in Marchantia they are borne upon special shoots, one, which has a disk at the apex that bears the antheridia, known as the antheridiophore, and one, the apex of which consists of a number of radiate divisions and bears the archegonia (Fig. 29) on the lower surface, known as the archegoniophore; these being borne on separate plants. In Riccia, the simplest of the Liverworts, the sporangium is enclosed by the thallus and the spores are not liberated until the decay of the plant.

(2) The Jungermannia Group, known as "Leafy Liverworts " or "scale mosses," includes those forms which are more or less moss-like and develop stems and small leaves. The sporogonium has a long stalk and the capsule is 4-valved, i.e., separates into four longitudinal sections at maturity. 
(3) In the Anthoceros Group (Fig. 3r) the gametophyte is thallus-like and very simple in structure, the sexual organs being embedded in the thallus. The sporogonium is characterized by a bulbous foot and an elongated, 2-valved capsule. Like the thallus it develops chlorophyll and possesses stomata resembling those found in certain groups of mosses and higher plants.

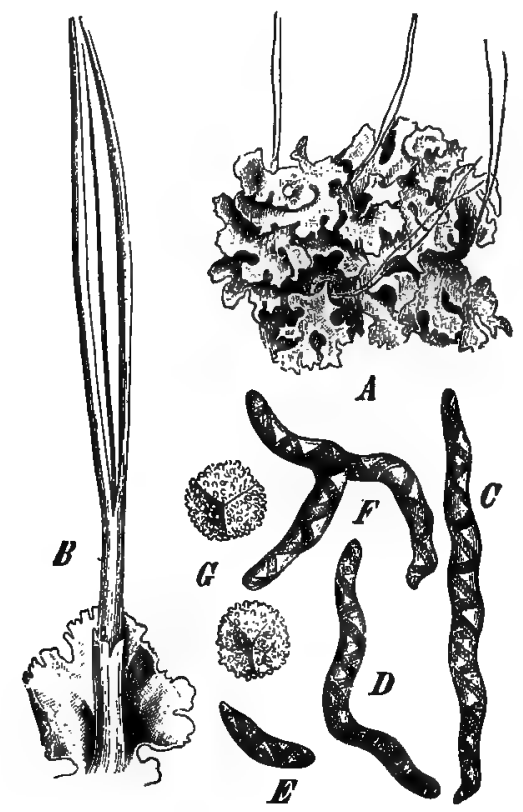

Fig. 3I. Anthoceros gracilis, one of the liverworts. A, thallus with 4 sporogonia; $B$, a ripe elongated sporogonium, dehiscing longitudinally and showing two valves between which is the slender columella; C, D, E, F, various forms of elaters; G, spores.-After Schiffner.

\section{MUSCI.}

In the Mosses the archegonia always form the end of the axis of a shoot, whether this be a main one or a lateral one. As has already been stated ( $p .48$ ) the sexual organs are surrounded by leaves or leaf-like structures, known as perichætia or perichætal leaves, and by hair-like structures or paraphyses, both of which are considered to act as protective organs. Sometimes the groups of sexual organs together with the protective organs 
are spoken of as the "moss flower." As already stated the Mosses are both monœcious (Fig. 32, C, D) and diocious (Fig. 32, $A$, $B$ ), hence a moss flower may contain only one of the sexual

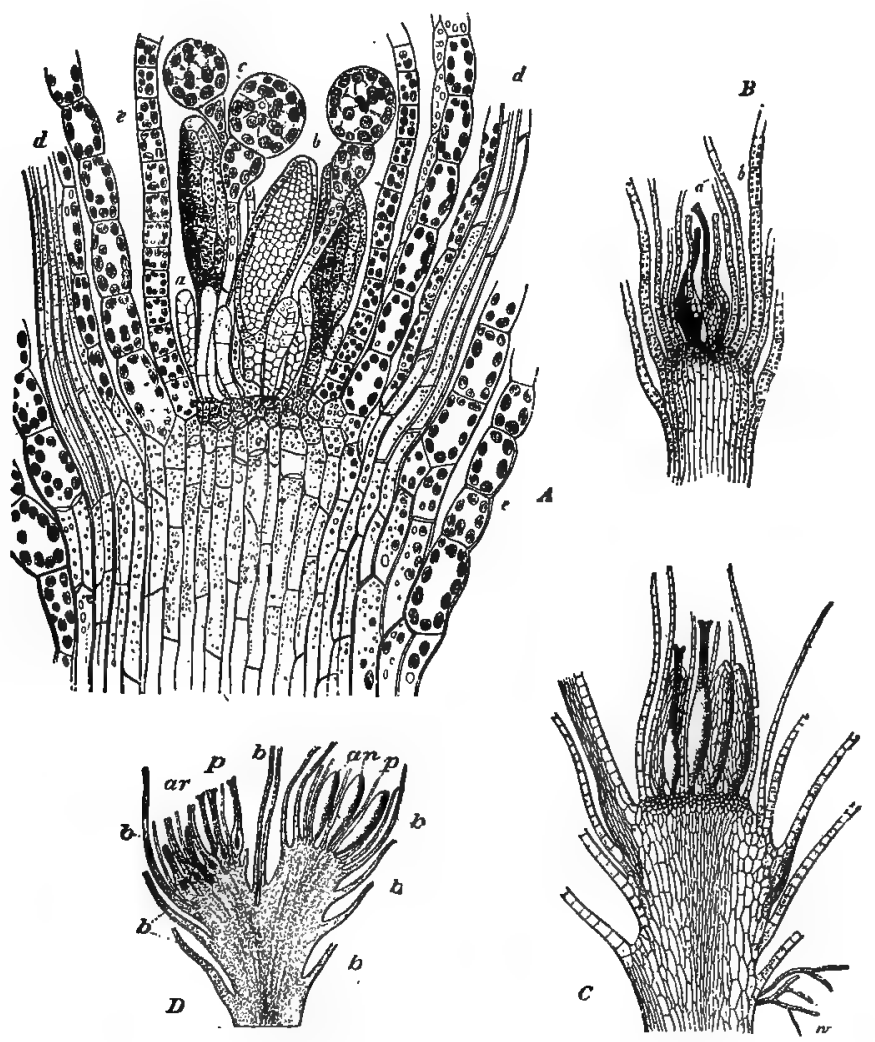

FIg. 32. Longitudinal sections through tips of leafy branches of mosses. A, showing antheridia $(a, b)$ in different stages of development and paraphyses or cell-threads (c), the apical cell of which is spherical and contains chlorophyll, and leaves (d, e); B, showing archegonia (a) and leaves (b); C, section of Bryum showing both archegonia, and antheridia, paraphyses and leaves; $D$, section of Phascum showing archegonia (ar). antheridia (an), thread-like paraphyses (p), and leaves (b).-A, and B, after Sachs; C, after Limpricht; D, after Hofmeister.

organs or it may contain both. Mosses are also characterized by an abundant vegetative propagation. New branches are developed from the old. "Almost every living cell of a moss can grow out into protonema, and many produce gemmæ of the most dif- 
ferent kinds." Entire shoots provided with reserve material are cut off and form new plants. In this way moss carpets are frequently formed in the woods, or masses in bogs.

Moss Groups.-There are two general classes of mosses: (I) SpHAGNum forms are those which produce leaves without nerves, and in which the sporogonium does not possess a long stalk or seta. What appears to be the stalk is the prolongation of the gametophyte stem which is known as the pseudopodium or "false stalk." These forms are characteristic of wet places. Some of the group as Sphagnum proper form "sphagnum bogs." New plants develop on top of the old which latter gradually die and finally pass into sphagnum peat, 'which forms thick masses and finds use as a fuel. (2) The True Mosses are especially distinguished by the differentiated character of the sporogonium, which not only produces a stalk but also the peristome (Fig. 28, $p$ ) which when present is of great importance in distinguishing the different species.

Economic Uses of Bryophytes.-The investigations on the chemistry of the Liverworts and Mosses have not been very numerous. The constituents which have been found are in the nature of tannin, resins, ethereal oils, glucosides, alkaloids, coloring compounds and organic acids like citric, oxalic, tartaric and aconitic. In the mosses starch and silicon salts are found in addition. Several species of Marchantia and Jungermannia are used in medicine. Of the mosses the following have been found to have medicinal properties; Sphagnum cuspidatum, Grimmia pulvinata, Funaria hygrometrica, Fontinalis antipyretica, and several species of Polytrichum and Hypnum.

\section{PTERIDOPHYTES.}

The Pteridophytes constitute the second subdivision of the Archegoniates. Like the Bryophytes these plants show a distinct alternation of generations, i.e., the gametophyte or sexual generation alternates with the sporophyte or asexual generation. Their relation is, however, somewhat changed. In the Bryophytes the gametophyte is the most conspicuous and is looked upon as constituting the plant proper, whereas in the Pteridophytes 
the gametophyte is rather insignificant in size, while the sporophyte constitutes the generation or phase which is ordinarily regarded as the plant. In the higher members of the Pteridophytes the sporophyte is entirely detached from the gametophyte and is able to lead an independent existence. This group also shows a distinct advance in structure. There is a differentiation into root, stem and leaves, and the development of a system of conducting tissue known as the VASCULAR SYSTEM.

The Pteridophytes include three principal groups, namely, (I) Filicales or Ferns, (2) Equisetales or Scouring Rushes, and (3) Lycopodiales or Club Mosses, which differ considerably in: general appearance and general morphological characters.

With the exception of the sperms in the Club Mosses, which are biciliate and somewhat resemble those in the Bryophytes, the sperms in the Pteridophytes are spirally coiled and multiciliate, and according to the number of cilia of the sperms some writers divide the Pteridophytes into two classes, namely, biciliate and pluriciliate (Figs. 34, C; 43, F).

Some of the Pteridophytes, as Selaginella (Fig. 4I), are distinguished by the fact that they produce two kinds of asexual spores, which are known respectively as MICROSPOREs (Fig. 4I, $F$ ) and Megaspores (Fig. 4I,E). The two kinds of spores are formed in separate sporangia which organs may occur on the same plant or on different plants. The sporangia have the corresponding names, microsporangia (Fig. 4I) and megasporangia (Fig. 4I). This differentiation in sporangia and spores also leads to a differentiation in the resulting gametophytes, the microspores giving rise to gametophytes which produce antheridia, and hence called male gametophytes; and the megaspores to gametophytes which give rise to archegonia, and hence called female gametophytes. When a plant produces both microspores and megaspores it is said to be Heterosporous, as in Selaginella (Figs. 4I, $43,44)$; while one that produces but one kind of sporangium and one kind of asexual spores is said to be Isosporous. In this connection attention should be called to the fact that the spores from a single sporangium of an isosporous plant may give rise to male and female gametophytes, which shows that a certain degree of differentiation in the spores has already taken place. The causes 
leading to the differentiation of the spores seem to be connected with nutrition, those nuclei which are in more favorable positions giving rise to larger and better nourished spores which eventually lead to the formation of the megaspores, and those which are less favorably placed leading to the microspores.

The subject of heterospory is one of great interest, and when it is pointed out that all of the higher plants are heterosporous the subject has even more interest.

\section{FILICALES.}

General Characters.-On germination the asexual spore in the Filicales or Ferns gives rise to a thallus-like body known as the prothallus which is frequently dorsiventral and in a number

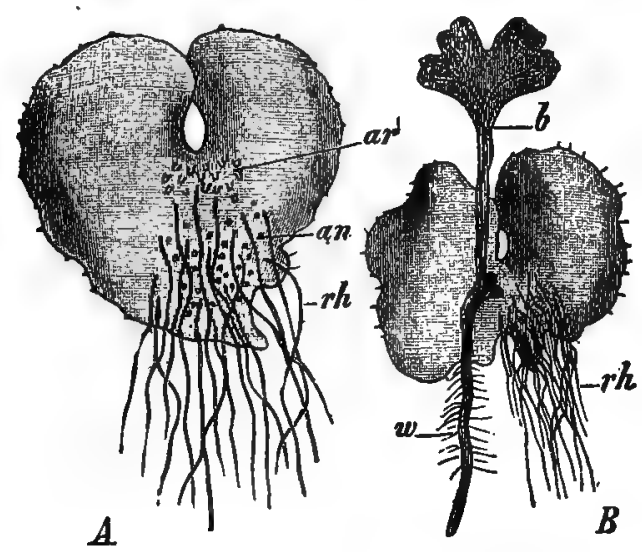

FIG. 33. Male fern [Aspidium (Nephrodium or Dryopteris) Filix mas]. A, prothallus of gametophyte as seen from the under (ventral) side showing archegonia (ar), antheridia (an), and rhizoids (Ih); B, prothallus showing young plant (sporophyte) which has developed from an oöspore and is still connected with the gametophyte, roots (w), and the first leaf (b).-After Schenck.

of cases somewhat heart-shaped, but varies considerably in outline, being sometimes more or less tuberous. The prothallus is frequently but a few millimeters in diameter and the cells usually contain chloroplasts. On the under or ventral surface rhizoids are usually present (Fig. 33, rh). The sexual organs usually arise on the lower surface (Fig. 33) but they may develop on the upper or dorsal surface or even laterally. A single prothallus 
gives rise to both kinds of organs unless stunted in its growth, when it produces antheridia only.

The antheridia either develop upon or are sunk in the tissues of the prothallus. The archegonia (Fig. 34) are not flask-shaped as in the Bryophytes. The venter containing the oösphere or egg-cell (Fig. 34, $e$ ) is embedded in the thallus, the structure being surmounted by a few-celled neck (Fig. 34, $h$ ). The inner cells of the neck are known as canal cells (Fig. 34, $k$ ) and these at the time of ripening of the egg swell and exit through the opening of
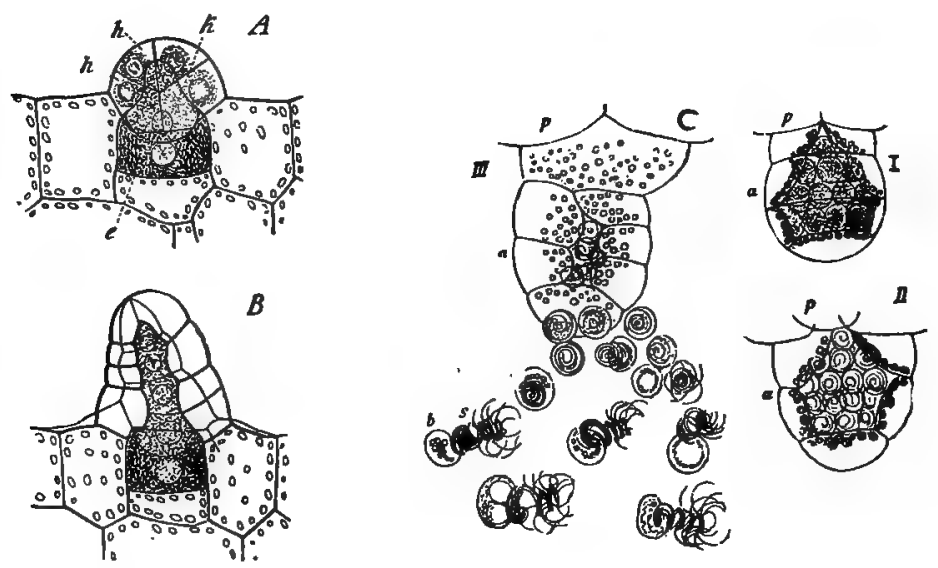

FIG. 34. A, B, development of archegonia of a fern (Pteris) showing the neck (h), the neck-canal cell $(k)$ and oossphere (e).-After Strasburger.

$\mathrm{C}$, development of antheridium in the Venus-hair fern (Adiantum Capillus-Veneris): prothallus (p), antheridium (a), sperm (s), sperm mother cell with starch grains (b); $I$. immature state of antheridium, II, sperms developed, and III, discharge of sperm mother cells and escape of coiled and pluriciliate sperms.-After Sachs.

the archegonium, through which then the sperms enter, one of which unites with the egg, thus effecting fertilization. The fertilized egg or oöspore takes on a cellulose membrane.

The oöspore which is held in the venter of the archegonium is not a resting spore but germinates immediately and early differentiates into the several organs (Fig. 35). These arise independently and include a stem-bud (Fig. 35, s); a first leaf or cotyledon (Fig. 35, b) so called because it does not arise out of the stem as the later leaves do; a first or primary root (Fig. 35, $\mathrm{w}$ ); and a foot or haustorial organ (Fig. 35, $f$ ) whereby it obtains nutri- 
ment from the prothallus (Fig. 35, pr). This latter organ is, however, only a temporary provision, for as soon as the root grows out and penetrates the soil, it dies off and the sporophyte thus becomes independent. The stems are frequently more or less condensed and lie prostrate in the soil, developing roots from the under surface and leaves from the sides and upper surfaces. The leaves which constitute the conspictuous part of the ordinary ferns consist of a stalk and lamina or blade on which are borne the sporangia (Figs. $277 ; 36, A$ ). The sporangia usually occur on the under surface of the leaf in groups or clusters known as SORI (Fig. 36;A). The sori are of characteristic shape in different

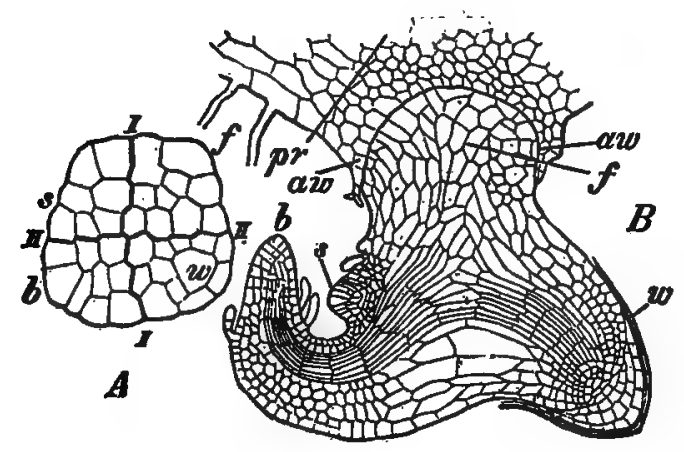

FIG. 35. The brake fern (Pteris). A, differentiation of cells in germinating oöspores; $B$, later stage showing development of embryo: pr, prothallus; $f$, foot embedded in the archegonium (aw); w, root; s, young stem; b, young leaf.-A, after Kienitz Gerloff; B, after Hofmeister.

species and are covered by a plate called the indusium (Fig. 36 , $B$ ) which rises from the epidermis. In some species the entire leaf becomes a spore-bearing organ, and is then known as a SPOROPHYLl (Figs. $36,37,3^{8}$ ), to distinguish it from the foliage leaves. The sporangia develop a row of cells around the margin constituting what is known as the ANNulus (Fig. $36, n$ ). The form of the annulus determines the manner of dehiscence of the sporangia, which occurs on drying. The spores are ejected with considerable force (Fig. 36, D). They (Fig. 36, E; Fig. 39) are either bilateral or tetrahedral and require a short period to elapse before they germinate. They retain their vitality for a long time and germinate in a few days after being sown. The 
spores are greenish or yellowish in color, variously sculptured and vary from $0.025 \mathrm{~mm}$. to $0.158 \mathrm{~mm}$. in diameter.

Fern Groups.-There are a number of distinct groups of ferns which vary considerably in appearance. ( I) In the Tropics

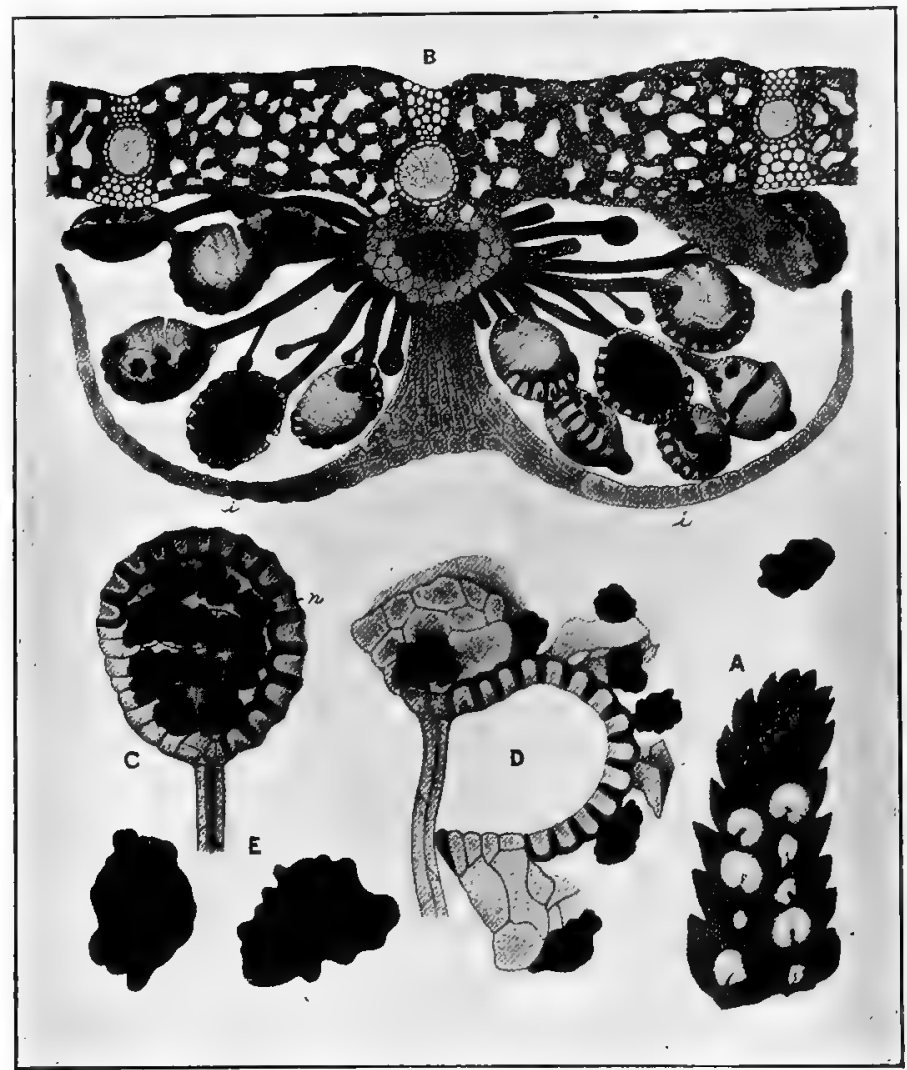

Fig, 36. Male fern [Aspidium (Nephrodium or Dryopteris) Filix mas]. A, portion of leaflet showing a number of more or less reniform sori near the mid-vein; $B$, transverse section through a ripe sori showing clusters of stalked sporangia, which are covered by

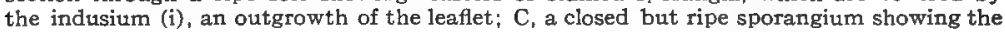
annulus or ring ( $n$ ), and the irregular-shaped spores within; $D$, showing the manner of opening of the mature sporangium and the dispersal of the spores; $E$, two spores much magnified.-After Dodel-Port.

as well as in greenhouses TREE FERNS, characterized by an overground stem, occur. The leaves arise at the summit of the stem or trunk and form a crown. 
(2) The True Ferns include by far the largest number of species which inhabit temperate regions. These vary considerably in size ranging from quite diminutive plants 5 to $12 \mathrm{~cm}$.

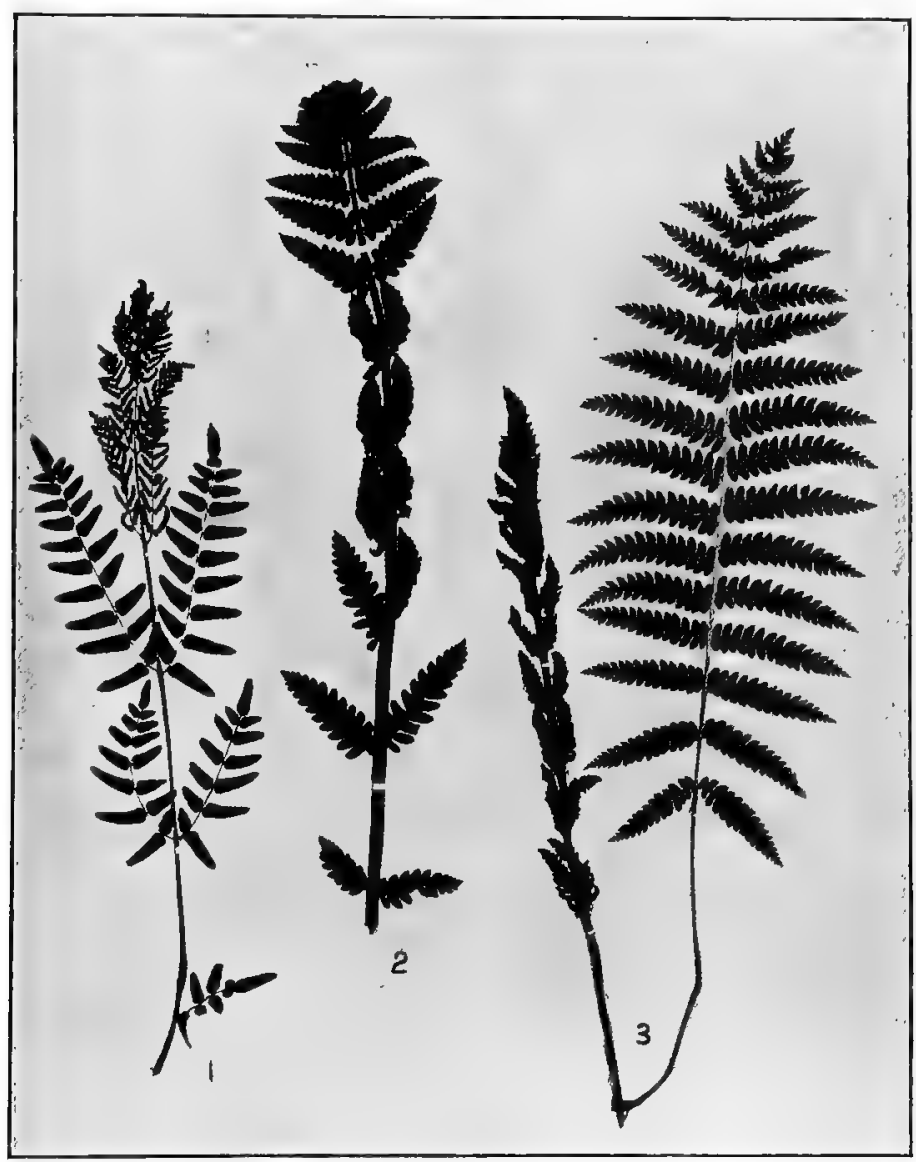

FIG. 37. Several Osmundas. I, the royal fern (O. regalis) showing fertile tip of branch and sterile bipinnate leaflets below; 2 , Clayton's fern (O. Claytoniana) showing three pairs of fertile leaflets in the middle and a number of sterile leaflets above and below; 3 , cinnamon fern (O. cinnamomea) showing a fertile leaf (sporophyll) to the left and a sterile Jeaf (foliage leaf) to the right.

high, as the slender Cliff Brake (Pellaca Stelleri) (Fig. 38, illus. I) and maiden hair spleenwort (Asplenizm trichomanes) (Fig. 38 , illus. 4), to plants several feet high, as in the several species of 
Osmunda (Fig. 37), Aspidium (Fig. 227), etc. This group is chiefly characterized by the underground or prostrate stems, known as rhizomes, the part of the plant that is seen above ground being the leaf.

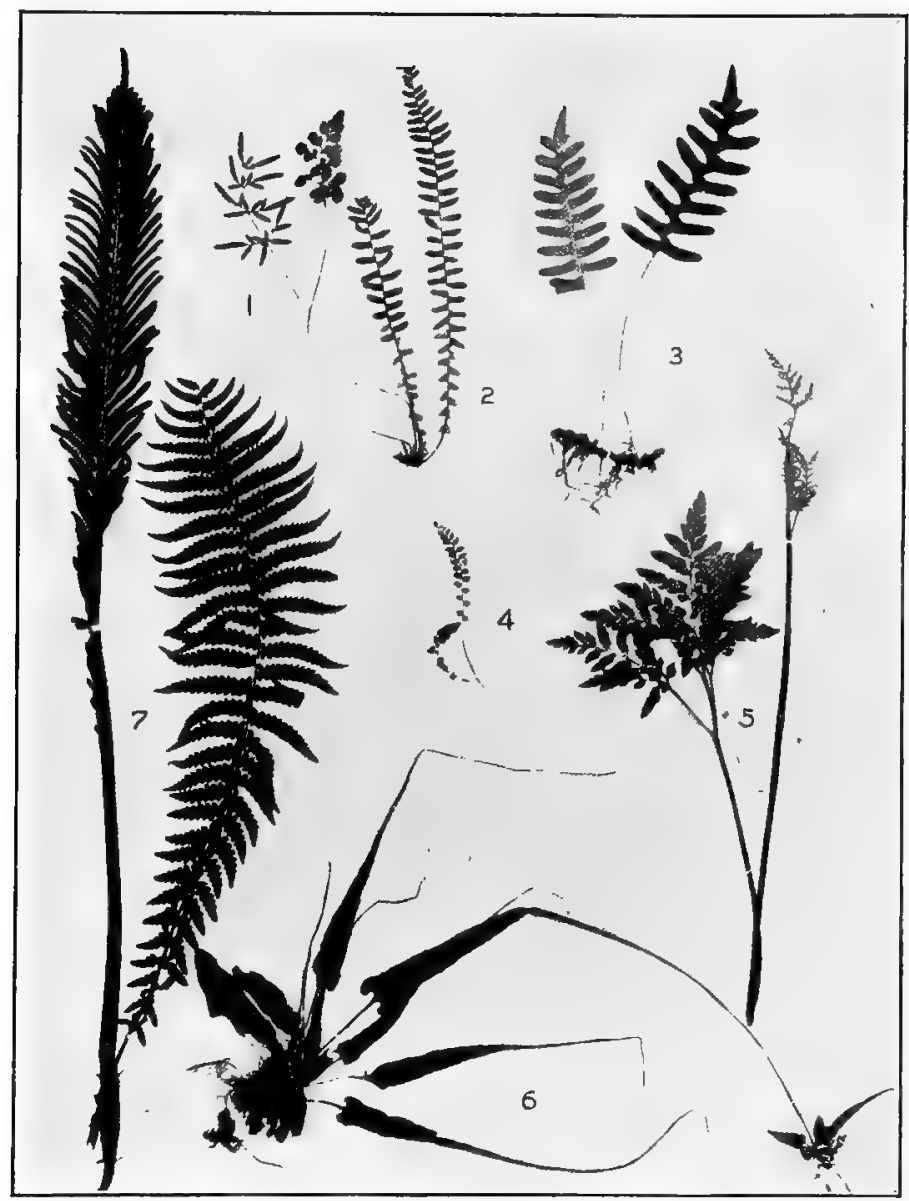

Fig. 38. Different types of Ferns and fern allies. I, fertile and sterile leaves of slender cliff-brake (Pellea Stelleri); 2, ebony spleen-wort (Asplenium platyneuron); 3 , rhizome with two leaves of the common polypody (Polypodium vulgare); 4 , maiden-hair spleenwort (Asplenium trchomanes); 5, ternate grape-fern (Botrychium ternatum), showing the tripinnate sterile leaf on the left and the upright sporophyll on the right: 6 , walking fern (Camptosorus rhizophyilus) showing a new plant developing from the tip of one of the leaves: 7 , fertile and young sterile leaves of ostrich fern (Onoclea Struthiopteris). 
(3) There is also a group of ferns known as Water Ferns which are aquatic in habit, that is, they live in marshy places or float on water. As representatives of this group may be mentioned Marsilia, which has a slender rhizone that is buried in the muddy bottom of streams, and 4-parted, clover-like leaves that float on the water; and Salrinia (Fig. 40) which is a small floating plant that develops two kinds of leaves, one which floats on the surface of the water and are more or less oblong, and another which are filiform, branching, root-like and submerged. The water ferns are further distinguished by the production of megaspores and microspores.

(4) The Adder's Tongue Family, to which Ophioglossum and Botrychium belong, develops a subterranean prothallus which is destitute of chlorophyll. The prothallus is in some cases

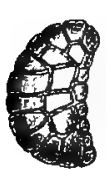

A
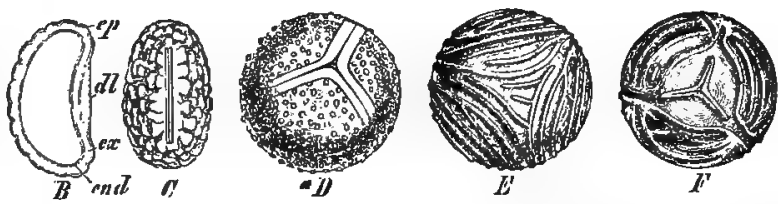

FIG. 39. Some fern spores. A, B, C, different views of the bilateral spores of the common polypody (Polypodium vulgare) showing outer wall (ep), middle wall (ex), inner wall (end) and line of dehiscence-(dl); D, a tetrahedral spore of the royal fern (Osmunda regalis); E, F, spores of Geratopteris thalictroides seen in two views.-A-D, after Sadebeck; E-F, after Kny.

tuberous, and the sporophyte produces two kinds of leaves, namely, foliage leaves, and fertile leaves or those which bear the sporangia. The sporangia occur on lateral branches of the sporophyll and open at maturity by means of a horizontal slit.

Ferns Used in Medicine and as Foods.-Many of the ferns contain tannin, a brownish coloring principle and in addition an anthelmintic principle. They may also contain ethereal oils, starch, coumarin, aconitic acid and other principles. A large number have been used in medicine, of which the following may be mentioned: Aspidium (Dryopteris or Nephrodium) marginalis and $A$. Filix mas, yielding the official Aspidium (Fig. 277). A number of other species of Aspidium, as well as species of Adiantum, Asplenium and Polypodium are also used in various parts of the world. The rhizomes of some of the ferns contain considerable 
starch and are used to some extent as foods, as Pteris esculenta of China;Pteridium aquilinum var. lanuginosa of the Canary Islands; Aspidium varium and Asplenium bulbosum of Cochin China. Polypodium vulgare contains a substance related to glycyrrhizin. Adiantum pedatum and Polypodium Phymatodes are said to contain coumarin, the latter plant being used in perfumery.

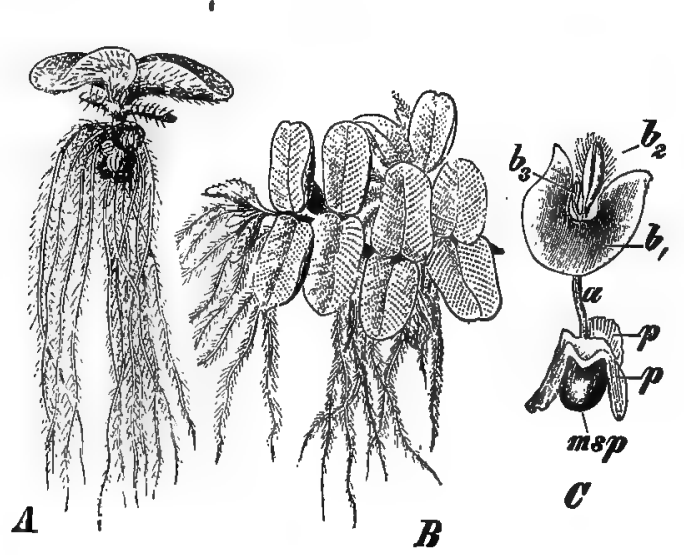

FIG. 40. A water fern (Salvinia natans). A, a plant seen from side and showing floating leaves at top attached to the horizontal stem, root-like finely divided leaves beneath, and a cluster of globose sporocarps; $\mathrm{B}, \mathrm{a}$ view from above showing especially the character of the upper leaves; $C$, young plant developing from a megaspore (msp).- $A$, and $B$, after Bischoff; C, after Pringsheim.

\section{EQUISETALES.}

The Horsetails, or scouring rushes (Fig. $45, B$ ) are perennial plants containing a large amount of silicon in their tissues. Like in the ferns the more or less branching, creeping rhizome persists from year to year, sending out each year new shoots. As in some of the ferns it develops two kinds of leaf-shoots, a fertile and a sterile one (Fig. 45, B), each of which are distinctly jointed. The scale-like leaves are arranged in circles about the joints or nodes, the work of photosynthesis being carried on by the green stems. The fertile branch develops at the apex a group of sporophylls known as a cone or strobilus. The archesporium, or initial spore-producing zone is unilocular. In Equisetum, the only representative of the group, the spores are spherical and each is 
furnished with two spiral bands or elaters which assist in its dispersal. Some of the Equisetums contain aconitic acid and are used in medicine. Common scouring rush (Equisetum hyemale) is used for polishing woods, and Equisetum arvense (Fig. 45, B) is used for scouring tin ware.

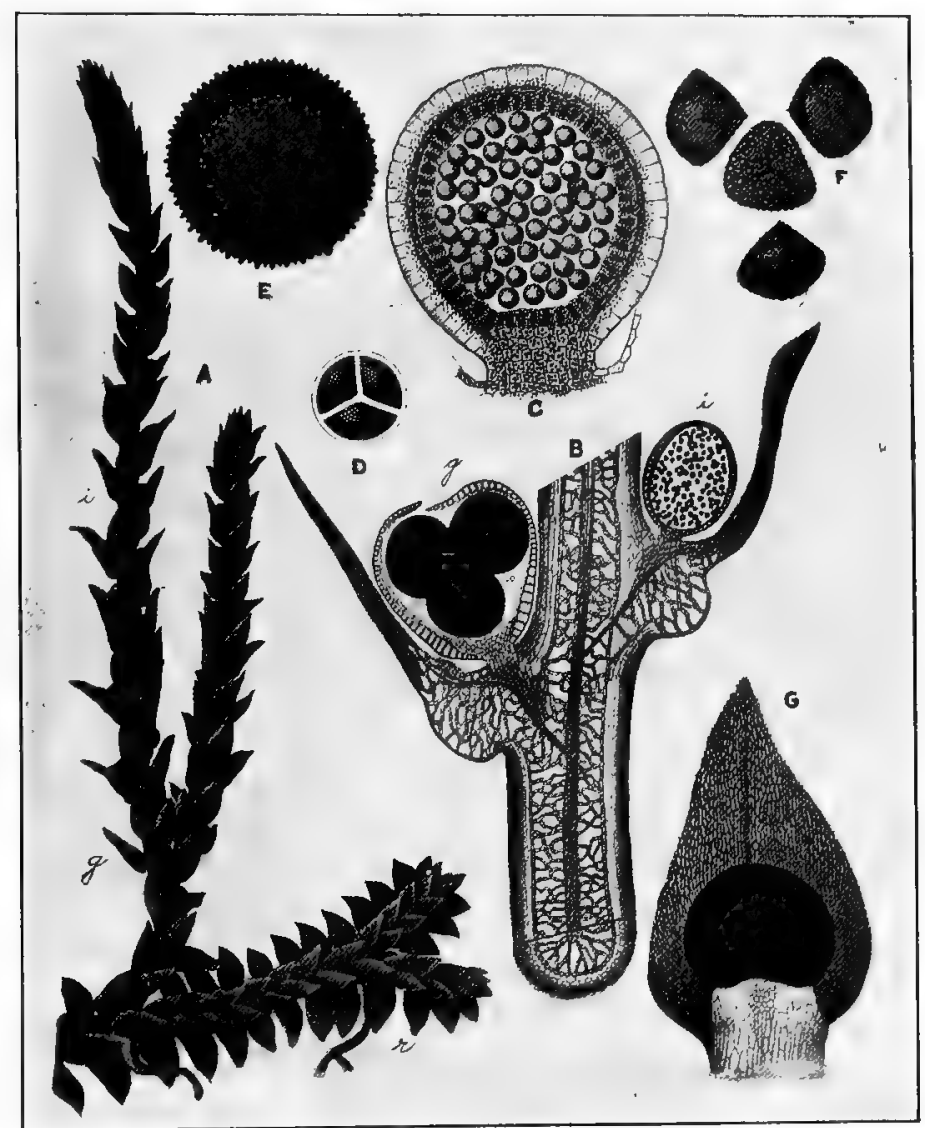

FIG, 4r. Selaginella helvetica. A, sporophyte consisting of leafy branches giving rise to microsporangia (i), megasporangia (g) and rhizoids $(r)$; $B$, longitudinal section of portion of branch showing a megasporangium (g) with 3 megaspores in view, a microsporangium (i) containing microspores; C, a young microsporangium showing free mother cells before formation of tetrads; $D$, tetrahedral division of spore mother-cell; $E$, ripe megaspore; $F$, four microspores of tetrad separated; $G$, microsporophyll seen from above showing ripe microsporangium.-After Dodel-Port. 


\section{LYCOPODIALES.}

The Lycopodiales, or Club Mosses (Fig. 46), are perennial moss-like plants, with more or less erect or creeping and branching stems, on which are borne numerous small simple leaves. The sporangia arise either at the base of the upper surface of the leaves or occur in terminal cones. They have short stalks, are unilocular and 2-valved. The asexual sporestiare of one kind in Lycopodium (Fig. 278b) and in the form of spherical tetrahedrons resulting from the manner in which division has taken place. In Selaginella (Fig. 4I) two kinds of asexual spores are produced,

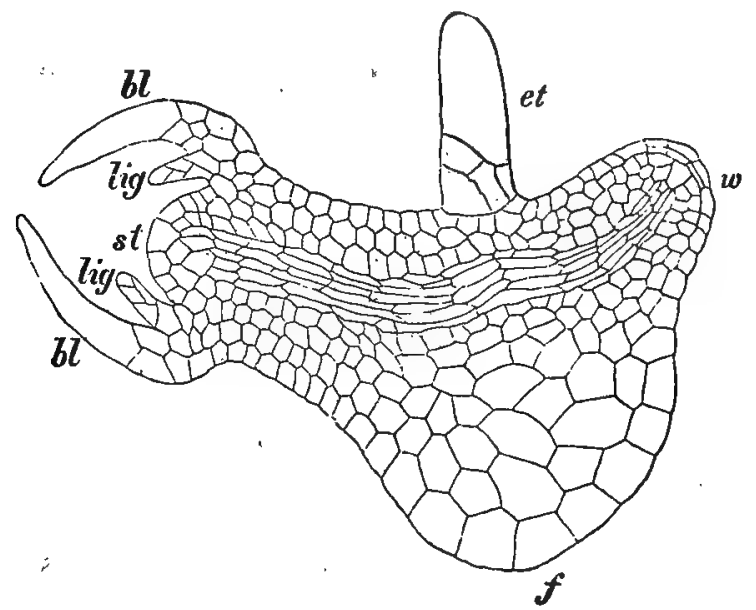

FrG. 42. Longitudinal section of young embryo of a Selaginella before separation from the prothallus: et, suspensor; w, root; $f$, foot; bl, cotyledons; lig, ligules or bud scales.-After Pfeffer.

that is, both microspores and megaspores, which in turn give rise to male and female prothalli respectively. The microspore develops a male gametophyte (Fig. 43) which remains entirely within the spore, and consists of a few-celled prothallus and a number of mother cells which produce sperms that eventually escape by the breaking of the wall.

The megaspore frequently begins to develop the gametophyte (Fig. 44) while still within the sporangium. The prothallus consists of a number of cells and partly protrudes through the ruptured spore wall. On the upper part of the pro- 
thallus or nutritive layer a few archegonia are borne. It should be stated that sometimes the archegonia are developed very early on the prothallus tissue, but usually they are developed after the spores have escaped from the sporangium. After fertilization of the egg a multicellular embryo develops which shows the following parts (Fig. 42): (I) An elongated cell or row of cells which extends into the tissues of the prothallus for the purpose of obtaining nutriment; (2) a root; and (3) a stem bearing at its tip (4) two leaves, or cotyledons. One of the specially notable

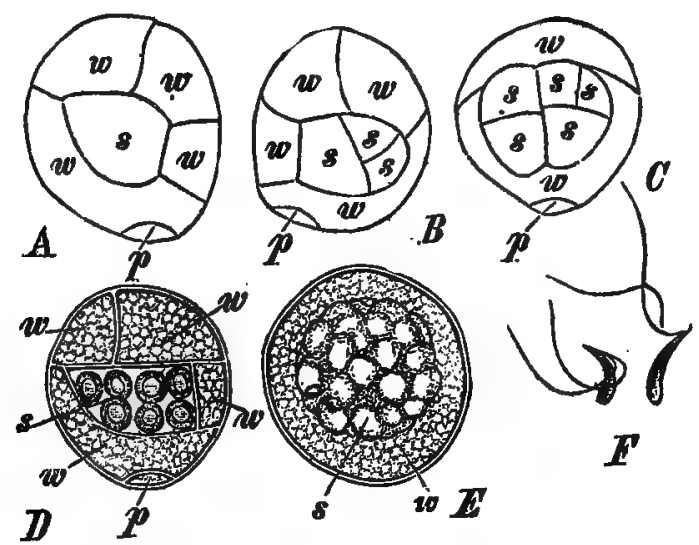

FIG. 43. Successive stages in the germination of the microspores of a Selaginella: $\mathrm{p}$ and $w$, cells of the prothallus; s, cells giving rise to sperms. A, B, D, views of spores from the side; $C$, view from the back; in $E$ the cells surrounding the sperm mother cell are disorganized; F, two biciliate sperms.-After Belajeff.

characters of the plants of the Selaginella group is, as we have seen, the great reduction in size of the gametophyte which in the case of the microspore does not enlarge beyond the wall of the spore, and in the case of the megaspore only partly protrudes beyond the wall of the spore.

Isoetes.-This is a genus of aquatic or marsh plants known as quillworts. The plants produce a number of filiform roots which penetrate the mud, and a compact tuft of rush-like leaves. The plants are heterosporous, as in Selaginella. The sporangia are borne in the axils of the leaves, the outer leaves bearing the megasporangia and the inner leaves the microsporangia. The 
gametophytes consist of but a few cells. While the group is heterosporous and the gametophytes resemble those in Selaginella, the sperms are multiciliate and coiled as in the Ferns.

Distribution and Uses of Lycopodiales.-A number of the Lycopodiums are common on rocks, damp woods, sandy bogs, and illustrations of several of these are shown in Fig. 46 . Some tropical species are used in medicine; the spores particularly of Lycopodium clavatum (Fig. 46, illus. 3) are used as a dusting powder (Fig. 278b), and for burning in the production of flash

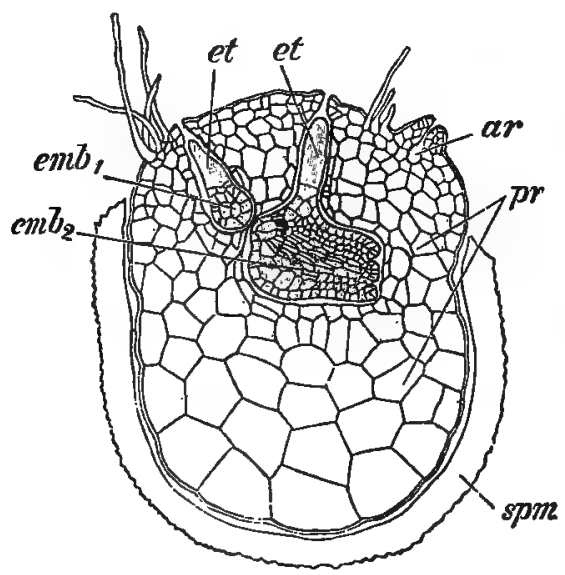

FrG. 44. The female gametophyte of a Selaginella; prothallus (pr) projecting through the ruptured wall (spm) of the megaspore; ar, sterile archegonium; emb1, emb², two embryos embedded in the tissue of the prothallus; et, et, suspensors.-After Pfeffer.

lights. The Selaginellas (Fig. 45, A), of which there are several species, are commonly used for decorative purposes. Some species are, however, also used in medicine, and it is interesting to note that the spores of one species (Selaginella selaginoides) are used like those of Lycopodium.

While the Pteridophytes do not form a very conspicuous portion of the flora at the present time and yield but few products of use to man, it may be pointed out that in former ages they former the dominant vegetation of the earth. Many of the ancestral forms of this group attained the size of trees and made up the forest vegetation during the Devonian and Carboniferous Ages, the latter being sometimes spoken of as the age of Pterido- 
phtyes. It is also called the Coal Age from the fact that the coal measures were chiefly laid down during this period. By some it is thought that the deposits of coal of this age were probably

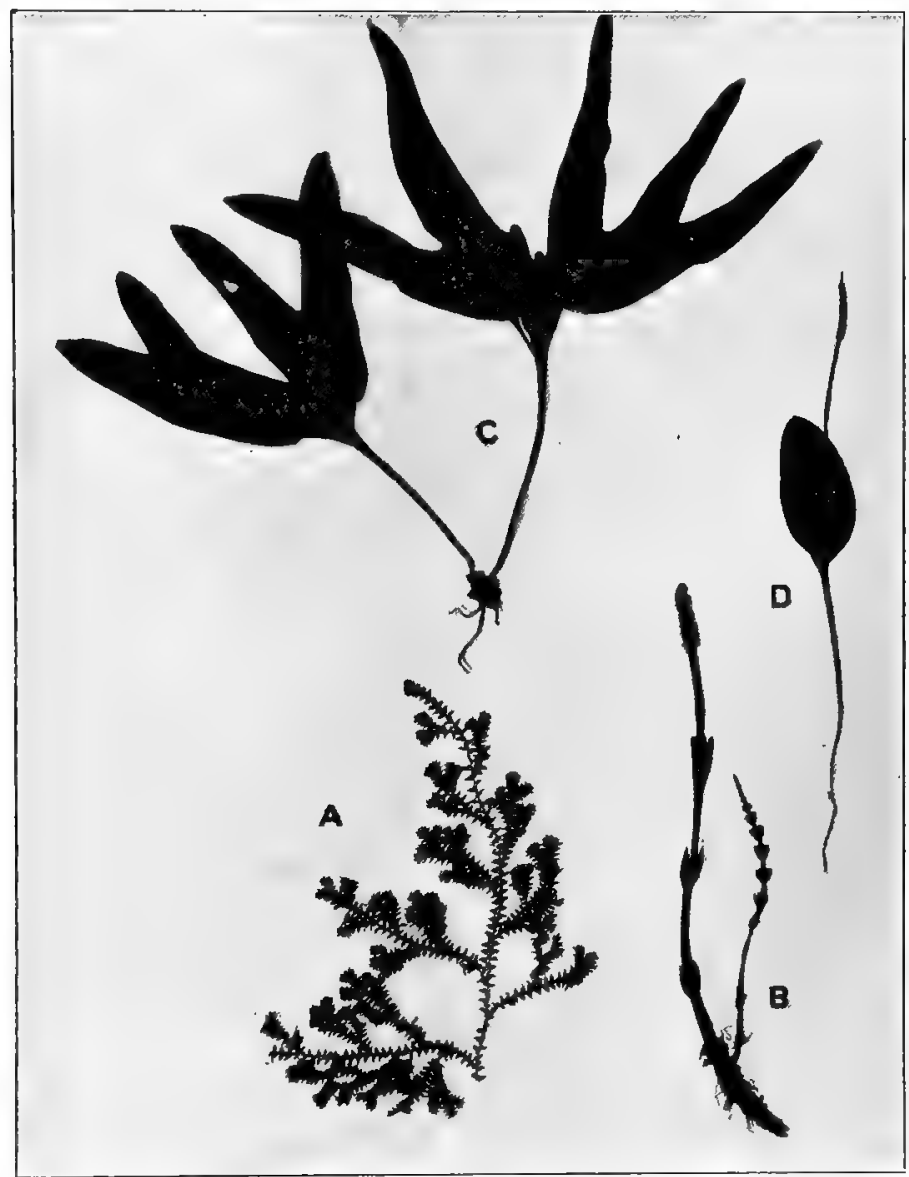

Fig. 45. Some Pteridophytes. A, Creeping Selaginella (Selaginella apus); B, field horsetail (Equisetum arvense) showing cone-bearing branch and foliage branch; $\mathrm{C}$, Ophioglossum palmatum; D, adder's-tongue (Ophioglossum vulgatum).

principally formed from the remains of certain marsh plants including two extinct groups of huge, tree-like club mosses (Lepidendron and Sigillaria) and the Calamites, representatives of the scouring rushes. 


\section{SPERMOPHYTES.}

The Spermophytes, or Seed Plants, constitute the third of the great divisions into which plants are divided. The plants belonging to this division not only form the most conspicuous feature of

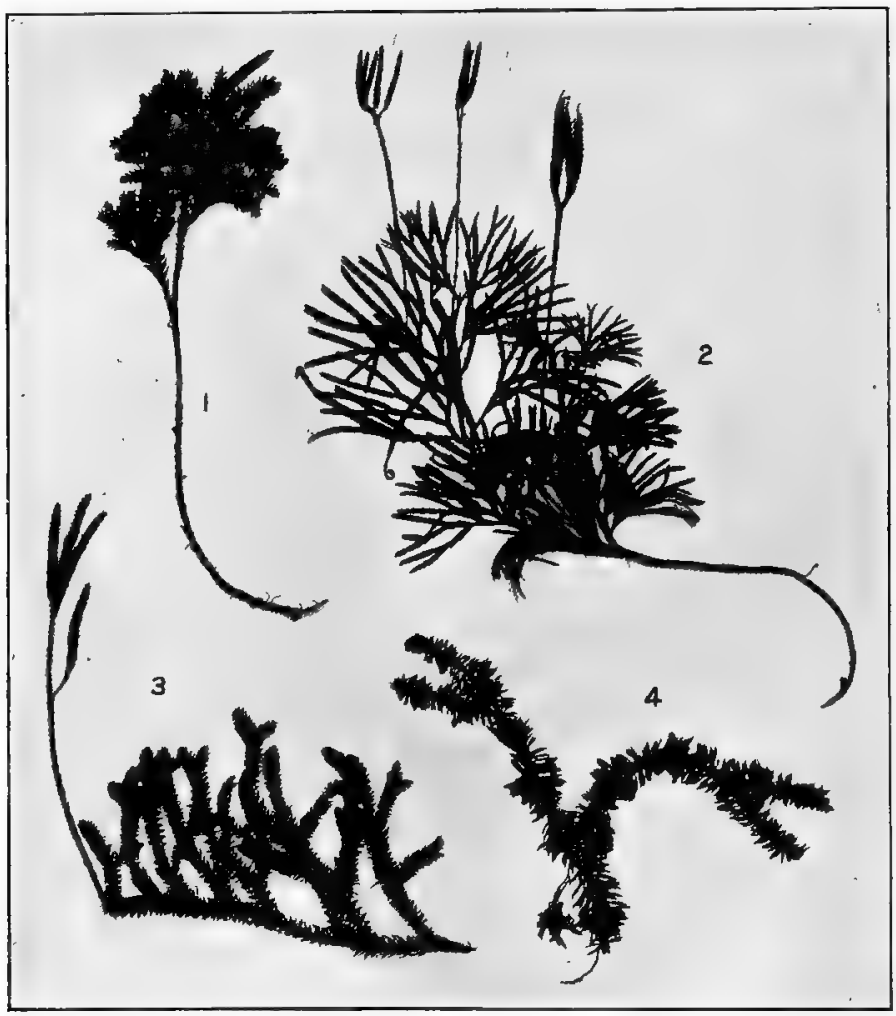

FIG. 46. Several species of Lycopodium. I, Ground pine (L. obscurum) showing a leafy branch with one strobile at the apex; 2, a branch of trailing Christmas green ( $L$. Complanatum) bearing four or five strobiles at the apex of long dichotomously branching stalks; 3 , club moss or running pine ( $L$. clavatum) with a branch bearing four strobiles: 4 , shining club moss ( $L$. lucidulum) with small sporangia borne in the axils of the leaves.

the flora because of their size and general distribution, but also because of the fact that the flowering plants render a large number of them especially attractive. The plants of this group are: also of great importance from an economic point of view. They 
furnish a large part of the food of man and other animals, as well as materials for clothing, shelter, fuel and divers other purposes. In this group of plants there is the highest differentiation of tissues and the most complicated structure. The one character which especially distinguishes them from the lower groups of plants is that of the production of seeds.

The plants have for the most part well differentiated stems and leaves, and represent the sporophyte or asexual generation. The sporophyte produces sporophylls which are of two kinds, namely, megasporophylls and microsporophylls. The megasporophylls bear small ellipsoidal bodies known as ovules, which develop into seeds. The megasporangium is not separate and distinct in the spermophytes as it is in Selaginella, but is embedded within an ovule and corresponds to that part of the ovule known as the nucellus. The nucellus encloses the embryo-sac, which is regarded as a megaspore (Figs. 49, 50, 56, 85). Each megasporangium (nucellus) therefore contains but a single megaspore, whereas in Selaginella the megasporangia contain from $I$ to 8 megaspores. The microsporophyll bears microsporangia (pollen sacs) which contain microspores (pollen grains). The female gametophyte in the Spermophytes is still more limited in its development than even in the highest Pteridophytes (as Selaginella and Isoetes) and remains wholly within the megaspore or embryo-sac. As a result of fertilization of the egg-cell an embryo is produced which consists of root, stem and one or more cotyledons and which with the integuments covering it constitutes the seed.

Spermophytes embrace two well defined groups, namely, (I) Gymnosperms or naked-seeded plants and (2) Angiosperms, or enclosed-seeded plants.

\section{GYMNOSPERMS.}

In the Gymnosperms the ovules, each of which contains a megasporangium (nucellus), are borne on an open sporophyll (carpel), and thus are exposed, as are also the seeds developed from them. In the Angiosperms the ovules are borne within closed sporophylls, and are thus protected or covered until the seeds, which develop from them, mature. 
The Gymnosperms represent an ancient group of plants and were more numerous during the Triassic period than now. They are mostly shrubs and trees, and do not shed their leaves periodically as the Angiosperms do, and hence are known as "evergreens." As in some of the Pteridophytes (Lycopodium, Equisetum) the sporophylls occur in groups forming cones or strobiles (Fig. 47). They not only differ in external appearance from the Angiosperns but also in the anatomical structure of the stem, which is without large conducting vessels. In order to understand the relation of the Gymnosperms to the Pteridophytes on the one hand and to the Angiosperms on the other, it will be necessary to consider briefly the life history of a representative group, such as the Coniferæ.

General Characters.-The seed consists essentially of three parts, namely, a woody or leathery seed-coat, a nutritive layer rich in oil known as the endosperm, and a straight embryo. The latter is a more or less differentiated plantlet, consisting of a stem with a varying number of cotyledons or first leaves ( 2 to I6), and a small root which is attached to a suspensor, as is the embryo in Selaginella (Fig. 44). When the embryo begins its development into the plant it uses up the nourishment with which it is surrounded in the endosperm, and as it increases in size the seedcoat is split. The root then protrudes and the cotyledons to some of which the seed-coat is still attached are carried upward by the stem through the surface of the soil, when the seed-coat is cast off and the plant begins an independent existence. The first root is the primary or tap root and from this are sent out numerous branches known as secondary roots, constituting a well developed root system which serves the double purpose of absorbing nutriment from the substratum or soil and of holding or fixing the plant in its upright position. The embryonal stem grows vertically upwards continuing its growth indefinitely. Lateral branches arise at more or less regular intervals which extend from near the ground to the apex, the younger branches continually succeeding the older ones from the ground upward, thus giving the trees a cone-like outline. The leaves arise on the branches and are of two kinds, primary leaves which are more or less scalelike and deciduous, and secondary leaves which are true foliage 
leaves, and are usually quite simple in structure. The leaves vary in form but are usually narrow and somewhat thickened giving them a needle-like appearance.

In addition sporophylls (spore-bearing leaves) are formed at the ends of the young shoots or in the axils of more mature ones

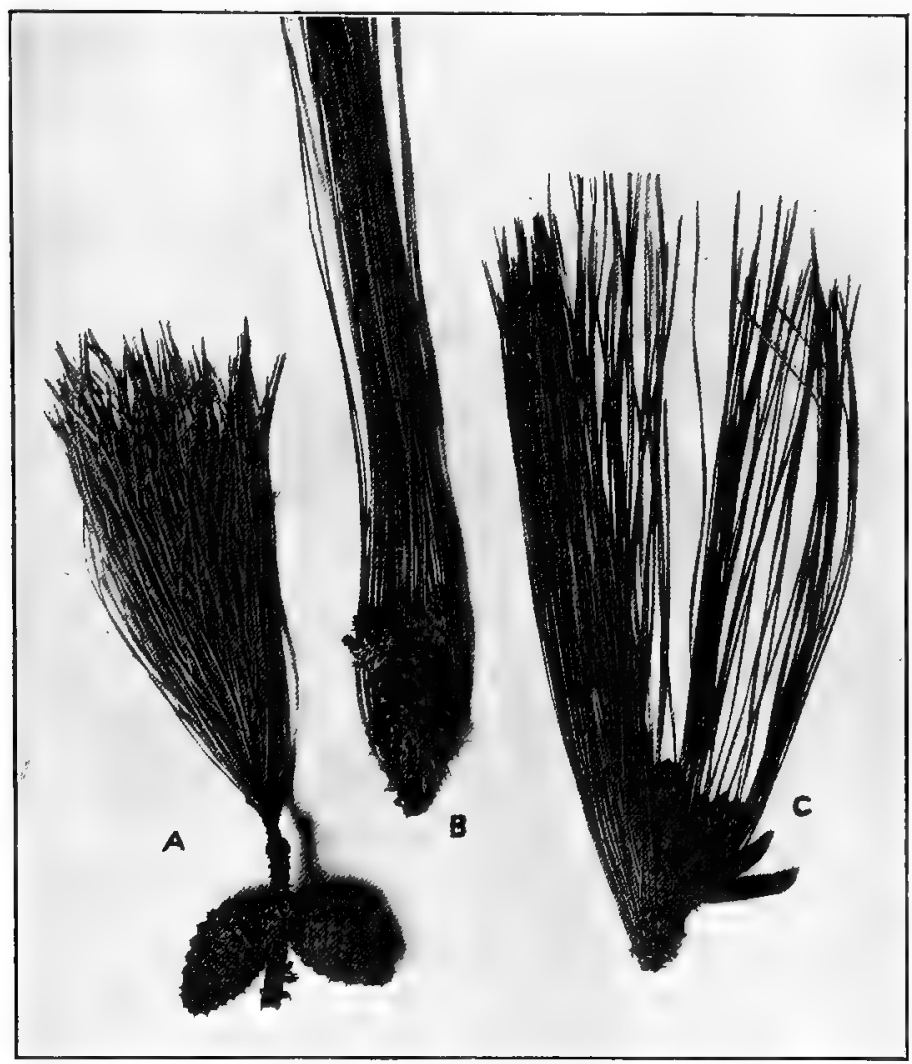

Fig. 47. Cones of several pines. A, two mature nearly lateral cones of pitch pine (Pinus rigida); B, young terminal cones composed of megasporophylls (carpels) of the long-leaved pine (Pinus palustris); C, numerous cones composed of microsporophylls (stamens) of the same pine.

(Fig. 47). These are compactly arranged forming cones or strobili which are always of two kinds and borne on different twigs of the same plant or on different plants. The staminate 
cones consisting of microsporophylls (stamens) are more or less elongated and cylindrical (Fig. 47, C). The carpellate cones consisting of megasporophylls (carpels) have a shorter longitudinal axis, and the cones vary considerably in the different groups (Fig. 47, $A, B$ ).

The Microsporophylls (Fig. 48) are usually of a yellowishbrown color, and consist of a slender stalk and a lamina which
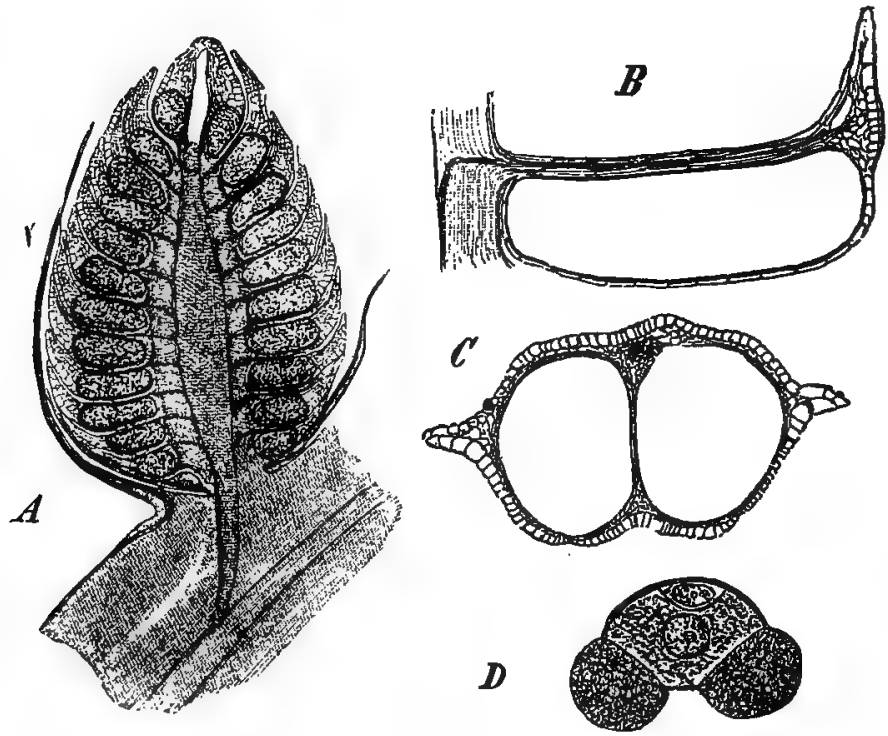

Fig. 48. A, longitudinal section of cone composed of microsporophylls, of one of the pines; $B$, longitudinal section of microsporophyll showing microsporangium (pollen sac); $\mathrm{C}$, the same in transverse section showing both microsporangia; $\mathrm{D}$, winged microspore (pollen grain), with a two-celled male gametophyte, the upper cell being the generative cell, the remaining nucleated cell giving rise to the pollen tube.-After Schimper.

bears the microsporangia (pollen sacs) on the lower or dorsal surface (Fig. 48, B, C). In this they show a resemblance to ferns where the sori are borne on the under surface of the leaves. The microsporangia vary in number from 2 to 15 , and are protected in various ways, either being sunk in the tissues of the sporophyll, as in Pinus and Abies or they are, as in Juniperus and Thuja, provided with a covering resembling the indusium of the sori of the ferns. The walls are variously thickened and on drying, 
owing to unequal tension, the sacs are ruptíred longitudinally and the spores scattered. The microspores are very numerous, sometimes forming powdery deposits. They are either I-celled or 3 -celled. In the latter case two lateral cells act as wings for the dispersal of the spores by the wind (Fig. $48, D$ ).

The Megasporophylls consist of sessile carpels (leaves) on which are borne one or two naked ovules containing the spor-

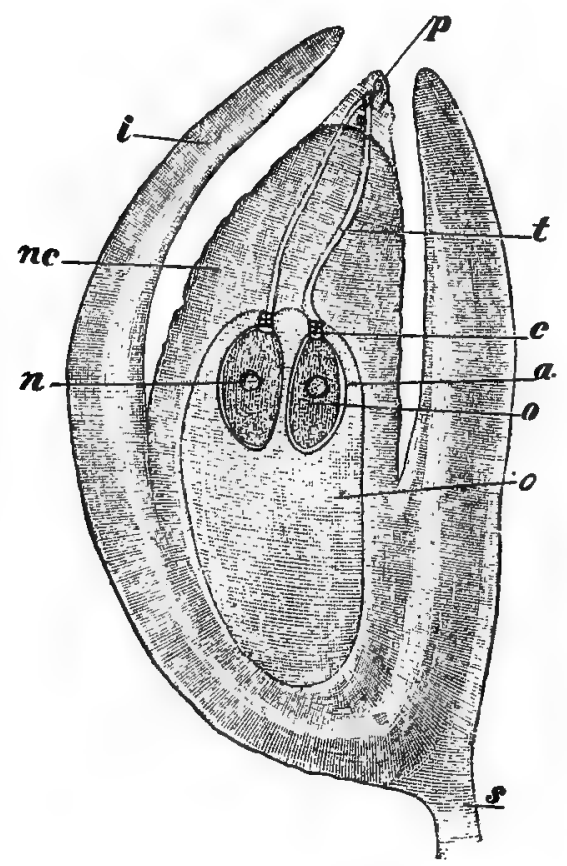

FIG 49. Longitudinal section of an ovule of a spruce (Picea): $i$, integument; nc rucellus (megasporangium); e, embryo-sac (megaspore) which has developed the female gametophyte consisting of endosperm (e), two archegonia (a), which show the neck (c), and the egg $(n)$; p, germinating pollen grains (microspores) with pollen tubes $(t)$ which have penetrated the nucellus (nc) and reached the neck cells of the archegonia.-After Schimper.

angia (nucelli). In certain groups, as in the pines, balsams, etc., a scale is formed at the base of the carpel which bears the ovtles, and this scale is called the seminiferous scale. The ovules consist of several parts (Figs. 49 and 50): a stalk; an integument or wall which has an opening at the apex known as the micropyle; 
a nucellus (megasporangium), being that portion next within the integument; and embedded within the nucellus a portion known as the megaspore or embryo-sac.

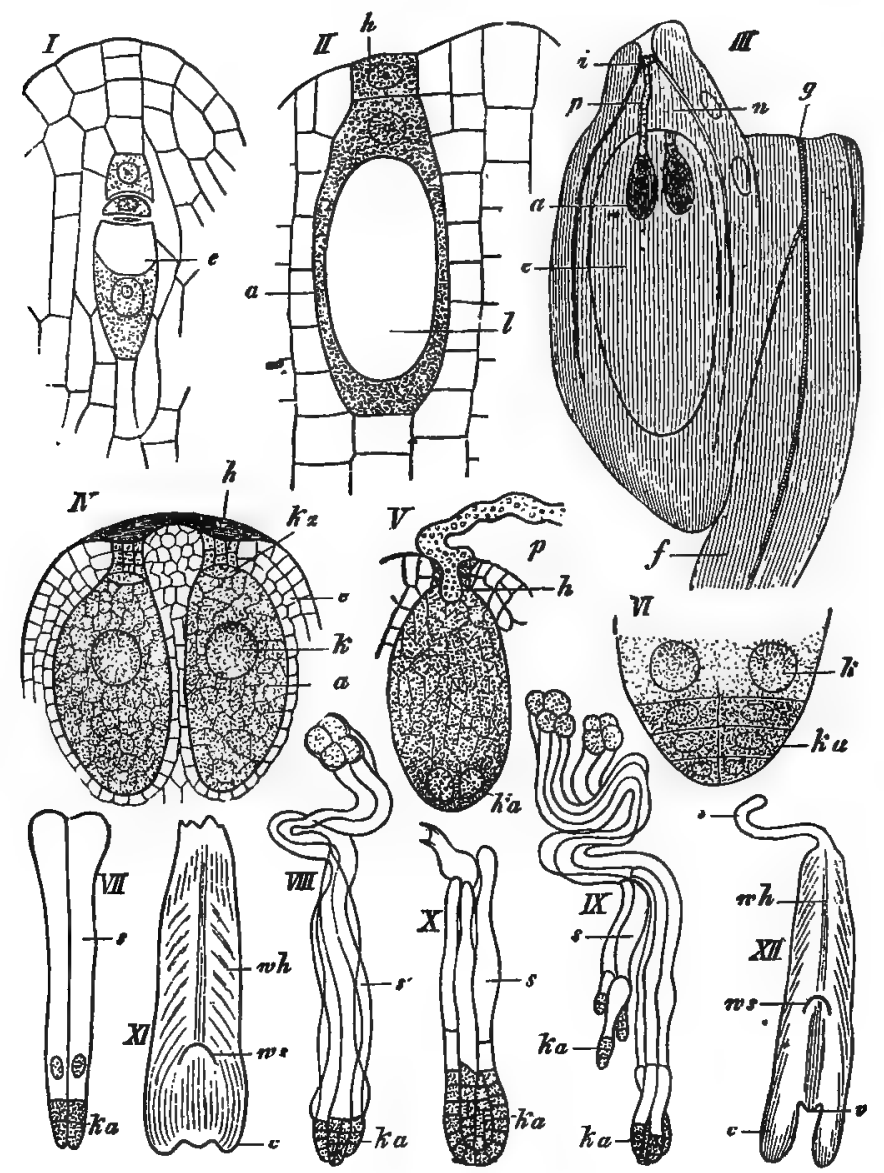

FiG. 50. Development of gametophyte and embryo in one of the Conifera. e, embryo-sac (megaspore); a, archegonium; h, reck of archegonium; $i$, integument; $p$, pollen tube; $n$, nucellus; $f$, wing of seed; $g$, fibrovascular tissue; $k z$, canal cells of archegonium; $\mathrm{ka}$, beginning of embryo; $\mathrm{k}$, nuclei; ws, tip of root; wh, root-cap; c, cotyledons; $\mathrm{v}$, point of growth of stem; s, suspensor.

I, early stages of embryo-sac (e); II, young archegonium (a) after development of neck cells (h), cell lumen (1); III, section of ovule with portion of attached seminiferous. scale(f) showing entrance of pollen tube; IV, embryo-sac with two developed archegonia; $\mathrm{V}$, archegonium after fertilization there being four nuclei at the lower part only two of which are seen; VI, further development of embryo; VII, VIII, IX, X, showing development of large tortuous suspensor, to which is attached the young embryo (ka); XI, XII, mature embryo.-After Strasburger. 
Gametophytes.-The development of the gametophytes from the asexual spores, namely, the microspore or pollen grain, and the megaspore or embryo-sac, is as follows: The nucleus of the megaspore divides repeatedly (Fig. 50), cell walls are formed and a multicellular structure known as the ENDOSPERM is produced. This structure constitutes the prothallus of the female gametophyte (Fig. 49, E; Fig. 50). In the upper portion of the prothallus (that is, at the micropylar end), three to five archegonia are formed (Fig. 49, a; Fig. 50), which are separated from one another by cells of the endosperm or prothallus which are rich in protoplasm. The structure of the archegonium is much like that of the preceding group, consisting of a venter which contains the egg, and a short neck composed of 4 to 8 cells.

The male gametophyte begins to develop while the pollen is still in the sporangium. At this stage it consists of a generative cell and a wall-cell, which constitute the antheridium, the cells of the prothallus being usually suppressed (Fig. 48,D).

In addition to the extreme minuteness of the gametophytes we have also to note the character of the male gamete or sperm. With the exception of the Cycads and Ginkgo, motile sperms are not found in the Gymnosperms; but these are represented by two male nuclei which are transferred directly to the archegonium from the male gametophyte, formed through germination of the microspore (pollen grain). It may be recalled that in the Pteridophytes the motile sperms are discharged from the antheridium and carried by the agency of water to the archegonium, but in the Gymnosperms water is no longer a medium of transferral. The microspores themselves are carried to the ovules usually through the agency of wind after which they germinate developing a tube which carries the male nuclei directly to the archegonium without their ever having been free.

The transferral of the microspores or pollen grains to the ovule is known as pollination. After pollination the wall-cell develops a tube, the pollen tube, and the generative cell gives rise to two male nuclei, which, with the remaining protoplasmic contents of the antheridium, are carried by the pollen tube to the micropyle, which it enters, penetrating the tissue of the nucellus (Fig. 49, $t$ ). On reaching the neck of an archegonium the pollen 
tube pushes its way down into the venter, where it discharges one of the sperm nuclei which unites with the egg, forming an oöspore. Cessation in growth does not yet take place and the oöspore develops into the embryo already described. The developing embryo obtains its nourishment by means of a suspensor (Fig. 50, $s$ ), which also places the embryo in a favorable position.

There being several archegonia in an ovule (Figs. 49, 50), a corresponding number of embryos may be formed, but rarely more than one survives. While the embryo is developing, the other tissues of the megaspore are likewise undergoing changes leading to the maturity of the seed. The carpels and seminiferous scales also continue to grow, and they usually become more or less woody, forming the characteristic cones of the pines (Fig. 5I), but may coalesce and become fleshy, producing the berry-like fruits of Juniper (Fig. 52). The seed on germination gives rise to the sporophyte (tree).

Groups of Gymnosperms.-There are two principal groups of Gymnosperms, (I) one of which includes the Cycads or Fern Palms, which are characteristic of tropical and sub-tropical countries. The trunk does not branch as in the ordinary evergreens, and the leaves form a crown at the summit of the stem or trunk. An important character of some of the Cycads is the production of multiciliate sperms, as in the ferns, Equisetum and Isoetes. (2) To the Coniferæ belong the pines, hemlocks, balsams, arbor vitæ, junipers (Fig. 52) and cedars, this being by far the largest group of Gymnosperms.

Economic Uses of the Coniferæ.-From an economic point of view the Coniferæ are by far the most important group of plants thus far considered. In fact they may be ranked first in the production of valuable timber. Of those yielding timber the following species may be mentioned: White pine (Pinus strobus) ; long-leaved or Georgia pine (Pinus palustris) (Fig. 47, $B, C$ ) ; spruce pine (Pinus echinata); the Redwood of Upper California (Sequoia sempervirens); pitch pine of New Mexico (Pinus ponderosa); the Scotch fir, the common pine of Europe (Pinus syluestris). Some of the woods are adapted for special purposes: as that of Pinus Cembra of the high mountains of Europe and Northern Siberia, which is excellent for wood-carv- 
ing; Red cedar (Junipcrus rirginiana) (Fig. 52) used in the making of cigar boxes and lead pencils; balsam fir (Abies balsamca) used in the manufacture of wood pulp.

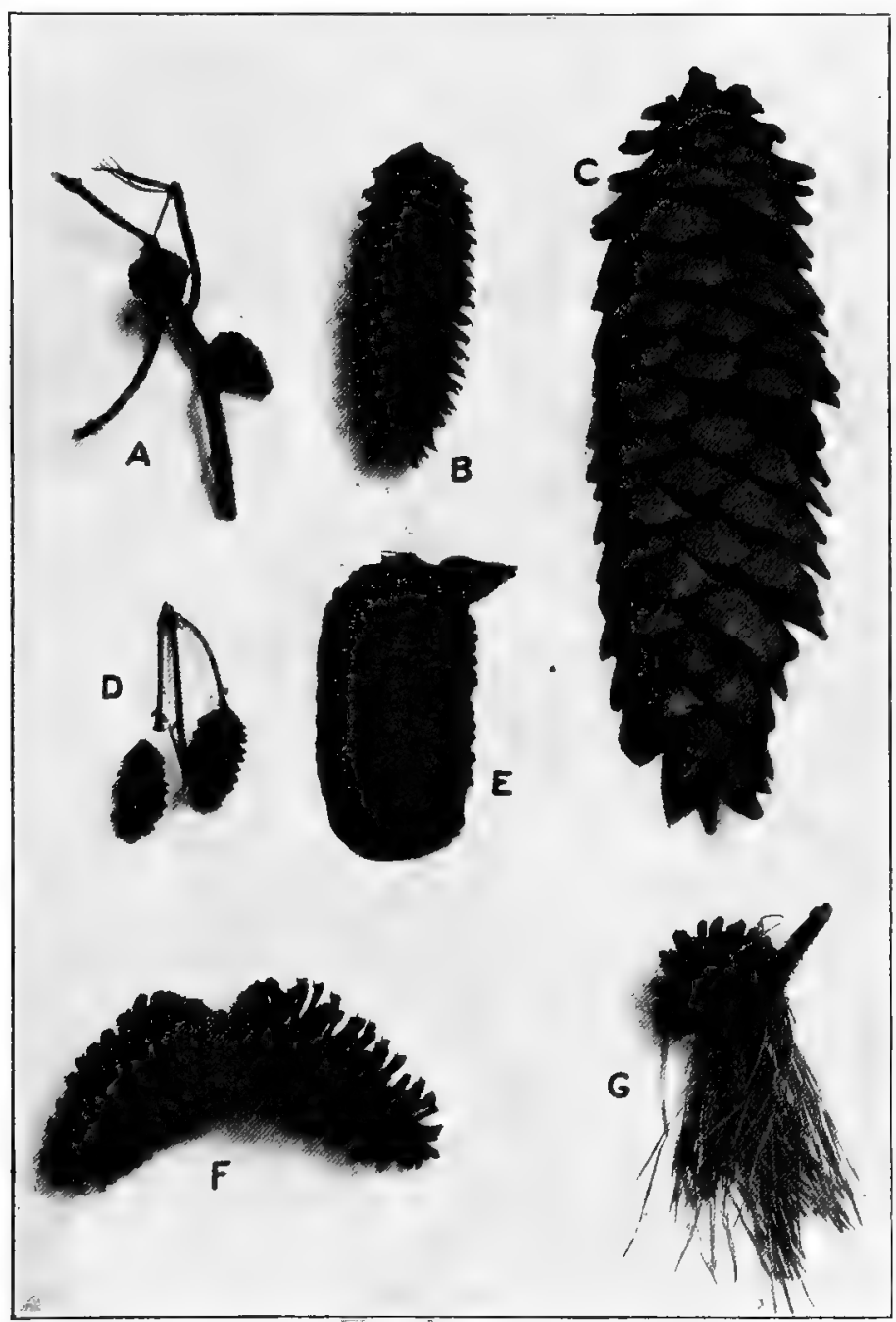

FIG. 51. Cones of some of the Coniferæ. A, branch of spruce pine (Pinus echinata) with 2 cones; B, from pitch pine (Picea excelsa); C, from great sugar pine (Pinus Lambertiana); D, from black spruce (Picea Mariana); E, from the California silver fir (Abies magnifica); F, from loblolly or frankincense pine (Pinus Tada); G, branch of pitch or torch pine ( $P$ inus rigida). 


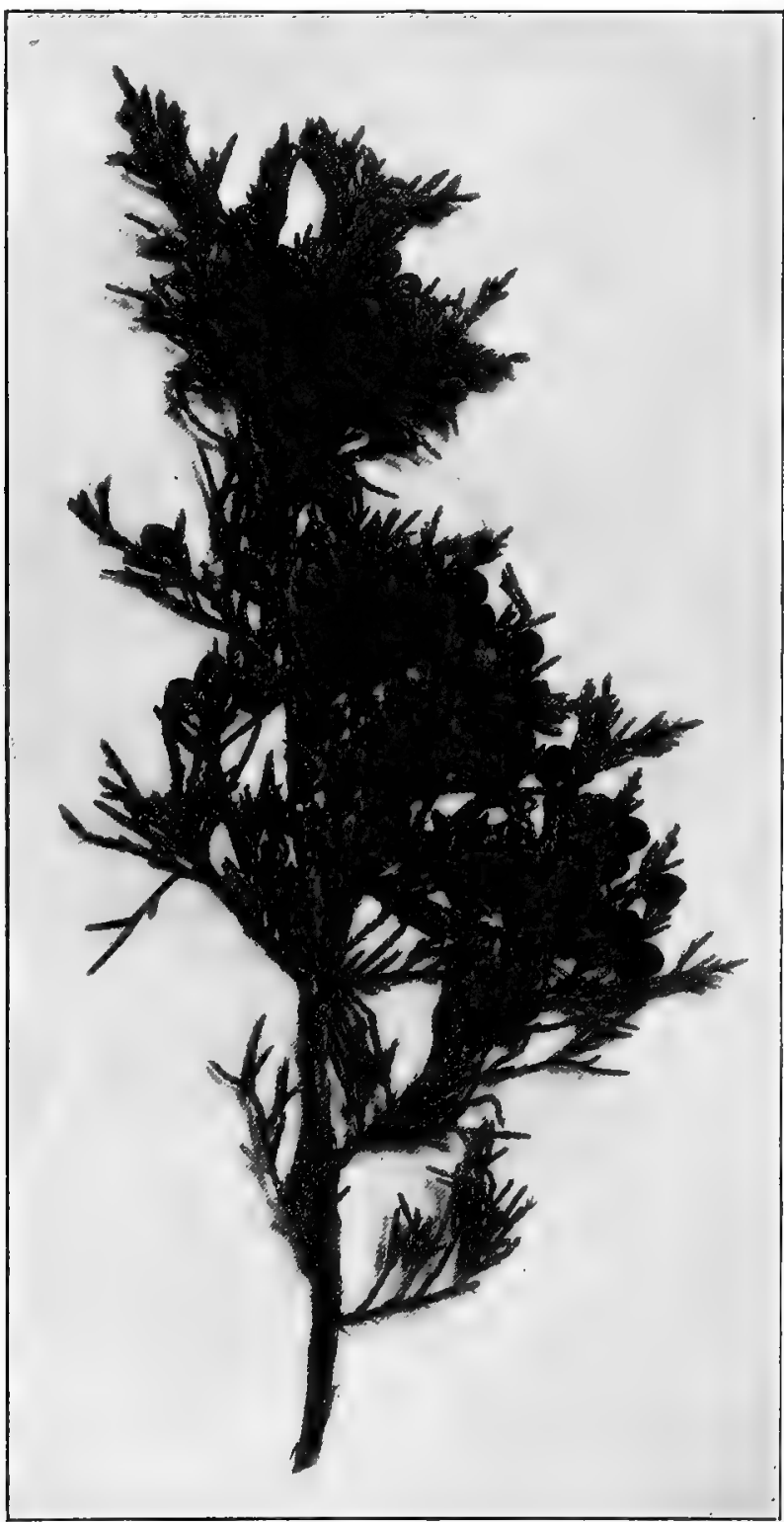

FIG. 52. A branch of red cedar (Juniperus virginiana) with numerous berry-like cones. 
Some of the pines yield edible seeds which have been used by the Indians of Western America: as the edible or "nut pine" of California and New Mexico (Pinus edulis) ; Pinus monophylla, discovered by Colonel Fremont in Northern California; Pinus Jeffreyi of Northern California; and Pinus Pinea of Europe, the seeds of the latter being used like almonds and known as "pignone." The seeds of Pinus Lambertiana (Fig. 51, C) of California are baked before being used as food. This latter species is also known as the sugar pine as it yields a manna-like product. A manna is also yielded by Cedrus Libani and Larix decidua. The latter is known as "Briancon Manna," and contains melizitose. The bark of some species furnishes valuable tanning material, as that of the hemlock spruce ( $T$ suga canadensis).

The Coniferæ yield large quantities of volatile oils, resins and allied products which are used both in medicine and the arts. A number of them yield turpentine (see drug), as Pinus palustris (Fig. 47, B, C), Pinus FGda (Fig. 5I, F), Pinus heterophylla and Pinus echinata. Larix decidua of the Alps and Carpathian mountains yields Venice turpentine. Abies balsamea is the source of Canada turpentine or balsam of fir; Picea Mariana or black spruce yields spruce gum largely used in the manufacture of chewing gum, and is also the source of spruce beer. Picea excelsa or Norway spruce yields Burgundy pitch (see drug). Abies alba or white fir tree yields the Strasburger turpentine. Canada pitch is the resinous exudation from the common hemlock ( Tsuga canadensis). Sandarac is yielded by Callitris quadrivalvis found growing in Northwestern Africa. Volatile oils are yielded by a number of the Coniferæ, of which the following may be mentioned: Juniperus Sabina yielding oil of savin; Jumiperus communis yielding oil of juniper, both of which are used in medicine. The remains of Coniferæ (Picea, etc.) are often found as fossils, as the fossil resin amber, which is used in the arts, and on distillation yields a volatile oil having medicinal properties.

ANGIOSPERMS.

General Characters.-The Angiosperms constitute the most conspicuous portion of the flora, embrace the greatest variety of forms, and are the most highly organized members 
of the plant kingdom. They vary in size from diminutive plants like the windflower to the giant oak which shelters it. They may. accomplish their life work in a few months, as the common stramonium, or they may persist for several hundred years, as the trees of our primitive forests. They may inhabit dry desert regions, as the Cacti and Chenopodiaceæ, or they may live wholly in water, as the water lilies. In short they show the greatest adaptability to their surroundings. But no matter how diversified they may seem in form and structure, they agree in this with possibly one exception, namely, mignonette, that the seeds are produced in a closed carpel. This has been considered, as already indicated, to be the chief difference between the Gymnosperms and Angiosperms.

The two groups are further distinguished by several other important characters: ( I) the carpel or carpels (megasporophyll) is developed into an organ commonly known as a pistil (Figs. 83 and 85 ). This organ consists of three parts, namely, ovary, style and stigma, the ovary enclosing the ovules (Figs. 83, 85). In the Angiosperms the megaspore (embryo-sac) develops a gametophyte which does not give rise to archegonia, but the egg arises directly from the megaspore nucleus by a series of divisions.

(3) The Microsporophyll (stamen) differs considerably in structure and appearance from that of the Gymnosperms. The stamen may be defined as a leaf which bears sporangia (spore cases). It usually consists of the following differentiated parts: filament and anther, the latter consisting of pollen sacs (microsporangia) in which the pollen grains (microspores) are developed (Figs. 8I, 83 and 85). (4) In a large number of cases in the Angiosperms there is developed in addition to the sporophylls or sporangial leaves (stamens and pistils) another series of leaves known as floral leaves (Fig. 83). The latter usually are of two kinds, known as sepals and petals.

The Development of the Two Generations, namely, the sporophyte and gametophyte, is much the same in the Angiosperms as in the Gynosperms. That is, the sporophyte constitutes the plant body and what is commonly considered to be the plant. The gametophytes are still more reduced than was the case in the Gymnosperms, the male gametophyte consisting of but two cells. 
Beginning with the germination of the seed we may outline the life history of the plant as was done under Gymnosperms. The seeds in the two groups are much alike with the exception that in the Angiosperms they usually have two integuments. Within the Angiosperms two classes of embryos are distin-
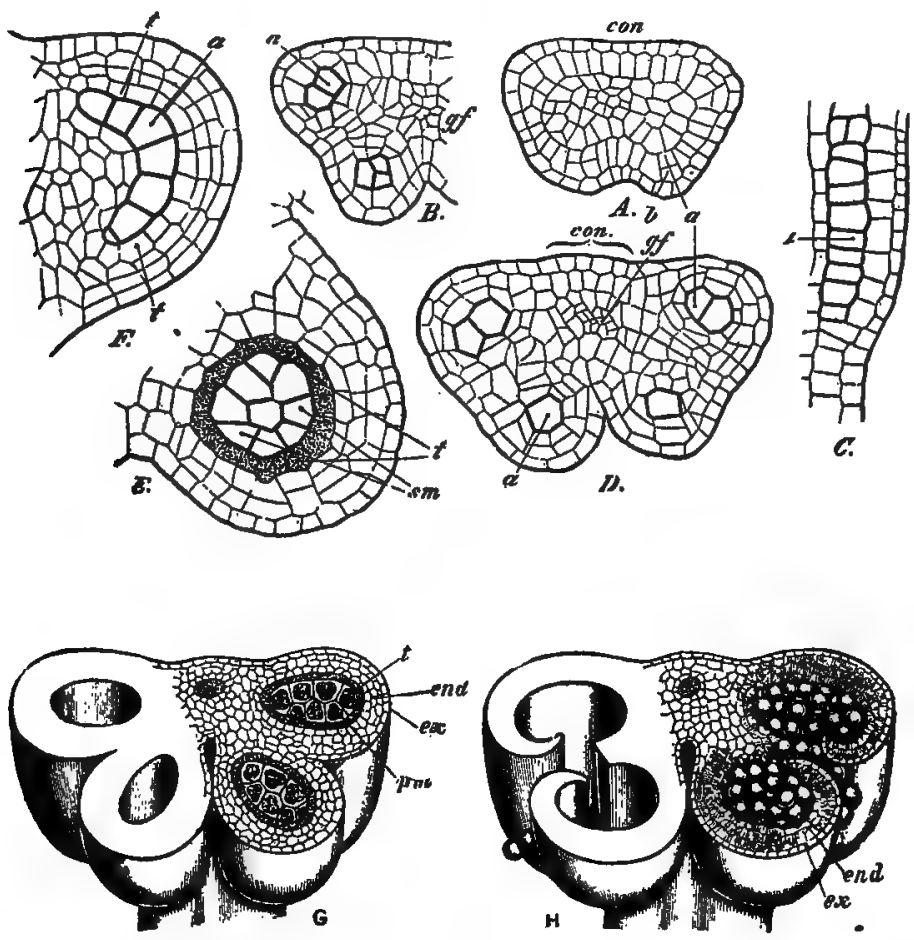

Frc. 53. Development of pollen sacs (microsporangia) in several of the Angiosperms: A, showing beginning of archesporium (a), an outer sterile layer (b), position of connective (con); B, later stage showing development of fibrovascular tissue (gf); C, longitudinal section of archesporium; D, E, F, successive later stages showing in addition pollen mother cells $(\mathrm{sm})$ and tapetum layer $(t)$. G, H, diagrammatic sections of mature pollen sacs showing pollen mother cells (pm), tapetum (t), endothecium (end), exothecium (ex), and in $H$ longitudinal dehiscence with formation of what appears to be a unilocular pollen sac on either side of the connective.-A-F, after Warming; $\mathrm{G}-\mathrm{H}$, after Baillon and Luerssen.

guished, which give rise to the most important division of this group of plants. In the one case a single cotyledon is formed at the apex of the stem, and all plants having an embryo of this kind are known as MONOCOTYLEDONS, that is, plants having one seed leaf. In the other case two cotyledons arise laterally on the stem 
and opposite each other, and those plants having an embryo of this type are grouped together as DICOTYLEDONS, or plants having two seed leaves. In the monocotyledons the cotyledon is limited to one, but in the dicotyledons the seed leaves are not limited in number and there may sometimes be three or more.

The sporophyte which develops from the germinating seed consists of the essential parts already given, i.e., root, stem and leaves. The leaves are of four kinds: (I) Foliage leaves, (2) scale leaves or bud scales, (3) floral leaves, which in some cases are wanting, and (4) sporangial leaves or sporophylls. Inasmuch as the latter give rise to the gametophytes (male and female) the development of the sporangia in each will be considered in detail.

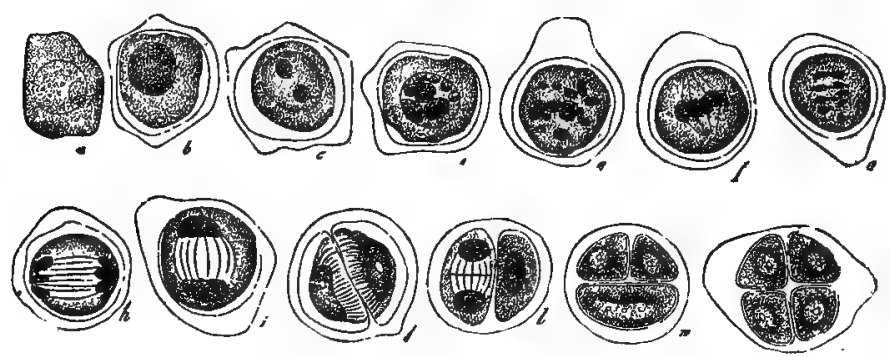

FIG. 54. Development of pollen grains (microspores) of garlic (Allium narcissifiorum): $a$, pollen mother cell with nucleus; $b$, the same with homogeneous nucleus and a thicker wall; $c-e$, changes in nucleus prior to division; $f$, formation of spindle with nuclear masses in the center from which nuclear threads extend to the poles of the spindle; $g$, division of nuclear substance and receding of it from the center of the cell; $h-i$, further stages in the organization of the nuclear substance at the poles; $\mathrm{k}$, formation of a wall between two daughter cells; 1 , beginning of division of one daughter cell; $m-n$, final divisions resulting in the formation of a tetrad (group of 4 cells). - After Strasburger.

The Microsporangia (pollen sacs) arise by the division of certain cells under the epidermis of the anther (Fig. 53). This process of division continues until four regions of fertile tissue (sporangia) are produced (Fig. 53, D). The sporangia are directly surrounded by a continuous layer of cells which constitutes the tapetum or tapetal cells (Fig. 53,t), these being in the nature of secretion cells and containing considerable oil. The tapetum is in turn surrounded by a layer of cells which are peculiarly thickened and which on drying assist in the opening of the anther and the discharge of the pollen, and this layer is called the endothecium (Fig. 53, end). There is still a third or 
external layer of cells, which constitutes the exothecium (Fig. 53, $e x)$. These four sporangial regions may remain more or less distinct and separate at maturity, or the two on either side may coalesce. This latter usually occurs at maturity, when dehiscence takes place, forming apparently a single pollen sac on either side of the connective or axis (Fig. 53, H).

The Microspores (pollen grains) are developed somewhat differently in Monocotyledons and Dicotyledons. In most monocotyledons the nucleus of each cell (pollen mother cell) making up the archesporium divides into two nuclei, each of which takes on a wall of cellulose. Each of these (daughter cells) in turn divides giving rise to four pollen grains. In dicotyledons (Fig. 54) the nucleus of a mother cell divides into four nuclei before the walls are formed which separate the nuclei, thus giving rise
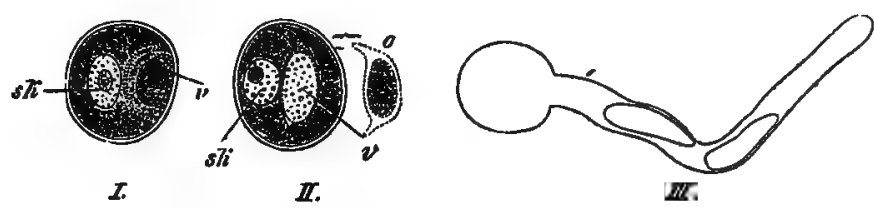

Fig. 55. Development of male gametophyte in an Angiosperm. I, pollen grain (microspore) which has divided into the mother or generative cell (v) and a larger tube-cell with nucleus (sk); II, appearance of pollen grain on treatment with osmic acid showing the separation of the generative cell ( $v$ ) from the wall of the pollen grain; $o$, at the right giving a view of the generative cell with the nucleus embedded in the hyaline protoplasm; III, showing the development of the tube-cell into the pollen tube which contains the two male cells (nuclei) or gametes formed by the generative cell.-After Elfving.

to the tetrad group of spores to which attention has already been called (page 49) under Bryophytes. The wall of each spore is divided into two layers, an inner layer consisting of cellulose known as the intine, which gives rise to the pollen tube on germination of the spore; and an outer layer somewhat clifferent in composition and variously sculptured, known as the exine. When the spores are mature the original walls of the cells of the archesporium dissolve and the ripe pollen grains are set free, forming a yellowish powdery mass filling the pollen sac. In some cases the spores of the tetrads hang together or even the whole mass of pollen tetrads may be more or less agglutinated, as in the orchids and milkweeds, these masses being known as pollinia. 
Male Gametophyte.-Before the dispersal of the pollen grains or microspores, certain changes leading to the development of the gametophyte have taken place (Fig. 55). The spore as we have seen is unicellular. This divides into two cells, one, which is relatively small, known as the mother cell of the antheridium (Fig. 55, $v$ ), and another, which, composed of the remaining nucleus with the surrounding cell-contents, constitutes the tube- or wall-cell of the antheridium.

Development of Ovule and Megasporangium (nucellus).The ovule at first develops as a small protuberance on the inner surface of the ovary, after which it differentiates into (a) a stalk or funiculus by which it is attached to the ovary, the tissue to which it is attached being called the placenta; and (b) an upper portion which becomes the ovule proper. The differentiation of the tissues is in a general way as follows: (I) The cells beneath the epidermis in the apical portion of the ovule go to make up the megasporangium (nucellus); (2) the peripheral cells from below the nucellus give rise to the integuments; and (3) while the integuments are developing the archesporium or mother cell of the embryo-sac (megaspore) is being formed within the nucellus near the apex.

Female Gametophyte.-The archesporium divides into two cells, the lower one of which repeatedly divides, finally giving rise to the embryo-sac which is sunk in the tissues of the nucellus. The nucleus of the embryo-sac divides and redivides until 8 cells are produced (Figs. 56 and 85 ), which are separated into the following groups: (I) Three of the cells form a group lying at the apex, the lower cell of the group being the egg or egg-cell. the other two cells being known as synergids or helping cells. (2) At the opposite end of the sac are three cells, known as antipodal cells, which usually develop a wall of cellulose and do not seem to have any special function. (3) Near the center of the sac are the two remaining nuclei, which unite to form a single nucleus, from which after fertilization the endosperm is derived. The embryo-sac, as it is organized at this stage, constitutes what is regarded as the female gametophyte (Fig. 56). The undifferentiated embryo-sac constitutes the megaspore, which latter after germination or differentiation into egg-cell and other cells, con- 

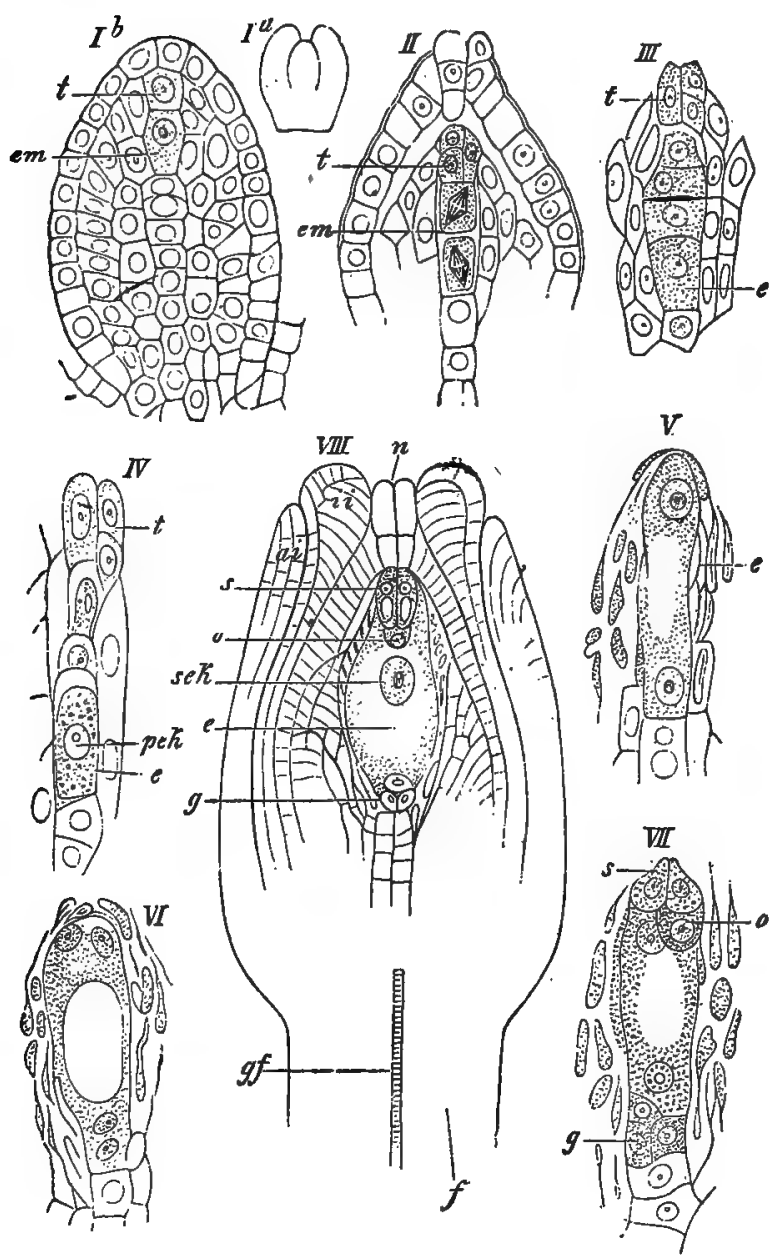

FIG. 56. Development of embryo-sac or megaspore in an Angiosperm. Ia, longitudinal section through a young ovule. Ib, longitudinal section through a rudimentary ovule before the formation of the integument, showing mother cell of the embryo-sac (megaspore) (em) and primary tapetal cell (t). II, later stage showing the two cells into which the mother cell has divided, the nuclei of which are in the act of dividing. III, mothercell of the embryo-sac divided into four cells (sporogenous mass of cells); the lowest of these cells (e) displaces the rest and becomes the embryo-sac in IV. IV, pek, is the primary nucleus of the embryo-sac. V, two daughter cells resulting from the division of the nucleus of the embryo-sac. VI, VII, show egg apparatus composed of two synergids (s) and the oösphere (o), and antipodal cells (g). VIII, longitudinal section through a mature ovule with the inner integument (ii), the outer integument (ai), the nucellus (n), the vascular bundle (gf) entering the funiculus (f), and secondary nucleus in the embryo-sac (sek). After Strasburger. 
stitutes the gametophyte. It is thus seen that in the female gametophyte of the Angiosperms archegonia are apparently not formed. The gametophyte, then, consists of the cell group containing the egg and the remaining portion of the embryo-sac, which latter may be compared to a prothallus. This comparison is not difficult to understand if we bear in mind the structure of the gametophyte in the Gymnosperms and particularly if we recall the structure in the higher Pteridophytes.

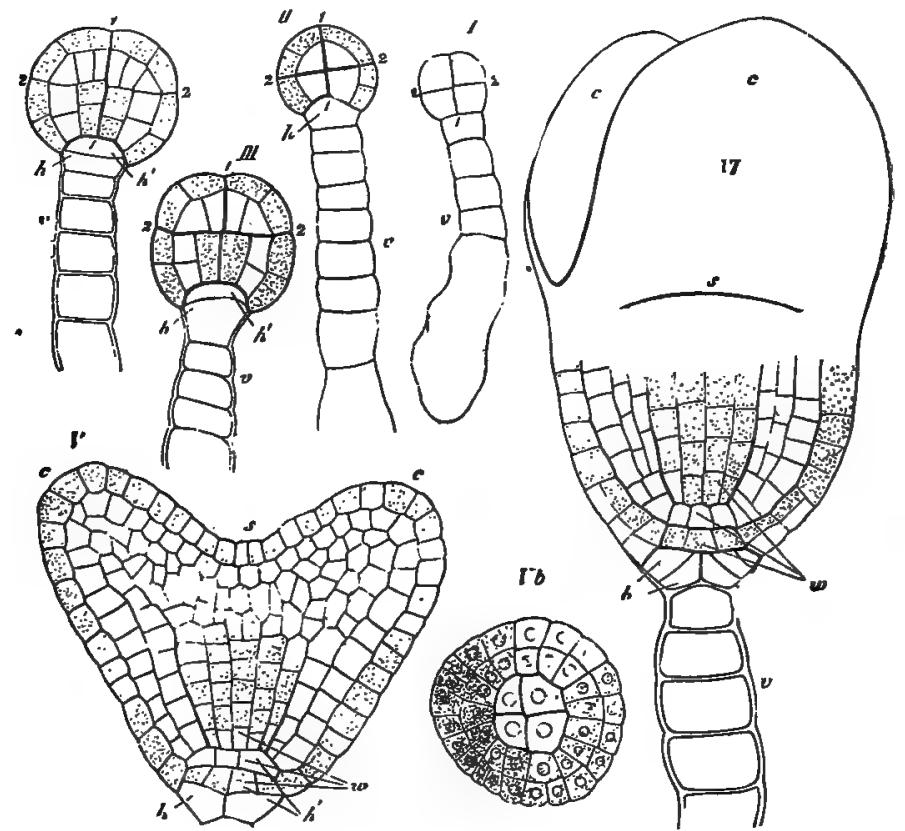

FIG. 57. Development of embryo in the shepherd's purse (Capsella Bursa-pastoris). I-VI, various stages of development: $\mathrm{Vb}$, apex of the root seen from below. I, $I, 2,2$, the first divisions of the apical cell of the pro-embryo (suspensor); $h, h$, cells from which the

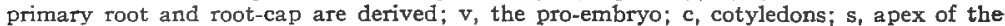
axis; w, root.-After Hanstein.

Fertilization.-While in the gymnosperms the pollen grains are usually provided with wings so as to bring about their transferral to the carpel by the agency of the wind, in the angiosperms, on the other hand, the grains are not provided with wings, but are adapted to transferral by insects. Pollination, however, may be also effected by the wind as is the case with many of our 
forest trees. After the deposition of the pollen grain on the stigma, the tube-cell begins to form a tubular process (pollen tube) which carries the male nuclei to the egg-cell (Fig. 85, $i$ ). It pierces the tissue of the stigma (Fig. 85, $h$ ) and traverses the style (Fig.

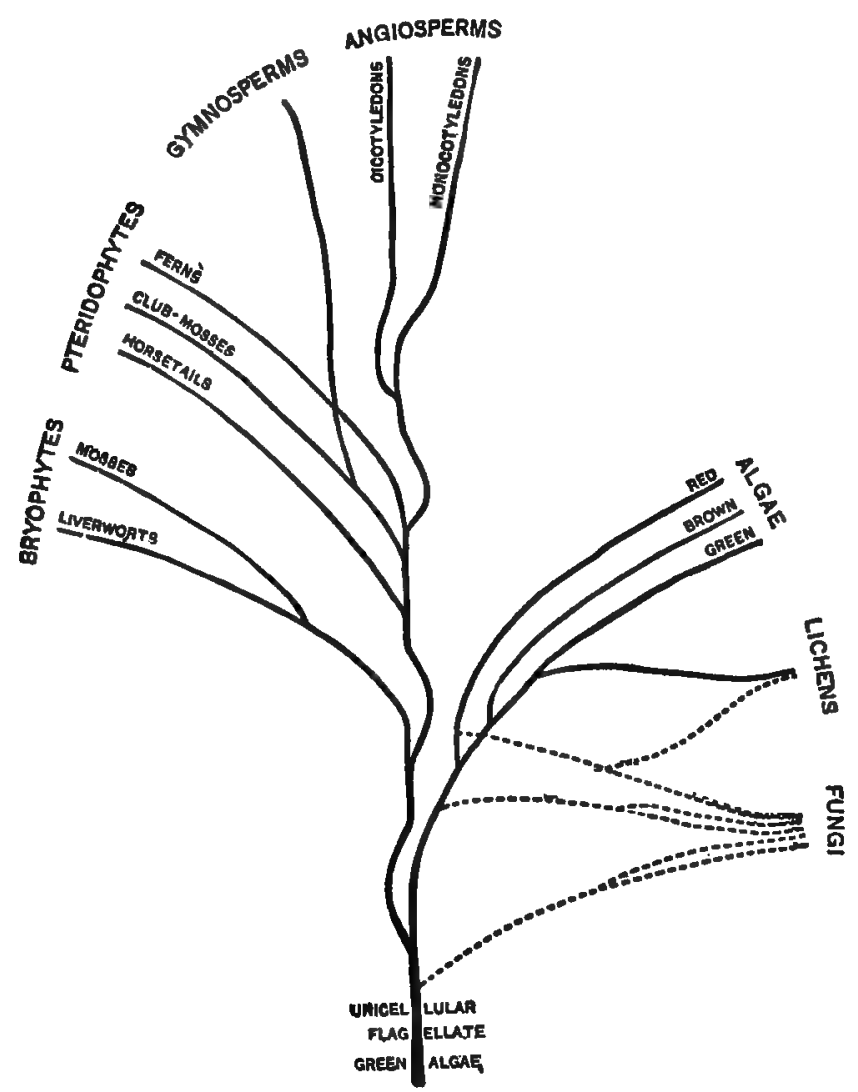

FiG. 58. Hypothetical tree of relationship and descent of the leading groups of plants.After Ganong.

$85, g)$ until it reaches the micropyle of the ovule, which it enters (Fig. $85, m$ ), then reaching the nucellus it penetrates this, entering the embryo-sac. The tip of the tube breaks and one of the generative nuclei which has been carried downward unites with the egg, after which a wall is formed, giving rise to an oöspore. The 
oöspore develops at once into the embryo or plantlet as seen in the seed, this stage being followed by a period of rest. In fact the young plant may lie dormant in the seed for years.

Development of Seed.-The steps in the development of the mature seed occur in the following order (Fig. 57): The oöspore divides into two parts, an upper portion which gives rise to the embryo, and a lower portion which by transverse segmentation gives rise to a short suspensor (Fig. $57, v$ ) which practically serves the same purpose as in the Gymnosperms (page 78). The embryonal cell develops the embryo which consists of: (I) a root portion which is connected with the suspensor (Fig. 57, w); (2) one or two cotyledons (Fig. $57, c$ ) which are attached to the stem; (3) a little bud at the apex of the stem which is known as the pilimule.

While the embryo is developing, the nucleus of the embryosac, either after fusing with the prothallial cell of the pollen grain, or in the absence of stuch union, begins active division, forming a highly nutritive tissue rich in starch, oil, or proteids, known as the endosperm (Figs. I2I and I22). Simultaneously with the development of the endosperm the nucellus may give rise to a nutritive layer called the perisperm, or the tissues of the nucellus may be modified and form with the altered integuments or coats of the ovule, the seed-coat.

Inasmuch as the Angiosperms furnish by far the larger proportion of plants and plant products used in medicine, it is desirable to give particular attention to the morphology of the plant as also to the distinguishing characters of a number of the important groups or families.

Economic Importance.-As indicating the great usefulness to mankind of the products obtained from the Angiosperms it will be sufficient to merely mention that all of our garden vegetables as well as the great crops of cereals like wheat, corn, rye, etc.; edible fruits and seeds; textile products, such as cotton, flax, etc.; medicinal products; timbers of various kinds, as oak, mahogany, walnut, chestnut, cherry, etc., are furnished by this great group of plants. 


\section{CHAPTER II. \\ THE OUTER MORPHOLOGY OF ANGIOSPERMS.}

\section{INTRODUCTORY.}

IT may be well to repeat at this point that on germination of the megaspore the female gametophyte bearing the egg-cell is formed, and that on germination of a microspore the male gametophyte bearing male nuclei is organized. The union of egg-cell and a male nucleus gives rise to the sporophyte embryo contained in the seed, which develops into the plant we see, namely, the sporophyte. The female gametophyte always remains concealed within the embryo-sac and the male gametophyte may be said to embody the protoplasmic contents of the pollen tube.

A complete flower is made up of floral leaves and sporophylls, the latter being essential for the reason that they give rise to the spores. While the flower belongs to the sporophyte generation the propagative organs may be said to be derived from both the sporophyte and gametophyte, and hence may be distinguished as asexual and sexual. The following outline illustrates their derivation:

$$
\begin{array}{r}
\text { Propagative } \\
\text { Organs }\left\{\begin{array}{c}
\text { Sexual, derived from } \\
\text { gametophytes (sexual } \\
\text { generation) }
\end{array}\right. \\
\begin{array}{c}
\text { Egg-apparatus, } \\
\text { containing egg-cell } \\
\text { Male Generative-cell, } \\
\text { giving rise to male nuclei } \\
\text { or male gametes }
\end{array} \\
\begin{array}{c}
\text { Asexual, derived from } \\
\text { sporophyte (asexual } \\
\text { generation) }
\end{array} \\
\begin{array}{c}
\text { Microsporangitum, } \\
\text { giving rise to microspores } \\
\text { (pollen grains) } \\
\text { Megasporangium, } \\
\text { giving rise to megaspore } \\
\text { (embryo-sac) }
\end{array}
\end{array}
$$


The vegetative organs comprise the root and shoot, the latter being usually differentiated into shoot axis or stem, and leaves. The usual type of shoot is one which bears leaves and is exposed to the light. The work of carbon dioxide assimilation (photosynthesis) being carried on for the most part by the leaves, it is sometimes spoken of as the "assimilation shoot."

\section{THE ROOT.}

True Roots are found only among plants having a vascular system, as the Spermophytes and the higher Pteridophytes,
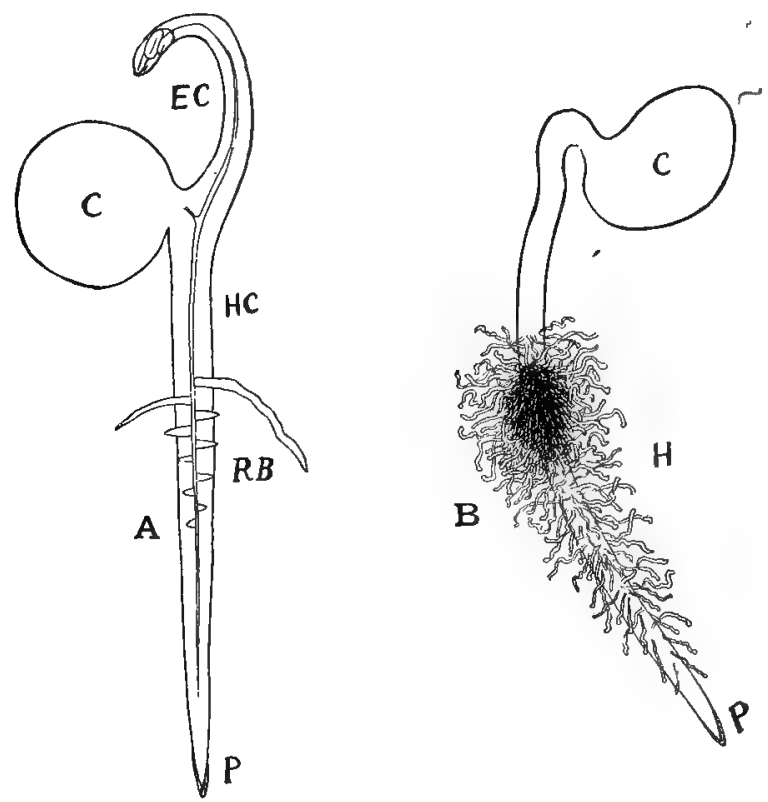

FIG. 59. A, advanced stage of germination of the common garden pea (Pisum sativum) showing growing point of root protected by root-cap (p); root branches or secondary roots (rb); hypocotyl (hc); epicotyl or stem above the cotyledons (ec); cotyledons (one in view) (c). B, plantlet of white or yellow mustard (Sinapis alba) showing copious development of root-hairs $(\mathrm{h})$.

although on the other hand some of the higher plants do not possess them, as certain of the Orchids. If we take a germinating plant and mark the root or descending axis, lengthwise, by means of a fine pen and India-ink, into ten equal divisions, beginning at 
the apex, and place the plant in a moist chamber, it will be found in the course of one or two days that the marks between $I$ and 5 have become much further apart, and that the growth in this region is about three times that between 5 and Io. This experi-

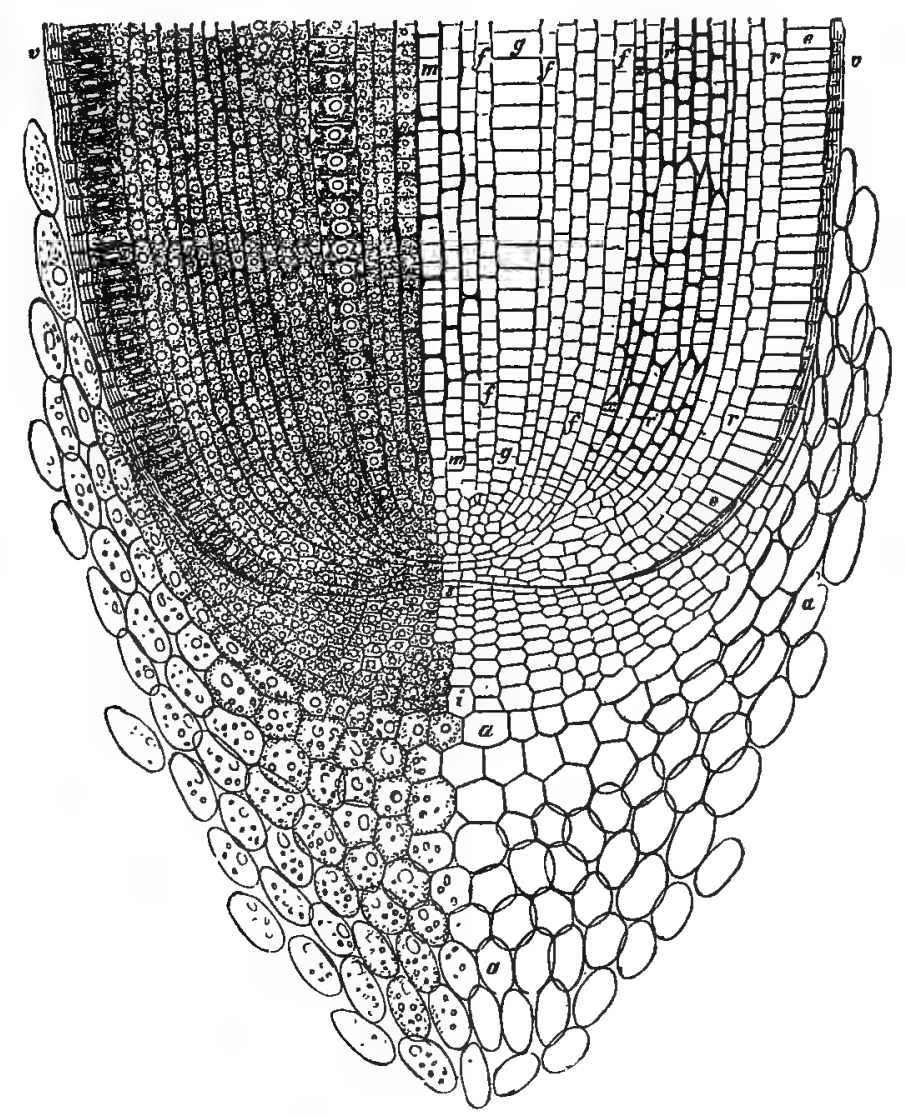

FIG. 6o. Longitudinal section through the tip of the root of Indian corn (Zea Mays) showing root-cap: a, outer layer; i, inner layer.-After Sachs.

ment indicates that the growth of the root takes place at or near the apex, this region being known as the point of growth, or point of vegetation (Fig. 60).

Upon examining the tip of a very young root by means of the microscope, it will be seen that the growing point is protected by 
a group of thin-walled parenchyma cells, which constitute the ROOT-CAP (Fig. 60). The root-cap varies in length, and it is only in rare cases that the roots of land plants are without a cap. In addition to its protective function the root-cap makes the passage of the roots through the soil easier by reason of the mucilaginous character of its outer cell-membrane.

Just above the root-cap there is developed a narrow zone of delicate hairs, which arise from the surface cells and are usually thin-walled and unicellular. These are known as ROoT-HAIRS (Fig. 59, B) and their function is twofold: (I) They secrete an acid which renders the inorganic substances of the earth soluble, and (2) they absorb these and other strbstances for the nourishment of the plant. It should be stated that there are a number of plants which for various reasons do not possess root-hairs, such as water-plants, marsh-plants, certain Coniferæ, etc.

When the germinating root persists, it is called the main, tap or primary root (Fig. 88); when it divides into a number of similar branches it is known as a multiple primary root, as in dahlia. Branches may arise in addition on both kinds of roots (Fig. 88).

There are some plants which complete their cycle of growth in one year, and such plants are spoken of as annuals. Other plants produce only roots, stems and leaves the first year. The roots are large and fleshy and contain large quantities of nutritive matter, which is stored for the use of the plant the following year, when it produces fruit and thus completes its cycle of growth. Plants of this class are known as biennials, and the roots as root-tubers or tuberous roots. Plants which persist year after year are known as perennials. Sometimes, as in temperate climates, the roots only are perennial, as in Phytolacca decandra, when the plant is spoken of as a perennial herb.

Influence of Gravity.-The root is popularly supposed to grow downward, in order to avoid the light. The roots of plants grown in hanging baskets, however, naturally emerge into the light, and then continue their downward growth. On the other hand, the theory has been established (as a result of Knight's experiments) that the root grows downward by reason of the influence of gravity. In addition it may be said that the principal 
functions of the root, namely, those of absorbing inorganic food materials, and of fixing the plant to the soil, determine in a measure the direction of its growth. The tendency of the root to grow downward is a characteristic which distinguishes it from other parts of the plant and it is said to be positively geotropic (Fig. 6I, $A$ ).

The influence which gravity has on plants may be best understood by bearing in mind that gravity is a constant force which acts perpendicularly to the surface of the earth, and that all parts of the plant are subject to its influence. The organs of plants

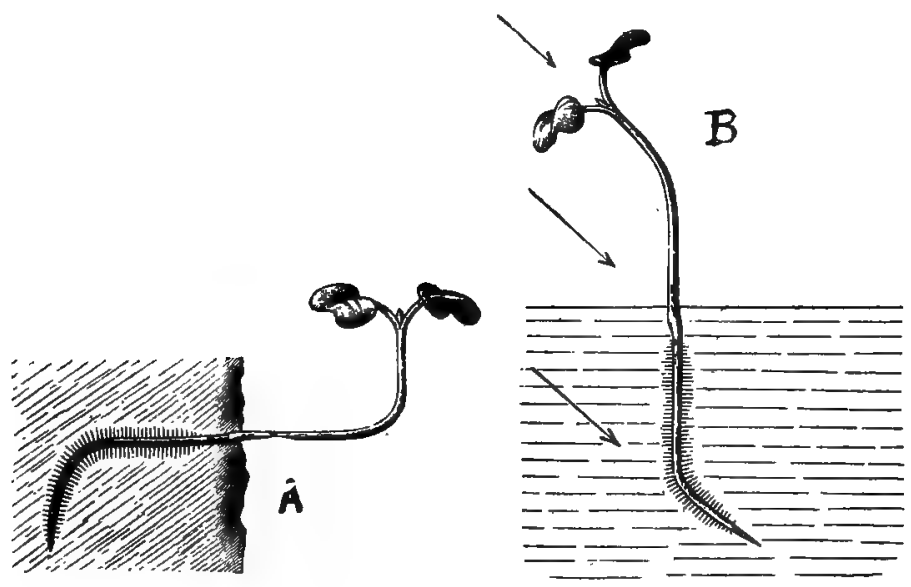

Fig. 61. A, seedling of Brassica nigra in which root and stem have curved into a vertical position after being laid horizontally. B, seedling of Sinapis alba, the hypocotyl showing a positive, the root in water a negative heliotropic curvature. The arrows show the direction of the incident rays of light.-After Pfeffer.

respond in different ways to the action of gravity, but a clear distinction should be made between mere mass attraction or that manifestation of the force of gravity whereby the heavily laden branch of a fruit tree bends downward and the stimulus which causes the primary root of a plant to grow downward and the shoot to grow upward. While all parts of the plant are subject to the influence of gravity not all the organs of plants respond in an equal degree. This is well illustrated by roots themselves. It is well known that whatever the position of the seed at the time of germination the young radicle begins to grow perpen- 
dicularly downward (Fig. 61, $A$ ). The branches, however, which arise on the primary root are less positively geotropic and instead of growing downward parallel with the primary or tap root, diverge at an angle from it (Fig. 88). The secondary branches are still less affected by gravity and diverge still more from the perpendicular, or grow out horizontally, while still others do not appear to be in the least affected by gravity and grow freely in any direction. In the case of large trees we frequently find that the lateral

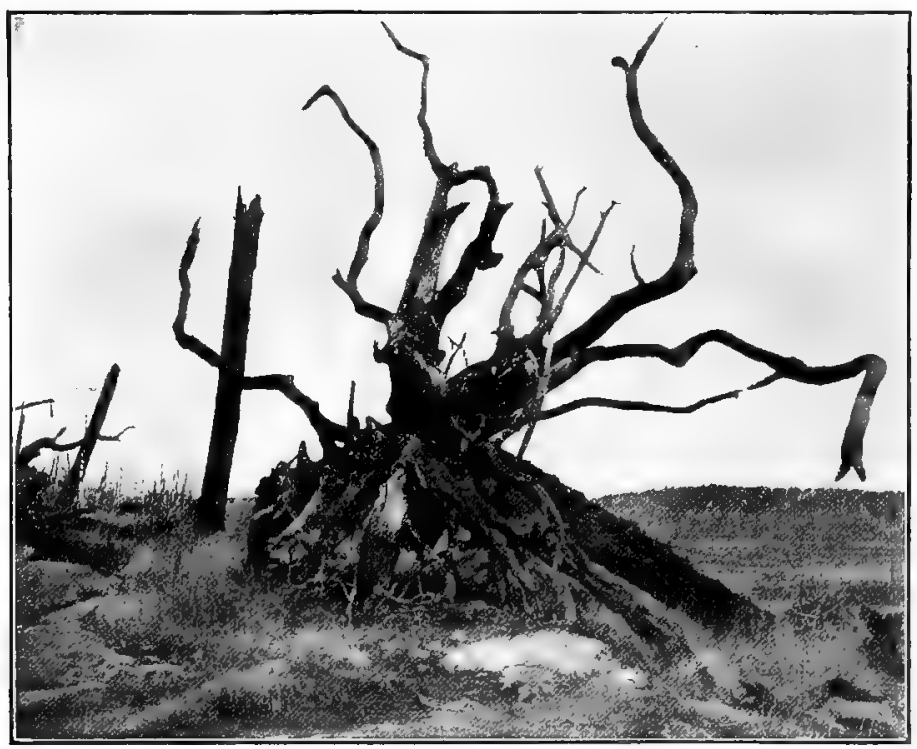

FIG. 62. Over-turned tree trunk showing spreading root-system, the main or tap root having died away.

roots spread out in a more or less horizontal plane near the surface of the earth, and if the main root has died the influence of gravity is not very evident (Fig. 62). But here it must be remembered that gravity was instrumental in determining the direction of growth at an earlier stage. This spreading of the roots near the surface of the earth is of decided advantage to plants, for it enables them to avail themselves of the better soil of the surface layers. As indicated, gravity also determines the upward perpendicular direction of the shoot, which is therefore said to be 
NEGATIVELY GEOTROPIC, but, as in the case of the root, the branches are less inftuenced by it and hence diverge at various angles from the main axis.

Some of the other effects of gravity may be noted. If the end of a shoot be cut off the branches next to the top will grow perpendicularly upward and thus assume the work of the main axis. Likewise in the case of roots, if the apex of the main or tap root be cut off the branches near the end will assume a perpendicular direction. It will frequently be noticed in the case of trees which have been uprooted or where branches have been bent over horizontally that the new branches which arise grow perpendicularly upward. Creeping shoots furnish another good example showing the influence of gravity, the branches growing upward and the roots downward.

Modified Roots.-Roots which arise from the nodes of the stem or other parts of the plant are known as secondary or adventitious roots. These include the aerial roots of the banyan tree, which are for the purpose of support; the roots of the ivy, which are both for support and climbing, and the roots of Indian corn and many palms which serve both for support and the absorption of nourishment. Under this head may also be included the aerial roots of orchids and the root-like structures, or haustoria, of parasites, as of mistletoe and dodder, which penetrate the tissues of their host plants.

Of special interest also are the breathing roots of certain marsh-plants which serve to convey oxygen to the submerged parts; and the assimilation roots of certain water-plants and epiphytes, which are unique in that they produce chlorophyll. In certain plants the roots give rise to adventitious shoots as in Prunus, Rubus, Ailanthus, etc., and in this way these plants sometimes form small groves.

Root Tubercles.-The roots of the plants belonging to the Leguminosæ are characterized by the production of tubercles, nodules or swellings (Fig. 64) which have been shown to have a direct relation to the assimilation of nitrogen by the plants of this family. Like carbon, nitrogen is one of the elements essential to plant-life, being one of the constituents of protoplasm and present in various nitrogenous (proteid) compounds which occur 
as normal constituents of the plant. The nitrogen required by plants is derived either from nitrogen salts contained in the soil,

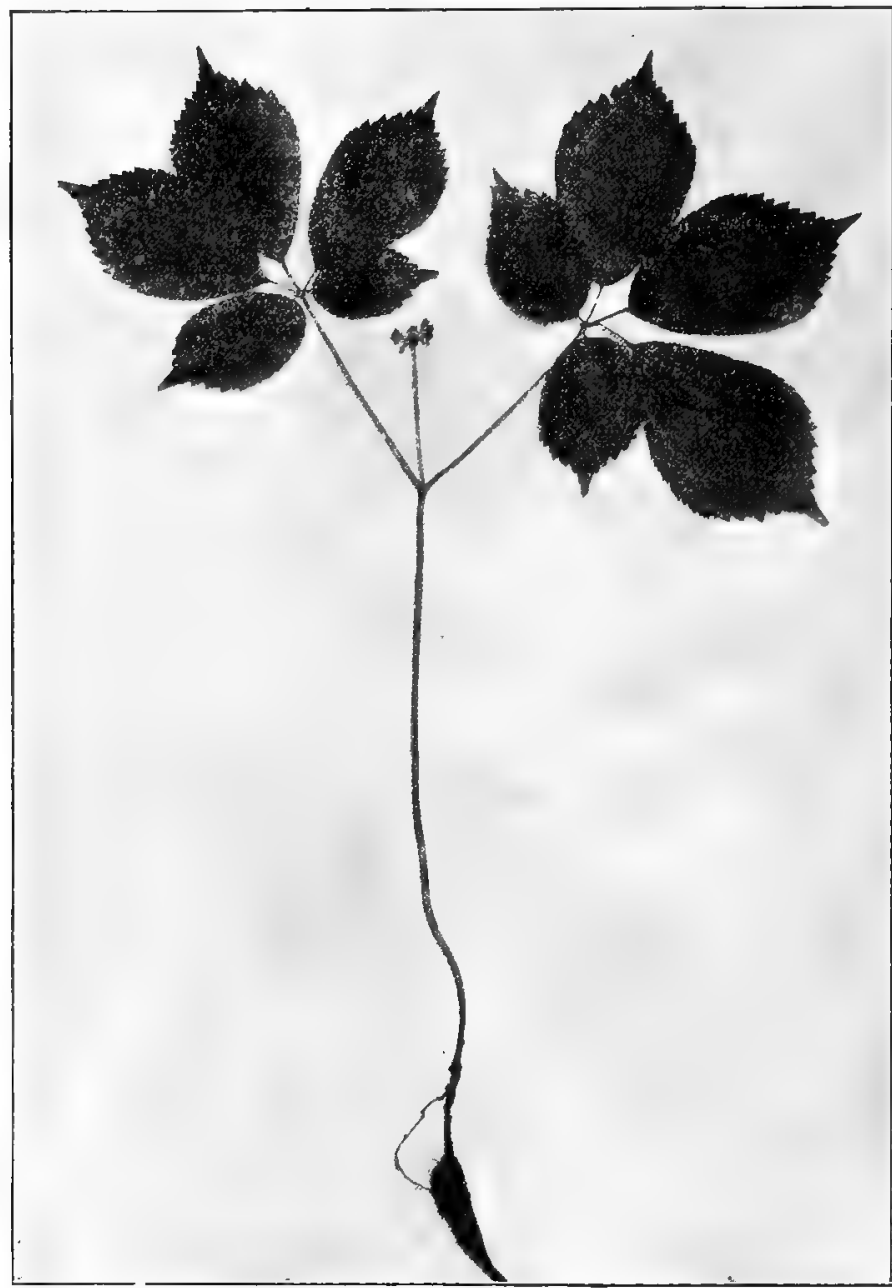

Fig. (3. Cinseng plant (Panax quinquefolium) showing fusiform luberous rout, palmately-compound leaves, and solitary umbel of flowers.

as nitrates and ammonium salts, or from the free nitrogen of the atmosphere. While most of the higher plants are able to assimilate nitrogen compounds existing in the soil, only the 
Leguminosæ, with possibly a few exceptions, are able to assimilate atmospheric nitrogen, and in this respect the majority of the Leguminosæ stand as a class by themselves. Apparently in direct relation to this character stands the fact that the seeds of these plants contain a high percentage of nitrogen. This special ability of the Leguminosæ to fix atmospheric nitrogen in the plants depends upon the presence of the nodules, which are due to the

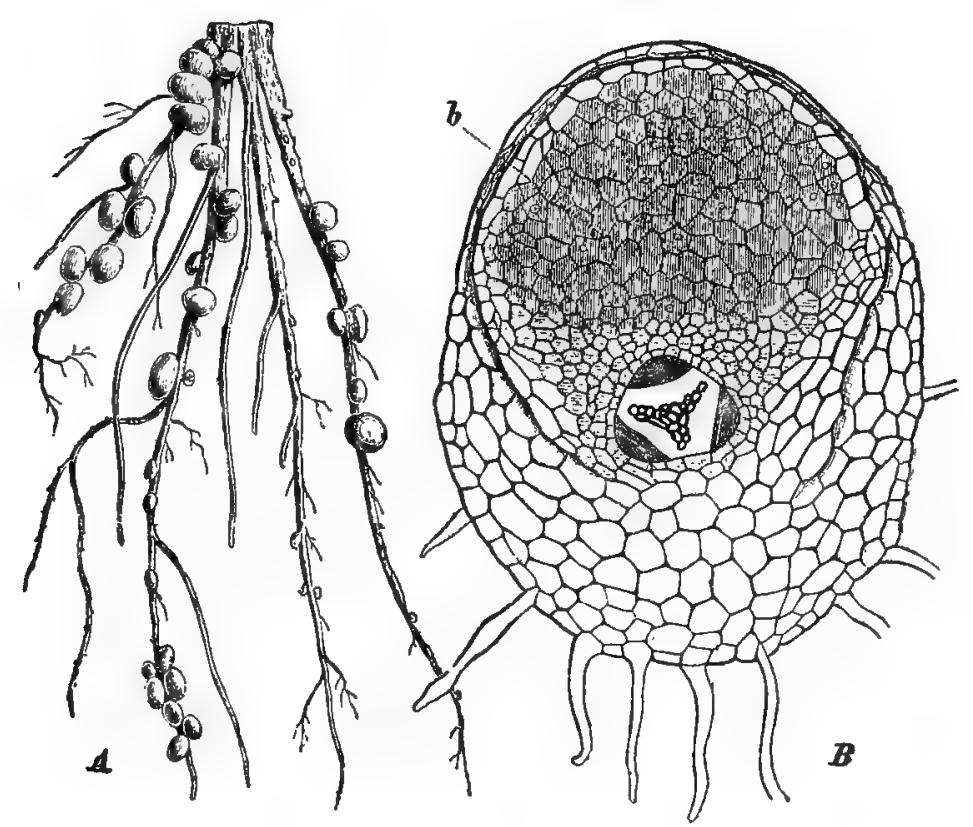

Fig. 64. Root tubercles on Lupinus, one of the Leguminosa: A, roots with tubercles; $B$, transverse section of root showing the cells (b) which contain the nitrogen bacteria.A, after Taubert; B, after Frank.

infection of the roots by a soil-bacterium (Pseudomonas radicicola), although the precise mode of fixing the nitrogen is not known. The bacteria seem to be localized in the nodules and are not found in any other part of the plant.

It has been shown that when the roots of leguminous plants. are free from nodules they do not have the power of assimilating. free nitrogen. On the other hand when the nodules produced by the bacteria are developed, the plants will grow in soil practically. 
free from nitrogen salts. Because of this power the plants of this family are useful in restoring worn-out land, i.e., land in which the supply of nitrogen is exhausted, and they thus play an important rôle in agricultural pursuits.

The enriching of the soil is accomplished by ploughing under the leguminous crops, as of clover or alfalfa, or allowing the nodule-producing roots to decay, when the nitrogen compounds are distributed in the soil.

\section{THE STEM.}

The stem, or ascending axis of the plant, usually grows in a direction opposite to that of the root, seeking the light and air. The tendency of the stem to grow upward is characteristic of the majority of plants, and is spoken of as NEGATIVE GEOTROPISM. The growing point of the stem is at the apex, and it is protected by the embryonic leaves (Fig. I08, $B$ ).

Stems are further characterized by bearing leaves, or modifications of them. The leaves occur at regular intervals in the same species, and that portion of the stem from which they arise is spoken of as a NODE, while the intervening portion is called an internode.

Stem Branches usually arise in the axils of the leaves, first appearing as little protuberances, sometimes spoken of as primordia, on the stem. Their origin differs from that of the root branches, in that they arise from meristematic or embryonic tissue (p. I8I) developed just beneath the epidermis. The branches, like the main axis, manifest negative geotropism. although to a lesser degree. They likewise possess a growing point at the apex, covered with embryonic leaves (Fig. 108). Not infrequently more than one branch arises in the leaf axil.

Buds may be defined as embryonic stems or branches. The buds at the ends of stems or branches are known as APICAL, Or TERMINAL BUDS, and those situated in the axils of the leaves, as IXILLARY BUDS. In some cases they are protected by scales, as in hickory, when they are known as scaly buds; while buds which are not thus protected, are called naked buds. They are further distinguished as leaf, flower, and mixed buds, accordingly as they develop into leaves, or flowers, or both. 
We have to distinguish between overground shoots and underground shoots. The former are sometimes designated as epigeous (upon the earth) and the latter as hypogeous (under the earth).

Epigeous Shoots.-As would be supposed these two kinds of shoots vary to a certain extent. In epigeous shoots a number

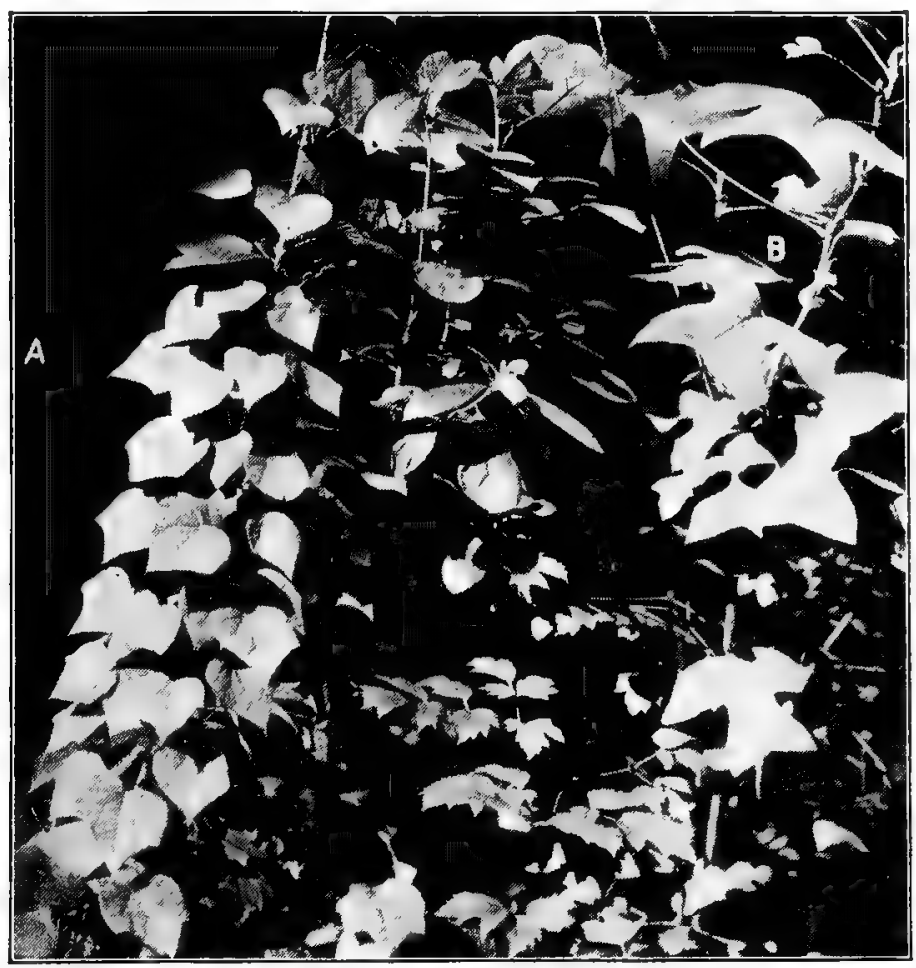

FIG. 65. A, woody vine of Canada moonseed (Menispermun canadense) which ascencls by twining to the right; $B$, young tulip poplar (Liriodendron tulipifera).

of features may be noted. If the internodes are long the leaves do not usually interfere with one another so far as exposure to light is concerned, but if the internodes are short, the leaves are all brought close together on the axis, and hence were it not for various modifications, their relation to light would be very unequal. Sometimes the shoot-axis may share with the leaves 
the work of assimilation, as in the case of certain green stems. Then again there are cases in which the leaves are reduced, and the work of assimilation is catried on exclusively by the shoot-

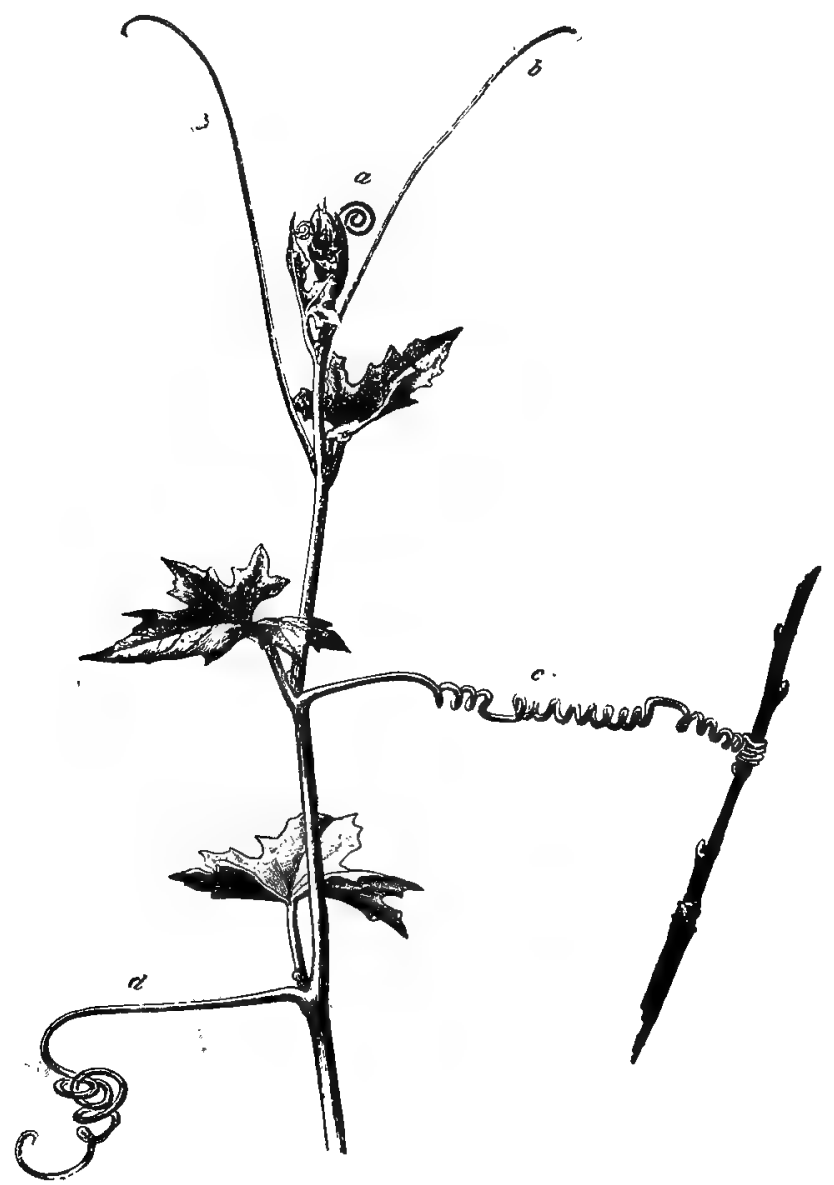

Fig. 66. Bryonia dioica. a, young, spirally coiled tendril; $b$, expanded and irritable tendril; $c$, tendril which has grasped a support; d, tendril which has not grasped a support, and has undergone the old-age coiling.-After Pfeffer.

axes, as in most Cactaceæ, certain marsh-plants and others, On the other hand the shoot-axis may be modified so as to increase the assimilating surface, as by a flattening of the axis, as in some of 
the Cacti, the leaves being suppressed or considerably reduced. Branches are not infrequently modified to hard, pointed and spiny structures, as in the Japanese quince, when they are spoken of as thorns. Leaves and even flowers may arise upon thorns, which shows that they are modified branches.

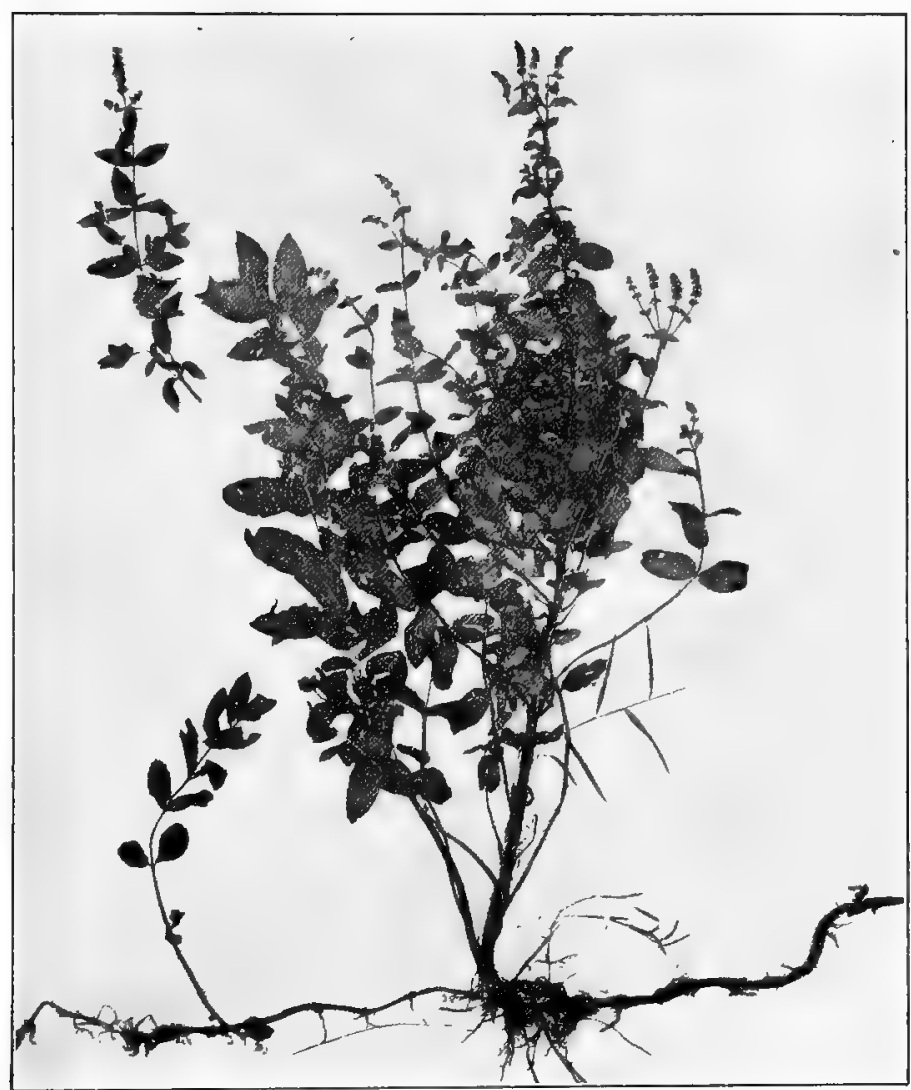

Fig. 67. Plant of spearmint (Mentha spicata) showing procumbent stems or leafy runners from which roots are developed at the nodes, and one erect branch at the left from which a new plant will be developed.

A number of plants ascend into the air on other plants, or other objects which serve as supports, either by attaching themselves to them or by crawling around them, when they are distinguished as twiners and climbers. TwINERS ascend by a special 
circumnutating movement of the stem, as in the morning glory, Menispermum (Fig 65), etc. Climbers, however, ascend by means of special structures, as the aerial roots of the ivy, and are termed root climbers; or they may climb by means of leaves, as in Clematis, and these are known as leaf climbers; still others climb by means of tendrils, as in the grape and Bryonia and these are known as tendril climbers (Fig. 66). These tendrils, which are thread-like modifications of the stem, are in some cases provided with disk-like attachments for holding the plant in position, as in the Virginia creeper. Twiners and climbers are sometimes spoken of as LIANES (lianas), particularly those of tropical regrons, where they form a prominent feature of the forest vegetation. The lianes usually have rope-like, woody stems, the

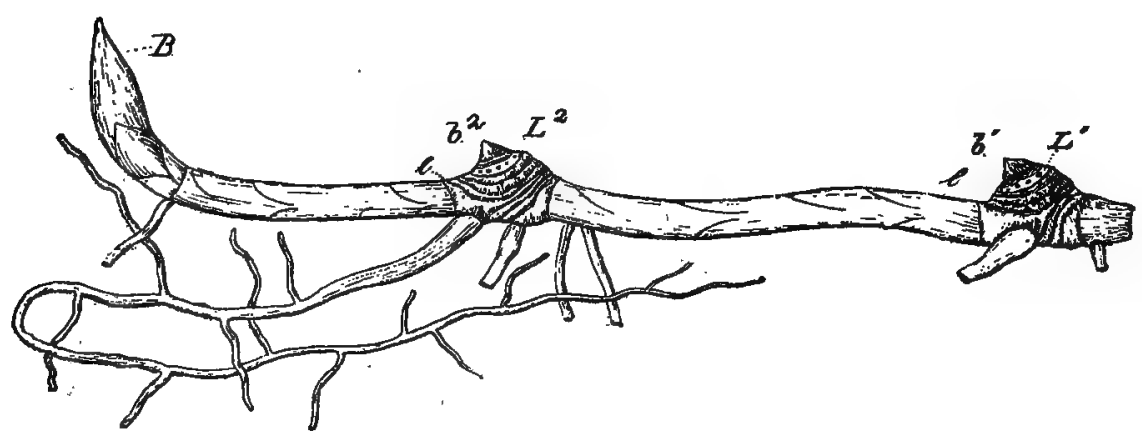

FIG. 68. Rhizome of Podophyllum representing three years' growth: $b^{\mathbf{1}}$, the terminal bud of last year; $b^{2}$, the corresponding one of the present year; $B$, the terminal one of the entire rhizome will develop in the spring of next year. $L^{1}$ and $L^{2}$ indicate the scars of aerial "leaves of the two preceeding yéars' growth; $b^{1}$ and $b^{2}$, latent buds.-After Holm.

formation of leaves being either suppressed or retarded, and they often run for long distances over the ground and climb to the tops of the tallest trees. They are also frequently characterized by an anomalous stem-structure.

Stems vary furthermore in size and form. While most stems are more or less cylindrical or terete, other forms also occur, as the flattened stems in the Cactaceæ; triangular in the Cyperaceæ, and quadrangular in the Labiatæ and Scrophulariaceæ.

Hypogeous Shoots.-While most stems attain a more or less erect position as in trees and shrubs there are others which bend over to one side, or lie prostrate on the ground, and in some 
cases produce roots from the nodes, as in Mentha spicata (Fig. $67)$. These latter are known as stolons or runners.

Furthermore the stems of a number of plants grow underground and these are known as RHIZOMES or ROoT-STOCKs; from the upper portion of the nodes overground branches arise which bear leaves (so that the work of assimilation may be carried on) as well as flowers, and from the lower surface, roots. A familiar example of this type of plant is the May-apple (Podophyllum) (Fig. 68).

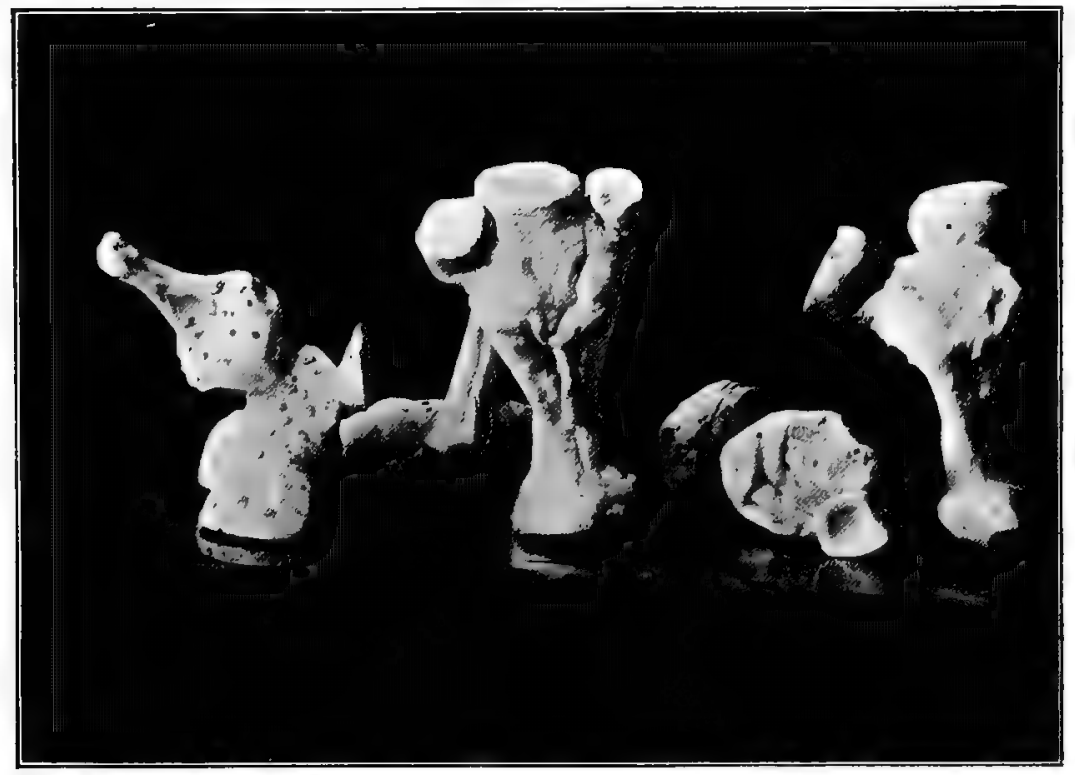

FIG. 69. Specimens of "orris root" of commerce consisting of peeled pieces of the rhizomes of Iris florentina. The rhizomes are mostly dichotomous, the branches becoming obconical and of characteristic shape.

While most rhizomes are perceptibly thickened, and more or less fleshy when fresh, as Sanguinaria, in other instances they are of the ordinary thickness of the overground stem.

There are some rhizomes that are excessively thickened, as in the common white potato, and these are called TUBERS. The so-called "eyes" represent the nodes, from which the leaves and branches arise. Tubers should not be confounded with 
tuberous roots, as those of the sweet potato and jalap, for these latter have the morphological characters of roots.

Instead of the node, or internode, or both, becoming excessively thickened, they may be reduced in size and crowded upon each other, the leaves at the same time becoming thickened and filled with nutriment. Such a modified stem and leaves, as in the onion, is called a BULB. Bulbs are sometimes produced in the axils of the leaves of overground stems, as in some lilies, and are then called bulbils or bud-bulbs, or they may be produced at the ends of branches replacing the flowers, as in Allium. Bulbs and tubers serve as storage-organs and carry the life of the plant over from one season to another or they may in some instances tide over unfavorable conditions. The thickened fleshy stems of Cactacex are also regarded as storage organs.

A CORM is intermediate between a true tuber and a bulb; it is more in the nature of a thickened internode, being surrounded in some cases by thin membranous scales, as in Crocus and Colchicum.

\section{THE LEAF.}

Leaves arise as lateral developments on branches, being derived from primordia which have their origin in the meristematic tissue at the vegetative point, and young leaves are accordingly at the ends of the branches.

A Simple Leaf consists of a LAMINA or blade, which is usually membranous and of a green color, and a PETIOLE or stalk, which, however, may be wanting when the leaf is said to be sessile. Leaves may also possess a pair of leaf-like structures at the base, which are known as stipules (Fig. 70). The principal function of the latter appears to be that of protecting the buds, as in the tulip poplar (Liriodcndron) (Fig. I44), although they may become leaf-like and assist in the functions of the lamina, as in the pansy (Viola tricolor) (Fig. 7o).

Light Relation of Leaves.-While the lamina of the leaf appears to assume a more or less horizontal position, it usually inclines at such an angle as to receive the greatest amount of diffused daylight. Wiesner has shown, for instance, that when plants are so situated that they receive direct sunlight only for a 
time in the morning, and diffused daylight during the rest of the day, the position of the upper surface is at right angles to the incident rays of daylight, and not to that of the rays of the morning sun. This phenomenon may be studied in the house geranium and other window plants. In endeavoring to explain this behavior of the leaves, Frank assumes it to be due to a kind of heliotropic irritability peculiar to dorsiventral organs, and terms it TR.ANSVERSE HELIOTROPISM.
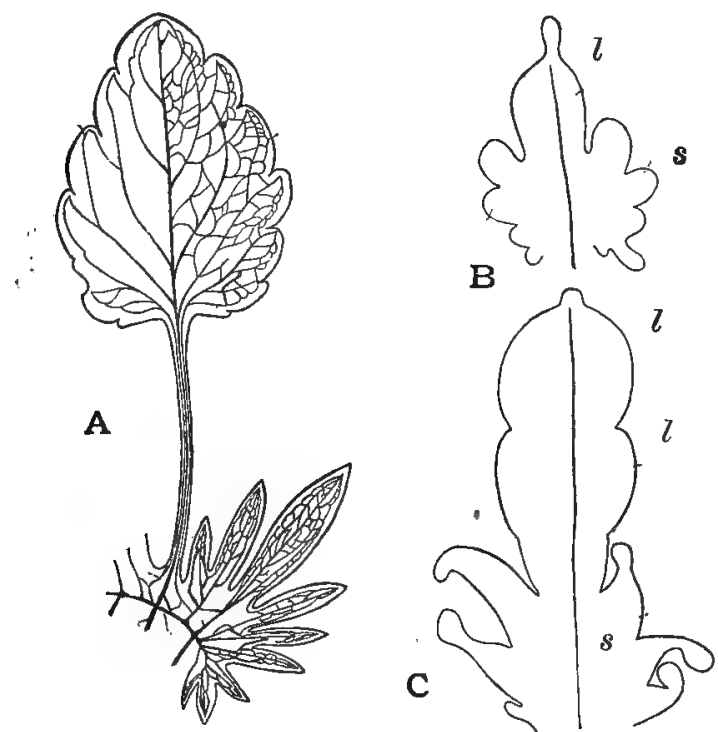

FIG. 70. A, leaf of violet (Viola tricolor) showing broad lamina, long petiole, and one of the palmately-lobed stipules at the base of the petiole. $\mathrm{B}, \mathrm{C}$, stages in the development of the leaf. The lobes of the stipules (s) develop before the lamina (1).

The stem, as well as the petiole or stalk of the leaf, is also influenced by the light, and is said to manifest positive heliotropism. Those parts of plants that turn away from the light, as the aerial roots of the ivy, are said to possess negative heliotropism.

Depending upon their relation to external agents, several forms of leaves are distinguished. In those which assume a more or less horizontal position the two surfaces of the lamina are quite different, and the leaves are said to be DORSIVENTRAL, or bifacial. 
Usually there is a more compact arrangement or stronger development of chlorophyll tissue on the upper or ventral surface, while on the lower or dorsal surface the veins stand out more prominently, and there is a greater number of stomata or breathing pores. Frequently when the wind is blowing strongly the dorsal surface of the leaves will be brought into view and in some instances they appear almost white, as in certain maples and willows.

In contrast with this type of leaf may be mentioned those which grow edgewise and in which both surfaces of the leaf are more or less alike, as in the Eucalypts and Acacias of Australia.

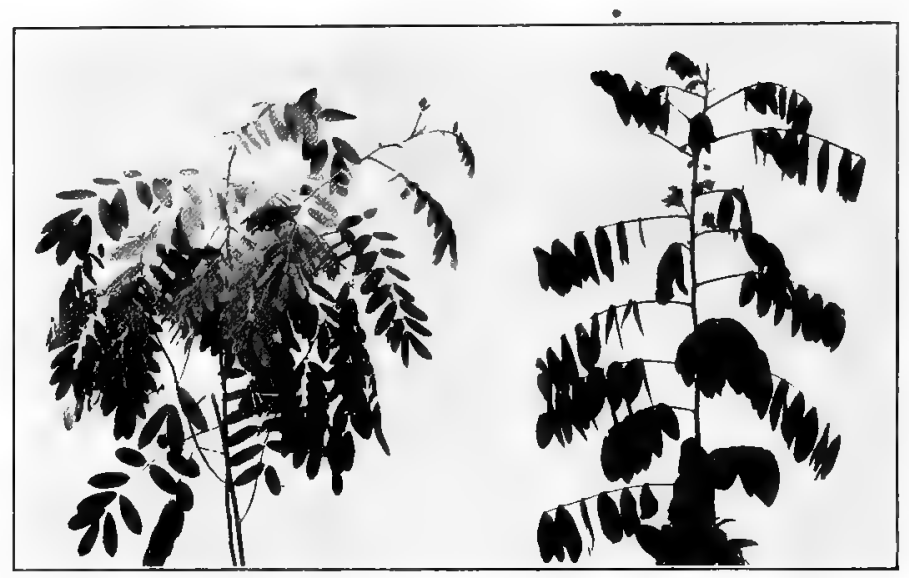

Fig. 7r. American senna (Cassia marilandica). The figure at the left shows the pinnately-compound leaves in the day position when under the influence of light, and the one to the right the drooping position of the leaflets at night.

Such leaves are bilateral, and other examples are furnished by Iris, Cat-tail (Typha) and Calamus. Another type of leaf is the radial. This is illustrated by Juncus, the leaves of which are hollow and cylindric.

Functions of the Leaf.-When we speak of the leaves of the plant we usually have in mind the foliage leaves or green chlorophyll leaves.

Under the influence of sunlight the chloroplasts are able to rearrange the elements in carbon dioxide and water, which are looked upon as inorganic substances, into starch or related com- 
pounds which are of an organic nature. This process is known as carbon dioxicle assimilation, or I'HOTOSYNTHESIS, which latter term means the building up of a compound under the influence of light. In this process, which is sometimes expressed by the following formula, oxygen is given off :

$$
\underset{\text { Carbon Dioxide }}{6 \mathrm{CO}_{2,}}+\underset{\text { Water }}{5 \mathrm{H}_{22} \mathrm{O}}=\underset{\text { Starch }}{\mathrm{C}_{6} \mathrm{H}_{10} \mathrm{O}_{5}}+\underset{\text { Oxygen }}{6 \mathrm{O}_{2}}
$$

The importance of this function can be best appreciated by bearing in mind that all of the organic products built up by the plant are derived almost entirely from the carbon dioxide of the air which is taken in through the leaves.

Transpiration and respiration are also functions of the leaf. TRANSPIRATION is the giving off of water (through water-pores), or watery vapor (through the stomata), which has been absorbed by the root hairs and transported through the tissues of the root, stem and leaf; the process of breathing, or RESPIRATION, consists in the taking in of oxygen and giving off of carbon dioxide, the exchange being just the reverse of what it is in photosynthesis. These several functions are, however, not confined to the leaf alone, but are carried on by all the green parts of the plant.

Leaf Venation.-The foliage leaves of higher plants are traversed by vascular bundles, which enter the blade through the petiole and diverge at the base, or, as in the case of Dicotyledons, branch in various ways; and it will be seen that the form of the leaves corresponds to the distribution of the bundles. These bundles are known as veins or nerves, and they have two functions, namely, (I) that of a mechanical support, and (2) that of carrying nutritive materials to and from the leaves.

The mode of venation in Monocotyledons and Dicotyledons differs somewhat, but it will be found that in a number of instances the venation of leaves of plants belonging to one of these great groups will resemble that of the leaves of certain plants in the other group. However, there are certain general types belonging to each group.

Venation in Monocotyledons.-An examination of the leaf of lily-of-the-valley shows that the veins arise at the base and run more or less parallel to the apex. Such a leaf is said to be PARALLEL-VEINED or NERVED. It will moreover be noticed that 
the distribution of the veins in this manner produces a lamina with an even, or entire margin, and such a system of venation is known as a closed system of venation. The leaves of Veratrum (Fig. 129) and Zea Mays, furnish other examples of parallelnerved leaves.

In palms (Fig. 25I) the venation is somewhat different. The veins instead of converging toward the apex as they do in the more or less lanceolate leaf of lily-of-the valley, radiate from the base to the margin of the more or less round leaf, and a leaf of this type is said to be PALMI-NERVED.

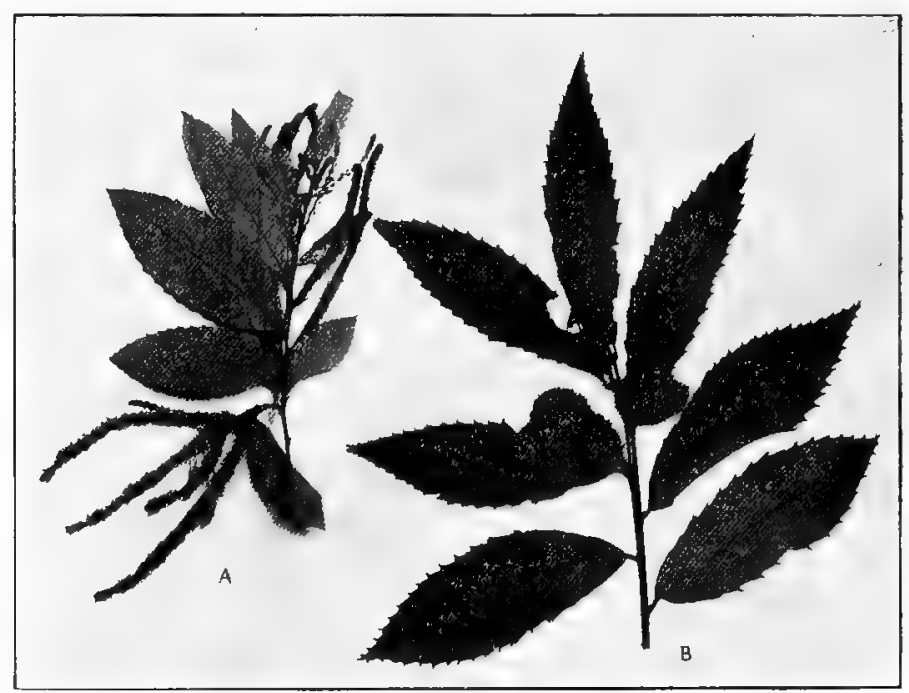

FIG. 72. Chinquapin (Castanea pumila). A, branch with long aments of staminate flowers; $B$, fruiting branch bearing alternate, exstipulate and pinnate, reticulately-veined leaves. The leaves are elliptical in general outline, acute at both apex and base, and with sharply serrate margins.

There is still a third type of venation in Monocotyledons. In this instance one principal vein runs from the base to the apex of the leaf, and from this branches run parallel to the margin. The banana furnishes an example of this type, and is said to be PINNI-NERVED.

Venation in Dicotyledons.-Here the veins are characterized by their habit of repeatedly branching and anastomosing, 
whatever the general type of venation may be and thus form a net-work or reticulum, hence the leaves are said to be RETICULATE or NETTED-IEINED. The principal types are as follows: A chest-

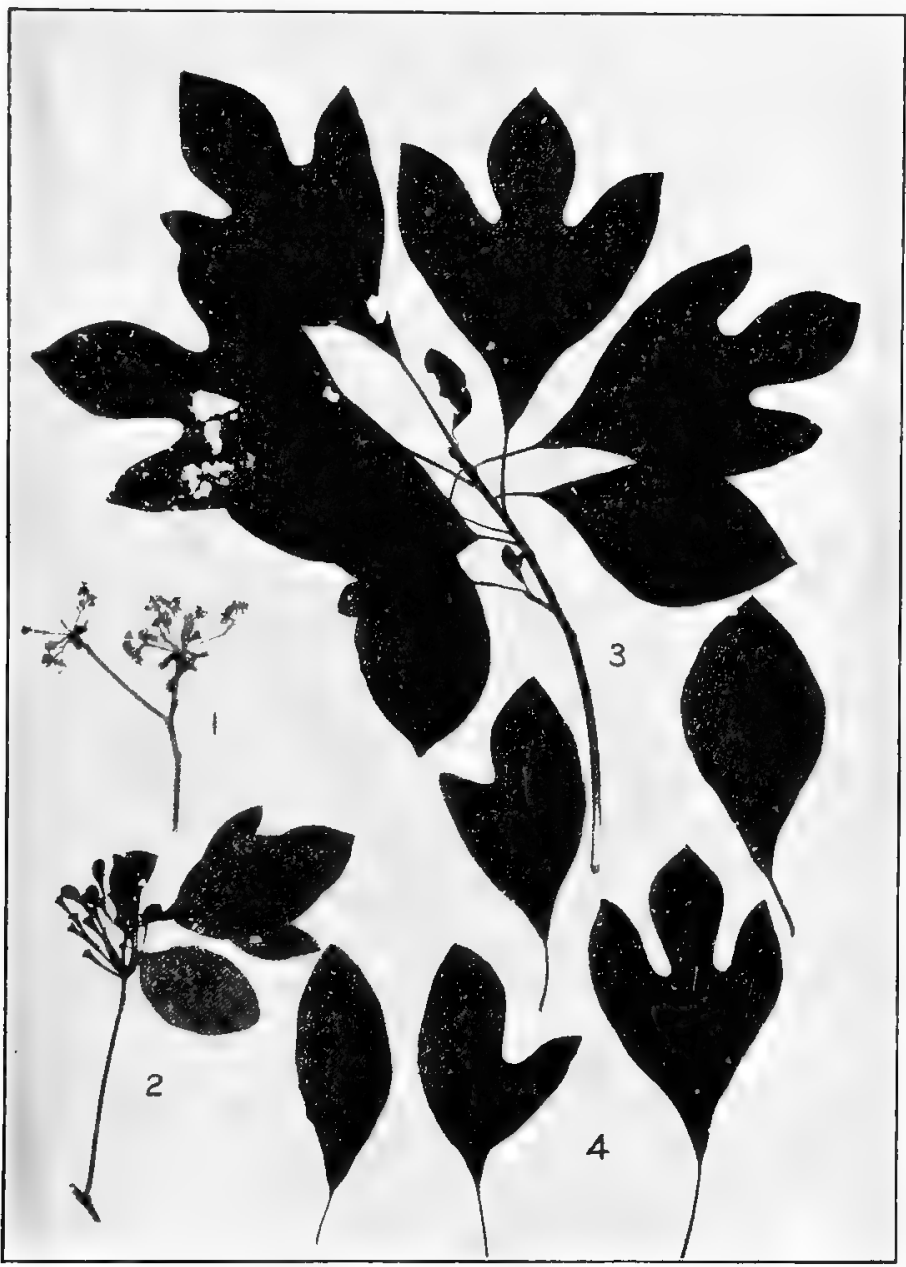

Frc. 73. Sassafras officinale. 3, 4, variable forms of leaves, some being entire and elliptical or oval, others with a single sinus (mitten-shaped), and still others 3 -lobed; 1 , a flowering branch; 2 , branch showing some of the drupes.

nut or chinquapin leaf (Fig. 72) furnishes a good illustration of a pinnately-reticulate leaf. The principal vein which runs from 
the base to the apex is called the MIDRIB, while the secondary veins which arise from it and run more or less parallel to the margin are sometimes spoken of as ribs and may be likened to the plumes on the shaft of a feather.

In other cases several large veins arise at the base and diverge toward the margin, giving rise to PALMATELI-VEINED leaves, as in the leaf of maple. There are still other types, as in cinnamon (Fig. I46) which is said to be rib-netted, etc.

Surface of Leaves.-In addition to the markings of leaves due to veining there are certain other characters which serve to distinguish them. Hairs are of frequent occurrence on leaves, being generally most abundant on the dorsal surface, especially the veins, and various terms having reference to the kinds of hairs have been applied to leaves (page 2 I0; Figs. $283,284,285$ ).

Texture of Leaves.-Leaves also vary in texture. A thin pliable leaf is called membranous; one which is thick and leathery, coriaceous; and one which is thick and fleshy, succulent, as that of the century plant and Aloe (Fig. I30).

Forms of Leaves.-The leaves of plants exhibit an almost innumerable variety of forms (Fig. 78); even on the same plant there are not infrequently several forms, as in Viola tricolor and sassafras (Fig. 73) ; even the two sides of the same leaf may vary, as in Hanamelis (Fig. 264) and Begonia, when it is known as an inequilateral or asymmetric leaf. It frequently happens that the lower leaves on a shoot are lobed while the upper ones are entire, or some of the leaves may be sessile and others petiolate. Many of the terms used in ordinary language in describing the forms of objects are applied here also, as linear, lanceolate, oblong, elliptical, spatulate, wedge-shaped, etc.

Apex of Leaf.-A number of descriptive terms are employed in describing the apex of the lamina, as ACUTE, when the form is that of an acute angle; овтUSE, when the angle is blunt; ACUMINATE, when the angle is prolonged; TRUNCATE, when the end of the leaf appears to be cut off ; RETUSE, when it is slightly notched at the apex; obCORDATE, when the notch is pronounced; EMARGINATE, when the degree of notching is between retuse and obcordate. Sometimes the apex appears like the continuation of the midrib, when it is termed CUSPIDATE or mucronate. 
B.ISE OF LEAF.-Some of the terms used in clescribing the general outline, as well as the apex of the leaf, are also applied to the

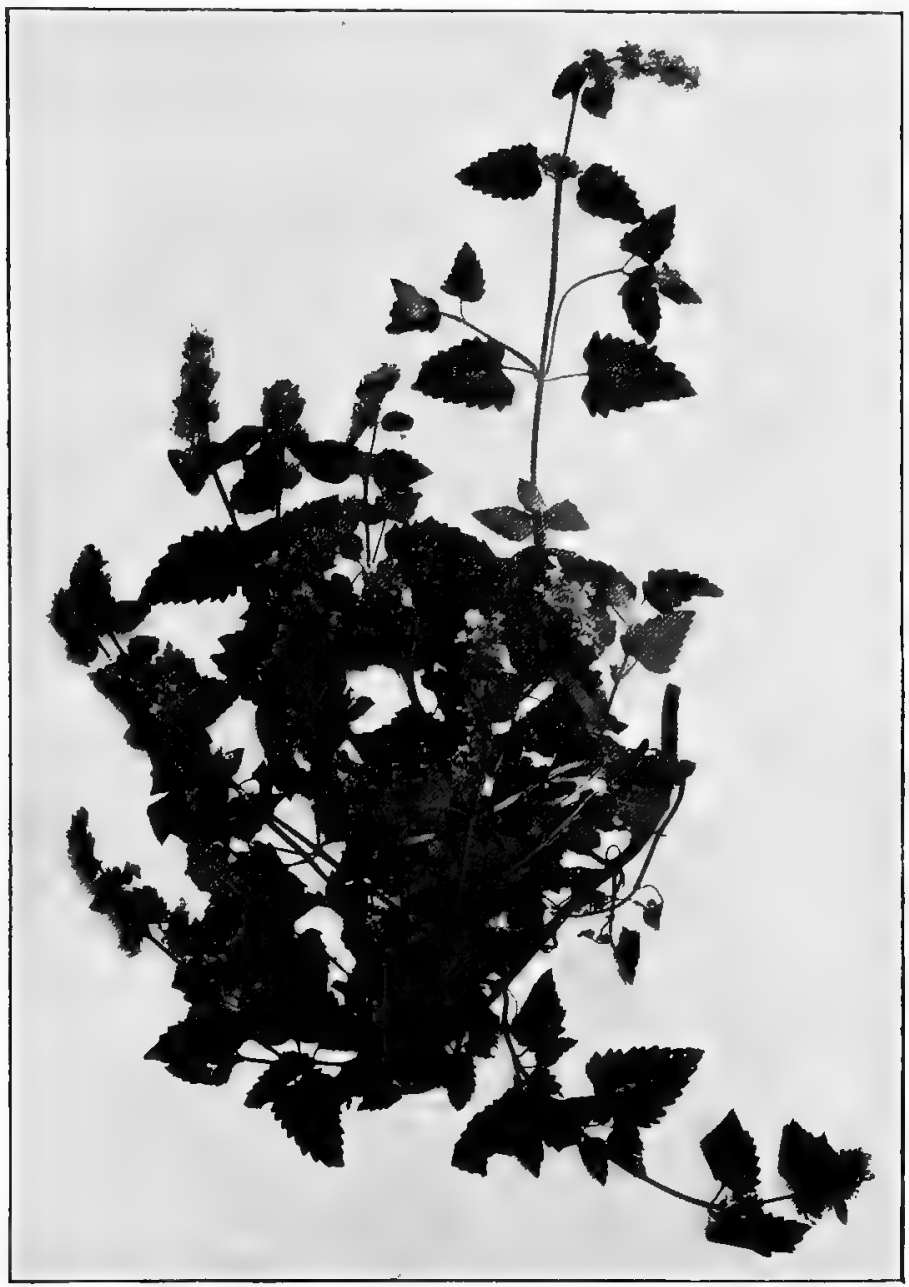

FIG. 74. Catnep (Nepeta Cataria) showing opposite, exstipulate, petiolate leaves, with more or less long-triangular outline, acute at the apex, slightly cordate at the base, and with a coarsely crenate margin.

base, as abtuse, truncate, cordate, reniform, etc. Other terms, however, especially apply to the base as CUNEATE or wedge- 
shaped; CONNATE-PERFOLIATE, when opposite leaves are connected at the base and surround the stem; PERFOLIATE, when the leaf simply clasps the stem. In Monocotyledons the base of the leaf is frequently prolonged into a sheath, which may entirely surround the stem, as in grasses, and is known as a LIGULE.

Margin of LeAF.-Very few leaves of dicotyledonous plants possess an even margin, and according to the degree and character of the incisions or indentations they are described as SERRATE, when the apex of the divisions or teeth is sharp and directed forward like the teeth of a saw ; DENTATE, when the divisions project outward; CREN.ITE, when the teeth are more or less rounded; REPAND, when the margin is somewhat wavy; SINUATE, when the wavy character is pronounced; LOBED, when the incisions extend not more than half-way into the lamina, and the sinus (or hollow) and the lobe are more or less rounded; CLEFT, when the incisions are still deeper and the sinuses and lobes are somewhat acute; and pIVIDED (Figs. 75 and 76 ), when the incisions extend almost to the midrib.

Compound Leaves.-The divisions of a parted leaf may assume the form of a simple leaf, when the divisions are known as LEAFLETS and the whole as a compound leaf. The distinction between a simple leaf and a leaflet is, that the former has a bud in the axil. The difference between the divisions of a simple leaf and those of a compound leaf is this,-in the former they never become detached from the petiole or midrib, whereas in the compound !eaf they are articulated and clrop off individually. Compound leaves may be divided into PINNATELY-compound (Fig. I63, $A$ ) or P.ALMATELY-compound (Fig. 78, E), this distinction depending upon whether the leaflets are arranged pinnately or palmately. A number of forms of pinnately-compound leaves are recognized. When the leaflets are all lateral (Fig. 7I) the leaf is said to be P.ARI-PINNATE; when there is an odd or terminal leaflet as in Sumac (Fig. I64) the leaf is IMPARI-PINNATE; when the midrib is prolonged into a tendril as in the garden-pea (Pisum), the leaf is said to be CIRRHIFEROUS-PINNATE.

Movements of Leaves.-The leaves as well as other organs of plants exhibit a variety of movements or curvatures in response to stimuli of different kinds, and are said to possess the property 
of irritability. Movements of organs are of two general classes: (I) Those due to stimuli which originate in the plant and (2)

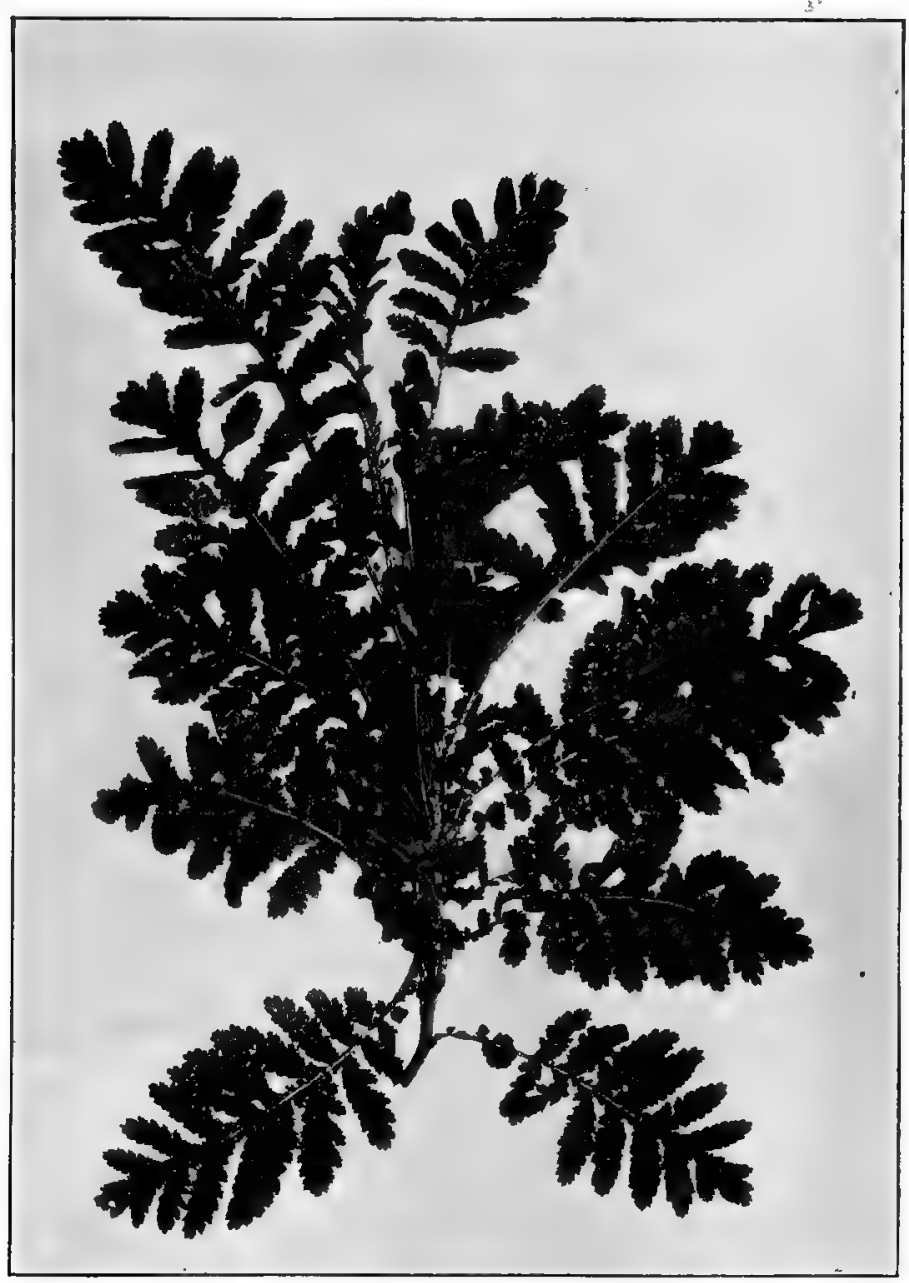

Fig. 75. Branch of Tansy (Tanacetum vulgare) showing closely alternating, deeply pinnatifid or pinnately-divided leaves, the divisions being linear, oblong and variously lobed and incised.

those due to the influence of external factors. To the former class belong all those movements which occur during the course of 


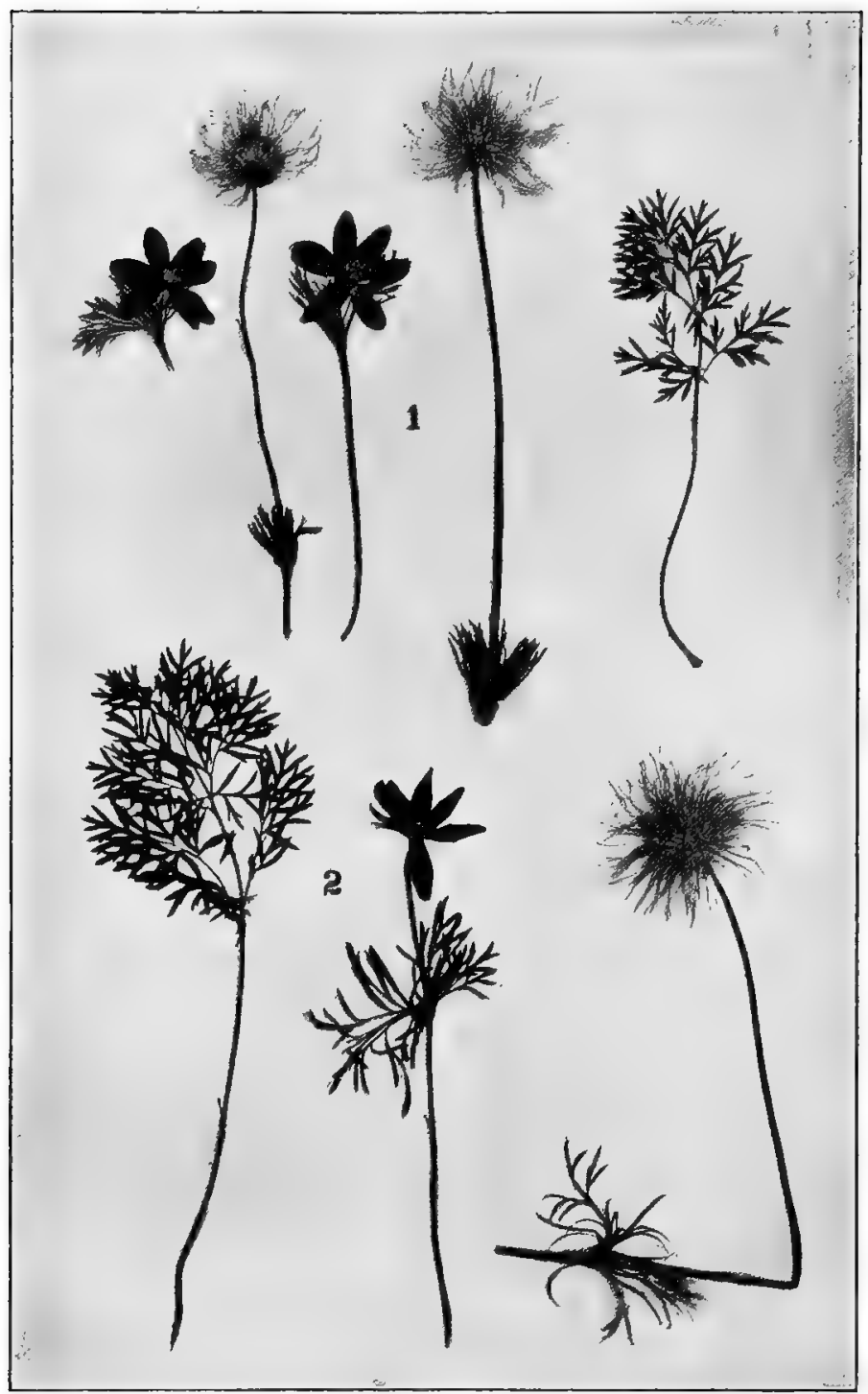

Frc. 76. , 1, Leaf, fruits and flowers of Anemone Pulsatilla. 2, Leaf, flower and fruit of Anemone pratense. The leaves are pinnately divided, the divisions being further incised or dissected. 
development from the young to the mature stage. These are known as growth movements or NUTATION. They are especially noticeable in tips of growing branches, which instead of growing in a straight line, move either from one side to the other, or coil or curve about an imaginary axis. This spiral movement is known as circumnutation and is characteristic of twining stems and tendrils, as the hop vine (Fig. 136) and tendrils of Bryonia (Fig. 66). Nutation curvatures are due to unequal growth on two sides of the organ and cease when there is a cessation in growth or when the plant has reached maturity.

The movements of organs due to external stimuli are usually in a direction which shows a relation to the direction of the stimulus, as those produced by gravity and light (Fig. 6I), and these movements are of use in bringing the organs into more favorable positions for growth. Stimuli of this kind are spoken of as orienting or TROPIC. The compound leaves of a number of plants exhibit in addition certain variable and periodic movements, which have their origin in a special mechanism known as the PULYINIS. The pulvinis appears as a swelling on the petiole and consists of parenchymatous tissue which is highly turgid, i.c., full of water. Any stimulus, such as mechanical shock, which causes a difference in the degree of turgidity on two sides, will result in a movement of the leaves in such plants as Mimosa, Oxalis and locust. The leaves of IImosa pudica, a common cultivated sensitive plant, show a very rapid response to such stimuli, the leaflets folding together and the petiole and petiolules drooping. In other cases there is a change in the position of the leaves following the alternations of day and night. During the day the leaflets are spread out freely, but at night or in darkness they droop and fold together. These are spoken of as nyctinastic (nyctitropic) or " sleep movements," and are exhibited by a number of leguminous plants, as clover, bean, Cassia (Fig. 7I), and by wood-sorrel (Oxalis Acetosella) and various cultivated species of Oxalis. The leaves of Oxalis as well as of some other plants fold together under the influence of intense light as well as at night or when the amount of light is reduced. Of special interest also are the lateral leaflets of Desmodium gyrans (telegraph plant) which describe curvatures at more or less regular intervals day and 
night when the temperature is favorable. The leaves of the sundew (Drosera) are remarkable for their sensitiveness to touch. The upper surface and margin are provided with peculiar hairs or tentacles (Fig. $77, I I$ ) which when touched, as by an insect, gradually curve inward. Not only this, the stimulus may be transmitted to other tentacles and sometimes even the blade itself may roll inward to some extent, thus entrapping small insects which serve as food to the plant. The leaves of a related plant Dionoea
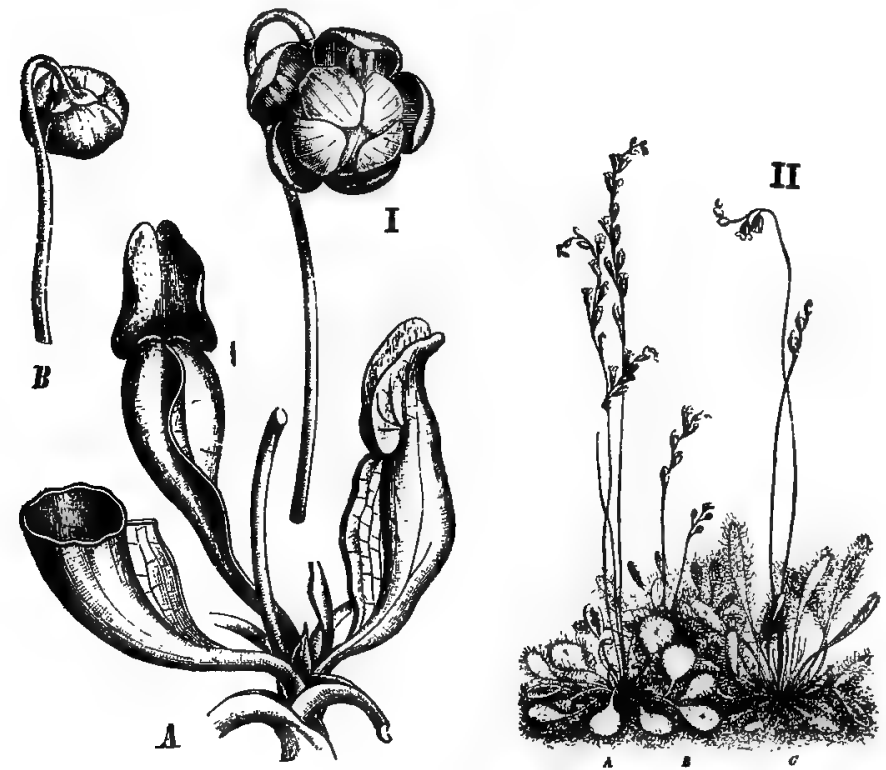

FIG. 77. So-called carnivorous plants. I, the pitcher plant (Sarracenia purpurea) showing the modified pitcher-like leaves (A) with inflated portion which narrows into the petiole, and a terminal, more or less spreading winged portion; and a flower and flower-bud (B). II, Three species of sundew: A, Drosera rotundifolia; B, D. intermedia; C, $D$. ongifolia.-I, after Gray; II, after Drude.

are even more sensitive and when special hairs on the blade are touched that part of the lamina bearing these hairs closes with a quick, trap-like movement imprisoning its insect prey.

Phyllotaxy, or phyllotaxis, is the study of the distribution of leaves upon the stem, and of the laws which govern it. If we examine germinating plants of the beech, the elm, or the oak, we observe that, while the seed-leaves are opposite to each other, the 
subsequent leaves are arranged according to a different order in these several plants, but in a definite manner in each. In the elm, the distribution of the leaves is such that the third leaf is directly above the first; in the beech, the fourth leaf is above the first, and in the oak, the sixth leaf is above the first. If these leaves are connected in the order of their development, it will be seen that they describe a spiral in their arrangement, and it will also be found that one or more circuits of the stem are made between the superimposed leaves. Furthermore, it will be found that this arrangement constitutes. a mathematical series which may be expressed in degrees, or the parts of a circle that the leaves are from each other, this measure being known as DIVERGENCE; or by the number of perpendicular rows of leaves on the stem, which are known as ORTHOSTICHIES.

The following may serve to illustrate the terms used:

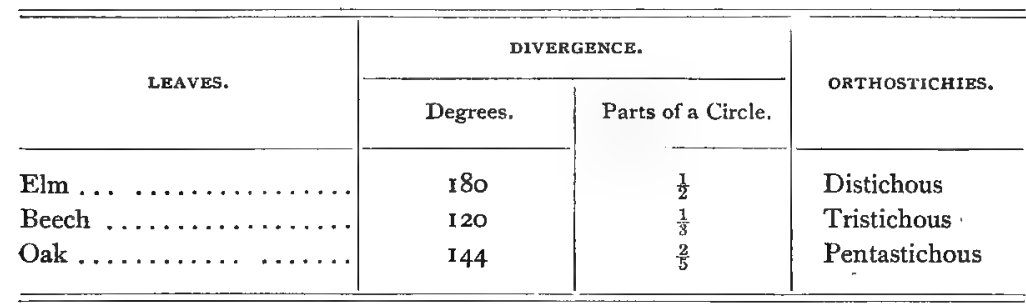

If we examine the fractions used, we will find that the numerator indicates the number of turns around the stem before encountering a superimposed leaf, and that the denominator indicates the number of leaves found the latter also expresses the number of orthostichies. On adding the numerators and denominators of any two successive fractions, a fraction is obtained which expresses the next highest arrangement, as

$$
\frac{1}{2}+\frac{1}{3}=\frac{2}{5} ; \frac{1}{3}+\frac{2}{5}=\frac{3}{8} .
$$

In quite a number of plants two leaves arise at the nodes, as in the Labiate. These are invariably situated opposite each other on the stem, and the successive pairs alternate with one another, forming the decussate arrangement of leaves (Figs. 67, 74, I68, I72). 
Modified Leaves.-Leaves are variously modified and serve for other purposes than those already described. They may be fleshy in character and serve as storehouses for nutritive material, as the seed-leaves of the oak, or they may serve for the storage of water, as in Agave and Aloe (Fig. 130). In some instances, particularly when situated near the flowers, they lose

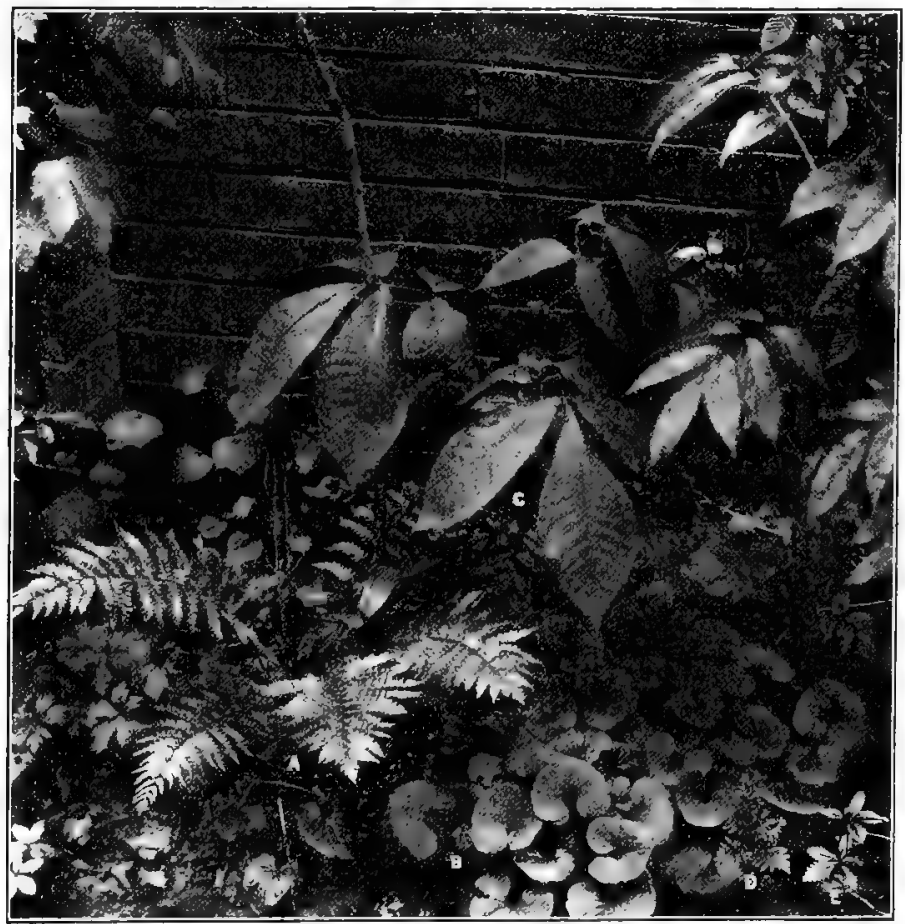

FIg. 78. Group of transplanted wild plants showing variation in form of leaves. A, Cinnamon fern (Osmunda cinnamomea) showing sporophylls (fertile leaves) and a cluster of pinnatifid sterile leaves, the pinnæ being linear-lanceolate and deeply pinnatifid; $B$, wild ginger (Asarum canadense) showing basal, reniform, long-petiolate leaves with cordate base and slightly pointed apex; $\mathrm{C}$, young hickory (Hicoria ovata) showing the odd-pinnate (imparipinnate), 5- to 7-foliate leaves; D, ternate, decompound leaf of Virginia grape fern (Botrychium virginianum); E, digitately compound leaves of cinquefoil (Potentilla).

their green color, as in the dogwood, skunk cabbage and others. In other cases they are modified so that they serve as a trap for insects, as in species of Sarracenia and Drosera (Fig. 77). The petiole may become enlarged and perform the functions of the 
leaf, as in the acacias, of Australia ; or it may become bladderlike and serve as a means for floating the plant, as in the water hyacinth. The stipules may likewise be modified, becoming leaflike, as in the pansy (Fig. 70); or metamorphosed into thorns, as in the locust; or clasping, as in Polygonum. In some cases the leaves are very much reduced, their functions being performed by the stem, as in Cactaceæ, or even by the roots, as in some orchids which have assimilating roots.

Prefoliation or vernation is the disposition of leaves in the bud. The terms used to describe the folding of the leaves in the bud are derived from an examination of transverse sections of the bud. The following are some of the terms which are employed: ConDUPLICATE, when the lamina of the leaf is folcled lengthwise along the midrib so that the two halves of the upper surface lie together, as in the Magnoliacece; PLICATE or plaited, when the lamina is folded along the veins, like a closed fan, as in the maples; convolute, when rolled lengthwise and forming a coil in cross section, as in the Rosacer; INvolute, when both margins are inrolled lengthwise on the upper surface, as in the violets; REVOLUTE, when both margins are inrolled lengthwise on the lower surface, as in Azalea.

In addition, there are several terms used which are derived from the appearance of the bud, as RECLINATE or inflexed, when the upper part is bent on the lower, as in Liriodendron; and CIRCINATE, when the upper part is coiled on the lower so that the tip of the leaf is in the center of the coil, as in the ferns.

\section{THE FLOWER.}

Structure of the Flower.-It is well known that if a portion of the stem of a plant, including one or more nodes, be placed under suitable conditions for growth, roots will arise from the nodes that are in the ground and a new plant will be developed. This method of increasing the number of individuals is frequently resorted to by horticulturists, and is known as vegetative propagation. The process is wholly asexual and depends upon the division of old cells to form new ones. It is fortunate, however, that owing to the special conditions required in this method of 
perpetuation of species, other methods of reproduction are followed in nature, the most important one of which depends upon the development of flowers and the production of seed.

While the flower is a very complicated structure in many cases, the definition given it by some writers is very simple. It is defined as a branch which bears sporophylls. As we have seen, a sporophyll is a leaf which bears sporangia. According to the definition given, the strobiles or cones of the Gymnosperms and certain Pteridophytes, as the horsetails and club mosses, are entitled to rank as flowers. In Angiosperms other leaves may be present, and these are known as the FLoral LEAvES. The flower then in Angiosperms is made up of sporophylls which are essential, and floral leaves which may or may not be present. But in speaking of the sporophylls of the flower in Angiosperms it is customary to use terms which were applied to them before their relation to the similar organs in the Gmynosperms and Pteridophytes was understood. Thus the microsporophylls as already pointed out, are known as stamens, and the megasporophylls as CARPELS.

For a great many years botanists taught that the stamens and carpels are transformed foliage leaves,-in other words that they are derived from foliage leaves, but in more recent years the view has been established that they arise as independent members, are in fact as independent as the foliage leaves themselves. Various transformations or modifications may and do occur, but these are not confined to the foliage leaves alone for under certain conditions the sporophylls may assume the character of floral leaves.

It is true that in the case of some ferns, the sporophylls bear a strong resemblance to foliage leaves, as in Aspidium Feli.t mas (Fig. 277), but this does not necessarily prove that the sporophylls of Angiosperms are transformed leaves, but only that the further back we go, the less the degree of differentiation of parts until we reach the unicellular alga.

The several parts of the flower are arranged more or less compactly at the terminus of an axis known as the flower branch, the special portion bearing these parts being known as the TORUS (sometimes spoken of as the receptacle), and that portion below the flower proper as the flower stalk (Fig. 83,PE). The carpel 
or carpels occupy the terminal portion of the branch while the stamens and floral leaves occur in circles or whorls below.

Pistil.-There may be only one carpel present in a flower or there may be more. In the latter case the carpels may remain distinct or they may be united, but whatever the number or the degree of union, it is the carpel or carpels which constitute the closed structure known as the pistil. The pistil is usually differentiated into three quite distinct regions: (I) A lower bulbous portion which contains the ovules, known as the ovary; (2) a neck-like portion known as the STYLE; and (3) at the top of the style a specialized portion which receives the pollen, known as the stigma (Figs. 83 and 85 ). When the pistil is made up of a single carpel it is said to be SIMPLE, and when composed of more than one carpel it is called compound.

The carpels in the compound pistil appear to be united in different ways. Sometimes they appear to have coalesced or grown together at the margins, thus forming an ovary with but one chamber or compartment (Fig. 84, B). In other cases the carpels appear as though they were incurved or folded together at the margins along the line of union, thus forming septa or walls which divide the inner cavity into several compartments or locules (Fig. 84, A, C).

When the carpels are not united but remain separate, there are as many pistils as carpels, as in the flowers of buttercup (Fig. $84, D$ ). Thus a unilocular ovary may belong to a simple or compound pistil.

GYN XCIUM.-The aggregate of pistils in a flower constitutes the gynæcium. If the gynæcium is made up of a number of simple pistils, as in the flower of buttercup (Fig. $84, D$ ), it is said to be APOCARPOUS. But if the carpels are united into one structure, then the gynæcium is said to be SYNCARPOUS, as in the orange flower, which is in reality equivalent to a compound pistil. Inasmuch as the styles and stigmas are frequently not united the expression compound ovary is usually employed. According as the gynæcium consists of one, two, three or many carpels, it is said to be monocarpellary, dicarpellary, tricarpellary or polycarpellary.

The pistil of the flower of the pea is simple and has an elongated ovary, and upon dissecting the ovary and also making a trans- 
verse section of it, it is observed that the ovules are borne upon the part which projects from the concrescent margins into the "cavity, this part being known as the PLACENTA, and the united margins of the carpel forming the "inner" or VENTRAL SUTURE. In the syncarpous gynæcium the ventral suture of the carpels is directed toward the axis of the flower; in some cases that portion
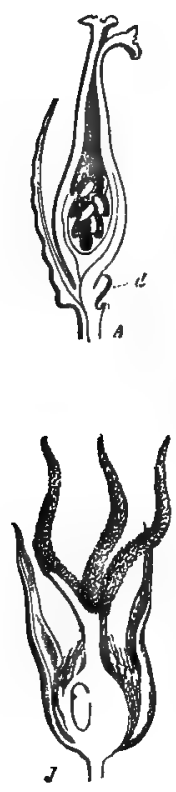
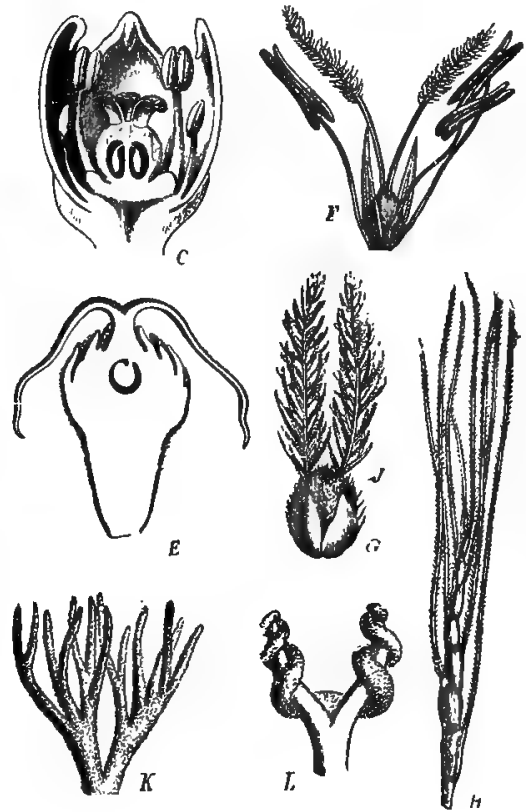

FrG. 79. Pistils and different kinds of stigmas. A, simple (monocarpellary) pisti of willow with lobed stigma; B, compotnd pistil of Fourcroya with head-like stigma; C, longitudinal section through flower of Spondias with five separate styles and stigmas, only three of which are shown; D, flower of Peperomia showing bristly stigma; E, recurved, thread-like stigmas of the Upas-tree (Antiaris); F, flower of a Canary grass showing the two simple plumose stigmas; $G$, pistillate flower of couch grass showing the two compound plumose stigmas; $\mathrm{H}$, thread-like stigmas of pistillate inflorescence of Euchlana one of the grasses; J, tri-parted stigmas of the pistillate flower of the castor-oil plant; $K$, L, two forms of stigmas of Begonia.-After Engler.

of the carpel corresponding to the midrib is very prominent, as in the Papilionatæ, and has received the name of "outer" or DORSAL SUTURE.

There are as many locules in the ovary as there are carpels, and the walls or partitions between the locules of a syncarpous gynæcium are known as DISSEPIMENTs; when three or more 
carpels are united the number of dissepiments corresponds to the number of carpels. It sometimes happens that a partition or wall is intruded from the mid-vein of the carpel, dividing a unilocular ovary into one that is bi-loctlar, as in species of Astragalus, and such a partition is termed a FALSE DISSEPIMENT.

When no other than the true dissepiments exist in the syncarpous gynæcium the placentas are borne along the axis of the flower and are termed axial placentas. In the Caryophyllacex the ovules are borne upon a central axis, and the dissepiments having been absorbed the gynæcium is said to possess a free central placenta. In other cases the placentas grow backward from the central axis toward the mid-vein of the carpel, carrying the ovules with them, when they are spoken of as parietal placentas, as in colocynth fruit (Fig. 254).

The STYLE not only varies in shape and size but in the manner of attachment to the ovary (Fig. 79); it may be very short, as in the clove; long and filiform, as in Enothera; club-shaped (clavate) as in.the orange; or broad and petalloid, as in Iris. It is usually situated at the summit of the ovary when it is said to be apical or terminal; it may, however, be laterally attached, as in the strawberry, or, as in a few instances, attached to the base of the ovary. It is usually smooth, but may be hairy, as in the Compositæ. The styles like the carpels may be separate or united, and in the latter case may have a central canal connecting the stigma with the ovary, as in the violets. While usually deciduous, the style may be more or less persistent-forming a part of the fruit-or even become much elongated, as in the dandelion.

The Stigma is an essential part of the pistil in that it is the germinating ground of the pollen grains, it being viscid and especially adapted for this purpose (Fig. 79). The stigmas may be separate, as in the Compositæ, or they may be united into a more or less club-shaped or globular head, consisting of as many lobes as there are stigmas, as in the poppy. The stigma, while usually solid, may have an opening, as in the violets, which sometimes has a lid-like appendage, as in Viola tricolor.

The Ovules (Fig. 85), as we have already seen, are small bodies which are borne on the placentas, and which, after fertilization develop into seeds. The number of ovules varies considerably 
-there may be but one, as in the almond, or there may be a large number, as in the watermelon.

There are several principal forms of ovules (Fig. 80) recognized, of which the following may be mentioned: (I) ATRopous, in which the ovtle is straight and erect on its stalk, as in the Urticacex; (2) ANATROPOUS, in which the ovule is bent over on to the stalk so as to be in an inverted position, the line of attachment of the ovule and stalk being known as the raphe (Fig. $85, n$ ); (3) CAMPYLOTROPous, in which the ovule is bent upon itself, as in Stramonimm, this form being less frequent than the other two. Most of the ovules of flowering plants are anatropous.

Stamen.-As already indicated the stamen consists of a stalk-like portion called the FILAMENT, and a specialized portion

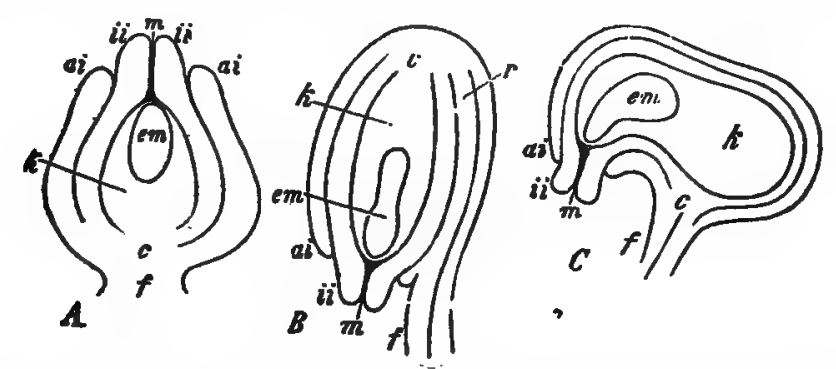

Fig. 80. Three positions of ovules. A, atropous; B, anatropous; C, campylotropous. (f) funiculus or stalk; (c) chalaza, or point of union of nucellus and integuments; (k) nucellus or megasporangium; (em) embryo-sac or megaspóre; (ai) outer integument; (ii) inner integument; $(\mathrm{m})$ foramen or orifice for entrance of pollen tube, known as the micropyle in the seed; ( $r$ ) raphe.-After Prant1.

which bears the sporangia, called the Anther (Fig. 8I). The filament may be long or short or wanting. It is commonly threadlike, but varies considerably, and is sometimes leaf-like.

The Antuer is the essential part of the stamen (Figs. 8I, 85) and consists of two lobes, each of which is composed of two divisions or pollen sacs (Fig. 53). These sacs contain the pollen which is commonly discharged either through a longitudinal suture or line of dehiscence, or through an opening at the tip. The anthers may be variously attached to the filament (Fig. 8I). When they face the axis of the flower they are said to be INTRORSE. as in the Violacex, and when they face the perianth they are said to be EXTRORSE, as in the Magnoliacex; when they lie horizontally 
on the tip of the filament, so that they swing as on a pivot, as in the tiger lily, they are said to be VERSATILE; when they adhere longitudinally to the sides of the filament and the dehiscence is

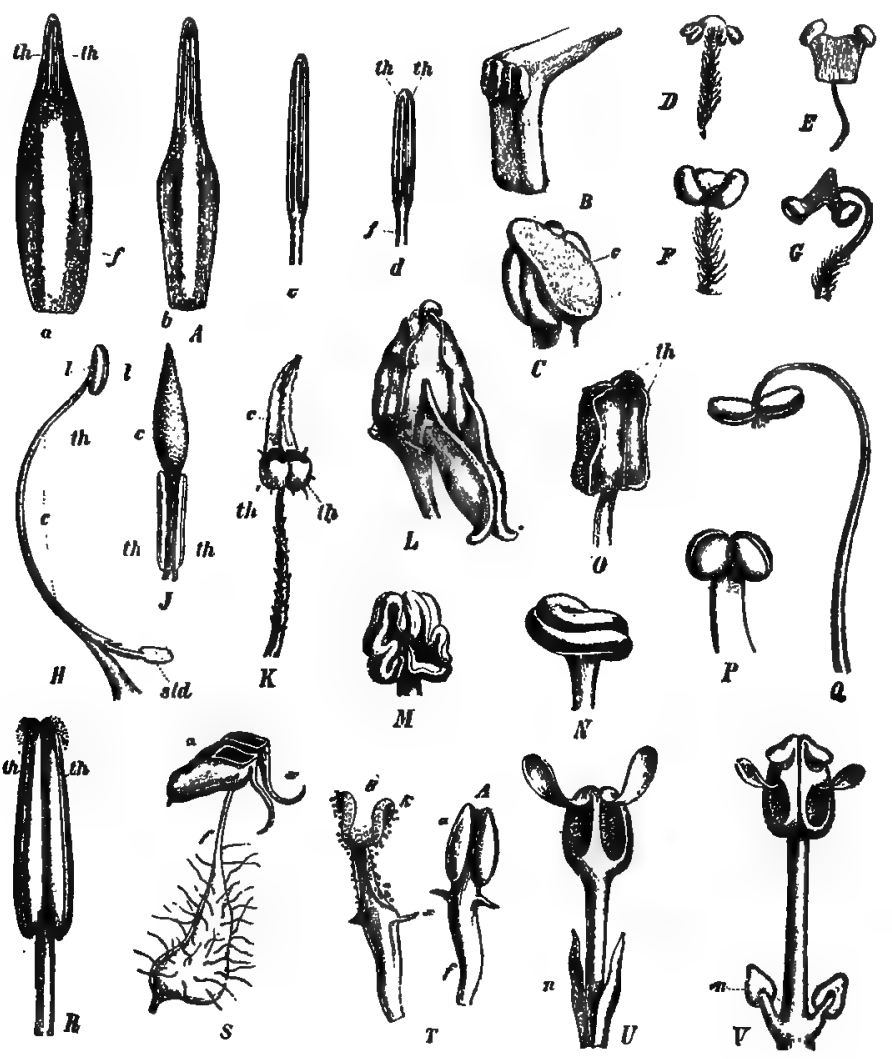

Fig. 8r. Different types of stamens. Abbreviations: filament (f), pollen sacs or theca (sporangia) (th), connective (c). A, stamens of a water lily (Nymphea) showing variation in the stamens (a-d); $B$, theca near middle of the stamen of Popoveia; $C$, anther of another species of Popowia with fleshy connective and pollen sacs on either side; D, stamen. of Tradescantia with transverse connective; E, F, G, stamens of several Commelinacece with broad connectives; $H$, stamen of Salvia with peculiar swinging connective and an aborted pollen sac or staminodium (std) at the lower end and the fertile pollen sac above; J. peculiar elongated connective of Unona; $\mathbf{K}$, elongated connective of Humiri; L, andrœcium of violet showing two spurred sessile stamens; $M$, stamen of Columelia with sinuous confluent anthers, broad connective and short filament; $N$, confuent transverse pollen sacs of Arisarum; $\mathrm{O}$, united pollen sacs of Columbine showing small connective; $\mathrm{P}$, spherical pollen sacs of Calla, with slightly developed connective; $Q$, versatile anther and long, slender filament of dead nettle (Lamium album); $\mathrm{R}$, dehiscence of anther of Solanum by means of terminal pores; $\mathrm{S}$, spurred anther of Arbutus with terminal pores; various kinds of valvular dehiscence, as in Berberis (T), Atherosperma (U) and Persea (V).-A, after Caspary; B, H-R, U, V, after Baillon; S, T, after Sachs; D-G, after Schönland. 
marginal, they are said to be INNATE; when they adhere longitudinally to the filament and the latter extends slightly beyond them, they are said to be ADNATE, in which case they may be extrorse or introrse. In some of the Labiatx the lobes of the anther are united at the apex of the filament, but diverge from the point of attachment and are said to be connate, coherent or CONFLUENT.

The Connective is that portion of the filament to which the lobes of the anther are attached or which connects them (Fig. 8r) ; usually, it is not very prominent; but in some of the Labiatæ, as

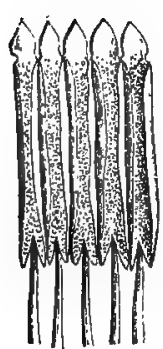

A
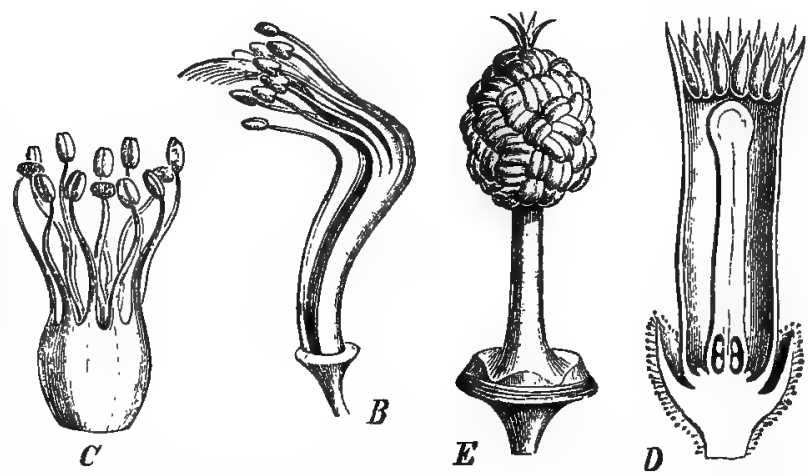

Fig. 82. Union of stamens. A, united anthers of flower of Composita; B, diadelphous stamens of Pisum with I free stamen and 9 united; several types of monadelphous stamens, as in Erythroxylon (C), Melia Azedarach (D), and common mallow (E).-After Baillon.

in Salvia, it is rather broad; in some of the Malvaceæ it is entirely wanting, the two lobes being confluent; in other cases it may be extended beyond the lobes of the anther, as in species of Asarum.

Appendages of Anther.-In certain instances the anthers are appendaged (Fig. 8r): In the violets there is a triangular growth at the apex; in the oleander the apex is plumose; in deer berry (Polycodium stamineum) there are two awn-like appendages upon the back of the anther; in the violets the two stamens that project into the spurred petal are also spurred and secrete a nectar; in the Asclepiadaceæ the anthers possess wing-like appendages, each sack or division of which contains a pear-shaped coherent mass of pollen grains (pollinium). 
When a flower has but one stamen it is termed MONANDROUS; and when there are two, three or many stamens, it is said to be diandrous, triandrous or polyandrous (Fig. 84). The aggregate of stamens in the flower is called the ANDRCECIUM. In the Labiatæ there are four stamens arranged in a longer and shorter pair and the stamens are said to be DIDYNAmous; in the Cruciferæ the flowers possess six stamens, four of which are longer than the other two, and the stamens are described as TETRADYN.imous; in some plants, as in the Lobeliaceæ, Papilionatæ, etc., the filaments cohere, forming groups (Fig. 82) which are termead monadelphous, diadelphous, etc.; in the flowers of the potato the anthers lie close together but are not united, forming apparently a continuous ring or band around the pistil, when they are said to be connivent; in the tubular flowers of the Compositæ the anthers are united, forming a closed ring, and the stamens are spoken of as SynGenEsious (Fig. 82, $A$ ); in many of the Cucurbitacece the filaments and anthers both are confluent; in the flowers of the Orchidaceæ the stamens are borne upon the pistil and are said to be GYNANDRous (Fig. I33).

Floral Envelopes.-As their name indicates the floral envelopes occupy the outermost or lowest position in the arrangement of the parts of the flower. In the bud condition they protect the essential elements, and in the expanded flower are considered to play an important rôle in securing pollination through the visitation of insects. The floral envelopes are made up generally of two kinds of leaves, petals and sepals (Fig. 83).

The PETALS form a circle which surrounds the androcium. They are as a rule quite bright and attractive, being frequently highly colored, as in the rose, Fuchsia, violet, etc., and are known collectively as the COROLLA.

The sEPals form the next and lowermost circle. They are usually green and leaf-like, as in the rose and carnation, and together constitute the CALYX. Sometimes the corolla and calyx are spoken of together as the PERIANTH, although strictly speaking the term has a more special application, and is used mostly in speaking of the sepals and petals of monocotyledonous flowers, these parts being much alike and not distinguishable, save in position, as in certain lilies (Fig. I23). 
When the divisions of the calyx and corolla remain separate and distinct the latter are spoken of as CHORISEPALOUS and CHORIPETALOUS, respectively; but when the divisions are united or coalesced the calyx and corolla are called gamosepalous (synsepalous) and GAMOPETALOUS (sympetalous), respectively.

When the divisions of the calyx or corolla are entirely united these elements are said to be ENTIRE, and when the divisions are partly united they are spoken of as "toothed," "lobed" or "parted," according to the degree of union.

In the flowers of the Cruciferæ and Caryophyllaceæ there is a conspicuous stalk to each of the separate petals, which is known as the UNGUIS or CLAW; while the upper outspreading portion is
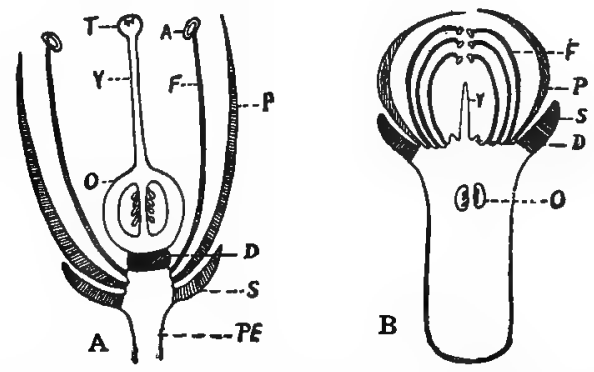

FIG. 83. A, longitudinal section through orange flower (Citrus Aurantium) showing stalk (PE); sepals (s); petals (P); stamen with filament (F) and anther (A); compound pistil (composed of united carpels) with stigma (T), style (Y) and superior ovary (O) with ovules; disk or nectary (D). B, longitudinal section of a bud of clove (Caryophyllus) showing inferior ovary $(O)$, style $(Y)$, stamens $(F)$, petals $(P)$, sepals (S), nectary (D).

known as the LAMina or blade. In the gamosepalous calyx and the gamopetalous corolla the lower united portion is known as the TUBE, and the upper outspreading portion as the LIMB or "border."

The form of the calyx and corolla is quite characteristic for a number of important families. In the Compositæ there are two characteristic forms of corolla, namely, the tubular in the disk flowers and the ligulate in the ray flowers; in the Papilionata the corolla, from its fancied resemblance to a butterfly, is described as PAPILIONACEOUS (Figs. $88 ;$ I $34, L$ ) ; in the Labiatæ the petals are united into two lip-like divisions, and the corolla is said to be milabiate (Fig. 84, F). There are two kinds of bilabiate 
corollas-one, as in lavender, where the mouth of the tube is open, known as RINGENT; and another, where the mouth is closed, as in Linaria, called PERSONATE.

There are a number of other special forms of calyx and corolla, particularly the latter, and of these may be mentioned the following: A corolla, like that of the harebell, which is more or less bellshaped, is termed CAMPANULATE; a more or less campanulate corolla contracted near the opening, as in Gaultheria, is spoken of as URCEOLATE or urn-shaped; in the morning glory and other Convolvulaceæ the corolla is said to be INFUNDIBULIFORM or funnel-shaped (Fig. I74); a corolla, in which the limb spreads abruptly from the tube, as in Phlox, is termed HYPOCRATERIFORM or salver-shaped; a corolla with a short tube and outspreading limb, as in potato, is said to be ROTATE or wheel-shaped; a rotate corolla with the margin more or less upturned is called CRATERIFORM or saucer-shaped; in aconite the upper petal is hood- or helmet-shaped, the corolla is spoken of as GALEATE; in the violets one of the petals has a spurred appendage and the corolla is described as SACCATE or calcarate, while the modified petal in the orchids is known as the LABELLUM.

Duration of Calyx and Corolla.-There is considerable difference in the length of time that the calyx and corolla persist, not only with reference to each other but in different plants. The parts are said to be CADUCous when they drop from the flower as soon as it opens, as the calyx of the poppy; when they remain for a day or so, they are said to be EPHEMERAL or fugacious, as in the petals of the poppy; in the rose and apple the petals fall away soon after the pollen reaches the stigma and they are said to be DEciduous; in some flowers the petals wither but persist until the maturing of the fruit, as in the Droseracex, and are known as MARCESCENT; the calyx may remain unaffected until the maturing of the fruit, as in the Labiatce, when it is said to be PERSISTENT.

Bracts.-In addition to the floral envelopes other more or less modified leaves are borne on the flower branch below the flower, frequently at the base of the flower stalk, and these have received the name BRACTS. The bracts closely resemble the foliage leaves but usually are smaller and frequently are mere scales, without chlorophyll. In some cases, however, they are large and 
showy, looking like petals (petaloid), as in the water arum (Fig. I28), the common dogwood; Bougainvillea and Poinsettia seen in greenhouses.

The Torus constitutes the terminal portion of the flower axis or stalk, and is usually more or less conical and somewhat enlarged. When the torus is of this shape the parts of the flower are inserted upon it in serial succession, all of the other parts arising below the pistil. It may, however, be modified into a hollow or cup-like structure which grows up around the ovary carrying the other parts of the flower (sepals, petals and stamens) with it, thus changing the relative position of the parts, although it should be understood that the ovary occupies practically the same position in the two cases.

When the torus is of the first type and the other parts of the flower are inserted below the ovary, the flower is said to be HYPOGYNous, as in the orange flower (Fig. 83, A) and the ovary superior; but when the torus forms a cup-shaped receptacle and the other parts of the flower arise on its margin above the ovary, the flower is called epigynous, as in the clove (Fig. 83, $B ; 84, C$ ) and the ovary inferior. In other cases a ring of leaf-like tissue arises from the torus, forming a cup-like receptacle or tube which is known as the perianth tube, the sepals, petals and stamens being inserted on its margin. The perianth tube may be free from the ovary, when the flower is said to be PERIGYNous and the ovary half inferior or half superior, as in cherry (Fig. 84, B); or in the case of an epigynous flower it may form a prolongation of the cup-shaped torus.

Prefloration or estivation is the arrangement of the parts of the flower-more especially the calyx and corolla-in the bud. Some of the terms used in this connection are also employed in the study of vernation. The following are some of the terms which are employed: VALVATE, when the sepals or petals meet each other at the edges, as in Malvaceæ; IM BRICATED, when the sepals or petals overlap each other, as in the Magnoliacex; PLICATE or PLAITED, when the divisions are united and folded together, as in the petals of Convolvulus and Datura.

The sepals and petals do not necessarily possess the same arrangement, as in the Onagraceæ, where the sepals are valvate 
and the petals are convolute. Furthermore, in addition to the principal types of estivation and vernation already given, there are a number of special modifications of these, depending upon the number and arrangement as well as direction of the overlapping parts of the flower- or leaf-bud.

A

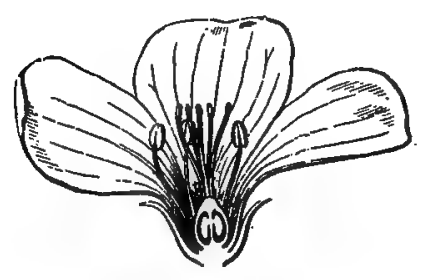

C
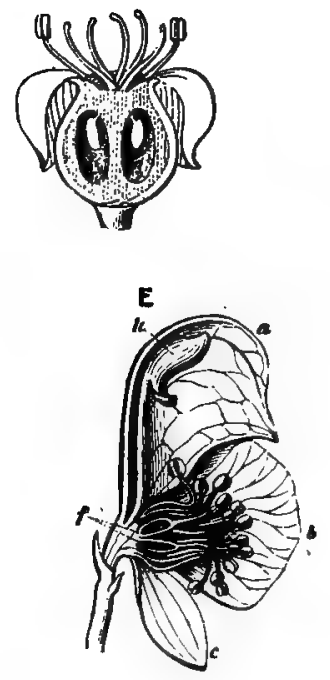

B

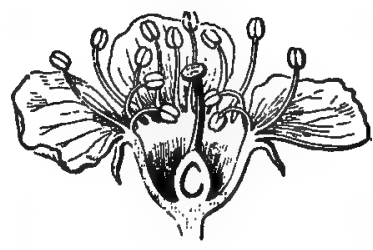

D
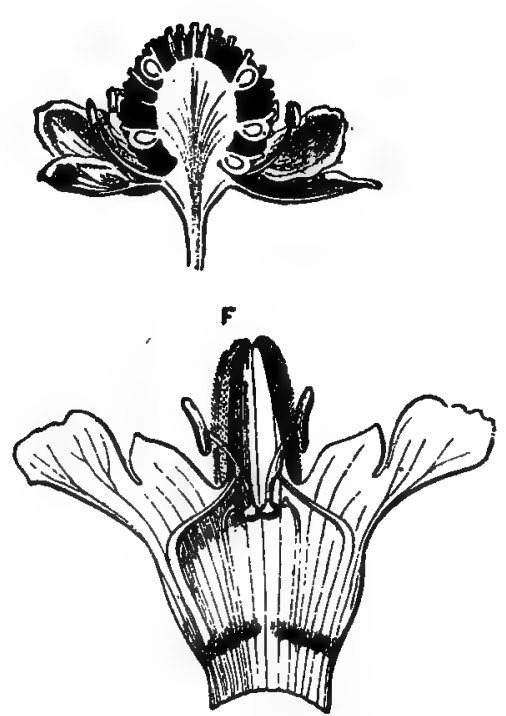

Fig. 84. Types of flowers: A, hypogynous flower of flax; B, perigynous flower of cherry, showing perianth tube with sepals, petals and stamens on its border; $\mathrm{C}$, epigynous: flower of American sarsaparilla; D, flower of buttercup showing apocarpous gynæcium and large conical torus; $\mathrm{E}$, irregular (bilateral or zygomorphic) flower of aconite showing half of helmet-like sepal (a), other sepals ( $b, c)$, long-clawed nectary $(k)$ developed from one of the posterior petals, separate pistils (f); F, corolla of Salvia spread open and showing the two rudimentary stamens and two fertile stamens. The connectives in the latter are long and filamentous and each bears at the upper part a normal pollen sac and at the lower end a non-fertile enlarged portion which the insect pushes against in entering the flower and thus causes the pollen to be deposited on its back.-A-C, after Gray; D-F, after Warming. 
Coalescence and Adhesion.-Not only may the divisions of the same circle or whorl of the flower be united but even those of different circles, and a number of terms are used to describe these modifications.

When the divisions of the same circle are united there is said to be a COHESION or COALESCENCE of the parts. When the divisions of different circles are united, as of stamens with corolla, the union is spoken of as ADHESION or adnation, as in Convolvulus.

Chorisis and Multiplication of Parts.-In contrast with the reduction in number of parts of the flower due to union, there may be an increase in the number of parts due to simple division or splitting of the parts, and this is known as. chorisis or deduplication. An illustration of this is furnished by the stamens of the orange flower, where from a single initial stamen or primordium a group of from 3 to I I stamens may be produced. In other cases there may be a multiplication in the number of parts from the beginning, each part arising independently on the torus, as in the stamens of rose. This of course would not be termed chorisis, as no splitting or branching takes place.

Double Flowers.-In double flowers there is an increase in the number of petals, which is considered to be due to the methods of cultivation and the stimulus of an increased foodsupply. This results in several ways: (I) By transformation of the sporophylls, more particularly the stamens, into petals; (2) by division or chorisis of the stamens or carpels with subsequent transformation into petals; (3) by division or branching of the petals; and (4) by the production of new series of petals. The extra petals in double carnations and double roses trace their origin to the stamens, while in Fuchsia they are the result of chorisis of the petals.

In the snow-ball (Viburnum opulus) and hydrangea the essential elements have undergone a complete transformation, and the flowers, while large and showy, are sterile. In the white water lily (Nymphaa) there is a series of parts ranging from stamens with narrow filaments and stamens with broad petaloid filaments to petals tipped with a small anther and regular petals (Fig. 8I, $A$ ). In this case the stamens are considered to result from the transformation of the petals. In the case of green roses and green 
strawberry flowers the petals become green and leaf-like, and the change is spoken of as CHLOROSIS or CHLORANTHY. In some flowers even the ovules are replaced by leaf-like processes or appendages, as in Drosera and clover.

Arrested Development.-The arrest or suppression of parts of the plant, particularly of the flower, is of very common occurrence. Just as there are millions of seeds that never find suitable conditions for germination, so in the flowers of a large number of plants a very large proportion of the ovules never develop into seeds, the plants in many instances not furnishing sufficient nutriment for all of the ovules to mature. Under leaves it was stated that in the axil of each leaf there is a bud. This is not always apparent, but if the plant be subjected to some special stimulus, some of the latent buds will become evident. For example, the rubber plant (Ficus), so commonly cultivated as an ornamental plant, shows a tendency to develop a straight, unbranched shoot, but if the tip of the shoot be cut off, the buds in the axils of the upper leaves will develop into branches, while some of those lower down will form small protuberances, but develop no further. In other cases there is a loss of parts which seems to be due to loss of function. When there is a partial loss of the element, as of the anthers in the flower of catalpa, it is said to be imperfectly developed or ABORTIVE. When the entire element remains undeveloped as in some of the stamens of the Labiatæ, it is said to be SUPPRESSED (Fig. 84, $F$ ). In flax the stamens of the outer whorl are reduced to thread-like processes. Such sterile or aborted stamens are called STAMINODES (staminodia). In other plants the parts are not apparently arrested, but have not yet been differentiated, as is the case in the Lily family where the perianth is composed of segments which are more or less alike (Fig. I23). In other cases, however, there seems to be a suppression or arrest of the floral envelopes.

Cleistogamous Flowers.-In addition to the regular flowers some plants produce cleistogamous or closed flowers. In these flowers the corolla is usually suppressed. The flowers develop stamens and pistils but remain closed, and thus there is no chance for cross-pollination. The cleistogamous flowers appear later than the regular flowers and are more or less inconspictous, 
developing under the leaves and sometimes underground. Of the plants producing cleistogamous flowers, the following may be mentioned : various species of Viola, Polygala, etc.

Classes of Flowers.-As we have seen the megasporophylls and microsporophylls in the Gymnosperms are borne on separate branches, thus giving rise to two kinds of flowers: or cones. While the separation of the stamens and pistils is exemplified in a number of plants in the Angiosperms, still it is not the rule and these two elements are usually borne close together on the same axis, i.e., they both enter into a single flower structure. Such a flower is said to be HERMAPHRODITE or bisexual, and most of the conspicuous flowers are of this kind, as roses, buttercups, lilies, etc. Inasmuch as the stamens and pistils constitute the essential elements of the flower, hermaphrodite flowers are also spoken of as PERFECT providing the stamens and pistils are capable of exercising their generative functions. When the stamens and pistils occur in separate flowers the flowers are said to be UNISEXUAL or IMPEREECT, as in willow, oak, hickory, etc. A flower having only a pistil or pistils is called pistillate (Fig. 79, $A$ ), while one having only a stamen or stamens is staminate (Fig. I35). The staminate and pistillate flowers may be borne on the same plant, when it is said to be monøcious, as in castor bean, chestnut (Fig. 72), alder ; or they may be borne on separate plants, when the plant is called drecious, as in willows and poplars. Plants bearing hermaphrodite and unisexual flowers on the same individual plant or on different individuals are called PoLYGAMOUS, as in Ailanthus.

A COMPLETE flower is one which possesses both kinds of essential elements and both kinds of floral envelopes, and is SYMMETRICAL when the parts are alike and when the number of parts in each circle is the same or when the number in one circle is a multiple of that in the others; as a rule the number of stamens is some multiple of one of the other parts, as in geranium (Fig. 155), where we find five sepals, five petals, ten stamens and five pistils.

Flowers are also spoken of as REGULAR or IRREGULAR, according to whether all the parts of a circle are uniform in shape or not; the flowers of geranium are regular while those of violets are irregular. Regular flowers are also spoken of as Actino- 
MORPHIC or RADIAL, and irregular flowers as ZYGOMORPHIC. The latter are also spoken of as DORSIVENTRAL and usually occur as lateral flowers in an inflorescence, as in Vanilla (Fig. I33), Aconitum (Fig. I4I)' and Lobelia (Figs. I80, I80a) ; whereas radial flowers are solitary, as in Sanguinaria (Fig. I48), or terminal as in Geranium (Fig. I55), or they may also be lateral as in Phytolacca (Fig. I39). Dorsiventral flowers either arise as such, as in some of the Leguminosæ (Fig. 88), or they may arise as radial flowers and become dorsiventral during the course of development, as in willow herb (Epilobium).

In some flowers the floral envelopes are wanting, and the flowers are said to be NAKED, as in the willows and grasses.

Anthotaxy.-Just as a flower may consist of one or more parts, so a flower-branch may bear more than one flower. The stalk of the individual flowers is called a PEDICEL, while the main axis, or branch bearing the collection of flowers, is called a PEDUNCLE. The study of the arrangement of flowers on the stem is known as anthotaxy.

If we compare the flower clusters of morning glory and bind weed (Fig. I74) with those of the poke weed (Fig. I39) we will find that in the former the number of flowers that may be produced is limited because the middle flowers of the group, or those at the apex of the branch, mature-first; while in the poke weed, on the other hand, the end of the branch has a large number of flower buds, and as these develop others continue to be formed. It is obvious that in the latter case the number of flowers that may be produced is more or less indefinite, and this kind of anthotaxy, or inflorescence, is known as indeterminate or indefinite inflorescence, while in the case of the morning glory, the inflorescence is said to be determinate or definite.

The INDETERMINATE or INDEFINITE INFLORESCENCE is the most general and includes the following kinds: In poke weed the individual flowers are of about the same size, and these are arranged along a central axis, or rachis, the inflorescence being known as a RACEME (Fig. I39); in oat, Yucca and Brayera the individual flowers are replaced by a cluster of flowers, constituting a compound raceme or PANICLE (Fig. I50); in the cultivated cherry the rachis is somewhat shorter than that in a raceme, and 
the pedicels of the flowers are so elongated that all of the flowers attain nearly the same height or level, this form of inflorescence being known as a CORYMB; in the milk weed the rachis is entirely suppressed and the flowers, which have pedicels of the same length, arise from the apex of the peduncle, this form of inflorescence being known as an UMBEL (Fig. I73) ; in the Umbelliferæ a flower cluster takes the place of the individual flowers of the umbel, and this is known as a CoMpound Umbel (Figs. I69, 170); in the plantain the flowers are arranged along a central axis, but the pedicels are wanting, and the inflorescence is known as a SPIKE (Fig. 87, illus. 3); in clover, Cephalanthus and the Compositæ, the rachis and pedicels are both more or less reduced, or wanting, and this form of inflorescence is known as a HEAD (Figs. 181, I82).

The DETERMINATE or DEFINITE INFLORESCENCE includes several types, the principal of which may be mentioned: when a stem or branch is terminated by a flower, or a cluster of flowers of the determinate type, it is known as a CYME, and an inflorescence of this character is described as cymose; when the peduncle bears a number of cymes, it is known as a compound CYME, as in elder, hydrangea and viburnum; and a cymose head is known as a GLOMERULE, as in the dogwood. When the cymes are opposite and sessile, or nearly so, the inflorescence is termed a VERTICILLASTER, as in the Labiatæ.

The flowers of the Compositc are borne on a common torus known as the clisk, which is subtended by one or more circles of bracts, these constituting an INvolUCRE. The flowers are of two kinds, and they receive different names because of their form and position. Those situated near the margin of the disk are known as RAY-FLOWERS, and because they possess more or less strapshaped corollas are also known as LIGULATE FLOWERs. Those occupying the central portion of the disk are known as DISKFLOWERS, or as TUBULAR FLOWERS because of the tubular shape of the corolla. Most of the Compositæ possess both ligulate and tubular flowers, as Arnica (Fig. 24I), matricaria, the common daisy, etc. But some of the members of the family have only ligulate flowers, as chicory and dandelion; and a relatively few have only tubular flowers. 
Pollination and Fertilization.-Fertilization represents the final stage in the work of the flower as a whole; and has already been defined as the union of the egg-cell and a male nucleus. Pollination may be considered to include the transferral of the pollen grains from the anther to the stigma and their subsequent germination thereon, this latter process resulting in the production of the male nuclei. Pollination thus represents but one series of changes or processes which prececle fertilization, for, while the

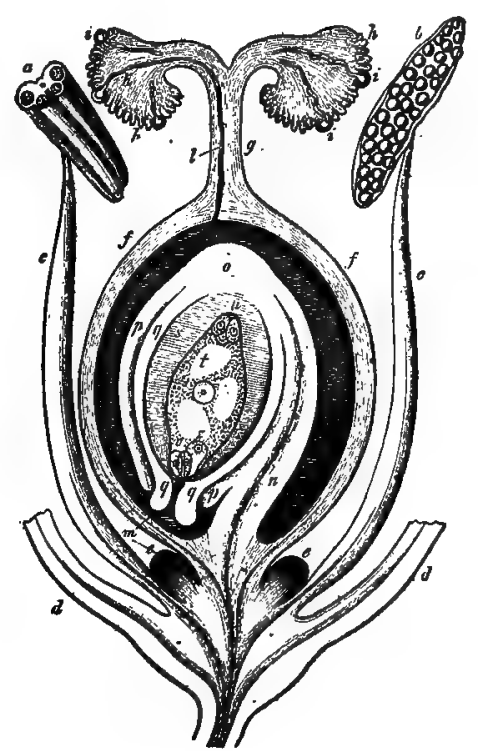

FIG. 85. Diagrammatic representation of fertilization in an Angiosperm. d, floral leaves: stamen consisting of filament (c) and anthers ( $a, b)$, one of which (b) has dehisced exhibiting numerous pollen grains; e, nectar-secreting bodies; pistil consisting of ovary (f), style (g) and stigma (h). On the latter pollen grains (i) are germinating, the tube (1) of one having penetrated through the tissues of the stigma and style, entered the ovary, passed along the wall, and entered the foramen $(\mathrm{m})$, or opening of the ovule. The ovule consists of that portion of the stalk which is united with the integuments and called the raphe $(n)$, outer integument $(p)$, inner integument $(q)$, chalaza $(0)$, nucellus $(s, s)$, embryo-sac or megaspore ( $t$ ) with egg-cell (z), synergids (v), antipodal cells ( $u$ ), and the nucleus in the center which gives rise to the endosperm.-After Sachs.

pollen grain is going through the various stages in development which lead to the formation of the male nuclei, a series of complex changes are going on in the embryo-sac leading to the development of the egg-cell (Fig. 85). 
Our special interest in pollination arises from the fact that the pollen grains are not retained in the pollen-sacs and are dependent upon various agencies for transferral to the stigma. This is a matter of great biological significance, for it is claimed that many of the special characters of flowers have a direct relation to pollination.

The various ways in which the anthers open for the discharge of the pollen when it is ripe have already been considered (Fig. 8I), but it may be added that the manner in which this is done usually appears to have a relation to the manner in which the pollen is to be carried to the stigma. In order that pollination may be effected, the stigma must be ripe or mature, when it is said to be receptive. It then usually secretes a sticky, sugary liquid which causes the pollen grains to adhere to the stigmatic surface (Fig. 85), and which at the same time serves as a nutrient to them. Usually the pollen grains begin to germinate in a short time after reaching the stigma, which is made evident by the protrusion of the pollen tubes. The stigma seems also to have the power of selection, for in many cases the pollen does not germinate as readily on the stigma of the same flower as on that of another flower provided it be of the same or a nearly related species.

When a flower possesses both stamens and pistils, that is, is bisexual or hermaphrodite, and its pollen germinates upon its own stigma, the process is known as close or SELF-POLLIN-ATION, and if fertilization follows this is known as SELF-FERTILIZATION. While most hermaphrodite flowers are self-pollinated there are some that are not, and this is brought about in several ways: ( I) As already pointed out the pollen may germinate better on the stigma of another flower than on the stigma of the same flower; (2) the anthers and pistils of the same flower may mature at different times, and this is one of the commonest ways of preventing self-pollination. Usually in such cases the stamens mature first. The common plantain (Plantago) furnishes an example of the maturing of the stigma before the anther. The flowers of this plant are arranged in spikes (Fig. 87, illus. 3 and 4) which belong to the indefinite class, and hence the lower flowers on the spike expand first. As stated, the pistil of each 
flower matures first, and after it withers the stamens protrude and discharge their pollen. It is evident that the flowers can not be self-pollinated, nor is it likely that one flower will be pollinated by another of the same spike. (3) The stamens and pistils of the same flower may vary in length, as in Polygonum (Fig. 87, illus. I and 2) and Lythrum (Fig. 87, illus. 5), or stand in such other relation to each other that self-pollination will not be effected, as in some of the irregular or zygomorphic flowers, like those of Orchids. In these several cases the pollen grains either fall upon

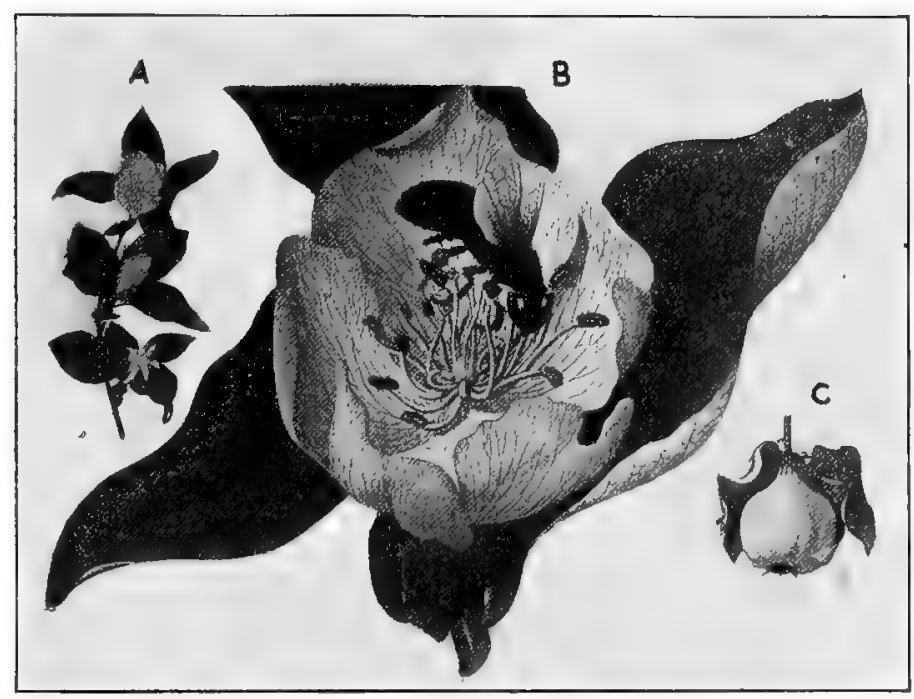

Fic. 86. Cross-pollination through the agency of a bee, in flower of quince ( $C y d o n i a$ vulgaris). A, flowering branch; B, flower showing bee extracting nectar, and masses of pollen adhering to its legs, some of which will fall upon the stigmas of other flowers when it visits them; C, ripe inferior fleshy fruit (pome) of quince,-After Dodel-Port.

or are carried by various agents to the stigmas of other flowers, and this is known as CROSS-POLlination, and the fertilization which follows as CROSS-FERTILIZATION.

Cross-fertilization is an advantage to the species for usually the seeds which result from this process give rise to plants which are more vigorous and otherwise superior to those which result from self-fertilization. In some cases in order to insure the pro- 
duction of fruit, hand-pollination is practiced, as by the growers of vanilla and some other tropical plants of economic importance.

In the case of unisexual flowers, or those in which the stamens and pistils are in separate flowers, there is of course no chance for self-pollination. Here, as in the case of cross-pollinated hermaphrodite flowers, pollination may be more or less close or it may be remote, as between flowers of the same cluster or inflorescence, between flowers of different clusters or inflorescences on the same plant, or between flowers on different plants.

In buckwheat (Fig. 87, illus. I and 2) and partridge berry (Mitchella repens) two kinds of flowers are froduced, viz.: (a) one with short styles and long filaments, and another $(b)$ with long styles and short filaments, and thus the flowers appear to be especially adapted for insect cross-pollination and are called DIMORPHIC. In still other cases one species gives rise to three kinds of flowers, depending upon the difference in the relative lengths of the styles and filaments, as in the purple loosestrife (Lythrum Salicaria), and such flowers are called TRIMORPHIC.

The external agents which are instrumental in carrying pollen from one flower to another and thereby promoting cross-pollination are the wind, water currents, insects, small animals and birds, such as humming-birds, which are, even in temperate regions, to be observed visiting the garden nasturtium.

In many of the early-flowering trees, as well as pines, Indian corn, etc., the flowers are devoid of showy, attractive features, but produce large quantities of pollen which is more or less dry and powdery and carried by the wind to other flowers. Flowers which are wind-pollinated are classed as ANEMOPHILOUS and it is estimated that about one-tenth of all the flower-producing plants belong to this class.

Plants which are pollinated by the aid of water-currents are known as HYDROPHILOUS, and under this head are included those plants which live under the water and those that produce flowers at or near the surface of the water.

Those plants which depend upon the visitation of insects for the transferral of the pollen in cross-pollination are called ENToMOPHILOUS (Fig. 86). They frequently possess bright, highly colored flowers and it is considered that these serve as an attrac- 

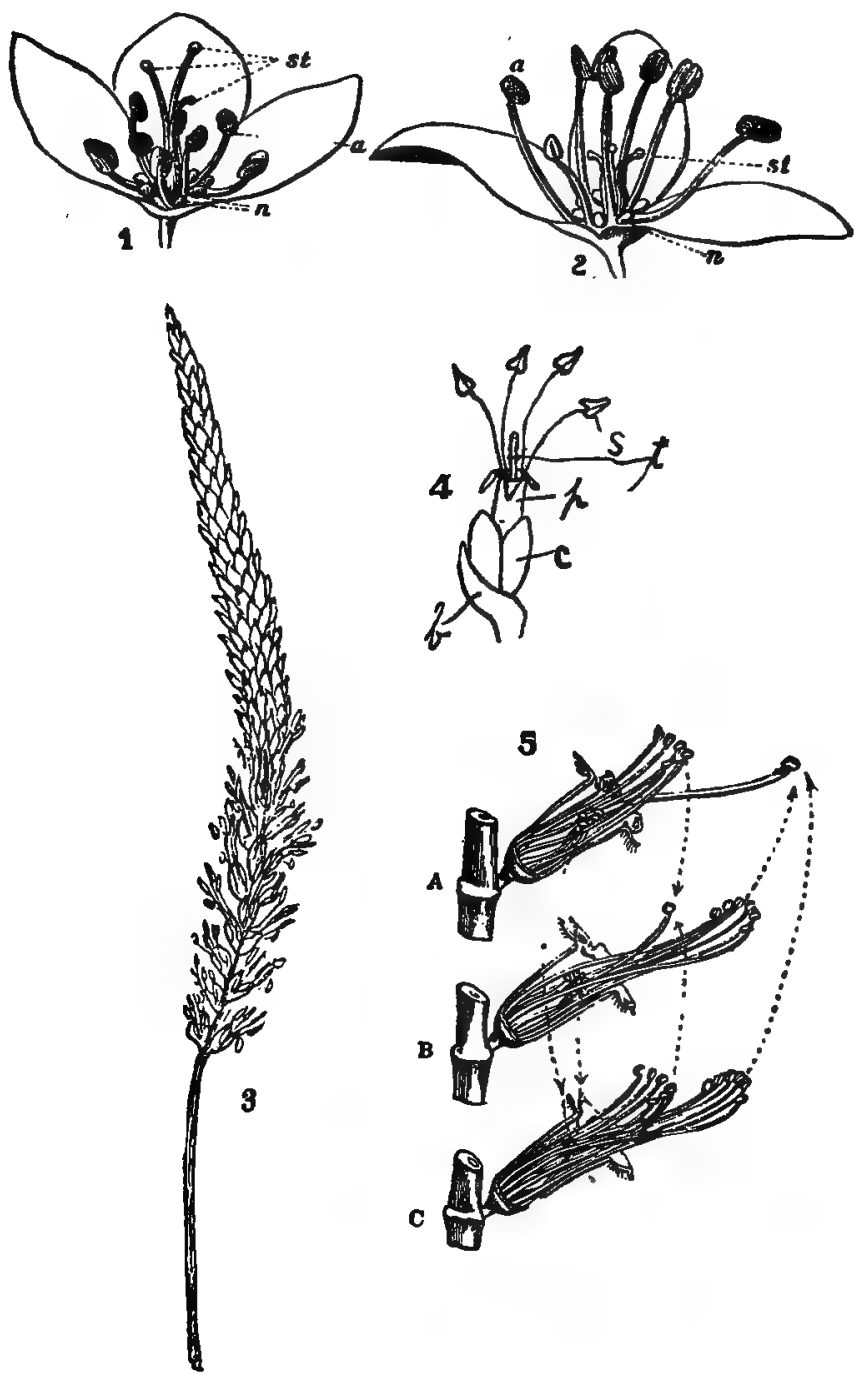

FIG. 87. Ways in which cross-pollination is effected in some hermaphrodite flowers. r, 2, Flowers of buckwheat, showing long style and short filaments in $r$, and short styles and long filaments in 2: a, anthers; st, stigmas; $n$, nectaries. 3 , Spike of plantain showing maturing of stamens below and pistils above. 4 , Dissected flower of plantain: $b$, bract; c, calyx; p, corolla tube; s, stamens; t, protruding withered style. 5, Flowers of Purple willow-herb (Lythrum Salicaria), one side of the perianth removed from each. A is longstyled, B medium-styled, and $\mathrm{C}$ short-styled. The direction of the arrows and dotted lines indicates the best methods of crossing.-1, 2, 5, adapted from Warming. 
tion to the insects which visit them. The insects are, however, probably more attracted by the odor and food products which they obtain, such as the nectar. The nectar is secreted by

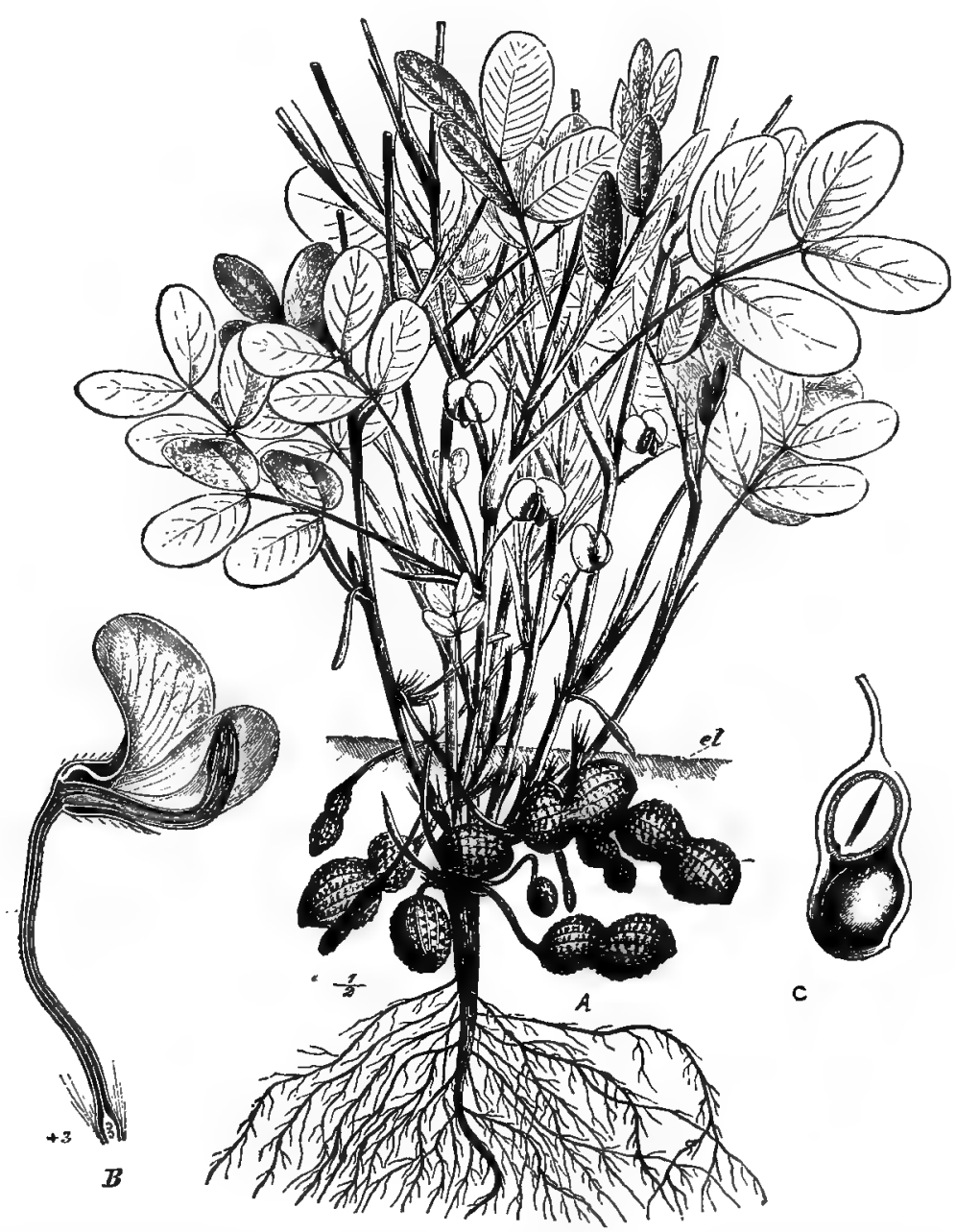

FIG. 88. A, flowering and fruiting plant of peanut (A rachis hypogad). The flowerstalk after fertilization grows in length, sometimes 4 to $8 \mathrm{~cm}$., and curves downward penetrating the soil (el), after which the fruit develops. ' B, longitudinal section through the papilionaceous (bilaterai) flower; $C$, longitudinal section through the pod (peanut).After Taubert. 
glands known as nectaries which are variously located; frequently they are on the torus either between the ovary and stamens (Fig. 83) or between the stamens and petals. Sometimes the stamen is modified to a nectar-secreting spur as in the violets. In aconite the nectary is developed from one of the posterior petals (Fig. 84, E). In seeking the nectar the pollen of the ripe anther may fall upon or adhere to the insects and thus be carried from one flower to another (Fig. 86).

HONEY is a product formed through transformation of the plant nectar by honey bees. The nectar is supposed to be acted upon by certain salivary secretions of the bee and changed into a fruit-sugar, the so-called honey, consisting of a mixture of dextrose and levulose. The nectar of buckwheat and clover (particularly white clover) is the principal source of the commercial article. The nectar of some plants is poisonous and may furnish a poisonous honey ( see p. 357).

\section{THE FRUIT.}

After the fertilization of the ovule or ovules, the parts of the flower that play no further part either in protecting the seed or aiding in its dispersal soon wither and are cast off; in most flowers the petals lose their color and, together with the stamens, style and stigma, wither and fall away shortly after fertilization. The stigma may, however, persist, as in the poppy; the style may likewise remain, as in Ranunculus, or even continue to grow or lengthen, as in Taraxacum; in other cases the calyx persists, as in orange and belladonna; in still other cases the torus may become fleshy and form a part of the fruit, as in pimenta and apple. The fruit may consist, therefore, not only of the ripened pistil, but also of other parts of the flower and torus which persist or develop with it.

The wall of the fruit is called the PERICARP, and, like the leaf, it consists of three distinct layers, viz.: (I) the outer layer corresponding to the outer epidermis of the ovary is called the EPICARP or EXOCARP; (2) the inner layer corresponding to the inner epidermis of the ovary is called the ENDOCARP, or, from the fact that it is sometimes hard and stone-like, it is called the PUTA- 
$M E N$, as in the prune; and (3) the middle layer situated between the epicarp and endocarp is called the MEsocarp;
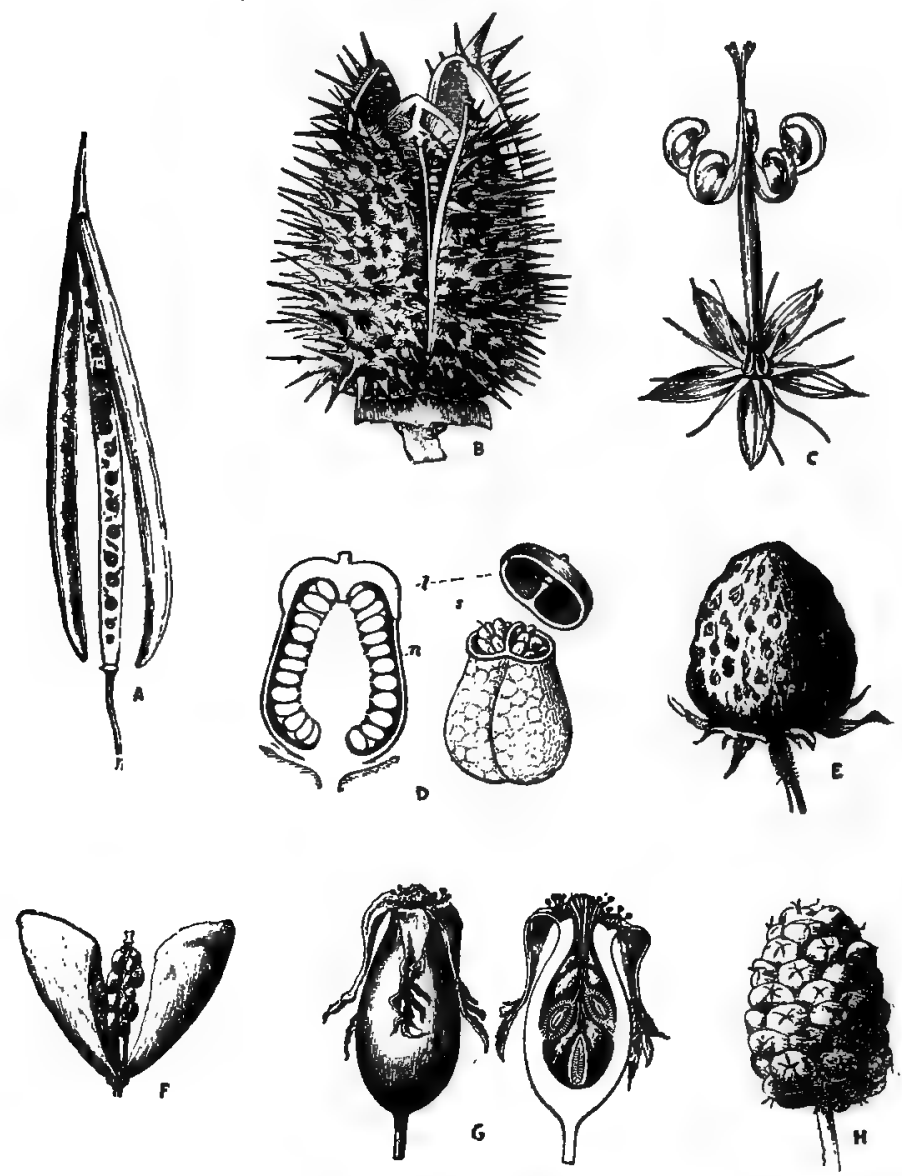

FIG. 89. Different types of fruits. A, silique of mustard showing the separation of the two valves leaving the seeds attached to the central axis: $B$, spinous capsule of Stramonium showing septifragal dehiscence into four valves, the capsule being strictly 2locular but apparently 4 -locular owing to the formation of false dissepiments; C, 5-valved capsule of Geranium in which the carpels become detached from one another and roll upwards remaining attached to the beak-like compound style; $\mathrm{D}$, capsule of Hyoscyamusshowing transverse dehiscence by means of a lid (I) and the two loculi containing numerous small seeds; E, fruit of strawberry showing fleshy torus and numerous embedded akenes; $F$, silicula of shepherd's-purse showing seeds attached to central axis and longitudinal dehiscence of the valves which remain attached below; G, fruit of rose, so-called rose "hip," the akenes being enclosed by the hollow oval torus which shows remains of calyx at the apex: H,multiplefruit of mulberry composed of small drupes, the pulpy portion of each consisting of the fleshy perianth.-Adapted from Warming. 
and from the fact that it is sometimes succulent or fleshy, as in the prune, it is also called the SARCOCARP.

There are a number of distinctive and descriptive names applied to fruits. Some of the more important are as follows:

An Akene is a non-fleshy, or so-called dry, unilocular and one-seeded, indehiscent fruit, in which the pericarp is more or less firm, and may or may not be united with the seed. Akenes may be inferior, as in the Compositæ (Fig. 24I) where they develop from inferior ovaries, being frequently surmounted by the pappus or calyx; or half inferior, as in the rose (Fig. 89, G) where they develop from half inferior ovaries; or superior, as in the buttercup (Fig. 84, D).

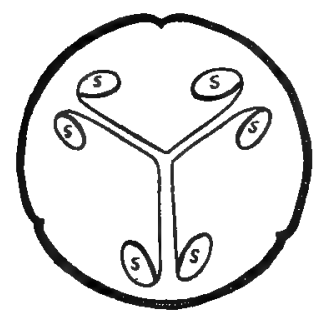

A

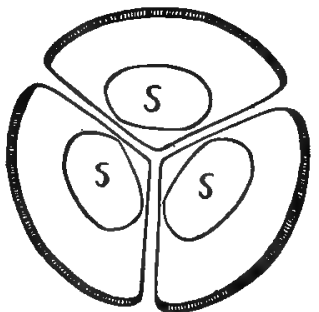

B

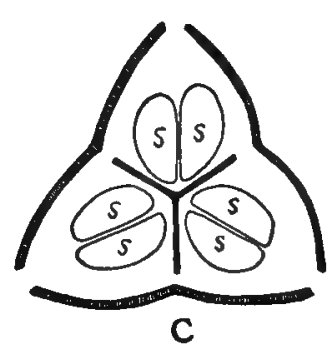

C

FIG. 90. A, transverse section of colocynth showing seeds (s) borne on parietal placentas; B, transverse section of fruit of Ricinus communis showing septicidal dehiscence of capsule, the seeds (s) being borne on axial placentas; $\mathrm{C}$, transverse section of cardamom showing loculicidal dehiscence, the seeds ( $\mathrm{s}$, as in $\mathrm{B}$, being borne on axial placentas.

A Berry is a fleshy, indehiscent fruit, the seeds of which are embedded in the sarcocarp; berries are superior when they develop free from the torus, as in belladonna (Fig. 268), capsicum, grape, etc., and inferior when the torus forms a part of the fruit, as in banana, cranberry and gooseberry.

A Capsule is a dry, dehiscent fruit, consisting of two or more united carpels. Dehiscence in capsules may occur in five different ways: In the castor-bean (Fig. 90, $B$ ) the carpels separate from each other along the walls or septa (dissepiments), the seeds being discharged along the ventral suture of the separated carpels, and this mode of dehiscence is called septicidal. In mustard (Fig. 89. A) the dissepiments remain intact and dehiscence occurs along the margin of the capsule, and is therefore called MARGINICIDAL; 
but as the partial carpels, or valves as they are termed, separate from the walls or septa, the dehiscence is also known as SEPTIFRAGAL. In cardamom (Fig. 9o, $C$ ) the septa as well as valves are united, and at maturity the latter separate and dehisce at points in the margin corresponding to the mid-vein of the carpel, and this form of dehiscence is known as Loculicidal. In poppy capsules (Fig. 9I) there are a few openings beneath the united

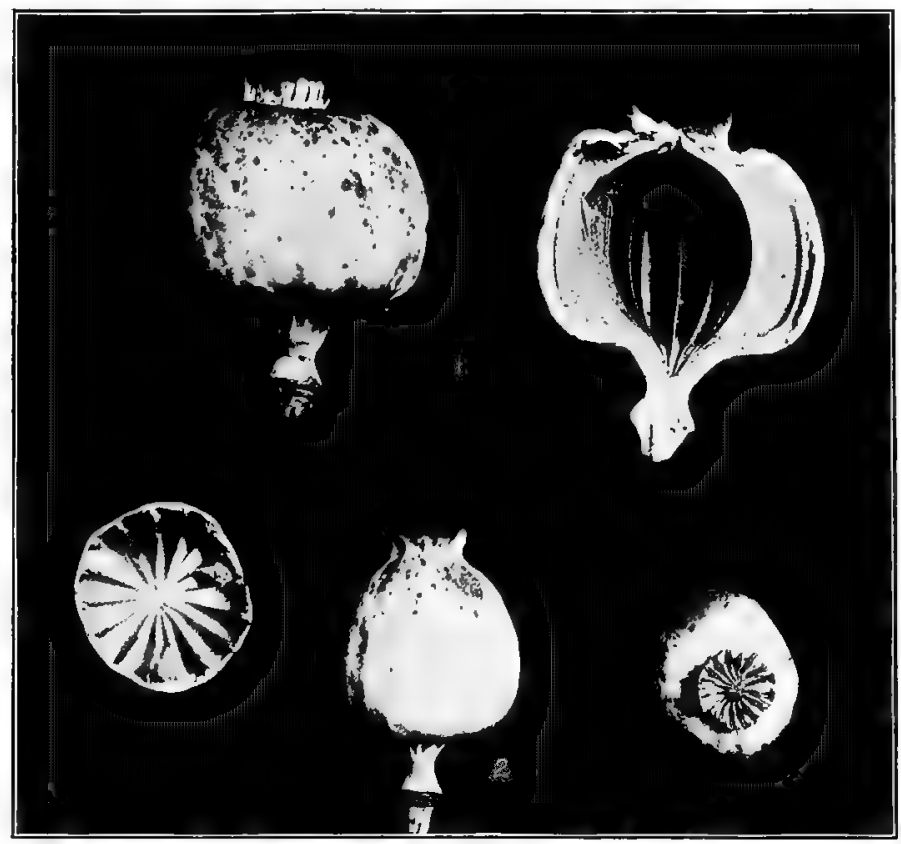

FIG. 91. Capstiles of poppy (Papaver somniferum), whole and in transverse and longitudinal sections, showing dissepiments and remains of radiate stigmas at the apex, which are porous and through which the seeds are discharged. I, French capsules; 2, German capsules.

stigmas through which the seeds are expelled, and this form of clehiscence is known as porous. In hyoscyamus (Fig. 89, D) a portion of the capsule comes off from the remainder like a lid, and this form of dehiscence being circular or transverse to the sutures of the carpel, it is called circumcissile. A capsule of this kind is known as a Pyxis or Pyxidium. 
A Caryopsis, or Grain, is an indehiscent, non-fleshy fruit possessing a thin pericarp, which is closely adherent to the thin seed-coats, as in wheat, corn and other Graminex (Figs. I20, 125).

A Cremocarp is a dry, indehiscent fruit which consists of two inferior akenes, known as MERICARPS; these are separated from each other by means of a stalk known as a CARPOPHIORE. This fruit is characteristic of the Umbelliferce (Figs. 245, 248).

A Drupe is a fleshy, indehiscent fruit with a more or less succulent and well-developed sarcocarp and an indurated endocarp. Drupes are superior when they are free from the torus, as in prune; inferior when the torus forms a part of the fruit, as in pimenta. Drupes are also spoken of as "dry" when the sarcocarp is less succulent, as in Rhus glabra (Fig. 249) or when they are collected unripe, as in pepper and cubeb (Fig. 250). The fruits of the raspberry and blackberry consist of a collection of little drupes, the whole being known as an ET KERIO. In the blackberry the drupelets cohere with the fleshy torus, while in the raspberry the drupelets cohere with one another, forming a cap which is separable from the cone-shaped torus.

A Follicle is a dry, dehiscent fruit which consists of one or more separate carpels, the dehiscence being usually along the ventral suture; in Delphinium the carpels are single; in aconite there are from three to five carpels, and in star-anise (Illicium) from seven to eight; in magnolia the carpels are numerous, forming a kind of succulent cone and dehisce along the dorsal suture.

A Galbalus is a berry-like fruit, formed by the coalescence of fleshy, open scales, as in juniper (Fig. 52 ).

Hesperidium.-The fleshy, indehiscent, superior fruit of citrus, as lemon and orange, is known as a hesperidium. The pericarp is more or less coriaceous, and from the inner walls secretion hairs develop, which contain sugar and an acid cell-sap, these constituting the fleshy portion in which the seeds are embedded.

A Legume is an elongated, monocarpellary, usually dry, dehiscent fruit, in which dehiscence takes place along both sutures, the carpel thus dividing into two halves, or valves, as in the garden 
pea (Pisum) and other members of the Leguminosæ (Fig. I53). In some cases legumes are jointed or articulated and indehiscent, breaking up at maturity into a number of parts which are dispersed in much the same manner as samara-fruits, as in Meibomia. Legumes may be not only indehiscent but fleshy, as in Cassia fistula (Fig. 255).

A Nut is an akene-like fruit, the pericarp of which is more or less indurated. Nuts are sometimes subtended (as in acorns) or enclosed (as in chestnuts) by a kind of involucre, forming what is technically known as a cupule; and a fruit consisting of a nut and cupule is known as a Glans (Fig. 72, $B$ ). The akenelike fruit of the Labiatæ is spoken of as a Nutlet.

A Pepo is an inferior berry, in which the placentas have become developed into succulent layers, as in the watermelon, cucumber and colocynth (Fig. 254).

A Pod is a general term used to designate all dry, dehiscent, apocarpous or syncarpous fruits, as capsules, follicles and legumes.

A Pome is an indehiscent, half-inferior, fleshy, syncarpous fruit, as in the apple. The carpels constitute the core and the fleshy part is developed from the torus (Fig. 86, C).

A Samara is a winged, akene-like fruit. The winged appendage may be at the apex, as in white ash, or around the edge, as in elm. Two samaras may be united into one fruit, which is called a "double samara" as in maple.

A Silique is a narrow, elongated, 2-valved capsule which is separated by the formation of a false dissepiment into two locules, as in the Cruciferæ (Fig. 89, $A$ ).

A Sorosis is a fleshy fruit resulting from the aggregation of the carpels of several flowers, as in mulberry (Fig. 89, $H$ ) and pineapple.

A Strobile or cone is a scaly fruit, at the base of each scale of which there is either a seed, as in the Coniferce, or an akene-like body, as in hop (Fig. I36).

A Syconium consists of a succulent hollow torus, which encloses a number of akene-like bodies, as in the fig (Ficus).

An Utricle is an inferior akene with a thin and loose pericarp, as in Chenopodium. 
Classification of Fruits.-More or less-artificial classifications of fruits have been made. They may be grouped either according to structure or according to their manner of protection or dispersal, the following classification being based on the structure:

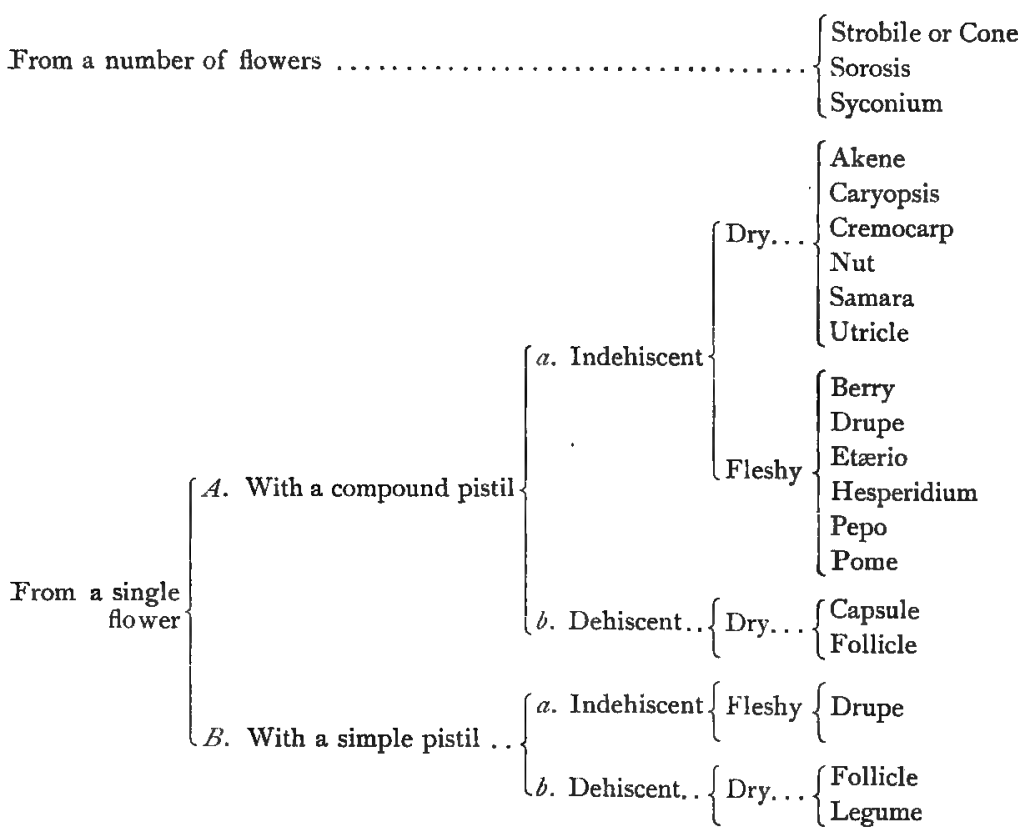

VI. THE SEED.

The seed may be defined as the fertilized and developed ovule. The seeds of different frtits vary in number as well as in size and shape. In form they correspond to the ovules; in size they vary from about I millimeter, as in the poppy, to Io or 15 centimeters in diameter, as in the cocoanut palm. Seldom are all of the ovules of the pistil fertilized, hence the number of seeds is ustually less than the number of ovules.

Structure of Seed.-After the fertilization of the egg-cell certain changes take place in the embryo-sac: At one end the developing embryo is attached to the wall by a short stalk or suspensor (Fig. 57); the nuclei, lying in a mass of cytoplasm 
around the wall of the embryo-sac, divide and re-divide; the large vacuole in the center becomes filled with a watery or milky fluid, and later the nuclei, with portions of the cytoplasm, may be enclosed by a cellulose wall and become permanent cells, in which the embryo is embedded. Likewise in the nucellus, changes are also taking place; the cells are found to be dividing, and storing starch, oil, aleurone and other food materials, like the cells of the embryo-sac. The cells in which these materials are stored are known as reserve cells and in the nucellus they constitute the PERISPERM, while those formed in the embryo-sac make up the ENDOSPERM. Usually the endosperm of seeds is prominently developed while the perisperm occurs as a thin layer; in cardamom, however, the endosperm and perisperm are both well developed (Fig. 253). In some instances the embryo may not fill the embryo-sac, as in cocoanut, and sometimes, as in the almond, both of the reserve layers are consumed in the development of the embryo when the seed is said to be without endosperm (Fig. 187).

The perisperm and endosperm are sometimes spoken of together as the albumen of the seed, but as the cells comprised in these layers contain not only protoplasmic contents and aleurone grains, but starches, oils and other substances, the term is misleading. On this basis, seeds containing either endosperm or perisperm, or both, have been designated as albuminous, but on account of these layers containing larger proportions of other substances than proteids it would be better to speak of them as RESERVE LAYERS (Figs. I2I, I22).

While these changes in the nucellus and embryo-sac have been going on there have been equally great changes in the coats of the ovules, which later constitute the seed-coats. In the seed the two coats are generally readily distinguishable. The inner, as in Ricinus, Pepo, etc., is thin, light in color, of a delicate structure, and is known as the TEGMEN ; the outer is more or less thickened, of a darker color and firmer in structure, and is known as the TESTA. In some instances the perisperm, or both perisperm and endosperm, may be reduced to a thin layer when it is considered to form a part of the seed-coat, as in mustard. In other cases the two coats are so closely united that they are not easily distinguished, as in stramonium. 
The terms used in describing the kinds of ovules (atropous, anatropous, campylotropous, etc.), are retained in the description of the seeds; and in describing the different parts of the seed some

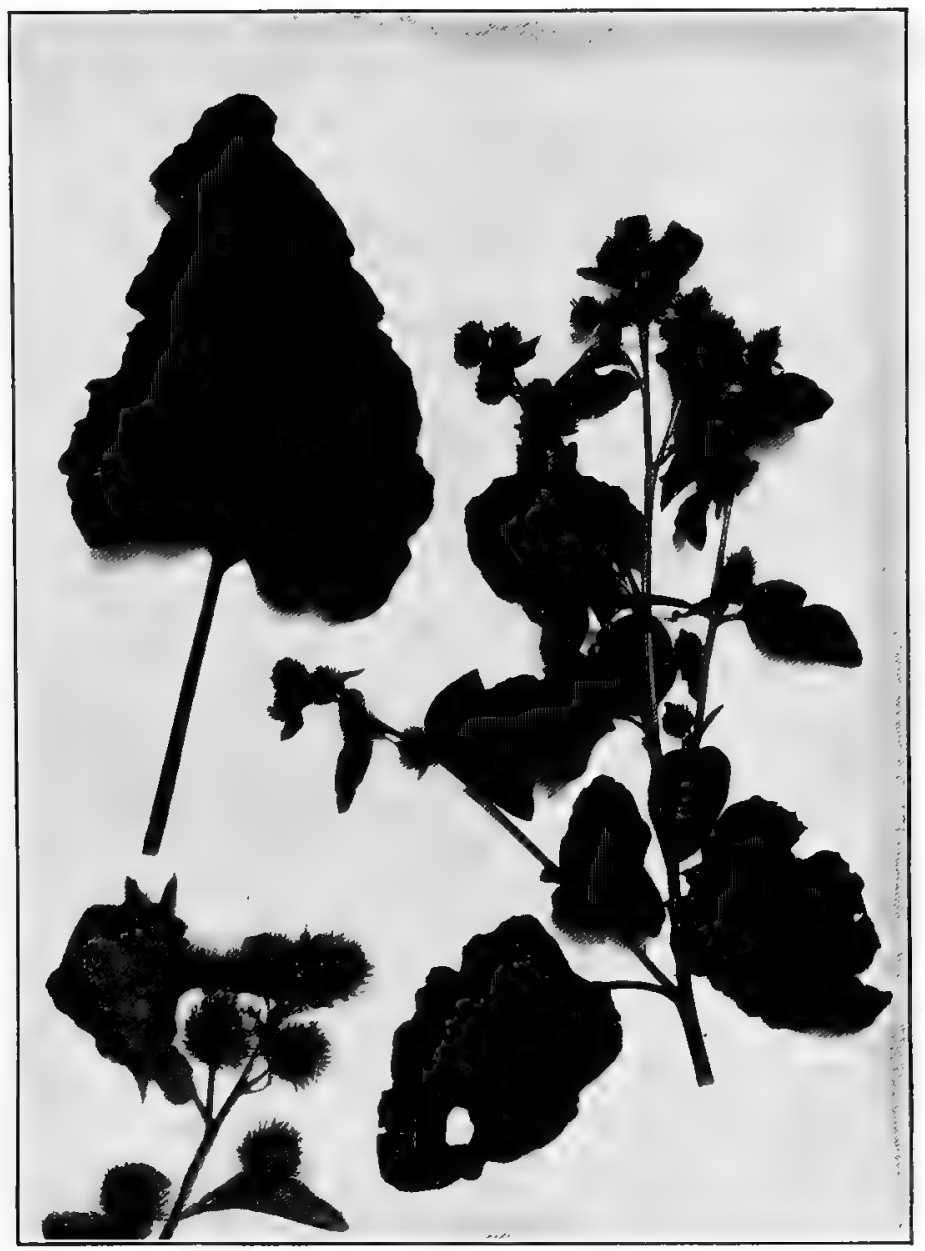

FIg. 92. Burdock (Arctium Lappa) showing large basal leaf, a flowering branch, and at the lower left-hand corner a few of the burs on which a bat has been caught and apparently held until it died.

of the terms which were applied to the ovule are also retained, as chalaza and raphe; the seed when ripe usually becomes detached 
from its stalk and the resulting scar is called the HILUm; that part of the seed corresponding to the foramen of the ovule is more or less closed and is known as the MICROPYLE; the embryo develops in such a way that the tip of the young root always points in the direction of the micropyle.

In the fully developed embryo three distinct parts may be differentiated (Fig. 59): (I) The Cotylenons; (2) the part below the cotyledons, known as the HypocotyL, the apical portion of

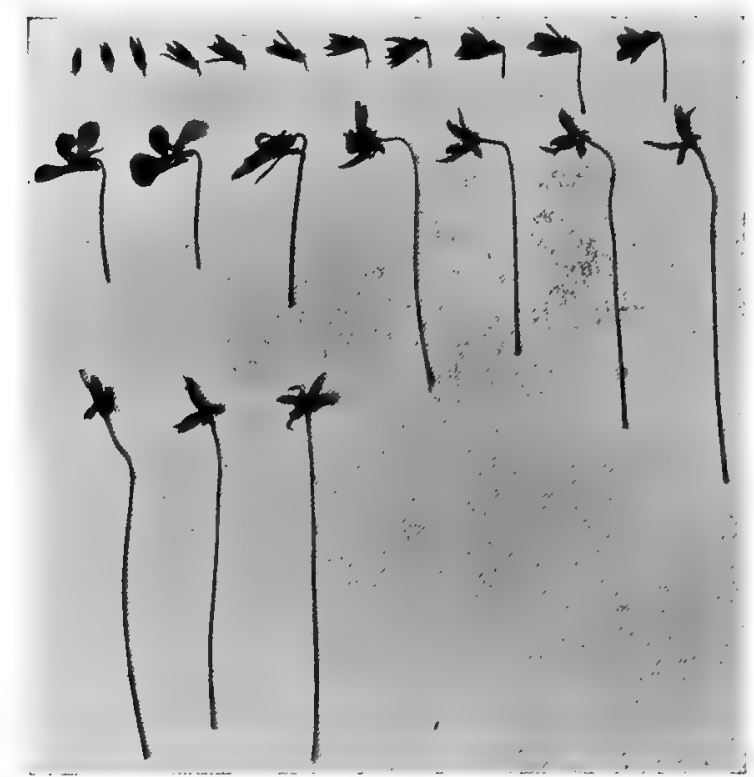

FIG, 93. Successive stages in the development of flower and fruit of Viola tricolor. The bud is at first erect, as the flower develops the ovary assumes a horizontal position, and after fertilization resumes the erect position.

which constitutes the young root or RADICLE; (3) the part above the cotyledons, known as the EPICOTYL, the apex of which consists of a more or less developed bud spoken of as the PLUMULE.

The position of the embryo (Figs. I2I, I22) in the seed varies somewhat: in most seeds it lies in the center, as in strophanthus and linum; it may, however, be excentral, as in colchicum and nutmeg. The cotyledons are usually situated above the hypocotyl, but in the Cruciferæ, either their edges lie against the hypocotyl, 
as in the mustards, when they are said to be ACCUMBENT or conduplicate, or they lie so that the back of one is against the hypocotyl, as in Lepidium, which position is known as INCUMBENT.

Externally, the seed-coats vary considerably; they may be nearly smooth, as in ricinus; finely pitted, as in the mustards; prominently reticulate, as in staphisagria; hairy, as in cotton (Fig. 166) and strophanthus (Fig. I85), or winged, as in the seeds of the catalpa. There are also a number of other appendages, these having received special names: the wart-like development at the micropyle or hilum of some seeds, as in castor-bean and violet, is known as the CARUNCLE; in the case of sanguinaria, a wing-like development extends along the raphe, and this is known as the STROPHIOLE; in some cases the appendage may completely envelop the seed, when it is termed an ARILLUS; when such an envelope arises at or near the micropyle of the seed, as the mace in nutmeg, it is known as a "false arillus," or ARILLODE.

Seed Dispersal.--Seeds and fruits are distributed in various ways, and so are often found growing in localities far from their native habitat. In some instances seeds are adapted for distribution by the wind, being winged, as in Paulorenia, Catalpa and Bignonia, or plumed and awned, as in Strophanthus (Fig. I85); Asclepias and Apocymum (Fig. 20I). As examples of fruits having special parts which aid in their distribution may be mentioned the akene of Arnica which is provided with a pappus (Fig. 24I), the bladder-like pericarp of Chenopodium, the winged fruit or samara of maple. The hooked or barbed appendages on some fruits serve to attach them to animals and thus they may be widely distributed, as in burdock (Fig. 92) and Spanish needles (Bidens bipinnata). In still other cases fruits may be carried long distances by water currents, or even by ocean currents, as those of the Double-cocoanut palm (Lodoicea Seychellarum), which while native of the Seychelles Islands is now found on many of the islands in the Pacific and Indian Oceans. It may also be mentioned in this connection that a number of fruits, as the garden balsam, castor-oil plant, violets (Fig. 93), Wistaria, etc., are elastically dehiscent and discharge the seeds with considerable force. 


\section{CHAPTER III.}

INNER MORPHOLOGY OF THE HIGHER PLANTS.

\section{CELL AND CELL-CONTENTS.}

A TYPICAL living cell may be said to consist of a wall and a protoplast (a unit of protoplasm), although it is often customary to refer to the protoplast alone as constituting the cell. This is in view of the fact that the protoplasm which makes up the substance of the protoplast is the living substance of the plant.

Besides the protoplasm other substances are also found in the cell, hence in a general way the cell may be said to be composed of a wall and contents (cell-contents). The wall, as well as the cell-contents, consists of a number of substances, and, as the cellcontents are of primary importance in the development of the plant, their nature and composition will be considered first.

Cell-contents.-With the distinction already made the cellcontents may be grouped into two classes: ( I) Protoplasmic, or those in which the life-processes of the plant, or cell, are manifested, and (2) non-protoplasmic, or those which are the direct or indirect products of the protoplast. The first class includes the protoplasm with its various differentiated parts, and the second, the various carbohydrates (starches and sugars), calcium oxalate, aleurone, tannin, oil, and a number of other substances.

\section{PROTOPLASMIC CELL-CONTENTS.}

Protoplasm.-Protoplasm occurs as a more or less semifluid, slimy, granular, or foam-like substance, which lies close to the walls of the cell as a relatively thin layer and surrounding a large central cavity or vacuole filled with cell-sap, or it may be distributed in the form of threads or bands forming a kind of network enclosing smaller vacuoles. Protoplasm consists of two comparatively well differentiated portions: (I) Certain more or less distinct bodies which appear to have particular functions and to which a great deal of study has been given, as the nucleus and I56 
plastids, and (2) a less dense portion which may be looked upon as the ground substance of the protoplast and which is now commonly referred to as the CyTOPLASM (see Frontispiece). These differentiated bodies and the cytoplasm are intimately associated and interdependent. The nucleus and cytoplasm are present in

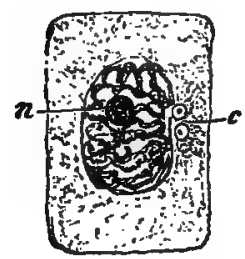

1

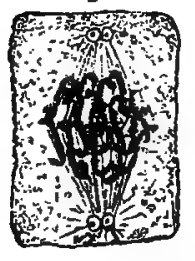

-

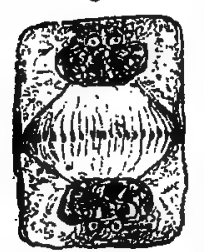

$\vartheta$

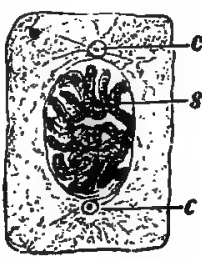

2

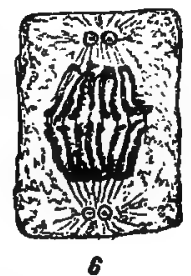

6

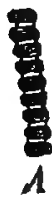

$=$
$=$
1
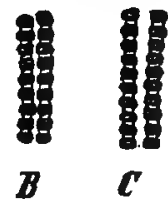
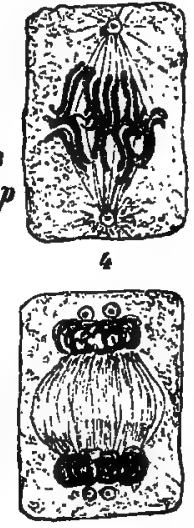

8

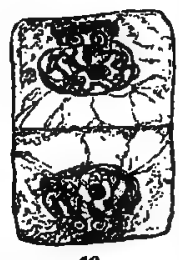

10

FIG, 94. Successive stages in nuclear and cell division, $n$, nucleolus; $c$, centrospheres s, chromosomes; sp, spindle fibers; A, B, C, division of chromosomes. $\mathbf{I}$, cell with nucleus containing nucleolus (n), and two centrospheres (c); 2, showing separation of nucleus into distinct chromosomes (s) and the centrospheres at either pole of the nucleus; 3 , formation of spindle fibers (sp); 4 , longitudinal division of chromosomes; 5 , division of the centrospheres; $6,7,8$, further stages in the development of the daughter nuclei; 9 , formation of cell-wall which is completed in Io giving rise to two new cells. - After Strasburger.

all living cells and it is through their special activities that cell division takes place. When in addition plastids are present, constructive metabolism takes place, whereby complex substances are formed from simpler ones (p. 222).

Besides the nucleus and plastids other protoplasmic structures are sometimes found embedded in the cytoplasm. These are the 
CENTROSPHERES (Fig. 94, c), small spherical bodies that are associated with the nucleus and appear to be concerned in cell division. There are in fact quite a number of minute bodies in the cytoplasm which may be always present or only under certain conditions, and which are grouped under the general name of MICROSOMES Or MICROSOMATA.

Chemically protoplasm is an extremely complex substance, but does not appear to have a definite molecular structure of its own, being composed in large measure of proteids, a class of organic compounds which always contain nitrogen, and frequently phosphorus and sulphur. The molecule of the proteids is large and more or less unstable, and hence subject to rapid changes and a variety of combinations, and it is to these interactions that the vital activities of the plant are attributed.

Nucleus. - The nucleus consists of (I) a ground substance in which is embedded (2) a network composed of threads containing a granular material known as CHROMATIN, and (3) generally one or more spherical bodies called NUCLEOLES, the whole being enclosed by (4) a delicate membrane (Fig. 94). The chromatin threads are readily stained by some of the aniline dyes, and are mainly composed of nucleins (proteids) rich in phosphorus, which by some writers are supposed to be essential constituents of the nucleus and necessary to the life of the protoplast. Chromatin is constant in the nucleus and prior to cell division the threads become organized into bodies of a definite number and shape known as CHROMOSOMES (Fig. 94, $s$ ).

Plastids.-The plastids or chromatophores form a group of differentiated protoplasmic bodies found in the cytoplasm (Frontispiece) and are associated with it in the building up of complex organic compounds, as starch, oil and proteids. The term chromatophore means color-bearer, but applies also to those plastids which may be colorless at one stage and pigmented at another. Hence we may speak of colorless chromatophores. According to the position of the cells in which these bodies occur and the functions they perform, they vary in color-three distinct kinds being recognized. (r) In the egg-cell and in the cells of roots, rhizomes and seeds the plastids are colorless and are called LEUcoPLASTIDS. (2) When they occur in cells which are more or less 
exposed to light and produce the green pigment called chlorophyll, they are known as CHLOROPLASTIDS or chloroplasts. (3) In other cases, independently of the position of the cells as to light or darkness, the plastids develop a yellowish or orange-colored principle, which may be termed chromophyll, and are known as CHROMOPLASTIDS. Chloroplastids are found in all plants except Fungi and non-chlorophyllous flowering plants, and chromoplastids in all plants except Fungi. Plastids vary in form from more or less spherical to polygonal or irregular-shaped bodies, and they increase in number by simple fission. They suffer decomposition much more readily than the nucleus, and are found in dried material in a more or less altered condition.

Leucoplastids.-The chief function of the leucoplastids is that of building up reserve starches or those stored by the plant for food, and they may be best studied in the common potato tuber, rhizome of iris, and the overground tubers of Phajus (Fig. I). The reserve starches are formed by the leucoplastids from sugar and other soluble carbohydrates.

The chloroplastids occur in all the green parts of plants (see Frontispiece). They vary from 3 to II $\mu$ in diameter and are more or less spherical or lenticular in shape, except in the Algæ, where they are large and in the shape of bands or disks (Figs, 6, 7), and generally spoken of as chromatophores. Chloroplastids are found in greater abundance in the cells near the upper surface of the leaf than upon the under surface, the proportion being about five to one. These grains upon close examination are found to consist of ( $\mathrm{x}$ ) a colorless stroma, or liquid, in which are embedded (2) green granules; (3) colorless granules; (4) protein masses; (5) starch grains; and (6) a membrane which surrounds the whole. The green granules are looked upon as the $\mathrm{CO}_{2}$ assimilation bodies; the colorless grains are supposed to assist in the storing of starch or in the production of diastase, the conditions for these processes being directly opposite, i.e., when $\mathrm{CO}_{2}$ assimilation is active, starch is stored, and when this process is not going on, as at night, diastasse is produced and the starch is dissolved. The protein grains may be in the nature of a reserve material of the plastid and are also probably formed as a result of $\mathrm{CO}_{2}$ assimilation. 
While the protoplasm has been termed by Huxley "The physical basis of life," the chloroplastid has been spoken of as the mill which supplies the world with its food, for it is by the process of photosynthesis that the energy of the sun is converted into vital energy, and starch and other products formed, which become not only the source of food for the plant itself, but also the source of the food-supply of the animals which feed upon plants. In other words, horse-power is derived from the energy of the sun which is stored by the chloroplastids in the plant.

Chromoplastids.-In many cases, as in roots, like those of carrot, or flowers and fruits, which are yellowish or orangecolored, there is present a corresponding yellow pigment, and to this class of pigments the name chromophyll may be applied. Some of these pigments, as the carotin in carrot, have been isolated in a crystalline condition.

Chromoplastids usually contain, as first pointed out by Schimper and Meyer, protein substances in the form of crystal-like bodies; starch-grains may also be present. The chromoplastids are very variable in shape and in other ways are markedly different from the chloroplastids. They are more unstable than the chloroplastids, and are formed in underground parts of the plant, as in roots, as well as in parts exposed to the light, as in the flower. Their formation frequently follows that of the chloroplastids, as in the ripening of certain yellow fruits, such as apples, oranges, persimmons, etc.

The PLASTID PIGMEÑTS are distinguished from all other colorsubstances in the plant by the fact that they are insoluble in water and soluble in ether, chloroform and similar solvents. In fact they are but little affected by the usual chemical reagents under ordinary conditions.

Apart from the difference in color, the yellow pigment (chromophyll) is distinguished from the green (chlorophyll) by the fact that the latter is said to contain nitrogen, and also by their difference in behavior when examined spectroscopically, chlorophyll giving several distinct bands in the yellow and orange portion of the spectrum, which are wanting in the spectrum of the yellow principle. 


\section{NON-PROTOPLASMIC CELL-CONTENTS.}

The non-protoplasmic constituents of plants may be said to differ from the protoplasmic cell-contents in two important particulars, namely, structure and function. For convenience in considering them here, they may be grouped as follows:

(I) Those of definite form including (a) those which are colloidal or crystalloidal, as starch and inulin; (b) those which are crystalline, as the sugars, alkaloids, glucosides, calcium oxalate; (c) composite bodies, as aleurone grains, which are made up of a number of different substances.

(2) Those of more or less indefinite form, including tannin, gums and mucilages, fixed and volatile oils, resins, gum-resins, oleo-resins, balsams, caoutchouc, and also silica and calcium carbonate.

\section{SUBSTANCES DEFINITE IN FORM.}

\section{COLLOIDAL OR CRYSTALLOIDAL.}

Starch is the first visible product of photosynthesis although it is probable that simpler intermediate products are first formed. This substance is formed in the chloroplastid (see Frontispiece) and is known as assimilation starch. Starch grains are usually found in the interior of the chloroplastid, but may attain such a size that they burst through the boundary wall of the plastid, which latter in the final stage of the growth of the starch grain forms a crescent-shaped disk attached to one end of the grain (see Frontispiece). Starch is changed into soluble carbohydrates by the aid of ferments and probably other substances, and in this form is transported to those portions of the plant requiring food. The starch in the medullary rays and in other cells of the wood and bark of plants is distinguished by being in the form of rather small and nearly spherical grains. In rhizomes, tubers, bulbs and seeds the grains are, as a rule, quite large, and possess more or less distinct characteristics for the plant in which they are found. Starch of this kind is usually spoken of as RESERVE STARCH.

Occurrence of Starch.-Starch is found in most of the algæ and many of the mosses, as well as in the ferns and higher 
plants. The amount of starch present in the tissues of plants varies. In the root of manihot as much as 70 per cent. has been found. This constituent also varies in amount according to the season of the year. Rosenberg has observed that in certain perennial plants there is an increase in the amount of starch during the winter months, whereas in other plants it decreases or may entirely disappear during this period. In the latter case, from six weeks to two months in the spring are required for its re-formation, and about an equal period is consumed in the fall in effecting its solution.
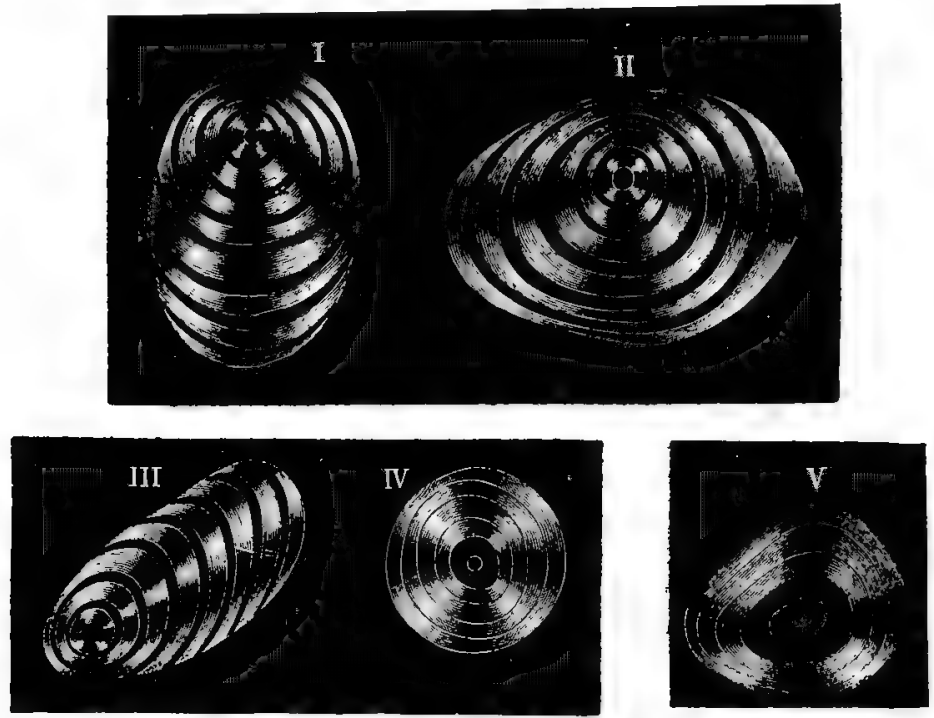

FIG. 95. A ppearance of various starches under polarized light: I, II, III, potatostarch grains; IV, wheat-starch grain; V, pea-starch grain,-After Dippel.

Structure and Composition of Starch Grains.-The formula which is generally accepted for starch is $\left(\mathrm{C}_{6} \mathrm{H}_{10} \mathrm{O}_{5}\right)_{\mathbf{n}}$, this being recognized by Pfeffer, Tollens and Mylius. It is supposed that the molecule of starch is quite complex, it being composed of different single groups of $\mathrm{C}_{6} \mathrm{H}_{10} \mathrm{O}_{5}$ or multiples of the same. While this formula may be accepted in a general way, still it has been shown that there are at least two substances which enter into the composition of the starch grain, and more recent studies tend 
to show that it is in the nature of a sphero-crystalloid, resembling inulin in some respects. Starch grains have an interesting structure. They vary in shape from ovoid or spherical to polygonal, and have a more or less distinct marking known as the "hilum,"
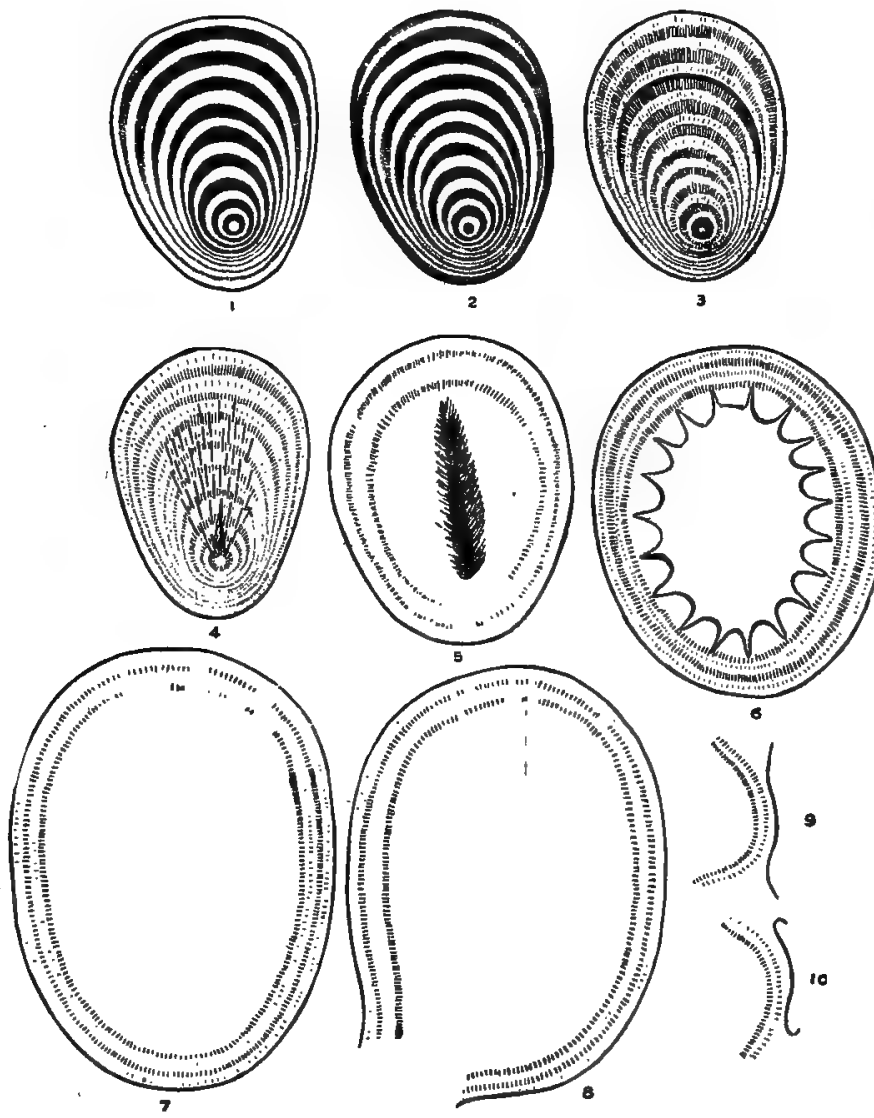

Fug. 96 . Successive stages in the swelling and disintegration of potato-starch grains on the application of certain chemicals or heat $\left(60^{\circ}-70^{\circ} \mathrm{C}\right.$.).

"nucleus" or the POINT OF ORIGIN OF GROWTH. The substances of which the grains are composed are arranged in concentric layers or lamellæ which are more or less characteristic and which sometimes become more distinct on the application of certain reagents (Figs. 96, 97). The point of origin of growth and alter- 
nate lamellæ are stained by the use of gentian violet and other aniline dyes, which may be taken to indicate that these layers contain a colloidal substance somewhat resembling a mucilage, while the alternating layers are stained with dilute iodine solutions and are probably composed of soluble starch, this latter corresponding to the $a$-amylose of Arthur Meyer or the granulose described by Nägeli. The peripheral layer of the grain appears to be a distinct membrane. It is quite elastic, more or less porous, and takes up stains readily.

While starch grains usually occur singly, they are not infrequently found in groups of two, three or four grains, when they are spoken of as two-, three-, or four-compound. In some of the cereals, as rice and oat, they are Ioo-compound or more. The individuals in compound grains are in some cases easily separated from one another. This occurs frequently in microscopical preparations, and is especially noticeable in the commercial starches.

The various commercial starches belong to the class of reserve starches and may be distinguished by the following characteristics :

(I) The shape of the grain, which may be spherical, ellipsoidal, ovoid, polygonal, or of some other characteristic form (Figs. 316, 317).

(2) The size of the grain, which varies from I or $2 \mu$ to about $100 \mu$ in diameter.

(3) The position of the point of origin of growth, which may be central (Fig. 316, $C, D$ ) or excentral (Fig. 316, $A, B$ ). In some cases there are apparently two points of origin of growth in a single grain, and it is then spoken of as "half-compound," as in potato (Fig. $3 \mathrm{I} 6, A$ ).

(4) The shape of the point of origin of growth, which may be spherical, as in potato (Fig. 316, $A$ ); cross-shaped, as in maranta (Fig. $316, B$ ) ; a three- or five-angled fissure or cleft. as in corn (Fig. $316, D$ ), or indistinct or wanting, as in wheat (Fig. $3 \mathrm{I} 6, C$ ).

(5) The convergence of the lamellæ, which may be either toward the broad end of the grain, as in maranta (Fig. $316, B$ ), or toward the narrow end, as in potato (Fig. $3 \mathrm{I} 6, A$ ). In most 
grains the lamellæ are indistinct or wanting, as in wheat and corn (Fig. 316, $C, D$ ).

(6) Behavior toward dilute iodine solutions, the color produced varying from a deep blue in most starches to a red or yellowish red, as in the amylodextrin grains of mace.

(7) The temperature $\left(45^{\sim}-77^{\circ} \mathrm{C}\right.$. $)$ at which the "kleister" or paste is formed, and its consistency.

(8) The appearance as viewed by polarized light, the distinctness of the cross, as well as the kinds of colors produced, varying considerably as Nichol's prism is revolved (Fig. 95).

(9) Behavior toward various reagents, as chromic acid, calcium nitrate, chlor-zinc-iodide, diastase and various aniline stains, peculiarities of both structure and composition being manifested (Figs. 96 and 97).

General Properties of Starch.-If starch is triturated with water and the mixture filtered, the filtrate does not give a reaction with iodine solution; if, on the other hand, the starch is previously triturated with sand and then with water, the filtrate becomes blue on the addition of iodine solution. It appears that in the latter operation the wall of the grain is broken and the soluble starch present in the grain is liberated.

If dry starch and iodine are triturated together no color or, at the most, a faint blue color is produced; whereas, if a little water is added and the trituration repeated, a deep blue color is immediately produced.

The blue color of starch solution and iodine disappears on the application of heat, but slowly returns on cooling the solution, but not with the same degree of intensity, part of the iodine being volatilized.

When starch is heated with glycerin it dissolves, and if alcohol is added to the solution, a granular precipitate is formed which is soluble in water, the solution giving a blue reaction with iodine.

When starch is heated with an excess of water at $100^{\circ} \mathrm{C}$. for varying periods of time, it completely dissolves with the formation, first, of soluble starch, which gives the characteristic blue reaction with iodine; then the production of dextrin compounds, giving violet-red, reddish and yellowish reactions with iodine; finally, maltose and dextrose are produced, these giving no reac- 
tion with iodine, but reducing Fehling's solution. The ferments and dilute acids have a similar effect on starch and the dry heating of it at temperatures of $150^{\circ}-170^{\circ} \mathrm{C}$. changes it to dextrin.
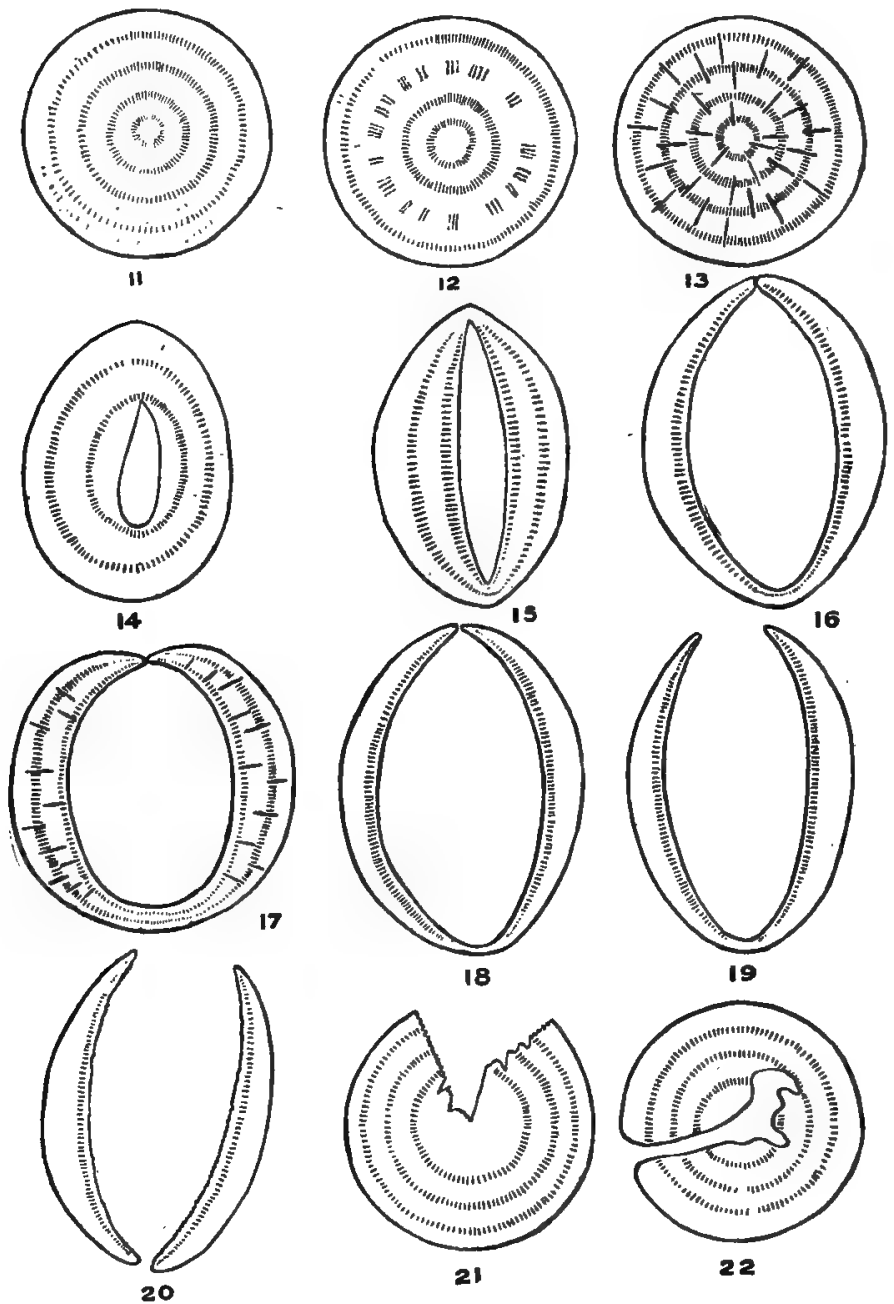

FIG. 97. Successive stages in the swelling and disintegration of wheat-starch grains under the influence of certain chemicals or heat $\left(60^{\circ}-70^{\circ} \mathrm{C}\right.$.)

Inulin appears to be an isomer of starch and occurs in solution in the cell-sap of various members of the Compositæ and 
several other families, being found in the lower orders of plants only in isolated cases.

It is stored chiefly in the parenchyma cells of the wood and bark of rhizomes, tubers and roots, being also found in the medullary-ray cells. It occurs in the form of a colorless, or yellowish, highly refractive, concentrated solution, about 30 per cent. being present in plants during the early fall and spring, when it exists in greatest amount. During winter and also during summer it is changed to levulose.

According to Dragendorff there are two forms of inulin; one of which is amorphous and easily soluble in water, and another which is crystalline and difficultly soluble in water. The latter is probably, however, a modification of the former, and it is not unlikely that the various principles known as pseudoinulin, inulenin, helianthenin and synantherin are all modifications of intlin.

If inulin-containing plants are preserved in alcohol and examined by aid of the microscope, the inulin will be found to have separated in the form of sphere-crystalloids, which are attached to the cell wall (Fig. IOI, E; Fig. IO5); but if the material is first allowed to dry out, the inulin will be found in irregular, almost gum-like lumps, which are with more or less difficulty dissolved in water.

Drugs Containing Inulin.--Inulin, in the form of irregular, strongly refractive masses, is found in the following drugs: Inula, lappa, pyrethrum and taraxacum.

\section{CRYSTALLINE SUBSTANCES.}

The sugars constitute a group of crystalline principles of wide distribution. They occur in the cell-sap, from which by evaporation or on treatment with alcohol they may be crystallized out. Quite a large number of distinct principles belonging to this class have been recognized, of which the following may be mentioned:

Dextrose (grape-sugar or dextro-glucose) is found in sweet fruits, the nectaries of the flowers, and stems and leaves of various plants. It crystallizes in needles and varies in amount from I to 2 per cent. (in peaches), to 30 per cent. in certain varieties of 
grapes. It also occurs in combination with other principles, forming the glucosides.

Levulose (fructose, fruit-sugar or levo-glucose) is associated with dextrose, occurring in some instances even in larger quantities than the latter.

Sucrose (saccharose or cane-sugar) is found rather widely distributed, as in the stems of corn, sorghum and the sugar-cane; in roots, as the sugar-beet; in the sap of certain trees, as sugarmaple and some of the palms; in the nectaries and sap of certain flowers as fuchsia, caryophyllus and some of the Cactacex; in seeds, as almond and chestnut, and in various fruits, as figs, melons, apples, cherries. In some plants, as in sugar-cane, the yield is as high as 20 per cent. It crystallizes in monoclinic prisms or pyramids and forms insoluble compounds with calcium and strontium.

Maltose is found in the germinating grains of cereals (see malt) ; it forms colorless, needle-shaped crystals resembling those of dextrose, and forms compounds with calcium, strontium, barium and acetic acid.

Trehalose occurs in some fungi, as ergot and Agaricus muscarius-the latter containing as much as Io per cent. in the dried plant.

Mannitol occurs in the form of needles or prisms and is found in the manna of Fraxinus ormus to the extent of 90 per cent. It is also found in some of the Umbelliferæ, as Apium graveolens, some of the Fungi and seaweeds, and is rather widely distributed.

Dulcitol, which is closely related to mannitol, is found in Euonymus europaus and in most of the plants of the Scrophulariaceæ.

Gentianose occurs in the root of Gentiana lutea.

The alkaloids probably arise in the protoplasm. Later they appear in the cell-sap in combination with various plant acids, as malic, tannic and others, and may be precipitated by the so-called alkaloidal reagents. They occur in greatest amount in those cells which are in a potential, rather than an active condition, being associated with starch, fixed oils, aleurone grains, and other reserve products, in the roots, rhizomes and seeds. They are found in fruits in greatest amount during the development of the seed, but after the maturing of the latter they slowly 
disappear, as in poppy and conium. The occurrence of alkaloids in the walls of the cells of certain plants, as in nux vomica, is probably due to their imbibition by the wall as a result of pathological changes in the cell (p. 437).

Many of the alkaloids which have been isolated by chemical means are in the nature of decomposition products of those naturally occurring in the plant, as certain of the alkaloids of tobacco, tea, coffee, cinchona, opium, etc. The alkaloids are of more frequent occurrence in the dicotyledons than in the monocotyledons, and are rather characteristic for certain groups, as those of the genera Strychnos, Cinchona, Erythroxylon, Papaver, etc.

While the microchemical study of the alkaloids requires considerable technic, still, in certain drugs, their detection is quite simple, as in nux vomica, strophanthus and hydrastis (Fig. 292).

The glucosides, like the alkaloids, are also probably formed in the protoplasm. They are compounds of glucose and other principles and may be classed as reserve products. In some instances they readily separate out in the plant cell, as hesperidin; while others give characteristic color-reactions, as crocin, salicin and coniferin, but in most instances they are with difficulty detected by microchemical means.

Gluco-alkaloids represent a class of compounds intermediate between the alkaloids and glucosides, possessing characteristics of each. To this class belongs achilleine, found in various species of Achillea, and also solanine, found in a number of species of Solanum. (See pages 373-375.)

Cell-sap Colors.-The majority of the other color-substances found in the higher plants besides the green and yellow principles previously mentioned occur in solution in the cell-sap, and may be in the nature of secondary substances derived from the plastid pigments, or they may be produced directly by the protoplasm. Upon making sections of the tissues containing cellsap color-substances, not infrequently strikingly contrasting colors are observed in contiguous cells; as in the petals of the poppy and petals of certain lilies, where we find some cells of a deep purple color, others of a deep red and still others of intermediate shades. 
These substances are easily extracted with water or dilute alcohol and are all more or less affected by certain chemicals (many of which occur naturally in the plant), such as citric acid, oxalic acid, salts of calcium, iron, aluminum, etc.

A number of plant pigments of this class are used as indicators in volumetric chemical analysis, their use in this connection being dependent upon their sensitiveness to acids and alkalies. The fact that they respond to iron salts, that is, give a blue ur green reaction with these salts, would indicate that they are associated with tannin or that they are tannin-like compounds, as has been supposed by some writers, but they behave very differently from tannin toward other reagents, such as organic acids, alkalies, lime water and solution of alum.

An examination of the color-substances of a large number of plants shows that the flower color-substances are distributed in all parts of the plant. For example, the flower color-substance of the rose occurs in the leaves and prickles as well as in the petals.

The color-substance in the root of the radish closely corresponds to that in the flowers, while the one in the grains of black Mexican corn corresponds to that in corn. silk.

The cell-sap color-substances are usually found in greatest amount at the tips of the branches, this being well marked in the foliage of the rose, and may be said to be rather characteristic of spring foliage. Not infrequently in the purple beech the young leaves will be of a distinct purplish-red color and almost entirely free from chlorophyll, suggesting a correspondence in position and color to a flower.

Color in Autumn Leaves.-The coloring matters in both spring and autumn leaves closely resemble the cell-sap colorsubstances of flowers, although it is the spring leaves which give the most satisfactory results when examined. The fact that in the autumn leaves there is little or none of the plastid pigment present would point to the conclusion that the color-substances occurring in these leaves are in the nature of by-products and of no further use to the plant. Of course in the case of autumn leaves we know that these products cannot be further utilized by the plant, and for this reason we are justified in regarding them as waste products. 
So-called White Colors.-The so-called white colors in plants do not properly belong to either class, but may be said to be appearances due rather to the absence of color, and depending upon the reflection of light from transparent cells separated by relatively large intercellular spaces containing air. In other words the effect produced by these cells may be likened to that produced by the globules in an emulsion. The white appearance is most pronounced in the pith cells of certain stems, where on the death of the cells the size of the intercellular spaces is increased and the colorless bodies in the cells as well as the walls reflect the light like snow crystals.

Calcium oxalate is found in many of the higher plants, and in the alga and fungi as well; while in the mosses, ferns, grasses and sedges it is seldom found. It occurs in plants in crystals of either the monoclinic or tetragonal system (Figs. 281, 282). The crystals dissolve in any of the mineral acids without effervescence and their identity is usually confirmed by the use of dilute hydrochloric acid. The crystals of the monoclinic system are rather widely distributed, while those of the tetragonal system are less frequent in their occurrence, being found in species of Allium, Tradescantia and Begonia, in Paulownia imperialis and in the Cactacex. The crystals belonging to the monoclinic system include a number of forms, as follows: (I) Rosette aggregates, or what are commonly termed rosette-shaped crystals; (2) prisms, pyramids and elongated or irregular hexagonal-shaped crystals; (3) crystal-fibers; (4) raphides; (5) cryptocrystalline crystals and (6) membrane crystals.

Rosette aggregates of calcium oxalate consist of numerous small prisms and pyramids, or hemihedral crystals more or less regularly arranged around a central axis, and have the appearance of a rosette or star (Fig. 28I, $A$ ). The development of these aggregates may be readily observed in the stem of Datura stramonium. Crystals of this class are more widely distributed than any of the others, and are found in a number of drugs. (See chapter on Powdered Drugs.)

Monoclinic prisms and pyramids are also widely distributed and are frequently so modified in form that they are of an elongated or irregular hexagonal shape (Fig. 28I, $C, E$ ). The 
crystals of this group are sometimes mistaken for silica, owing to the fact that in some instances the lumen of the cell is completely filled by the crystal, and the inner wall having the contour of the crystal, it is impossible to determine whether the crystal is affected by the use of hydrochloric acid. It should be stated in this connection that silica never occurs as a cell-content in sharp, angular crystals, but either in more or less ellipsoidal or irregular hollow masses, or in somewhat solid, irregularly branching masses.

Crystal Fibers.-In quite a number of drugs a single monoclinic prism occurs in each of the parenchyma cells adjoining the sclerenchymatous fibers, and to this single longitudinal row of superimposed cells the name crystal fiber has been applied (Fig. 282, $B$ ).

Raphides are groups of needle-shaped crystals which are found in various plants (Fig. 28I, $B$ ). These have been mistaken by several observers for calcium phosphate. Calcium phosphate, however, occurs in plants either in solution or in combination with protein substance. The cells containing raphides are long, thin-walled and contain sooner or later a mucilage, which arises from the cell-sap and behaves with reagents much like cherrygum. The cells are either isolated or occur in groups placed end to end, as in Veratrum viride.

Cryptocrystalline crystals are exceedingly small (about 0.2 to Io $\mu$ in diameter), deltoid or arrow-shaped, and so numerous as to entirely fill the parenchyma cells in which they occur, giving the cells a grayish-black appearance which readily distinguishes them from other plant cells (Fig. 28I, D). It has been supposed that they are tetrahedrons, but they are probably hemihedral forms of monoclinic crystals, inasmuch as monoclinic prisms occur in neighboring cells in the same plant or drug, as in stramonium, quassia, etc.

Membrane Crystals.-There are several forms of crystals which may be included in this group. The so-called Rosanoff crystals consist of rosette aggregates attached to inward-protruding walls of the plant cell. These, however, do not concern us so much as the large monoclinic crystals which have a membrane surrounding them. The crystal first appears in the cell-sap and 
then numerous oil globules appear in the protoplasm around it; later some of the walls of the cell thicken and grow around the crystal, which they finally completely envelop, as in Moraceæ.

\section{COMPOSITE BODIES.}

Aleurone or protein grains are made up of protein-crystalloids, globoids and a ground mass, the whole being enclosed by a membrane-like material (Fig. I22, $D$ ). Calcium oxalate crystals may, or may not, be present; when they do occur, they are of special value in the study of the plants in which they are found, as in the fruits of the Umbelliferæ.

The aleurone grains arise in the cell-sap, usually in that of seeds; the calcium oxalate, if present, separates first; then the globoids, which are small globular bodies composed of the double phosphate of calcium and magnesium, appear; after which the crystalloids arise; and finally, from the mother liquor, the ground mass separates, the whole becoming enclosed in a membrane.

Aleurone grains may be studied by taking advantage of the difference in solubility of the substances composing them. The membrane is a protoplasmic membrane and, while soluble in water, remains intact on examining sections in any of the fixed oils, as cotton-seed oil. Usually seeds which contain aleurone are rich in fixed oils, and if this oil is first removed by placing fresh sections in alcohol, or alcohol and ether, the subsequent study is facilitated. If the sections thus treated are mounted in water, the membrane gradually dissolves, leaving the crystalloids, globoids and calcium oxalate. On adding a O.I to I per cent. solution of either sodium or potassium hydrate, the crystalloids dissolve, the globoids and calcium oxalate crystals remaining unaffected. The globoids may be dissolved by the use of a I per cent. acetic acid solution, or concentrated solutions of ammonium sulphate or monopotassium phosphate. The calcium oxalate remaining may then be treated with hydrochloric acid in the usual way.

\section{AMORPHOUS SUBSTANCES.}

Cystoliths.-Occasionally cells are found among the parenchyma or in the inner row of the epidermal cells on the upper side 
of the leaf, the walls of which form an inward protrusion into the cell and become impregnated with and encrusted by calcium carbonate, giving rise to more or less stalked bodies known as cystoliths (Fig. 22I). The calcium carbonate dissolves on the application of acetic acid, leaving a core which responds to the tests for cellulose. Cystoliths are not of common occurrence, being found with but few exceptions in the two families Acanthaceæ and Moraceæ, and in a few species of the Cucurbitaceæ. In the leaves of the cultivated rubber plant the cystoliths have long stalks, whereas in cannabis indica (Fig. 279), they are sessile.

Tannin and Tannoids.-Tannins are astringent principles which belong to the class of phenol acids and give blue or green precipitates with iron salts. The tannoids, in addition, precipitate albuminous compounds, and when applied to animal hides convert them into leather. These principles are widely distributed, occurring dissolved in the cell-sap, in parenchyma cells or in distinct reservoirs or vessels, and vary in amount from I per cent. or less to as high as 70 per cent. in Chinese galls. Tannin occurs in relatively large amount in the following families: Anacardiaceæ, Betulaceæ, Cornaceæ, Ericaceæ, Fagaceæ, Geraniaceæ, Hamamelidaceæ, Lythraceæ, Leguminosæ, Myrtaceæ, Plumbaginaceæ, Polygonaceæ, Rosaceæ, Rubiaceæ, Salicaceæ, Saxifragaceæ and Filices. It not only occurs in the normal cells of plants but also in the excrescences known as galls, which are produced by the sting of various species of the insects Cynips. and Aphis.

The following microchemical reagents are used in the study of the tannins and tannoids: Carbonates of the alkalies, chromic acid, cupric acetate, iron acetate, lime water, methylene blue, potassium dichromate, sodium wolframate, ammonium molybdate, bromine water.

Mucilages and Gums.-By the terms mucilages and gums are meant those substances which are soluble in water, or swell very perceptibly in it, and which, upon the addition of alcohol, are precipitated in the form of a more or less amorphous or granular mass. Mucilage originates in the plant as a cell-content, or as a modification of the wall. In the former case it arises as a 
product of the protoplasm, or it may be a disorganization product of some of the carbohydrates of the cell-contents. When it arises through modification of the wall it is spoken of as "membrane mucilage" (Fig. 99), and owes its origin to several causes: either to a secondary thickening of or an addition to the cell wall, or a metamorphosis of it, at least in part. In the latter case it
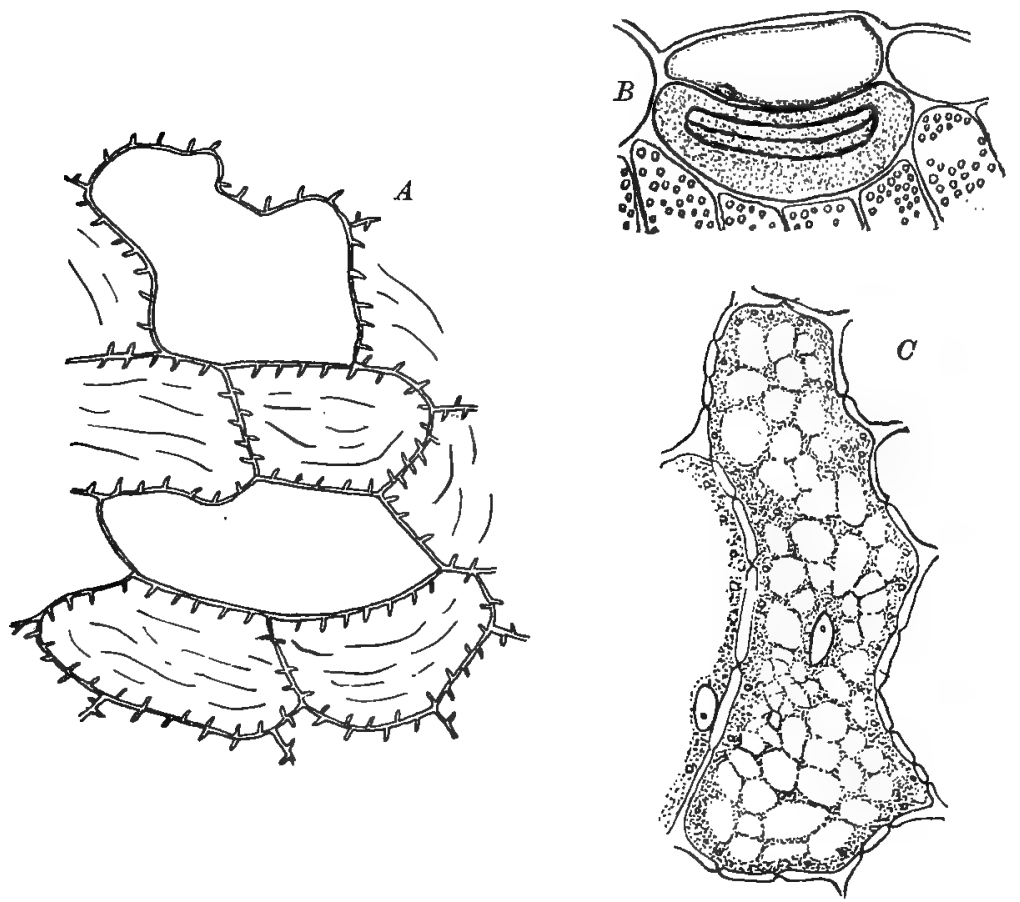

Fig. 98. Cell-content mucilage in sub-epidermal cells of Viola tricolor: A, surface view of portion of petal, the cells without marking being above the mucilage-cells; $B$, transverse section of leaf showing epidermal cell and sub-epidermal mucilage-cell beneath it; C, surface view of a sub-epidermal mucilage-cell.

may arise either as a disorganization product of the primary wall, or of the subsequent lamella making up the walls of the cells of the pith, medullary rays, parenchyma and other tissutes, as in Astragalus gummifor (Fig.274), or it may arise as an intercellular substance.

The following is a classification of some plants, based upon the origin of the mucilage which they contain: 
A. Cell-content Mucilage: Tuber of Orchis sp. (salep); rhizome of Agropyron repens; bulb of Urginea maritima; bulb of Allium sp. (onion, garlic); stem, leaf and elements of flower,
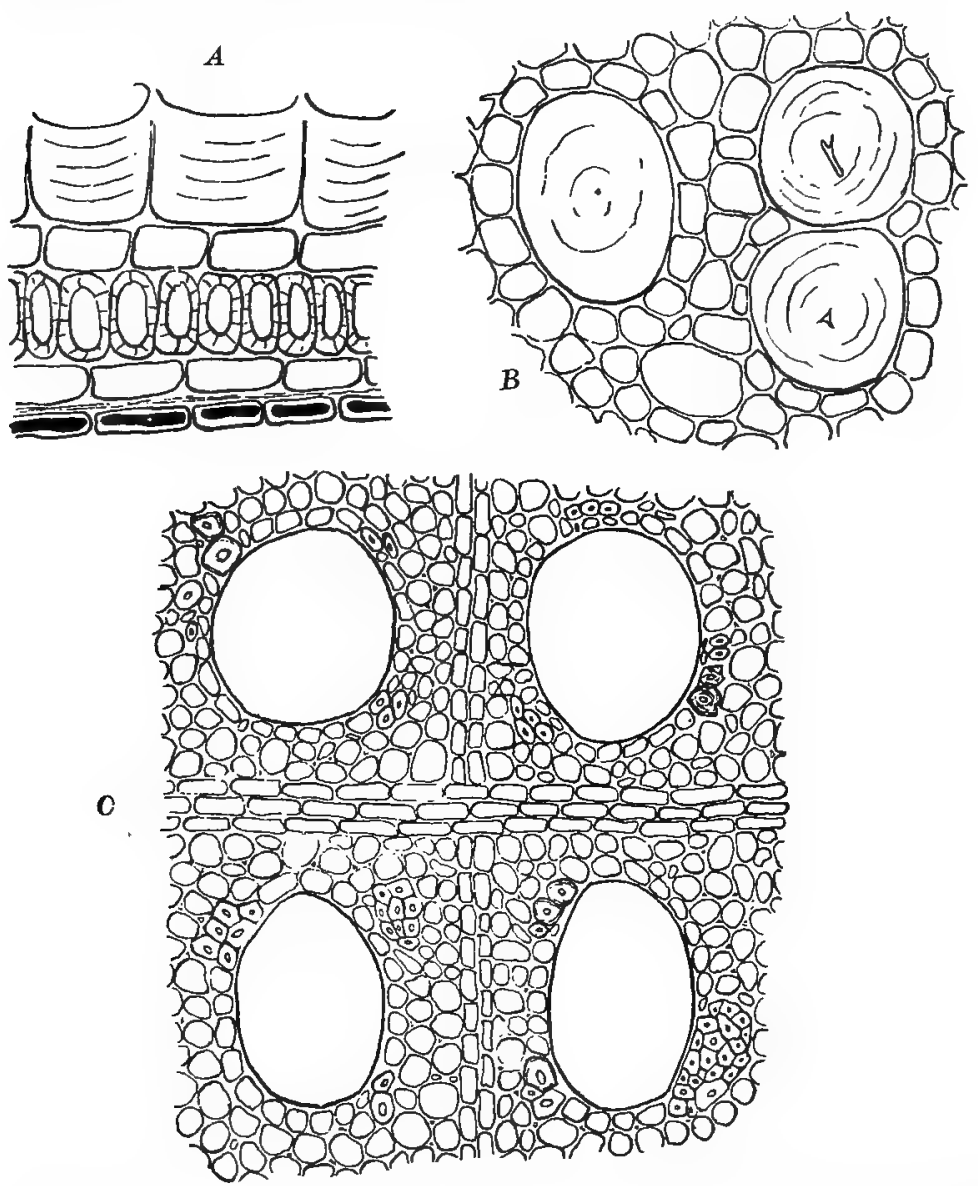

Fig. 99. Cell-wall mucilage. A, transverse section of seed-coat of flaxseed treated with water, showing the swelling of the mucilaginous layer beneath the cutin; B, section of Althæa root showing three large mucilage-cells; C, transverse section of eln bark showing four large mucilage-cells.

excepting stamens, of Viola tricolor; flower-stalls of Hagenia abyssinica; pulp of fruit of Musa paradisiaca (banana) ; succulent plants, as aloe, etc. (See Fig. 98.) 
B. Cell-membrane Mucilage. $a$. Secondary thickening of wall: Root of Althaa officinalis; bark of Cinnamomum sp.; bark of Rhamnus Frangula; bark of root of Sassafras officinale; inner bark of Ulmus fuli'a; leaves of Barosma betulina, and $B$. crenulata; seed-coat of Cydonia vulgaris; seed-coat of Linum usitatissimum; seed-coat of Sinapis alba, and Brassica nigra. b. Metamorphosis of Cell wall: I. Pith and medullary-ray.cells; Astragalus sp., yielding tragacanth. 2. Parenchyma cells of wood and bark; cherry gum, yielded by some of the Amygdal-
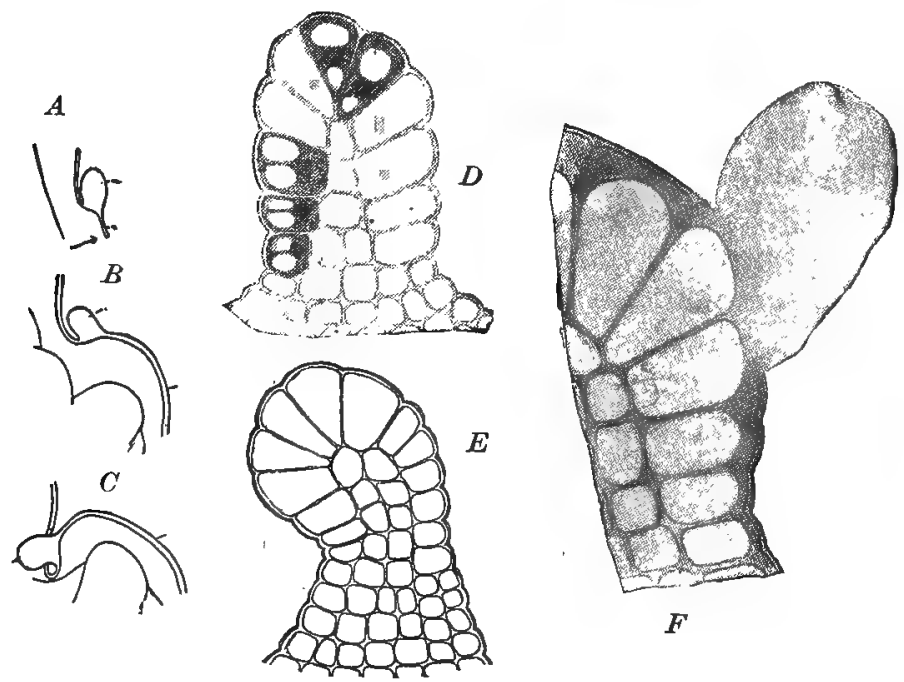

FIG. roo. A, B, C, successive stages in the development of the mucilage hairs or glands on the lobes of the leaves of Viola tricolor: D, young secretion hair showing some of the cells with large nuclei and several vacuoles; $E$, mature hair; $F$, gland showing mucilaginous layer beneath the cutin and the protrusion of a portion of the mucilage through the broken wall.

aceæ. 3. Various cells of the bark; Acacia Senegal, yielding gum arabic. 4. Primary wall as intercellular substance; thallus of Chondrus crispus (Irish moss). (See Figs. 99, roo, 274.)

C. Glandular Hairs (Drüzenzotten) : Leaf and calyx of Viola tricolor (Fig. IOo) and leaves of Coffea arabica (coffee) and of Prunus avium.

The origin of mucilage may be satisfactorily studied in the fresh tuber of salep and in the root of althæa-in the former as a cell-content mucilage, and in the latter as a cell-wall mucilage. 
The mucilages are further distinguished by their behavior toward reagents; those which are colored blue by chlor-zinciodide, and are soluble in ammoniacal solution of cupric oxide, are known as cellulose mucilages. To this class belong the mucilages of the tuber of salep and the seeds of cydonium. Most of the other mucilages, particularly the pectose-mucilages, are colored by alcoholic and glycerin solutions of the basic aniline dyes.

Mucilage which occurs in cells containing raphides is stained by corallin, which is not usually the case with the other mucilages.

Oils, resins and their associated products, like the mucilages and tannins, are formed in the plant either as a result of the activities of the protoplasm, or by reason of abnormal or pathological changes in some of the constituents of the cell. The oils may be divided into two principal classes, namely, the reserve or fixed oils, which are more or less intimately associated with the protoplasm in fruits and seeds; and the volatile oils which occur in special secretion cells or special canals. The former are large parenchyma cells, the walls of which are not infrequently suberized, and are found in rhizomes, as of calamus (Fig. IOI, $B$ ) and ginger; in barks, as sassafras (Fig. 236) and cascarilla ; in fruits, as capsicum, cubeba (Fig. 250), piper and cardamomum. Oil secretion canals are cavities formed either as a result of the enlargement of the intercellular spaces, due to the separation of the cells, or as a result of the disintegration of a number of cells. The former are spoken of as being SCHIZOGENous in origin, and the latter as Lysigenous. These terms are also used to designate similar reservoirs holding mucilage, gum-resins and other products. The schizogenous reservoirs are of more common occurrence, and are found in inula, arnica rhizome, caryophyllus and the umbelliferous fruits (Figs. 244-248) and various leaves, as eucalyptus and pilocarpus (Fig. 257). The volatile oils are characteristic of some of the largest families of plants, as the Compositæ, Labiatæ, Rutaceæ and Umbelliferæ.

The oils, both fixed and volatile, are insoluble, or nearly so, in water; but are soluble in ether, carbon disulphide, chloroform, benzin, benzol and acetone. Most of the volatile oils and a few of the fixed oils are more or less soluble in alcohol. They are colored brownish or brownish-black with osmic acid. The volatile 
oils are stained red by alcoholic solutions of alkanet, and some of them by certain of the aniline dyes, as fuchsin. The distinctive test for the resins is that when treated with concentrated aqueous solutions of copper acetate they acquire a green color. They are likewise stained by many of the aniline dyes. The reserve or fixed oils are liberated as oily globules on treatment of sections with sulphuric acid or concentrated chloral solution.

The volatile oils are not infrequently associated with other substances of the plant cell in varying proportions, as resins, gums, cinnamic and benzoic acids. 'Those products which consist chiefly of oil and resin are known as OLEO-RESINS, and include turpentine and copaiba ; those consisting chiefly of gum and resin and containing but little volatile oil, are known as GUM-RESINS, and include ammoniac, asafetida, galbanum and myrrh; oleo-resins associated with aromatic acids are known as BALSAMs, as balsam of tolu, balsam of Peru, storax and benzoin, which latter is usually called a balsamic resin.

The enzymes or ferments form a group of proteid substances which bring about certain decompositions in the food substances in plants previous to their assimilation, and are of quite general distribution in both lower and higher plants. They have received different names according to the class of substances which they decompose. Thus, those acting upon starch in changing it to sugar are known as DIASTASES. Those which change cane sugar into dextrose are known as INVERTASES (or invertins), while those which act on proteids are called PROTEOLYTIC.

One of the interesting properties of the ferments is that in comparison with the amount of ferment employed the product formed through its influence is very large. Thus it is stated that diastase is able to hydrolize 10,000 times its own bulk of starch. Results of this kind are considered to be due to a catalytic action of the ferments, i.e., their power of inducing chemical reactions by their mere presence without themselves entering into the products formed. The ferments require specific temperatures for their action, as, for example, emulsin or sinaptase, which decomposes a number of the glucosides at a temperature of $35^{\circ}$ to $40^{\circ}$ C., while diastase, the ferment of germinating seeds, requires a somewhat higher temperature, namely, $50^{\circ}$ to $70^{\circ} \mathrm{C}$. 
While some of the vegetable ferments have been isolated and are prepared on a commercial scale, as diastase and the peptic enzyme papain found in the latex of Carica papaya, in other cases the ferment-producing organisms themselves are used in a number of industries involving fermentation processes, as the yeast-plants and certain of the molds and bacteria.

The microchemical study of the ferments is attended with certain difficulty on account of the lack of specific reagents for their detection. The most that can be clone is to study the products formed by their action upon certain other constituents of the cell.

Enzymes may be divided into two classes according to whether they require oxygen or water for their reaction with other substances. (I) The former are called oxidase enzymes, and are rather limited in number, and include laccase, found in the lacquer trees, and those which produce nitric fermentation in nature. (2) The latter or hydrolytic enzymes include diastase, which acts on starch, changing it into dextrose; inulase, which acts on inulin, producing levulose; pectase, acting on pectin, producing vegetable jellies; emulsin or sinaptase, which decomposes amygdalin, arbutin, salicin and other glucosides; myrosin, which acts on the glucoside sinigrin (potassium myronate), producing the essential oil of mustard, and papain the proteolytic enzyme of Carica papaya.

EXAMINATION OF CELL-CONTENTS.

\begin{tabular}{|c|c|c|c|}
\hline \multirow{2}{*}{ PKOTOPLASMIC. } & \multicolumn{3}{|c|}{ NON-PROTOPLASMYC. } \\
\hline & Crystalline. & Crystalloidal. & Amorphous. \\
\hline $\begin{array}{ll}\text { I } & \text { Cytoplasm } \\
2 & \text { Nucleus } \\
3 & \text { Plastids }\end{array}$ & $\begin{array}{ll}4 & \text { Calcium Oxalate } \\
5 & \text { Sugars } \\
6 & \text { Alkaloids }\end{array}$ & $\begin{array}{ll}7 & \text { Starch } \\
8 & \text { Inulin } \\
9 & \text { Protein Crystal- } \\
& \text { loids }\end{array}$ & $\begin{array}{l}\text { Io Mucilage } \\
\text { I I Tannin } \\
\text { I } 2 \text { Resin } \\
\text { I3 Oil }\end{array}$ \\
\hline
\end{tabular}

I, 2 and 3 have characteristic appearance (see Frontispiece). 4. Crystals of characteristic shape, soluble in hydrochloric and insoluble in acetic acid. 5. Crystalline in fresh material treated with alcohol. The glucoses give a reddish precipitate with Fehling's solution. 6. Concentrated sulphuric acid gives: either a distinct color reaction, as with strophanthus (p. 43I), or the sep- 
aration of crystals, as in hydrastis (Fig. 292). 7. Blue with dilute iodine solution, except the dextrin starches, as in mace, which are colored red. 8. Sphere-crystalloids in fresh material treated with alcohol. 9. (See page I67.) Io. Colored blue with alcoholic solutions of methylene blue. II. Reddish-brown with copper acetate solutions. I2. Green with copper acetate solutions. I3. Separation in the form of large globules on the application of sulphuric acid or solution of chloral hydrate. The essential oils are more soluble in alcohol than the fixed oils, which are usually only completely removed from the cells by the use of ether or a similar solvent.

\section{THE CELL WALL.}

Origin and Composition.-The cell wall is formed by the protoplasm, and varies in composition at different stages of the growth of the cell, and according to the various functions it has to perform.

In order to thoroughly understand the nature and composition of the cell wall, it is necessary to study the origin and formation of new cells. Growth of the plant is attended not only by an increase in the size of the cells, but by the division of these new cells are also formed. Cells that have the property to divicle and form new cells are known as meristematic cells and constitute the MERISTEM. The new and dividing walls resulting from the division of the cells consist of a number of substances. When a cell divides the two daughter protoplasts which result from the division of the nucleus and cytoplasm are separated by the formation of a new wall between them (Fig. 94, IO). The first layer formed is apparently different from the subsequent layers and is known as the middle plate or MIDDLE LAMELLA. This layer is soluble in, or readily attacked by, solutions of the alkalies or solutions containing free chlorine. It is insoluble in sulphuric acid, and readily stained by the aniline dyes. While usually more or less permanent, this middle plate may be finally absorbed, as in the secreting hairs of kamala, or it may be changed into mucilage, as in chondrus, or transformed into pectin compounds, as in fleshy roots and fruits. 
To this middle plate is added on either side by the newly formed protoplasts a layer of substance closely resembling cellulose, this constituting the PRIMARY MEMBRANE or primary lamella.

Still other layers may be added, consisting of one or more of the following substances: cellulose, or some modification of it; wax, silica or calcium oxalate, these layers constituting what may be termed the SECONDARY LAMELLA.

Kinds of Walls.-Cellulose in its various modifications constitutes the greater proportion of the cell wall. The cellulose making up the cotton fiber may be said to be the typical cellulose, and is known as "cotton cellulose." It is soluble in copper ammonium sulphate solution; is colored blue with chlor-zinc-iodide solution or iodine and sulphuric acid, and is stained by acid phenolic dyes, as alizarin, if previously treated with basic mordants, as basic salts of aluminum, etc.

According to their origin in the plant, or their behavior toward reagents, the cellulose walls may be divided into the following groups: (I) Lignocellulose walls; (2) protective cellulose walls; (3) reserve cellulose walls; (4) mucilage cellulose walls, and (5) mineral cellulose walls.

Lignocellulose walls are composed of trute cellulose and a non-cellulose (the so-called lignin or lignone), these constituting the woody (so-called lignified) portion of plants and, in some instances, also the bast portion of the bark. The lignocelluloses are colored yellow with chlor-zinc-iodide, or iodine and sulphuric acid. On account of their containing in some instances furfurol, coniferin, vanillin, cinnamic aldehyde, benzaldehyde or other aldehydic substances, they give definite color-reactions with certain reagents. They are also stained by the aniline dyes, as fuchsin. safranin, gentian violet, aniline blue, methylene blue, etc.

A 2 per cent. phloroglucin solution, used in conjunction with hydrochloric acid, gives a reddish-violet color with the lignocelluloses, although there are some celluloses of this class which do not respond to this test, as flax (the bast fibers of Linum); while in other plants phloroglucin may occur as a constituent of the cells.

Aniline hydrochloride with hydrochloric acid and aniline sulphate with sulphuric acid produce a golden-yellow color in cell walls containing lignocelluloses. 
Protective cellulose walls are composed of mixtures of lignocellulose and oils and waxes, and frequently contain in addition tannin, vanillin and other compounds. In the cuticle or epidermis of leaves and green stems, the cellulose is associated with a fatty compound known as cutin (or cutose), while in the cork of stems and roots it is combined with suberin (or suberose). This class of celluloses is distinguished from cotton cellulose and lignocellulose by being insoluble in sulphuric acid.

Reserve cellulose walls are those found in various seeds, as in coffee, date, nux vomica, etc. They behave toward reagents much like the true celluloses.

Mucilage cellulose walls consist of cellulose and mucilage and are found in all parts of the plant, and in the case of seeds are associated with the protective celluloses. They dissolve or swell in water, are colored blue or yellowish with iodine, and are stained with alcoholic or glycerin solutions of methylene blue.

Mineral cellulose walls are composed of cellulose and various inorganic substances, as silica, calcium oxalate or calcium carbonate. These are more commonly found in the cell wall of the lower plants, as Algæ, Fungi and Equisetaceæ. Calcium carbonate also occurs in the cystoliths of the various genera of the Moraceæ and Acanthaceæ (Fig. 22I).

From what has just been said of the chemical composition and structure of the cell wall, it is seen that it consists of lamellæ or layers of different substances, and in no case does it consist of but a single substance; but for convenience we speak of a wall as consisting of cellulose, lignin, or suberin, meaning thereby that the wall gives characteristic reactions for these substances.

In some cells, as in lignified cells, the lamellæ are quite apparent, whereas in other cases the use of reagents, as chromic acid, or chlor-zinc-iodide, is necessary to bring out this structure. The layering which is observed in transverse sections of the cell wall is spoken of as stratification of the wall, whereas the layering observed in longitudinal or tangential sections is referred to as striation of the wall (Fig. 299, B).

Thickening or Marking of Walls.-In the formation of the cell wall each cell appears to work in unison with its neighbors for the building up of the plant. The thickening of the walls 
of the cell is primarily for the purpose of strengthening the walls, but if the walls were uniformly thickened, osmosis, or the transferral of cell-sap from one cell to another, would be hindered. Thus we find that the contiguous walls of the cells are thickened at definite places opposite each other, leaving pores or canals which permit rapid osmosis. The pores thus formed are known as simple pores, and when seen in surface view are somewhat elliptical or circular in outline, and may be mistaken for some of the cell-contents. These thickenings assume a number of forms, which are quite characteristic for the plants in which they are found. They may have the form of transverse or oblique rings, longitudinal spirals, or be ladder-like or reticulate in appearance (Fig. 102). In other instances the thickening of the wall is quite complex, as in the wood of the pines and other Coniferæ (Fig. 103). The thickening, or sculpturing, as it is sometimes called, may not only occur on the inner surface of the wall, when it is spoken of as CENTRIPETAL, but may also take place on the outer surface, when it is known as CENTRIFUGAL; as examples of the latter, may be mentioned the spores of lycopodium (Fig. 278b) and the pollen grains of the Compositæ (Fig. 280).

\section{FORMS OF CELLS.}

Upon examining sections of various portions of the plant, it is observed that not only do the cell-contents and cell wall vary in composition, but that the cells are of different forms, depending more or less upon their functions. Groups of cells which are similar in form and function constitute the various tissues of the plant; and they may be classified, for convenience of study, as follows: (I) parenchyma cells, (2) mechanical cells, (3) conducting cells and (4) protective cells.

Parenchyma.-Under the head of parenchyma are included those cells which are nearly isodiametric and thin-walled, the walls consisting of cellulose lamellæ (Fig. IOI, $A$ ). They may contain both protoplasmic and non-protoplasmic cell-contents. According to the function and nature of contents, three kinds of parenchyma cells are recognized: (a) CHLOROPHYLL-PARENCHYMA or assimilation parenchyma contains numerous chloroplastids and 
occurs in leaves and all green parts of the plant. (b) RESERVE PARENCHYMA occurs in seeds, roots, rhizomes, etc., and contains starch, aleurone grains, fixed oils and other reserve materials. The parenchyma in stems and leaves of various of the orchids,
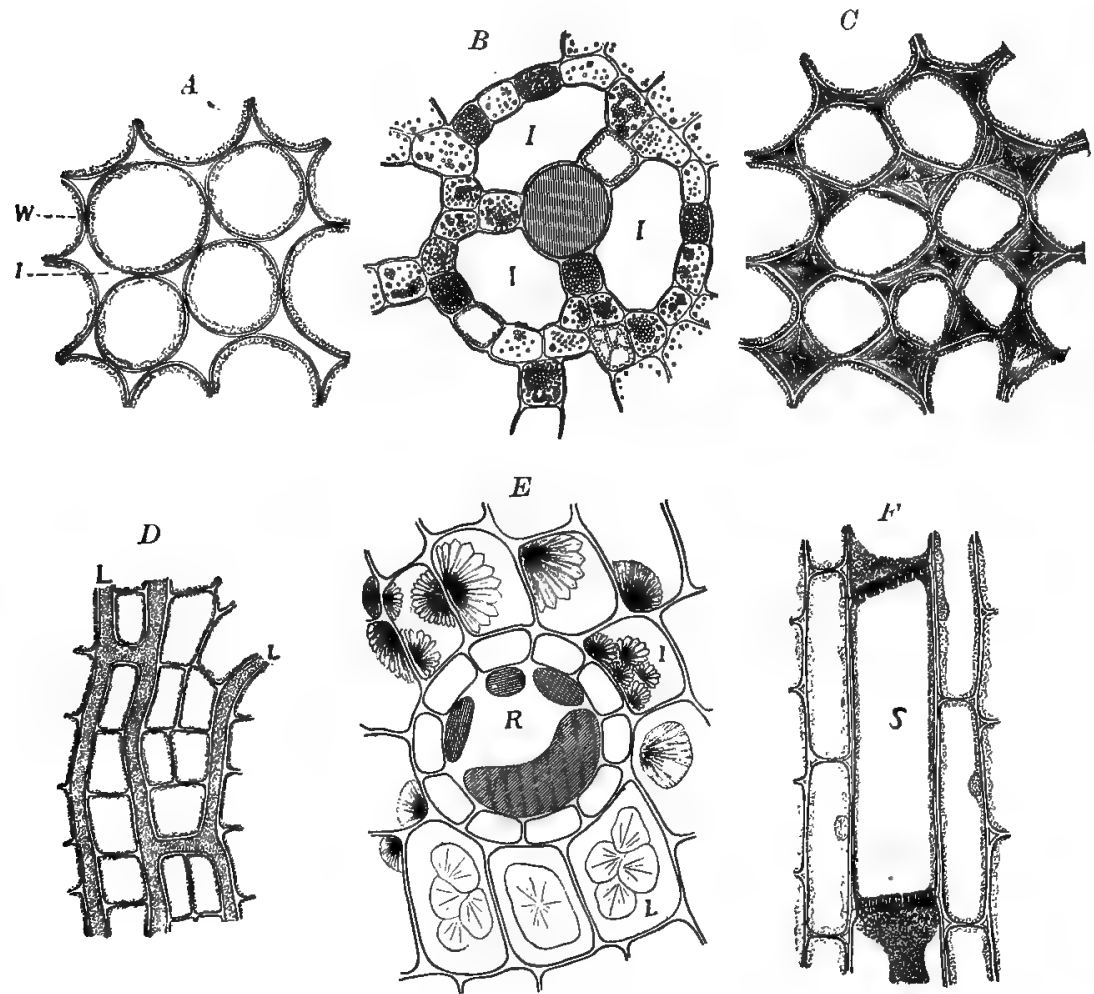

Fig. ror. Forms of cells. A.-Transverse section of the pith of Tradescantia virginica: I, intercellular space; W, cell wall. B.-Transverse section of calamus rhizome showing a large oil-secretion cell, smaller cells containing starch, and large intercellular spaces (I). C.-Transverse section of the stem of Phytolacca decandra showing collenchymatous cells beneath the epidermis. D.-Longitudinal section of taraxacum root showing branched laticiferous tissue (L). E.-Transverse section of pyrethrum root: $R$, oil-secretion reservoir with oil globules; I, cells with sphere-crystals of inulin, such as separate in alcoholic material; $\mathbf{L}_{v}$.cells containing irregular masses of inulin, as found in dried material. F.- Longitudinal section of stem of Cucurbita Pepo: S, sieve-cell with protoplasm-like contents, and transverse walls (sieve plates) showing simple pores.

as well as that of plants of arid regions, which store water, may be included in this group. (c) ConduCting PARENCHyma assists in the transferral of food from one part of the plant to another. 
Besides these forms of parenchyma there are some special kinds which may be mentioned, as the somewhat branching cells in leaves, and in the stems of various marsh plants, as in species of Juncus and Pontederia. In calamus, large intercellular spaces are formed, and these may be mistaken for the cells themselves (Fig. IOI, $B$ ).

Mechanical cells or stereome include all those cells which serve to keep the various parts of the plant in their proper positions one with reference to the other, and which enable it to withstand undue strain and pressure. There are two principal forms of mechanical cells, namely, (a) collenchyma and (b) sclerenchyma.
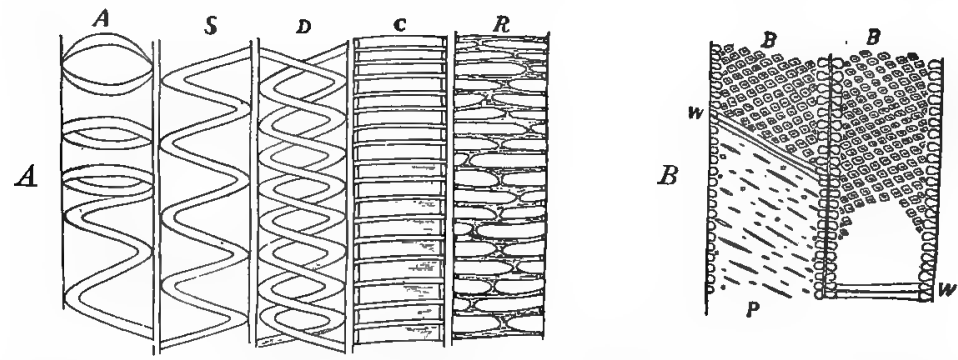

FIg. ro2. Forms of ducts. A.-Longitudinal section of stem of Cucurbita Pepo showing various forms of ducts: $A$, annular; S, spiral; D, double spiral; C, close annular; R, reticulate. B.-Ducts of glycyrrhiza rhizome: W, wall; B, bordered pores; P. oblique simple pores.

The Collenchyma cells are long cells (occasionally $2 \mathrm{~mm}$. long) which are thickened at the angles (Fig. IOr, $C$ ). The walls consist of cellulose, or a modification of it, known as collenchym, and have a silvery or grayish-blue luster. Besides protoplasm these cells occasionally contain starch. They are found directly beneath the epidermis of herbaceous stems, petioles, and the mid-rib of various leaves, and are particularly noticeable at the angles of all stems that are ribbed or angled in transverse section.

Sclerenchyma cells include all of those cells which have more or less uniformly thickened walls composed of lignocellulose and permeated by simple or branching pores. They have a thin layer of protoplasm and relatively large vacuoles, which contain tannin or tannin-like masses, and occasionally calcium oxalate crystals or starch, and in dead cells the lumen or cell-cavity 
contains air. Two kinds of sclerenchyma are recognized: one in which the cells are more or less isodiametric, known as sTone CELLS (short sclerenchyma) (Figs. $30 \mathrm{I}$ and 302); and another in which the cells are elongated, being from 0.5 to $2 \mathrm{~mm}$. long, as a rule, and known as SCLERENCHYMa FIBERS (or long sclerenchyma) (Figs. I04, 299, 300). Of these latter, two kinds are distinguished, chiefly according to their position in the plant, namely, bast fibers and wood fibers (or libriform). Seldom are the wood
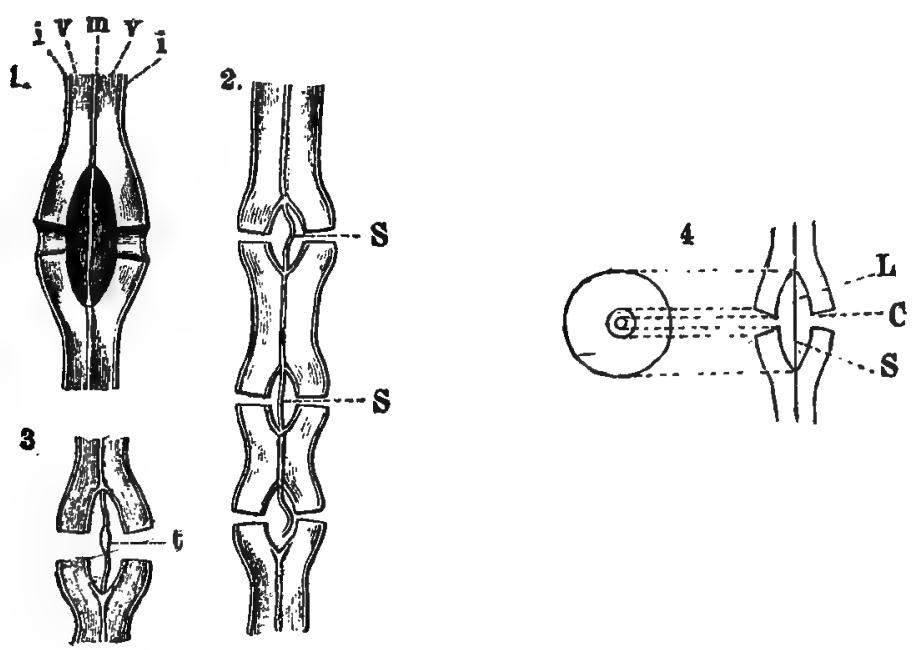

Fig. ro3. Bordered pores of the tracheids of the wood of Abies alba as viewed in Jongitudinal section: $m$, middle lamella; $v, i$, middle and inner layers of walls of contigisous cells; C, pore-canal through which sap passes from one cell to another; $L$, domeshaped cavity of pore; $\mathrm{S}$, separating wall or closing membrane which is usually thickened in the middle.as shown at $t$. In older cells the separating membrane is broken as shown in the lower pore in figure 2. At the right in figure 4 is shown a surface view of a bordered pore, the dotted lines indicating the relation of the circles to the structure of the pore.After Vogl.

and bast fibers in the same plant uniform in structure and composition, as in glycyrrhiza and althæa. On the other hand, they are with difficulty distinguished in monocotyledonous roots, and the term sclerenchymatous is here best employed to include both kinds of cells. In the study of powdered drugs the term sclerenchymatous fiber may be employed with advantage when speaking of wood and bast fibers, as in this condition they are not readily distinguishable. 
Stone cells are usually polygonal, or more or less irregular in outline, sometimes even branching (Figs. 301 and 302). The walls are distinctly lamellated, and they give the characteristic reaction for lignocellulose with phloroglucin or aniline sulphate; occasionally, however, one or more of the walls remain unthickened. The pores are elliptical or circular on surface view.

Bast fibers are sclerenchymatous fibers occurring in the bark and are usually associated with sieve cells. They may, or may not, give a pronounced reaction for lignocellulose with phloroglucin or aniline sulphate. In transverse section they are more or less round or polygonal, depending upon whether they are isolated or in groups. They vary in diameter and length, and also in the thickness of the walls (Figs. I04, 299, 300); while most bast fibers are between $I$ and $2 \mathrm{~mm}$. in length, they may be more than $200 \mathrm{~mm}$. in length, as in Boehmcria nivea. The ends may be more or less obtuse, or drawn out to a fine point; occasionally they are somewhat branched. The pores in surface view are narrow-elliptical and are arranged according to a left-handed spiral. The spiral arrangement of the component elements of the wall is supposed to give strength to the fibers, and, according to Schwendener, they will sustain a weight nearly equivalent to that sustained by wrought-iron and steel.

Bast fibers may be isolated by the use of Schulze's macerating fluid (which is prepared by dissolving a few crystals of potassium chlorate in nitric acid) and moderately heating the solution containing the material either on a slide or in a test tube.

Wood fibers are sclerenchymatous fibers occurring in the wood and are usually associated with trachex. They give a more or less distinct reaction for lignocellulose. They occur more frequently than bast fibers (gentian being one of the few drugs in which they are wanting) but seldom attain the length of the latter. They are not infrequently branched at. the ends, and besides a thin protoplasmic layer, they usually have no other contents than water and air. They frequently have the yellowish color, characteristic of stone cells, and also exhibit a similar lamellation and refraction of the wall (Fig. I04).

Conducting cells or mestome include those cells which are chiefly concerned in the transferral of either crude or assimilable 
food materials. The more or less crude inorganic materials are carried from the root through the woody portion of the stem to the leaves, and from the leaves the products of $\mathrm{CO}_{2}$ assimilation, as well as other plastic substances, are distributed through some

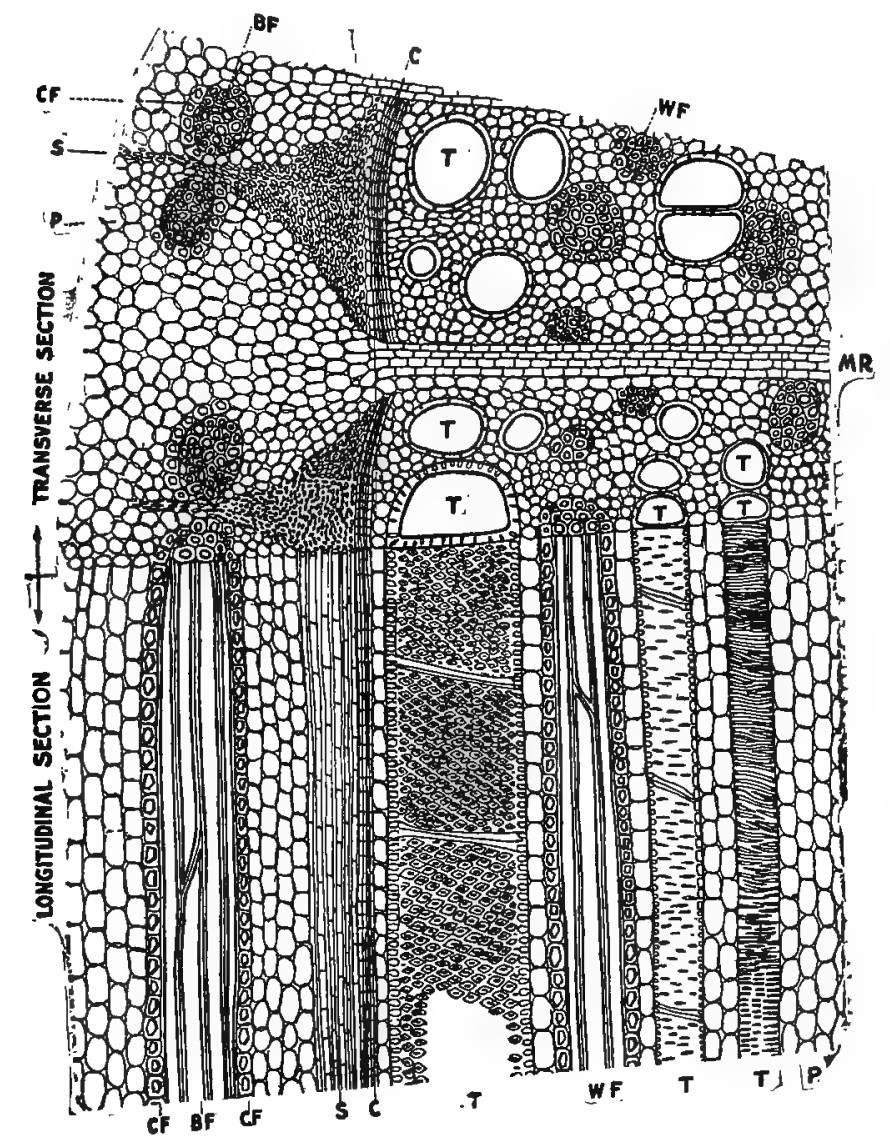

FIG. I04. Longitudinal-transverse section of licorice rhizome including the cambium $P$, parenchyma: T, tracheæ or ducts; WF, wood fibers; C, cambium; S, sieve; CF, crystal fibers; BF, bast fibers; MR, medullary ray.

of the tissues of the bark to other parts of the plant. The tissues or elements of the wood which conduct food materials are of several forms and include tracheæ or ducts, tracheids and conducting parenchyma; and the elements of the bark which transport the 
assimilable materials, comprise the sieve and conducting parenchyma, although there are other elements which sometimes assist these two groups of cells in the work of conduction (Fig. IO4, $T, S)$.

The tracheæ or ducts are formed by the disintegration and removal of the transverse walls between certain superimposed cells, forming an elongated cell or tube, which occasionally retains some of the transverse walls (Fig. I02, $A, B$ ). 'The longitudinal walls are relatively thin and consist of lignocellulose, giving more or less pronounced reactions with phloroglucin or aniline sulphate.

The thickenings of the longitudinal walls of ducts are quite characteristic, several forms being distinguished: Those having
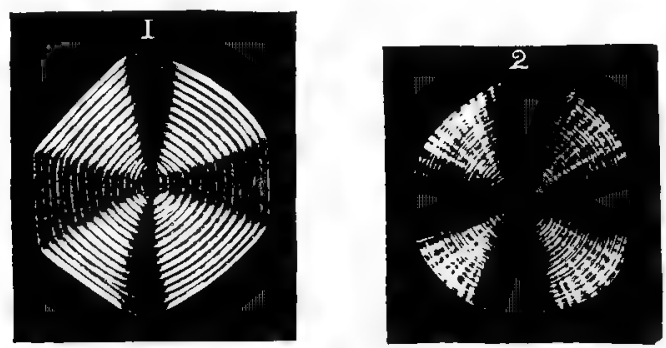

FIG. I05. I, cross section of a bast fiber of Begonia as viewed by means of the micropolariscope. 2, polariscopic view of a sphere-crystal of inulin in Helianthus tuberosus. The crystals are produced by allowing the roots to remain in alcohol for some months.After Dippel.

the thickenings in the form of horizontal or oblique rings are known as ANNULAR DUCTS; those having the thickenings in the form of spirals, which usually run from right to left, are known as SPIRAL DUCTS; those having the thickenings in the form of a reticulation are known as RETICULATED DUCTS, and those with horizontal, disconnected thickenings which occur in parallel lines, resembling a flight of steps, are known as SCALARIFORM DUCTs.

In those ducts in which but few of the transverse walls are obliterated, the walls are marked by both simple and bordered pores, which latter are described under tracheids. Ducts contain water, water-vapor and air; in some cases they contain sugar, tannin, mucilage or resin. 
The tracheids are intermediate in character between ducts and wood fibers, resembling the former in possessing bordered pores (Fig. IO3) and scalariform thickenings; and the latter in being true cells, which are usually elongated and quite thickwalled, the walls giving distinct reactions for lignocellulose with phloroglucin or aniline sulphate.

One of the chief characteristics of tracheids are the BORDERED PORES (Fig. IO3). These differ from simple pores in that the wall surrounding the pore forms a dome-shaped or blister-like protrusion into the cell. On surface view the pores are either circular or elliptical in outline, the dome being circular or, if the pores are numerous and arranged close together, more or less polygonal (Fig. IO2, $B$ ).

The number and distribution of bordered pores in the Coniferæ are quite characteristic for some of the genera, and may be studied in any of the pines, the pores being most numerous in the radial walls.

The sieve (sieve tubes) is distinguished from the other conducting elements in that the walls are thin and are composed of cellulose (Fig. IOI, F). It consists of superimposed elongated cells, the transverse walls of which possess numerous pores which are supposed to be in the nature of openings, permitting of the direct passage of the contents from one cell to the other. This transverse wall, which may be either horizontal or oblique, is known as the SIEve PLATE, and the thin places, as pores of the sieve. The sieve plates are sometimes also formed on the longitudinal walls. When the activities of plants are suspended during the winter, there is formed on either side of the sieve plates a layer of a colorless, mucilaginous substance, known as callus, which has somewhat the appearance of collenchyma, but is colored brownish by chlor-zinc-iodide.

The sieve cells contain an albuminous substance somewhat resembling protoplasm; in some instances starch grains have also been found.

When the activities of the sieve tubes have ceased, they become altered in shape, and are then known as obliterated sieve. In the drying of plants a similar alteration is produced, and for this reason the sieve of vegetable drugs is of this character. 
: Protecting cells include those cells which are located on the outer parts of the plant. The function of these cells is to lessen the rate of transpiration, or the giving off of water; to furnish protection against changes of temperature, and to protect the inner tissues against the attack of insects; they also have a mechanical function (Figs. I06; III, E).

Depending principally upon their composition, these cells may be divided into two classes, namely, epidermal cells and cork cells.

The epidermal cells constitute the outermost layer of the plant. They contain cytoplasm but the plastids in some instances are wanting; in some instances they also contain dissolved coloring principles; and on account of the relatively large amount of water which they contain, they are classed among the important water-reservoirs of the plant.

The outer walls are principally characterized by one or more lamellæ of cutin, these uniting to form a continuous wall. The cutin is often associated with wax, this constituting the bloom of fruits; less frequently such inorganic substances as calcium carbonate, calcium oxalate and silica are present, and not infrequently mucilage is present, as in the walls of certain seeds (Fig. 99, $A$ ).

On surface view the form of these cells varies from nearly isodiametric to oblong; they may also be polygonal or branched. In transverse section their radial diameter is much the shorter. In some instances the inner and side walls are considerably thickened, as in the seeds of a number of the Solanaceæ (Fig. 302, $A$ ).

The epidermis usually consists of a single layer of cells, but may have additional layers underneath forming the HYPODERMIS, as in the upper surface of the leaves of species of Ficus; in some instances the hypodermis undergoes a mucilage modification, as in the leaves of buchu. (See also Figs. 99, $A$; 100.)

Plant Hairs.-The epidermal cells are sometimes specially' modified centrifugally, giving rise to papillæ, to which the velvety appearance of the petals of flowers is due; in other cases this modification is in the form of hairs or trichomes (Figs: IIO, I I $8,283,284$ ). These may be unicellular or multicellular, and in addition the latter may be glandular or non-glandular. Glandular hairs possess a head-like apex, consisting of one or more cells, and they secrete oil, mucilage and other substances (Fig. 285). 
Stomata.-Distributed among the epidermal cells are pairs of crescent-shaped cells having an opening between them, known as a pore or STOMA, which leads to a cavity beneath it. The two
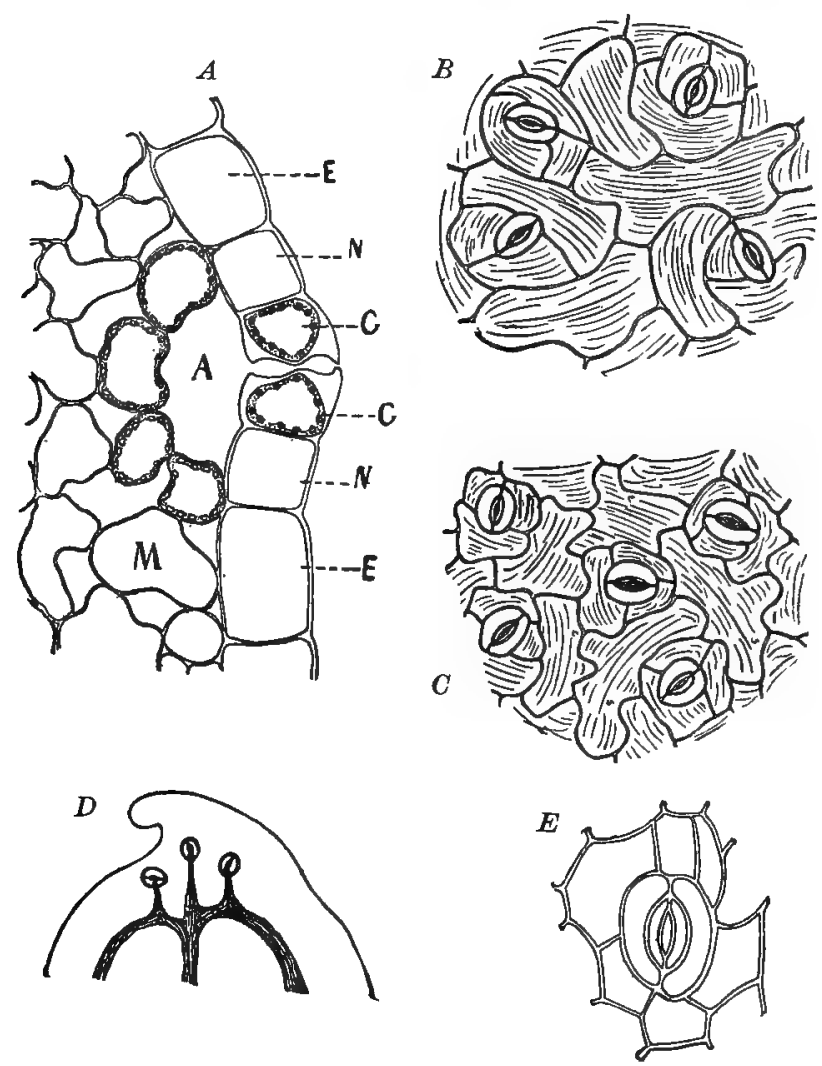

Fig. 106. Stomata and water-pores, A.-Transverse section through lower surface of leaf of stramonium: stoma, with guard cells (G), containing cytoplasm, nucleus and chloroplastids; N, surrounding cells; A, intercellular cavity usually filled with cell-sap or watery vapor; E, epidermal cells; $M$, mesophyll. B.-Surface section of upper surface of leaf of Viola tricolor showing four stomata. C.--Surface section of under surface of leaf of Viola tricolor showing five stomata. D.-A section through the margin of the leaf of Viola tricolor showing a tooth with three water-pores. E.-A water-pore of Viola tricolor in surface section.

contiguous cells are known as GUARD cells (Fig. I06; $G$ ). The adjoining walls of the guard cells are alike in transverse section, but the cells vary in shape in different plants ; they are more or less elas- 
tic, and when the cells are turgescent, as when there is an abundance of water and root pressure is strongest, the contiguous walls of the guard cells recede from each other, forming an opening between the cells, thus permitting the exit of the excess of water taken up by the plant and the exhalation of the oxygen given off during assimilation, as well as the intake of the carbon dioxide used in photosynthesis. The cells beneath the stomata are loosely arranged, there being large intercellular spaces so that carbon dioxide soon finds its way to the cells containing the chloroplastids. On the other hand when the amount of water in the plant is reduced below the normal and the plant shows signs of wilting the guard cells expand and the stoma or pore is closed, thus preventing transpiration or at least reducing it.

The guard cells may be slightly raised above or sunk below the surrounding epidermal cells, the number of the latter being characteristic for certain plants. (Compare Figs. 106, 263, 286.)

In surface view the stomata may be elliptical or circular. They occur in the largest numbers on the blades of foliage leaves, being more numerous on the under surface, except in aquatic plants where they occur only upon the upper surface.

Water Pores.-Near the margin of the leaf and directly over the ends of conducting cells, not infrequently occur stomata, in which the function of opening and closing is wanting, and which contain in the cavity below the opening water and not air, thus differing from true stomata (Fig. I06, $D, E$ ). These are known as WATER PORES, and they give off water in the liquid form, the drops being visible on the edges of the leaves of nasturtiums, fuchsias, roses, etc., at certain times.

Cork cells replace the epidermal cells of roots and stems that persist year after year (Fig. I I $5, K$ ). They differ from the epidermal cells in that the walls are uniformly thickened and on surface view are polygonal in shape. The walls consist of suberin, a substance allied to cutin ; in some instances they also contain lignocellulose, forming cork stone-cells, as in asclepias and calumba (Fig. I98). The young cells may contain a thin layer of protoplasm and a nucleus; they usually also contain brownish tannin, or tannin-like compounds, and occasionally crystals of cerin, or calcium oxalate (Fig. 302, $H$ ). 
Cork not only occurs as a secondary protective layer, but may also arise in other parts of the plant as a result of injury, as in leaves, fruits, stems and tubers. It also arises as a result of the disarticulation of the leaf in autumn.

Lenticels may be described as biconvex fissures in the cork which permit of the easy access of air to the intercellular spaces of the rather loosely arranged cells lying beneath them (Fig. 107). They usually arise as the product of a meristem situated beneath the stomata of the epidermis, the stomata being replaced by them when cork is developed. Several types of lenti-

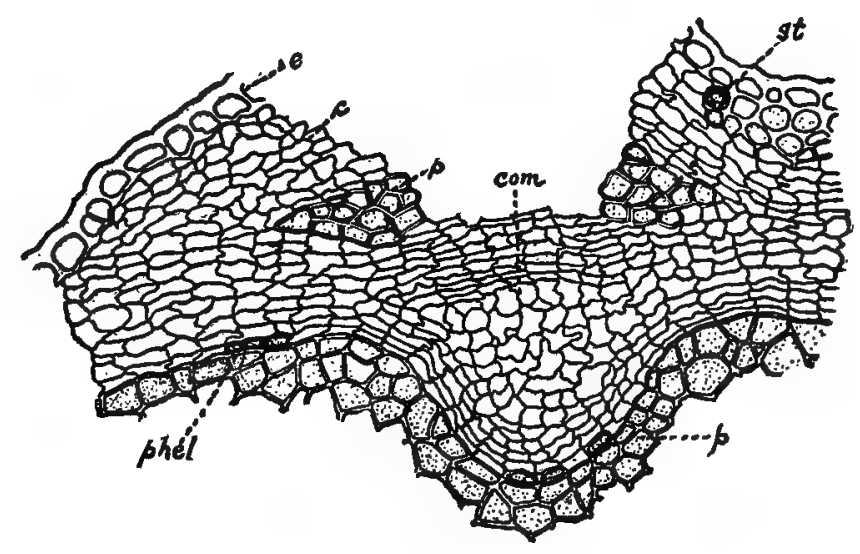

FIG. I07. Section through a secondary lenticel in the bark of Sassafras; e, epidermis; st, stone cells; phel, phelloderm derived from secondary phellogen and having thick lignified wall; p, parenchyma; c, cork; com, complementary cells.-After Weiss.

cels are distinguished. They are quite characteristic and prominent in a number of barks, as those of species of Betula, Prunus, Rhamnus, etc.

Laticiferous or milk tissue occurs in all those plants which emit a milk-juice on being cut or otherwise wounded. The juice may be colorless, as in the oleander; whitish, as in the Ascilepiadaceæ and Apocynaceæ; or yellowish or orange, as in the Papaveraceæ. It contains caoutchouc, oils, resins, mucilage, starch, calcium oxalate and alkaloids as well. The walls are relatively thin and consist chiefly of cellulose. The tissue consists either of single cells of indefinite length, as in the Asclepiadacex, or it 
196 BOTANY AND PHARMACOGNOSY.

\begin{tabular}{|c|c|c|c|c|c|c|}
\hline \multirow{2}{*}{ 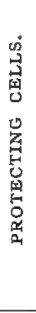 } & 总 & 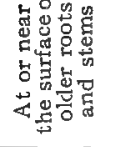 & 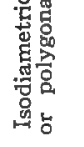 & 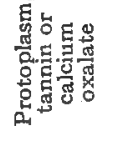 & $\begin{array}{l}\text { 营 } \\
\text { 营 }\end{array}$ & $\begin{array}{l}\text { 总 } \\
\text { : } \\
\text { : }\end{array}$ \\
\hline & 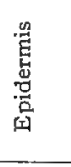 & 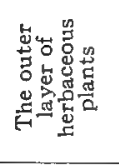 & 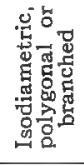 & 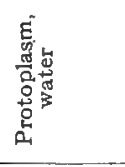 & 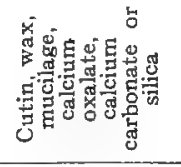 & 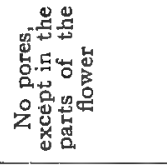 \\
\hline \multirow{3}{*}{ 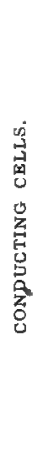 } & 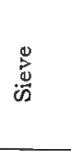 & 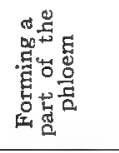 & 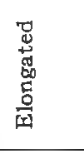 & 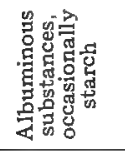 & 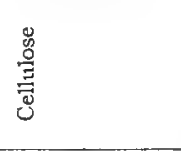 & 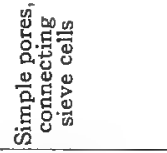 \\
\hline & 悉 & 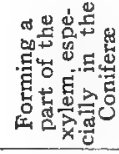 & 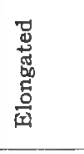 & 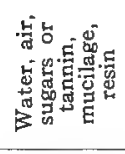 & 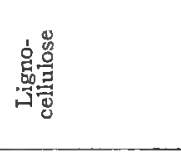 & 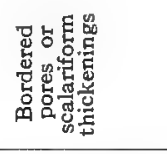 \\
\hline & 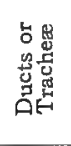 & 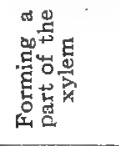 & 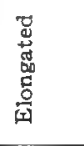 & 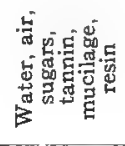 & 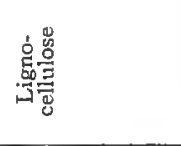 & 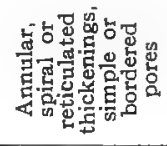 \\
\hline \multirow{3}{*}{ 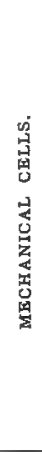 } & 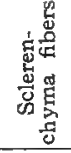 & 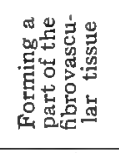 & 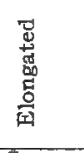 & 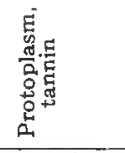 & 总 & 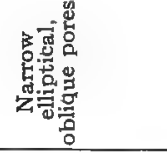 \\
\hline & 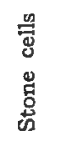 & 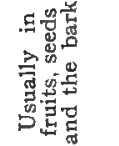 & 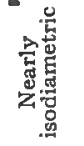 & 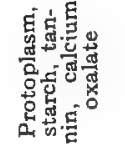 & 递兽 & 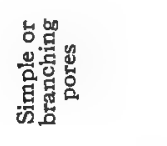 \\
\hline & 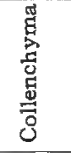 & 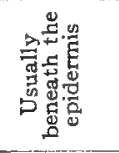 & 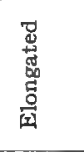 & 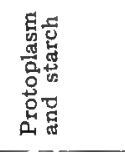 & 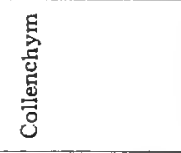 & 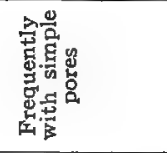 \\
\hline 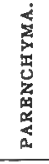 & 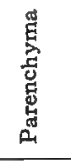 & 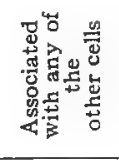 & 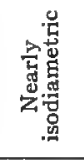 & 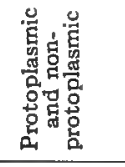 & 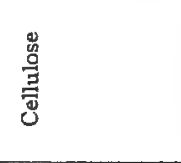 & 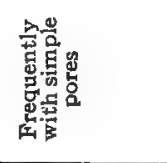 \\
\hline 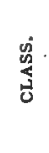 & 思 & 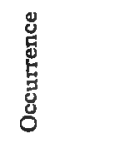 & 芸 & 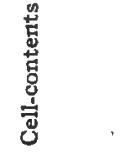 & 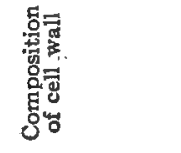 & 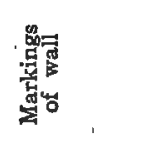 \\
\hline
\end{tabular}


may consist of a more or less branching net-work formed by the anastomosing of a number of cells, as in Taraxacum (Fig. IOI, $D$ ). It is distributed or associated with the sieve in nearly all parts of the plant; in the earlier stages the cells contain protoplasmic cell-contents which later disappear or are with difficulty distinguished from the other substances already enumerated as present in the milk-juice.

Secretion Cells or Canals.-In Sanguinaria there occurs a rudimentary laticiferous tissue, most of the juice being contained, however, in special parenchymatous cells, which may be more or less isolated, or arranged in irregular longitudinal rows. Cells of this character are known as secretion cells and usually contain oil, resin, tannin, calcium oxalate, mucilage (Figs. 98; Iо1, $B$ ), etc., instead of substances which form an enulsion or milk-juice; these cells are distributed in all parts of the plant, and include the epidermal cells and glandular hairs. The walls usually consist of cellulose but may have lamellæ of cutin and suberin, the latter being found particularly in the oil-secretion cells of rhizomes. roots, barks and fruits (Figs. 10I, $B ; 2$ 12; 236;250).

In some instances mucilage cells containing raphides occur in longitudinal rows resembling the secretion cells of Sanguinaria; in some of the ferns, the barks of elder and locust, and leaves of the Crassulaceæ, the tannin-cells are very much elongated, resembling the simple laticiferous cells in the Asclepiadacea.

Oils, resins, mucilage, gum-resins and allied products occur quite frequently in special reservoirs or cavities formed as already described (p. I78).

\section{INNER STRUCTURE OF MEMBERS OR ORGANS.}

Point of Vegetation.-Plants are distinguished for the most part by having distinct growing points known as vegetative points. These occur at the apex of shoots and roots and at definite lateral points, being in the stem near the surface and in roots beneath the endodermis. The walls of the cells in these regions are very thin and consist almost entirely of cellulose. The cells are compactly arranged and are more or less polygonal or somewhat elongated. They are rich in protoplasm, capable of rapid divi- 
sion, and constitute the tissue known as PRIMARY MERISTEM. In the root three kinds of primary meristem (Fig. 60) are distinguished: (I) The PLEROME $(m, f, g)$ or axial meristem, which gives rise to the central cylinder or stele; $(2)$ the Periblem $(x, r)$ or meristematic tissue, which gives rise to the primary cortex, and (3) the DeRmatogen $(e)$, from which the epidermis is developed. In addition to these three meristematic zones there is at the apex, lying next to the dermatogen, a meristematic group of cells which give rise to the root-cap, known as the CALYPTROGEN $(s)$.

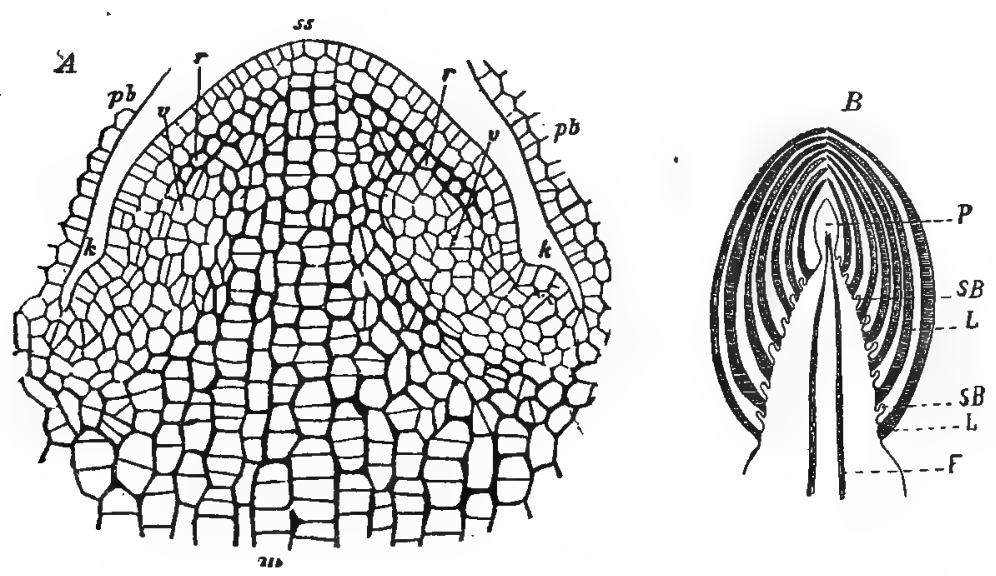

FIG. 108. A, longitudinal section through the apical region of the stem of the embryo of a bean (Phaseolus multiflorus); ss, apex; pb, parts of the two first leaves, and their axillary buds $(k, k$,$) ; , periblem or primary cortex. B, diagram of longitudinal section$ through winter bud of Quercus coccinea: $\mathrm{P}$, growing point; $\mathrm{L}$, young leaves; $\mathrm{SB}$, stem branches; F, fibrovascular bundle.-A, after Sachs.

At the growing point of the stem three meristematic zones are also distinguished, namely, plerome, periblem and dermatogen (Fig. 108, A). They are not, however, so well marked as in the case of roots.

The tissues which are developed from the primary meristems constitute the PRIMARY STRUCTURE (Fig. 60). With the growth in thickness of the stems and roots of Dicotyledons other meristematic cells known as SECONDARY MERISTEMS arise. These are of two kinds: (I) one which gives rise to the xylem and phloem, 
known as CAMBIUM, and (2) one which gives rise to the cork, known as PHellogen. The tissues formed from the secondary meristems constitute the SECOND.IRY STRUCTURE of older dicotyledonous stems and roots.

While the point of vegetation in the higher plants' (spermophytes) embraces a number of cells, in the lower plants the tissues can be traced back to a single APICAL CELL.

\section{THE STRUCTURE OF THE ROOT.}

Primary Structure.-If we make a transverse section of the root of a germinating plant, through the portion developing root hairs, the following arrangement of tissues is observed (Figs.

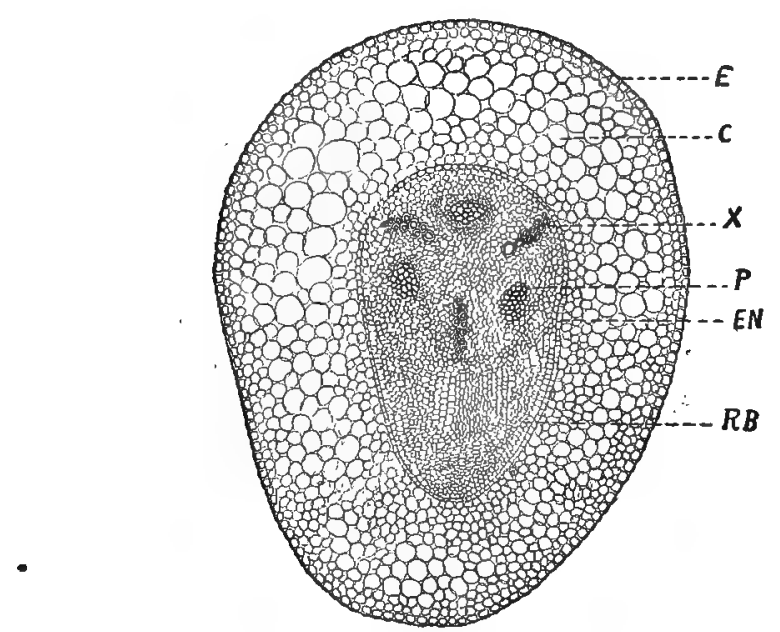

FIG. Iog. A transverse section through the root of a germinating pea-plant' (Pisum) about $40 \mathrm{~mm}$. from the tip showing the origin of a root branch'(RB); $\mathrm{E}$, epidermis; CO, primary cortex; $\mathrm{X}$, xylem; $\mathrm{P}$, phloem; EN, endodermis.

I09, I Io) : ( I) An EPIDERMAL layer with root hairs ( $\mathrm{E}, \mathrm{H}) ;(2)$ a HYPODERMIS of a few layers of cells; (3) a CORTEX made up of a number of layers of parenchyma cells $(C) ;(4)$ a single layer of more or less lignified cells, known as the ENDODERMis (EN); (5) a CENTRAL CXLINDER consisting of parenchyma and alternating groups of ducts (X) and sieve (P), the number of which is more or less constant for certain genera. This arrangement constitutes what is known as the primary structure of the root, 
and is essentially the same in both monocotyledons and dicotyledons. The terms monarch, diarch, triarch, tetrarch, polyarch, etc., are used to designate the number of plates or groups of ducts, there being usually a larger number of groups in the roots of monocotyledonous plants than in those of dicotyledons.

Secondary Structure.-While monocotyledonous roots grow in length, they do not grow perceptibly in thickness, so that, for instance, a sarsaparilla root, which may be nearly three

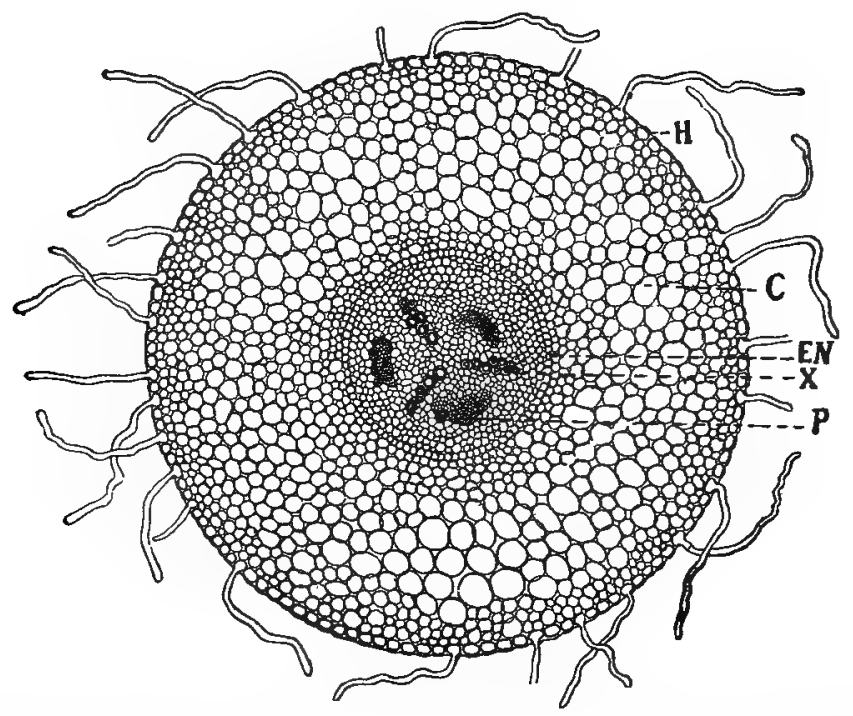

Fig. 110. Primary structure in the root. Transverse section of root of pea (Pisum) about $40 \mathrm{~mm}$. from the root-cap: $\mathrm{H}$, epidermal cells, some of which are developed into root hairs; C, primary cortex; EN, endodermis; $X$, xylem ray composed of trachex; $P$. phioem composed of sieve cells, the xylem and phloem forming a triarch radial fibrovascular bundle.

meters in length, will show but little variation in thickness throughout its entire length. Dicotyledonous roots, however, soon begin to grow in thickness, as well as in length, the latter being less marked than in the Monocotyledons.

In Monocotyledons the primary structure of the root is for the most part retained, the only change being an increase in thickness of the walls of some of the cells. On the other hand, the increase in diameter of dicotyledonous roots is accompanied by marked 
changes in the primary structure (Fig. III). Some of the cells lying between the ducts and the sieve become meristematic, forming a continuous zone or ring, known as the CAMBIUM (CA). On the outside of the cambium not only sieve cells but bast fibers and bast parenchyma may be developed, and these constitute the PHLOEM (P). Besides the ducts upon the inside of the cambium tracheids, wood fibers and wood parenchyma may develop, forming the XyLEM (X). One group of xylem and phloem, together

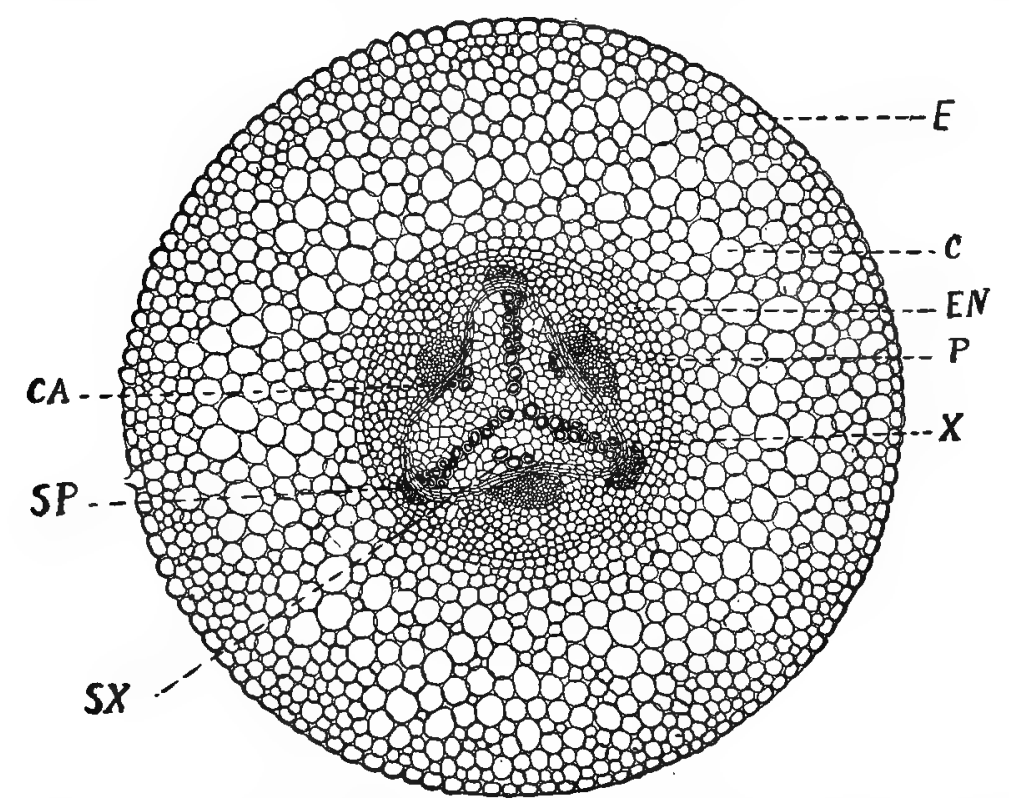

FIG. III. Section in the older part, higher up on the root of pea (Pisum) showing in addition to what has been observed in Fig. I 10 , the beginning of the change from primary to secondary structure: $\mathrm{CA}$, the development of a cambium; $\mathrm{SX}$, secondary xylem, and $\mathrm{SP}$, secondary phloem.

with the intervening cambium, constitutes an open collateral FIBROVASCULAR BUNDLE. Another kind of cells, which are nearly isodiametric or radially elongated, also arise from the cambium and form radial rows, which are known as the MEDULLARY RAYS (Fig. II2, PM, SM). The latter separate the fibrovascular bundles, and the number of cells, both as regards the width and depth of the rows, is characteristic for certain genera. 
While the cambium is developing xylem and phloem, another meristem, known as the PHELLOGEN, arises beneath the endodermis. It produces upon the inside parenchyma, known as the

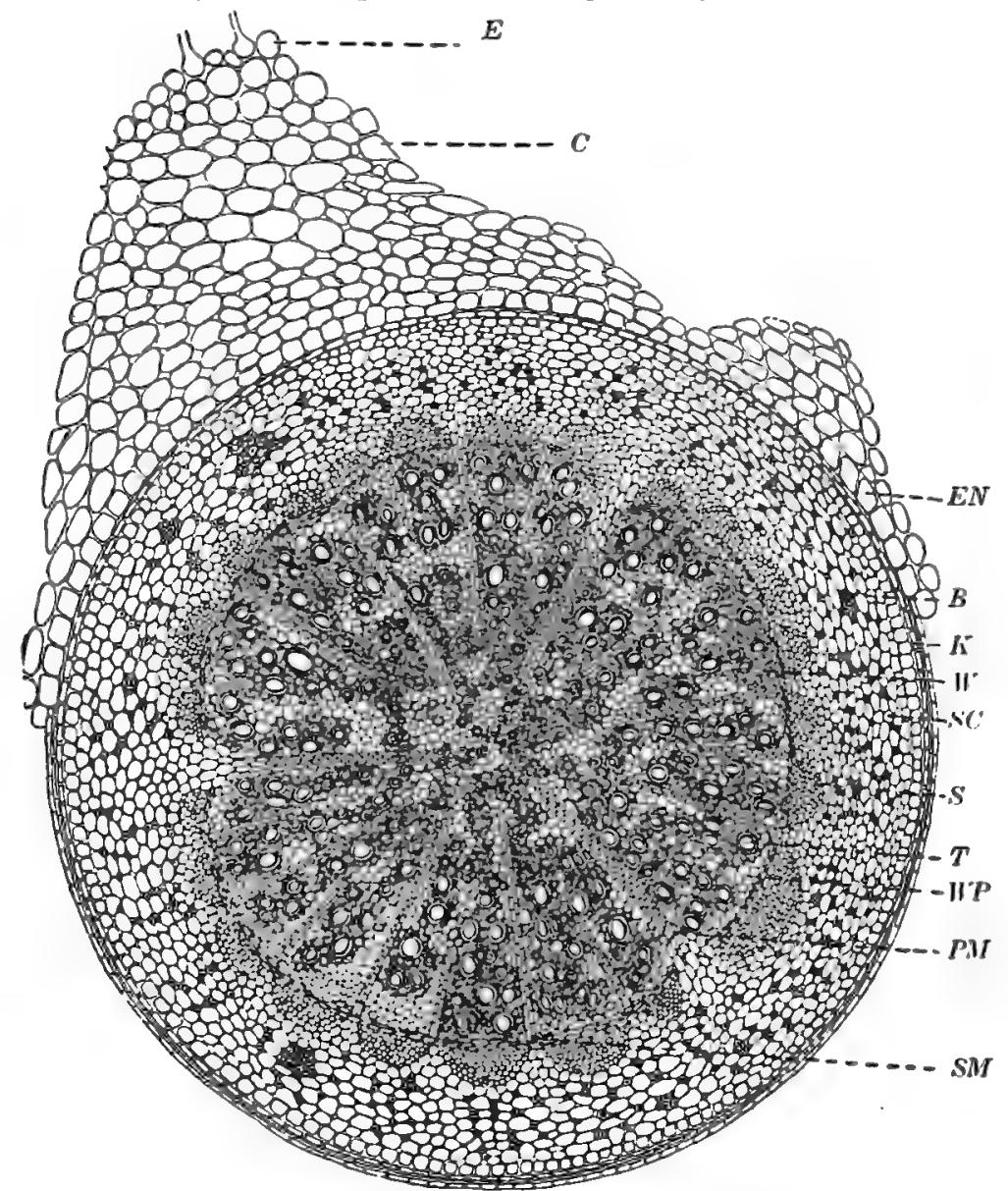

Fic. 112. Fully developed secondary structure in root. Transverse section of root of pea (Pisum) at the end of the summer's growth: E, some epidermal cells with fragments of root hairs; $C$, primary cortex; $E N$, endodermis; $\mathbf{K}$, cork; $B$, bast fibers; SC, secondary cortex: S sieve: T ducts: W, wood fibers: WP wood parenchyma: PM, primary medullary rays; SM, secondary medullary rays; the xylem and phloem forming open collateral fibrovascular bundles, these being found in dicotyledons with but few exceptions.

SECONDARY CORTEX (SC), and upon the outside, cork (K). This stage in the growth of the root marks the completion of the devel- 
opment of the secondary structure. There is a disintegration of the cells of the endodermis (EN), cortex (C) and epidermis (E) of the primary root, these being replaced by the secondary structure as shown in Fig. I I 2.

The characteristics distinguishing the primary and secondary structures of dicotyledonous roots may be summarized as follows:

Primary structere: Epidermis and root hairs. Hypodermis. Primary cortex consisting of parenchyma. Endodermis. Xylem arranged in radial rays which alternate with phloem plates, constituting a radial fibrovascular bundle (Fig. I Io).

Secondary structure: Cork cells. Phellogen. Secondary cortex consisting of parenchyna. Phloem, cambium and xylem, arranged in radial groups, forming open collateral fibrovascular bundles. Medullary rays separating the fibrovascular bundles.

Sometimes, as in glycyrrhiza and valerian, a number of parenchyma cells are found in the center of the root, these constituting the PITH (Fig. II5) or medulla; but they are usually wanting in dicotyledonous roots.

Wood and bark are terms used to distinguish those portions of the root or stem separated by the cambium; all that portion inside of the cambium, including xylem, medullary rays and pith, being known as the woon. The BARK includes the phloem, the medullary rays outside of the cambium, and the tissue formed by the phellogen.

The following difram of the secondary structure of a dicotyledonous root may be of assistance in understanding the origin and relation of the tissues comprising it:

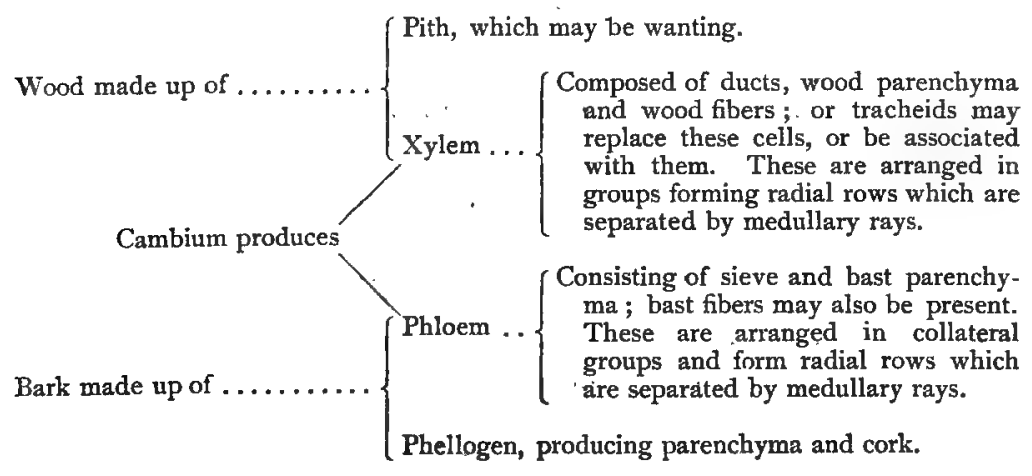


The root branches arise as the product of a meristem, known as the PERICAMBIUM, situated beneath the endodermis (Figs. 59, RB; I09). The tissues forming the branches are directly connected with the fibrovascular tissues of the root and protrude through the overlying tissues without having any connection with them. The structure of the branches thus formed

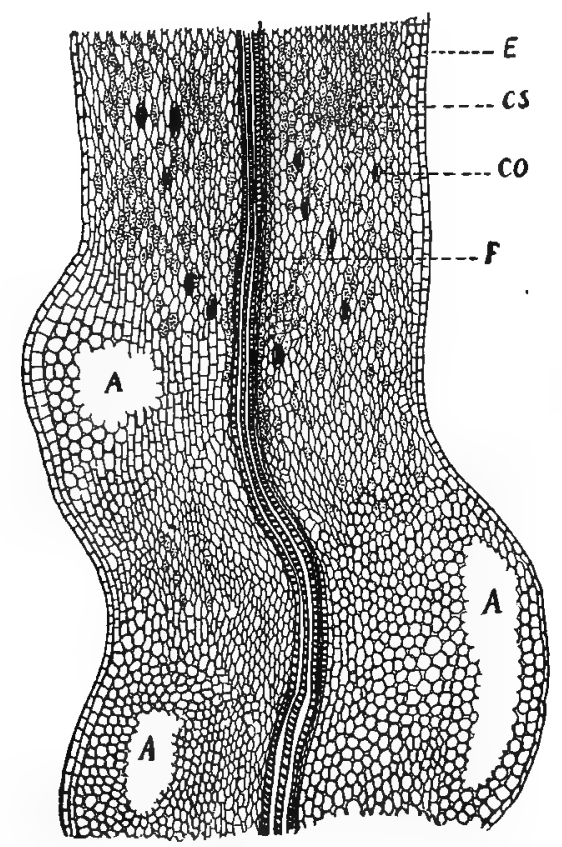

FIG. II3. Longitudinal section through a root of Veratrum viride showing the nature of the contraction of the root: E, epidermis; CS, cells of cortex containing starch; CO, cells of cortex containing raphides; $F$, fibrovascular bundle; $A$, rifts or cavities formed as a result of the radial swelling of the cells of the cortex.

corresponds to the primary structure of the roots, and in the case of dicotyledonous roots may also subsequently develop a secondary structure.

Contraction of roots is observed in both monocotyledons and dicotyledons, it being most apparent in the former, as in the roots of Veratrum viride (Fig. II3). The uneven or corkscrewlike appearance is due to a contraction, which arises as follows: 
Some of the longitudinally elongated cells beneath the epidermis absorb large quantities of water, which causes them to assume a spherical form (as the cells of a potato are altered on boiling), the result being a longitudinal contraction of the root at this point. In this way the plant is fastened more securely to the earth, and at the end of the season's growth the apical buds of plants, with upright thizomes, as of Vcratrum viride, Dracontium, etc., are drawn into the earth and thus protected during the winter season.

Abnormal Structures of Roots.-It is frequently difficult to recognize the type-structure of dicotyledonous roots, owing to the development of anomalous and abnormal secondary structures. Sclerenchymatous fibers, while present in glycyrrhiza (Fig. I04) and althæa, are not infrequently wanting. Wood fibers may be sparingly developed, as in young belladonna roots or even wanting, as in gentian. In other cases the medullary rays are abnormal, being replaced in calumba (Fig. 198) by wood parenchyma, and in ipecac (Fig. 203) and taraxacum by sclerenchymatous cells. In asclepias and calumba (Fig. Ig8) a layer of stone cells occurs near the periphery; in gentian, sieve cells develop in the xylem; in senega the xylem is not uniformly developed, and in still other cases, as in jalap (Fig. 195), pareira (Fig. 199) and phytolacca, successive cambiums develop, producing concentric series of open collateral fibrovascular bundles.

\section{THE STRUCTURE OF THE STEM.}

Primary Structure.-If we make a transverse section of a dicotyledonous stem a little below the growing point, we observe a differentiation of the tissues, as follows, this arrangement representing the primary structure: (I) The epidermis with glandular or non-glandular hairs; (2) hypodermis; (3) cortex; (4) endodermis; (5) open collateral fibrovascular bundles separated by primary medillary rays, and (6) a pith in the center. The essential difference between the primary structures of the stems of Dicotyledons and Monocotyledons, is that in the latter the fibrovascular bundle is of the closed collateral or concentric type, the medullary rays being wanting (Figs. II4, II5). 
On comparing the primary structure of the root with that of the stem, the following essential differences are observed:

\begin{tabular}{|c|c|}
\hline коот. & STEM. \\
\hline Epidermis with root hairs. & Epidermis. \\
\hline $\begin{array}{l}\text { Cortical parenchyma without chloro- } \\
\text { plastids. }\end{array}$ & $\begin{array}{l}\text { Cortical parenchyma with chloroplas- } \\
\text { tids. }\end{array}$ \\
\hline $\begin{array}{l}\text { Fibrovascular bundles, radial, more } \\
\text { numerous in monocotyledons than } \\
\text { in dicotyledons. }\end{array}$ & $\begin{array}{l}\text { Fibrovascular bundles, open collateral } \\
\text { (in Dicotyledons), or closed col- } \\
\text { lateral (in Monocotyledons). }\end{array}$ \\
\hline Pith usually wanting. & Pith always present. \\
\hline
\end{tabular}

Secondary Structure.-The development of the secondary structure in dicotyledonous stems is quite simple compared to that of the root. The cambium develops into a continuous ring, producing xylem within and phloem without. A phellogen arises beneath the endodermis, and the cork replaces it and the overlying primary tissues (Figs. II5, II6).

The arrangement of the tissues in the primary and secondary structures of dicotyledonous stems may be compared as follows:

Primary structure: Epidermis. Hypodermis. Primary cortex. Endodermis. Fibrovasculàr bundles, open collateral and few. Pith.

Secondary Structure: Cork. Phellogen. Secondary cortex. Fibrovascular bundles, open collateral, numerous and separated by secondary medullary rays. Pith cells frequently disintegrated.

Monocotyledonous stems, like monocotyledonous roots, usually grow in length, without much increase in thickness, except in certain cases, as in rhizomes and palm stems, and retain for the most part the primary structure (Fig. II4). The fibrovascular bundles are distinct and distributed in the form of small circular groups throughout the parenchyma within the endodermis as well as in the cortex. The bundles are usually of the collateral type and spoken of as closed from the fact that there is no cambium between the xylem and phloem. In some cases the phloem is in the center of the bundle, the xylem forming a concentric ring around it. In some monocotyledons these two types of bundles are associated (Fig. II4), those of the concentric type 


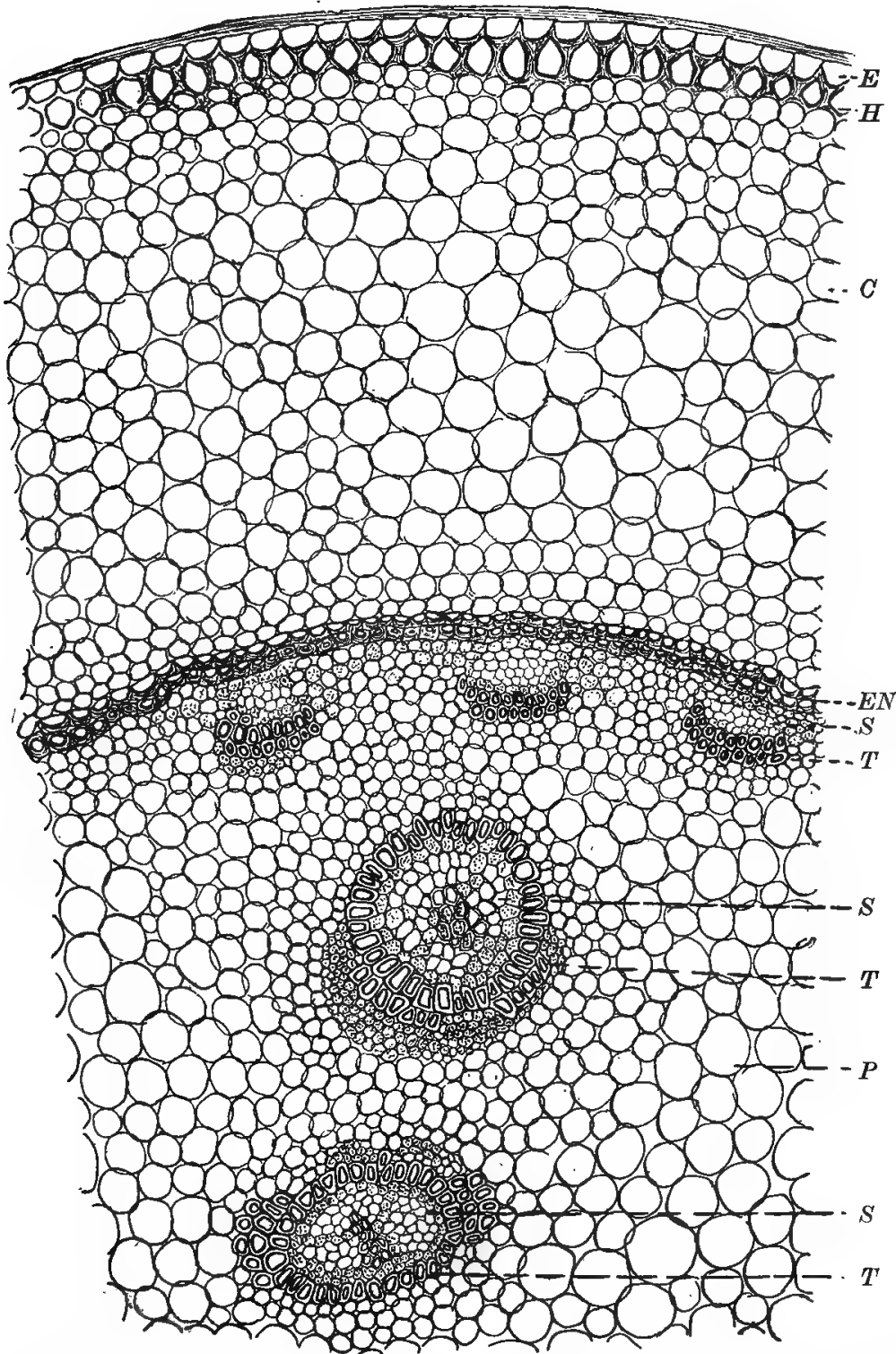

Fig. Ir4. :Monocotyledonous stem structure. "Transverse section of convallaria rhizome: $\mathrm{E}$, epidermis; $\mathrm{H}$, hypodermis composed of collenchyma; $\mathrm{C}$, cortex; $\mathrm{EN}$, endodermis; $S$, sieve; $T$, ducts; $P$, parenchyma. The bundles are of the closed collateral and concentric types. 


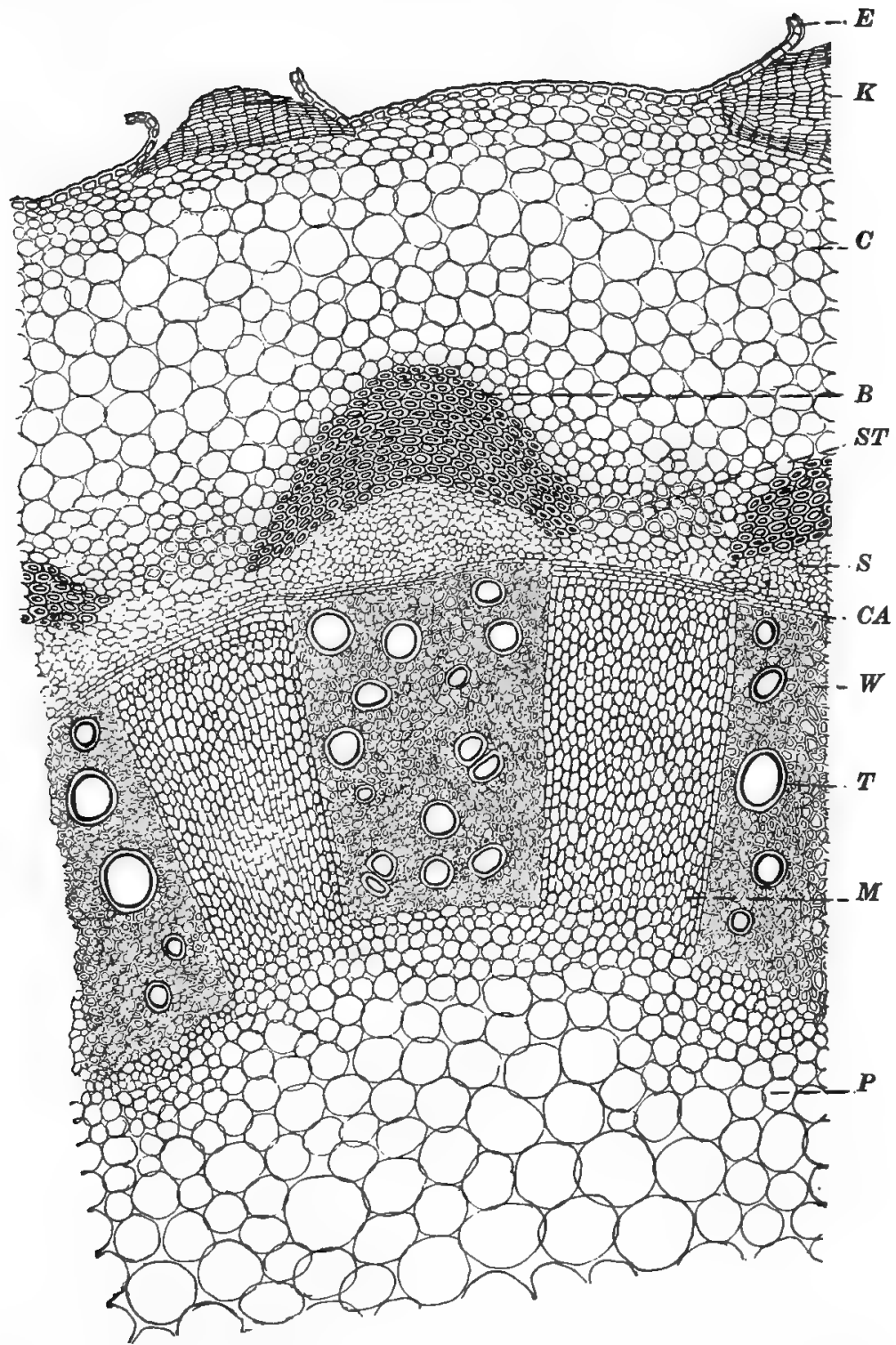

Fig, II5. Dicotyledonous stem structure. Transverse section through menispermum rhizome: $E$, epidermis, which is being replaced by cork $(K) ; C$, cortex; $B$, bast fibers; $S$, sieve; ST, stone cells; CA, cambium; T, ducts; W, wood fibers; $M$, medullary-ray' cells: P. pith. 
being regarded as a modification of those of the closed collateral type. Where increase in thickness of the stem takes place, the cells of the endodermis are altered in shape, and the walls of the hypodermal cells become thickened with lignocellulose and suberin.

The stem as well as the root develops abnormal and anomalous. structures, although they are not of sufficient importance to warrant consideration in this connection.

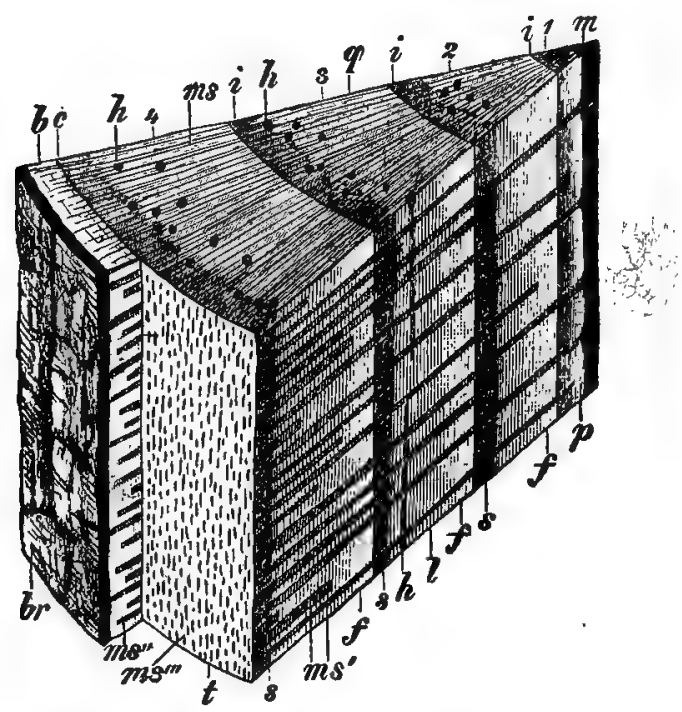

FIG. I 16. Section of a four-year-old stem of a pine cut in winter; q, view in transverse section; 1 , radial-longitudinal section; $t$, tangential-longitudinal section; $f$, spring wood; s, fall wood; $\mathrm{m}$, pith; $\mathrm{I}, 2,3,4$, successive years' rings of growth in which $i$ shows the dividing line; $m s$, medullary rays in transverse section; $\mathrm{ms}^{1}, \mathrm{~ms}^{\mathrm{Il}}$, medullary rays in radial-longitudinal section; ms ${ }^{111}$, medullary rays in tangential-longitudinal section; ¿, cambium; b, bast; $h$, resin-canals; br, bork.-After Strasburger.

\section{STRUCTURE OF THE LEAF.}

The leaf usually consists of three kinds of tissues (Fig. II7): (I) epidermal, (2.) parenchymatous, and (3) fibrovascular; in some cases there may also be a development of collenchyma.

The Epidermis forms the surface of the leaf and may consist of one or more layers of cells. The outer walls are cutinized, and when nearly smooth the leaf is said to be GLABrous. They 
may be covered or whitened with a bloom, as in magnolia, when the leaves are spoken of as GLAUcous.

In other cases the outer walls of the epidermal cells are modified to hairs (Figs. 283-285). When the hairs are unicellular and lie over one another in one direction, they give the leaf a SERICEOUS or silky appearance; when they are very short and straight, the surface is described as PURERULENT; or when they are still longer, as PUBESCENT; or when long and straight, as

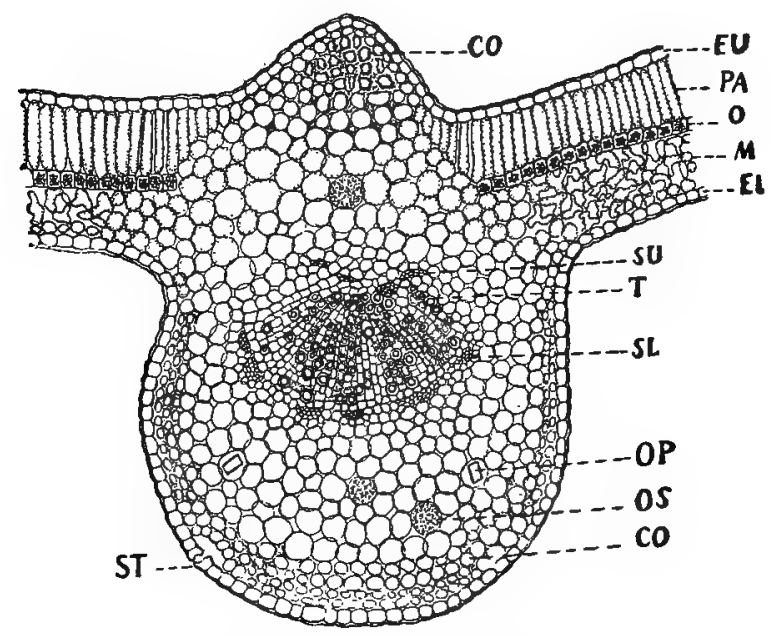

FIG. 117. Transverse section of midrib of leaf of stramonium: EU, upper epidermis; $C O$, collenchyma; $P A$, palisade cells; $O$, layer of cells containing rosette aggregates of calcium oxalate; $M$, loose mesophyll; $\mathrm{EL}$, lower epidermis; $O P$, prisms of calcium oxalate: OS, cryptocrystalline crystals of calcium oxalate; ST, stoma; T, ducts; SU, sieve on upper side of ducts; SL, sieve on lower side of ducts, this arrangement of sieve and ducts forming bicollateral fibrovascular bundles.

PILOSE; when the hairs are long and matted together, as TOMENTOSE, or woolly; when they are hard and prickle-like, the leaf is spoken of as HISPID, or STRIGOSE; when modified to spines, as SPINOSE, and when they are hooked as ECHINATE.

In still other cases the epidermal cells are uneven, forming depressions and protuberances which, if slight, the surface is described as RUGOSE; or if wart-like, as varicose. Furthermore, the veins may be quite prominent, particularly on the lower sur- 
face, and if they are much reticulated in addition, the surface is described as reticulate.

The epidermis is further characterized by the presence of stomata and water-pores, the origin and function of which have already been described (p. 193).

The parenchyma of leaves, known as MESOPHYLL, may be of two kinds: one in which the cells are nearly isodiametric, or branching, and between which are large intercellular spaces; and another, consisting of elongated cells, which are compactly arranged, and known as the PALISADE cELLS. The latter usually occur beneath the upper epidermis, as in coca (Fig. 26I), digitalis and pilocarpus (Fig. 257); or they may occur upon the lower surface as well, as in senna (Fig. 263) ; or they may constitute the entire parenchyma of the leaf, as in eucalyptus. Oilsecretion reservoirs are sometimes found in the parenchyma, as in pilocarpus (Fig. 257) and eucalyptus, when the leaf is said to be GLANDULAR-PUNCTATE.

The fibrovascular tissue of the leaf consists of xylem and phloem, surrounding which is a layer of cells corresponding to the endodermis or bundle-sheath of the young stem. This tissue is found in the middle of the veins, the phloen being situated on the side toward the upper surface of the leaf, and the xylem toward the under surface. Collenchyma is frequently found under the epidermis of the veins of the leaves, as in Mentha piperita, seinna (Fig. 263) and stramonium (Fig. II7).

\section{INNER MORPHOLOGY OF THE FLOWER.}

The inner structure of the flower bears a close resemblance to that of the stem and leaf. The BRACTS in almost all particulars are like the foliage leaf of the same plant and the FLOWER STALK closely resembles the foliage stem. The CALYX, while resemblingthe foliage leaf, usually contains calcium oxalate in greater amount, and the mesophyll consists wholly of rather loose chlorophyll parenchyma; the outer or under epidermis contains the stomata, and if hairs are present, they also arise from this surface; the fibrovascular bundles are generally simple in structure, although in some cases, as in lavender, sclerenchymatous fibers are strongly developed. 
In the COROLL $\Lambda$ the epidermal cells are generally more or less entrifugally developed, forming prominent papillæ (Fig. II8, $1, B)$, which give the petals a velvety or satiny appearance, as in he rose; glanclular and non-glandular hairs are also developed. which are peculiar to the corollas of irregular flowers, as in $L a$ -
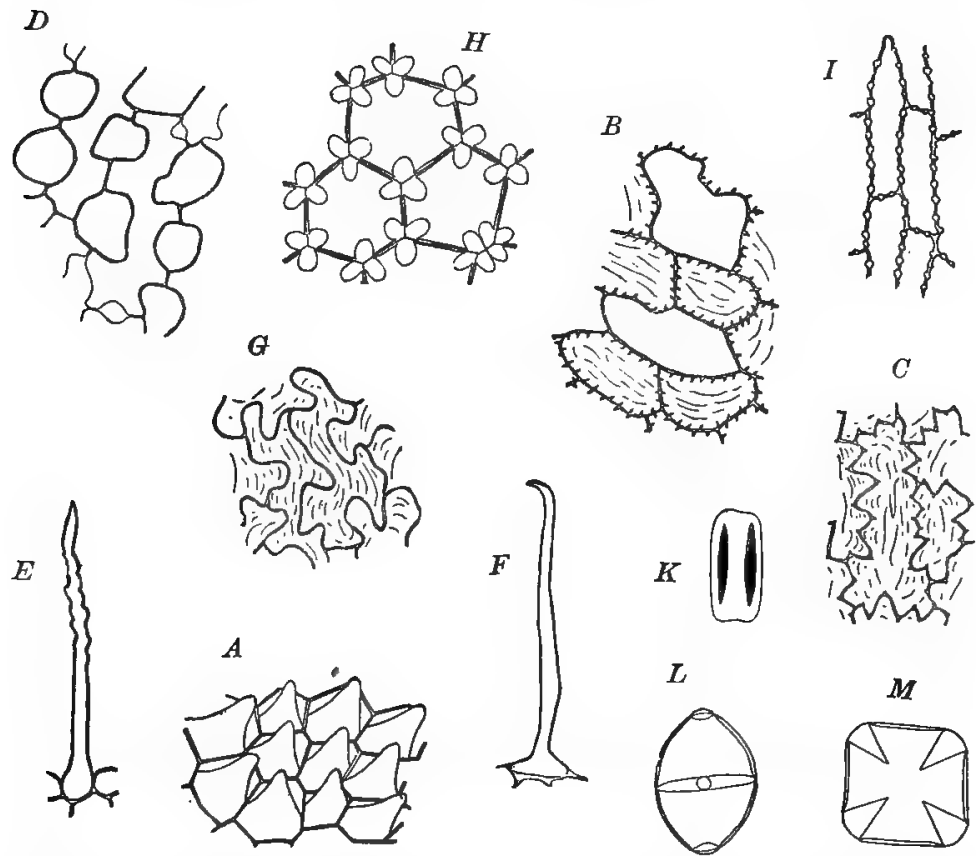

FIG. II8. Inner morphology of the flower as illustrated in Viola tricolor. A, epideral cells from the outer surface of the spurred petal showing papille; B, epidermal cells rom the under surface of the petals, some of the cells showing centripetal thickenings, the wo without thickenings covering sub-epidermal mucilage-cells; $C$, epidermal cells from he under surface of the petals showing a zigzag outline and short centripetal thickenings: , surface view of the mesophyll of the petals; E, corkscrew-like hair from the inner surace of the spurred corolla near the throat; F, a hair from the edge of an anther; G, epidernal cells of the anthers; $H$, surface view of the mesophyll cells from the spurred stamen howing collenchymatous thickening; $I$, surface view of cells of endothecium; $K$, pollen rain viewed from the side; $L$, pollen grain examined in water; $M$, pollen grain observed $x$ chloral solution.

'andula vera (Fig. $285, A$ ) and Viola tricolor (Fig. II $8, E$ ); ;tomata are comparatively few in number. The epictermal cells ire but slightly cutinized, and in surface view are strongly undulIte and appear striate owing to the papillose development (Fig. 
106, $B, C$ ). The mesophyll is made up of rather loose, branching parenchyma cells (Fig. II8, D), with large intercellular spaces. The cells are free from chloroplastids, may contain chromoplastids, or, like the epidermal cells, a colored sap; in some instances, as in the buttercups, starch grains are also found in the mesophyll. Calcium oxalate crystals are usually present, and milk vessels are sometimes found, as in the Papaveraceæ.

The FILAMENT and connective possess a central fibrovascular bundle, around which are arranged comparatively small parenchyma cells and among which secretion cells are sometimes scattered, as in Tilia. The pollen sacs consist of but two layers of cells-an outer layer called the "exothecium," which resembles the epidermis of the corolla, and an inner layer called the "endo-
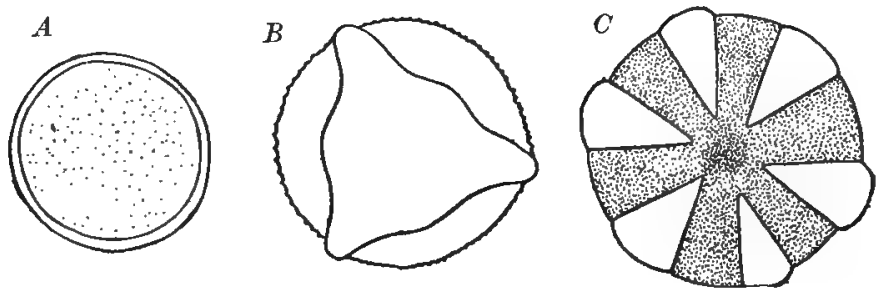

Frg. I I9. Several forms of pollen grains: A, crocus; B, arnica, with three thin places in the wall through one of which the pollen tube may protrude; $C$, lavender showing six thin places in the wall.

thecium," the cells of which are contractile and peculiarly thickened, this feature being rather characteristic for certain species (Fig. II $8, I$ ). Lining the pollen sacs during their development, there is a layer of cells, called the "tapetal cells;" but these are usually sooner or later absorbed.

The POLLEN GRAINS vary greatly in number, as well as in size and shape. They are usually more or less ellipsoidal but may be spherical, as in Crocus (Fig. I19, $A$ ) ; more or less threesided, as in the Compositæ and in cloves; four or five-sided, as in Viola tricolor (Fig. II8, $K, L, M$ ), and in some cases, as in the Coniferæ, they may be winged. In addition to protoplasm and one or more nuclei, pollen grains contain considerable oil and starch. The outer or enclosing membrane (Fig. II9) consists of two parts: an inner one known as the "intine" and consisting of 
cellulose, and an outer, known as the "exine," apparently consisting chiefly of cutin; in some cases the exine also contains an oil which is colorless, as in Salvia, or yellowish, as in lavender, and in some instances it may contain a viscid substance, causing the pollen grains to adhere, as in Enothera. The grains may be smooth or variously sculptured; in most instances the exine is unevenly developed, leaving thin places through which the pollen tubes protrude in germination; these give the appearance of grooves when the grains are dry, and the number of grooves is characteristic for different species; in most of the Compositz they are three in number; in the Labiatæ there are six, while in Crocus they are wanting (Fig. II9).

The epidermal cells of the sTIGMA are quite characteristic. The cells of the epidermis, or so-called "stigma-epithel," may be palisade-like, forming a more or less wart-like mass, as in the viscous stigmas of the Umbelliferæ, or the outer walls may be modified to rather broad papillæ, as in matricaria and arnica, or they may be developed into hair-like processes, as in Crocus. The pollen tubes either enter the style through an open canal, as in the violets, or they penetrate into the conducting tissues of the style, either through the papillæ, as in Malva, or through the middle lamella of two neighboring papillæ, as in Atropa Belladonna.

The important tissue of the STYLE is the conducting tissue; in styles which are hollow it forms the lining of the canal, the cells resembling those of the stigma-epithel; in styles that are solid the conducting tissue occupies the central axis and consists of somewhat elongated cells, the walls of which are generally thick, frequently strongly refractive and possess the property of swelling, being furthermore separated by large intercellular spaces. Surrounding the conducting tissue are thin-walled parenchyma cells, in which the fibrovascular bundles are distributed, the number of groups of the latter corresponding to the number of carpels that compose the gynæcium. There may also occur secretion cells, containing mucilage, as in Malva, or oil and resin, as in matricaria. Occasionally, the parenchyma is replaced either in part or entirely by mechanical cells, and the epidermal cells may be modified to hairs. 
The tissues of the ovary are, as a rule, in a very rudimentary condition; in fact, so rudimentary that it is diffictlt to distinguish the ovaries of two flowers that develop into quite different fruits. In some instances it is said that notwithstanding the subsequent changes, each cell of the fruit is already indicated in the ovary. The ovary possesses an outer and an inner epidermis; the outer is provided with stomata and may also possess hairs; the inner may also have stomata and after fertilization may develop secretion hairs, as in the orange. Between the epidermal layers occur thin-walled parenchyma cells which contain leucoplastids and chloroplastids, and in which the fibrovascular bundles are distributed, these being usually simple, or complex, as in the pea. The number of fibrovascular bundles is more or less dependent upon the number of carpels that make up the gynæcium; as a rule, there is a strong fibrovascular bundle which corresponds to the midvein of each carpel.

The placenta is a development from the inner epidermis. It is traversed by a fibrovascular bundle from which branches are given off to the individual ovules; it may have a conducting tissue similar to that found in the style, and in some cases the epidermis of the stalk of the ovule may be developed to a stigma-epithel.

The ovULE not only possesses a distinct form as already given, but the internal structure, by reason of the changes associated with fertilization, is more or less characteristic for certain species and genera. It has an epidermal laver, the outer walls of which are more or less cutinized, and it consists for the most part of parenchyma cells rich in protoplasm and food-materials; in addition the embryo-sac contains a number of nuclei. The stalk and raphe are connected with the placenta by means of a fibrovascular bundle.

The NECTAR may be secreted by certain of the epidermal cells of various parts of the flower; these may resemble the ordinary epidermal cells or they may be modified to papillæ, as in the spurred stamens of the violets, or to hair-like processes, as in Malva. The cells which secrete nectar constitute the " nectarapparatus," and the walls are usually thin and more or less cutinized. The nectar-apparatus is found more generally upon some part of the stamen, but the sepals and petals are not infrequently saccate or spurred, which adapts them for holding the nectar. 


\section{INNER MORPHOLOGY OF FRUITS.}

The inner structure of fruits is quite variable and it is difficult to treat of this in a general way. In the simplest fruits there are

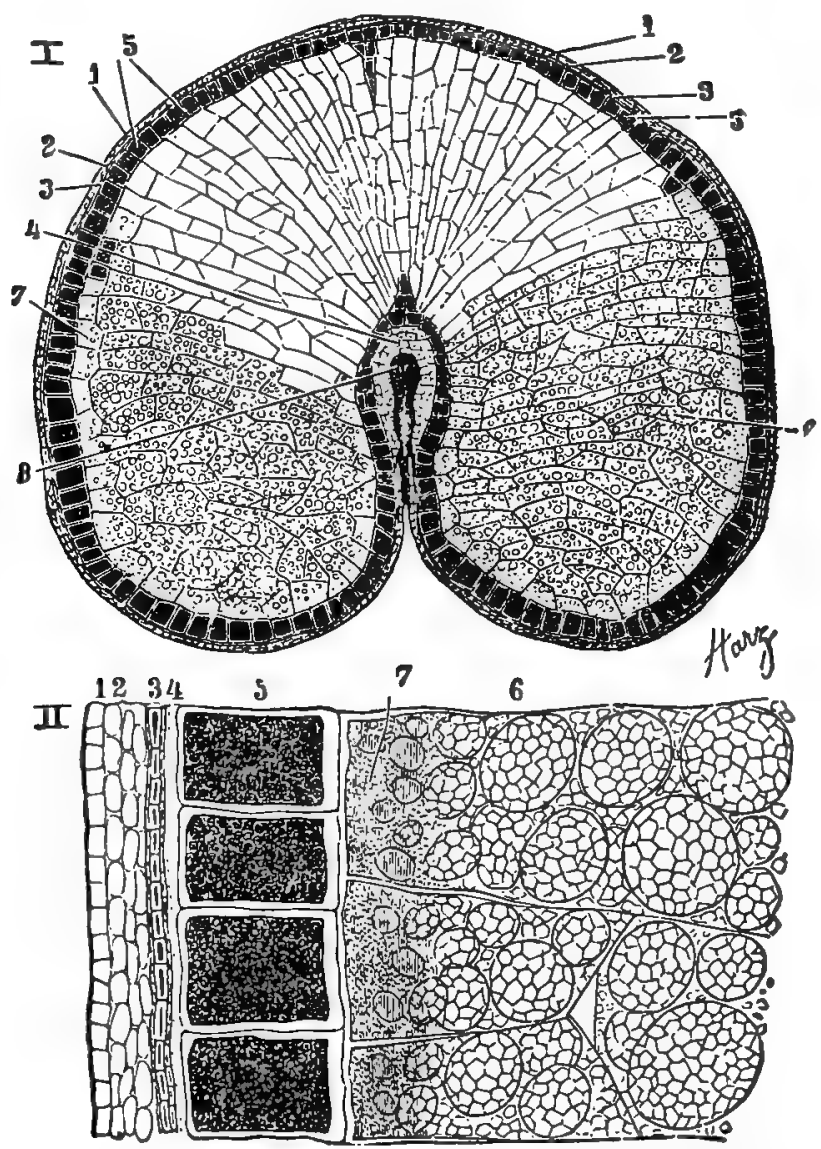

Fig. 120. Transverse (I) and longitudinal (II) sections of oat grain (Avena sativa): 1, 2, cells of pericarp; 3, seed-coat; 4, remains of perisperm; 5, cells containing gluten; 7 , endosperm cells containing considerable proteids and some starch; 6, endosperm cells with polygonal compound starch grains; 8 , fibrovascular bundle of the pericarp.-After Harz.

three distinct layers, as in the capsule of cardamom, in which there is an:outer epidermis of isodiametric or polygonal cells, 
an inner epidermis of more or less obliterated and elongated cells, between which is a thin-walled parenchyma traversed by a number of fibrovascular bundles (See also Figs. 246, 250, 252).

In some cases the outer epidermis contains numerous stomata, as in poppy capsules, or is developed into hairs and other outgrowths or appendages, as in anise (Fig. 244), arnica, rhus glabra and raspberry.

The inner epidermis may also contain stomata, as in the poppy, or be developed into hairs, as in vanilla (Fig. 256) and orange, or more or less obliterated, as in akene-like fruits, or modified to sclerenchymatous elements, as in drupes.

The middle layer, which is composed of parenchyma, may contain protoplasm, starch, sugars, calcium oxalate, coloring principles, alkaloids and other principles, and it may also have oil-secretion cells, as in cubeb (Fig. 250) or oil-secretion canals, as in orange and the fruits of the Umbelliferæ, in the latter of which they are known as vittre (Figs. 244 to 248 ) ; milk vessels sometimes occur, as in poppy; a collenchymatous layer is sometimes developed beneath the epidermis, as in capsicum (Fig. 252), in somse cases sclerenchymatous cells may be present, as in pimenta and cubeb (Fig. 250); and in still other instances the entire pericarp may be made up of stone cells.

\section{INNER MORPHOLOGY OF THE SEED.}

The SEED-COAT usually consists of from two to six layers of cells: (I) an outer layer or so-called epidermis, (2) a layer of sclerenchymatous cells or stone cells, (3) a pigment layer, $(4,5)$ one or two rows of parenchymatous cells, (6) a row of more or less obliterated parenchyma cells.

The EPIDERMAL CELLS vary considerably in different species, both as regards the form of the cells and the composition of the walls (Fig. 302). The cells may be more or less isodiametric in cross-section, as in cardamom (Fig. 253) ; elliptical, as in almond (Fig. 302, D) ; palisade-like, as in Abrus precatorius, or more or less irregular, as in Delphinium. While the outer and side walls are usually thickened, in hyoscyamus (Fig. 302, $A$ ) it is the inner and side walls which are thickened, the outer wall remaining thin. The outer wall may be in part modified to mucilage, as in mustard 
and flaxseed (Fig. I84); or to non-glandular hairs which consist either of cellulose, as in cotton (Fig. I66), or lignocellulose, as in nux vomica (Fig. 283, B).

The PERISPERM and ENDOSPERM (Fig. I2I) consist chiefly of parenchyma cells, which contain, besides protoplasm, starch, as in physostigma; oil, as in strophanthus (Fig. I86); aleurone

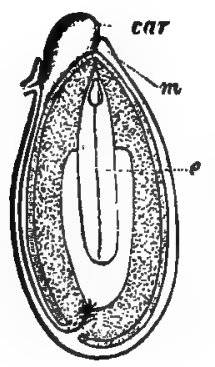

f

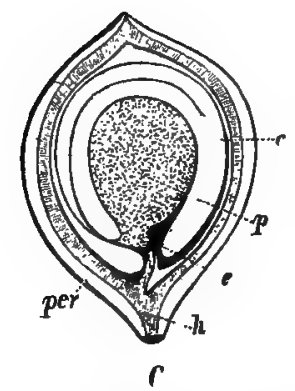

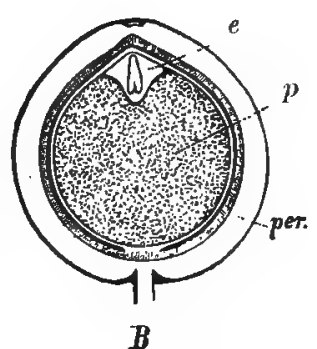

$B$

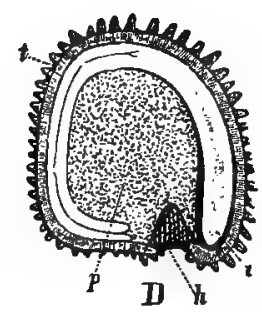

FIG I2I. Form of embryo and distribution of endosperm in various seeds and fruits. A, Ricinus seed: car, caruncle; $m$, micropyle; e, embryo. $B$, superior drupe of Piper: per, pericarp; e, endosperm; $p$, perisperm. $C$, spinach fruit and $D$, corn cockle seed (Agrostemma Githago): per, peticarp; $t$, seed-coat; h, hilum; p, perisperm; e, endosperm c, curved embryo.-A, C, D, after Harz; B, after Baillon.

grains, as in ricinus (Fig. I22) ; glucosides, as in almond; alkaloids, as in stramonium. The walls are usually thin, but may in some instances be considerably thickened, as in coffee, colchicum and nux vomica (Fig. 122, C).

The embryo consists chiefly of parenchyma cells with a few fibrovascular bundles; the cotyledons may be thin and leaf-like, as in ricinus and nux vomica, or thick and fleshy, as in almond 
(Fig. I88) and cola, or partly developed as in strophanthus (Fig. I86); the hypocotyl is usually small, but in the Umbelliferæ it is as large as the cotyledons.
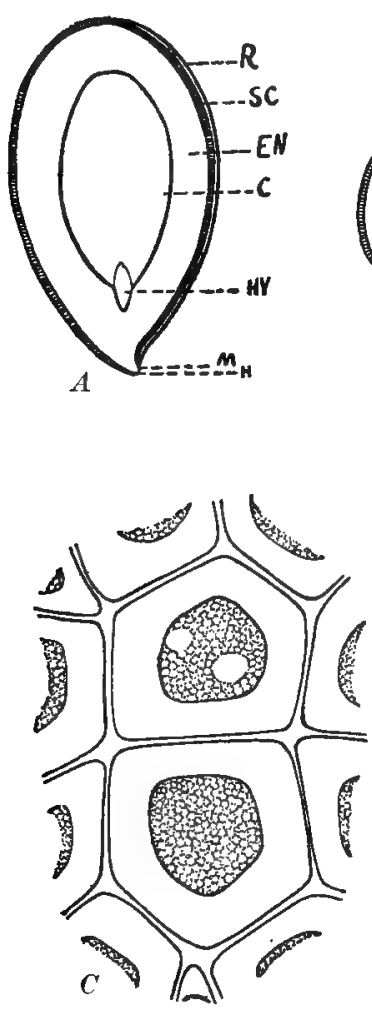
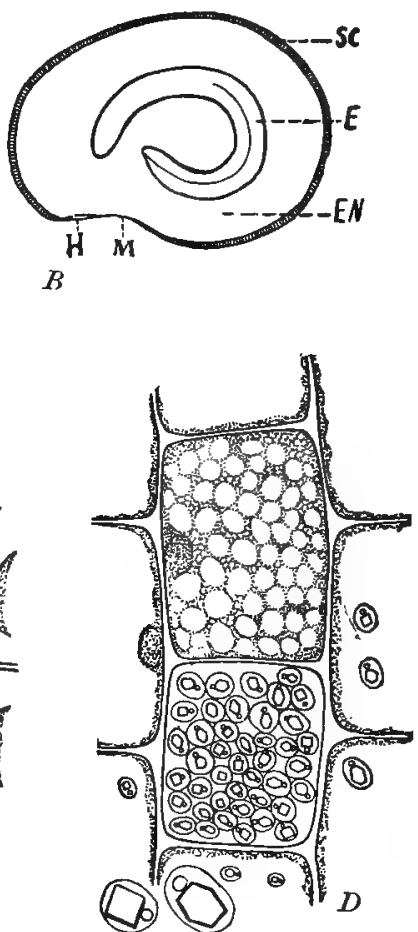

FIG. I22. A.-Longitudinal section through anatropous seed of linum: $R$, raphe; SC, seed-coat; $M$, hilum; $H$, micropyle; $E N$, endosperm; $C$, cotyledon; $H Y$, hypocotyl. $B .-$ Longitudinal section through stramonium seed: SC, seed-coat; H, micropyle; $\mathrm{M}$, hilum; EN, endosperm; E, curved embryo. C.-Transverse section through endosperm of nux vomica showing thick-walled parenchyma, the cells containing oil and protoplasm. D.Transverse section through endosperm of seed of Ricinus communis, one cell filled with aleurone grains containing a crystalloid and globoid, and another in which the aleurone grains have been dissolved, the cytoplasm and nucleus remaining.

\section{PLANT METABOLISM.}

Food of Plants. - It has already been pointed out that certain of the chemical elements are necessary for the growth of plants (p. 3), and that these are derived partly from the surrounding 
atmosphere and partly from the soil. Those elements derived from the air are either themselves gases or exist in combination in the form of gas, and include oxygen, nitrogen in exceptional cases (p. 99), and carbon dioxicle, the source of the carbon entering into the carbon compounds formed by plants.

The elements obtained by plants from the soil exist in combination with other elements and must be in the form of solution to be absorbed. The soil consists largely of mineral substances, together with certain organic products (humus). The water held in the soil not only acts as a medium for carrying the soluble constituents in the soil to the plant, but is itself an important food product, being the source of the hydrogen used by plants, as also of assimilable oxygen. Among the mineral constituents of the soil that are useful to plants are ammonium salts and nitrates, sulphates, phosphates, chlorides, silicates and carbonates. When plants are collected and subjected to a temperature of about $\mathrm{IIO}^{\circ}$ C. the water is driven off, and then if heat sufficient to incinerate the material be applied the organic matter is driven off in the form of gases, leaving the mineral constituents in the form of ash, as calcium, magnesium, iron, potassium, sodium and a few other elements.

Root AbSORPTION.-Notwithstanding the various agents which are at work tending to break down and dissolve the substances contained in the soil, as soil bacteria, the liquids given to the soil by the roots of the plants themselves, the presence of the so-called humic acids, and the action of water and air, it has been shown that the soil water is an exceedingly weak solution. This is largely due to the peculiar absorptive and fixing power of the soil itself.

The dilution of the aqueous solution of the soil constituents is a matter of very great significance, for upon this depends its absorption by the root hairs. While other parts of roots have certain absorptive powers, the root hairs have been defined as the organs of absorption of the plant. They are very delicate in structure and contain protoplasm. Their absorbent function depends upon the principle that when a membrane (animal or vegetable) is interposed between two liquids of unequal density, the less dense liquid will pass through the membrane and mix 
with the denser liquid. This process is known as osmosis, and when a liquid passes outward through a membrane or cell-wall it is called exosmosis, and when inward it is called endosmosis. The soil is made up of minute earth particles, each of which is surrounded by a thin film or envelope of water, and it is this portion of the soil liquid that is absorbed by the root hairs. The root hairs come into close contact with these soil particles; in fact, appear to grow fast to them, and the cell-liquid in the root hairs being denser than that surrounding the soil particles, the latter passes through the wall into the root hairs.

If, on the other hand, the water supplied to the roots of plants should contain an excess of soluble material, the plant will be injured. In this case exosmosis ensues and the plant loses some of its own liquids or cell-sap and will show signs of wilting. It is well known that if cultivated plants are supplied with strong solutions of fertilizer the plants will be injured rather than benefited.

Root PRESSURE.--The distribution of the water absorbed by the roots to other parts of the plant is influenced by a number of factors, which are commonly spoken of together as root-pressure. Among these are osmosis within the plant, due to unequal density of the liquids in different cells; the changes in the equilibrium of the cell-liquids, dte to chemical changes, and the transpiration of water from the leaves, thus establishing a flow of liquids from the roots upward, which is usually spoken of as the ASCENT OF SAP. The cell-sap passes upward through the xylem for the most part carrying constituents obtained from the soil to the growing parts, where they are combined with the products of photosynthesis, and through a series of reactions protoplasm is finally built up.

Oxidation.-The free oxygen taken in by plants through the stomata and lenticels serves the same purpose in plants as that inhaled by animals, namely, the oxidation of certain compounds, whereby part of the energy necessary for vital activity is liberated. Oxygen is required by all parts of the plant. When the roots of plants, such as those of Zea Mays, are surrounded by water so as to exclude the air the plants will become yellow. Germinating seeds consume a large amount of oxygen, but not 
all the energy formed is used by the plantlet, much of it escaping as heat, as in the germination of barley in the preparation of malt (p. 575). Those plants dependent upon the presence of free atmospheric oxygen are called $\Lambda$ EROBES, while those which are not thus dependent, as certain fungi and bacteria, are called ANAEROBES.

Metabolism.-Processes of construction and destruction are going on simultaneously in the plant, and these are all grouped under the general name of metabolism. The processes whereby complex substances are built up from simpler ones, as in photosynthesis, are together spoken of as CONSTRUCTIVE METABOLISM (anabolism), while those which involve the breaking down of complex compounds into simpler ones, either through oxidation or other chemical action, as when sugar is changed into carbon dioxide and water, are grouped under the head of DESTRUCTIVE METABolism (catabolism). 


\section{CHAPTER IV. \\ CLASSIFICATION OF ANGIOSPERMS YIELDING VEGETABLE DRUGS.}

INTRODUCTORY.

INASMUCH as the plants yielding drugs and proximate principles, represent a large number of families it will be found that the study of the important characters of these groups will give a rather comprehensive view of the important groups of the Angiosperms. Reference will also be made to other economic products yielded by the angiosperms, as food-products, fibers, coloring principles, woods and timbers, as well as to the plants commonly cultivated for ornamental purposes.

Drugs which are recognized by the pharmacopoias are said to be official. It should be understood that those referred to in this book as being official are those recognized by the United States Pharmacopoia.

Nomenclature.-The names first given to plants consisted of a single Latin name, as Quercus, Rubus, Rosa, etc. Later some of the names applied to plants were obtained from the Greeks through Latin literature, as Aristolochia, Colchicum. The list of classical names was added to from time to time from both the Latin and Greek, as Convallaria, Glycyrrhiza, etc. Later the names applied to plants in other countries were Latinized, as Datura from the Arabic, Guaiacum from America. Since very early times the names of distinguished men have been applied to plants, as Asclepias which was dedicated to Esculapius, and Linnæa which was named after the great Swedish botanist Linnæus. When it was found that there were different kinds of plants in what had been considered a single type these were distinguished by the addition of other names indicating their specific characters, and in this way plant names became quite long and cumbersome. Botanical science is indebted to the Swedish botanist Linnæus for proposing names for plants separate from their 
description. He reduced plant names to two: a generic name and a specific name. The specific name is the name applied to plants which are of one kind, and these constitute a SPECIES; and the generic name is that applied to a group of nearly related species, each group constituting a GENUS. Thus the oaks make up a genus of plants to which the Latin name Quercus signifying "beautiful tree" is applied. But we know that the oaks are not all alike and different names are applied to the different kinds, as the white oak which has the specific name alba; the plant therefore is known scientifically as Quercus alba; while the black oak is known as Quercus velutina.

Nearly related genera are brought together in groups known as Families. Thus we have the Mint Family known as the Labiatæ, which comprises a number of related genera, such as Mentha, Hedeoma, Salvia, etc. Still larger groups of related families make up ORDERS, as the Graminales, including the Graminex or Grass Family and the Cyperaceæ or Sedge Family. Orders make up classes and sub-classes, as the Monocotylectons and Dicotyledons.

The names of genera consist of one word which is a singular Latin noun, and are derived in various ways, as Sanguinaria, so named because of the red or sanguine character of the juice; Castanea which is named from Castanea in Thessaly the home of the chestnut; Ricinus from the Latin word meaning " bug," because of the resemblance of the seed to a bug; Digitalis, so named from the finger-shaped corolla.

Specific names are generally adjectives and must agree in gender with the generic name. Thus we have Medicago airginica in which the endings are feminine; Lepidium zirginicum in which the endings are neuter, and Sporobolus virginicus which has masculine endings. Like the generic name the specific name is derived in various ways, but it usually indicates some peculiarity of the plant. Thus the specific name in Gentiana lutea, refers to the golden-yellow flowers; in Conium maculatum, the specific name has reference to the brownish-purple spots on the stem; in Brassica nigra, the word nigra has reference to the black seeds; in Aristolochia reticulata, the specific name refers to the reticulated leaves; and in Phytolacca decandra, the word decandra has reference to the ten stamens. 


\section{A. CLASS MONOCOTYLEDONS.}

The Monocotyledons are mainly distinguished by having (I) leaves which are parallel (closed) veined, the margins being for the most part entire; (2) the parts of the flower in five circles of three divisions each (Fig. I24); (3) a stem with no distinction of pith, wood and bark, but having closed collateral bundles scattered through the parenchymatous tissue of the stele (Fig. II4); and (4) an embryo with one cotyledon.

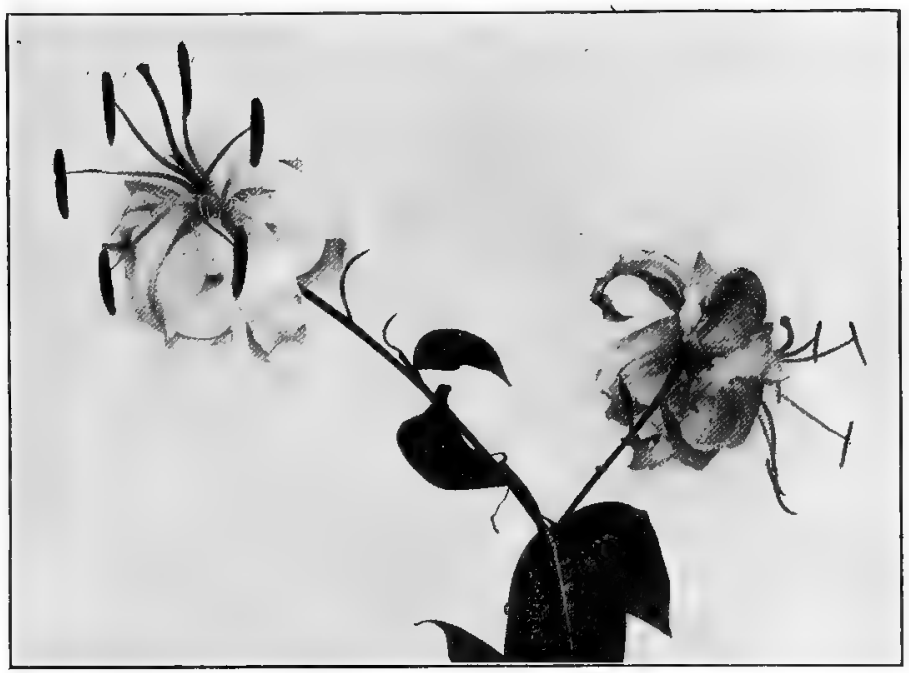

Fig. I23. Cultivated white lily (Lilium album) showing typical monocotyledonous flowers.

\section{ORDER GRAMINALES OR GLUMIFLORA.}

This order is composed of the two families, grasses (Gramineæ) and sedges (Cyperaceæ). The plants are for the most part annual or perennial herbs with fibrous roots or long rhizomes and slender, usually simple, overground stems (culms). "The flowers are small, arranged in spikes or spikelets and are windpollinated. Each spike is subtended by one or two bracts known as glumes or scales. The ovary is I-locular and I-seeded and the stigmas are large, hairy or plumose (Figs. $79, F, G ; 125, D$ ).

a. GRAMINE $巴$ OR GRASS FAMILY.-The culms are mostly hollow; the leaves are slender and sheathing, usually split 
to the base on the side opposite the blade, and with a slight projection at the juncture of the blade and sheath called the ligule; the flowers are perfect, monœcious or diœcious, the stamens being usually three in number (Figs. I25, 126). Each flower is subtended by one to three minute hyaline scales known as LODICULES, and below the lodicules is a scale leaf known as the INNER PALE, while each individual flower stalk is subtended by still another scale known as the OUTER PALE. In addition each spikelet is subtended by one or two empty scales or GLUMES, the various bracts, which persist, constituting the CHAFF. The fruit is a seed-like grain, in which the seed is closely united with the thin pericarp,
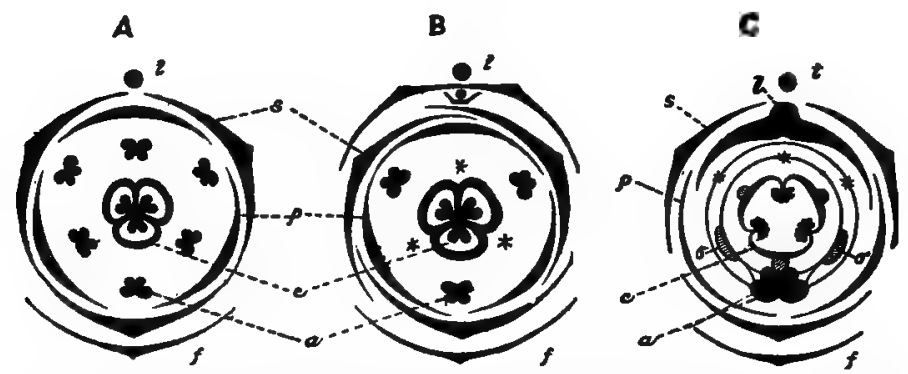

Fig. 124. Diagrams of cross sections of monocotyledonous flowers: $t$, stem of plant: $f$, bract; $s$, sepals or outer circle of perianth; $p$, petals or inner circle of perianth; a, stamens; c, ovary. A, regular flower of the lily; B, irregular flower of iris; $C$, flower of an orchid, in which 1 is the lip and $\delta \delta$ the two staminodes.-After Warming.

and is called a caryopsis (Fig. 120). The endosperm contains numerous starch grains and oil, while the gluten layer around the endosperm contains proteids. The number of layers of glutenor aleurone-containing cells varies in the different cereals. In corn, wheat and rye it consists of but a single layer; in oat and rice, of $I$ or 2 layers; while in barley it is made up of 2 to 4 layers.

The Grasses comprise about 3,500 species and are distributed in all parts of the world. While most of the plants are grass-like still some of them, as the bamboos of the Tropics, become quite tall, having woody silicious stems and bearing many branches in the axils of the leaves. They yield the cereal grains forming so large a proportion of the food of man, and forage constituting the food of many of the lower animals. The following are some of 
the important cereals: Wheat (Triticum sativnm and its varieties), corn (Zea Mays), oat (Avena sativa), rice (Oryza sativa), barley (Hordeum satizum and its varieties), rye (Secale cereale). A number of the species yield a sweet cell-sap from which cane sugar is made, of which the most important are the sugar cane (Saccharum officinarum) and sorghum (Andropogon arundinaceus saccharatus and other varieties).

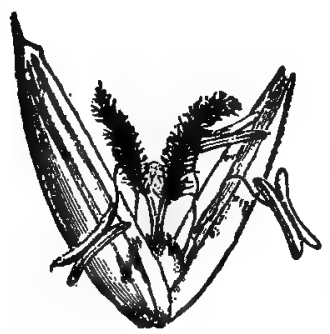

c

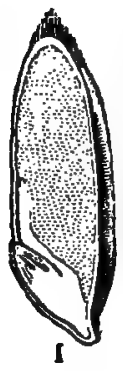

Eunante.

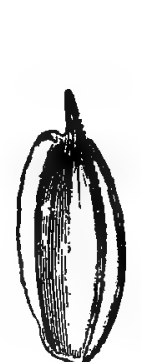

E

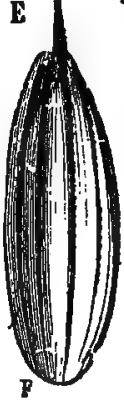

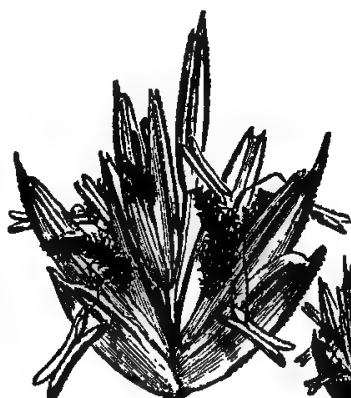

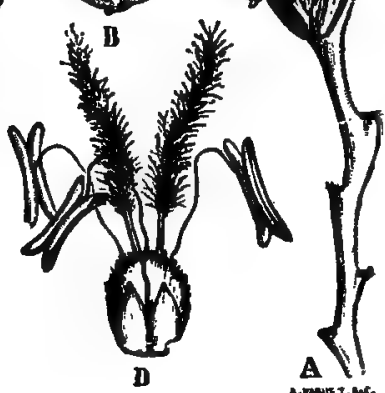

Fig. 125. Wheat (Triticum): A, zigzag axis or rachis of ear showing the notches where the spikelets were inserted; $B$, an entire spikelet; C, a flower with the pales; D, a flower without the pales, showing the lodicules at the base; $E$, glume; $F$, outer pale; $G$. inner pale; $H$, fruit (caryopsis); I, longitudinal section of fruit.-After Warming.

A large number of the grasses are used in medicine, one of which, couch-grass (Agropyron repens), is official (p. 490).

Agropyron repens is a common perennial grass, forming slender jointed rhizomes, by means of which the plant is extensively propagated; the culms vary from one to four feet in height, the spikelets are $3^{-}$to 7 -flowered; and the empty glumes, 5- to 7-nerved, acute or with an awn-like apex (Fig. 214). 
Hordeum sationm is an annual grass with the flowers in terminal cylindrical spikes resembling wheat. The spikelets are sessile, I-flowered, and usually in clusters of three on opposite sides of the notched rachis. The empty glumes are long and narrow, forming a kind of involucre around the spikelet. It is supposed that Hordeum satizum is a cultivated form of $H$. spontaneum growing in the countries between Asia Minor and other parts of Western and Southwestern Asia. Three important varieties are distinguished depending upon the number of rows of grains in the ear. H. saticum distichon includes the plants having 2-rowed

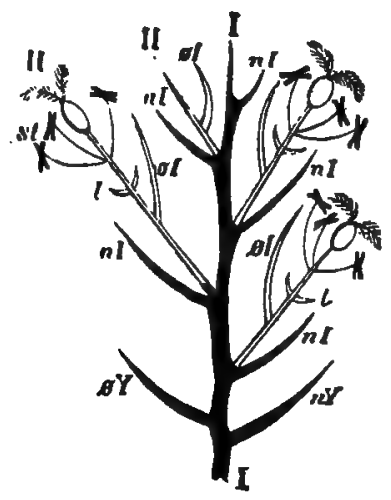

Frg. 126 . Diagrammatic outline of a spikelet: $n Y$, lower glume; $\phi Y$, upper glume; $n I$, outer pale; $\phi I$, inner pale; 1,1 , lodicules; st, stamens; I-I, main axis; II, lateral axes or branches.-After Warming.

ears and these are chiefly grown in Middle Europe and England. $H$. sativum herastichon includes the plants having the grains in six rows, these having been cultivated since prehistoric times and now cultivated in Southern Europe. H. satizum oulgare includes the plants in which the grains are in four irregular rows, and these are cultivated in northern temperate regions. The latter plant is cultivated in the United States and furnishes the grain used in the preparation of malt (p. 575).

Zea Mays (Indian Corn) is a cereal plant probably indigenous to Central Mexico. It is extensively cultivated in the United States and other parts of the world for its grain. From a multiple, primary; somewhat fibrous root arise one or more erect simple 
culms, which are grooved on alternate sicles in the successive internodes and from the nodes of which arise aerial secondary roots. The leaves are alternate and consist of three parts: (a) a blade, which is long, broadly-linear and tapering toward the apex, the tip being pendulous; (b) a lower sheathing portion which is open; and (c) a short, translucent, somewhat hairy ligule, situated between the sheath and the blade. The flowers are monœcious, the staminate, which are arranged in a terminal panicle, maturing first; the pistillate occur in axillary spikes, the axes of which constitute the corn cob. They are enclosed in spathe-like bracts or husks, from which the long filiform styles (p. 558) protrude. The grain is somewhat ovate or triangular, flattened, pointed at the base, grooved on one side, indicating the position of the embryo, from Io to I $5 \mathrm{~mm}$. long and about Io $\mathrm{mm}$. broad, more or less translucent, and varies in color in the different varieties. The constituents of the corn grain are 50 to 70 per cent. of starch; about Io per cent. of proteids; 4.29 per cent. of a fixed oil ; about five per cent. of sugar, and 1.29 per cent. of ash.

There are a large number of varieties and sub-varieties of $Z e a$ llays, some of the former being ranked as species. The following well defined varieties may be mentioned:

( I) Zea Mays everta, to which belong the POP-CORns. The size of the ears and grains is about one half or less that of the other corns; the grains have a more or less translucent and horny endosperm, the cells of the latter containing numerous compactly arranged polygonal starch grains, which are from 7 to Io $\mu$ in diameter and have a central rarified area from 2 to $7 \mu$ in diameter. It is owing to the structure of the starch grains that the peculiar popping of the corn grains results when they are heated. Heating the corn grains at $145^{\circ}$ to $160^{\circ} \mathrm{C}$. for from 4 to ro minutes causes the bursting of the starch grains, and at the same time a rupture of the cells and splitting of the pericarp into 4 parts. The white appearance of the popped grains is due to the inclusion of air in the bursted cells. During the heating the starch is converted into a soluble form and this gives popped corn its nutritive -value. Some of the flint and dent corns show a similar tendency to pop when heated, but it is only in those parts of the endosperm that are horny and the cells of which contain compactly 
arranged polygonal starch grains in which the rarified area is at least from one-tenth to one-fifth the diameter of the entire grain. Pieces of the pop-corn, as well as the horny portions of some of the flint and dent corns, will pop as readily as the whole grains.

(2) Zea Mays indentata yields the DENT or FLINT CORNS, the grains of which have a corneous (horny) endosperm on the sides and are indented at the summit, owing to the shrinking of the cells which contain more cell-sap and less compactly arranged starch grains.

The starch grains in the cells of the horny endosperm resemble those of pop-corn, but the starch grains in the other cells are more or less rounded or slightly polygonal, and vary from 5 to 25 $\mu$ in diameter; the central rarified area is either wanting or usually not more than $2 \mu$ in diameter.

(3) Zea Mays saccharata yields the SUGar corns. While the grains are more or less translucent and horny, they have a wrinkled or shrivelled surface. The cells of the endosperm contain gum-like substances and a relatively small number of nearly spherical starch grains from 4 to Io $\mu$ in diameter.

BRoOm CORN (Andropogon arundinaceus vulgare) is a plant which is cultivated for the panicles or seed heads, which are used in the manufacture of brooms. This plant differs from the other species of Andropogon in that the branches of the panicles are longer, straighter and stronger, forming a so-called "brush."

Quite a number of the grasses contain odorous principles, as Andropogon citratus which yields lemon-grass oil ; $A$. Schonanthus which yields gingergrass or geranium-grass oil; $A$. squarrosus the rhizome of which is known as Vetiver. Coumarin is found in Vanilla grass (Anthoxanthum odoratum) and white or Dutch clover (Hierochlo odorata). Some species of Stipa are used in the manufacture of paper (Alfa or Esparto) in North Africa and Spain.

b. CYPERACEÆ OR SEDGE FAMILY.-The culms are mostly solid; the leaves are narrow, 3-ranked, and with closed sheaths, the ligule being absent or quite small; the perianth is composed of six bristles or represented by an indefinite number of hairs, or entirely wanting; the lodicules are wanting; the fruit is an akene; and the endosperm contains starch. 
A number of the sedges yield food products, as the rhizomes of Cyperus esculentus and Eleocharis tuberosa, the latter of which is used in the manufacture of starch in China and India. Quite a number of species of Scirpus, Cyperus, Carex, etc., are used in medicine. Various species of Cyperus (C. scariosus, of the East Indies, and $C$.pertenuis, of India) yield ethereal oils and are used in making perfumery. Cyperus Papyrus is also used in medicine and furnished the paper of the Ancients.

\section{ORDER PRINCIPES.}

In this order is included that interesting group of tropical and sub-tropical plants the PALMs (Palmæ). They are arborescent, having simple unbranched trunks which are terminated by clusters of leaves, in the axils of which flowers are produced. The leaves are pinnate (Feather Palms) or palmate (Fan Palms) and often very large. The petiole is well developed with an amplexicaul, more or less fibrous sheath. The inflorescence is usually lateral, in some cases forming a large spadix with a woody, boatshaped spathe. In comparison the individual flowers are very small. The fruit is either a berry, as in the Date palm, or a drupe, as in the Cocoa-nut palm, generally I-seeded and with a large horny or bony endosperm, as in the Date palm (p. 233) and Phytelephas macrocarpa, the latter of which yields vegetable ivory, used in the making of buttons.

The fruit of the saw palmetto [Serenoa (Sabal) serrulata], one of the fan palms, is official (p. 578). The saw palmetto is characterized by having a creeping root-stock or rhizome one end of which rises a short distance above ground, this portion being surmounted by a dense crown of leaves. The petioles are slender and spinose on the edges; the blade is fan-shaped and consists of a number of palmate divisions which are slightly cleft at the apex. The inflorescence is densely tomentose and shorter than the leaves. The fruit is a I-seeded drupe (Fig. 25I).

The palms yield a number of useful products. The Betel-nut palm (Areca Catechu) produces a seed having medicinal properties (Fig. 127). The seeds, known as ARECA NUT, are 20 to 25 $\mathrm{mm}$. long, conical, grayish-brown, with numerous spiral, reddish 
veins, heavy, hard, somewhat aromatic; astringent and slightly acrid. They contain about o.I per cent. of an oily liquid alkaloid, arecoline, which chemically and in its physiological action resembles pelletierine; I4 per cent. of tannin, resembling catechutannic acid; gallic acid; a red coloring principle; and I4 per cent. of a fixed oil. They also contain 3 other alkaloids: arecaine, arecaidine and guvacine, but these do not seem to give the drug its properties.
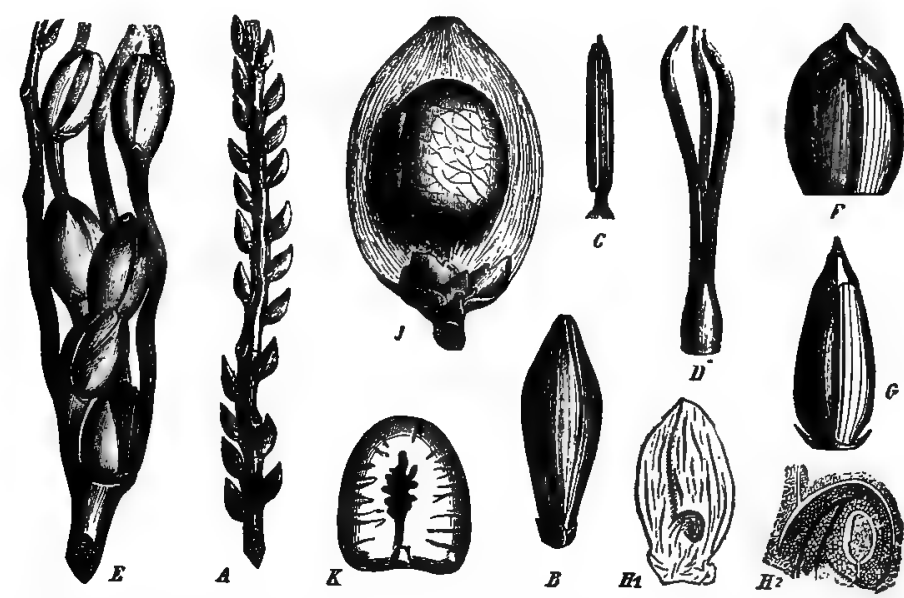

F1G. I27. A reca Catechu (Betel-nut palm). A, upper portion of an inflorescence bearing staminate flowers: $B$, enlarged view of staminate flower; $C, 3$ stamens; D, upper part of ovary with 3 styles; E, a branch bearing 4 pistillate flowers in the lower portion and 2 staminate flowers above; F, a pistillate flower with bracts removed showing the calyx; $\mathrm{G}$, an ovary with rudimentary stamen; $\mathrm{H}_{I_{1}}$ longitudinal section through ovary: $\mathrm{H}_{2}$, the same giving a magnified view of the ovule; J, section through a berry showing the fibrous sarcocarp and the seed covered by reticulated branches of the raphe; $K$, section of seed showing the ruminating endosperm with small embryo near the base-After Drude.

CARnaUba-WAX is obtained from the Carnauba-palm of Brazil (Copcrnicia cerifera). The wax exudes from the surface of the young leaves and is obtained by boiling them with water. DRAGON'S BLOOD, a bright red resinous substance, is obtained from the juice of the fleshy fruit of Calamus Draco. It consists chiefly of resin, some tannin and about 3 per cent. of benzoic acid.

The Oil palm (Elceis guineensis) of equatorial West Africa yields a drupe with an oily sarcocarp, from which by means of 
pressure or boiling with water, PALM oIL is obtained. The Cocoanut palm (Cocus mucifera) yields the COCOA NUT of the market and is probably one of the most useful palms to the natives, furnishing as it does, food, clothing, utensils of all kinds, building materials, etc. The Sago-palms (Metroxylon Rumphii and $M$. lave) yield SAGO, which is prepared by washing out the starch from the cut stems and subsequently heating it. A tree I5 years old yields from three to four hundred kilograms of sago starch. The Date palm (Phoniv dactylifera) yields the D.ITES of the market, and it is interesting to note that since very early times the fruits produced by the growers in the Orient have been the result of artificial or hand-pollination.

\section{ORDER ARALES OR SPATHIFLORE.}

This order includes two families which are markedly different in their habits: (I) The Araceæ which are rather large herbs with an inflorescence known as a spadix and consisting of a fleshy spike, which is subtended or enclosed by a large bract known as a spathe, as in the Calla-lily where it is large and white, and (2) the Lemnaceæ or duckweed family, which is composed of minute, floating, thalloid plants that develop one or more flowers on the margin or upper surface of the thallus.

ARACE正 OR ARUM FAMILY.-The plants belonging to this family are perennial herbs with tuberous or fleshy thizomes and simple or compound leaves which are usually longpetioled. The spadix is densely flowered, the staminate flowers being above and the pistillate below on the same axis, or the plants are wholly diocious. The perianth when present consists of 4 to 6 scale-like segments. Frequently the spadix is subtended or enclosed by a more or less showy spathe. The fruit is usually a berry, sometimes a utricle.

A number of the plants of this family have medicinal properties and one of them yields the official drug CaLAMus (p. 496). The drug is derived from sweet flag (Acorus Calamus) a plant common in swamps and along streams in the Eastern United States, and characterized by its long, narrow, linear, bilateral. leaves which are from two to six feet high and one inch wide or 
less. The inflorescence is a spike-like spadix having greenishyellow flowers.

Many of the Araceæ possess an acrid juice. The acridity may be due to certain acrid principles or to mechanical irritation caused by the presence of raphides of calcium oxalate. Frequently these principles are dissipated or destroyed on cooking and the plants are then used as food, as the WATER ARUM (Calla palustris),

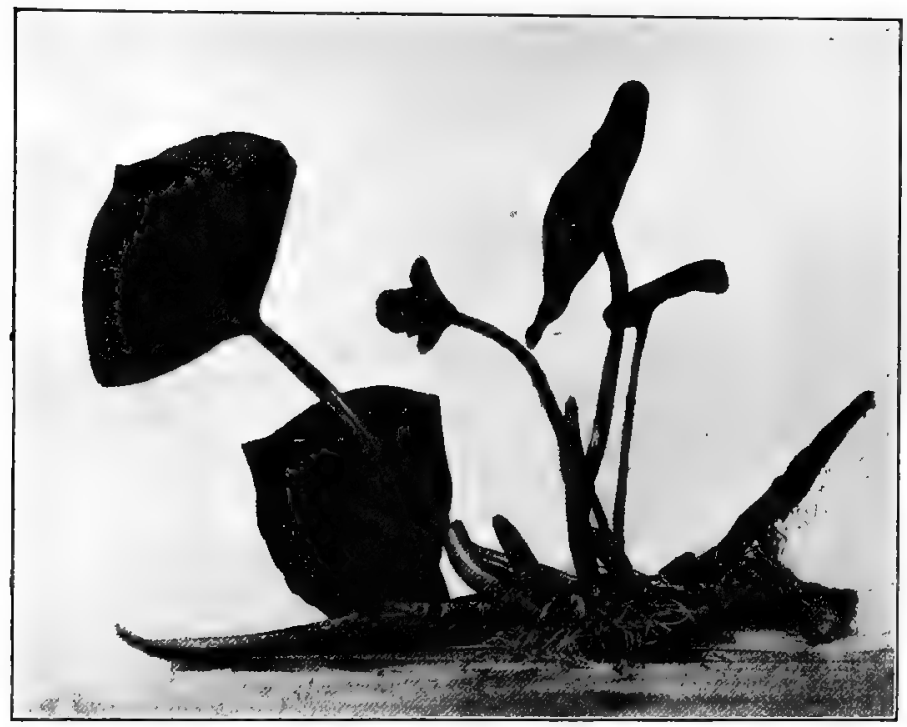

FIG. 128. Water arum (Calla palustris) showing portion of rhizome, the broadly ovate and cordate leaves, and the inflorescence which consists of a cylindrical spadix and an elliptical spreading spathe.

which on account of its acrid principles is used as a remedy for snake bites when in the fresh condition, but which on drying loses its acridity and being rich in starch is used as a food (Fig. I28). To this family also belong Jack-in-the-pulpit, or INDIAN TURNIP (Arisama triphyllum), the acrid corm of which is used in medicine; SKUNK CABBAGE (Spathyema fotida), the fetid rhizome of which has medicinal properties. A number of plants of the Arum family are rich in starch, as the tubers of Xanthosoma edule of Surinam which contain 62 per cent. of starch. 


\section{ORDER XYRIDALES OR FARINOS.N.}

The plants are mostly perennial herbs of tropical and subtropical America. The order includes a number of families among which is Bromeliaces, to which the pineapple (Ananas sativus) belongs. Pineapple is a native of Brazil and is now cultivated in warm countries of the eastern and western hemispheres. The fruit contains a proteolytic enzyme resembling trypsin and also a milk-curdling ferment. The bast fibers of the leaves are used for textile purposes. Some of the Bromeliacex are epiphytic (air-plants), the best known member being probably the Florida moss (Tillandsia usneoides) which is used in upholstery.

The family Commelinacex is represented in the United States by Cemmelina or day-flower, some species of which have medicinal properties. The roots of some tropical species contain saponin, as $C$. deficiens, of Brazil. The rhizomes of a number of species of Commelina contain notable quantities of starch and are edible. The spiderworts (Tradescantia) common in rich soil in the United States, and the Wandering Jew (Callisia repens) commonly cultivated as an ornamental plant, also belong to this family.

\section{ORDER LILIALES OR LJLIIFLORA.}

The plants of this order are mostly perennial herbs with rhizomes, tubers, bulbs, or fibrous roots. The leaves are parallelveined except in the rushes (Juncaceæ) where they are long, slender and cylindrical (radial).

a. LILIACE E OR LILY FAMILY.-The plants are the most typical of the Monocotyledons. They are scape-like herbs with bulbs or corms; the flowers are symmetrical, and the perianth is parted into six more or less distinct segments (Figs. I23; 124, $A$ ). The fruit is a loculicidal capsule. The following plants yield official drugs:

Veratrum viride is a plant two to eight feet high, which is characterized by the broad, clasping, strongly veined leaves, and by having the flowers in large terminal panicles (Fig. 129). The plant is found in swamps and wet woods in the United States in 
spring and early summer. The rhizome is upright, and is the part used in medicine (p. 492). The plant including the rhizome closely resembles the Veratrum album of Europe.

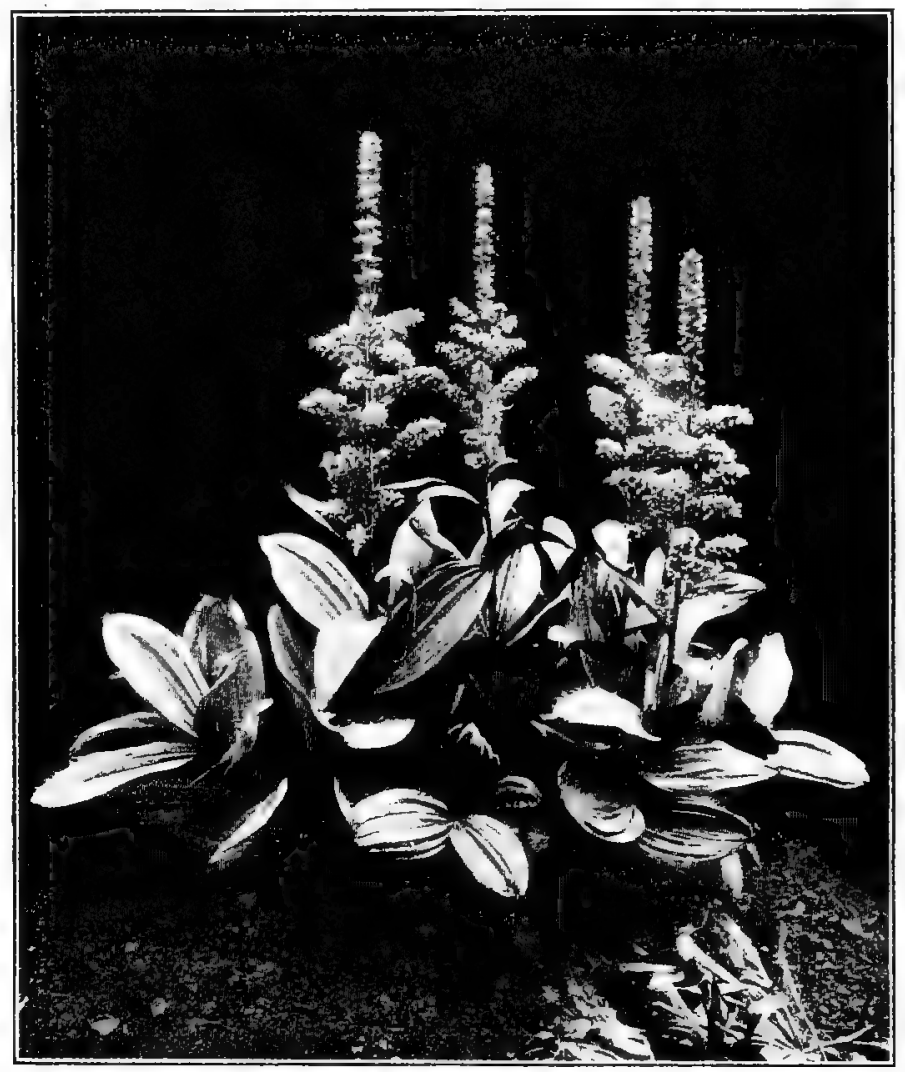

FIG. I 29. Plants of Veratrum viride growing in the Royal Botanic Society's Gardens (London) and showing the parallel veined (or nerved) leaves with entire margin, and the large terminal panicles of flowers.-After Pérrédès.

Colchicum autumnale.-This is the autumnal-flowering colchicum, a perennial herb but a few inches high which arises from a corm and bears proportionately large lilac-colored flowers. The fruit consists of three follicles containing numerous seeds. The corm (p. 509) and seeds (p. 426) of this and other species of Colchicum are the parts used in medicine. 
Aloe species.-The stems are about a meter high and bear at the summit a cluster of thick succulent leaves which are lanceolate and spinous-toothed. The inflorescences are in long spikes

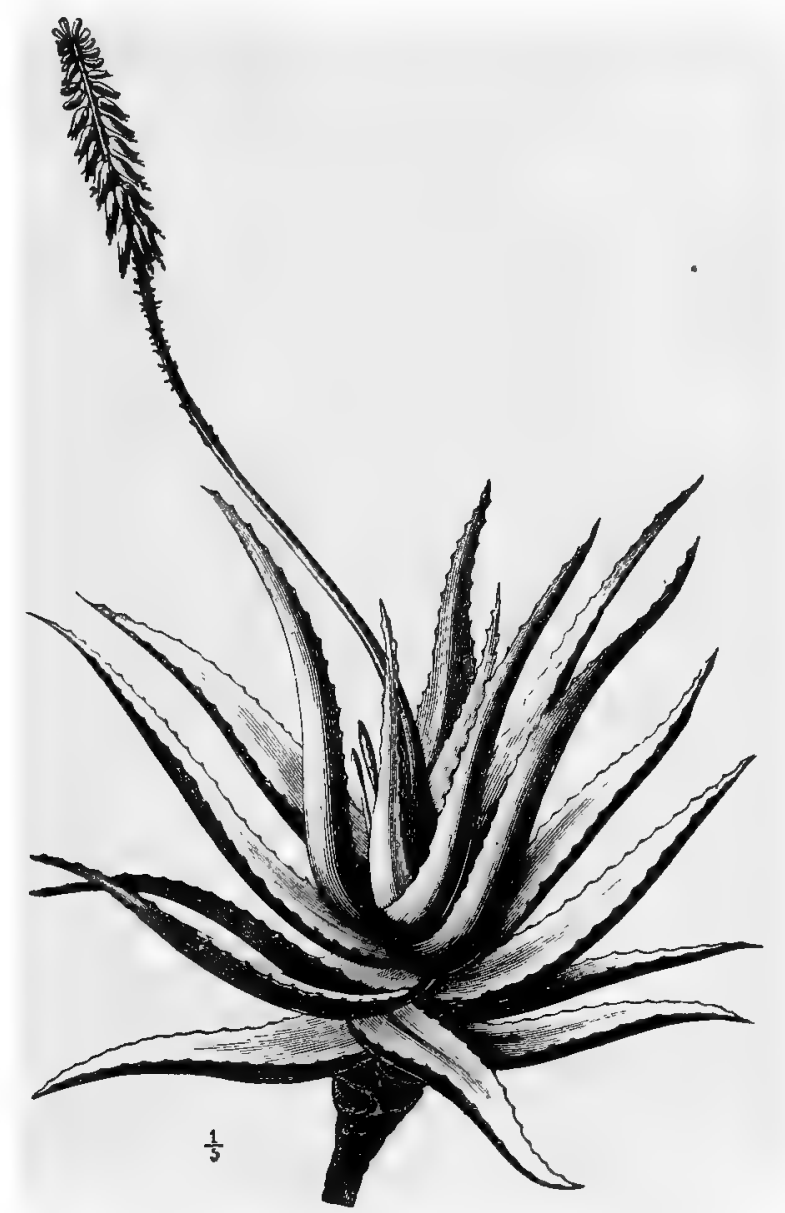

Fig. r30. Aloe vera, the plant yielding Barbadoes aloes. Showing crown of thick, succulent leaves and the long spike (inflorescence) with the flowers on the apper portion of the axis.-After Engler.

which are quite showy and characteristic for the different species. Aloe Perryi which yields the Socotrine aloes possesses leaves with white spines and flowers that are orange-red or scarlet at 
the base, the stamens being unequal; Aloe vera which yields the Barbadoes or Curaçao aloes has leaves with yellow or reddish spines and yellow flowers in which the stamens are as long as the corolla (Fig. I 30) ; Aloe spicata and some other African species which yield CAPE ALOES, have flowers in close spikes, the petals being white and marked by green lines, and the stamens much longer than the corolla. The inspissated juice is official in all the pharmacopœias (p. 66r).

Urginea maritima, which yields the drug squill, is characterized by. its large onion-like bulb, from which arise ten to twenty broadly lanceolate, grayish-green leaves; and by having the inflorescence in long spikes consisting of whitish flowers which have a distinctly purple stripe on each division of the perianth (p. 510).

Convallaria majalis or Lily-of-the-valley is a plant which is well known. It produces a raceme of delicately odorous white flowers and beautiful oblong leaves with prominent parallel veins: The rhizome and roots are official (p. 488).

Smilar species.-The drug sarsaparilla (p. 446) is yielded by a number of species of Smilax. These are mostly vines with woody or herbaceous, often prickly stems and leaves with petioles which have a pair of persistent tendril-like appendages. The flowers are small, mostly greenish, diœcious and in axillary umbels. The fruit is a globose berry. Not a great deal is known of the species which yield the drug, with the exception of Smilax medica which yields the Mexican sarsaparilla. In Smilax medica (Fig. $\mathrm{r} 3 \mathrm{I}$ ) the leaves vary from cordate to auriculate-hastate; in Smilax officinalis which yields the Jamaica sarsaparilla they are ovate, as they are also in Smilax papyracea which yields Para sarsaparilla. Nothing is known of the plant yielding Honduras sarsaparilla, although this drug has been in use for nearly four centuries. The plants have short rhizomes which give rise to long roots which are the part used in medicine.

A DRAGON'S BLOOD, resembling that derived from Calamus Draco (p. 232) is obtained from Draccena Draco, a tree growing in the Canary Islands. Some of the trees of this species are of historic interest, as the dragon tree of Orotava which is 46 feet in circumference at the base. 
A number of the plants of this family contain saponin, as the species of Smilax. Some contain coniferin and vanillin, as Asparagus officinalis. Some of the group contain glucosidal principles which under the influence of ferments yield ethereal oils containing sulphur, as the various species of Allium.

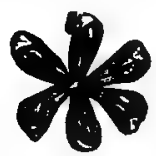

4
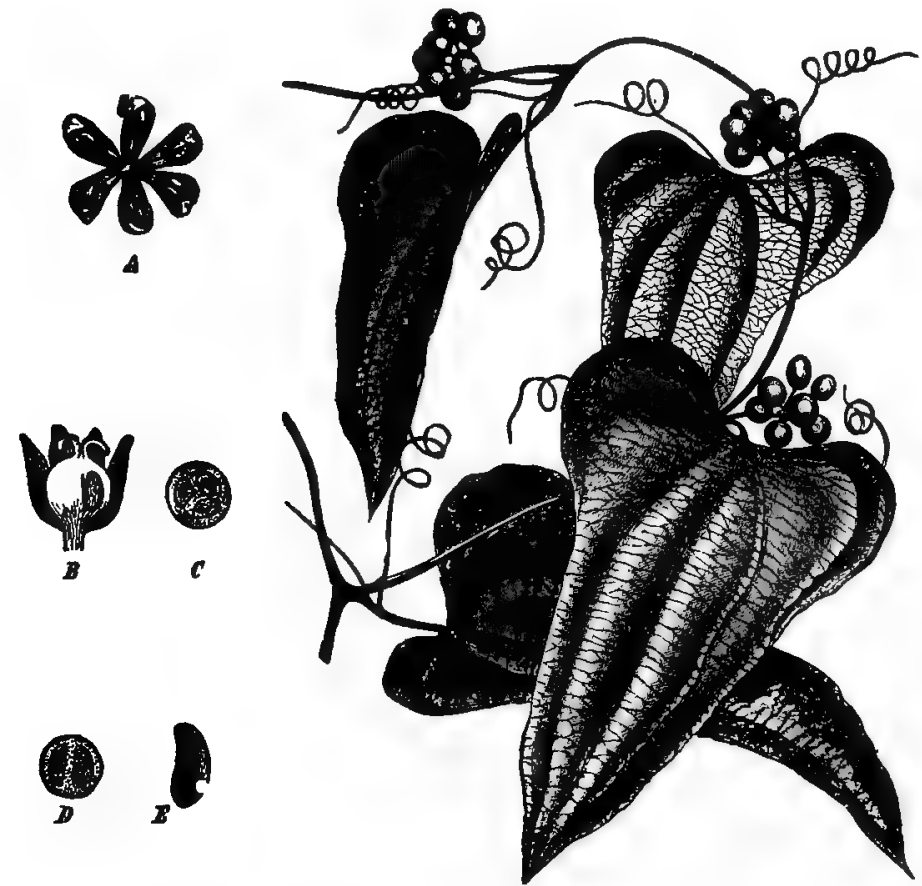

FIG. I3r. Smilax medica, the roots of which yield a sarsaparilla. To the right a portion of branch showing the characteristic veined leaves, the tendril-like appendages on the petioles, and the axillary, umbel-like clusters of fruits; A, staminate flower; B, pistillate flower in longitudinal section; $C$, transverse section of the tri-locular ovary; $D$, longitudinal section of ovary; E, seed.-After Bentley and Trimen.

A number of plants of the Liliaceæ are tused as vegetables, as the onion (Allium Cepa), leek (A. Porrum), garlic (A. sativum), and chives (A.Schonoprasum), asparagus (Asparagus officinalis). A number also are quite poisonous when fresh but edible when cooked.

b. AMARYLLIDACE王 OR AMARYLLUS FAMILY.This group is of special interest because it includes the Agave 
or Century plant. This is a characteristic genus of plants of the hot and arid regions of North America. The best known of these is the Centery plant (Agar'c americana) which is one of the most important economic plants of Mexico. The stem axis of the plant is very short and the thick 'fleshy leaves form a tuft at the tip. The leaves are lanceolate, with spinose margins, and furnished with stout terminal spines. The leaves as well as the roots contain a large amount of muciláge which retains water and thus helps to adapt the plants to these arid regions. The plants grow slowly and may flower when they are ten or twelve years old.

The Agaves contain saponin and other principles of medicinal value. They yield a number of other products as follows: PuLoue a fermented drink of the Mexicans, Mezcal a distilled drink resembling rum; various fibers, as SisAL HEMP, "Henequen" or "Sacci," etc. Other members of the Amaryllidaceæ likewise find use as medicines and as foods, many of them being cultivated as ornamental plants, as Narcissus, Hymenocallis, Crinum" and Amaryllis.

c. DIOSCOREACE $Æ$ OR YAM FAMILY.-The plants belonging to this family are twining shrubs or herbs with tubers either above or below ground. The general characters of the plants are shown in the wild yam-root (Dioscorea villosa) of the United States. Several species, notably, D. Batatas, yield the yAMs or Chinese potatoes of commerce.

Many of the species of Dioscorea, as well as other members of this family contain active principles which like those of the Araceæ and Liliaceæ are destroyed on heating. The rhizome of Tamus communis contains saponin and Rajania subamarata contains tannin.

d. IRIDACE $Æ$ OR IRIS FAMILY.-The plants of this family are perennial herbs with mostly equitant (bilateral) leaves and horizontal rhizomes, or corms. The flowers are regular or irregular and with a petalloid stigma (Fig. I24, $B$ ).

Iris versicolor is a flag-like plant commonly known as the LARGER BLUE FLAG and found abundantly in the marshes and wet meadows of the Eastern United States. It is distinguished by its tall stems and sword-shaped, somewhat glaucous leaves. The 
flowers are violet-blue. The rhizome somewhat resembles that of calamus, but is of a dark brown color and contains 25 per cent. of acrid resins, a volatile oil, starch and tannin.

Iris florentina, which yields the ORRIS ROOT of commerce (Fig. 69 ), is a plant cultivated in Middle and Southern Europe, and closely resembles the above mentioned species. The rhizome contains a volatile oil resembling that found in violets, and is used in perfumery. Orris root is also obtained from Iris germanica and $I$. pallida. The violet odor is developed on keeping the rhizome a year or two.

Crocus sativus, the orange-red stigmas of which have been used in medicine since ancient times, is an autumnal-flowering plant. The flowers are lilac-purple, somewhat like those of Colchicum, and occur at the tip of a scape rising ${ }_{5} 5$ to 20 centimeters above ground. The leaves are linear and rise directly from a more or less globular corm. The plant is cultivated in Spain and other parts of Europe and in the United States as well. The stigmas constitute the drug SAFFRON (Crocus) which was formerly official, and contain a coloring principle, I part of which will impart a distinct yellow color to 100,000 parts of water. Saffron contains a yellow glucoside, CROCIN, which is soluble in alcohol but not in water, and is colored blue by sulphuric acid. The drug also contains 7.5 to Io per cent. of a volatile oil, which appears to be derived from a coloring principle that resembles carotin; and the bitter principle picro-crocin.

e. JUNCACE\& OR RUSH FAMILY.-These are grass-like marsh plants, which are distinguished by the fact that the flowers are small, with 6-parted glumaceous perianth, and the fruit is a loculicidally dehiscent capsule. The stems are mostly solid, slender, usually arise in tufts from the rhizome and are characterized by stellate parenchyma cells, among which are large intercellular spaces, the latter also being characteristic of the leaves. The rushes are principally found in cold and temperate regions.

Several species of Juncts and Luzula have been used in medicine, particularly in Europe. The seeds of Luzula campestris, a common wood rush of the United States naturalized from Europe, are edible. Soft rush (Juncus effusus) and Hard rush (J. conglomeratus) are used in Japan in the manufacture of rush 
matting. In Holland the rush is grown on the embankments along the coast to prevent the action of the tides.

\section{ORDER SCITAMINALES OR SCITAMINEX.}

The plants of this order are mostly found in the Tropics and are perennial herbs with fleshy rhizomes. The leaves are large, more or less elliptical and pinnately veined. The leaf sheaths close tightly around each other and form a kind of false stem. The flowers are epigynous, unsymmetrical or zygomorphic, and frequently only one stamen is completely developed.

a. THE ZINGIBERACE $\mathbb{A}$ OR GINGER FAMILY is distinguished from the other Scitaminex by the fact that the seeds have endosperm as well as perisperm. The plants are rich in volatile oils and a number are used in medicine and perfumery.

Zingiber officinale yields the official ginger (p. 486). From a creeping, fleshy, branching and laterally compressed rhizome arises a stem about I M. high bearing numerous lanceolate leaves. The flowering stalk arises directly from the rhizome, terminating in a spike which bears flowers having greenish-yellow petals with violet or purple stripes (Fig. I32).

Elettaria Cardamomum (E. repens) yields the cardamom of the several pharmacopoias ( $\mathrm{p} .5^{8 \mathrm{I}}$ ). The plant has a leafy as well as floral stem which rises from a tuberous rhizome. The leaves are broadly lanceolate. The flowers are greenish-white, the labellum (consisting of two petal-like staminodes) being bluish. The fruit is a capsule, and the seeds are the part used in medicine.

The so-called PARADISE GRAINs are the seeds of Amomum Melegueta growing in Western Africa. They are about $3 \mathrm{~mm}$. in diameter, dark brown, nearly smooth, friable and contain a volatile oil.

GALANGAL, which is used in perfumery, is the rhizome of Alpinia Galanga growing in the East Indies and cultivated in China and Bengal. It is frequently referred to as "Galangal major" to distinguish it from the rhizome of Alpinia officinarum growing in China near Hainan. Galangal occurs in short, branched pieces of a reddish-brown color, with numerous circular scars 
and has an aromatic and pungent taste. It contains 0.5 per cent. of a volatile oil, the principal constituent of which is cineol; a

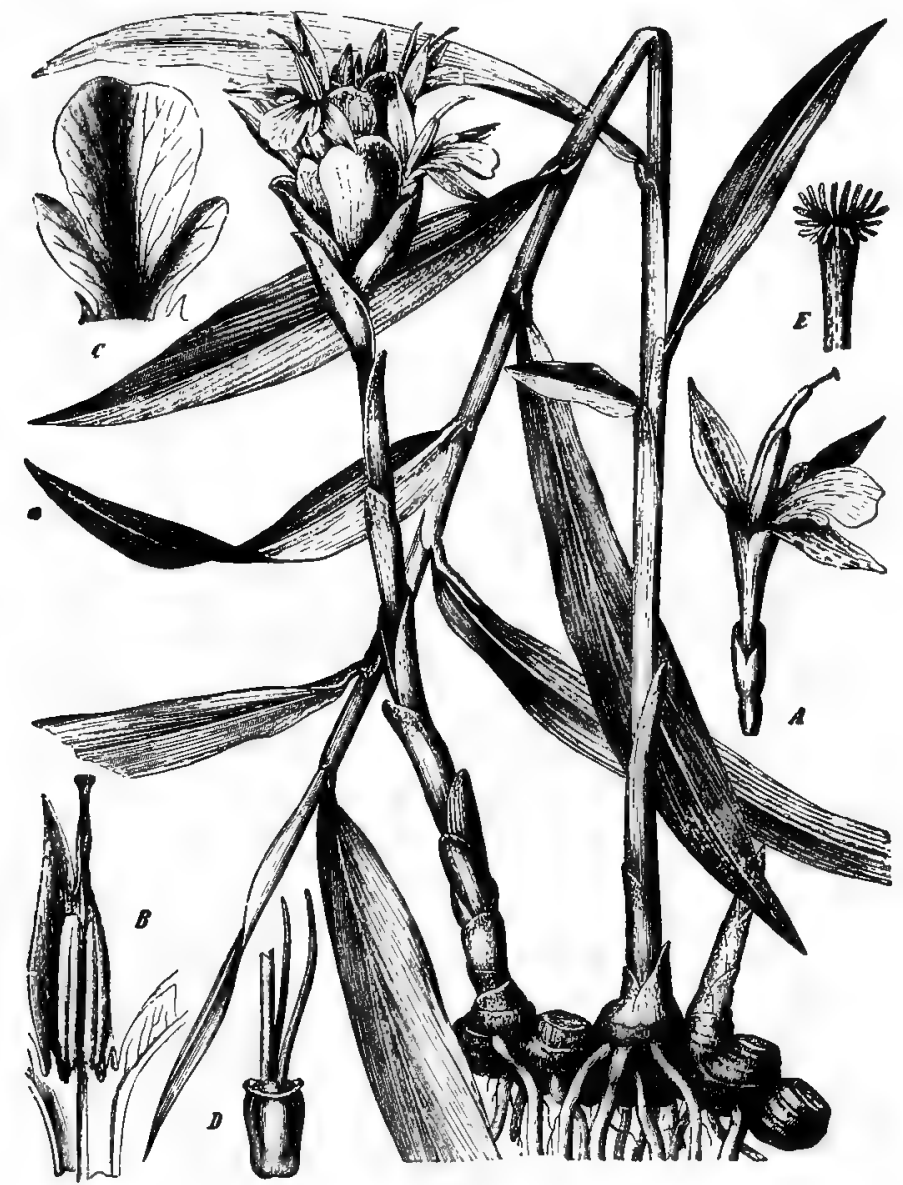

FIG. 132. Zingiber officinale, the rhizome of which constitutes the ginger of the market. Entire plant showing rhizome and roots, a leaf-branch and a flower-branch, as also scars of previous year's growth after decay of leaf- and flower-branches. A, entire flower; B, section of flower showing beak-like appendage at the apex of the fertile stamen, which encloses the style; $\mathrm{C}$, three-parted labellum or irregular segment of corolla showing 2 tooth. like staminodes (rudiments of stamens) at the base; D, the ovary with lower portion of style and two epigynous, filiform processes which secrete nectar; E, apex of funnel-shaped, fringed stigma.-After Berg and Schmidt.

pungent principle, galangol; an acrid, pungent resin; 25 per cent. of starch; and three crystalline principles. 
Curcuma or tURmeric is the rhizome of Curcuma longa, a reed-like plant which is largely cultivated in India and other tropical countries. In preparing the rhizome for market it is subjected to a scalding or par-boiling process which agglutinates the starch in the cells. While turmeric is used as a condiment it is also used on account of its color as an adulterant of mustard and other articles, but is very easily detected (Fig. 290). Several forms of curcuma are found in commerce, as "round çurcuma," consisting of the main rhizome, and "long curcuma," composed of the short branches. They occur in cylindrical or ovoid pieces, 2 to $5 \mathrm{~cm}$. long, of a yellowish-brown color externally, bright yellow internally, and aromatic odor and taste. Curcuma contains I per cent. of volatile oil containing phellandrene and turmerol; 0.3 per cent. of a yellow crystalline principle, CURCuMIN, which is soluble in alcohol, sparingly soluble in water, forms reddish-brown solutions with alkalies and is converted into vanillin with weak oxidizing agents. It also contains considerable starch and a smiall quantity of an alkaloid.

Other families of the Scitaminex are of great importance on account of the food-products obtained from them, as the Musacere which contains the group of plants to which the BANANA (Musa paradisiaca and M. Sapientum) belongs. To the Cannacece belong the cultivated Cannas, one of them, Canna edulis, being grown extensively in the West Indies and Australia as a vegetable, and another, Canna coccinea, which grows in the West Indies and South America furnishing "Tous les mois," the arrow-root starch of the English and French. To the Marantacere belongs Maranta artundinacea, which is cultivated in tropical America, and the rhizome of which yields the starch, Maranta ARROWROOT (Fig. 316, B).

\section{ORDER ORCHIDALES OR MICROSPERMAE.}

The most important family of this order is the ORCHIDACEx or Orchid FAMiLy. The orchids are the most highly specialized of the Monocotyledons. They are perennial herbs with diverse habits, many tropical species being epiphytes, and varying morphological structure which is particularly evident in the zygomorphic 
flowers. The perianth consists of six segments. The three outer correspond to sepals and are similar. Two segments of the inner circle correspond to petals and are alike, while the third, which is known as the LIP, is remarkably modified, being usually larger, often spurred, and sometimes inferior (below the ovary) by the torsion of the ovary or stalk of the flower. The stamens are variously united with the style, forming an unsymmetrical coLumN. The anther is 4-locular and does not dehisce at maturity. The pollen grains form from two to eight club-shaped masses (pollinia) which are withdrawn by visiting insects and carried to other flowers. The viscid stigma either faces the lip of the corolla or is embedded between the pollen sacs. The seeds are very numerous, exceedingly small and without endosperm.

Vanilla planifolia, which yields the official vanilla, is a highclimbing plant with long internodes and distinct nodes from which arise more or less oval or broadly lanceolate, somewhat fleshy leaves and also a single aerial root (Fig. 133). The long stem is terminated by a raceme, flowers also arising in the axils of the leaves for some distance back on the stem. The flowers are yellowish-green and the segments of the perianth are similar, and erect or spreading. The lip is united with the column, forming a cylindrical body which is strongly concave on one side and spreading at the top (Fig. I33, $A$ ). The pollinia are granular. Pollination may be effected by insects but is usually brought about by artificial means (hand-pollination). The fruits require several months to become fully grown and an equal period of time is necessary for their maturity which is indicated by their yellow color. They are then gathered and cured by alternately steaming and drying them when they acquire the dark brown color and the odor of the commercial article. Vanilla is cultivated in all tropical countries where the temperature does not fall below $18^{\circ} \mathrm{C}$., and the humidity is considerable. Usually vanilla culture is combined with that of Cacao. The plants begin to yield fruits the third year and continue bearing for thirty or forty years (p. 585 ).

The yellow-flowering Cypripediums of the United States (Cypripedium hirsutum and $C$. parviflorum) yield the cypripedium of the Pharmacopœia (p. 490). The plants are a foot or two high. The leaves are oval or elliptical (C. hirsutum) or 
elliptical or lanceolate (C. parviflorum). In C. hirsutum the lip is pale yellow with purple veins, 25 to 50 millimeters long, and

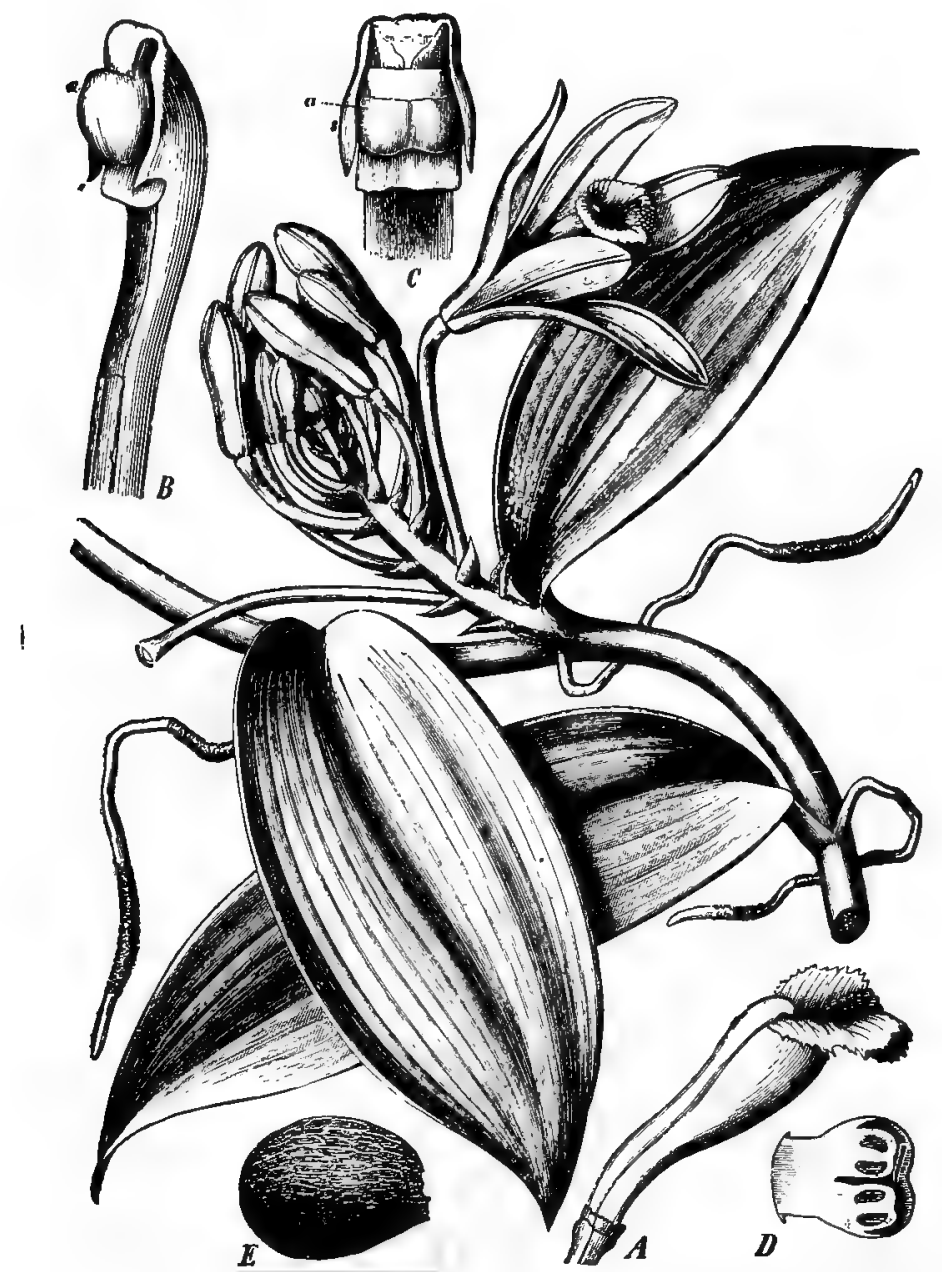

FIG. I33. Vanilla planifolia, showing portion of stem bearing typical monocotyledonous leaves, aerial roots and inflorescence. A, column (formed by the union of the filaments, style and stigma), and the labellum (irregular segment of perianth); B, column seen from the side; C, apex of column seen from the front showing anther (a), stigma (s); $D$, section of anther; $E$, seed.-After Berg and Schmidt.

possesses a tuft of white, jointed hairs at the throat. In C. parviflorum the lip is from 20 to $40 \mathrm{~mm}$. long and non-hairy (Fig. 213). 
The root-stocks of a number of Orchids are rich in mucilage and yield the drug salep or a product resembling it. Salep occurs in the form of globular or somewhat flattened, more or less translucent, light yellowish-brown tubers, 2 to $4 \mathrm{~cm}$. long, of a horny texture and a mucilaginous taste. The principal constituent is mucilage which originates in the cell-contents. It may contain in addition either starch or sugar.

\section{B. CLASS DICOTYLEDONS.}

The following are some of the prominent features of the Dicotyledons: ( I) The leaves are reticulately (open) veined and asually with an irregular margin, being sometimes deeply lobed; (2) the parts of the flower are usually in circles of 2 to 5 each; (3) the stem is isually differentiated into pith, wood and bark and the fibrovascular bundles are of the open collateral type, arranged radially about the pith and separated from each other by medullary rays; (4) the germinating plant usually has two cotyledons which are opposite each other. The Dicotyledons are divided into two series or sub-classes, depending upon whether the parts of the corolla are distinct or are united, namely, the Archichlamydeæ and Metachlamydeæ.

\section{ARCHICHLAMYDE压 OR CHORIPETAL .}

The Archichlamydeæ or Choripetalæ comprise those dicotyledonous plants in which the petals are separate and distinct from one another or are entirely wanting.

\section{ORDER PIPERALES.}

The plants of this order are mostly tropical herbs and shrubs and possess very small flowers which have neither petals nor sepals. The leaves are simple and without stipules, the most important family medicinally as well as in other ways being the Piperace 2 , to which the following medicinal plants belong.

Piper nigrum is a woody climber that has leathery, grayishgreen, ovate, cordate or ovate-elliptical leaves, with three prom- 


\section{BOTANY AND PHARMACOGNOSY.}
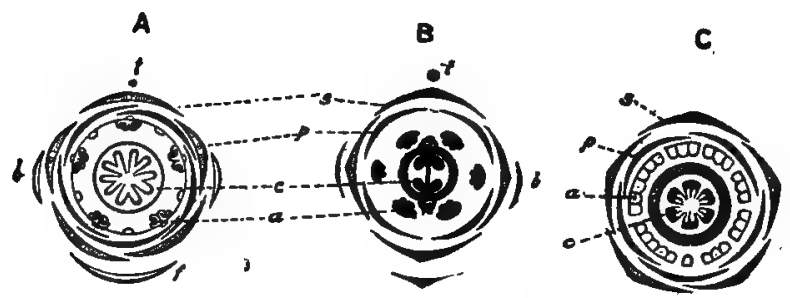

D

E
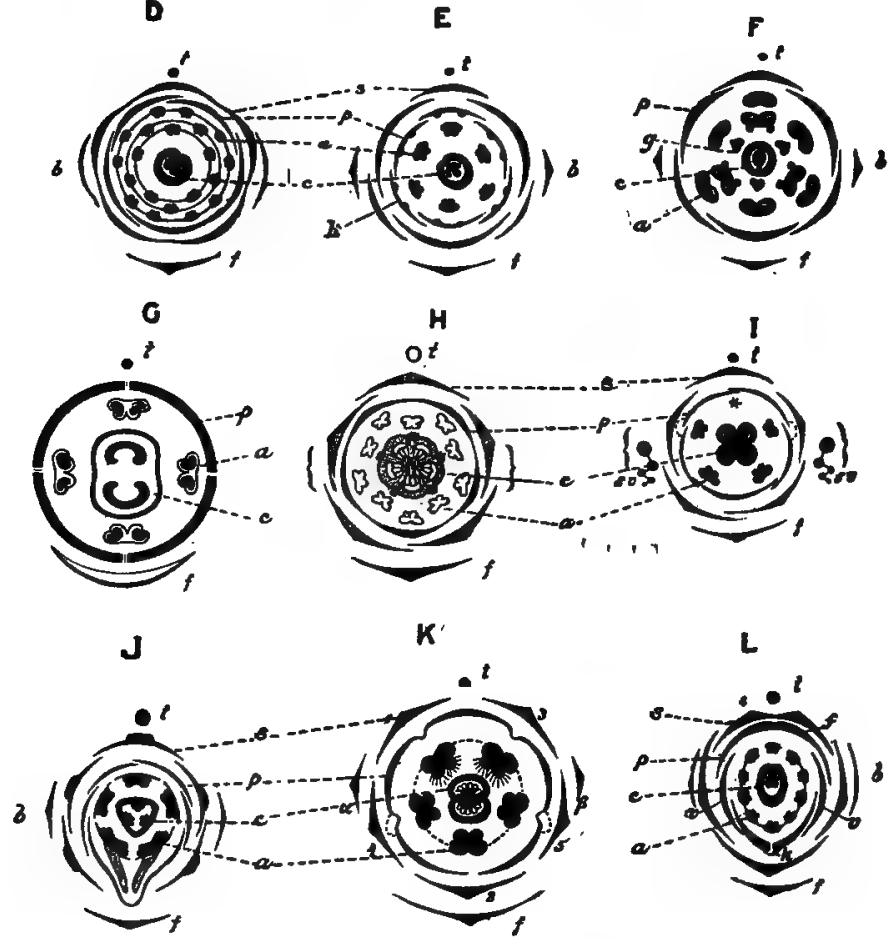

FIG. 134. Diagrams of cross sections of the flowers of a number of families of dicotyledonous plants showing the number and position of the parts with reference to each other: $t$, stem of plant; $f$, foliage leaf; $b$, bracts or leaves on the flower-stalk; $s$, sepals; $p$, petals; a, stamens; c, ovary; per, perianth. A, Linaceæ; B, Cruciferæ; C, genus Citrus; D, Rosaceæ; E, Berberidaceæ, showing nectaries $(\mathrm{k})$ on the petals; F, Lauraceæ, showing staminodes (g); G, epigynous flower of Rubiaceæ; H, Ericaceæ; I, Labiatæ, showing position of other flowers (sv) in the cymes; J, Violaceæ showing spurred stamens; $K$, Campanulaceæ, showing bracts $(\alpha, \beta)$ the relation of the sepals $(1,2,3,4$ and 5$)$, and two posterior hairy stamens; L, Leguminosa, showing the large posterior petal ( $p$ ) known as the vexillum or standard, the two lateral petals (v) situated under the standard known as alæ or wings, and the two anterior petals which are covered by the wings and partly cohering to form a prow-shaped body called the carina or keel (k).-Adapted from Warming. 
inent middle nerves and two side nerves; the flowers are perfect, sessile and form an elongated fleshy spike; the fruit is a berry which is yellowish-red when ripe. The unripe fruit constitutes the BLACK PEPPER of commerce (p. 57I). WhITE PEPPER (p. 573 ) is the ripe berry from which the epicarp is removed, while "LONG PEPPER" (p. 573) is obtained from Piper longum, an entirely different plant.

Piper Cubeba is a climbing perennial with leathery ellipticalovate or long elliptical leaves; the flowers are diœcious and arranged in spikes; the fruit is a berry, the pedicel becoming much elongated after fertilization. The unripe fruit is the part used in medicine and is official as cubeb (p. 569; Fig. 250).

Piper angustifolinm yields the official Matico (p. 617). The plant is a shrub growing in Central and South America and is characterized by its long, oblong-lanceolate, deeply reticulate, very hairy leaves. The flowers and fruits are very small and arranged in long, slender spikes, which are frequently found in the drug. Matico contains 2 to 3 per cent. of a volatile oil, containing a stearoptene matico camphor, which appears to be the most important constituent. It also contains an acrid resin, a bitter principle and a crystalline principle artanthic acid. Other related species of Piper are used in tropical America similarly to Piper angustifolium.

The leaves of a number of species of Piper (known as "betel leaves") are mixed with the Areca nut and lime and constitute what is known as "Betel," which compound is used for chewing, in India and other countries, chiefly on account of its astringency. The root of Piper methysticum is also chewed, and when mixed with the milk of the Cocoantr yields an intoxicating drink which is used by the inhabitants of the Sandwich Islands. The dried root has been used in medicine under the name of Methysticum or Kava-Kava. It consists of large, branching, soft, spongy, dark brown pieces, which are tough, fibrous and with a pungent, somewhat bitter taste. Kavakava contains 3 resins, one of which has marked anæsthetic properties; an alkaloid, kavaine; a neutral body, methysticin; and about 50 per cent. of starch. The drug is free from calcium oxalate crystals, these being usually wanting in the Piperaceæ. 


\section{ORDER SALICALES.}

This order comprises but a single family, namely, the SALICACEx or Willow Family, to which belong the willows and poplars. The plants are diocious shrubs and trees; the flowers being in aments or catkins and without petals or sepals. The fruit is a capsule containing many seeds which are small and with long silky hairs at the base.

The barks of a number of the members of this group contain glucosides, as salicin which is found in Sali.r alba the white willow of Europe and the United States, and the brittle willow Salix fragilis; and populin which is found in the white or silver-leaf poplar (Populus alba) of Europe, Asia and the United States and Populus pyramidalis of Italy. These principles are also found in other species of willow and poplar. A number of the barks contain a yellow coloring principle allied to quercitrin, as Salix daphnoides of Europe and Salix alba. Tannin is a common constituent in both the willows and poplars. The buds of many of the poplars contain in addition a volatile oil which is in the nature of a di-terpene, as those of Populus pyramidalis. Populus balsamifera, the tacamahac or balsam poplar of the United States and Canada, furnishes the BALM of GILExD buds which are coated with an oleo-resin that gives them their aromatic properties. Populus nigra yields a volatile oil of which the important constituent is humulene.

The charcoal used medicinally is prepared by burning the wood of the young shoots of the white and black willow, poplar, beech or linden without access of air.

\section{ORDER MYRICALES.}

This group somewhat resembles the Salicales in that the flowers are in aments. The flowers are either pistillate or staminate and mostly diœcious in our native species. The most important family is the MyrICACE⿸ or Bayberry Family. The genus Myrica is especially characterized by the fact that the outer layer of the drupe is waxy. This is particularly true of the following species: Myrica cerifera the wax myrtle of the sandy 
swamps of the United States, and M. ralapcnsis of Mexico. The fruit of sweet gale (M. Gale) yields a volatile oil containing a camphor. The sweet fern (Comptonia peregrina) found in the United States, yields a volatile oil resembling that of cinnamon. The rhizome of this plant contains also tannin and possibly gallic and benzoic acids.

\section{ORDER JUGLANDALES.}

The plants are trees with alternate, pinnately-compound leaves. The staminate flowers are in drooping aments, the pistillate being solitary or several together. The flowers are monœcious and have a more or less distinct perianth consisting of three to six lobes. The fruit is a kind of drupe formed by the union of the torus with the wall of the ovary. There is but one family in this order, namely, the Juglandaces (Walnut family), which includes the hickory. (Hicoria) and walnut. The black walnut (Juglans nigra) of the United States yields a valuable timber and an edible nut; the white walnut or butternut ( $J$. cinerea) of the United States yields the butternuts which are edible, and a bark which has medicinal properties and was formerly official uncler the name of Juglans. Butternut bark occurs in quills or channelled pieces of variable length, 2 to Io mm. thick; it is dark brown externally; has a short, fibrous fracture, characteristic odor and bitter, pungent and acrid taste. It contains about 7 per cent. of a yellow, crystalline acrid principle which is colored purple with alkalies; 2 to 2.5 per cent. of a crystalline resin; volatile oil, tannin, sugar and a fixed oil.

J. regia native of Persia and cultivated in varinus parts of Europe and California, yields the edible ENGLISH WALNCiT.

The following species of hickory yield edible nuts: The shellbark hickory (Hicoria or'ata); the pecan ( $H$. pecan) common from Illinois southward; and western shell-bark hickory ( $H$. sulcata). The wood of these as well as $H$. glabra and other species of hickory is used where strength and elasticity are required.

Coloring principles are found in the barks of a number of species and are used for technical purposes. The following con- 
tain yellow coloring principles: Hicoria ovata, $H$. sulcata, and H. glabra (pig-nut hickory); green coloring principles are found in H. tomentosa, and yellowish-brown principles in Juglans nigra, $J$. cinerea and $J$. regia.

The fatty oils from the cotyledons (kernels) of both liickorynuts and walnuts are articles of commerce, and they have been used in medicine.

\section{ORDER FAGALES.}

The plants are trees or shrubs with alternate, petiolate, simple, pinnately veined leaves. The flowers are in aments, monœcious, and with a more or less distinct perianth. The fruit is a nut which is subtended by the mature involucre (bur or cup) or samara, the seeds being without endosperm (Fig. I35).

a. BETULACE $\mathbb{E}$ OR BIRCH FAMILY.-The plants are aromatic trees or shrubs and are represented in the United States by such trees as hornbeam (Carpinus), ironwood (Ostrya), and birch (Betula); and by such shrtibs as the hazelnut (Corylus) and alder (Alnus). The plants yield a volatile oil consisting largely of methyl salicylate. The bark of the sweet birch (Betula lenta) yields the oil of betula which is official and closely resembles the - oil of wintergreen. The bark of a number of plants of this family yields tannin and yellow coloring principles. A number of species of Betula yield a sweet sap, as $B$. lenta, and B. Bhojpattra of Russia. The nuts of some species are edible, as the filbert or hazelnut of Europe (Corylus Avellana), the hazelnut of the Orient ( $C$. Colurna), the American hazelnut ( $C$. americana).

b. FAGACE王 OR BEECH FAMILY.-This family includes some of our largest forest trees, these being rather characteristic of temperate regions. They are all highly valued for their timber and vield other valuable products besides. One notable characteristic is that all of the chestnuts and oaks and some of the beeches contain tannin in the wood, bark and leaves. The oaks are further notable in being prone to the attack of gall-producing insects. (varions species of Cynips) whereby the peculiar excrescences known as galls are formed on the leaves and young shoots. Among the oaks which yield galls rich in tannin are the follow- 
ing: Quercus infectoria of the Mediterranean, which yields the Turkish or Aleppo galls which are official (p. 646); Quercus Robur, which is sometimes divided into $Q$. pubescens and $Q$. pedunculata, yields a European gall; the live oak ( $Q$. virginiana) of Texas; and Q. lobata of California. Various oaks of the Southern States also produce "ink balls" or "ink galls," as Q. coc-

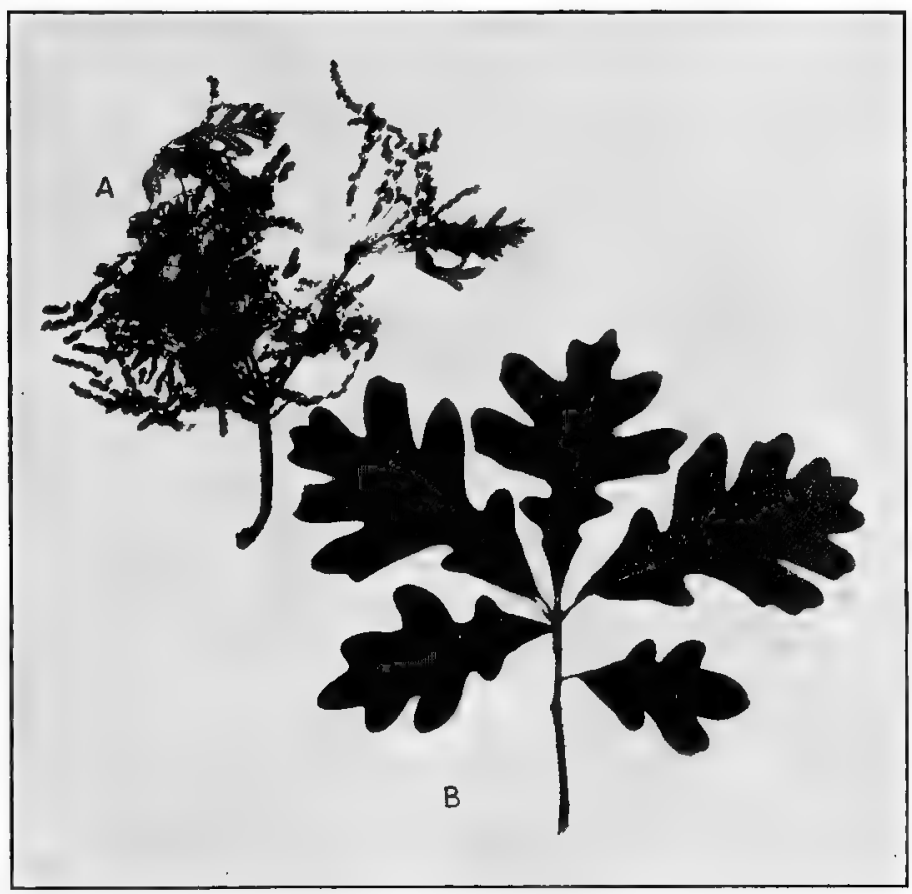

FIG. 135. White oak (Quercus alba): A, branch with staminate flowers; $B$, branch showing the characteristic lobed leaves.

cinea and $Q$. imbricaria. Because of the high tannin content the barks of several species of oak are used in the tanning industry, as that of white oak (Quercus alba), red oak (Q. rubra), Spanish oak (Q. digitata), and black oak (Q. velutina) all of North America; $Q$. pedunculata and sessiliflora of. Germany, and $Q$. dentata of Japan. 
The glucosidal coloring principle quercitrin is found in the bark of Quercitron or black oak (Q. velutina). Q. coccifera of Southern Europe yields a red coloring principle which is used in dyeing.

The wood of the American beech (Fagus americana) and of the European red beech ( $F$. syliatica) yields a tar from which on distillation the official cEOSOTE is obtained (p. 678).

The cork of commerce which is used for a variety of purposes is derived from the bark of several species of Quercus, namely, $Q$. Suber and $Q$. occidentalis growing in Spain, Southern France and Algiers.

The cotyledons of the seeds of the Beech family are rich in proteids, starch and oil, and some of the nuts are Spanish chestnuts obtained from Castanea a'ulgaris, American chestnut from $C$. dentata and CHINQUAPIN from $C$. pumila (Fig. 72).

\section{ORDER URTICALES.}

This order embraces three families which, while they agree in certain characters, are quite distinct in other ways.

a. ULMACE E OR ELM FAMILY.-The plants are trees or shrubs with alternate, simple, serrate, petiolate leaves. The flowers are monœcious or diocious, with a $4^{-}$to 6-divided perianth. The fruit is a I-seeded drupe, samara or nut. The typical group of this family is that of the elms, of which the American or white elm (Ulmus americana) is the most prized for ornamental purposes. The elms yield valuable timber and the bark of Ulmus campestris of Europe is used for tanning and dyeing because of the presence of tannin and a yellow coloring principle.

The inner bark of the red or slippery elm (Ulmus fulva) is used in medicine on account of its mucilaginous character (p. 544 ; Fig. 99, C). The tree has a gray, fragrant bark; leaves which are very rough above and hecome fragrant on drying, and the wood is reddish-brown. The samara is not hairy as in some of the other species.

b. MORACE $Æ$ OR MULBERRY FAMILY.-The members of this family are herbs, shrubs or trees, many of them containing a milk-juice or latex. There are many representatives in 
the tropical regions and some in temperate regions. The flowers are unisexual, with a $4^{-}$to 5 -parted perianth and occur in spikes or ament-like clusters.

Cannabis sativa.-This is the plant yielding hemp and the drug Cannabis Indica (p. 635). The plant is an annual branching herb from I to $3 \mathrm{M}$. high. The leaves are alternate above, opposite below, digitate with 5 to I I linear-lanceolate, serrate lobes (Fig. 273). The flowers are diœcious, the staminate occurring in panicles and the pistillate in erect simple spikes. The inner bark of the stem is fibrous and it is from this that the HEMP FIBER is prepared.

Humulus Lupulus or hop is a twining perennial plant, curving to the right, with opposite, palmately $3^{-}$to 7 -lobed (or simply dentate above) rough leaves (Fig. I36). The flowers are diocious, the staminate ones occurring in panicles and the pistillate in ament-like spikes. On the inner surface of each scale of the ament occur two flowers consisting of a membranous perianth and a bicarpellary ovary with two long styles. After fertilization the aments become cone-like and this compound fruit constitutes the hop of commerce. This fruit differs essentially from the true strobiles or cones of the Gymnosperms in that the seed in the latter is replaced by an akene. "Hops" are used in medicine (p. 582 ) and in brewing.

Ficus Carica, which yields the official fig, is a deciduous tree from 3 to $7 \mathrm{M}$. high, and with large, 5-lobed, petiolate leaves. The flowers are situated in a hollow torts, the walls of which after fertilization become thick and fleshy constituting the fruit (p. 590$)$.

A large number of the plants belonging to the Moraceæ yield economic products, some of which, as the drug Cannabis indica obtained from Cannabis sativa, are extremely poisonous. HASHISH or BHANC is a preparation made from the dried leaves, stems. and flowers of the pistillate plants and is smoked either alone or with tobacco, or chewed in combination with other substances, or an intoxicating drink is made from it, it being extensively used by the inhabitants of Arabia, Persia, India and other oriental countries. The leaves of Ficus Ribes of the Philippine and Molucca Islands are smoked like opium. The milk-juice of a number 
of plants belonging to the Moraceæ is the source of arrow poisons. The URARI POISON of Brazil is obtained from Ficus atrox; the IPOH ARROW POISON of Java and Borneo is derived from the Upas-tree, Antiaris toxicaria. Many of the plants of the group

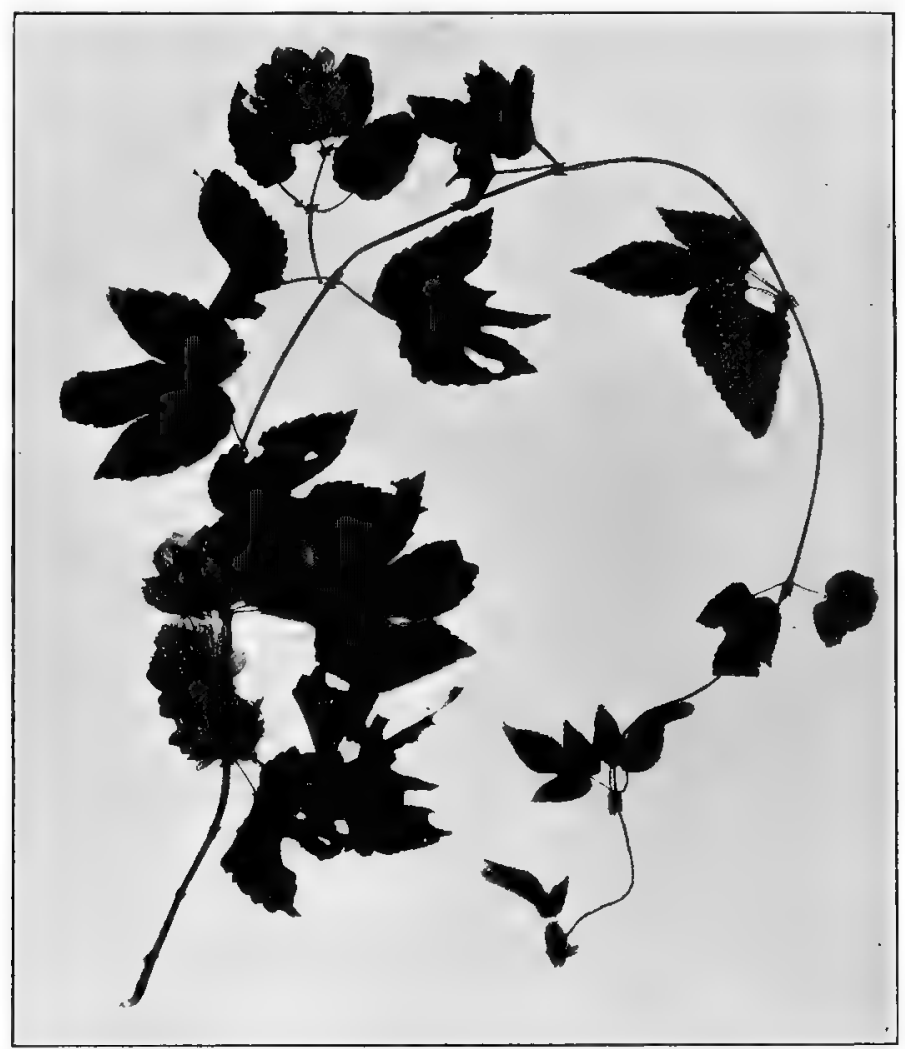

Fig. ${ }^{36}$. Hop vine (Humulus Lupulus) showing opposite, petiolate, entire or 3-lobed leaves, and the cone-like fruiting aments, which constitute "hops."

contain emetic principles, as the Cocillana PARK of Guarea Rus$b y i$, a tree of Bolivia.

The milk-juice of quite a number of species of Ficus yields India-rubber or caoutchouc (p. 667), as Ficus elastica of the East Indies, F. toxicaria of South America, F. elliptica and F. pri- 
noides of New Granada and several other species of Brazil, Brosimum spurium of Jamaica, Cecropia peltata of the West Indies and South America, and Castilloa elustica of Mexico and the West Indies. Ficus benghalensis of India and tropical Africa, and Ficus Tsicla of India, yield gum-lac. Ficus altissima and $F$. religiosa of tropical Asia yield shellac on puncture of the stems by a hemipterous insect (Coccus lacca).

A yellow coloring principle is found in Cudrania javancnsis of tropical Asia and Africa, Chlorophora tinctoria of Mexico, Maclura aurantiaca (Toxylon pomiferum) or osage orange, a hedge plant of North America; Ficus tinctoria of the Friendly Islands and $F$. asperrima of India. A fatty oil is obtained from Artocarpus Blumei of Java.

A large number of the plants of the Moraceæ yield edible fruits besides the fig tree already described, as the BREAD-FruIT trees (Artocarpus incisa) of the Sunda Islands and the JACK-TREE ( A. integrifolia) of the East Indies, the white MulberRy (Morus $a l b a$ ) and the BLACK MULBerRy (Morus nigra).

The leaves of the white mulberry (Morus alba) indigenous to China and ctltivated since the twelfth century in Europe and now in cultivation to a limited extent in the United States, are the chief food of the silkworm.

c. FAMILY URTICACE $Æ$ - - The plants belonging to the Urticaceæ or Nettle Family are chiefly herbs with mostly petiolate, stipulate, simple leaves. The flowers are small and with 2 to 5 distinct or more or less united sepals. The fruit is an akene; the embryo is straight and surrounded by an oily endosperm. The stems and leaves of several of the genera are characterized by stinging hairs, this being especially true of the sub-group to which the genus Urtica or stinging nettle belongs. Of the stinging nettles the following are used in medicine: Urtica dioica of Europe and naturalized in the United States, U. spatulata of Timor, Laportea cremulata of tropical Asia, L. moroides of Queensland, and Girardinia palmata of India. In the small nettle (Urtica urens) of Europe and the United States an alkaloid has been found, and Laportea stimulans has been used as a fish poison. Boehncria cordata of Brazil is used as a substitute for Arnica. The fibers of a number of the Urticaceæ have been 
found useful, of which the following may be mentioned: Urtica cannabina of Asia, $U$. dioica, $U$. urens and Boehmeria nivea of the Sunda Islands and China, the latter of which yields Ramie. The akene of Debregeasia edulis of Japan and the rhizome of Pouzolzia tuberosa of China and Japan are edible.

\section{ORDER PROTEALES.}

The members of this group are mostly shrubs and found principally in the Tropics and southern hemisphere, several species being cultivated in greenhouses for the sake of the beautifully colored flowers which are in crowded inflorescences. The order is represented by but a single family, namely, the Proteaceæ. The leaves are leathery and vary even on the same plant from simple to compound. The glucoside proteacin and a bitter principle are found in Leucadendron argenteum and $L$. concinnum. both of Africa. A gum-resin is found in Grevillea robusta of Australia, and a tannin in the bark of Lomatia obliqua of Chile.

A golden-yellow coloring principle is obtained from the flowers of Persoonia saccata of Australia. The wood of Protea grandiflora of Abyssinia is used in wagon building, and Leucospermum conocarpum of Cape Colony yields a valuable red wood and a tan bark.

Banskia amula of Australia and the sugar-bush (Protea mellifera) of Australia and $P$. speciosa have a sugary cell-sap. The oily seeds of the Chilean hazelnut (Guezina Avellana) are highly prized as food by the inhabitants. The seeds of Brabeium stellatifolizm or wild chestnut of Cape Colony are poisonous when fresh, but on roasting they become edible and are used as a substitute for coffee.

\section{ORDER S.INTALALES.}

This order embraces a number of families which are quite distinct in several respects.

a. LORANTHACE ER MISTLETOE FAMILY.-The plants are half-parasites with well developed leaves containing chloroplastids. They live on trees by means of haustoria. To 
this family belongs the American mistletoe (Phoradendron flavescens) parasitic on oaks, elms, the tupelo (Nyssa), red maple and other decidtous trees. The white, globose berries of this plant are quite poisonous, as are also those of the European mistletoe (Viscum album) and the oak mistletoe of Southern Europe (Loranthus europaus). The fruits of this family contain a substance known as VISCIN which is due to the action of an enzyme. This substance serves to attach the seeds to the barks of trees, where they germinate, and it is used in the manufacture of BIRDLIME, which owing to its viscid character is used to catch small birds.

b. SANTALACE $Æ$ OR SANDALWOOD FAMILY.The plants are chlorophyllous herbs or shrubs which are common in warm countries, and many of which are parasitic on the roots of other plants. A number of them contain volatile oils, as the wood of various species of Santalum. The official oil of santal is obtained from the scented wood of the white sandalwood (Santalum album) a small tree growing wild and also cultivated in India and the East Indian Archipelago. The wood from the East Indies is known as Macassar sandalwood and yields I. 6 to 3 per cent. of oil, while the Indian wood yields 3 to 5 per cent. The oil consists of 90 to 98 per cent. of santalol. Fiji oil of santal is obtained from S. Yasi: and Australian oil of santal from Fusanus acuminatus and $F$. spicatus. The Chinese oil is obtained from Santalum Freycinctianum and S. Preisci.

c. FAMILY BALANOPHORACE王-The plants of this group are indigenous to tropical and sub-tropical regions. They are root-parasites and develop tuberous rhizomes and fleshy shoots which are yellow and without foliage leaves. Balanophora elongata of Java grows on the roots of Ficus and other plants, and contains a large quantity of wax and resin. Sarcophyte, sanguinea of Cape Colony, which lives on the roots of certain Acacias, contains a principle with the odor of scatol. Cynomorium coccineum, found in the countries bordering the Mediterranean, has a blood-red, astringent sap. The torus of the flower of Langsdorffia hypogaa of tropical America is edible. The plant is also rich in wax and in New Granada it is sold under the name of "Siejas" and burnt like a candle. 


\section{ORDER ARISTOLOCHIALES.}

This order includes two families which are very different in their general habits. (a) The Rafflesiaceæ are parasitic herbs that are almost devoid of chlorophyll. The reddish vegetative parts penetrate into the tissues of the host and from these arise almost mushroom-like flowers which in the case of Rafflesia Arnoldii of Stumatra are I M. in diameter, being probably the largest flowers known. The plants of this family are rich in astringent substances.

b. ARISTOLOCHIACE $\Psi$ OR BIRTHWORT FAMILY. The plants are non-parasitic herbs or shrubs, some of which are twining. The leaves are simple and in many of the plants more or less cordate and reniform. The flowers are perfect and the perianth is 3- to 6-lobed. While the flowers of our native species are rather small and insignificant those of the tropical plants are extremely curious, being generally of some striking color and of various odd forms.

Aristolochia reticulata is one of the plants that furnishes the official drug serpentaria (P. 5OI). From a slender rhizome with numerous hair-like roots, arise one or more short, leafy branches which are more or less simple, somewhat hairy, and bear oblongcordate, prominent-reticulate, hairy leaves (Fig. I37). The flowers are borne on slender, scaly, basal branches; the calyx tube is purplish and curved like the letter " $s$," being enlarged around the ovary and at its throat. The fruit is a capsule containing numerous flat or concave seeds. An allied species Aristolochia Serpentaria furnishes the drug Virginia snakeroot. It is a more delicate plant, the leaves being ovate-lanceolate, acuminate; the flowers are solitary, and in some cases cleistogamous. This species is found growing in the United States, more especially east of the Mississippi, while Aristolochia reticulata is found west of -the Mississippi from Arkansas to Texas. The plants of this genus contain volatile oils and in addition to the two species mentioned forty-five other species are used in medicine in varous parts of the world.

Asarum canadense (Canada snakeroot or wild ginger) is a plant common in the Northern United States and Canada (Fig. 


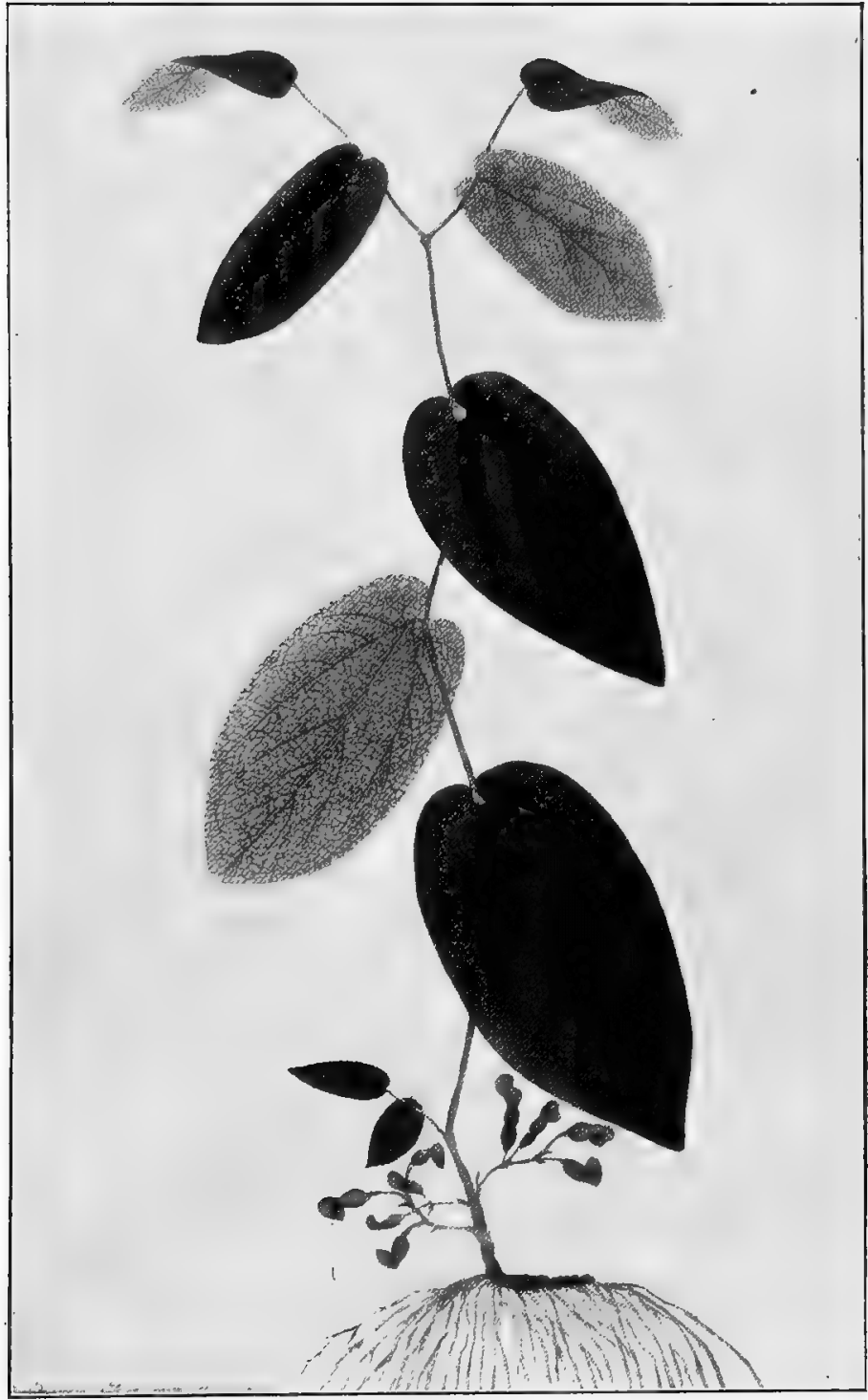

FIG. 137. Southern serpentaria (Aristolochia reticulata) showing the cordate, reticulately-veined leaves, and the clusters of irregular flowers on the lower part of the stem. -After Carson. 
$78, B)$. The long and slender rhizomes are used in medicine. They are 5 to $15 \mathrm{~cm}$. long, about $2 \mathrm{~mm}$. thick, more or less bent and curved, purplish-brown externally; whitish internally; the bark is thick, wood with about I 2 fibrovascular bundles, pith large ; the odor is aromatic; the taste pungent and bitter. The drug contains 2 to 3 per cent. of a volatile oil containing a fragrant body, asarol; a pungent, fragrant resin; a yellow coloring principle which is colored dark green with ferric salts; and starch. The volatile oil obtained from $A$. europaum contains a principle (asarone) which forms irritating vapors on heating.

\section{ORDER POLYGONALES.}

This order is represented by a single family, the PolygonACEA or Buckwheat family. The plants are mostly herbs but include sone twining vines and shrubs. The leaves are simple, mostly entire, and characterized by having a stipulate appendage (ocrea) which sheaths the stem. The flowers are small, perfect and with a 2- to 6-parted perianth. The fruit is a 3-to 4-angled akene. The embryo is either straight or curved, and the endosperm is mealy.

Rheum officinale is the source of Chinese rhubarb (p. 474). The plant is a perennial herb resembling the common garden rhubarb or pieplant (Fig. 205). The rhizome is vertical and gives rise to a leafy branch terminated by the inflorescence which is a panicle. The leaves are large, with a sub-cylindrical petiole, a cordate or orbicular lamina which is either entire or coarsely and irregularly dentate. There are several nearly related species which also viell the drug. Rhetm palmatum of Western China has leaves which are lobed or deeply incised, which character is especially marked in the variety tanguticum. Rheum Rhaponticum, which yields English rhubarb, has leaves which are heartshaped at the base and with a more or less irregularly undulate margin. All of these species are more or less common in cultivation in botanical gardens in Europe.

Rume.t crispus or curled dock is a perennial herb growing in fields and waste places in the United States and Canada (Fig. 138). The leaves are oblong-lanceolate, with an undulate margin 
and rather long petiole. The flowers have a 6-parted, dark green perianth, are perfect or polygamo-diøcious and arranged in a

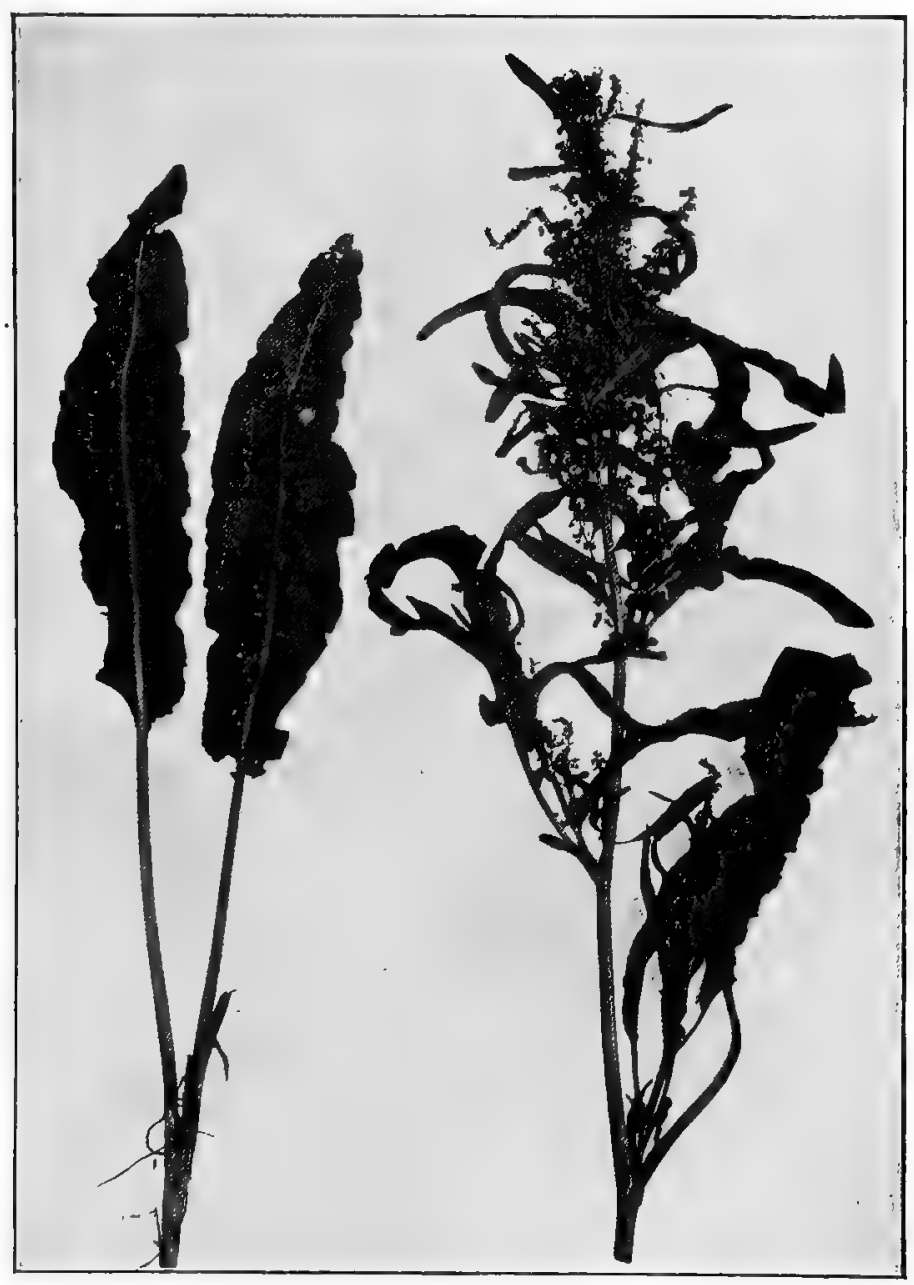

Fig. 138. Curled dock (Rumex crispus) showing two lower, long-petioled, oblonglanceolate and wavy-margined leaves, and a flowering branch, the upper leaves of which are narrowly-oblong and short-petioled.

compound panicle. The fruit is a dark brown, cordate-winged, 3-angled akene. The root was formerly official. The dried root 
is somewhat fusiform, reddish-brown and with a bitter, astringent taste. It contains chrysophanic acid, tannin, calcium oxalate and some of the other constituents found in rhubarb.

Rume.r Acetosella (field or sheep sorrel) is a slender annual herb with hastate leaves, having flowers in compound racemes. The leaves contain oxalic acid, both free and in combination with calcium and potassium.

Tannin is obtained from a number of the plants belonging to. the Polygonacex, as the root of Rumex hymenosepalus of Texas which is known as Canargre; the rhizome of Polygonum bistorta of Europe which yields the drig BistorTA.

The leaves of Polygonum orientale of China and other parts. of Asia are smoked like tobacco. Polygonum rivulare of the East. Indies is used as a fish poison. The following yield indigo: Polygonum alatum of tropical and sub-tropical Asia and Africa, and $P$. tinctorium of China. P. Hydropiper and $P$. aviculare, both common in the United States, are poisonous to sheep. The latter plant when eaten by cows gives a blue color to the milk.

A number of the plants of this family yield food products. Buckwheat is the fruit of Fagopyrum esculentum indigenous to Central Asia and cultivated in many parts of the world.

Some are also cultivated as ornamental plants, as the Prince's. feather (Polygonum orientale).

\section{ORDER CHENOPODIALES OR CENTROSPERM}

This order includes seven families, in all of which the embryo is curved or coiled, and the reserve consists chiefly of perisperm.

a. CHENOPODIACE $Æ$ OR GOOSEFOOT FAMILY.The plants are annual or perennial herbs with simple leaves and. small perfect flowers, the fruit being a utricle. The fruits of a number of the group contain volatile oil, and are used in medicine, as the common wormseed (Chenopodium anthelminticum), which is found in waste places in the United States, an allied species $C$. ambrosioides, and other species of Chenopodium as well. Spanish wormseed is obtained from Anabasis tamariscifolia.

Chenopodium mexicanum yields saponin. Atriplex hortensis of Tartary yields indigo. The ash of very many species of 
Atriplex as well as genera of the Chenopodiacex yields soda. The seeds of several species are edible, as of Chenopodium viride of Europe and Asia, C. Quinoa of Chile, etc. Seeds of Spinacia tetrandra of the Orient are used in bread-making.

A number of species are used as garden vegetables, as spinach (Spinacia oleracea) (Fig. I21,C) and beet (Beta vulgaris).

The SUGAR BEET (Beta vulgaris Rapa) which contains from 4 to 15 per cent. of cane sugar (sucrose) is largely cultivated in Germany, as well as to some extent in the United States, and is an important source of cane sugar. While the jurice of the beet contains a larger amount of nitrogenous substances than the sugar cane it is practically free from invert sugar.

b. AMARANTACEÆ.-The plants are weed-like and much resemble the Chenopodiaceæ. They yield anthelmintic principles, edible seeds, and the leaves of a number of species are used as vegetables. The ash yielded by some species contains potash, as Achyranthes aspera and Amaranthus ruber. Some are ornamental plants having a fasciated inflorescence, as the Cock'scomb (Celosia cristata).

c. NYCTAGINACE 2 OR FOUR-O'CLOCK FAMILY.The plants are mostly herbs growing in America. The leaves are entire and simple, and the flowers are regular and in terminal or axillary clusters. The perianth consists of a 4- to 5-lobed corollalike calyx. The most common representative of this family is the Marvel-of-Peru or four-o'clock (Mirabilis Jalapa). While this plant is an annual in the United States, in the Tropics the tuberous root is used as a substitute for jalap, and is sometimes sold for it. The seeds of this plant are edible, as are also the leaves of several species, as of Barhavia erecta, which are used as green vegetables. Some members of the group, as Bougaini illea spectabilis, are handsome plants with bright rose-colored bracts which envelop the small greenish flowers.

d. PHYTOLACCACEA.-The plants of this family are mostly tropical and are represented in this region by only one species, namely, the common poke (Phytolacca decandra), the root ( $\mathrm{p}$. 465 ) and fruit (p. 466) of which are used in medicine. This is a succulent, branching herb I to $4 \mathrm{M}$. high, having a large perennial root. The stem is hollow except for the thin, papery partitions. 
The leaves are simple, ovate-lanceolate (Fig. I39). The flowers are in racemes and characterized by having ten stamens. The fruit is a dark purple, juicy berry.

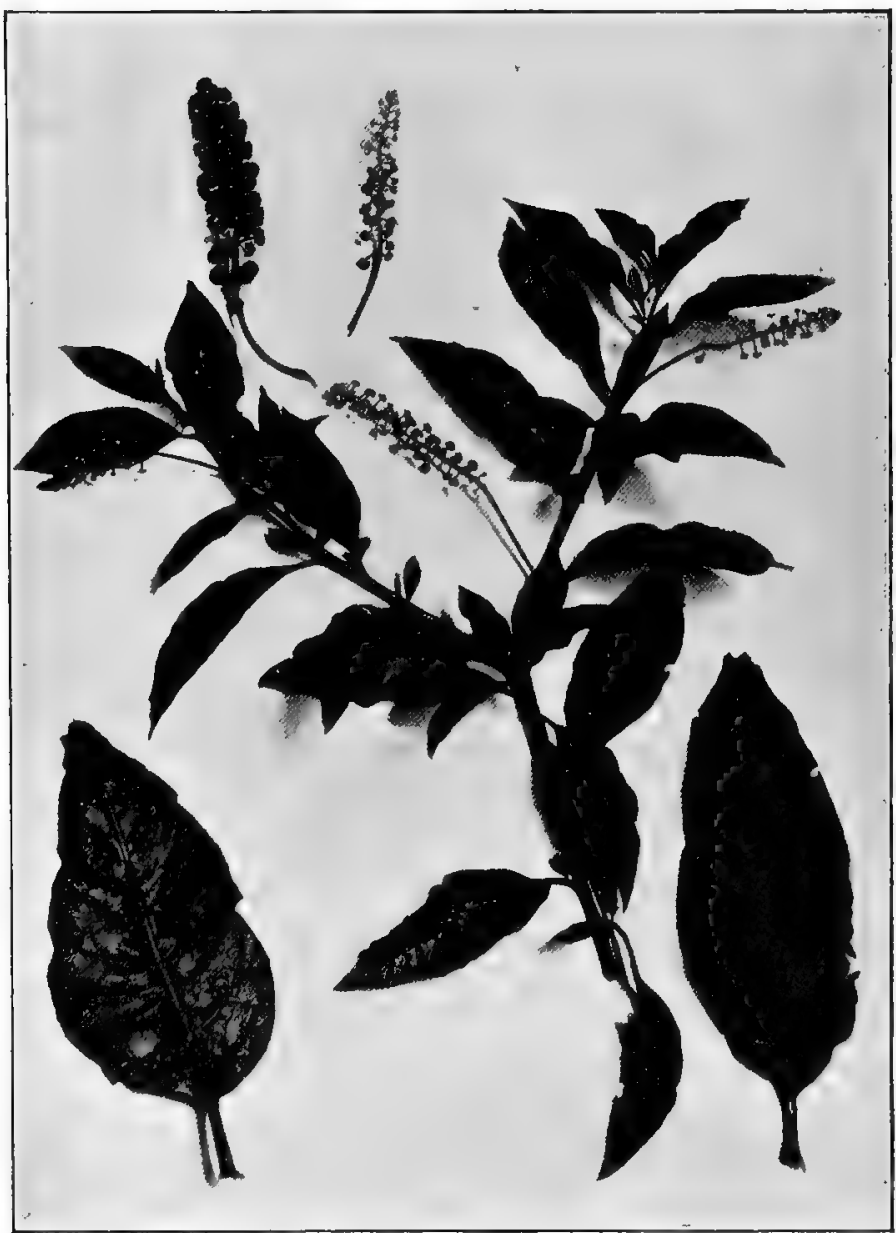

FIG. 139. Poke (Phytolacca decandra) showing a flowering branch, two of the lower leaves, a raceme of flowers and a fruit cluster.

The roots of this species as well as others contain powerful drastic principles, as Pircunia littoralis and Anisomeria drastica of Chile. Phytolacca abyssinica contains saponin, and a red color- 
ing principle is found in the berries of Phytolacca decandra and Rivinia tinctoria of Venezuela. The leaves of some species of Phytolacca are used as greens.

e. AIZOACEA.-This is a group of mostly tropical plants, very many of them having fleshy leaves and adapted to arid regions. Many of the plants, particularly those belonging to the genus Mesembryanthemum, are much prized on account of their beautiful flowers, which expand only in the sunshine. The common ice-plant of the gardens, so called because of the numerous glistening globules of water which cover the leaves, is $M$. crystallinum. This plant as well as other species of Mesembryanthemum are used in medicine. The ashes yielded by the plants of this family also contain soda. The seeds of some species of Mesembryanthemum as well as other members of this family are edible, and the leaves of some species are used as vegetables like lettuce.

f. PORTULACACE Æ⿸厂 -The plants are fleshy or succulent herbs mostly indigenous to America. The two common representatives are the spring beauty (Claytonia virginica), the tubers of which are rich in starch, and purslane (Portulaca oleracea) sometimes used as a green vegetable. The seeds of the latter plant as well as of other species of Portulaca are used in medicine.

g. CARYOPHYLLACE无.-The plants are annual or perennial herbs often swollen at the nodes, with opposite, entire leaves, and usually perfect regular flowers. The perianth has a distinct corolla of 4 or 5 petals. The fruit is a capsule and the seeds are half anatropous. The plants are most abundant in the northern hemisphere; and some of them arè quite showy, as the CARNATION (Dianthus caryophylluts) and pinks (Dianthus species) and the cultivated pink or Sweet William (D. barbatus). $A$ number of the members of this group contain saponin, as bouncing bet (Saponaria officinalis), which is naturalized in the United States from Europe, Gypsophila Struthium of Spain and other species of this genus, as well as species of Lychnis and Herniaria. The leaves of Paronychia argentea are used in Morocco as a substitute for tea. The roots of Scleranthus perennis of Eastern Europe are inhabited by an insect (Coccus polonica) 
which is used in the preparation of a red dye. The fleshy stitchwort (Alsine crassifolia) of Europe and the United States is poisonous to horses.

\section{ORDER RANALES.}

The plants are mostly herbs but include some shrubs and trees, and comprise eight families of economic importance.

a. NYMPHÆACEÆ OR WATER LILY FAMILY.These are aquatic perennial herbs with thick root-stocks and floating, peltate leaves. The flowers are perfect and have large petals. The seeds are enclosed in an aril and the embryo has fleshy cotyledons.

Nuphar luteum of Europe and Middle Asia contains the alkaloid nupharine and tannin, the latter of which splits into ellagic and gallic acids. The yellow pond lily ( $N$ ymphra advena) of the United States contains similar principles. The seeds and rhizomes are rich in starch and are used as food, in some cases starch being manufactured from them, as of various species of $N y m p h c a$, Nelumbo (Lotus) and Victoria, and Euryale ferox.

b. RANUNCULACE无 OR CROWFOOT FAMILY.These are annual of perennial herbs with simple or compound leaves, regular or irregular flowers, and fruits which are akenes, follicles, or berries.

Hydrastis canadensis yields the drug hydrastis (p. 498). From a short, thick, horizontal rhizome with numerous slender roots rises a short stalk with a few palmately lobed, reniform, petiolate, pubescent leaves. The flowers are small, solitary and greenish-white, and the fruit is a head of crimson berries somewhat resembling the raspberry (Fig. 218).

Cimicifuga racemosa (black cohosh or black snakeroot) yields the drug cimicifuga (p. 497). This is a tall perennial herb with large knotty rhizome, large decompound leaves and a long raceme of white flowers (Fig. I 40).

Aconitum napellus yields the official drug aconite (p. 477). This is a perennial herbaceous plant indigenous to Europe and extensively cultivated. From a tuberous root arises a simple leafy stem with palmately lobed or divided leaves, and large, irregular, blue flowers which form a rather loose panicle (Fig. 
14r). The sepals are five in number, the posterior upper one being large and helmet-shaped. The petals are 2 to 5 and rather

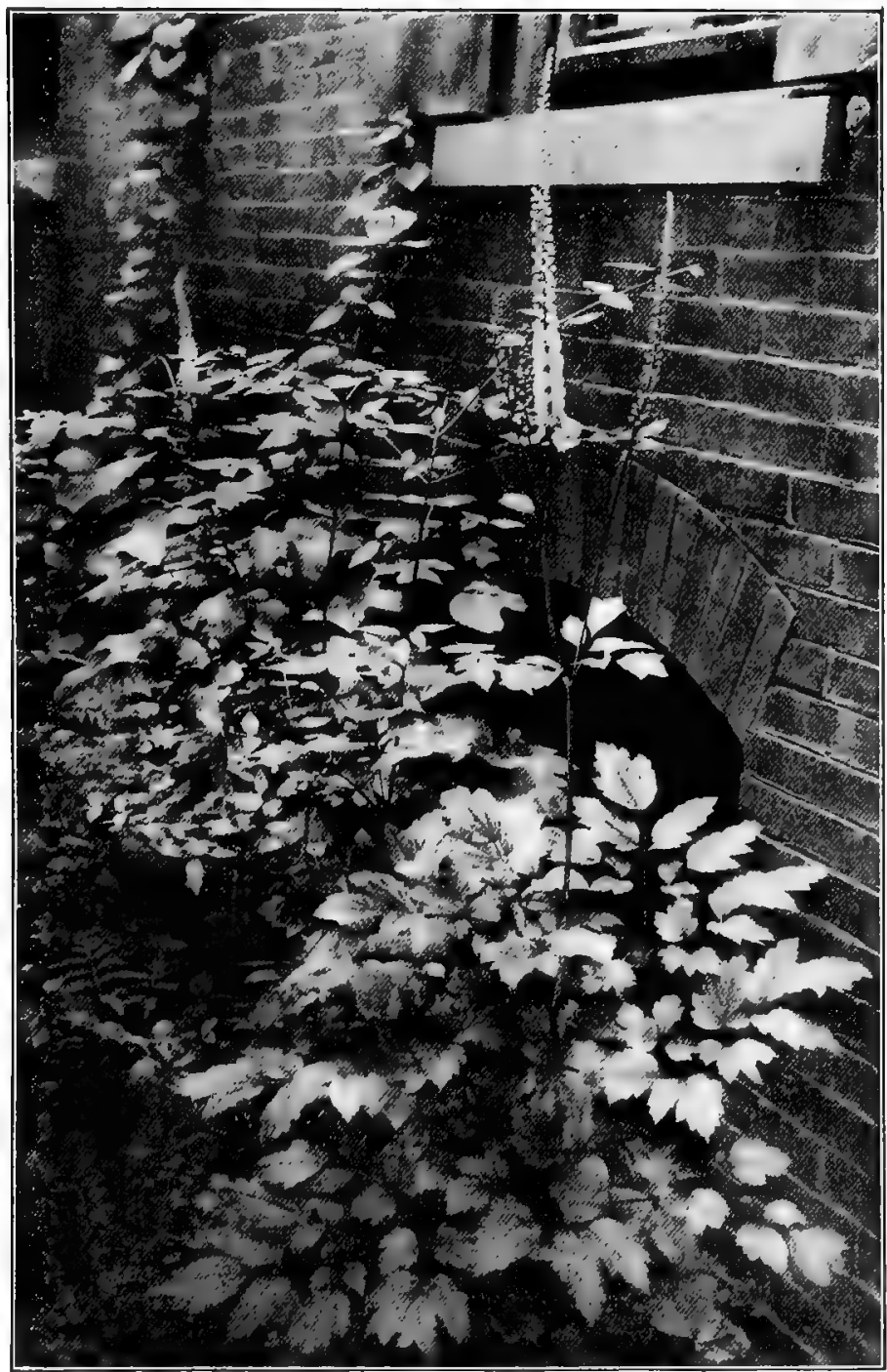

FrG. I40. A group of transplanted wild plants with a plant of Cimicifuga racemcsa in the foreground, showing the characteristic, large, decompound leaves and long raceme of flowers. 
small, the two posterior or upper ones which are hooded and concealed in the helmet-shaped sepal are nectar-secreting (Fig. $84, E)$. The fruit is a follicle and contains numerous small seeds.

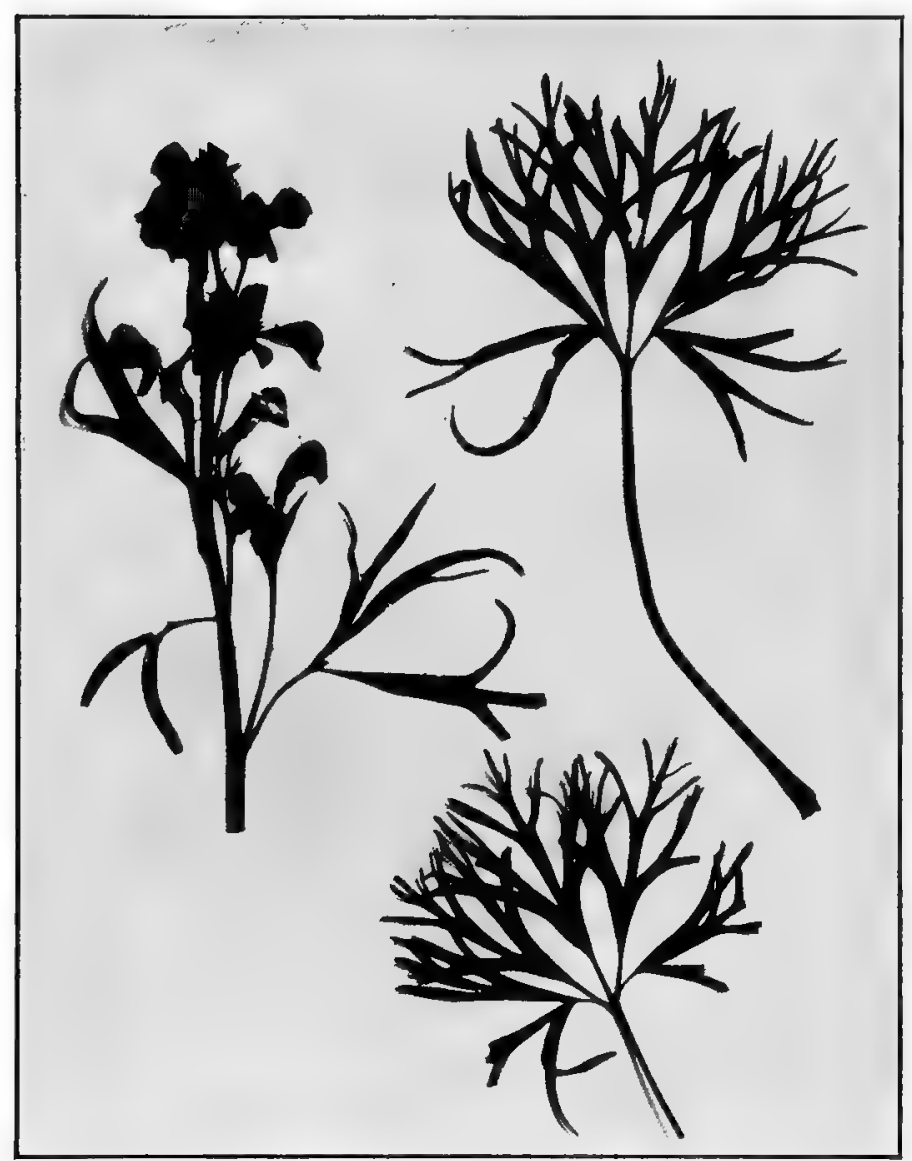

FIg. 14I. Aconitum napellus showing the long-petiolate, divided leaves, and a branch with racemes of irregular (zygomorphic or bilateral) flowers.

Delphinium Staphisagria, which yields staphisagria (p. 427) or stavesacre, is a handsome, tall, biennial larkspur, with dark green, palmate, 5 - or 7 -lobed leaves, and blue or purplish flowers 
in racemes. The flowers are zygomorphic and somewhat resemble those of Aconite.

Pulsatilla, which was formerly official, is obtained from several species of Anemone growing in Europe. These are perennial herbs (Fig. 76) with basal leaves which are deeply lobed or dissecterl, those of the stem forming a kind of involucre near the flower. The flowers are rather large and with numerous petaloid sepals. The fruit is a densely woolly akene in those

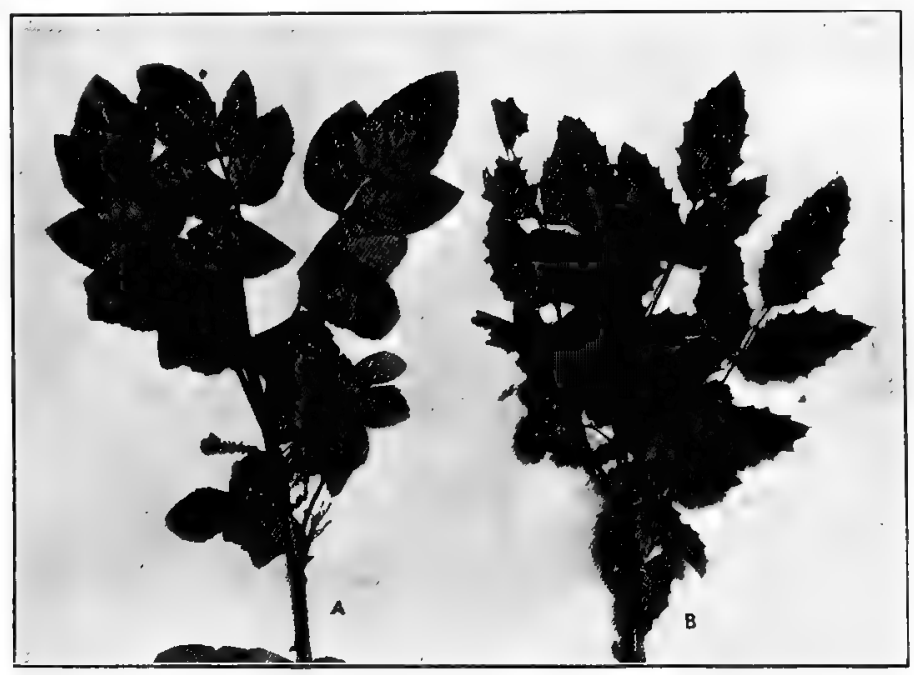

FIG. 142. Trailing mahonia (Berberis Aquifolium): A, fruiting branch with a few globular berries; $B$, flowering branch with several racemes of flowers in the middle portion.

species which are used in medicine. The entire plant is used and contains an acrid volatile oil the principal constituent of which is an anemone camphor (anemonol). The latter is easily decomposed into anemonin, which on fusion becomes exceedingly acrid. Similar principles are found in other species of Anemone as well as in certain species of Ranunculus (buttercup) and Clcmatis vitalba of Europe.

Very many of the other Ranunculaceæ contain active principles. The glucoside helleborein, which resembles digitalin in its medicinal properties, is found in Helleborus niger the BLACK HEL- 
LESORE of Europe, and probably in other species of Helleborus, as well as in Actca spicata the baneberry of Europe and Adonis vernalis the false hellebore of Europe and Asia.

c. BERBERIDACEÆ OR BARBERRY FAIILY.-The plants of this family are herbs or shrubs with simple or compound

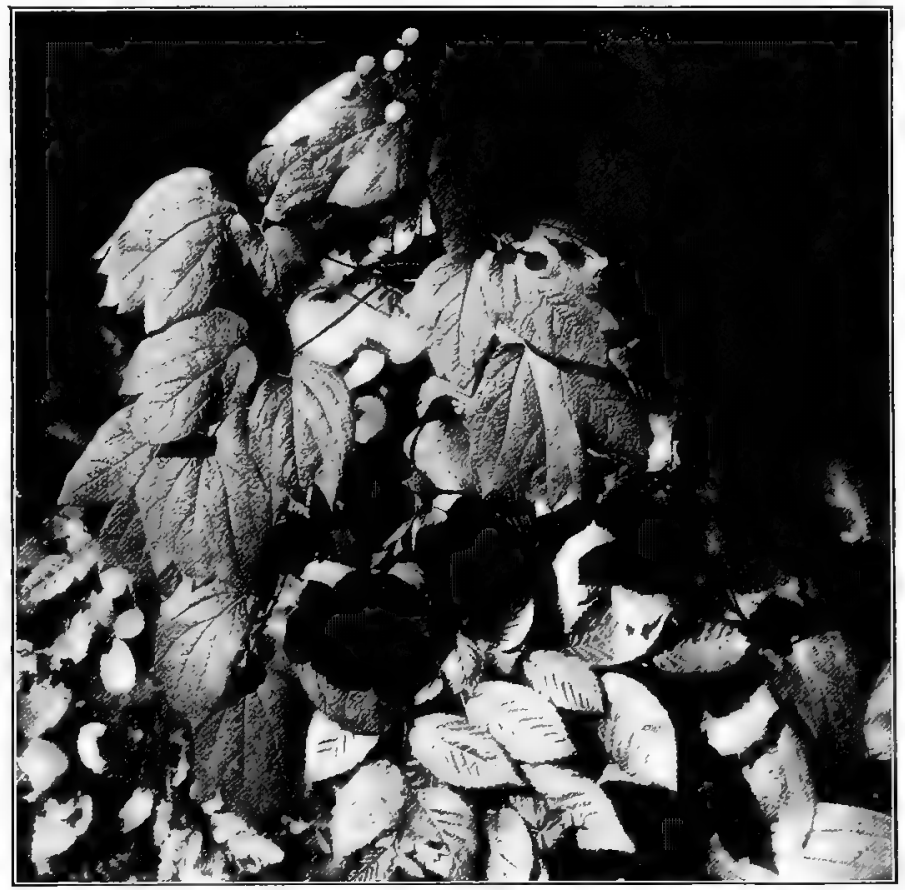

FIG, I43. A group of transplanted plants, showing in the upper portion a fruiting plant of blue cohosh (Caulophyllum thalictroides).

leaves, and flowers either single or in racemes (Figs. 134, E; $8 \mathrm{I}, T$ ). The fruit is a berry or capsule.

Berberis Aquifolium (trailing mahonia) yields the official drug berberis (p. 482). It is a low, trailing shrub with $3^{-}$to 7 -compound leaves (Fig. I42). The leaflets vary from oval to nearly orbicular, are obtuse at the apex, slightly cordate at the base, finely reticulate, and spinose-dentate. The flowers are yellow and in dense terminal racemes. The fruit is a blue or purplish berry. 
Caulophyllum thalictroides or blue cohosh of the Eastern United States is a perennial herb with a thick rhizome and large ternately compound leaves (Fig. I43). The flowers are small and greenish-purple. The fruit is peculiar in that it resembles a berry and consists only of blue, globular, naked seeds, the pericarp being ruptured and falling away soon after fertilization. The rhizome and roots were formerly official. It is a horizontal, much branched rhizome with broad, concave stem-scars, and numerous roots; it is grayish-brown externally, sweetish, slightly bitter and somewhat acrid. The drug contains an acrid, saponin-like glucoside, leontin; a crystalline alkaloid, caulophylline; two resins; and starch.

Podophyllum peltatum or May apple is the source of the official podophyllum (p. 506). This is an early, herbaceous, perennial plant forming large patches by reason of its long dichotomously branching rhizome (Fig. 222). It forms two kinds of branches, one bearing a single," peltate, 5- to 7-lobed leaf; and another bearing in the axil of two similar leaves a white flower which gives rise to a large, yellowish, ovoid berry which is edible.

d. MENISPERMACE $Æ$ OR MOONSEED FAMILY.The plants are climbing or twining, herbaceous or woody vines with simple, entire or lobed leaves and small, greenish-white dioecious flowers. The fruit is a drupe and contains a characteristic crescent-shaped seed.

Menispermum canadense or Canada moonseed yields the drug menispermum which was formerly official. It grows in the Northern UInited States and Canada and is a high-climbing vine with broadly ovate, cordate and 3 - to 7 -lobed leaves (Fig. 65). The flowers are in panicles giving rise to a characteristic cluster of bluish-black berries.

The rhizome occurs in pieces which are 5 to $7 \mathrm{dm}$. long and 2 to $5 \mathrm{~mm}$. in diameter; externally it is longitudinally wrinkled, of a yellowish-brown color and somewhat resembles Sarsaparilla. In transverse section, however, it is very distinct (Fig. II5). The drug has a bitter taste and contains a bitter alkaloid menispine, berberine and starch. In addition it contains the alkaloid oxyacanthine which is also found in Berberis zulgaris of Europe and the West Indies. 
Jatcorhiza palmata yields the official drug calumba (p. 459). The plant is a herbaceous climber somewhat resembling Menispermum, the leaves being more decidedly lobed. The flowers form long racemes.

Chondrodenaron tomentosum, the source of the official drug pareira (p. 460), is a high woody twiner. The leaves are large, petiolate, broadly ovate or rounded, slightly cordate, and densely tomentose on the lower surface.

Anamirta paniculata is a woody climber of the East Indies. The fruits, known as fishberries or Cocculus, are used as a fish poison by the natives and contain the neutral principle picrotoxin.

Very many other plants of the Menispermaceæ contain powerful toxic principles and are used as fish poisons and as antidotes to snake poison. Several species of Abuta are used in the preparation of curare poison.

e. MAGNOLIACE $\mathrm{E}$ OR MAGNOLIA FAMILY.-The plants are mostly trees or shrubs and are represented in the United States by the magnolias and tulip tree (Liriodendron tulipifera). The latter is a magnificent tree with characteristic leaves (Fig. I44) and large, fragrant, orange-colored, tulip-like flowers.

The plants of this family contain a variety of constituents. Ethereal oils containing anethol and resembling those of anise are found in the fruit of Illicium anisatum (I. verum) or STAR ANISE, a small evergreen tree growing in the mountains of Southern China. A volatile oil with a disagreeable odor is found in a closely related species $I$. religiosum (Shikimi) of Japan. The fruit of the latter plant is known as JAPANESE STAR ANISE and contains in addition a poisonous neutral principle. The fruits of both star anise (Illicium) and the Japanese star anise are made up of 6 to 8 radially arranged follicles, which are dark brown, dehiscent on the upper (ventral) surface and each contains a single, brown, shiny seed. Star anise has an odor and taste resembling anise. Japanese star anise has a bitter taste and in addition is brownish-black, very woody and strongly beaked.

Volatile oils are also found in the flowers of the various species of Magnolia and in Michelia Champaca found in the Malay Archipelago and cultivated in India and Brazil, and in M. nilagirica of India, the latter being used in perfumery. 
Winter's bark is derived from Drinys Wintcri, a shrub of South America. It occurs in quills which are from 5 to $10 \mathrm{~mm}$. thick; externally it is grayish-brown and covered with numerous lichens; the fracture is short, the broken surface being marked by stone cells and resin canals; the odor is fragrant; taste aromatic, pungent and bitter. The drug contains a volatile oil which consists essentially of a hydrocarbon known as winterin; it also contains a resin.

A crystalline principle magnolin, a glucosicle and a volatile oil are found in Magnolia macrophylla (or cucumber-tree of the

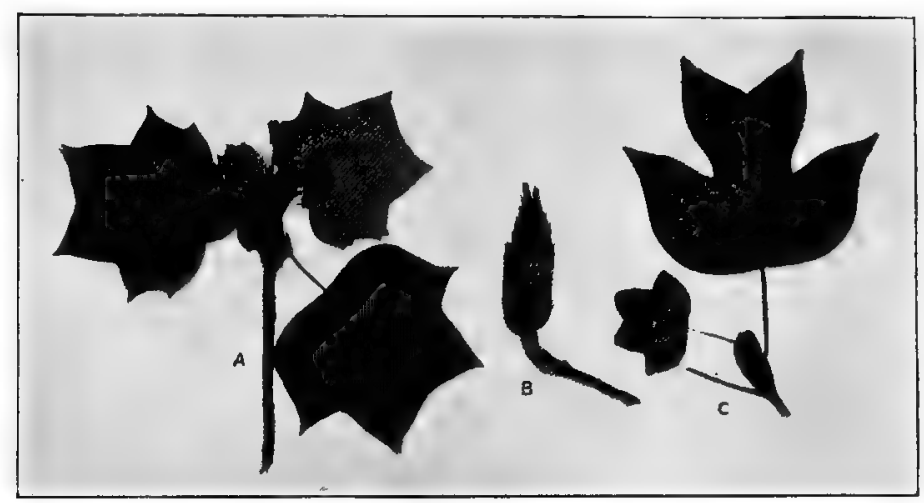

Frg. 144. Tulip poplar (Liriodendron 'iulipifera): A, branch with characteristic 4- to 6-lobed leaves and solitary, large, tulip-like flower; B, fruit composed of a number of carpels; $C$, tip of branch showing the large coherent stipules which serve to protect the leaf-buds (p. I06).

Southern States) and $M$. tripetala or tumbrella tree growing southward from Pennsylvania. A bitter principle liriodendrin, a volatile oil, an alkaloid, and a glucoside are found in the tulip poplar or tulip tree.

The bitter and aromatic bark of Michelia montana of Java is used like cascarilla (Euphorbiacex). A bitter resin is found in the fruit of Talanma Plumieri of the Antilles.

A glucoside which dissolves the blood corpuscles is found in Talauma macrocarpa of Mexico. A red coloring principle soluble in water occurs in the leaves of Michelia tsiampaca of Java. The fruits of Schizandra propinqua of Nepal and Kadsura Rox- 
burghiana of Japan contain considerable mucilage and are edible. The latter plant is also used as a hair-restorer. From the ash of Schisandra chinensis of China and Japan sodium chloride is obtained.

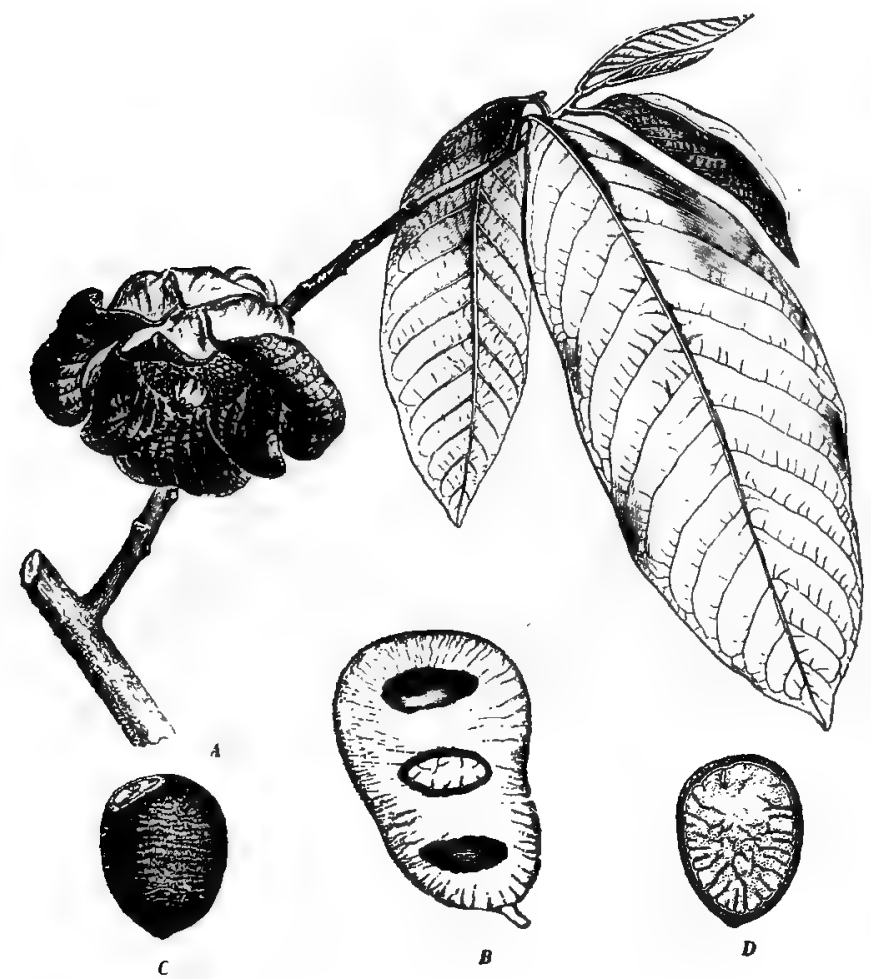

FIG. 145. North American papaw (Asimina triloba): A, branch showing lateral nodding flower and the large, pinnately-veined, entire leaf; $B$, section of the oblong, 3-seeded berry: C, D, seeds, the one in longitudinal section.-After Baillon.

The flowers of Magnolia Juglans are used to flavor tea and the leaves of Talauma oz'ata are used as a substitute for tea in Brazil.

f. ANONACE $Æ$ OR CUSTARD-APPLE FAMILY.These are shrubs or small trees chiefly inhabiting warm-temperate and tropical regions. They rield very many economic products. The fruit of Xylopia brasilcnsis is used as a substitute for cubeb. Some yield fruits having an aroma similar to that of 
nutmeg, as Monocarpia Blancoi of Africa and Jamaica. The flowers of Cananga odorata of tropical countries are used in the preparation of a pomade from which the perfume YLANG-YLANG is made. Ethereal oils are also found in other species, as Unona ligularis of Amboyna, the seeds of which are used in perfumery. The bark of Popowia pisocarpa of Java contains an alkaloid.

The seeds of Xylopia salicifolia of Trinidad and X. muricata of Jamaica are very bitter, as are also the wood and bark of $X$. glabra of the West Indies.

The seeds of Asimina triloba the North American papaw (Fig. I45), contain an emetic principle. This plant should not be confounded with Carica Papaya (Caricacer) which contains the ferment papain.

Many of the Anonaceæ yield large succulent fruits, some of which are edible, as the sugar apple obtained from Anona squamosa and CUSTARD APPLE from $A$. reticulata both abundant in the Tropics. The fruit of $A$. muricata sometimes weighs as much as two Kilograms.

g. MYRISTICACE $巴$ OR NUTMEG FAMILY.-This family is represented by the single genus Myristica. Nutmeg (p. 439) and mace are obtained from Myristica fragrans, an evergreen tree with ovate, petiolate, coriaceous, entire and pinnately-veined leaves. The flowers are small, yellow and diocious. The fruit is a berry having somewhat the shape and size of the green fruit of black walnut. It has a line of dehiscence, and when ripe is yellow. The arillode of the seed constitutes MACE while the kernel is the NUTMEG, the pericarp of the fruit and coat of the seed being rejected.

h. LAURACE无 OR LAUREL FAMILY.-The members of this family are chiefly shrubs and trees which are distributed mostly in the Tropics although a few are found in the temperate zones (Fig. I $34, F$ ).

Sassafras officinale.-This is a tree common in the eastern and central portion of the United States and is characterized by its rough bark and its I- to 3 -lobed leaves, from whence it received its former name Sassafras variifolium (Fig. 73). The flowers are yellow, diccious and appear in the spring before the leaves. The fruit is an oblong, blue drupe (p. 539). 
Cinnamomum zeylanicum, which is the source of the Ceylon, cinnamon (p. $5^{\mathrm{I}} 3$ ), is a small, handsome, evergreen tree with opposite, coriaceous, broadly lanceolate, 3- to 5-nerved leaves (Fig. 146). "The flowers are yellowish-white. hermaphrodite, or both

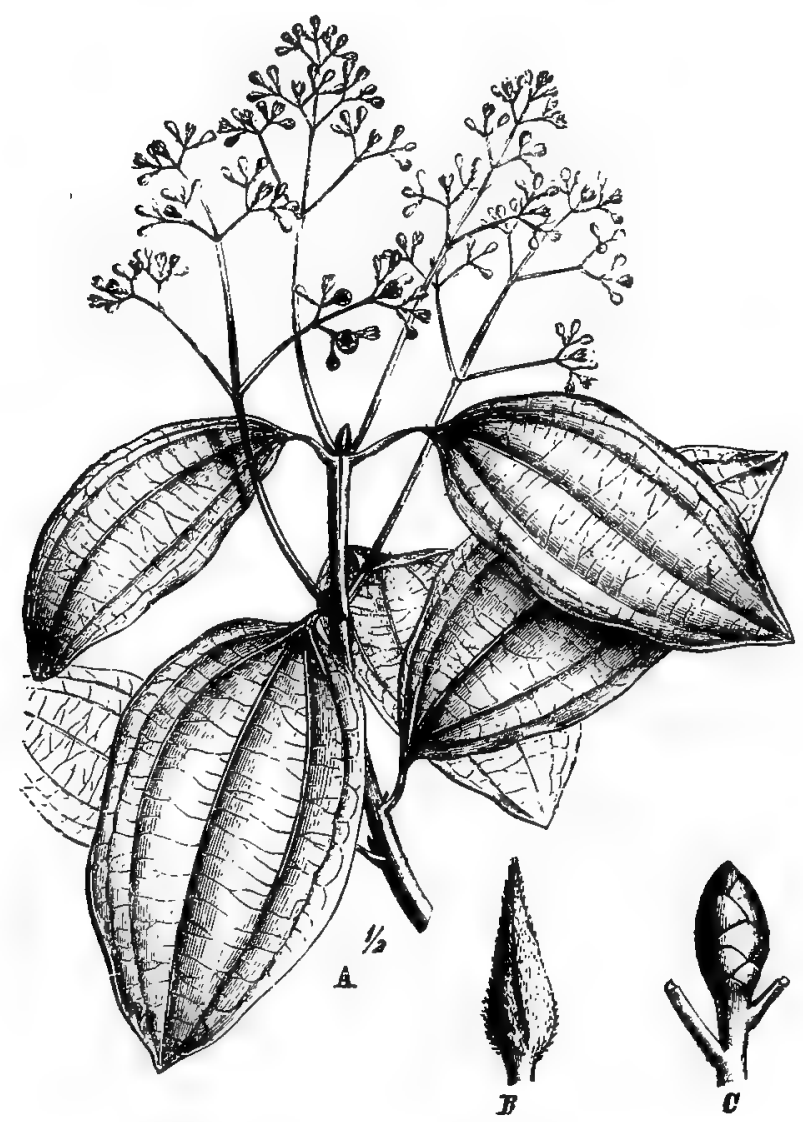

FIG. 146. A, flowering branch of Cinnamomum zeylanicum; B, leaf-bud of the same; C, leaf-bud of Cinnamomum Camphora.-A, after Berg and Schmidt; B, C, after Pax.

pistillate and staminate. The fruit is a black, ovoid berry. $C$. Cassia which yields Cassia cinnamon is a tree growing in China, Sumatra, and cultivated in Java. It has long, oblong-lanceolate leaves which are pubescent on the lower surface. Cassia cinna- 
mon (bark) is also obtained from Cassia Burmanni. Saigon cinnamon (p. 5I3) is derived apparently from wild trees growing in the mountainous regions of Anam, the botanical origin of which has not been determined.

- The volatile oils of the members of the Lauracex vary considerably in composition. In addition to the oils of Sassafras and Cinnamon the following may be mentioned: A CINNEOLcontaining oil is found in Cinnamomum Oliveri of Australia, Umbellularia californica of Western North America and Laurus nobilis the noble laurel of the Mediterranean and Mexico. A воRNEOL-containing oil is obtained from the root of Dicypcllium caryophyllatum of Guiana, the wood of which is known in Cayenne as rose-wood. An oil containing a notable amount of METHYL SALICYLATE is obtained from the spice-bush (Lindera Benzoin) of the United States.

Cinnamomum Camphora, or the camphor tree, is indigenous to China, Japan and Formosa, and is now cultivated in many warm countries as a shade and ornamental tree, growing very well in Southern California and the Southeastern States. All parts of the tree contain a volatile oil which on oxidation yields camphor which latter is obtained by distillation and sublimation. Camphor of poor quality is obtained from C. Parthenoxylon of Burmah, Malaya and China, and C. glanduiliferum of the Himalayas. Camphor is also a constituent of other ethereal oils of this same family, as the Massoy bark oil obtained from the root bark of $C$. zeylanicum and C. Burmanni of Java.

A EUGENOL-containing volatile oil is obtained from Ravensara aromatica of Madagascar, and Machilus Thunbergii of Japan. Eugenol is also found in oil of laurel leaves (L. nobilis), Massoy bark oil, the oil of the leaves of Ceylon cinnamon, and the oils obtained from Cinnamomum Culilawan of the Malay Peninsula and China, and C. Wightii of East India, and possibly is also found in Dicypellium caryophyllatum.

The wood and the bark of Nectandra or Beeberu (Nectandra Rodicei) of Guiana and Brazil contain several alkaloids, one of which is known as bebeerine and is supposed to be identical with the alkaloids in Buxus sempervirens (Fam. Buxaceæ); pelosine found in Pareira ; and paricine found in the bark of the cultivated 
cinchonas of Java. Coto bark which is used in medicine, is obtained from an unknown tree in Northern Bolivia belonging to this family. The bark contains a volatile oil having a pungent taste, and a volatile alkaloid.

Fatty oils are obtained from Ravensara aromatica of Madagascar, Litsea glauca of Japan and other species of Litsea found growing in Cochin China and India. A red sap with a very fetid odor is obtained from Ocotea fortens of tropical and sub-tropical America, and the stink-wood of South Africa (O. bullata).

\section{ORDER RHGADALES OR PAPAVERALES.}

These are mostly herbaceous, seldom woody, plants. The flowers are perfect and the fruit capsular. This order includes two families of importance medicinally.

a. PAPAVERACEÆ OR POPPY FAMILY.-These are herbs with a milky or colored latex.

Papaver somniferum or opium poppy is an annual herb I to 2 M. high. The stem is sparingly branched, with alternate, deeply lobed, pubescent, clasping (by a cordate base), dull green leaves (Fig. I47, A). The flowers in the variety album, from which opium is obtained, are white or silver-gray, and in many cultivated varieties are large and extremely showy. The two sepals drop away with the expansion of the corolla; the ovary is smooth, more or less globular and subtends the radiate stigma; the fruit is a capsule (Fig. 9I), dehiscing by means of terminal pores, and contains a large number of extremely small white seeds, the latter being known as MAW-SEED and which on expression yield a fixed oil known as poppy-oil. (For opium see p. 658.)

Other allied members of the Papaveraceæ possess narcotic properties, but the alkaloid morphine has not been isolated from any of them, as the California poppy (Eschscholtzia californica) (Fig. 147, B); the Mexican poppy (Argemone mexicana); Hypecoum procumbens, and Fumaria plicata both of Southern Europe. These latter plants probably contain also the alkaloid protopine which is apparently identical with fumarine.

San guinaria canadensis or bloodroot, the rhizome of which is official (p. 508), is a small, herbaceous, perennial herb with a red 
latex. The rhizome is horizontal, short and thick, and gives rise to a single, petiolate, palmately $5^{-}$to 9 -lobed leaf and a single white flower with a long peduncle (Fig. I48). The capsule is oblong, 2-valved and contains a number of smooth but crested seeds.

Chelidonium majus (celandine) is the source of the herb CHELIDONIUM which was formerly official. The plant is a delicate branching herb about $0.5 \mathrm{M}$. high; with alternate, deeply pinnati-
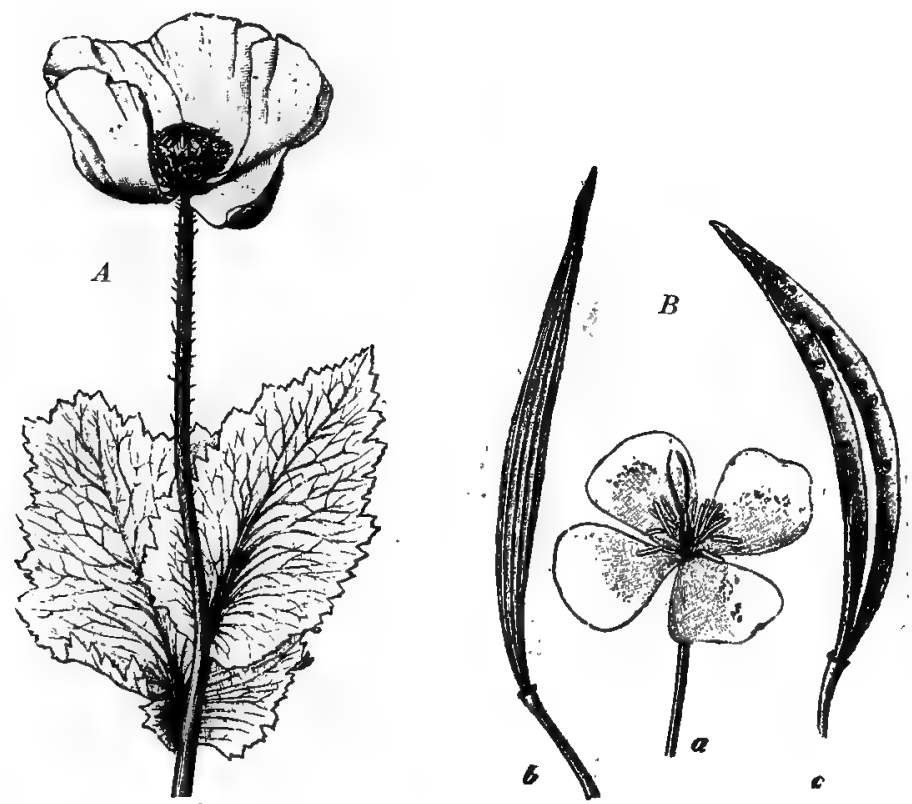

Fig. 147. A, Opium poppy (Papaver somniferum); B, California poppy (Eschscholtzia californica) showing flower (a), and capsules $(b, c)$, one of which (c) is Aehiscent.-After Schimper.

fid leaves; yellow flowers; slender elongated capsule resembling that of the mustards, and a yellow latex in every part. Celandine is indigenous to Europe and Asia and is common in waste places in the United States. The drug contains the following alkaloids: Chelidonine (identical with stylophorine), chelerythrine (which is fluorescent), and protopine (found also in opium and sanguinaria). It also contains a bitter neutral principle chelidoxanthin and several organic acids. 
To this family belong a number of other plants which contain principles similar to or identical with those found in Sanguinaria and Chelidonium, and of these the following are common in the United States: Yellow or celandine poppy (Stylophorum diphyllum) and the Dutchman's breeches (Bicuculla Cucullaria).

The alkaloid PRotopine (fumarine) is found in the following plants of this family: Sanguinaria canadensis; Chelidonium majus; Stylophorum diphyllum; Eschscholtsia californica; Glau-

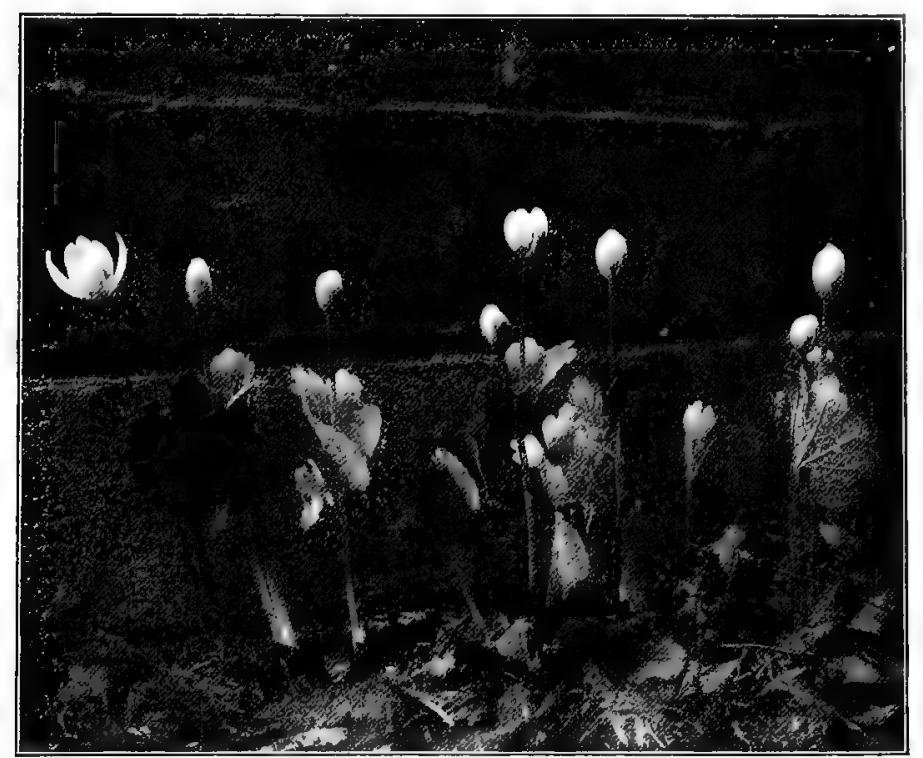

FIG. 148. A group of transplanted bloodroot plants (Sanguinaria canadensis) showing I-flowered scapes, and the palmately veined and lobed leaves.

cium corniculatum of Middle Europe; Bicuculla Cucullaria; Adlumia fungosa, the climbing fumitory of the United States and Canada; Fumaria officinalis, the fumitory of Europe, which is naturalized in the United States and Canada; Bocconia cordata of China and Japan, and B. frutescens of the West Indies, Mexico and Paraguay.

The tubers of squirrel corn or corydalis (Bicuculla canadensis) contain the alkaloid corydaline. 
b. CRUCIFER E OR MUSTARD FAMILY.--These are herbaceous plants with characteristic flowers and fruits. The flowers have four sepals in two sets, four petals which are more or less spreading and clawed at the base, and six stamens which are tetradynamous (Fig. I34, B). The fruit is a 2-celled silique or silicle, which varies in shape in the different genera (Fig. 89).

Sinapis alba (white mustard).-The plant is a slender, branching, more or less hispid (bristly hairy) annual or biennial herb usually less than $0.5 \mathrm{M}$. high, with deeply pinnatifid lower leaves and lanceolate, dentate upper leaves. The flowers are yellow, and the silique is densely hispid, constricted between the seeds and terminated by a long, flat, sword-like beak. The seeds are official as white mustard (p. 428) but are known in commerce as yellow mustard.

Brassica nigra or black mustard, the seeds of which constitute the official black mustard (p. 429), is a larger, more branching plant than Sinapis alba, being from I to $3 \mathrm{M}$. high. The silique is shorter, more cylindrical and with a slender, filiform beak.

Glucosides similar to those which occur in SinAPIS ALBA and Brassici NIGRA, are also found in other species of SinApIs and BrassicA, as well as in the following plants, but the oils produced are not identical: Horseradish (Roripa Armoracea), the oil being similar to volatile oil of mustard; water cress ( $R$. Nasturtium); garden radish (Raphanus sativus); Sisymbrium Alliaria of Europe, and the hedge mustard ( $S$. officinale) naturalized in the United States; TURnip (Brassica rapa) of Europe; field pennycress (Thlaspi arvense) of Asia and found in waste places in the Eastern and Middle United States; the narrow leaved peppergrass (Lepidium ruderale) naturalized from Europe; scurvy-grass (Cochlearia officinalis) of Northern and Middle Europe, the herb of which, known as Herba COCHLEARIF, is used in medicine; "HONESTY" (Lunaria annua) common in cultivation on account of the ornamental use of the dry pods; Parrya macrocarpa of Southern Europe; treacle mustard (Erysimum cheiranthoides) of Northern Europe and the United States, and garlic mustard (E. Alliaria).

The seeds of most of the Cruciferæ are also rich in fixed oils, and the commercial oils are obtained from the following species: 
Wild mustard or charlock (Brassica arvensis) naturalized in the United States from Europe; Hesperis tristis of Southern Europe; cabbage (Brassica oleracea). An INDIGo-forming glucoside is found in Isatis tinctoria of Europe and I. indigotica of China; Neslia paniculata of Europe and the Orient; and Lepidium owaihiense of the Hawaiian Islands. Shepherd's purse (Capsella Bursa-pastoris) contains an alkaloid (bursine) and tannin. The leaves and roots of many of the Cruciferæ are used as garden vegetables, and some are cultivated as ornamental plants, as sweet alyssum which is a cultivated variety of Alyssum maritimum of Europe.

c. There are several other families of the Rhœadales which yield economic products. The RESEDACE.E include the mignonette (Reseda odorata) the flowers of which yield a fragrant volatile oil ; and $R$. luteola of Europe which contains a yellow coloring principle and also an anthelmintic principle. The Moringacese comprise a single genus, Moringa. The root of $M$. olifera of tropical and sub-tropical countries contains a volatile oil resembling the volatile oil of mustard, and the stem yields an astringent gum resembling that of Bombax malabaricum (Bombaceæ).

\section{ORDER SARRACENIALES.}

This order includes several families which are of special interest because of the fact that the leaves are of peculiar construction and adapted to the catching and digestion of insects (Fig. 77).

Probably all of the plants of this order produce proteolytic ferments resembling those in the pine-apple and are capable of acting upon and digesting animal substance. Some writers have supposed that the properties of these plants might be due to bacteria present in the liquid contained in the pitchers of the leaves, but there seems to be no question that a distinct enzyme resembling trypsin is formed in those plants which have been studied.

(a) The genus Sarracenia of the family SARRACENIACEx or pitcher-plant family, is represented in the United States by a number of species. The rhizome and roots of Sarracenia purpurea contain several alkaloids, one of which, sarracenine, seems to have some resemblance to veratrine.

(b) The Droseracese or stun- 
dew family includes the Droseras or sundew plants and Dion muscipula the Venus's flytrap of North Carolina. A number of species of Drosera probably contain the red coloring principle which has been isolated from the rhizomes of $D$. Whittakerii of Australia and is a derivative of methylnaphthoquinone. Citric acid has been found in D. longifolia, a sundew common in the United States as well as in Europe and Asia. (c) The family Nepenthace contains the single genus Neponthes, several species of which are extensively cultivatecl in greenhouses. The leaves and roots of $N$. Boschiana of Borneo contain an astringent principle.

\section{ORDER ROSALES.}

The plants range from herbs to shrubs and trees and have complete flowers which are mostly perigynous. The carpels are solitary, or several either distinct or united.

a. PODOSTEMACE $\&$ OR RIVER-WEED FAMILY.The plants are aquatic and more or less alga-like, and are represented in the United States by the river-weed (Podostemon ccratophyllum) which is a densely tufted plant found in running water attached to stones. The ash of these plants contains a considerable amount of sodium chloride, the ash of Mourera IV eddelliana of Brazil containing 50 per cent. of salt and being used as a source of table salt.

b. CRASSULACE $\approx$ OR ORPINE FAMILY.-The plants are chiefly succulent herbs and represented by such plants as houseleek (Semperititum tectorum), which is cultivated largely as an ornamental plant, and the common sedtums, of which there are numerous species in temperate regions. The common mossy stonecrop or wall-pepper (Sedum acre) naturalized in the Northern United States contains a ferment capable of dissolving the membrane formed in diphtheria and croup; Sempervivum balsamiferum of the Canary Islands contains a substance resembling the viscin found in certain Loranthaceæ. Ditch or Virginia stonecrop (Penthomm sedoides) contains tannin.

c. SAXIFRAGACE $\approx$ OR SAXIFRAGE FAMILY.-The plants are mostly found in temperate regions and among the important members are mitrewort (Mitella), false mitrewort 
(Tiarella cordifolia), alum root (Heuchcra americana), golden saxifrage (Chrysosplenium), grass of Parnassus (Parnassia), mock orange (Philadelphus coronarius) and the wild hydrangea (Hydrangea arborescens).

The plants are rich in tannin, as the alum root of Eastern and Central North America, which contains to to 20 per cent. of tannin. A glucoside hydrangin, a volatile oil, and possibly also a saponin are found in "SEVEN BARKS" or wild hydrangea ( $H$. arborescens); a glucoside is also found in the root of garden hydrangea ( $H$. paniculata grandiflora).

d. GROSSLLARIACE $\mathbb{E}$ OR GOOSEBERRY FAMILY.The family includes the single genus Ribes. These are more or less spinous shrubs with alternate or fascicled, more or less pubescent, 3- to 7-lobed petiolate leaves. The flowers are solitary, as in gooseberry or in racemes, as in the currants. The fruit is an inferior globular berry. The cultivated cuRRANTs are varieties of Ribes rubrum: the cultivated GOOSEBERRIES are varieties of R. Uva-crispa. Both of these plants are natives of Europe and Asia and have escaped from cultivation in the United States and Canada. The fruits contain fruit-acids and fruit-sugars and are used in a variety of ways. The fetid currant (Ribes prostratum) has a very fetid odor and it is said that the flowers of the buffalo currant (Ribes aureum) contain hydrocyanic acid.

e. HAMAMELIDACE $\&$ OR WITCHHAZEL FAMILY. The plants are shrubs or trees and are most abundant in subtropical cotıntries.

Hamamelis virginiana, or witchhazel, the leaves (p. 610) and bark (p. 527) of which are official, is a shrub which is especially characterized by its asymmetric, undulate leaves and by its producing flowers in the autumn when the leaves are falling and the mature, but not ripe, capsules of the preceding year are still present (Fig. 264).

Liquidambar Styraciflua or sweet gum-tree of the Atlantic coast of the United States and Mexico, is a tall tree with characteristic cork-wings on the branches; 3 - to 7 -lobed, petiolate, finely serrate leaves; monœcious flowers, and a spiny, globular, capsular fruit. The tree yields a balsam allied to the official styrax (p. 679 ), which is obtained from a very similar tree (L. orientalis). 
f. ROSACE E OR ROSE FAMILY.-The plants are herbs, shrubs or trees usually with alternate, stipulate, simple or compound leaves, and regular perfect flowers with or without petals, and numerous stamens (Fig. I34, D). The fruit is a pome, drupe, follicle or akene (Fig. 89).

Prunus serotina or wild black cherry is a tree varying from Io to $30 \mathrm{M}$. in height, with a more or less smooth bark marked by prominent transverse lenticels, and showing a tendency to peel off in semicirctular pieces, which gives the older bark, which is more or less black, a roughened appearance. The leaves and inner bark have an agreeable aromatic odor; the leaves are oval- or oblong-lanceolate, acute or acuminate, serrate, the teeth being glandular; the flowers are white and in racemes; the fruit is a dark purple or blackish, globular drupe (Fig. 235). The nearly related species wild cherry or choke cherry (Prunus virginiana) is a shrub or small tree with broadly oval, acuminate leaves, red or nearly black drupes, and flowers and fruits several weeks earlier than $P$. serotina (p. 538).

Prunus. Anngdalus is a small tree resembling somewhat the peach tree. The leaves are lanceolate, serrate; the flowers are rose-colored, and the fruit is a dehiscent drupe in which the leathery sarcocarp separates from the endocarp, which latter, with the seed which it encloses, constitutes the almond of the market (Fig. I87). The kernels of some of the seeds are bitter (bitter almonds, p. 433), and some are bland and free from bitterness. By a process of selection plants yielding the latter are now extensively cultivated in sub-tropical and warm-temperate regions, and yield the sweet almond (p. 434) of the market. In Turkestan some of the almonds have a smooth endocarp.

A glucosidal substance having the properties of amygdalin is found in the buds, leaves, bark and seeds, more especially the latter, of some members of the following genera: Prunus, Sorbus (mountain ash), Cotoneaster, Amelanchier, and Eriobotyra (E. japonica or Japanese medlar).

Prumus domestica yields the French plum or prune of commerce (p. 576). The leaves are ovate or ovate-lanceolate, dentate, and pubescent on the lower surface. The flowers are greenish-white, with a hairy peduncle. The fruit is a drupe with 
a black or bluish-black epicarp, a brownish sarcocarp, and a hard, oval, smooth and flattened endocarp.

The endocarps of the members of the genus Prunus vary greatly. The endocarp in the apricot ( $P$. armeniaca) is quite smooth as is also that of the cherry ( $P$. Cerasus); in the peach (Prunus persica) it is reticulate.

The apple (Pyrus malus), the pear (Pyrus communis), and the quince (Cydonia vulgaris) are inferior fruits known as pomes, the fleshy part developing from the torus and persistent calyx, the core being composed of the united carpels. The edible fruits of the Rosacer contain a number of FRUIT-ACIDS, such as malic, citric, tartaric, and FruIT-Sugars, as dextrose and levulose. The acids vary from 0.20 per cent. in pears to 1.50 per cent. in plums; and the sugars from 4.48 per cent. in peaches to 8.26 per cent. in pears. The carbohydrates mannit and sorbit are found in the fruit of Prunus Lauro-cerasus of Europe. In the unripe fruits there is more or less tannin and also a principle known as PECTOSE. This latter during the ripening of the fruit is converted into PECTIN, a viscid principle which is further changed into pectic and pectosic acids, the solutions of which gelatinize on cooling, so that these fruits are adapted to jelly making.

Rubus nigrobaccus, or high bush-blackberry, is a branching shrub I to $2 \mathrm{M}$. high with reddish, prickly, erect or recurved stems. The leaves are $3^{-}$to 5 -foliate, the leaflets being ovate, coarsely and unequally serrate, and midrib and petiolules with stout, recurved prickles. The flowers are white, in terminal racemes and with hairy and prickly stalks. The fruit is broadly ovoid and consists of an aggregate of drupelets which ripen in August and September (Fig. 232).

Rubus villosus Ait. (Rubus canadensis L.) or low-blackberry (Northern dewberry), is a trailing, shrubby, prickly plant the leaves of which are $3^{-}$to 7 -foliate, the leaflets being oval or ovate-lanceolate, serrate and nearly smooth. The flowers are in racemes and the fruit resembles that of $R$. nigrobaccus, but is smaller.

Rubus cuneifolius or sand-blackberry of the Eastern and Southern States is a small shrub less than I M. high, much branched, and with straight or recurved, stout prickles. The 
leaflets are ovate or cuneate, and densely pubescent, as are also the young shoots. The inflorescence consists of two to five flowers, the petals of which are white or pinkish. The fruit is oblong, more or less cylindrical, and sometimes $20 \mathrm{mmm}$. long.

Rubus Idcus or the cultivated European recl-raspberry is a shrub with a glaucous, bristly stem and with 3 - to 7 -foliate leaves. The flowers are white and the red fruit consists of a cap-like collection of hairy drupelets which is easily detached from the nonfleshy receptacle. The fruit is used in the preparation of syrup of raspberry which is used for flavoring. There are a number of varieties of this species of raspberry in cultivation, the fruits of which vary in color from crimson, brown, or yellow to nearly white. The fine flavored but watery fruit of the wild red-raspberry ( $R$. strigosus) is sometimes substituted for the fruit of Rubus Idaus.

Rosa gallica which yields the red rose-petals, official in a nummber of the pharmacopœias (p. 557), is a native of Southern Europe and is extensively cultivated.

Rosa centifolia which is now known only in cultivation, and of which there are a large number of varieties, is clistinguished by its glandular leaflets, and its pale red or pink petals. The conelike collection of petals of the flower-bud is the part which is used in medicine, but it is deficient in coloring principles and fragrance as compared to Rosa gallica.

Rosa damascona, the petals of which yield the oil of rose or attar of rose, is extensively cultivated in Bulgaria and to some extent in France and Germany. It flowers very profusely, and the yield of oil is about 0.02 per cent. The oil consists of a crystallizable hydrocarbon known as rose-camphor which is odorless, and a liquid portion consisting of geraniol, 1-citronellol, 1-linalool, citral, n-nonyllic aldehyde and phenyl ethyl alcohol. Similar oils are obtained from other species of Rosa growing in Northern Africa, Abyssinia and Northern India, as $R$. moschata, and $R$. somperivens.

The fruits of wild brier (Rosa canina) naturalized from Europe as well as of other species of Rosa (R. pomifcra and $R$. rugosa), contair considerable malic and citric acids and fruitsugars, and are made into a confection by boiling with syrup. 
In addition to the fruit-ethers found in the common edible fruits of this family and the volatile oil of rose, it should be mentioned that oils containing salicylic acid are also present. A number of species of Spirca contain salicylic aldehyde and methyl salicylate.

Quillaja Saponaria is a large tree having a thick bark and hard wood. The leaves are oval, coriaceous, slightly dentate and evergreen (Fig. 149). The flowers are monœcious or diøcious, white, apetalous, and axillary in groups of one to four. The ovary
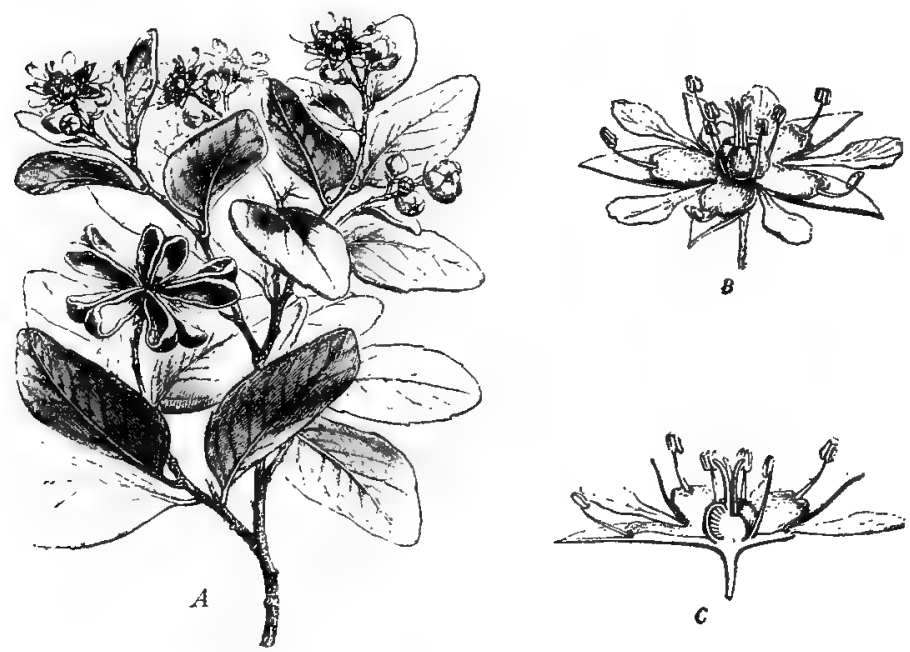

FIG. r49. Soap-bark tree (Quillaja Saponaria): A, flowering branch; B, one of the hermaphrodite flowers; $\mathrm{C}$, the latter in longitudinal section.-After Baillon.

consists of 4 to 5 carpels and on ripening forms a star-like, spreading group of follicles. The inner bark is the part used in medicine (p. 54 I).

Hagenia abyssinica is an ornamental tree with 7 - to 13 -foliate leaves. The flowers are monœcious and occur in panicles; the staminate being greenish-yellow and with 20 stamens; and the pistillate fragrant, bicarpellary, and with a reddish calyx (Fig. I50). The fruit is a nutlet. The pistillate flowers are official under the name of Cusso (p. 556).

Various species of Prunus yield GUMS, as cherry, peach, apricot, etc. MuciLAGE is found in the testa of certain seeds, as 
of quince. The manna of Luristan is obtained from Pyrus glabra of Persia. Tannin and gallic acid are found in Tormentilla

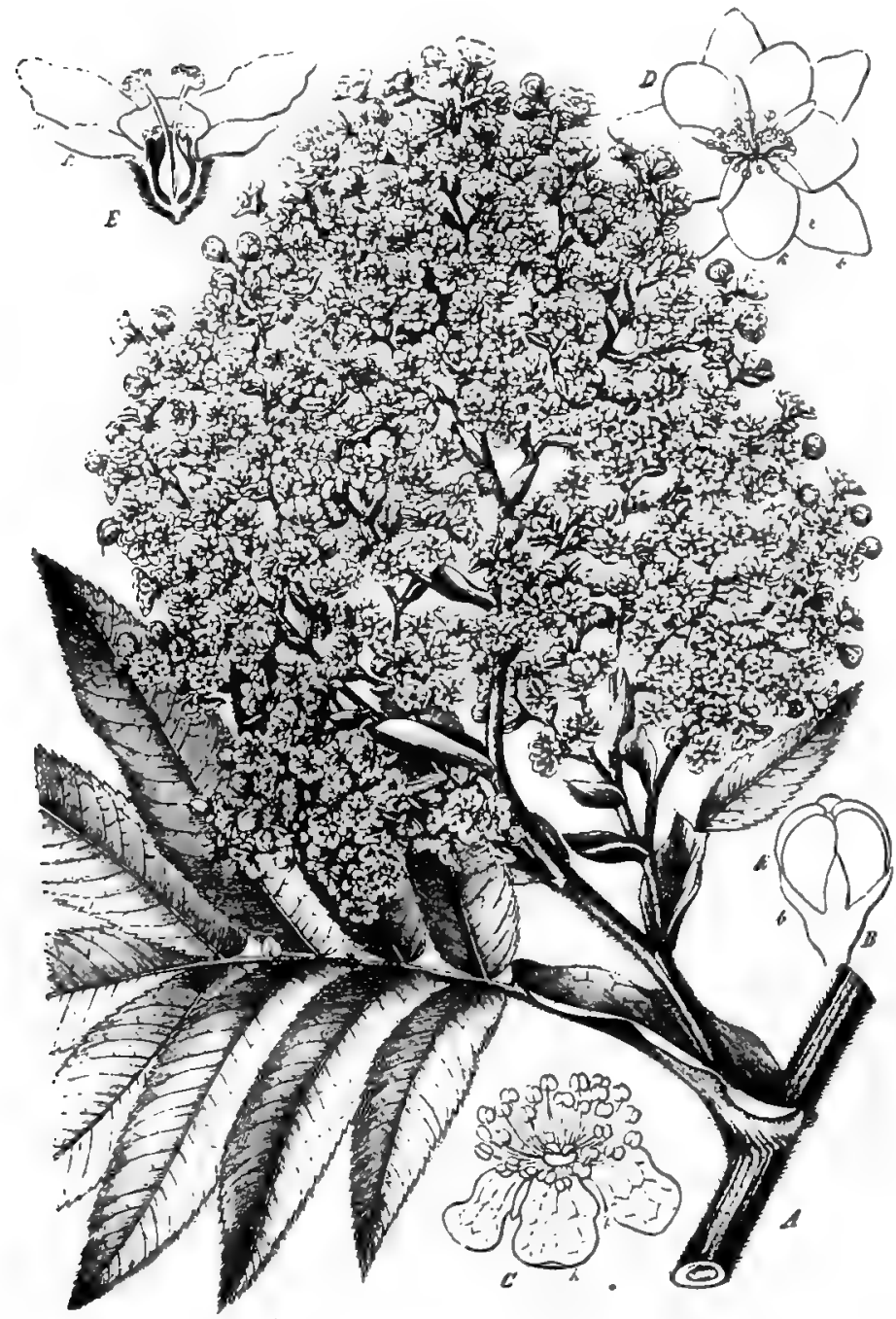

FIG. 150. Hagenia abyssiniox: A, branch showing a large panicle of pistillate flowers and the stipulate, compound leaves; B, C, staminate flowers; D, E, pistillate flowers.-After Berg and Schmidt.

rhizome which is obtained from Potentilla silvestris, a perennial herb of Europe, and other species of Potentilla. The fruit of the 
hawthorn (Cratcgus oxyacantha) contains quercitrin. A bitter principle and tannin are found in Purshia tridentata of the Rocky Mountains. Phlorizin is found in the root bark of a number of species of Pyrus and Prunus.

In the gentis Fragaria to which the strawberry belongs, the torus becomes large and fleshy and is the edible part of the fruit. The garden strawberry ( $F$ Chilonsis) has a large, dark-colored fruit, the akenes being sunken in the periphery of the torus. In the wild strawberries the fruit is smaller, usually somewhat fleshcolored and the akenes are either embedded in the torus as in $F$. zir giniana or borne on the surface as in F. a'csca. The strawberry fruit contains about 87 per cent. of water; 6 per cent. of cane sugar; 5 per cent. of invert sugar (a mixture of dextrose and levulose); I per cent. of free fruit-acids; and about 2 per cent. of nitrogenous substances.

g. LEGUMINOSÆ OR PULSE FAMILY.-The plants are herbs, shrubs, trees, or vines with alternate, stipulate and usually compound leaves. The flowers are complete, and the corolla is either regular or irregular; the stamens are usually united, and the pistil is simple and free, becoming in fruit a legume. The plants are widely distributed, many of them being found in the Tropics. Three principal sub-groups, which have been ranked as families by some botanists, are recognized.

x. Papilion.itze.-Those species with papilionaceous flowers are separated into a group called the Papilionatæ. This subgroup has a number of representatives in the United States, as clover, locust, and Baptisia (Fig. I34, L).

2. Cesalpiniolde include the sennas and have flowers which are nearly regular, or imperfectly, or not at all papilionaceous.

3. The Mrmosotdex include the acacias and have flowers that are regular.

Cassia acutifolia is a small shrub with leaves that are 8- to Io-foliate. The leaflets are official as Alexandria senna (p. 607); the flowers are yellowish and in axillary racemes; the fruit is a smooth, flat, dehiscent pod, with 6 to 8 seeds (Fig. 262).

Cassia angustifolia is a shrub which is cultivated in Southern India and resembles Cassia acutifolia. The leaflets which consti- 
tute India or Tinnevelly senna (p. 607) are longer and narrowlanceolate, and the pods are longer, and slightly crescent shaped, as compared to those of C. acutifolia (Fig. 262).

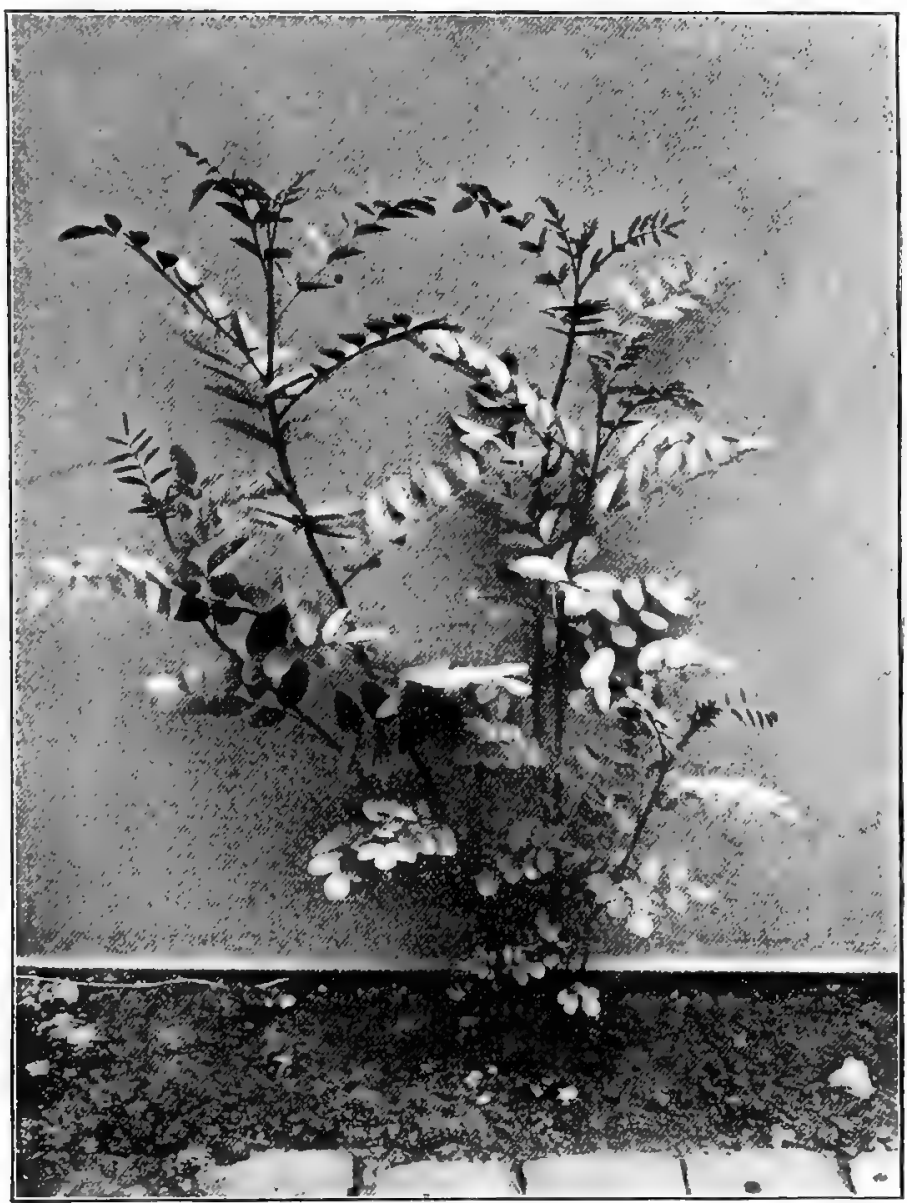

FzG. I51. Spanish licorice (Glycyrrkiza glabra) plant grown from a cutting by the late Henry N. Rittenhouse of Philadelphia.

Cassia fistula or purging cassia, the pods of which are official (p. 585), is a tree about $15 \mathrm{M}$. high. The leaves are IO- to I2foliate; the flowers golden-yellow and in racemes; and the fruit 
is a long, cylindrical, indehiscent legume (Fig. 255). The leaves of quite a number of species of Cassia are used in medicine and the following are the source of Folia Malabathri: C. Tamala of Assam and C. jar'anica.

Glycyrrhiza glabra is a perennial herb, with 8- to I4-foliate leaves (Fig. 15I), the leaflets being glandular in the variety glandulifera; the flowers have a violet-colored, papilionaceous corolla, and the fruit is a flat, dehiscent legume. The rhizome and roots are the parts used in medicine (p. 472 ).

Cytisus Scoparius or green or Scotch broom is a shrub naturalized from Europe. The branches are numerous, slender, erect and grow close together adapting them for use as brooms. The tops are used in medicine (p. 637).

Tamarindus indica is a tree attaining a height of $25 \mathrm{M}$. The leaves are pinnately compound having numerous sessile, entire leaflets (Fig. 256a); the flowers are in terminal racemes and the petals are yellow with reddish veins; the fruit is a curved, indehiscent legume which has a thin epicarp and a pulpy sarcocarp with numerous fibers, and contains a number of flat, quadrangular seeds. The pulp is the part used in medicine and is official as tamarind (p. 593).

Astragalus gummifer is a tomentose shrub less than I M. high. The leaves are pinnately compound, the leaflets being narrow and elliptical; the flowers are pale yellow, sessile and axillary; the fruit is a small, somewhat cylindrical, hairy pod (Fig. 152). The gummy exudation constitutes the Tragacanth of commerce (p. 650).

Acacia Senegal, which yields gum Arabic or acacia (p. 643), is a small tree with bipinnate leaves which are subtended by curved spines; the flowers are yellow and in dense spikes; the fruit is a broad pod containing five or six seeds (Fig. I53).

Acacia Catechu is a small tree which resembles Acacia Senegal and furnishes Black Catechu (p. 666).

Pterocarpus Marsupium is a fine timber tree with spreading branches. The leaves are $5^{-}$to 7 -foliate, the leaflets being coriaceous, obovate, and emarginate; the flowers are pale yellow, and the fruit is an indehiscent, orbicular pod with a single reniform seed. The official Kino is prepared from the juice (p. 654). 
Pterocarpus santalinus is a small tree with trifoliate leaves, and flowers and fruits resembling those of P. Marsupinm. The heart-wood is official (p. 547).

Hamatoxylon canipechianum is a small tree with irregular spinous branches. The leaves are 8 - to Io-foliate, the leaflets being sessile and obcordate. The flowers are fragrant, have a

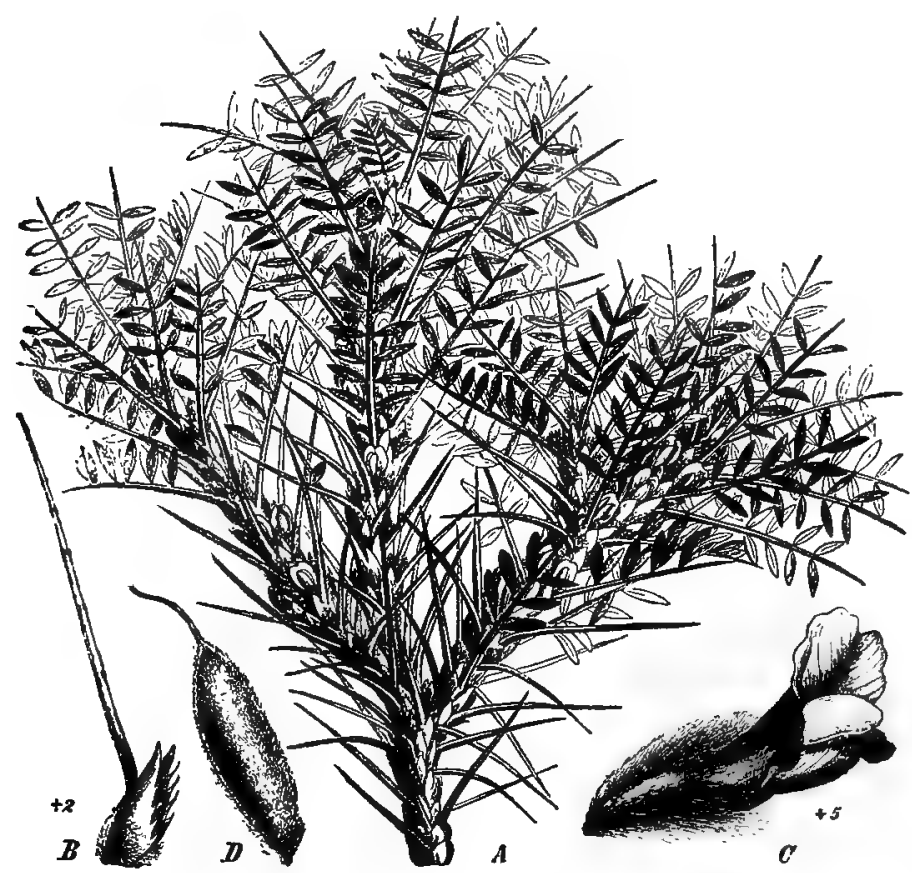

F1G. I52. Tragacanth plant (Astragalus gummifer): A, flowering branch; B, modified, thorn-like leaf with stipules at the base; C, irregular (bilateral) flower; D, legume of $A$. aristatus.-After Taubert.

purple calyx and yellow corolla, and are in racemes. The fruit is a slender, lanceolate, flat pod, which dehisces laterally instead of along the sutures. The heart-wood of this tree constitutes the official Logwood which is recognized in nearly all the pharmacopœias (p. 546).

Krameria triandra is a shrub with simple, ovate-lanceolate, sessile, silver-white, glistening leaves (Fig. 154). The flowers are 
complete, having two purple petals and three stamens. The fruit is a I-seeded, globular, prickly, indehiscent pod. K. Ixina found growing from Mexico to Northern South America, and $K$. argentea of Northern Brazil, are distinguished by having flowers with three petals and four stamens. The root is the part used in medicine (p. 453).

Copaiba Langsdorffi is a small tree found growing in Brazil. The leaves are 6-to Io-foliate, the leaflets being ovate-lanceolate,

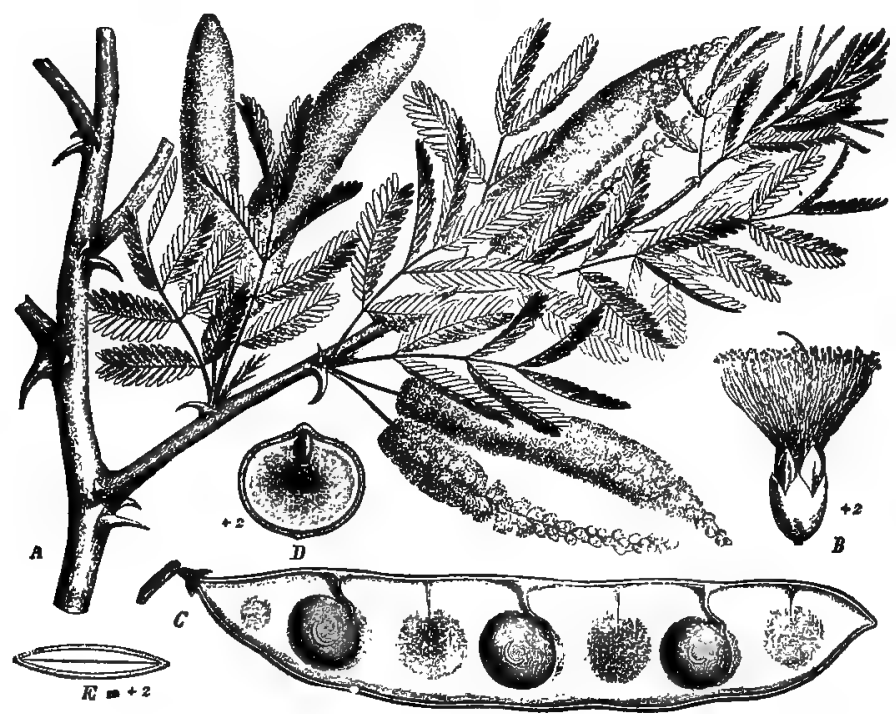

FIG. I53. Acacia Senegal: A, flowering branch: B, a single flower showing numerous stamens; $C$, part of legume showing attachment of seeds; $D, E$, sections of seeds.After Taubert.

glabrous, coriaceous, and pellucid-punctate. The flowers are apetalous, and the fruit is an ellipsoida1, coriaceous, 2-valved pod having a single glandular seed with an arillus. An oleo-resin collects in longitudinal cavities in the trunk of the tree, often amounting to many liters, and sometimes the pressure thus produced is sufficient to burst the trunk in places. The oleo-resin is official as Copaiba. The latter consists of 30 to 75 per cent. of a volatile oil from which the sesquiterpene caryophyllene has been isolated; a bitter acrid resin and a bitter principle. A similar product 
is obtained from a number of other species of Copaiba growing in South America as well as $C$. copallifera of Western Africa, and Hardrickia Mannii of tropical Africa, and $H$. pinnata of India.

Toluifera Balsamum is a tree about $25 \mathrm{M}$. high, with a straight trunk, on which the branches first appear at a height of from

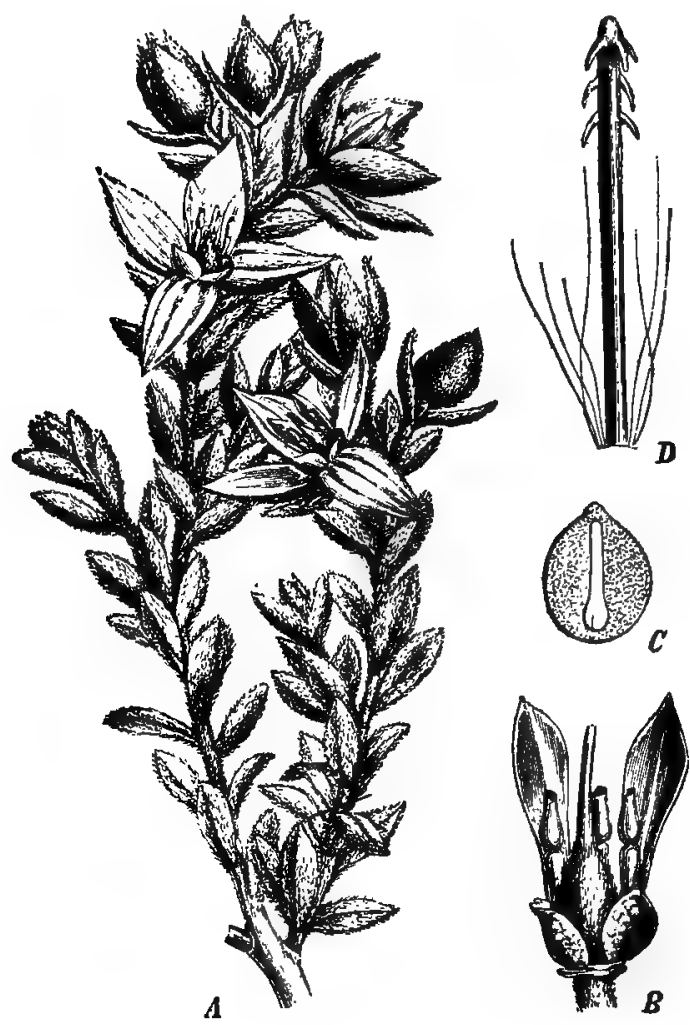

FIG. 154. Krameria triandra: A, flowering branch; B, a single flower after removal of the calyx; C. longitudinal section of seed showing straight embryo; D, barbed hair of the fruit.-After Berg and Schmidt.

I 5 to 20 M., and is found growing in Northern South America. The leaves are compound and with seven to eleven alternate, oblong, acuminate, pellucid-punctate leaflets; the flowers are white and in simple axillary racemes; the fruit is a winged, indehiscent, I-seeded legume. The plants yield a balsam (official in all the 
pharmacopœias and known as BALSAM of TOLU) which occurs in schizogenous cavities in the bark of young twigs, and is obtained by incising the bark, it being usually collected in gourds. The balsam consists of 75 to 80 per cent. of resin, which is a compound of tolu-resinotannol, cinnamic and benzoic acids; I 8 to 20 per cent. of free cinnamic acid; 0.2 to I per cent. of a volatile oil; and 0.05 per cent. of vanillin. A good tolu balsam is also obtained from $T$. peruifera growing in the northeastern part of South America.

Toluifcra Pcreire is a tree about $15 \mathrm{M}$. high, which has a short trunk and begins to branch at a height of 2 or $3 \mathrm{M}$. It otherwise resembles T. Balsamum. It is found over the whole of Northern South America, extending through Central America to Mexico, and is cultivated in Singapore. The balsam, which is formed as a result of injury to the trunk, consists chiefly of esters of benzoic and cinnamic acids, some free cinnamic acid, and vanillin. A very fragrant vanilla-like balsam is obtained from the fruit of this same plant, and in San Salvador it is known as white Peru balsam to distinguish it from the black Peru balsam obtained from the trunk.

Physostigma venenosum is a woody climber. The leaves are 3 -foliate, the leaflets being ovate-acuminate; the flowers are violet in color and in axillary racemes; the fruit is a broadly linear, somewhat flattened, distinctly veined, dehiscent pod which tapers at both ends, and contains two or three seeds (Fig. I89). The seeds are official as Physostigma (p. $43^{8}$ ).

The blue coloring principle INDIGo is mostly obtained from the herbs Indigofera tinctoria and I. Anil which are indigenous, to, and cultivated in tropical and sub-tropical countries. It is prepared by extracting the leaves with water. The glucosidal principle indican (or mother-substance of indigo blue) undergoes oxidation and the insoluble indigo blue separates out. This is the commercial indigo. A similar principle is found in the wild indigo (Baptisia tinctoria) of the United States and Canada; the leaves of Robinia Psendacacia of North America; several species of Psoralea and Amorplia, as well as some other Leguminosæ. It is also found in other families, as in Polygonaceæ, Cruciferæ; Asclepiadaceæ, and Apocynaceæ. 
A yellow coloring principle is found in the dyer's broom (Genista tinctoria) of Europe and Asia and naturalized in the New England States. G. oz'ata of Europe yields a similar dye.

Cop.IL Resins are clerived from a number of the Leguminosa: American copal from Hymenca Coubaril of the West Indies and South America; Brazilian copal from H. Martiana of Rio Negro; Zanzibar or Chakazzi-copal from Trachylobium mosambiccnsis of Western Africa; Sierra Leone copal (yellow gum, red gum) from Copaiba Guibourtia of Sierra Leone; Inhambane copal from Copaiba conjugata and C. Gorskiana of Singapore, Jamaica and Australia.

Probably the majority of the Loco-weEns or plants containing principles poisonous to cattle belong to the Leguminosæ, and of these the following may be mentioned: California loco-weed (Astragalus crotalaric), Texas or woolly loco-weed (A. mollissimus), rattle-box (Crotalaria sagittalis) found in the Eastern United States and Canada. It is not certain to what principles the poisonous action of these plants is due. Clitoria glycinoides of Brazil, Phaca ochroleucaca of Chile and O.rytropis Lambertii of Mexico are poisonous to horses and should probably be included with the loco-weeds.

A large number of the plants belonging to the Leguminosæ contain toxic principles and those which have not already been considered might be grouped according to the principles which they contain.

I. ARrow-PoISon group, including the genera Erythrophloum, Afzelia and Pithecolobium.

2. Fish-Poison group, including the genera Albizzia. Afzelia, Bauhinia, Jarbiera, Enterolobium, Leucæna, Millettia, Tephrosia, Acacia, Abrus, Clitoria, Mundulea, Derris, Lonchocarpus, Piscidia ( $P$. Erythrina or Jamaica dogwood, which contains a curarelike alkaloid).

3. Saponin-containing plants, as the genera Acacia, Albizzia, Entada (E. scandens or the sea bean of the East and West Indies), Enterolobium, Gleditschia and Gymnocladus (G. dioica or Kentucky coffee-tree growing in the United States and Canada).

4. Cytisine-containing plants; the alkaloid cytisine is found in Laburnum vulgare and L. alpinum growing wild in Southern 
Europe and also cultivated, and in one or more species of the following genera: Anagyris, Baptisia, Coronilla, Crotalaria, Cenista, and Ulex.

Abrin, composed of a globulin and albumose and whose properties are affected at a temperature of $50^{\circ} \mathrm{C}$. or over, is found in the seeds of JEQUIRITY (Abrus precatorius) and Cassia hispidula of Mexico; two alkaloids (lupinine and lupinidine) and a bitter glucoside (lupinin) are found in the white lupine (Lupinus albus) of Europe and in other species of Lupinus; a glucoside (wistarin) and a poisonous resin are found in WISTARIA (Kraunhia floribunda) a common woody climber in cultivation as an ornamental plant; the glucoside ononin is found in Radix ONonidis the root of Ononis spinosa of Europe; the glandular hairs on the pods of Mucuna pruriens and M. urens growing in the Tropics of both hemispheres constitute the COWHAGE of medicine; butyric acid is found in ST. JoHN'S BREAD the fruit of Ceratonia Siliqua which grows in European countries bordering the Mediterranean, and also in Eperua falcata of Guiana.

A bitter principle, bondicine, known as poor man's quinine, is found in Casalpinia Bonducella and other species of Casalpinia growing in Sumatra, Borneo, New Zealand and Brazil; the seeds of Phaseolus lunatus of the East Indies contain a principle from which hydrocyanic acid is derived.

The seeds of many of the plants belonging to the Leguminose are rich in starch and proteids and hence are used as foods. The proteid LEGUMIN is characteristic of this family. The following are some of the important food plants: the garden pea (Pisum satiz'mm), the garden bean (Phaseolus vulgaris); lentil (Lens esculcuta), Japanese Soy bean (Glycine hispida). The peanut (Arachis hypogaa) indigenous to Brazil and extensively cultivated in most of the Southern States and in Southern Europe, belongs to the group of plants which have geocarpic fruits, that is, fruits which penetrate the soil during their development and ripen under ground (Fig. 88). In peanuts the starch is replaced by a fixed oil which is present to the extent of about 45 per cent. and which is an article of commerce. In addition to the seeds mentioned those of a number of other plants as well as some fruits, roots and leaves are used as foods in various parts of the 
world, particularly in the Tropics. The plants of a number of species are used as forage, as those of clover (Trifolinm); some are cultivated as ornamental plants, as sweet pea (Lathyrus odoratus), and some yield valuable timber, as the locust (Robinia).

\section{ORDER GERANIALES.}

This order includes a númber of families of economic importance. The sepals are mostly distinct; the stamens are few; the carpels are united, and the ovules are pendulous (epitropous).

a. GERANIACEÆ OR GERANIUM FAMILY.-The plants are herbs with alternate or opposite, usually stipulate leaves, regular and perfect flowers, and capsular fruit (Fig. $89, C)$.

Geranium maculatum is a perennial herb (Fig. I55) with a short, thick, horizontal rhizome, from which arises a simple, somewhat branching, hairy stem, with 3- to 5-parted, variously toothed and cleft, petiolate leaves, those on the upper part of the stem being opposite; the flowers are regular and 5-merous, occurring singly or in twos in the axils of the leaves; the petals are rose-purple and hairy at the base; the fruit is a dehiscent capsule; the five carpels when ripe separate and roll upwards remaining attached to a central column by means of a slender carpophore, the individual carpels being in the nature of akenes. The rhizome constitutes the official geranium (p. 505).

The cultivated geraniums belong to the genera Pelargonium, and some of the species furnish oil of rose geranium, as $P$ odoratissimum, $P$. capitatum and $P$. radula, all of which are cultivated in France, Spain, Germany, Algiers and Retnion for the oil, which is largely used in perfumery. The oil contains geraniol, citronellol, and various esters. The leaves of Pclargonium peltatum, growing in certain parts of Africa and Australia, contain oxalic acid and acid oxalates.

b. OXALIDACEÆ OR WOOD-SORREL FAMILY.-To this family belongs the genus $O x a l i s$, some species of which have leaves that are quite sensitive to light as well as mechanical stimuli, which applies especially to the cultivated forms of South Africa, and to the common wood-sorrel (Oralis Acetosella) of 
the United States and Canada, as well. The leaves contain oxalic acid and acid oxalates.

c. THE TROP正OLACEA OR NASTURTIUM FAMILY comprises but a single genus, Tropæolum. Some species.

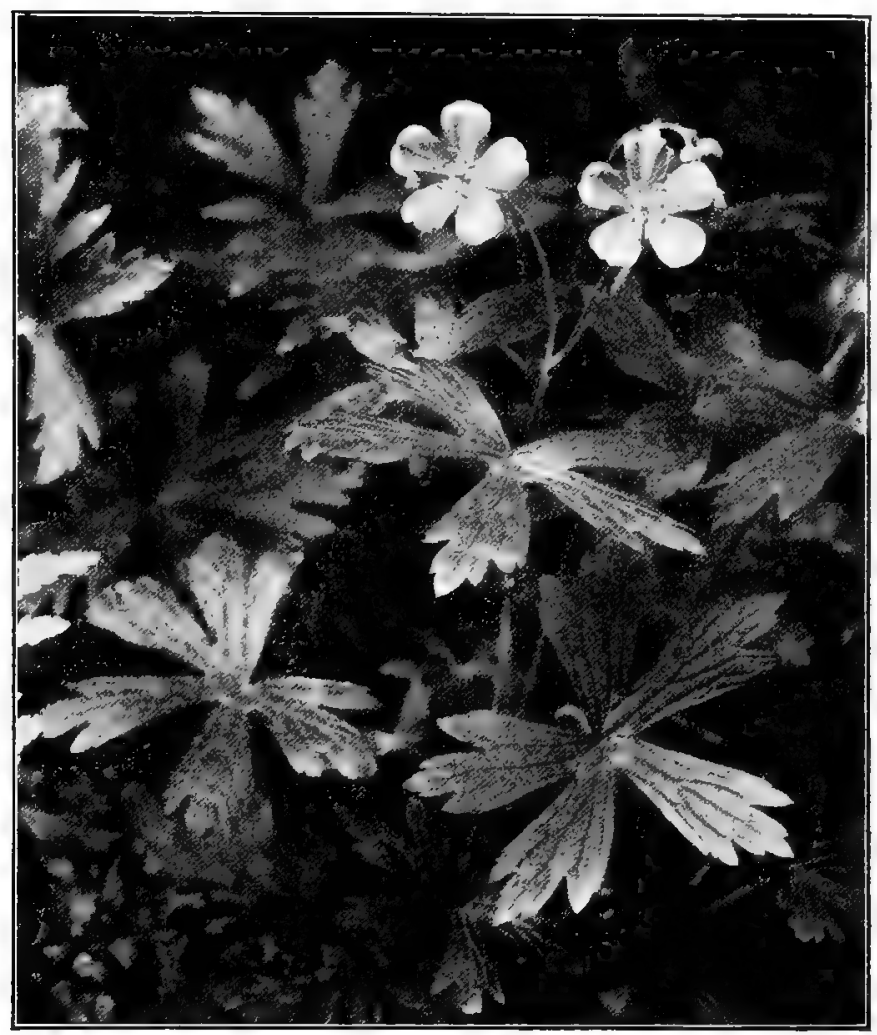

FIG. 155. Geranium maculatum showing typical dicotyledonous flowers and the 5-parted, reticulately-veined leaves.

are cultivated for ornamental purposes and are the nasturtiums of the gardens. The young shoots are succulent and taste like some of the cresses, hence they have received the name "Indian cress." They contain volatile constituents resembling those of the Cruciferæ, and in the leaves of Tropacolum majus benzyl 
mustard-oil is found. The flower-buds and young fruits of this species are used for pickling like capers.

d. LINACE无 OR FLAX FAMILY.-The most important plant of this family is the common flax (Linum usitatissimum). This is an erect, slightly branching annual herb with alternate, lanceolate and 3 -nerved leaves. The flowers are in terminal, leafy panicles, the pedicels being slender, the calyx non-glandular, and the petals blue (Fig. $134, A$ ). The fruit is a Io-locular, Io-seeded capsule. The seeds are official (p. 426). There are a number of cultivated varieties and the seeds of the var. Humile contain a glucoside which yields, under the influence of ferments, hydrocyanic acid. A cathartic principle has been found in L. catharticum growing in Europe. The bast fibers of Linum usitatissimum are used in the manufacture of linen. These fibers are distinguished from many other vegetable fibers in not containing lignin.

e. ERYTHROXYLACE OR COCA FAMILY.-This family contains but two genera, one of which is Erythroxylon. The official coca leaves (p. 604) are obtained from Erythroxylon Coca. The plant is a shrub and requires a very humid atmosphere and a comparatively high elevation. The leaves are alternate, petiolate and entire; the flowers are white and very small; the fruit is a I-seeded, reddish drupe resembling that of dogwood (Fig. 260).

Other species of Erythroxylon also yield useful products. An aromatic oil is found in the wood of E. monogymum of Ceylon and India, and the wood is known as "bastard cedar" or "bastard santal." A brownish-red coloring principle is found in the red-wood (E. arolatum) of Jamaica and in E. suberosum and E. tortuosum. Purgative and anthelmintic principles are found in some species of this genus.

f. ZYGOPHYLLACE王 OR CALTROP FAMILY.-The plants are mostly herbs and shrubs which are widely distributed in warm-tropical regions. The leaves are mostly opposite, pinnate and stipulate. The genus Guaiacum is of interest on account of the wood containing considerable resin, which is used in medicine.

Guaiacum officinale is a small tree with $4^{-}$to 6 -foliate leaves, the leaflets being ovate, entire and sessile; the flowers are large, 
blue, and in axillary clusters; and the fruit is a 2-valved capsule (Fig. 156). G. sanctum is a tree resembling $G$. officinale, but is distinguished by having leaves which are' 8 -foliate and with smaller leaflets, and a 4- to 5-valved capsule. The resin of both species is official (p. 668).

A resin having an odor resembling that of creosote occurs in the Creosote busin (Covillea tridentata) of Mexico and Texas.

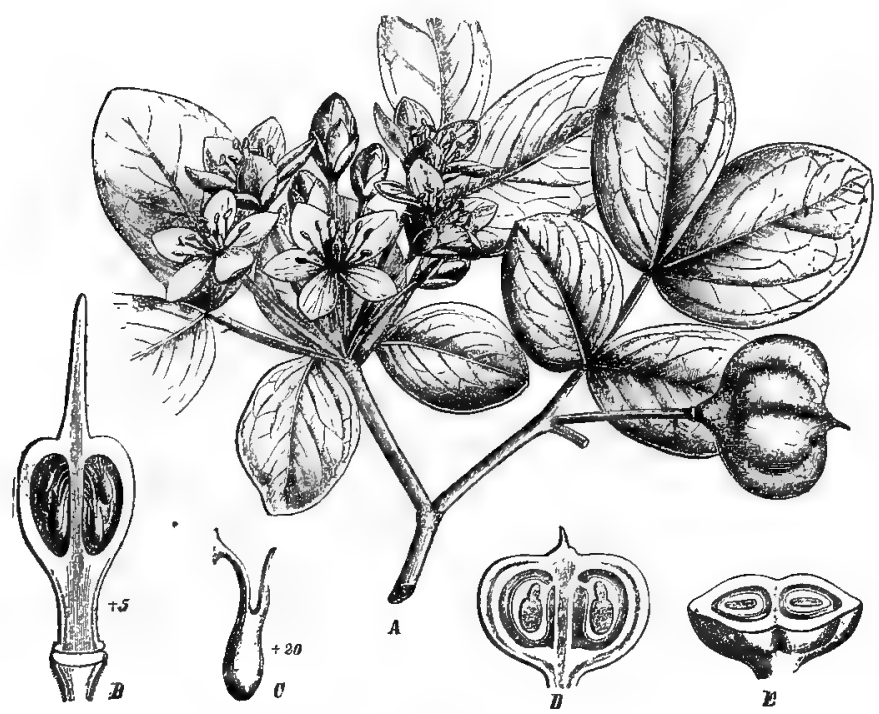

FIG. I56. Guaiacum officinale: A, flowering and fruiting branch; B, gynacium in longitudinal section showing the pendulous ovules; $C$, a seed; D, E, the fruit in longitudinal and transverse sections,- After Berg and Schmidt.

The juice of Peganum Harmala contains a yellow coloring principle used in dyeing. A number of the plants of this family contain powerful poisonous principles.

g. RUTACE $Æ$ OR RUE FAMILY.-The plants are shrubs or trees, seldom herbs, with lysigenous oil-secretion cells. The leaves are usually alternate, simple or compound and pellucidpunctate (Fig. 1 34, C).

Xanthoxylum americanum or northern prickly ash, is a shrub or small tree with $5^{-}$to II-compound leaves, the leaflets being ovate and nearly sessile; the flowers are diœcious, greenish, and 
in axillary cymes; the fruit is a black, 2 -valved capsule. X. ClavaHerculis or the southern prickly ash is a very prickly shrub, which is characterized by having cork-wings on the bark. The leaves are $5^{-}$to 17 -foliate, the leaflets being ovate and crenulate; the flowers are in terminal racemes and have a calyx of 4 or 5 sepals,

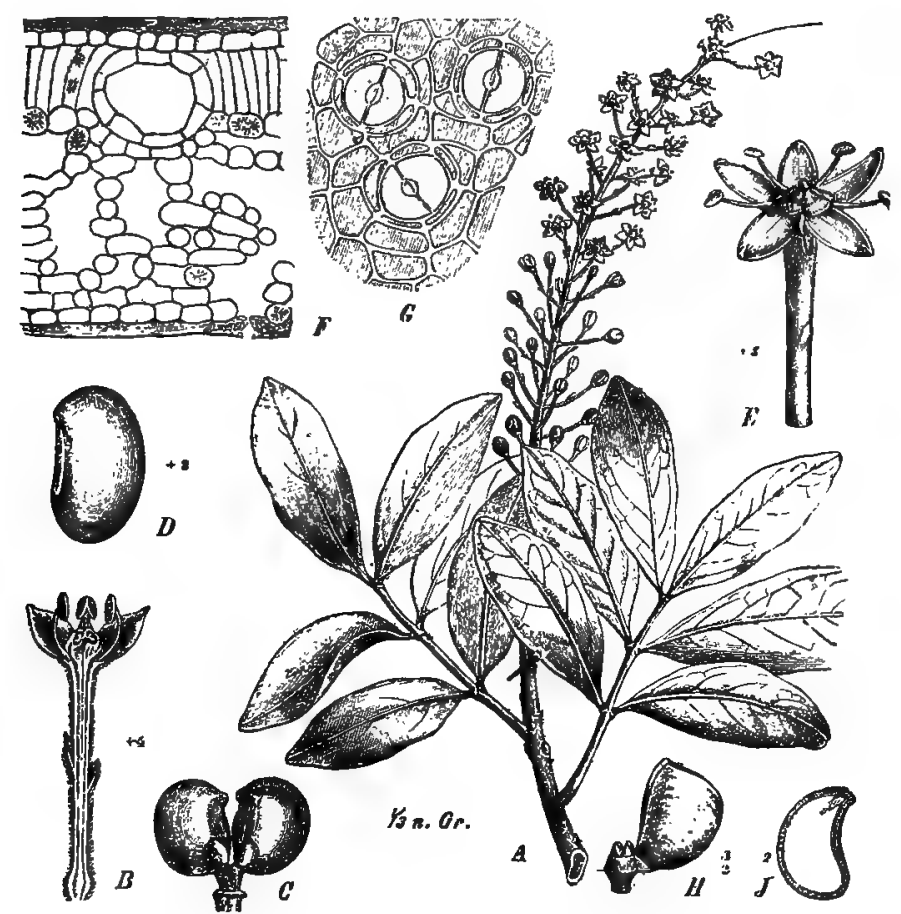

Frg. 157. Species of Pilocarpus: A, branch of $P$. Selloanus showing determinate inflorescence; $\mathrm{B}$, flower of the same; $\mathrm{C}$, fruit of $P$. giganteus; $\mathrm{D}$, seed of $P$. macrocarpus; $\mathrm{E}-J, P$. pinnatifolius, - E, flower; $\mathrm{F}$, transverse section of leaf; $\mathrm{G}$, surface view of lower epidermis; $H$, part of a fruit; J, longitudinal section through seed. $-F, G$, after A. Meyer; the remainder after Engler.

the calyx being wanting in $X$. americanum. The bark of these two species is official (p. 532 ).

PILOCARPUS.-To this genus belong a number of species which are shrubs or small trees and indigenous to tropical America. The leaves are mostly pinnately-compound, the leaflets being coriaceous and entire; the flowers are small, greenish and in 
axillary or terminal racemes; the fruit is a I-seeded, 2 -valved capsule (Fig. 157). The leaves of three species are official as Pilocarpus or Jaborandi (p. 596).

B.trosma.-The buchu leaves of medicine are obtained from several species of Barosma (see Buchu). The plants are branching shrubs with opposite, coriaceous, serrate or dentate leaves with glandular margins; the flowers are white or red and occur, 1 to 3 , in the axils of the leaves; the fruit is a 5 -valved capsule. The leaves contain a volatile oil, one of the constituents of which is diosphenol.

Citrus.-The fruits of a number of species of this genus are edible, and the plants are also valued for their volatile oils. They are aromatic, glandular, mostly thorny shrubs or small trees indigenous to tropical and sub-tropical Asia, and now extensively cultivated in tropical, sub-tropical and warm-temperate regions. The leaves are more or less winged-petiolate (Fig. I58), coriaceous, mainly unifoliate (or trifoliate); the flowers are complete, with $3^{-}$to 6-toothed gamosepalous calyx, and 4 to 8 glandular petals; the stamens are 20 to 60 , in groups of $I$ to 9 ; the ovary is subtended by a cushion-shaped disk, and the fruit is a spherical, oblong or pear-shaped berry, having a coriaceous pericarp with numerous lysigenous oil-glands, a juicy pulp made up of peculiar hair-structures which arise from the endocarp, and in which are embedded white polyembryonic seeds (Fig. I34, C).

Botanists have divided this genus into two sub-groups: (a) the Pseudo-Ægle group is represented by the trifoliate orange (Citrus trifoliata), cultivated widely in the United States as a hedge. The leaves are trifoliate and deciduous, the petals spatulate and the ovary and disk hairy. (b) In the Eucitrus group the leaves are unifoliate and evergreen, the petals oblong, and the ovary and disk glabrous. This latter group includes the two species which yield most of the edible Citrus fruits.

Citrus Aurantium includes a number of sub-species and varieties. The plants are small trees with leaves having winged petioles (Fig. I.58); white flowers; and a more or less globular fruit. The Sweet Orange (Malta, Portugal) is derived from the sub-species sinensis. The Bitter Orange (Seville, Curaçao) is derived from the sub-species amara. The flowers of both the 
Sweet and Bitter Orange tree contain a volatile oil known as OIL of Neroli, and composed of limonene, geraniol, linalool, etc. The oil from the rind of the fruit is known as OIL OF ORANGE PEEL, and is obtained chiefly from Italy and Sicily. It is composed of limonene, citral, citronellol, etc. The oil from the Bitter Orange peel has a superior flavor and is known as Bigaradia olL. The Bergamot Orange is the fruit of the sub-species Bergamia, cultivated in Europe, but only rarely in the United States. The oil of the rind of the fruit is known as BERGAMOT oIL and consists

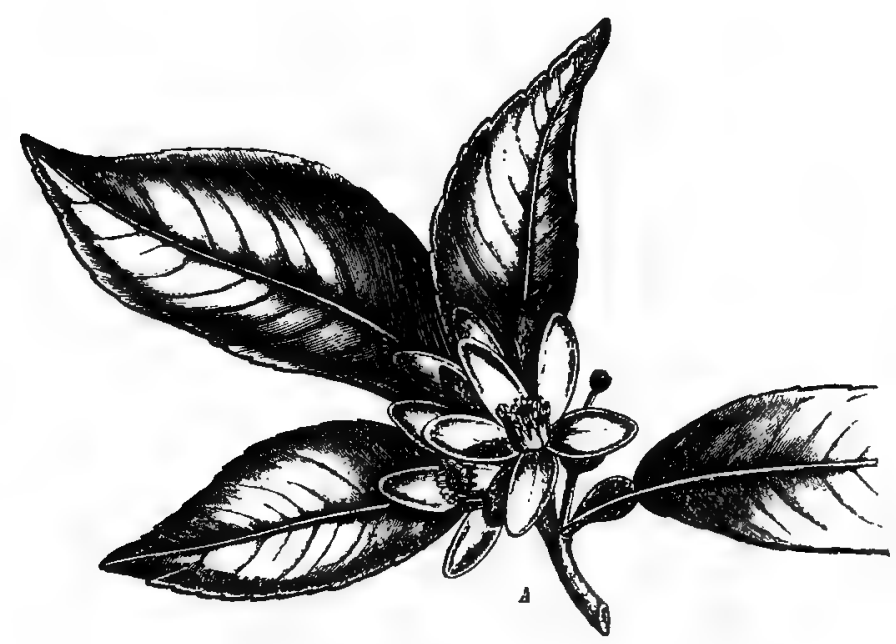

FIG. 158. Citrus Aurantium showing axillary cluster of flowers.After Berg and Schmidt.

largely of linalyl acetate. The SHADDOCK or grape-fruit is derived from the sub-species sinensis var. decumana, a tree indigenous to the Malay Archipelago and extensively cultivated in India, Florida, California and elsewhere. The fruits are quite large, sometimes weighing several kilograms, and those which are round are the most valuable commercially, being known as Pomelos or Grape-fruits. The Blood Orange is the fruit of the sub-species sinensis var. sanguinea. The Otaheite Orange which is extensively cultivated as a dwarf pot plant and the foliage and flowers of which resemble those of lemon, is probably a variety of 
the sub-species sinensis, or it may be a hybrid of lemon and orange. The Navel Orange is a sweet orange in which an additional compound ovary is developed within the fruit.

LEMON and LIME fruits are derived from sub-species of Citrus medica, which are mostly shrubs with simple, petiolate leaves, reddish twigs and flowers, and more or less ellipsoidal fruits. Lemons are derived from the sub-species Limonum. The rind of the fruit yields the OIL OF LEMON, which consists of limonene, citral, etc. Most of the commercial article comes from Sicily and Calabria. Lime fruits or limes are derived from the sub-species acida, a shrub cultivated in the West Indies and Florida. The Citron fruit, the rind of which is used in the making of preserves and confections, is derived from the sub-species genuina. The fruit is large and lemon-like but with a thick rind, the plant being cultivated to some extent in Florida and California.

The Satsuma Oraxge is obtained from Citrus nobilis, a thornless tree with spreading dwarf habit extensively cultivated in China and Japan and very hardy even in Northern Florida. The fruit is oblong, from 4 to $9 \mathrm{~cm}$. long and 4 to $7 \mathrm{~cm}$. in diameter, and of an orange-yellow color; the pulp is acid as well as sweet, and usually free from seeds, although from $\mathrm{r}$ to 4 slightly beaked seeds may be present.

The inner white portion of the rind of the Citrus fruits contains a crystalline, tasteless glucoside known as hesperidin. Those which are bitter contain in addition several bitter glucosides, namely, aurantiamarin and naringin. (See Aurantii Amari Cortex, p. 592, and Aurantii Dulcis Cortex, p. 59r.)

Volatile oils are also found in other members of the Rutacex. The garden rue (Ruta graveolens), the leaves of which are used in medicine, contains a volatile oil consisting of several ketones. It also contains a glucoside known as rutin which resembles the barosmin of buchu; and quercetin, which is said to be derived from rutin. The Hop tree (Ptelea trifoliata) of Eastern North America contains besides a volatile oil, a resin and an alkaloid. The volatile oil of pepper-moor (Xanthoxylum piperitum) of China and Japan is known as Japanese oil of pepper.

Angustura bark obtained from Cusparia trifoliata or $C$. officinalis, plants growing in the region of the Orinoco River, con- 
tains a volatile oil, resin, a bitter principle and four alkaloids. The wood of Amyris balsamifera of Guiana and Jamaica, yields on distillation a volatile oil resembling Oleum Rhodii.

h. SIMARUBACE E OR AILANTHUS FAMILY.-The plants are chiefly shrubs or trees with alternate and pinnatelycompound leaves. The flowers are regular, diocions or polygamous and in axillary racemes. The plants are natives of tropical countries.

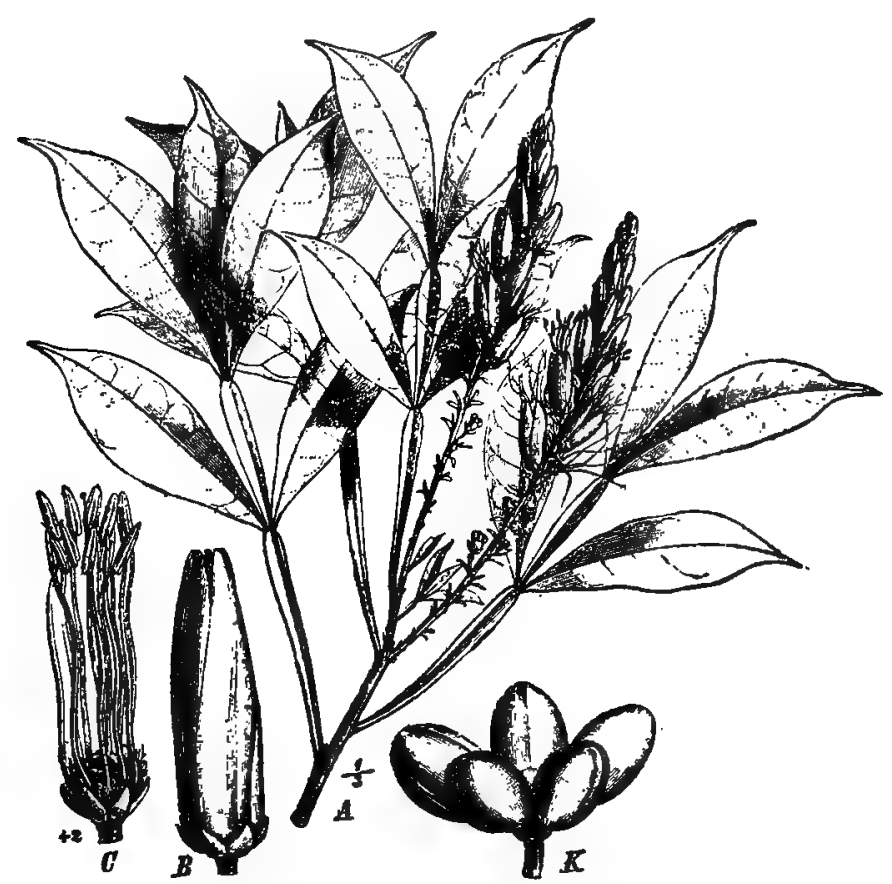

FIG. 159. Quassia amara: A, flowering branch showing peculiar winged leaf stalk; $B$, flower-bud; $C$, the same after removal of the perianth; $K$, fruit.-After Engler.

Picrasma excelsa is a small tree with 9- to $\mathrm{r} 7$-foliate leaves, the leaflets being ovate and more or less tomentose, particularly in the bud; the flowers are yellow, polygamous and in axillary panicles; the fruit is a large, spherical drupe. The wood of the plant constitutes Jamaica quassia (p. 544).

Quassia amara is a small tree or shrub with 4 - to 5 -foliate leaves; the leaflets are narrow, obovate and acuminate, and the 
rachis and petiole are winged (Fig. I59); the flowers are hermaphrodite, with Io stamens, bright red corolla, and in terminal racemes; the fruit is a 5-valved indehiscent pod or nutlet. The wood constitutes Surinam quassia (p. 544).

A red coloring principle is found in Samadera indica of India, Ceylon and Java. The alkaloid cedronin is found in the seeds of Simaba Cedron of New Granada, the seeds being used as an antidote for the bites of poisonous animals. A similar principle may exist in the bark of Simaruba versicolor of Brazil, the plant being used for a similar purpose. The alkaloid brucamarine is found in the fruit of Brucea sumatrana. A tragacanth-like gum is obtained from Ailanthus excelsa of India. Dika or Gabun ChосoLATE is obtained from the seeds of Irvingia gabonensis of tropical West Africa. Cay-Cay-Butter is obtained from the seeds of Irvingia Oliveri and I. Malayana of Malacca and Cochin China.

A gum resembling acacia is also obtained from the bark, petioles and seeds of the species of Irvingia.

i. BURSERACE $Æ$ OR MYRRH FAMILY.-The plants are shrubs or trees, the latter being sometimes quite large, with resin-canals in the bark, and alternate compound leaves; the flowers are small, occurring in racemes. The members of this family are found in tropical countries.

Commiphora abyssinica is a shrub to $\mathrm{M}$. high, the branches being modified to thorns; the leaves are trifoliate, the leaflets being oblong, dentate, sessile and the terminal one much larger than the other two; the flowers are diœcious, and the fruit is a drupe with fleshy, resinous sarcocarp (Fig. I60). The official Myrrh is obtained from this plant (p. 673).

A number of other resinous products are yielded by plants of this family. West India ElEMi resin or Elemi Occidentale (Anime) is obtained from the stems of Protium Icicariba of Brazil. The resin is greenish-yellow, soft, with a bitter taste and dill-like odor. Manila Elemi is a soft, granular, lemon-yellow or grayishwhite resin derived from Canarium commune of the Philippine Islands. Bengal Elemi is derived from Commiphora Agallocha of the East Indies and Madagascar. The Tacamahac Resins are balsamic resins, of which there are several commercia! varieties: Mauritius tacamahaca is obtained from Protium hepta- 
phyllum of Columbia, and Mexican or West Indian tacamahaca from Bursera tomentosa of Mexico, West Indies, and South America. India BDELlium is a resin obtained from the bark of Commiphora Roxburghiana of Northwestern India and Beluchistan. Copal-like resins are obtained from Canarium Bengalense (East Indian Copal) and possibly several species of

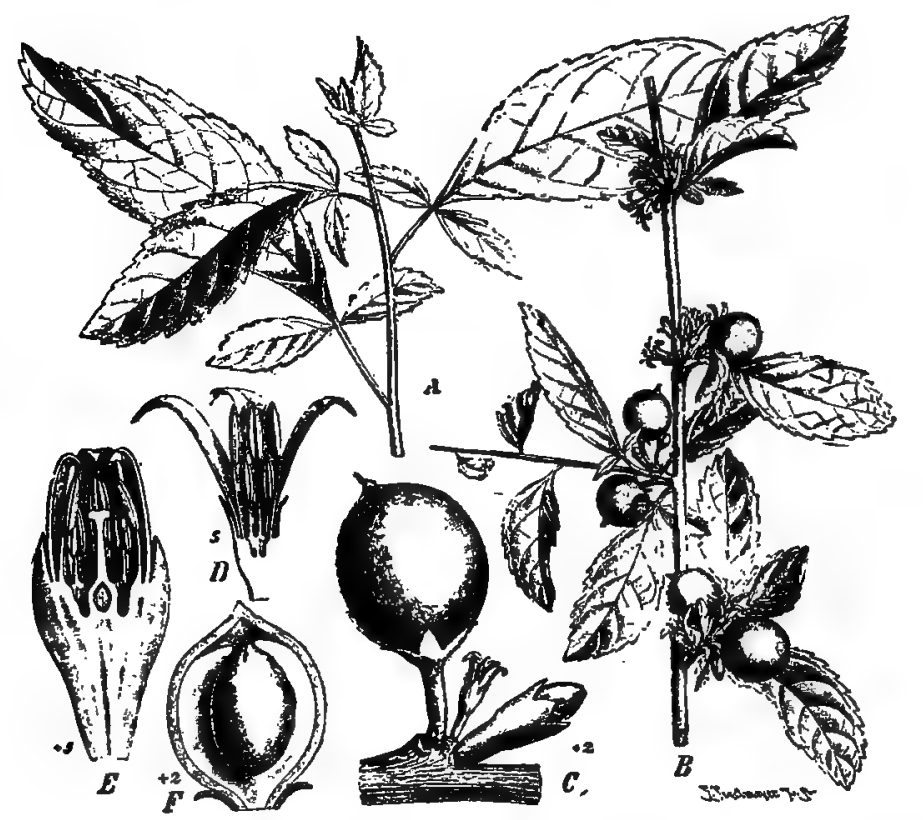

FIG. r60. Myrrh plant (Commiphora abyssinica): A, young branch showing trifoliate leaves; B, flowering and fruiting stem with thorn-like branches; C, leaf axis in which occur a fruit and staminate and pistillate flowers; D, staminate flower in longitudinal section; E, longitudinal section of pistillate flower; F, longitudinal section of fruit showing arillus-like mesocarp and the easily dehiscent endocarp.-After Engler.

Bursera. Black Dammar resin is obtained from Canarium rostratum of the Molucca Islands. Olibanum or Frankincense is a gum-resin obtained from several species of Boswellia of Asia and Somali Land. American Olibanum or Soft Resin of Cayenne exudes spontaneously from the stems of Protium heptaphyllum and $P$. guianense. Gilead BAlsam is obtained from Protium altissimum and $P$. carana of Guiana and Brazil. MexicAn LiN- 
ALE OIL is obtained from Bursera graveolens, and several species of Bursera of Mexico are used as a substitute for Aloe wood.

j. MELIACE E OR MAHOGANY FAMILY.-This is a large family of tropical trees and shrubs with mostly alternate, compound and exstipulate leaves, the leaflets being entire, with secretion cells, but not pellucid-punctate (Fig. I6I). The flowers are complete, the filaments being united into a tube; and they occur

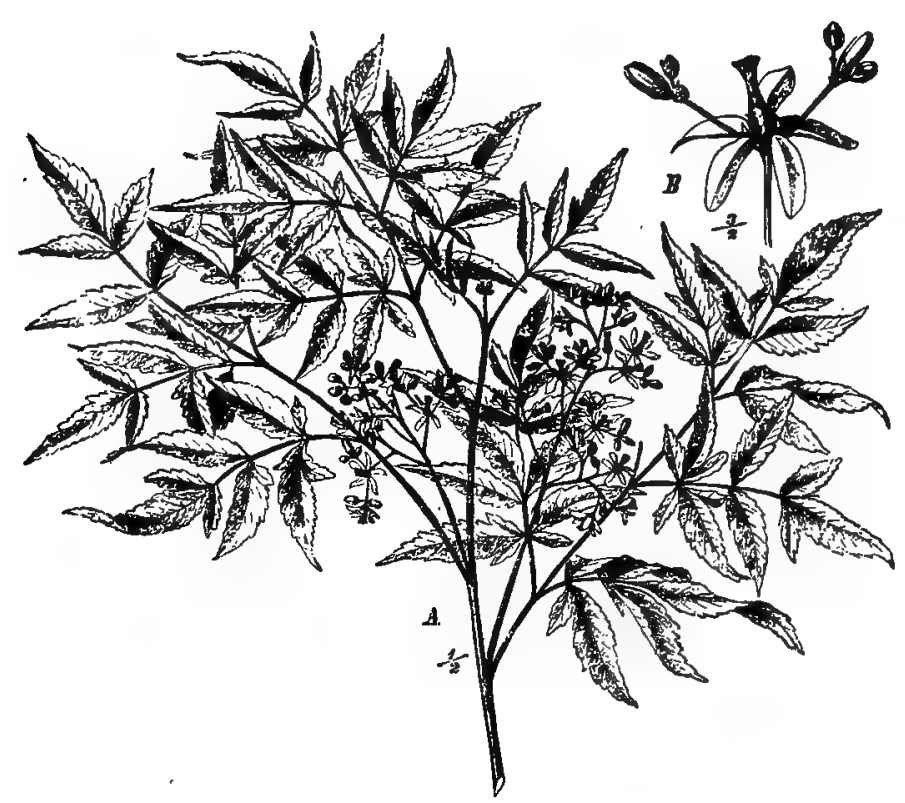

Fig. I6r. Pride of China (Melia Azedarach): A, flowering branch; B, a part of the inflorescence.-After Harms.

in axillary clusters or racemes; the fruit is a capsule, berry or drupe; the seeds are sometimes winged and with fleshy or leaflike cotyledons.

The bitter principle mangrovin is found in the bark of the China Tree or Pride of China (Melia Azedarach) indigenous to Asia, and extensively cultivated in tropical and warm-temperate regions, and naturalized in the southern part of the United States (Fig. I6I). A similar principle is found in other plants of this family. 
Carapa Oil, which has a characteristic odor and bitter taste and is toxic to insects, is obtained from the seeds of Carapa procera and C. guianensis, of tropical West Africa and tropical America, and also from Srvietenia Mahagoni (Mahogany Tree). Cedar-wood oil ("Oleum Cedrelæ") is obtained from several species of Cedrela growing in tropical America. The most important constituent of the oils is cadinine. Oils with a garlic-like odor are found in the seeds of Melia Azedarach, the bark of Cedrela australis of Australia and the fruit of Dysoxylum binectariferum of Java. Besides the Mahogany tree there are other trees of this family which yield valuable woods. Cigar boxes and sugar boxes are made from the wood of Cedrela odorata of the West Indies and Guiana, and from other species of Cedrela.

k. MALPIGHIACE $\circledast$ is a rather large family of shrubs, small trees, or lianes with anomalous stem-structure, found in the Tropics, principally in South America. The leaves are ustually opposite, the sepals are glandular, and the fruit is a winged samara somewhat like that of maple (Acer).

The plants contain a notable amount of tannin and the woods of some species contain a red coloring principle.

1. POLYGALACE $Æ$ OR MILKWORT FAMILY.-The members of this family are herbs or shrubs, occurring in all parts of the world except in the Arctic regions.

Polygala Senega is a perennial about 1/3 M. high. It has a fleshy root, producing at the crown a large number of buds and giving rise to a cluster of stems or so-called plants (Fig. 197). The leaves are alternate, lanceolate or oblong-lanceolate and sessile; the flowers are faintly greenish-white and in cylindrical spikes; the capsule is loculicidally dehiscent, and the seed is hairy and slightly longer than the lobes of the caruncle. The root is official (p. 456).

Polygala alba or White Milkwort yields the White or Texas senega. The stems are numerous and taller than those of $P$. Senega; the leaves are narrow-lanceolate or linear with revolute margin; the flowers are white and in elongated conic spikes; the caruncle lobes are about half as long as the seed. The plant is found west of the Mississippi River extending as far south as Texas and Mexico and west as far as Arizona and New Mexico. 
m. EUPHORBIACE王 OR SPLRGE FAMILY.-The plants are herbs, shrubs or trees with acrid and often milky latex. The fruit is mostly a trilocular, dehiscent capsule; the seeds are anatropous and have an oily endosperm.

Stillingia sylvatica or Queen's-Root yields the official Stillingia (p. 462). The plant is a perennial herb about I M. high and diffusely branched. The leaves are obovate, short-petiolate, with glandular-serrate margin; the flowers are in terminal spikes, light yellow, monœcious, the staminate being above and the pistillate below, the latter solitary in the axils of the lower bractlets (Fig: 162).

Ricinus communis or Castor-Oil Plant is an annual herb in the temperate regions but is shrub-like and perennial in tropical and sub-tropical countries. In temperate regions the plant is from I to $5 \mathrm{M}$. high ; the leaves are peltate and 6- to I I-palmately-lobed; the flowers are greenish, apetalous, monœcious and in racemes, the pistillate being above the staminate on the flower-axis; the fruit is a 3 -locular, oval, spinous capsule, which dehisces septicidally (Fig. 90, B). The seeds are anatropous, somewhat flattened-oblong; Io to $16 \mathrm{~mm}$. long and 4 to $8 \mathrm{~mm}$. in diameter; smooth, mottled grayish-brown or yellowish-red, with a prominent caruncle; hard but brittle testa, thin white tegmen, large oily endosperm, and thin foliaceous cotyledons at the center. The seeds contain 45 to 50 per cent. of oil which constitutes the Castor Oil of medicine and a large amount of proteids in the form of aleurone grains (Fig. 122, D). The cake from which the oil is expressed contains a poisonous principle known as ricin which is apparently poisonous to cattle, but not to poultry.

Croton Tiglium is a shrub or small tree indigenous to tropical Asia and extensively cultivated in tropical countries; the leaves are alternate, oblong-lanceolate with petioles which are glandular at the base, but wanting in the star-shaped hairs so characteristic of other species of this genus; the flowers are small, monœcious and in terminal racemes, the pistillate being above and the staminate below; the fruit is a 3 -locular, septicidally dehiscent capsule. The seeds resemble those of Ricinus in size and structure, except that they are less smooth, more brownish in color and the caruncle is quite small. 
They contain a fixed oil which is obtained by expression and which is poisonous and a powerful cathartic. The seeds of a number of the other members of the Euphorbiacex contain fixed oils resembling those of Croton and Ricinus, as CurCas the seeds of Jatropha Curcas of tropical America. Mexican Croton Oil

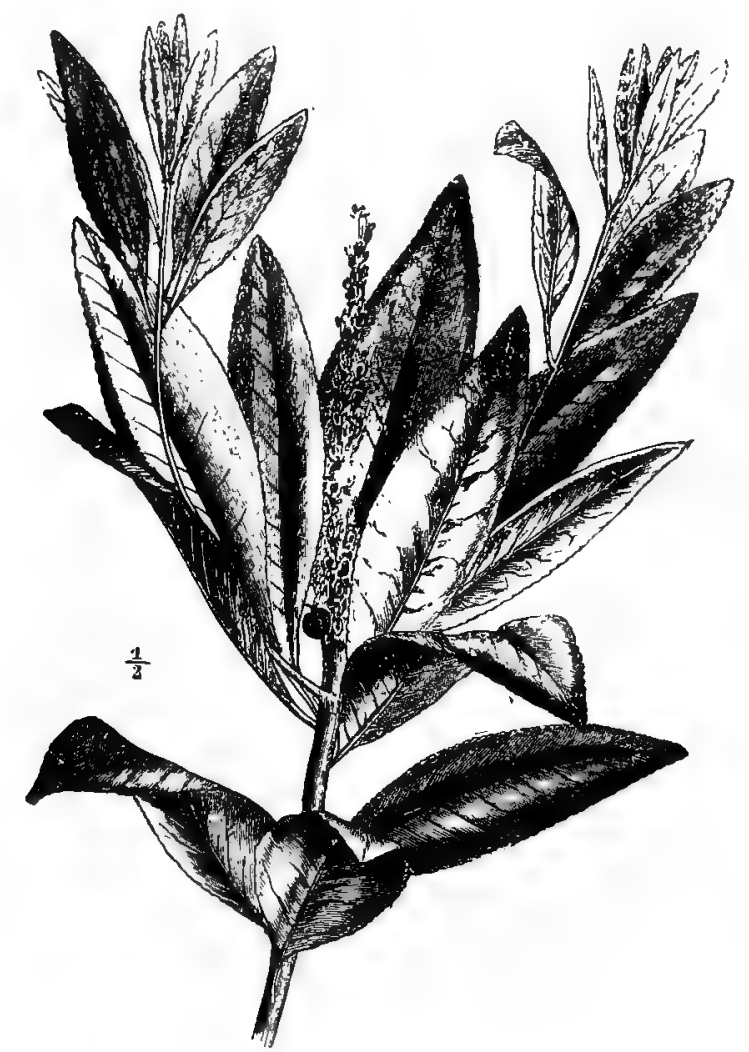

Frg. 162. Stillingia sylvatica: showing the more or less closely arranged leaves and the terminal spike of flowers,-After Bentley and Trimen.

is obtained from the seeds of Euphorbia calyculata. The seeds of the Caper Spurge or Wild Caper (Euphorbia Lathyris) naturalized in the United States from Europe, also contain a fixed oil resembling that of Croton. The seeds of Joannesia princeps of the maritime provinces of Brazil are also powerful purgatives. 
Wallotus philippinensis is a shrub or small tree found in tropical countries of the Eastern Hemisphere. The leaves are alternate, petiolate, ovate, acuminate, coriaceous and evergreen; the flowers are small, diocious, and in racemes; the fruit is a 3 -locular, glandular-hairy capsule. The hairs of the capsule are official in a number of pharmacopœias under the name of KAMALA and occur as a reddish-brown, granular powder, consisting of two kinds of hairs, the one colorless and occurring in branching clusters (Fig. 284, B) and the other with yellowish-red, multicellular, glandular heads. The important constituent is about 80 per cent. of a dark-brownish-red resin composed of a crystalline principle rottlerin; isorottlerin; two reddish-yellow resins; a coloring principle and wax. It also contains a trace of volatile oil, starch, sugar, tannin, oxalic and citric acids.

A red coloring principle is found in the bark of Aleurites triloba of the Polynesian Islands, Euphorbia parviflora of Ceylon, E. pulcherrima of Mexico and Brazil and the other species of Euphorbia.

CASCARILLA BARK is obtained from Croton eluteria and other species of Croton growing in the Bahama Islands and other parts of the West Indies and Florida. Cascarilla bark is official in a number of pharmacopœias. It occurs in small curved pieces or quills, I to $3 \mathrm{~mm}$. thick, externally brownish-gray; inner surface is reddish-brown, the fracture short, resinous; odor aromatic; particularly on burning; taste aromatic and bitter. Cascarilla contains I to I.5 per cent. of a volatile oil, containing eugenol, limonene, an oxygenated portion, and some other constituents; I5 per cent. of resin; a bitter principle, cascarillin; tannin and vanillin.

COPALCHI BARK or Quina blanca which is derived from Croton niveus of Mexico contains a bitter principle, copalchin, which is also found in other species of Croton. Malambo bark is derived from Croton Malambo of Venezuela, the latter two barks being sometimes substituted for Cascarilla bark.

Elastica or India Rubber (Caoutchouc) is the prepared milkjuice obtained from one or more species of the following genera: Hevea, Mabea, Euphorbia and Excœcaria. The fresh latex of a number of species is a powerful irritant, as that of the Sand-box tree (Hura crepitans) of tropical America, which contains an oily 
and an acrid volatile principle; the Blinding-tree (Excoccaria Agallocha) of Southern Asia and Australia, the juice of which produces blindness.

The gum-resin EUPHORBICM is obtained from Euphorbia resinifera, a cactus-like plant of Morocco, and is also found in other species of Euphorbia. It contains, among other constituents, $3^{8}$ per cent. of an acrid resin, and 22 per cent. of a crystalline principle euphorbon.

The milk-juice of several species of Euphorbia is used in the preparation of arrow poisons in Brazil. One or more species of the following genera are used as fish poisons: Flueggea, Phyllanthus, Bridelia, Excœcaria and Euphorbia. A number of plants are used as remedies for the bites of serpents, as the bark of Phyllanthus mollis of Java; the leaves of several species of Antide'sma of Malabar and the East Indies: and Euphorbia pilulifora of South America and India. The young twigs of Croton flavens of Jamaica, Hayti and South America, are used as an insecticide.

A camphor-containing oil is found in the bark of Pcntalostigma quadriloculare of Australia; the aromatic wood of Colliguaya odorifera of Chile is used as a substitute for santal and on burning emits a rose-like odor; the leaf of Croton menthodorus of Peru contains an oil with an odor of mentha; a balsam resembling Copaiba is derived from the bark of Croton origanifolius of the West Indies; methylamine is found in Morcurialis annua of Europe and other species of Mercurialis. Tannin is found in the following genera: Macaranga, Phyllanthus and Bridelia; Brazil kino is obtained from a species of Croton ( $C$. crythreus?) of Brazil. A gum-lac is formed on the stems of Aleurites laccifora of the Antilles and Ceylon as a result of the sting of an insect, and contains among other substances a large amount of melyl- and ceryl-alcohols, and a substance resembling abietic acid. The sap of Euphorbia cyparissias of Europe yields a resin which is sometimes substituted for scammony.

A reddish resinous substance resembling dragon's blood is obtained from Croton crythrena of Brazil; a yellow coloring principle is found in the seed of Croton tinctorius of Mexico; poncetin, a violet coloring principle, occurs in Euphorbia heterophylla of Brazil; a blue coloring principle is found in Chrozo- 
phora tinctoria of Southern Europe and Africa and in Argithamnia tricuspidata lanceolata of Chile; an indigo-like principle is obtained from Mercurialis perennis of Europe. The fresh latex of Euphorbia phosphorea of Brazil is phosphorescent.

Quite a number of the seeds of this family contain fatty oils. The Chinese Tallow tree (Sapium sebifcrum) yields a fat which is used for burning and for technical purposes; a similar fat is obtained from the seeds of several species of Aleurites and Euphorbia.

TAPIOCA starch is derived from the tuberous roots of Manihot utilissima, extensively cultivated in tropical countries; other species of Manihot also yield starchy food products.

Edible fruits are obtained from the following genera: Phyllanthus, Baccaurea and Antidesma; the seeds of Hevea brasiliana are edible; a sweet sap is found in Baccaurca ramiflora of Cochin China and Brazil; a peptone-like ferment is found in Euphorbia heterodoxa of South America and other species of Euphorbia.

\section{ORDER SAPINDALES.}

The plants of this order are chiefly trees and shrubs. The flowers are mostly regular and the seeds ustually without endosperm. The order has a number of representatives in both tropical and temperate regions.

a. FAMILY CORIARACEE.-This family is represented by but a single genus, Coriaria. The plants are shrubs found in Europe, Asia and South America, and yield several important economic products. The leaves and bark of C. myrtifolia of Southern Europe and Northern Africa are rich in tannin and used in dyeing. This plant also contains a narcotic principle, resembling picrotoxin, known as coriamyrtin, which is also found probably in C. atropurpurca of Mexico. The leaves of Coriaria myrtifolia or TANNER'S SUMAC are coriaceous, distinctly 3-nerved, astringent and bitter and were at one time substituted for senna leaves. A black dye is obtained from C. ruscifolia of New Zealand and Chile. While the fruits of some species are quite poisonous the sap of the fleshy leaves is used in New Zealand in making an intoxicating drink. 
b. BUXACE E OR BOX TREE FAMILY.-The plants are shrubs with alternate or opposite, evergreen leaves, and usually axillary monœcious or diœcious flowers. The most important plant of this family is the Box tree (Buxus sempervirens) which is extensively cultivated. The wood is used for making musical instruments and for other purposes, and the twigs have been used in medicine. The latter contain several alkaloids, the most important being buxine which resembles beberine; a volatile oil containing butyric acid and a wax containing myricyl alcohol and myricin.

c. ANACARDIACE E OR SUMAC FAMILY.-The plants are trees or shrubs with an acrid, resinous or milky latex, and alternate leaves.

Rhus radicans, PoISon Ivy or Poison Oak, is a woody vine, climbing by means of aerial roots and sometimes becoming quite shrub-like, which is common along roadsides in the United States. The leaves are 3 -foliate, the leaflets being ovate, acuminate, nearly entire, inequilateral and with short stalks; the flowers are green and in loose axillary panicles; the fruit is a globular, glabrous, grayish drupe (Fig. I63, $D, E$ ). The poisonous properties of this plant are due to a fixed oil known as TOXICODENDROL, a principle somewhat resembling the vesicating principle C.ARDOL found in the CASHew Nut. The latter is the fruit of Anacardium occidentale, a shrub growing in tropical America. A principle resembling cardol is found in the East India Marking tree or Ink tree (Semecarpus Anacardium) and Holigarna ferruginea of India.

The Poison Sumac or Poison Elder (Rhus vernix) is a shrub or small tree found in swamps in the United States and Canada. The leaves are 7- to I3-foliate, with obovate or oval, acuminate, entire leaflets; the flowers are small, green, and in axillary panicles; the fruit resembles that of $R$. radicans (Fig. 163, $A, B, C)$. The plant is poisonous like $R$. radicans and probably contains the same principle. Other species of Rhus are also poisonous, as the western Poison Oak ( $R$. diversiloba) of the Pacific Coast, and the Japanese Lacquer or Varnish tree $(R$. vernicifera and $R$. succedanea). The lacquer trees grow wild in both China and Japan where they are also cultivated. The lac is obtained by incising the bark and removing it with a pointed 
spatula. The grayish-white emulsion is strained and on exposure to air it changes to brown becoming finally black. This change

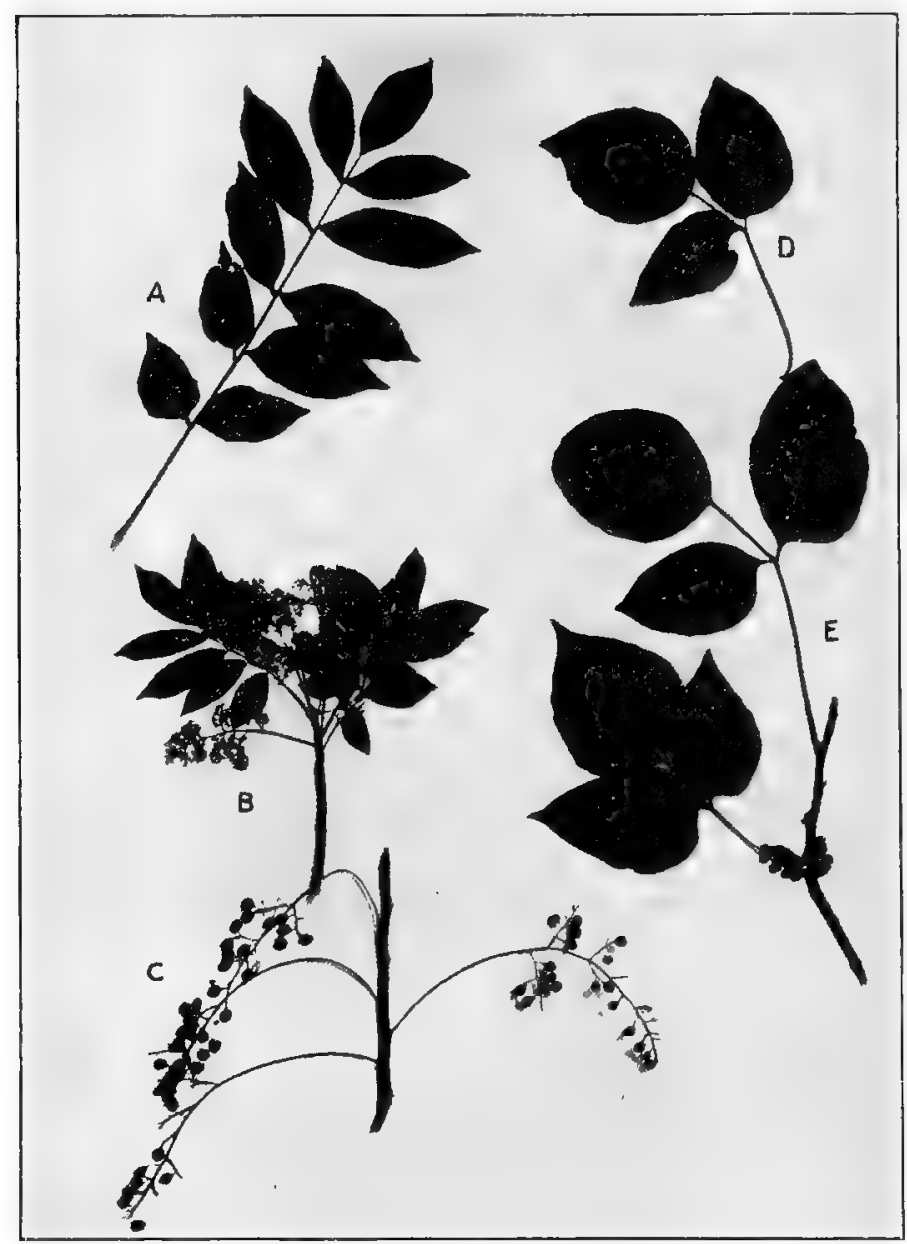

FIG. I63. A, pinnately compound leaf of poison sumac (Rhus vernix); B, flowering branch, and C, fruiting branch of the same; D, tri-foliate leaves of poison ivy (Rhus radicans); $\mathrm{E}$, fruiting branch of the same with axillary cluster of globular drupes.

is due to the oxidizing enzyme laccase. The natural lac (Kiurushi) contains a non-volatile poisonous principle, resembling 
toxicodendrol, and is closely associated with some resinous substances. Japanese lac is thinned with camphor, or mixed with linseed oil and on drying in a moist atmosphere forms the most indestructible varnish known. Various pigments are used, as vermillion, gamboge, acetate of iron and other substances. The best glossy black colors are obtained by the addition of iron.

Rhus glabra or the Scarlet Sumac is a shrub (Fig. I64). The leaves are II- to 3 I-foliate, the leaflets being lanceolate, acu-

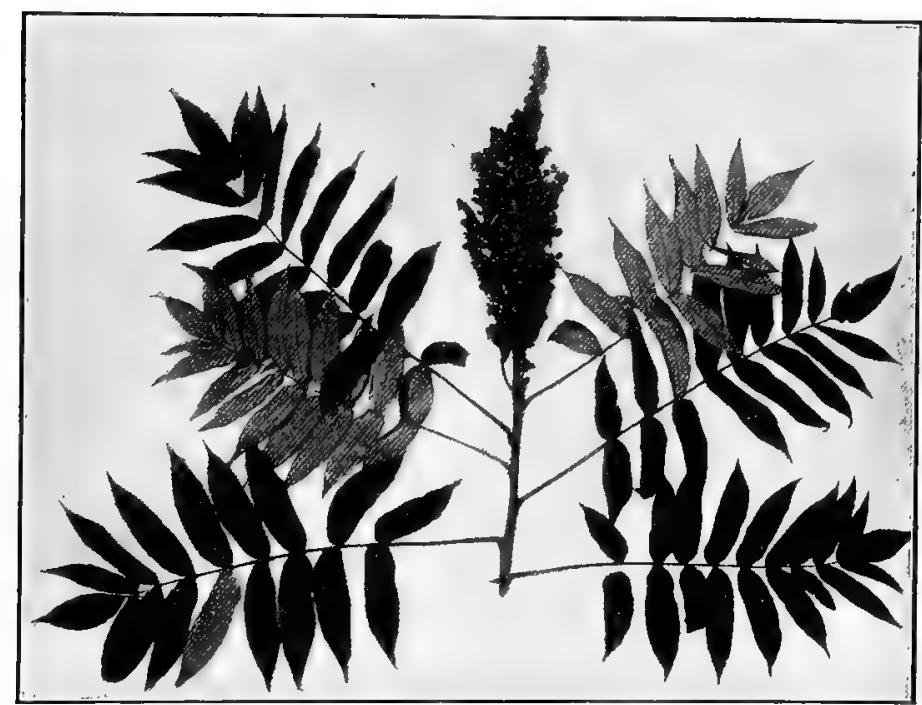

FIG. I64. Rhus glabra. Portion of leafy branch with terminal compound panicle of fruits.

minate, sharply serrate, dark green above and tomentose below; the flowers are greenish, polygamous and in terminal panicles; the fruit is official (p. 569).

CHINESE GALls are excrescences produced on Rhus semialata as a result of the stings of an Aphis. JAPANESE GALLS are similar formations occurring on Rhus japonica. ' (See Galla.)

Pistacia Lentiscus is a shrub or tree, which is found growing in the Grecian Archipelago. The leaves are pinnately compound and with winged axis, the leaflets being alternate, oblong, entire, 
sessile; the flowers are small, diocious, and in axillary clusters. In the bark of this plant there are large cavities which contain an oleo-resin that is official as Mastic in a number of pharmacopœias (p. 645). The wood of Schinopsis Lorent ii and S. Balansa, growing in Argentine and Paraguay, is known in commerce as QUEBRACHO COLORADO. It is red and very hard and contains tannin, gallic and ellagic acids.

The Pistacio nuts or Pistacia almonds are obtained from Pistacia vera indigenous to Syria and Mesopotamia and extensively cultivated in the countries bordering the Mediterranean. The kernels are used extensively in confectionery. The nuts are about $20 \mathrm{~mm}$. long, somewhat quadrangular in cross-section, and the seed consists of two fleshy, green cotyledons. The seeds of Buchania latifolia and other pecies of Buchania are used in India much like almonds.

Gums are found in several species of Anacardium and Sclerocarya. ACAJOU GUM is obtained from Anacardium occidentale. Considerable sugar and citric acid are found in Mangos, the fruit of Mangifera indica native of Farther India and Ceylon and cultivated in the Tropics. A fruit used like lemons is obtained from Dracontomelum mangiferum of Malacca and the Sunda Islands.

d. AQUIFOLIACE (ILICACE $\mathbb{E}$ ) OR HOLLY FAMILY.-The plants are mostly shrubs or trees with alternate, petiolate, simple leaves and small, white, regular flowers. The fruit is a berry-like drupe containing several nutlets. The most important genus of this family is Ilex, a number of species of which are found in the United States.

The European holly (Ilex. Aquifolium) contains a bitter glucosidal principle, ilicin, which is found in the bark as well as the drupes. The drupes contain a principle which is a homologue of benzyl alcohol, and a glutinous substance which renders them useful in the manufacture of birdlime. The American holly ( $I$. opaca) growing in the Eastern United States, probably contains similar constituents to the European holly. This is the plant which furnishes the CHRISTMAS HOLLY.

Maté, Paraguay or Brazilian tea, consists of the leaves of Ilex paraguayensis found in Southern Brazil Argentine and 
Paraguay. They contain about I per cent. of caffeine, I 5 per cent. of tannin and some volatile oil, and are used like tea in the making of a beverage. Cassine or Appalachian tea consists of the leaves of the Dahoon holly (Ilex Cassine) growing in the Southern United States. These leaves contain about half as much caffeine and tannin as Maté.

e. CELASTRACEÆ OR STAFF-TREE FAMILY.-These are shrubs, as Euonymus, or woody climbers, as the climbing bittersweet (Celastrus scandens). The plants are especially characterized by their dehiscent fruits and scarlet or reddish arilled seeds.

Euonymus atropurpureus (Wahoo or Burning. Bush) is a shrub or small tree. The twigs have four distinct cork-wings making them somewhat 4 -angled. The leaves are opposite, petiolate, ovate-oblong, acuminate, crenulate-serrulate and hairy beneath. The flowers are purplish and in axillary cymes. The fruit is a $3^{-}$to 4 -lobed, persistent, loculicidally dehiscent capsule with 6 to 8 scarlet seeds. The bark of the root is official (p. 531).

The leaves of Catha edulis growing in Arabia and Abyssinia are chewed and also used like tea. They contain the alkaloids cathine and celastrine which are supposed to have similar properties to cocaine, as well as tannin and an ethereal oil. A yellow coloring principle is found in the bark of Euonymus tingens of the East Indies. The yellow coloring principle in the arils of the seeds of Celastrus and Euonymus appears to closely resemble carotin. The seeds of a number of plants of this family contain a considerable quantity of fixed oil, as Celastrus macrocarpus of Peru, and Maytenus Boaria of Chile.

f. ACERACE E OR MAPLE FAMILY.-The plants of this family are trees or shrubs, the most widely distributed representative of which is the maple (Acer). The most distinguishing character of this family is the fruit, which is a double samara. The sap of a number of species of Acer contains cane sugar or sucrose, and the sap of the sugar maple (Acer saccharinum) which grows in the United States and Canada contains from 3 to 4 per cent. The making of maple syrup and maple sugar is quite an industry in some localities. Maple sugar is also obtained from the black sugar maple (Acer nigrum) and the ash-leaved maple 
(A. Negundo). The bark of the latter species is used to some extent in medicine. Valuable timber is yielded by the maple trees.

g. HIPPOCASTANACEÆ OR BUCKEYE FAMILY.The plants are shrubs or trees with opposite, petiolate, and $3^{-}$to 9-digitately-foliate leaves. The flowers are in terminal panicles and the fruit is a 3 -lobed capsule, which usually contains one large, shiny seed.

The horse-chestnut (Esculus Hippocastanum) contains in the bark two fluorescent bitter principles, æsculin and paviin, the former of which is in the nature of a glucoside, and in the bark, leaves and flowers the coloring principle, quercitrin is present; in the seed-coat saponin is supposed to occur, and the glucoside æsculin as well. The cotyledons contain considerable starch, some proteids and stigar, a small quantity of a fixed oil having a bitter taste, and a saponin-like substance. A narcotic principle is present in the bark, twigs and leaves of the red buckeye (AEsculus Pavia) of the Southern United States.

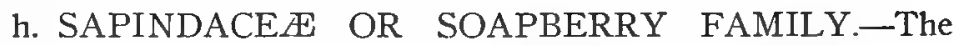
plants are mostly trees or shrubs indigenous to the Tropics. In some genera there are herbaceous or woody vines (lianes). The plants of this family usually have either a milky sap or contain saponin, and it seems strange that a plant yielding caffeine, namely, Paullinia Cupana, which furnishes the official Guarana (p. 44I), should belong to this group.

Narcotic principles are found in a number of species of Serjania, Nephelium, Magonia and Harpullia. Four or five per cent. of SAPONIN is found in the fruit of Sapindus trifoliatus of India. A principle related to saponin is found in Sapindus Saponaria of tropical America. Saponin is also found in the fruits of other species of Sapindus, the bark of Pometia pinnata of the Sunda and South Sea Islands, and the kernels of the seeds of the two species of Magonia indigenous to Brazil. The latter plants also yield a poisonous nectar and the root-bark is used in the poisoning of fish. A shellac is obtained from Schleichera trijuga of India and the seeds of this plant yield "marcassa oil."

Paullinia Cupana is a woody climber indigenous to and cultivated in Northern and Western Brazil. The leaves are alternate and 5 -foliate, the leaflets being oblong, acuminate, coarsely, irreg- 
ularly dentate, and with short stalks; the flowers are yellow and in axillary panicles; the fruit is a 3 -locular, 3-seeded sub-drupose capsule (Fig. 165).

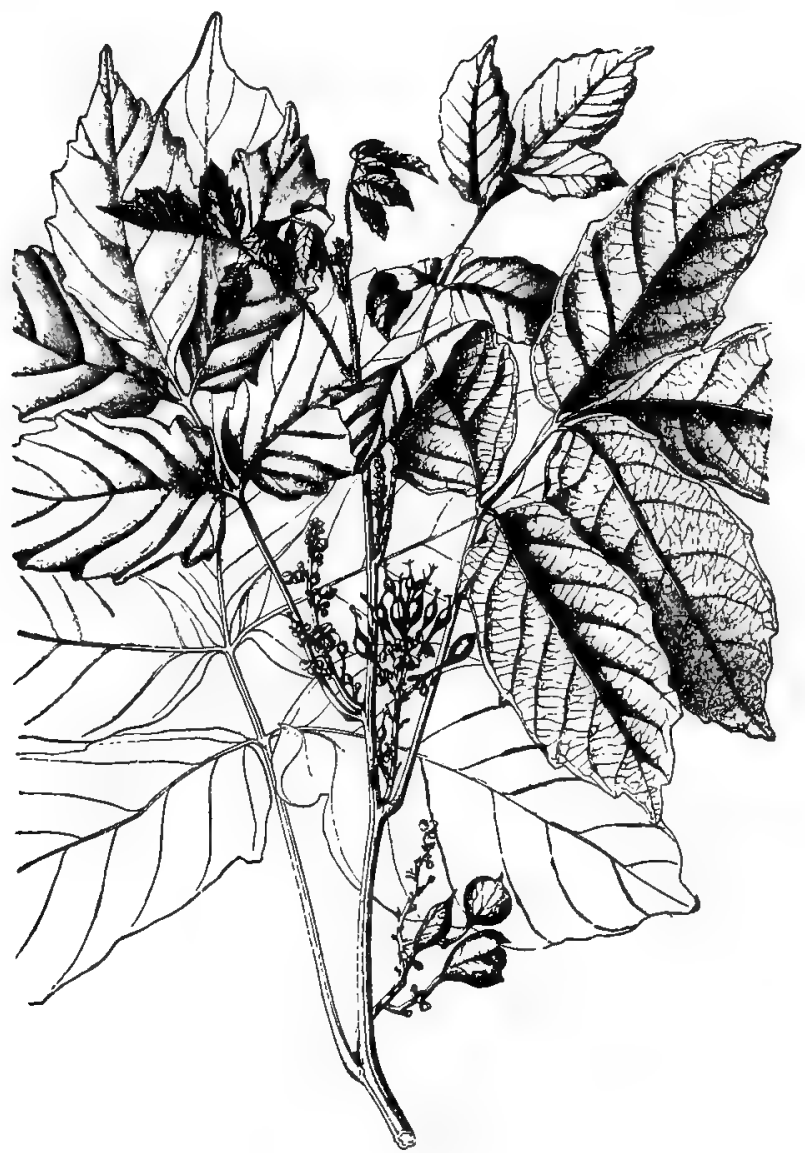

FrG. 165. Flowering and fruiting branch of Brazilian cocoa (Paullinic Cupana).After Radlkofer.

i. BALSAMINACE E OR JEWEL-WEED FAMILY.The plants are succulent herbs with alternate, petiolate leaves and conspicuous axillary flowers; the fruit is a capsule which at maturity breaks into five valves, discharging the seeds with considerable force. 
The balsam of the gardens (Impatiens Balsamina), which flowers all summer, belongs to this family. Other species of Impatiens are also cultivated.

The stem sap as well as that of the flowers of a number of species of Impatiens is used on account of its red and yellow coloring matters, to color the skin of the hands and feet as also the nails by the people of India, Tartary and Japan. The seeds of some species of Impatiens yield an oil which is used for burning.

\section{ORDER RHAMNALES.}

This order includes two large families which are characterized by having 4 or 5 stamens which are either alternate with the sepals or opposite the petals when the latter are present. The ovules are atropous.

a. RHAMNACE $A$ OR BUCKTHORN FAMILY.-The plants are woody climbers, shrubs or small trees.

Rhamnus Purshiana is a large shrub or small tree. The leaves are petiolate, oblong, elliptical, acuminate, finely serrate and pubescent beneath; the flowers are small and in axillary umbellate cymes, and the fruit is 3-lobed, black, ovoid, and drupaceous. The bark constitutes the official Cascara sagrada (p. 523).

Rhamnus Frangula or Alder Buckthorn, is a shrub the botanical characters of which closely resemble those of $R$. Purshiana. The bark of this plant is also official (p. 521).

The leaves of the shrub known as New Jersey Tea (Ceanothus americantus) are said to have been used as a substitute for tea during the Revolutionary times. This plant is found in the Eastern United States and Canada and the root, which contains considerable tannin and possibly an alkaloid, has been used in medicine. The leaves of Sageretia theezans of Asia have also been used as a substitute for tea. A number of plants of this family have been SUBSTITUTED FOR IIOPS in the fermentation industry, as Ceanothus reclinatus of the West Indies: Colubrina fermenta of Guiana, and Gouania domingensis of Martinique and Hayti. Saponin is found in the bark of Gollania tomentosa of Mexico. A crystalline bitter principle, colletin, occurs in the wood of Colletia spinosa of South America. The bark of Discaria febrifuga 
of Brazil has been used as a substitute for cinchona. A number of genera furnish fish poisons, as Zizyphus, Tapura, and Gouania. Gum-lac is formed on the twigs of Zisyphus Jujuba of Asia as the result of the sting of an insect (Coccus lacca).

The fruits of several species of Zizyphus, thorny shrubs found growing in South America, are edible and enter into the French or Spanish confection known as JUJUBE-PASTE.

b. VITACE 2 OR GRAPE FAMILY.-The plants of this family are woody climbers or erect shrubs with alternate, petiolate -leaves, and small, greenish, regular flowers, the fruit being a berry.

The most important genus, economically, is Vitis to which belong the cultivated grapes, the fruits of which furnish raisins, wine and brandy. The GRAPE-VINE indigenous to Europe (Vitis vinifera) is cultivated in all temperate and sub-tropical countries, and the variety silvestris which is found distributed in the Mediterranean countries as far east as the Caucasus Mountains is supposed to have furnished the cultivated wine grape. The CONCORD and CATAWBA GRAPES are cultivated varieties of the northern Foxor Plum-grape (Vitis Labrusca) indigenous to the Northern United States east of Minnesota. The Delaware Grapes are cultivated varieties of the frost-grape ( $V$. cordifolia) and the sweetscented grape ( $V$. vulpina) of the Eastern United States. The pulpy part of the grape contains from 9 to 18 per cent. of grapesugar and 0.5 to $\mathrm{I} .36$ per cent. of tartaric acid. In unfavorable seasons the tartaric acid is replaced in part by malic acid. The soil has a marked influence on the quality of grapes, a sandy soil producing a light colored wine, a soil rich in calcium a sweet wine, and a clay soil a fine boquet, etc.

Wines are made by fermenting the grape juice, and contain from 5 to 20 per cent. of alcohol, from I or 2 to 12 per cent. of sugar, about 0.5 per cent. of tartaric, acetic and other fruit-acids, tannin and coloring matter from a trace to 0.3 per cent., and various compound ethers, giving them their characteristic flavors or boquets. White wines are made from the juice of the pulp of the white or colored grapes after separation from the epicarp and seeds. In the manufacture of RED WINE no care is taken to separate the seeds and skins of colored grapes or even the stems on which the fruits are borne. PORT WINE is made from a grape 
grown in Portugal, the wine being chiefly exported from Oporto. The term CLARET is applied to a red wine containing a small amount of alcohol. BRANIY is obtained by the distillation of the fermented juice of the grape. Champagne is a product obtained by fermenting grape juice to which other substances have been added, and contains about 1o per cent. of alcohol and 67 per cent. of carbon dioxide. RaIsins are obtained from a variety of $V$ itis vinifera containing a high percentage of sugar. In the preparation of raisins the ripe grapes are dried either by exposure to the sun or artificial heat. In grape preserves in addition to the indistinguishable cells of sarcocarp, raphides of calcium oxalate occur.

A principle resembling toxicodendrol is found in Vitis inconstans of Japan. A greenish-blue coloring principle occurs in Vitis sicyoides of South America. The leaves and twigs of Virginia CREEPER or American ivy (Parthenocissus quinquefolia) contain tartaric acid, glycollic acid, paracatechin and inosit.

\section{ORDER MALVALES.}

This order includes several families having rather diversified characters. The stamens are numerous, the sepals are valvate and the placentas are axillary.

a. FAMILY ELEOCARPACEA.-The members of this family are shrubs or trees mostly indigenous to the Tropics. They are distinguished from the plants of the other families of this order in not containing lysigenous mucilage canals. A principle yielding hydrocyanic acid is found in Echinocarpus Sigun of Java. A yellow coloring principle is found in the leaves of Vallea cordifolia of Peru. A fatty oil is found in the seeds of several species of Elcocarpus. A number of fruits of this family are edible. Maqui Fruit is obtained from Aristotelia Maqui of Chile and is used to color wine. The seeds of Sloanea dentata are eaten like chestnuts in Guiana.

b. TILIACE $A$ OR LINDEN FAMILY.-The plants are shrubs or trees with alternate, simple leaves, and with white flowers in cymes or panicles. In the Linden or Basswood (Tilia) the peduncles are partly adnate with the long, leaf-like bracts. The fruits are dry drupes. 
The flowers of the European Linden (Tilia europaca) contain a fragrant volatile oil and are used in medicine. The flowers of other species of Tilia also contain volatile oils, and the flowers of Tilia tomentosa of Southern Europe are used to flavor champagne. The leaves of Tilia europaca contain the glucoside tiliacin. Several species of Grewia are used as fish poisons. A purgative principle is found in the seeds of Corchorus olitorins of Southern Asia, Africa and South America. A bitter principle occurs in the seeds of Corchorus tridens of Arabia, India and Egypt. A reddish-colored, fatty oil known as APEIBA OIL is obtained from the seeds of Apeiba Tibourbon of Guiana. The root of Grervia scabrophylla is used as a substitute for Althæa in India. Mucilage is found in the flowers and fruits of a number of genera. The leaves of Corchorus siliquosus are used in Panama as a substitute for tea. A number of the fruits of this family are edible, as of Muntingia and Apeiba. The bast fibers of several species of Corchorus, particularly $C$. capsularis of China and India, constitute jute, which is used in the making of cordage. The fiber is separated by cold retting in stagnant water.

c. MALVACE E OR MALLOW FAMILY.-The plants are mostly herbs or shrubs with alternate, simple leaves, and regular, perfect, large flowers, with the stamens united into a column which encloses the styles (Fig. 82, E), and a capsular fruit. The cultivated ornamental Hollyhock and Althæa belong to this family.

Althea officinalis or marshmallow is a perennial herb about $\mathbf{I}$ M. high with broadly ovate, petiolate, acute, dentate and lobed, pubescent leaves; the flowers are 2 to 4 in number in the axils of the leaves and have rose-colored petals. The bractlets are linear and the fruit consists of 15 to 20 indehiscent carpels. The root is official (p. 450).

Gossypium species.-The plants are herbs or shrubs with 3 - to 5 -lobed leaves, and large axillary flowers; the fruit is a 5 -locular, dehiscent capsule (Fig. I66); the seeds are spherical or somewhat angular and covered with long I-celled hairs, which latter constitute cotton (p. 440).

There are three important cultivated species. (I) SEA IsLAND COTTON is obtained from Gossypium barbadense, a plant which is principally cultivated in the Southern United States and 
also in Northern Africa, Brazil, Peru and Queensland. This species is distinguished by the fact that after removal of the hairs from the seeds they are smooth. (2) G. arboreum has purplishred flowers, yields a particularly white cotton, and is cultivated in Egypt, Arabia and India. (3) G. herbaceum is distinguished by its broadly lobed leaves and yellowish flowers. The plant has

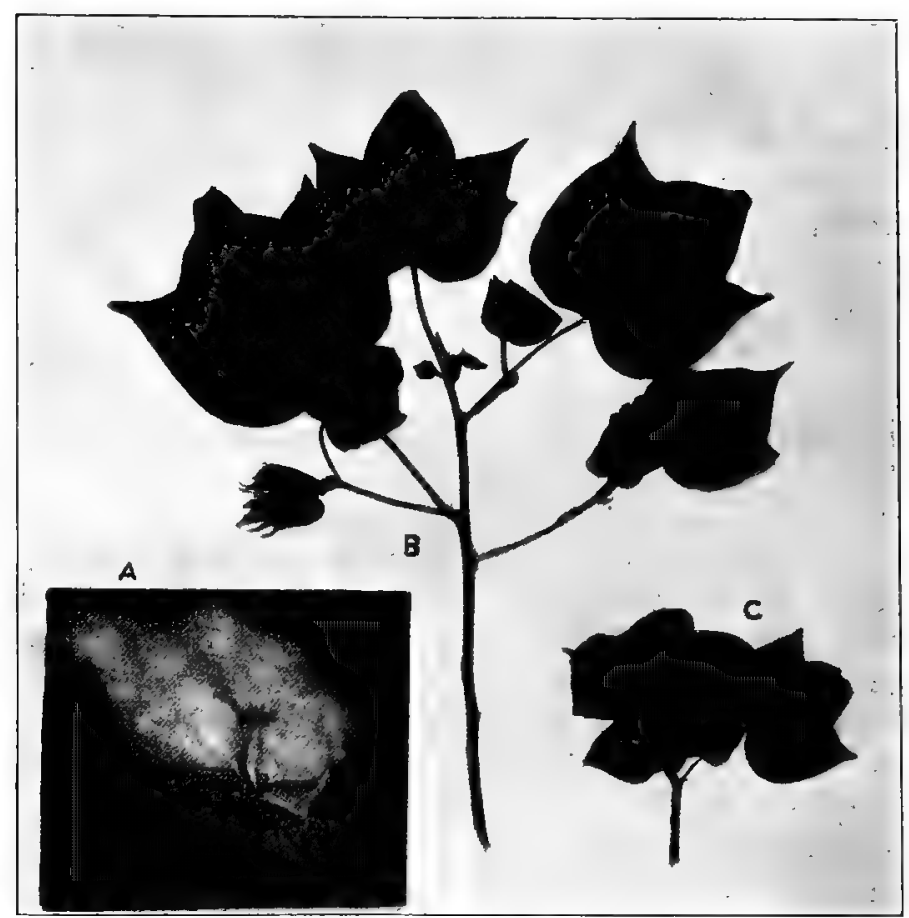

FIG, I66. Cotton plant (Gossypium): A, dehiscent capsule showing mass of cotton fibers which surround the small seeds; B, leaf-branch; C, large axillary flower.

been cultivated for over 26 centuries in Arabia and the East Indies, and since 1774 in the United States. Of this latter species there are a number of cultivated varieties. The bark of the root constitutes the cotton-root bark of medicine (p. 527).

The seeds of the genus Gossypium contain a large percentage of fixed oil, which is obtained by expression and is official as 
CotTon SEED oil. The residue is known as cotton seed oil-cake, and contains a considerable amount of proteids with a small quantity of oil and a poisonous principle, ricin. A fat resembling that of Cacao is obtained from the seeds of Pachira macrocarpa of Brazil; Kapak oil is derived from the seeds of Eriodendron anfractuosum caribcum of the West Indies.

The flowers of some of the members of the Malvacex contain coloring principles, and have been used for dyeing, as Hollyhock (Althea rosa) and Mallow (Malva sylvestris). MUSK SEED or - Amber seed, which is used in perfumery as a substitute for musk, is obtained from Abelmoschus moschatus indigenous to the East Indies and now cultivated in other tropical countries. Malva moschata also has the odor of musk, and is found in Middle and Southern Europe.

Saponin is found in the roots of Sida jamaicensis and Hibiscus Sabdariffa of the East and West Indies; Sida paniculata of Peru is used as an anthelmintic and the action is supposed to be due to the secreting hairs. The seeds of several members of this family are used as substitutes for coffee, as Abutilon muticum of Egypt, and Okra or Gumbo (Hibiscus esculentus). The leaves of Sida canariensis and S. retusa, the latter of India, have been substituted for tea leaves. The fruits of several of the members of this family are edible, as Hibiscus esculentus, which yields the vegetable okra, and $H$. ficulneus of Ceylon and Egypt which are used like beans.

Fibers are obtained from a number of the other members of this family, as the bast fibers of Hibiscus tiliaceus of the Tropics, H. cannabinus of the East Indies, Urena lobata, Abutilon indicum, Sida retusa, and Napca lavis, all ctltivated more or less in tropical countries.

d. FAMILY BOMBACE无.-This is a group of tropical trees yielding a variety of useful products. A gum is obtained from Bombax malabaricum, and mucilage is contained in the genus Ochroma and several species of Bombax. The root of Bombax malabaricum contains tannin in addition. The bast fibers of a number of the plants of this family are used like cotton in making fabrics, as species of Bombax, Chorisia and Adansonia. The fruits of several of the Bombacex contain tartaric acid, as the 
Sour Cucumber tree or Cream-OF-TARTAR TREe (Adansonia Gregorii) of Northern Australia; and the MONKEY-BREAD TREE or BaOBAB (Adansonia digitata) of India and South America, which attains a diameter of $9 \mathrm{M}$. The green fruit of Matisia cordata of the Andes region is edible. The seeds of Bombax insigne and Matisia Castonon of South America yield a product on roasting which is used like cacao bean. The seeds of Cavanillesia umbellata of Peru are edible and contain a considerable quantity of fixed oil.

e. STERCULIACE $\mathbb{A}$ OR COLA FAMILY.-The plants are herbs, shrubs or trees, sometimes lianes, with mostly simple, petiolate, alternate leaves; the flowers are small and form a rather complex inflorescence.

Theobroma Cacao is a small tree 5 to Io M. high, with coriaceous, glaucous, entire leaves, and clusters of brownish 5-merous flowers arising from the older branches or stem; the fruit is large, fleshy, ovoid, Io-furrowed longitudinally, yellow or reddish, and contains five rows of seeds, Io or I2 in each row (Fig. I67). The seeds are ovoid, somewhat flattened, and with large, convoluted cotyledons which break up into more or less angular fragments on drying. The seeds contain 35 to 50 per cent. of a fixed oil known as CACAO BUTter and official as Oleum Theobromatis; I 5 per cent. of starch; I5 per cent. of proteids; I to 4 per cent. of theobromine; 0.07 to 0.36 per cent. of caffeine, about 0.5 per cent. of sugar, and also a small amount of tannin. The red color of the seed is due to a principle known as cacao-red which is formed by the action of a ferment on a glucoside.

The Cacao tree is indigenous to the countries bordering the Gulf of Mexico and is now cultivated in many tropical countries. Most of the cacao of the market is obtained from Ecuador (the Guayaquil variety being especially valued), Curaçao, Mexico, Trinidad, and the Philippine Islands. The seeds of the wild plants contain a bitter principle, the quantity of which is found to be greatly reduced in the plants when under cultivation. The bitter principles in the raw product are more or less destroyed by the process of fermentation to which the seeds are subjected in preparing them for use, which at the same time develops the aroma. 
Cola acuminata is a tree with lanceolate or obovate, acuminate, entire, petiolate leaves. The flowers are yellowish, unisexual, and in small axillary clusters, frequently arising from the old wood; the fruit consists of five follicles, each containing 4 to 8 seeds. The seed is made up of two large, fleshy cotyledons. They have much the same constituents as Cacao, but the proportions of these differ. (See Cola.) The leaves of Waltheria glomerata are used as a hemostatic in Panama like matico, as are also the

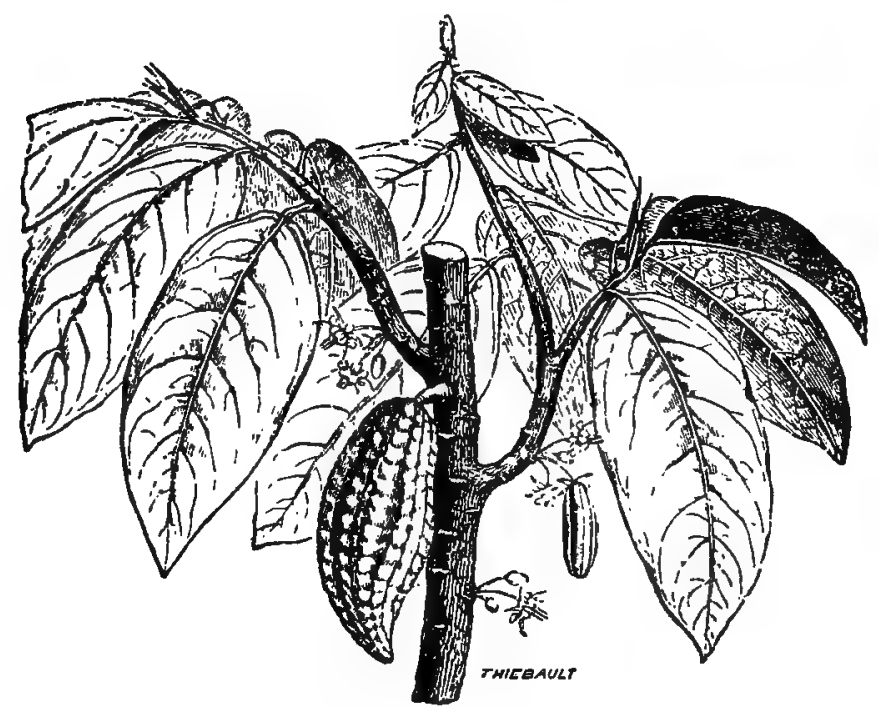

Frg, 167. Cocoa tree (Theobroma Cacao) showing the peculiar habit of the fruits in developing on the main axis as well as on the branches.-After Baillon.

leaves of Pterospermun Acerifolium. The inner bark of Fremontia californica is used for purposes similar to those of elm bark. Mucilage is also found in the following genera: Pentapetes, $W$ altheria, Guazuma, Helicteres, and Sterculia. Tannin is found in the bark of Guazuma ulmifolia of South America. An oil is manufactured from the seeds of Sterculia fotida of the East Indies and Cochin China. The seeds of a number of species of Sterculia are edible. Abroma an gusta of India yields a fiber which has been suggested as a substitute for silk. 


\section{ORDER PARIETALES.}

This is a group of plants of rather wide distribution, and includes perennial herbs like the wiolets; evergreen shrubs, such as the Tea plant; and vines like the Passion flower. As the name indicates the plants of this order are characterized by the flowers having, for the most part, ovaries with parietal placentas.

a. FAMILY DILLENIACE 3 .- The plants are mostly tropical trees which yield valuable timber. The wood of a species of Dillenia growing in the East Indies also contains red coloring substances. The fruits of Dillenia indica contain citric acid and are used like lemons. The leaves of Curatella americana contain considerable silicon and are used to polish wood. Dillenia speciosa of India contains a large percentage of tannin. Some species of Dillenia are cultivated and the foliage and flowers combine to make the plants the most beautiful in the plant kingdom.

b. MARCGRAVIACE Ad.-The members of this family are partly epiphytic, and have dimorphic leaves, the smaller ones being pitcher-like. The plant which is cultivated in greenhouses, Marcgravia umbellata, is used in the Antilles in medicine.

c. THEACE无 OR TEA FAMILY.-The plants are shrubs or trees with alternate, evergreen leaves, and perfect, regular flowers with numerous stamens, occurring one or more in the axils of the leaves. The fruit is a $3^{-}$to 5 -locular, dehiscent capsule. The most important member of this family is Thea sinensis, the two varieties viridis and Bohea furnishing the leaves known as TEA. The Tea tree is indigenous to Eastern Asia, and is now extensively cultivated in China, Japan, India, Java, Brazil, Sicily, Portugal and France, and to some extent in the Southern United States.

The fresh leaves of Thea do not have the properties which characterize the commercial article, the aroma and other qualities being developed after special treatment. Two general classes of tea are found in commerce, these depending on the mode of treatment. Those which are rapidly dried by means of artificial heat constitute GREEN TEA. The leaves which are slowly dried, permitting fermentation to set in. furnish BLACK TEA. Tea leaves contain I.5 to 3.5 per cent. of caffeine; theobromine and the- 
ophylline (an isomer of theobromine) ; Io to 20 per cent. of gallotannic acid; quercitrin, and a volatile oil containing among other components, methyl salicylate. The seeds contain about 30 per cent. of fixed oil, I per cent. of caffeine, and saponin. The leaves furnish one of the sources of the official caffeine. Saponin is found in the seeds of Thea Sassanqua of China and Japan. Two saponin-like substances (assamin and assaminic acid) are found in the seeds of Thea assamica. The flowers of T. Sassanqua are used in China and Japan to flavor teas. The flowers and leaves of Thea kissi are used as an insecticide. The red colored sap of Laplacea Hamatoxylon of New Granada is used in medicine.

d. GUTTIFER E OR GAMBOGE FAMILY.-The plants are principally shrubs and trees of the Tropics, that is, if we exclude the Hypericaceæ which are now put in a group by themselves.

Garcinia Hanburyi is a tree with ovate, petiolate, coriaceous, opposite leaves. The flowers are small, yellow, diøcious, occurring in small clusters in the axils of the leaves. The fruit is a pome-like berry, with a papery endocarp and an oily sarcocarp, and 3 or 4 seeds, I in each loculus (Fig. I68). The trees are chiefly valued on account of the gum-resin known as gamboge (p. 648), which they contain.

A resin used in making plasters is obtained from Calophyllum brasiliense of Brazil. Balsams resembling Copaiba have been obtained from Calophyllum Calaba of the West Indies. Balsams known as TACAMAHAC are also derived from the following plants: Bourbon Tacamahac from Calophyllum Tacamahaca, India Tacamahac from C. apetalum and Brazilian Tacamahac from Rheedia Madrunno. Baisams are also obtained from Caraipa grandiflora of Brazil, and Rheedia acuminata of Peru. Resins and balsams are obtained from a number of species of Clusia.

A yellow coloring principle, mangostin, is obtained from the bark and fruit of Mangosteen (Garcinia Mangostana) of the East Indies. Yellow coloring principles are found in Ochrocarpus longifolius of India and Vismia acuminata of South America. Tannin occurs in Mahurea palustris of Brazil, Mesua forrea of the East Indies, the flower-buds of Ochrocarpus longifolins of India, and several species of Cratorrylum of China and Java. 
A butter-like fat is obtained from the seeds of Garcinia indica. A fixed oil known as LAUREL-NUT oIL is derived from the seeds of Calophyllum Inophyllum and other species of Calophyllum growing in the East Indies, Cochin China and Brazil, as well as the seeds of Symphonia fasiculata of Brazil.

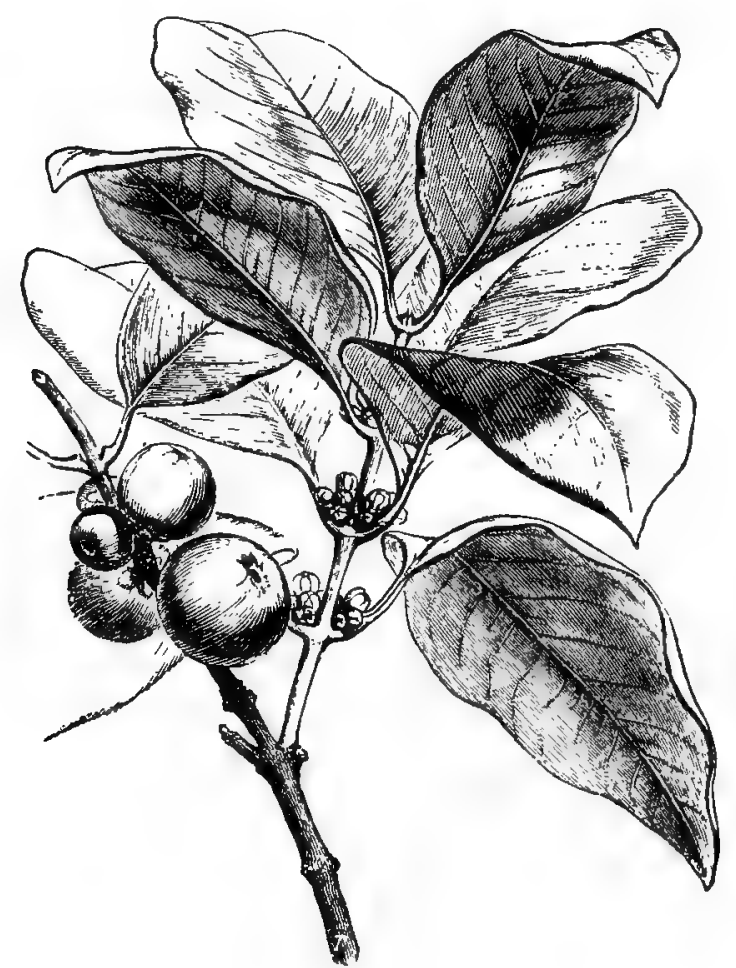

FIG. I68. Gamboge plant (Garcinia Hanburyi). A branch showing the axillary pistillate flowers and pome-like fruits.-After Baillon.

The bark of Clusia Pseudo-china is used in Peru as a substitute for cinchona. An alkaloid is found in Vismia robusta of Java. A gum is obtained from Calophyllum tomentosum of India and Vismia acuminata, that of the latter being purgative. The flower buds of the India Suringi (Ochrocarpus longifolius) have an aromatic odor resembling cloves. Aromatic principles are also found in other plants of this family. 
Edible fruits are yielded by the following plants: MANGO FRUIT from Garcinia Mangostana and other species of Garcinia; Mammei APPLE or Apricot of St. Domingo from Mammea americana of tropical America, the latter being used in the preparation of Mammey wine or "Toddy" and a liquor known as "Eau de Creole." The seeds of Platonia insignis are used like almonds in Brazil and Paraguay; the fruit of the latter plant is quite acid and is eaten with sugar.

e. HYPERICACE $巴$ OR ST. JOHN'S-WORT FAMILY.The plants are herbs or shrubs of the temperate regions, and are represented in the United States by the Hypericums, which are quite common. The flowers are characterized by the numerous stamens which are united into distinct groups or clusters. The flowers of Hypericum perforatum or Common St. John's-wort contain yellow and red coloring principles. Yellow coloring principles have also been isolated from Hypericum laricifolium of Ecuador and $H$. elodes of Northern Europe. The entire plant of $H$. perforatum is used in medicine and contains considerable resin, and a small amount of volatile oil.

f. FAMILY DIPTEROCARPACE E.-The plants of this family are principally trees and indigenous to tropical Asia. The family derives its name from the winged fruits of the principal genus Dipterocarpus. A number of economic products are furnished by this group of plants. BORNEO CAMPHOR is obtained from Dryobalanops aromatica. The camphor separates in canals in the older parts of the wood and between the wood and bark, and is obtained by felling the trees, splitting the wood, and then removing the camphor by hand. Owing to the fact that some of the trees do not contain camphor, it is sometimes necessary to fell a hundred trees in order to obtain 6 or $8 \mathrm{~K}$. of the product. The young twigs of this plant as well as the older wood yield a volatile oil known as Oil of Borneo camphor.

GURJUN BALSAM or Wood oil is obtained from a number of species of Dipterocarpus growing in the East Indies by incising the stems as in the collection of turpentine. The balsam is used as a substitute for copaiba and contains an ethereal oil which consists chiefly of a sesquiterpene, an indifferent resin, and gurjunic acid. Sindor balsam is obtained from Dipterocarpus mar- 
ginatus of Borneo. A resin known as "PINEY RESIN," which is used as a substitute for Dammar, is obtained from a number of species of Vateria growing in India. ChaIA Resin is obtained from Shorea rubifolia of Cochin China. The bark of Shorea robusta of Northern India contains 32 per cent. of tannin. The seeds of species of Shorea, Pinanga, Gysbertsiana and Isoptera yield the fatty oil known in Java as TANGKawANG. The seeds of a number of plants of this family contain considerable starch, as Vateria, Vatica and Doona. The woods of the following genera are extensively used: Vatica, Shorea, and Hopea.

g. FAMILY TAMARICACE.E.-The plants are halophytic shrubs found in the desert regions of Central Asia and Mediterranean countries and one genus (Fouquieria) is found in Mexico. Fouquieria splendens is cultivated to some extent, and is known as Ocotilla or Coach-whip Cactus. The bark contains gum, resin and wax; the latter is known as Ocotilla wax and resembles beeswax. The twigs of Myricaria germanica of Europe are used as a substitute for hops. A manna-like sugar is formed on the stems of Tamarix mannifera growing in Egypt, Arabia and Afghanistan, as the result of the sting of an insect (Coccus manniparus). Tannin is found in a number of species of Tamarix as well as in the galls formed on the plants, the tannin being used for dyeing. A table salt is prepared from the ash of several species of Reaumuria found in Northern Africa and the East Mediterranean region.

h. FAMILY BIXACEA.-These are shrubs or trees found in the Tropics, and are of interest chiefly on account of the seeds of Bixa Orellana which furnish the coloring matter known as Annatro (Orlean. Arnotta). The plant is found in tropical America and also in Polynesia and Madagascar. The seeds are covered with a fleshy arillus from which the coloring matter is prepared by means of water. The insoluble matter is collected. made into cakes and chiefly used for dyeing and coloring. Annatto contains a red crystalline principle, bixin, a yellow coloring principle, orellin, and an ethereal oil. The root of this plant also contains some coloring matter. A yellow coloring principle is found in Cochlospermum tinctorium of Senegambia and an aromatic resin is obtained from Cochlospermum Gossypium of Ceylon and Malabar. 
i. FAMILY WINTERANACE $\mathbb{E}$ OR CANELLACE无These are trees with aromatic barks having an odor of cinnamon; pellucid-punctate leaves; and golden-yellow flowers. The most important member of this family is IVinterana Canella growing in the Antilles and in Southern Florida, which furnishes the Canelda BARK or False Winter's bark used in medicine. The bark occurs in large quills or broken pieces, from 3 to Io $\mathrm{mm}$. thick, with the periderm nearly entirely removed, the outer surface yellowish or orange-red with transversely elongated patches of cork and shallow, whitish depressions; the fracture is short with numerous resin canals; the odor aromatic; taste aromatic, bitter and pungent. It contains mannitol, resin and 0.5 to 1.28 per cent. of a volatile oil containing eugenol, cinneol, caryophyllene and pinene. The bark of one or more species of Cinnamodendron of tropical America is sometimes substituted for Canella bark, but it is distinguished by containing tannin, which constituent is not found in Canella.

j. VIOLACE $\mathbb{E}$ OR VIOLET FAMILY.-The plants are herbs or shrubs with basal or alternate leaves, perfect, irregular flowers, and 3-valved dehiscent capsules (Fig. I34, $J$ ). The best known representatives of this group are the cultivated species of the genus Viola, including the English or sweet violet (Viola odor$a t a$ ), which produces a volatile oil containing ionon; and the varieties of Viola tricolor vulgaris which furnish the pansies of the garden. The entire herb of Viola tricolor has been used in medicine and contains the yellow coloring principle viola-quercitrin, salicylic acid and methyl salicylate (Figs. 70, 93, Ioo, II8).

k. FAMILY FLACOURTIACEA. - These are tropical shrubs and trees, and are chiefly of interest because of their valuable woods and acid, juicy fruits. A number of them are of medicinal interest. Chaulmugra orl is said to be obtained from the seeds of Gynocardia odorata of Farther India. The seeds also contain gynocardic acid and hydrocyanic acid. The latter is also present in the seeds of Hydnocarpus venenata of Southern India and Ceylon and the leaves of Kiggelaria africana.

A number of species of Latia growing in Cuba yield a resin resembling sandarac. The Coccos oil which is used in perfumery is obtained from several species of Myroxylon growing in Polynesia. The fixed oils from the seeds of Gynocardia odorata and of 
several species of Panginm are used in cooking. A bitter principle occurs in the bark of Casearia adstringens of Brazil. A purgative principle is found in C. esculenta of tropical Asia and Australia. The root of Homalium racemosum of Guiana contains an astringent principle.

1. FAMILY TURNERACE无.-These plants are herbs, shrubs and trees mostly found in tropical America, and are of interest on account of the leaves of Turnera diffusa, particularly the variety aphrodisiaca, which yield the Damiana of medicine esteemed as a tonic laxative like Rhamnus Purshiana. The drug usually consists of leaves although the reddish stems, yellowish flowers and globular capsules may be present. The leaves are about $25 \mathrm{~mm}$. long, varying from oblanceolate to obovate; the margin is serrate-dentate; the color, light-green (older leaves somewhat coriaceous and pubescent); the odor aromatic; taste aromatic and bitter. Damiana contains a volatile oil, resin, and the bitter principle damianin. Ethereal oils are found in other species of Turnera, and $T$. angustifolia of Mexico contains considerable mucilage. m. PASSIFLORACE无 OR PASSION-FLOWER FAMILY.-The plants are mostly herbaceous or woody vines climbing by means of tendrils, with alternate, palmately-lobed, petiolate leaves and solitary, perfect, regular flowers. The flowers are peculiar in that between the corolla and stamens there are numerous, frequently petaloid, colored, sterile, filamentous bodies which are known collectively as the "corona." The fruit is a berry or dehiscent capsule. The genus Passiflora is known as the Passionflower because the flowers are considered to be emblematic of the Crucifixion, the corona representing the crown of thorns, the stamens the nails, and the gynæcium with its three styles, the three thieves. The rhizomes of the Passion-flowers of the Southern States (Passiflora incarnata and $P$. lutea) have been used in medicine. Not much is known with regard to the active principles of these two plants or of the thirty other species of Passiflora which are used in medicine. The fruits of several species of Passiflora are edible, and a number of them are cultivated on account of their beautiful as well as odorous flowers.

n. CARICACE $\approx$ OR PAPAW FAMILY.-This family is composed of two genera of latex-containing trees growing in trop- 
ical America, the best known of which is the genus Carica. The Papaw or Melon tree (Carica Papaya) is a small tree with a straight, slender, usually unbranched trunk which bears at the summit a cluster of long-petiolate, deeply-lobed leaves. The flowers are diocious, and the fruit is a large, melon-like berry. The green fruits as well as the leaves contain a milk-juice which is obtained by incising them. The material is dried and is used in medicine on account of its containing a proteolytic ferment, papain or papayotin, which is active in the presence of both acids and alkalies. The leaves and fruit also contain the alkaloid carpaine, and in addition the leaves contain the glucoside carposid. The root contains a glucoside somewhat resembling potassium myronate and a ferment which has a decomposing action upon it. A proteolytic ferment is also present in the leaves of Carica quercifolia of Argentina. The melon tree is cultivated on account of the fruits, which are edible.

o. BEGONIACE E.-This is a family of tropical plants which are extensively cultivated. They are herbs or shrubs frequently with tuberous rhizomes and with characteristic, asymmetric, variegated leaves. They are easily propagated by cuttings providing they have sufficient moisture, even the leaves giving rise to new plants. The roots of Begonia anemonoides of South America and $B$. gracilis of Mexico contain purgative principles. Calcium oxalate and acid oxalates are found in the leaves of probably all of the species of Begonia. The roots of a number of species of this genus are astringent.

p. DATISCACEÆ.-The plants are trees or shrubs found principally in the Tropics. A bitter principle is found in the Yellow hemp (Datisca cannabina) of Southern Europe and the Orient. The root contains a yellow coloring principle, datiscin, which is used in the dyeing of silk. The wood of Octomeles and Tetrameles is used in the making of tea-chests.

XXI. ORDER OPUNTIALES.

The plants of this order are succulent, with much reduced leaves, and with flowers characterized by having a perianth with numerous segments and an inferior ovary. 
a. CACTACE 2 OR CACTUS FAMILY.-This is a remarkable family of succulent plants growing largely in the arid regions of Mexico, Brazil and other parts of America. The stems are more or less flattened, terete or tuberculated, in some cases becoming branched and woody. The leaves are reduced to scales, but are sometimes larger, more or less cylindrical or dorsiventral, and usually drop off sooner or later. In the axils of the leaves or leafscars there are usually groups of hairs and spines. The flowers are mostly solitary, sessile, perfect, regular and conspicuous. The fruit is usually a fleshy berry, the fruits of a number of species being edible.

Quite a number of the Cacti have been used in medicine, the one most commonly employed being the Night-BLooming Cereus (Cereus grandiflorus), which is extensively cultivated on account of its flowers. The flowers and fresh stems are the parts used. They contain several acrid principles including probably an alkaloid and a glucoside, the drug resembling in its action digitalis.

Mescal buttons (Anhalonium), are the dried tops of several species of Lophophora growing in Northern Mexico. The main axis of the plant is under the ground and produces at certain points small aerial shoots which are more or less button-shaped or disk-like, being about 20 to $50 \mathrm{~mm}$. in diameter. In the center of the disk occur tufts of hairs which vary in the different species. and among which are usually found one or more pinkish flowers. The drug has been used like Night-blooming Cereus, and contains several alkaloids, namely, anhalonine (similar to pellotine), mescaline, anhalonidine and lophophorine. Alkaloidal principles are also found in other members of this family.

The sap of several species of Cereus of the Antilles has anthelmintic properties, as also that of certain species of Rhipsalis and Opuntia. A caoutchouc-like exudation is obtained from Opuntia vulgaris and other species of Opuntia growing in the West Indies. An astringent principle is found in the root and bark of Opuntia Karreinskiana of Mexico. A tragacanth-like gum is found in Peireskia Guacamacho of Venezuela, Opuntia rubescens of Brazil and O. Tuna of the West Indies, Mexico and South America. An alcoholic beverage is made by the Indians of Sonora from the fruit-juice of Cercus Thumbergii. 
A number of species of Opuntia yield edible fruits. The PrICKLy PEAR is the fruit of Opuntia Tuna growing in the West Indies and tropical America; INDIAN FIG is derived from Opuntia Ficus-Indica growing in Southern Europe, particularly Sicily; a fruit also known as Prickly pear or Indian fig is derived from Opuntia vulgaris, a common Cactus growing in sandy soil in the Eastern United States. The Cochineal Insect which is official under the name of coccus in a number of pharmacopoias (Pseudo-coccus Cacti) lives on the following Cacti: Nopalea coccinellifera of Jamaica and South America, Opuntia Tuna and $O$. Dillenii both of tropical America, and Peireskia aculeata of the Antilles.

\section{ORDER MYRTALES OR MYRTIFLORA.}

The plants are herbs or shrubs with complete flowers, rarely apetalous, producing one or more ovules in each loculus.

a. THYMEL ÆACE $A$ OR MEZEREUM FAMILY.-The characters of this family are illustrated by the Spurge laurel or Mezereon (Daphne Mezereum) which is a small shrub about I $M$. high, with oblong-lanceolate, acute, entire, sessile leaves, and small groups of fragrant flowers, the perianth tube of which is purplishred or white. The fruit is an ovoid, reddish drupe. The bark of Daphne Mezereum and other species of Daphne is used in medicine (p. 536).

The bark of Funifera utilis of Brazil contains a vesicating principle. A principle with similar properties is found in the bark of Leather wood (Dirca palustris) of the Eastern United States and Canada. The fruit and leaves of Gnidia carinata of Cape Colony contain emetic and drastic principles. A poisonous principle is found in Pimelea trichostachy'a of Australia. A yellow coloring principle is found in several species of.Daphne and Thymelea. The wood of Aquilaria Agallocha of India and China is aromatic and resembles the "Aloe wood." A balsam is obtained from the wood of Pimelea oleosa of Cochin China. The bast fibers of quite a number of plants are used in the making of paper, as of Daphne in India, Gnidia of Madagascar, Lagetta ( $L$. lintearia or Lace-tree) of Jamaica and St. Domingo, Thymelcea 
of the Mediterranean countries and Linodendron of Cuba. The fibers of Leather wood (Dirca palustris) of the Eastern United States and Canada are said to be used in a similar manner.

b. FAMILY ELÆAGNACE E.-This is a small family represented in the United States by several genera, among which is the Buffalo berry (Lepargyrcea argentea), a thorny shrub found in the western part of the United States and the Northwest Territory. The fruit is a reddish drupe-like berry which contains a small amount of citric and malic acids, 5 per cent. of sugar, and in composition is much like the currant. It is eaten by the Indians, and used to a great extent in the Western States in the making of jellies. The leaves and flowers of a number of species of Elragnus are used in medicine.

c. LYTHRACEÆ OR LOOSESTRIFE FAMILY.-The members of this family are herbs, shrubs and trees usually with opposite, entire leaves. The flowers are in racemes and the fruit is a capsule. Quite a number of the plants yield valuable woods and a number are cultivated as ornamental plants.

The flowers of Woodfordia floribunda of India contain a red coloring principle, and the bark and leaves of Lafonsia Pacari of Brazil contain a yellow coloring principle. Considerable tannin is found in the root of the Purple loosestrife (Lythrum Salicaria), of the Northern United States and Canada, and widely distributed in the Old World; and also in the fruit of Woodfordia floribunda, a plant which is extensively cultivated in greenhouses. A bitter principle, nessin, is found in the leaves of Nesca syphilitica of Mexico and probably other species of this genus. Cuphea viscosa of Mexico is said to resemble digitalis in its physiological action. A vesicating principle, resembling cantharidin in its action, is obtained from the fresh leaves of Ammanni baccifera of India. A narcotic principle is found in the seeds of Lagerstromia Flos regince of India. The flowers of Laresonia inermis, native to and cultivated in the Orient, have an odor resembling that of the Tea rose. The shrub is also cultivated to some extent in the West Indies and is known in the Orient as the Henna plant. The leaves are used in the preparation of the cosmetic Hinna. They contain an orange or brownish-yellow dye which is used in the dyeing of the skin and hair. 
d. PUNICACEA OR POMEGRANATE FAMILY includes a single genus of two species. The Pomegranate (Punica granatum) indigenous to the Levant and now extensively cultivated is of chief interest. The plants are small trees, the young twigs of which are 4-angled and frequently thorn-like. The leaves are opposite, ovate-lanceolate, entire, short-petiolate. The torus, calyx and corolla are scarlet, and the gynæcium consists of two whorls of carpels. The fruit is an inferior edible berry with hard pericarp or rind. The pulpy portion is formed from the outer layer of the seed-coat. The bark of the root and stem is used in medicine. (See Granatum, p. 534.) The rind of the fruit is used as an astringent because of the tannin which it contains. It does not appear, however, to contain the alkaloids found in the official bark.

e. FAMILY LECYTHIDACE E.-The plants are mostly shrubs and trees indigenous to the Tropics. They are of chief interest on account of the BRAZIL-NUT or Para-nut obtained from Bertholletia excelsa, and the Sapucaya-nut obtained from the Monkey-pot tree (one or more species of Lecythis), both genera of South America. The seeds (so-called nuts) are rich in oil and proteids and are edible. The fruit of Careya arborea is drupaceous and is also edible, the seeds being considered, however, to be poisonous. Bitter narcotic or poisonous principles are also found in the fruit of Planchonia valida of the Molucca Islands and the seeds of a number of species of Lecythis. The fruits and roots of a number of species of Barringtonia are used in China and Java to stupefy fish. The pericarp of the fruit of Fatida moschata of Guiana contains considerable quantities of an ethereal oil. The flowers of Grias cauliflora of the Antilles are used like tea. A cooling drink is made from the sarcocarp of Couroupita guianensis of the West Indies and Guiana.

f. RHIZOPHORACE $\nexists$ OR MANGROVE FAMILY.These are tropical shrubs or small trees with evergreen, coriaceous leaves, small cymose and axillary flowers, and seeds which germinate while the fruit is still attached to the plant. The best known genus of this family is Rhizophora (Mangrove tree), of which there are three species, the AmERICAN Mangrove being $R$. imangle. This tree produces aerial roots on the stems and 
branches, and leaves which are characterized by a number of layers of water-containing cells. The plants grow in muddy swamps, or along the sea-coast where the water is brackish, a number together forming the so-called "Mangrove swamps."

The root and bark of the Mangrove, as well as other species of Rhizophora and several species of Bruguiera, contain a large quantity of tannin which resembles catechu. The aerial roots of Rhizophora are used by the natives of Polynesia in the making of bows, and the woods of several genera are used in carpentry.

g. MYRTACE正 OR MYRTLE FAMILY.-This is a group chiefly of shrubs and trees, some, as of species of Eucalyptus, being the loftiest trees known, attaining a height in some instances of $105 \mathrm{M}$. The plants are indigenous to Australia and tropical America and some are extensively cultivated.

EuCalyptus species.-The leaves frequently vary in shape and in arrangement on the young and older branches of the same plant. On the young branches they may be, as in Eucalyptus Globulus, ovate or broadly elliptical, opposite and sessile, while on older branches they are scythe-shaped, pellucid-punctate, petiolate and alternate (Fig. 258). In the latter case the petioles are twisted and the leaves stand edgewise so that both surfaces are equally exposed to the light and hence of similar structure. The flowers are solitary, or in cymes or umbels, occurring in the axils of the leaves. Petals are wanting and the whitish stamens, which are numerous and inflexed in the bud, are covered by an operculum or lid which is considered to be formed by the union of the sepals, and which dehisces on the maturing of the stamens, this being one of the most characteristic features of the genus. The fruit is a 3- to 6-locular truncated capsule or pyxis.

This is a very important genus from an economic point of view, among the products being the volatile oil (oil of eucalyptus), and eucalyptol, both of which are official, and the tannin or socalled" "gum," known as Eucalyptus kino (p. 655).

Jambosa Caryophyllus (Engenia Caryophyllata).-This is a small tree indigenous to the Molucca Islands and now extensively cultivated in the Tropics. The leaves are opposite, ovate-lanceolate, acuminate, petiolate, entire and evergreen. The flowers are rose-colored and in cymes; the fruit is berry-like and constitutes 
the Anthophylli or Mother-cLove. The unexpanded flower-buds constitute the drug or spice known as Cloves. (See Caryophyllus.)

Pimenta officinalis is a tree with opposite, lanceolate, acute, petiolate, pellucid-punctate and evergreen leaves. The flowers are small, white and in axillary racemes. The fruit is drupaceous, 2-locular and 2-seeded, and constitutes the allspice which is used for flavoring and in medicine. (See Pimenta.)

Not only are ethereal oils obtained from the genera Eucalyptus, Jambosa and Pimenta already described, but also from other members of the Myrtacex. OrL of BAY or oil of Myrcia is distilled from the leaves of Pimenta acris of the West Indies. The oil. consists largely of eugenol, methyl-eugenol, chavicol, methyl-chavicol, citral, phellandrene and myrcene, and is used in the preparation of BAY RUM.

Cheken leaves are obtained from Eugenia Cheken. They are about $25 \mathrm{~mm}$. long, ovate or rectangular, with entire, somewhat revolute margin, light green, pellucid punctate, aromatic, astringent and bitter. Cheken leaves yield about I per cent. of a volatile oil containing cineol and pinene; 4 per cent. of tannin; a volatile alkaloid and a glucoside.

Oil of Cajeput is obtained from the leaves and twigs of Melaleuca Leucadendron, particularly the varieties Cajeputi and minor of the East Indies. The principal constituents of this oil are cineol, terpineol, pinene, and a number of aldehydes and acid esters. An oil resembling Cajeput oil is obtained from the leaves and flowers of Myrcengenia camphorata of Chile.

The leaves of Myrtus communis, a plant extensively cultivated in the Mediterranean countries of Europe, yield a distillate with water known as EAU D'ANGE and used as a toilet article.

The leaves of the following plants are used as substitutes for tea leaves: Myrtus Molince of Chile, Melaleuca genistcefolia of Australia, and Leptospermum scoparium and other species of this genus growing in New Zealand. The seeds of Eugenia disticha are known in the Antilles as Wild coffee. Quite a number of the genera of this family yield edible fruits. GuAva or Guayava fruit is obtained from Psidium Guavava of tropical America. ROSE APPLE is the fruit of Jambosa malaccensis, growing in the East Indies and Oceanica. JAmbuse BerRies are derived from 
Jambosa vulgaris which is extensively cultivated in the Tropics. The lemon-like fruit of Myrcia coriacea is used in medicine, the bark in tanning, and the wood in dyeing. The fibrous bark of Eugenia ligustrina is used like oakum.

h. FAMILY COMBRETACE 2 .- The members of this family are shrubs or trees, sometimes climbing, with usually alternate, petiolate, simple leaves; sessile flowers in racemes; somewhat fleshy, winged, I-seeded fruits, and are mostly found in the Tropics.

Like the Fagacex the plants of this family contain a tannin, similar to gallotannic acid, in nearly all parts of the plant. The Myrobalans of the East Indies are the young fruits of Terminalia Chebula. The pericarp contains from 5 to 45 per cent. of tannin, the latter amount being found in the fruits known as Long or Chebula Myrobalans. The fruits also contain ellagic and chebulinic acids. The fruits of Terminalia belerica constitute the Beleric Myrobalans. The galls of Terminalia macroptera of Africa and other species of Terminalia as well as of Bucida Buceras of tropical America are particularly rich in tannin. A yellow coloring principle is found in Terminalia Brownii of Africa and is used in dyeing leather. The bark of T. Catappa of Asia and Africa is used to dye leather black.

A gum-resin with cathartic properties is obtained from Terminalia fagifolia of Brazil. An aromatic resin is found in Terminalia angustifolium of the East Indies. The fruits of one or more of the Combretaceæ are said to be used in the preparation of the arrow-poison of the Negritos. The seeds of Terminalia Catappa and Combretum butyrosum contain about 50 per cent. of fixed oil. These seeds as well as those of other species of Terminalia and Quisqualis indica of Farther India and tropical Africa are edible. The seeds of the latter plant when unripe are said to be used like mustard. The woods of a number of the plants of the Combretaceæ are valuable for building purposes, and some of the genera furnish ornamental plants which are cultivated in greenhouses.

i. FAMILY MELASTOMACEA.-This is a large family of herbs, shrubs and trees with opposite, 3- to 9-nerved leaves and regular, perfect, often showy flowers. They are chiefly found in South America and are represented in temperate regions by 
the Mẹadow beauty (Rhexia). Quite a number of the plants are cultivated and a large number yield edible fruits. The fruits, barks and leaves frequently contain COLORING PRINCIPLIES. A yellow coloring principle is found in the leaves of a number of species of Memecylon of the East Indies and Africa, which resembles that of saffron and curcuma. Red coloring principles are found in the berries of a number of species of Blakea of South America. A black coloring principle is obtained from the fruit of several species of Tamonea of tropical America, Melastoma malabathricum of the East Indies and Tococa guianensis of Northern South America and Tibouchina Maximiliana of Brazil. Tannin is found in considerable quantity in the barks of Tibouchina, Dissotis and Rhynchanthera.

The leaves of Tamonea thecezans are used in Peru as a substitute for tea. A mucilage is found in the bark of Medinilla crispata of the Molucca Islands. The flowers of the latter plant as well as of $M$. macrocarpa are used as a remedy for the bite of poisonous serpents.

j. ONAGRACE A OR EVENING PRIMROSE FAMILY. These are mostly annual or perennial herbs with usually entire or toothed, simple leaves. The flowers are perfect, regular or irregular, epigynous, variously colored, solitary in the axils of the leaves or in somewhat leafy spikes. The fruit is a dehiscent capsule, berry, drupe, or nut. This family is represented in temperate regions by such plants as the Willow herb (Epilobium), Evening primrose (Enothera), on which De Vries has carried on his famous mutation experiments, and Enchanter's nightshade (Circæa). The cultivated Fuchsia also belongs to this family, the plants representing several species of Fuchsia which are native to tropical America. Plants of quite a number of other genera are cultivated, the flowers of some of them being quite irregular and orchid-like in appearance, as Lopezia of Central America. The flowers of a number of genera are light in color and somewhat luminous in the dark and hence are known as "night candles." The seed-hairs of some of the Epilobiums are used in the Arctic regions in making lamp-wicks. A yellow coloring principle is obtained from the herb and unripe fruits of Jussiena pilosa of Brazil. Considerable tannin is found in the leaves of Jussieua 
caparosa and $J$. scabra of tropical America, and the wood of several species of Fuchsia. The roots of Enothera biennis, O. muricata and other species of this genus are edible.

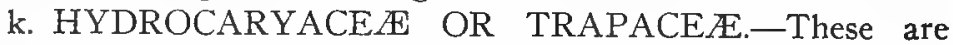
aquatic plants comprising a single genus, one of which Trapa natans or Water chestnut is naturalized to some extent in the ponds of Massachusetts and New York. The fruit is coriaceous, 2- to 4 -spinose, and 1 -seeded. The cotyledons are unequal, rich in starch, and are edible, sometimes being ground and made into bread by the people of Europe and Northern Asia.

\section{ORDER UMBELLALES OR UMBELLIFLOR.⿻.}

The plants of this order are widely distributed in northern temperate regions although there are some representatives in the Tropics. The flowers are small, 4- or 5-merous and epigynous.

a. ARALIACE $Æ$ OR GINSENG FAMILY.-The plants are mostly trees or shrubs with alternate, petiolate, simple or $3^{-}$to 7-compound leaves. The flowers are either in umbels or panicles. The fruit is a drupe or berry. The best known representatives of this family are the English ivy (Hedera helix) of Europe, and Ginseng (Panax quinquefolium) (Fig. 63) growing in the Eastern and Central United States. This plant is the source of the ginseng root of commerce, considerable quantities of which are exported to China where it is used like the root of Panax Ginseng, a plant growing wild in Manchuria and Korea. Both plants are also cultivated in the United States, the roots from the wild plants being preferred. The root contains a volatile oil, and considerable starch. Several species of Aralia are used in medicine (p. 450).

The leaves of the English ivy contain the glucoside helixin, and a carbohydrate, inosit. They also contain formic, oxalic, malic, tannic and hederic acids, besides the yellow principle carotin. The fruits of the ivy contain a purplish-red coloring substance and are said to be poisonous.

The Chinese RICE PAPER is made from the pith of Tetrapanax papyrifer which grows wild in Formosa and is extensively cultivated in China. The pith is cut spirally into thin strips which are spread out flat and then cut into pieces varying from 15 to 
$30 \mathrm{~cm}$. long and to to $12 \mathrm{~cm}$. broad. This paper differs from other papers in that it is a natural product.

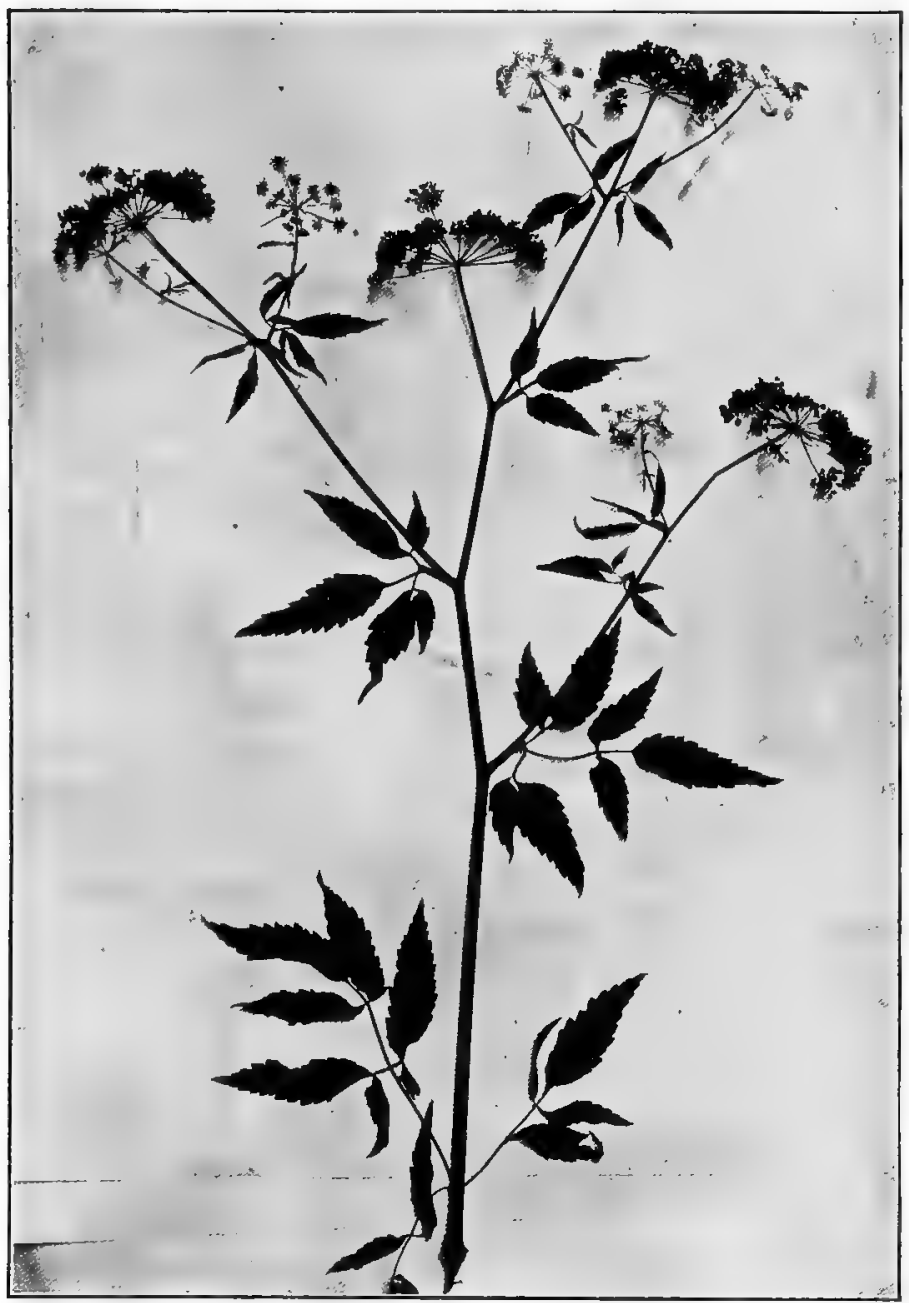

Frg. I69. Water hemlock (Cicuta maculata) with pinnately-compound leaves and terminal compound umbels.

A number of the Araliaceæ are cultivated on account of their beautiful foliage, the plants in some cases resembling the palms. 
b. UMBELLIFER $Æ$ OR CARROT FAMILY.-The plants are herbs, frequently with hollow stems; alternate, simple or compound leaves, the base of the petiole often forming an inflated sheath; and small white, yellowish, greenish or somewhat purplish flowers occurring in simple or compound umbels. The fruit is a cremocarp, having characters which are of important taxonomic value, as the presence or absence of secondary ribs, number and position of the vittæ, etc.

Coriandrum sativum is an annual herb the fruits of which are official (p. 562). The leaves are bi-or tri-pinnate, the leaflets being narrow linear-lanceolate; and the flowers are white or rose-colored.

Conium maculatum or Poison Hemlock is a tall, erect, branching, biennial plant, with purplish spotted stems, pinnately decompound leaves and small, white flowers (Fig. I7o). The fruit is official (p. 567).

Carum Cari' (Caraway) is a biennial herb with bi- or tripinnate, deeply incised leaves," and white flowers. The fruit is official (p. 565) and the leaves are also used in medicine.

Pimpinella Anisum is a small, hairy, annual herb. The leaves are variable, the lower being somewhat cordate and serrate, the middle distinctly lobed, and the upper ones trifid; the flowers are white. The fruit is official ( $\mathrm{p} .560$ ) and is also used for flavoring.

Foniculum vulgare is an annual or perennial, glabrous herb with very finely dissected leaves, the divisions being narrowlinear. The flowers are yellow, and the involucre and involucels are wanting. The fruit is official ( $p .563)$.

Ferula fotida is a stout, perennial herb with few, ternately compound leaves and small, polygamous, light yellow flowers. The root is rather large and yields the gum-resin asafetida ( $p$. 67I ). Asafetida is also derived from other species of Ferula.

Ferula Sumbul is a tall peremnial herb with purplish latexcontaining stems. The basal leaves are ternately compound and with amplexicaul base. The leaves decrease in size from the base upward, becoming bract-like near the inflorescence. The flowers are polygamous, resembling those of $F$ fotida. The root is official (p. 462) and is probably also obtained from other closely related species of Ferula. 


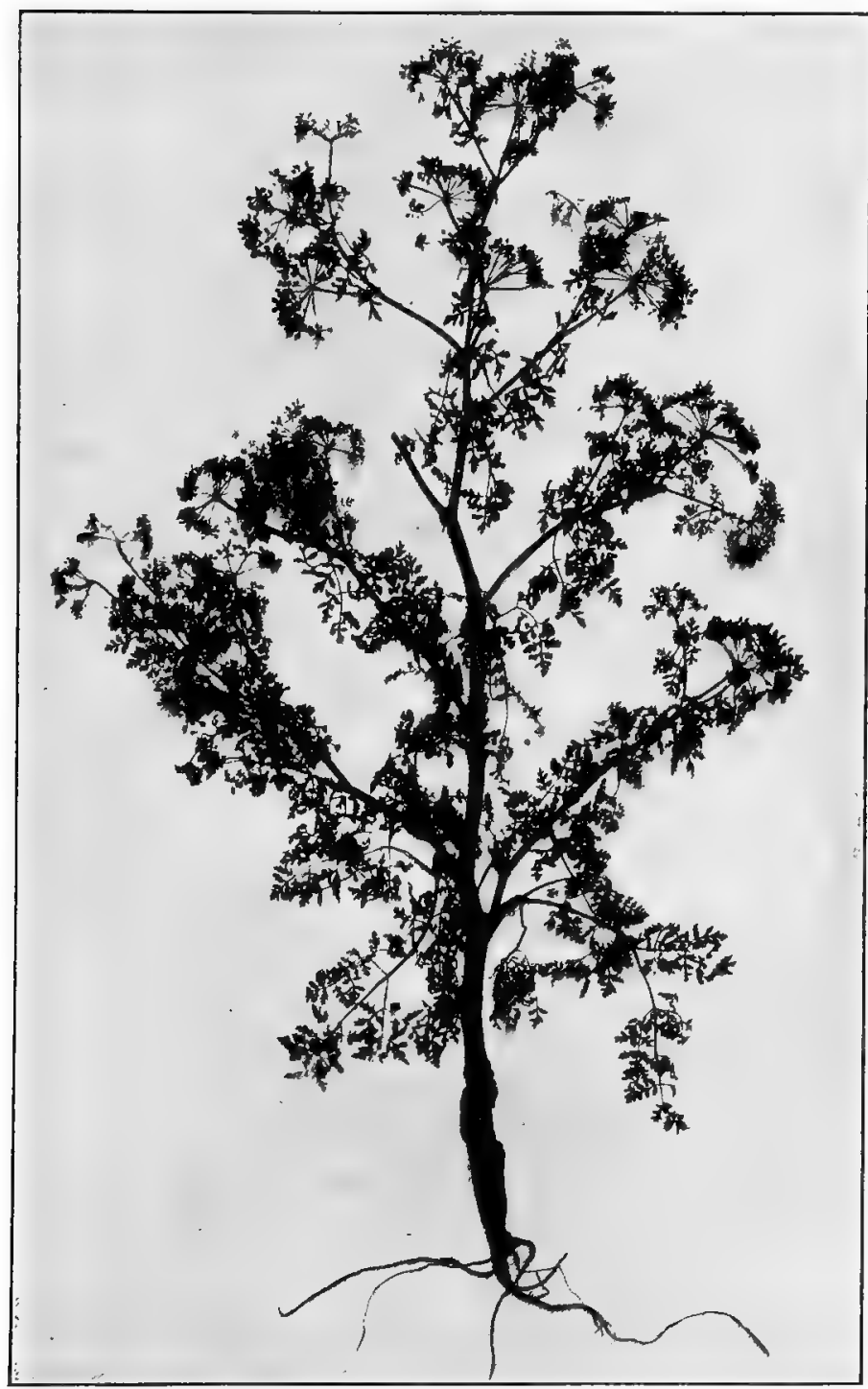

FIG. I70. Poison hemlock (Conium maculatum) showing pinnately decompound leaves, the leaflets of which are much dissected, compound, many-rayed umbels, and the tuberous root. 
A large number of the plants belonging to the Umbelliferæ contain essential oils, resins, gum-resins and related substances. The gum-resin AMMONIAC is an exudation found on the stem and branches of Dorema Ammoniacum and other species of Dorema as a result of the sting of an insect. The plant is found in Western Asia. The gum-resin occurs in yellowish-brown, globular, or somewhat flattened tears which are brittle, milky-white internally, with a distinct balsamic odor and bitter, acrid, nauseous taste. It contains a small quantity of volatile oil having the odor of Angelica. African ammoniac is obtained from Ferula tingitana growing in Northern Africa and Western Asia.

The gum-resin GALBANUM is obtained by incising the root of Ferula galbanifula and other species of Ferula growing in the Levant. Galbanum occurs in pale yellowish-brown agglutinated tears, forming a more or less hard mass, which is brittle when cold but soft and sticky at $37^{\circ} \mathrm{C}$.; the odor is distinct, balsamic; the taste bitter and acrid. It contains from ro to 20 per cent. of a volatile oil composed of d-pinene, cadinene, and other principles.

A volatile oil, known as Ayow.in oIL, and containing thymol. is obtained from the fruit of Carum Ajowan of Europe, Asia and Africa. A volatile oil containing APIOL is found in the fruit and leaves of the garden parsley (Pctrosclinum satic'um). DiLl oIL is obtained from the garden Dill (Ancthum gravcolens). The fruit of Sweet cicely (Washingtonia longistylis) yields a volatile oil known as sweet anise oil, which contains anethol. The oit of water fennel (Enanthe Phellandri) contains about 80 per cent. of phellandrene. Cumin oIL is obtained from Cumimum Cyminum of Turkestan and Egypt, and contains cymene.

The roots of a number of the plants of this family contain volatile oils, as Lovage (Lczisticum officinale) of Southern Europe; European angelica or garden angelica (Angelica Archangclica); American angelica or the purple-stemmed angelica (A. atropurpurca) found in the Northern and Eastern United' States and Canada; Wild angelica (A. sylz'cstris) of Europe.

The following garden vegetables are yielded by this family: Carrot, from cultivated species of Daucus Carota; parsnip (Pastinaca satiza); celery (Apium graz'colcns). The leaves of some species are used as pot-herbs, as parsley (Petroselinum sativum). 
c. CORNACE E OR DOGWOOD FAMILY.-The plants are shrubs or trees with simple, opposite leaves, and flowers in cymes or heads, which in the case of the Flowering dogwood (Cornut florida) are subtended by four large, petal-like, white, or pinkish bracts.

The bark of Cornus florida, a shrub or small tree growing in the United States, contains a bitter principle, cornin; and a small quantity of gallic and tannic acids.

\section{METACHLAMYDEÆ OR SYMPETALÆ.}

This is the highest group of plants and is marked by the following characters: The corolla is sympetalous; the flowers are mostly perigynous or epigynous and both the corolla and stamens are borne on the perianth tube. The number of parts is definite, there being 5 sepals, 5 petals, 5 or ro stamens and 2 or 5 carpels. This sub-class includes but six orders, to which, however, belong a large number of medicinal and economic plants.

\section{ORDER ERICALES.}

The plants of this order are distinguished by the fact that the stamens are mostly free from the perianth tube.

a. PYROLACE $\mathbb{E} .-$ The plants are small, mostly evergreen perennials, and are represented in the United States by several genera.

Chimaphila umbellata (Prince's pine or Pipsissewa) is a small trailing or creeping plant producing distinct flower- and leafbranches. The leaves are official (p. 603). The flowers are in small corymbs and the petals are white or pinkish. In Chimaphila maculata the leaves are lanceolate, mottled with white along the veins and the flowers are considerably larger.

With the Pyrolacere are sometimes grouped the saprophytic plants of the genus Monotropa. There are two representatives of this genus which are common in the United States, namely, Indian pipe (Monotropa uniflora) and false beech-drops (M. Hypopitys) (Fig. I7I). The latter contains a glucoside or an ester of methyl salicylate, and a ferment gaultherase. 
b. ERICACE无 OR HEATH FAMILY.-This is a large family and the plants are widely distributed, especially in the northern mountainous parts of both the Eastern and Western Continent. They vary from perennial herbs to trees. The flowers are usually regular, the stamens being mostly 2-spurred (Fig. $8 \mathrm{I}, S)$, and the fruit is either a superior or inferior drupe or berry (Fig. I34, $H$ ).

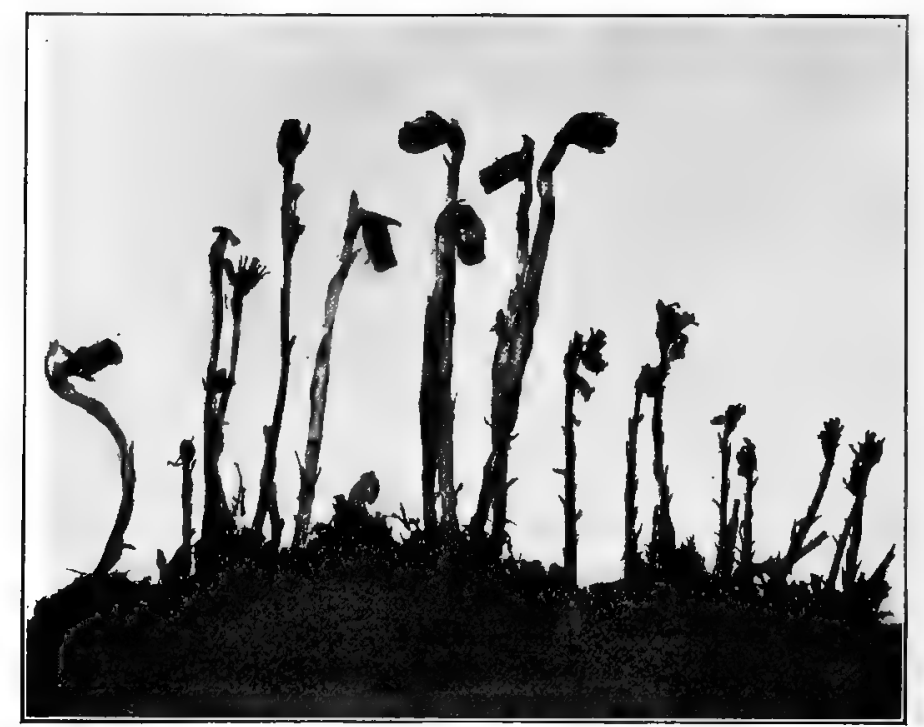

FIG. I71. A group of saprophytic higher plants (humus-plants). The taller ones at the left are Indian pipe (Monotropa uniflora), and those to the right are the false beechdrops (Monotropa Hypopitys).

Arctostaphylos Uva-Ursi is a low branching shrub which trails or spreads on the ground. The leaves are used in medicine (p. 6or). The flowers are small, white or pink, few and in short racemes. The fruit is a red, globular drupe.

Trailing arbutus (Epigea repens) is a trailing, shrubby, hairy plant with broadly elliptical or ovate, coriaceous, evergreen leaves and white or rose-colored, fragrant flowers which are either perfect, with styles and filaments of varying length, or diœcious. The leaves contain similar constituents to those in Uva Ursi and Chimaphila. 
The leaves of wintergreen (Gaultheria procumbons) are the source of true oil of wintergreen, which consists almost entirely of methyl salicylate. It contains a small quantity of an alcohol and an ester giving the characteristic odor. The same principles probably also occur in several other species of Gaultheria.

The poisonous principle andromedotoxin is found in a number of species of Rhododendron, Leucothœ, and Pieris. This principle is a powerful emetic and one of the most toxic principles known. It probably occurs in the nectar of the flowers of Kalmia and Rhododendron, being the cause of the poisonous properties of the honey from this source. The leaves of several species of laurel (Kalmia) contain considerable quantities of this principle, and are poisonous to cattle.

The plants of the genus Gaylusaccia are small shrubs distinguished by having an inferior, berry-like drupe with ten loculi. To this genus belong the huckleberries, as black huckleberry (G. resinosa) ; blue huckleberry (G. frondosa) ; and dwarf huckleberry (G. dumosa). The latter plant grows in sandy swamps in both the United States and Canada and the fruit ripens in May and June. The fruits of the other two species ripen in July and August.

The plants belonging to the genus Vaccinium vary from very small shrubs to tree-like shrubs and the fruit is an inferior. 5-locular berry with numerous seeds. The blueberries or bilberries (whortleberries) are the fruits of several species of Vaccinium. The low bush blueberry ( $V$. pcnnsylvanicum) yields the berries which ripen in June and July, while the high bush blueberry ( $V$. corymbosum) furnishes the fruits which are found in the market in July and August.

The bilberry of Europe, I acciniutm Myrtillus, a plant growing in Northern Europe and Asia and the Western United States and Canada, is said to destroy Bacillus typhosus and B. Coli, an infusion of the dried berries being used for this purpose. The leaves of this plant contain ericolin and kinic acicl.

Cranberry is the fruit of several species of Vaccinium which are sometimes grouped in a separate genus, Oxycoccus. There are two principal species: The large or American Cranberry ( $V$. macrocarpum) in which the berries are ovoid or oblong and the 
small or European Cranberry ( $I$. Oxycoccus) in which the berries are globose. The berries contain from I.4 to 2.8 per cent. of citric acid; and a bitter glucoside, oxycoccin.

\section{ORDER EBENALES.}

This order includes three families which are chiefly indigenous to the Tropics. The leaves are alternate, and the flowers vary in the different families, the fruit being a berry or drupe.

a. SAPOTACE Æ. OR SAPODILLA FAMILY.-The plants usually have a milky latex, and many of them yield GUTTAPERCHA, of which the following may be mentioned: Palaquium Gutta, $P$. oblongifolium, $P$. borneense and $P$. Treubii, all growing in the East Inclies. The latex is obtained by incising the trees and collecting the exuding juice in suitable vessels. It soon coagulates and forms grayish or reddish-yellow hard masses, which are plastic at $65^{\circ}$ to $70^{\circ} \mathrm{C}$. Owing to the fact that the material is plastic when heated and firm and tenacious when cold, it is used for a variety of purposes, as in the manufacture of surgical instruments and as a material for filling teeth. Gutta-percha as it exucles from the tree is supposed to consist of a terpene-like hydrocarbon, which on coagulation is oxidized, forming a number of resinous compounds. The plants of other genera of this family also yield gutta-percha, as Mimusops Balata, M. Elengi and about fifteen species of Payena growing in the East Indies.

A gum resembling gutta-percha is obtained from the Sabodilla tree (Achras Sapota). This gum is known in commerce as Gum CHICLE and is obtained from Yucatan. It is whitish, brittle and yet somewhat elastic, aromatic, and contains about 75 per cent. of resin. It is used in large quantities in the making of chewing gum.

The seeds of Illipe butyracea yield a fixed oil which is known as VEGETABLE BUtTER. A fixed oil is also obtained from other species of Illipe as well as various species of Bassia, Argania and Butyrospermum, that from the latter being known as "shea butter." A saponin-like substance is obtained from Omphalocarpum procerum and other plants of this family. A principle yielding hydrocyanic acid is found in the seeds of Vitellaria salicifolia and 
Payena latifolia. The bark of a number of species of Lacuma and other genera contains tannin.

The family is notable on account of the hard woods, known as IronwooDs, which it furnishes, these being yielded by Mimusops Kauki of Farther India and tropical Australia and Argania Sideroxylon of Southwestern Morocco.

A number of species also yield highly prized edible fruits, as the Sapotilla yielded by Achras Sapota indigenous to the Antilles and cultivated in tropical countries, and STAR APPLE yielded by Chrysophyllum Cainito of tropical America.

b. EBENACE E OR EBONY FAMILY.-The plants differ. from those of the preceding family in not containing a latex. The flowers are monœeious or diøecious and they usually have from two to eight styles. The chief interest is in the genus Diospyros, which yields the wood known as EBONY. Black ebony is obtained from various species of Diospyros growing in tropical Africa, and Asia, and the Philippine Islands. White ebony is obtained from several species of Diospyros growing in the Philippines. A red ebony is obtained from D. rubra of Mauritius, a green ebony from $D$. chloroxylon of Farther India, and a striped ebony from several species growing in the Philippines.

Persimmon fruit is obtained from Diospyros rirginiana, a tree growing from Rhode Island south to Texas. The astringency of the unripe fruit is due to the tannin which it contains. When it is ripe, which is not until after the appearance of frost, it is palatable and contains considerable malic acid and sugars. The Japanese persimmon is a cultivated variety of $D$. Kaki and produces a large orange-colored fruit which is not uncommon in the fruit markets in many parts of the world. At the present time the plant is cultivated in California.

The bark of our native persimmon is used in medicine. It contains considerable tannin which resembles gallotannic acid, and a crystalline resinous principle with a peculiar odor and slightly astringent taste.

c. STYRACEA OR STORAX FAMILY.-The flowers of this family somewhat resemble those of the Ebenacex, but the filaments of the stamens are united in a single series, and there is a single slender style. 
Styra.t Bensoin is a medium-sized tree with long, ovate, acuminate leaves which are very hairy on the under surface. The flowers occur in terminal racemes, and are silvery white on the outer surface and reddish-brown on the inner surface. The balsamic resin yielded by this plant is official as benzoin (p. 672).

\section{ORDER GENTIANALES OR CONTORTA.}

The plants of this order have opposite leaves, the flowers are regular and the gynæcium consists of two separate carpels. The order includes five families all of which furnish medicinal plants.

a. OLEACE E OR OLIVE FAMILY.-This family is chiefly of interest because of the olive and manna trees.

The olive tree (Olea europaa) is indigenous to the Orient and is now cultivated extensively in Southern Europe, Northern Africa, the islands of the Mediterranean, tropical America, including the Southern United States, and in California. The leaves are narrow-lanceolate, entire, coriaceous and evergreen. The flowers are small, white, diandrous and in axillary racemes. The fruit is a drupe, the sarcocarp of which is rich in a fixed oil known as olive oil. The oil is obtained by expression, and is official. Depending upon the character of the fruits and the amount of oil which they yield, over forty varieties are recognized. The trees attain a great age, some of them being known to be over a thousand years old.

Fra.tinus Ornus is a tree resembling the ash, with 7 -foliate leaves, and polygamous flowers occurring in compound racemes. The fruit is a flat samara with the wing at the apex. The saccharine exudation from this plant is official as manna (p. 649).

The white ash (Fraxinus annericana) is a valuable tree on account of the timber which it yields. The bark contains a bitter glucoside, fraxin, the solutions of which are fluorescent; a bitter substance, fraxetin ; an ethereal oil of a butter-like consistency, and tannin. Some of these principles are also found in other species of Fraxinus growing in the United States and Europe.

The bark of the fringe tree (Chionanthus virginica) of the Southern United States, contains an intensely bitter glucosidal principle, chionanthin, and possibly also saponin. 
The leaves of the garden lilac (Syringa rulgaris) contain a crystalline glucoside, syringin, and syringopicrin, both of which

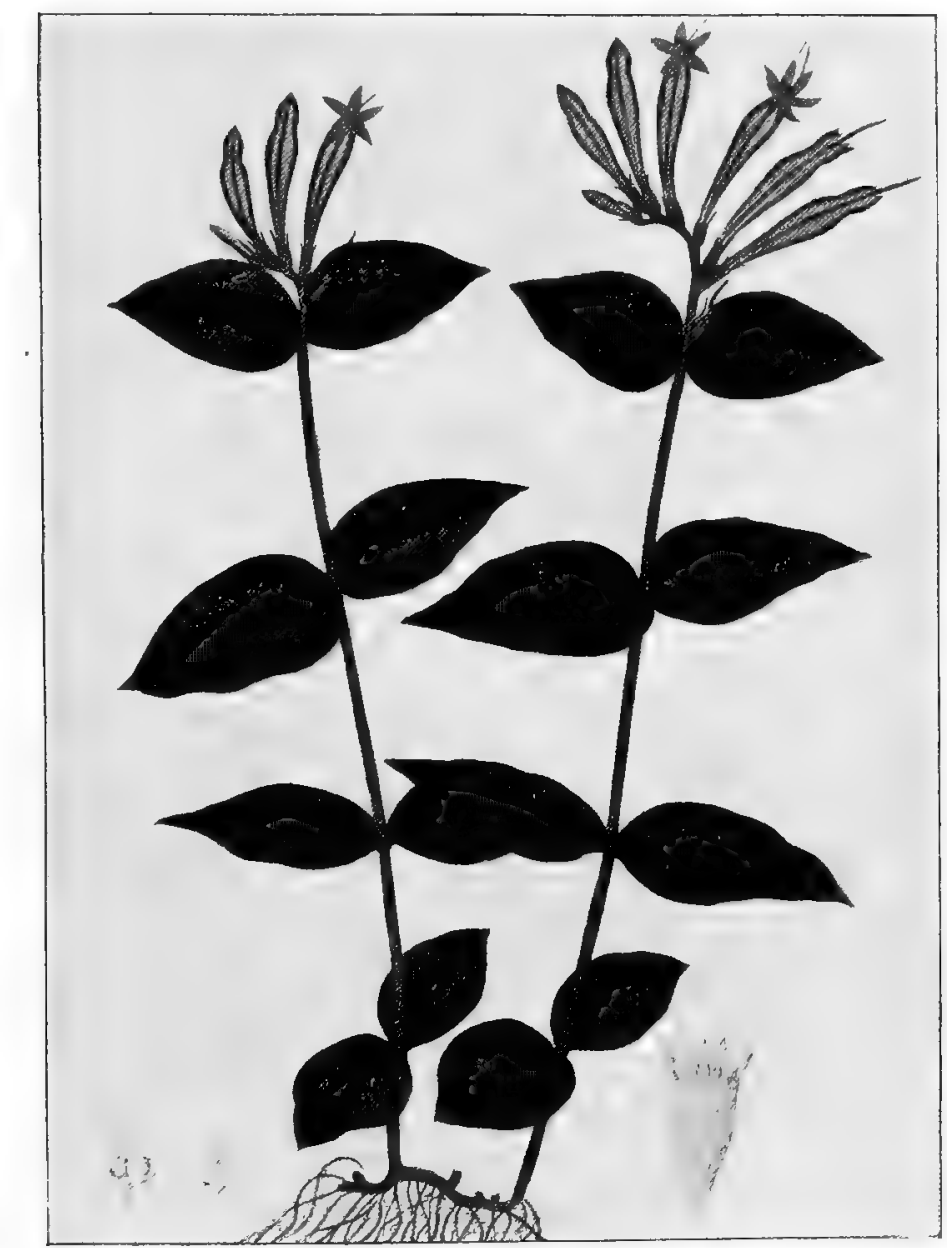

FIG. 172. Carolina pink (Spigelia marilandica) showing the rhizome bearing two branches with opposite leaves and flowers in terminal scorpioid cymes.-After Carson.

are probably also found in other species of Syringa as well as the bark and leaves of privet (Ligustrum vulgare) which latter plant is extensively used for hedges. 
b. LOGANIACEÆ OR LOGANIA FAMILY.-The plants are variable in character, being herbs, shrubs, trees or vines.

Yellow jessamine (Gelsemium sempervirens) is a twining woody vine, sometimes trailing on the ground for a considerable distance (Fig. 207). The leaves are oblong-lanceolate and evergreen. The flowers are bright yellow and dimorphic. The fruit is a septicidally dehiscent capsule. The rhizome and roots are official (p. 480 ).

Carolina pink (Spigclia marilandica) is a perennial herb with ovate-lanceolate, more or less acute and nearly sessile leaves. The flowers are yellow on the inner and scarlet on the outer surface, and occur in a I-sided spike or scorpioid cyme. The fruit is a circumscissile, 2-valved capsule (Fig. 172). The rhizome and roots are official (p. 503).

Strychnos Nux-z'omica is a small tree with broadly elliptical, $3^{-}$to 5-nerved, reticulately-veined, somewhat acuminate, coriaceous leaves. The flowers are whitish and in terminal cymes. The fruit is a berry of varying size and contains several seeds, which are official (p. 436).

CLRARE which is used by the Indians of South America as an arrow-poison is supposed to be made from the bark of Strychnos toxifera growing in Guiana, and probably other species of this genus. The active principle of this poison is the alkaloid curarine, which when administered hypodermically has a powerful action resembling that of digitalis.

c. GENTIANACE $E$ OR GENTIAN FAMILY.-The plants are mostly herbs with regular, perfect, showy flowers occurring usually in small cymes or racemes.

Yellow gentian (Gentiana lutea) is a large, perennial herb (Fig. 209) with large, 5- to 7-nerved, broadly elliptical leaves. The flowers are yellow and occur in axillary cymes. The fruit is a 2-valved, ovoid capsule. The rhizome and roots are official (p.483).

Sucertia Chirata.-The entire plant is official (p. 637).

it number of other plants of the Gentianacea contain bitter principles, including one or more species of Centaury (Erythræa) and Sabbatia, growing in the United States and Europe. Sabbatia Elliottii occurring in the pine barrens of the Southern States is known as the "quinine herb." 
d. APOCYNACEÆ OR DOGPANE FAMILY,-The plants vary from perennial herbs to shrubs and trees, contain an acrid latex, and have flowers with the stigmas and styles united and the stamens distinct. They are mostly found in the Tropics.

Apocynum cannabinum is a perennial herb with erect or ascending branches. The leaves are oblong-lanceolate, opposite, nearly sessile or with short petioles (Fig. 20I, $C, D$ ). The flowers are greenish-white, the lobes of the corolla being nearly erect and the tube about as long as thc calyx. The fruit is a slender, terete follicle containing numerous seeds tipped at the micropylar end with a tuft of hairs. The root is official (p. 467).

The root of a closely related species, namely, spreading dogbane (Apocynum androscmifolium) is sometimes substituted for the official drug. The plant is distinguished by being more spreading in its habit. The leaves are ovate (Fig. 20I, $A, B$ ), the flowers are pinkish, the lobes being revolute and the tube several times as long as the calyx.

Strophanthus Kombe.-The plant is a woody climber with elliptical-acuminate, hairy leaves. The flowers are few, characterized by long styles, and occur in axillary racemes. The fruit consists of two long follicles containing numerous awned seeds (Fig. I85), which are official (p. 430). In the closely related plant $S$. hispidus the flowers are numerous and occur in terminal cymes.

Quebracho or Aspidosperma is the bark of Aspidosperma Quebracho-blanco, a tree growing in Argentine. It occurs in nearly flat pieces which are I to $3 \mathrm{~cm}$. thick; the outer surface is yellowish-gray and deeply fissured, the inner bark being very hard and tough. It is aromatic and bitter and contains six alkaloicls, all of which are present in the commercial aspidospermine. They are aspidospermine, which is colored brown, then cherryred or purplish by sulphuric acid and potassium dichromate; aspidosamine, which is colored blue by sulphuric acid and potassium dichromate; aspidospermatine, which is colored deep red by perchloric acid like the two preceding alkaloids, but not by sulphtric acid and potassium dichromate; quebrachine, which is colored yellow by perchloric acid; and quebrachinamine, which resembles quebrachine but has a much lower melting point. The bark is used for tanning leather and yields a commercial extract. 
The leaves and bark of the cultivated oleander (Neriun Olean$d c r$ ) contain the glucoside oleandrin, resembling digitalin in its action; a fluorescent principle, and probably several other principles.

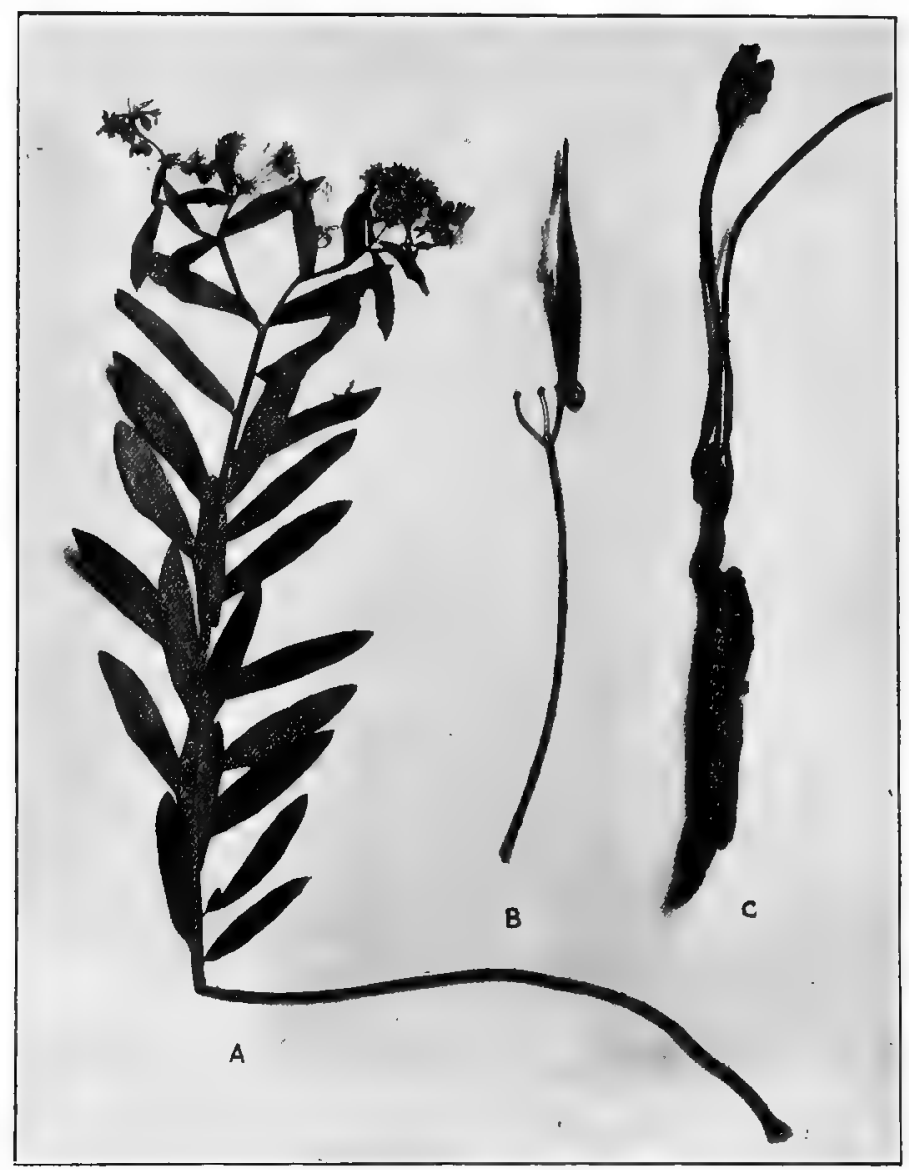

FL. 173. Asclepias tuberosa: A, simple stem with alternate leaves and terminal cymose umbels; B, fruit-branch with a dehiscent follicle; C, large tap root with young shoots.

The common periwinkle (Vinca minor) contains the principle vincin which is supposed to be a glucoside and which probably occurs in other species of Vinca. 
e. ASCLEPIADACEÆ OR MILKWEED FAMILY.-The plants somewhat resemble those of the Apocynaceæ. The flower, however, is distinguished by having distinct styles, a 5 -lobed corona connecting the corolla and stamens, which latter are mostly monadelphous, and pollen grains that are coherent, forming characteristic pairs of pollinia. It is rather remarkable that while this family contains a large number of plants that are used in medicine none of them are official. Pleurisy Root, which was formerly official, is obtained from Asclepias tuberosa, a plant growing in the Eastern United States and one of the two members of this genus that have orange-colored flowers. The root is more or less fusiform (Fig. I73), about I or $2 \mathrm{~cm}$. thick, and is usually cut into longitudinal pieces. In the dried condition it is light brown externally, more or less irregular, with a tough fracture and a bitter, slightly acrid taste. The active principle is the glucoside asclepiadin. A similar principle is found in the root of other species of Asclepias.

Condurango is the bark of Marsdenia Cundurango, a liane of Ecuador and Columbia. It occurs in quilled pieces, the bark being from 2 to $6 \mathrm{~mm}$. thick. Externally it is brownish-gray and with a more or less scaly cork. The taste is bitter, acrid and aromatic. The drug contains two or three glucosides and a resinous substance.

\section{ORDER POLEMONIALES OR TUBIFLOR 2 .}

This is a large order of plants, which are mostly herbaceous. The leaves are either opposite or alternate; the flowers are regular or irregular, the stamens being usually adnate to the corolla.

a. CONVOLVULACE $Æ$ OR MORNING-GLORY FAMILY.-The plants are mostly herbs or shrubs, frequently twining (to the left). They are found mostly in the Tropics, but quite a number of genera occur in temperate regions (Fig. I74).

Exogonium Purga is a perennial twining herb with distinctly veined, cordate leaves; purple flowers with the stamens exserted. and occurring in cymes. The fruit is a 2 -locular capsule. The plants produce slender rhizomes with tuber-like roots, these being used in medicine (p. 45 I). 
Contolitulus Scammonia is a peremnial twining herb, with a large tap root, containing a resinous latex, and is the source of the official scammony (p. 656). The leaves are sagittate; the flowers are large, yellowish-white and funnel-form, as in the morning-glory, and occur in the axils of the leaves, either solitary or in clusters. The fruit is a 4 -seeded, 4 -locular, dehiscent capsule.

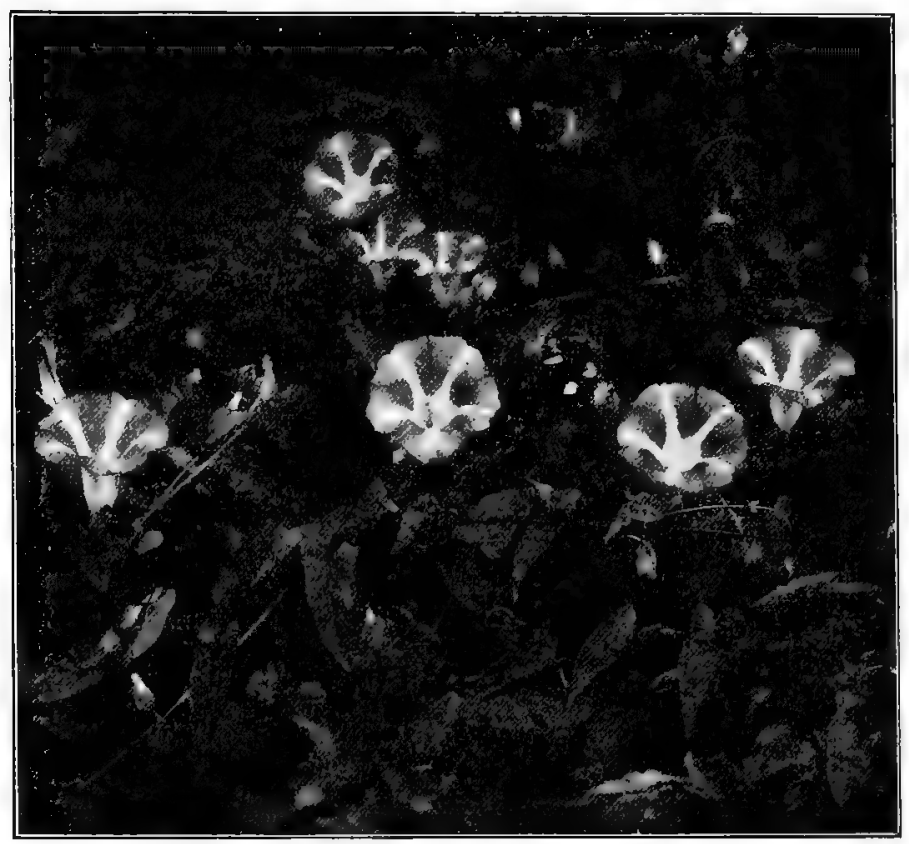

FIG. 174. Great bind weed (Convolvulus sepium) showing trailing or twining habit, the hastate leaves and funnel-shaped corolla. The plant is very resistant to noxious fumes and is usually found in smelter regions.

A number of the plants of the Convolvulaceæ are cultivated, probably the most important of which is the SIIEET POTATO vine (Ipomca Batatas), a plant extensively cultivated in tropical and sub-tropical countries on account of the edible tuberous roots. The roots contain from 3 to Io per cent. of sugar and 9 to 15 per cent. of starch, which occurs in larger proportion in plants grown in sub-tropical countries. The starch is a commercial product and is known as sweet-potato starch or BRAZILIAN ARROW-ROOT. 
The grains are more or less bell-shaped and 2 - or 3 -compound, about the size of wheat-starch grains, and in other ways resemble those of tapioca.

To this family also belongs rather an interesting group of parasitic plants, namely, dodder (Cuscuta). They contain the principle cuscutin, and quite a number have been used in medicine.

b. HYDROPHYLLACE $F$ OR WATERLEAF FAMILY. The plants are herbs or shrubs which are indigenous to Western North America. Very few of the plants of this family are of use medicinally, although quite a number are ornamental plants.

Eriodictyon californicum (E. glutinosum) or Yerba Santa is a shrub growing in Northern Mexico and California. The leaves are official (p. 6r2). The flowers are funnel-form, white or purple, occurring in cymes. The fruit is a dehiscent capsule and the seeds are small and few.

c. BORAGINACE $\approx$ OR BORAGE FAMILY.-The plants are mostly herbs with regular blue flowers, occurring in scorpioid inflorescence. The best examples of the group are the forget-me-not (Myosotis), the roots of several species of which have been used in medicine; and the garden heliotrope ( Hcliotropum peruzianum), the fragrance of the flowers being due to a volatile oil. This plant, as well as other species of Heliotropum, contains a poisonous volatile alkaloid.

At one time considerable interest attached to ALKANET, the root of Alkanna tinctoria of Southern Europe and Asia, on account of the red coloring principle alkannin, which is soluble in alcohol, ether, fixed and ethereal oils, but insoluble in water. Comfrey or symphytum is the root of Symphytum officinale and other species of this genus naturalized from Europe in waste places in the United States. It occurs on the market in small, purplishblack, more or less curved pieces, which are quite mucilaginous and astringent to the taste. The drug contains a gluco-alkaloid, consolidin, and an alkaloid, cynoglossine. It also contains a small amount of dextrin-starch, i.c., one which is not colored blue with iodine, and tannin. The root and herb of Hound's tongue ( $C$ y'noglossum officinale) are both used in medicine. The drug contains the powerful alkaloid cynoglossine, which resembles curarine in its action; and the gluco-alkaloid, consolidin. 
d. VERBENACE E OR VERVAIN FAMILY.-The plants are chiefly herbs or shrubs with usually opposite or verticillate leaves and more or less irregular flowers.

To this family belongs the group of verbenas, some of which are used in medicine, as blue vervain (Verbena hastata), which resembles eupatorium in its medicinal properties; nettle-leaved vervain ( $L$. urticifolia) which contains a bitter glucoside. The drug LIPPIA MEXICANA consists of the leaves of Lippia dulcis mexicana, and contains a volatile oil, the camphor lippiol, tannin and quercetin. Lippia citriodora, found growing in the central part of South America, contains a volatile oil, of which citral is a constituent. TEAK-WOOD, which is one of the hardest and most valuable of woods, is derived from the teak tree (Tectona grandis), a large tree indigenous to Farther India and the East Indies.

e. LABIAT E OR MINT FAMILY.-The plants are mostly aromatic herbs or shrubs, with square stems, simple, opposite leaves, bilabiate flowers and a fruit consisting of four nutlets. The calyx is persistent, regular or 2-lipped and mostly nerved. The corolla is mostly 2-lipped, the upper lip being 2-lobed or entire, and the lower mostly 3 -lobed. The stamens are adnate to the corolla tube, and are either 4 and didynamous, or 2 perfect and 2 aborted. The ovary is deeply 4-lobed (Fig. I34, I).

The Labiatæe are especially distinguished on account of the volatile oils which they yield and a few contain bitter or glucosidal principles.

I. The following PL.INTS ARE OFFICLIL:

Scutellaria lateriflora (skullcap). The entire plant is official. (See page 638.) The plant is a perennial herb producing slender stolons somewhat resembling those of peppermint and spearmint. The stems are erect or ascending, commonly branching and from 22 to $55 \mathrm{~cm}$. high.

.lYarrubium inlgare (white hoarhound) is a perennial woolly herb with ascending branches, the leaves and flowering tops being official (p. 628).

Salitia officinalis or garden sage is a perennial, somewhat shrubby, pubescent herb. The leaves are official (p. 6I2). The flowers are bluish, somewhat variegated, the calyx and corolla 
both being deeply bilabiate. Only the two anterior stamens are fertile (bear anthers); the connective is transverse, the upper end bearing a perfect pollen-sac and the lower, a somewhat enlarged rudimentary pollen-sac, while the posterior pair of sta-

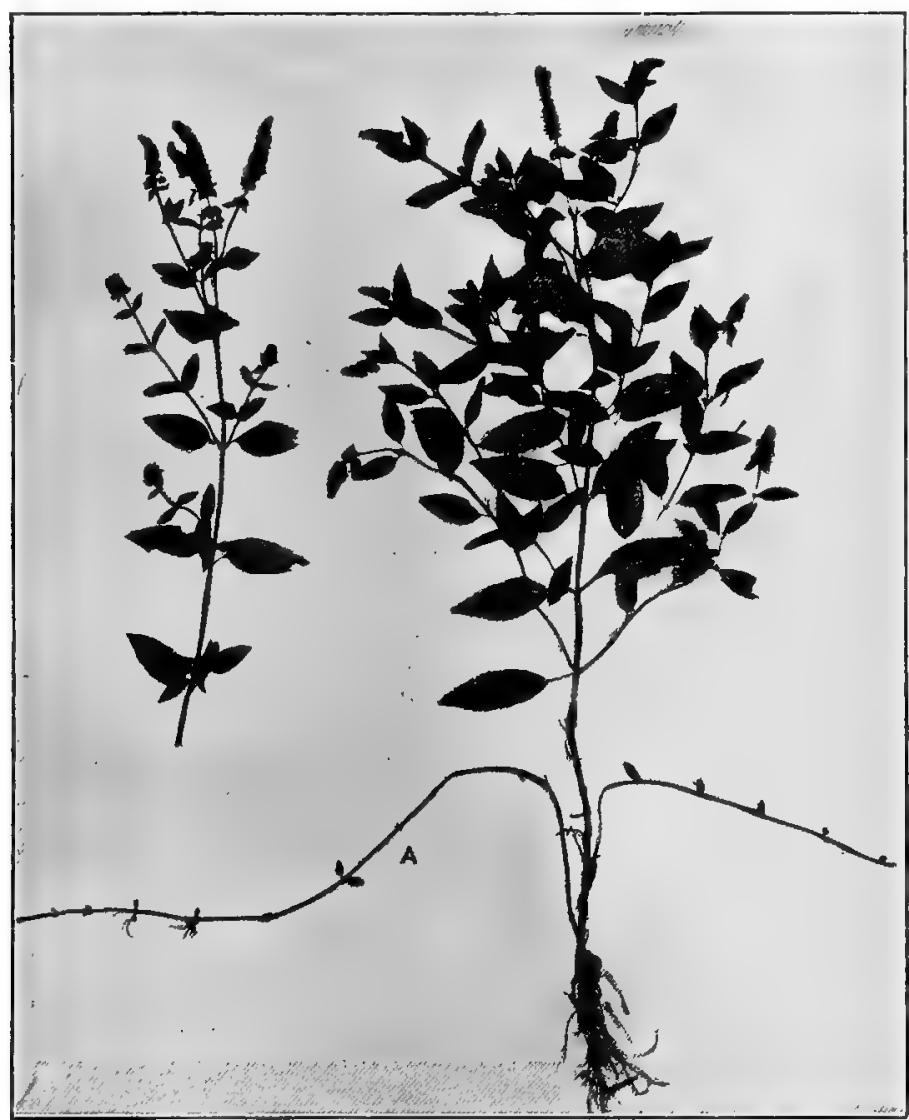

FIG. 175. Peppermint (Mentha plpertia) showing the stolons (A), the opposite petiolate leaves and the spikes with crowded flowers.

mens are entirely rudimentary (Fig. $84, F$ ). The nutlets are eggshaped, 3-angled, smooth and have an outer mucilaginous layer.

Hedeoma pulegioides (American pennyroyal) is an annual herb (Fig. 27I) with a slender, erect stem and numerous ascending branches. The leaves and flowering tops are official (p. 628). 
Mentha species.-The plants are nearly glabrous, diffusely branching herbs, which form leafy stolons that are perennial (Figs. 67, I75). The leaves and flowering tops of both Mentha piperita (p. 631) and Mentha spicata (p. 632) are official.

2. Volatile orls of the following plants are official:

Rosmarinus officinalis is a shrub growing in the Mediterranean countries. The plant has linear, coriaceous leaves, and bluish, bilabiate flowers, the middle lobe of the lower lip of the corolla being large, concave, and toothed on the margin. The flowering tops yield from I to $\mathrm{I} .5$ per cent. of oil which is composed of I5 to I8 per cent. of borneol; about 5 per cent. of bornyl acetate; and pinene, camphene, camphor and cinneol. There are two commercial varieties of the oil, the Italian and French, the latter having the finer odor.

Lavandula officinalis (garden lavender) is a shrub growing in the Northern Mediterranean countries, as well as in England. The leaves are linear, coriaceous; the flowers are small, light blue, bilabiate, with a tubular calyx, and occur in opposite cymes (verticillasters).

The oil is derived from the fresh flowering tops, the flowers yielding about 0.5 per cent. Two kinds of oil are on the market, namely, French and English. The French oil contains 30 to 45 per cent. of 1-linalyl acetate; linalool; geraniol, both of which latter constituents occur free and as esters. The English oil contains about 5 to Io per cent. of linalyl acetate and a slight amount of cineol. Spike lavender (Lariendula Spica) is sometimes distilled with true lavender (p. $37 \mathrm{I}$ ).

Thy'nuts z'ulgaris (garden thyme) is a small shrub having linear or linear-lanceolate leaves, and pale blue flowers with strongly bilabiate, hairy calyx that occur in axillary cymes. The plant grows in the mountains of Southern France. The herb contains from 0.3 to 0.9 per cent. of volatile oil, which is of a dark reddish-brown color, and contains from 20 to 25 per cent. of thymol; and cymene, 1-pinene, borneol and linalool. The Spanish oil of thyme contains from 50 to 70 per cent. of carvacrol, but no thymol.

3. Of Other plants OF the LABIATA which are of interest, the following may be mentioned: 
Laz'andula spica yields oil of spike, which has an odor of lavender and rosemary. The oil contains camphor, borneol, cineol, linalool and camphene.

Origanum majorana (Sweet marjoram) is an annual cultivated herb that has more or less oval, entire leaves, white flowers and an aromatic odor and taste. It produces a volatile oil which contains terpinene and d-terpineol. Origanum ''ulgare (Wild marjoram) grows in fields and waste places in the Eastern United States and Canada. The calyx is equally 5-toothed and the corolla varies from white to pink or purple. It contains a volatile oil having an odor somewhat like that of the oil of O. majorana. Origanum hirtum and $O$. Onites yield an origanum oil containing carvacrol and cymene. The oils obtained from Cretian Origanum are the source of commercial carvacrol.

Pogostemon Patchouli, a plant cultivated in Southorn China and the East and West Indies, furnishes the oil of P.stchouli used in perfumery. Patchouly camphor and cadinene have been isolated from the oil, but nothing, however, appears to be known of the nature of the odorous principle.

Hyssopus officinalis (Garden hyssop) contains about 0.5 per cent. of a volatile oil to which the characteristic odor of the plant is due. Satureja hortensis (summer savory) yields a volatile oil containing carvacrol, cymene and terpene. Ocimum basilicun (Sweet basil) is an herb growing in Europe, and yields an oil which is used in the preparation of Chartreuse and sinilar liquors. The oil contains methyl chavicol, linalool, cineol, camphor, pinene and terpin hydrate.

Melissa officinalis (Sweet balm) is a perennial herb indigenous to Europe and Asia and also cultivated. The leaves are ovate, dentate, and the flowers are bilabiate, the calyx being bell-shaped and I3-nerved. The taste is bitter, this being due to a bitter principle. The fresh leaves are quite aromatic and produce from o.I to 0.25 per cent. of a volatile oil containing a stearoptene.

Several species of Monarda known as HORSEMINT or wild bergamot are used in medicine. The oil was at one time official. The oil of Monarda punctata, a perennial herb found growing from New York to Texas, contains thymol, thymoquinone, hydrothymoquinone, carvacrol, cymene and limonene. 
Nepeta Cataria (catnip) is a perennial herb naturalized in the United States from Europe (Fig. 74). It contains a bitter principle, tannin, and an oxygenated volatile oil. Glecoma hcdcracea or GROUND IVY is a creeping perennial herb with blue bilabiate flowers and reniform, crenate leaves. It contains a bitter principle and volatile oil. Cunila origanoides or American DitTANY, is a small perennial herb growing from New York to Florida, and characterized by its pungent aromatic properties.

Leomurus Cardiaca or MOTHERIIORT is a perennial herb naturalized in the United States and Canada from Europe. The leaves are 3 -lobed; the calyx is 5-nerved and with 5 prickly teeth; the corolla varies from white to pink or purple. The plant contains a volatile oil of rather an unpleasant oclor; a bitter principle; two resins and several organic acids, namely, malic, citric and tartaric.

f. SOLANACE $E$ OR POTATO FA.MILY.-The family inclucles herbs, shrubs, trees and vines, which are most abundant in tropical regions. The leaves are alternate and vary from entire to dissected. The flowers are mostly regular, except in hyoscyamus. The stamens are adnate to the corolla tube, the anthers connivent and the pollen-sacs apically or longitudinally dehiscent. The fruit is a berry or capsule in which the sepals mostly persist and sometimes become enlarged or inflated. The seeds have a large reserve layer and the embryo is frequently curved.

Datura Stramonium (Jimson weed) is a large, annual, branching herb (Fig. 269), found in waste places in the United States and parts of Canada, being naturalized from Asia. The leaves and flowering tops are official (p. 622). The large, spiny capsule is shown at Fig. 89, B. The seeds are described on page 624 .

Atropa Belladonna (Deadly nightshade) is a perennial herb producing a large fleshy root, which is used in medicine (p. 463), as are also the leaves and flowering tops (Fig. 268, p. 620).

Scopolia carniolica is a perennial herb with nearly entire or somewhat irregularly toothed leaves. The flowers are campanulate and dark purple. The fruit is a globular. transversely dehiscent capsule (pyxidium). The rhizome is official (p. 509).

Hyoscyamus niger or henbane is a biennial herb (Fig. 267), the leaves and flowering tops of which are official (p. 6i7). 
Pichi is the dried leafy twigs of Fabiana imbricata, a shrub with small, scale-like leaves, indigenous to Chile. It contains a volatile oil; O.I per cent. of a bitter alkaloid; a glucoside resembling æsculin; and a bitter resin.

Solanum Dulcamara (Bitter sweet) is a perennial, climbing herbaceous plant (Fig. 176), indigenous to Europe and Asia and

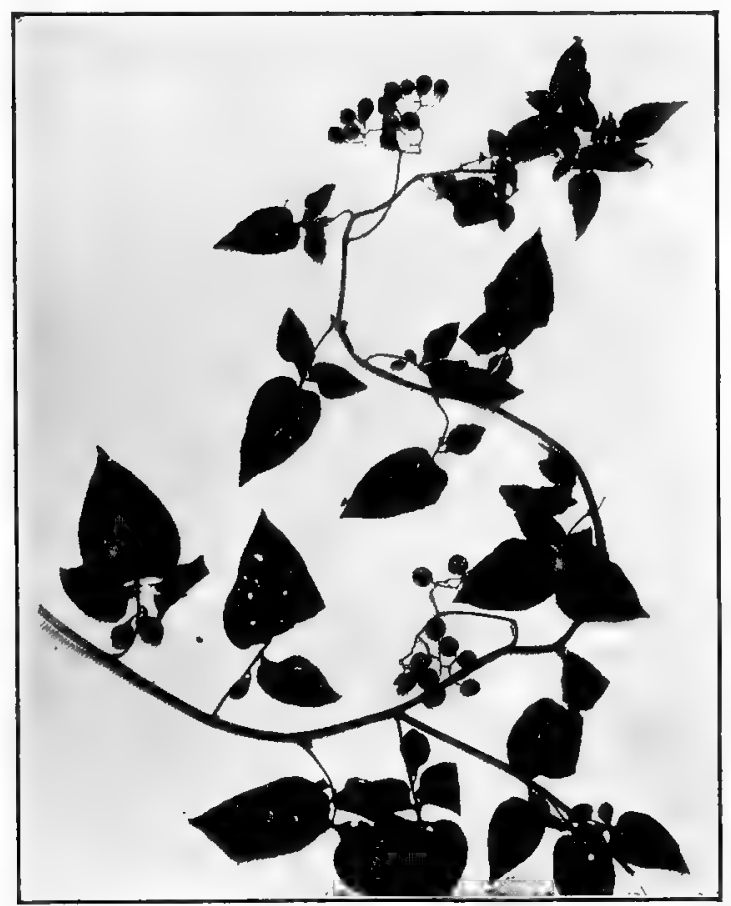

FIG. 176. Bitter sweet (Solanum Dulcamara), a climbing ،ine showing the peculiar 3-divided leaves with large terminal segment, and cymose clusters of berries.

naturalized in the Northern United States. The young branches were formerly official as Dulcamara. The branches which have hegun to develop periderm are collected and cut into pieces Io to $20 \mathrm{~mm}$. long. The pieces are somewhat angular, greenish-brown, hollow, of a slightly narcotic odor and a sweetish, somewhat bitter taste. The drug contains a bitter glucoside, dulcamarin, and the gluco-alkaloid solanine. 
Solanum carolinense (Horse nettle) is a perennial herb having numerous yellow prickles on the branches and leaves. The leaves are oblong or ovate, irregularly lobed (Fig. I76a). The flowers

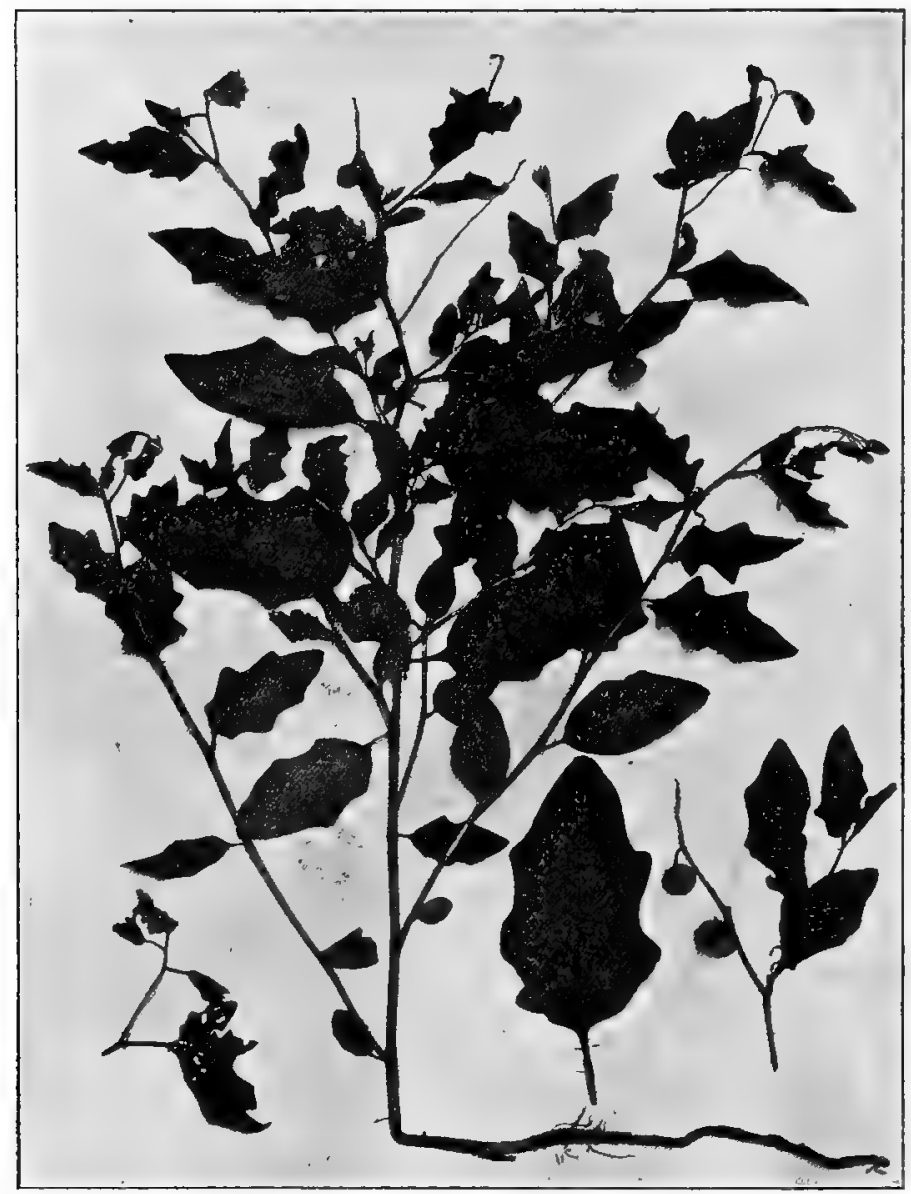

FIG, I76a. Horse nettle (Solanum carolinense) showing the prickly, repand or lobed, leaves and the small globular berries.

are white or light blue and occur in lateral cymes. The fruit is an orange-yellow, glabrous berry. The plant is common in waste places in Canada and the United States east of the Mississippi. 
The root and berries are used in medicine. The root is simple and quite long, 5 to $10 \mathrm{~mm}$. in diameter, yellowish-brown, the bark readily separating from the wood. It has a narcotic odor and a sweetish, bitter, somewhat acricl taste. Both the root and berries contain the gluco-alkaloid solanine, which varies from 0.I 5 (in the root) to 0.8 per cent. (in the berries).

Capsicum fastigiatum (Cayenne pepper) is a perennial, smooth, herbaceous, or somewhat shrubby plant, with ovate, acuminate, petiolate, entire leaves; the flowers are greenish-white, and solitary in the axils of the leaves. The fruit is official and is known in commerce as African pepper (p. 578). This plant and a number of other species of Capsicum are indigenous to tropical America, where they are extensively cultivated, as also in Africa and India.

Nicotiana Tabacum. (Virginia Tobacco plant) is a tall annual herb indigenous to tropical America and wiclely cultivated. The stem is simple, giving rise to large, pubescent, ovate, entire, decurrent leaves, the veins of which are prominent and more or less hairy. The flowers are long, tubular, pink or reddish, and occur in terminal spreading cymes. The various forms of tobacco are made from the leaves, which are hung in barns, whereby they undergo a slow drying or process of curing. Other species of Nicotiana are also cultivated, as N. persica, which yields Persian tobacco; and N. rustica, the source of Turkey tobacco. Tobacco leaves contain from 0.6 to 9 per cent. of the alkaloid nicotine; an aromatic principle nicotianin or tobacco camphor, to which the characteristic flavor is due and which is formed during the curing of the leaves. The dried leaves yield from I4 to I5 per cent. of ash, consisting in large part of potassium nitrate.

Solanum tuberosum (Potato plant) is indigenous to the Andes region of South America and is extensively cultivated on account of the edible tubers. The tubers (potatoes) contain about 75 per cent. of water, 20 per cent. of starch, and nearly 2 per cent. of proteids in the form of large protein crystalloids. The fruits and young shoots contain the gluco-alkaloid solanine and the alkaloid solanidine. The tubers contain a small amount of solanine, which is increased when they are attacked by certain fungi or exposed to light. 
Besides the potato plant, several other plants belonging to the Solanaceæ yield vegetables, as the Tomato plant. (Solanum Lycopersicum) and the Egg plant (Solanum Melongena). Various cultivated species of Capsicum annumm furnish the common red peppers of the market.

g. SCROPHULARIACE $\approx$ OR FIGWORT FAMILY.The plants are herbs, shrubs or trees with opposite or alternate leaves and perfect, mostly complete and irregular flowers. The corolla and stamens show some resemblance to those of the Labiatæ in that the corolla is frequently more or less 2-lipped and the stamens are didynamous. The fruit is a dehiscent capsule and the seeds have a reserve layer and a straight or slightly curved embryo.

Leptandra rirginica (Veronica virginica) or Culver's root, is a perennial herb with leaves in whorls of 3 to 9 , those on the upper part of the stem being opposite. They are lanceolate, serrate, and pinnately veined; the flowers are white or bluish, tubular, and in dense racemes. The rhizome and roots are official (p. 50I).

Digitalis purpurea (Foxglove) is a tall, biennial, pubescent herb, producing the first year a large number of basal leaves: (Fig. 265), and the second, a long raceme of drooping, tubular. slightly irregular, purplish flowers; the inner surface of the corolla is spotted, the stamens are didynamous and the upper calyx segment is narrower than the others. The leaves are official in all the pharmacopoeias (p. $6 \mathrm{r}_{3}$ ).

The Scrophulariaceæ are well represented in the United States, and a number of the plants have medicinal properties. The common MULLein (Verbascum Thapsus) contains a volatile oil, two resins and a bitter principle. The flowers of mullein contain the same principles and in addition a yellow coloring principle. Other species of Verbascum are used in medicine in different parts of the world.

BUTTER-AND-EGGS (Linaria onlgaris) contains a crystalline principle, linariin, antirrhinic acid, a volatile oil, resin and tannin. Several species of Scrophularia, as $S$. nodosa of Europe and $S$. marilandica of the Eastern United States, contain a pungent resin and a trace of an alkaloid. TuRTLE-HEAD (Chelone glabra) contains a bitter principle and gallic acid. The entire plant of 
HySSOP (Gratiola officinalis) of Europe contains gratiolin, a bitter glucoside, and gratiosolin. The leaves of Curanga amara of the East Indies contain a glucoside, curanjiin, which resembles digitalin in its action.

h. BIGNONIACE $\nRightarrow$ OR TRUMPET-CREEPER FAMILY.-The plants are shrubs, trees or woody vines, and are represented in the United States by the catalpa tree (Catalpa bignonioides) and the trumpet creeper (Tecoma radicans). The bark, pods and seeds of CATALPA have been used in medicine and contain a bitter principle, catalpin, a glucoside and several crystalline principles. The TRUMPET CREEPER contains narcotic poisonous principles. The leaflets of CARoBa (Jacaranda Copaia), and other species of Jacaranda contain the alkaloid carobine, an aromatic resin, carobone and a principle having the odor of coumarin.

i. PEDALIACE $Æ$.-The plants are herbs incligenous to the Tropics of the Old World, some of which are now cultivated in the Tropics of both hemispheres. Benne oil (oil of sesame) is obtained from the seeds of Sesamum indicum by expression. It consists chiefly of a glycerite of oleic acid, a glycerite of linoleic acid, and myristin, palmitin and stearin. It is a bland, non-drying oil and is used like olive oil.

j. ACANTHACE E OR ACANTHUS FAMILY.-The plants are mostly tropical perennial herbs, or shrubs with opposite leaves, in the mesophyll or epidermal cells of which cystoliths usually occur (Fig. 22I). Several genera are represented in the United States, one of which, Ruellia (Rucllia ciliosa), is the source of the spurious spigelia which has been on the market for some years past (p. 504).

Ruellia ciliosa is a perennial herb which is distinguished from the other species of the genus Ruellia by the leaves, stems and calyx being distinctly pubescent. The leaves are ovate-lanceolate, nearly sessile and entire; the flowers are blue, sessile, solitary, or two or three in a cluster, in the axils of the leaves; the stamens are 4 , and exserted. The fruit is an oblong, terete capsule containing from 6 to 20 orbicular seeds. The plant is found from New Jersey and Pennsylvania to Michigan and as far south as Florida and Louisiana. Long cystoliths are found in some of the epidermal cells of both surfaces of the leaf. 
Quite a number of the plants of the Acanthacex are used in the Tropics in medicine. One of these, Adhatoda vasica of tropical Asia, contains the alkaloid vasicine, and is said to have the property of destroying algæ which grow in the rice swamps.

k. PLANTAGINACE E OR PLANTAIN FAMILY.-The plants are annual or perennial herbs, represented by but few genera, but numerous species. The principal genus is Plantago, which includes 200 species that are widely distributed. Several species of Plantago are used in medicine. The common plantain (Plantago major) contains a bitter principle and a resin. The short rhizome contains considerable starch. The seed-coat has an outer mucilaginous layer, and the mucilage of the seeds of Plantago psyllitm, $P$. arenaria (both of Europe) and P. ispaghul (of the East Indies) is used as a sizing material. The seeds of a number of the species of Plantago are used as bird food, particularly for canaries.

\section{ORDER RUBIALES.}

The plants of this order are distinguished from all of the preceding Sympetalæ by having flowers which are distinctly epigynous. The leaves are opposite or verticillate.

a. RUBIACE E OR MADDER FAMILY.-The plants are herbs, shrubs or trees, and of the representatives found in the United States the following may be mentioned: Bluets (Houstonia species), Partridge-berry (Mitchella repens) and Bedstraw (Galium species). In Mitchella and Houstonia the flowers are dimorphic.

Cinchond species.-The plants are mostly trees, or rarely shrubs, with elliptical or lanceolate, entire, evergreen, petiolate, opposite leaves (Fig. I77). The flowers are tubular, rose-colored or yellowish-white, and occur in terminal racemes. The fruit is a capsule, which dehisces into two valves from below upward, the valves being held above by the persistent calyx. The seeds are numerous and winged. There are from 30 to 40 species of Cinchona found growing in the Andes of South America at an elevation above $800 \mathrm{M}$. and in a restricted area about 500 miles in length extending from Venezuela to Bolivia. The plants are 
cultivated in Java, Ceylon, New Zealand and Australia, as well as in Jamaica.

There are two species which furnish the Cinchona bark ( $p$. 517) of medicine: (I) Cinchona Ledgeriana (C. Calisaya Ledgcriana), which has small, elliptical, coriaceous leaves, the under surface of which is reddish; small, yellowish, inodorous flowers, and a short capsule; (2) C. succirubra which has large, thin, broadly-elliptical leaves, purplish-red calyx, rose-colored petals and

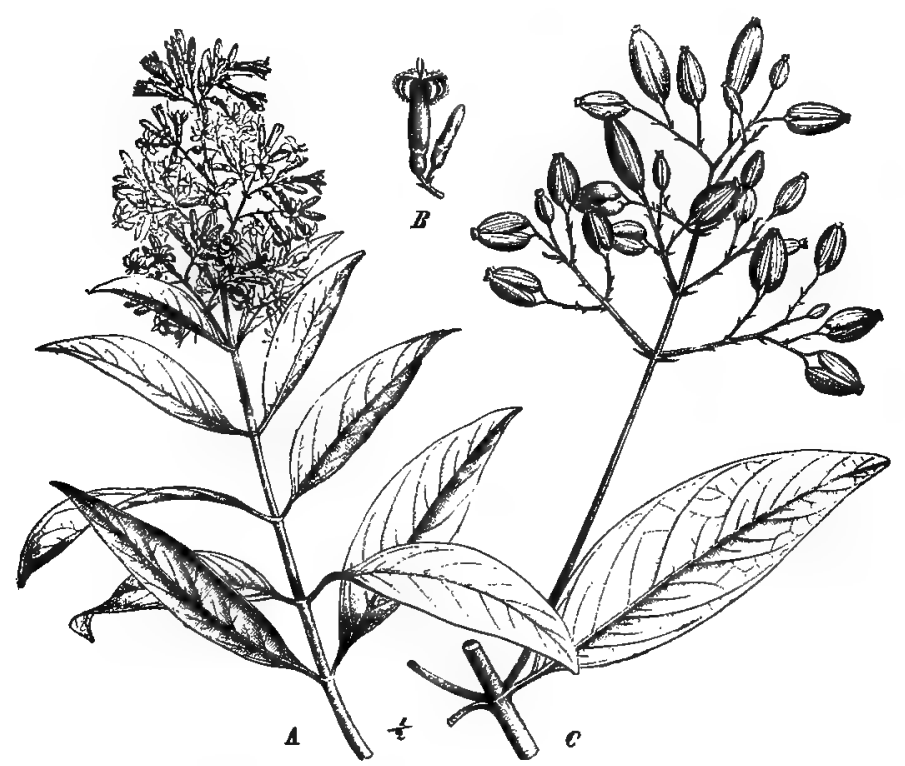

FIG. 177. Cinchona Ledgeriana: A, flowering branch; B, bud and open flowerC, fruiting branch.-After Schumann.

a very long capsule. While $C$. Ledgeriana yields barks containing the highest amount of alkaloids, $C$. succirubra is most cultivated.

Uragoga (Cephälis) Ipecacuanha.-The plants are perennial herbs 10 to $20 \mathrm{~cm}$. high, with a creeping, woody, hypogeous stem. The roots are official in all of the pharmacopœias (p. 467). The leaves are elliptical, entire, short-petiolate, and with divided stipules (Fig. I78). The flowers are white and form small terminal heads. The fruit is a blue berry, with characteristic spiral arrangement of the carpels. 
Coffea arabica is a small evergreen tree or shrub with lanceolate, acuminate, entire, slightly coriaceous, dark green, shortpetiolate leaves, which are partly united with the short interpetiolar stipules at the base. The flowers are white, fragrant, and occur in axillary clusters. The fruit is a small, spherical or ellip-

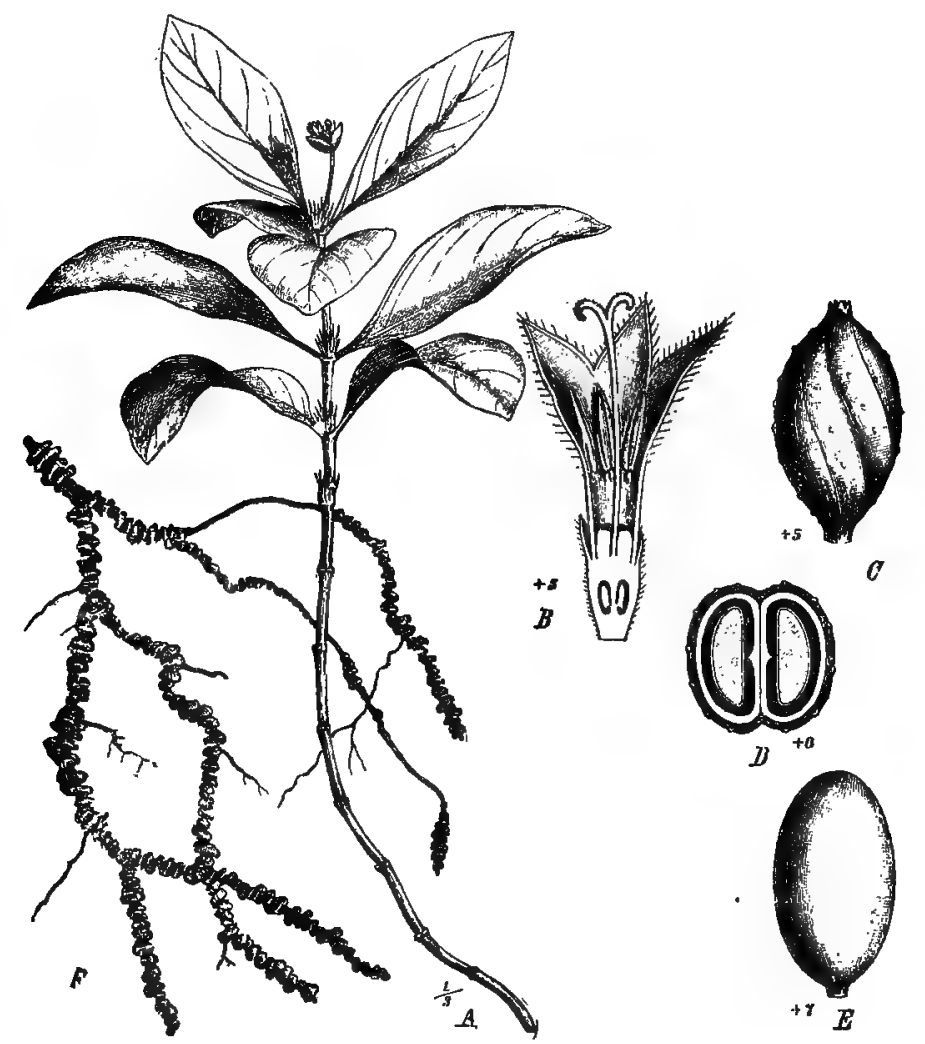

FIG. 178. Ipecac plant [Cephaëlis (Uragoga) Ipecacuanha]: A, flowering shoot; B, flower in longitudinal section; C, fruit; $D$, fruit in transverse section; $E$, seed; $F$, annulate root.-After Schumann.

soidal drupe with two locules, each containing one seed, or COFFEe GRAIN. The coffee plant is indigenous to Abyssinia and other parts of Eastern Africa, and is widely cultivated in tropical countries, notably in Java, Sumatra. Ceylon and Central and South America, particularly Brazil, over 600,000 tons being produced 
annually in the latter country. The yield of one tree is between I and 12 pounds. There are two methods of freeing the seeds from the parchment-like endocarp: In the one case the fruits are allowed to dry and are then broken; in the other case, which is known as the wet method, the sarcocarp is removed by means of a machine, and the two seeds with the parchment-like endocarp are allowed to dry in such a manner as to undergo a fermentation, and after drying the endocarp is removed. Coffee seeds contain from I to 2 per cent. of CAFFEINE; from 3 to 5 per cent. of tannin; about 15 per cent. of glucose and dextrin; Io to 13 per cent. of a fatty oil consisting chiefly of olein and palmitin; Io to $\mathrm{I} 3$ per cent. of proteids; and yield 4 to 7 per cent. of ash. The official caffeine is derived in part from coffee seeds.

In the Rotsting of coffee there is a change in the physical character of the seeds, as well as a change in some of the constituents. The AROMA is supposed to be due to an oil known as coffeol, which is said to be a methyl ether of saligenin.

Ourouparia Gambir is a liane climbing by means of hooks. The leaves are ovate or oblong and coriaceous, with linear recurved, interpetiolar stipules. The flowers are white, silky, and arranged in single, axillary heads, like those in the button bush (Cephalanthus occidentalis). The fruit is a 2-valved, dehiscent capsule with persistent calyx. The seeds are numerous and have several filiform appendages. It yields Gambir (p. 666).

A number of the Rubiacex contain valuable coloring principles, as the madder plant (Rubia tinctorum), which is a perennial herb occurring wild in Southern Europe and formerly cultivated in France and Germany on account of the coloring principle in its roots. The root is known commercially as MADDER, and contains when fresh a yellow coloring principle, which on the drying of the root breaks up into several glucosides, one of which on further decomposition yields ALIZARIN, the principle to which the red color of the dried root is due. At present alizarin is made artificially from anthracene, a coal-tar derivative, and hence the demand for madder has declined.

Morinda citrifolia, a shrub widely distributed in tropical countries, contains a red coloring principle in the flowers and a yellow coloring principle in the roots, the latter being known as morindin 
and resembling the color principle in madder. The wood of Morinda is not attacked by insects, and the same is said of clothing dyed with the extract of the roots.

The pulp of the fruit of Cape jasmine (Gardenia jasminoides) contains a yellow coloring principle resembling crocin, found in Crocus.

The stem and root barks of Button-bush (Cephalanthus occidentalis) common in swampy regions in the United States, are sometimes used in medicine. The barks contain a bitter glucoside, cephalanthin, and a tasteless glucoside which is fluorescent in solution. Mitchella repens contains a saponin-like body in the fruit and a tannin and bitter principle in the leaves. Quite a number of species of Galium (bedstraw) are used in medicine and for other purposes. A principle resembling glycyrrhizin is found in wild licorice (Galium circazans), a perennial herb growing in dry woods in the United States, and also in Galium lanceolatum, which is found from Virginia northward to Ontario. The yellow bedstraw (Galium z'crum), naturalized from Europe, contains a milkcurdling ferment.

b. CAPRIFOLIACE E OR HONEYSUCKLE FAMILY.The plants are perennial herbs, shrubs, trees, or woody climbers with opposite, simple or pinnately compound leaves. The flowers are perfect, epigynous, regular, or bilabiate, and arranged in corymbs. The fruit is a berry, drupe or capsule. They are mostly indigenous to the northern hemisphere.

Viburnum prunifolium (Black haw) is a shrub or small tree $25 \mathrm{~cm}$. in diameter. The winter buds are acute and reddishpubescent; the leaves are ovate, elliptical, obtuse or acute at the apex, somewhat rounded at the base, finely serrulate, glabrous and short-petiolate (Figs. I79, 230); the flowers are white and in nearly sessile cymes; the fruit is a small, oval, bluish-black, glaucous, inferior drupe. The root-bark is official (p. 525).

I'iburnum Opulus (Wild guelder-rose or cranberry-tree) is a shrub about half the height of $l^{\gamma}$ prunifolium, with broadly ovate, deeply 3-lobed and coarsely dentate leaves (Fig. 179, C). The flowers are white and in compound cymes, the outer being sterile and large and showy. The fruit is a reddish, globular, very acid drupe. The bark is official (p. 532). The Snow-ball 
or guelder-rose of the gardens is a sterile variety of this species. Another varicty $(c d u l c)$ is also cultivated on account of its edible fruits, particularly in Canada and the Northern United States.

A number of species of Viburnum are rather common in various parts of the L'nited States, as the Maple-leaved arrow-

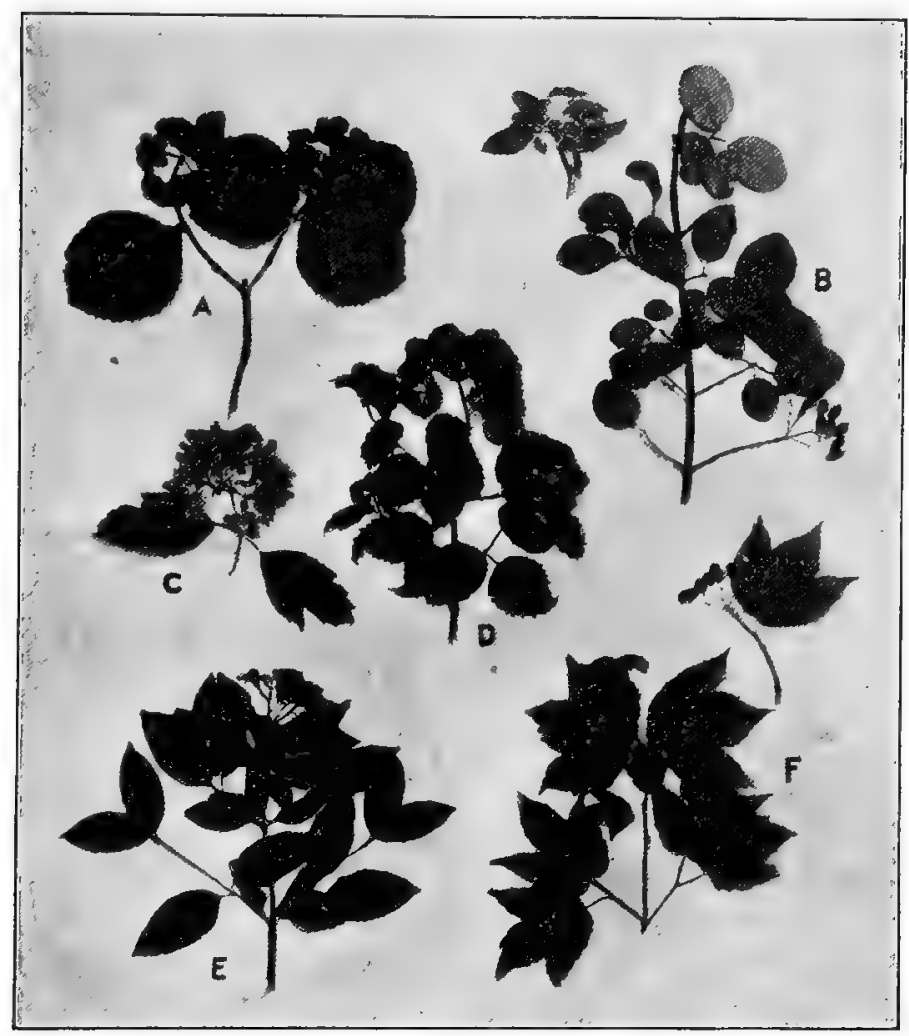

FIG. 179. Species of Viburnum: A, Viburnum molle; B, V. prunifoliun; C, V. Opulus; D, V. dentatum; E, V. nudum; F, V. Acerifolium.

wood ( $l^{r}$. Acerifolitum), which is a small shrub with deeply 3-lobed, coarsely dentate leaves and nearly black drupes (Fig. I79, F); Arrow-wood ( $V$ dcntatum), with broadly ovate, coarsely clentate leaves and blue drupes, which become nearly black (Fig. I79, D) ; Soft-leaved arrow-wood (I'. molle), which 
somewhat resembles $V^{\prime}$ dentatum, but has larger leaves that are crenate or dentate and stellate-pubescent on the lower surface; Larger withe-rod ( $V$. undum), having nearly entire leaves and a pink drupe, which becomes dark blue (Fig. I79, E).

Sambucus canadensis (American elder) is a shrub growing in moist places in the U'nited States as far west as Arizona and in Canada. The leaves are 5- to 7 -foliate, the leaflets being ovate, elliptical, acuminate, sharply serrate and with a short stalk; the flowers are small, white and in convex cymes. The fruit is a deep purple or black berry-like drupe. The dried flowers are used in medicine. They are about $5 \mathrm{~mm}$. broad, with a 5 -toothed, turbinate calyx, and a 5 -lobed, rotate corolla, to which the 5 stamens are adnate. The odor is peculiar and the taste is mucilaginous and somewhat aromatic and bitter.

The active principles have not been determined, but are probably similar to those of $S$. nigra. The inner bark is also used in medicine and contains a volatile oil, a crystallizable resin and valerianic acid. It does not appear to contain either tannin or starch. The roots of elder contain a volatile principle somewhat resembling coniine. The pith consists chiefly of cellulose, is delicate in texture and has a variety of uses.

The Plack elder (Sambucus nigra), which is a shrub common in Europe, is characterized by narrower leaflets, a 3 -locular ovary and black berries. The flowers are official in some of the European pharmacopœias. They contain about 0.4 per cent. of a greenish-yellow, semi-solid volatile oil, which when diluted has the odor of the flowers. They also contain an acrid resin.

The Red-berried elder or mountain elder ( $S$. pubens) somewhat resembles the common elder, but the stems are woody, and the younger branches have a reddish pith. The flowers are in paniculate cymes, and the fruits are scarlet or red.

Other plants of the Caprifoliacese are also used in medicine. Horse gentian (Triostcum perfoliatum), a perennial herb with connate-perfoliate leaves and small, orange-red, globular drupes, growing in Canacla and the United States as far west as Kansas, furnishes the drug (rhizome) known as WILD IPECAC or Triosteum. The rhizome is yellowish-brown, somewhat branched, cylinclrical, io to $20 \mathrm{~cm}$. long, io to I $5 \mathrm{~mm}$. in diameter, with 
numerous cup-shaped stem-scars, and coarse, spreading roots; it is rather hard and tough, and has a bitter, nauseous taste. Triosteum contains an emetic alkaloid, triosteine, and considerable starch. The seeds of Triosteum perfoliatum are sometimes roasted and employed like coffee, the plant being known as Wild coffee.

The roots and stems of the following plants are sometimes employed: The Snowberry (Symphoricarpos racemosus), the Bush honeysuckle (Dierzilla trifida) and various species of Lonicera, these being also known as honeysuckles.

\section{ORDER VALERIANALES OR AGGREGATæ.}

The plants"are mostly herbs with an inferior ovary, which is either unilocular with a single pendulous ovule, or tri-locular with frequently but a single anatropous ovule.

a. VALERIANACE $A$ OR VALERIAN FAMILY.-The plants are herbs with opposite, exstipulate leaves, small, perfect, or polygamo-diocious flowers, occurring in corymbs. The fruit is dry, indehiscent and akene-like. The calyx is persistent, becoming elongated and plumose, and resembling the pappus in the Compositæ.

Valeriana officinalis (Garden or Wild valerian) is a tall, perennial herb, more or less pubescent at the nodes. The leaves are mostly basal, pinnately parted into seven or more segments, which are lanceolate, entire or dentate. The flowers are white or pink and arranged in corymbed cymes. The calyx is much reduced, consisting of 5 to I 5 pinnately branched teeth (pappus); the corolla is tubular, somewhat sac-like on one side, but not spurred as in other members of this family; the stamens are 3 in number and adnate to the corolla tube; the stigma is 3 -lobed. The fruit is ovoid, glabrous, and with a conspicuous plumose pappus. The rhizome and roots are official (p. 504).

The young leaves of several species of Valerianella are used as a salad and are cultivated like spinach, as the European cornsalad ( $V$. olitoria), which is also cultivated to some extent in the United States.

b. DIPSACACE 2 OR TEASEL FAMILY.-The plants are annual or perennial herbs, chiefly indigenous to the Old 
World. The flowers are arranged in heads on a common torus, resembling in some cases those of the Compositæ.

Some of the plants are used in medicine, as the roots, leaves, flowers and seeds of Fuller's teasel (Dipsacus fullonum), the roots of Succisa pratensis of Europe, and several species of Scabiosa and Cephalaria. The seeds of Ccphalaria syriaca when admixed with cereals give a bread that is dark in color and bitter. This family is, however, chiefly of interest on account of Fuller's teasel, which is a cultivated form of Dipsacus ferox, indigenous to Southwestern Asia, the plant being cultivated in Europe and New York State. The elongated, globular heads, with their firm, spiny and hooked bracts, are used in the fulling of cloth.

\section{ORDER CAMPANULAT}

This order differs from the two preceding by having the anthers united into a tube (syngenesious). It includes three principal families, which are distinguished by differences in the character of the androcium: (a) Cucurbitaceæ, in which there are three stamens, having not only the anthers united but the filaments also (monadelphous); (b) Campanulacex, in which there are five stamens, both the filaments and anthers being united into a tube; (c) Compositx, in which there are five stamens, but the anthers only are united, the filaments being separate (Fig. 82, $A$ ).

a. CUCLRBITACE 2 OR GOLRD FAMILY.-The plants are mostly annual, tendril-climbing or trailing herbs (Fig. 66), mainly indigenous to tropical regions. The leaves are alternate, being opposite the tendrils, petiolate, and entire, palmately lobed or dissected. The flowers are epigynous; the petals are borne on the calyx tube and frequently are united (campanulate) ; the ovary is 1 - to 3 -locular and with few or many anatropous ovules. The fruit is a pepo, which is indehiscent but may burst somewhat irregularly.

Citrullus Coloc.nnthis is a trailing herb with deeply lobed leaves. The flowers are yellow, axillary and monœcious, the staminate being with short filaments and glandular pistillodes (aborted pistils), and the pistillate having a 3-locular, globose ovary and three short staminodes. The fruit is globular, 5 to Io 
$\mathrm{cm}$. in diameter, smooth, greenish and mottled (Fig. 254). The fruit deprived of the epicarp (Fig. 254) is official (p. 583).

Cucurbita Pepo (pumpkin-vine) is an extensively trailinghispid vine, with large, nearly entire, cordate leaves with long petioles. The tendrils are branching. The flowers are large, deep yellow and monoecious; the staminate ones being in groups and the pistillate single. The fruit is a large, yellowish berry, sometimes weighing from Io to $72 \mathrm{~K}$. The seeds are numerous and are official as Pepo (p. 429).

Ecballium Elaterium (Squirting cucumber) is a bristly-hairy, trailing perennial herb with thick, rough-hairy, cordate, somewhat undtulate leaves. The flowers are yellow, monocious. The fruit is ellipsoidal, about $4 \mathrm{~cm}$. long, rough-hairy or prickly, pendt1lous, and at maturity separates from the stalk, when the seeds are discharged upward through a basal pore. The plant is indigenous to the European countries bordering the Mediterranean. the Caucasus region, Northern Africa and the Azores. The juice of the fruit yields the drug Elaterium, which is official in the British Pharmacopœia. Elaterium contains about 44 per cent. of a neutral principle, ELATERIN, which latter is official in the U. S. Pharmacopœia. Elaterium also contains a bitter yellow glucosicle, prophetin; a bitter, acrid, resin-like substance, ecballin (elateric acid); a bitter principle, elateric, precipitable by tannin; and a principle which is not bitter, hydro-elaterin. The juice of the other parts of the plant apparently contains the same principles.

Bryonia or BRYONy is the dried root of Bryonia alba (White bryony), a climbing lierb indigenous to Southèrn Sweden, Eastern and Central Europe, including Southern Russia, and Northern Persia (Fig. 66). Bryony occurs in the market in nearly circular disks, which are 2 to $10 \mathrm{~cm}$. in diameter, 5 to $10 \mathrm{~mm}$. thick, white or yellowish-white, with concentric zones of collateral fibrovascular bundles; short, mealy fracture; slight odor," and bitter, natuseous taste. The drug contains two bitter glucosides, bryonin and bryonidin; two resinous principles and considerable starch. Bryonia dioica (Red bryony) also has medicinal properties and is a source of the drug. $B$. dioica has red berries, while the fruit of $B$. alba is black. The latter plant is sometimes known 
as Black bryony, but this plant should not be confounded with Tamus communis (Fam. Dioscoreaceæ), of Southern Europe, the rhizome of which is known commercially as Black bryony.

The fruits and seeds of various members of the Cucurbitacex contain powerful drastic and anthelmintic principles. A number of the plants, however, are cultivated on account of the fruits, which are used as food, as the pumpkin already mentioned, the . WATER MELON (Citrullus a'ulgaris), indigenous to Southern Africa and cultivated in Egypt and the Orient since very early times; CANTALOUPE or musk-melon, derived from cultivated varieties of Cucumis melo, indigenous to tropical Africa and Asia, also cultivated since early times. The common CUCUMBER is obtained from Cucumis satiz'us, which is probably indigenous to the East Indies. These fruits contain from 90 to 95 per cent. of water, and the water melon contains 3.75 per cent. of dextrose, 5.34 per cent. of saccharose and yields 0.9 per cent. of ash.

Luffa cylindrica is an annual plant indigenous to the Tropics of the Old Worlcl. It is cultivated to some extent in America, but especially in the Mediterranean region. The fruit is more or less cylindrical and $20 \mathrm{~cm}$. or more long. The pulp is edible and the fibrovascular tissue forms a tough network, which, when the seeds, epicarp and pulpy matter are removed, constitutes the LUFFA-SPONGE.

The fruits of Luffa opcrculata and L. cchinata, both found in Brazil, contain a bitter principle resembling colocynthitin.

b. CAMPANULACE $刃$ OR BELL-FLOWER FAMILY.The plants are mostly annual or perennial herbs, but are sometimes shrubby, with an acrid juice containing powerful alkaloids. The rhizomes and roots of about twelve of the genera centain inulin. The leaves are alternate; the corolla is regular, campanulate and rotate, or irregular, as in Lobelia. The fruit is a capsule or berry containing numerous small seeds.

Lobelia inflata (Indian or Wild tobacco) is an annual pubescent, branching herb (Fig. 272), the dried leaves and tops of which are official (p. 633). About 15 different species of Lobelia are used in medicine. The most important of those growing in the United States is the Cardinal flower or Red lobelia (Lobelia cardinalis), a plant found in moist soil from Canada to Texas, 
and characterized by its long, compound racemes of bright scarlet or red flowers (Fig. I8oa). The Blue cardinal flower (Fig.

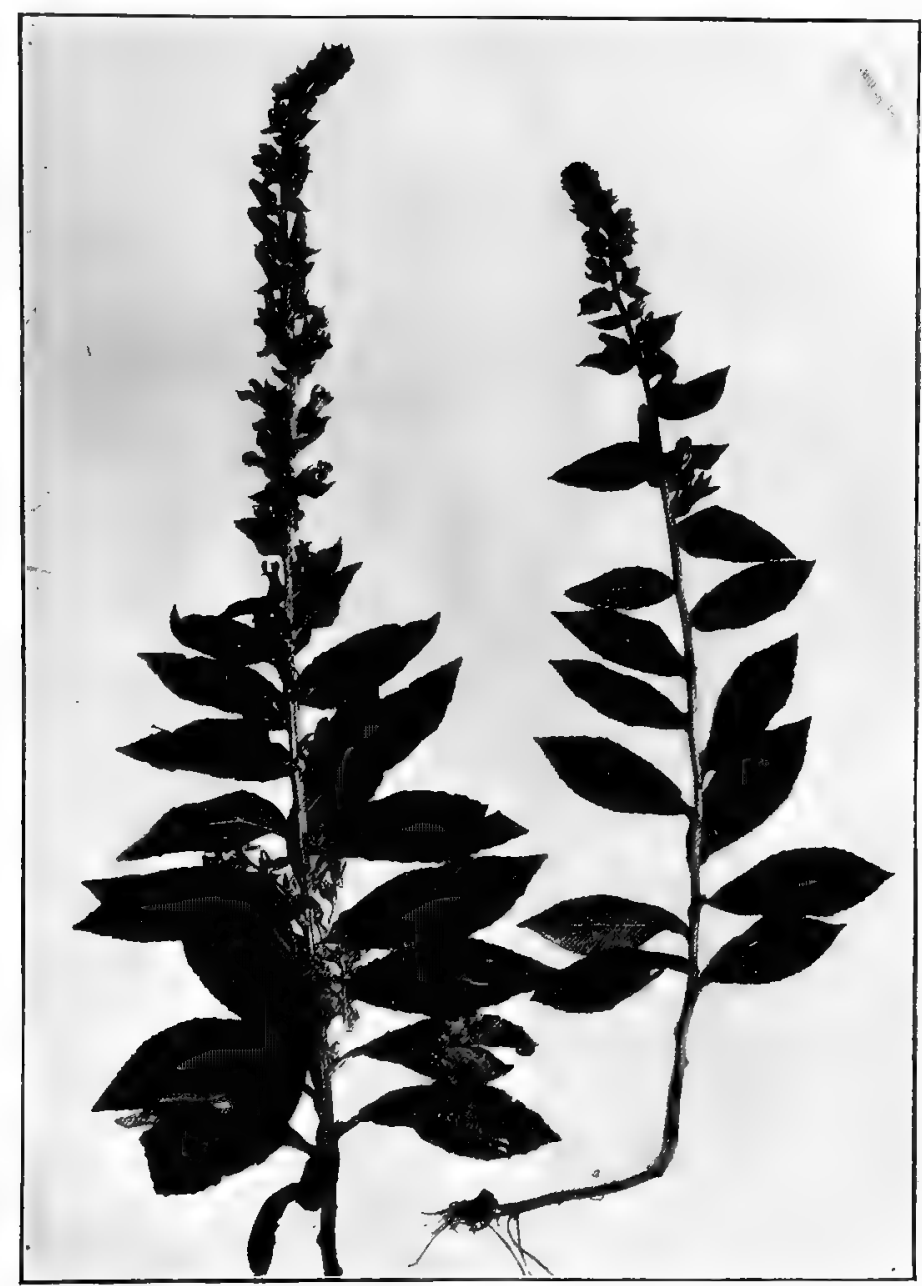

FIG. I80. Blue cardinal flower (Lobelia syphilitica).

I8o) or Blue lobelia (L. syphilitica) is a plant of nearly the same habit and same general character, except that the flowers are of a bright dark blue color or occasionally white. 
c. FAMILY COMPOSIT.E.-This is a large group of plants, half of which are annual, biennial or perennial herbs, the remainder including under-shrubs, shrubs, trees and twiners or

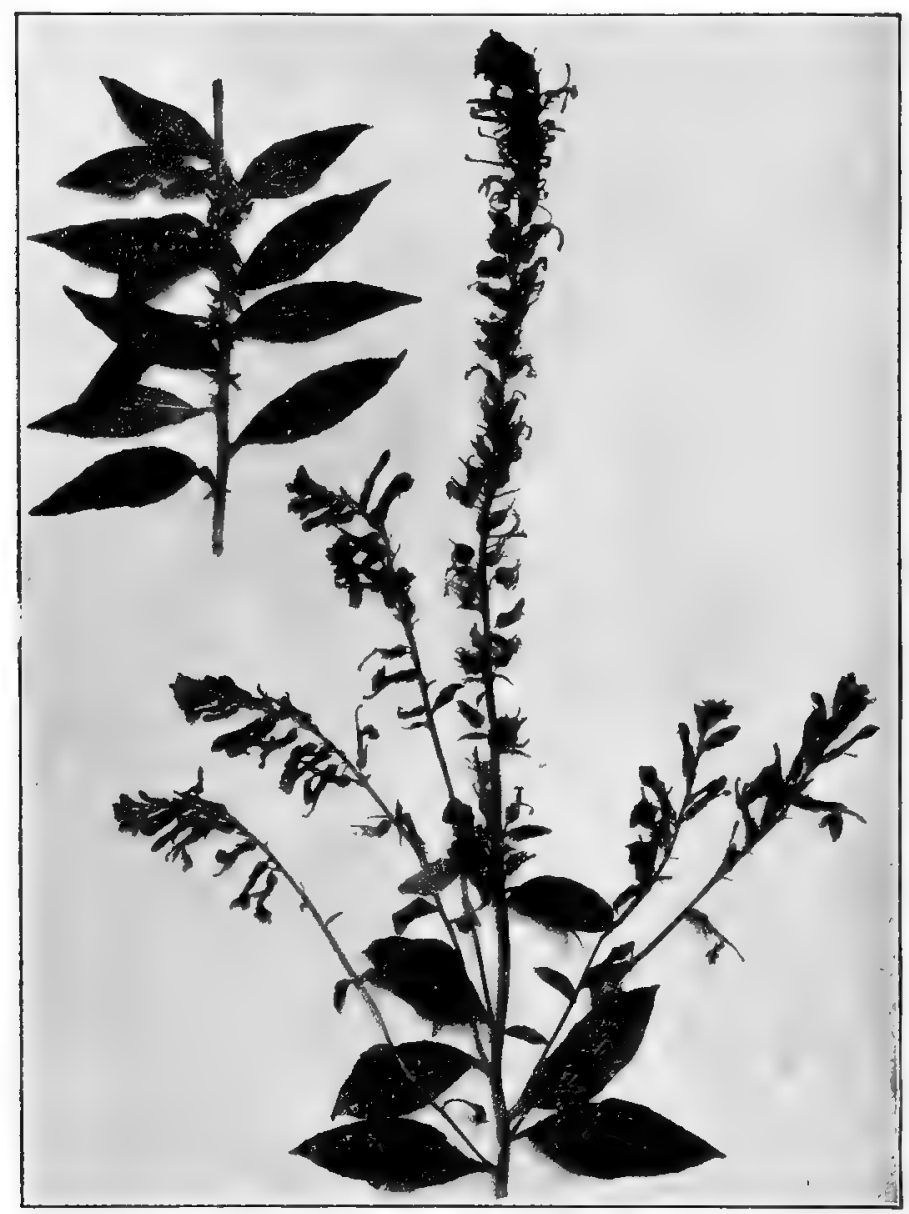

FIG. 180a. Part of stem and flowering top of the cardinal flower (Lobelia cardinalis).

even climbers, as Climbing boneset (Mikania scandens). The root is simple and spindle-shaped (Fig. I82), sometimes branched and usually contains inulin, a constituent peculiar to this group 
of plants. In some cases the stems are fleshy, as certain species of Senecio, and a few of the plants are aquatic. The leaves vary in arrangement, being opposite (Fig. 270), alternate (Fig. I82) or basal, and also in form and size. The most distinguishing character is the inflorescence, which is a head or capitulum (Figs. I8I, 242), consisting of 1 or 2 kinds of flowers, arranged on a common torus, and subtended by a number of bracts, forming an involucre. The flowers are epigynous and the fruit is an akene, ustrally surmounted by the persistent calyx, which consists of hairs, bristles, teeth or scales, which are known collectively as the PAPPUS (Fig. 24I).

The individual flowers are called florets (Figs. 24I, 242), and may be hermaphrodite or pistillate, monœcious, diœcious or neutral. Depending upon the shape of the corolla, two kinds of flowers are recognized, one in which the corolla forms a tube, which is 5-lobed or 5-cleft, known as tubular FLowers (Figs. $24 \mathrm{I}, C ; 242, C)$; and one in which the petals are united into a short tube, with an upper part that forms a large, strap-shaped, usually 5-toothed limb, known as LIGULATE FLOWERS (Figs. 24I, $B ; 242, D)$.

In some of the plants of the Compositæ the head consists of ligulate flowers only, but in the larger number of plants the head is composed of both tubular and ligulate flowers or tubular flowers alone and accordingly two main groups or sub-families are distinguished. The sub-family in which all of the flowers are ligtilate is known as Liguliflores, or Cichoriacese, by those who give the group the rank of a family. This group includes plants like dandelion, chicory, lettuce and Hieracium. The group or sub-family in which the flowers are all tubular or ligulate on the margin only, is known as the TUBULIFLoRæ. When the head consists only of tubular flowers it is called DISCord, but when ligulate flowers are also present it is called RADIATE. When the heads are radiate, as in the common daisy, the tubular flowers are spoken of as DISK-FLOWERS, and the ligulate flowers as RAYFLOWERS. The disk-flowers are usually perfect, while the rayflowers are pistillate or neutral (without either stamens or pistils). By some systematists the Tubulifloræ are divided into groups which have been given the rank of families. This division is 
based especially on the characters of the stamens. In a small group represented by the ragweed and known as the AmbrosiACEX, the anthers, while close together (connivent) are not united, and the corolla in the marginal or pistillate flowers is reduced to a short tube or ring. In a large group, which includes probably 10,000 species and which is considered to be the СомPosit $A$ proper, the stamens in the tubular flowers are syngenesious and the marginal or ray flowers are distinctly ligulate. This group includes the daisy, sunflower, golden-rod, aster, thistle and most of the plants which yield official drugs.

It may also be added that the Compositx is considered to be the highest and youngest group of plants.

Taraxacum officinale (Dandelion) is a perennial, acaulescent herb with milky latex; oblong-spatulate, pinnatifid or runcinate, decurrent leaves, and with a I-headed scape, the stalk of which is hollow. The flowers are ligulate, golden-yellow and numerous; the involucre consists of two series of bracts, the inner one of which closes over the head while the fruit is maturing, afterward becoming reflexed. The fruit consists of a loose, globular head of akenes, each one of which is oblong-ovate and with a slender beak at the apex which is prolonged into a stalk bearing a radiate tuft of silky hairs, which constitute the pappus. The root is fusiform and usually bears at the crown a number of branches 2 to 5 $\mathrm{cm}$. long, having a small pith and other characters of a rhizome. The root is official (p. 458).

Lactuca zirosa (Poison lettuce) is a biennial prickly herb, with milky latex and oblong-obovate, spinose-toothed, runcinate basal leaves and with alternate, somewhat sessile or auriculate, scattered stem leaves, the apex and margin being spinose. The flowers are pale yellow and occur in heads forming terminal panicles. The involucre is cylindrical and consists of several series of bracts. The flowers are all ligulate and the anthers are sagittate at the base. The akenes are flattish-oblong, and the pappus, which is raised on a stalk, is soft-capillary, as in Taraxacum. The prepared milk-juice is official as Lactucarium (p. 649).

Eupatorium perfoliatum (Boneset or Common thoroughwort) is a perennial, branching, pubescent herb (Fig. 270), with opposite, connate-perfoliate, long-lanceolate, crenate-serrate leaves, 
which are rugose, and pubescent on the under surface. The leaves and flowers are official (p. 625).

Grindelia species.--The plants are perennial, greenish-yellow, resinous herbs, sometimes being under-shrubs, with alternate, sessile or clasping, oblong to lanceolate, spinulose-dentate leaves, and large, terminal, yellowish heads, consisting of both ligulate and tubular flowers. The leaves and flowering tops of Grindelia robusta and G. squarrosa are official (p. 626).

Erigeron canadensis (Leptilon canadense) (Canada fleabane) is an annual or biennial, hispid-pubescent herb found growing in fields and waste places in nearly all parts of the world. The stems are simple, with numerous crowded leaves and numerous flowers occurring in terminal panicles. The plants are sometimes branched and I to $3 \mathrm{M}$. high. The leaves are linear, nearly entire, of a pale green color, the lower and basal ones being spatulate, petiolate and dentate or incised. The flowers are white and the heads are composed of both ligulate and tubular florets, the former being pistillate and not longer than the diameter of the disk. The pappus consists of numerous capillary bristles and the involucre, which is campanulate, consists of five or six series of narrow, erect bracts. The fresh flowering herb contains 0.3 to 0.4 per cent. of a volatile oil which is official, tannin, and a small amount of gallic acid. The oil is obtained by distillation and consists chiefly of d-limonene.

The genus Erigeron includes a number of species which have medicinal properties. E. annuus (Sweet scabious or Daisy fleabane) is a low, branching, annual herb, characterized by its linearlanceolate or ovate-lanceolate leaves and its conspicuous flowers, which resemble those of the common daisy, the ray-flowers often being tinged with purple (Fig. I8I). It contains a volatile oil resembling that of Canada fleabane, and tannin. The Philadelphia fleabane (Erigeron philadelphicus) is a perennial herb producing stolons, and has clasping or cordate leaves, the basal being spatulate, and is further distinguished by its light purplish-red ray-flowers.

Anthemis nobilis (Roman chamomile) is an annual or perennial, procumbent, branched herb, with numerous 2- to 3-pinnately divided leaves, the ultimate segments being narrow-linear. The 
-flowers occur in terminal heads with long peduncles, a conical torus and few white pistillate ray-flowers. The flowers of cultivated plants are official (p. 554), the heads consisting mostly of ligulate flowers, forming so-called "double flowers," as in the cultivated chrysanthemums.

Anacyclus Pyrethrum (Pellitory) is a perennial herb resembling Anthcmis nobilis in its general characters. The ray-flowers, however, are white or purplish, and the papptus consists of a ring or scale. The root is official (p. 455).

IIatricaria Chamomilla (German chamomile) is an annual, diffusely branched herb, with pinnately clivided leaves, consisting of few, linear segments. The flowers are official (p. 553).

Arnica montana is a perennial herb with small rhizomes; nearly simple stems; opposite, somewhat connate, entire, spatulate, hairy leaves, and yellow flowers in large heads with long peduncles. The flowers are official (p. $55 \mathrm{I}$ ).

Arctilum Lappa (Burdock) is a coarse, branched, biennial or perennial herb, with alternate, broadly ovate, repand, entire, tomentose, mostly cordate leaves, the basal ones being from 30 to $45 \mathrm{~cm}$. long. The flowers are purplish-red or white, tubular and form rather large corymbose heads; the involucre consists of numerous lanceolate, rigid, nearly glabrous bracts, which are tipped with hooked, spreading bristles. The akenes are oblong and somewhat 3 -angled, and the pappus consists of numerous short bristles (Fig. 92). The root is official (p. 465).

The common burdock (Arctium minus) resembles $A$. Lappa, but is a smaller plant and is more common in the United States. The heads are smaller and the inner bracts are shorter than the tubular flowers, the bristles of this series being erect and with the outer spreading.

Calendula officinalis (Marigold) is an annual herb, with alternate, spatulate, oblanceolate, entire or serrate leaves. The flowers are yellow and form solitary heads, consisting of both ray and tubular florets. In the cultivated varieties most of the tubular florets are changed to ligulate, the latter being official (p. 555).

While the Compositx include a large number of genera and species, the plants do not yield many important drugs, although a number are used in medicine and for other purposes. 
The so-called Insect Flowers (Pyrethri Flores) are the partly expanded flower-heads of several species of Chrysanthemum, and are nsed in the preparation of a powder which is a powerful insecticide. The plants are perennial herbs resembling

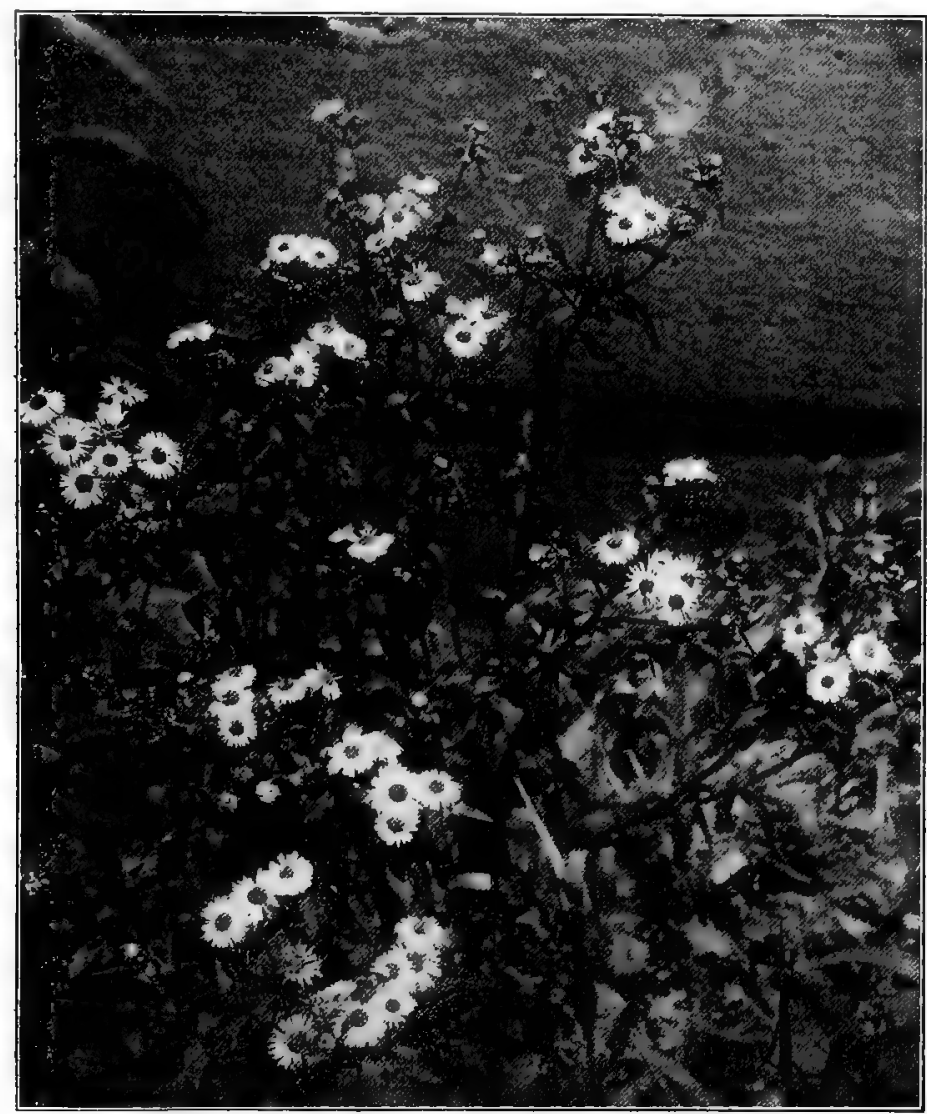

Fig. I8r. Daisy-fleabane (Erigeron annuus).

in their habits the common white daisy (C. Leucanthemum). The Dalmatian Insect Flowers are obtained from $C$. cinerariifolium, growing in Dalmatia, and cultivated in Northern Africa, California and New York. The heads as they occur in the market are about $12 \mathrm{~mm}$. broad, light yellowish-brown and have a slightly 
rounded or conical torus, which is about $12 \mathrm{~mm}$. in diameter and 2 or 3 series of lanceolate, obtuse, involucral scales. The rayflorets are pistillate, the corolla varying in length from I to $2 \mathrm{~cm}$. and having numerous delicate veins and 3 short, obtuse or rounded teeth. The tubular flowers are perfect and about $6 \mathrm{~mm}$. long. The ovary is 5 -ribbed and the pappus forms a short, toothed crown. The odor is distinct and the taste bitter.

Persian Insect Flowers are derived from $C$. roseum and $C$. Marshallii, growing in the Caucasus region, Armenia and Northern Persia. The heads are about the same size as those of $C$. cinerariifolium; the torus is dark brown; the involucral scales and ray-florets are purplish-red; the ovary is 1o-ribbed.

Insect flowers contain from a trace to 0.5 per cent. of a volatile oil, the Persian flowers containing the larger proportion, and the amount decreasing with the maturing of the flowers. They also contain two resins, varying from 4 to 7 per cent., the larger amount being found in the Dalmatian flowers; a small quantity of a glucoside and a volatile acid.

While it is claimed that the insecticidal effects of insect powder are due to a mechanical action in closing the breathing pores of non-biting insects, it is probable that they also have a toxic action, due to some poisonous principle, which apparently may be extracted with alcohol and applied in solution.

WORMWOOD or Absinthium consists of the dried leaves and flowering tops of Artemisia Absinthium, a perennial, somewhat woody, branching herb, indigenous to Europe and Northern Africa, cultivated in New York, Michigan, Nebraska and Wisconsin and naturalized in the United States from plants that have escaped from cultivation. The leaves are grayish-green, glandular-hairy, I- to 3-pinnately divided, the segments being obovate, entire, or lobed; the flowèrs are yellowish-green, the heads being about $4 \mathrm{~mm}$. broad and occurring in raceme-like panicles; the torus is hemispherical and the involucre consists of several series of linear bracts, the inner being scale-like; the florets are all tubular, the outer ones sometimes being neutral. The herb is aromatic and very bitter.

The fresh drug contains about 0.5 per cent. of a volatile oIL which is of a dark green or blue color, has a bitter, persistent taste 
but not the pleasant odor of the plant, and consists of d-thujone (absinthol), thujyl alcohol free and combined with acetic, isovalerianic and palmitic acids, phellandrene and cadinene. The other constituents of the drug include a bitter glucosidal principle, * ABSINTHIn, which forms white prisms and yields on hydrolysis a volatile oil; a resin; starch; tannin; succinic acid, potassium succinate, and about 7 per cent. of ash. The plant is used in the preparation of the French liquor known as Ausinthe.

Artemisia Cina furnishes the official Santonica (p. 350).

Other species of Absinthium also yield volatile oils, as the COMMON MUGwort (Artemisia vulgaris), which yields from o.I to 0.2 per cent. of an oil containing cineol; Artemisia Barrelieri, which contains an oil consisting almost entirely of thujone, and said to be used in the preparation of Algerian absinthe.

SAFFLOWER consists of the dried florets of Carthamus tinctorius, an annual herb which is known only in cultivation. The florets are tubular, yellowish-red, the corolla tube being about 2 $\mathrm{cm}$. long and with 5 small, linear lobes; the stamens are exserted. The ovary with the long, slender style is usually not present in the drug (Fig. 296, C). Safflower contains a small percentage of a yellow coloring principle (safflower-yellow), which is soluble in water, and 0.3 to 0.6 per cent. of a red coloring principle (carthamin or carthamic acid), which is insoluble in water but soluble in alcohol, the solution having a purplish-red color. A volatile oil is also present. Carthamin is used in conjunction with French chalk in the preparation of a rouge.

TANSY is the dried leaves and tops of Chrysanthemum (Tanacetum) vulgare (Fig. 75), a perennial herb indigenous to Europe, extensively cultivated and naturalized in the United States. The leaves are large and pinnately divided, and the flowers, both tubular and ligulate, are yellow, the heads being in terminal corymbs.

The plant yields from o.I to 0.3 per cent. of a volatile oil, consisting of thujone, borneol and camphor.

Elecampane (Inula Helenium) is a large, perennial, densely pubescent herb with alternate leaves and large, solitary terminal heads, consisting of yellow tubular and ligulate florets (Fig. 182). The plant is indigenous to Central Europe and Asia, and naturralized in North America from Canada to North Carolina. The 
root is used in medicine and was formerly official as ÍnULA. It is cylindrical, tapering, and in preparing the drug it is usually cut into longitudinal pieces, which after drying are grayish-brown or dark brown and longitudinally wrinkled on the outer surface,

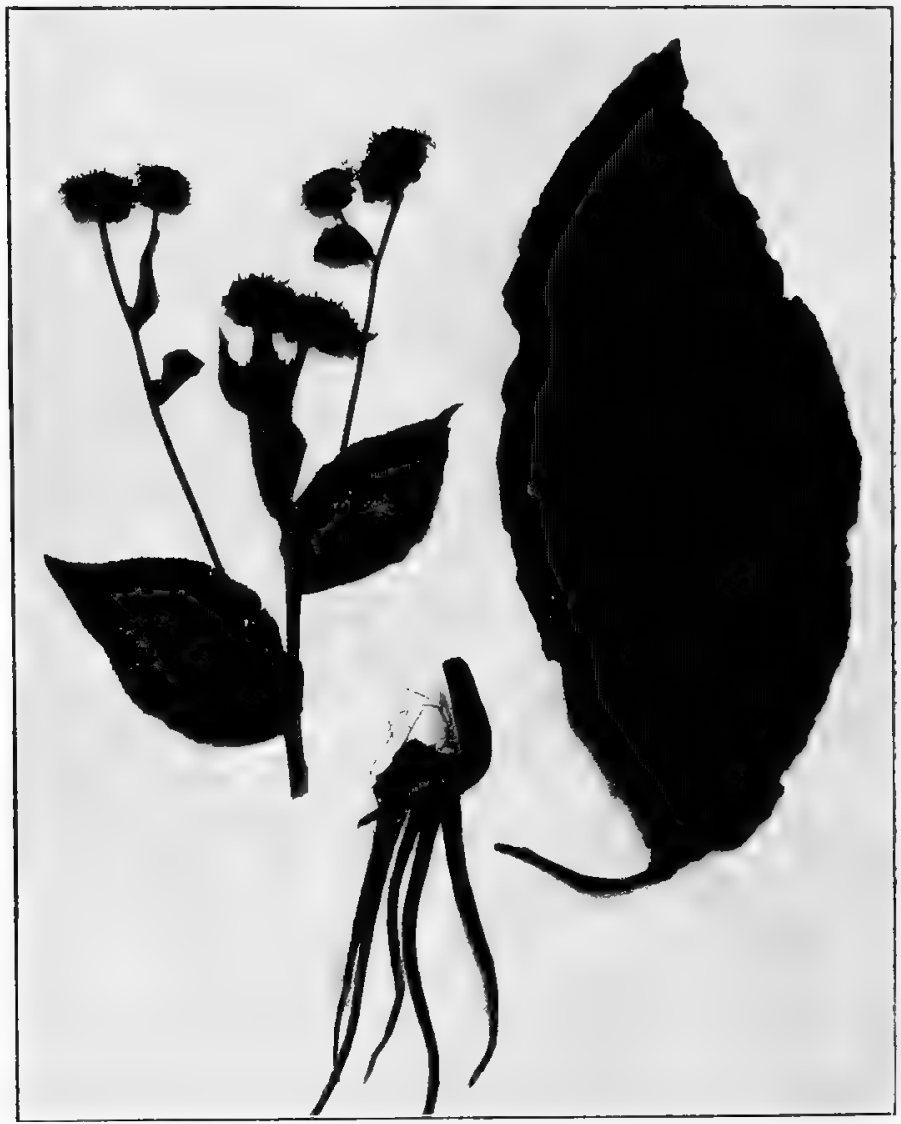

FIG, 182. Elecampane (Inula Helenium): One of the large basal leaves, a root cluster and a flowering branch.

somewhat lighter in color on the cut surface; the fracture of thicker pieces is tough, of thinner pieces, short when dry; it is pale yellow internally, with numerous radiate resin canals; the odor is aromatic; the taste bitter and acrid. It is distinguished 
from belladonna root (Fig. 200), which has been sometimes substituted for it, by the latter having a characteristic odor and taste, and containing starch (p. 463).

Inula contains about 44 per cent. of inulin, which on hydrolysis yields levulose, which latter replaces inulin in the roots gathered in spring. From I to 2 per cent. of a crystalline substance is obtained by distillation with water, which consists of a colorless, crystalline principle, alantolactone, that is insoluble in sodium carbonate solution, and alantolic acid, which crystallizes in fine needles, is soluble in sodium carbonate solution and is largely decomposed on heating with water. The drug also contains helenin, which crystallizes in 4 -sided prisms and is not affected by ordinary reagents; and alantol, a yellowish liquid isomeric with common camphor and apparently occurring only in the fresh root.

The root of Polymnia Uvedalia, a plant closely related to Inula, but indigenous to the United States east of the Mississippi, contains a volatile oil, a glucoside, tannin, and a resinous substance consisting of two resins, one of which is pale yellow and soft, the other dark brown and hard.

The following Compositæ, while not of very great importance, are used in some localities:

YARROW (Achillea Millefolium) is a common weed naturalized from Europe and Asia, and contains about o.I per cent. of a dark blue volatile oil with a strongly aromatic odor and a small amount of a bitter alkaloid, achilleine. The roots of yarrow, on the other hand, yield a volatile oil with a valerian-like odor. Achillea nobilis of Europe contains an oil resembling that of yarrow, but it is of finer quality and has a spice-like taste. Achillea moschata, an alpine plant of Europe, yields three alkaloids and a volatile oil containing cineol, and is used in Italy in the preparation of the liquor, "Esprit d' Iva." Achillea tanacctifolia yields a blue volatile oil having the odor of tansy.

The HigH Golden-Rod (Solidago canadensis) yields 0.63 per cent. of a volatile oil, consisting chiefly of pinene, with some phellandrene and dipentene, and containing about 9 per cent. of borneol, 3 per cent. of bornyl acetate and some cadinene. The True or Anise-SCented Golden-Rod (Solidago odorata) yields an aromatic volatile oil and a small amount of tannin. 
The rhizome of the large Button-snakeroot (Lacinaria scariosa), growing in the eastern and central portion of the United States and Canada, contains o. I per cent. of volatile oil, about 5 per cent. of resin, and 2 per cent. of a caoutchouc-like substance.

Coltsfoot (Tussilago Farfara) is a plant indigenous to Europe and naturalized in the Northern United States and Canada. It is an acaulescent herb with a slender rhizome 30 to 40 $\mathrm{cm}$. long; nearly orbicular, somewhat lobed and tomentose leaves, and large, solitary, yellow flowers appearing before the leaves. The plant contains an acrid volatile oil, a bitter glucoside, resin and tannin.

ECHINACEA is the root of Brauneria (Rudbeckia) purpurea, a plant growing in rich soil from $V$ irginia to Illinois and southward, and of $B$. pallida, growing from the Northwest Territory to Texas. It occurs in pieces from 5 to $10 \mathrm{~cm}$. long and 5 to 15 $\mathrm{mm}$. in diameter; it is grayish-brown or reddish-brown externally, longitudinally wrinkled, sometimes spirally twisted; the fracture is short, the fractured surface exhibiting a number of resin cells and a greenish-yellow wood. The odor is distinct and the taste is aromatic, acrid and pungent. The drug contains an alkaloid and 0.5 to I per cent. of an acrid resinous substance to which the medical properties are due.

Rosin Weed or Compass Plant (Silphium laciniatum), found growing from Ohio to South Dakota and south to Texas, produces an oleo-resin which exudes either spontaneously or from the punctures of insects, and contains about I9 per cent. of volatile oil, and 37 per cent. of acid resin.

The THISTLE (Cnicus benedictus) contains a crystalline bitter principle, cnicin, which is colored red with sulphuric acid.

The Mexican drug pipitzanoac is the rhizome of Perezia Wrightii, $P$ nana and $P$ adnata, plants found in Southwestern Texas and Mexico. It contains about 3.6 per cent. of a goldenyellow crystalline principle, pipitzahoic acid, which appears to be related to oxythymoquinone and is colored an intense purple with alkalies and alkaline earths.

Lion's Foot, the root of Nabalus Serpentaria, N. alba and other species of Nabalus growing in the United States, contains bitter principles, resin and tannin. Мıо Mro (Baccharis cordi- 
folia), of South America, is poisonous to sheep and cattle and contains an alkaloid, baccharine, and a bitter principle. SpIny CLOTBUR (Xanthium spinosum) contains a bitter resin and possibly a volatile alkaloid. The fruit of Xanthium strumarium, a common weed naturalized from Europe, contains an amorphous, non-glucosidal substance, xanthostrumarin, which forms precipitates with a number of the alkaloidal reagents. SNEEZE-INEED (Helenium autumnale) contains a volatile oil, a bitter glucoside and tannin. Helenium tenuifolinm, of the Southern United States, is a narcotic poison. PARA Cress (Spilanthes oleracea), of tropical America, contains a soft pungent resin and a crystallizable principle, spilanthin. The common white daisy (Chrysanthemum Leucanthemum) yields about o.I 5 per cent. of a greenish volatile oil with the odor of chamomile and mint.

CHICory, the root of Cichorium Intybus, a perennial herb with blue ligulate florets, indigenous to and cultivated in Europe and naturalized in certain localities in the United States, is used in medicine as well as in the preparation of a coffee substitute. The root is spindle-shaped, somewhat resembling Taraxacum, but is of a light brown color and the laticiferous vessels are arranged in radial rows in the somewhat thinner bark. It contains a bitter principle and a large amount of inulin. In the preparation of a coffee substitute the root is cut into rather large, equal pieces and roasted, after which it is ground to a yellowish-brown, coarse powder. The grains are heavier than water, imparting to it a yellowish-brown color. Under the microscope it is distingtuished by the branching latex-tubes and rather short, oblique trachex with rather large, simple pores.

The SUNFLower (Helianthus annutus) is an annual herb indigenous to tropical America and extensively cultivated. The plant is grown on a large scale in Russia, Hungary, Italy and India for its fruits, which yield a fixed oil resembling that of cotton seed. The akenes (so-called seeds) are obovate, flattened, externally black or with alternate white and black stripes, the pappus consisting of two deciduous, chaffy scales. Sunflower seed-cake is readily distinguished by a few of the fragments of the epicarp, with the characteristic twin, unicellular, non-glandular hairs and large, oblique, but rather short, sclerenchymatous fibers. Besides 
40 per cent. of a fixed oil, the seeds contain a peculiar glucosidal tannin, helianthic acid, which is colored deep green with ferric chloride and yellow with alkalies. The root contains inulin; the shoot asparagin, and the fresh pith about $\mathrm{I} .5$ per cent. of potassium nitrate. The latter has been used in the preparation of MoxA, a combustible vegetable material which burns without fusing and is used by the Portuguese to destroy any deep-seated inflammation. The pith of various species of Artemisia, which also contains considerable potassium nitrate, furnishes the Chinese Moxa.

Jerusalem Artichoke (Helianthus tuberosus) is a large, coarse, pubescent herb with yellow ray-florets, which is indigenous to the Middle United States and sometimes cultivated. The tubers, which resemble artichokes, are more or less elongated or pear-shaped, reddish-brown, somewhat annulate, and internally white or reddish. They have been used as a substitute for potatoes and contain about I6 per cent. of the following carbohydrates: Inulin, pseudo-inulin, inulenin, saccharose, helianthenin, and synantherin. In early spring with the development of the tubers there is formed a small quantity of dextrose and levulose.

The Globe artichoke of the gardens (Cynara Scolymus) is a hardy perennial and is valued on account of the fleshy involucral scales and torus, which are edible.

The POLLEN of a number of plants of the Compositæ, as ragweed (Ambrosia), goldenrod (Solidago), aster and chrysanthemum, is said to be responsible for the autumnal cold, known as HAY FEVER. A similar disease is produced in spring and early summer by the pollen of certain grasses. It has been found that the pollen grains of these plants contain a highly toxic substance, belonging to the toxalbumins, which is the cause of the disease. By inoculation of rabbits, goats and horses with this toxalbumin a serum containing an antitoxin is obtained which neutralizes the pollen toxin and protects those who are susceptible to hay fever from its attacks. In practice the serum is prepared by injecting the toxalbumin subcutaneously into horses, the serum being known in commerce as POLLANTIN. 


\section{CHAPTER V.}

\section{CULTIVATION OF MEDICINAL PLANTS.}

THERE is a growing scarcity of many of the native medicinal plants in the United States, due both to the destruction of the woodlands where they grow and to the direct extermination of the plants themselves by drug collectors, and it seems not improbable that if the collecting of vegetable drugs continues at the present rate it will not be many years before a number of the most important drug-yielding plants will be exterminated, unless some measures are taken to conserve them in their native localities or to propagate them by cultivation. There seems, however, to be little chance for their conservation unless by cultivation, for already the demand is far greater than the supply and in some cases the drugs are scarcely to be had at all. Of the important medicinal plants which are becoming markedly limited in their area of growth may be mentioned those yielding the drugs serpentaria, senega, cypripedium, hydrastis, spigelia and cascara sagrada.

Not only is there a necessity for the cultivation of medicinal plants on account of the scarcity of the drugs yielded by them, but experiment has shown that in some instances the drug has been improved by giving attention to cultural conditions. The possibilities of what can be done in this direction are shown in the case of coca and cinchona, where by selection and cultivation the plants have not only been conserved but the yield of the medicinal products has been greatly increased. It is true also that very many of our economic plants have been improved by selection and cultivation, as corn, wheat, potatoes, fruits of various kinds, and there is reason to believe that like results would follow the cultivation of medicinal plants. The fact should not, however, be overlooked that in some instances the wild plants, as those of the solanaceous-drug group, are said to give a better yield of the active principles than the cultivated ones; but this would probably not result if the nature of the plants were better understood and the methods of cultivation improved accordingly. 
It is well known that when growth is very rapid the plant will produce few or no flowers, whereas if growth is slower the production of flowers and seed will be increased. So in the case of some of the medicinal plants it is probable that the yield of active principles would be less in a very vigorous plant than in one less thrifty. The conditions must, therefore, be studied in relation to the object to be attained.

In 'undertaking the cultivation of native medicinal plants they should first be studied in their natural surroundings until a knowledge is gained of the peculiar requirements and habits of each, including the composition and physical condition of the soil, the climatic conditions, their relation to other plants, etc. It should at the same time be borne in mind that most plants can in time adapt themselves to surroundings differing from those of their original habitat. Still, notwithstanding this general law of adaptation, in order to be sure of results we must take into consideration the particular conditions under which a given species will thrive best, or yield the largest percentage of active principles. For example, some plants appear to prefer a dry soil, as Sassafras officinale; others, a damp location, as Veratrum viride; some, a rich soil, as Asarum canadense, while still others grow in waste places and on ballast, as Matricaria Chamomilla. Some prefer shade, as Arisama triphyllum, and others exposure to direct sunlight, as Datura Stramonizm. Among the other factors which must also be taken into consideration is that of altitude, some plants appearing to thrive best high up on hills and mountains, while others are found in the lowlands and marshes. The question of latitude ought also to be considered owing to the extremes in our country in this particular.

PROPAGATION.--The methods of propagation used in the cultivation of other useful plants apply also to medicinal plants. These include propagation from seeds, from cuttings, and from grafts. A cutting is a severed portion of a plant having one or more nodes or buds. A GRAFT is a severed twig or branch which is embedded in a branch of another plant in such a way that the cambiums or growing regions of the two branches are brought into such intimate contact that they fuse or grow together. This method is largely followed in fruit culture, the branch of a more 
desirable fruit tree being frequently engrafted on one which produces an inferior grade of fruit; besides, the process consumes much less time than would be required for a fruit-bearing tree to develop from seed.

Most annuals and biennials are propagated from seeds. Considerable care is necessary in the buying of seeds in order to obtain those that will germinate and are true to name. Frequently some of the seeds are immature, and in some cases many of them are sterile, as those of Eucalyptus (Fig. 258, $H$ ). This latter fact may explain why it is so difficult to grow the eucalypts from seeds. In some instances the seeds may be sown where the plants are to be grown, but probably in most cases it would be better to germinate them under glass or in seed boxes and then transplant the young plants when the conditions are most favorable. It may be pointed out that there is much variation in seeds in regard to the length of time-required for germination. This applies not only to seeds of different species, but even to seeds of the same plant. With many plants, as corn, wheat, beet and others, it has been found that by selecting the best seeds or those produced by plants having some specially desirable quality, as a large percentage of oils, proteids, or sugar, and repeating the selection from year to year, decided improvements have been brought about and maintained. It is reported that in the cirichona plantations in Java methods of selection have largely supierseded the system of "mossing" (p. 5I8) for increasing the alkaloidal percentage.

Cuttings are extensively employed in the propagation of plants, particularly by florists. They are derived either from over-ground shoots, as in carnation, rose, geranium and coleus, or, where the plant produces root-stocks or rhizomes, they are made from these rather than from the over-ground shoots. Not all plants can be propagated equally well from cuttings. Some plants are readily propagated in this way, as the willows, the twigs of which when they fall off or are broken off frequently take root in the moist soil. Other plants, like the oak, are very difficult to grow from cuttings. In propagating plants from thizomes the latter are cut into pieces, each of which has one or two buds, and these pieces are planted. Among the medicinal plants 
which have been grown from cuttings of rhizomes are licorice and ginger, but it is likely that all plants which produce rhizomes can be readily propagated from cuttings. Cuttings of overground stems are made from the growing parts of branches, and it is necessary to have them of such a length that at least one node may be placed in the soil. These are at first planted in micaceous soil or river sand, which should be kept well moistened. It is desirable that the leaves be as few as possible, so as to reduce the transpiring surface until the young roots have been formed, .which may take several weeks or several months. Usually the lower leaves should be cut off entirely, while the others may be partially trimmed. The cuttings should also be protected from strong light, as this tends to increase transpiration, and also against a dry atmosphere, which may be accomplished by covering them with glass, particularly during the day, when the weather is dry. Cuttings of hard wood plants intended for outdoor culture should be made in the fall. They should be 6 or 8 inches in length, kept covered with sand in a suitable place during the winter, and planted in the spring.

One of the methods for producing new varieties is by hybridization, or cross-pollination, of different related species or varieties. The offspring is known as a HYBRID, and has a blending of the qualities or characters of the two parent plants. This method is mostly employed by florists who desire to produce some new or striking flower, or by horticulturists who desire to establish some new quality or transfer a desirable quality from a foreign plant to one which is adapted to a given locality. The method has not been largely employed in the cultivation of medicinal plants, except in the case of cinchona, where it is claimed that the barks richest in alkaloids are the direct result of hybridization and selection. By transplanting and special methods of treatment, as that of mossing, the alkaloidal percentage has been increased from 8 per cent. to Io, whereas by hybridization the amount of total alkaloids has reached as high as 16 per cent., about threefourths being quinine.

THE COLLECTION, CURING AND YIELD OF DRUGS. On page $4 \mathrm{I} 8$ are given some general rules for the collection of vegetable drugs, and attention is directed to the importance of 
properly drying them and preparing them for the market. When not only the nature of the plant but the diversity of the constituents of vegetable drugs is taken into consideration, it will be seen that the collection and preparation of them for the market is really a fine art, requiring extended knowledge and experience, and a keen appreciation of the difference in quality due to factors of this kind. The large crude-drug collectors give instruction to their employes as to the methods to be followed in the preparation of the drug, this knowledge having been acquired as the result of years of experience. We are apt to think that the only drugs that require particular care are those like tobacco, vanilla and gentian, in which in addition to drying there is a curing process that takes place; but this is true also of digitalis, the solanaceous leaves and many of the other important drugs. While the quality thus acquired, like that of teas and wines, etc., cannot readily be determined by any assay process, the therapeutist is able to detect the difference between the drug that has been carefully collected and prepared and the one that has been carelessly handled.

It has already been pointed out that plants consist in large proportion of water, and when they are collected and dried there is necessarily considerable loss. The loss is greater in the case of herbaceous plants, where the yield of crude drug is only about Io per cent., as in eupatorium and stramonium. Roots and rhizomes yield on an average from 20 to 30 per cent. of dried drug. In some cases, as in hops, the yield of dried drug is over 60 per cent., and in fruits and seedsulere is very little loss.

CULTIVATED MEDICINAL PLANTS.-Of the strictly medicinal plants which arf under successful cultivation in the United States attention may be called to the following: Mentha piperita, Crocus sativus, Digitalis purpurea, Atropa Belladonna, Conium maculatum, Matricaria Chamomilla, Calendula officinalis, Valeriana officinalis, Inula Helenium, Ricinus communis, Panax quinquefolium, and Urtica urens. In addition, a number of medicinal plants are cultivated as garden herbs for domestic use, some of them since colonial times, as anise, balm, sweet basil, bene, boneset, borage, caraway, catnip, coltsfoot, coriander, cumin. dill, sweet fennel, hoarhound, lavender, pennyroyal, rosemary, rue, sage, summer and winter savory, sweet marjoram, symphy- 
tum, tansy, tarragon, thyme, and wormwood. A number of other plants have been successfully grown in an experimental way, as Glycyrrhiza glabra, Hyoscyamus niger, Papaver somniferum, Cinnamomum Camphora, Citrullus Colocynthis, Capsicum fastigiatum, Datura Tatula, Scopolia Carniolica, Cassia angustifolia, Convallaria majalis, Anacyclus Pyrethrum, Chrysanthemum cinerariifolinm, Aristolochia Serpentaria, and Althea officinalis.

CULTIVATED ECONOMIC PLANTS WHICH ARE ALSO OF MEDICINAL VALUE.-Several hundred of the plants cultivated in the United States either for the food products which they yield or for ornamental or other purposes, are more or less esteemed for their medicinal properties. To this class belong the following plants, both the name of the drug, or the part of the plant used in medicine, and the botanical name of the plant being given. The name of the drug is sometimes synonymous with the common name of the plant.

Deciduous and Evergreen Trees.-The buckeye or American horse-chestnut (Esculus glabra); the European horsechestnut (Asculus Hippocastanum); tree of heaven (Ailanthus glandulosa) ; black birch bark (Betula lenta); chestnut (Castanea dentata); Judas tree (Cercis canadensis); orange and lemon (Citrus species); dogwood (Cornus florida); persimmon bark (Diospyros virginioma); eucalyptus (Eucalyptus Globulus); red gum (Eucalyptus rostrata); American or white ash bark (Fraxinus americana); black ash bark (Fraximus nigra); butternut (Juglans cinerea); black walnut (Juglans nigra); juniper (Juniperus communis); savine (Juniperus Sabina); tamarac bark or -American larch (Larix americana); spice bush or fever bush (Lindera Benzoin); sweet gum bark (Liquidambar Styraciflua); tulip tree bark (Liriodendron Tulipifera) ; sweet bay or magnolia bark (Magnolia glauca); pride of China (Melia Azedarach); ironwood (Ostrya virginiana); white pine (Pinus Strobus); balsam poplar (Populus candicans); white poplar (Populus tremuloides); wild cherry (Prumus serotina); hop tree or wafer ash (Ptelea trifoliata) ; mountain ash (Sorbus americana); apple tree bark (Pyrus Malus); white oak bark (Quercus alba); red oak bark (Quercus rubra); black oak bark (Quercus velutina) ; white willow (Salix alba); black willow (Salix nigra); sassafras (Sas- 
safras officinale); hemlock spruce (Tsuga canadensis); elm bark (Ulmus fulva); prickly ash (Xanthorylum americanum).

Deciduous and Evergreen Shrubs.-Swamp-, bush- or tagalder (Alnus serrulata); barberry bark (Berberis vulgaris) ; boxwood (Buxus sempervirens); Jersey tea (Ceanothus americanus); fringe tree (Chionanthus virginica); sweet fern (Comptonia peregrina); red osier bark (Cornus stolonifera); English hawthorn (Cratogus oxyacantha); mezereum (Daphne Mezereum); American burning bush or wahoo (Euonymus atropurpureus) ; broom tops (Cytisus Scoparius); witchhazel (Hamamelis virginiana); hydrangea (Hydrangea arborescens); black alder (Ile.x verticillata); mountain laurel (Kalmia latifolia); sweet bay (Laurus nobilis); wax myrtle or bayberry (Myrica cerifera); peach (Amygdalus persica) ; buckthorn berries (Rhamnus cathartica); buckthorn bark (Rhamnus Frangula); cascara sagrada (Rhamnus Purshiana); sumac (Rhus glabra); rose flowers (Rosa gallica and Rosa centifolia) ; rosemary (Rosmarinus officinalis); elder flowers and bark (Sambucus canadensis); European elder (Sambucus nigra); hardhack (Spirca tomentosa); common arbor vitæ (Thuja occidentalis); cramp bark (Viburnum opulus); black haw (Viburnum prunifolium).

Twining and Climbing Plants.-American ivy or Virginia creeper (Parthenocissus quinquefolia); staff vine or false bittersweet (Celastrus scandens); Carolina jasmine (Gelseminm sempervirens) ; hops (Humulus Lupulus); yellow parilla or moonseed (Menispermum canadense); passion-flower (Passiflora incarnata); bittersweet (Solainum Dulcamara).

Herbaceous Perennials-Yarrow (Achillea Millefolium); aconite (Aconitum napellus); sweet flag (Acorus Calamus); star grass (Aletris farinosa); garlic (Allium sativum); hollyhock (Althcea rosea); pulsatilla (Anemone species); chamomile (Anthemis nobilis); pleurisy root (Asclepias tubcrosa); wild indigo (Baptisia tinctoria); wood betony. (Betonica officinalis); American senna (Cassia marilandica); helonias or blazing star (Chamalirium luteum); black snake root (Cimicifuga racemosa); bitter apple (Citrullus Colocynthis); lily-of-the-valley (Convallaria majalis) ; foxglove (Digitalis purpurea) ; echinacea (Echinacea angustifolia); water eryngo (Eryngium aquaticum); fennel 
(Foniculum vulgare); cranesbill (Geranium maculatum); Indian physic (Gillenia trifoliata); blazing star (Lacinaria spicata); ground ivy (Glecoma hederacea); liverwort (Hepatica triloba); lavender (Lavandula vera); peppermint (Mentha piperita); peony (Paonia officinalis); ginseng (Panax quinquefolium); anise (Pimpinella Anisum); solomon's seal (Polygonatum biflorum); abscess root (Polemonium reptans); thimbleweed (Rudbeckia laciniata); East Tennessee pink root (Rucllia cili$o s a$ ) ; rue (Ruta graveolens); sage (Salvia officinalis); rosinweed or compass plant (Silphium laciniatum); garden thyme (Thymus vulgaris); blood root (Sanguinaria canadensis) ; comfrey (Symphytum officinale); beth-root (Trillium erectum); white and red squill (Urginea maritima and its varieties).

The CACTI.-Night-blooming cereus (Cereus grandiforus); and mescale (Lophophora Levinii).

ANNUALS.-Broom corn seed (Andropogon arundinaceus vulgare); hemp (Cannabis sativa); cayenne pepper (Capsicum fastigiatum); common or garden parsley (Petroselinum sativum); caraway (Carum Carri); coriander (Coriandrum sativum); watermelon (Citrullus vulgaris); pumpkin (Cucurbita Pepo); larkspur seed (Delphinium Consolida); cotton (Gossypium species) henbane (Hyoscyamus niger); lactucarium (Lactuca virosa and other species of Lactuca); garden marigold (Calendula officinalis) ; tobacco (Nicotiana Tabacum) ; sweet basil (Ocimun Basilicum); sweet marjoram (Origanum Majorana); poppy (Papaver somniferum) ; horseradish (Roripa Armoracia); summer savory (Saturia hortensis) ; red clover (Trifolium pratense); white clover (Trifolium repens); corn silk (Zea Mays).

The following ORCHIDS may be obtained through nurserymen: Small yellow lady's slipper (Cypripedium parviflorum); yellow lady's slipper (Cypripedium hirsutum).

The following FERns may likewise be procured: Male fern (Aspidinum marginalis) ; polypody leaves (Polypodium onlgare); maiden hair (Adiantum hirsutum).

INDIGENOUS OR NATURALIZED MEDICINAL PLANTS.--The following medicinal plants, not mentioned in the preceding lists, grow in such numbers in this country that it ought not to be difficult to procure them or their seeds for pur- 
poses of cultivation. Possibly the cheapest way to procure both American and foreign plants for purposes of cultivation would be to purchase the fresh or green drug, as of roots, rhizomes, etc., gathered at the resting period of the plant. The recently gathered drug will in some instances contain mature fruits and seeds from which plants may be successfully grown, as the leafand herb-drugs of the Compositæ, Labiatæ, Solanaceæ, etc.

Balsam fir or spruce (Abies balsamea); calamus (Acorus Calamus); European agrimony (Agrimonia Eupatoria); couch grass or dog grass (Agropyron repens); tree of heaven (Ailanthus glandulosa); common chickweed (Alsine media); marshmallow (Althrea officinalis); scarlet pimpernel (Anagallis arvensis); angelica seed (Angelica Archangelica) ; mayweed (Anthemis cotula) ; bitter root (Apocynum androscmifolium); Canadian hemp (Apocynum cannabinum); dwarf elder (Aralia hispida); American sarsaparilla (Aralia nudicaulis); Uva Ursi (Arctostaphylos Uva-Ursi); mescale (Anhalonium Lervinii); burdock (Arctium Lappa); manzanita (Arctostaphylos glauca); Indian turnip (Ariscma triphyllum) ; serpentaria (Aristolochia Serpentaria); southern wood (Artemisia Abrotanum) ; common wormwood (Artemisia Absinthium); wormwood, mountain sage, or Sierra salvia (Artemisia frigida); common mugwort (Artemisia vulgaris) ; Canada snake root (Asarum canadense); white Indian hemp (Asclepias incarnata); silkweed (Asclepias syriaca); pawpaw seed (Asimina triloba); spice bush (Lindera Benzoin); Oregon grape (Bcrberis Aquifolium); black sampson or purple cone flower (Echinacea angustifolia, syn. Brauneria purpurea); borage (Borago officinalis); Indian hemp (Cannabis sativa); shepherd's purse (Capsella Bursa-pastoris) ; blessed thistle (Cnicus benedictus) ; pond-lily or sweet-scented white water-lily (Castalia odorata); blue cohosh (Caulophyllum thalictroides); red root or New Jersey tea (Ceanothus americanus); true unicorn root, star grass (Chamalirinm luteum); celandine (Chelidonium majus); turtle head or snake head (Chelone glabra); American wormseed (Chenopodium anthelminticum); pipsissewa (Chimaphila umbellata); common feverfew (Chrysanthemum Parthenium); Canada thistle (Carduus arvensis); black cohosh (Cimicifuga racemosa); stone root (Collinsonia canadensis); sweet fern (Comptonia pere- 
grina, syn. Myrica asplenifolia); gold thread (Coptis trifolia); coral root or crawley root (Corallorhiza odontorhiza) ; green osier bark (Cornus circinata); red osier dogwood (Cormus stolonifera) ; American dittany (Cunila origanoides); broom tops (Cytisus Scoparius) ; stramonium leaf and seed (Datura Stramonium); turkey corn or squirrel corn (Bicuculla canadensis); wild yam root (Dioscorea villosa); sundew (Drosera rotundifolia); male fern (Aspidium màrginalis and A. Filitr mas) ; bittersweet (Solanum Dulcamara) ; scouring rush (Equisctum hyemale) ; fireweed (Erechtites hieracifolia); fleabane (Erigeron canadense); yerba santa (Eriodictyon californicum ); European centaury (Erythraia Centaurium); boneset (Eupatorium perfoliatum); joe-pye weed (Eupatorium purpureum); yerba reuma or flux herb (Frankenia grandifolia); European wood-strawberry leaves (Fragaria vesca) ; American columbo (Frasera carolinensis) ; cleavers (Galium aparine) ; California fever-bush (Garrya Fremontii) ; wintergreen (Gaultheria procumbens); 5-flowered gentian (Gentiana quinquefolia); purple or water-ayens (Geum rivale); sweet or fragrant life-everlasting (Gnaphalium obtusifolium); grindelia (Grindelia robusta and G. squarrosa); pennyroyal (Hedeoma pulegioides) ; frostwort (Helianthemum canadensis); false unicorn root (Helonias bullata); masterwort, cow parsnip (Heracleum lanatum); hydrastis (Hydrastis canadensis); common St. John's wort (Hypericum perforatum) ; hyssop (Hyssopus officinalis); wild.celandine, pale touch-me-not (Impatiens aurea); twin leaf (Jeffersonia diphylla); mountain or sheep laurel (Kalmia latifolia) ; mountain mint (Koellia incana and K. virginiana); lactucarium (Lactuca virosa); motherwort (Leonurus cardiaca); cancer root or beech drop (Leptamnium virginianum); Culver's root (Leptandra zirginica); lovage (Levisticum officinale); deer tongue, vanilla plant, vanilla leaf (Liatris odoratissima, syn. $\cdot$ Trilisa odoratissima); lobelia (Lobclia inflata); bitter bugle-weed, water or marsh horehound (Lycopus europaus) ; purple bugleweed (Lycopus vinginicus); low, dwarf or running mallow (Malva rotundifolia); horehound (Marrubium rulgare); wild or German chamomile (Matricaria Chamomilla); yellow sweet clover, yellow melilot (Melilotus officinalis); spearmint (Mentha spicata); buckbean; marsh or bean trefoil (Menyanthes trifoli- 
ata); yerba buena (Micromcria Douglasii); squaw-vine, partridge berry (Mitchella repcus) : horsemint leaves (Monarda punctata) ; catnip (Nepcta Cataria) ; large yellow porid lily ( Nymphca advena) ; common evening primrose (Enothcra biennis); sourwood leaves (Oxydendrum arboreum) ; field, red or corn poppy flowers (Papazcr Rhocas); American ivy or Virginia creeper (Parthenocissus quinquefolia); ditch or Virginia stonecrop (Penthorum sedoides); American mistletoe (Phoradendron flaz'scens) ; poke root and berries (Phytolacca decandra) ; small burnet saxifrage, small pimpernel (Pimpinella Sa.rifraga); common or greater plantain leaves (Plantago major); mandrake (Podophyllum peltatum) ; poison-ivy (Rhus toxicodendron) ; senega (Polygall Senega); American, dotted or water smartweed (Polygonum punctatum); bearsfoot (Polymina Uvedalia); hair cap moss (Polytrichum juniperinum); balm of gilead buds or balsam poplar buds (Populus candicans); Indian black-root (Pterocaulon pychnostachyum); dewberry, low running blackberry (Rubus. canadensis); wild red raspberry leaves (Rubus strigosus); high bush blackberry root (Rubus nigrobaccus) ; sheep sorrel (Rume.r Acetosella); yellow dock (Rumex crispus); saw palmetto (Serenoa serrulata); red or American centaury (Sabbatia angularis); quinine flower (Sabbatia Elliottii); blood root (Sanguinaria canadensis) ; soapwort (Saponaria officinalis); trumpet plant (Sarracenia flava); pitcher plant (Sarracenia purpurea); Maryland figwort, heal-all or pilewort (Scrophularia marilandica); maddog skullcap (Scutellaria lateriflora); uncum or liferoot (Senecio aureus); button snake-root, rosin weed (Silphium terebinthaceum); carrion flower (Smila.r herbacea); bamboo-brier root (Smilax Pseudo-china); horsenettle (Solanum carolinense); sweet or anise-scented goldenrod (Solidago odora); European goldenrod - (Solidago Virgaurea); pink-root (Spigelia marilandica); marsh-rosemary (Limonium carolinanum); queen's root (Stillingia sylvatica) ; pencil flower (Stylosanthes biflora); skunk cabbage (Spathyema fetida); tansy (Tanacetum vulgare); dandelion (Taraxacum officinale); cancer root or beech drop (Thelesia uniflora) ; vanilla leaf, deer-tongue (Trilisa odoratissima); hemlock (Tsuga canadensis); coltsfoot (Tussilago Farfara); California laurel (Umbellularia californica); stinging or great nettle 
(Urtica dioica); American hellebore (Veratrum viride); mullein (Verbascum Thapsus) ; blue vervain (Verbena hastata); common speedwell (Veronica officinalis).

Foreign Medicinal Plants.-The following are some of the foreign plants that might be profitably cultivated in this country, but plants and seeds can probably only be obtained through dealers in foreign plants and seeds: Guaco root (Agave planifolia); pellitory (Anacyclus Pyrethrum); safflower or American saffron (Carthamus tinctorius); angelica root (Angelica Archangelica) ; Roman chamomile (Anthemis nobilis); arnica (Arnica montana); sabadilla (Asagrca officinalis); blood flower or bastard ipecacuanha (Asclepias Curassavica); belladonna (Atropa Belladonna); wood betony (Betonica officinalis); borage (Borago officinalis) ; bou-nefa or thapsia (Thapsia Garganica) ; manaca (Brunfelsia Hopeana); bryony (Bryonia alba); canella (Canella Winterana) ; cayenne pepper (several species of Capsicum, see p. 578); senna (Cassia acutifolia and C. angustifolia); lippia Mexicana (Cedronella mexicana); colocynth (Citrullus Colocynthis); colchicum corm and seed (Colchicum autumnale); conium (Conium maculatum); cascarilla (Croton Eluteria); stavesacre seed (Delphinium Staphisagria); duboisia leaves (Duboisia myoporoides); eye-bright (Euphrasia officinalis); gentian (Gentiana lutea); licorice (Glycyrrhiza glabra and the var. glandulifera); black hellebore (Helleborus niger); henbane (Hyoscyamus niger); maté or Paraguay tea (Ilex paraguayensis) ; elecampane (Inula Helenium) ; Florentine orris root (Iris florentina) ; laurel, sweet bay (Laurus nobilis) ; bitter bugleweed, water or marsh horehound (Lycopus europaus); wild or German chamomile (Matricaria Chamomilla); water fennel seed, fine-leaved water-hemlock (Enanthe Phellandrium); poppy (Papaver somniferum); bistort (Polygonum bistorta); tormentilla root (Potentilla Tormentilla); lungwort (Pulmonaria officinalis); rhubarb (Rheum officinale); cevadilla (Schonocaulon officinale); scopola (Scopolia Carniolica) ; figroot or carpenter's square (Scrophularia nodosa); European goldenrod (Solidago Virgaurea); water germander (Teucrium scordium); thapsia (Thapsia Garganica); squill (Urginea maritima); valerian (Valeriana officinalis) ; pansy (Viola tricolor). 
The following medicinal plants grow wild or are cultivated in various tropical and sub-tropical countries, and, while some of them might be grown in this country, still their cultivation would be difficult except under special conditions, which would add very much to the expense of the drug: Jequirity seed (Abrus precatorius); catechu (Acacia Catechu); galangal (Alpinia officinarum) ; fish-berries (Anamirta paniculata); areca or betel nut (Areca Catechu) ; quebracho (Aspidosperma Quebracho-blanco); buchu (Barosma betulina and B. crenulata); manaca (Brunfelsia Hopeana) ; pareira (Chondrodendron tomentosum) ; cinchona bark (Cinchona species); cinnamon bark (Cinnamomum species) ; cola (Cola acuminata) ; myrrh (Commiphora Myrrha) ; turmeric (Curcuma longa); angustura (Cllsparia angostura); tonka bean (Coumarouna odorata and $C$. oppositifolia); coto bark (Drimys Winteri) ; cardamom (Elettaria repens); embelia (Embelia ribes); coca (Erythroxylon Coca); cloves (Eugenia Caryophyllata); chequen (Eugenia Chequen); jambul seed (Eugenia Jambolana); pichi (Fabiana imbricata); asafetida (Ferula fotida) ; musk root (Ferula Sumbul) ; mangosteen fruit (Garcinia Mangostana); guaiac wood and resin (Guaiacum officinale and G. sanctum) ; cocillana bark (Guarea Rusbyi); chaulmugra oil (Gynocardia odorata); logwood (Hematoxylon campechianum) ; cusso (Hagenia abyssinica) ; ipecac (Cephaëlis Ipecacuanha) ; caroba leaves (Jacarandra procera); jalapa (Exogonium Purga) ; calumba (Jateorhiza palmata); rhatany (Kraneria triandra and other species); muirapuama (Liriosma ovata); malabar nut (Adhatoda vasica); kamala (Mallotus philippinensis); condurango (Marsdenia cundurango); nutmeg and mace (Myristica fragrans); guarana (Paullinia Cupana); boldo (Peumus Boldus); calabar bean (Physostigma venenosum); quassia ( $P i$ crcena excelsa); jaborandi (Pilocarpus Jaborandi and other species); allspice (Pimenta officinalis); matico (Piper angustifolium); cubeb (Piper Cubeba); kava-kava (Piper methysticum), black pepper (Piper nigrum); Jamaica dogwood (Piscidia erythrina); tonga bark (Premna taitensis); kino (Pterccarpus marsupium) ; sandal wood (Pterocarpus santalinus) ; pomegranate bark (Punica Granatum); soap-tree bark, Panama bark (Quillaja Saponaria) ; cedron seed (Simaba Cedron); simaruba bark (Sim- 
aruba amara); sarsaparilla (Smilax medica and other species of Smila.r) ; strophanthus (Strophanthus Kombe and S. hispidus); ignatia (Strychnos Ignatii); Hoag-nan (Strychnos malaccensis); nux-vomica (Strychnos Nurr-romica); chirata (Sweertia Chirata); tolu (Toluifera Balsamum); balsam of Peru (Toluifera Pereirce); damiana (Turnera diffusa) ; gambir (Uncaria Gambir) ; ginger (Zingiber officinale).

The following is a summary of the preceding lists:

Cultivated medicinal plants in the U. S........... I90

Wild indigenous or naturalized medicinal plants..... I78

Foreign medicinal plants that might be cultivated..... 56

Foreign medicinal plants uncertain as to cultivation.... 75

These figures, while more or less approximate, show that about three-fourths of all the medicinal plants are growing either wild or in cultivation in this country; and that of the remaining one-fourth, probably one-half of these could be grown in this country, leaving but a comparatively small number of plants that could not be cultivated. 


\title{
PART II.-PHARMACOGNOSY.
}

\author{
CHAPTER I.
}

CRUDE DRUGS.

INTRODUCTORY.

Pitarmacognosy is a term derived from two Greek words which, together, mean a knowledge of drugs. According to modern usage it is generally tunderstood to mean the study of the structure and chemical constituents of crude drugs.

The origin of the word drutg is more or less obscure, but it is now applied to any crude substance which may be employed in medicine, whether of vegetable, animal or mineral origin.

The NATCRAL ORIGIN is the scientific name (generic and specific names) of the plant or animal yielding the drug. In the case of vegetable drugs the nattral origin is spoken of as the вот $\Lambda \mathrm{N}$ ICAL ORIGIN. A vegetable drug usually represents some special part of the plant, but in some instances the entire plant is employed, as chirata.

The habitat of plants is the region where they grow. Sometimes this term is applied erroneously to the drugs themselves. Neither the scientific name of the plant nor the commercial name of the drug may be relied upon as indicating the true habitat of medicinal plants. For example, the specific name of Spigelia marilandica indicates that the plant is found in greatest abundance in Maryland, whereas it is only accasionally met with in that State. In other cases plants are common to a much larger territory than the specific name would indicate, as Prunus rirginiana. The geographical names associated with drugs frequently apply to the places from which they are exported, rather than to the habitat of the plant yielding the drug, as, for example, Para sarsaparilla, which is obtained from a plant growing in the upper Amazon region, is shipped to Para, from whence it is exported. 
Plants which yield drugs may grow wild, as is most usually the case, or they may be cultivated, as those yielding anthemis, cannabis indica and the solanaceous leaves. Plants growing in their native countries are said to be INDIGENous to those regions, as Stillingia sylvatica, of the Southern United States; Aconitum napellus; of the mountainous regions of Europe, etc. Plants are said to be N.ITUR.LIIZED when they grow in a foreign land or in another locality than their native home. Some of these may have been distributed by natural agencies, or they may have escaped from cultivation, or they may have been introduced with the seeds of cultivated plants or with the ballast of ships.

The term COMMERCIAL ORIGIN applies solely to the drugs themselves, and indicates their commercial source, which may be either the country where the plant yielding the drug is grown, or the port from which the drug is sent into the marts of the world. English hyoscyamus leaves are gathered from plants grown in England; Canton rhubarb is the product of plants grown in various parts of China, but shipped by way of Canton.

The official or PHARMACOPCIAL TITLES of vegetable drugs are derived from either the generic name of the plant, as gelsemium, or the specific name, as ipecacuanha, or they may include both the generic and specific names, as viburnum prunifolium, or they may be derived from other sources, as opium and sarsaparilla.

In addition to the botanical names of plants and the pharmacopoial titles of drugs, a number of vernacular names and synonyms are also applied to vegetable drugs, as licorice root for glycyrrhiza; prickly ash for xanthoxylum.

The official or PHARMACOPGIAL DEFINITION of drugs is given in the leading paragraph under each drug in the different pharmacopœias, and includes the botanical origin as well as the name of the part of the plant yielding the drug; and in some cases other special features or requirements are given, as the habitat of the plant yielding the drug, the time of collection, mode of preservation, etc.

The time of the collection of vegetable drugs is of prime importance, and, while we may not be able to make extended generalizations, still, the following general rules for the collection of various drugs may be given: 
(I) Roots, rhizomes and barks should be collected immediately before the vegetative processes begin in the spring, or immediately after these processes cease, which is usually in the fall.

(2) Leaves should be collected when the $\mathrm{CO}_{2}$ assimilation process is most active, which is usually about the time of the development of the flowers and before the maturing of fruit and seed.

(3) Flowers should be collected prior to or just about the time of pollination.

(4) Fruits should be collected near the ripening period, i.c., full grown but unripe.

(5) Seeds should be collected when fully matured.

The PRESERVATION of vegetable drugs is likewise deserving of careful consideration, and attention should be given to the influence of temperature, moisture, air and light, and the attacks of insects. The temperature of the room or part of the store devoted to the storage of dry drugs should not be more than about $25^{\circ} \mathrm{C}$., and nearly uniform throughout the year.

Drugs containing volatile principles require to be kept in airtight containers, as the herbs of the Labiatæ and Compositæ, and wild-cherry bark. Air-tight tin cans are probably the most economical and satisfactory containers for the purpose, and the suggestion has been made to paint the edges of the cans with melted beeswax. Drugs are sometimes stored in wooden boxes or in drawers. This method is objectionable, not only because they are more liable to deteriorate, but because the odors are communicable from one to the other. The storage of drugs in parcels is the most objectionable, particularly, as is usually the case, when the different parcels are stored together.

Those drugs that are difficult to dry, as the inulin-containing drugs, and some fleshy roots and rhizomes, as Veratrum, are liable to become moldy and should be thoroughly dried before placing them permanently in containers.

The preservation of drugs against the attacks of insects is, unfortunately, generally overlooked. Most drugs are subject to their depredations, and are usually attacked by the insects in the larval stage. The insects which infest vegetable drugs belong 
chiefly to the Lepidoptera, Coleoptera and Diptera. The Lepidoptera are the most destructive, and include the cornmeal moth (Tinea zea), which, during its larval (the caterpillar or grub) stage, is known to attack aconite, capsicum, ergot, lappa, linseed, rhubarb, taraxacum and many other drugs. Among the Coleoptera are various members of the Ptinedæ, as Ptinus brumneus, Anobium paniceum and Lasioderma serricome, which attack the spices chiefly, as capsicum, cinnamon and pimenta. Chief among the Diptera is Trypcta arnicivora, which is sometimes found in arnica flowers.

For the destruction of these insects and prevention of their attacks a number of substances and methods have been employed, the simplest method of all being to expose the drug to a temperature of about $100^{\circ} \mathrm{C}$. This method is, however, open to objection, as there is liability either to decomposition or loss of active principle. Camphor and tar-camphor have been employed, but it is doubtful if they should be used, unless in the case of animal drugs. In some instances, as with nutmeg and ginger, the drug is sprinkled in the drying-room, and when packed for market, with quicklime. Benzin and carbon disulphide have been proposed, but these are of a disagreeable odor as well as inflammable. Ether has been suggested, but it is very volatile and inflammable. Formaldehyde has been proposed for the preservation of orris root. The use of chloroform as a preservative was formerly sanctioned by the L.S.P. in the case of ergot, and is probably the best preservative that has been proposed. A few drops of chloroform - added to a drug on placing it in the container will usually prevent it from becoming "wormy." Some drugs, however, as taraxacum and glycyrrhiza, may require inspection from time to time and the addition of a little more chloroform.

Commercial. Forms of Drugs. - Vegetable drugs are brought into market in various forms; they may be crude, that is, more or less entire, or in a powdered condition. Crude drugs may be nearly entire, as seeds, flowers, fruits, leaves, and some roots and rhizomes; or they may be cut or sliced, as in woods, barks, many roots and a few rhizomes. They may be more or less matted together, as in chondrus and the solanaceous leaves; or they may be pressed together by means of hydratulic pressure, giving the 
so-called pressed drugs; or they are first powdered and then molded into forms, as " rhubarb fingers." In some cases the periderm is removed, as in a number of roots (althæa) rhizomes (zingiber) and barks (ulmus).

The oUALITY of vegetable drugs is injured by a number'of factors, of which the following may be mentioned: (I) lack of knowledge or want of care in collecting them;.(2) carelessness in drying and keeping them; (3) insufficient care in garbling and preparing them for the market; $(4)$ inattention in preserving them and storing them; (5) accidental admixture in the store, and (6) adulteration and substitution.

The influence which the TIXIE OF COLLECTION has on the quality of vegetable drugs may be best shown by a few illustrations. It is well known that when the fruits of conium are green they will yield over 3 per cent. of coniine, but when they become yellow the alkaloid diminishes rapidly in quantity, and, therefore, much of the commercial drug will not yield I per cent. of coniine. The same thing may be said of santonica: when the flower heads are unexpanded they will yield over 3 per cent. of satonin, but just so soon as the flower matures there is a rapid disappearance of the anthelmintic principle. Dealers in insect powder (Flores pyrethri) know that the flowers gathered when they are closed produce the finest and most powerful insect powder, worth nearly twice as much as that made from the half-closed or open flowers. It may be that the variation in quality of some of the commercial aconite is due to improper drying, or to the extraction of the active principles; still, there is no doubt but that much of the trouble with this drug is due to the variation in the time of collection in different countries, as well as to its being collected from different species.

Another factor affecting the quality of vegetable drugs is carelessness in drying them and caring for them after they are gathered. In some cases the Pharmacopœia specifies that the drug shall be kept a certain length of time before being used, as in the case of frangula. A similar specification should be made in regard" to rhamnus purshiana; but since the results of the changes on keeping are now ascertained, and since a similar effect may be obtained by heating the bark at $100^{\circ} \mathrm{C}$. for forty-eight hours, this specification seems no longer necessary. 
In some drugs a sort of ripening process takes place in the drying, as in gentian, guarana, vanilla and the solanaceous leaf drugs. In still others a marked deterioration takes place if they are placed in heaps and allowed to ferment, as in the case of lavender and most other drugs yielding essential oils. In the preparation of oil of peppermint, the yield of oil is greater and the quality better if the plants are allowed to dry and are distilled immediately or soon after. On the other hand, the yield of methyl salicylate is greater in the leaves of Gaultheria procumbens or the bark of Betula lenta if they are first macerated in water for about 12 hours.

Quite a number of drugs are not infrequently observed in commerce in a moldy condition, as taraxacum, veratrum, aconite, maranta starch, etc. The question as to what influence this mold has on the quality of the drug has not been decided.

A third cause of inferiority of vegetable drugs is lack of sufficient care in Garpling. This applies to a number of drugs, as leaves, with which may be admixed a large number of stems and roots; rhizomes and tubers, in which the proportion of stemremnants may be excessive, or, as in other cases, the proportion of roots to rhizomes may be large. The roots contain much less of the active principles, and have been found in cypripedium and hydrastis to the extent of 50 per cent.

A fourth factor influencing the quality of drugs is the MANNER OF PRESERVATION. While it is generally conceded that most drugs deteriorate on keeping, still this depends largely upon the manner in which they are kept. Thus, the Pharmacopœia limits the time of keeping of ergot and states how it shall be preserved; yet a number of writers call attention to the fact that, if properly prepared and preserved, the time of keeping may be very much extended. In order to preserve ergot, Grover proposed the removal of the oil, and Moss found the drug thus treated to retain its therapeutic value for six and a half years. Zanon suggests placing the drug in alternate layers with sand and keeping it in a closely sealed jar. Others grind the fresh ergot and preserve with chloroform in paraffin paper, while some first extract the oil from the powder with alcohol or ether.

Accidental admixture in the store or warehouse depends upon the care of the individual, and need not receive attention here. 
The adulterations, substitutions and sophistications will be considered under the respective drugs.

The Valuation of Drugs.-In the identification of vegetable drugs certain characters are taken into account, such as color, odor, general appearance, structure, texture, etc., these at the same time indicating in a greater or less degree the qualitative value of the drug. While these characters may enable the expert to detect very slight variations in quality, and to estimate approximately the value of a given drug, still the true value is based upon the amount of the medicinal principles or so-called active constituents. The methods employed in the valuation of drugs may be grouped as follows: ( I) Chemical, (2) Physical, (3) Microscopical, and (4) Biological.

(I) Chemical methods are more generally employed and usually involve the isolation and estimation of the active principles.

(2) Physical methods involve such processes as the determination of specific gravity of the drug, as of jalap, or the determination of the elasticity or measurement of the fibers, as of cotton, and still other special methods which apply to individual drtigs, showing indirectly their quality.

(3) Microscopical methods of valuation may oftentimes be employed when other methods fail, as, for example, when foreign starches are added to starchy products, as the cereals and spices. Microchemical reactions may also be depended upon in some instances to indicate the value of a drug, as in strophanthus, where the quality of the drug appears to bear a direct relation to the number of seeds giving a green coloration with sulphuric acid. The separation of the salts of the alkaloids in hydrastis on the addition of sulphuric acid is also of value in determining the quality of this drug.

(4) Biological methods involve the consideration of the effects of drugs upon animals or plants. They may be conveniently grouped as follows: I. Effects or influence upon animals, including $(a)$ those dependent upon the perceptions or senses of the experimenter or tester, as color, taste and odor; $(b)$ those which are physiological or pathological. These are usually determined by experiments upon lower animals, as insects, frogs, rabbits, guinea pigs, fowls, and even upon man. 2. The effect or influence 
produced upon plants by drugs, or solutions of their active principles. For experiments of this kind seedlings are usually employed and the effects are based upon the amount of growth of the root of the plant in a given time when placed in the solution. Some of the lower plants (p. 5) are also used in testing the properties of chemicals, which may have a toxic action on the protoplast or a plasmolytic action on the cell (Fig. 55, II).

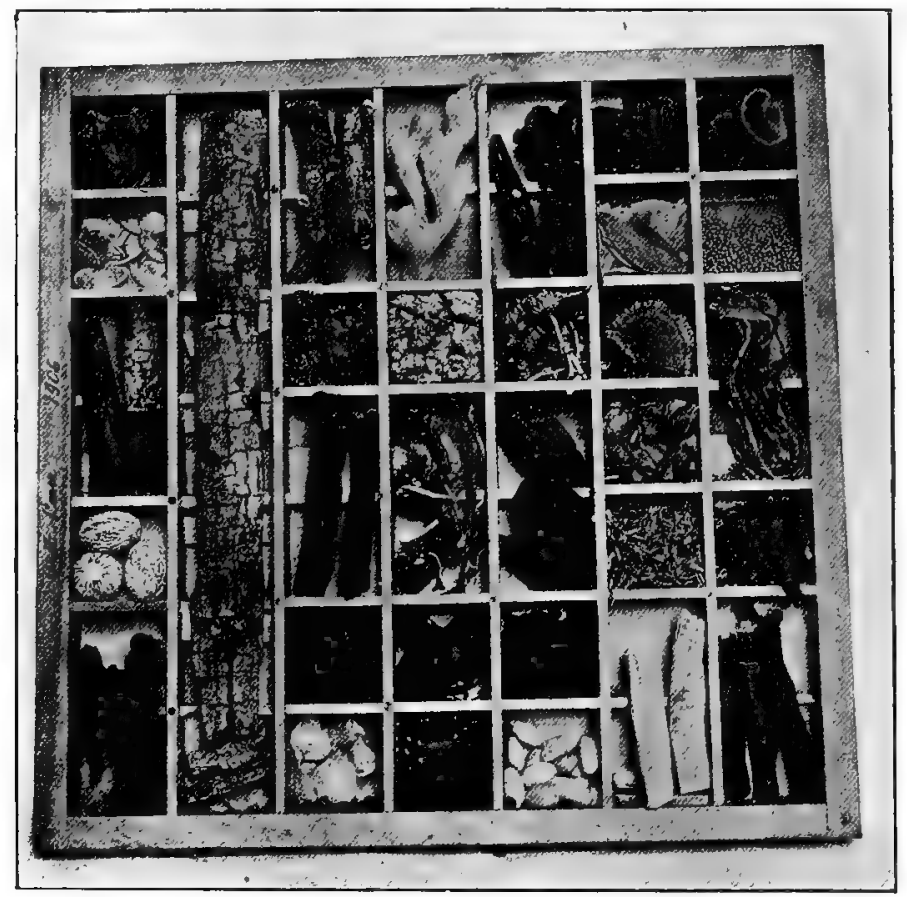

FIG. I83. Case for drug specimens.

Drug Collections.-It is important that the student, pharmacist and analyst possess a collection of typical drug specimens. It is necessary in the study of drugs and also for purposes of identification and comparison. Specimens may be kept in various kinds of boxes and bottles, but one of the most satisfactory ways is to keep them in type cases (Fig. I83) such as are used by printers, the top being covered with glass which can be removed. 
The glass can be kept in place by means of long, broad-headed tacks or can be fastened permanently by means of hinges. The frames may be hung on the wall or held by means of molding.

\section{DRUGS DERIVED FROM ANGIOSPERMS.}

\section{SEEDS.}

Seeds should, as a rule, be collected when they are ripe and carefully preserved against the attacks of insects and changes of various kinds, as those incident to germination. They may, or may not, be dried before using.

The medicinal seeds may be classified as follows:

\section{ENTIRE SEEDS.}

I. Not more than 5 to $6 \mathrm{~mm}$. long.

I. With an appendage (carunclc) :

Ovoid or irregularly globular, dark brown .... Colchici Semen

2. Without an appendage:

A. Anatropous.

a. Ovate, flattened, smooth................. Linum

b. Triangular or quadrangular, reticulate... Staphisagria

B. Campylotropous.

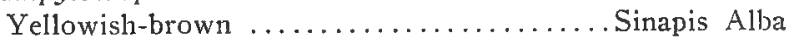

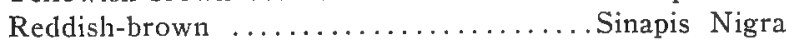

II. From to to $20 \mathrm{~mm}$. long.

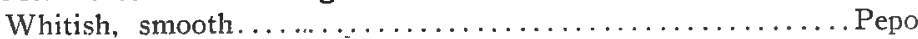

Yellowish-green or light brown, hairy........... Strophanthus

III. From 20 to $30 \mathrm{~mm}$. long.

1. More or less flattened:

$a$. Ovate or oblong-lanceolate.

Taste bitter.................... Amygdala Amara

Taste bland................... Amygdala Dulcis

b. Plano-convex or $3^{-}$to 6 -sided.....................

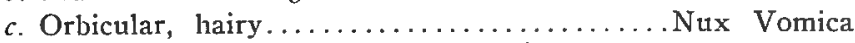

d. Reniform, brownish-red ............... Physostigma

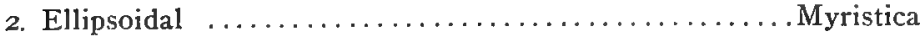

II. PRODUCTS OF OR PARTS OF SEEUS.

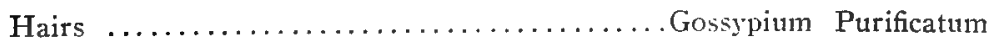

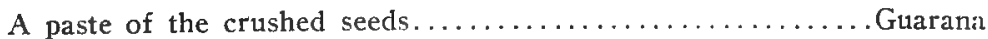

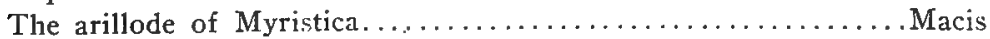


COLCHICI SEMEN.-COLCHICUM SEED.-The dried, ripe seeds of Colchicum autumnale (Fam. Liliaceæ), a perennial bulbous plant, native of and growing in moist meadows in Southern and Middle Europe and Northern Africa (p. 236). The commercial supplies come chiefly from England and Germany.

DESCRIPTION.-Hemi-anatropous, ovoid or irregularly globular, more or less beaked, with an easily detachable strophiole, 2 to $3 \mathrm{~mm}$. in diameter; externally dark brown, becoming darker with age, minutely pitted, the epidermis detached in irregular patches in older seeds; frequently agglutinated when fresh, due to the presence of a saccharine exudation; very hard when dry, tough when damp, internally whitish, endosperm hard, embryo

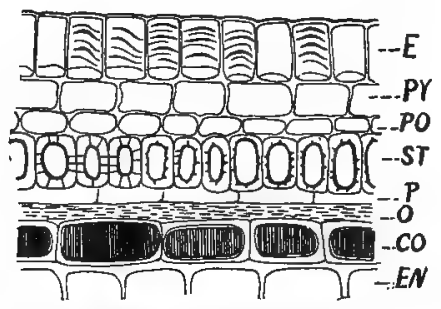

Fro. 184. Transverse section of flaxseed; E, epidermal cells with small lumen and very thick outer wall showing mucilage lamellæ; PY, PO, parenchyma cells; ST, stone cells; $P$, parenchyma below stone cells; $O$, obliterated cells; $C O$, cells with reddishbrown contents; EN, endosperm.

$0.5 \mathrm{~mm}$. long and situated at end opposite the strophiole; nearly inodorous; taste feeble, bitter and somewhat acrid.

Constituents.-Proteids; fixed oil about 6 per cent.; a tannin-like substance in the seed-coat; starch grains in the caruncle; an alkaloid colchicine 0.4 to 0.6 per cent. ( 0.55 per cent. required by the U.S.P.) ; a resinous principle colchicoresin; ash about 2.5 per cent. (See also Colchici Cormus.)

LINUM.-LINSEED OR FLAXSEED.-The seed of $L i$ num usitatissimum (Fam. Linaceæ), an annual, which is cultivated in nearly all temperate and tropical regions, either for the fiber (flax) or seed (p. 303).

DESCRIPTION.-Anatropous, ovoid or oblong-lanceolate, flattened, somewhat less rounded on one side and on one margin, apex acute or beaked, chalazal end rounded, plano-convex in trans- 
verse section, 4 to $5 \mathrm{~mm}$. long, 2 to $2.5 \mathrm{~mm}$. broad, 0.5 to 0.75 $\mathrm{mm}$. thick; externally light brown, very smooth and glossy, the raphe extending as a distinct, light-yellow ridge along one edge, outer wall of epidermal cells transparent, mucilaginous and swelling in water; easily cut; endosperm white, adhering to the seedcoat, embryo light green, straight, 3 to $4 \mathrm{~mm}$. long, I to $2 \mathrm{~mm}$. broad, cotyledons plano-convex; odor slight; taste mucilaginous and slightly unpleasant.

Inner Structure.-See Figs. 99, $A$; I84; 293.

Constituents.-Fixed oil 30 to 40 per cent.; proteids about 25 per cent.; mucilage in outer walls of the epidermal cells; ash I to 4 per cent.

GRound FLAXSEED (flaxseed meal or crushed linseed) is not infrequently deficient in oil on account of its being admixed with "oil-cake" or "cake-meal." The latter is the residue after expressing about 20 to 30 per cent. of the oil naturally occurring in the crushed linseed, and the deficiency is sometimes made up by the addition of mineral oils. Ground flaxseed sometimes contains fragments of the cereals rye and wheat, which is partly due to the fact that these cereals grow in with the flax, and partly because it is sometimes shipped in meal or flour sacks.

STAPHISAGRIA.-STAVESACRE.-The ripe seed of $D \mathfrak{l} l$ phinium Staphisagria (Fam. Ranunculacex), an annual or biennial native of Southern Europe and Asia Minor, and cultivated in Austria (Trieste), Italy and Southern France, from which latter countries the commercial supplies are obtained (p. 27o).

DESCRIPTION.--Anatropous, irregularly triangular or somewhat tetrahedral, one side convex, the others plane, the micropylar end acute or obtuse, 5 to $6 \mathrm{~mm}$. long, 3 to $6 \mathrm{~mm}$. broad; externally dark brown, becoming lighter and duller with age, more or less uniformly reticulate, the pits being about $0.5 \mathrm{~mm}$. in diameter, raphe forming a more or less distinct ridge on the largest of the plane surfaces or on the edge of two united sides, epidermis modified to distinct papillæ; inner seed-coat yellowish-brown, adhering to the endosperm when moistened, the latter white or yellowish, and enclosing at the pointed end a small, straight embryo I $\mathrm{mm}$. long and with a relatively large hypocotyl; slightly odorous; taste of endosperm intensely bitter and acrid. 
Constituents.-Two alkaloids, about one per cent. These are delphinine, which crystallizes in rhombic prisms and resembles aconitine in its physiological action; and staphisagroine, which is amorphous and insoluble in chloroform. The alkaloids delphisine and delphinoidine are probably decomposition products of delphinine. The seeds also contain 25 to 30 per cent. of a fixed oil; an equal amount of proteids; 8 or 9 per cent. of ash; and several resins.

Allied Plants. A number of other species of Delphinium have been investigated and found to have poisonous properties. The seeds of Delphiniun consolida resemble stavesacre, but are only about one-fifth the size.

SINAPIS ALBA.-IVHITE MUSTARD.-The dried, ripe seeds of Sinapis alba (Fam. Cruciferæ), an annual native of Europe and Southwestern Asia and naturalized and extensively cultivated in many countries. The commercial supply of the drug is obtained from plants grown in England, Germany, Holland and Italy (p. 283).

Description.-Campylotropous, irregularly spherical, somewhat compressed, I to $2 \mathrm{~mm}$. in diameter, externally yellowishbrown, seed-coat membranaceous, and minutely pitted, marked on one side by a distinct ridge and two parallel furrows formed by the hypocotyl and cotyledons; internally light yellow, without a reserve layer, hypocotyl curved, cotyledons conduplicate; inodorous; taste pungent and acrid.

Inner Structure.-See Figs. 294; 302, E, F.

Constituents.-Fixed oil 20 to 25 per cent.; mucilage in the outer wall of the epidermal cells; proteids about 30 per cent.; a glucoside sinalbin $\left(\mathrm{C}_{:: 0} \mathrm{H}_{44} \mathrm{~N}_{2} \mathrm{~S}_{2} \mathrm{O}_{16}\right)$, and a ferment myrosin, which yield on interaction a yellowish non-volatile oil (acrinyl sulphocyanide) which is pungent to the taste, but owing to its non-volatile character, does not affect the eyes or nose. In the reaction there is also formed glucose and acid sinapine sulphate. Sinapine is an alkaloid which is decomposed, on heating its solutions with alkalies, into choline and sinapic acid.

Adulterants.-While the whole mustard is seldom, if ever, adulterated, ground mustard may contain wheat middlings or shorts, and occasionally rice or pea flour; when these cereals are 
employed, turmeric is also added to bring up the color, which latter may be detected by means of the microscope (Fig. 290) and by its becoming deep red with sulphuric acid and blue with iodine.

Allied Plants.-The seed of Turnip (Brassica campestris) is supposed to be the white mustard of Sanscrit writers.

SINAPIS NIGRA.-BLACK ML'STARD.-The dried, ripe seeds of Brassica nigra (Fam. Cruciferæ), an annual occurring. much the same as Sinapis alba (p. 283).

Description.-Campylotropous, ellipsoidal or irregularly spherical, I to $1.5 \mathrm{~mm}$. in diameter; externally brownish-red, seed-coat membranaceous, finely pitted, hilum whitish, forming a conical projection, micropyle occurring as a slight depression; without a reserve layer, hypocotyl curved, cotyledons conduplicate; inodorous; taste pungent and acricl.

Inner Structure.-See Fig. 295.

Constituents.-Black mustard contains the same constituents as white mustard, save that it contains more fixed oil (3o to 35 per cent) ; less of the ferment, myrosin; and the sinalbin is replaced by the glucoside, sinigrin (potassium myronate), which is present to the extent of about I per cent. and vielcls on interaction with the myrosin a light yellowish volatile oil (allyl isosulphocyanide or volatile oil of mustard), which has an acrid, burning taste, pungent odor, and also affects the eyes. In the reaction there is also formed glucose and potassium acid sulphate.

Allied Products.-Of the seeds of the other Cruciferæ which somewhat resemble black mustard, the following may be mentioned: The seeds of Field mustard or Sinapis arecnsis, which are almost black and perfectly smooth; the seeds of Sarepta mustard, (Brassica Besseriana), which are larger and distinctly reticulate; Rape or colza seeds (Brassica Napus), which are larger, not reticulate and of a bluish-black color; Turnip seeds yielded by Brassica campestris, which are somewhat larger but less acrid, and are used in India in place of black mustard; and Brassica juncea, which is cultivated in tropical Asia for the same purpose.

PEPO.-PUMPKIN SEED.-The ripe seeds of Cucurbita Pepo (Fam. Cucurbitaceæ), a procumbent herb native of tropical America and possibly tropical Asia, and long cultivated in tropical and temperate zones (p. 387 ). 
Description.-Anatropous, broadly elliptical, acute, acuminate or truncate, flattened, about $20 \mathrm{~mm}$. long, ro $\mathrm{mm}$. broad, about $2 \mathrm{~mm}$. thick; externally white or light yellow, very smooth or somewhat rough from adhering fruit pulp, marked by a shallow groove or slight ridge parallel to and within $\mathrm{I} \mathrm{mm}$. of the margin; raphe not conspicuous, hilum characterized by a minute depression; seed-coat consisting of two distinct layers-the outer white and coriaceous and the inner dark green and membranaceous; embryo white, straight, with a small hypocotyl and two planoconvex cotyledons; slightly odorous when contused; taste bland.

Constituents.-Fixed oil about 40 per cent.; starch about 30 per cent.; proteids; an acrid resin; a glucoside (cucurbitin) and possibly an alkaloid (cucurbitine), the presence of the last two principles needing confirmation; ash 3 to 4 per cent.

Allied Plants.-The seeds of other species of Cucurbita are also used in medicine; in Italy C. martima and in the West Indies $C$. occidcntalis are the sources of the drug.

The seeds of other members of the Cucurbitacex are also employed in medicine; they include the seeds of watermelon (Citrullus aulgaris), cucumber (Cucumis sativus), muskmelon (Cucumis melo) and lagenaria (Cucurbita Lagenaria).

STROPHANTHUS.-The ripe seeds of Strophanthus Kombe (Fam. Apocynaceæ), a twining shrub found in Zambesi and other parts of Eastern Africa (p. 363). The plumose awns at the apex of the seeds are usually removed before exportation (Fig. I85).

Description.-Hemi-anatropous, oblong-lanceolate or spatulate, acute or acuminate, unevenly flattened and in transverse section deltoid or plano-convex, 8 to I $5 \mathrm{~mm}$. long, 3 to $5 \mathrm{~mm}$. broad, $\mathrm{r}$ to $1.5 \mathrm{~mm}$. thick; externally yellowish-green, covered with long hairs giving a silky appearance to the seed, the raphe extending as a distinct ridge from the hilum about half the length of the seed; fracture short; internally whitish, endosperm about $0.2 \mathrm{~mm}$. thick, embryo 6 to $12 \mathrm{~mm}$. long and I to $2 \mathrm{~mm}$. broad, cotyledons plano-convex, about I $\mathrm{mm}$. thick, hypocotyl conical, $2 \mathrm{~mm}$. long; inodorous except when broken; taste very bitter.

When treated with concentrated sulphuric acid the endosperm, in about 65 per cent. of the seeds, becomes green; the cotyledons red or purple and finally green, in some instances. 
Inner Structure.-See Figs. I86; 284, $A ; 306$.

Constituents.-Strophanthin, a crystalline principle occurring chiefly in the endosperm and varying from 0.95 to 3 per cent.; strophanthin is colored greenish with sulphuric acid, and yields on decomposition a crystalline body called strophanthidin; the other constituents are kombic acid and about 30 per cent. of a fixed oil.

Allied Plants.-The seeds of a number of other species and varieties of Strophanthus find their way into the market, but

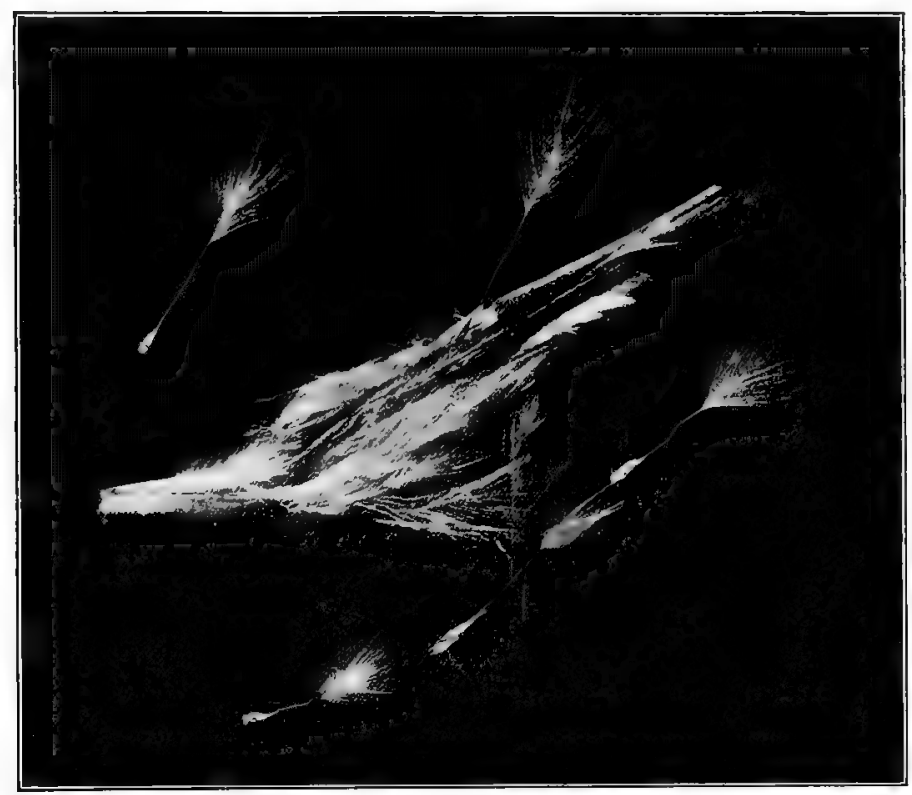

FIG. 185 . A dehiscent follicle of strophanthus showing plumose seeds.

these are usually more or less deficient in strophanthin and hence do not give a greenish color with sulphuric acid. The most important of these are the seeds of Strophanthus hispidus, a plant growing in Upper Guinea and other parts of Western Africa. These are smaller, thicker and less hairy than those of $S$. Kombe and yield less than I per cent. of strophanthin. The commercial drug may contain other Strophanthus seeds, some of which contain calcium oxalate prisms. 
Another principle, pseudo-strophanthin, has been isolated from the seeds of some undetermined species of Strophanthus. This

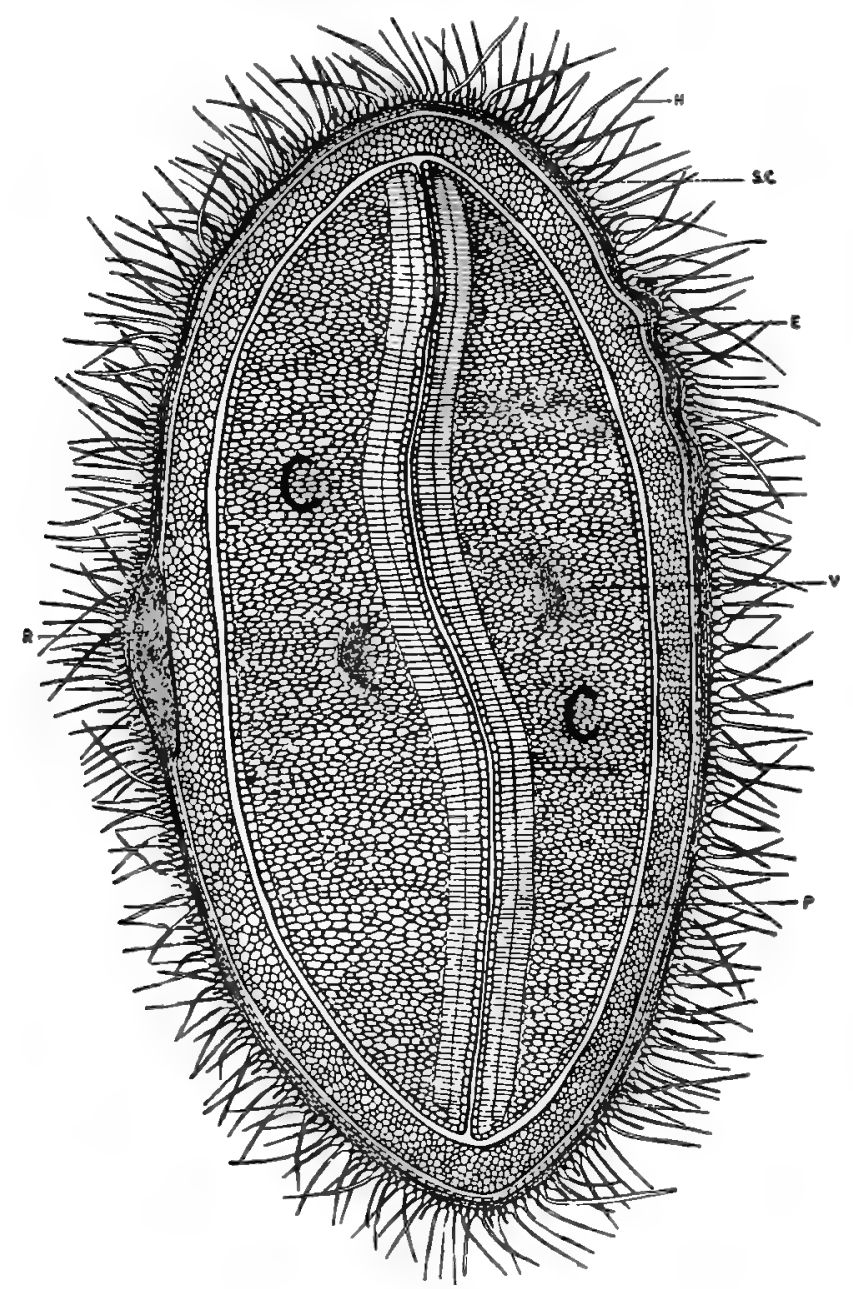

FIG. 186. Transverse section of strophanthus seed; SC, seed-coat with unicellular non-glandular hairs $(\mathrm{H})$; $R$, raphe; $\mathrm{E}$, endosperm; $\mathrm{C}, \mathrm{C}$, cotyledons with fibrovasculer bundle (V) and palisade cells (P).

principle appears to be more powerful than strophanthin, but is less satisfactory as a heart tonic. 
AMYGDALA AMARA.-BITTER ALMOND.-The ripe seed of Prunus Amygdalus anara (Fam. Rosaceæ), a tree native of Asia Minor, Persia and Syria, and cultivated and naturalized in tropical and warm-temperate regions (p. 287). The commercial product is obtained mostly from Sicily, Southern France, Southern Italy and Northern Africa. In commercial almonds the yellowish, more or less porous, fibrous and brittle endocarp is frequently present, and this should be remóved (Fig. 187).

DESCRIPTION.-Anatropous, ovate or oblong-lanceolate, flattened, more rounded on one margin, apex acute or beaked, chalazal end rounded or obliquely truncate, 20 to $30 \mathrm{~mm}$. long, i i to I7
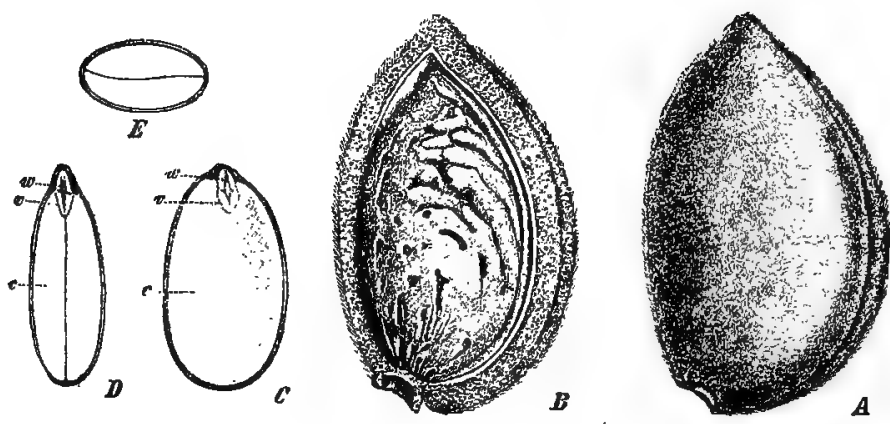

Frg. 187. Drupe-like fruit of almond (Prunus Amygdalus): A, whole fruit with distinct suture; $\mathrm{B}$, longitudinal section showing fibrous sarcocarp, and thin shell-endocarp: C, D, E, sections of the seed; c, cotyledons; w, hypocotyl; v, epicotyl or plumule.-After Focke.

$\mathrm{mm}$. broad, 7 to $9 \mathrm{~mm}$. thick; externally light brown, with numer ${ }^{-}$ ous parallel veins extending from the chalaza to the micropyle, outer walls of epidermal cells modified to distinct papillæ, seedcoat thin, membranaceous, easily removed on soaking the seed in water, the raphe extending on the more rounded edge as a more or less distinct ridge from the hilum to or near the chalaza; fracture short; without reserve layers, embryo straight, whitish, hypocotyl conical, 2 to $3 \mathrm{~mm}$. long, cotyledons plano-convex, sometimes slightly unequal, plumule I mm. long; odorless, except on treatment with water, when an odor of hydrocyanic acid is emitted, or of benzaldehyde when old; taste bitter.

Inner Structure.-See Figs. I 88 ; 302, D; 319. 
Constituents.-Fixed oil 45 per cent.; proteids 25 to 30 per cent.; a glucoside, amygdalin, I to 3 per cent.; and a ferment, emulsin, which acts upon amygdalin, decomposing it into a volatile oil (benzaldehyde or oil of bitter almond) and hydrocyanic acid. In addition to the proteid emulsin, there is another casein-like proteid present, amandin, both of which act as emulsifying agents in the preparation of emulsion of almonds.

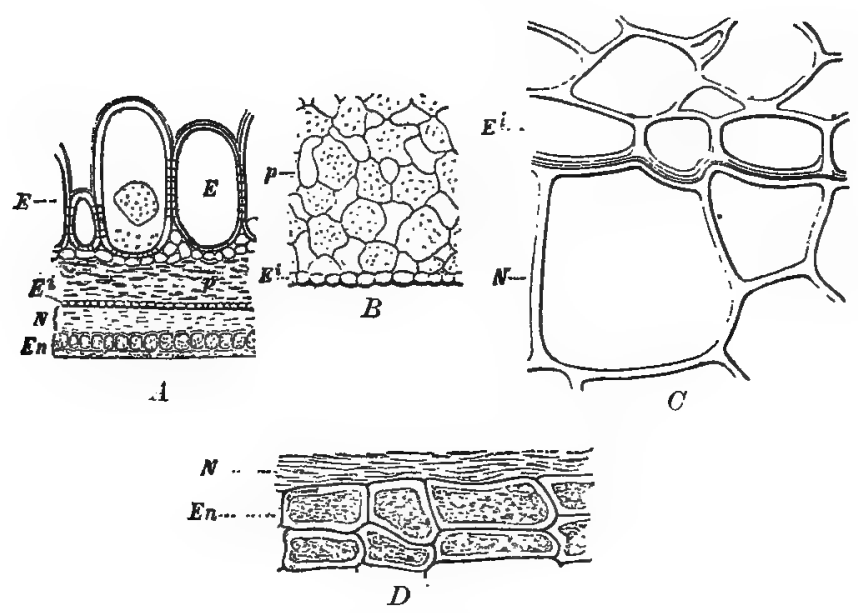

FIG. I88. Sections of almond seed: A, cross section of seed-coat treated with cold potassium hydrate solution and showing outer epidermis $(E)$, inner epidermis (Ei), between which is rather loose parenchyma (p), tissues of nucellus $(\mathrm{N})$ and endosperm $(\mathrm{En})$. B, parenchyma (p) with large intercellular spaces and the inner epidermis of the seed-coat (Ei). C, transverse section of inner epidermis ( $\mathrm{Ei}$ ) and the outer cells of the nucellus (N). $\mathrm{D}$, more or less obliterated cells of nucellus (N) and two layers of the endosperm (En), which remain intact in the ripe seed.-After Meyer.

Amygdalin, or a similar principle, is found in the young shoots and flower-buds, as well as seeds, of apricot, peach, plum, cherry and cherry laurel. (See Wild Black-cherry Bark.)

AMIYGDALA DULCIS.-SWEET ALMOND.-The ripe seeds of Prunus Amygdalus dulcis (Fam. Rosacer), a tree like the bitter almond but more extensively cultivated. The commercial supply is obtained from Northern Africa, Southern France, Italy and Spain, the choicest seeds being imported from Malaga and known as "Jordan almonds" (p. 287). 
DeSCRIPTION.-Closely resembling the Bitter Almond but giving no odor of hydrocyanic acid when treated with water, or of benzaldehyde when old; taste bland and sweet.

Constituents.-Resembling bitter almond, but containing; slightly more fixed oil (about 50 per cent.), and being free from amygdalin.

COLA.-KOLA.-The kernel of the seed of Cola acuminata (Fam. Sterculiaceæ), a tree indigenous to Guinea, and now extensively cultivated in the West Indies and South America. The commercial supplies come principally from Western Africa and the West Indies. The seed obtained from the West Indies is known commercially as Bichy or Bissy-bissy nut. The kernels are used in a.fresh condition or the cotyledons are separated and dried (p. 333).

Description.-Anatropous, plano-convex, polygonal, three to six-sided, 18 to $35 \mathrm{~mm}$. long and 5 to $20 \mathrm{~mm}$. in diameter; externally yellowish or yellowish-red when fresh, but becoming darker with age and on drying, with a shallow furrow indicating the line of union of the two cotyledons, micropyle forming a distinct cleft at one end, otherwise nearly smooth; easily cut when fresh, but hard when dry; without reserve layers, cotyledons unequal and varying from two to five in number, the hypocotyl small; odor distinct; taste astringent, somewhat sweet.

Constituents.-Starch 35 to 40 per cent., the grains resembling those of potato starch but uniformly smaller; caffeine' $\mathbf{I} .5$ to 3.6 per cent.; theobromine 0.02 to 0.09 per cent.; $\mathrm{I} .5$ to 4 per cent. of a tannin which gives a greenish reaction with iron salts, and is in part combined with the caffeine.

CAFFEINE or theine (trimethyl xanthine or methyl theobromine) also occurs in coffee (p. 380), tea (p. 334), cacao (p. 332) and Paraguay tea (p. 322). It separates in the form of acicular crystals having a bitter taste, is soluble in water and alcohol, the solutions being neutral ; and may be sublimerl without decomposition on heating. On treating a small quantity of caffeine with a few drops of nitric acid or chlorine water and evaporating the solution to dryness on a water bath the reddish-yellow residue is colored purplish by ammonia. A similar reaction is also obtained by treating the alkaloid with hydrochloric acid and a crystal 
of potassium chlorate, evaporating the solution and adding a drop of ammonia water to the residue. Caffeine forms crystallizable salts with mineral acids, which are readily decomposed with water or alcohol and yield with mercuric-potassium iodide acicular crystals.

Theobromine (dimethyl xanthine) also occurs in cacao (p. 332 ) and crystallizes in rhombic prisms, which are sparingly soluble in water and alcohol, the solutions being slightly acid. It sublimes on heating without decomposition, and forms crystallizable salts with mineral acids, which are readily decomposed with water. Theobromine on treatment with methyl iodide yields caffeine. Both caffeine and theobromine are also prepared synthetically. Fresh kola nuts also yield from 0.3 to 0.4 per cent. of the glucoside kolatine, which forms prismatic crystals and yields on hydrolysis glucose and a phenolic substance, the latter giving a green color with ferric chloride.

The red color in clried kola seeds is due to an oxydase similar to that which causes the darkening of apples when freshly cut and exposed to the air. If the seeds are first heated in boiling water for 30 minutes and then dried they do not darken.

Allied Plants.-The seeds of a number of other plants are said to be sometimes admixed with kola, and of these the following may be mentioned: Cola Ballayi, a plant growing in the Gaboon, the seeds of which contain six cotyledons and are deficient in alkaloids. The seeds of Garcinia Cola (Fam. Guttiferæ) have been substituted for Cola under the name of "Staminate Cola." These seeds do not contain caffeine, but two resins which seem to have a physiological effect.similar to Cola. The seeds of Pentadesma butyraccum, of Sierra Leone, have also been used as a substitute for Cola; they contain a fat, having a turpentinelike odor, which is used by the natives in place of butter, and hence the tree is known as the "Butter or Tallow tree."

NUX VOMICA.-The dried, ripe seeds of Strychnos Nuxvomica (Fam. Loganiacex), a small tree native of the East Indies and also found growing in the forests of Ceylon, on the Malabar Coast and in Northern Australia. The fruit is a kind of berry with from three to five seeds, which are freed from the bitter pulp by washing, and dried before exportation (p. 362). 
DesCription.-Orbicular, compressed, concavo-convex, sometimes irregularly bent, margin acute or rounded, 17 to $30 \mathrm{~mm}$. in diameter, 3 to $5 \mathrm{~mm}$. thick; externally grayish-yellow or grayishgreen, covered with long hairs giving the seed a satiny luster, sometimes with adhering dark-brown fragments of the fruit pulp, hilum near the center of one side, and a more or less distinct ridge resembling a raphe extending from it to the micropyle; very hard when dry, tough when damp; internally whitish, horny, endosperm in two more or less regular concavo-convex halves, embryo small, situated near the micropyle, and with two heart-shaped cotyledons; inodorous; taste intensely and persistently bitter.

Inner Structure.-See Figs. I22, $C ; 283, B ; 318$.

Constituents.-Ash I to 4 per cent.; igasuric acid, which is related to tannic acid, gives a green color with ferric salts and exists in the seeds in combination with the alkaloids; 1.5 to 5 per cent. of alkaloids consisting of strychnine and brucine, the former comprising from one-third to one-half of the total amount. Strychnine crystallizes in rhombic prisms and gives with concentrated sulphuric acid, in connection with potassium dichromate, a blue or violet color. Brucine forms rectangular octohedra and gives a deep-red color with nitric acid. A glucoside, loganin, is present in the seeds in small amount, but it is found in the pulp of the fruit to the extent of 5 per cent. The alkaloids are probably distributed in both the cell-contents and cell wall. Their presence in the wall is shown by the use of iodine solution and in the contents by the use of potassium dichromate and sulphuric acid. The thick cellulose walls give the hard, horny character to these seeds (Fig. I22, C), as also the date seed. A small amount of starch is found in the fragments of adhering pulp. The seeds are sometimes made to look fresh by the use of a blue dye which is soluble in dilute alcohol.

Allied Plants.-The seeds of Strychnos Ignatii, a woody climber of the Philippine Islands, contain about the same amount of total alkaloids as nux vomica, of which one-third to two-thirds is strychnine. The seeds are irregular, somewhat oblong or ovoid, pebble-like, 20 to $30 \mathrm{~mm}$. long, grayish or brownish-black, more or less translucent, and are nearly free from lignified hairs, such as are found in nux vomica. 
PHYSOSTIGMA.-CALABAR BEAN.-The ripe seed's of Physostigmad z'enenosum (Fam. Leguminosæ), a woody climber growing in the region of the Gulf of Guinea on the western coast of Africa (p. 298). The seeds are also known as "the ordeal bean of Calabar " (Fig. 189):"

DÉSCRIPTION.--Anatropous; 'somewhat reniform or irregularly oblong or ellipsoidal, 25 to $30 \mathrm{~mm}$ : long, 15 to $18 \mathrm{~mm}$. in diam-

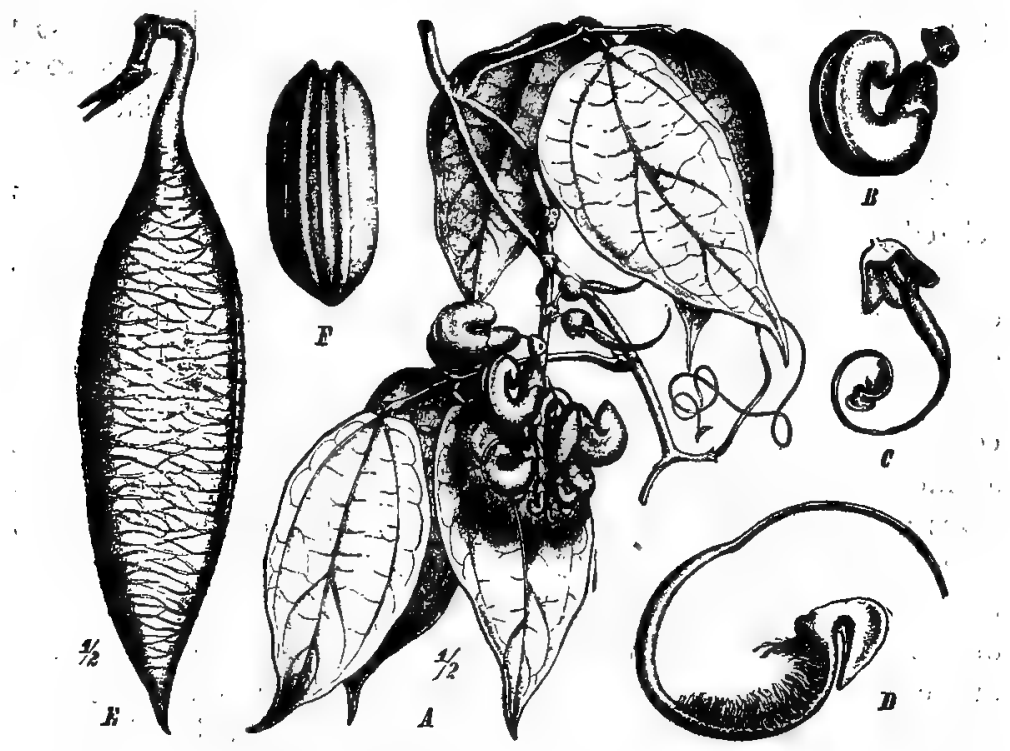

FIG. 189. Physostigma venenosum: A, flowering branch; B, a single flower; C, flower showing. ovary and part of the calyx; $D$, enlarged view of style and stigma; $E$, legume; F, seed.-After Bentley and Trimen.

eter, Io to ' $15 \mathrm{~mm}$. thick, with a brownish-black groove from $\mathrm{I}$ to 2 $\mathrm{mm}$. in diameter extending about half-way around the edge, containing the raphe as a narrow line, and in which is frequently found the remains of the white membranaceous funiculus, the micropyle occurring near one end of the groove as a slight depres $\downarrow$ sion; seed-coat brownish-red, hard, thick, smooth, but somewhat 'rough near the groove; reserve layers' wanting, embryo large, white, with short hypocotyl and two concavo-convex cotyledons; inodorous; taste starchy. 
Constituents.-Starch about 45 per cent.; proteids about. 20 per cent.; fixed oil about 2 per cent.; ash about 3 per cent. Sevi eral alkaloids have been isolated, the most important of which is physostigmine (eserine), which occurs in the embryo to the extent of $0 . \mathrm{I}$ to .25 per cent. It crystallizes in rhomboidal plates; has a strong alkaline reaction, is colored red with alkalies and yellow with sulphuric or nitric acid. With the latter reagent the solur tion changes to olive-green. The aqueous solutions of physostig mine are easily decomposed and a reddish colored substance, rubreserine, separates. The salicylate and sulphate of physostigmine are official, the solutions of the former being more stable. Physostigma also contains eseridine (isophysostigmine), an alkaloid resembling physostigmine in its physiological action; a liquid alkaloid, calabarine, which is physiologically antagonistic to physostigmine, and a crystalline alkaloid, eseramine, which is inactive.

Allied Plants.-The seeds of P. cylindrospermum have been substituted for Calabar bean; they are nearly cylindrical and are said also to contain physostigmine.

The lenticular, brown, glossy seeds of Entada scandens have been offered as a substitute for physostigma. Canavalia obtusifolia, of the East Indies, is also said to have been used as an adulterant of physostigma.

MYRISTICA.-NUTMEG.-The kernel of the seed of $M y$ ristica fragrans (Fam. Myristicaceæ), a tree indigenous to the Molucca and neighboring islands, and now extensively cultivated in other tropical regions, including the West Indies. The commercial supply is largely derived from the Malay Archipelago, from whence it is shipped to Amsterdam and London. The testa and arillode are removed, the latter constituting MACE. With the exception of those from Penang, nutmegs are not infrequently partially coated with lime to protect them from the attacks of insects (p. 277).

Description.-Ellipsoidal, 20 to $30 \mathrm{~mm}$. long, 15 to $20 \mathrm{~mm}$. in diameter; externally light brown, usually whitish from a dressing of lime, reticulately furrowed, at one end a white, smooth projection 3 to $5 \mathrm{~mm}$. in diameter, in the center of which is the micropyle, the chalaza indicated near the other end by a slight, dark depression, from which there extends a more or less distinct. fur- 
row indicating the position of the raphe; easily cut, the surface having a waxy luster, and mottled by reason of the light-brown perisperm penetrating into the yellowish-brown endosperm, the shrunken embryo lying in an irregular cavity about 4 or $5 \mathrm{~mm}$. long, near the micropyle; odor and taste aromatic and pleasant.

Constituents.-Fixed oil, sometimes occurring in prismatic crystals, 25 to 40 per cent.; volatile oil 8 to 15 per cent. The oil is official as oleum myristicæ and contains myristicin and a number of terpenes. Nutmegs also contain considerable proteids and starch, the latter being colored blue by iodine solutions.

Allied Plants.-Other species of Myristica yield nutmegs which are used by the natives, as $M$. succedanea of Timor, $M$. fatua of the Indian Archipelago, and M. Kombo of Guinea. The kernels of the seeds of $M$. fatua constitute the LONG, WILD, OR MALE NUTMEG. They are narrow-ellipsoidal, feebly aromatic and have a more or less disagreeable taste. The seeds of $M$. officinalis and $M$. Bicuhyba of Brazil have medicinal properties, a balsam being obtained from the latter, which is used as a substitute for copaiba. The so-called African nutmegs derived from M. surinamensis of the West Indies soon lose their odorous properties. M. sebifera of Guiana yields a fatty oil which has but little odor of nutmeg. Fatty and ethereal oils resembling those of nutmeg are found in the "American nutmegs" obtained from Cryptocarya moschata (Fam. Lauraceæ) of Brazil.

Adulterants.-False nutmegs consist of exhausted powdered nutmegs or defective nutmegs and mineral matter.

GOSSYPIUM PURIFICATUM.-PURIFIED COTTON. The hairs of the seeds of Gossypium hirsutum, G. barbadense, and other species of Gossypium (Fam. Malvaceæ), biennial or triennial shrubs indigenous to sub-tropical Asia and Africa, and cultivated in all tropical and sub-tropical countries (Fig. I66). The seeds are hand-picked, freed from dust by screens or drums, and the cotton removed in the cotton-gin. It is then freed from mechanical impurities, deprived of fatty and other substances and finally bleached. It is estimated that 1000 million $\mathrm{K}$. of cotton are produced annually. Long staple or sea-island cotton is obtained from G. hirsutum, while short staple or upland cotton is derived from G. barbadense (p. 329). 
Description.-A white, soft tufted mass, consisting of somewhat flattened, twisted and spirally striate, I-celled, non-glandular hairs, from 2.5 to $4.5 \mathrm{~cm}$. long ; inodorous and tasteless.

Absorbent cotton is soluble in ammoniacal solution of cupric oxide, yields less than I per cent. of ash, and on treating it with water the solution should have a neutral reaction and not give any reaction with ammonium carbonate, barium chloride, mercuric chloride or silver nitrate.

Adulterants.-Various substances may be addled to absorbent cotton to increase the rate of absorption of water, as chlorides of calcium, magnesium and zinc, glycerin and glucose; as loading materials, barium and calcium salts, and clay are added to inferior grades of the article.

The hairs from immature seeds are known as "dead cotton" and are distinguished by having very thin walls, a thin outer layer of cutin, but lack the essential properties for technical uses.

GUARANA.-A dried paste consisting of the crushed seeds of Paullinia Cupana (Fam. Sapindaceæ), a climbing shrub native of Brazil and Uruguay. The commercial product is obtained from cultivated plants. The ripe seeds are deprived of the appendage or aril, crushed, made into a doughy mass with water, sometimes tapioca being added to increase the adhesiveness, molded into forms and dried at a gentle heat. During the drying the mass undergoes a kind of curing. Considerable skill is required in supervising the operation, which is performed by special workmen. In addition to its use in medicine, Guarana is used in the preparation of a beverage which is used like tea and coffee by the people of Brazil (p. 324).

Description.-Cylindrical sticks, 15 to $30 \mathrm{~cm}$. long, 35 to 50 $\mathrm{mm}$. in diameter; externally blackish-brown, surface marked by depressions, but otherwise smooth; hard, heavy and brittle, the fracture being uneven; internally light brown to reddish-brown, somewhat variegated from the fragments of contused seeds; odor slight; taste astringent, bitter.

Constituents.-Caffeine 2.5 to 5 per cent. ; tannin (catechutannic acid) about 25 per cent.; ash about 2 per cent. Guarana also contains considerable starch, a small amount of catechin, a volatile oil, an acrid, green fixed oil, and saponin. (Also see Cola.) 
MACIS.-MACE.-The arillode of the seed of Myristica fragrans (Fam. Myristicaceæ). (See Nutmeg.) According to Warburg the arillode arises in the region of the hilum before the flower opens and fertilization is effected (p. 277).

DESCRIPTION.-In coarsely reticulate bands about I mm. thick, the whole having the outline of the nutmeg, the basal portion

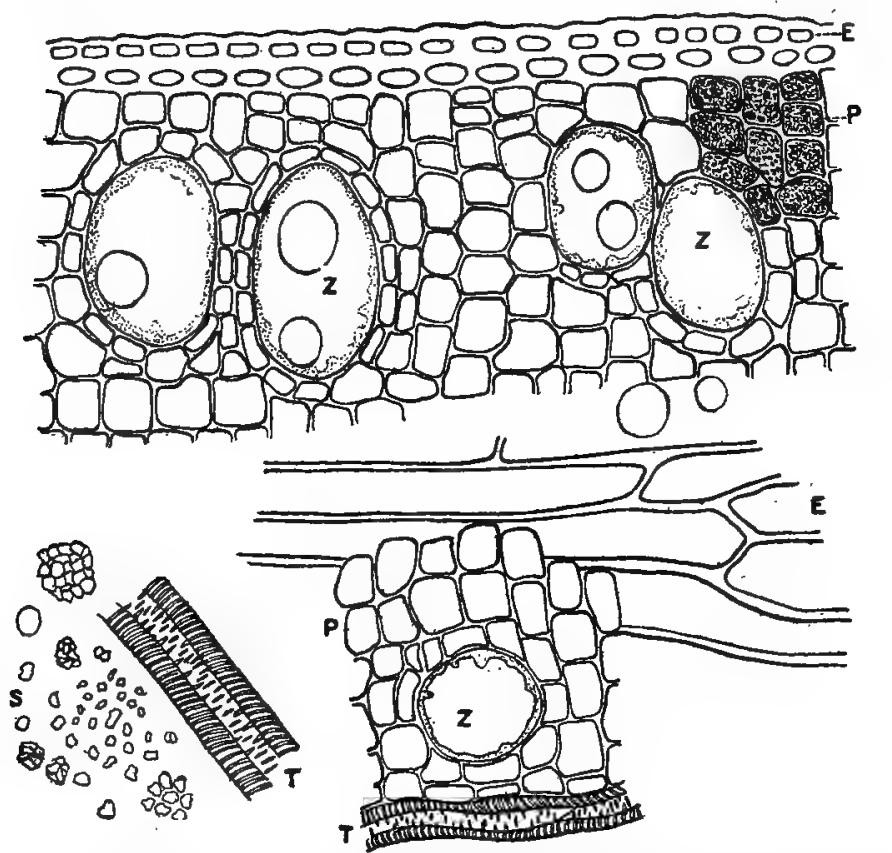

FIG, Igo. Mace: E, epidermal cells, which in transverse section are nearly isodia. metric, but in longitudinal section are elongated, sometimes being $\mathbf{I ~ m m}$. in length; $\mathbf{P}$, parenchyma cells with small starch grains which are colored reddish with iodine; $Z$, large oil cells showing oil globules and protoplasmic contents lining the walls; T, trachex; S, smail, irregular starch grains.

united, but with a small, irregular opening; usually in compressed, nearly entire pieces, reddish or orange-brown, somewhat translucent, brittle when dry; odor and taste aromatic.

Inner Structure.-See Fig. Igo.

Constituents.-An aromatic balsam 24.5 per cent.; volatile oil 4 to 7 per cent. and resembling that obtained from nutmegs but containing a,larger percentage of terpenes; fixed oil, and con- 
siderable starch, which is colored red by iodine solution, distinguishing it from nutmeg; starch. Mace also contains from 2 to 4 per cent. of a dextrogyrate sugar.

True mace should yield from 20 to 30 per cent. of non-volatile ether extract, from 20 to 30 per cent. of starch, and not more than 3 per cent. of ash.

Allied Plants.-Macassar or Papua mace, derived from Myristica argentea, is somewhat darker and with broader segments than true mace. It gives a cherry-red color with concentrated sulphuric acid, is very pungent and yields over 50 per cent. of non-volatile ether extract, and less than ro per cent. of starch.

Bombay mace, or wild mace, is the product of Myristica malabarica; it is distinguished from true mace in that the entire mace is narrow-ellipsoidal, the reticulations are not so coarse, the apex is divided into numerous narrow lobes, and it is darker in color. With alkalies or sulphuric acid wild mace assumes a darker color than the true mace does. It is slightly aromatic, but has little value as a spice, and yields nearly 60 per cent. of non-volatile ether extract.

\section{ROOTS AND RHIZOMES.}

Roots and rhizomes represent those parts of plants which develop under ground, the latter having all of the characteristics of stems except their manner of growth. Most drugs derived from roots and rhizomes possess the typical characteristics of these plant parts, the commercial products being readily distinguishable as such. There are some, however, that are more or less intermediate in character, and, while commonly spoken of as roots, they are in reality modifications of the stem, at least in part, as aconite, gelsemium, glycyrrhiza and rhubarb. For this reason, and in order to facilitate their study, roots and rhizomes are here considered in one class, which is subdivided as follows: (I) True Roots ; (2) Rhizomes that are root-like, at least in part; (3) True Rhizomes; (4) Corms ; (5) Bulbs.

Some of the roots and rhizomes that are employed in medicine are prepared for market by removing a part of the periderm; in a general way this treatment is objectionable, particularly in the case of those drugs containing volatile principles, as these 
exist in greatest amount in the cortical portion, and the periderm serves to prevent the volatilization as well as deterioration of these principles.

Rhizomes are distinguished as upright, horizontal or oblique, depending upon their manner of growth, and this may be determined in the drug by placing the rhizome in such a position that the stem-scars are horizontal.

\section{True Roots.}

I. Monocotyledons Sarsaparilla

2. Dicotyledons.

A. Peridern removed Althæa

B. Periderm present.

a. Roots nearly entire.

Tuber-like ..........................Jalapa

Long, thin and of a reddish color......... Krameria

Fusiform, very acrid................Pyrethrun

Keeled, crown knotty.................... Senega

Fusiform, small, yellowish central wood. Taraxacum

b. Roots cut into transverse pieces.

Ycllowish-green disks .....................

Concentric zones of collateral fibrovascular bundles ......................... Pareira

Bark soft, spongy and finely fibrous....... Stillingia

Very light in weight, wood large with

fibers interlacing .................. Sumbul

c. Roots cut into longitudinal pieces.

Characteristic odor and taste..... Belladonnæ Radix

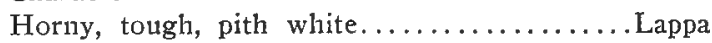

Ribbon-like slices, very fibrous.......... Phytolacca

$d$. Roots more or less broken into pieces.

Bark transversely fissured and easily separable from the wood.............Apocynum

Somewhat tortuous, bark irregularly annulate and sometimes transversely

fissured ...................... Ipecacuanha

\section{Rhizomes that are Root-like.}

A. Periderm renoved.

Yellowish, fibrous, taste sweetish......Glycyrrhiza (Russian)

Reddish-brown, heavy, granular................ Rheum 
II. Rhizomes that are Root-like.-Continucd.

B. Periderm priscut.

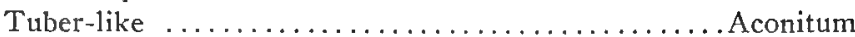

Cylindrical, fracture tough, wood whitish..........Gelsemium

Cylindrical pieces, tough, wood yellowish............Berberis

Annulate above, odor characteristic................ Gentiana

Fibrous, taste sweetish..............lycyrrhiza (Spanish)

\section{True Rhizomes.}

I. Filices See Aspidium

2. Monocotyledons.

A. Periderm remored ..................... Zingiber

B. Pcridcrm present.

u. Rhizome and roots.

a Horizontal in growth.

Light brown, few roots.......... Convallaria

Dark brown with densely matted

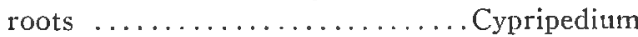

Small pieces, grass-like, hollow

in the center ................. Triticum

$\beta$ Rhizome upright............ Veratrum Viride

3. Dicotyledons.

b. Rhizome without roots............................

a. Rhizome with roots.

a Rhizome horizontal.

Numerous upright or curved branches

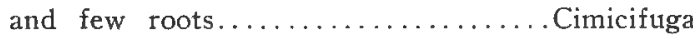

Internally deep yellow................Hydrastis

Light brown and with numerous coarse roots $\ldots \ldots \ldots \ldots \ldots \ldots \ldots \ldots \ldots$ Leptandra

$\dot{\beta}$ Rhizome oblique.

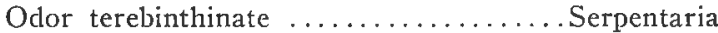

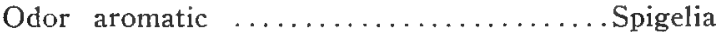

$\gamma$ Rhizome upright .................Valeriana

b. Rhizome without roots.

u Entire rhizomes.

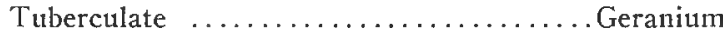

Prominent seal-like stem-scars........ Podophyllum

Internally with reddish resin cells...... Sanguinaria

$\beta$ Longitudinal pieces ................. Scopola

IV. Corm.

Transverse reniform disks

.Colchici Cormus

V. Bulb.

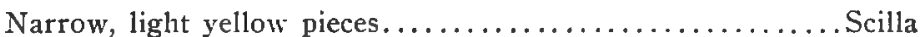


SARSAPARILLA.-The dried root of various species of Smilax (Fam. Liliaceæ), perennial climbers indigenous from Mexico to Brazil (p. 238). There are four principal commercial varieties: (I) Honduras sarsaparilla yielded by Smilax offici-

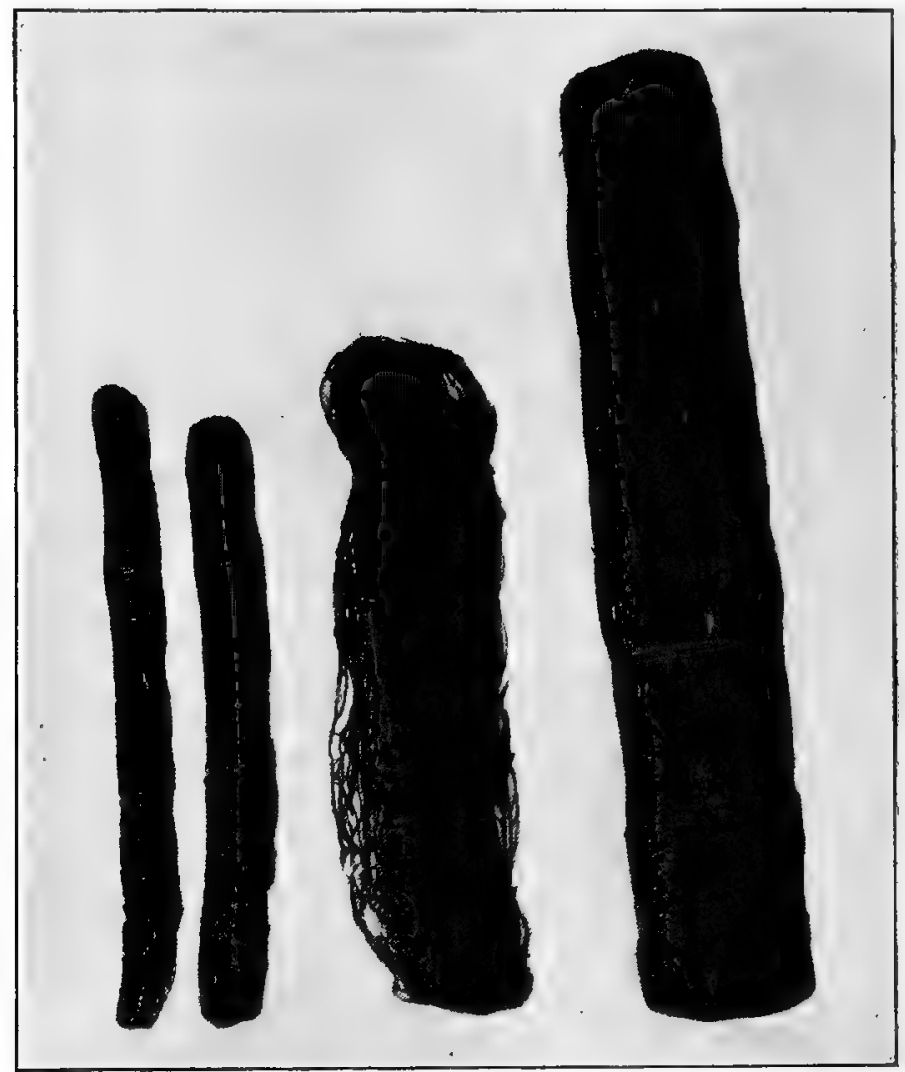

Fig. Igr. Bundles of sarsaparilla, the two on the left being Honduras; the next one, Mexican, and the large one, Para.

nalis, growing in Guatemala, Honduras and Nicaragua, and exported from Honduras and Belize; (2) PARA sarsaparilla, yielded by Smila.r papyracea, growing in the upper Amazon region, and exported from Para; (3) Mexican sarsaparilla. yielded by Smilax medica (Fig. I3I), growing in Mexico, and 
exported from Vera Cruz and Tampico, and (4) Jamaica or Central American sarsaparilla, derived from Smila.t ornata, growing in the United States of Colombia, Costa Rica and Nicaragua, and shipped to Jamaica, from whence it is exported-chiefly to London. There is also a native Jamaica sarsaparilla which is obtained from plants cultivated in Jamaica. The Honduras and Mexican varieties are chiefly used in this country, although Para sarsaparilla has been employed to a certain extent for years.

Description.-Honduras Sarsaparilla.-In bundles about I $M$. in length and from 8 to $15 \mathrm{~cm}$. in diameter, consisting of

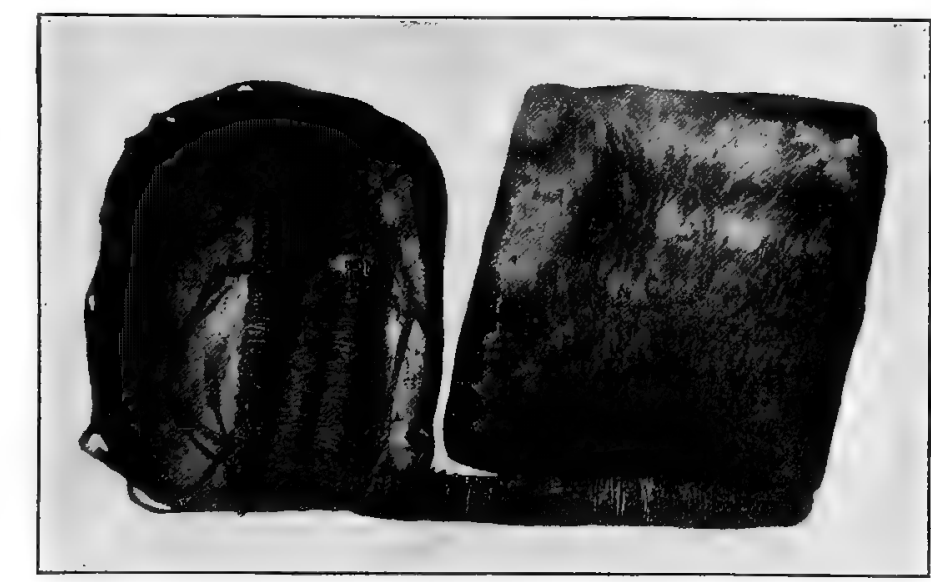

FIG. 192. "Ceroons" made of hide, in which Honduras sarsaparilla is imported.

the long, folded roots, and rhizomes, bound together by roots of the same plant or stems of some other plant, the ends of the bundles being trimmed in some cases (Figs. 19r, I92); roots about $2 \mathrm{M}$. long and uniformly about 2 to $6 \mathrm{~mm}$. in diameter; externally dark or reddish-brown, longitudinally furrowed, minutely hairy and having slender rootlets, the furrows usually free from soil; fracture fibrous; internally consisting of a white pith, a light-yellow, porous, central cylinder and a grayish-white or dark-brown cortex, the latter being lighter and more starchy near the growing end, and darker (more resinous) near the union with the rhizome; odor slight; taste slightly acrid (Fig. I93). 


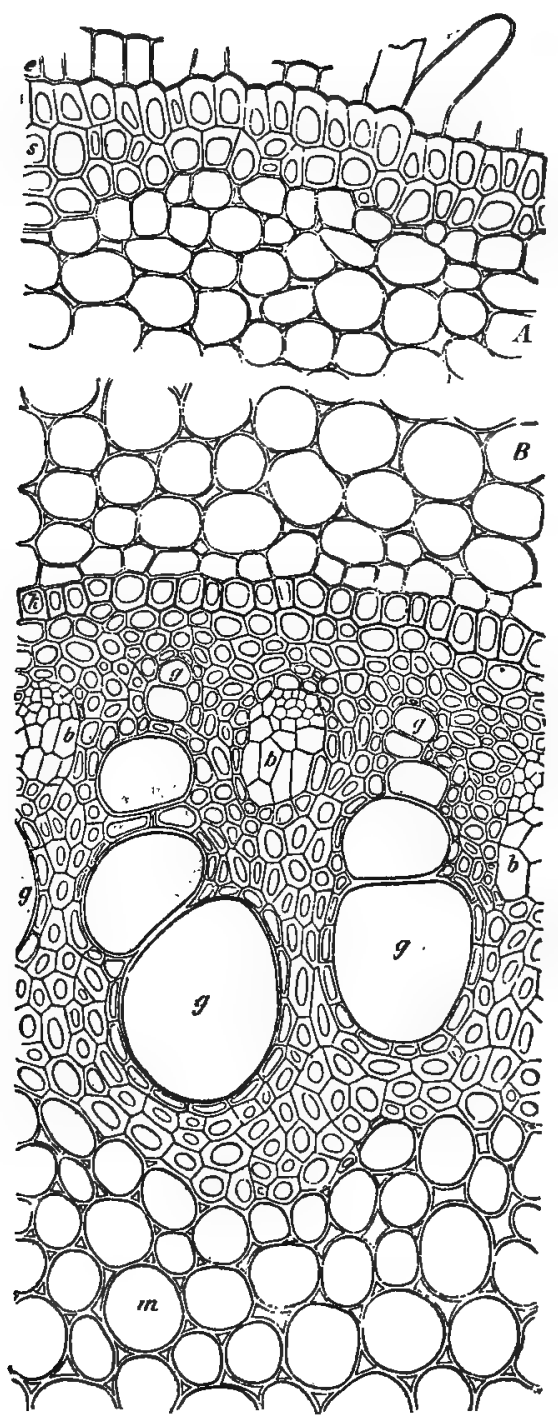

FIG. I93. Transverse section of Honduras sarsaparilla in which the middle portion of the cortex is omitted; e, epidermis with root hairs; $s$, hypodermis: A, outer portion of cortex; $B$, inner portion of cortex; $k$, endodermis; $g$, trachea; $b$, sieve cells; $m$, parenchyi $\mathrm{ma}$ at the center of the root. The thick-walled cells around the tracheæ and sieve cells are sclerenchyma fibers.-After Luerssen. 
The cells of the endodermis and hypodermis are oblong in transverse section and nearly uniformly thickened (Fig. I94).

Mexican Sarsaparilla.-In bundles, with the roots more or less free (Fig، 19I); the latter grayish-brown, somewhat shrunken, the furrows containing larger or smaller amounts of
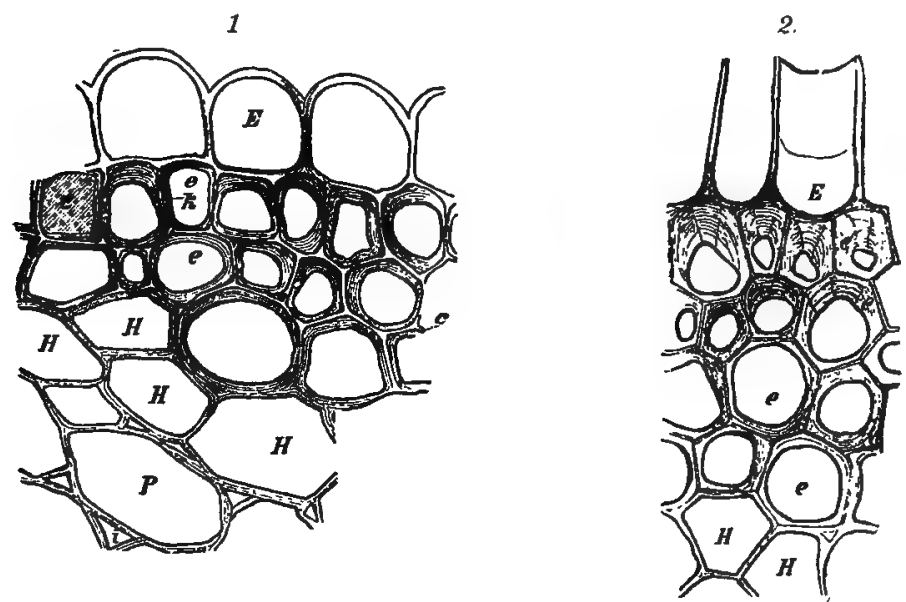

4.
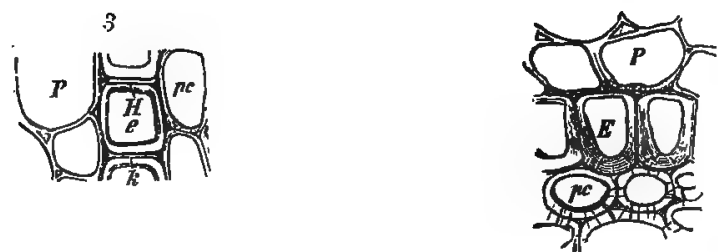

FIG. I94. I, transverse section of Honduras sarsaparilla showing the hypodermal cells (e) with cork lamella (k); 2 , similar section of Mexican sarsaparilla; 3 , transverse section of Honduras sarsaparilla showing endodermal cells (e) with cork lamella (k) and lignified walls $(\mathrm{H}) ; 4$, similar section of Mexican sarsaparilla showing endodermal cells $(E)$. -After Meyer.

soil. The outer walls of the cells of the hypodermis and the inner walls of the cells of the endodermis are considerably thickened (Fig. I94.)

Para Sarsaparilla,-Closely resembling Honduras sarsaparilla in structure, but coming into market in the form of large bundles (Fig. I9I), closely bound by means of the stem of a vine, and the ends evenly trimmed. 
Jamaica Sarsaparilla occurs in rather loose bundles. The roots are especially marked by the numerous coarse rootlets. The cells of the hypodermis and endodermis somewhat resemble those of Mexican sarsaparilla.

Constituents.-Sarsaparilla contains three glucosidal principles, which are present to the extent of about 3 per cent-Darillin, saponin and sarsosaponin, of which the latter is the most active; it also contains about 15 per cent. of starch; raphides of calcium oxalate; volatile oil, and resin.

Allied Products.-American Sarsaparilla is the thizome of wild or Virginia sarsaparilla (Aralia nudicaulis, Fam. Araliaceæ), a perennial acaulescent herb, indigenous to Canada and the Northern United States as far west as Nebraska. The rhizome is of variable length, from 5 to $15 \mathrm{~mm}$. thick; externally brownishgray and somewhat annulate; internally light brown, more or less spongy, and having an aromatic odor and taste. It contains about 0.33 per cent. of a volatile oil, which is bitter and pungent; 3 per cent. of resin; tannin, starch and rosette aggregates of calcium oxalate.

The rhizome and roots of American spikenard (Aralia racemosa), growing in the Eastern and Central United States, have constituents similar to those of $A$. nudicaulis, but are more aromatic. The bark of Hercules' Club (Aralia spinosa), of the Eastern and Central United States, contains the glucoside araliin and possibly also saponin.

The roots of Cocculus villosus (Fam. Menispermacex) are used in the East Indies like sarsaparilla.

ALTHÆA.-MARSHMALLOW.-The dried root of $\mathrm{Al}$ thea officinalis (Fam. Malvaceæ), a perennial herb (p. 329) native of Central and Southern Europe, and naturalized in the United States in the marshes from Massachusetts to Pennsylvania. The commercial supply is obtained from plants cultivated in Germany, France and Holland. The roots are collected from plants of the second year's growth, and the periderm and rootlets are removed.

DESCRIPTION.-Nearly entire, cylindrical, tapering, to to 20 $\mathrm{cm}$. long, 5 to $20 \mathrm{~mm}$. in diameter; externally very light brown, obscurely $4^{-}$to 6 -angled, deeply furrowed longitudinally, covered with detachable bast fibers, with few circular root-scars; fracture 
of bark tough, fibrous, of wood short and granular; internally light brown, finely radiate, bark 0.5 to $2 \mathrm{~mm}$. thick, and easily separable from the wood, cambium zone marked by a distinct brown line, wood porous; odor faint, aromatic; taste sweetish, mucilaginous (Fig. 99, $B$ ).

Constituents.-Mucilage 25 to 35 per cent.; asparagin (amido-succinamide) I to 2 per cent., which occurs in hard crystals with an acid reaction, insoluble in alcohol but soluble in 50 parts of cold water; starch about 35 per cent.; pectin about Io per cent.; sugar about to per cent.; ash about 5 per cent. An infusion of althæa is colored bright yellow with dilute solutions of the alkalies.

Allied Plants.-The roots of a number of other genera of this family are used for similar purposes, as those of Kosteletzyka pentacarpa of Southern Europe; Hibiscus Bancroftianus of the West Indies ; Malvaviscus pentacarpus of Mexico; H. Rosa. Sinensis of tropical Asia and cultivated; Althea rosea of the Levant and cultivated; and Sida ovalis of Peru. Mucilage is also found in the flowers and leaves of one or more species of Malva, Sida, Pavonia, Hibiscus, Pachira and Eriodendron.

JALAPA.-JALAP.-The tuberous root or tubercle of Exogonium Purga (Fam. Convolvulaceæ), a perennial twining herb (p. 365) native of the eastern slopes of the Mexican Andes, and cultivated in Jamaica and India. The roots are collected in the fall and dried by artificial means, the larger ones being first cut into longitudinal pieces. Mexico furnishes the principal part of the commercial supply, which is exported from Vera Cruz.

DESCRIPTION.-Fusiform, irregularly ovoid or pyriform, upper end more or less rounded, lower end obtuse or slightly acuminate; 3 to $8 \mathrm{~cm}$. long, I to $5 \mathrm{~cm}$. in diameter; externally dark brown, deeply and irregularly furrowed longitudinally, otherwise nearly smooth or wrinkled, with numerous lenticels 2 to $4 \mathrm{~mm}$. long and few circular rootlet-scars; fracture horny and resinous; internally dark brown and marked by more or less distinct, secondary, concentric cambitum zones; odor fruity; taste starchy and slightly acrid.

Tubercles which have a specific gravity less than 1.275 and are white internally should be rejected.

InNER Structure.-See Fig. I95. 
Constituents.-Resin 8 to 12 per cent., 85 to 90 per cent. of which consists of a glucoside jalapurgin (convolvtulin), which is

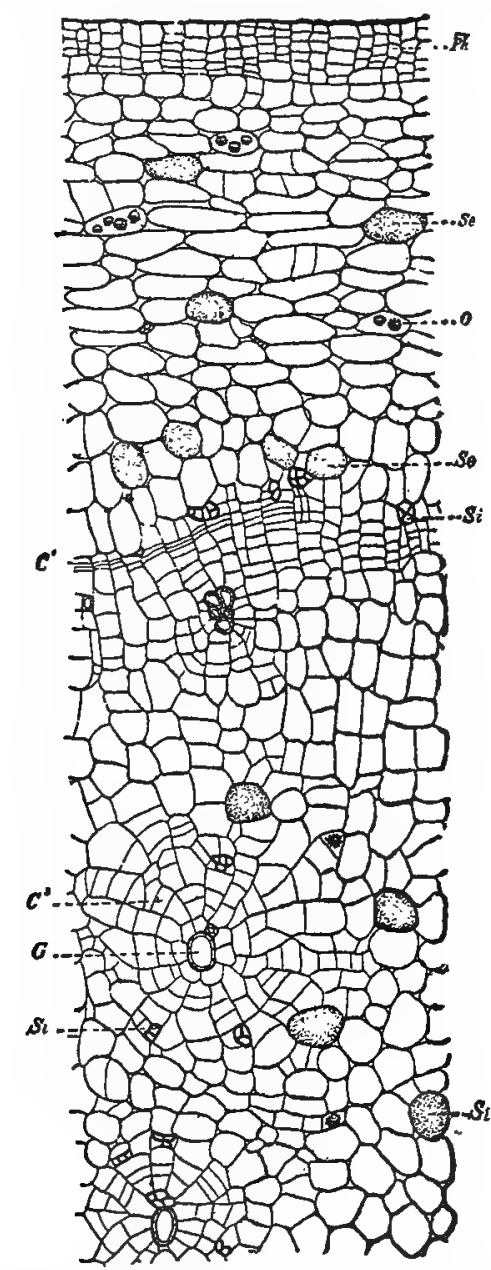

Frg. 195. Transverse section of jalap: Ph, cork cells; Se, resin cells; O, rosette

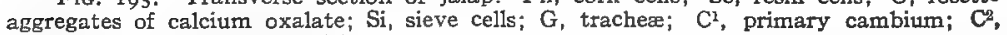
secondary cambium.-After Meyer.

insoluble in ether and the more active constituent; and jalapin, which is soluble in ether and resembles scammonin. Jalap also contains calcium oxalate, starch, gum and sugar. 
Allied Plants.-Turpeth root or Indian Jalap, is the root of Operculina Turpethum, a plant growing in the East Indies. It contains a resin consisting chiefly of turpethin and some jalapurgin.

Male Jalap or Orizaba is the root of Ipomcea orizabensis, a plant indigenous to Mexico. The drug consists of the entire, spindle-shaped roots, or of more or less rectangular pieces, and contains about to per cent. of scammonin.

Ipomoe simulans, indigenous to the eastern slope of the Mexican Andes, yields the Tampico jalap, which is more or less uniform in thickness, somewhat tortuous, and without any lenticels; it contains about to per cent. of resin, which is completely soluble in ether and resembles scammonin.

Wild jalap is the tuberous root of Ipomoea pandurata, a plant growing in the Eastern and Southern United States. It contains I.5 per cent. of an active resin.

KRAMERIA.-RHATANY.-The dried root of various species of Krameria (Fam. Leguminosæ), shrubs (Fig. 154) indigenous to South America, Mexico and the West Indies (p. 295). There are three principal commercial varieties: (I) Peruvian Rhatany, which is derived from plants of Krameria triandra, growing in Peru and Bolivia; (2) Savanilla Rhatany, which is derived from more or less disputed species of Krameria ( $K$. Ixina), growing in the United States of Colombia, British Guiana and Brazil, and (3) Para or Brazilian Rhatany, which is supposed to be derived from Krameria argentea, growing in Brazil.

Peruvian Rhatany.-Consisting of a more or less cylindrical crown $50 \mathrm{~mm}$. long and 15 to $20 \mathrm{~mm}$. in diameter, and numerous cylindrical, somewhat tapering, branching roots 10 to $40 \mathrm{~cm}$. long and I to $7 \mathrm{~mm}$. thick; externally brownish-red; crown with rugged and scaly bark; roots smooth or slightly wrinkled longitudinally; fracture of bark slightly fibrous, of wood, tough and splintery; internally reddish, bark I to $2 \mathrm{~mm}$. thick, somewhat easily separable from the lighter colored, slightly radiate wood; odor slight ; wood nearly tasteless, bark astringent (Fig. I96).

Savanilla Rhatany.-Crown more or less cylindrical or spherical, rough, knotty; root externally dark reddish-brown, somewhat purplish, with numerous transverse fissures at more or 


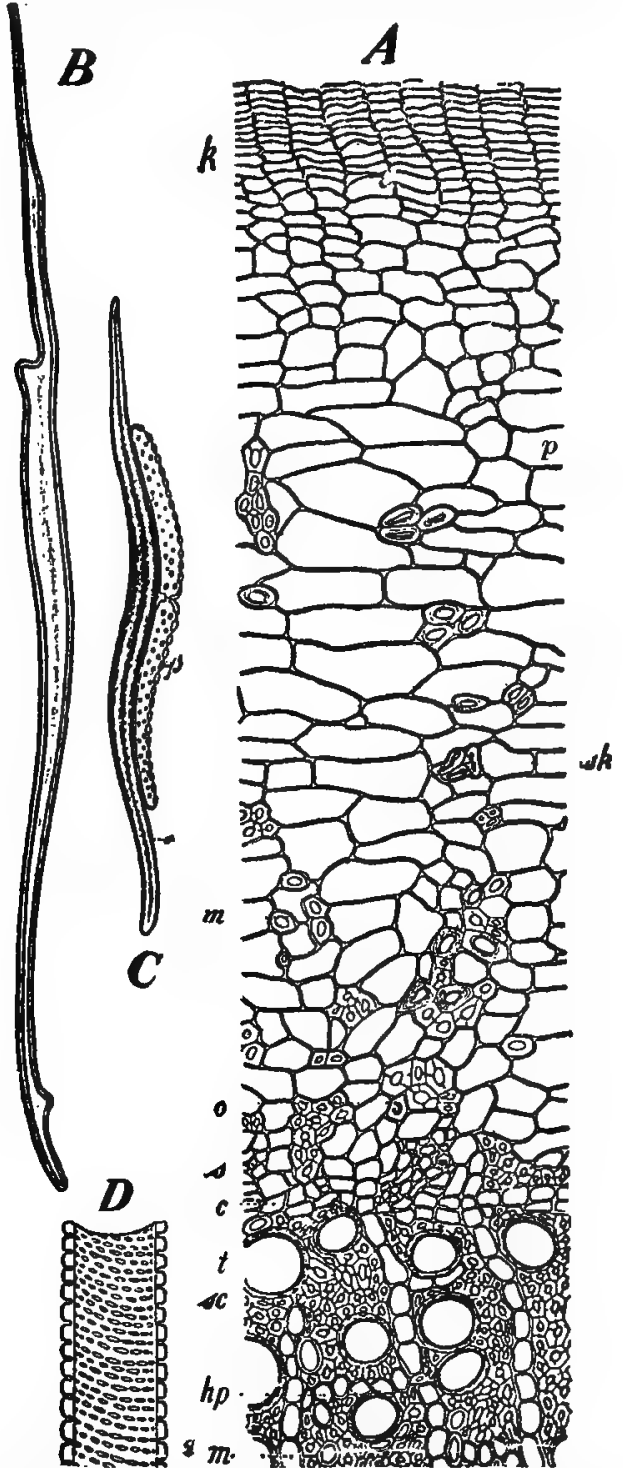

Fig. rg6. Peruvian rhatany: A, transverse section showing cork (k), a group of bast fibers (sk), parenchyma of cortex (p), one cell near the middle containing a monoclinic prism of calcium oxalate (o), medullary-ray cells of bark (m), cambium (c), trachex $(t)$, wood fibers (sc), wood parenchyma (hp), medullary-ray cells $(m)$; B, bast fiber; $C$, wood fiber with neighboring parenchyma cells which are somewhat elongated and have somewhat thickened, porous walls; D, trachea.-After Meyer. 
less regular intervals; periderm not scaly; bark about twice as thick as that of Peruvian rhatany.

Para Rhatany closely resembles the Savanilla variety.

Constituents.-Tannin from 8 to 20 per cent., krameric acid, starch, an uncrystallizable sugar, and calcium oxalate. The tannin is colored dark green with ferric salts and is in the nature of a glucoside resembling the one found in Potentilla Tormentilla (Fam. Rosaceæ) and Esculus Hippocastanum (Fam. Hippocastanaceæ). The tannin also yields phloroglucin and protocatechuic acid.

The tincture of Savanilla rhatany forms a clear solution with water, which gives with alcoholic lead acetate test-solution a purplish precipitate and a colorless filtrate; the tincture of Peruvian rhatany forms a cloudy mixture with water, and gives with alcoholic lead acetate test-solution a reddish-brown precipitate and a light-brown filtrate.

Allied Plants.-Krameria lanceolata of the Southern United States furnishes the TEXAS krameria, and $K$. cistoides of Chile is the source of the PAYta krameria. The root of Leca speciosa (Fam. Vitaceæ) of India has been used as a substitute for Krameria.

PYRETHRUM.-PELLITORY.-The root of Anacyclus Pyrethrum (Fam. Compositæ), a perennial herb indigenous to Northern Africa and Southern Europe (p. 394), the commercial article coming from Algeria. The root is collected in autumn and dried.

DESCRIPTION.- Nearly cylindrical, slightly tapering, or broken into irregular pieces, 2.5 to $10 \mathrm{~cm}$. long, 3 to $20 \mathrm{~mm}$. in diameter ; externally dark brown, wrinkled and somewhat furrowed longitudinally, with few rootlets or rootlet-scars; crown somewhat annulate from scars of bud-scales, and sometimes tufted with coarse fibers of fibrovascular tissue or with long, soft-woolly, nearly straight, one-celled hairs; fracture short and horny when dry, tough when damp; bark dark brown internally, with two circular rows of secretion reservoirs, 0.5 to $\mathrm{I} \mathrm{mm}$. thick. and closely adhering to the light-yellow, radiate, porous wood, in the medullary rays of which secretion reservoirs are also found; odor distinct, penetrating; taste pungent, acrid. 
Inner Structure.-See Fig. Ioi, $E$.

Constituents.-An alkaloid pyrethrine, which occurs in colorless, acicular crystals, has an intense pungent taste, and which is decomposed by alkalies into piperidine (a pungent principle occurring in black pepper) and pyrethric acid, a principle resembling piperic acid. Pyrethrum also contains a brown acrid resin, two other acrid resins, a volatile oil and about 50 per cent: of inulin.

Allied Plints.-German pellitory, the root of Anacyclus officinarum, is smaller; the bark contains but one row of secretion reservoirs, which are wanting in the medullary rays; and the roots contain tannin in addition to the constituents found in Pyrethrum.

SENEGA.-SENEGA ROOT.-The dried root of Polygala Senega (Fam. Polygalaceæ), a perennial herb (p. 313) found in Canada and the Eastern United States as far south as North Carolina and as far west as Minnesota and Missouri (Fig. 197). There are two representative commercial varieties-the northern, collected in Manitoba and in the State of Minnesota; the southern, from Virginia to Texas.

Description.-Southern Senega.-Nearly entire, with broken and detached rootlets, crowned with numerous buds and short stem-remnants, slenderly conical, more or less tortuous, somewhat branched, 3 to $8 \mathrm{~cm}$. long, 2 to $6 \mathrm{~mm}$. thick; externally dark yellow, the crown being rose-tinted, longitudinally wrinkled, slightly annulate, marked with circular scars of detached rootlets. and in some cases by a keel which is more prominent near the crown and in perfectly dry roots; side opposite keel more or less flattened; cross-section elliptical or triangular; fracture short when dry, tough when damp; internally, wood lemon-yellow, 2 to $5 \mathrm{~mm}$. in diameter, usually excentral, bark dark yellow, much thickened on one side, forming the keel on drying; odor slight, penetrating; taste sweetish and acrid (Fig. I97a).

Manitoba Senega is 8 to $15 \mathrm{~cm}$. long, 6 to $12 \mathrm{~mm}$. thick, externally dark brown and somewhat purplish near the crown.

Constituents.-The principal constituents are about 5 or 6 per cent. of two glucosides: senegin, which resembles saponin, and polygalic acid, which is sternuatory. The root also contains o.r 2 per cent. of a volatile oil which is chiefly methyl salicylate; resin, pectin, sugar and considerable proteids. 
Allied Plants.-Saponin-like substances and methyl salicylate are found to a greater or less extent in other species of Polygala, of which at least forty have been used in medicine.

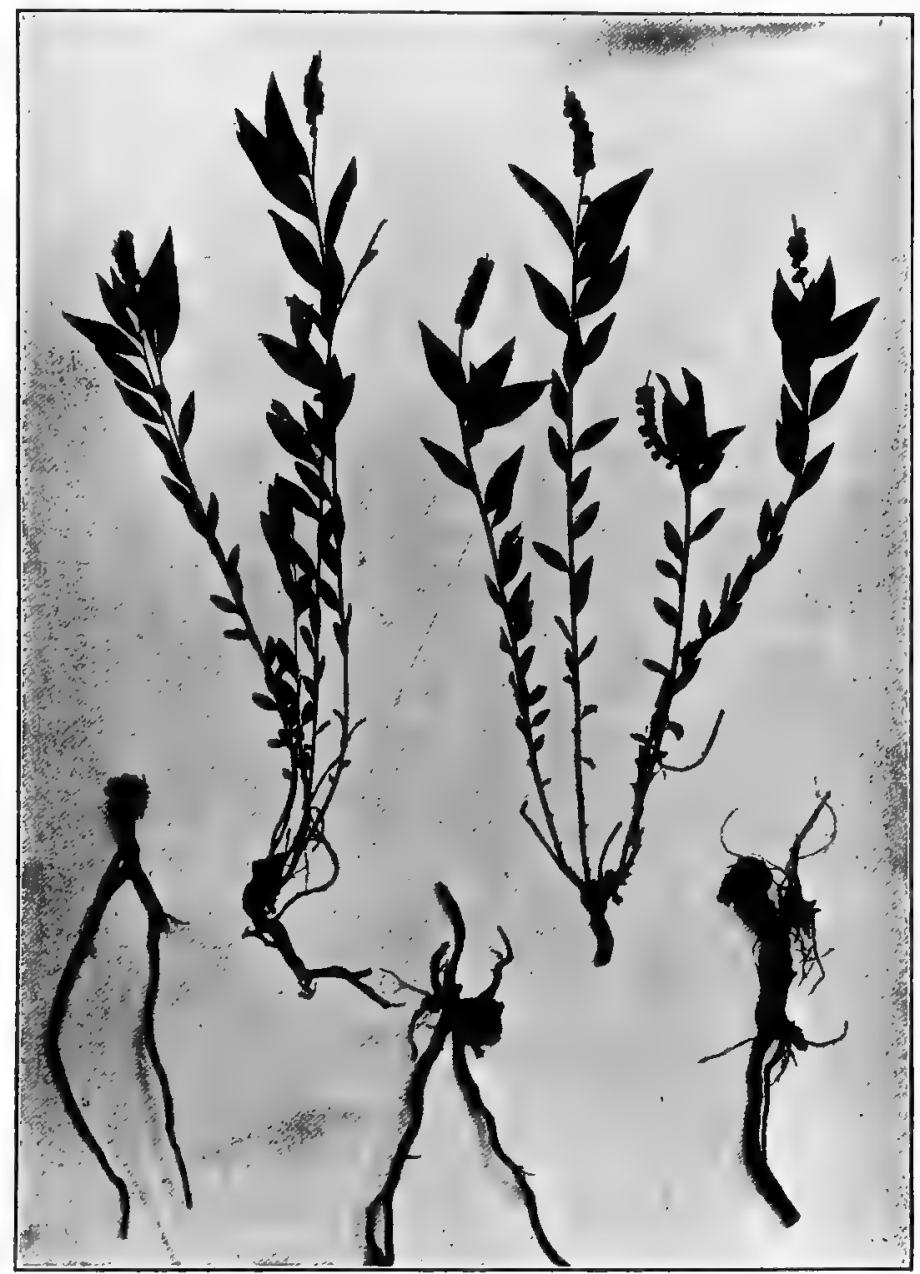

Fig. 197. Senega snakeroot (Polygala Senega). Two flowering plants and three large roots.

Other genera of the Polygalaceæ seem to have constituents similar to Senega, as Comesperma of Australia and Monnina of South America. 
Adulterants.-The rhizomes and roots of Cypripedium hirsutum and C. spectabile of the United States are said to be sometimes used as adulterants of Senega.

TARAXACUM.-DANDELION.-The root of Taraxacum officinale (Fam. Compositæ), a perennial herb indigenous to Europe and Asia, but now naturalized in all civilized parts of the world (p. 392). The root should be collected in spring or in autumn either directly before or directly after the vegetative activity of the plant. It is used in either the fresh or dried condition, the principal supply of the dried root coming from Europe. The pith of the rhizome portion is liable to be attacked by insects.
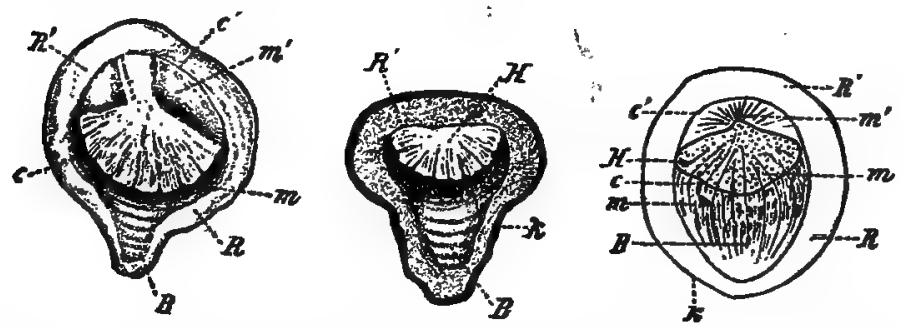

FIG. 197a.-Transverse sections of senega, the two on the left being of the dry drug, and the one on the right showing the appearance after soaking the material in water: $R$, outer bark; $\mathbf{R}^{1}$, bark on the side having abnormal development of wood; $\mathrm{B}$, inner bark, which gives rise to the "keel" on the drying of the root; H, wood; C, Cl, cambium; m, medullary rays; $\mathrm{m}^{1}$, parenchyma developed in place of wood on one side.-After Meyer.

DesCription.-Somewhat cylindrical, tapering, more or less flattened, slightly branched or broken into irregular pieces 6 to I $5 \mathrm{~cm}$. long, 5 to $15 \mathrm{~mm}$. in diameter; externally light brown, wrinkled, with numerous rootlet-scars; crown simple or branched, slightly annulate from numerous leaf-bases; fracture short, horny when dry, tough when damp; internally, bark light brown, 2 to 6 $\mathrm{mm}$. thick, made up of concentric layers of laticiferous vessels and sieve alternating, with white parenchyma, wood lemon-yellow, I to $4 \mathrm{~mm}$. thick, porous and non-radiate; odor slight; taste bitter.

Inner Structure.-See Fig. Ioi, $D$.

Constituents.--The drug contains about 0.05 per cent. of a bitter principle, taraxacin, which gives reactions with certain of the alkaloidal reagents; it also contains two resins, one soluble in 
alcohol and the other in chloroform; a waxy substance, taraxacerin; 24 per cent. of inulin; and about 5 per cent. of ash.

CALUMBA.-COLUMBO.-The root of Jateorhiza palmata (Fam. Menispermaceæ), a perennial herbaceous climber, native of
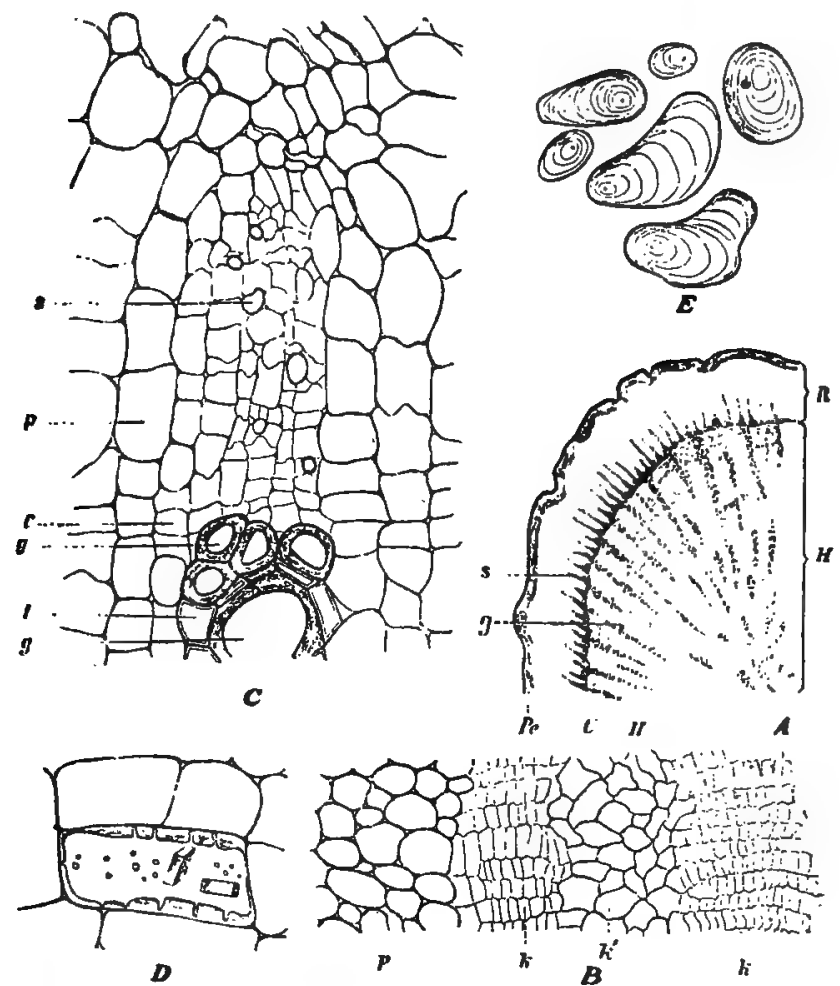

FIG. I98. Calumba: A, transverse section showing bark (R), cambium (C), and wood $(\mathrm{H})$, wood fibers (II), trachex $(\mathrm{g})$, periderm ( $\mathrm{Pe}$ ) and sieve (s); $\mathrm{B}$, longitudinal section of periderm showing parenchyma (p), small-celled cork (k) and large-celled cork $\left(\mathrm{k}^{-1}\right)$; $\mathrm{C}$, transverse section near cambium showing tracheæ ( $\left.\mathrm{g}, \mathrm{g}\right)$, intermediate fiber (f) cambium (c), parenchyma (p) and sieve cell (s); D, stone cell from the periderm containing calcium oxalate,-After Meyer.

the forests of Eastern Africa (p. 274). The large, fleshy roots are collected in the dry season, cut into transverse pieces, dried and exported by way of Zanzibar and Bombay.

DesCRIPTION.-In nearly circular or elliptical disks, sometimes irregularly bent, 2 to $5 \mathrm{~cm}$. in diameter, 2 to $10 \mathrm{~mm}$. thick; 
bark externally yellowish-green or dark brown, wrinkled; fracture short, mealy; internally, radiate, yellowish-green, collateral wood bundles forming a concentric zone, bark 4 to $6 \mathrm{~mm}$. thick, cambium zone distinct, center either depressed or more or less prominent; odor slight; taste bitter and aromatic.

Inner Structure.-See Fig. I98.

Constituents.-Two yellowish alkaloids, closely resembling berberine and varying from 0.98 to $\mathrm{I} .3^{8}$ per cent. in the bark and I.02 to 2.05 in the wood. To one of these bases the name columbamine has been given. Calumba also contains a volatile oil 0.0056 per cent., starch about 35 per cent, pectin 17 per cent., resin 5 per cent., calumbic acid, calcium oxalate, mucilage, and yields 6 per cent. of ash.

Substitutes.-Various substitutes for calumba have been offered, but these are free from starch, or they may contain tannin, as American columbo, the root of Frasera carolinensis (Fam. Gentianaceæ), an herb indigenous to the Eastern United States. This root formerly occurred in the market in transverse disks somewhat resembling calumba, but without the radiate structure. It contains a larger amount of a yellow coloring principle and less gentiopicrin than gentian.

Adulterants.-Calumba has been adulterated with the roots of Tinospora Bakis of tropical Africa and Coscinum fenestratum (both of the Fam. Menispermaceæ), the latter growing in India. The disks are woody, the center being prominent and not depressed, and the ash varies from II.9 to I 6.6 per cent.

PAREIRA.-PAREIRA BRAVA.-The root of Chondrodendron tomentosum (Fam. Menispermacex), a perennial climber indigenous to Brazil and Peru (p. 274). The commercial article is exported from Rio Janeiro.

Description.-Nearly cylindrical, more or less tortuous, cut into pieces of various lengths, usually from to to $20 \mathrm{~cm}$. long and to to $30 \mathrm{~mm}$. in diameter, rootlets few; externally brownishblack, longitudinally furrowed and transversely ridged and fissured, with numerous rootlet-scars and occasional grayish patches of lichens; fracture fibrous, lustrous when cut; internally dark brown, with three or more irregular, excentral (Fig. 199), distinctly radiate, concentric zones of secondary fibrovascular bun- 
dles, each 2 to $3 \mathrm{~mm}$. wide, and separated by distinct, concentric zones of parenchyma and stone cells; odor slight; taste slightly bitter.

Constituents.-An alkaloid pelosine (cissampeline) about $\mathbf{I}$ per cent., somewhat resembling beberine in bebeeru bark (Nectandra Rodici, one of the Lauracex) and buxine in box wood (Bur.tus sempervirens, one of the Sapindacex); starch, tannin, wax, ash 4 to 5 per cent.

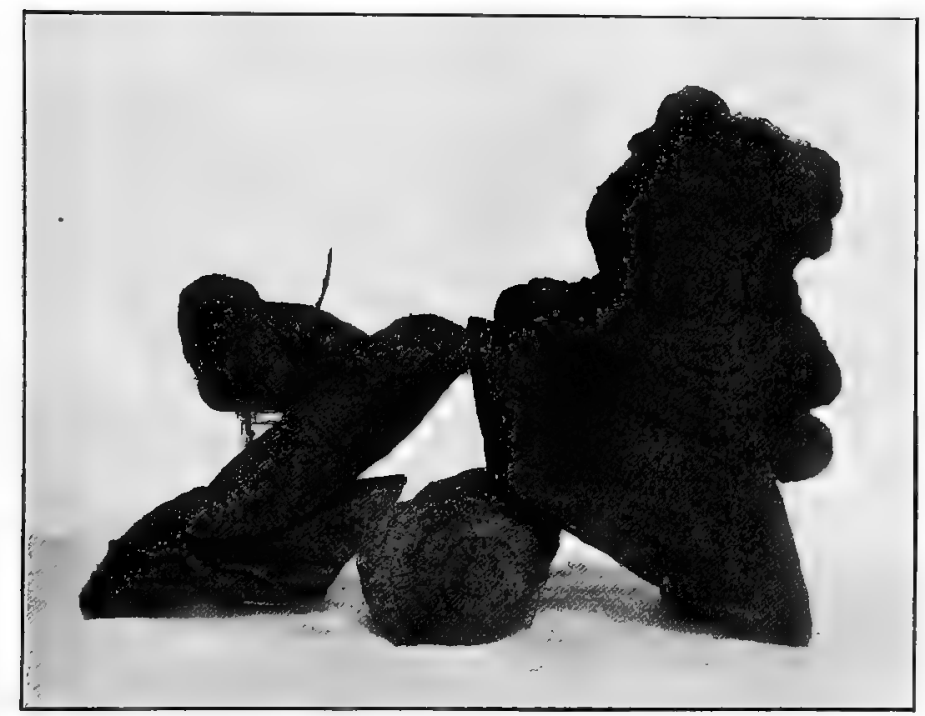

FIG. I99. Specimens of pareira showing the concentric rings of fibrovascular tissue.

Substitutes.-Other roots are frequently substituted for genuine pareira brava, which are no doubt derived from other menispermaceous plants; these roots are of a brownish color, possess numerous concentric zones of fibrovascular bundles, and do not have a waxy luster when cut.

FALSE PAReira is obtained from a related species (Cissampelos Pareira), growing in South America, West Indies and East Indies. The root is somewhat flattened, externally dark brown, internally yellowish-brown, free from the concentric zones of wood bundles, and contains about 0.5 per cent. of pelosine. 
The stems of Chondrodendron tomentosum are also sometimes found in the drug; these are more woody, possess a distinct pith and are marked externally by the apothecia of lichens.

The roots of several other plants of this family are used as substitutes for pareira, among which may be mentioned Chondrodendron platyphyllum of Brazil and Paraguay, and Stephania discolor of India. White Pareira is obtained from Abuta rufescens, the roots of which are whitish or pale yellow and very starchy. Yellow Pareira is obtained from $A$. amara. The root is bright yellow internally, very bitter and apparently contains alkaloids resembling beberine and berberine.

STILLINGIA.-QUEEN'S ROOT.-The root of Stillingia sylvatica (Fam. Euphorbiaceæ), a perennial herb (Fig. I62) indigenous to the Southern United States (p. 314). The root is collected in August; it is deprived of its rootlets, cut into transverse pieces and carefully dried.

DesCription.-Cylindrical, tapering, and slightly branched, about $40 \mathrm{~cm}$. long; usually cut into pieces 2 to Io $\mathrm{cm}$. long, 5 to $30 \mathrm{~mm}$. in diameter; externally dark brown, longitudinally wrinkled, rootlets or rootlet-scars few ; fracture of bark fibrous; internally, bark light reddish-brown, 0.5 to $4 \mathrm{~mm}$. thick, soft, spongy, with numerous resin cells and easily separable from the porous, radiate wood; odor faint; taste bitter, acrid and pungent.

Constituents. - A volatile oil with the odor and taste of the root from 3 to 4 per cent.; an acrid resin sylvacrol ; an acrid fixed oil ; Io to I2 per cent. of tannin; starch; calcium oxalate; ash about 5 per cent.

SUMBUL.-The dried rhizome and root of Ferula Sumbul (Fam. Umbelliferæ), a perennial herb indigenous to Turkestan (p. 352). The drug is exported by way of St. Petersburg, and is commonly known as musk-root.

Description.-In cylindrical, sometimes branched, transverse segments, 3 to to $\mathrm{cm}$. long and $\mathrm{r} .5$ to $7 \mathrm{~cm}$. in diameter, very light; externally light to dark brown, distinctly annulate, periderm easily separable; the upper part of the rhizome with occasional circular scars and leaf-remnants consisting of stout fibers; fracture short, fibrous but irregular; internally, light yellow, resinous, spongy, porous, arrangement of wood irregular, due to 
anomalous secondary cambiums, bark dark brown, about $0.5 \mathrm{~mm}$. thick; odor musk-like; taste bitter, pungent.

Constituents.-Volatile oil having the taste of peppermint, from 0.3 to I per cent.; two balsamic resins, one soluble in alcohol and having the odor and taste of the root, the other soluble in ether; fixed oil I 7 per cent.; ash about 8 per cent.; starch and several acids, as angelic, valerianic and methyl-crotonic.

BELLADONN $\approx$ RADIX.-BELLADONNA ROOT.-The root of Atropa Belladonna (Fam. Solanaceæ), a perennial herb (p. 372), native of Central and Southern Europe, and cultivated in England and Germany, from which countries most of the commercial supply is obtained (Fig. 268). The roots are collected in autumn from plants three to four years old and carefully dried.

DesCrIPTION.-Cylindrical, slightly tapering, somewhat twisted, or split into longitudinal pieces 5 to $15 \mathrm{~cm}$. long, 4 to 25 $\mathrm{mm}$. in diameter; externally light brown, smooth, longitudinally wrinkled or fissured, sometimes with transverse ridges and with rootlet-scars or fragments of rootlets; fracture short, mealy when dry and emitting a dust consisting of starch grains and fragments of cells, tough when damp ; internally light yellow, slightly radiate, bark 0.5 to $2 \mathrm{~mm}$. thick, not fibrous, and adhering closely to the wood, cambium zone distinct; odor narcotic; taste sweetish, acrid.

Roots that are shrunken, spongy, dark brown and free from starch should be rejected, as also old woody roots and stemremnants.

Phytolacca root and Althæa are distinguished from belladonna root by having numerous sclerenchymatous fibers, while inula has neither starch nor cryptocrystalline crystals of calcium oxalate.

Inner Structure.-See Figs. 200, 281, 303.

Constituents.-There are two principal alkaloids-hyoscyamine and atropine-which together amount to 0.2 to I. per cent., the proportions of these varying according to the age of the root, the hyoscyamine, however, usually being in excess. The atropine appears to be derived from its isomer hyoscyamine and not to preëxist in the root; a small amount of scopolamine (hyoscine) is also present. Other alkaloids, as belladonnine, apoatropine, etc., have been isolated, but these are decomposition products of hyoscyamine. The drug also contains a fluorescent 


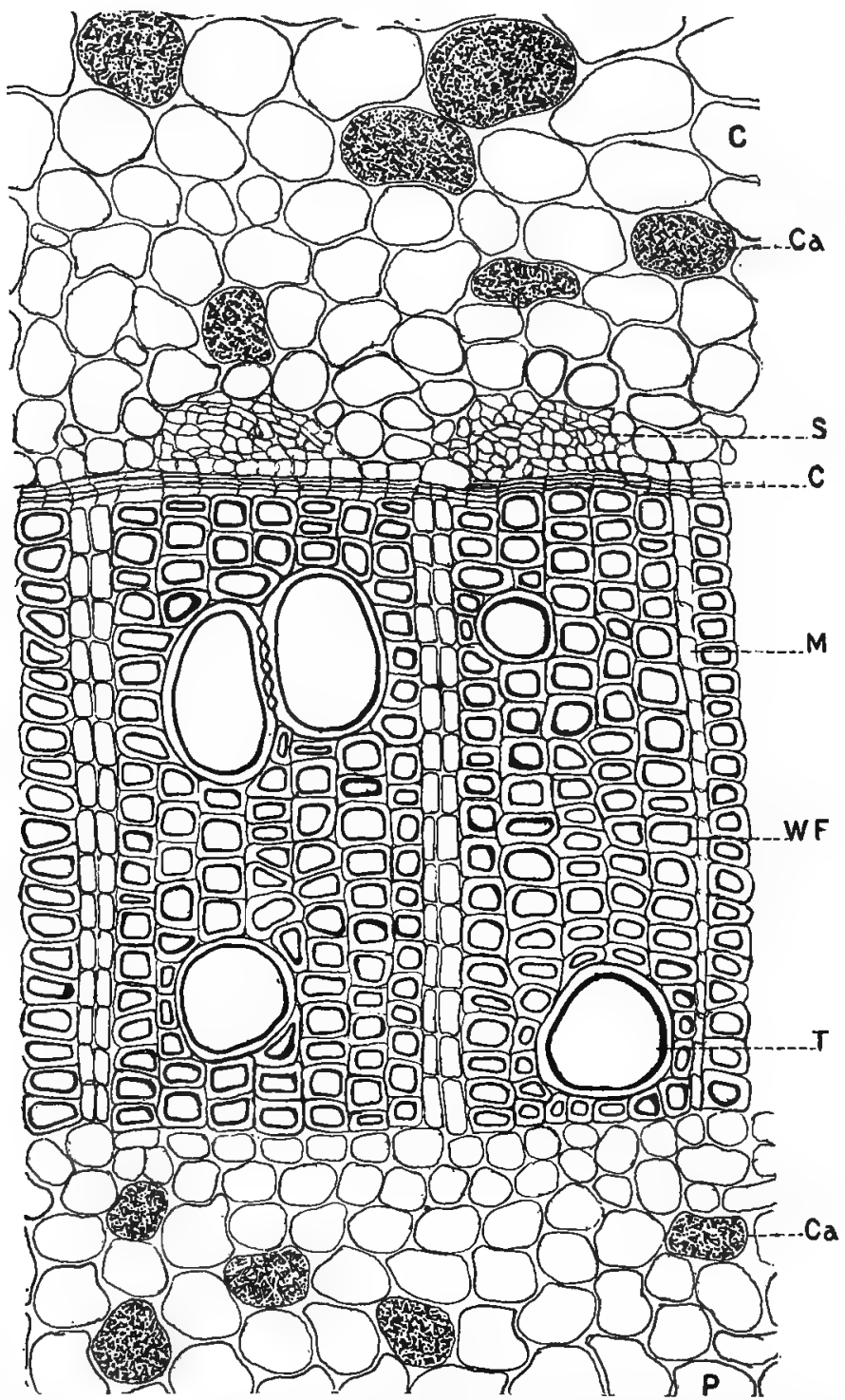

FIG, 200. Transverse section of a somewhat woody piece of belladonna root near the cambium: C, parenchyma of the cortex, some of the cells shown with cryptocrystalline crystals of calcium oxalate $(\mathrm{Ca})$; $\mathrm{S}$, sieve; $\mathrm{C}$, cambium; $\mathrm{M}$, medullary rays; WF, woodfibers: T, trachez; $P$, parenchyma of pith, some of the cells with cryptocrystalline srystals of calcium oxalate. 
principle, B-methyl æsculetin, considerable starch and calcium oxalate in the form of cryptocrystalline crystals. See also Hyoscyamus (p. 619), Belladonnæ Folia (p. 620) and Stramonium (p. 622).

Allied Plants.-Mandragora or European mandrake is the root of Atropa Mandragora. The drug occurs in fusiform, somewhat bifurcated pieces and contains two mydriatic alkaloids : mandragorine (isomeric with atropine) and an alkaloid resembling hyoscyamine.

LAPPA.-BURDOCK.-The root of Arctium Lappa and of other species of Arctium (Fam. Compositæ), biennial herbs ( $\mathrm{p}$. 394) indigenous to Europe and Northern Asia, and naturalized in waste places in the United States and Canacla (Fig. 92). The root is collected in autumn from plants of the first year's growth, and carefully dried.

Description.-Nearly cylindrical, slightly tapering, or broken and split longitudinally into pieces, Io to $20 \mathrm{~cm}$. long, 5 to $20 \mathrm{~mm}$. in diameter; externally, bark dark brown, longitudinally wrinkled, with few rootlets or rootlet-scars, crown somewhat annulate from scars of bud-scales and sometimes surmounted by a soft, woolly tuft of leaf-remains with I-celled, twisted hairs; fracture short. horny when dry, tough when damp; internally light brown, radiate, bark 2 to $3 \mathrm{~mm}$. thick, wood porous, cambium zone distinct; odor feeble; taste mucilaginous, slightly bitter.

Old woody roots in which the pith is more or less obliterated and which have been collected from the fruiting plant should be rejected.

Constiruents.-Inulin about 45 per cent.; a glucoside probably identical with that found in the seed, to which the name lappin has been applied; and about 0.4 per cent. of a fixed oil.

PHYTOLACCA.-POKE ROOT.-The root of Phytolacca decandra (Fam. Phytolaccacex), a perennial herb (p. 265) indigenous to Eastern North America, and naturalized in the West Indies and Southern Europe (Fig. I39). The root is collected in autumn and, after removal of the rootlets, cut into transverse and longitudinal pieces and dried.

Description.-Fusiform or nearly cylindrical, tapering, usually in longitudinal ribbon-like slices, 8 to $16 \mathrm{~cm}$. long, 5 to 15 
mm1. in diameter, 2 to Io mm. thick; externally, bark dark brown, more or less wrinkled; fracture fibrous, tough; internally light brown, characterized by alternating zones of collateral fibrovascular bundles and parenchyma formed by secondary cambiums; odor slight; taste acrid.

Constituents.-A bitter, acrid glucoside resembling saponin; a crystalline alkaloid phytolaccine, which is soluble in alcohol and

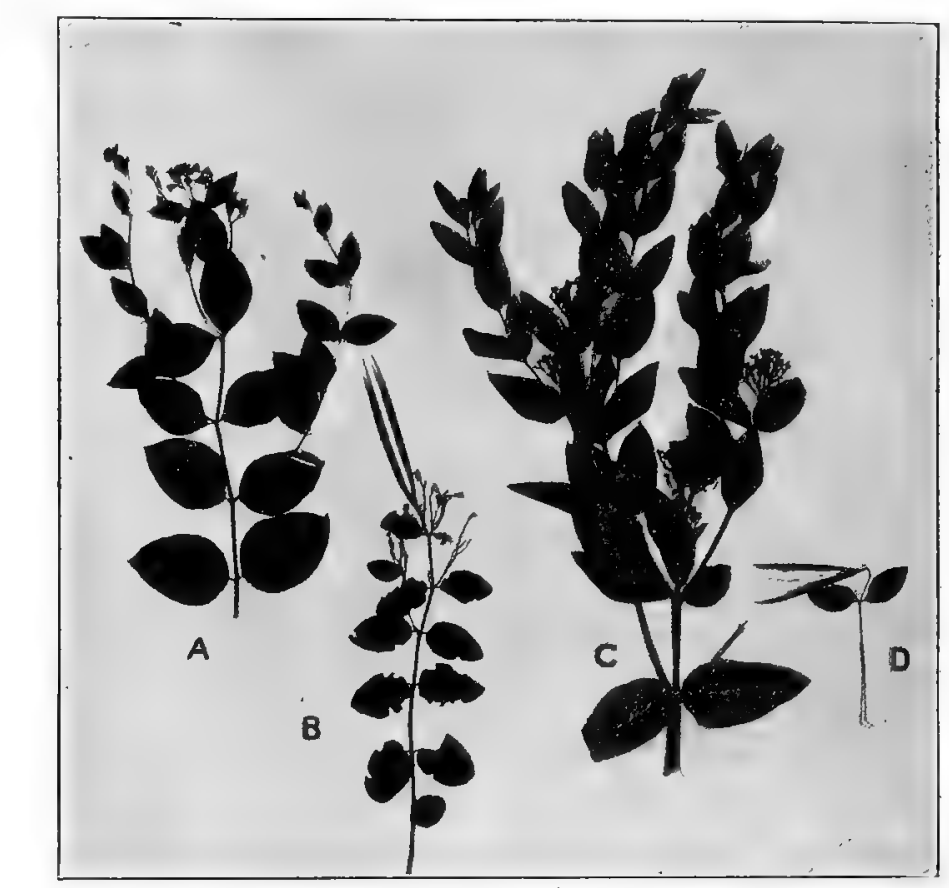

FIG. 20I. .4pocynum androscmifolium: A, flowering branch; B, fruiting branch. A pocynum cannabinum: C, flowering branch; D, fruiting branch.

sparingly soluble in water; sugars Io per cent.; starch Io per cent.; phytolaccic acid; formic acid; potassium formate 2 per cent.; calcium oxalate 6 per cent.; and ash I 3 per cent., of which about one-half is potassium oxide.

Phitolacces Fructus or Phytolacea Fruit occurs in agglutinated masses of a purplish-black color, and consisting of the compound berries, which are about $8 \mathrm{~mm}$. in diameter and com- 
posed of Io loculi, each of which contains a single, lenticular, black seed. The sarcocarp is fleshy, sweet and slightly acrid and contains a purplish-red coloring principle which is soluble in water but not in alcohol, and which is decomposed on heating the aqueous solution. The fruit also contains phytolaccic acid, several fruit-acids and phytolaccin, a substance resembling tannin.

APOCYNUM.-CANADIAN HEMP.-The dried root of Apocynum cannabinum (Fam. Apocynaceæ), a perennial herb (p. 363) growing in fields and thickets in the United States and Southern Canada (Fig. 20I).

Description.-Cylindrical, somewhat branched, usually broken into pieces 4 to $10 \mathrm{~cm}$. long, 5 to $10 \mathrm{~mm}$. in diameter; externally light brown, longitudinally wrinkled and transversely fissured, with few rootlets or rootlet-scars; fracture short; internally, bark light brown, I $\mathrm{mm}$. thick, easily separable from the lemon-yellow, porous, slightly radiate wood; odor slight; taste of bark bitter and acrid, of wood slightly bitter.

Stem fragments are distinguished by having a comparatively thin, finely fibrous bark and a hollow center.

Inner Structure.-See Fig. 202.

Constituents.-Two glucosides: apocynin, which is amorphous, resinous and soluble in ether, and apocynein, a yellowish principle which is insoluble in ether but soltuble in alcohol and water and has the physiological properties of digitalin; resin, tannin, starch and about Io per cent. of ash.

Allied Plants. - The commercial article frequently contains the root of a closely related plant, Apocynum androscmifolium (p. 363), growing in the same regions but having a thinner bark, which is characterized by one or more groups of stone cells.

IPECACUANHA.-IPECAC.-The dried root of Cephaëlis Ipecacuanha (Uragoga Ipecacuanha) (Fam. Rubiaceæ), a shrub indigenous to Brazil, and sparingly cultivated near Singapore (Fig. I78). The commercial supply is obtained from Matta Grosso, Brazil, and is known as Rio, Brazilian or Para Ipecac. The roots of Cephaëlis acuminata, a plant closely related to Cephaëlis Ipecacuanha and indigenous to the northern and central portion of the United States of Colombia, are exported from Carthagena and Savanilla, and are known commercially as Car- 
thagena Ipecac. Two commercial sub-varieties of Ipecac are also recognized, depending upon the proportion of wood and bark in

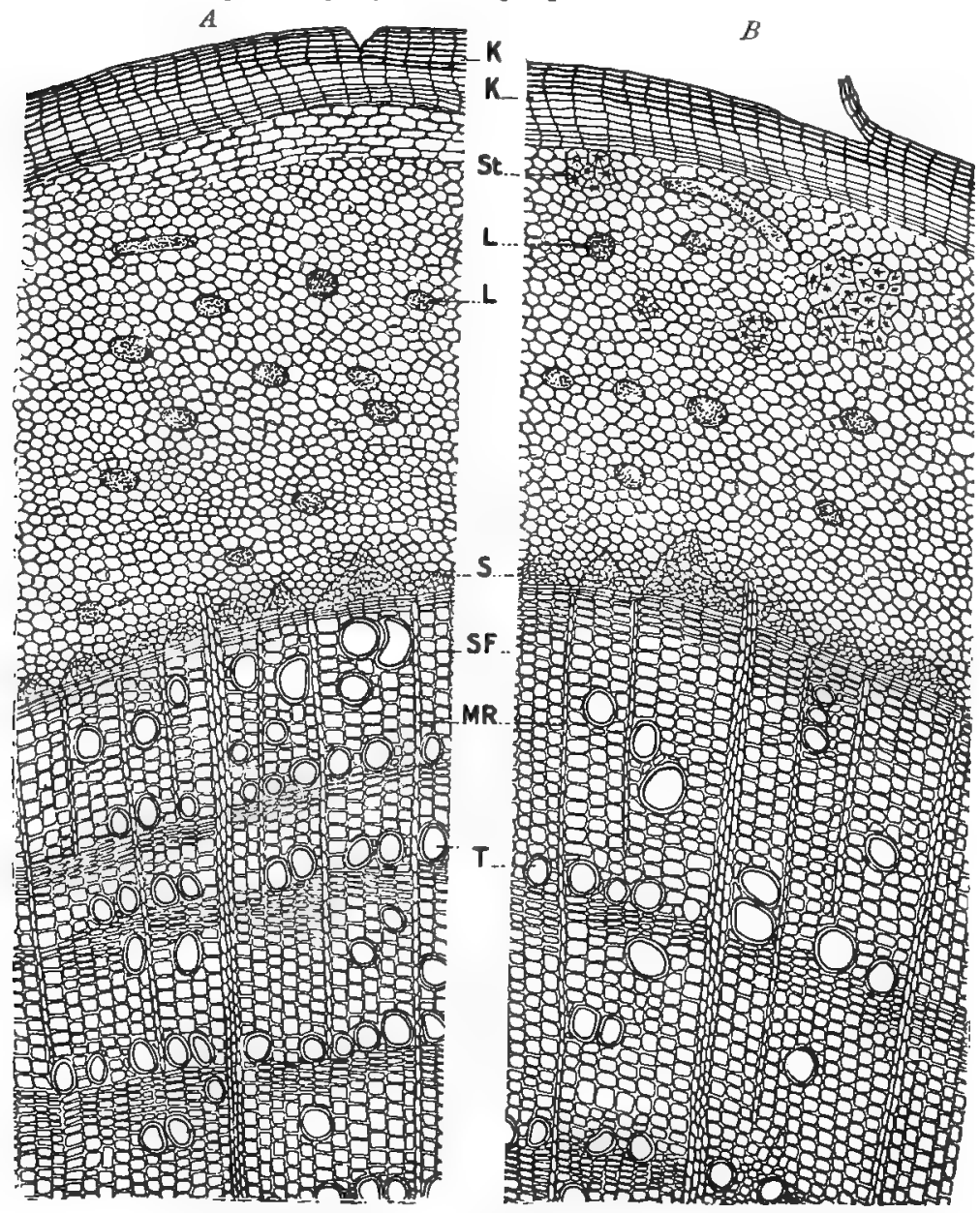

Fig. 202. A, transverse section of the root of Apocynum cannablnum showing cork (K); latex cells (L) in the cortex; sieve (S), beneath which is the cambium zone; wood fibers (SF), trachea (T), and medullary rays (MR). - B, transverse section of the root of Apocynum androsamifolium showing in addition groups of stone cells $(\mathrm{St})$ in the cortex.

the drug. Specimens in which the wood is more pronounced are known as "WIRY ROoTs," while those which are characterized by a thicker bark are called "FANCY" or "Bold" roots (p. 379). 
Rio or Brazilian IpeCaC.-Cylindrical, more or less tortuous, 5 to $15 \mathrm{~cm}$. long, I to $5 \mathrm{~mm}$. in diameter; externally dark brown, irregularly annulate, sometimes transversely fissured, with occasional rootlets or rootlet-scars; fracture of bark brittle, of the wood tough; internally, bark light brown, 0.5 to I mm. thick, easily separable from the dark-yellow, non-porous wood; odor slight; taste bitter, acrid.

An aqueous infusion of ipecac gives a copious precipitate with potassio-mercuric iodide solution; a hydro-alcoholic infusion gives a yellow precipitate with picric acid, or if hydrochloric acid and potassium chlorate are added the solution becomes orange-red with a reddish fluorescence.

Inner Structure.-See Figs. 203, 29i.

Carthagena Ipecac closely resembles the Rio or Brazilian ipecac, but the roots are uniformly thicker ( 4 to $7 \mathrm{~mm}$. in diameter), of a brownish-gray color, and the annulations are less pronounced.

The stems are usually more slender, 5 to Io $\mathrm{cm}$. long, I to $\mathbf{I} .5$ $\mathrm{mm}$. in diameter, nearly smooth or longitudinally wrinkled; bark o.I mm. thick, with bast fibers either single or in groups; pith distinct, $0.5 \mathrm{~mm}$. in diameter.

Constituents.-Ipecac contains three alkaloids ( 2 to 3 per cent.) - emetine, cephaëline and psychotrine, that are said to be contained chiefly in the bark, which makes up about 90 per cent. of the drug.

EMETine (methyl-cephaëline) is white, amorphous, forms crystalline salts, becomes darker on exposure to light, and with Frohde's alkaloidal reagent (consisting of o.or $\mathrm{Gm}$. of sodium molybdate in I c.c. of concentrated sulphuric acid) becomes dirty green, changing to a bright green on the addition of hydrochloric acid. CEPHAËLINE occurs in silky needles, forms amorphous salts and is quite unstable, becoming yellow even in the dark. With Frohde's reagent, cephaëline changes to purple, becoming deep blue on the addition of hydrochloric acid. Psychotrine is amorphous, quite unstable, and becomes purplish with Frohde's reagent, changing to green on the addition of hydrochloric acid. Ipecac also contains 2.25 per cent. of ipecacuanhic acid, with which the alkaloids are combined; a glucoside resembling saponin ; 

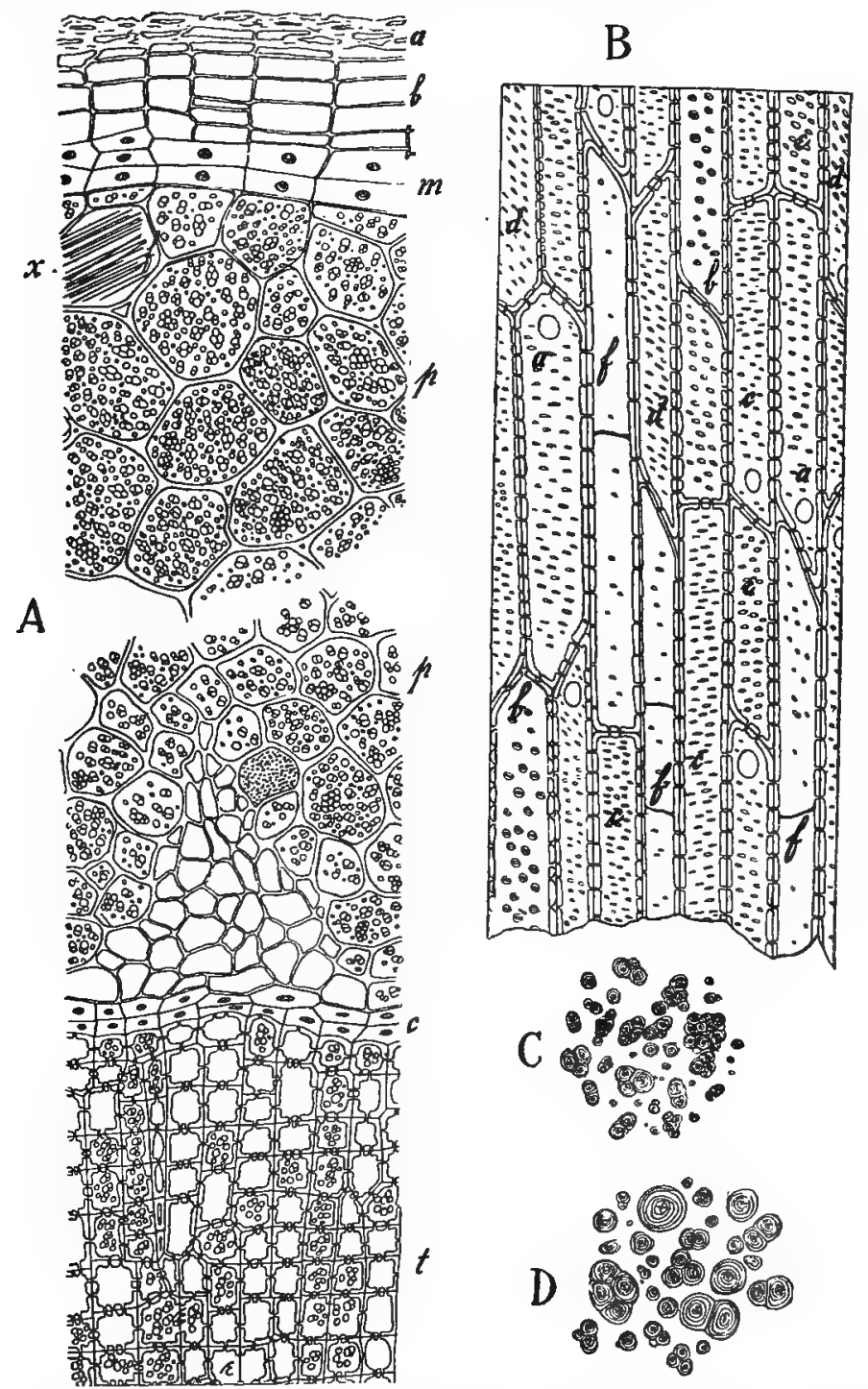

FIG. 203. Ipecac. A, transverse section of Rio ipecac showing outer layers of cork (a); cork cells (b); phellogen $(m)$; parenchyma containing starch (p); raphides $(x)$; cambium (c): tracheiđs (t). B, longitudinal section of a portion of the wood showing ductlike tracheids (a); tracheids with bordered pores (b), linear pores (c) and oblique linear pores (d); transition tracheids (e); tracheids with delicate pores (f). C, starch grains of Rio ipecac. D, slightly larger starch grains of Carthagena ipecac.-After Schneider. 
about 40 per cent. of starch; and calcium oxalate in the form of raphices.

The total amount of alkaloids in Rio and Carthagena ipecac not only varies but there is a difference in the proportions of emetine (the expectorant alkaloid) and cephaëline (the emetic alkaloid); in Rio ipecac the proportion is one-third cephaelline to two-thirds emetine, while in Carthagena ipecac there are fourfifths cephaëline to one-fifth emetine.

Allied Plants.-A number of drugs, some of which resemble ipecac, sometimes find their way into commerce, and, while they all possess emetic properties, none of them contain emetine. The following drugs obtained from plants of the RUBIACE E have been substituted for Ipecac. Undulated (or Farinaceous) IPECAC from Richardsonia scabra, a plant growing in tropical and subtropical America, is an undulate, annulate root, the bark of which is nearly as thick as the yellowish, soft wood. StrI.ıTed IpeCaC from Cephaëlis emetica, a plant growing in South America, is a dark purplish-brown root, with a few transverse fissures and a thick bark in which starch is absent. Several members of the ROSACE $A$ contain emetic principles and the roots of the following plants growing in the United States have been substituted for Ipecac: American Ipecac (Porteranthus stipulatus), the root of which is annulate, and in other ways resembles ipecac, but has a thinner bark with numerous resin cells; and Indian Physic ( $P$. trifoliatus), the roots of which resemble those of American Ipecac but are not annulate.

The roots of several of the plants of the EUPIORBIACE瓜 are used as emetics. IPECAC SPURGE is the root of Euphorbia Ipecacuanha, a plant common in sandy soil of the Eastern United States. The roots are $30 \mathrm{~cm}$. or more long, about I cm. thick, nearly cylindrical, light brown; internally the wood is yellow and the bark white and with numerous latex vessels. The taste is sweet, somewhat acrid and bitter. Ipecac spurge contains a crystalline resin, euphorbon; probably a glucoside, and starch. Purging or EMETIC ROOT is obtained from the large flowering spurge (Euphorbia corollata), a plant found in sandy soil east of the Mississippi. The root resembles the Ipecac spurge but is dark brown or brownish-black externally, and the constituents are similar. 
The following emetic drugs are obtained from plants belonging to the Violaces: Ionidium or the so-called White Ipecac is obtained from the root of Hybanthus Ipecacuanha of Brazil. It is easily distinguished from ipecac by being somewhat branched, larger and with a thin bark. An emetic principle is also present in the roots of other species of Hybanthus, the root of Anchieta salutaris of Brazil, and possibly also in the rhizome of Viola odorata.

A few emetic drugs are also obtained from plants belonging to the Meliaces. The alkaloid naregamine is found in the Goanese Ipecac derived from Naregamia alata of the East Indies. The alkaloid rusbyine is found in the bark of Cocillana (Guarea Rusbyi) of Bolivia, a drug having properties similar to those of Ipecac. The roots of several of the Polygalas (Fam. PoLYGAL.ICEA) possess emetic properties, viz.: P. scoparia of Mexico and $P$. angulata of Brazil. The root of the latter plant, which is also known as White Ipecac (Poaya blanca) resembles senega, is free from starch and contains considerable saponin.

GLYCYRRHIZA.-LICORICE ROOT.-The dried rhizome and root of Glycyrrhiza-glabra, and of the var. glandulifera (Fam. Leguminosæ), perennial herbs (Fig. I5I), found growing in the countries of the Eastern Mediterranean region and Eastern Asia and cultivated in Spain, Russia, other parts of Europe and to a limited extent in the United States (p. 294). There are two principal commercial varieties: (I) Spanish Licorice, yielded by cultivated plants of G. glabra, and chiefly exported from Spain and Southern France, and (2) Russian Licorice, obtained from wild plants of G. glabra glandulifera or G. echinata, growing in Southern Russia. The latter consists more largely of roots which are deprived of the periderm, whereas the Spanish variety consists mostly of rhizomes.

SPAnish LicoRice.-Nearly cylindrical, more or less tortuous, cut or broken into pieces $\mathrm{I} 4$ to $20 \mathrm{~cm}$. long, 5 to $25 \mathrm{~mm}$. in diameter; crown knotty; externally dark brown, longitudinally wrinkled or furrowed, with few rootlet-scars, rhizome with corky patches and numerous small conical buds; fracture coarsely fibrous; internally lemon-yellow, radiate, bark I to $3 \mathrm{~mm}$. thick, wood porous, rhizome with small pith; odor distinct; taste sweetish, slightly acrid. 


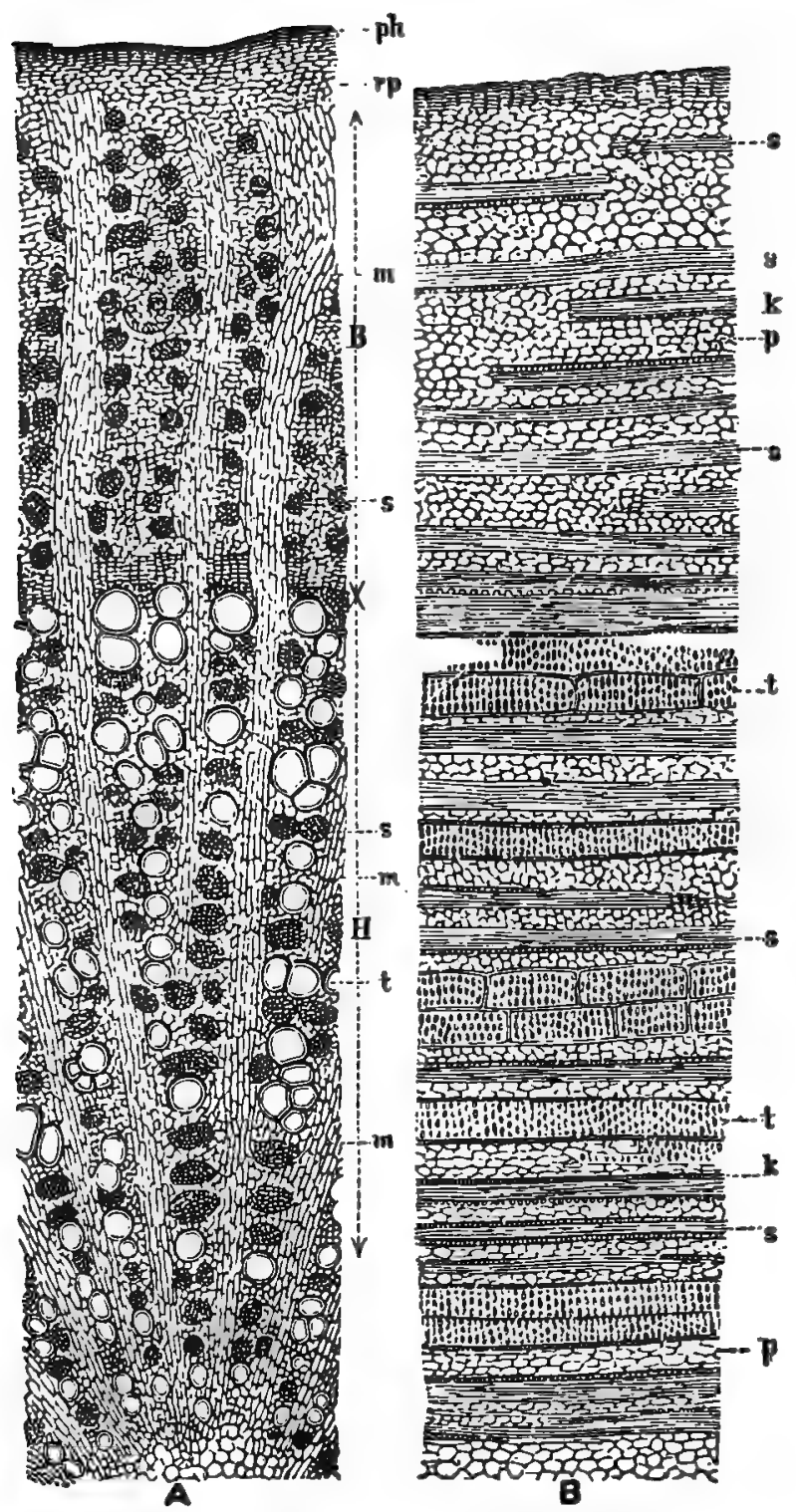

Fic. 204. Glycyrrhiza: A, transverse section; B, longitudinal section. B, bark; $H$, wood; $X$, cambium zone; ph, cork cells; rp, cortex; $p$, parenchyma; $k$ crystal fibers; $s$, sclerenchyma fibers; $t$, trachez; $m$, meduilary rays.-After Meyer. 
Inner Structure.-See Figs. I04; 204; 282, $B$.

Russian Licorice.-Nearly cylindrical, tapering, sometimes split longitudinally, I 5 to $30 \mathrm{~cm}$. long, to to $30 \mathrm{~mm}$. in diameter; externally lemon-yellow, nearly smooth, porous, with detachable bast fibers and circular rootlet-scars, cork, if present, more or less easily detachable; internally lemon-yellow, bark coarsely fibrous, wood radially cleft, not so fibrous as the Spanish variety.

Constituents.-A glucoside glycyrrhizin (anmonium salt of glycyrrhizic acid) from 2.5 to 6 per cent. (Russian licorice is said to contain as much as 7.5 per cent.), to which the drug owes its characteristic taste; asparagin 2 to 4 per cent. (see Althæa); a bitter principle glycyramarin, which occurs principally in the bark and hence is less abundant in the Russian licorice; a volatile oil 0.03 per cent.; mannit; considerable starch and calcium oxalate chiefly as crystal fibers.

Allied Plants.-The root of wild or American licorice, Glycyrrhiza lepidota, a perennial herb indigenous to Western North America, is somewhat similar to Spanish licorice. It contains about 6 per cent. of glycyrrhizin and considerable glycyramarin.

A number of plants of this family contain principles similar to glycyrrhizin, as the root and leaves of Indian or Jamaica licorice (Abrus precatorius) of India and the West Indies; the root of Ononis spinosa, a perennial herb of Europe, and other species of Ononis as well; the locust (Robinia Psendacacia) of the United States and Canada; Caragana pygmea of Siberia and Northern China; Hedysarum americanum of the Northern United States and Canada; Periandra mediterranea, and $P$. dulcis of Brazil and Paraguay. (See also Galium. p. 382.)

A principle resembling glycyrrhizin has also been obtained from the rhizome of Polypodium vulgare (Filices).

RHEUM.-RHUBARB.-The rhizome of Rheum officinale, Rheum palmatum, Rheum palmatum tanguticum, and probably other species of Rheum (Fam. Polygonaceæ), perennial herbs (Fig. 205) indigenous to Northwestern China and Eastern Thibet, and sparingly cultivated in other parts of the world (p. 262). The rhizomes are collected in autumn from plants that are eight to ten years old, most of the bark is removed, and they are then 


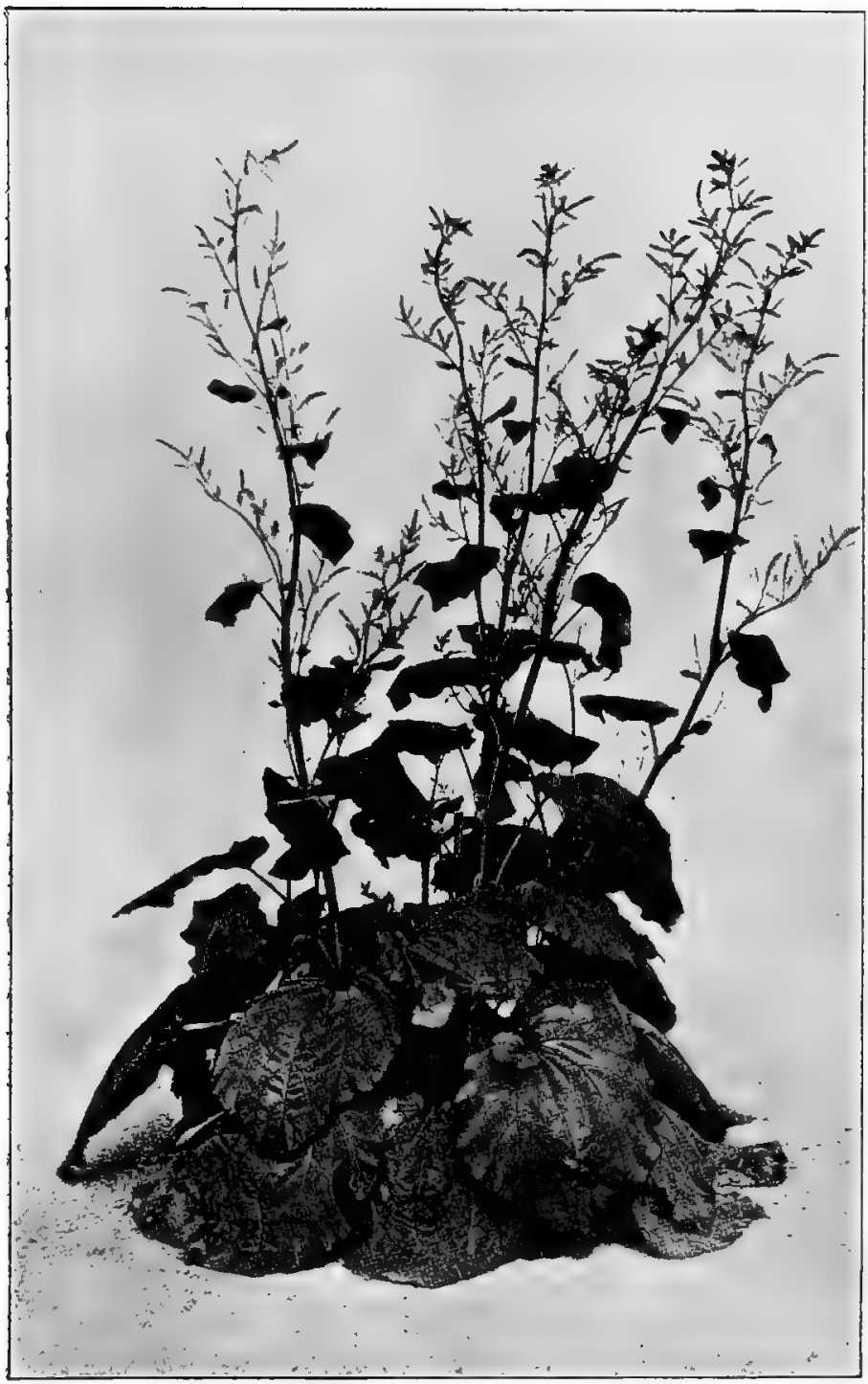

FIG. 205. Rheum officinale, growing in the Chelsea Physic Garden (London).After Pérrédès. 
perforated, strung on ropes and dried either in the sun or by artificial heat. The drug is exported chiefly from Shanghai. The principal commercial varieties are known as Chinese rhubarb, Canton rhubarb and Shensi rhubarb, the latter being preferred.

DesCRIPTION.-Cut into irregular plano-convex and oblong pieces, frequently with a large perforation, hard and moderately heavy, 5 to $15 \mathrm{~cm}$. long, 5 to $8 \mathrm{~cm}$. broad and 3 to $6 \mathrm{~cm}$. thick ; externally mottled from alternating strix of light-brown parenchyma cells and dark-brown medullary rays, occasionally with reddish-brown cork patches and small radiate scars of fibrovascular tissue, smooth and sometimes covered with a light-brown powder; fracture somewhat granular ; internally light brown; odor distinct; taste bitter, astringent and gritty.

Light and spongy rhizomes should be rejected.

InNer Structure.-See Figs. 28r, $A ; 289$.

Constituents.-The principal constituent appears to be a glucoside (possibly the chrysophan of some authors) or an undetermined substance which yields successive oxidation products, viz.: chrysophanic acid (di-oxy-methyl-anthraquinone), emodin (tri-oxy-methyl-anthraquinone), and rhein (tetra-oxy-methyl-anthraquinone). Chrysophanic acid crystallizes in golden-yellow, clinorhombic prisms and dissolves in alkalies and in concentrated sulphuric acid, the solutions having a deep-red color. It is re-formed in rhubarb after extracting it by exposing the moistened root to air. EModin occurs to the extent of I.5 per cent. and forms orange-red needles which are soluble in hot toluene and give with alkalies and alkali carbonates purplish colored solutions. RHEIN forms yellowish-brown scales which are insoluble in hot toluene, soluble in hot acetic acid and produce purplish-red solutions with the alkalies or alkali carbonates. Rhubarb also contains the tanno-glucoside (tannin) which yields rheumic acid; the glucoside glucogallin, which yields gallic acid; the glucoside tetrarin, which yields cinnamic acid in addition to gallic acid; an aldehyde rhoosmin, which has the odor of rhubarb; considerable starch; calcium oxalate in the form of rosette aggregates; and yields about $r 5$ per cent. of ash.

Allied Plants.-The rhizomes of other species of Rheum are also used to a limited extent, as English or Austrian rhubarb 
from Rheum rhaponticum; they are more or less cylindrical, distinctly radiate, and contain, besides chrysophanic acid, rhapontin. Rheum palmatum, which is cultivated in France, Germany and Russia, produces rhizomes that are lighter in color and less valuable than the Chinese rhubarb, the constituents being similar to those of Austrian rhubarb.

The rhizomes of other plants of the Polygonacer have been used as substitutes for rhubarb, as follows: Calligonum songaricum of Soongaria; Rumcx acutus of Europe; $R$. obtusifolius of Europe and Asia; R. abyssinicus of Abyssinia; and Polygonum cuspidatum of China and Japan.

ACONITUM.-ACONITE.-The tuberous root of Aconitum napellus (Fam. Ranunculaceæ), a perennial herb (Figs. 84, I4I), growing in the mountainous districts of Europe, Asia and Western North America. It is also cultivated in temperate regions (p. 268). The commercial supplies are obtained from England and Germany, and in England the root is collected in autumn from cultivated plants after the overground parts have died down, whereas in Germany the roots are collected from wild plants during the flowering period, this being done to distinguish the particular species yielding the drug. The root should be carefully dried.

DeSCRIPTION.-More or less conical or fusiform, 4 to $10 \mathrm{~cm}$. long, 5 to $20 \mathrm{~mm}$. in diameter; externally dark brown, smooth or somewhat wrinkled, the upper portion with a bud, remains of bud-scales or stem-scars, with numerous root-scars or short roots; fracture horny, somewhat mealy ; internally, bark light or dark brown, I to $2 \mathrm{~mm}$. thick, cambium irregular, 5- to 7-angled, wood yellowish, in small bundles at the angles, pith light brown, about 2 to $6 \mathrm{~mm}$. in diameter; odor very slight; taste sweetish, acrid, pungent, accompanied by a sensation of numbness and tingling.

The shrunken, hollow, older tubers, together with the overground stem-remnants, should be rejected.

Inner Structure.-See Figs. 206, 309.

Constituents.-A number of alkaloids have been isolated, of which aconitine is the most important; it occurs to the extent of about 0.75 per cent., and forms rhombic prisms, which are not colored by concentrated sulphuric or nitric acid. An aqueous solution of the alkaloid, after acidulating with acetic acid, gives on 
the addition of a solution of potassium permanganate a red crystalline precipitate. Aconitine decomposes quite readily and several of its derivatives have been isolated: benzaconine, an inert alkaloid and aconine which produces apparently contrary physio-

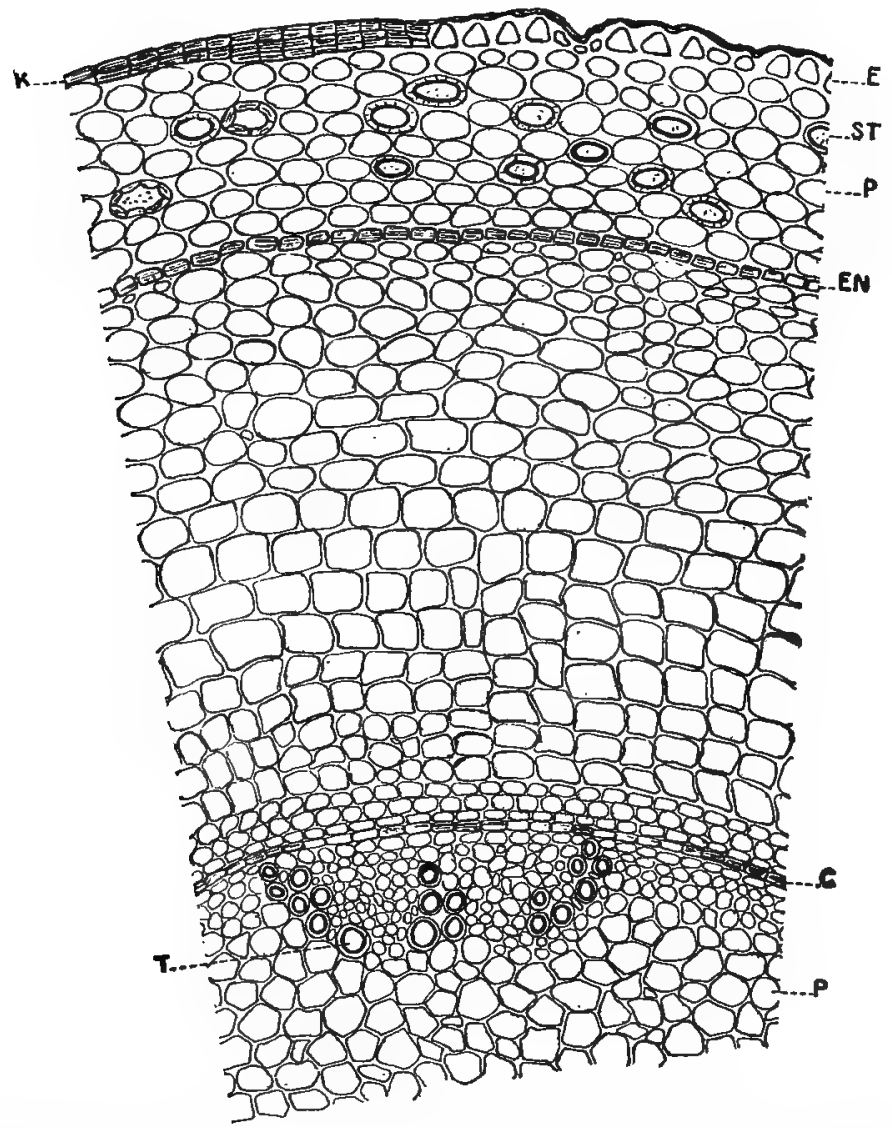

FIG. 206. Transverse section of aconite: K, cork; E, epidermis; ST, stone cells; EN, endodermis; C, cambium; T, trachea; P, parenchyma.

logical effects to aconitine. The alkaloid napelline may be isomeric with aconine. Aconite also contains considerable aconitic acid which is chiefly combined with calcium and occurs in other genera of the Fam. Ranunculaceæ, viz. : Delphinium and Adonis; 
considerable starch; a little mannitol and a resin. The other alkaloids are amorphous and non-toxic, and of these isaconitine (napelline) has been employed medicinally.

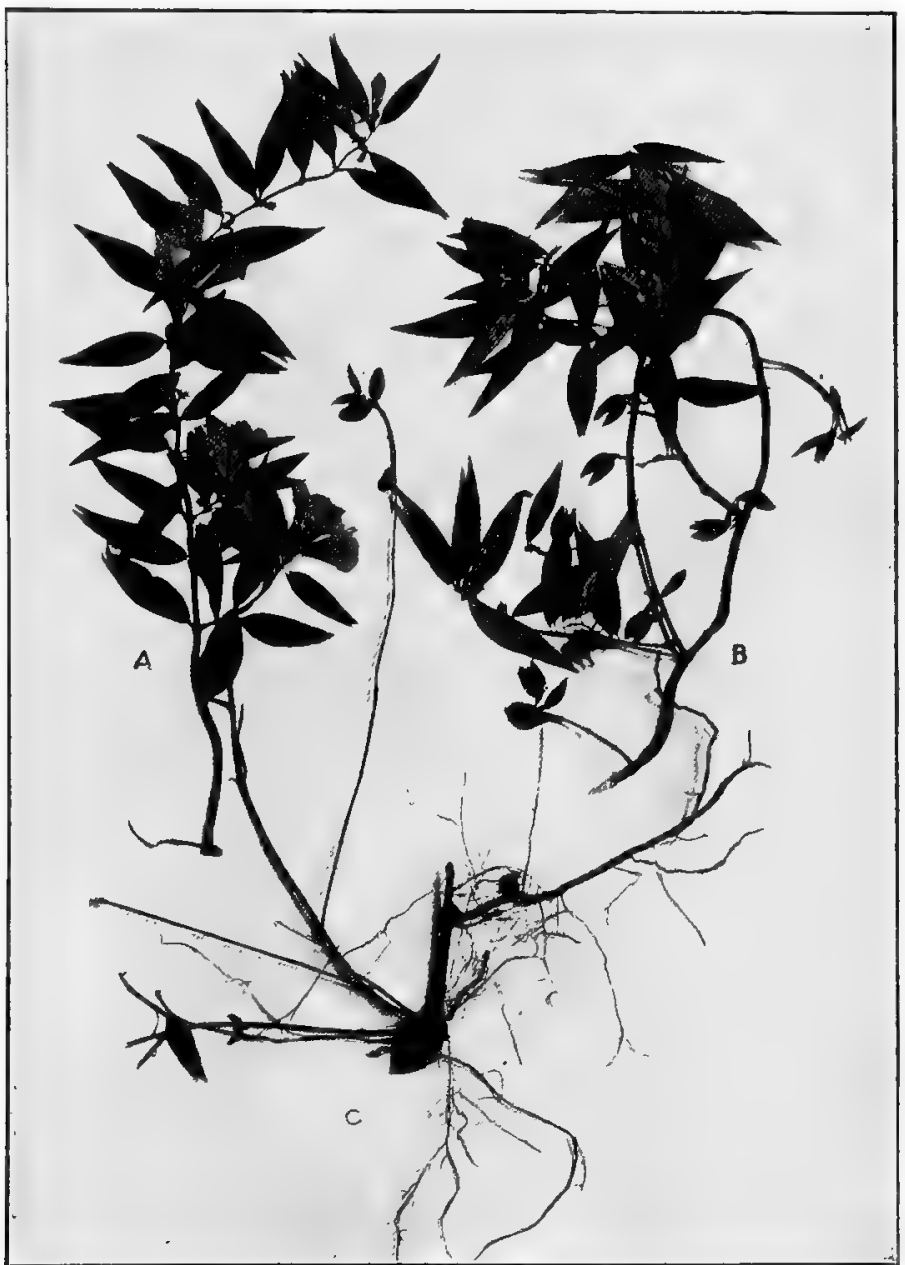

Fig. 207. Yellow jessamine (Gelsemium sempervirens): A, flowering branch; B, frulting branch showing dehiscent capsules; C, portion of rhizome with roots.

Allied Plants.-Japanese aconite is obtained from Aconitum Fischeri; the root is smaller, conical, nearly smooth and with starch grains that are much larger than those of the official 
drug (Fig. 309). Indian aconite, the product of Aconitum ferox, is a much larger root and somewhat horny, owing to the gelatinization of the starch in its preparation for market.

A very large number of species of Aconitum are used medicinally. These may be brought into five groups: (I) Those containing the alkaloid aconitine, as Aconitum napellus; (2) those containing pseudaconitine, which, while it resembles in some of its properties aconitine, is not chemically identical with it, and is found in the Indian aconite obtained from $A$. ferox, $A$. luridum and A. palmatum; (3) those containing the alkaloid, japaconitine, which closely resembles pseudaconitine and is found in Japanese aconite, obtained from A. Fischeri; (4) those which contain the narcotic bases, lycaconitine and myoctonine, found in A. lycoctonum of Asia and Europe; (5) those yielding lappaconitine, a powerful alkaloid occurring in $A$. septentrionale, a nearly related species to $A$. lycoctonum.

Aconite leaves, the dried leaves (Fig. I4I) of Aconitum napellus, are extensively used (p. 268). The constituents resemble those of the tuber and the amount of aconitine varies from 0.25 to 0.50 per cent. The ash is about 16 per cent. In Great Britain the fresh or recently dried leaves are largely employed.

GELSEMIUM.-YELLOW JESSAMINE, YELLOW JASMINE.-The dried rhizome and roots of Gelsemium sempervirens (Fam. Loganiaceæ), a perennial climber (Fig. 207) of the Southern United States and Guatemala (p. 362). The drug should be collected in autumn.

Description,-Rhizome horizontal, cylindrical, usually cut into pieces 9 to $20 \mathrm{~cm}$. long, 4 to $\mathrm{I} 5 \mathrm{~mm}$. in diameter; externally light brown, longitudinally wrinkled, transversely fissured; upper surface with few stem-scars; uncler and side portions with numerous roots and root-scars; fracture tough, wiry; internally light brown or pale yellow, bark about I mm. thick, wood distinctly radiate, excentral, with four groups of internal phloem, pith disintegrated; odor slight; taste bitter.

In Ner Structure.-See Figs. 208, 208a.

Roots light brown, 3 to $20 \mathrm{~cm}$. long, 2 to $8 \mathrm{~mm}$. thick; internally light yellow, bark about $0.5 \mathrm{~mm}$. thick, wood distinctly radiate. 
The overground stem is dark or reddish-brown, longitudinally wrinkled and has numerous lenticels and few, somewhat elliptical branch-scars; the bark is about $0.2 \mathrm{~mm}$. thick and somewhat greenish.

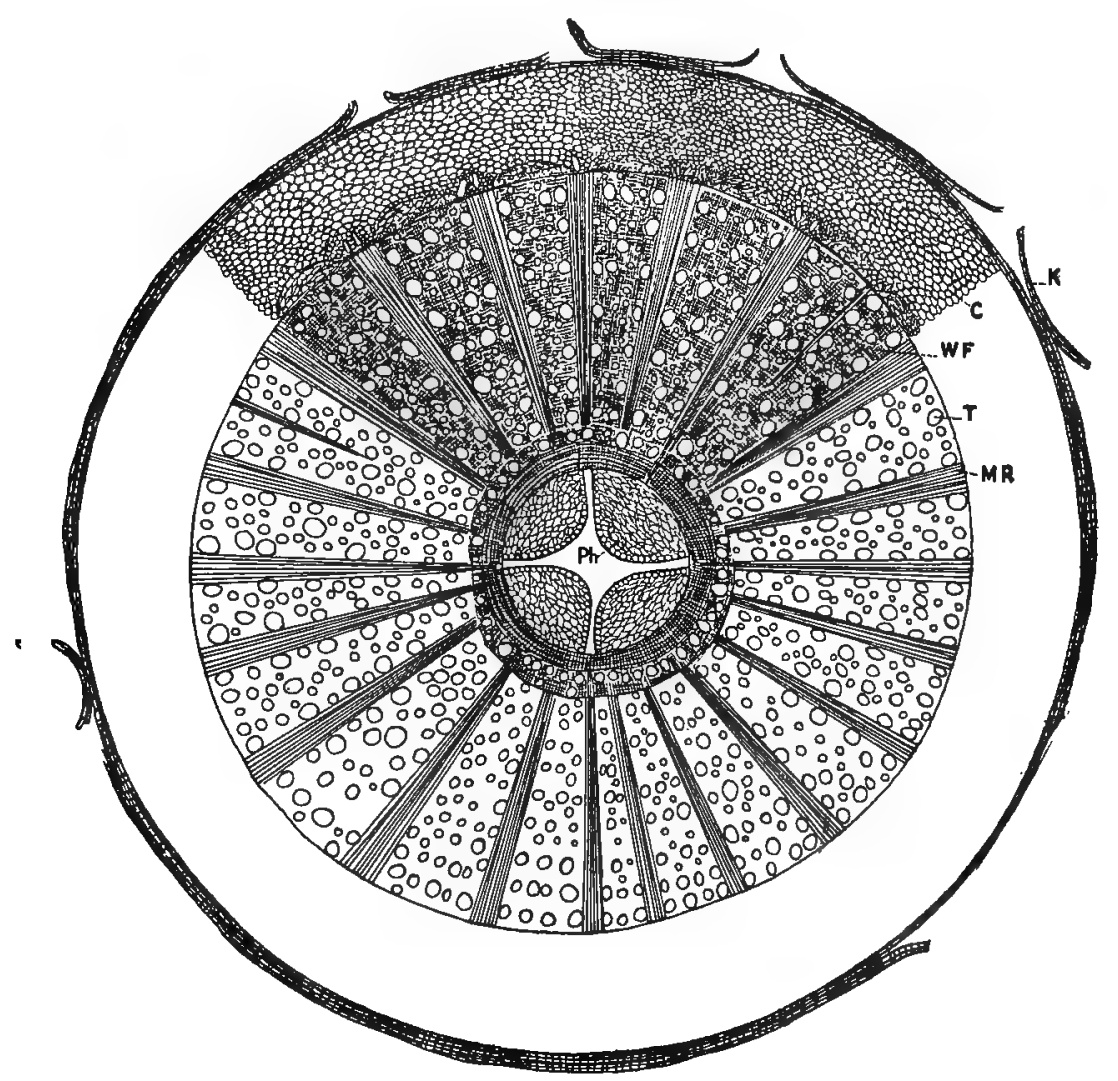

Fig. 208. Transverse section of rhizome of gelsemilum: $K$, cork; C, cortex; WF, wood fibers; $\mathrm{T}$, tracheæ; $\mathrm{MR}$, medullary rays; $\mathrm{Ph}$ internal phloem.

Constituents.-Two alkaloids of great toxicity, the one known as GELSEMINE, crystallizes in silky needles and on the addition of concentrated nitric acid and heating the solution is colored reddish and then dark green; the other GELSEMININE, occurring in amorphous masses and forming yellowish amorphous salts, is colored greenish on the addition of nitric acid. In addition the 
drug contains 0.2 to 0.5 per cent. of B-methyl-æsculetin (gelsemic acid), which also occurs in scopola and other plants, and which gives with solutions of the alkalies, a bluish fluorescence; 0.5 . per cent. of a volatile oil; about 4 per cent. of resins, one of which is acrid; starch; and calcium oxalate in the form of monoclinic prisms.

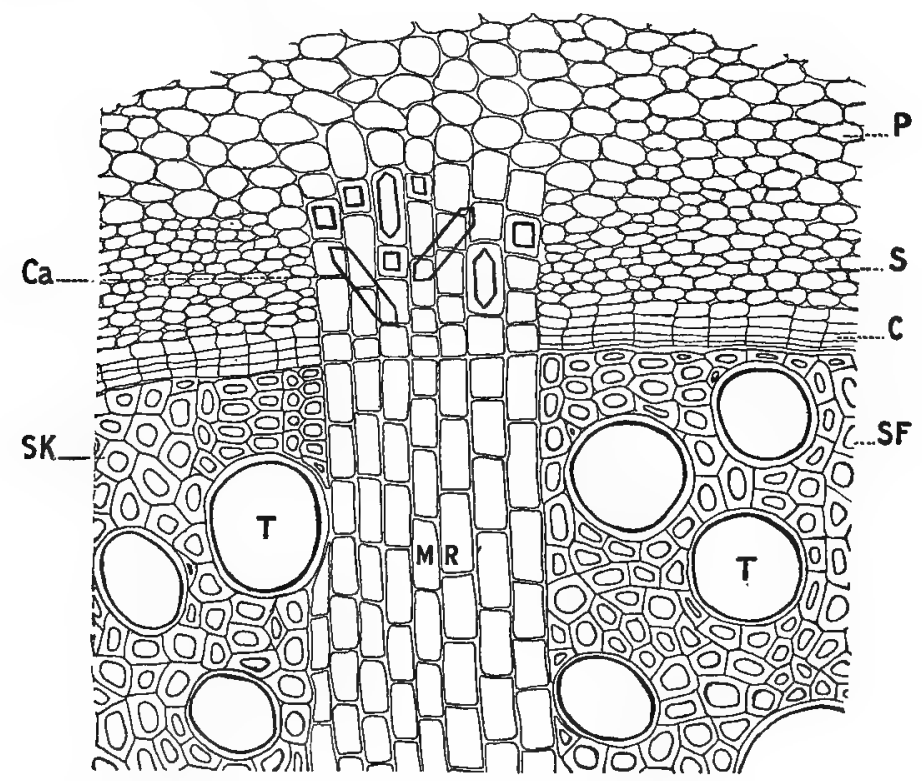

Fig. 208a. Transverse section of gelsemium near the cambium: $P$, parenchyma; $S_{\text {n }}$

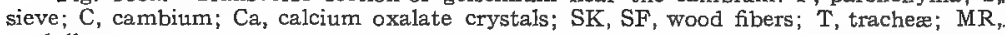
medullary rays.

BERBERIS.-OREGON GRAPE-ROOT.-The rhizome and roots of Berberis Aquifolium (Fam. Berberidaceæ), a low trailing shrub (Fig. I42), which is indigenous to the Rocky Mountain region of the United States, extending into British Columbia and as far east as Nebraska (p. 272).

Description.-In cylindrical pieces which vary from 8 to I 2 $\mathrm{cm}$. long and $\mathrm{x} .5$ to $3.5 \mathrm{~cm}$. in diameter; externally pale yellowishbrown to dark yellowish-brown, longitudinally wrinkled, with few root branches and occasionally rootlets; hard and tough. Internally, bark dark brown, less than I mm. thick and rather soft; 
wood lemon-yellow, distinctly radiate, with narrow medullary rays; pith bright yellow, 2 or $3 \mathrm{~mm}$. in diameter. Slightly odorous. Taste bitter.

Constituents.-Four alkaloids, namely, berberine; oxyacanthine, which acquires a yellow color in sunlight; berbamine, which is distinguished from the above-mentioned alkaloids by being soluble in water; and another alkaloid whose properties have not been investigated. The drug also contains resin and considerable starch.

Allied Plants.-Berberis anlgaris (European barberry), naturalized in the United States, furnishes a drug which has similar properties. Not only the rhizomes and roots but also the stem and root barks are employed, the root bark containing a larger amount of alkaloids than that of the stem.

The bark and root of Berberis asiatica of the Himalaya region and $B$. aristata of India are similarly employed, the latter containing about 2 per cent. of berberine.

The flowers and berries of Berberis Aquifolium and $B$. a'ulgaris contain berberine, oxyacanthine, volatile oil, about 6 per cent. of malic acid and 3.5 to 4.7 per cent. of sugar.

The alkaloid berberine is also found in Argenone mexicana (Fam. Papaveraceæ) and in the following members of the Ranunculaceæ: Hydrastis canadensis, Coptis trifolia and Xañthorrhiza apiifolia.

GENTIANA.-GENTIAN.-The rhizome and roots of Gentiana lutea (Fam. Gentianaceæ), a perennial herb (Fíg. 209) indigenous to Central and Southern Europe and Asia Minor. (p. ). The fleshy rhizomes and roots are collected in autumn and frequently cut into longitudinal pieces and slowly dried, during which latter process they develop a distinctive color and odor. The commercial supplies are obtained from France, Germany, Spain and Switzerland.

DESCRIPTION.-Nearly cylindrical and sometimes branched, split longitudinally or broken into irregular pieces, 3 to $15 \mathrm{~cm}$. long, 5 to $40 \mathrm{~mm}$. in diameter; externally light brown, the upper or rhizome portion annulate from scars of bud-scales, longitudinally wrinkled, and with few buds, stem- and root-scars, roots longitudinally wrinkled; fracture short when dry, tough and flex- 
ible when damp; internally dark yellow, bark 0.5 to $2 \mathrm{~mm}$. thick, porous, cambium zone distinct; odor heavy; taste bitter.

In ner Structure.-See Fig. 2 Io.

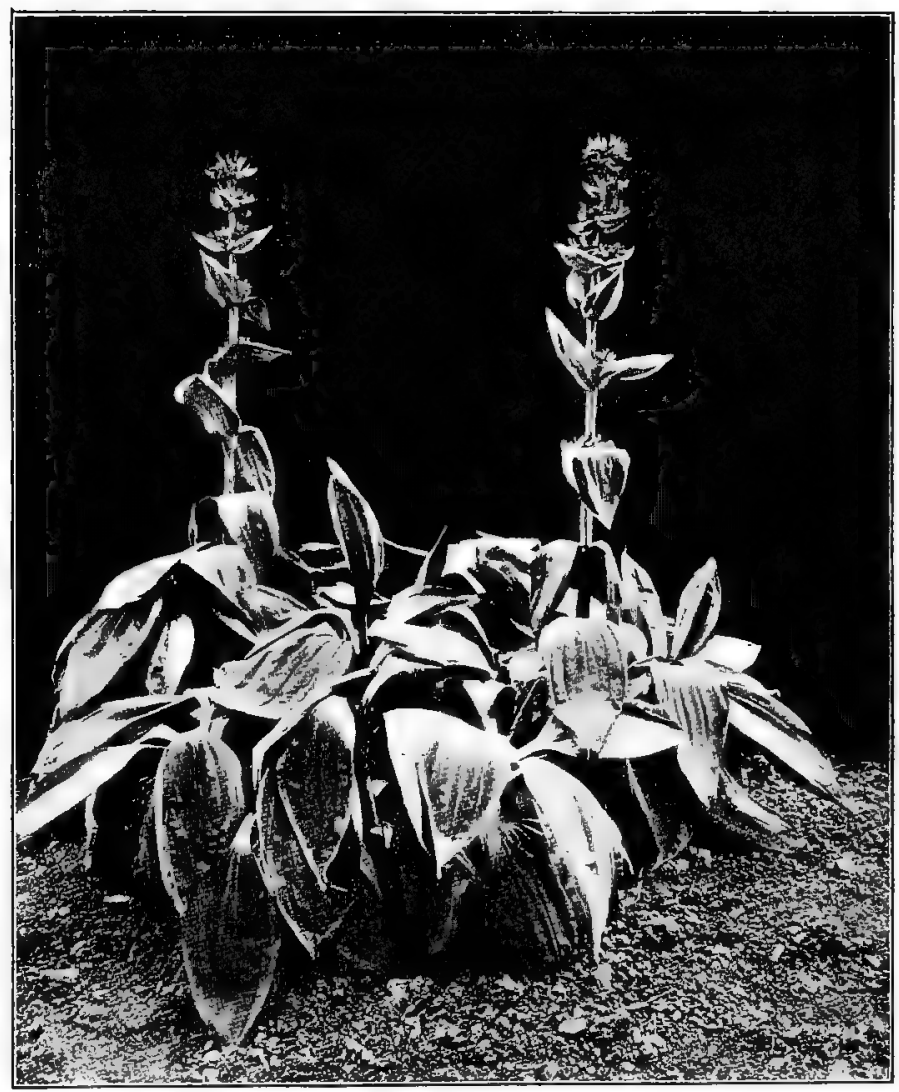

FIG. 209. Gentiane lutea, growing in the Royal Botanic Society's Gardens (London). -After Pérrédès.

Constituents.-A bitter glucoside gentiopicrin, about o.I per cent., occurring in yellow needles which are readily soluble in water but less so in alcohol and to which the drug owes its peculiar bitterness and odor; a coloring principle gentisin (gentianin or gentisic acid), occurring in yellowish prisms which are 
soluble in alcohol but nearly insoluble in water, and becoming greenish-brown with ferric salts, whence some consider it to be a kind of tannin and have named it gentiotannic acid; quercitrin,
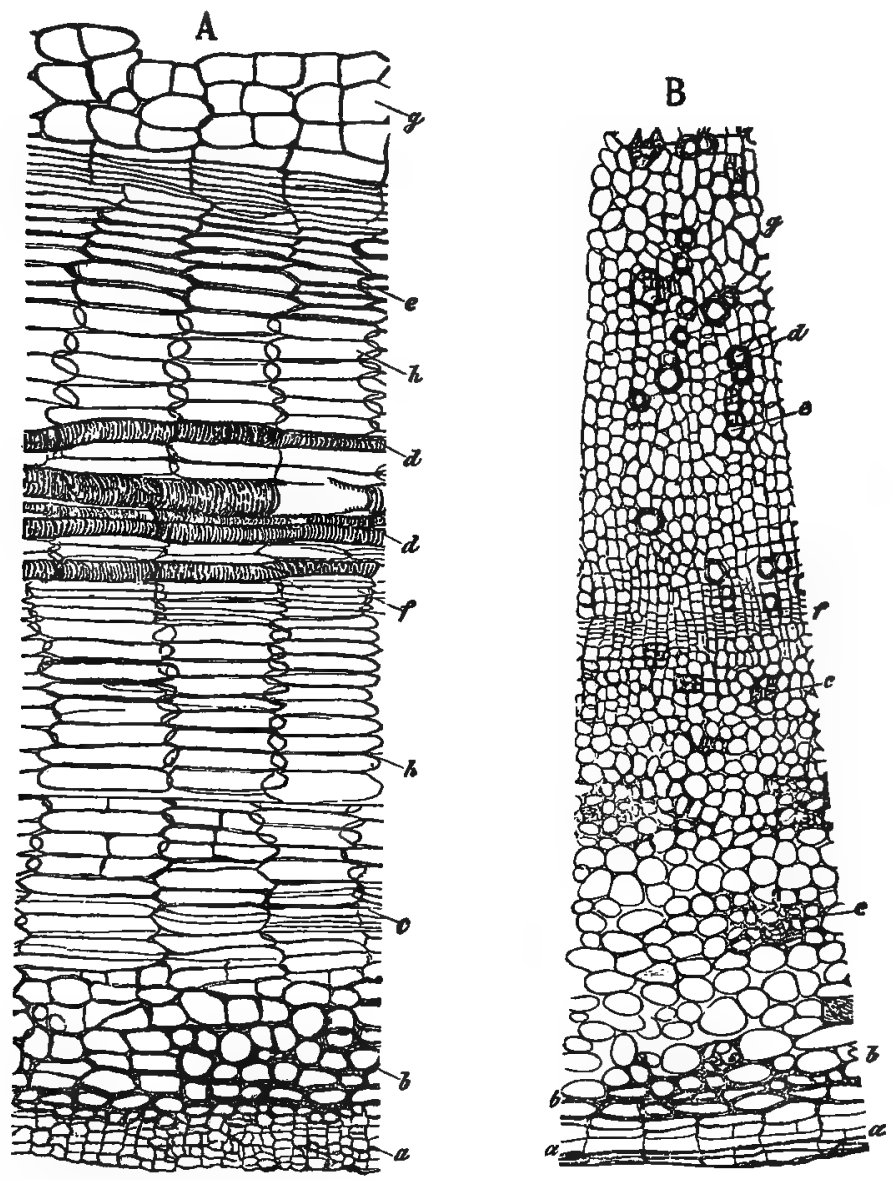

FIG. 2ro. Longitudinal (A) and transverse (B) sections of gentian: a, cork; $b, a$ kind of hypodermal layer; c, sieve; $f$, cambium; e, elongated fiber-like cells; $h$, somewhat elongated parenchyma cells; $g$, short parenchyma cells.-After Meyer.

or an allied product, crystallizing in yellowish needles; gentianose, a crystalline carbohydrate which occurs in the fresh root and which does not reduce Fehling's solution; I 2 to $\mathrm{I} 5$ per cent. of glucose; and pectin. Gentian also contains two other glucosides: 
gentiamarin, which is amorphous, has a disagreeable bitter taste and gives a slight darkening with iron salts; and gentianin, which occurs in yellowish needles, gives a greenish-black color with ferric salts and on hydrolysis yields gentienin, xylose and glucose.

Allied Plants.-The rhizomes and roots of various other European species of Gentiana are sometimes collected and employed medicinally, as of Gentiana purpurea, collected in Switzerland, and G. Pannonica and G. Punctata, collected in Austria. The rhizome and roots of Elliott's gentian. Gentiana Elliottii, indigenous to the southeastern part of the United States, was at one time official in this country.

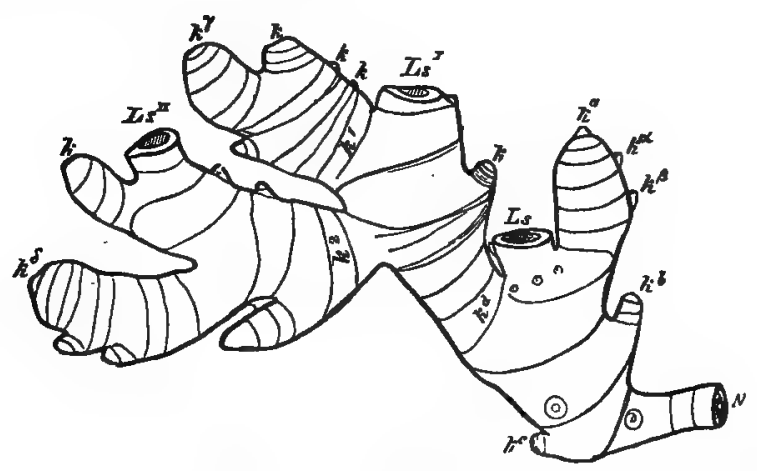

FIG. 2xI. Rhizome of African ginger showing scars of overground branch (Ls) and buds $(\mathrm{k})$. The more or less parallel lines represent leaf-scars and scars of bud-scales, and the small circles, root-scars.-After Meyer.

The root of American Columbo, also known as yellow gentian (Frasera carolinensis), a perennial herb growing in the Eastern United States and Canada, resembles in the whole condition the official gentian, but is of a lighter color (p. 460).

ZINGIBER.-GINGER.-The rhizome of Zingiber officinale (Fam. Zingiberaceæ), a perennial herb (Fig. 132) indigenous to Asia, and cultivated in most tropical countries, notably in the West Indies and Africa (p. 242). The rhizomes are collected between December and March; they are cleaned by washing, peeled, again washed in water, sometimes containing juice of the lime fruit, and dried in the sun. There are several kinds of the drug, depending upon the manner of treatment. That from Africa has the 
periderm removed from the vertical sides only, and is known as "coated " or " uncoated" ginger; in the Jamaica variety the periderm is completely removed and the product is known as "peeled" or "scraped" ginger. The latter is sometimes steeped in milk of lime to protect it against the attacks of insects. The Jamaica variety is the official ginger.

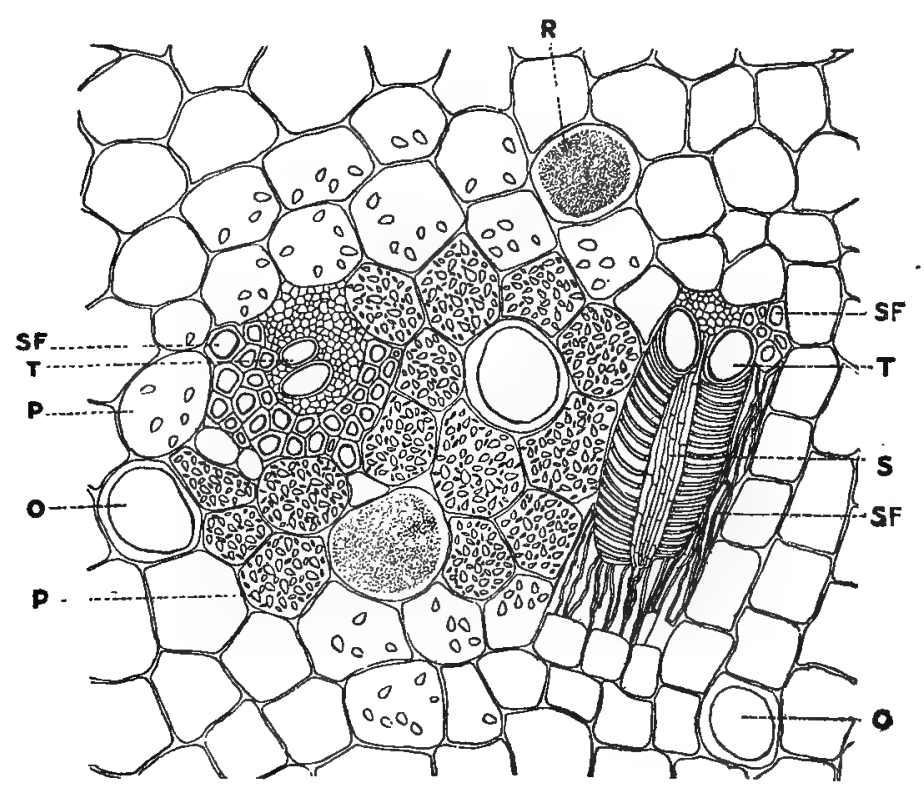

Fig. 212. Transverse section of portion of rhizome of ginger: $P$, parenchyma containing ovoid starch grains; $O$, oil cells; $R$, cells containing resin; $S F$, sclerenchymatic fiber; $T$, trachea; $S$, sieve.

Jamaica Ginger.-Horizontal, laterally compressed, irregularly branched pieces (Fig. 2I I), 4 to Io $\mathrm{cm}$. long, 4 to $20 \mathrm{~mm}$. broad, 5 to Io $\mathrm{mm}$. thick; externally light brown, longitudinally wrinkled, with somewhat elliptical, depressed stem-scars, with few fibers of fibrovascular tissue or achering fragments of periderm; fracture mealy and with short projecting fibrovascular bundles; internally, cortex light brown, o.I to $0.4 \mathrm{~mm}$. thick; central cylinder with numerous circular groups of fibrovascular tissue and yellowish secretion cells; odor strongly aromatic; taste pungent. 
Inner Structure.-See Fig. 2 I 2.

Ginger which is bleached by means of sulphur fumes or bleaching powder (chlorinated lime) or that is coated with lime should not be used.

Constituents.-Volatile oil, possessing the aromatic odor of the drug, I to 3 per cent., and consisting chiefly of a sesquiterpene, some dextro-camphene and phellandrene; a colorless, viscid principle GINGEROL, which has the pungent taste of the drug, 0.5 to $\mathrm{I} .5$ per cent. ; two resins, one of which is acid in character; starch, 20 per cent.

COMMERCIAL VARIETIES.-The following are derived from Zingiber officinale: (I) NATURAL JAMAICA ginger occurs in long, slender, flattish, branching, light yellowish-brown pieces, the periderm being completely removed. (2) BLEACHED JAMAICA ginger is the natural Jamaica rhizome coated with lime. (3) Cochin ginger occurs in shorter, broader and thicker pieces than the Jamaica variety, is light brown in color and has only part of the periderm removed. (4) AFrICAN ginger, somewhat resembles Cochin ginger but is of a dark grayish-brown color. (5) RACE ginger occurs in irregular, more or less twisted, branching pieces with the dark-brown periderm partly removed, the remaining surface being more or less brownish-black.

JAPAN ginger is said to resemble Cochin ginger and to be derived from other species of Zingiber, as Z. Zerumbet, Z. Cassumunar, Z. Mioga and Z. Cemenda.

Preserved Ginger is made by boiling the young rhizomes while fresh, after removing the periderm, in syrup. In this form it occurs in translucent, yellowish-brown fragments, which are used as a confection.

CONVALLARIA.-LILY-OF-THE-VALLEY.-The dried rhizome and roots of Convallaria majalis (Fam. Liliaceæ), a perennial herb (p. 238) indigenous to Europe, Asia and the higher mountains of Virginia, North Carolina and South Carolina and extensively cultivated for its flowers. The rhizome and roots should be collected late in summer and carefully dried. The leaves and flowers have also been used in medicine.

DESCRIPTION.-Rhizome horizontal, cylindrical, and sometimes branched, jointed, in pieces from 3 to $17 \mathrm{~cm}$. long, internodes Io to 
$50 \mathrm{~mm}$. long, I to $3 \mathrm{~mm}$. in cliameter, nodes with a circular scar, not much thickened; externally light or dark brown, longitudinally wrinkled, somewhat annulate from scars of bud-scales, mostly smooth between the nodes, upper surface of nodes marked by

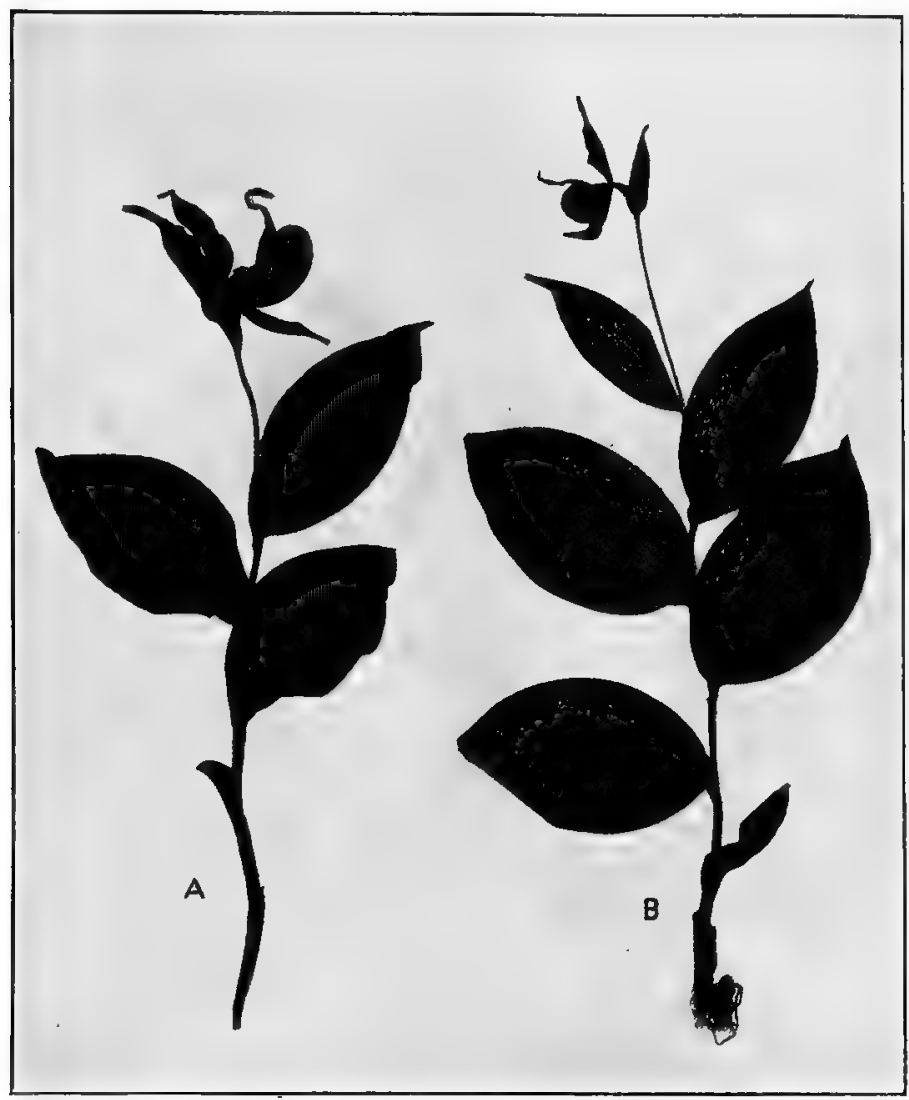

FIG. 213. A, Cypripedium hirsutum; B, Cypripedium parviflorum, the flower of the latter being the smaller.

stem-scars, side and under surface with root-scars, or usually with three to five roots, fracture short or fibrous; internally light or dark brown, cortex $0.5 \mathrm{~mm}$. thick, separable from the central cylinder; odor faint ; taste bitter, slightly acrid. 
Roots somewhat tortuous, 5 to $6 \mathrm{~cm}$. long, about 0.3 to 0.5 $\mathrm{mm}$. in diameter, rootlets few.

Inner Structure.-See Fig. II4.

Constiruents.-A bitter, somewhat crystalline glucoside, convallamarin, about 0.6 per cent., which is soluble in water, alcohol and ether and has a physiological action similar to digitalin. An acrid glucoside, convallarin, forming rectangular prisms which are insoluble in ether and sparingly soluble in water, the solution foaming on shaking like a saponin solution.

The FLOW'ERS of Lily-of-the-valley contain a volatile crystalline principle which is fragrant in even dilute solutions.

CYPRIPEDIUM.-LADY'S SLIPPER.-The dried rhizome and roots of Cypripedium pubescens (C. hirsutum), and Cypripedium parviflorum (Fam. Orchidacex), perennial herbs (Fig. 2r3) native in woods and thickets of the Eastern and Central United States and Canada (p. 245).

DEs.CRIPTION.-Rhizome horizontal, somewhat tortuous and bent, 3 to $7 \mathrm{~cm}$. long, 2 to $4 \mathrm{~mm}$. in diameter ; externally dark brown, annulate from scars of bud-scales, upper surface with numerous large, sometimes depressed scars, under and side portions with numerous roots and few root-scars; fracture short; internally light brown, cortex about $0.5 \mathrm{~mm}$. thick, central cylinder somewhat porous, and with numerous scattered fibrovascular bundles; odor heavy, distinct; taste bitter, somewhat pungent. The walls of the endodermal cells are but slightly cutinized.

Roots 3 to I I cm. long, 0.5 to $1.5 \mathrm{~mm}$. in diameter; externally light or dark brown, longitudinally wrinkled; fracture somewhat fibrous; internally, cortex white, central cylinder yellowish.

Constituents.-Volatile oil, several resins, a bitter glucosidal principle, tannin, gallic acid, starch, calcium oxalate in the form of raphides, and ash about 6 per cent.

TRITICUM.-COUCH GRASS.-The rhizome of Agropyron repens (Fam. Graminex), a perennial grass (Fig. 214), indigenous to Europe and Asia, and naturalized in North America, except in the Arctic region ( $p .227$ ). The rhizome is gathered in spring, deprived of the rootlets, cut into pieces and carefully dried. Our commercial supplies come chiefly from Central - Europe. 


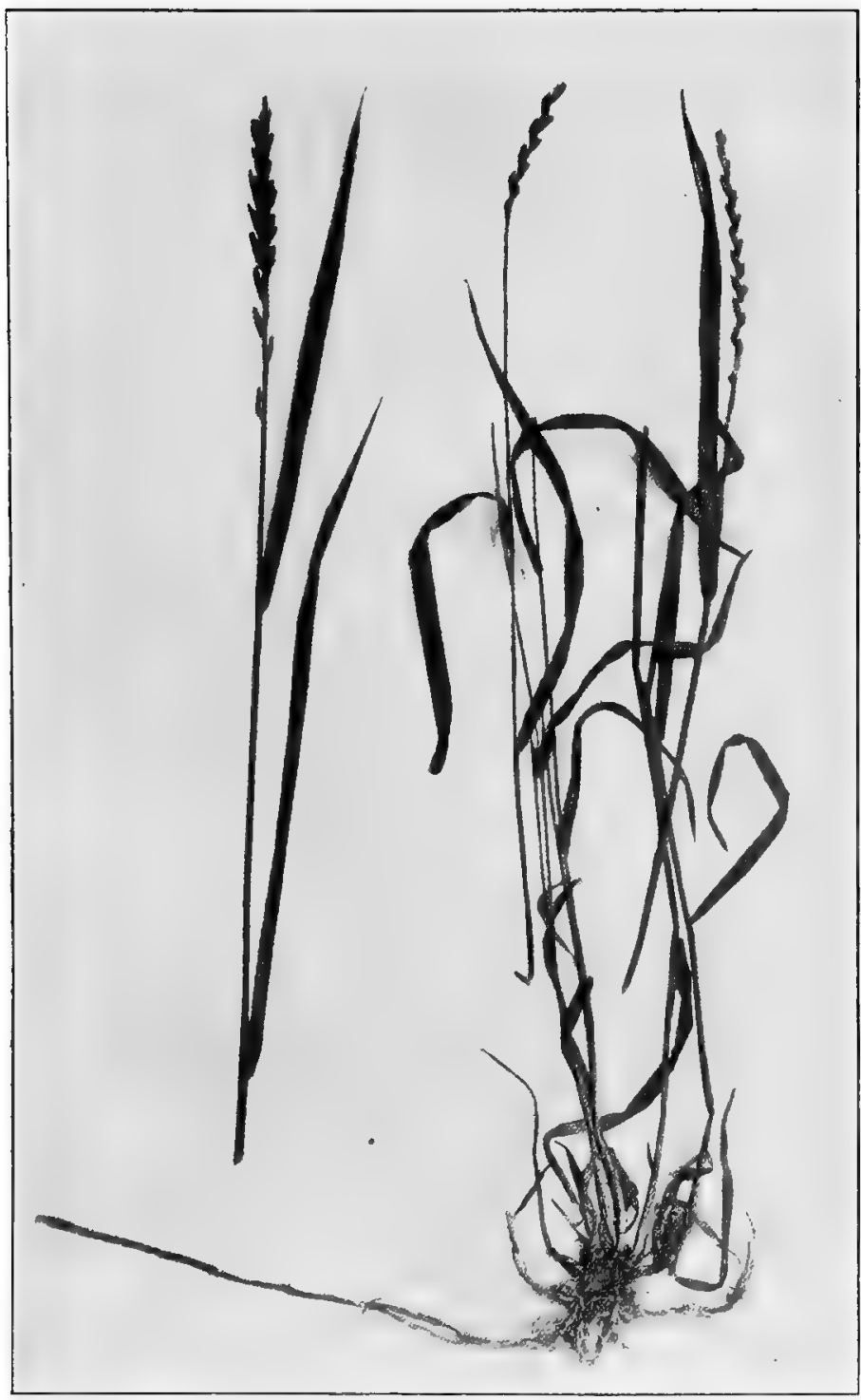

Frg. 2I4. Agropyron repens, showing the long, slender rhizome, slender culms with narrow leaves and compressed spikes resembling those of wheat. 
DESCRIPTION.-Horizontal, somewhat cylindrical or 4- to 6-angled, usually cut into pieces 5 to $8 \mathrm{~mm}$. long, I to $2 \mathrm{~mm}$. in diameter; externally light yellow, longitudinally furrowed, smooth, shiny, nodes with circular leaf-scars and few root-scars; fracture tough, fibrous; internally, bark light brown, about 0.5 $\mathrm{mm}$. thick, wood light yellow and porous, center hollow; odor slight, taste sweetish, slightly acrid.

Constituents.-Triticin, a lævo-rotatory carbohydrate resembling inulin, 8 per cent.; dextrose and levulose 2.5 to 3.3 per cent. ; a nitrogenous, gummy substance, I I per cent.; acid malates; and about 4.5 per cent. of ash containing much silica. The rhizome is free from starch and calcium oxalate, and the lactic acid found in the extract is apparently a fermentation product.

VERATRUM.-The rhizome and roots of Vcratrum viride (Fam. Liliaceæ), a perennial herb (Fig. I29) found growing in wet meadows usually associated with skunk cabbage (Spathyema fotida), and indigenous to the Eastern and Central United States and naturalized in Canada, British Columbia and Alaska; and Veratrum album, a similar plant, indigenous to Central and Southern Europe, the former being known as American or green hellebore and the latter as European or white hellebore. The plant dies down early in the summer and the rhizome may be collected soon thereafter. It is cut longitudinally and dried. Much of the drug used in this country is derived from Veratrum album and imported from Germany (p. 235).

American or Green Heilebore.-Rhizome upright, obconical, usually cut longitudinally into halves or quarters, 2.5 to 5 $\mathrm{cm}$. long, 1.5 to $3 \mathrm{~cm}$. in diameter; externally dark brown or brownish-black, rough and wrinkled, somewhat annulate from scars of bud-scales, top truncate, lower part more or less decayed, with numerous roots and few root-scars; fracture hard and horny; internally light yellow, cortex 2 to $3 \mathrm{~mm}$. thick, endodermis distinct, central cylinder with scattered yellow fibrovascular bundles; odor slight; taste bitter and acrid.

Roots yellowish-brown, nearly cylindrical, 3 to $8 \mathrm{~cm}$. long, 2 to $3 \mathrm{~mm}$. in diameter; externally yellowish-brown, longitudinally or transversely wrinkled (Fig. I I3) ; internally, bark white, I to 2 $\mathrm{mm}$. thick; wood porous, cylindrical; fracture short. 
Euroyean or White Hellebore closely resembles the American Hellebore, but the color varies from whitish to yellowishbrown and usually the rootlets are removed.

The drug should be kept in well closed vessels, and the leaf and stem bases, if present, should be removed.

Inner Structure.-See Figs. 215, 216.

Constituents of Ver.itrum album.-The drug contains a number of alkaloids, of which the most important is PROTOVER.1-

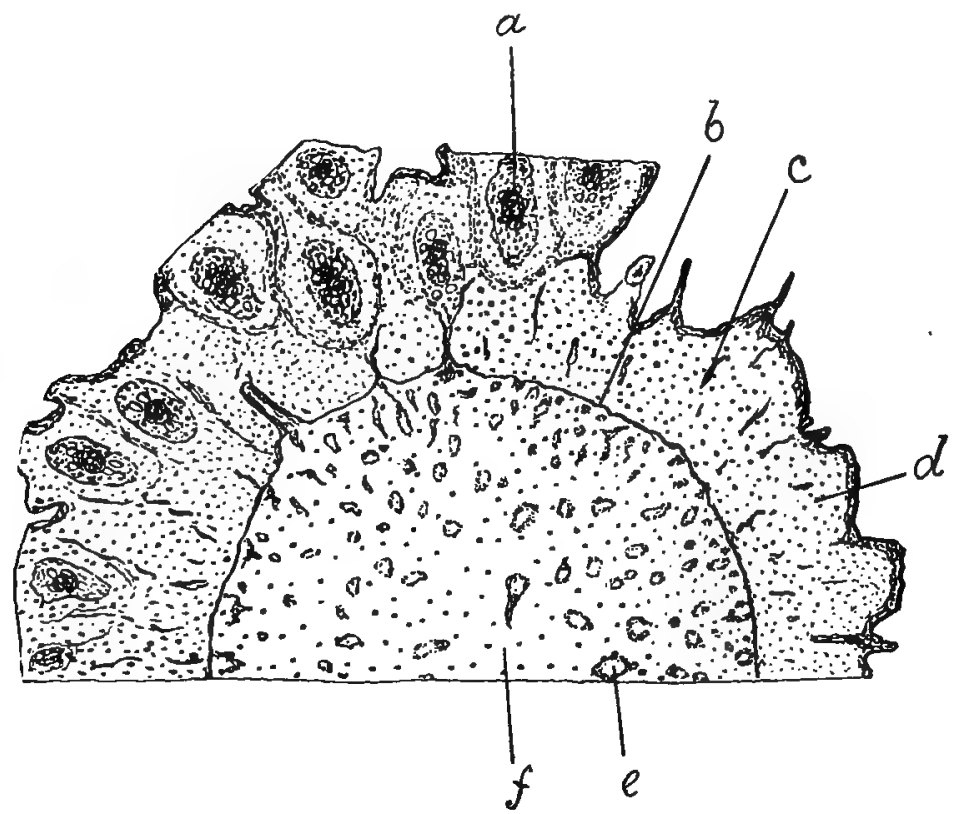

FIG. 215. Cross section of rhizome of Veratrum viride: a, section of a root near its origin; $b$, endodermis; c, one of the wavy fibrovascular bundles in the cortex; $d$, parenchyma; e, fibrovascular bundle of the central cylinder; f, parenchyma.-After Bastin.

TRINE, which occurs to the extent of 0.03 per cent. and forms monoclinic prisms which are insoluble in water, soluble in strong alcohol, and with concentrated sulphuric acid give a greenishcolored solution which gradually changes to blue and finally to violet. It also contains the following alkaloids which are physiologically inactive or but feebly toxic: JeRvine (O.Io to o.I3 per cent.) forms satiny, lustrous prisms which are colored yellow with hydrochloric acid, the solution afterwards changing to green; 
RUBIJERVINE (about 0.005 per cent.) forms long prisms which are colored yellow with concentrated sulphuric acid, the solution becoming orange and finally red; PSEUDOJERVINE forms hexagonal prisms which are colored yellow with concentrated sulphuric acid; TROTOVERATRIDINE is a decomposition product of protoveratrine and forms cubical prisms which are colored violet with concentrated sulphuric acid, the solution afterward becoming cherry-red. Veratrum also contains a bitter glucoside veratramarin; jervic

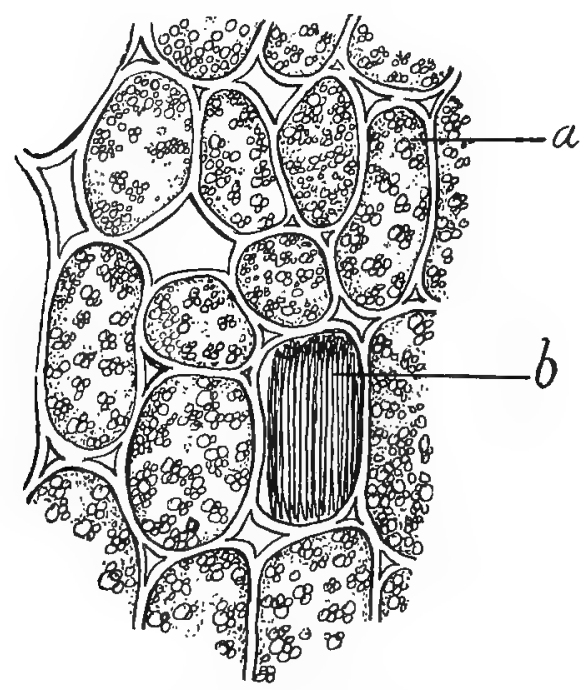

Fig. 216. Several parenchyma cells from thizome of Veratrum viride: a, cells containing starch grains; $b$, cell containing raphides of calcium oxalate.-After Bastin.

acid, which is identical with chelidonic acid, and crystallizes in silky needles; considerable starch; ash 3 to 4 per cent.; and calcium oxalate in the form of raphicles.

Constituents of Veratrum Viride.-Green hellebore contains about 0.08 per cent. of total alkaloids. Of these about onehalf consists of CEVADINE, an exceedingly toxic ether-soluble alkaloid, also found in Sabadilla seeds, which crystallizes in needles and gives a violet color on warming with nitric acid, the solution changing to scarlet-red on boiling. The remainder consists chiefly of the ether-insoluble alkaloids JERVINE and PSEUDOJER- 
VINE, both of which are found in Veratrum album; a small quantity of VERATRINE, that occurs as an amorphous, resinous mass which is colored yellow with concentrated sulphuric acid, the solution becoming deep red (thus resembling protoveratrine); and veratalbine, an amorphous alkaloid. Veratroidine is now considered to be a mixture of amorphous bases.

Allied Plants.-The rhizome of Veratrum viridifolium, a plant with greenish flowers growing in the mountainous districts of Europe and Northern Asia, contains jervine and veratroidine. The rhizome of Veratrum nigrum, a plant with purplish-red flowers, indigenous to Middle and Eastern Europe, Siberia, Manchuria and Japan, contains jervine.

SABADILLA SEEDS are the source of the official veratrine. They are obtained from Schonocanlon officinale (Fam. Liliaceæ), a bulbous plant indigenous to Mexico and the West Indies. The seeds are brownish-black, 5 to $8 \mathrm{~mm}$. long, narrow, angular, flat, beaked and have a very bitter and acrid taste. They are frequently exported from Mexico in the small trilocular dehiscent capsules there being 3 to 6 seeds in each loculus. They contain about I per cent. of a mixture of alkaloids known as VERATRINE. This consists of cevadine and veratrine (veratridine), both of which are found in the rhizome of Vcratrum viride, and three other alkaloids : cevadilline, sabadine and sabadinine, the two latter being crystalline.

The bulbs of Deati Camas ( $Z_{y}$ gadentus venchosus), known to the Nez Perce Indians as "Wa-i-mas," contain the alkaloids veratalbine, sabadine and sabadinine.

BLACK HeLleBore consists of the rhizome and roots of $\mathrm{Hcllc}$ borus niger (Fam. Ranunculaceæ), a perennial herb indigenous to the Eastern and Southern Alps and also cultivated. The rhizome is 2.5 to $7.5 \mathrm{~cm}$. long, 6 to $12 \mathrm{~mm}$. in diameter; with numerous short, knotty branches and short, brittle roots; externally, of a grayish-black color; internally, with a characteristic dicotyledonous structure; odor slight; taste sweet, somewhat bitter and acrid. The drug contains two crystalline glucosides: helleborin, a narcotic poison with a burning taste, and helleborein; a cardiac stimulant and having a sweetish taste. The former gives a violetred color with concentrated sulphuric acid and the latter a deep 
violet color with the same reagent. The drug also contains a volatile oil, two acricl resins, an acrid fixed oil, aconitic acid and gallates of calcium and potassium.

The rhizome of Helleborus viridis (so-called "Green HelleBORE"), a plant found in Middle and Southern Europe, has been used similarly to that of $H$. niger. It contains the same principles as $H$. niger, the helleborein apparently predominating.

FaLse Hellebore is the entire herb of Adonis z'crnalis (Fam. Ranunculaceæ) and other species of Adonis indigenous to Europe and Asia. The drug contains adonidin, a mixture of several principles, the most important being the amorphous glucoside picradonidin, a principle resembling digitalin in its physiologic action.

CALAMUS.-SWEET FLAG.-The dried, unpeeled rhizome of Acorus Calamus (Fam. Araceæ), a perennial herb widely distributed in all north-temperate regions (p. 233). The commercial supplies are obtained from the United States, Germany. England, Russia and India. The rhizomes are collected in autumn, the drug from India being the more aromatic, whereas the German product, on account of the removal of the outer portion of the rhizome, is probably the least aromatic. A confection was at one time made by "candying" the fresh rhizome.

DesCRIPTION.-Horizontal, cylindrical, slightly compressed, usually split longitudinally into pieces 5 to $5 \mathrm{~cm}$. long, 5 to $\mathrm{I} 2$ mm. in diameter; externally light brown or yellowish green, annulate from remnants of circular bud-scales, upper surface with triangular leaf-scars or hair-like fibers of fibrovascular tissue, the sides with large circular branch-scars, and the under and side portions with root-scars or short fragments of roots; fracture short; internally light brown, distinctly porous, with numerous intercellular spaces, endodermis distinct; odor aromatic; taste strongly aromatic (Fig. IOI, $B$ ).

Constituents.-Volatile oil I.5 to 3.5 per cent., having the odor and taste of the drug; acorin, a bitter, viscid, aromatic glucosidal principle, which when hydrolized in a current of hydrogen yields oil of calamus; choline (trimethyl-oxyethyl ammonium hydrate), a strong, non-poisonotis base, and formerly known as calamine ; a soft resin about 2.3 per cent. ; tannin ; mucilage; starch and calcium oxalate. 
An Indian variety contains from I to 2.5 per cent. of oil and is mostly preferred.

CIMICIFUGA.-BLACK SNAKEROOT, BLACK COHOSH.-The dried rhizome and roots of Cimicifuga raccmosa

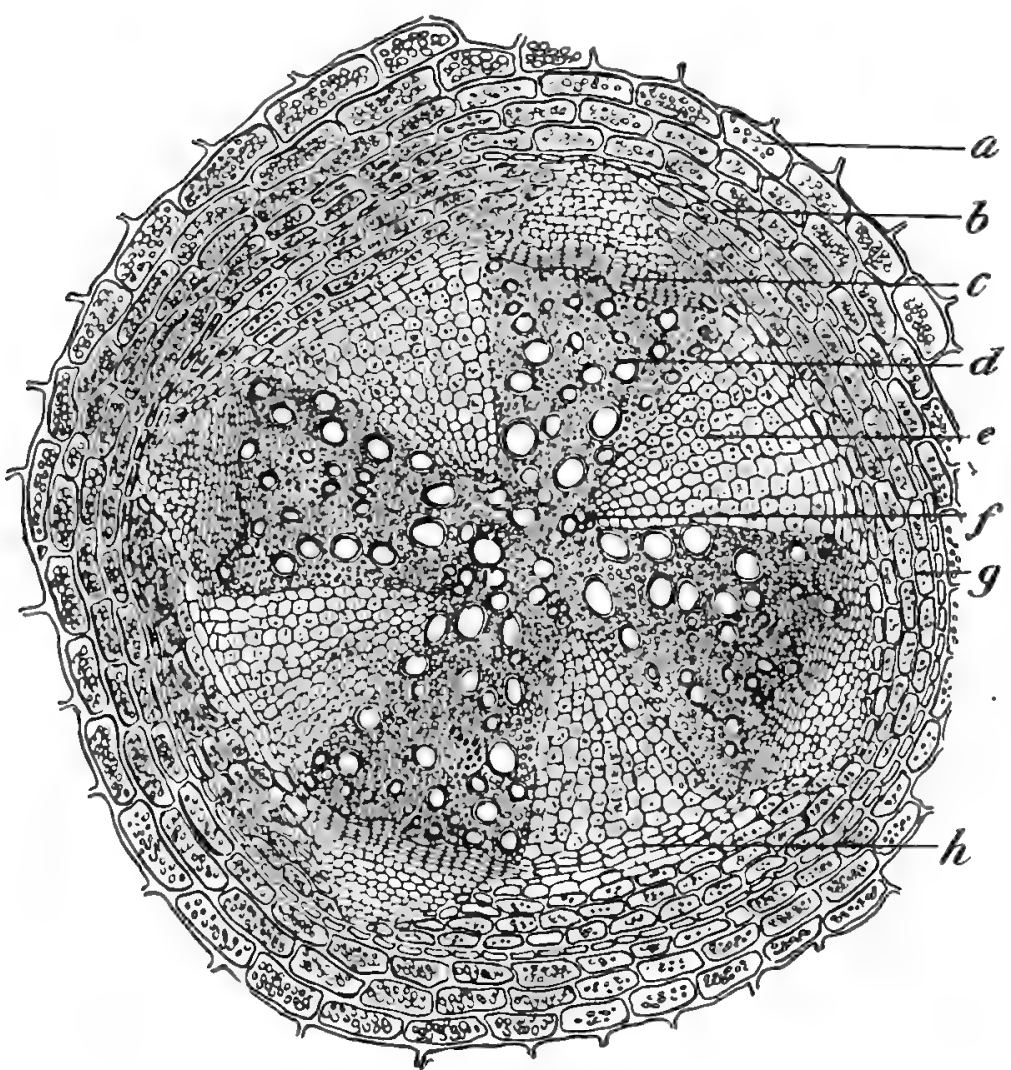

FiG. 2*7. Cimicifuga. Transverse section of the central part of a mature root in which the secondary changes are completed: a, parenchyma; $b$, endodermis; $c$, cambium zone; d, trachex in secondary xylem; e, broad, wedge-shaped medullary ray; $f$, outer portion of one of the primary xylem bundles; $g$, parenchyma beneath the endodermis; $h$, inter-fascicular cambium.-After Bastin.

(Fam. Ranunculacex), a perennial herb (Fig. I40), indigenous to Asia, Eastern Europe and North America (p. 268). The drug is collected in autumn, the United States furnishing the principal supply. 
Description,-Rhizome horizontal, with numerous upright or curved branches and few roots, 2 to $15 \mathrm{~cm}$. long, I to $2.5 \mathrm{~cm}$. in diameter; externally dark brown, slightly annulate from circular scars of bud-scales, the upper surface with buds, stem-scars and stem-remnants, under and side portions with numerous rootscars and few roots; fracture horny; internally, bark dark green, about I mm. thick, wood dark brown, 4 to $5 \mathrm{~mm}$. thick, distinctly radiate; pith 3 to $5 \mathrm{mmm}$. in diameter; odor slight; taste bitter and acrid.

Roots brittle, nearly cylindrical or obtusely quadrangular; externally dark brown, longitudinally wrinkled, 3 to $12 \mathrm{~cm}$. long, $\mathrm{I}$ to $2 \mathrm{~mm}$. in diameter; fracture short; internally, bark dark brown, 0.2 to $0.4 \mathrm{~mm}$. thick, wood light brown, usually four-rayed.

InNer Structure.-See Fig. 217.

Constituents.-Cimicifugin (macrotin or macrotyn), a mixture of resinous substances of a yellowish-brown color, possessing the active properties of the drug and amounting to about 3 per cent.; considerable starch and a tannin-like principle giving a green color with ferric salts, thus distinguishing the drug from the rhizome of Helleborus niger (p. 495).

HYDRASTIS.-GOLDEN SEAL.-The dried rhizome and roots of Hydrastis canadcnsis (Fam. Ranunculaceæ), a perennial herb (Fig. 218) indigenous to the Eastern United States and Canada (p. 268). The rhizome and roots are collected in autumn.

DESCRIPTION.-Rhizome horizontal or oblique, sub-cylindrical, 2 to $5 \mathrm{~cm}$. long, 3 to $6 \mathrm{~mm}$. in diameter; externally yellowish or dark brown, slightly annulate from circular scars of bud-scales, upper surface with numerous short stem-remnants or stem-scars, under and side portions with numerous roots or root-scars; fracture short, waxy; internally deep yellow, bark about $0.5 \mathrm{~mm}$. thick, wood radiate, aboit I mm. thick, pith light yellow; odor distinct; taste bitter.

Roots 4 to $7 \mathrm{~cm}$. long, 0.2 to $0.4 \mathrm{~mm}$. in diameter; internally bright yellow, wood somewhat quadrangular.

InNer Structure.-See Figs. 219, 292.

Constituents.-Two alkaloids-one, hydrastine, occurring to the extent of 2 to 3 per cent., and forming colorless, tasteless 4 -sided prisms, although the salts are pale yellow and bitter; the 


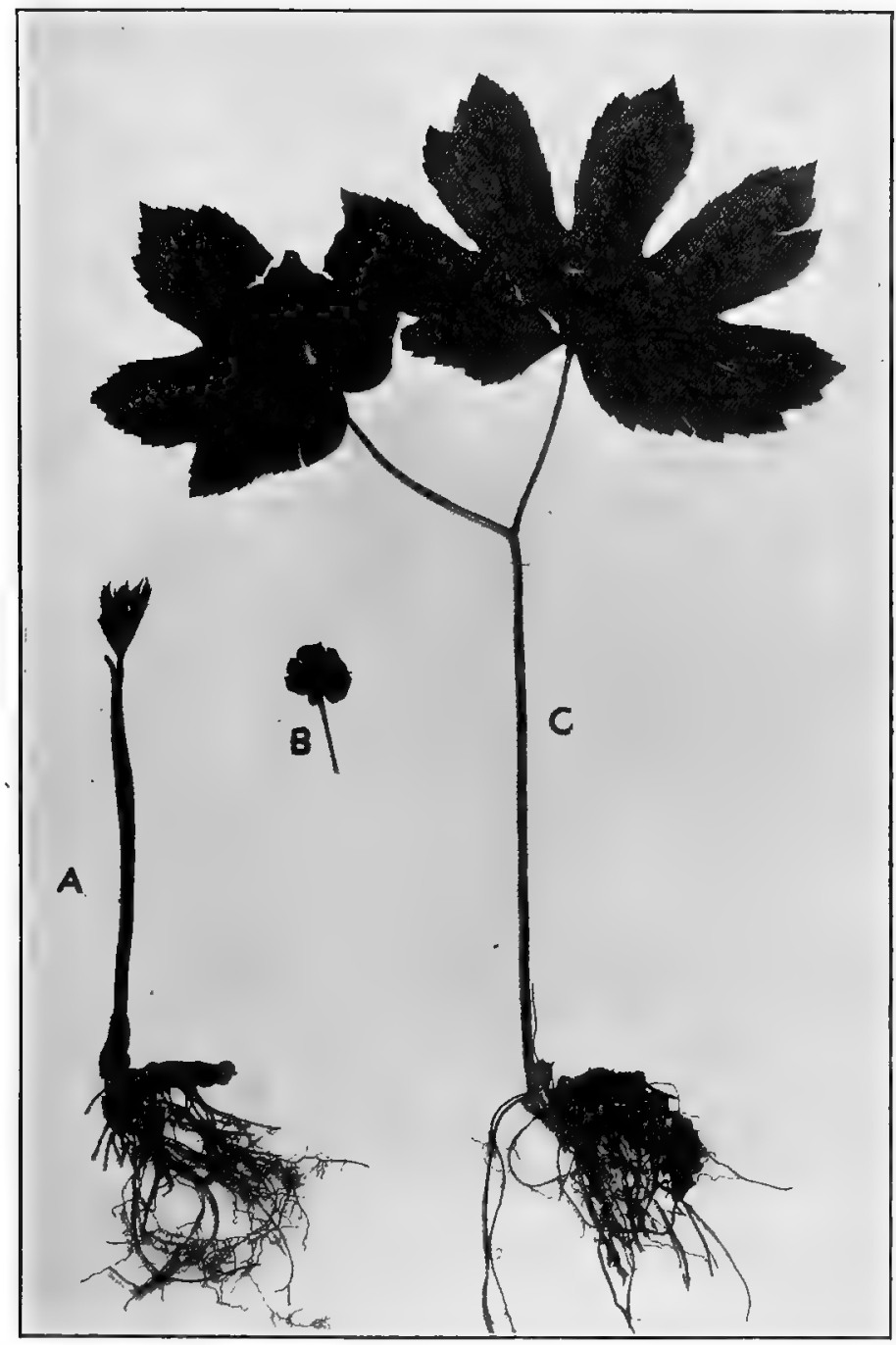

FIG. 2I8. Golden seal (Hydrastis canadensis): A, young plant with horizontal rhizome and numerous roots; $\mathrm{C}$, older plant showing the palmately lobed leaves: $\mathrm{B}$, fruithead of small berries. 
other, berberine, occurring to the extent of 3 to 4 per cent. in the form of yellow needles, which are bitter and readily form compounds with acetone, alcohol and chloroform. In addition,

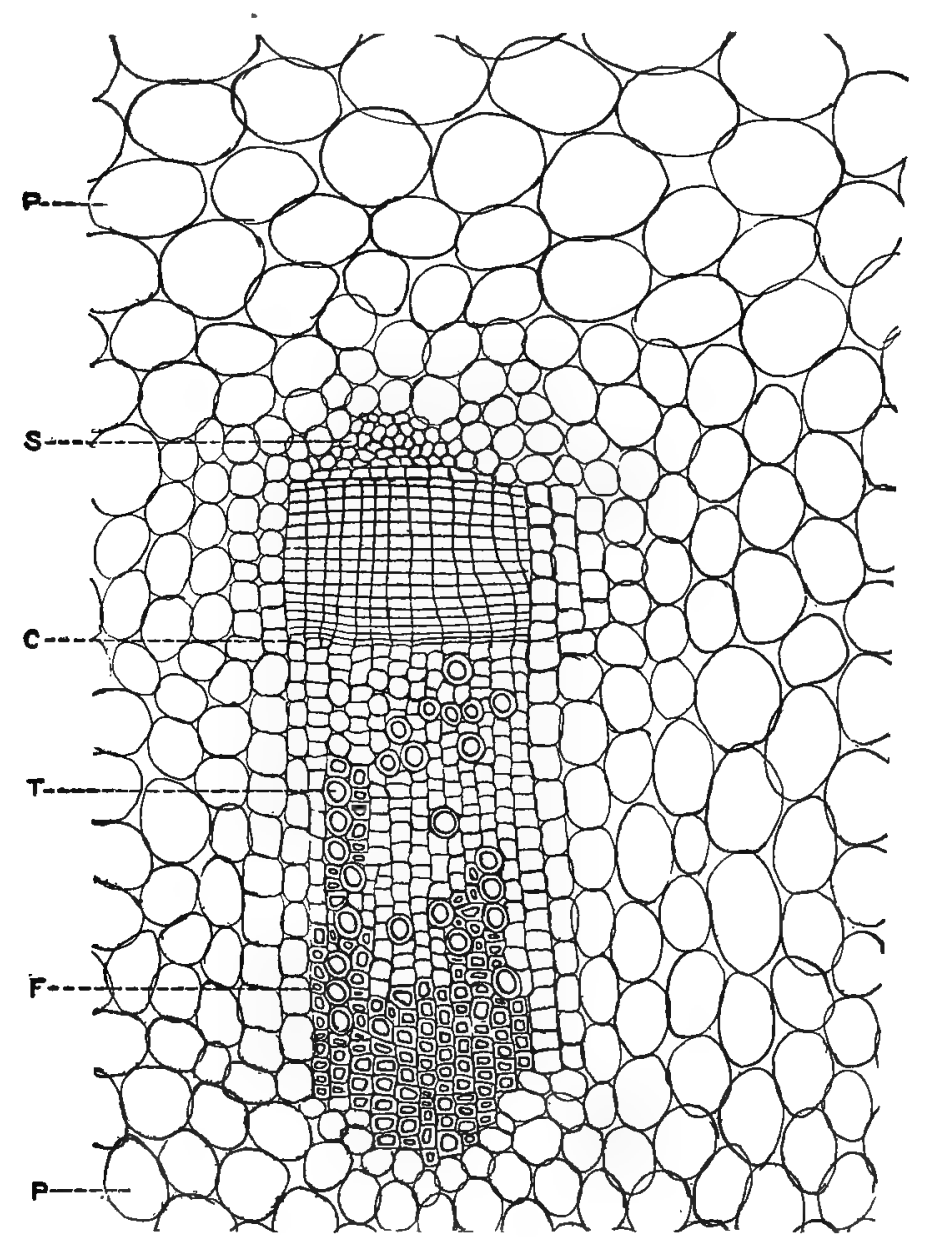

FrG. 219. Transverse section of a part of the rhizome of hydrastis near the cambium: P, parenchyma; $S$, sieve; $C$, cambitum; $T$, tracheæ; $F$, wood fibers.

the drug contains a small amount of an alkaloid, canadine (tetrahydro-berberine), and considerable starch. Calcium oxalate is wanting. 
Allied Plants. - The alkaloid berberine, or a principle closely resembling it is found in the following plants of the Ranunculaceæ: False rhubarb (Thalictrum favum) of Europe; and the following plants growing in the United States: Gold-thread (Coptis trifolia), yellow root (Xanthorrhiza apiifolia), and marsh marigold (Caltha palustris). A principle resembling berberine is found in the following plants belonging to the Rutacex: Several species of Zieria found in Southern Australia and Tasmania, and Toddalia aculeata found in the mountains of Eastern Africa, tropical Asia and the Philippine Islands (see also p. 483).

LEPTANDRA.-CULVER'S ROOT.-The dried rhizome and roots of Leptandra virginica (Fan. Scrophulariaceæ), a perennial herb growing in meadows and moist woods of the Eastern and Central United States and Canada (p. 376). The rhizome and roots are collected in autumn from plants of the second year's growth. When fresh the drug has an almond-like odor and a bitter, nauseous taste, which it loses in a measure on drying, and may be kept indefinitely.

DESCRIPTION.-Rhizome horizontal, nearly cylindrical, somewhat branched, 4 to Io $\mathrm{cm}$. long, 3 to $8 \mathrm{~mm}$. in diameter; externally light brown to brownish-red; annulate from circular scars of bud-scales, upper surface with conical buds, short stem-remnants or stem-scars, the under and side portions with numerous roots or root-scars; fracture tough ; internally, bark dark brown, 0.3 to I mm. thick, wood about 0.5 to $\mathrm{I} .5 \mathrm{~mm}$. thick, pith light brown or brownish-black; odor slight; taste bitter, slightly acrid.

Roots from I to $4 \mathrm{~cm}$. long, 0.5 to I $\mathrm{mm}$. in diameter, externally smooth; longitudinally wrinkled, fracture short; internally, bark brownish-black, wood light brown.

Constituents.--Leptandrin, a glucoside, occurring in yellowish-green crystals ; resin, about 6 per cent. ; saponin ; tannin ; and starch. The drug yields a distillate containing formic acid.

SERPENTARIA.-The rhizome and roots of several species of Aristolochia (Fam. Aristolochiaceæ), perennial herbs indigenous to the Southern United States. There are two commercial varieties: (I) Virginia Snakeroot, yielded by Aristolochia Serpentaria, found growing east of the Mississippi, and (2) Texas or Red River Snakeroot, yielded by Aristolochia reticulata, grow- 
ing west of the Mississippi. The rhizome and roots are collected in autumn and dried (p. 260).

Virginia Snakeroot.-Rhizome oblique, sub-cylindrical, with numerous roots (Fig. 220) and frequently with leaves or fruiting stems, Io to $25 \mathrm{~mm}$. long, and 2 to $4 \mathrm{~mm}$. in diameter; externally dark brown, slightly annulate from scars of bud-scales, 11pper por-

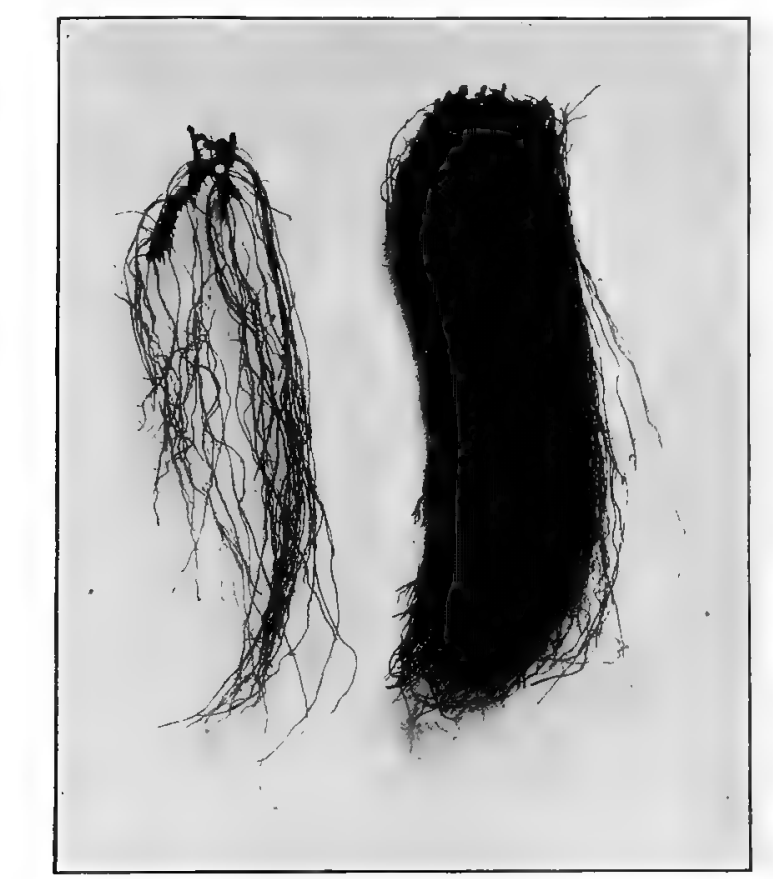

FIG. 220. Serpentaria (Virginia snakeroot) showing oblique rhizomes with numerous long, slender roots.

tion with stem-scars or stem-remnants, under and side portions with numerous roots and root-scars; fracture short; internally, bark dark brown, 0.3 to $0.5 \mathrm{~mm}$. thick, wood yellow, radiate, porous, I to I. 5 mm. thick, pith I mm. in diameter; odor terebinthinate; taste bitter, aromatic.

Roots nearly straight, 4 to $7 \mathrm{~cm}$. long, about $0.5 \mathrm{~mm}$. in diameter, longitudinally wrinkled, bark light brown, wood yellowish, 5 -rayed. 
Texas Snakeroot.-Rhizome 5 to Io $\mathrm{mm}$. long, I to $2 \mathrm{~mm}$. in diameter; roots about $0.3 \mathrm{~mm}$. in diameter, with numerous more or less interlacing rootlets.

Constituents.-Volatile oil 0.5 to I per cent., the important constituent of which is borneol; a bitter poisonous principle, aristolochin (serpentarin); an alkaloidal principle, aristolochine; several organic acids; starch; ash about Io per cent.
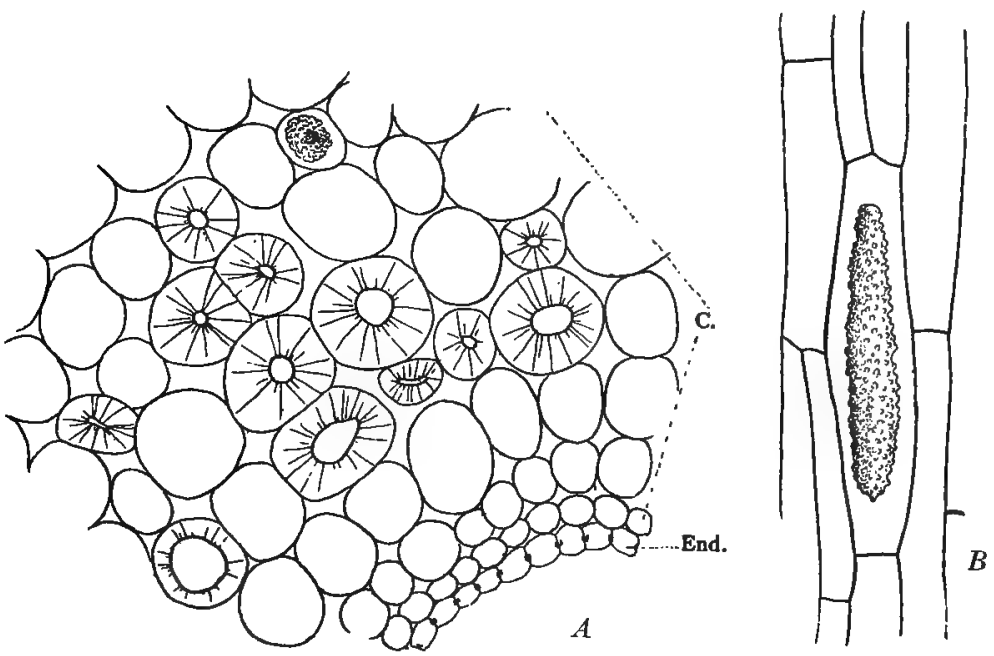

FIG. 221. Ruellia ciliosa, the rhizome and roots of which are a common adulterant of spigelia. A, transverse section of a secondary root: $C$, cortical parenchyma with one cystolith and a number of stone cells with very thick walls and radiating simple pores; End, endodermis. B, longitudinal section of the same root, showing a single cell with an elongated cystolith, the encrustation being of calcium carbonate.-After Holm.

SPIGELIA.-PINKROOT.-The rhizome and roots of $S p i-$ gelia marilandica (Fam. Loganiaceæ), a perennial herb (Fig. I72) indigenous to the Southern United States (p. 362). Spigelia should be collected in autumn, carefully dried and preserved, and not kept longer than two years.

DESCRIPTION.-Rhizome horizontal or slightly oblique, more or less branched, $\mathbf{I} .5$ to $3 \mathrm{~cm}$. long, 2 to $3 \mathrm{~mm}$. in diameter; externally dark brown, slightly annulate from scars of bud-scales, the upper portion with stem-scars or stem-remnants, under and side portions with numerous roots and root-scars; fracture short; inter- 
nally, bark dark brown, 0.2 to $0.5 \mathrm{~mm}$. thick, wood yellow, slightly radiate, $I$ to $I .5 \mathrm{~mm}$. thick, pith $I \mathrm{~mm}$. in diameter; odor slightly aromatic; taste bitter, pungent.

Roots 5 to $10 \mathrm{~cm}$. long, about $0.3 \mathrm{~mm}$. in diameter, with numerous rootlets; externally dark brown, longitudinally wrinkled; internally light brown, wood nearly cylindrical, porous.

Constituents.-A crystalline, volatile alkaloid, spigeline, which somewhat resembles coniine and nicotine and which forms precipitates with iodine or Mayer's reagent that are soluble in mineral acids; a bitter, acrid principle, volatile oil, resin, tannin and starch.

AdUlterants.-For some years past another rhizome has been substituted for Spigelia, viz.: that of Ruellia ciliosa (p. 377). The rhizome is oblique, with shorter internodes at the lower portion and the basal part of the aerial shoots usually remains attached. The roots are quite long, sparingly branched and generally coarser than those of Spigelia. The inner structure of Ruellia is quite distinct from Spigelia, showing numerous stone cells and cystoliths in the cortex (Fig. 22I).

VALERIANA.-VALERIAN.-The rhizome and roots of Valeriana officinalis (Fam. Valerianaceæ), a perennial herb ( $p$. 385 ) indigenous to Europe and Asia, and cultivated in Holland, Germany, England and the New England States, being more or less naturalized in this country as far south as New York and New Jersey. The rhizome is collected in autumn, cut into longitudinal slices and dried by artificial heat. There are several commercial varieties, and it is said that some of the drug is derived from Valeriana sylvatica.

DESCRIPTION.-Rhizome upright, slightly ellipsoidal, more or less truncate at both ends, from 2.5 to $4 \mathrm{~cm}$. long and I to $2 \mathrm{~cm}$. in diameter, usually cut longitudinally into two, four or more pieces; externally dark brown, upper portion with circular stemand leaf-scars, the sides sometimes with short branches or stolons from 5 to $8 \mathrm{~cm}$. long, with numerous roots and few root-scars; fracture short, horny; internally light brown; odor pronounced, becoming stronger on keeping the drug; taste somewhat aromatic.

Roots 3 to Io $\mathrm{cm}$. long, 0.5 to I mm. in diameter, longitudinally wrinkled; fracture brittle. 
Constituents.-Volatile oil 0.5 to 3 per cent., of which 9.5 per cent. is bornyl valerate. It also contains bornyl formate, acetate and butyrate; borneol; pinene; camphene, and a sesquiterpene. The odor of valerian is due to the isovalerianic acid which is formed from the bornyl valerate by the action of an oxydase during the drying of the drug. The drug also contains free formic and acetic acids and malates, which develop in the same way by the decomposition of compound esters. In addition valerian contains two alkaloids, valerianine and chatinine; resin; tannin; and starch.

Allied Plants.-Kesso root oil is obtained from Japanese Valerian (Valeriana angustifolia). The constituents are similar to those of the volatile oil in Valerian, but it contains in addition kessyl acetate and kessyl alcohol. Mexican Valerian, derived from $V$. mexicana, yields an oil containing about 89 per cent. of isovalerianic acid.

The small rhizomes of Valeriana celtica, a plant growing in the Styrian Alps, yields a volatile oil with an odor resembling that of Anthemis and patchouly.

Adulterants and Sunstitutes.-The most dangerous admixture that has been reported is Veratrum, which is readily distinguished (p. 492). Cypripedium macranthum (Fam. Orchidaceæ), of Germany, has been used as a substitute for valerian.

GERANIUM.-WILD OR SPOTTED CRANESBILL.The dried rhizome of Geranium maculatum (Fam. Geraniaceæ), a perennial herb (Fig. I55), indigenous to Canada and the Eastern and Central United States (P. 3OI). The rhizome is collected in the late summer or early autumn.

DesCription.-Horizontal, cylindrical, tuberculate, curved or bent pieces, 2.5 to $5 \mathrm{~cm}$. long, 3 to Io $\mathrm{mm}$. in diameter; externally dark brown, wrinkled, upper and side portions with numerous buds or circular stem-scars, under surface with numerous rootscars; fracture short; internally light brown, bark thin, wood indistinct, pith large; odor slight; taste astringent.

Constituents.-Tannin I 5 to 25 per cent., which on hydrolysis yields gallic acid; starch; and calcium oxalate.

Allied Plants.-Other species of geranium contain similar principles. 
PODOPHYLLUM.-MAY APPLE.-The rhizome of Podophyllum peltatum (Fam. Berberidacex), a perennial herb (Fig. 222) indigenous to Eastern North America (p. 273). The rhizome is collected late in summer and dried, after the removal of the rootlets.

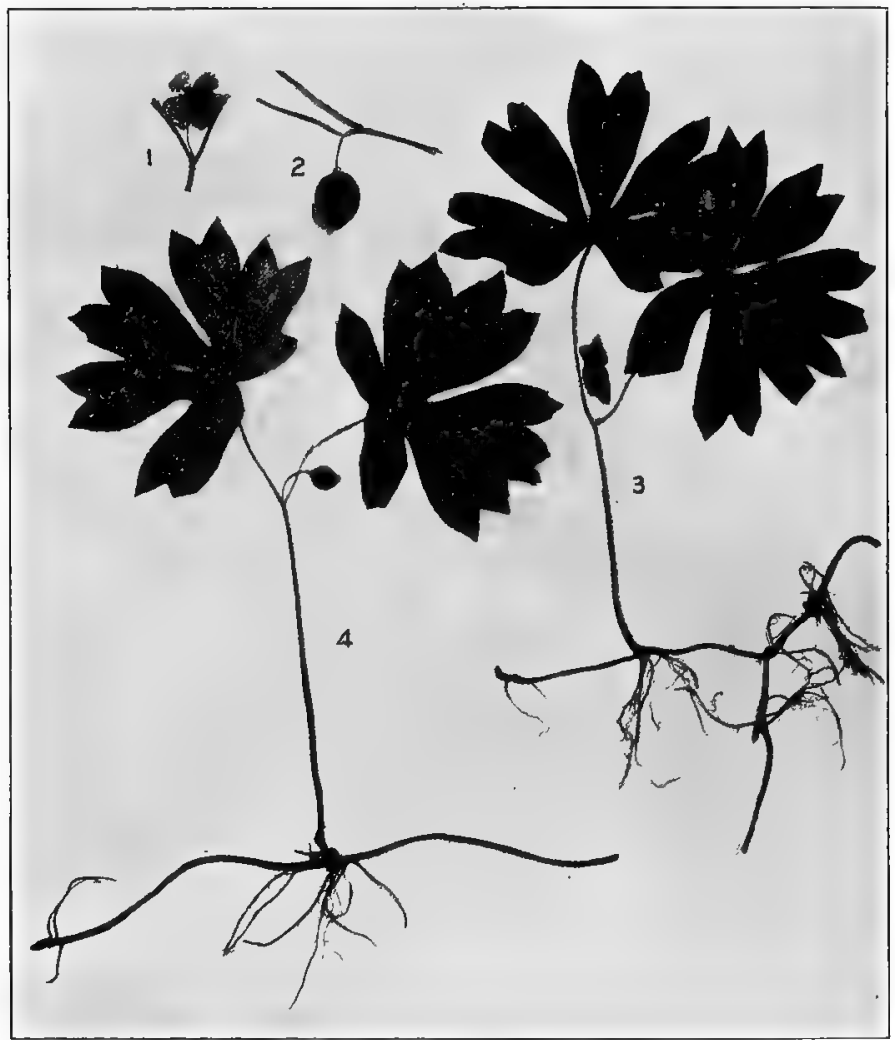

FIg. 222. May apple (Podophyllum peltatum): 1, flower; 2, berry-like fruit; 3, 4, flowering and fruiting plants showing long, slender, branching rhizomes.

Description.--Horizontal, nearly cylindrical, flattened, sometimes branched, jointed, in pieces 3 to $8 \mathrm{~cm}$. long, internodes 4 to ro $\mathrm{cm}$. long, 5 to $9 \mathrm{~mm}$. in diameter, nodes 7 to $18 \mathrm{~mm}$. in diameter and 5 to $12 \mathrm{~mm}$. thick; externally dark brown, longitudinally wrinkled or nearly smooth, with irregular scars of bud-scales, 
nodes annulate from remains of bud-scales, upper part marked with large circular, depressed stem-scars and sometimes with buds; numerous root-scars at and near the lower portion of the nodes;
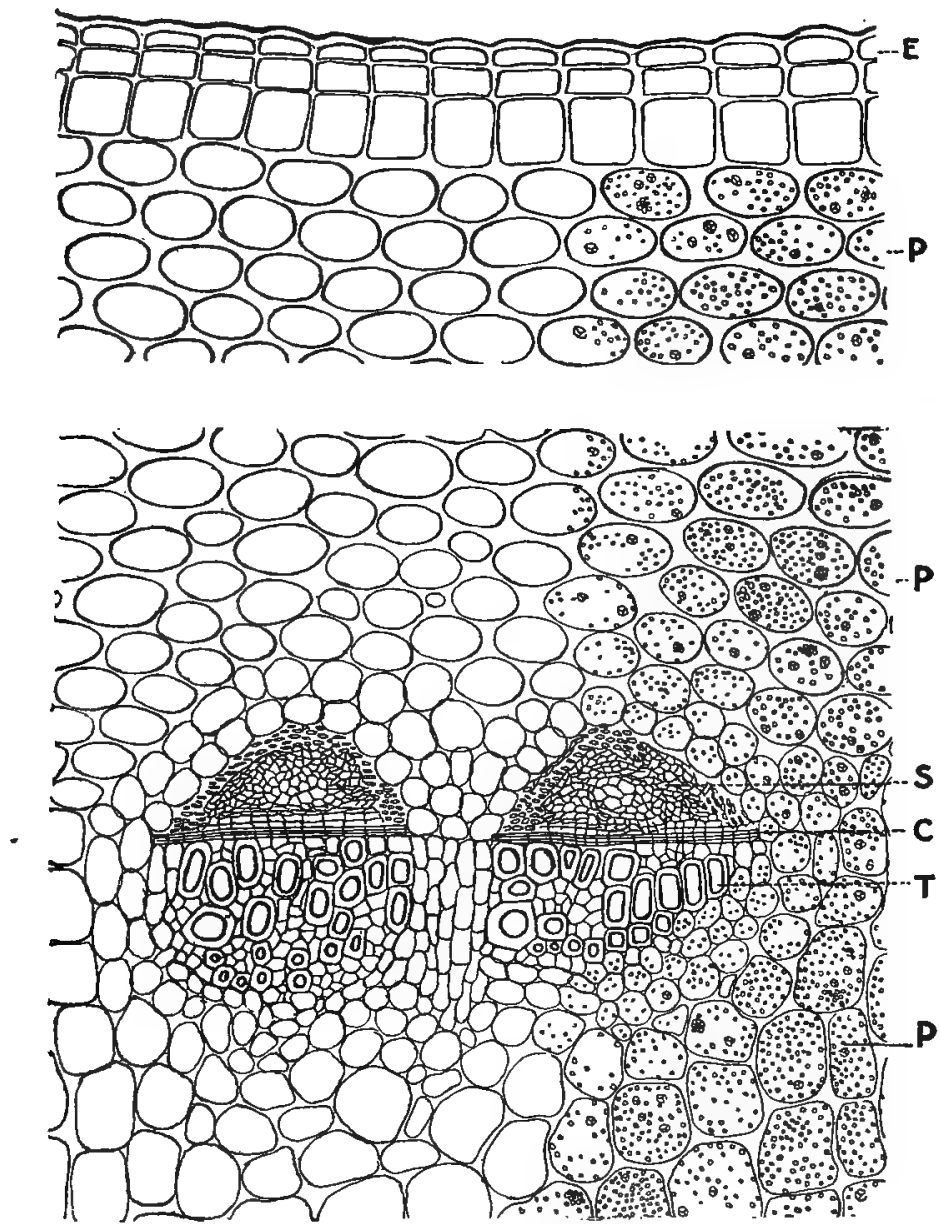

FIG. 223. Transverse section of podophyllum rhizome: E, epidermis; P, parenchyma containing starch; $\mathrm{S}$, sieve; $\mathrm{C}$, cambium; $\mathrm{T}$, trachea.

fracture short; internally lemon-yellow, bark $x \mathrm{~mm}$. thick, wood yellowish, $0.5 \mathrm{~mm}$. thick, pith large, white; odor slight; taste somewhat bitter and acrid. 
InNer Structure.-See Fig. 223.

Constituents.-Resin (official as Resin of Podophyllum) 3.5 to 5 per cent., consisting of two poisonous principles: (a) podophyllotoxin, 20 per cent., occurring in white crystals that are sparingly soluble in water and yield on treatment with water podophyllic acid and picropodophyllin; and (b) picropodophyllin (an isomer of podophyllotoxin), which crystallizes in needles and is insoluble in water but soluble in 90 to 95 per cent. alcohol. The resin also contains a yellow crystalline coloring principle resembling quercetin, a green fixed oil and podophyllic acid. The rhizome also contains a purgative resin, podophylloresin; considerable starch, and some gallic acid.

Allied Plants.-The rhizome of Podophyllum. Emodi, a plant growing on the lower slopes of the Himalayas, is larger and yields II.4 to I 2 per cent. of resin, which consists of but half as much podophyllotoxin as the resin obtained from $P$. peltatum.

SANGUINARIA.-BLOODROOT.-The rhizome of Sanguinaria canadensis (Fam. Papaveraceæ), a perennial herb (Fig. I48) indigenous to the Eastern and Central United States and Canada (p. 280). The rhizome should be collected in July or August and dried.

Description.-Horizontal, irregularly cylindrical, flattened, sometimes branched, 2.5 to $6 \mathrm{~cm}$. long, 5 to 1o $\mathrm{mm}$. in diameter; externally dark brown, slightly annulate, with few buds or stemscars on ụpper surface and numerous root-scars on lower surface; fracture short and somewhat waxy; internally, bark dark brown, about $0.5 \mathrm{~mm}$. thick, wood and pith with numerous reddish resincells; odor slight; taste bitter and acrid.

Shriveled rhizomes which are gray internally and free from starch should be rejected.

Constituents.-The drug contains a number of alkaloids, of which the most important is SANGUINARINE; it occurs to the extent of about I per cent., crystallizes in colorless needles and yields reddish salts with nitric or sulphuric acid. The other alkaloids include CHELERYTHRINE, which forms yellowish salts; protopine, also found in other plants (p. 282), and $\beta$ - and $\gamma$-homochelidonine, which, like the last two alkaloids, are found in Chelidonium and some other plants (p. 28I). In addition, the drug 
contains a reddish resin, several organic acids, as citric and malic, and considerable starch.

SCOPOLA.-BELLADONNA SCOPOLIA.-The dried thizome of Scopolia Carniolica (Fam. Solanacex), a perennial herb growing in the region of the Eastern Alps, Carpathian Mountains and neighboring regions.

DesCRIPTION.-Rhizome horizontal, nearly cylindrical, somewhat tortuous, usually cut longitudinally into pieces 5 to $12 \mathrm{~cm}$. long, 7 to $\mathrm{I} 5 \mathrm{~mm}$. in diameter; externally grayish-brown, longitudinally furrowed, slightly annulate, with numerous circular stem-scars about $5 \mathrm{~mm}$. in diameter, under portion with rootscars and root-remnants; fracture short, mealy; internally whitish or light grayish-brown, bark I mm. or less thick, wood slightly radiate, rather large, horny pith ; odor slight ; taste starchy, sweetish, afterward acrid.

The roots, which are attached to the rhizome or in separate pieces, are cylindrical, tapering, varying in diameter from 2 to ro mm., longitudinally wrinkled, and marked by lenticular whitish areas resembling lenticels.

Constituents.-About 0.6 per cent. of total alkaloids, including atropine, hyoscyamine and scopolanine (hyoscine). Scopolamine is official as a hydrobromide, and exists in the drug to the extent of 0.06 per cent. Scopolamine decomposes into scopoline and atropic acid when treated with boiling baryta water. Scopoline resembles tropine, a principle formed from atropine. and hyoscyamine, when similarly treated.

Allied Plants.-Japanese belladonna is the rhizome of Scopolia japonica, growing in Japan, and closely related to $S$. Carniolica. The drug resembles scopola and apparently contains the same principles. The rhizomes of six other species of Scopolia are also used.

Scopolia Leaves are used in medicine like belladonna leaves, and are said to be sometimes admixed with them. They are obovate, slightly acuminate, and taper gradually into the rather long petiole (p. 372).

COLCHICI CORMUS.-COLCHICUM CORM.-The corm of Colchicum autumnale (Fam. Liliaceæ), a perennial bulbous plant, native of and growing in moist meadows and pastures of 
England, Southern and Middle Europe and Northern Africa (p. 236). The corm is collected in early summer before the flowering period, deprived of the membranous, scaly coat, cut into transverse pieces, and dried at a temperature below $65^{\circ} \mathrm{C}$. Tubers that are collected in the fall either during the flowering season or later are considered to be more active. The commercial supply is obtained from England and Germany.

Description.-Obconical, with a groove on one side, sometimes with fragments of the flower-stalk, usually in transverse, reniform sections from $\mathrm{I} 5$ to $20 \mathrm{~mm}$. long, about $\mathrm{I} 2 \mathrm{~mm}$. wide and 3 to $5 \mathrm{~mm}$. thick; externally dark brown, longitudinally wrinkled; fracture short, mealy; internally light brown, with numerous scattered fibrovascular bundles; odor slight; taste bitter and acrid.

Inner Structure.-See Fig. 3 Io.

Constituents.-A yellowish, amorphous alkaloid, COLCHICINE, about 0.4 per cent., which has a peculiar odor, particularly on heating slightly, is soluble in hot water and gives with concentrated sulphuric acid a yellowish solution which is colored deep red on heating. If the sulphuric acid contains a mere trace of nitric acid the solution of the alkaloid becomes yellowishgreen, green, bltiish-green, blue, violet, wine-red and finally yellow. The salts of colchicine are quite unstable. The drug also contains the alkaloid COLCHICEINE, which crystallizes in needles and is apparently formed during the extraction of the drug by reason of the decomposition of colchicine. The latter may be formed on the esterification of colchiceine with methyl alcohol. The corm also contains two resins; a large amount of starch; ash about 2.5 per cent.

SCILLA.-SQUILL.-The fleshy scales of the bulb of Urginea maritina (Fam. Liliacer), a perennial herb indigenous to the Mediterranean region. The bulbs are collected late in August, and after the removal of the membranous outer scales and the central portion, the fleshy scales are cut into transverse pieces and dried in sunlight or by artificial heat. The article used in France is collected from bulbs having reddish scales and is obtained from Algeria and Malta (p. 238).

DesCRIPTION.-In irregular, curved, flat, narrow, somewhat translucent pieces 3 to $5 \mathrm{~cm}$. long, 5 to $8 \mathrm{~mm}$. wide, 2 to $7 \mathrm{~mm}$. 
thick, whitish, lemon-yellow or light brown, epidermis forming a thin layer, mesophyll more or less shrunken, slightly crystalline and with numerous circular projections of fibrovascular bundles; fracture brittle when dry, tough when damp; odor slight; taste bitter and acrid.

Constituents.-Squill contains a number of active principles, of which the most important are the amorphous glucoside scillitoxin, which resembles digitoxin physiologically, and scillipicrin, an amorphous, bitter principle, which is employed as a diuretic. It also contains a yellow crystalline glucoside scillin; an amorphous bitter glucoside, scillain; a little volatile oil; sugar, about 22 per cent.; considerable calcium oxalate in the form of raphides (Fig. $28 \mathrm{I}, B$ ), which is associated in the parenchyma cells with a peculiar mucilage sinistrin, which yields levulose on hydrolysis.

Allied Plants.-The bulbs of several species of Crinum (Fam. Amaryllidaceæ) found growing in Brazil, China, Southern Asia and the East Indies are used as substitutes for squill.

\section{PARTS OF ROOTS AND STEMS.}

PITI, WOOD AND BARK.

The active principles are not uniformly distributed throughont all parts of the plant, but occur in greater amount in the bark than in the wood, as in Ipecac; in larger proportion in the root bark than in the stem bark, as in Granatum; and in larger amount in the inner bark and cortex than in the periderm layers, as in Quercus alba. This is in general true of herbaceous plants, as well as of trees and shrubs, but in most of the medicinal roots and rhizomes it has not been found economical to separate the bark from the wood, which usually contains some of the active principles. A large number of the barks alone of shrubs and trees are used medicinally. By the term bark is usually meant all that portion of the root or stem which is developed outside of the cambium, and this is commonly differentiated into two distinct partsone next to the cambium, in which the life-processes take place, contains the greatest amount of active principles, and is known as the INNER BARK (Figs. 227, 23I , 234); another, external to 
this, having a greater or less development of corky layers among more or less obliterated sieve and parenchymatous cells, is known as the OUTER BARK. The term bark is sometimes restricted to this outer layer, but this is more or less confusing and has not been generally adopted. The term BORK is frequently applied to the outer corky layers and the dead tissues enclosed by them (Figs. 237, 238). The term PERIDERM is applied to all the tissues produced by the phellogen, the older layers of periderm being included in the bork.

In a few cases the wood alone is employed in medicine and, like the bark, may be differentiated into two layers-the one next to the cambium, in which the ascent of the cell-sap takes place, known as the SAP-WOOD, and another at the center of the trunk or stem, which is usually darker in color and may contain resinous, coloring and other substances, and denominated the HEART-WOOD, the latter being the part usually employed in medicine and the arts.

The pith being in the nature of a reserve tissue may contain various of the carbohydrates. Sassafras pith furnishes an example of this, being used in medicine on account of the mucilage it contains.

The following artificial classification may be found of assistance in the study of the drugs of this class:

\section{Barks.}

I. With periderm.

A. Yellowish-red to dark brown.

a. Fracture short.

a Aromatic odor and taste.

Dark brown......... Cinnamomum Saigonicum $\beta$ Without aromatic odor and taste.

* Usually in quills.

Few lenticels ................... Cinchona

Numerous lenticels .............. Frangula

** Usually in flattened or transversely curved pieces.

Inner surface reddened with alkalies........ Rhamnus Purshiana Odor of Valerian....Viburnum Prunifolium Astringent ........... Hamamelidis Cortex 
I. Barks.-Continued.

$b$. Fracture fibrous.

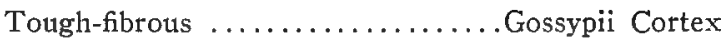

Short-fibrous ........................Rubus

B. Grayish to grayish-black.

a. Fracture fibrous.

Fracture silky-fibrous $\ldots \ldots \ldots \ldots \ldots \ldots$. Euonymus

Fracture uneven, fibrous.........Viburnum Opulus

b. Fracture short.

a With conical cork-wings... Southern Prickly Ash

$\beta$ Cork-wings wanting.

Inner surface with acicular

crystals .............. Northern Prickly Ash

Inner surface non-crystalline.........Granatum

C. Greenish in color.

Fracture tough-fibrous $\ldots \ldots \ldots \ldots \ldots \ldots$.............

Fracture short, granular.............Prunus Virginiana

2. Periderm removed.

A. Aromatic odor and taste.

Yellowish-brown ............Cinnamomum Zeylanicum

Reddish-brown ........................ Sassafras

B. Without aromatic properties.

$a$. Surface crystalline .................... Quillaja

$b$. Surface non-crystalline.

Taste astringent................ Quercus Alba

Taste mucilaginous.....................Ulmus

II. Woods.

I. Light or bright yellow........................ Quassia

2. Yellowish-red to yellowish-brown.

A. Imparts a violet or zvine-color to water..... Hæmatoxylon

$B$. Coloring matter insoluble in water..... Santalum Rubrum

III. Pith.

Whitish, light in weight................. Sassafras Medulla

CINNAMOMUM.-CINNAMION BARK.-The dried bark of the stem and branches of various species of Cinnamomum (Fam. Lauraceæ), trees indigenous to tropical Asia (p. 278), where they are now extensively cultivated, and from which three commercial kinds of bark are obtained: (I) Saigon Cinnamon, 
obtained from Cinnamomum Loureirii (?) and other species cultivated in Cochin China and other parts of China, and exported

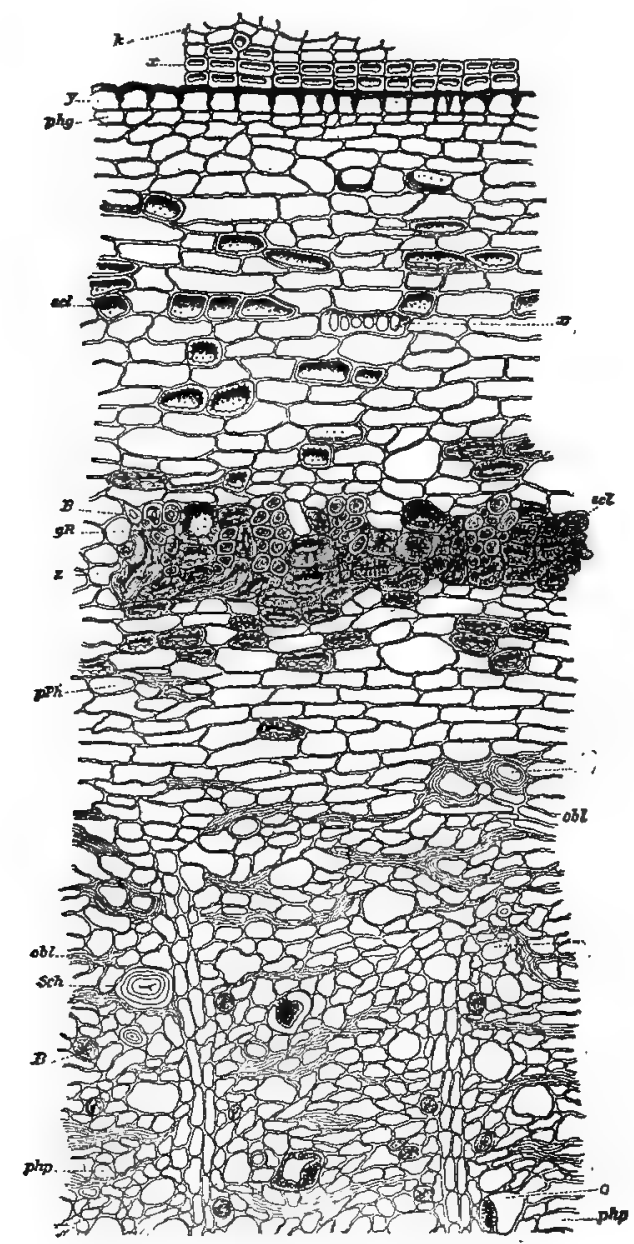

FIG. 224. Transverse section of Cassia cinnamon bark: $k$, cork; $x$, thick-walled cork cells; $y$, cork cells, the outer walls of which are thickened; phg, cork cambium; scl, stone cells; $x$, parenchyma cell with large pores; $B$, bast fibers; $g R$, short sclerenchyma; $z$, parenchyma separating the groups of sclerenchyma tissue; $\mathrm{pPh}$, protophloem; obl, obliterated sieve; Sch, mucilage canals; php, bast parenchyma; o, oil cells.-After Tschirch and Oesterle.

from Saigon; (2) Cassia Cinnamon, yielded by Cinnamomum Cassia, cultivated in the southeastern provinces of the Chinese 
Empire, and exported by way of Calcutta, and (3) Ceylon Cinnamon, collected from Cinnanomum zeylanicum, indigenous to and cultivated in Ceylon (Fig. I46).

Saigon Cinnamon.-In bundles about 30 to $40 \mathrm{~cm}$. long, and $20 \mathrm{~cm}$. wide, Io $\mathrm{cm}$. thick, weighing $\mathrm{I} .5$ to $2 \mathrm{~K}$., and consisting of

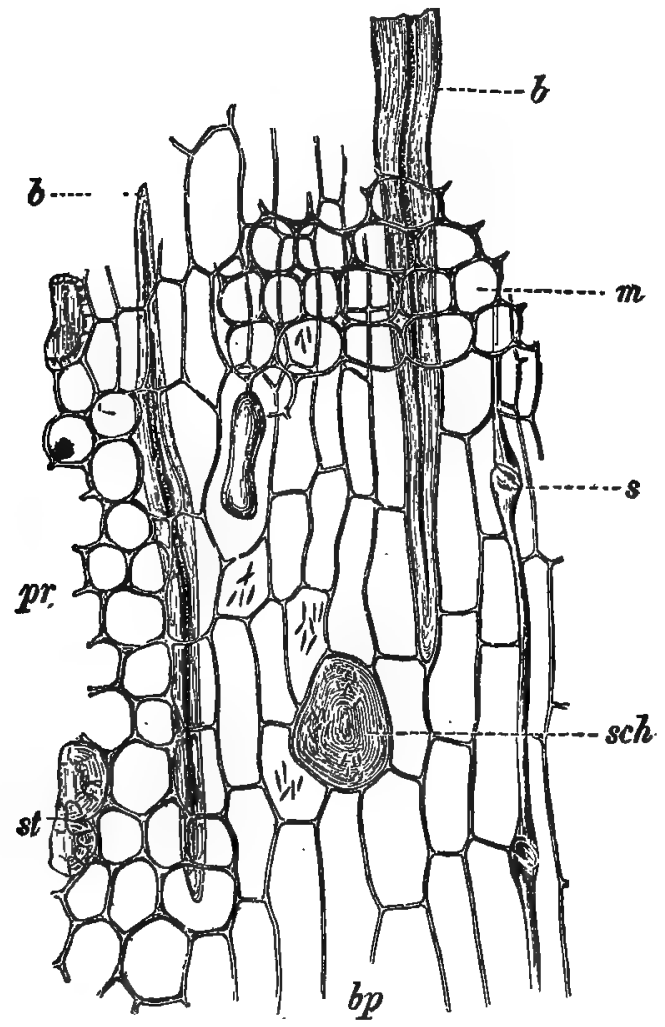

FIG. 225. Radial-longitudinal section of China Cassia (Cinnamomum Cassia) bark: pr, parenchyma of outer bark; bp, parenchyma of the inner bark, some of the cells of which contain raphides; $b$, bast fibers; st, stone cells; sch, mucilage cells; s, sieve; m. medullary rays.-After Moeller.

pieces varying in size and color from small, brownish-black single quills to large, thick, grayish-brown, transversely curved pieces. Pieces 6 to $30 \mathrm{~cm}$. 'long, 1.5 to $3 \mathrm{~cm}$. in diameter; bark 0.2 to 2 'mm. thick; outer 'surface dark brown, longitudinally wrinkled, with grayish patches of foliaceous lichens, and numerous lenticels; 
inner surface light brown, smooth; fracture short; thick inner bark separated from the very thin periderm by a layer of small stone cells; odor aromatic; taste mucilaginous, aromatic and pungent.

Cassia Cinnamon.-In quilled pieces, usually shorter than those of Saigon Cinnamon, the periderm more or less removed, and the bark aromatic and somewhat astringent.

Ceylon Cinnamon occurs in closely rolled double quills composed of numerous thin layers of the inner bark of the shoots; the odor is delicately aromatic, and very distinct from either Cassia or Saigon bark.

InNER Structure.-See Figs. 224, 225, 305.

Constituents. - The most important constituent is the volatile oil, which in Ceylon cinnamon is delicately aromatic and amounts to from 0.5 to I per cent., in Cassia from 0.93 to I.64 per cent., and in the Saigon from 3 to 6 per cent., the latter bark being most pungent and aromatic. The oil of cinnamon consists in large part of cinnamic aldehyde and other compounds, such as camphor, which is found in the oil from the root bark; safrol, which is found in the leaves; and eugenol, which is found in both leaves and stem bark and which gives the characteristic odor to Ceylon Cinnamon.

Cinnamon also contains the hexatomic alcohol mannitol (cinnamanin) giving the sweetish taste to the several barks; a tannin ( 3 to 5 per cent.) somewhat resembling that in Quercus alba and found in greatest amount in Cassia bark and least in the Saigon variety; a bitter principle especially characteristic of Cassia bark; and a mucilage which may be the source, at least in part, of the volatile oil.

Alered Plants.-Batavia Cassia or Fagot Cassia is the bark of Cinnamomum Burmanni. In double quills, the larger sometimes enclosing smaller quills, 5 to $8 \mathrm{~cm}$. long, 5 to $5 \mathrm{~mm}$. in diameter, bark 0.5 to $3 \mathrm{~mm}$. thick; outer surface light or reddishbrown, nearly smooth; inner surface dark-brown with occasional longitudinal ridges and depressed areas ; fracture short; odor pronounced, aromatic; taste aromatic and distinctly mucilaginous. It forms a shiny glutinots mass with water and yields with alcohol II to I7 per cent. of extract. A number of barks come into the 
market under the name of "CASSIA BARK." In fact Cassia Cinnamon is frequently known as China Cassia, or Canton Cassia or Cassia lignea, all being synonymous for the same variety of bark: Saigon Cinnamon is also known commercially as Saigon Cassia. The barks of other species of Cinnamomum also find their way into market and are used as substitutes or adulterants of Cassia Cinnamon. These are bitter or nearly tasteless and are free from any aromatic properties.

ClOVE BARK is obtained from Dicypellium caryophyllatum (Fam. Lauraceæ), a tree indigenous to Brazil. The bark comes in long quills consisting of 6 to Io pieces of bark. Externally dark brown or purplish-brown; fracture short, with a circlé of whitish stone cells near the periderm; odor clove-like; taste mucilaginous and aromatic, resembling cinnamon.

A number of other products are also derived from species, of Cinnamomum, as the immature fruits of $C$. Loureirii, which constitute the CASSIA BUDS of the market. The latter are club- or topshaped, 5 to Io $\mathrm{mm}$. in diameter, with a short stem or pedicel, externally dark brown, the 6-lobed perianth folded over the depressed and smooth ovary. The odor is aromatic; taste pungent, aromatic and astringent. Cassia buds yield a volatile oil containing cinnamic aldehyde, which resembles that of Cassia Cinnamon.

Wild CinNAMON, the bark of Cinnamomum pedatinervum, a tree indigenous to the Fiji Islands, yields a volatile oil containing from 40 to 50 per cent. of linalool and safrol, 15 to 20 per cent. of a terpene; I per cent. of eugenol, and about 3 per cent. 'of engenol methyl ether.

CINCHONA.-CINCHONA BARK.-The dried bark of the stem and branches of various species of Cinchona (Fam. Rubiaceæ), trees indigenous to South America, but cultivated in nearly all tropical countries, from which latter the commercial supplies are obtained. There are two principal commercial varieties: (I) Red Cinchona, which is yielded by Cinchona succirubra (p. 379); and (2) Calisaya Bark, yielded by Cinchona Ledgeriana Calisaya. When the trees are from 6 to 9 years old they are considered to have the maximum amount of alkaloids and the bark of the trunk as well as the roots is removed and allowed to dry. The BARK OF THE STEM is used in the manufacture of galenicals, while 
the ROOT BARK is employed for the extraction of the alkaloids, especially quinine. Owing to the fact that light seems to influence the production of quinine in the plant, a larger amount being produced in the root bark and also in the stem bark if excluded from the light, it is now customary to cover the bark of the trunk with moss, leaves and other protecting materials. The bark collected from trees treated in this manner is known as "MOSSED

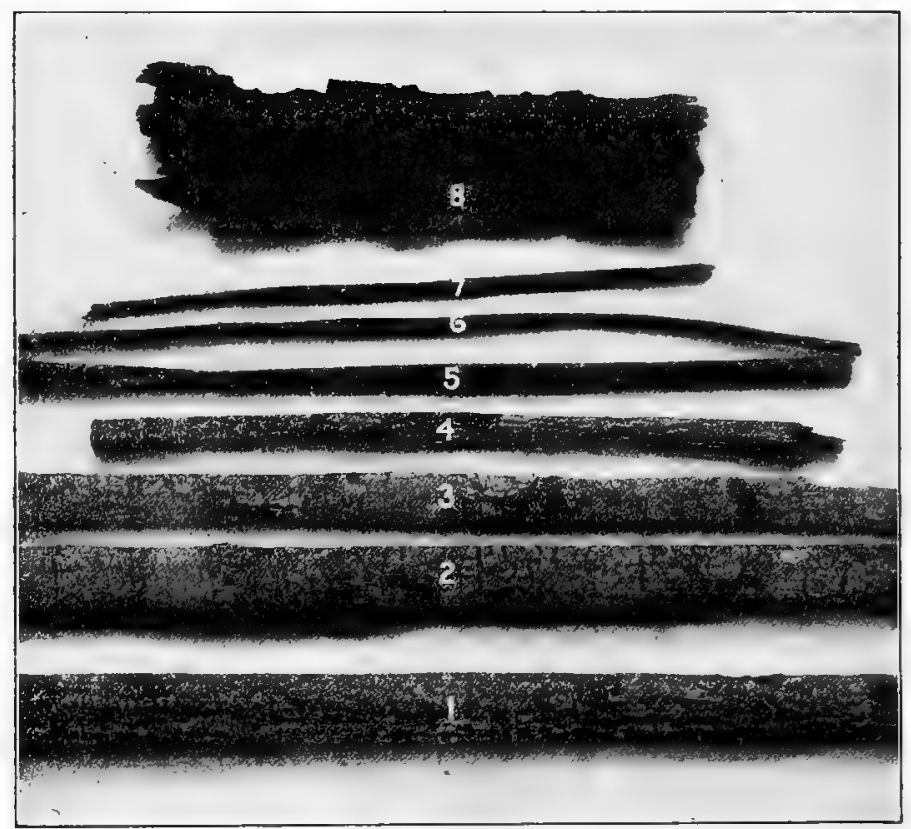

FIG. 226. Commercial cinchona barks: $1,2,3$, red cinchona with transverse fissures; 4, 5, red cinchona, the former with longitudinal furrows; 6,7 , Loxa bark (Cinchona pallida); 8, flat bark (Cinchona calisaya).' About $\frac{1}{5}$ actual size.

BARK." At the present time cultivators remove the bark from the trunk in alternate strips, the denuded places being again covered, after which another layer of bark develops that is very rich in alkaloids and is known as " RENEWED BARK." The outer bark, consisting of the periderm layer and some of the cortex, is flattened out and allowed to dry under pressure, and constitutes the "FLAT" (or Tambla) bark (Fig. 226). 
Red Cinchona.-Usually in double quills or rolled pieces (Fig. 226) cut into lengths from 25 to $40 \mathrm{~cm}$. long, 15 to $20 \mathrm{~mm}$. in diameter, bark 2 to $5 \mathrm{~mm}$. thick; outer surface reddish or dark brown, with grayish patches of foliaceous lichens, longitudinally wrinkled, with few usually widely separated transverse fissures; inner surface reddish-brown, distinctly striate; fracture smooth in periderm, in inner bark with projecting bast fibers; odor distinct; taste bitter, astringent.

CALISAYA BARK.-Gray or brownish-gray, with numerous patches of foliaceous lichens, having brownish-black and reddishbrown apothecia, and numerous transverse fissures, which give the bark a very characteristic appearance.

The trunk bark is comparatively thick, while renewed bark is comparatively smooth and uniform in color.

Inner Structure.-See Figs. 227; 299, B; 307; 307 a.

Constituents.-A large number of alkaloids have been isolated from this drug, of which the most important are quinine, quinidine, cinchonine and cinchonidine. The total alkaloids amount to about 6 or 7 per cent., of which from one-half to twothirds is quinine in the yellow barks, whereas, in the red barks, cinchonidine exists in greater proportion. QUinine occurs in small crystals which are sparingly soluble in water, soluble in alcohol and readily form crystallizable salts with acids. On the strccessive addition of dilute sulphuric acid, bromine or chlorine water and ammonia water the solution becomes of an emeraldgreen color (thalleioquin). Quinidine, an isomer of quinine, crystallizes in rhombohedra or monoclinic prisms which are nearly insoluble in water and otherwise conforms to the characteristics given for quinine. The solutions of quinidine are, however, dextrogyre, while those of quinine are lævogyre. CINCHONINE separates in lustrous prisms or needles which are nearly insoluble in water, and does not give the thalleioquin test, but forms a white precipitate upon the addition of dilute sulphuric acid, bromine water and ammonia. Cinchoninine crystallizes in prisms and resembles cinchonine in many of its properties. Its solutions, however, are lævogyre, while those of cinchonine are dextrogyre.

The other important alkaloids of Cinchona which have been separated are: Quinamine, hydroquinine, hydroquinidine, hydro- 
cinchonidine and homocinchonidine. Of the other alkaloids which have been isolated the following may be mentioned: Conquinamine, paranine, paricine and quinamidine. Among the other

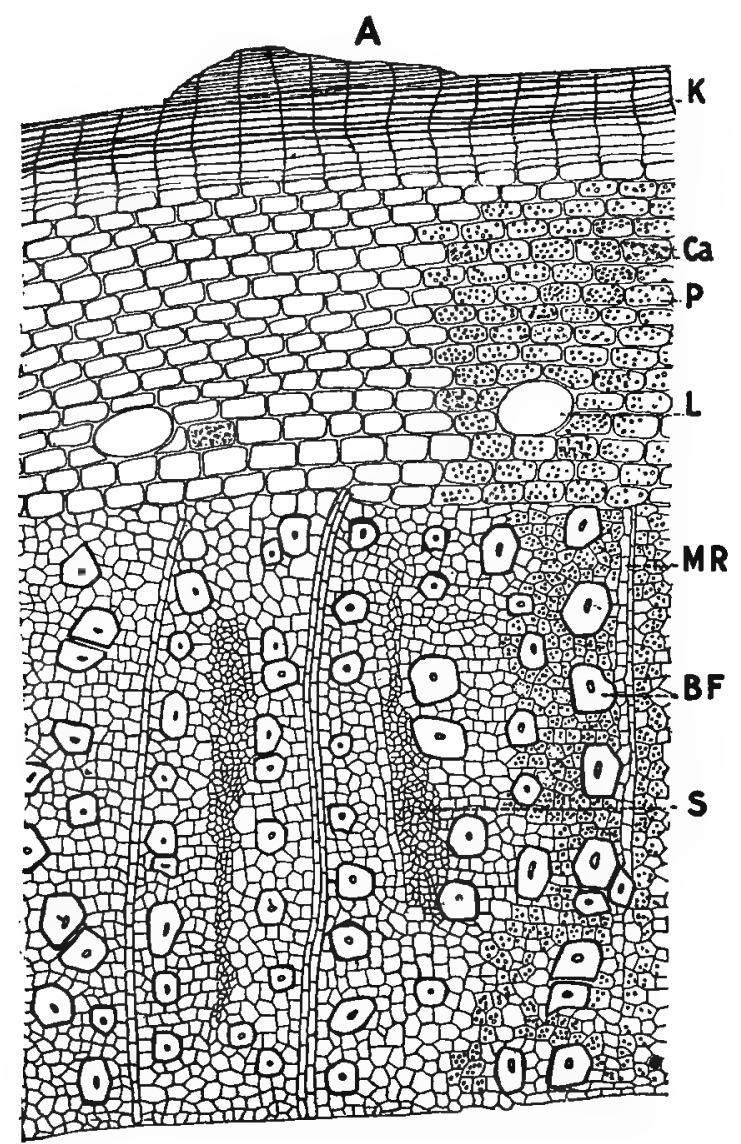

B

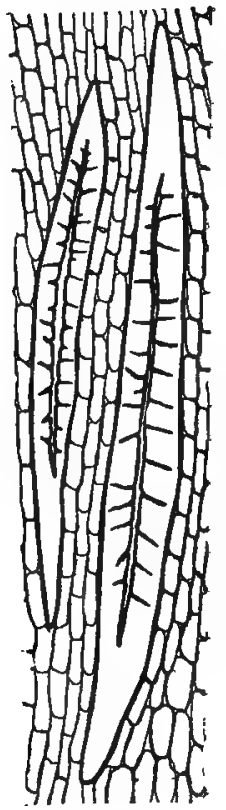

FIG. 227. A, transverse section of red cinchona: $K$, cork; $C a$, cryptocrystalline crystals of calcium oxalate; $P$, parenchyma containing starch; $L$, latex cells containing gum, resin and tannin; $M R$, medullary rays; $B F$, bast fibers; $S$, sieve. $B$, longitudinal section of same showing two bast fibers surrounded by parenchyma cells.

constituents of Cinchona are: KINIC ACid from 5 to 9 per cent., which forms colorless rhombic prisms and yields a sublimate consisting of golden crystals of kinone (quinone) on treatment with manganese peroxide and sulphuric acid; KINOVIN (quinovin) an 
amorphous, bitter glucoside, to the amount of o.II to I.74 per cent.; CINCHOTAN rIC ACID from 2 to 4 per cent., which decomposes into the nearly insoluble CINCHONA RED, occurring in red barks to the extent of Io per cent.; considerable starch; calcium oxalate in the form of cryptocrystalline crystals; and ash about 3 per cent. The red color in cinchona bark is due to an oxydase similar to that which causes the darkening of fruits when cut. If the fresh bark is heated in boiling water for 30 minutes and then dried it does not become red.

Allied Plants.-Loxa or Huanco (Cinchona pallida) bark is obtained from Cinchona officinalis, a shrub indigenous to Ecuador, which was the species first discovered. The plant is cultivated in nearly all the large cinchona plantations and yields a bark (Fig. 226) that contains I to 4 per cent. of total alkaloids, from one-half to two-thirds of which is quinine.

CUPREA BARK is obtained from Remijia Purdieana and $R$. pedunculata, of Central and Southern Colombia. It has a copperred color, is hard, compact and heavy, contains numerous transversely elongated stone cells and 2 to 6 per cent. of alkaloids, of which one-third may be quinine. Cinchonidine has never been isolated from this bark. Cuprea bark also contains caffeate of quinine and caffeic acid, of which there is about 0.5 per cent., and which closely resembles the same acid obtained from caffeotannic acid in coffee.

FRANGULA.-ALDER BUCKTHORN BARK.-The dried bark of the stem and branches of Rhamnus Frangula (Fam. Rhamnaceæ), a shrub indigenous to Europe, Northern Africa and Central Asia; and naturalized in Northern New Jersey and Long Island. The bark is collected in spring and kept at least one year before being used, so as to render inert the irritating and nauseating principles which are destroyed by a ferment during the curing of the drug. The same results are said to be obtained by heating the bark at $37.7^{\circ} \mathrm{C}$. for 48 hours (p. 326 ).

DEsCRIPTION.-In single or double quills and transversely curved pieces, 2 to $20 \mathrm{~cm}$. long, I to $3 \mathrm{~cm}$. in diameter, bark 0.3 to I mm. thick; outer surface dark brown or purplish-black, longitudinally wrinkled, with numerous lenticels I to $3 \mathrm{~mm}$. long, and with grayish patches of foliaceous lichens and groups of 
light brown or brownish-black apothecia; inner surface yellowish or dark brown, smooth, longitudinally striate, and reddened by alkalies; fracture short, with projecting bast fibers in inner bark; odor slight; taste slightly bitter.

Inner Structure.-See Fig. 228.

Constituents.-A glucoside frangulin (rhamnoxanthin), which forms yellow crystals, is insoluble in water and nearly so in alcohol, gives a bright purple color on the addition of solutions

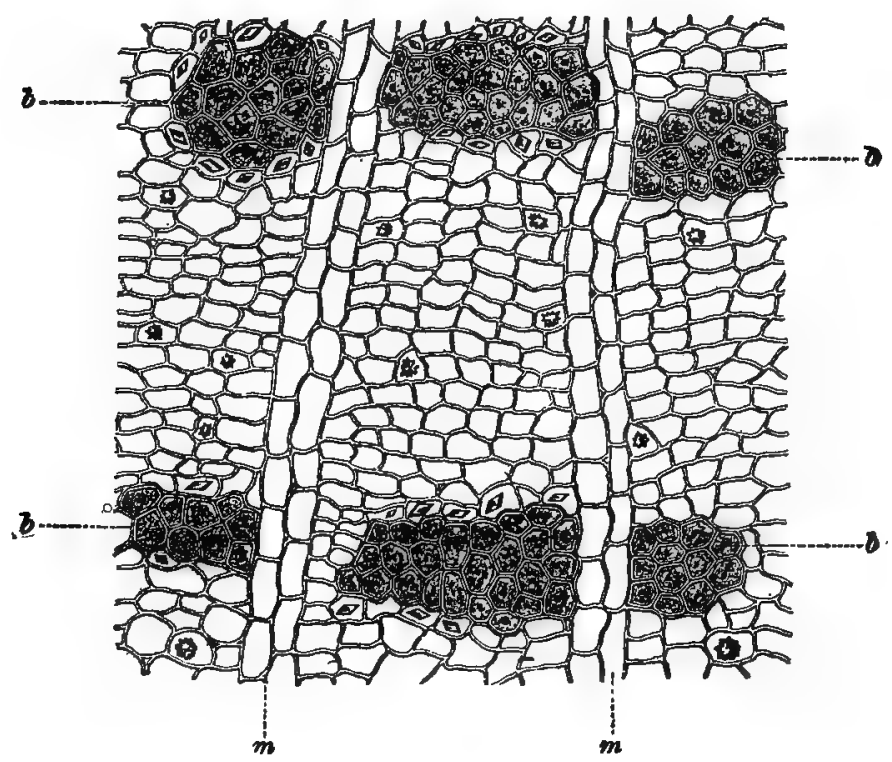

F1G. 228. Transverse section of inner bark of Rhamnus Frangula: b, bast fibers: surrounded by crystal fibers; $m$, medullary rays; parenchyma containing rosette aggre. gates of calcium oxalate--After Vogl.

of the alkalies, and on hydrolysis yields rhamnose and emodin (see Rhubarb). It also contains the glucoside pseudofrangulin (frangulic acid), which yields pseudoemodin; rhamnoxanthin, a coloring principle; a volatile oil ; tannin; starch ; calcium oxalate; and ash 5 to 6 per cent.

Allied Plants.-The bark of Rhamnus Carniolica has been substituted for R. Frangula. The older pieces are distinguished by having a deeply fissured cork and groups of stone cells. In 
the younger bark the medullary rays are from 4 to 7 cells wide; otherwise the pieces resemble Frangula.

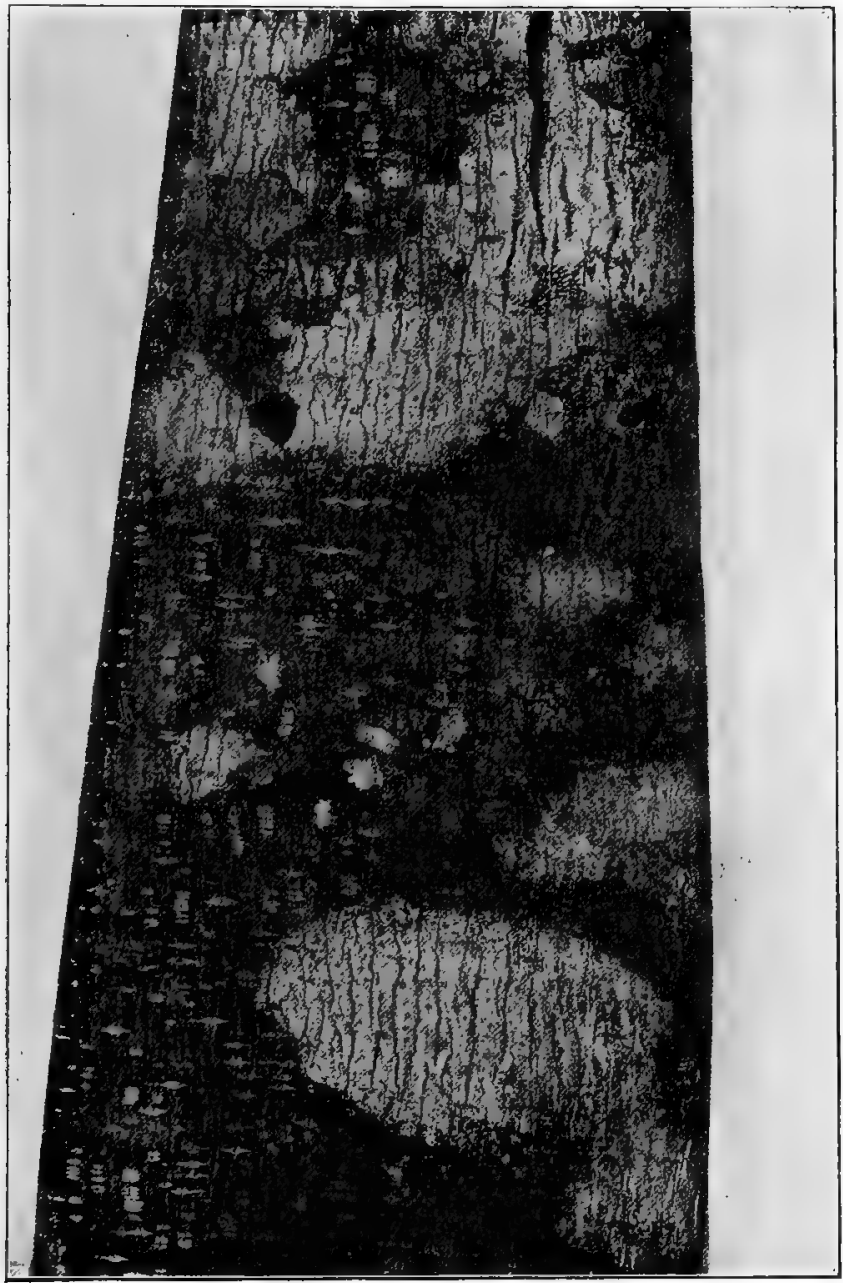

Fig. 229. Bark of Rhammus Purshiana showing large whitish patches of lichens, and numerous lens-shaped lenticels.

RHAMNUS PURSHIANA.-CASCARA SAGRADA.The bark of Rhamnus Purshiana (Fam. Rhamnacex), a shrub indigenous to Northern California, Washington, Oregon and the 
southwestern part of British America (p. 326). The bark is collected in spring and early summer, and kept at least one year before being used.

Description.-Usually in flattened or transversely curved pieces, occasionally in quills 2 to $10 \mathrm{~cm}$. long, I to $3 \mathrm{~cm}$. in diameter, bark $\mathrm{x}$ to $3 \mathrm{~mm}$. thick; outer surface dark brown or brownishred, frequently completely covered with grayish or whitish lichens (Fig. 229), several of which are peculiar to this bark, and with

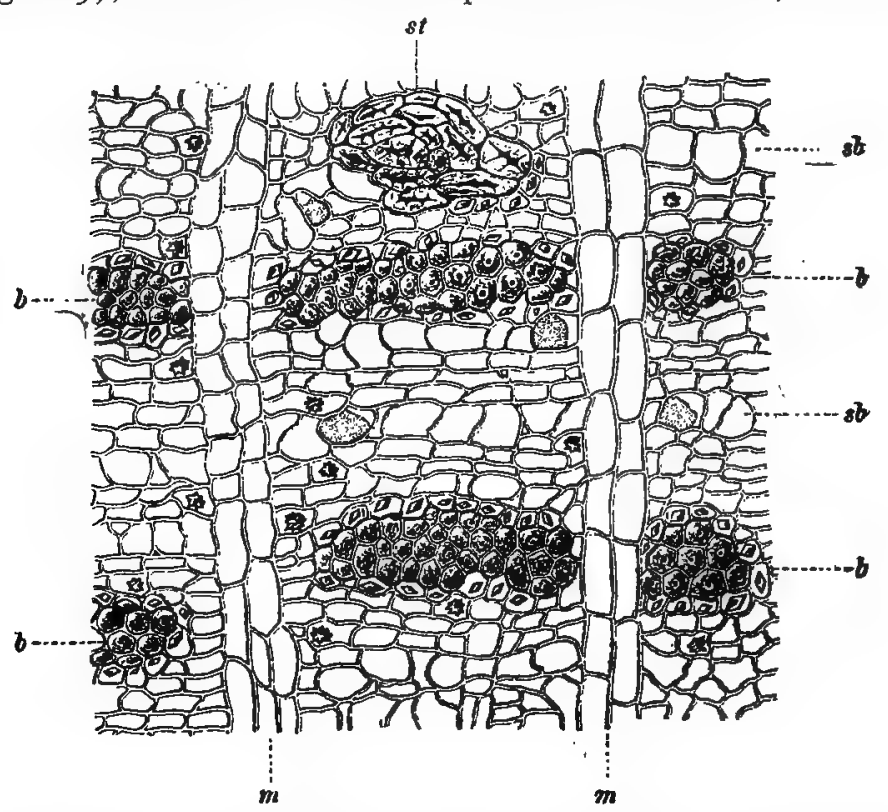

Frg. 229a. Transverse section of inner bark of Rhamnus Purshiana: st, group of stone cells; b, groups of bast fibers surrounded by crystal fibers; $m$, medullary rays; sb, sieve cells; parenchyma containing rosette aggregates of calcium oxalate.-After Vogl.

small groups of brownish apothecia, longitudinally wrinkled, sometimes with numerous lenticels 3 to $6 \mathrm{~mm}$. long; inner surface light yellow or reddish-brown, smooth, longitudinally striate, turning red when moistened with solutions of the alkalies; fracture short, with projections of bast fibers in the inner bark, the medullary rays one to two cells wide, forming converging groups; in cross section the inner surface of the bark indistinctly crenate; odor distinct; taste bitter, slightly acrid. 
Inner Structure.-See Figs. 229a, 304.

Constituents. - The nature of the active constituents of this drug is not known. It may contain the glucosicle cascarin (purshianin), which on hydrolysis yields emodin and one or more active principles; and the neutral principle chrysarobin, which yields chrysophanic acid (see Rhubarb). The bark apparently contains emodin; isoemodin, a principle which is isomeric with emodin, insoluble in ammonia and resembles a similar principle in Frangula; a principle which yields on hydrolysis syringic acid; a fat consisting of rhamnol arachiclate; a bitter principle; several resins; tannin; glucose; starch ; calcium oxalate; and ash about 7 per cent.

Adulterants.-Rhammis californica, a shrub indigenous to Southern California and the neighboring States, yields a bark which closely resembles that of Rhamnus Purshiana, but may be distinguished from it by the medullary rays, which are from 3 to 5 cells wide, and occur in more or less parallel wavy rows, and by the distinct crenation of the inner margin of the bark.

Allied Plants.-The fruits of Rhamnus cathartica, a shrub indigenous to Central and Southern Europe and Asia, are used under the name of Buckthorn berries. They are globular, about $5 \mathrm{~mm}$. in diameter, greenish-brown or black, and consist of four I-seeded nutlets; the seeds are dark brown and triangular-convex. The odor is slight but disagreeable. The taste is bitter and acrid, the saliva being colored yellow. The fruits contain a glucoside, rhamnonigrin, which yields emodin; a bitter principle; and three yellow coloring principles, viz.: rhamnocitrin, rhamnolutin and thamnochrysin.

The fruits of Rhamnus cathartica, as well as of $R$. infectoria (known as French Berries) and of $R$. sa.tatilis (called Persian berries) have been used as yellow dyes. The fruits of several species growing in China yield a green indigo.

VIBURNUM PRUNIFOLIUM.-BLACK HAW BARK. The dried bark of the root of Viburnum prunifolium or of $T^{\prime}$ Lentago (Fam. Caprifoliaceæ), shrubs (Figs. I79, 230) indigenous to the Eastern and Central United States (p. $3^{82}$ ). The root bark is more highly esteemed than that of the stem and branches. 
STEM BARK.-In transversely curved pieces, or irregular oblong chips, I. 5 to $6 \mathrm{~cm}$. long, 0.5 to $1.5 \mathrm{~cm}$. in diameter, 0.5 to $1.5 \mathrm{~mm}$. thick; outer surface brownish-red or grayish-brown, longitudinally wrinkled, periderm occasionally exfoliated, with occasional grayish patches of foliaceous lichens and numerous

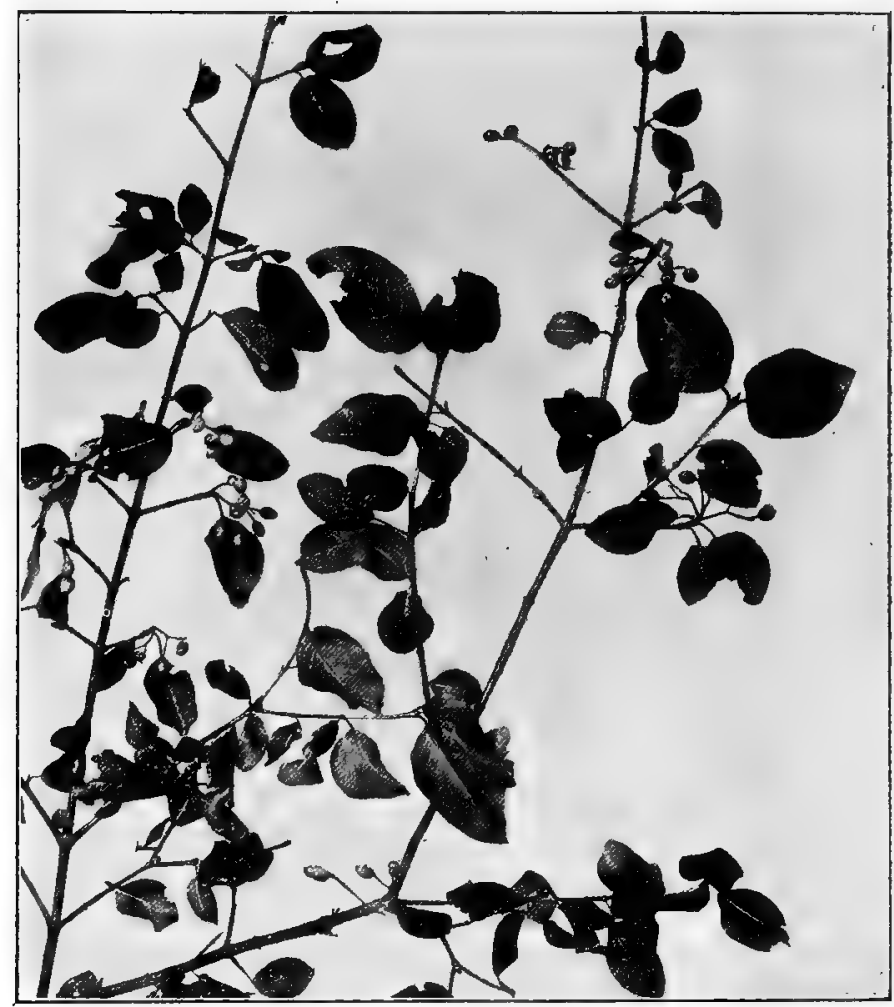

FIG. 230. Fruiting branch of Viburnum prunifolium.

lenticels; inner surface yellowish- or reddish-brown, longitudinally striate; fracture short, periderm brownish-red, inner bark with numerous light yellow groups of stone cells; odor slight; taste astringent and bitter.

ROoT BARK.-Somewhat resembling the stem bark, but smoother externally, without lichens and having fewer lenticels. 
Constituents.-A bitter, somewhat resinous principle, viburnin; valerianic (viburnic) acid and other organic acids; resin; tannin; calcium oxalate; ash about Io per cent.

Adulterants. - The barks of one or more allied species (especially Viburnum dentatum, Fig. I79, D), are said sometimes to be substituted for the official bark.

HAMAMELIDIS CORTEX.-WITCHHAZEL BARK.The bark and twigs of Hamamelis virginiana (Fam. Hamamelidaceæ), a shrub (Fig. 264) indigenous to Canada and the United States west to Minnesota and south to Texas (p. 286).

Description.-Bark in transversely curved pieces 5 to 20 $\mathrm{cm}$. long, 5 to $15 \mathrm{~mm}$. in diameter, bark 0.5 to I mm. thick; usually with the grayish-brown or reddish-brown periderm removed, outer surface light brownish-red, smooth; inner surface light reddish-brown, longitudinally striate; fracture short-fibrous; odor slight; taste astringent.

Twigs 2 to $5 \mathrm{~mm}$. in diameter; the outer surface varying in color from yellowish-brown to blackish-brown, smooth or somewhat scurfy, longitudinally wrinkled, and with numerous small lenticels; small twigs somewhat zigzag from numerous leaf-scars; bark thin, easily separable from the whitish, hard, radiate wood; pith small.

Constituents.-Gallotannic acid, a glucosidal tannin, and gallic acid. The bark apparently also contains a volatile oil which is obtained by distillation in the preparation of hamamelis water or extract of witchhazel.

GOSSYPII CORTEX.-COTTON ROOT BARK.-The dried bark of the root of Gossypium herbaceum, and of other species of Gossypium (Fam. Malvaceæ), biennial or triennial shrubs (Fig. I66) indigenous to sub-tropical Asia and Africa, and now cultivated in all tropical and sub-tropical countries (p. 329).

Description.-In flexible, transversely curved, or slightly quilled pieces, 6 to $30 \mathrm{~cm}$. long, 5 to $15 \mathrm{~mm}$. in diameter, bark 0.2 to $\mathrm{I} \mathrm{mm}$. thick; outer surface light brown, longitudinally wrinkled, with small lenticels, periderm frequently exfoliated; inner surface light brown, longitudinally striate; fracture tough, fibrous, surface light brown, tangentially striate, readily separable into fibrous layers; odor faint; taște slightly astringent and acrid. 


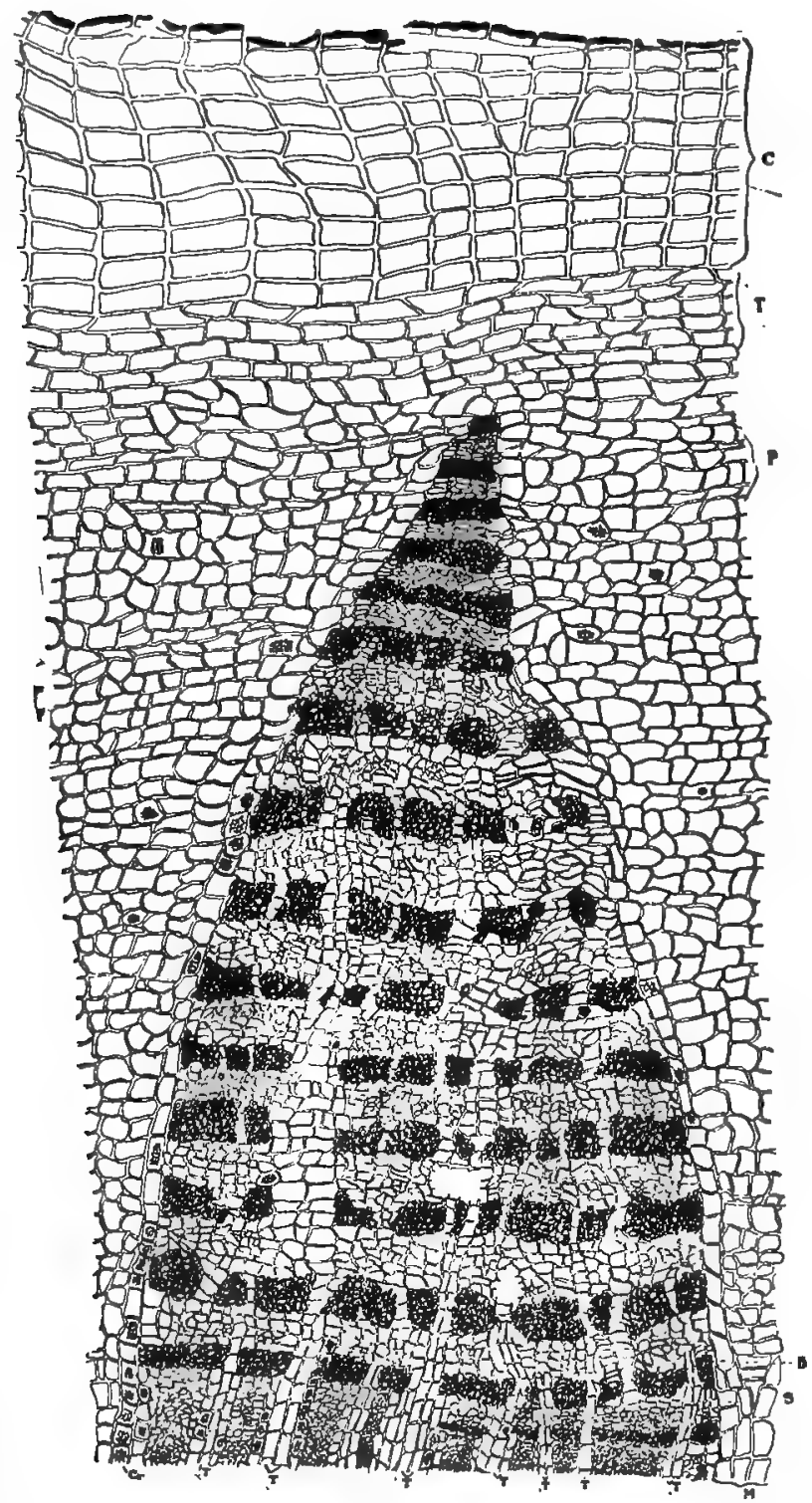

Fig, 23I. Transverse section of cotton root bark; $C$, cork; $C_{r}$, rosette aggregates of calcium oxalate; $B$, bast; $M$, medullary rays; $T$, cells containing tannin; $S$, sieveAfter Morgan. 


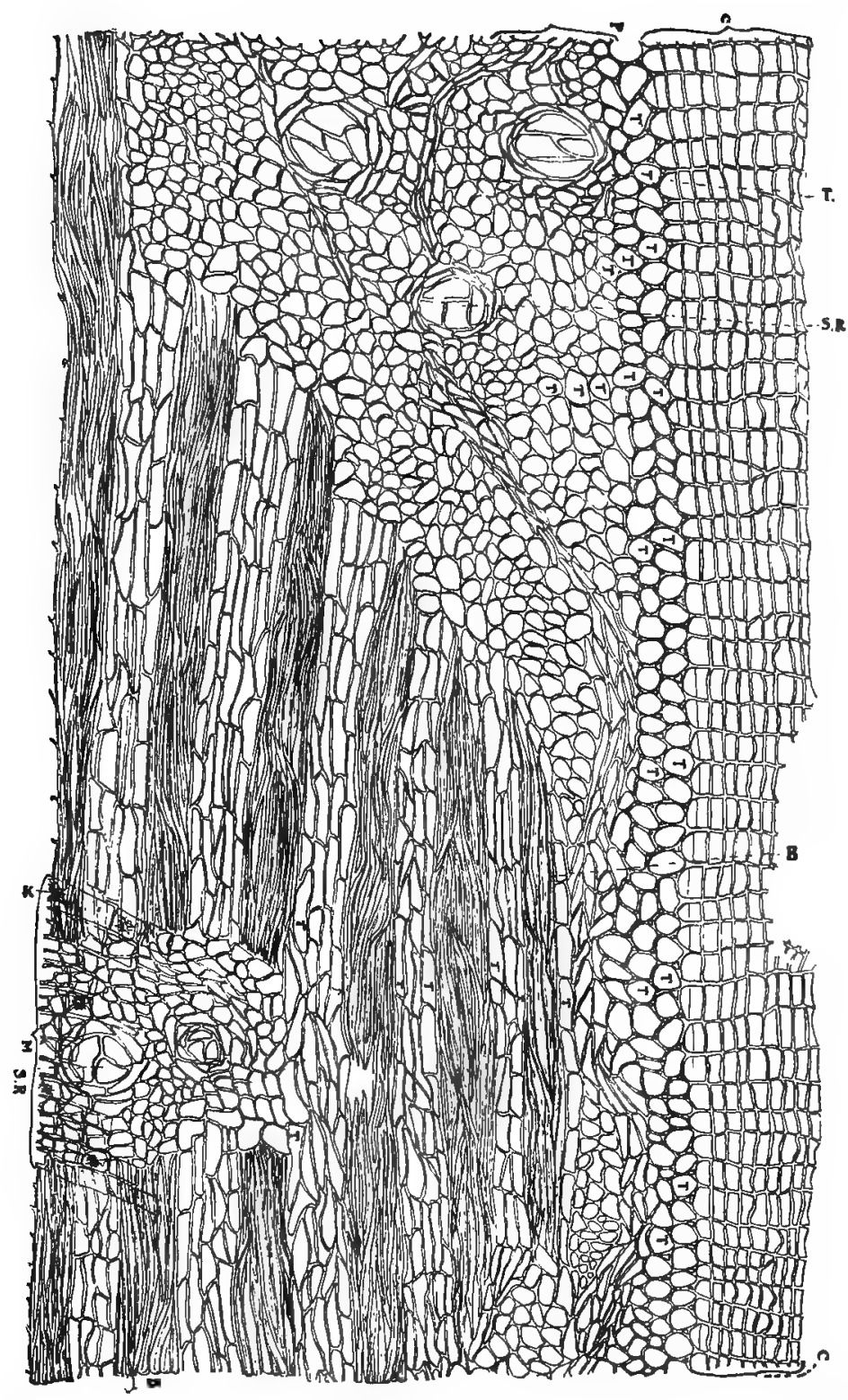

Frg. 231a. Longitudinal section of cotton root bark; C, cork cells; P, parenchyma ; $B$, bast fibers; SR, secretion reservoirs: $M$, medullary rays; $T$, cells containing tannin. $\mathbf{K}$, rosette aggregates of calcium oxalate.-After Morgan. 
Inner Structure.-See Figs. 231; 231a ; 300, $H$.

Constituents.-About 8 per cent. of a peculiar, colorless acid resin, which is soluble in water and becomes reddish and insoluble on exposure to air. The drug also contains fixed oil; tannin; starch and calcium oxalate.

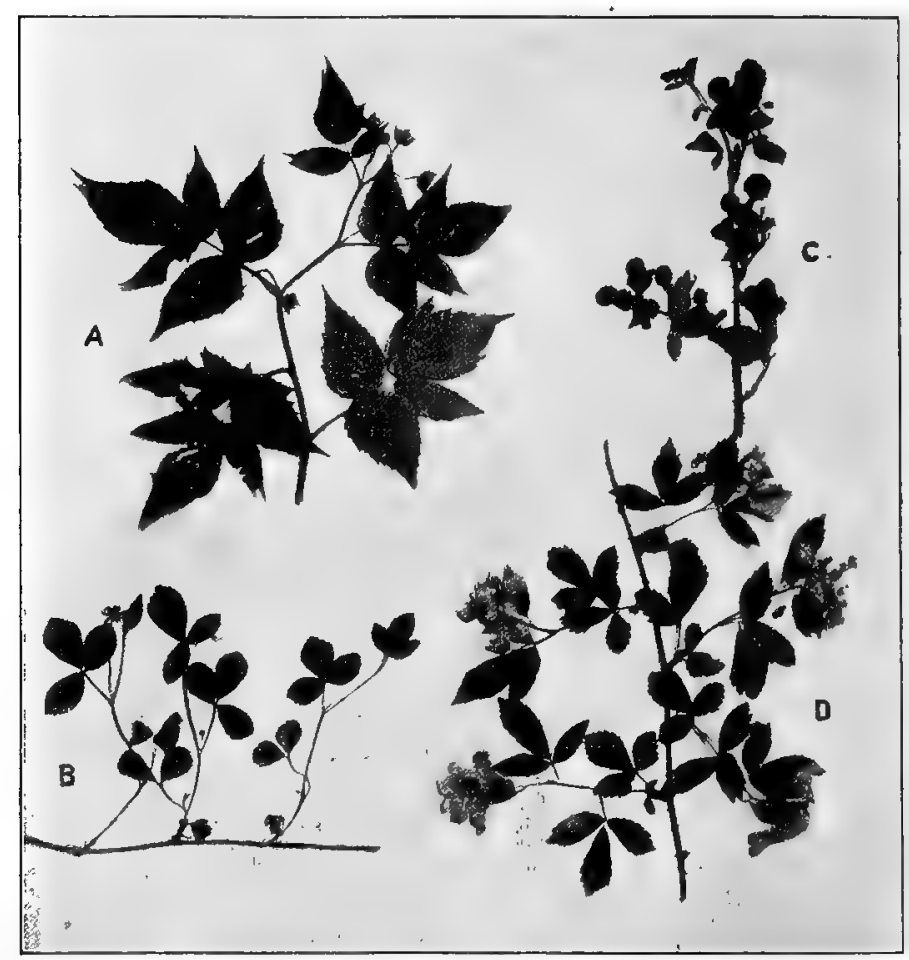

FIG. 232. Species of Rubus; A, wild red raspberry (Rubus strigosus); B, running swamp blackberry (Rubus hispidus); C, D, high bush blackberry (Rubus nigrobaccus), the former fruiting and the latter flowering.

The FLOWERS of the cotton plant contain an interesting glucoside, gossypetin, which becomes green on oxidation and is colored orange-red with solutions of the alkalies. It somewhat resembles a similar principle found in arbor vitæ (Thuja occidentalis).

RUBUS.-BLACKBERRY BARK.-The bark of the rhizome of the perennial shrubs (p. 288) Rubus villosus, $R$. nigro- 
baccus and R. cuneifolius (Fam. Rosacex). R. villosus occurs in dry fields from Canada to Virginia and as far west as Kansas. $R$. nigrobaccus or common blackberry (Fig. 232, C, D) is common in woods in the Eastern and Central United States and extensively cultivated. $R$. cuneifolius is the sand blackberry and is found in sandy woods from New York to Floridla and west to Missouri and Louisiana. The bark should be collected in spring or autumn and dried.

Description.-In flexible, transversely curved or slightly quilled pieces 4 to $20 \mathrm{~cm}$. long, 3 to $5 \mathrm{~mm}$. in cliameter, bark 0.2 to $2 \mathrm{~mm}$. thick; outer surface light brown, longitudinally wrinkled, with few.root-scars, periderm frequently exfoliated; inner surface light brown, coarsely striate longitudinally; fracture short, fibrous, surface light brown, with oblique radiate wedges of bast; odor slight; taste astringent.

Constituents.-Tannin to to 20 per cent.; gallic acid about o.4 per cent.; a bitter, crystalline glucoside villosin somewhat resembling saponin, about 0.8 per cent.; starch ; calcium oxalate; ash about 3 per cent.

Allied Plants.-Blackberries (the fruits of $R$. nigrobacculs, $R$. nigrobaccus sativus and $R$. rillosus), RED RASPBERRies (the fruit of $R$. Idceus, a plant native to the old world), BLACK RASPBERRIES (the fruit of $R$. occidentalis, native of the Northern United States) and Strawberries (the fruits of cultivated varieties of Fragaria chilcensis, $F$. vesça and $F$. rirginiana) all contain about 2 per cent. of malic and citric acids, 4 per cent. of levulose, about 4 per cent. of pectin substances and a small amount of volatile oil to which their distinctive flavors are due. Blackberries contain in addition considerable tannin and the wine made therefrom is valued in addition for its astringency.

EUONYMUS.-WAHOO BARK.-The dried bark of the root of Euonymus atropurpureus (Fam. Celastraceæ), a shrub (p. 323) indigenous to the Central and Eastern United States and Labrador.

DESCRIPTION.-Usually in transversely curved pieces, occasionally in single quills, 3 to $7 \mathrm{~cm}$. long, 0.5 to $1.5 \mathrm{~cm}$. in diameter, bark 0.5 to I mm. thick; very light; outer surface light brown, somewhat wrinkled, with scaly patches of soft cork, few lenticels, 
root-scars and adhering roots, which frequently perforate the bark; inner surface light brown, longitudinally striate, somewhat porous, occasionally with small pieces of yellow wood adhering; fracture short, with silky, projecting, modified bast fibers, cork light brown, inner and middle bark somewhat tangentially striate and with irregular, dark brown bast areas; odor faint; taste bitter; acrid.

The stem bark occurs in very long, fibrous strips with a grayish-black cork and should be rejected.

Constituents.-Euonymin, a crystalline bitter glucoside $\mathbf{2 . 1 6}$ per cent., which resembles digitalin in its physiological action; volatile oil about I.3 per cent.; a yellow and brown resin; dulcitol (isomeric with mannitol); euonic, malic, citric and tartaric acids; starch; and calcium oxalate.

Allied Plants.-E. europaus and other species of Euonymus are also used in medicine, and probably contain the same constituents.

VIBUR.NUM OPULUS.-CRAMP BARK.--The dried bark of the stem and branches of Viburnum Opulus (Fam. Caprifoliaceæ), a shrub (Fig. I79, $C$ ) indigenous to the Northern United States and Southern Canada, and also found growing in Europe and Asia (p. 382).

Description.-In transversely curved pieces, 6 to $20 \mathrm{~cm}$. long, I to $2 \mathrm{~cm}$. in diameter, 0.5 to $\mathrm{I} .5 \mathrm{~mm}$. thick; outer surface light brown or brownish-black, longitudinally wrinkled, periderm, sometimes exfoliated, revealing a nearly smooth reddish-brown surface, with numerous grayish patches of foliaceous lichens, and small brownish-black apothecia and large brownish lenticels; inner surface light or reddish-brown, finely striate longitudinally, fracture uneven, fibrous, surface light or reddish-brown, with groups of stone cells and bast fibers; odor slight; taste astringent, bitter.

Constituents.-The constituents resemble those of Viburnum prunifolium.

XANTHOXYLUM.-PRICKLY ASH BARK.-The dried bark of Xanthoxylun anericanum and Fagara (Xanthoxylum) Clava-Herculis (Fam. Rutaceæ). X. americanum is a shrub or small tree (p. 304) indigenous from Quebec to Virginia and west: to South Dakota, Nebraska and Kansas, and yields Northern 
Prickly Ash. F. Clava-Herculis is a shrub (p. 305) found south from Virginia to Texas, and furnishes the Southern Prickly Ash. The latter, however, appears to be less valuable medicinally.

Northern Prickly Ash.-In transversely curved pieces, occasionally in single quills, 2 to $\mathrm{I} 7 \mathrm{~cm}$. long, I to $2 \mathrm{~cm}$. in diameter, 0.5 to $3 \mathrm{~cm}$. thick; outer surface light brown to brownishblack, with grayish patches of foliaceous lichens, numerous small black apothecia and whitish lenticels; fracture short, uneven;

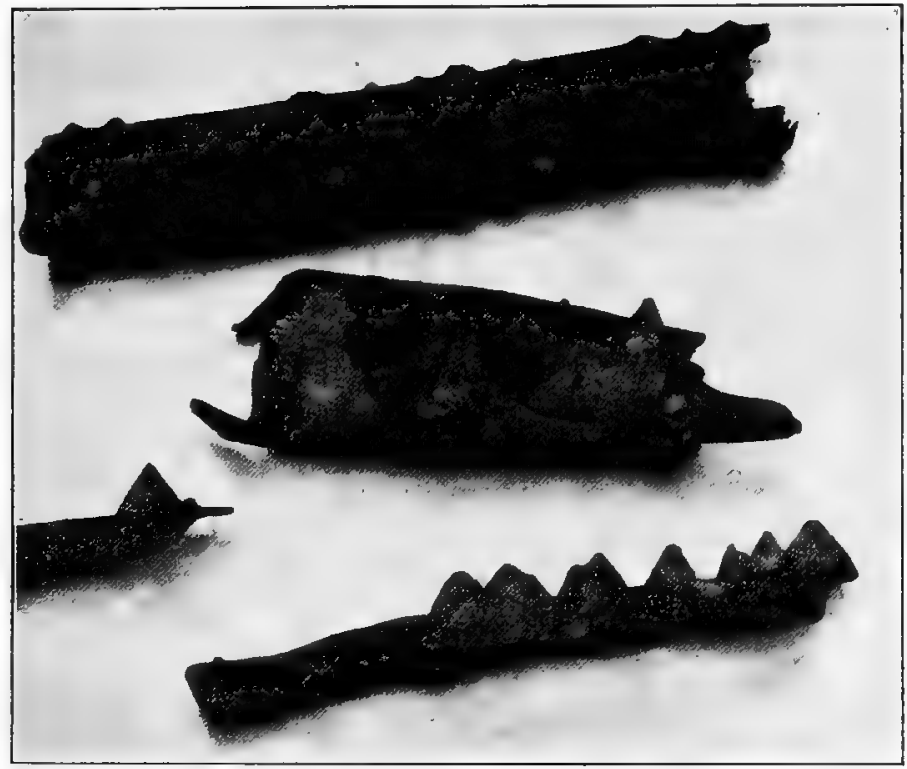

FIG. 233. Bark of southern prickly ash showing cork-wings.

inner surface light brown, finely striate longitudinally, with numerous acicular crystals, phelloderm layer dark green, inner bark with groups of converging medullary rays; odor slight; taste bitter, acrid and pungent.

Southern Pírickly Ash.-Transversely curved or irregularly oblong flattened pieces, occasionally in single quills 5 to $30 \mathrm{~cm}$. long, I to $7 \mathrm{~cm}$. in diameter, I to $4 \mathrm{~mm}$. thick; outer surface with numerous conical cork-wings or their scars (Fig. 233); inner surface free from acicular crystals. 
Constituents.-Two resins, one acrid, the other crystalline and bitter; an acrid volatile oil ; a bitter, alkaloidal principle, somewhat resembling berberine; a crystalline phenol compound xanthoxylin; ash about I2 per cent.

Allied Plants.-The fruits of both $X$. americanum and Fagara Clava-Herculis are found in commerce and known as Prickly Ash berries. They consist of 2 to 3 follicles, each of which is 5 to $6 \mathrm{~mm}$. long, brownish-green, dehiscent along the ventral suture and contains one or two sub-globular, somewhat flattened, black, glossy seeds; odor is aromatic; taste pungent and bitter. Xanthoxylum fruits contain a volatile oil and resin.

GRANATUM.-POMEGRANATE BARK.-The dried bark of the root and stem of Punica Granatum (Fam. Punicaceæ), a shrub (p. 345) indigenous to Northwestern India, and cultivated in the sub-tropical regions of the Old World. The bark of the root is preferred to that of the stem and by some the drug obtained from wild plants is also preferred. The bark deteriorates with age and should not be used after it is a year or two old.

StEm BARK.-Usually in transversely curved pieces, occasionally in single quills, 2 to $8 \mathrm{~cm}$. long, 5 to $20 \mathrm{~mm}$. in diameter, bark 0.5 to $2 \mathrm{~mm}$. thick; outer surface yellowish-brown, with grayish patches of foliaceous lichens, brownish-black apothecia and small lenticels, longitudinally wrinkled; inner surface light yellow or yellowish-brown, finely striate, smooth; fracture short, smooth, phelloderm layer dark green, inner bark light brown, somewhat checkered; odor slight; taste astringent.

Roor BARK.-Dark brown, with slight longitudinal patches and scales of cork, green phelloderm layer wanting, medullary rays extending nearly to the outer surface.

Inner Structure.-See Fig. 234.

Constituents.-Four alkaloids to the extent of $\mathrm{I}$ to 3 per cent. in the root bark, but only about half as much in the stem bark. The most important of these alkaloids is pelletierine, the tannate of which is official. Pelcetrerine (punicine) is a colorless, volatile liquicl alkaloid, which readily absorbs oxygen and becomes dark on exposure to air. Its sulphate is lævorotatory. ISOPELLETIERINE (isomeric with pelletierine) is optically inactive and forms an amorphous sulphate. Methylpelletierine some- 


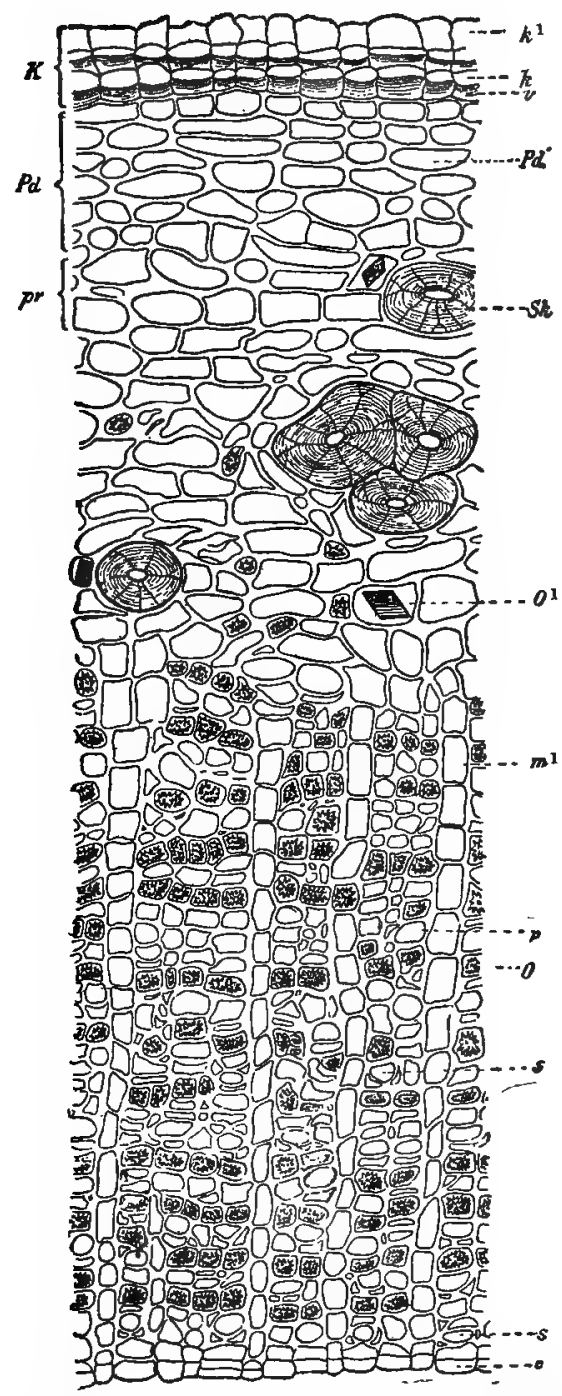

Frg, 234. Transverse section of granatum; $\mathrm{K}$, corky layer composed of thin-walled cork cells $\left(\mathrm{k}^{\mathrm{1}}\right)$ and thick-walled cork cells $(\mathrm{k})$ only the inner walls $(v)$ of which are thickened; Pd, phelloderm cells; pr, some parenchyma cells of the primary cortex; Sk, stone cells with thick, lamellated walls and fine branching pores; $O$, rosette aggregates of calcium oxalate; $\mathrm{O}^{1}$, monoclinic prisms of calcium oxalate; $\mathrm{m}^{1}$, medullary rays; s, sieve cells; p, parenchyma cells; c, cambium.-After Meyer. 
what resembles pelletierine, but its hydrochloride is dextrorotatory. PSEudopelletierine (methylgranatonine) occurs in prisms, is optically inactive, and resembles in its reactions and decomposition products tropinone. The latter is formed from tropine, a compound which results on the decomposition of most of the solanaceous alkaloids. Granatum also contains 20 to 22 per cent. of a mixture of TANNINS, one of which yields gallic acid and the other ellagic acid. A yellow coloring principle, considerable starch and calcium oxalate are also present in the drug.

Allied Drugs.-The rind of the fruit of Punica Granatum, known as pomegranate rind, occurs in irregularly curved yellowish-brown fragments about $2 \mathrm{~mm}$. thick. It contains 23.8 to 25 per cent. of a tannin which is colored bluish-black with ferric salts.

MEZEREUM.-MEZEREON BARK.-The dried bark of Daphne Mezereum, and of other species of Daphne (Fam. Thymelacex), shrubs indigenous to Europe and Asia, and naturalized in New England and Canada (p. 343). The bark is collected in early spring; it is dried and frequently made up into small bundles, the commercial supplies being obtained from Thuringia, Southern France and Algeria.

Description.-In flexible double quills or somewhat flattened strips ro to $90 \mathrm{~cm}$. long, 3 to $20 \mathrm{~mm}$. in diameter, bark about 0.3 $\mathrm{mm}$. thick; outer surface light or dark brown, smooth, obliquely striate or wrinkled, with numerous lenticels, occasional brownishblack apothecia, and sometimes with buds or bud-scars; inner surface yellowish-green, somewhat lustrous, finely striate; fracture tough, fibrous, the dark-brown periderm readily separable from the yellowish-green cortex, inner bark yellowish-green, lamellated; odor slight; taste very acricl.

Constituents.-An acrid resin known as mezerein; a crystalline, bitter glucoside daphnin (isomeric with æsculin) occurring in greatest amount in the stem bark during the flowering and fruiting season; volatile and fixed oils; malic acid; several sugars; and starch.

Allied Drugs.-The berry-like frutits of Daphne Mezereum and $D$. Gnidium are sub-globular, dark brown or brownish-black, about $5 \mathrm{~mm}$. in diameter, with a black, glossy seed and acrid pungent taste. The fruits contain 0.38 per cent. of coccogonin, a 
principle which on sublimation gives off an odor of coumarin; 0.22 per cent. of an acrid resin; and $3 \mathrm{I}$ per cent. of a fixed oil which absorbs oxygen on exposure to air and is in the nature of a drying oil.

The barks of a number of other plants of this family are used like that of Mezereum, as Daphnopsis Schrcartzii of the West Indies, Lasiosiphon eriocephalus of India and Ceylon, and various species of Stellera, Struthiola and Thymelæa.

PRUNUS VIRGINIANA.-WILD BLACK CHERRY BARK.-The bark of the stem and branches of Prunus serotina Ehrhart (Syn. Prunus virginiana Miller) (Fam. Rosaceæ), a tree (Fig. 235) indigenous to the Eastern and Central United States and Canada. The bark is collected in autumn, and should be carefully dried and preserved in air-tight containers (p. 287).

Description.-Usually in transversely curved pieces 2.5 to 8 $\mathrm{cm}$. long, I to $5 \mathrm{~cm}$. in diameter, 0.5 to $4 \mathrm{mmm}$. thick; outer surface light brown or greenish-brown, somewhat glabrous, with numerous lenticels 3 to $4 \mathrm{~mm}$. long; inner surface light brown, longitudinally striate and occasionally fissured; fracture short, granular; cork dark brown, thin, easily separable from the green phelloderm, inner bark porous and granular; odor of the drug distinct, and on the addition of water developing an odor of benzaldehyde and hydrocyanic acid; taste astringent, aromatic.

The bark of the trunk is dark brown and rough externally.

Constituents.-A glucoside analogotis to amygdalin or laurocerasin; a ferment which resembles emulsin; these two principles yielding by interaction hydrocyanic acid and benzaldehyde; also a glucoside which is crystalline, bitter and fluorescent; tannin 2.5 to 4.5 per cent.; gallic acid; starch and calcium oxalate. Amygdalin occurs chiefly in the inner bark and varies in amount from 3.I 6 to 4.12 per cent. in the bark which yields from 0.23 to 0.32 per cent. of hydrocyanic acid. The root bark contains more amygdalin than either the bark of young twigs or the trunk. The latter may contain but 0.5 per cent. of amygdalin and yield as little as 0.03 per cent. of hydrocyanic acid. The amount of amygdalin present varies even in the bark of the same thickness from the same tree. When the exposure is such that the chloroplastids are abundant in the cells of the bark, then the per cent. 
of amygdalin is higher, whereas when the exposure is such that the cells do not take an active part in photosynthesis the per cent.

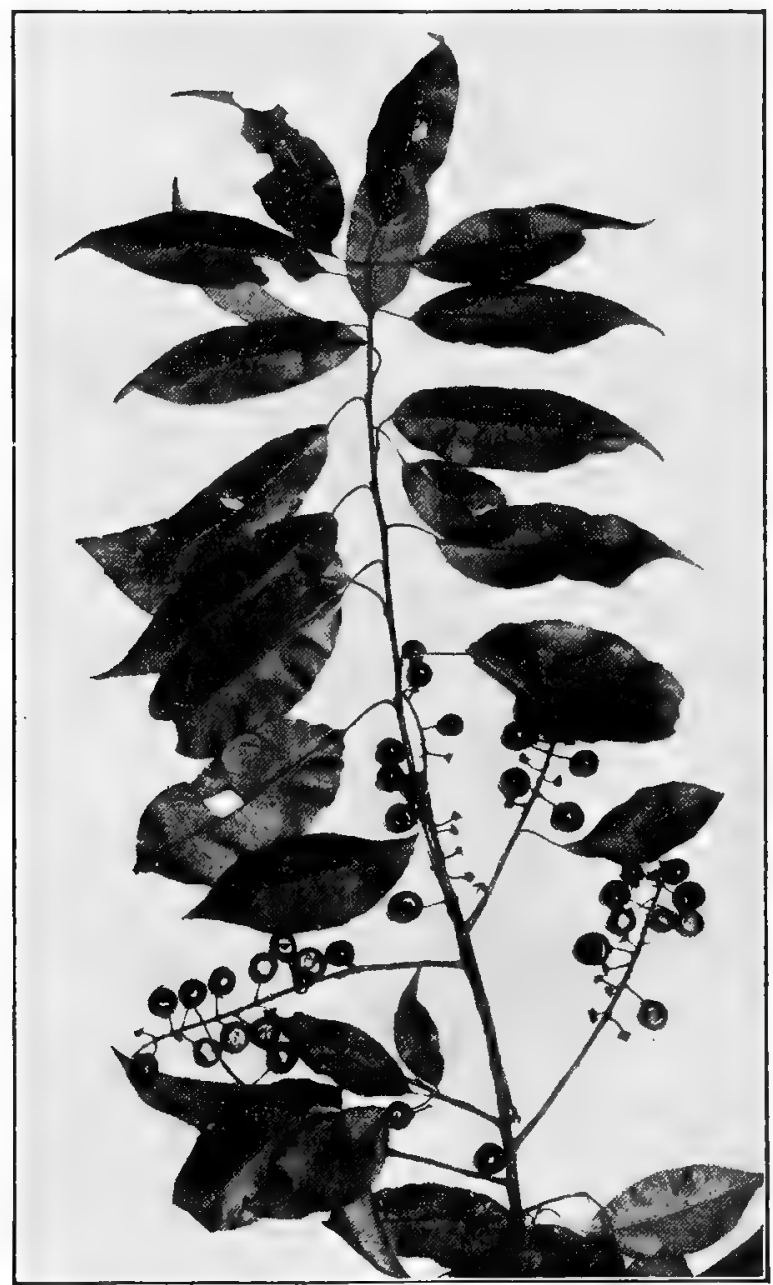

FIG. 235. Fruiting branch of wild black cherry (Prunus serotina).

of amygdalin is lower. In the latter case the bark is yellowishbrown. On keeping the bark for a year it deteriorates from to to 50 per cent. 
Adulter.INTS.-It is likely that the barks of other species of Prunus are now entering the market. They are more astringent and less aromatic.

Allied Plants. - The leaves of the Ciierry laurel (Prumus Laturo-Cerasus) are used in the fresh condition. They are oblong or oblong-lanceolate, about $I_{5} \mathrm{~cm}$. long, sharply serrate, coriaceous, with an almoncl-like odor on being bruised and an aromatic, bitter taste. They contain about I.3 per cent. of a glucoside laurocerasin, which is associated with amygdalic acid; a ferment emulsin, which acts on the laurocerasin, causing it to be more slowly decomposed than amygdalin and yielding but half as much hydrocyanic acid (about 0.12 per cent.) and benzaldehyde (about 0.5 per cent). The leaves also contain a crystalline principle phyllic acid, which is insoluble in water, soluble in alcohol and occurs in the leaves of almond, peach and apple. A glucoside resembling laurocerasin is found in the leaves of Sambucus nigra.

The leaves of the PEACH (Persica rulgaris), which is extensively cultivated for its fruit, contain about 3 per cent. of amygdalin (see Almond).

The FRUIT of Prinnis serotina consists of small, black drupes (Fig. 235), which when ripe are sweet, slightly acid and astringent. They are used in making a wine and might be employed in other preparations of wild cherry.

SASSAFRAS.-SASSAFRAS BARK.-The bark of the root of Sassafras officinalc (Fam. Lauraceæ), a tree (Fig. 73) indigenous to Eastern North America (p. 277). The bark is collected in the early spring, or autumn, deprived of the periderm, and used either in the fresh or dried condition.

DesCRIPTION.--In transversely curved or recurved, irregular, oblong pieces, 3 to $8 \mathrm{~cm}$. long, Io to $30 \mathrm{~mm}$. in diameter, 0.5 to 3 $\mathrm{mm}$. thick; outer surface light reddish-brown, nearly smooth, somewhat porous; inner surface distinctly striate, somewhat scaly; fracture short, soft, surface slightly porous; odor aromatic; taste somewhat mucilaginous, astringent and aromatic.

Inner Structure.-See Fig. 236.

Constituents.-Volatile oil 5 to 9 per cent.; tannin about 6 per cent.; a reddish-brown altered tannin compound (sassafrid) about 9 per cent.; resin and starch. 


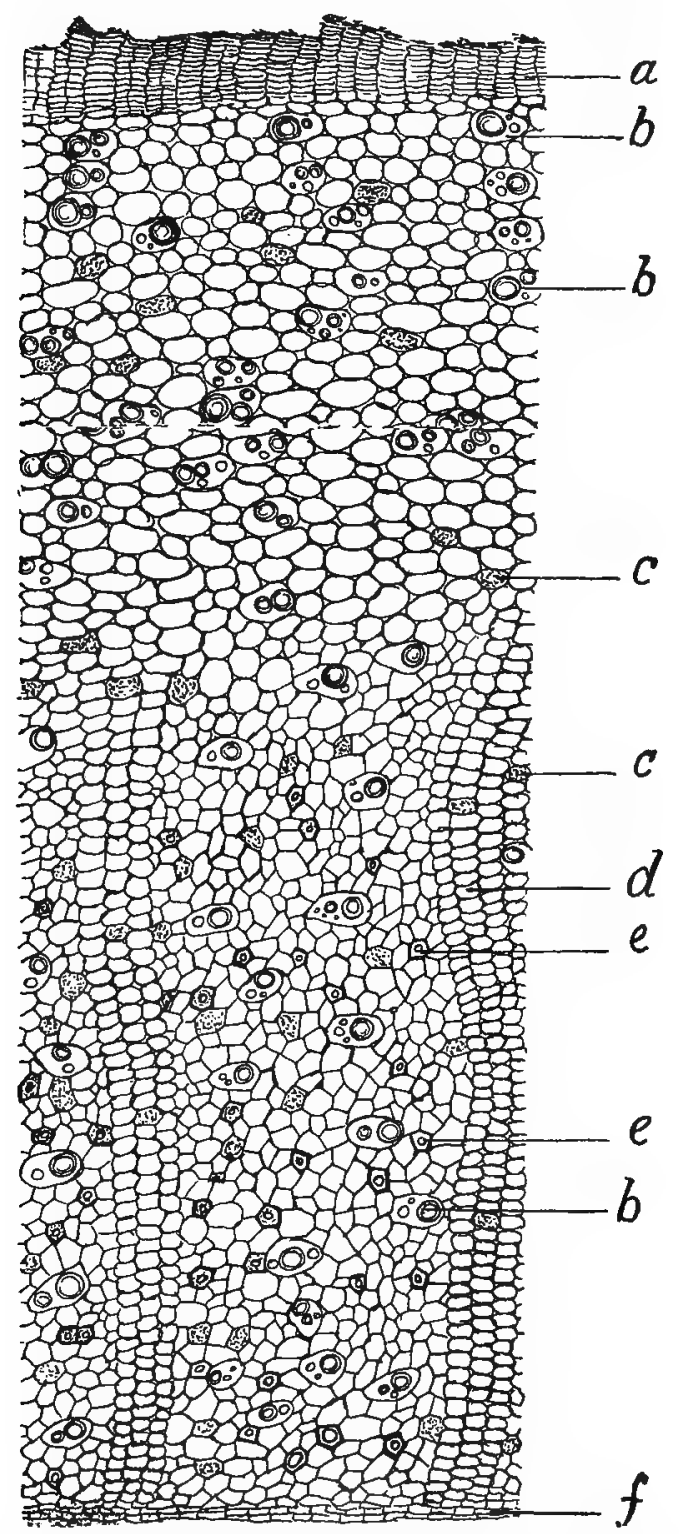

FIG. 23 . Transverse section of root bark of sassafras: a, cork; b, oil cells; c, tannin cells; $\mathrm{d}$, medullary rays; e, bast fibers; $f$, cambium.-After Bastin. 
The principal constituent of the volatile oil is safrol. The oil from the leaves differs essentially in composition from that of the root bark, containing linalool and geraniol.

Allied Plants.-Other plants of this family also yield a volatile oil containing safrol, as Beilschnicedia oppositifolia of Queensland and New South Wales; Mespilodaphne Sassafras and Nectandra Puchury-minor, both of Brazil.

QUILLAJA.-SOAP BARK.-The bark of Quillaja Saponaria (Fam. Rosaceæ), a tree (Fig. r49) indigenous to Chile and Pert. The bark is removed in large pieces, deprived of the periderm and dried (p. 290).

Description.-In flat pieces 25 to $90 \mathrm{~cm}$. long, io to $15 \mathrm{~cm}$. wide, 4 to $6 \mathrm{~mm}$. thick; outer surface light brown, longitudinally striate, with numerous crystals of calcium oxalate and occasional patches of the dark-brown periderm; inner surface yellowishbrown, finely wrinkled, with numerous crystals of calcium oxalate, and occasional circular depressions, conical projections or transverse channels; fracture uneven, coarsely fibrous, surface porous and with groups of white sclerenchymatous fibers; odor slight; taste acrid.

InNer Structure.-See Fig. 315.

Constituents.-The drug contains two amorphous glucosides amounting to about 9 per cent., which are closely related to saponin-one soluble in alcohol and known as quillajic acid, and the other nearly insoluble in alcohol and known as quillajasapotoxin; it also contains starch and about ro per cent. of calcium oxalate.

Substitutes.-A spurious Quillaja is being offered at the present time. The bark yields less saponin, is more brittle than the official bark and is covered with a thin, brownish layer.

QUERCUS.-WHITE OAK BARK.-The bark of Quercus alba (Fam. Cupuliferæ), a tree indigenous to the Eastern and Central United States and Canada. The bark is collected in spring from the branches and trunks of trees from ten to twenty-five years of age, and deprived of the periderm and dried (Fig. I35).

DESCRIPTION.-In flat, irregular, more or less oblong pieces 5 to $30 \mathrm{~cm}$. long, Io to $20 \mathrm{~mm}$. in diameter, 2 to $4 \mathrm{~mm}$. thick; outer surface light brown, longitudinally striate, with occasional patches 
of dark-brown periderm; inner surface yellowish-brown, coarsely striate and fissured longitudinally, and with detachable bast fibers; fracture uneven, coarsely fibrous, surface porous and dotted with

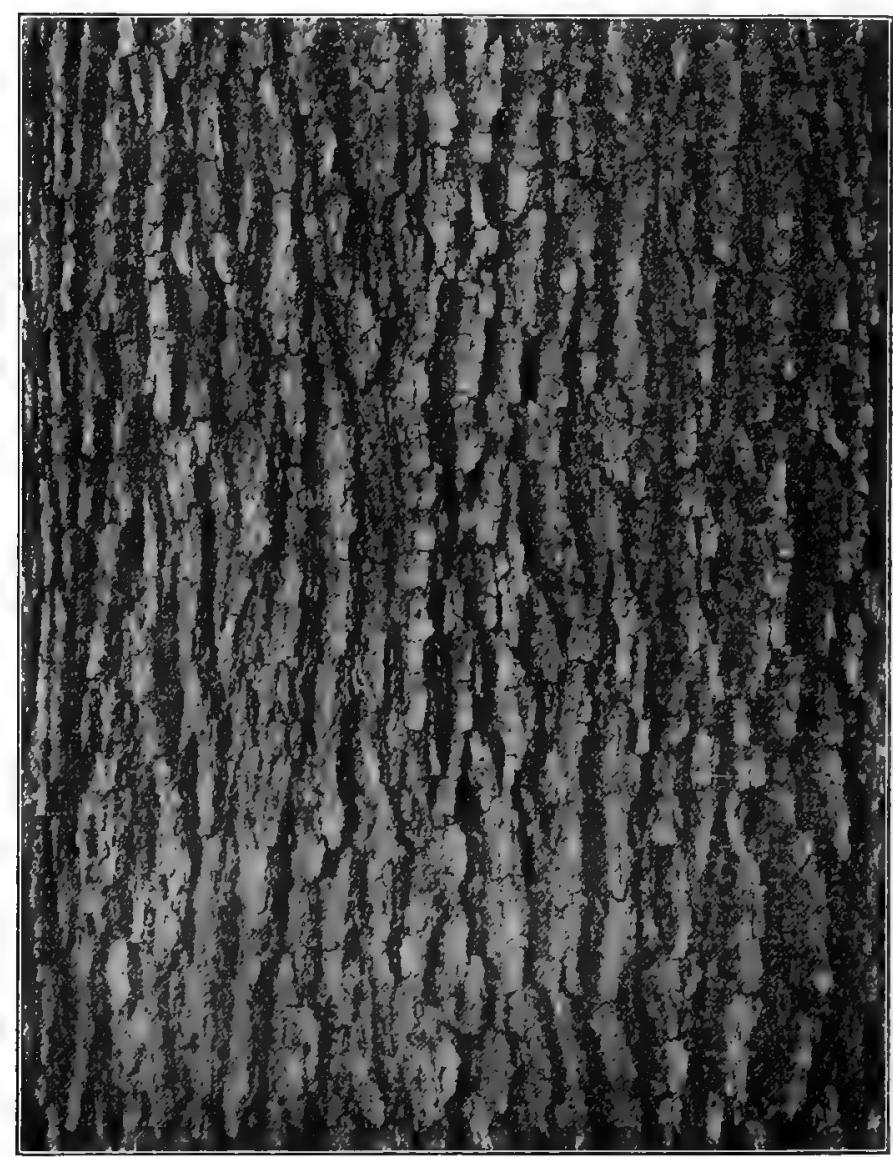

FIG. 237. White oak bark with the fissured corky layers (bork) still present.

groups of white sclerenchymatous cells and fibers; odor slight; taste astringent (Figs. $237 ; 300, B ; 301, A$ ).

Constituents.-Tannin about io per cent.; starch and calcium oxalate. The tannin yields upon sublimation a crystalline 
principle resembling pyrocatechin; upon fusion with potassium hydrate a phenol similar to protocatechuic acid is formed; dilute solutions are colored olive-brown with ferric chloride and possess a slight fluorescence; alkalies give a deep red color to the solutions which also have a decided blue fluorescence.

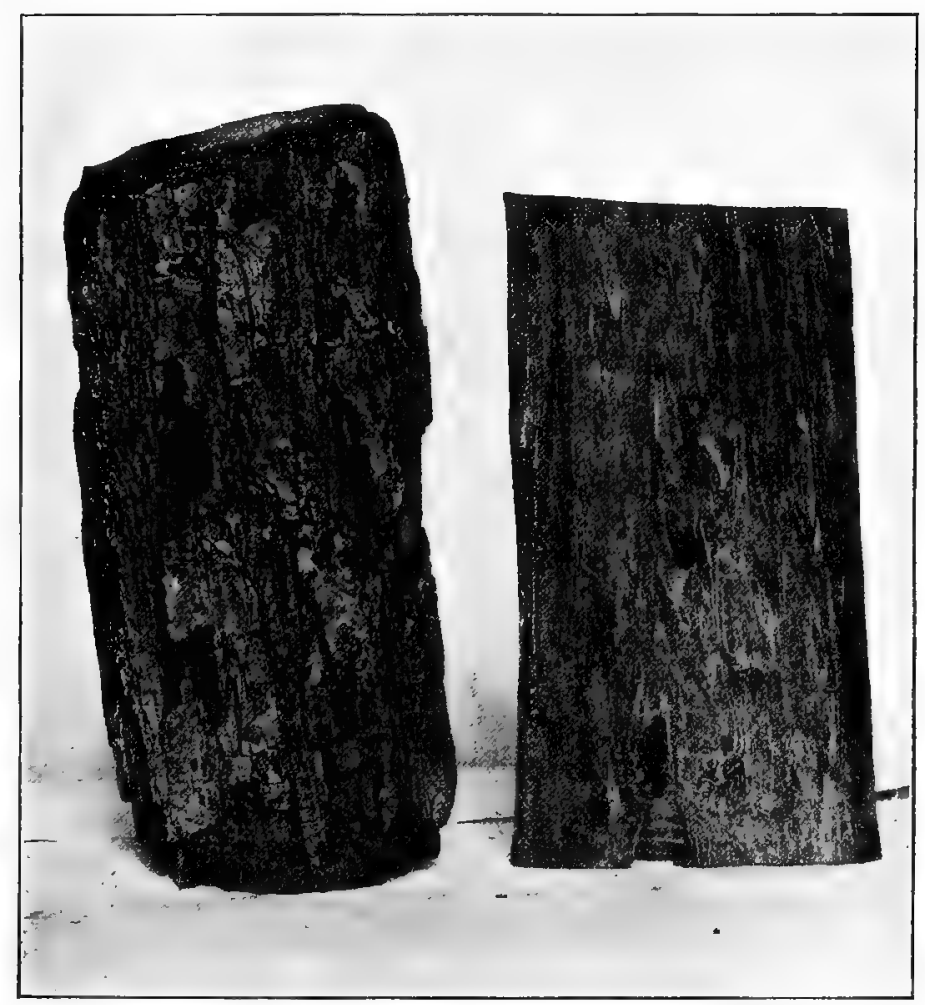

FIG. 238 . Elm bark, the specimen to the right with the periderm removed representing the official bark.

Allied Plants.-Quercus rober, indigenous to Europe, is the source of the bark used in England and Continental Europe; the bark closely resembles that of Quercus alba, but the periderm is not removed; it contains from to to i6 per cent. of tannin, besides gallic and ellagic acids. Quercus velutina, or black oak, yields the quercitron bark, which resembles that of Quercus alba 
but is reddish-brown, and tinges the saliva yellowish; it contains besides tannin a yellow glucosidal principle quercitrin, which yields quercetin, a yellow coloring principle.

ULMUS.-SLIPPERY-ELM BARK.-The bark of Ulmus fulva (Fam. L'lmaceæ), a tree indigenous to the Eastern and Central United States and Canada (p. 254). The bark is collected in spring (Fig. 238), deprived of the periderm and dried, the commercial article coming chiefly from Michigan.

Description.-In flat oblong pieces about $30 \mathrm{~cm}$. long, to to I $5 \mathrm{~cm}$. in diameter, 3 to $4 \mathrm{~mm}$. thick; outer surface light brown, longitudinally wrinkled and furrowed and with occasional darkbrown patches of periderm; inner surface yellowish or light brown, more or less uniformly wrinkled longitudinally; fracture fibrous, surface light brown, porous from large mucilage cells; odor slight, distinct; taste mucilaginous.

Inner Structure.-See Fig. 99, $C$ :

Constituents. - The principal constituent is mucilage; it also contains starch and calcium oxalate.

Allied Plants.-Ulmus campestris, or European elm, yields a bark which is dark brown, and contains, besides mucilage, a bitter principle and tannin.

QUASSIA.-QUASSIA WOOD.-The wood of Picrasma excelsa (Fam. Simarubacex), a tree indigenous to Jamaica and other islands of the West Indies (p. 309). The trees are felled and cut into billets. The latter are exported and afterward manufactured into "quassia cups," the shavings constituting the drug known as Jamaica Quassia. The market supply of this drug was at one time almost exclusively obtained from Quassia anara (Fam. Simarubacex), a small tree (Fig. 'I59) indigenous to Brazil and cultivated in Columbia, Panama, West Indies and other tropical countries (p. 309). The wood exported from Surinam is known as Surinam Quassia; this is the variety used in continental Europe and is now also official.

JAmaica Quass 1 -U Usually in raspings, light or bright yellow, medullary rays two to five cells wide in transverse section (Fig. 239, A), the cells containing tetragonal prisms or cryptocrystalline crystals of calcium oxalate; fracture fibrous; odor slight; taste bitter. 
Surinam Quassia usually occurs in small billets; the medullary rays are $\mathrm{I}$ to 2 cells wide in transverse section, and calcium oxalate crystals are wanting (Fig. 239, B).

Constituents.-Jamaica quassia contains from 0.05 to 0.75 per cent. of a bitter crystalline substance quassiin. This really consists of two crystalline bitter principles-a-picrasmin and

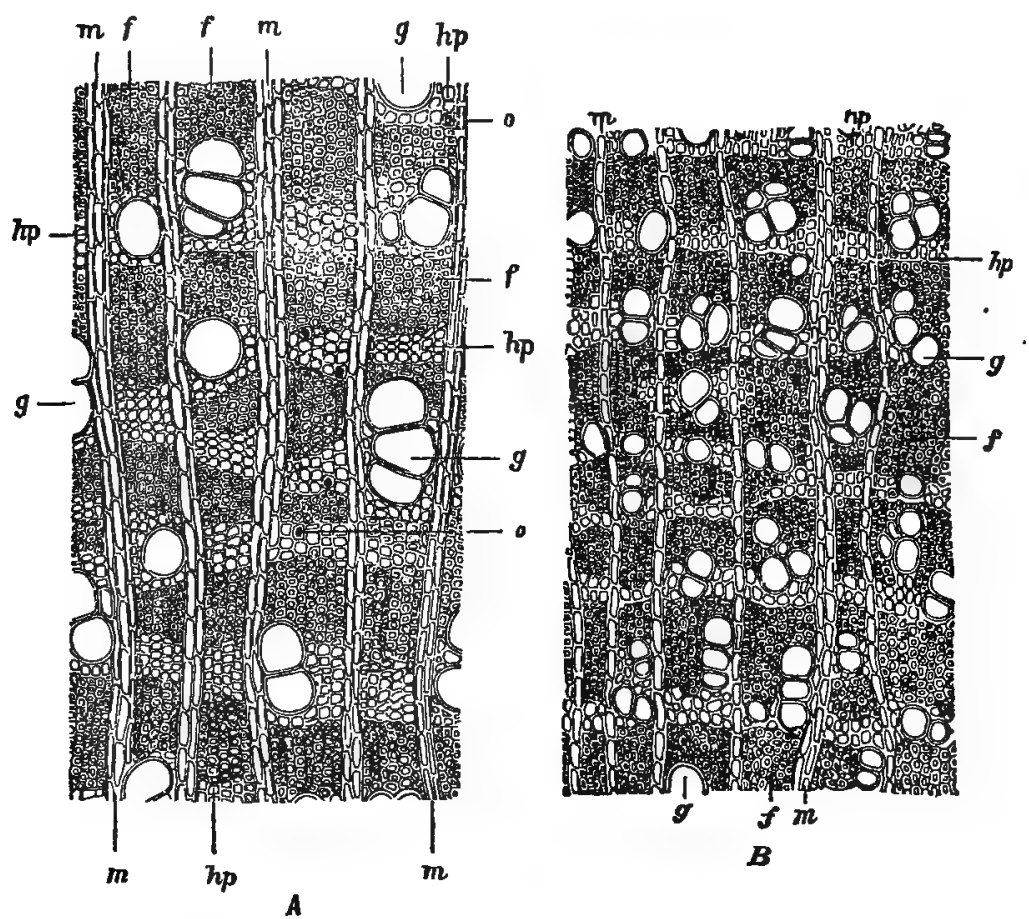

FIG. 239. A, transverse section of Jamaica quassia; B, transverse section of Surinam quassia: ' $g$, tracheæ; $f$, wood-fibers; hp, wood parenchyma; 0 , cells containing calcium oxalate; m, medullary rays.-After Meyer.

$\beta$-picrasmin. Jamaica Quassia also contains a crystalline alkaloidal principle which gives a blue fluorescence in acidified alcoholic solution.

Surinam quassia contains one or more bitter principles, which are related to the picrasmins of Jamaica quassia, and which are known as quassiins. 
Allied Drugs.-The barks of Picrasma excelsa and Quassia amara are used in medicine and probably contain similar principles to the wood. The Surinam bark occurs in thinner, light-colored pieces and is sometimes admixed with the powdered drug. It is determined by the large stone cells. The wood of Picrana quassioides quite closely resembles Jamaica Quassia in general appearance, microscopical structure and chemical constituents. Bitter principles are also found in other species of Picrasma and Quassia, and in the following genera: Samadera, Simaruba, Bytteria and Ailanthus. An allied bitter principle and an alkaloid are found in CASCARA Amarga or Honduras Bark, which is derived from Picrana Vellozii, of Southern Brazil.

Simaruba is the bark of the root of Simaruba amara and $S$. officinalis, plants growing in Guiana. The bark comes in flat or somewhat curved pieces about I M. long, $7 \mathrm{~cm}$. wide, 3 to $5 \mathrm{~mm}$. thick; the outer corky surface is bluish-brown or dark brown, the periderm, however, being frequently removed, when it is grayishor yellowish-brown; the fracture is tough-fibrous, and the surface shows the presence of light yellow stone cells. The taste is very bitter. Simaruba contains a bitter principle resembling quassiin; a resin; a volatile oil with an odor of benzoin; gallic acid, and calcium oxalate and malate.

HÆMATOXYLON.-LOGWOOD.-The heartwood of Hcematorylon campechianum (Fam. Leguminosæ), a tree indigenous to Central America, and naturalized in the West Indies. Much of the commercial logwood being used for dyeing is allowed to ferment, and as a result the chips become dark red and have a greenish, metallic lustre, but it is the unfermented wood that should be used for medicinal purposes (p. 295).

DeSCRIPTION.-Usually in small chips, externally reddishbrown, freshly cut surface dark yellowish-red, in transverse section slightly radiate and with numerous, alternate, yellowish and reddish concentric rings, medullary rays four cells wide; fracture hard, fibrous; odor slight; taste sweet, astringent; the wood imparting to water a violet or wine color.

Constituents.-Hæmatoxylin, io to i2 per cent., which occurs in colorless or pale yellow needles or prisms, tastes like glycyrrhizin, becomes red on exposure to light and is soluble in 
water and alcohol. The solutions are cclored with the alkalies, purplish-red, then purple and finally deep red. The compound formed with ammonia yields hæmatein, a dark violet, crystalline principle having a green, metallic lustre and which is supposed to form in the fermented wood used by dyers. Logwood also contains volatile oil, resin, tannin and calcium oxalate.

Allied Plants.-The woods of certain species of Casalpinia also contain red coloring principles and furnish the red woods of tropical America. BRAzIL WOOD is obtained from C. echinata and contains the principle known as brasilin, which is colorless when first extracted but assumes a red color on exposure; SAPPAM or false sandal wood is obtained from C. Sappam of Farther India. Red coloring principles are also found in other species of Casalpinia and in a number of other genera of the Leguminosæ as well.

SANTALUM RUBRUM.-RED SAUNDERS.-The heartwood of Pterocarpus santalinus (Fam. Leguminosæ), a tree ( $\mathrm{p}$. 295) indigenous to the southern part of Farther India, and cultivated in the Southern Philippines, Ceylon and Southern India, the chief supplies coming from Madras.

DESCRIPTION.-Usually in small chips or coarse powder, red or brownish-red, in transverse section slightly radiate, with numerous alternate lighter and darker concentric rings, medullary rays one cell wide ; fracture hard, fibrous; inodorous ; taste slight.

Constituents.-A coloring principle santalin (santalic acid), which occurs in red needles that are insoluble in water, soluble in alcohol. forming a deep red solution which is colored violet with solutions of the alkalies. It also contains tannin and several colorless crystalline principles.

Allied Plants. - The African sandal wood or barwood is obtained from $P$. santalinoides of tropical West Africa. Camwood or African red-wood (obtained from Baphia nitida, in Sierra Leone) is also valued on account of its red coloring principle.

SASSAFRAS MEDULLA.-SASSAFRAS PITH.-The pith of young stems and branches of Sassafras officinale (Fam. Lauraceæ), a tree (Fig. 73) indigenous to Eastern North America (p. 277). The pith is collected late in autumn, after frost, and dried. 
Description.-Cylindrical, cut longitudinally into pieces 2 to Io $\mathrm{cm}$. long, about 5 to $7 \mathrm{~mm}$. in diameter, or in irregular, somewhat curved or angled pieces; very light; externally whitish or light brown, occasionally with small fragments of wood adhering; consisting for the most part of parenchyma cells with thin walls having numerous simple pores, and swelling perceptibly in water; fracture short; slight odor of sassafras; taste mucilaginous.

Constituen'ss. - The principle constituent is the mucilage, which is not precipitated by alcohol; it also contains a trace of volatile oil.

\section{FLOWERS.}

In quite a number of plants, particularly the Labiatæ and Compositæ, principles having medicinal and other properties occur in relatively large amount in the flowers. These principles are, as a rule, more or less volatile and aromatic, many of them being used in perfumery and for flavoring, as well as for medicinal purposes.

\section{KEY FOR THE STUDY OF FLOWERS.}

\section{Flower Buds.}

With a stalk and globular upper portion........... Caryophyllus Small, ellipsoidal, composite heads............... Santonica

II. Expanded Flowers.

I. Flower heads.

A. Tubular and ligulate forets.

Ligulate florets, bright yellow............Arnicæ Flores

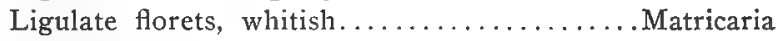

B. Chiefly ligulate florcts.

Whitish globular heads..................Anthemis

2. Ligulate florets only.

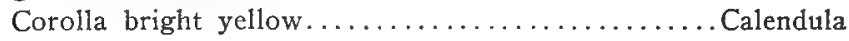

\section{Entire Inflorescence.}

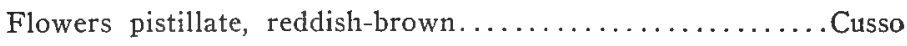

\section{Part of Flower.}

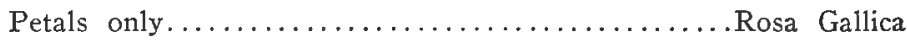

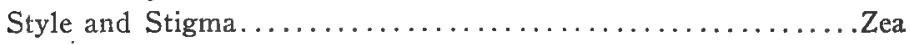


CARYOPHYLLUS.-CLOVES.-The flower-buds of Jambosa Caryophyllus (Syn. Eugenia Caryophyllata and E. aromatica) (Fam. Myrtaceæ), an evergreen-tree indigenous to the Molucca Islands, where it is also cultivated, as well as in Zanzibar, Ceylon and Java (p. 346). The flower-buds are collected, dried in the sun or artificially, the color changing from a crimson to a brownish. The chief commercial supplies come from Amboyna, Penang and Zanzibar, the former two varieties being preferred.

DESCRIPTION.-About I5 $\mathrm{mm}$. long, 3 to $6 \mathrm{~mm}$. in diameter, more or less cylindrical, dark brown, calyx epigynous (Fig 83 , $B$ ), with four incurved teeth about $3 \mathrm{~mm}$. long, surmounted by a light brown globular portion consisting of four petals which are imbricated, punctate and alternate with the calyx teeth; stamens numerous, crowded and incurved, style one, ovary 2 -locular, with numerous ovules; odor and taste strongly aromatic.

Cloves should not contain more than 5 per cent. of clove stems or yield more than 8 per cent. of ash; nor yield less than Io per cent. of volatile ether extract or I 2 per cent. of gallotannic acid.

Inner Structure.-See Fig. 3 I 2.

Constituents. - The chief constituent is the volatile oil, which occurs to the extent of 15 to 20 per cent., and consists of caryophyllene and eugenol, the latter constituting 50 to 85 per cent. of the oil. The darkening of old oil of cloves is supposed to be due to furfurol, an aldehyde formed on decomposition of some of the carbohydrates and albuminoids. Cloves also contain an odorless, tasteless principle caryophyllin, which crystallizes in silky needles and yields upon the addition of fuming nitric acid crystals of caryophyllinic acid; vanillin; eugenin (isomeric with ettgenol or eugenic acid), which resembles caryophyllin but becomes reddish with nitric acid; gallotannic acid to to I3 per cent.; calcium oxalate, and 5 to 7 per cent. of ash.

Adulterants.-Clove stalks are less aromatic and yield from 4 to 7 per cent. of volatile oil. The so-called mother of cloves is the nearly ripe fruit of Jambosa Caryophyllits or clove tree, which furnishes cloves. The fruit is an ovoid, brownish berry about 25 $\mathrm{mm}$. long; it is less aromatic than cloves and contains large, branching stone cells, or short bast fibers, and numerous pearshaped or truncated starch grains from io to $40 \mu$ in diameter. 
It is stated that artificial cloves have been made by using starch, gum and oil of cloves; or from dough and clove powder. These are easily distinguished by adding the spurious article to water, when the compound disintegrates.
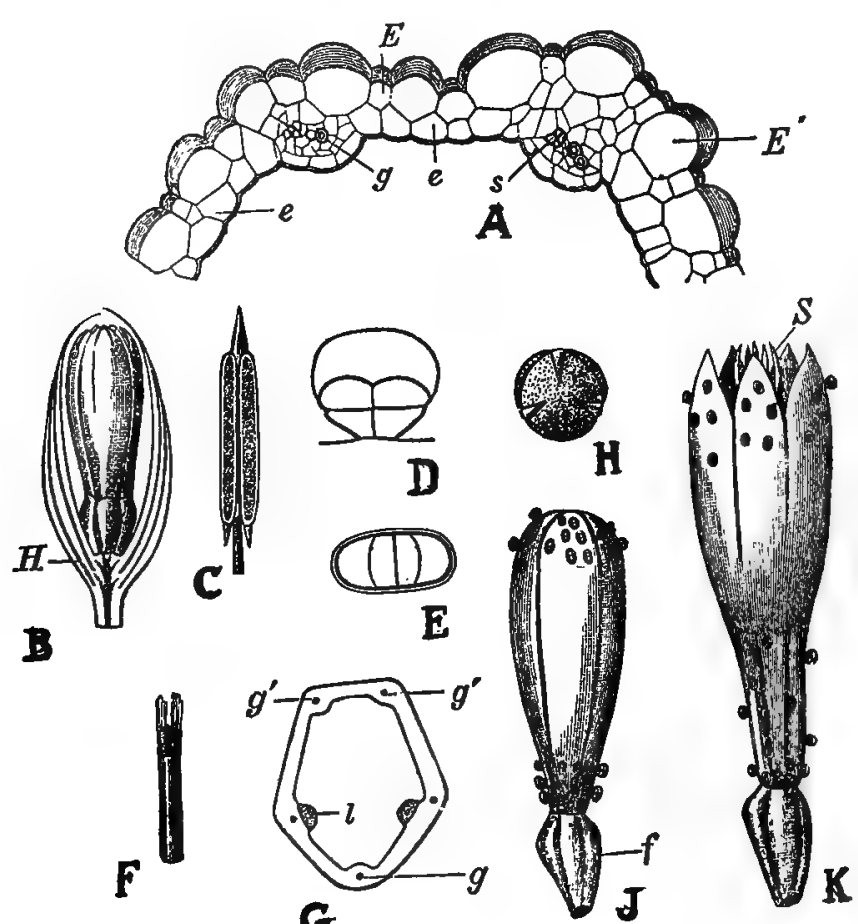

FIG. 240. Santonica. A, transverse section of the wall of the ovary: E, E1, e, epidermal cells; $g$, tracheæ; $s$, sieve. $B$, longitudinal section through a flower bud showing involucre $(\mathrm{H})$ : C, stamen; D, glandular hair of a bud-scale; E, glandular hair as viewed from above; $F$, style; $G$, transverse section of the wall of the ovary showing tracheæ $\left(g, g^{1}\right)$ and conducting cells (1); $H$, pollen grain; $J$, flower bud showing ovary ( $\left.\mathrm{f}\right)$; $\mathrm{K}$, expanded flower showing stamens (S).-After Meyer.

SANTONICA.-LEVANT WORMSEED.--The flowerhearls of Artemisia Cina (Fam. Composita), a small shrub (p. 397) indigenous to the deserts in Northern Turkestan. The flower-heads are collected in July and August before they expand, and carefully dried and preserved. 
Description.-Oblong or ellipsoidal, 2 to $4 \mathrm{~mm}$. long, I to I.5 $\mathrm{mm}$. in cliameter; involucre ovoid, consisting of twelve to eighteen closely imbricated, ovate or ovate-lanceolate, glandular, somewhat shiny bracts, about $2 \mathrm{~mm}$. long, with a yellowish-green or greenish-brown middle portion and whitish margin; torus flat, naked, with three to six unexpanded, perfect tubular flowers about $1.5 \mathrm{~mm}$. long and completely inclosed by the upper bracts; ovary oblong; pappus wanting; odor distinct; taste aromatic.

Inner Structure.-See-Fig. 240.

Constituents.-A crystalline neutral principle, santonin, which occurs to the extent of 2 to 3.5 per cent. just before the expansion of the flowers; volatile oil about 2 per cent., consisting chiefly of cineol; a crystalline principle artemisin, which is apparently oxysantonin; and a resin. Santonin crystallizes in rhombic prisms, becoming yellow on exposure to light : it is nearly insoluble in water, sparingly soluble in alcohol; and colored red by alcoholic solutions of the alkalies.

Allied Plants.-Artemisia gallica, a plant abundant in France, contains santonin and about I per cent. of a volatile oil. ARNICA.-ARNICA FLOWERS.-The dried, expanded flower-heads of Amica montana (Fam. Compositæ), a perennial herb (p. 394) indigenous to Central Europe, and growing in the mountains of Switzerland, Asia and Western North America. In Germany, on account of the involucre and torus being injured by the larva of the insect Trypeta arniciziora, these parts are removed and the florets alone used.

Description.-Sub-globulat or truncate-conical, about I5 $\mathrm{mm}$. in diameter; involucre campanulate, bracts twenty to twentyfour in two rows, linear-lanceolate, dark green, pubescent, glandular; torus solid, slightly convex, deeply pitted, bristly hairy; ray or ligulate florets (Fig. 24I, B), fourteen to twenty, about $2 \mathrm{~cm}$. long, bright yellow, pistillate, corolla 3-toothed, 7- to I2-veined, very pubescent and glandular below, ovary about $4 \mathrm{~mm}$. long, erect, pubescent and glandular, pappus consisting of a single row of about thirty rough bristles; clisk or tubular florets (Fig. 24I, $C)$. forty or fifty, about I7 mm. long, perfect, bright yellow, corolla 5 -toothed, very glandular and pubescent below, ovary about $6 \mathrm{~mm}$. long, glandular and pubescent; akene spindle-shaped, dark 
brown, finely striate, glandular-pubescent and surmounted by a pappus of white barbed bristles about $7 \mathrm{~mm}$. long; odor distinct; taste bitter and acrid.

Constituents.-A bitter crystalline principle, arnicin, about 4 per cent.; and volatile oil 0.04 to 0.07 per cent, consisting of a butyraceous substance.

Adulterants.-Arnica flowers are not infrequently adulterated with the flowers of various other Compositæ, or even entirely substituted by them; of these may be mentioned the flowers of Calendula officinalis (see Calendtula); species of Inula, the akenes

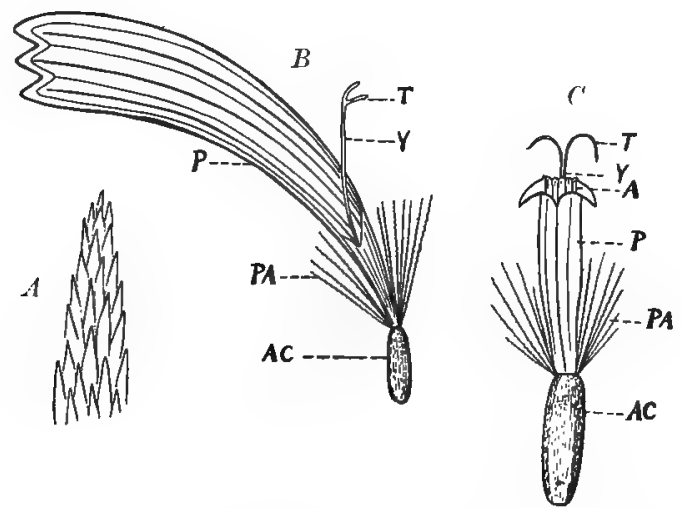

FIG. 24r. Arnica florets: A, overlapping hairs of pappus considerably magnified; B, ray floret; $\mathrm{C}$, disk floret. $\mathrm{AC}$, inferior ovary becoming in fruit an akene; $\mathrm{PA}$, pappus; P, corolla; A, anthers; $Y$, style; T, stigma.

of which are glabrous; and Tragopogon pratensis, the ligulate florets of which are 5 -toothed at the apex.

Allied Drugs.-The rhizome and roots of Arnica montana are official in a number of pharmacopœias. The rhizome is oblique, about $5 \mathrm{~cm}$. long and $3 \mathrm{~mm}$. thick, the upper portion with buds or stem-remnants, externally dark brown, longitudinally wrinkled and irregularly annulate, with numerous light brown, fragile roots which may be Io $\mathrm{cm}$. long; fracture short, bark rather thick, with a single circle of large resin canals. The drug contains the bitter principle arnicin, which is also found in the flowers; and a volatile oil, 0.5 to 0.1 per cent., with a radish-like odor and consisting of hydrothymoquinone methyl ether, phloryl 
methyl ether, phloryl isobutyrate and formic and butyric acids. Arnica rhizome also contains about ro per cent. of inulin.
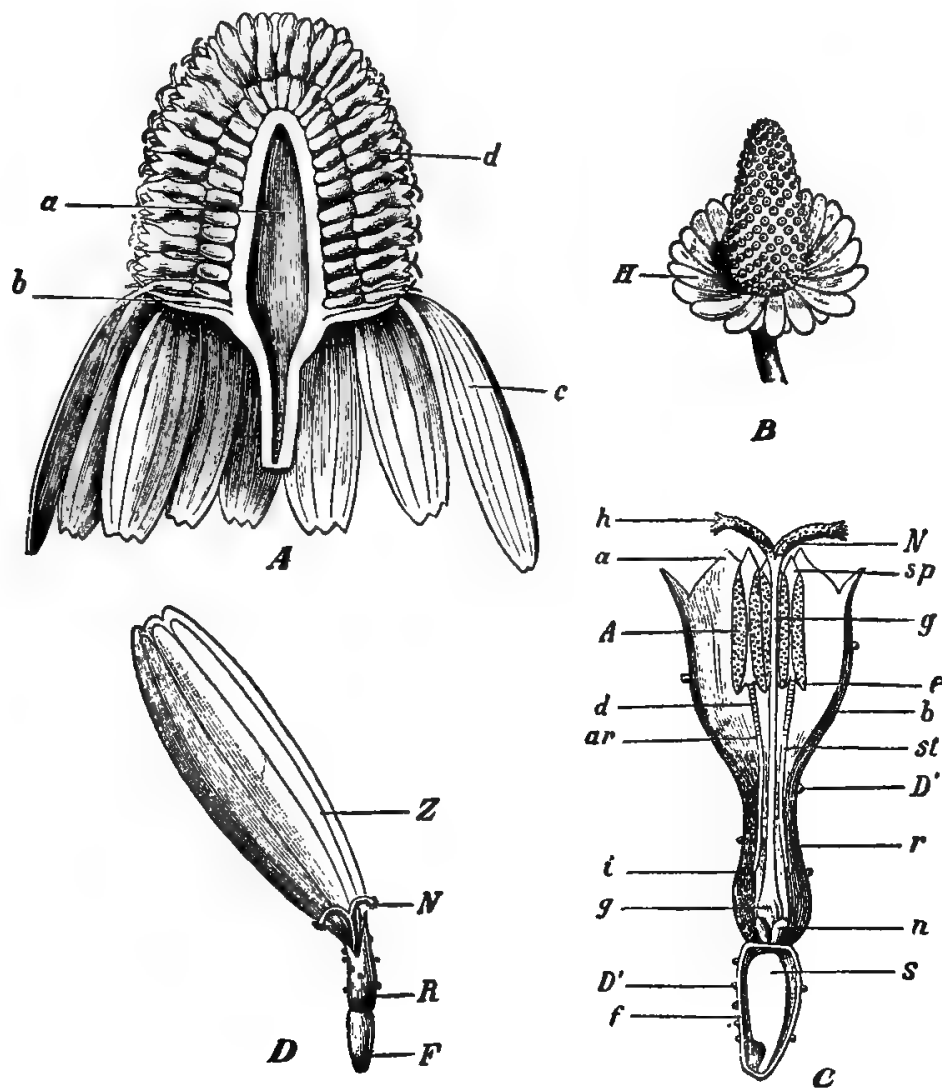

Fig. 242. Matricaria: A, longitudinal section of head showing torus (a), involucre (b), ray florets (c) and disk florets (d). B, head with the florets removed, showing the long conical torus and the involucre $(H)$. C, tubular floret showing the ovary $(f)$ with glandular hairs $\left(D^{1}\right)$ and the embryo $(S)$, which develops after fertilization; style $(g)$ and bifid stigma (N), the surface of which is covered with hairs; $n$, nectaries; $b$, corolla tube with narrow lobes (a); stamens showing filaments (st), united anthers (A) and apex of connective (sp). $D$, ligulate floret showing ovary $(F)$, and bifid stigma $(N)$; tube of corolla $(R)$ and the upper ligulate portion (Z).-After Meyer.

MATRICARIA.-WILD OR GERMAN CHAMOMILE.The flower-heads of Matricaria Chamomilla (Fam. Compositæ), an annual herb (p. 394), indigenous to Europe and Western Asia, and naturalized in Australia and certain parts of the United States, 
including New York and Pennsylvania. The flower-heads are collected, when they are mature or expanded, from wild plants.

Description.-Rounded, conical, 3 to Io $\mathrm{mm}$. broad (Fig. 242 ) ; peduncle 0.5 to $3.5 \mathrm{~cm}$. long, nearly glabrous; involucre hemispherical, scales twenty to thirty, imbricated, oblanceolate, the middle portion brownish, margin whitish, pubescent; torus ovoid, becoming conical and hollow, deeply pitted, naked, 3 to 5 $\mathrm{mm}$. high, about $1.5 \mathrm{~mm}$. in diameter; ray or ligulate florets (Fig. 242, D), twelve to eighteen, pistillate, about $12 \mathrm{~mm}$. long, corolla whitc, 3-toothed, 4-veined; disk or tubular flowers (Fig. 242, C), numerous, yellowish, perfect, oblong, small, somewhat glandlular, about $2.5 \mathrm{~mm}$. long; akenes somewhat obovoid, about $0.5 \mathrm{~mm}$. long; faintly 3 - to 5-ribbed; pappus none, or forming a membranous crown; odor distinct; taste aromatic and bitter.

Constituents.-Volatile oil, about 0.25 per cent., of a viscid consistency and an intense blue color. The color is due to azulene, a principle similar to that found in the volatile oils derived from Absinthium, Achillea (yarrow), Sumbul and Valerian. The flowers are also said to contain a bitter principle anthemic acid, which forms colorless, silky needles soluble in water and alcohol, and anthemidin, which separates from the alcoholic solution in the form of a tasteless crystalline compound. Malic acid and tannin are also present in the drug.

AdULTERAnTs.-Matricaria is not infrequently adulterated with the flower-heads of other Compositæ, as Anthcmis arvensis. In these, the peduncle is pubescent; the receptacle solid and conical; involucral scales lanceolate; chaff-scales lanceolate or lanceolate-acuminate, about $4 \mathrm{~mm}$. long. In Anthemis Cotula the peduncles are slightly pubescent and the ligulate flowers neutral.

ANTHEMIS.-ROMAN OR ENGLISH CHAMOMILE.The expanded flower-heads of Anthemis nobilis (Fam. Compositæ), a perennial herb indigenous to Southern and Western Europe and cultivated in Belgium, England, France, Germany, Hungary and the United States, and naturalized from Rhode Island to Michigan and south to Delaware (p. 393). The flowers are collected from cultivated plants, and dried by artificial means, the principal supplies coming from Belgium, France and Saxony. 
Description.-Globular, compressed, 1.5 to $2 \mathrm{~cm}$. in diameter; involucre hemispherical, with two or three rows of imbricated, nearly equal, somewhat elliptical, very pubescent scales, having a greenish middle portion and a yellowish margin; torus conical or convex, solid, 3 to $4 \mathrm{~mm}$. high, occasionally hollow, and sometimes containing the larvæ of an insect; chaff-scales resembling the involucral scales, about $2 \mathrm{~mm}$. long; ligulate florets numerous, 6 to Io $\mathrm{mm}$. long, corolla white, 3 -toothed, 4-nerved, ovary about I mm. long, glandular, style slender, stigma bi-cleft; tubular florets few or none, lemon-yellow, perfect; akene oblong, pappus none; odor distinct; taste aromatic and bitter.

Construtuents.-Volatile oil, which is bluish-green when fresh, 0.8 to I per cent.; a bitter crystalline glucoside anthemic acid (see Matricaria) ; 5.25 per cent. of resin; 1.50 per cent. of a bitter crystalline wax; and tannin. The volatile oil consists principally of the isobutyl, amyl and hexyl esters of butyric, angelic and tiglic acids, and anthemol, an isomer of camphor.

CALENDULA.-MARIGOLD.-The ligulate florets of $\mathrm{Cal}$ endula officinalis (Fam. Compositæ), an annul herb indigenous to Southern Europe and the Levant, and widlely cultivated as a garden plant. The flowers are collected when fully expanded, and dried (p. 394).

DESCRIPTION.-Florets usually without the ovary; corolla bright yellow, 15 to $25 \mathrm{~mm}$. long, I- to 3 -toothed, 4 - or 5 -veined, margin nearly entire, tube sometimes inclosing the remains of a filiform style and bifid stigma, pubescent on the outer surface; ovary oblong, about $0.5 \mathrm{~mm}$. long, pubescent; odor distinct; taste faintly saline, slightly bitter.

Constituents.-Volatile oil; an amorphous bitter principle; a gummy substance, calendulin, which forms with water a transparent mucilage that is not precipitated by tannin; and resin.

Aldied Plants. - The florets of various Compositæ are sometimes admixed with or substituted for Calendula, of which the following may be mentioned together with their principal distinguishing characteristics: The ligulate corolla of Taraxacum officinale is 5 -toothed; the ligulate corolla of Amica montana is 7 - to I2-veined; the ligulate corolla of Tussilago Farfara is linear, about I $3 \mathrm{~mm}$. long and about $0.3 \mathrm{~mm}$. broad, apex acute, entire; 
and the ray florets of Tagetes patula are somewhat spatulate, about $20 \mathrm{~mm}$. long and ro $\mathrm{mm}$. wide, sometimes marked with darker stripes, and have undulate margins.

CUSSO.-KOUSSO, BRAYERA.-The pistillate flowers of Hagenia abyssinica (Fam. Rosaceæ), a tree indigenous to

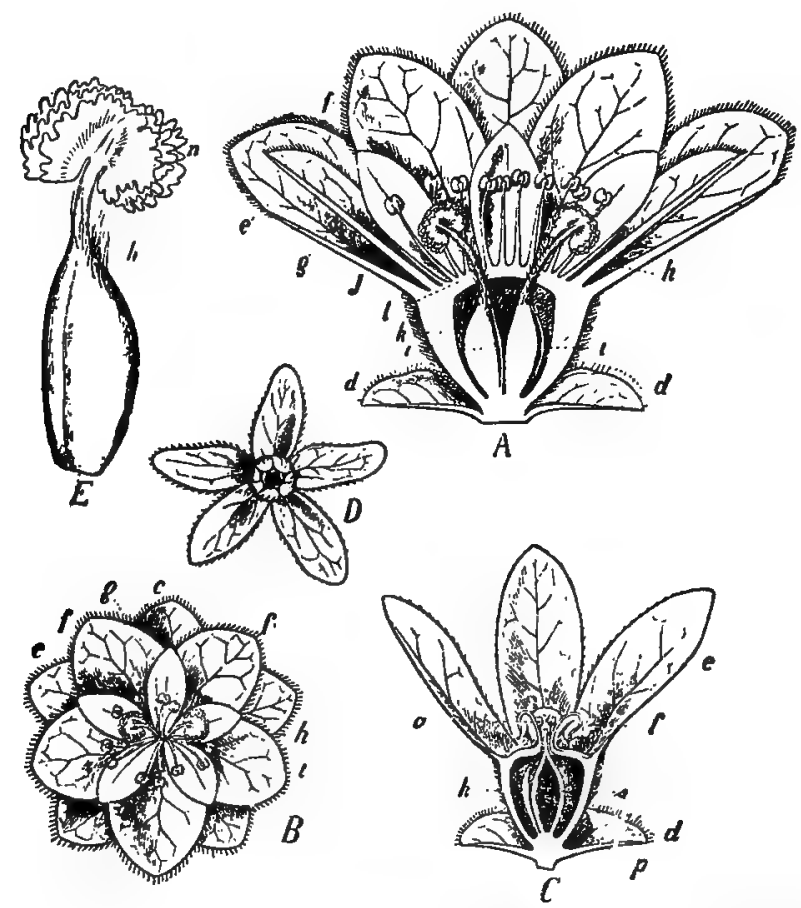

FIg. 243. Cusso: A, longitudinal section through an expanded pistillate flower showing bracts (d), outer series of sepals (e), inner series of sepals (f), petals (g), perianth tube $(\mathrm{k})$, sterile stamens (h), pistil (i). B, mature flower viewed from above and showing the relation of sepals and petals. C flower just before the maturing of the fruit showing pericarp (p), seed (s). D, mature pistillate flower as seen from above. E, pistil showing cylindrical ovary, slender style with hairs $(h)$ and large, slightly lobed stigma.-After Meyer.

Northeastern Africa, and cultivated in Abyssinia. The entire panicles (Figs. I50, 243) are collected after fertilization and dried in the sun; the flowers are sometimes stripped from the panicles, or the panicles are made into rolls (p. 290).

DESCRIPTION.-In more or less cylindrical rolls about $30 \mathrm{~cm}$. long and about $5 \mathrm{~cm}$. in diameter; branches cylindrical, flattened, 
about $3 \mathrm{~mm}$. in diameter, longitudinally furrowed or wrinkled, internodes about $15 \mathrm{~mm}$. long, externally light brown, tomentose, glandular, internally, cork yellowish-brown, fibrovascular bundles in distinct wedges, bast and wood fibers yellow, distinct, pith large, yellowish-brown; flowers (Fig. 243) subtended by two ovate, reddish, pubescent and glandular bracts, pedicel short, calyx turbinate, pubescent below, consisting of two alternate whorls of four or five obovate or oblanceolate sepals, the outer ones Io to I2 $\mathrm{mm}$. long, obtuse, entire, purplish veined, persistent and becoming much elongated in the fruit, the inner about 3 to 4 $\mathrm{mm}$. long, becoming shriveled and bent over the young fruit; carpels two, ovary about I $\mathrm{mm}$. long, the upper portion very pubescent, styles exserted, about as long as the ovary, stigma large, compressed, with prominent papillæ; fruit an ovoid akene, about $2 \mathrm{~mm}$. in diameter, inclosed by the remains of the calyx; odor slight; taste bitter and acrid.

Constituents. - The active principle appears to be an amorphous substance cosotoxin; several other principles have been isolated, but their real nature and properties have not been fully determined; the drug also contains about 3 per cent. of an inactive crystalline principle cosin (koussein or brayerin), which is bitter and acrid, and sparingly soluble in water but soluble in alcohol; a crystalline principle which on hydrolysis yields isobutyric acid; about 6 per cent. of a resinous principle; volatile oil ; tannin about 24 per cent., and about 5 per cent. of ash.

Adulterants.-Sometimes the flowers are stripped from the panicles and sold as such, when the drug is known as "loose cusso." In this condition they are likely to be admixed with the staminate flowers, which, with their numerous stamens, are readily distinguishable and inferior in quality.

ROSA GALLICA.-RED ROSE.-The petals of Rosa gallica (Fam. Rosacex), a shrub (p. 289) indigenous to Southern Europe and probably Western Asia, and extensively cultivated in all parts of the world. The petals are obtained from cultivated plants before the expansion of the flower, the lower clawed portion usually being removed; they are used fresh or are carefully dried and preserved. The chief supply of the drug is from the south of France. 
DESCRIPTION.-Imbricated, numerous, usually in small cones; petals broadly ovate, the upper part rose-colored and retuse, the lower part brownish-red, more or less rounded, acute or truncate, with numerous papillæ and fine longitudinal veins; texture velvety; odor agreeable; taste astringent and slightly bitter.

Constituents.-Volatile oil in small amount; a yellow, crystalline glucoside quercitrin, which yields, on decomposition, quercetin; tannin and gallic acid. The coloring principle is soluble in water and alcohol and gives a deep yellowish-red color with acids; a green color changing to brown with alkalies; purple or violet with potassium alum or iodine solutions; and a deep blue with ferrous or ferric salts.

Allied Plants. - The petals of Rosa centifolia are collected after the expansion of the flowers and dried; they are brownish and not so fragrant as those of Rosa gallica. The flowers of cultivated plants of Rosa damascena yield the commercial volatile oil of rose (p. 289).

ZEA.-CORN SILK.-The fresh styles and stigmas of Zea Mays (Fam. Graminex), an annual plant indigenous to tropical America and known only in cultivation, being cultivated widely in nearly all tropical, sub-tropical and temperate regions (p. 228 ).

DESCRIPTION.-In matted masses consisting of several hundred or more slender, very delicate, thread-like, purplish-red to greenish-white, more or less translucent styles; Io to $20 \mathrm{~cm}$. long; stigmas bifid, slender, 2 to $3 \mathrm{~mm}$. long; slightly odorous; taste insipid.

When viewed under the microscope the upper part of the styles and the stigmas are seen to have numerous multicellular, non-glandular hairs from 0.2 to $0.5 \mathrm{~mm}$. long, among which are numerous spinose pollen grains io to $5 \mu$ in diameter.

Constituents.-Not much is known concerning the constituents of this drug, and the analyses have been chiefly of the dried commercial article. The fresh drug contains about 83 per cent. of water. The dried drug contains a volatile alkaloid; two resins about 5.5 per cent.; a crystalline principle, maizenic acid, about I.25 per cent.; fixed oil, 5.25 per cent.; sugar; ash, about I 2 per cent. The coloring principle of the fresh drug is soluble in water and alcohol and is changed to yellowish-red with acids, green 
with alkalies, purple with potassium alum, and olive-green changing to greenish-brown with ferric chloride.

\section{FRUITS,}

The fruits of a large number of plants are used in medicine; these vary greatly, not only in their medicinal properties, but also in their botanical origin. The active principles of fruits vary according to their stage of development, so that fruits which contain relatively large amounts of poisonous principles when green or immature, may be quite free therefrom and even edible when they are ripe. It is for this reason that by far the larger number of medicinal fruits are collected in the fully developed but unripe condition. (See Classification of Fruits, p. I5I.)

\section{KEY FOR THE STUDY OF FRUITS.}

\section{Entire Fruits.}

I. Not more than Io $\mathrm{mm}$. long (exclusive of the stalk).

A. Cremocarps.

a. Hairy.

Slender pedicel, 4 to ro $\mathrm{mm}$. long............ Anisum

b. Nearly smooth.

a Mericarps more or less united.

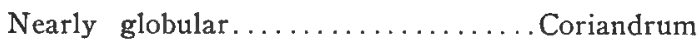

Oblong, pedicel, 3 to $10 \mathrm{~mm}$. long...... Fœniculum

$\beta$ Mericarps usually separate.

Dark brown, odor and taste aromatic...... Carum

Grayish-green, odor peculiar........... Conium

B. Dry drupes.

a. Hairy.

Pericarp reddish................ Rhus Glabra

b. Not hairy.

a Coarsely reticulate.

Slender pedicels, 5 to $7 \mathrm{~mm}$. long........ Cubeba

Stalk wanting..................... Piper

$\beta$ Not reticulate.

Inferior drupe................... Pimenta

C. Caryopsis or Grain................................ 
I. Entire Fruits.-Continued.

2. Between ro and $50 \mathrm{~mm}$. long.

A. Drupes.

Epicarp thin and wrinkled; sarcocarp sweet........Prunum

Epicarp coriaceous, nearly smooth; sarcocarp acrid... Sabal B. Not drupes.

Berry...$\ldots \ldots \ldots \ldots \ldots \ldots \ldots \ldots$. Capsicum

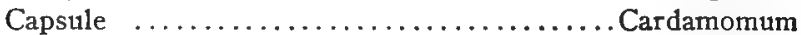

Strobile ............................mulus

3. More than $50 \mathrm{~mm}$. long.

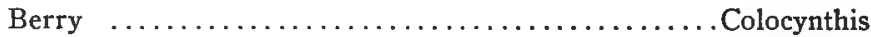

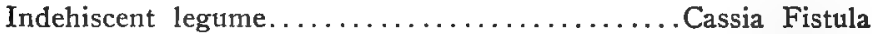

Pod ................................ Vanilla

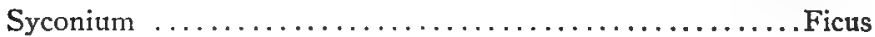

II. Parts of Fruits.

1. Outer rind.

A. Fresh.

From sweet oranges............Aurantii Dulcis Cortex

From lemons....................... Limonis Cortex

B. Dried.

In quarters or in ribbon-like bands. Aurantii Amari Cortex

2. Pulp.

Blackish-brown masses or cakes............... Tamarindus

3. Glandular Hairs.

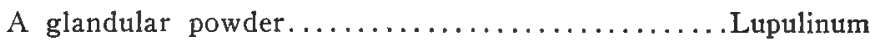

ANISUM.-ANISE.-The dried, ripe fruit of Pimpinella Anisum (Fam. Umbelliferæ), an annual herb (p. 352), indigenous to Asia Minor, Egypt and Greece, and cultivated in South America, Germany, Spain, Italy and Southern Russia. The drug is derived from ctilivated plants, and that obtained from Spain, and known as "Alicante Anise," is preferred.

Description.-Mericarps usually coherent and attached to a slender pedicel 4 to ro $\mathrm{mm}$. long; cremocarp ovoid, laterally compressed, 4 to $5 \mathrm{~mm}$. long, about $2 \mathrm{~mm}$. in diameter, externally greenish-brown or grayish-green, with ten yellowish, filiform, primary ribs, finely pubescent, apex with a ring-like disk and two projecting divergent styles about $0.5 \mathrm{~mm}$. long; internally yel- 


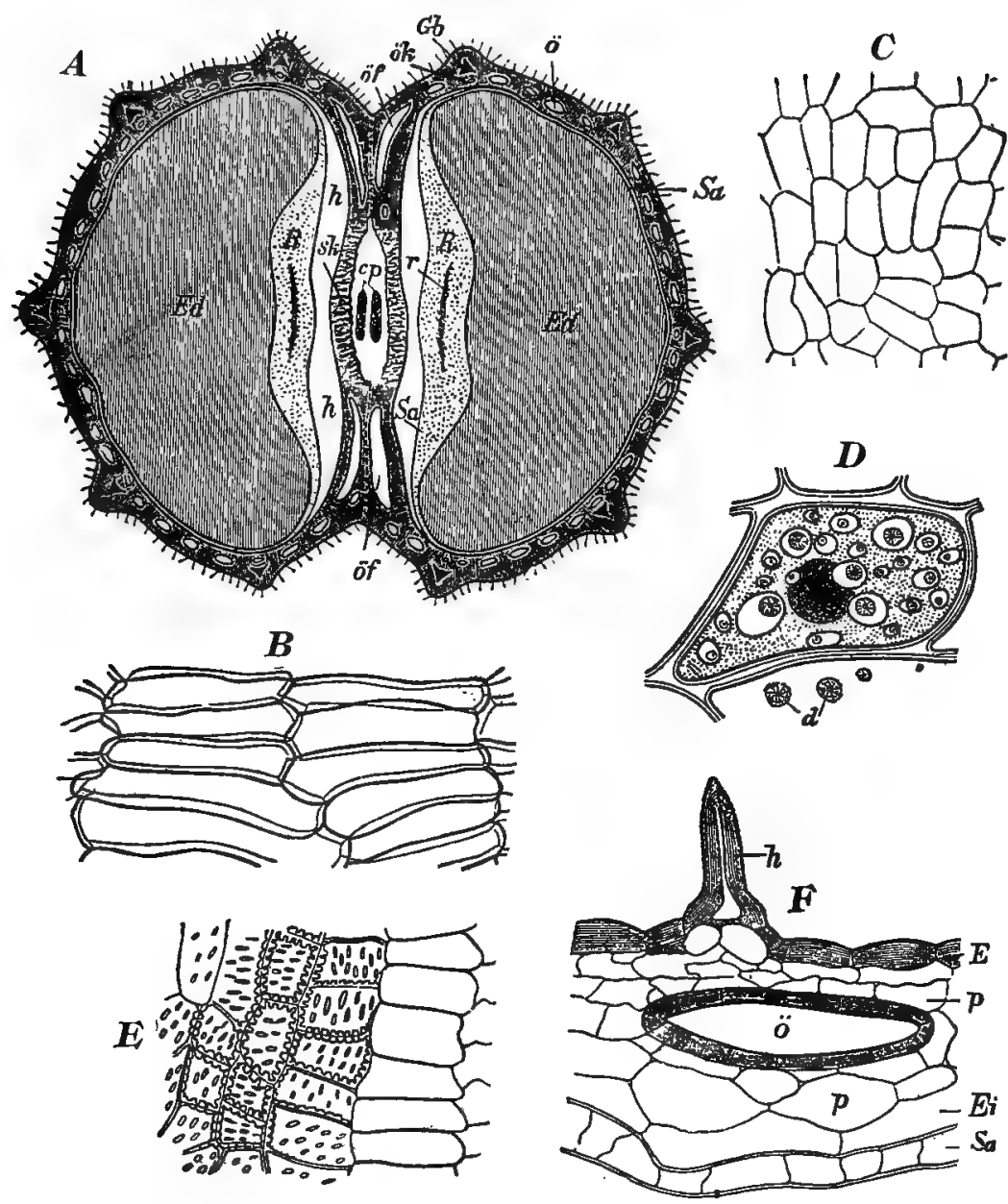

FIG. 244. Anise: A, transverse section of cremocarp showing carpophore ( $c p$ ), wide vittæ (öf) on ventral (commissura1) surface and smaller vittæ (ö, ök) between the ribs on the dorsal surface, fibrovascular bundles of ribs (Gb), sclerenchyma fibers (sk), an air cavity in the wall of the pericarp on the ventral side (h), raphe tissue (R) with fibrovascular bundie ( $r$ ), seed-coat (Sa) and endosperm (Ed). B, inner epidermis of pericarp. C, epidermis of seed-coat. D, cell of endosperm showing a number of aleurone grains containing small rosette aggregates of calcium oxalate, a large nucleus in the center of the cell, and a few isolated aggregates of calcium oxalate (d). E, sclerenchyma cells of the inner epidermis of the pericarp in the neighborhood of the carpophore. F, transverse section of pericarp and seed-coat showing epidermal cells (E) and a non-glandular hair with thick, cutinized walls (h), parenchyma (p), a vitta (o), inner epidermis (Ei) and seed-coat (Sa).After Meyer. 
lowish-brown, with a slender carpophore attached to each mericarp, the latter in section irregularly plano-convex, slightly concave on the commissural side and ustrally with two large vittæ on each face, dorsal surface with 30 to 40 vittæ; seed somewhat reniform in section, closely cohering to the pericarp, with a small embryo at the upper end of the reserve layer; odor and taste pleasantly aromatic.

Inner Structure.-See Fig. $2+4$.

Constituents. - Volatile oil ( $\mathrm{I}$ to 3 per cent.) consisting of about 80 to 90 per cent. of anethol (p-propenylanisol), and methyl-chavicol and terpenes; fixed oil 3 to 4 per cent.; calcium oxalate; ash about 7 per cent.

Russian aniseed is used chiefly for the manufacture of the volatile oil.

Allied Drugs.-Illicium or star-anise (p. 274) yields an oil closely resembling that of anise. It contains 80 to 90 per cent. of anethol, d-pinene, d-phellandrene, ethyl ether of hydroquinone and possibly safrol.

Piarpernel (or Pimpinella) the root of Pimpinclla Sarifraga and $P$. magna, is used like anise. It occurs in fusiform pieces about 8 to Io $\mathrm{cm}$. long, 4 to $10 \mathrm{~mm}$. in diameter, externally yellowish-brown, fracture short, internally whitish, with numerous yellowish resin canals; the taste is acrid, pungent and aromatic. The drug contains a volatile oil, an acrid resin, a tasteless crystalline principle pimpinellin, about 8 per cent. of stggar, starch and tannin.

ADULTER.ANTS.-Italian aniseed is sometimes contaminated with conium, and the friuts of some of the grasses and rushes as well.

CORIANDRL $M$ I.CORIANDER.-The dried, ripe fruit of Coriandrum satizum (Fam. Cmbelliferæ), an amnual herb (p. 352), indigenous to the Mediterranean and Caucasian region, naturalized in the temperate parts of Europe, and cultivated there and in Africa and India. The fruit is collected when full grown from cultivated plants, from which it is separated by thrashing, and dried. The fruits from plants grown in Russia and Thuringia are preferred. The young plants, particularly the leaves, as well as immature fruits, emit a disagreeable odor, whence the name Coriandrum. 
Description.-Mericarps usually coherent; cremocarp (Fig. 245) nearly globular, 4 to $5 \mathrm{~mm}$. in cliameter, externally light brown or rose-colored, with ten prominent, straight, longitudinal primary ribs, between which are faint, somewhat undulate secondary ribs, apex with 5 calyx teeth and a conical stylopodium about $0.5 \mathrm{~mm}$. long, internally with a slencler carpophore attached to each mericarp, the latter grayish-purple, concavo-convex, with two vittæ on the commissural surface; seed plano-convex, with a small embryo at the upper end of the reserve layer; odor and taste aromatic.
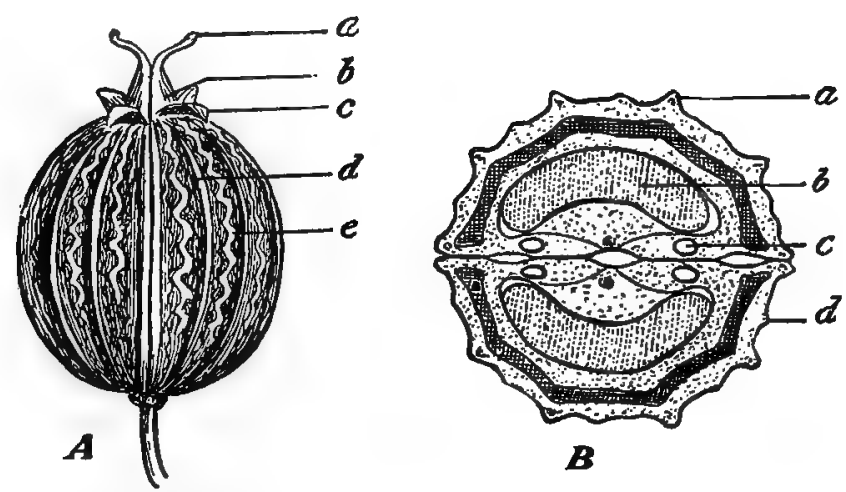

FIG. 245. Coriander: A, cremocarp showing remains of two stigmas (a), stylopodia (thickened persistent styles) (b), calyx teeth (c), straight primary ribs (d) and wavy, somewhat obscure, secondary ribs (e); $B$, transverse section of the cremocarp showing primary ribs (a), secondary ribs (d), vittæ (c) on commissural side, and seed (b).-After Bastin.

Constituents.-Volatile oil 0.5 to I per cent.; fixed oil about I3 per cent.; tannin; calcium oxalate; ash about 5 per cent. The volatile oil consists of about 90 per cent. of d-linalool (coriandrol), about 5 per cent. of d-pinene and some other constituents.

The unripe fruits are said to yield a volatile oil that has a fetid, bedbug-like odor, which it loses on keeping.

FCENICULUM.-FENNEL.-The fruit of Foniculum vulgare, and of the var. dulce (Fam. Umbelliferæ), perennial herbs indigenous to the Mediterranean region of Europe and Asia, and cultivated in France, Galicia, Germany, Roumania, Russia, India, and Japan. The fruit is collected when ripe and dried. That 
obtained from plants cultivated in Germany (Saxony and Thuringia), Galicia and Russia is preferred (p. 352).

DESCRIPTION.-Mericarps usually separated; cremocarp oblong or nearly cylindrical, straight, 4.5 to $8 \mathrm{~mm}$. long, 2 to 3 $\mathrm{mm}$. in diameter, externally yellowish-green, apex with a somewhat depressed disk, and a conical stylopodium about $0.5 \mathrm{~mm}$. long, each mericarp with five prominent, yellowish, slightly winged primary ribs, internally somewhat greenish-brown, with a slender carpophore attached to each mericarp, the latter une-

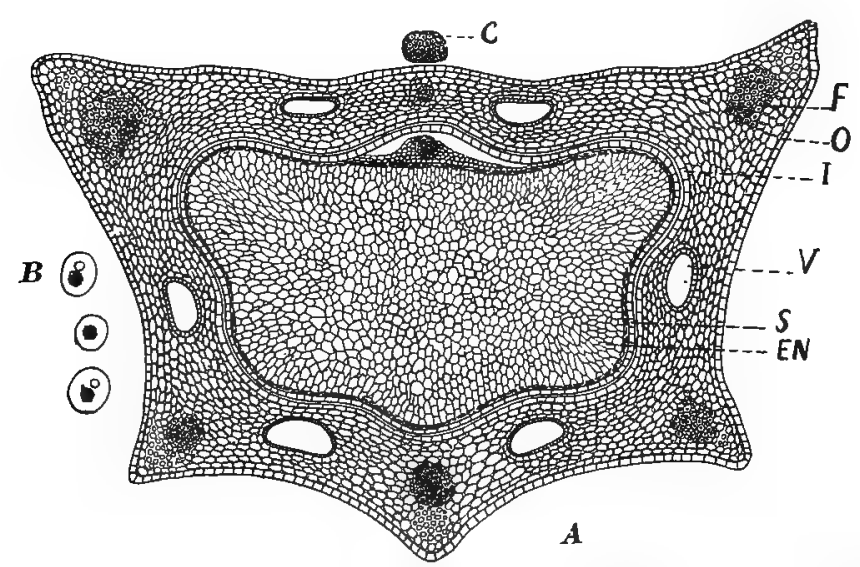

FIG. 246. A, transverse section through a mericarp of fennel: $O$, outer epidermis of pericarp; I, inner epidermis of pericarp; F, fibrovascular bundles; V, vittæ; S, seed-coat; EN, endosperm; $C$, section through the carpophore, which is composed chiefly of sclerenchymatous cells. B, isolated aleurone grains from cells of endosperm of fennel showing globoids and small rosette aggregates of calcium oxalate.

qually 5 -angled in cross-section, the commissural surface slightly grooved and with two vittæ, dorsal surface with a single vitta between each of the primary ribs; seed irregularly plano-convex, with a small embryo at the upper end of the reserve layer; pedicel 3 to ro $\mathrm{mm}$. long; odor and taste aromatic.

Inner Structure.-See. Fig. 246.

Constituents.--Volatile oil 2 to 6.5 per cent.; fixed oil about I2 per cent.; calcium oxalate, and about 7 per cent. of ash.

The volatile oil of fennel contains 50 to 60 per cent. of anethol; about 20 per cent. of fenchone, which gives the fruit its 
characteristic odor and taste; chavicol (isomer of anethol); anise ketone; anisic aldehyde; anisic acid, d-pinene and dipentene.

The sweet or Roman fennel, obtained from plants ( $F$. dulce) cultivated in Southern France, has longer and somewhat curved mericarps, and yields about 2 per cent. of oil, containing considerable anethol but no fenchone. MaCEDONIAN fennel oil contains considerable anethol, some limonene and phellandrene, but no fenchone. WILD BITTER fennel oil obtained from wild plants contains scarcely any anethol, but consists in part of phellandrene and fenchone.

Allied DRUGS.-The more or less fusiform root of Faniculum z'ulgare is also used like fennel. It is 8 to $15 \mathrm{~cm}$. long, Io to $15 \mathrm{~mm}$. in diameter, externally light brown, internally whitish, with numerous yellowish-brown oleo-resin canals, and with an aromatic odor and taste. Fennel root contains a volatile oil, resin, starch and sugar.

CARUM.-CARAWAY.-The fruit of Carmm Cari (Fam. Umbelliferæ), a biennial herb (p. 352) indigenous to Europe and Asia, and cultivated in England, Germany, Holland, Norway, Russia, Sweden and the United States, being naturalized in the Northern United States and parts of Canada. The plants are cut when the fruits are ripe, the latter being separated by thrashing. The fruits from plants grown in Holland are preferred.

DESCRIPTION.-Mericarps ustally separated; cremocarp oblong, laterally compressed, 4 to $6 \mathrm{~mm}$. long, 2 to $3 \mathrm{~mm}$. in diameter, externally dark brown, surmounted by a small, somewhat globular stylopodium and 5 minute calyx teeth; primary ribs Io in number, filiform, yellowish, between each of which are slight, secondary ribs; internally dark brown, mericarps curved, narrowed at both ends, and with a slender carpophore attached to each, the latter 5-angled in cross-section, the commissural surface with 2 vittæ, the dorsal surface with a vitta between each of the primary ribs; seeds irregularly oblong in section, with a small embryo at the upper end of the reserve layer; odor and taste aromatic.

Inner Structure.-See Fig. 247.

Constituents.-Volatile oil from 5 to 7 per cent.; fixed oil; tannin; calcitum oxalate, and 5 to 8 per cent. of ash. 


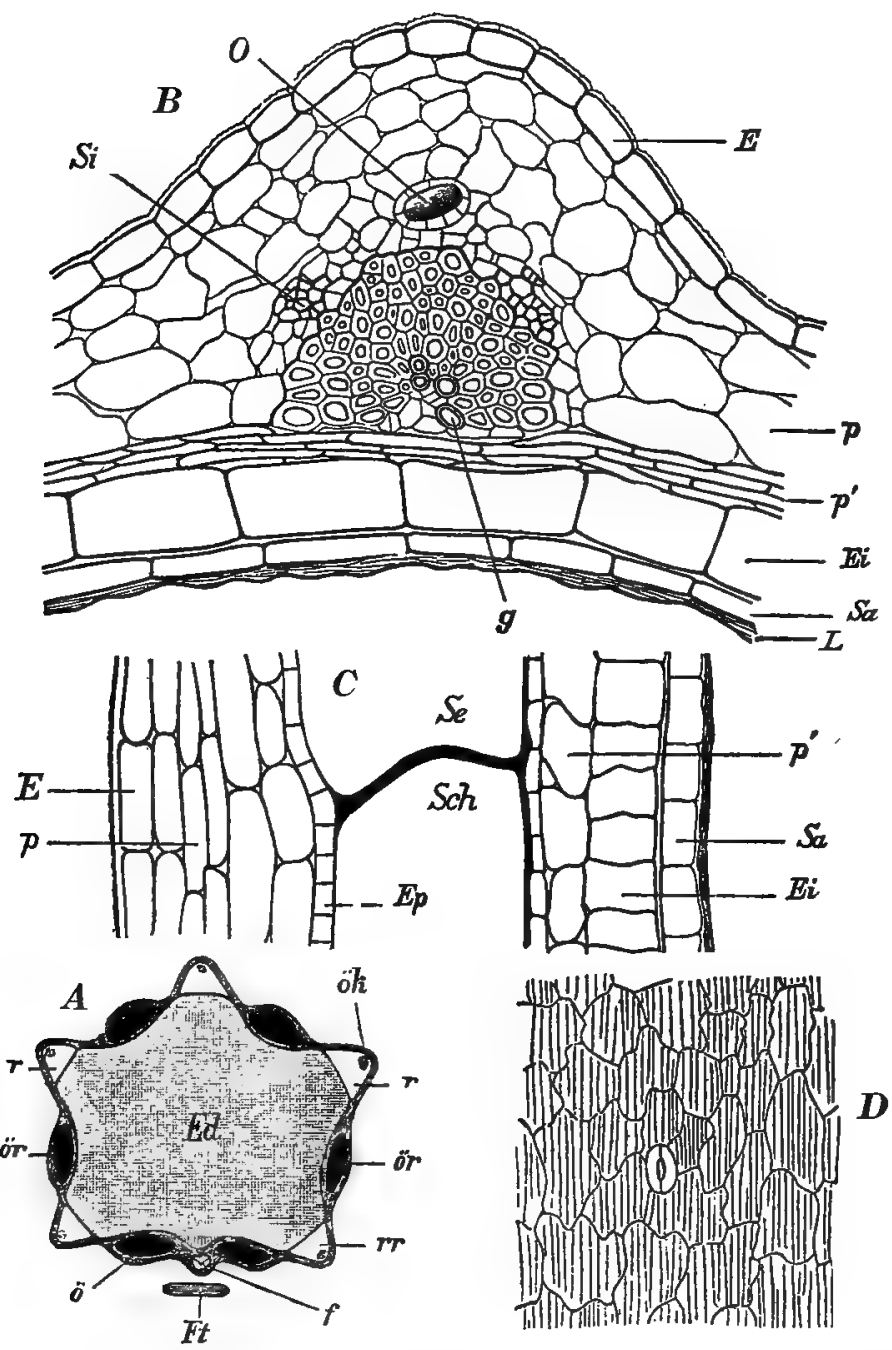

FIG. 247. Caraway: A, transverse section of a mericarp and carpophore (Ft) showing vittæe (o, ör), primary ribs ( $r, \mathrm{rr}$ ), with fibrovascular bundle (ök), tissue of raphe (f) and endosperm (Ed). B, transverse section through a primary rib showing part of pericarp and seed-coat, outer epidermal cells (E), a small vitta (O), sieve ( $\mathrm{Si}$ ), trachea ( $\mathrm{g}$ ), around which are thick-walled sclerenchymatic fibers; parenchyma $\left(p, p^{1}\right)$, inner epidermis $(E i)$, outer epidermis of seed-coat (Sa) and collapsed cells (L) of remainder of seed-coat. C, longitudinal section through part of a mericarp showing outer epidermis ( $E$ ), parenchyma $\left(p, p^{1}\right)$, epithel $(E p)$ and separating wall $(S c h)$ of vittæ (Se), inner epidermis of pericarp (Ei) and seed-coat $(\mathrm{Sa})$. D, surface view of outer epidermis of fruit showing a single stoma. -After Meyer. 
Volatile oil of caraway contains 50 to 60 per cent. of d-carvone (carvol), and 40 to 50 per cent. d-limonene (carven). Caraway oil, particularly carvone, is colored yellow on exposure to air, and the old oil gives a reddish-violet color with ferric chloride solution.

Allied Drugs.-The seeds of Nigclla sativa and $N$. damascena (Fam. Ranunculacex), are used in medicine and for flavoring like caraway. They are commonly known as BLACK CARAW.MY. The seeds are ovate, $3^{-}$to $4^{-a n g l e d}$, about $3 \mathrm{~mm}$. long, externally black and reticulate; internally, a large, white, oily reserve layer in which is embedded the small, greenish embryo. Black caraway contains I.5 per cent. of a volatile oil; I.5 per cent. of a glucoside, melanthin, which resembles saponin and helleborin; a fluorescent alkaloid, damascenin, giving the volatile oil from $N$. damascena its fluorescence; another alkaloid, connigelline; and about 35 per cent. of a fixed oil.

CONIUM.-POISON HEMLOCK.-The fruit of Conium maculatum (Fam. Umbelliferæ), a biennial herb (Fig. I70), indigenous to Europe, and naturalized in North and South America and in various parts of Asia (p. 352). The fruit is collected when full grown but still green from wild plants, carefully dried and preserved.

Description.-Mericarps usually separated; cremocarp broadly ovoid, slightly compressed laterally, 3 to $4 \mathrm{~mm}$. long, about $2 \mathrm{~mm}$. in diameter, with a pedicel 3 to $5 \mathrm{~mm}$. long, externally grayish-green, with Io straight more or less crenate yellowish ribs, stylopodium depressed, internally greenish-brown, with a slender carpophore attached to each mericarp, the latter 5 -angled in cross-section and without any vittæ; seeds reniform, with a deep furrow on the commissural sicle, and with a small embryo at the upper end of the reserve layer; odor distinct; taste slight.

Inner Structure.-See Fig. 248.

Constituents. - The most important constituent is the liquid alkaloid conine (hexa-hydropropyl pyridine), which exists to the extent of 0.5 to 3 per cent.; the drug also contains CONYDRINE (oxyconiine), which crystallizes in plates, is dextrorotatory and very poisonous; PSEUDOCONYDRINE (an isomer of conydrine), 
which crystallizes in needles; $\gamma$-CONICEINE, which is a colorless, oily alkaloid with a disagreeable odor, and 18 times more poisonous even than coniine; volatile oil, fixed oil, starch, calcium oxalate, and yields about 6 per cent. of ash.

Coniine is naturally combined in the drug with organic acids, from which it is liberated on treatment with alkalies, and may be readily extracted from the mixture by means of ether. When pure, coniine is a colorless, nearly odorless liquid and forms a

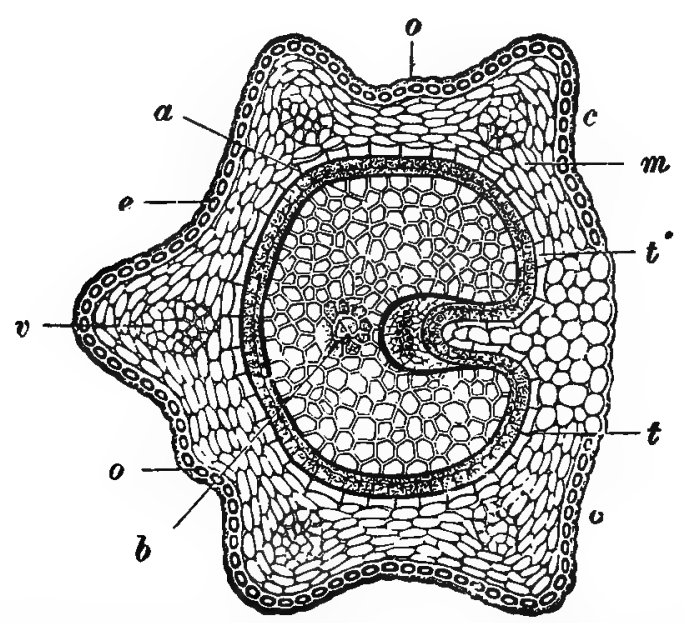

FIG. 248. Cross section of a mericarp of conium: c, c, commissural surface; e, portion without secondary ribs; o, portion showing slight development of secondary rib; $o^{1}$, secondary rib; $v$, fibrovascular bundle of pericarp $(m) ; t, t^{1}$, layers containing conine: $a$, endosperm; b, tissues of the embryo.-After Flïckiger.

number of crysta1line salts. On the addition of concentrated sulphuric acid to coniine the latter is colored blood red and afterwards green. The disagreeable odor in commercial coniine, as well as in conium, is due to the alkaloid coniceine.

Allied Drugs.-The entire plant of Conium maculatum (Fig. I70) is official in several pharmacopœias. It probably contains the same constituents as the fruit, but in smaller amounts. The root contains 0.018 to 0.047 per cent. of total alkaloids; the stems 0.064 per cent.; the leaves 0.187 per cent. and the flowers and flower stalks 0.236 per cent. 
Water hemlock (Cicuta maculata) is a stout, perennial herb growing in wet meadows throughout the United States (Fig. I69). The stems are streaked with purple, the leaves are pinnately compound, the leaflets being oblong-lanceolate and coarsely serrate; the flowers are white, occurring in large compound umbels. The fruit is ovoid, with prominent ribs and six conspicuous vittæ. The rhizome is large and fleshy and sometimes mistaken for parsnip. The fruits contain a volatile alkaloid, cicutine, which is said to resemble coniine, and about I per cent. of a volatile oil resembling oil of cumin. The rhizome, stems and leaves contain a resinous stubstance, cicutoxin, which is saicl to be quite poisonous.

RHUS GLABRA.-SUMAC BERRIES.-The fruit of Rhus glabra (Fam. Anacardiacex), a shrub (Figs. 164, 249), indigenous to Canada and the United States, extending as far west as Arizona (p. 32I).

DesCriPtion.-Drupe dry, superior, nearly globular, flattened, 3 to $4 \mathrm{~mm}$. in diameter, $2.5 \mathrm{~mm}$. thick, and with a slender peduncle about $2 \mathrm{~mm}$. long; reddish externally, very pubescent, apex with a scar and with the remains of the style, base occasionally with the 5-cleft calyx; endocarp smooth, shiny, light red; I-locular, I-seeded; seed campylotropous, dark brown, smooth, hilum marked by a distinct scar, reserve layer wanting, embryo curved; inodorous; taste acidulous and astringent.

Constituents.-Tannic acid about 2 per cent.; gallic acid, and acid calcium and potassium malates.

Allied Drugs.-The LEaves of Rhus glabra contain from I 6 to 25 per cent. of tannin. The galls formed on the petioles and leaves resemble the Chinese or Japanese galls and contain about 60 per cent. of tannin and some gallic acid.

CUBEBA.-CUBEB BERRIES.-The fruit of Piper Cubeba (Fam. Piperaceæ), a woody climber (p. 249), indigenous to Borneo, Java and Sumatra, where it is apparently also cultivated. The fruit is gathered when full grown but still green, and carefully dried in the sun, the commercial supplies being shipped from Batavia and Singapore.

Description.-Drupe dry, superior, globular, 4 to $6 \mathrm{~mm}$. in diameter, with a straight, slender peduncle 5 to $7 \mathrm{~mm}$. long: 
externally dark brown, coarsely reticulate, apex with remains of 3 to 4 stigmas; pericarp about $0.3 \mathrm{~mm}$. thick; internally light brown, smooth, oily, I-locular, $\mathrm{x}$-seeded; seed atropous, broadly

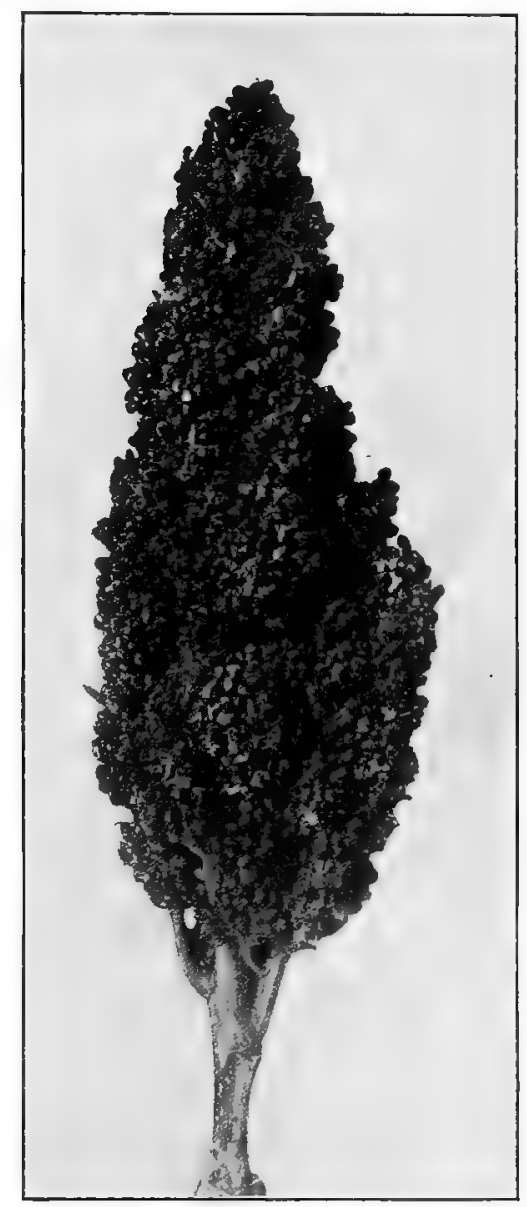

FIG. 249. A panicled-cluster of Rhus glabra fruits.

ovoid, 4 to $5 \mathrm{~mm}$. in diameter, reddish-brown, straight, mostly smooth on one side where it lies against the pericarp, chalazal end with a broad scar, micropyle with a slight depression, a small 
embryo at the upper end of the reserve layer; odor distinct; taste aromatic and pungent.

Inner Structure.-See Fig. 250.

Constituents.-Volatile oil io to I8 per cent., consisting chiefly of terpenes and sesquiterpenes and a sesquiterpene hydrate known as cubel) camphor; several resins, 2.5 to 3.5 per cent., one of which is acrid and one a so-called indifferent resin; cubebic acid, I to 3.5 per cent., this being colored reddish with sulphuric acid; a bitter crystalline principle, cubebin, 0.4 to 3 per cent.; fixed oil, $x$ per cent.; gum, 8 per cent.; starch, and about 6 per cent. of ash.

Allied Plints.-A number of other species of Piper yield fruits resembling cubeb, as Piper Clusii, of West Africa; P. borbonense, of Bourbon; $P$. sumatranum and $P$ pedicellosum, of Farther India.

The fruit of Toddalia lanceolata (Fam. Rutaceæ) is used in Africa in place of cubeb (berries). The fruits of Litsea citrata have been sold as false cubeb, and those of Litsea Cubeba (Fam. Lauraceæ) are substituted for cubeb in Cochin China and China.

Adulterants.-The fruits of other species of Piper sometimes find their way into market; these are grayish in color, somewhat bitter, and do not give a wine-colored reaction with sulphuric acid. Not infrequently a considerable amount of the rachis is present and this contains a relatively small amount of the active principles.

PIPER.-BLACK PEPPER.-The fruit of Piper nigrnm (Fam. Piperacea), a woody, perennial climber (p. 247), indigenons to Cochin China and various parts of India and cultivated in the East Indies, West Indies and other tropical countries. The fruit is gathered when full grown, removed from the rachis and dried in the sun. The commercial supplies are obtained from plants cultivated in Java, Sumatra and other islands of the Malay Archipelago, the principal.points of export being Batavia and Singapore. The latter furnishes the best grade of black pepper and as it is dried by artificial heat it has a somewhat snoky odor and taste. The most of the other black peppers or peppercorns are dried in the sun. 
DESCRIPTION.-Drupe dry, superior, nearly globular, 4 to 6 min, in diameter, epicarp very thin, easily separable from the sarcocarp; externally blackish-brown, coarsely reticulate, apex with remains of sessile stigma, base with scar of pedicel, sarcocarp and endocarp dark brown and with numerous longitudinal veins; seed atropous, broadly ovoid, 4 to $5 \mathrm{~mm}$. in diameter,

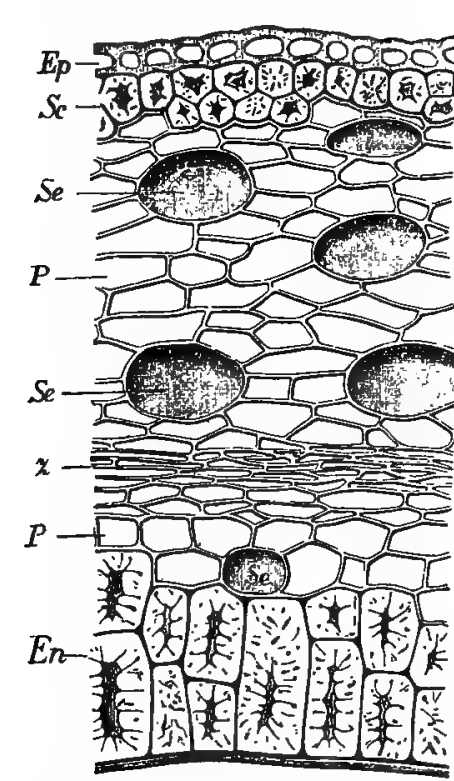

A

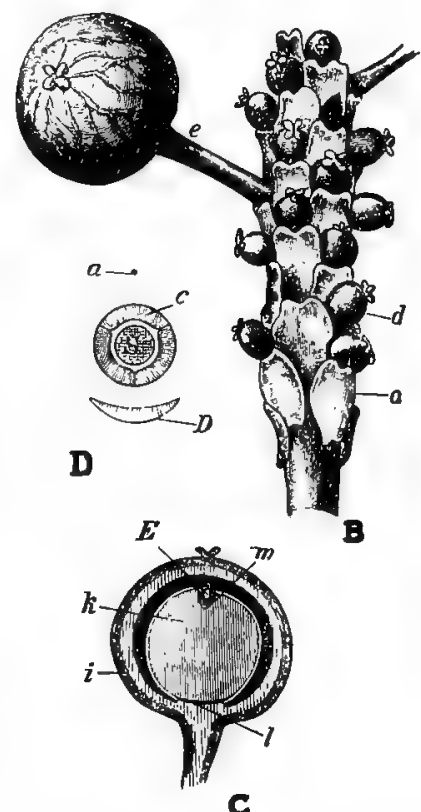

C

Fig. 250. Cubeb: A, transverse section of the pericarp showing epidermis (Ep), stone cells (Sc), oil cells (Se), parenchyma ( $P$ ), collapsed parenchyma tissue ( $z$ ), endocarp (En) composed of stone cells. B, spike showing bracts (o), young sessile fruits (d), and a mature fruit with long pedicel (e). C, longitudinal section of mature fruit showing pericarp (i), union (1) of seed and pericarp, large perisperm $(\mathrm{k})$, small endosperm $(\mathrm{m})$, which surrounds the embryo (E). D, flower diagram showing the position of the flower in reference to the rachis (a), bract (D) and pericarp (c) which surrounds the ovule (S).-After Meyer.

externally reddish-brown, micropylar end pointed, chalazal end marked by a small scar; internally yellowish-green; perisperm large and usually with a cavity near the middle I mm. or more wide, the endosperm small, situated at one end of the fruit and embryo small, frequently more or less shrivelled; odor aromatic, slightly empyreumatic; taste aromatic and pungent. 
Black pepper should yield not less than 6 per cent. of a nonvolatile ether extract nor less than 25 per cent. of starch. The ash should be not more than 7 per cent., of which only two per cent. is insoluble in hydrochloric acid. The crude fiber should be not more than 15 per cent.

InNER STRUCTURE.-The epicarp consists of a layer of polygonal cells with dark brown contents; beneath this, one or more interrupted rows of strongly lignified, more or less radially elongated stone cells occur ; the sarcocarp contains a more or less interrupted layer of oil cells with suberized walls; the endocarp consists of characteristic stone cells, which are horse-shoe shaped, the inner and radial walls being thickened and commonly referred to as "beaker cells." The perisperm consists chiefly of radially elongated cells containing numerous starch grains which are 2 to $6 \mu$ in diameter; some resin cells; cells containing needleshaped crystals of piperine, and in the outer layers small aleurone grains (Figs. I2I, $B$; 3I I).

Constituents.-Volatile oil I to 2 per cent., containing dipentene, phellandrene and a peculiar terpene; the alkaloid PIPERINE, 4.5 to 8 per cent., which crystallizes in colorless, tasteless, 4-sided prisms which are colored bright green by means of concentrated sulphuric acid and formaldehyde, and with potassitum hydrate or sulphuric acid give a red color; piperidine, a colorless liquid alkaloid, which is a derivative of piperine, about 0.5 per cent. ; a pungent resin, chavicin ; starch, 25 to 40 per cent.; tannin ; proteids, about Io per cent.; ash, about 5 per cent.

Allied Products.-The fruits of Piper nigrum are sometimes allowed to ripen and the epicarp is separated by hand or machinery after the fruits have been soaked in salt water or lime water. The fruits are then known as white peppercorns or WHITE PEPPER, are nearly smooth, of a light gray or yellow color, and while less aromatic and pungent than the black pepper or black peppercorns, possess a fine flavor. White pepper yields 3.9 to 6.47 per cent. of piperine.

Piper longum, a shrub indigenous to the Malay Archipelago, yields the so-called "LONG PEPPER," which consists of the entire spikes of the immature fruit; the spikes are cylindrical, from 2.5 to $4 \mathrm{~cm}$. long, about $5 \mathrm{~mm}$. thick, of a grayish-black color, 
and the drupes are less aromatic and pungent than the official pepper. In structure long pepper is distinguished by the absence of oil cells in the sarcocarp, and "beaker cells" of the endocarp, and the larger starch grains ( 2 to Iо $\mu$ ) in the perisperm. Long pepper yields about I per cent. of a volatile oil with the pungent taste of the oil of pepper but an odor resembling that of ginger; and about 4.24 per cent. of piperine.

Long pepper is also obtained from Piper officinarum, of Java, India and the Philippine Islands; Piper sylzaticum, of Eastern India; Chavica officinarum, of the West Indies; and Pepcromia acuminata, of Peru.

Adulterants.--The poorer black peppers, known as AcheEN pepper, are light in weight, consist more or less of shells and are usually considerably broken. They are frequently contaminated with stems, earth and small stones. Penang white PEPPER has a grayish color and is coated with a substance containing considerable calcium carbonate. PEPPER HULLS or pepper shells, representing the broken pericarp of the fruit obtained in the preparation of white pepper, consist of small grayish-black fragments, containing numerous stone cells, and they yield a high percentage of fiber and ash.

Sunstitutes. - The fruit of Embelia ribes (Fam. Myrsinaceæ), a small tree of India, has been used as an adulterant of both pepper and cubeb. The blackish drupes resemble black pepper. They are very aromatic and yield a principle, embelic acid, which crystallizes in golden-yellow prisms, the alcoholic solution of which is colored red with ammonia.

The fruit of Polyadenia pipericarpa (Fam. Lauraceæ), of Sumatra, is also used in place of pepper. The fruits of a number of species of Xylopia (Fam. Anonaceæ) contain aromatic and bitter principles, some of these being used as a condiment like pepper, as $X$. athiopica, which are also used as a medium of exchange by the natives of Uadai (Africa), and $X$. grandiflora, $X$. sericea and $X$. frutescens of Brazil. $X$. aromatica vields the Guinea pepper.

PIMENTA.-ALLSPICE.-The fruit of Pinchta officinalis (Fam. Myrtacex), a tree (p. 347) indigenous to the West Indies. Mexico, Central America and Venezuela, where it is also culti- 
vated, especially in Jamaica. The panicles are collected when the fruit is full grown but still green, and dried in the sun, the fruit being- subsequently separated.

Description.-Drupe dry, inferior, sub-globular, 5 to $7 \mathrm{~mm}$. in diameter; externally dark brown, glandular-punctate; apex with four minute calyx teeth or forming a minute ring and surrounding the remnants of the somewhat depressed style; base with scar of pedicel or occasionally with a pedicel 4 to $6 \mathrm{~mm}$. long; pericarp about I mm. thick; internally light brown, 2-locular,-2-seeded, dissepiments thin; seeds campylotropous, planoconvex, slightly reniform, about $4 \mathrm{~mm}$. long and about $3 \mathrm{~mm}$. thick, externally reddish-brown, smooth, somewhat wrinkled, shiny, internally dark brown, reserve layer wanting, embryo spirally curved, with a long, thick radicle and minute cotyledons; odor and taste aromatic, supposed to resemble those of a mixture of cloves and other spices, whence the name "Allspice."

Constituents. - Volatile oil ( 3 to 4 per cent.) consisting of about 60 per cent. of eugenol; resin; an acrid fixed oil about 6 per cent. ; tannin; starch ; calcium oxalate; ash about 4 per cent.

Allied Plants.-A variety of $P$. officinalis yields a fruit with large drupes known as Tobasco or Mexican Allspice. The structure of this fruit resembles that of pimenta, as also does the Crown Allspice obtained from P. acris, a tree of tropical America, the fruits of which are 8 to $10 \mathrm{~mm}$. long.

MALTUM.-MALT.-The partially germinated and dried grains of Hordeum satic 'um, particularly of the variety inulgare (Fam. Graminex) (p. 228). In the preparation of malt the barley grains are soaked in water for 12 to 24 hours, placed in heaps, allowed to germinate, being occasionally stirred so that the heat generated on germination does not become excessive. After the protrusion of the caulicle and radicle the material is quickly dried and deprived of these parts.

B.RLEY.-Narrow-ellipsoidal, somewhat 4-angled, 8 to Io $\mathrm{mm}$. long, 2 to $3 \mathrm{~mm}$. in diameter, having an outer, readily separable coat consisting of the inner and outer pales, which are membranous, chaff-like, pale straw-color and somewhat translucent; within the pales and adhering to the base of the grain, two very small lodicules consisting chiefly of unicellular hairs 
from 0.5 to I mm. long. Grain nearly smooth, grooved on one side and with a slight projection at the apex consisting of numerous I-celled hairs, usulally with pollen grains adhering, embryo on side opposite the groove and forming a slight projection at the base of the grain; endosperm large and consisting chiefly of cells filled with spherical starch grains resembling those of wheat, the two to four outer layers of cubical cells containing aleurone grains. The embryo is connected with the endosperm by means of a sheathing membrane (by some regarded as a modified cotyledon), through which it obtains nutriment during germination. On germination the embryo produces about 5 multiple primary rootlets and a stem portion with sheathing green leaves.

MaLT.-Grains resembling those of barley, of a yellowishbrown to dark brown color, and with a short fracture; starch grains altered, exhibiting numerous radial and concentric fissures; odor agreeable and taste sweetish.

Constituents.-Barley grains contain from 60 to 68 per cent. of starch; I 2 to 18 per cent. of proteids; about 1.5 per cent. of sugar, and I to 3 per cent. of fixed oil. Two ferments are developed during the process of germination, namely, diastase, which acts on the starch, changing it to dextrin and maltose; and another ferment which acts on the proteids, converting them into peptones. The germinating seeds of barley contain a white crystallizable alkaloid, hordenine, which is slightly toxic.

Commercial malt contains nearly the same constituents as are found in barley, the starch grains being somewhat altered and converted partly into soluble starch through the action of the ferment diastase, a small amount of which is still present in malt after drying. In the preparation of the extract of malt the starch is mostly converted into dextrin and maltose, the proportion of the latter being larger.

PRUNUM.-PRUNE.-The fruit of Prunus domestica, and of the var. Iuliana (Fam. Rosaceæ), a small tree (p. 287) indigenous to Southern Europe, and largely cultivated in Southern France, Germany, Asia Minor and California, but not found growing wild. The fruit is collected when ripe and partially dried by artificial means, or completely dried in the sun. The fruit exported from Bordeanx is of superior quality. 
Description.-Drupe superior, fleshy, ellipsoidal, more or less compressed, 3.5 to $4 \mathrm{~cm}$. long, about $3 \mathrm{~cm}$. broad; externally brownish-black, glabrous, wrinkled, with two faint lines

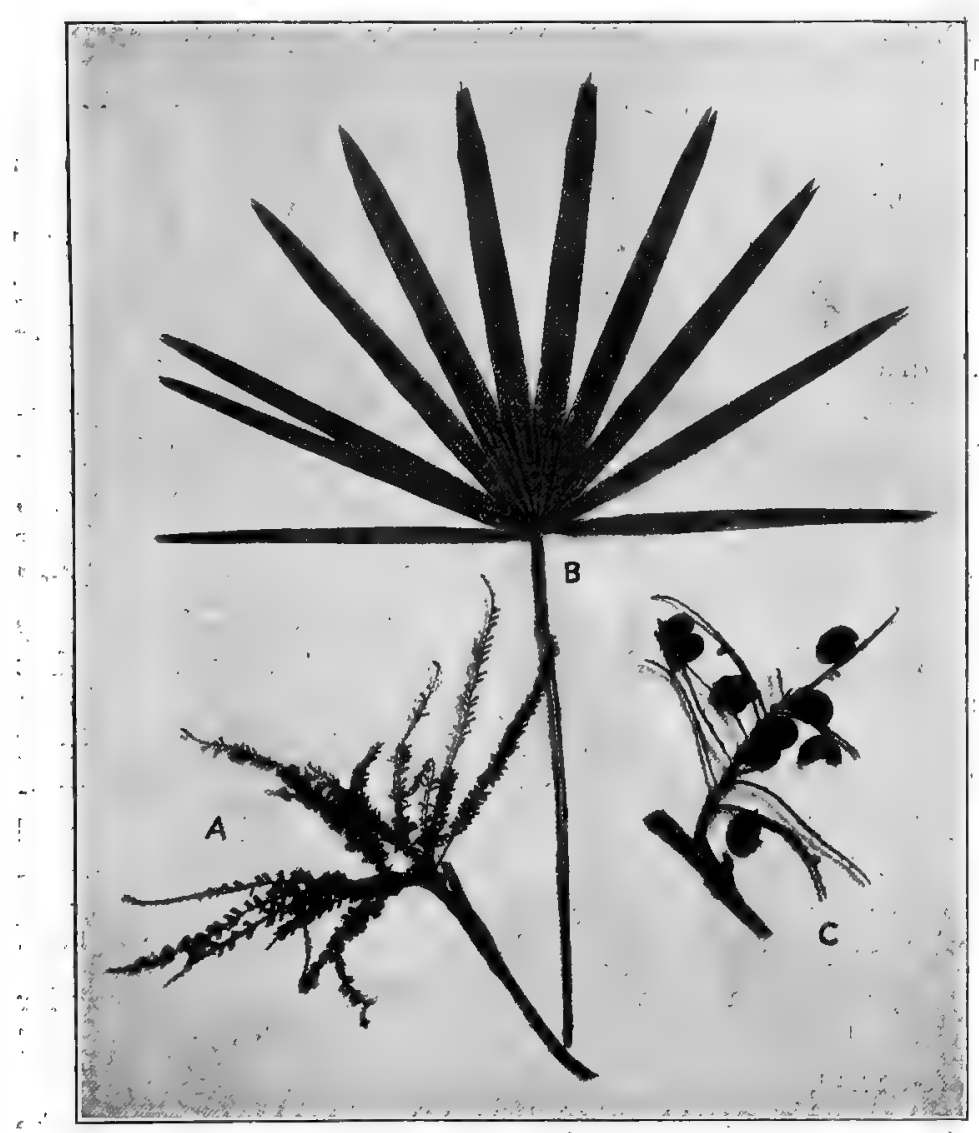

FIG. 251. Saw palmetto (Serenoa serrulata): A, inflorescence of small flowers; B, palmately veined leaf which is entire in the bud but later becomes torn along the folds, giving the appearance of a palmately divided leaf; C, fruiting branch with some of the ovoid-oblong drupes.

indicating the dorsal and ventral sutures, apex with a slight scar from the remains of the style, base with a depressed stalk-scar 3 to $5 \mathrm{~mm}$. in diameter, sarcocarp yellowish-brown, fleshy, somewhat stringy, $1.5 \mathrm{~cm}$. thick; taste sweet and acidulous; endocarp 
ellipsoidal, flattened, about $2 \mathrm{~mm}$. thick, externally dark brown, reticulate, with a groove on one side, frequently extending nearly around the edge, internally light brown, smooth, I-locular, I-seeded, occasionally 2 -seeded; seed about $2 \mathrm{~cm}$. long, $8 \mathrm{~mm}$. wide, $5 \mathrm{~mm}$. thick, closely resembling Bitter Almond (see Amydala Amàra).

Constiruents.-Sugar 25 to 44 per cent.; organic acids, as malic and tartaric, partly free and partly combined, chiefly with potassium, about 2 per cent., and water about 30 per cent.

SABAL.-SAW PALMETTO.-The ripe drupe of Sabal (Serenoa) serrulata (Fam. Palmæ), a small palm found growing in sandy soil from South Carolina to Florida. The fruit is partially dried by artificial means (p. $23 \mathrm{I}$; Fig. 25I).

Description.-Drupe superior, ellipsoidal, ovoid or somewhat globular, I. 5 to $3 \mathrm{~cm}$. long, I to $1.5 \mathrm{~cm}$. in diameter; externally brownish-black, smooth, somewhat oily, with few large, somewhat angular depressions due to the contraction of the inner layer on drying; apex marked by remains of style; base marked by stem-scar or with remains of stem; epicarp and sarcocarp together forming a thin coriaceous shell enclosing a hard but thin endocarp which is externally reddish-brown and somewhat fibrous, as is also the inner layer of the sarcocarp; inner layer of endocarp smooth, enclosing an ellipsoidal or ovoid, hard, somewhat flattened, anatropous, reddish-brown seed which is marked on the raphe side by an arillus-like appendage and on the opposite side near the end by the micropyle, which forms a slight projection; internally, with a large endosperm of thick-walled parenchyma and a very small embryo at the micropyle; odor pronounced, aromatic and fruity; taste sweetish, aromatic and slightly acrid.

Constituents.-About 1.2 per cent. of a volatile oil (in the fresh fruit); 4 to 5 per cent. of a green or brownish oil, consisting of a number of fatty acids and their esters, as caproic, caprylic, capric, lauric, palmitic and oleic; a resin; considerable glucose and possibly an alkaloid.

CAPSICUM.-CAYENNE PEPPER (AFRICAN PEPPER).-The dried ripe fruit of one or more species of Capsicum, probably Capsicum fastigiatum, Capsicum frutescens, and Cap- 
sicum minimum (Fam. Solanaceæ), shrubs indigenous to tropical America, and cultivated in tropical Africa, India and America, and Japan. The commercial supplies are obtained from plants cultivated in Natal, Sierra Leone and Zanzibar. The latter variety
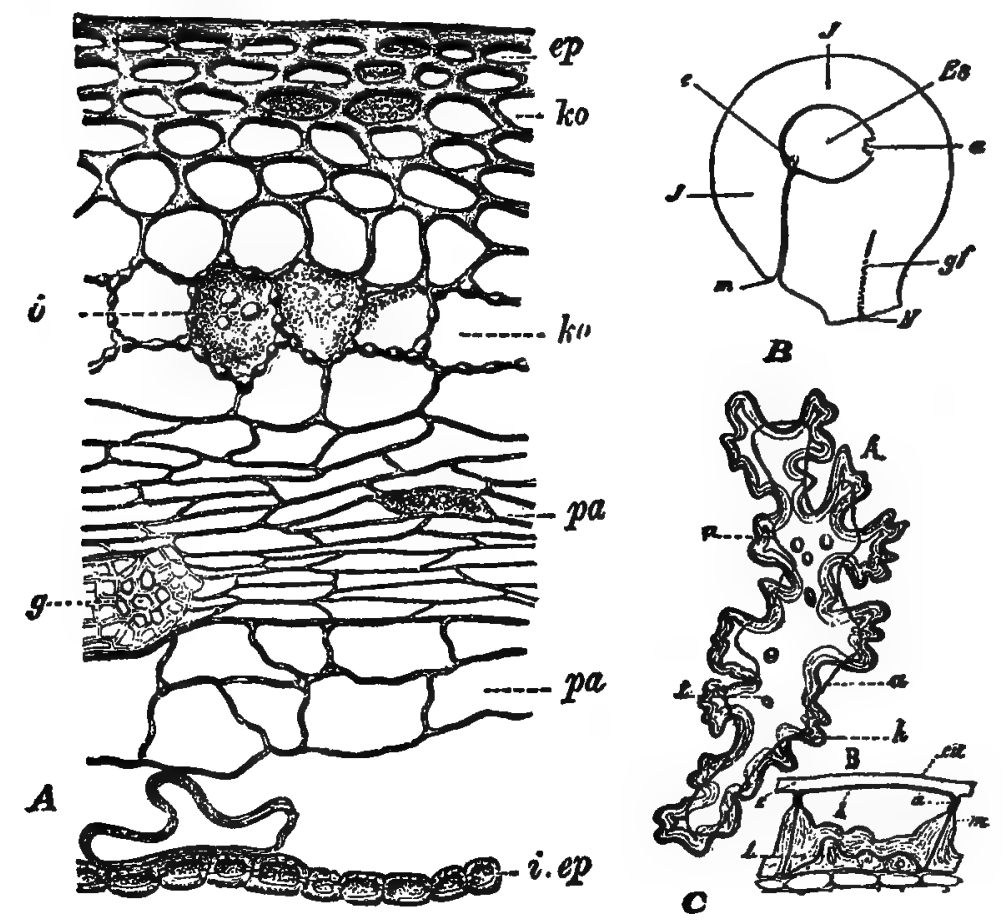

FIG. 252. Garden pepper (Capsicum annum): A, transverse section of pericarp showing epidermis (ep); hypodermis (ko), some of the cells of which have thick suberized walls and contain oil (o) and resin; parenchyma (pa); fibrovascular bundle ( $\mathrm{g}$ ); inner epidermis (i, ep) composed of thick, lignified, porotis cells. B, diagram of fertilized ovule showing hilum $(\mathrm{N})$, micropyle $(\mathrm{m})$, integument $(\mathrm{J})$, fibrovascular btundle (gf), embryo-sac (Es), egg-cell (e), antipodal cells (a). C, longitudinal and transverse sections of a stone cell from the inner epidermis showing the thickening of the inner and side walls,- $\mathbf{A}$, after Hanausek; B, C, after Meyer.

furnishes one of the best grades. Cayenne pepper is also known as red pepper or chillies (p. 375).

DESCRIPTION.-Oblong, conical, laterally compressed, I.5 to $4 \mathrm{~cm}$. long, 6 to Io $\mathrm{mm}$. in diameter, with an inconspicuous 5 -toothed calyx and sometimes a slender, straight pedicel about 
I5 $\mathrm{mm}$. long; externally yellowish- or brownish-red, glabrous, shiny, somewhat translucent, more or less shriveled; apex acute, base somewhat rounded; pericarp coriaceous, thin; inner surface with two or three distinct longitudinal ridges, longitudinally striate, 2 - or 3-locular, dissepiments thin, united below; seeds Io to 20 , campylotropous, irregularly circular or obovate, flattened, pointed, about 3 to $4 \mathrm{~mm}$. in diameter, $0.5 \mathrm{~mm}$. thick, edge slightly thickened, embryo curved, embedded in the endosperm; odor distinct; taste of pericarp pungent, of dissepiments, very pungent.

- Cayenne pepper should yield not less than I5 per cent. of nonvolatile ether extract; nor more than I.5 per cent. of starch; 6.5 per cênt. of ash.

Inner Structure.-See Figs. 252; 30r, $C$.

Constituents.-Two crystalline pungent principles which are found principally in the dissepiments of the fruit: CAPSAICIN, which is slightly soluble in water and is volatile at $115^{\circ} \mathrm{C}$., forming irritating vapors; and CAPSACUTIN, which is so powerful that I part in I I,000,000 of water has a distinct pungent taste. Capsicum also contains a volatile alkaloid resembling coniine; a volatile oil with an odor of parsley; resin; a small quantity of starch; a fixed oil, consisting of oleic, palmitic and stearic acids; and yields 4 to 6 per cent. of ash.

Allied DRUGS.-A capsicum of inferior quality known. as BOM-BAY. PEPPER is obtained from plants growing in the vicinity of the River Niger in Africa. The fruits are dull yellow or brown in color, 2 to $3 \mathrm{~cm}$. long and about $10 \mathrm{~mm}$. in diameter.

JAPAN PEPPER resembles the official Cayenne pepper in size. The fruits are of a bright yellowish-red color, and more shiny but not so pungent. GARDEN or POD-PEPPER, also known as paprika or Spanish pepper, is the product of Capsicum annutum, an herb extensively cultivated in Hungary, Italy and Spain, and this kind is recognized by the German Pharmacopoia. The fruits when fresh are 5 to $10 \mathrm{~cm}$. long, 5 to $7 \mathrm{~cm}$. in diameter, more or less inflated, externally of a bright green, yellow or red color; the pericarp is 2 to $3 \mathrm{~mm}$. thick, enclosing a large cavity," which has I or 2 dissepiments at the base, and contains numerous flattened seeds about 3 to $5 \mathrm{~mm}$. in diameter. 
CARDAMOMUM.-CARDAMOM.-The fruit of Elettaria Cardamomum (Syn. E. repens) (Fam. Zingiberacex), a perennial herb (p. 242) indigenous to Farther India, and cultivated near the Malabar Coast and in Ceylon. The commercial article is obtained from wild plants growing in the southern part of the western coast of Farther India. The fruit is gathered in autumn-either the entire spike, when some of the fruits have matured, or the full-grown fruits are cut from the rachis in succession as they ripen; they are bleached by exposure to the sun,
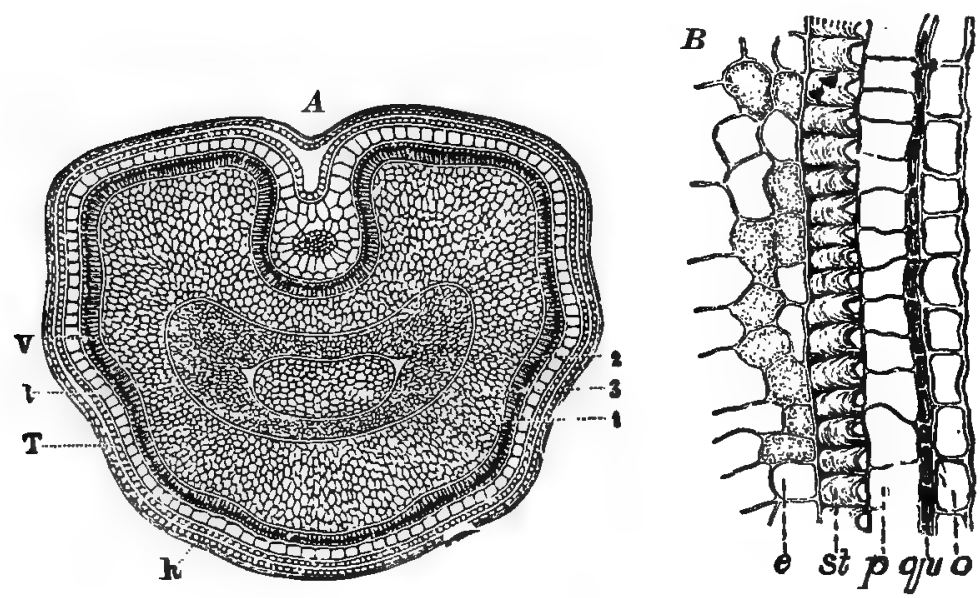

FIG. 253. Cardamom: A, transverse section showing the arillus (h), the several layers of the seed-coat $(T, 1, V)$, perisperm ( $I$ ), endosperm (2) and embryo (3) at the center. $B$, transverse section of the seed-coat and perisperm of Malabar cardamom showing epidermal cells (o), cells having a brown content (qu), cells containing ethereal oil ( $p$ ), brown stone cells $(\mathrm{S} t)$ with very thick inner wails, and perisperm (e), the cells of which contain numerous small starch grains and usually a pair of small crystals which may be seen on treating sections with chloral.-A, after Meyer; B, after Moeller.

sometimes sulphurous acid or steam being also used, after which they are dried and freed from extraneots matter. Seeds which have been discharged from the capsules are inferior to those which have been retained. A greater portion goes to Bombay. from where it is estimated that Ioo,o0o kilograms are exported yearly to London. The commercial varieties are known as Malabar and Mysore Cardamom.

Malabar Cardamom.-Capsule loculicidally dehiscent, broadly ellipsoidal, occasionally ovoid, more or less triangular in 
transverse section, Io to $17 \mathrm{~mm}$. long, 6 to $8 \mathrm{~mm}$. in diameter, pericarp about $0.5 \mathrm{~mm}$. thick; externally light brown or faintly pink, apex slightly beaked, and with remnants of style, base rounded, with scar of stalk, longitudinally striate, 3-grooved, 3 -valved, 3-locular, dissepiments thin; seeds 15 to 18 in number, anatropous, irregularly angular, enclosed in a thin membranous aril, about $3 \mathrm{~mm}$. long, externally dark reddish-brown, deeply wrinkled, embryo small, straight, endosperm and perisperm distinct; odor aromatic; taste aromatic, pungent (Fig. $90, C)$.

Mysore Cardamom.-Ovoid, somewhat oblong, white or very light brown, I2 to $20 \mathrm{~mm}$. long, 7 to $9 \mathrm{~mm}$. in diameter, nearly smooth or faintly striate longitudinally; seeds 9 to 12, and less pungent than those of Malabar Cardamom.

Inner Structure.--See Fig. 253.

Constituents.-Volatile oil 4 to 5 per cent., with a penetrating but agreeable odor and a camphoraceous, burning taste; fixed oil Io per cent.; starch about 3 per cent.; calcium oxalate; ash 4 to 6 per cent. The pericarp contains about 0.2 per cent. of a volatile oil.

Ar.lied Prants.-Ceylon Cardamom is obtained from wild plants of Elettaria major. The capsules are 2 to $4 \mathrm{~cm}$. long and about ro $\mathrm{mm}$. in diameter, distinctly triangular in transverse section, deeply striate longitudinally and slightly pubescent. In each loculus there are about 20 seeds, which are about $4 \mathrm{~mm}$. long, bitter and less aromatic than the official cardamom.

The so-called BASTARD CARDAMOMS are yielded by one or more species of Amomum, but these rarely find their way to market.

HUMULUS.-HOPS.-The fruit of Humulus Lupulus (Fam. Moracex), a perennial herbaceous climber (Fig. I36), indigenous to Europe, Asia and North America, and extensively cultivated in England, Germany and various parts of the United States, South America and Australia, where it is also naturalized (p. 255). Hops are collected in September, when they are ripe, carefully dried by means of artificial heat, and packed into bales or sent loose into commerce. They are sometimes treated with sulphur dioxide to improve the color and to prevent change of the active principles. The development of the odor of valerianic 
acid is said to be prevented by sprinkling the hops with a small quantity of alcohol before packing them. Hops lose their active properties on keeping.

Description.-Cone-like, flattened, oblong or ovoid, 2 to 3 $\mathrm{cm}$. long, I.5 to $2 \mathrm{~cm}$. wide, about $7 \mathrm{~mm}$. thick, consisting of a sharp undulate rachis and about 50 membranous bracts, the latter distinctly veined, light green or brownish-green, glandular-hairy, entire, Io to $\mathrm{I} 4 \mathrm{~mm}$. long, 7 to I I $\mathrm{mm}$. broad, with acute apex and rounded base, frequently infolded on one side and enclosing a subglobular, light-brown, very glandular akene; the seed with two flat, spirally coiled cotyledons and without a reserve layer; odor aromatic; taste bitter.

Constituents.-Volatile oil about 0.7 per cent., of which 60 to 70 per cent. is humulene; a crystalline, bitter principle, lupamaric acid; tannin 4 to 5 per cent.; resin to to I8 per cent.; asparagin, about I per cent.; trimethylamine; choline or lupuline; malic and citric acids, chiefly in the form of salts; calcium oxalate, and ash about Io per cent.

COLOCYNTHIS.-BITTER APPLE.-The fruit of Citrullus Colocynthis (Fam. Cucurbitaceæ), a perennial herbaceous vine (p. 386), indigenous to warm, dry regions of Africa and Asia, and cultivated in the northwestern provinces of India and the countries bordering the Mediterranean. The fruit is collected in autumn when ripe, and after removal of the epicarp by paring, is quickly dried in the sun or by artificial means. The commercial supplies are obtained from Tutkey and Spain, the finer grade coming from Turkey. The seeds should be removed from the pulp before it is used.

DESCRIPTION.-Berry nearly globular, 6 to $7 \mathrm{~cm}$. in diameter (Fig. 254) ; light; externally yellowish-white; internally, with three longitudinal, somewhat elliptical fissures 8 to $14 \mathrm{~mm}$. wide; seeds ntumerots, ovoid, compressed, yellowish-green, and borne on the divided parietal placentas between the fissures; odor slight; taste very bitter.

Constituents.-A bitter glucoside, colocynthin, 0.2 to 0.5 per cent., which may be crystallized but usually is obtained as an amorphous powder that is inflammable, soluble in water and alcohol, and yields upon hydrolysis colocynthein; a tasteless resin, 
584 BOTANY AND PHARMACOGNOSY.

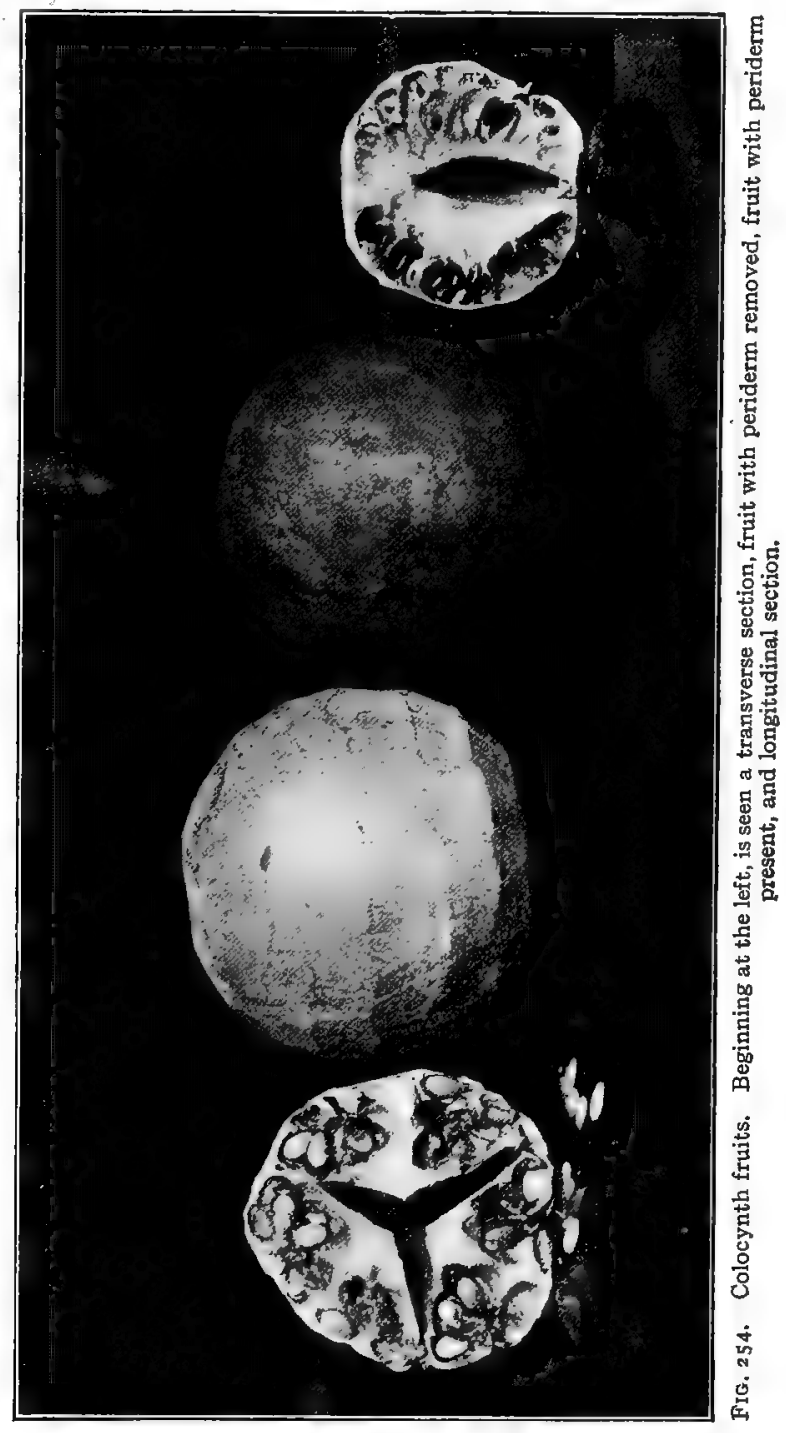


colocynthitin, which occurs in small, white prisms; fixed oil in pulp about 3 per cent., and in seeds about I 5 per cent.; ash about Io per cent. in pulp and about 3 per cent. in the seeds.

Attempts have been made to grow Colocynth in England and in New Mexico. The fruits are much larger than the official, and while very bitter appear to be less active than the fruits obtained from wild plants.

CASSIA FISTUULA.-PURGING CASSIA.-The ripe fruit of Cassia Fistula (Fam. Leguminosæ), a tree (p. 293) indigenous to India, and naturalized in tropical Africa, South America and the West Indies. The principal stipply of the drug used in this country comes from tropical America.

DESCRIPTION.-Legume (Fig. 255), many-loctlar, indehiscent, cylindrical, 25 to $50 \mathrm{~cm}$. long, I5 to $20 \mathrm{~mm}$. in diameter; externally reddish-brown, apex acute or acuminate, base rounded, sometimes with a woody pedicel about $55 \mathrm{~mm}$. long and $4 \mathrm{~mm}$. in diameter, smooth, shiny, transversely striate, on one side a longitudinal groove (the ventral suture), and on the other a smooth line or slight ridge (the dorsal suture); pericarp hard and woody; internally divided by transverse partitions into numerous compartments about $5 \mathrm{~mm}$. long, each containing a brownish-black pulp and a single seed; seed anatropous, ovoid, compressed, about $8 \mathrm{~mm}$. long, $6 \mathrm{~mm}$. wide, $4 \mathrm{~mm}$. thick, light brown, the raphe as a distinct line on one of the compressed sides, internally light yellow, embryo curved and embedcled in the endosperm; odor of pulp distinct, prune-like; taste sweet.

Constituents.-The fruit yields about 30 per cent. of pulp, which contains 40 to 60 per cent. of sugar. The drug apparently does not owe its laxative properties to any of the anthraquinone derivatives found in senna and related plants.

Allied Plants.-The legumes of related species of Cassia found in tropical America are similar to those of Cassia Fistula, and are also used in medicine.

VANILLA.-The fruit of Vanilla planifolia (Fam. Orchidaceæ), a perennial climber (Fig. I33) indigenous to Eastern Mexico, and now cultivated (p. 245) in various tropical islands, including the Seychelles, Mauritius, Java, as well as in the provinces of Vera Cruz and Oaxaca, in Mexico, from whence the best 


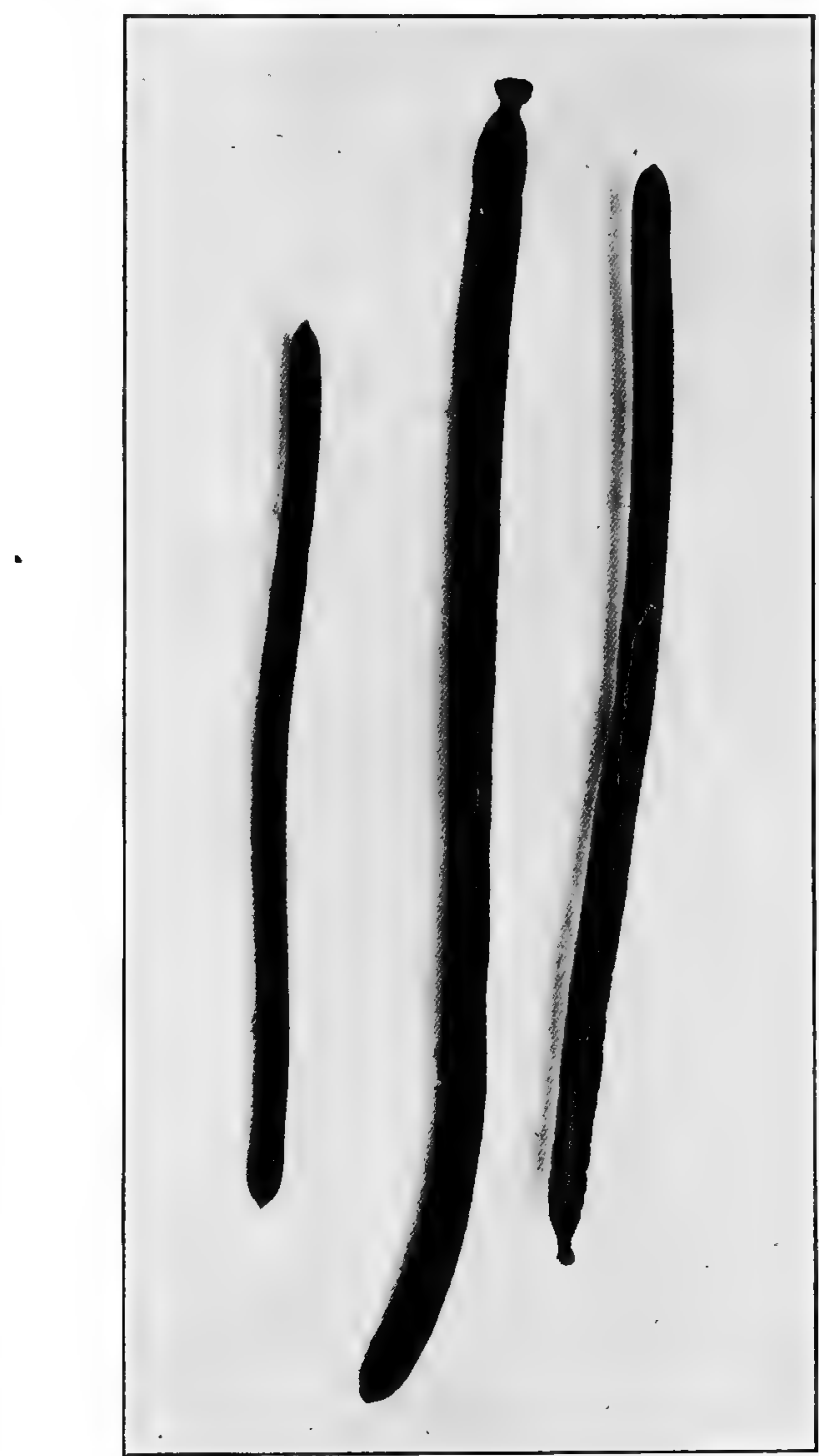

FIG. 255. Legumes of Cassia Fistula, the one to the right showing the transverse partitions. 
fruit is derived. Most of the vanilla used in the United States comes from Mexico. Some of the Reunion (or Bourbon) fruit is now also entering the market. For method of curing the fruit see p. 245 .

Mexican Vanilla.-Pods narrow, linear, about $20 \mathrm{~cm}$. long, $7 \mathrm{~mm}$. in diameter, $4 \mathrm{~mm}$. thick; apex oblique, with a circular scar; base curved or bent, with a slightly enlarged circular scar; externally blackish-brown, longitudinally wrinkled, moist, glossy, sometimes with acicular crystals or monoclinic prisms; pericarp about $\mathrm{I} \mathrm{mm}$. thick; internally dark brown, I-locular, with numerous seeds embedded in a dark-colored pulp; seeds anatropous, ovoid, flattened, 0.2 to $0.3 \mathrm{~mm}$. in diameter, black, finely reticulate, reserve layers wanting, embryo shrunken; odor and taste distinct.

Bourbon Vinilla resembles the Mexican Vanilla, but is about two-thirds as long and the outer surface is ustually covered with crystals.

IN NER Structure.-See Figs. 256, 313.

Constituents.-An odorous crystalline principle, vanillin, from 1.5 to 3 per cent.; an odorous, balsamic or resinous principle, which is developed during the process of curing and to which the peculiar odor of vanilla is due; sugar about Io per cent.; fixed oil about Io per cent.; calcium oxalate in raphides; ash about 5 per cent.

Vanillin or methyl protocatechuic aldehyde is manufactured on a large scale from eugenol or coniferin. It occurs in white, acicular crystals, which are sparingly soluble in water, soluble in aclohol and glycerin, the solutions being colored blue with ferric chloride. Vanillin may be formed as a result of certain oxidation changes rather than through the action of a ferment like emulsin which, as has been recently shown, does not exist in the fresh pods.

The fruits of a number of species of Vanilla yield vanillin, which is also found in the Orchid Selenipedinm Chica, of Panama; the fruit of Rosa canina, of Northern and Middle Europe; the flowers of Spirca Ulmaria; the balsams and resins of the genus Toluifera; and in the seeds of Lupinus albus, of Europe, which is cultivated. 
Commercial V.arieties. - In addition to the Mexican and Bourbon beans other varieties are found in the market. MAURITIUS Vanilla occurs in cylindrical pods that are nearly as long as the Mexican variety, but paler in color and less odorous.

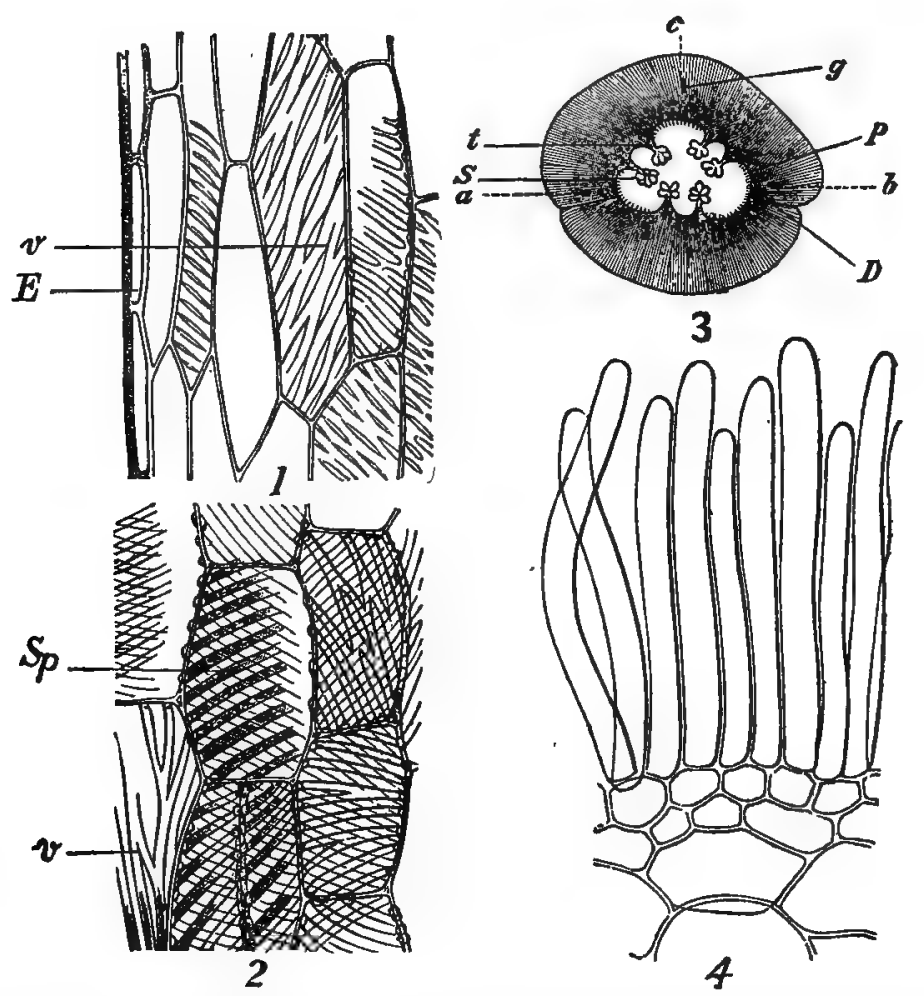

FIG. 256. Vanilla: 3, transverse section of an unripe fruit showing lines of union of the three carpels $(a, b, c)$, line of dehiscence (D), placenta ( $t$ ), seeds (S), fibrovascular bundle $(\mathrm{g})$, papillæ (P). I, radial-longitudinal section of the outer part of the pericarp showing epidermis (E), and parenchyma cells with oblique pores (v). 2, tangentiallongitudinal section of the outer part of the pericarp showing cells with oblique pores (v) and spirally thickened bands $(S p) .4$, inner layer of the pericarp showing the very long simple hairs or papillæ seen at $\mathrm{P}$ in No. 3.-After Meyer.

TAHIti Vanilla, which is produced on the Island of Tahiti and the Hawaiian Islands, occurs in somewhat broader, flattened pods. The pods are nearly as long as the Mexican variety and sharply attenuated and twisted at the lower portion. The color 
is reddish-brown and the odor is disagreeable, unfitting it for use for flavoring. VANILLONS are the fruits of wild plants and are used in the manufacture of tobacco and sachet powders. They are Io to $\mathrm{I} 2 \mathrm{~cm}$. long, I.5 to $2.5 \mathrm{~cm}$. in diameter, gradually tapering towards each end, somewhat triangular in outline, externally dark-brown to reddish-brown, frequently with transverse markings, due to their being wrapped with twine during the process of curing, when they are spoken of as "braided," and generally longitudinally split; the odor is peculiar, somewhat resembling "heliotrope," and is due to the phenol aldehyde heliotropin (piperonal) which is closely related to vanillin.

POMPONA Vanilla is the fruit of wild and cultivated plants of I'anilla pompona, which is considered to be the original plant from which $V$. planifolia has been derived by cultivation. The fruits resemble the vanillons in appearance, but the odor is disagreeable, like that of Tahiti V $r$ anilla.

Vanilla SPLITS and cuTs represent the more mature fruits in which dehiscence has taken place and which are cut up into short lengths.

TONKA SEEDS contain the odorous principle coumarin, which somewhat resembles vanillin. The ripe seeds of Coumarouna odorata (Fam. Leguminosæ), growing in the northern part of the Amazon region, furnish DUTCH TONKA, and C. oppositifolia, of Northern Brazil and Guiana, yields the EnGLish tonkA. The seeds are oblong-ovoid, somewhat flattened, 3 to $4 \mathrm{~cm}$. long and about $\mathrm{I} \mathrm{cm}$. wide, externally nearly black, frequently with numerous white crystals, the coriaceous testa being deeply wrinkled; internally yellowish-brown, consisting of two plano-convex cotyledons, enclosing a plumule with two pinnately-compound leaves and a fleshy radicle which is directed towards the micropyle sitwated at the rounded end of the seed; the odor is fragrant, and the taste aromatic and somewhat pungent. Tonka seeds contain I. 5 to 3 per cent. of COUMARIN or ortho-oxycinnamic anhydride, which forms colorless prisms having a fragrant odor and a bitter, aromatic taste. Coumarin is sparingly soluble in water, but quite so in alcohol. Tonka also contains a large quantity of a fixed oil, -irregularly elongated aleurone grains to to $35 \mu$ long, and spherical starch grains from 4 to $9 \mu$ in diameter. 
Coumarin is rather widely distributed in nature. Of the plants in which it has been found the following may be mentioned: Vanilla grass or sweet vernal grass (Anthoxanthum odoratum) ; Carolina vanilla or dog's tongue (Trilisa odoratissima), one of the Compositæ; the yellow melilot (Melilotus officinalis), a leguminous herb found in waste places in the Eastern United States and in which it occurs free as well as combined with melilotic acid; other species of Melilotus, as well as in other genera of the Leguminosæ; sweet-scented bed straw (Galium triflorum), an herb of the Rubiacex growing in the United States; the rhizome of Vitis sessilifolia (Vitaceæ) of Brazil, and in Prunus Mahaleb (Fam. Rosacex), of Europe.

A number of the orchids contain coumarin, and these belong chiefly to the genus Orchis, as Orchis odoratissima, of Europe; $O$. coriophora, of Europe and the Orient; O. Simia, of Europe and the Orient; O. militaris, of Europe and Asia; Habenaria conopsea, of Europe and Asia; Aceras anthropophora, of Europe and Arabia.

FICUS.-FIG.-The fruit of Ficus Carica (Fam. Moraceæ), a tree indigenous to Persia and cultivated in most sub-tropical and tropical countries. The fruit is collected when ripe, partially dried in the sun, and tightly packed in boxes (p. 255).

Description.-Syconium pyriform or obovoid, usually compressed, about $6 \mathrm{~cm}$. long and $1.5 \mathrm{~cm}$. in diameter; externally light brown, longitudinally veined, wrinkled, frequently with an efflorescence of grape sugar, apex with a small scaly orifice, base with a scar or stalk about $7 \mathrm{~mm}$. long and $4 \mathrm{~mm}$. thick, and also with a leaf-remnant; torus hollow, the walls 2 to $3 \mathrm{~mm}$. thick, coriaceous, tough, the inner portion with numerous lanceolate divisions, upon which are borne numerous ovoid, brownish-yellow, glossy akenes about I mm. in diameter, the latter with a reserve layer and a curved embryo; odor distinct, fruit-like; taste sweet.

Constituenrs.-Grape sugar 50 to 60 per cent.; about I.5 per cent. of fat in the form of oily globules found in the milkvessels; starch in the form of spherical grains; water about 30 per cent. in the partially dried fruit.

Allied Plants. - Other species of Ficus also yield edible figs, as the mulberry fig tree (F. Sycomorus), of Africa; $F$. 
regligiosa, of India; $F$. glomerata, of Burmah; the false banyan tree, $F$. bengalensis, of tropical Africa and India; and F. Rumphii, of Asia.

A peptonizing ferment is obtained from the milk-juice of Ficus Carica, F. Sycomorus, of Africa, and F. exima, of Brazil.

When figs are dried, roasted and ground they form a coffee substitute kown as FIG CoFFEE, which is also used sometimes as an adulterant of coffee. It is dectected by the large, thin-walled and broad non-glandular hairs of the outer epidermis; the broad latex-tubes, 30 to $50 \mu$ wide, and the small akenes. The latter somewhat resemble the akenes of strawberry fruits, but are distinguished by the reticulated thickening of the outer cell-wall.

AURANTII DULCIS CORTEX.-SWEET ORANGE PEEL.-The outer layer of the rind of the fresh fruit of Citrus Aurantium sinensis (Fam. Rutaceæ), a tree (Fig. I58) extensively cultivated in sub-tropical countries and warm-temperate regions (p. 306). The outer yellowish layer is the part employed, and is usually removed from the fruit by grating. The dried rind is an article of commerce.

DesCription.-Cut into small pieces or shreds, externally orange-yellow, with numerous circular depressions and numerous large oil-secretion reservoirs; texture coriaceous, tough; soft when fresh; odor aromatic; taste slightly bitter.

Constituents.-Resembling those of bitter orange peel, except that there is but a very small quantity of the bitter principle. The volatile oil which exists in large reservoirs beneath the epidermis is obtained by expression from the fresh peel and is official. It consists of about 90 per cent. of d-limonene and 5 per cent. of citral, citronellal and the methyl ester of anthranylic acid.

LIMONIS CORTEX.-LEMON PEEL.-The rind of the fresh fruit of Citrus medica Limonum (Fam. Rutacex), a tree (p. 308) indigenous to Northern India and cultivated in the European countries bordering the Mediterranean, the West Indies and other tropical and sub-tropical countries. The outer yellowish layer is the part used and it is removed by grating.

DESCRIPTION.-In freshly grated, lemon-yellow fragments, with numerous large oil-secretion reservoirs and oil-globules; odor aromatic; taste aromatic and slightly bitter. 
Constituents.-Volatile oil; a very small quantity of hesperidin and other bitter principles (see bitter orange peel); a principle resembling tannin; calcium oxalate; ash about 4 per cent. The volatile oil obtained by expression from fresh lemon peel consists of 90 per cent. d-limonene; 7 to ro per cent. of citral, which is the most important constituent; and a small quantity of citronellal, geranyl acetate, pinene, terpineol, methyl heptenone, a sesquiterpene and octyl and nonyl aldehydes.

AURANTII AMARI CORTEX.-BITTER ORANGE PEEL.-The rind of the unripe fruit of Citrus Aurantium amara (Fam. Rutacex), a tree (Fig. I58) indigenous to Northern India and cultivated in the Mediterranean region, the West Indies and the States bordering on the Gulf of Mexico (p. 306). The fruit is collected before it is ripe, the rind removed and used either in the fresh or dried condition. The commercial article is obtained from Malta, Sicily and Spain.

Description.-Usually cut longitudinally into quarters; elliptical, acute at both ends, 4 to $6 \mathrm{~cm}$. long, 2 to $3 \mathrm{~cm}$. wide, 2 to 6 mm. thick; externally yellowish or brownish-green, with numerous circular depressions, a scar at one end and occasionally the remains of the calyx; internally light yellowish-brown, wrinkled, with numerous conical projections and numerous large oil-secretion reservoirs; fracture short, tough, surface porous; odor aromatic; taste aromatic and bitter.

Occasionally in ribbon-like bands 2 to $\mathrm{I} 2 \mathrm{~cm}$. long, 5 to 10 $\mathrm{mm}$. wide, about $2 \mathrm{~mm}$. thick; externally yellowish-brown.

Constituents.-Volatile oil, resembling that of sweet orange peel but with a superior flavor and a bitter taste; several hitter principles: (a) AURANTIAMARIN ( 1.5 to 2.5 per cent.), an amorphous, bitter glucoside, to which the bitter taste is chiefly due; (b) AURANTIAMARIC ACID (o.I per cent.), a very bitter; green, amorphous, resinous principle; (c) NARINGIN (aurantiîn), a yellowish, crystalline, bitter glucoside; (d) IsOHESPERIDIN ( 0.4 to 3 per cent.), a slightly bitter glucoside. The drug also contains 5 to 8 per cent. of a white, crystalline, tasteless glucoside HESPERIDIN, which separates in sphere-crystals on placing the fresh fruit in alcohol. Hesperidin is colored reddish-brown'with ferric chloride and on hydrolysis yields a sweet principle hespere- 
tin, which crystallizes in prisms. A fixed oil, resin, and a principle resembling tannin; calcium oxalate, in the form of rhombohedral crystals; and ash about 5 per cent. are also present.

Allied Drugs.-The immature fruits of Citrus Aurantium are sometimes collected and are known as ORANGE BERRIES. They are nearly globular; 5 to $20 \mathrm{~mm}$. in diameter, greenish or brownishblack, granular rugose; the internal structure resembles that of orange fruits, but the seeds are rudimentary; and the taste is aromatic and bitter.

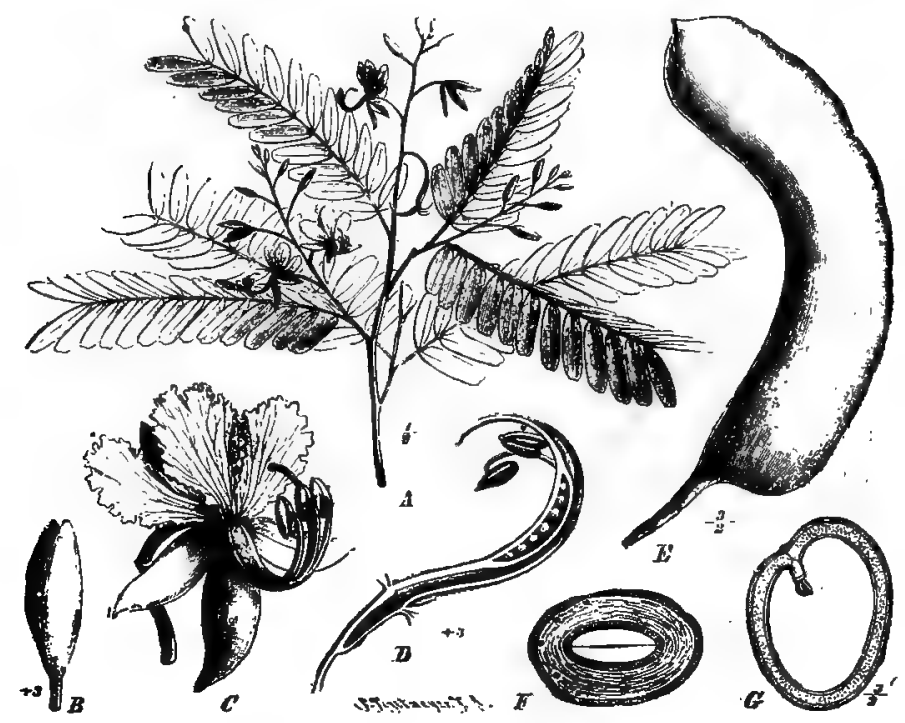

FIG 256a. Tamarindus indica: A, flowering branch with paripinnate leaves; $B$ flower bud; C, dorsiventral (irregular) flower; D, longitudinal section of flower showing unilocular ovary; $E$, somewhat curved, indehiscent legume; $F, G$, transverse and longitudinal sections of the seed.-After Taubert.

TAMARINDUS.-TAMARIND.-The preserved pulp of the ripe fruit of Tamarindus indica (Fam. Leguminosæ), a tree (Fig. 256a) indigenous to tropical Africa and cultivated in the West and East Indies (p. 294) from whence the two chief commercial varieties are obtained.

West Indian TAMARIND.-Usually a blackish-brown mass, with a distinct odor and strongly acidulous, sweet taste, and in which are embedded numerous seeds enclosed in a loose, tough 
membrane; seeds anatropous, oblong or flattened-quadrangular, 12 to $14 \mathrm{~mm}$. long, 8 to II $\mathrm{mm}$. broad, 5 to $7 \mathrm{~mm}$. thick, dark reddish-brown, smooth, one edge furrowed, transversely striate, very hard; cotyledons plano-convex.

EAST Indian TAMARIND.-In blackish cakes, containing less sugar and more acid.

Constituents.-Tartaric acid 5 to 9 per cent.; citric acid 3 to 6 per cent.; potassium bitartrate 6 to 7.3 per cent., and other salts of organic acids; invert sugar 32 to 42 per cent.; tannin (in the seed-coats).

Allied Plants.-The pulp of the fruits of several species of Nephelium (Fam. Sapindaceæ), of Southern China, resembles tamarind.

LUPULINUM.-LUPULIN.-A powder separated from Hops (see Humulus), and consisting chiefly of the glandular hairs. Lupulin may be systematically separated from the hops, or it may be obtained as a by-product during the handling of the hops. Commercial lupulin consists for the most part of sweepings collected where hops are prepared for the market, the extraneous matter being removed by sifting and washing. The powder is then carefully dried and preserved.

Description.-Granular, yellowish- or reddish-brown, consisting of glandular hairs with a somewhat globular or ellipsoidal, bright-yellow, multicellular head 0.1 to $0.3 \mathrm{~mm}$. in diameter (Fig. 298) ; odor aromatic; taste aromatic and bitter.

Not less than 60 per cent. of lupulin should be soluble in ether, and the ash should not be more than Io per cent.

Constiruents.-A volatile oil, identical with that of hops, about 3 per cent.; a crystalline bitter principle lupamaric acid (hop bitter), which becomes yellow on exposure to air and on hydrolysis yields lupuliretin and a crystalline substance lupulic acid; a tasteless resin; myricin; valerianic acid, which together with the oil is obtained on the distillation of lupulin with water; and ash from 3 to 5 per cent.

The volatile oil of hops or lupulin is sparingly soluble in alcohol and is not converted into valerianic acid by means of oxidizing agents. This acid is, however, produced upon treating the extract of hops with potassium permanganate. 


\section{LEAVES AND HERBS.}

Some of the most valuable and potent vegetable drugs are those furnished by leaves and herbs. In quite a number of instances the leaves alone are collected; not infrequently, as with herbaceous plants, the leaves, together with the flowering and fruiting tops, are collected; rarely, however, are the tops alone employed; occasionally the drug may consist of the entire plant. It may be noted in this connection that some of the so-called leafdrugs, as belladonna, hyoscyamus and stramonium, may contain the tops of the plants as well, and some of the commercial herbs, as lobelia, may consist entirely of leaves.

\section{KEY FOR THE STUDY OF LEAVES AND HERBS.}

\section{Leaves.}

I. Whole Leaves.

A. Texture coriaceous.

a. Margin entire.

« Glandular-punctate.

Apex emarginate.................Pilocarpus

Scythe-shaped ..................Eucalyptus

$\beta$ Not glandular-punctate.

Apex obtuse...................... Uva Ursi

b. Margin dentate or serrate.

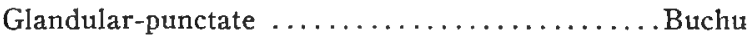

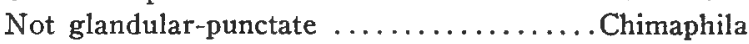

B. Texture not coriaceous.

a. Margin entire.

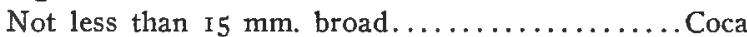

Not more than $15 \mathrm{~mm}$. broad............... Senna

$b$. Margin not entire.

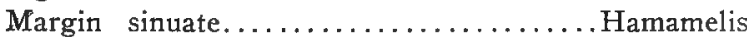

Margin crenulate...................... Salvia

2. Leaves crumpled or in broken fragments.

A. Texture coriaceous.

Upper surface resinous................. Eriodictyon

B. Texture not coriaceous.

a. Hairy.

Surface reticulate, veins whitish.......... Digitalis

Surface reticulate, veins brownish............. Matico

Surface not reticulate.................Hyoscyamus 
I. Leaves.-Continued.

$b$. Not very hairy.

Margin entire..................... Belladonnæ Folia

Margin sinuate................. Stramonii Folia

II. Leaves and Flowering Tops.

I. With composite flowers.

Leaves reticulate....................... Eupatorium

Leaves resinous............................ Grindelia

2. With labiate flowers.

A. Very hairy.

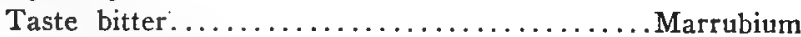

B. Not vcry hairy.

a. Margin slightly serrate.

Leaves dark green, pubescent............. Hedeoma

b. Margin serrate, midrib and veins somewhat rose- or purple-colored.

Taste aromatic, followed by a

cooling sensation.................. Mentha Piperita

Taste aromatic................... Mentha Viridis

3. Odor heavy, like that of tobacco.

A. Margin entire.

Purplish flowers, brownish berries........Belladonnæ Folia

B. Margin not entire.

Margin sinuate, surface hairy.............. Hyoscyamus

Petiolate, margin four-lobed,

surface not hairy................. Stramonii Folia

4. With inflated capsules.

Leaf divisions with gland-like apex................ Lobelia

III. Flowering Tops, leaves few.

Compressed resinous masses.....................nabis Indica

IV. Stem Tops, leaves few.

Branches with yellowish-green wings............. Scoparius

V. Entire Plant.

Stems cylindrical, leaves entire, capsule bicarpellary........Chirata

Stems square, leaves serrate, flowers bilabiate......... Scutellaria

PILOCARPUS.-JABORANDI.-The leaflets of various species of Pilocarpus (Fam. Rutaceæ), shrubs (Fig. 157) indigenous to Brazil. There are three principal commercial varieties: (I) Pernambuco Jaborandi, obtained from P. Jaborandi; (2) 
Paraguay Jaborandi, yielded by $P$. pinnatifolitls, and (3) Maranham Jaborandi, obtained from $P$. microphyllus. The name, jaborandi, is applied to a number of other plants growing in Brazil besides those of the genus Pilocarpus (p. 305).
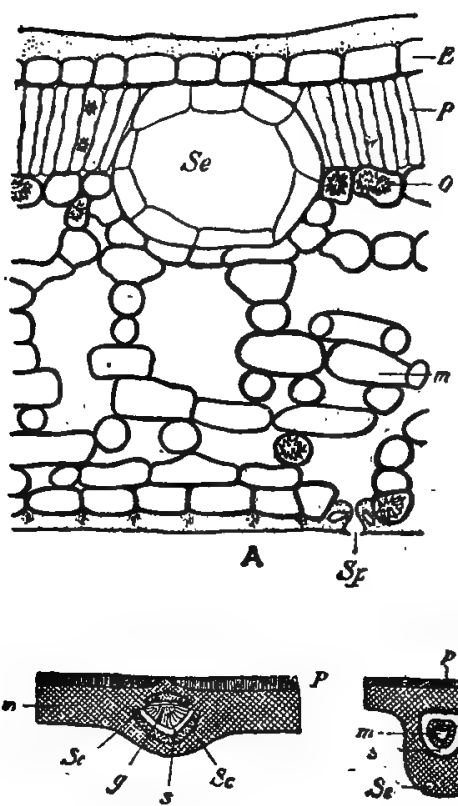

D

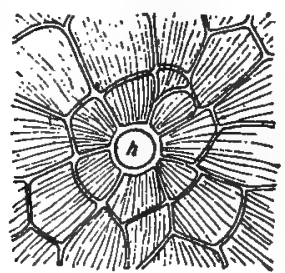

B

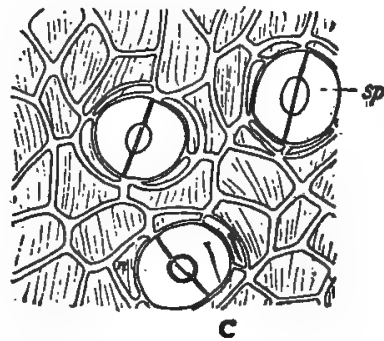

C

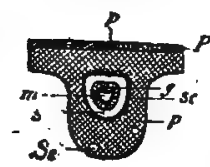

E

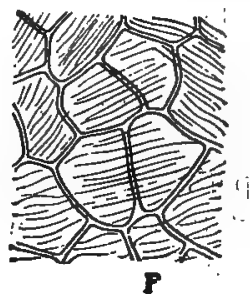

Frg. 257. Pilocarpus prinnatifolius: A, transverse section of lamina showing upper epidermis (E), oil gland (Se), palisade cells (P), some of which contain rosette aggregates of calcium oxalate, loose parenchyma (m), some of the cells of which contain calcium oxalate (o), and lower epidermis'with a stoma (Sp). B, surface view of epidermis showing basal portion of a non-glandular hair (h). The remains of hairs are often found, the hairs themselves having beet rubbed off. $\mathrm{C}$, view of the under surface of the lamina showing stomata (sp). D, diagram showing the arrangements of the tissues in one of the secondary veins: $\mathrm{P}$, palisade cells; $m$, loose parenchyma; Sc, sclerenchyma; s, sieve; $g$, trachér. $\mathrm{E}$, transverse section of the primary or middle vein showing palisade cells (P), elongated parenchyma (p), oil glands (Se), sieve (s), tracheæ $(\mathrm{g})$, which surrotunds parenchyma (m), thus distingurshing it from the secondary vein. F, surface view of upper epidermis. of lamina.-After Meyer.

Perinambuco Jaborandi,-iElliptical, lanceolate or obloniglanceólatè, 6 to I $2 \mathrm{~cm}$. long; I.5 to $4 \mathrm{~cm}$. broad; apex obtüse, more or less emarginate; base rounded or acute, unequal; margin 
entire, slightly revolute; upper surface dark green or brownishgreen, glabrous, midrib more or less depressed near the apex, veins of the first order prominent, diverging at an angle of $35^{\circ}$ to $50^{\circ}$ and uniting with each other near the margin; under surface yellowish- or greenish-brown, pubescent, with numerous lightbrown projections, midrib prominent, yellowish-brown; petiolule 3 to $5 \mathrm{~mm}$. long; glandular-punctate; texture coriaceous, brittle; odor slight; taste bitter, somewhat aromatic, becoming pungent.

Paraguay Jaborandi.-Oblong-lanceolate, ovate or obovate, 8 to $\mathrm{I} 2 \mathrm{~cm}$. long, 2.5 to $5 \mathrm{~cm}$. broad; apex slightly emarginate; base equal; margin very slightly revolute; upper surface dark green, midrib and veins of the first order not very prominent, the latter diverging at an angle of $25^{\circ}$ to $45^{\circ}$; under surface grayish-green or light green, glabrous, with numerous papillæ; midrib yellowish, with few short hairs; frequently with numerous black disks of a species of Puccinia on both surfaces; texture as in Pernambuco jaborandi, but only about one-half as thick.

MaRAnham JaboRAnDI.-Oblong-ovate, or oblanceolate, I.5 to $4 \mathrm{~cm}$. long, I. 5 to $2.5 \mathrm{~cm}$. broad; apex deeply emarginate; base tapering into the petiolule; margin distinctly revolute; upper surface bright green, glabrous, sometimes shiny, midrib prominent, veins of the first order not very prominent, diverging at an angle of $35^{\circ}$ to $45^{\circ}$; under surface grayish-green; frequently with numerous black disks of a species of Puccinia on both surfaces; petiolule about $8 \mathrm{~mm}$. long; texture as in Paraguay jaborandi but thinner.

Inner Structure.-See Fig. 257.

Constituents.-About 0.5 to $\mathrm{I}$ per cent. of the alkaloid PILOCARPINE, which occurs as a colorless, syrupy liquid, but forms well-defined crystalline salts, the hydrochloride and nitrate being official. It is very soluble in water, the solutions being dextrorotatory. Pilocarpine is decomposed by heat or alkalies and yields an isomeric substance, ISOPILOCARPINE, which is an oily compound and is usually present in the commercial nitrate of pilocarpine. The alkaloid PILOCARPIDINE has been obtained from the mother liquors, after the crystallization of pilocarpine, as a syrupy substance forming a crystalline nitrate and resembling somewhat pilocarpine in its physiological action. An alkaloid related to 
pilocarpidine has been isolated from the leaves of $P$. pinnatifolius in the form of an amorphous substance called JABORINE, and resembling atropin in its physiological properties. Recent investigations do not seem to show that these alkaloids occur in either the leaves of Paraguay or Maranham Jaborandi. Fresh pilocarpus leaves also yield 0.2 to I.I per cent. of a volatile oil which contains a hydrocarbon pilocarpene and a stearoptene belonging to the olefine series.

Allied Drugs.-Nearly all of the species of Pilocarpus contain some pilocarpine, as well as other principles which are found in the official leaves. Many of these find their way into commerce and in some instances their assays compare favorably with the official leaves. Aracati Jaborandi is obtained from P. 'spicatus, the leaflets being broad and coriaceous and said to contain o.I6 per cent. of alkaloids. The leaflets of $P$. racemosus of the West Indies are large and nembranous and contain about .66 per cent. of pilocarpine.

EUCALYPTUS.-The leaves of Eucalyptus Globulus (Fam. Myrtaceæ), a tree (Fig. 258) indigenous to Eastern Australia and Tasmania, and cultivated in Southern Europe, California and the Southern United States (p. 346). The leaves are collected from older parts of the tree and dried, the principal part of the commercial supply coming from the south of France.

Description.-Bilateral, lanceolate, scythe-shaped, 15 to 30 $\mathrm{cm}$. long, 2.5 to $5 \mathrm{~cm}$. broad; apex acuminate; base somewhat unequal, actute; margin entire, revolute; surface light green, glabrous, with numerous small, circular, reddish-brown depressions or projections in the neighborhood of the stomata and veins, consisting of cork cells ${ }^{1}$; midrib usually with a small groove on one side; veins of the first order diverging at an angle of about $55^{\circ}$, running to within I $\mathrm{mm}$. of the edge, where they anastomose, forming a vein parallel with the margin; petiole 2 to $3 \mathrm{~cm}$. long, flattened and somewhat twisted; pellucid punctate; texture coriaceous; odor slightly aromatic; taste aromatic, somewhat bitter and cooling.

${ }^{1}$ These corky patches appear to be due to an irritation caused by some of the constituents. 
Constituents.-Volatile oil 3 to 6 per cent., of which over 60 per cent. is eucalyptol. (cineol), the remainder consisting of d-pinene (eucalypten) and other terpenes; several resins, one of which is crystalline and colored brownish-red with ferric chloride; a neutral bitter principle; eucalyptic acid; tannin and calcium oxalate.

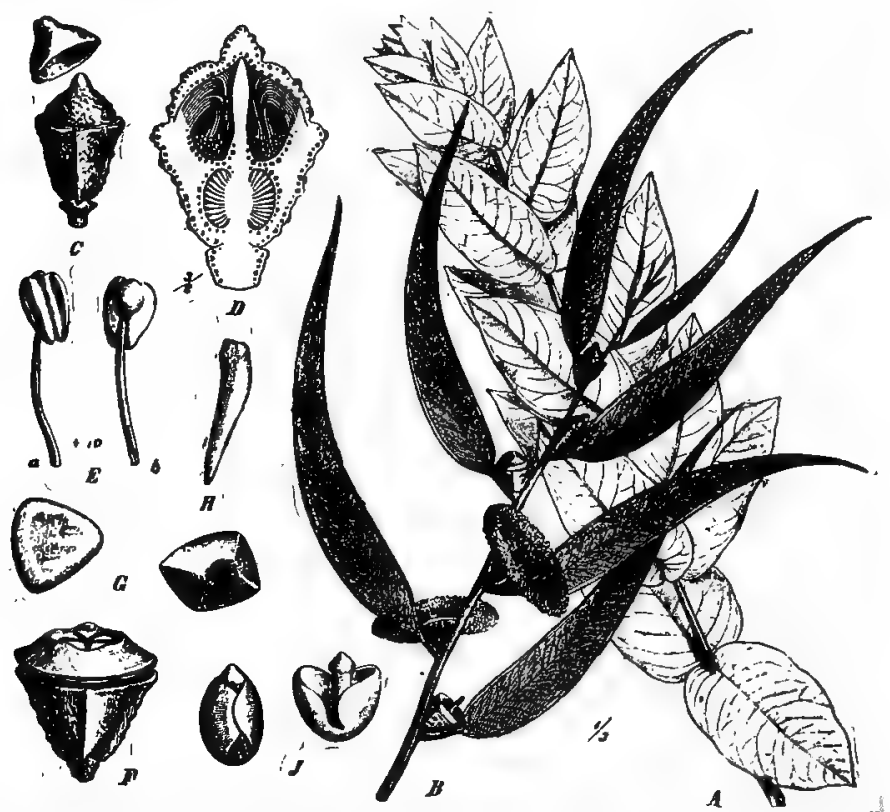

Fig. 258. Eucalyptus Globulus: A, young branch with opposite, oblong, dorsiventral, sessile leaves. B, floweritig branch with scythe-shaped, petiolate, scattered, bilateral leaves. C, flower-bud showing the detached upper portion of the perianth (operculum or lid) which co'ver's the stamens until they are fully mature. D, longitudinal section of a flower bud showing incurved flaments which curve outwards when the flower matures. $E$, stamens in two views, $F$, truncated capsule or pyxis. G, two fertile seeds. H, sterile seed, seeds of this kind usually being most numerous. J, two germinating plants.-A-F, after Niedenzu; G-J, after Müller.

Allied Plants:-The following Eucalypts yield an oil consisting principally of eucalyptol and pinene, and in which the eucalyptol exceeds 40 per cent., phellandrene being absent: Eucalyptus resinifera, E. polyanthema, E. Behriana, E. Rossii, E. pendula, E. dealbata, E. tereticornis linearis, E. rostrata borealis, E. maculosa, E. camphora, E. punctata, E. squamosa, E. Bridgesiana, E. goniocalyx, E. bicolor, E. viminalis, E. populifolia, 
E. longifolia, E. Maidcni, E. Globulus, E. pulverulenta, E. cinerea, E. Stuartiana, E. Stuartiana var. cordata, E. LLorrisii, E. Smithii and E. sideroxylon.

UVA URSI.-RED BEARBERRY.-The leaves of Arctostaphylos Uva-ursi (Fam. Ericaceæ), a procumbent shrub indigenous to Europe, Asia and the Northern United States and Canada (p. 357).

Description.-Obovate, spatulate, 18 to $30 \mathrm{~mm}$. long, 6 to Io $\mathrm{mm}$. broad; apex obtuse; base acute, tapering; margin entire, slightly revolute; upper surface dark green, glabrous, finely reticulate; under surface yellowish-green; petiole about $3 \mathrm{~mm}$. long, slightly pubescent; texture coriaceous, brittle; odor slight; taste slightly bitter, astringent.

When a solution of vanillin and hydrochloric acid, to which a few drops of fresh ferrous sulphate solution are added, is applied to a section of Uva Ursi a crimson color is produced which distinguishes the drug from its adulterants, with the exception of Vaccinium Vitis-Idca. It is distinguished from leaves of the latter plant as well as other adulterants by becoming bluish-black with ferrous sulphate.

Constrtuents.-Two glucosides-arbutin and ericolin; a crystalline, resinous principle ursone; tannin about 5 per cent.; gallic acid; ellagic acid; a yellow, crystalline coloring principle; calcium oxalate; ash about 3 per cent.

ARBUTin forms colorless, bitter needles, which are soluble in water and alcohol, the solutions being colored azure blue upon the addition of an alkali followed by phosphomolybdic acid. It yields on hydrolysis hydroquinone (arctuvin) and methyl hydroquinone.

ERICOLIN is a yellow, hygroscopic, bitter substance, which yields on hydrolysis the volatile oil ericinol. URSONE occurs in tasteless needles insoluble in water and capable of being sublimed.

Allied Plants.-Various other species of Arctostaphylos contain principles similar to Uva Ursi. The leaves of trailing arbutus (Epigcea repens) contain ericolin and possibly arbutin. Ericolin occurs in a number of species of Ledum and Rhododendron, and European huckleberry (Vaccinium myrtillus), small cranberry (Oxycoccus palustris) and heather (Calluna vulgaris), all of 
Europe. The two latter plants are naturalized in New Jersey, the New England States and Eastern Canada. A number of species of Rhododendron contain, in addition to andromedotoxin (see page 357), the same principles found in Uva Ursi. Marsh tea or narrow-leaved Labrador tea (Lcdum palustre), growing in the Northeastern United States and Canada, as well as Northern Europe and Asia, contains ericolin, arbutin, an ethereal oil (the principal component of which is Ledum camphor), valerianic, acetic and butyric acids. (Compare also Chimaphila.)
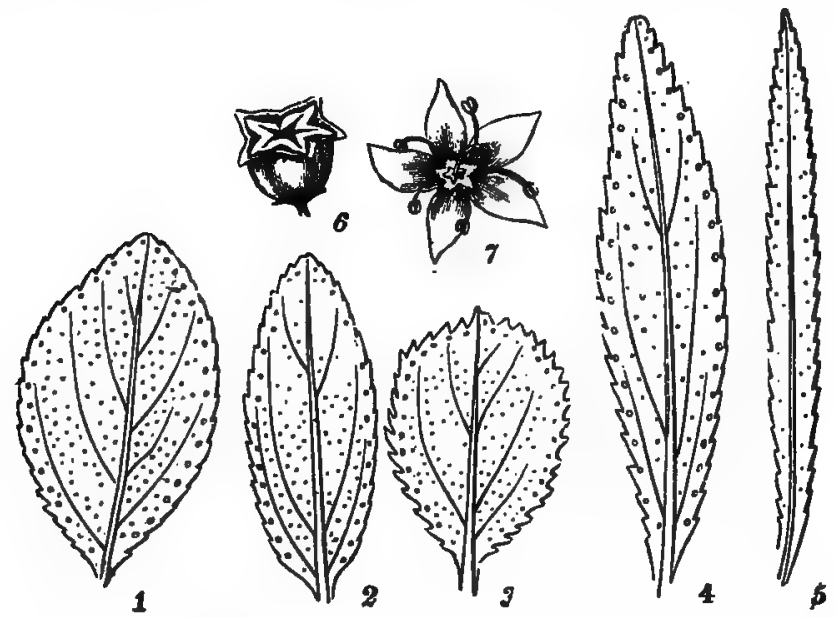

Fig. 259. Buchu leaves showing oil glands which give the leaves the pellucid-punctate appearance: $I$, Barosma crenata ovalis; $2, B$. cremulata latifolia; 3 , B. betulina; 4 , $B$. serratifolia; 5, Empleurum ensatum; 6, dehiscent fruit of $B$. crenulata; 7 , flower of the same.After Tschirch.

BUCHU.-The leaves of several species of Barosma (Fam. Rutaceæ), a shrub indigenous to Cape Colony. There are two chief commercial varieties: (I) Short Buchu obtained from $B$. betulina and (2) Long Buchu, obtained from $B$. serratifolia, the short buchu being official (p. 306; Fig. 259).

Short Buchu.-Obovate, rhomboid-obovate, ovate or elliptical or somewhat cuneate; 9 to $18 \mathrm{~mm}$. long, 6 to $12 \mathrm{~mm}$. broad; apex obtuse, somewhat recurved; base acute or cuneate; margin sharply dentate or denticulate and with an oil-secretion reservoir at the base of each tooth; upper surface yellowish-green, glab- 
rous; under surface yellowish-green, longitudinally striate; both surfaces papillose; petiole about I mm. long; texture coriaceous; odor and taste distinct, aromatic.

Long Buchu.-Linear-lanceolate, 25 to $40 \mathrm{~mm}$. long, 4 to 6 mm. broad; margin sharply serrate and glandular; apex somewhat rounded or truncate.

Constituents.-Short buchu contains about I.2 to I.45 per cent. of volatile oil, of which about 30 per cent. is the crystalline body diosphenol; long buchu contains only about one-third as much volatile oil and it contains little or no diosphenol; buchu also contains two crystalline glucosides, diosmin and hesperidin (see Aurantii Amari Cortex); mucilage and calcium oxalate.

Allied Plants.-The leaves of Barosma cremulata are occasionally found in the market; they are ovate, obovate or oblonglanceolate, about twice as broad as long buchu, with slightly toothed and glandular margin, more or less rounded apex, and yield about I.6 per cent. of volatile oil resembling that of short buchu.

Adulterants.-The leaves of Empleurum ensatum (Fam. Rutaceæ) have been offered for long buchu. They are linearlanceolate, 4 to $6 \mathrm{~cm}$. long, with acuminate and glandless apex; sharply serrate and glandular. They have a bitter taste and yield about I per cent. of a volatile oil which does not contain a crystalline principle.

Karoo BUchu is derived from Diosma succulenta, of South Aftica. The leaves are ovate, 3 to $6 \mathrm{~mm}$. long, coriaceous, obtuse and slightly recurved at the apex. They yield an oil with a peppermint-like odor and containing diosphenol. They also contain considerable mucilage and yield about 26 per cent. of extractive matter.

CHIMAPHILA.-PIPSISSEWA.-The dried leaves of Chimaphila umbellata (Fam. Ericaceæ), a perennial. herb (p. 355 ) indigenous to the United States and Southern Canada and Northern Europe and Siberia.

Description.-Lanceolate or oblariceolate, 2.5 to $5 \mathrm{~cm}$. long, 8 to $18 \mathrm{~mm}$. broad; apex obtuse or acute; base acute or cuneate; margin sharply serrate; upper surface dark green, not mottled, glabrous, shiny; midrib and veins depressed, the latter diverging 
at an angle of about $60^{\circ}$ and uniting with each other near the margin; under surface yellowish-green; petiole about I $\mathrm{mm}$. long; texture coriaceous, brittle; odor slight; taste astringent, bitter.

Constituents.--A neutral, tasteless principle chimaphilin, occurring in golden-yellow needles; two glucosides-arbutin and ericolin (see Uva Ursi); several other crystalline principles; a volatile oil; tannin 4 to 5 per cent.; calcium oxalate; ash about 5 per cent.

COCA.-COCA LEAVES.-The leaves of Erythroxylon Coca, and its varieties (Fam. Erythroxylaceæ), shrubs (Fig. 260) probably indigenous to Bolivia and Peru, where they are extensively cultivated, as well as in Java and Ceylon (p. 303). The leaves when fully grown are picked and quickly dried in the sun. Two or three harvests are obtained a year. There are two principal commercial varieties-Bolivian (Huanco) and Peruvian (Truxillo), the former being preferred. On keeping the leaves the alkaloid cocaine is dissipated and they lose their stimulating properties, particularly if they are not thoroughly dried.

Bolivian Coc..-O Oval, obovate or elliptical, 3 to $7 \mathrm{~cm}$. long, 2 to $3 \mathrm{~cm}$. broad (Fig. 260) ; apex acute, slightly mucronate; base acute; margin entire, somewhat revolute; upper surface dark green, glabrous, midrib with a distinct ridge; under surface yellowish-green, distinctly undulate, with numerous minute papillæ, frequently with a parallel line about $4 \mathrm{~mm}$. from the midrib on either side and extending from the base to the apex; petiole dark brown, I to $6 \mathrm{~mm}$. long; texture somewhat coriaceous; odor distinct; with a bitter taste, and producing a sensation of numbness:

Peruvian Coca.—Leaves usually more broken, 3 to $5.5 \mathrm{~cm}$. long, I.5 to $2 \mathrm{~cm}$. broad; upper surface light green, ridge on the midrib faint or wanting; under surface light yellowish-green, the curved line on either side of the midrib usually wanting; more or less fragile; sensation of numbriess on tasting the drug not so pronounced.

The flowers of a species of Inga (Fam. Leguminosæ) are frequently present. The pedicel is about $2 \mathrm{~mm}$. long; the calyx yellowish-brown, about $\mathrm{I}$ cin. long, five-toothed, pubescent; corolla cylindrical, or somewhat funnel-shaped, 5-toothed, about 
I $\mathrm{cm}$. long, yellowish-brown, very pubescent; stamens numerous, more or less united into a tube, exserted; filaments reddish-brown.

Inner Structure.-See Figs. 26i, 286.

Constituents.-Several alkaloids, including cocaine, cinnamyl-cocaine, truxilline and ecgonine. Of these cocaine is the

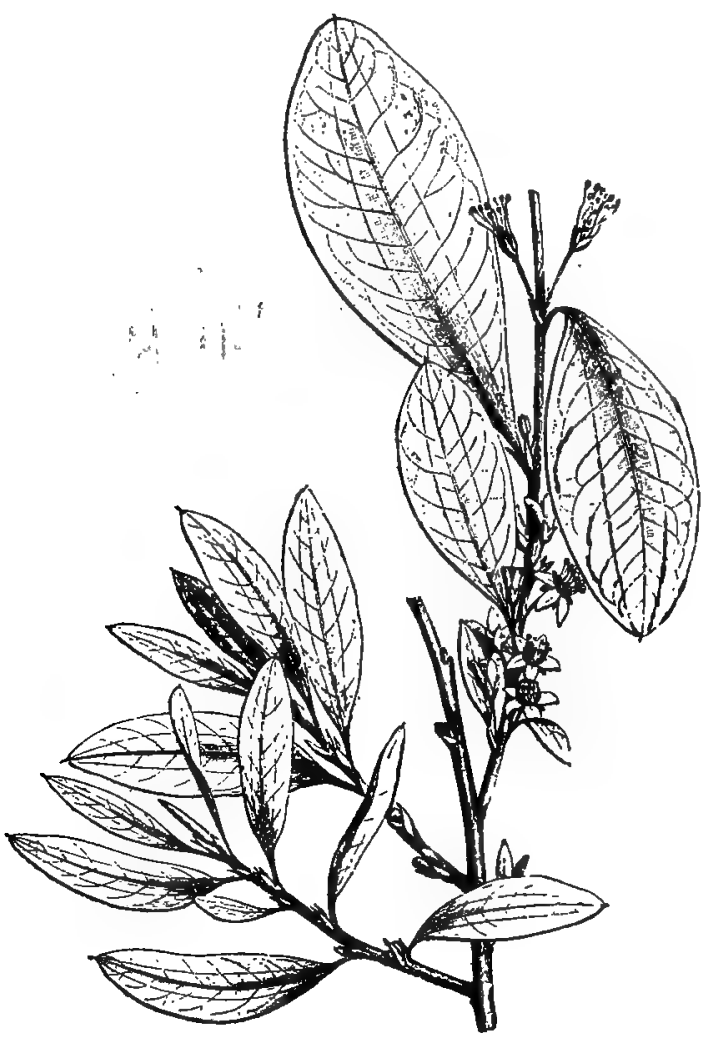

Frg. 260. Flowering branch of Erythroxylon Coca showing the parallel lines on either side of the midrib, which are not true veins, but due to an extra development of hypodermal cells in this region.

most important, the Bolivian leaves containing the greatest amount, or 0.5 to I per cent.; the other alkaloids preponderate in the Peruvian leaves, which usually do not contain more than one-half or two-thirds as much cocaine as the Bolivian leaves; the Java leaves also contain benzoyl-pseudotropine; in addition, 
coca leaves contain a volatile aromatic principle; a tannin giving a green color with ferric salts; and calcium oxalate.

CocAINe (benzoyl-methyl-ecgonine) occurs in monoclinic prisms which are sparingly soluble in water, soluble in' alcohol,

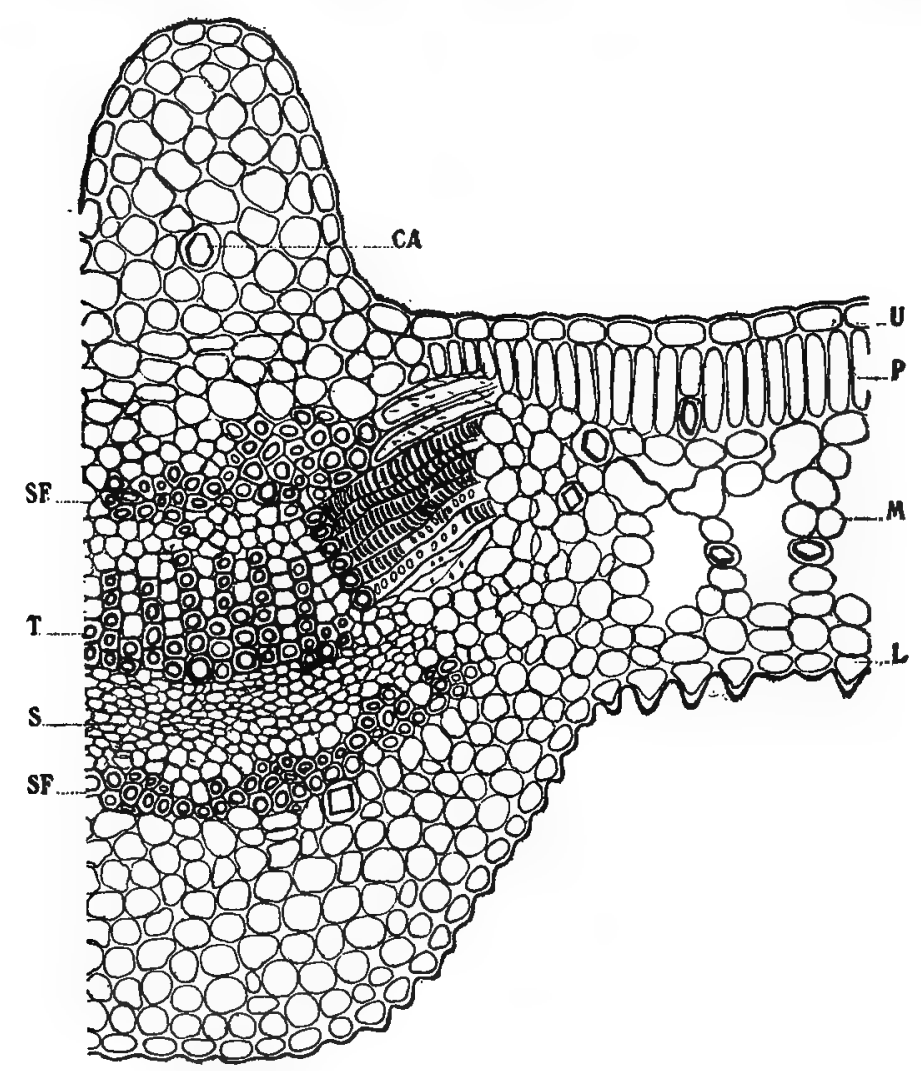

Frg. 26I. Transverse section of coca leaf near the midrib: $U$, upper epiciermis; $P$, palisade cells, some of which contain monoclinic prisms of calcium oxalate; $M$, loose parenchyma, some of the cells of which also contain monoclinic prisms of calcium oxalate; L, lower epidermis with distinct papilla; CA, monoclinic prism of calcium oxalate; SF, sclerenchymatic fibers; $\mathrm{T}$, tracheæ; $\mathrm{S}$, sieve.

the solution having a bitter taste and producing a characteristic numbness. It forms crystalline salts and yields, on hydrolysis, which is rather easily accomplished, benzoic acid, methyl alcohol and ecgonine. 
ECGONINE crystallizes in monoclinic prisms, which are slightly bitter, readily soluble in water and sparingly soluble in alcohol. Cinnamyl COCAINE is found in commercial cocaine and occurs in rosettes of needle-shaped crystals which are nearly insoluble in water, soluble in alcohol and on hydrolysis yield cinnamic acid, methyl alcohol and ecgonine. $a$-Truxilline (cocamine) is a bitter alkaloid which occurs either in an amorphous form or in large crystals and yields on hydrolysis truxillic acid, methyl alcohol and ecgonine. Truxilline occurs sometimes to the extent of 0.5 per cent. in Peruvian (Truxillo) leaves. Cocaine is found in the seeds and roots as well as in the leaves. The leaves contain a small amount of methyl salicylate.

It has been shown that young coca leaves contain 2.02 per cent. of total alkaloids, or more than twice as much as the older leaves, while the amount of ash yielded by them is slightly less, being 6.4 per cent. The constituents of Ceylon Coca resemble those of the Java variety.

SENNA.-SENNA LEAVES.-The leaflets of various species of Cassia (Fam. Leguminosæ), small shrubs indigenous to Upper Egypt and Southern Arabia. There are two important commercial varieties: (I) Alexandrian Senna, derived from wild plants (Fig. 262) of Cassia acutifolia, a small shrub growing in the region of the Nile River from Assouan to Kordofan ( $p$. 292), and exported by way of Alexandria and Red Sea ports; (2) Indian or Tinnivelly Senna, derived from cultivated plants of Cassia angustifolia, growing on the East African coast, in Arabia and Northwestern India, and cultivated in Southern India (p. 292). The leaves are carefully collected and dried, the Tinnivelly variety being more largely used, although the Alexandrian is more highly esteemed.

Alexandrian Senna,-Lanceolate or ovate-lanceolate; I.5 to $3 \mathrm{~cm}$. long, 5 to $8 \mathrm{~mm}$. broad (Fig. 262, F) '; apex acute, mucronate; base unequal, acute; margin entire; upper surface pale green, nearly glabrous, midrib sometimes depressed, veins of first order more or less prominent, under surface light grayishgreen, midrib prominent, minutely pubescent, especially near the veins; petiolule about $\mathrm{I} \mathrm{mm}$. long; texture coriaceous, fibrous; odor slight; taste somewhat bitter. 
Tinnivelly Senna.-From 2.5 to $5 \mathrm{~cm}$. long (Fig. 262, $H$ ), upper surface light green, lower surface slightly pubescent.

Inner Structure.-See Fig. 263.

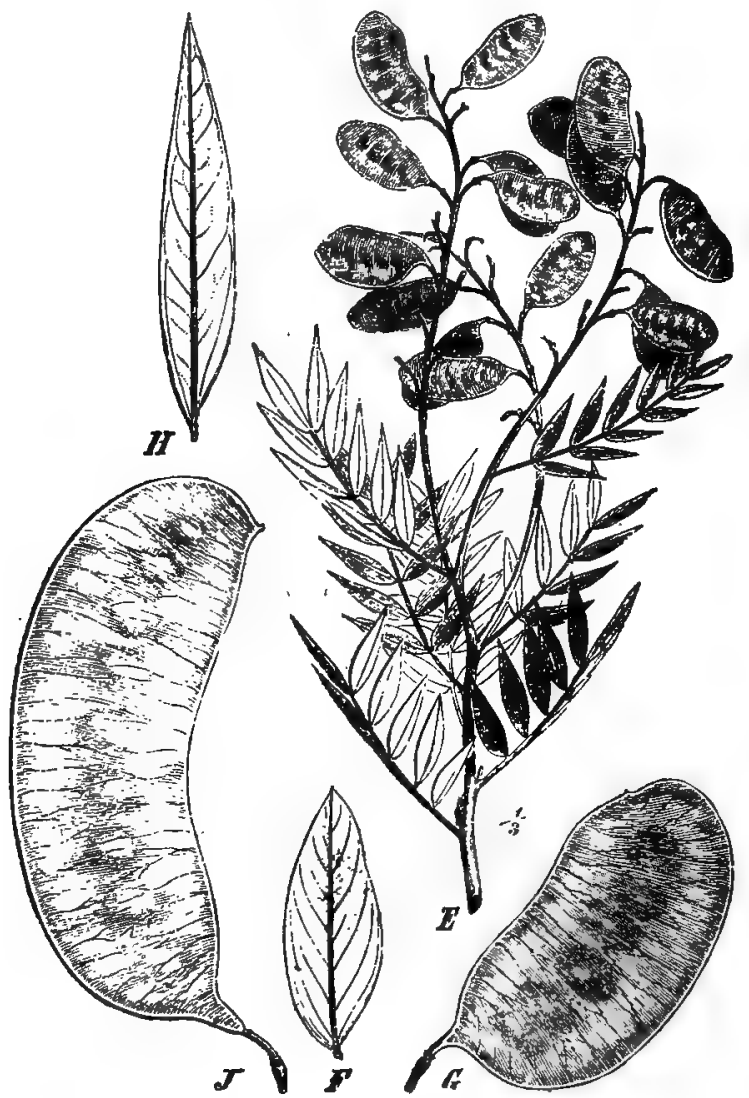

Fig. 262. Casșia acutifolia: E, fruiting branch; F, a single leaflet; G, a pod. Cassia angustifolia: $\mathrm{H}$, a single leaf; J, a pod.-After Taubert.

Constituents.-Senna leaves contain several glucosides which yield oxymethylanthraquinone compounds resembling those found in aloes and rhubarb; a glucosidal substance, ANTHRAGLUCOSENNIN, which occurs as a brown-black powder and yields on hydrolysis senna-emodin (tri-oxymethylanthraquinone) and 
senna-chryosphanic acid (cli-oxymethylanthraquinone). (See Rhubarb.) Anthraglucosennin when acted upon by alkalies produces an amorphous black powder, SENAL-NIGRIN, which also
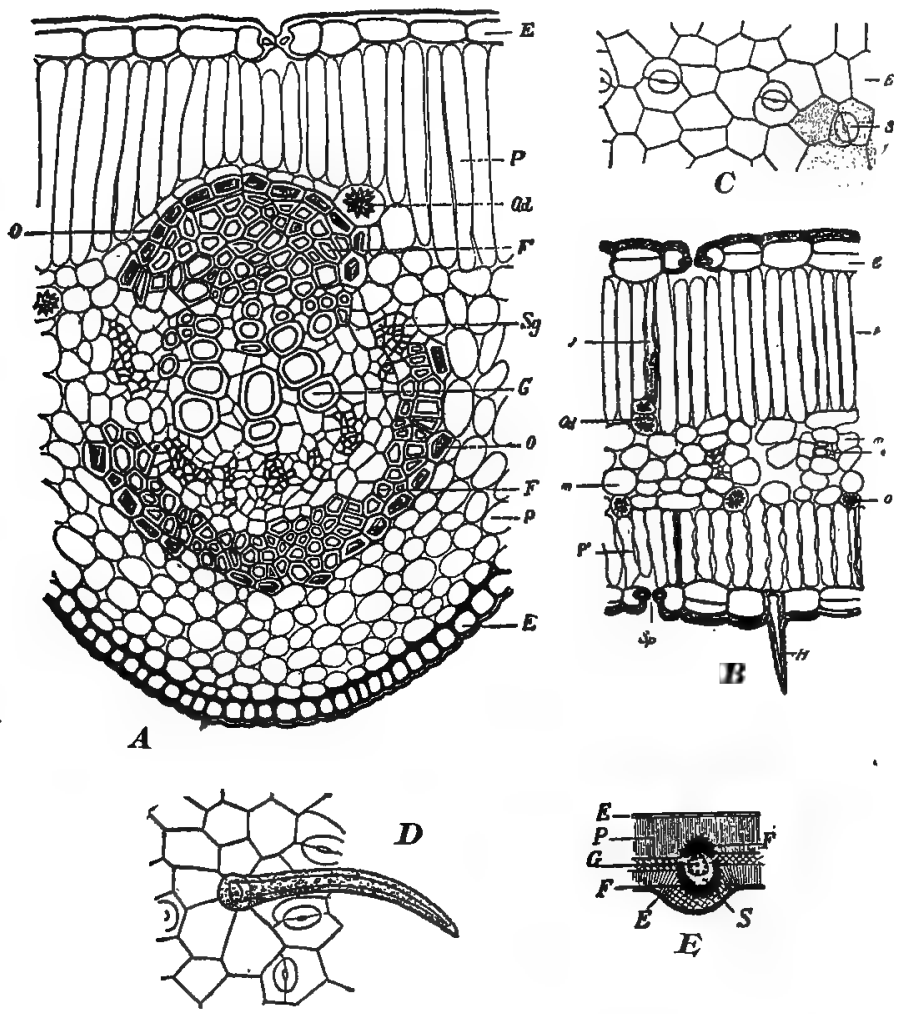

FIg. 263. Cassia angustifolia (India senna): A, transverse section through the middle vein showing upper epiderndis (E), palisade cells $(P)$, rosette aggregate of calcium oxalate (Od), monoclinic prisms of calcium oxalate (o), tracheæ (G), sieve (Sg), sclerenchyma fibers (F), lower epidermis with rather thick-walled cells (E). B, transverse section through portion of leaf between the veins showing the absence of monoclinic prisms of calcium oxalate, the presence of palisade cells and stomata in both the lower and upper portion, and a hair $(\mathrm{H})$ on the lower surface. $\mathrm{C}$, lower epidermis on surface view; $\mathrm{D}$, upper epidermis showing stomata and a single hair. E, diagram of section through the middle vein, the letters corresponding to those in A.-After Meyer.

yields on hydrolysis emodin and chrysophanic acid. Senna also contains a yellowish, amorphous glucoside, GLUCOSENNIN ; a reddish-brown, amorphous substance, SENNA-RHAMNETIN, which dif- 
fers from rhamnetin found in the fruit of Rhammus cathartica in that the latter is crystalline and forms a fluorescent solution with sulphuric acid; senna-isoemodin (isomeric with senna-emodin), which is soluble in petroleum ether; CATHARTIC ACID; calcium oxalate; and ash Io to I2 per cent. The active principles of senna are emodin, chrysophanic acid and cathartic acid. The percentage of emodin is from 0.8 per cent. in Tinnivelly leaves to I per cent. in the Alexandria variety.

Allied Plants.-Senna pods (Fig. 262), derived from both C. acutifolia and C. angustifolia, are also found in the market, either admixed with the leaves or sold separately; they are from 3.5 to $7 \mathrm{~cm}$. long and about $2 \mathrm{~cm}$. broad, greenish to dark brown externally, and contain from five to seven obovate, dark brown, nearly smooth seeds. They contain apparently the same active principles as the leaves.

Similar principles are found in other species of Cassia, especially in the AMERICAN SENNA (C. marilandica), which is an herbaceous perennial (Fig. 7I), indigenous to the Eastern and Central United States and Canada, with I2- to 20-foliate leaves, yellow flowers and a linear, slightly curved legume. The leaves of senna are sometimes admixed with those of Cassia oborata, which are broad and obovate, while the pods of the latter species are distinctly curved. Mecca or ARABIAN SENNA is obtained from a variety of $C$. angustifolia, growing in Arabia. The leaves of C. holosericea, of Abyssinia, are quite hairy and found occasionally in the market under the name of AdEN SENNA. The leaves of other members of the Leguminosæ are used like senna, as Cytisus purgans of Southern France, Tephrosia Apollinea of Egypt, and Colutea cruenta of the Caucasus region.

The root of Viviania esculenta. (Fam. Geraniacex), of the East Indies contains a principle resembling cathartic acid, a glucoside also found in senna and rhubarb.

HAMAMELIDIS FOLIA.-WITCHHAZEL LEAVES.The leaves of Hamamelis zirginiana (Fam. Hamamelidaceæ), a shrub (Fig. 264) indigenous to the Eastern and Middle United States and Canada (p. 286). The leaves are collected in autumn, and are used in the fresh condition, or dried; when dried they should be carefully preserved and not kept longer than one year. 
Description.-Broadly elliptical, or rhomboid-obovate, more or less unequal; 3.5 to $12 \mathrm{~cm}$. long, 2.5 to $7 \mathrm{~cm}$. broad; apex rounded, acute or acuminate; base obliquely cordate; margin sin-

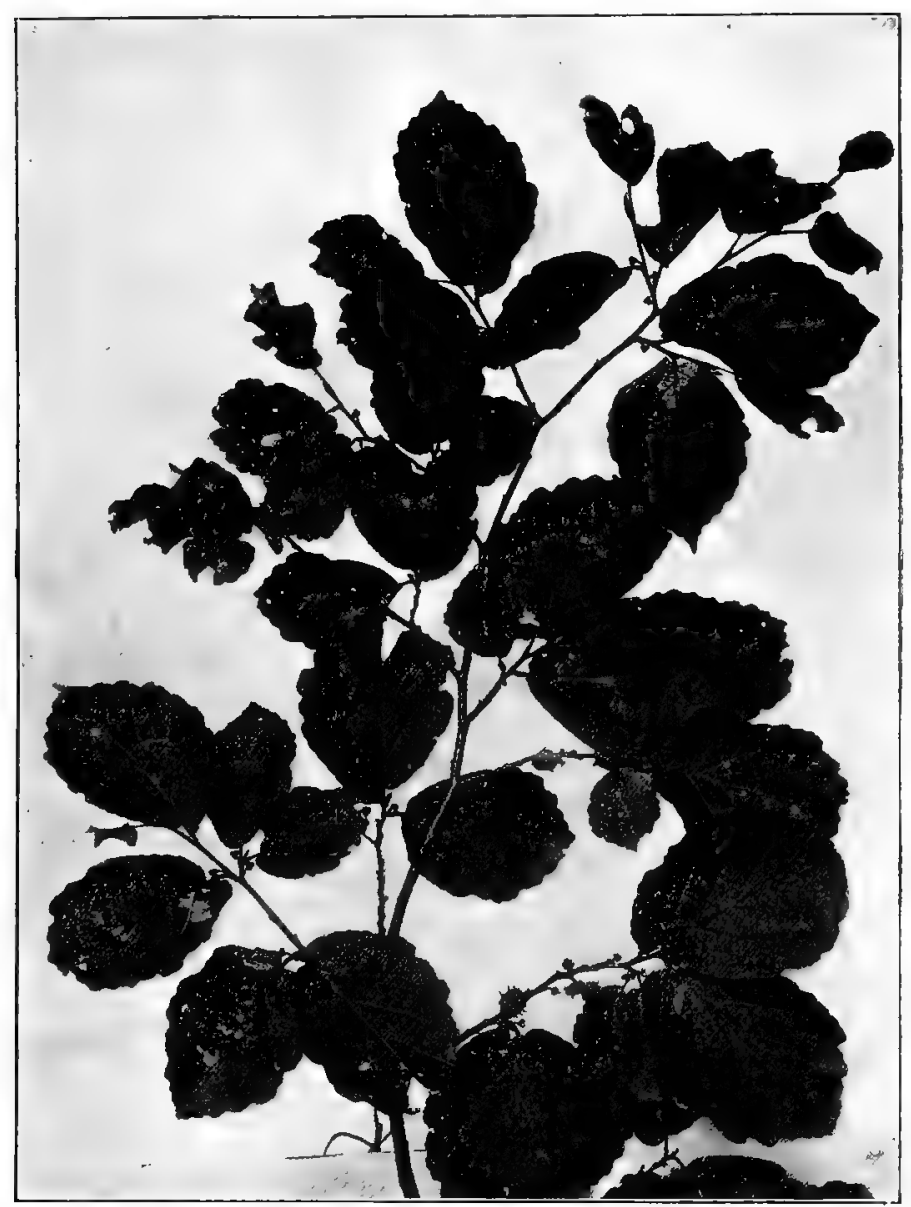

FIG. 264. Branch of Witchhazel (Hamamelis virginiana) showing alternate, shortpetiolate and pinnate-reticulately veined leaves, having a broadly oval or obovate outline, round, acute, or slightly acuminate apex; slightly cordate, inequilateral base; and undulate or sinuous margin.

uate or sinuate-dentate; upper surface dark green, veins of the first order diverging at an angle of about $60^{\circ}$ and running nearly parallel to the margin, with grayish patches of a mold and slightly 
pubescent; under surface light green, pubescent, midrib and veins prominent; petiole 5 to $\mathrm{I} 2 \mathrm{~mm}$. long; texture coarse, brittle; odor slight; taste astringent.

Constituents. - Volatile oil; a bitter principle; tannin, about 3 per cent.; gallic acid, and calcium oxalate.

The distillate, obtained on distilling either the fresh or dried leaves of Hamamelis with water, contains an aromatic substance that apparently does not exist as such in the leaves. The substance sold as hamamelin is a mixture consisting of an evaporated alcoholic extract of either the leaves or bark, that of the former being greenish-black and more permanent and the latter brownishblack and more or less hygroscopic.

SALVIA.-SAGE.-The leaves of Salria officinalis (Fam. Labiatæ), a perennial herb (p. 368) indigenous to Southern Europe, and cultivated in England, France, Germany and the United States, both for use as a drug and as a pot herb. The leaves are collected when the plants are in flower, and carefully dried in the shade.

Description.-Oblong-lanceolate or ovate, 2 to Io $\mathrm{cm}$. long, I to $2.5 \mathrm{~cm}$. broad; apex acute ; base rounded or somewhat heartshaped, frequently lobed; margin crenulate; upper surface grayish-green, densely pubescent (Fig. 284,F) when the leaves are young, the older leaves being nearly smooth, midrib and veins depressed; under surface light grayish-green, midrib prominent, veins of first order diverging at an angle of $55^{\circ}$ and running nearly parallel to the margin, minutely reticulate and densely pubescent; petiole I to $4 \mathrm{~cm}$. 1cing, upper side grooved, grayish purple; texture velvety; more or less pliable; odor aromatic; taste aromatic and bitter.

Constituents.- Tolatile oil 0.5 to 2.5 per cent., containing pinene, cineol, thuijon and borneol; a bitter principle somewhat rescmbling marrubiin; resin; and tannin, or a principle closely resembling it in its, astringency and behavior with ferric salts.

Altied PlanT\%, -The oil from Muscatel Sage (Salvia Scla$r c a)$ has an odor of lavender and apparently contains linalyl acetate.

ERIODICTYON-YYERBA SANTA.-The dried leaves of Eriodictyon californicum (Syn. E. glutinosum) (Fam. Hydro- 
phyllacex), an evergreen shrib (p. 367) indigenous to the mountains of California and Northern Mexico.

DESCRIPTION.-Usually broken into fragments; lamina lanceolate, 7 to $15 \mathrm{~cm}$. long, I to $3 \mathrm{~cm}$. broad; apex acute; base acute, slightly tapering into the petiole; margin nearly entire or unevenIy serrate; upper surface yellowish-green, glabrous, resinous; under surface grayish-green, reticulate, minutely tomentose between the reticulations, midrib light yellow, prominent; petiole 5 to $10 \mathrm{~mm}$. long; texture coriaceous, brittle; odor and taste balsamic.

Constituents.-A greenish-yellow acrid resin about 9 per cent.; a yellow crystalline principle eriodictyonic acid (about 2 per cent.), with a somewhat sweetish but acid taste and becoming reddish-black with ferric chloride; volatile oil; ericolin (see Uva Ursi); an inert resin; tannin, and calcium oxalate.

DIGITALIS.-FOX GLOVE.-The leaves of Digitalis purpurea (Fam. Scrophulariaceæ), a biennial herb (Fig. 265) probably indigenous to Central and Southern Europe, and cultivated and naturalized in various parts of Europe and the United States and Canada ( $p .376$ ). The leaves are collected in June from plants of the second year's growth, just before the commencement of flowering, immediately dried (preferably with the leaves on the stem as in the drying of tobacco), and carefully preserved. Germany furnishes the chief supply, the leaves from both cultivated and wild plants being used. Leaves which have been carefully dried and are kept in air-tight vessels will retain their properties for some years. It is necessary to avoid moisture and light, these being the factors which bring about deterioration of the drug.

DeSCRIPTION.-Ustally more or less crumpled and broken into fragments; lamina ovate-oblong or ovate-lanceolate, Io to 25 $\mathrm{cm}$. long, 5 to $\mathrm{I} 5 \mathrm{~cm}$. broad; apex obtuse or rounded; base somewhat cuneate, tapering into the petiole; margin dentate or crenate, the divisions with a yellowish-brown gland-like apex; upper surface dark green, minutely hairy, somewhat wrinkled, with a single water-pore near the apex of each tooth; inder surface grayishgreen, midrib grayish-brown, prominent, from which veins of the first order diverge at angles of $45^{\circ}$ to $65^{\circ}$ and unite with one another near the margin, and from which arise other anastomos- 
ing veins, giving a distinctly reticulate appearance; distinctly pubescent on the veins and frequently on the reticulations; petiole

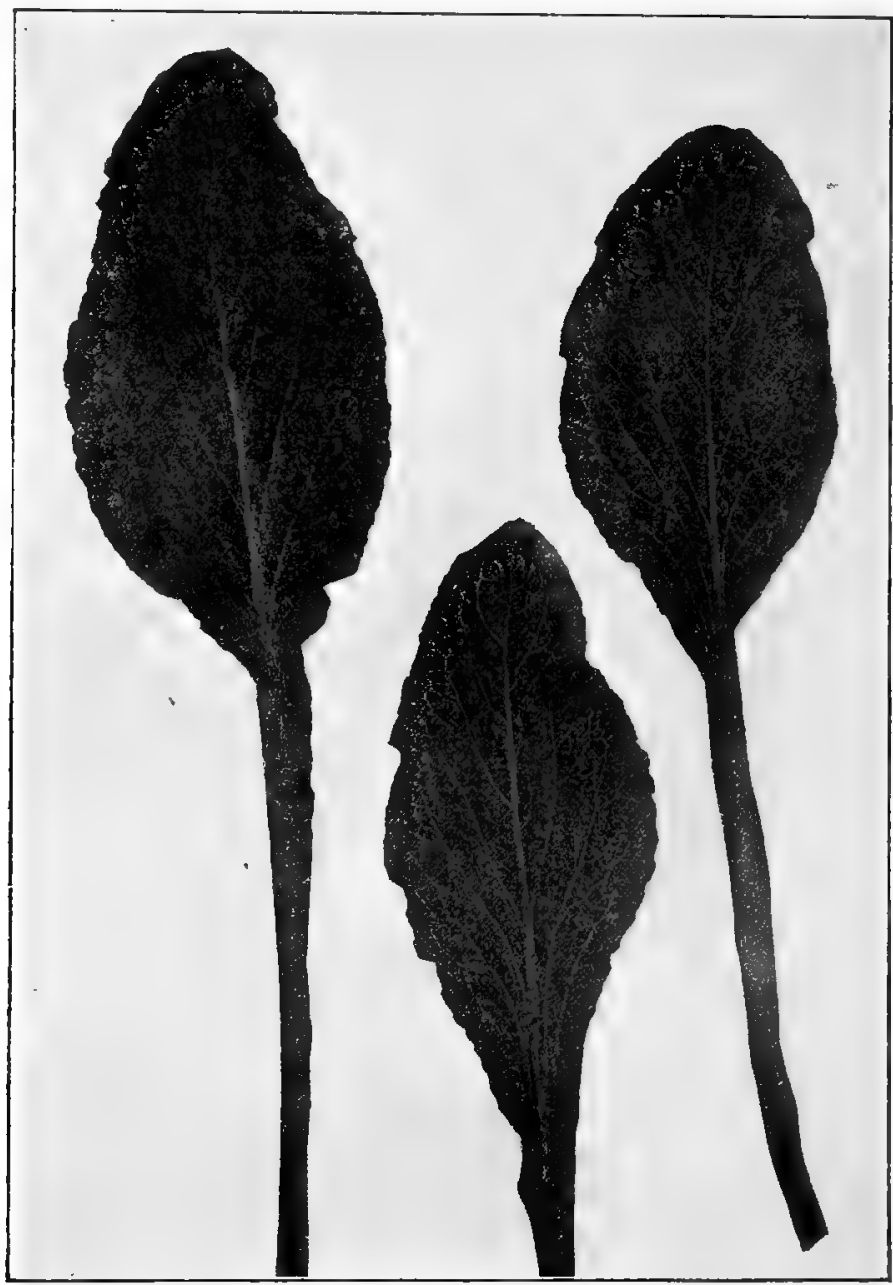

FIG. 265 . Leaves of first year plant of Digitalts purpurea showing reticulate venation and long, winged or laminate petioles.

about one-third the length of the lamina or in the upper leaves nearly wanting, grayish-brown, laminated; texture fragile; odor distinct; taste bitter. 
Leaves that are more than $30 \mathrm{~cm}$. long should be rejected, as also the tuft of radical leaves of the first-year plant.

Inner Structure.-See Fig. 266.

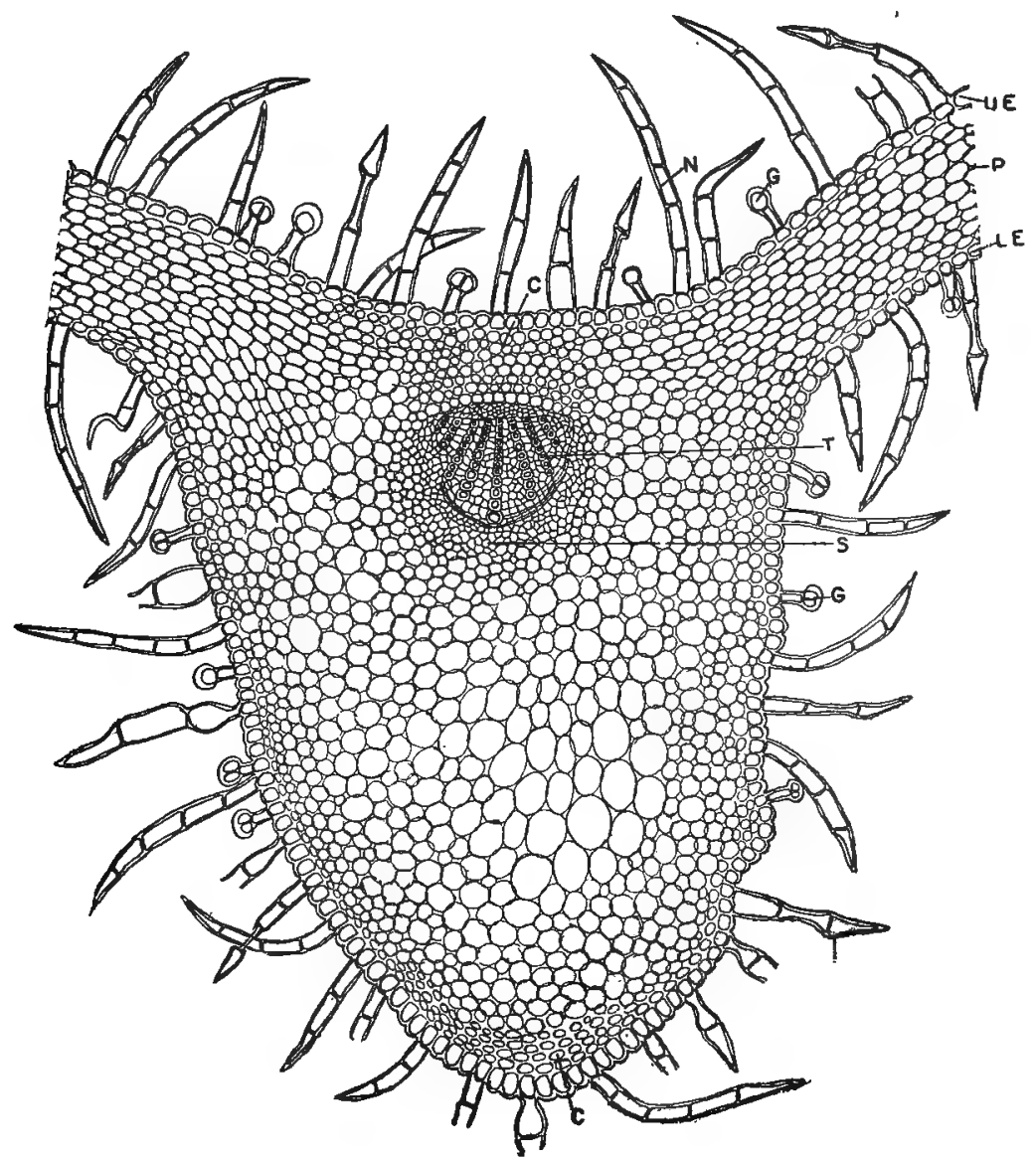

FIG. 266. Transverse section of digitalis leaf through one of the veins: UE, upper epidermis: P, mesophyll; LE, lower epidermis; G, glandular hairs; N, non-glandular hairs; C, collenchyma; T, trachex; S, sieve.

Constrtuents.-Several crystalline glucosides, including digitoxin ( 0.2 to 0.3 per cent.), digitalin and digitonin, the former two being the more important. The drug also contains a volatile oil containing a stearoptene digitalosmin, which has the odor of 
digitalis and a nauseous, acrid taste; a volatile principle, antirrhinic acid, somewhat resembling valerianic acid; digitalic acid, separating in white needles; two coloring principles, one red and the other yellow, resembling chrysophan, a glucoside found in rhubarb; an oxydase ferment which occurs in the recently dried leaves; and ash to to I6 per cent.

Digrroxin occurs in white, needle-shaped crystals which are insoluble in water but more or less soluble in alcohol, of a bitter taste and colored deep green with hydrochloric acid. Digitalin (digitalinum verum) occurs in white, rather characteristic granules which are sparingly soluble in water and more or less soluble in alcohol, forming yellowish-colored solutions with concentrated hydrochloric or sulphuric acid. If the latter acid contains a trace of ferric sulphate solution a permanent bluish-red color is produced. Digitonin is a saponin-like crystalline substance which is nearly insoluble in water, somewhat soluble in alcohol, and remains colorless on treatment with hydrochloric acid, but a dilute sulphuric acid solution becomes garnet-red in color on boiling for some time. Digitalein occurs as a yellowish-white powder and is supposed to be a mixture of digitoxin, digitalin and digitonin. FRENCH DIGITALIN consists chiefly of digitoxin, while in GERM.IN DIGITALIN the principal substance is digitonin. The latter is distinguished by being more soluble in both water and alcohol. Digitin is a physiologically inactive substance. Nativelle's DIGITALINE CRISTALLISÉE consists chiefly of digitoxin.

Allied Drugs.--The seeds of Digitalis purpurea are about I $\mathrm{mm}$. or less in diameter, yellowish- or dark-brown, oblong or spatulate in section, more or less plano-convex and somewhat tuberculate. They contain apparently the same principles as the leaves. The digitoxin is said to be different from that obtained from the leaves and is known as a-digitoxin. It is claimed that the leaves of the first year's non-flowering plant when properly dried are equally as active as the official leaves.

The leaves of Digitalis grandiflora growing abundantly in Switzerland appear to be as efficient as those of Digitalis purpurea.

ADCLTERANTS.-The leaves of other cultivated varieties of Digitalis have been substituited for those of $D$. purpurea, as those of the Mammoth Foxglove (D: monstrosa), which is distin- 
guished by producing long, spike-like racemes which are terminated by one large flower.

The leaves of Inula Helenium (Fig. I82) (Fam. Compositæ) when submitted to assay will compare favorably with those of digitalis, althongh they do not contain any digitoxin. This shows that the assay processes should be followed by confirmatory tests, unless the identity of the drug has been determined beyond doubt.

MATICO.-The dried leaves of Piper angustifolium (Fam. Piperacex), a shrub indigenous to Peru and Bolivia (p. 249).

Descriptron.-Usually in large, compressed, matted masses; lamina narrow, oblong-lanceolate, to to $20 \mathrm{~cm}$. long, 2 to $5 \mathrm{~cm}$. broad; apex acute and long-tapering; base unequal, slightly cordate; margin finely crenulate, with broad, truncate teeth; upper surface dark green, tessellated, harsh to the touch from the presence of numerous very small papillæ and minute, bristly hairs; lower surface grayish-green, reticulate, matted hairy, velvety to the touch, the veins being very prominent and yellowish-brown, those of the first order diverging at an angle of $65^{\circ}$ to $80^{\circ}$, then curving and converging at the apex; petiole 2 to $3 \mathrm{~mm}$. long, texture fragile when dry; odor pronounced, aromatic; taste aromatic, pungent, pepper-like.

The drug is generally admixed with the flower spikes, which are 2.5 to $15 \mathrm{~cm}$. long and about $2 \mathrm{~mm}$. in diameter, yellowishbrown, and consisting of very small perfect flowers, which are subtended by bracts fringed on the margin with long, multicellular, non-glandular hairs; or the spikes may bear the mature -fruits, consisting of somewhat cubical or tetragonal, reddish-brown drupes, which are 0.5 to $\mathrm{I} \mathrm{mm}$. in diameter and finely reticulate, somewhat like the seeds of lobelia.

A few of the jointed stems with swollen nodes are also present. Constituents.-Volatile oil, resin, a bitter principle, and artanthic acid (see p. 249).

HYOSCYAMUS.-HENBANE.-The leaves and flowering tops of Hyoscyamus niger (Fam. Solanacex), an annual or biennial herb (Fig. 267) probably indigenous to Europe, Western Asia and Northern Africa and cultivated in Germany, Russia, England and the Northern United States and Canada, and also 
naturalized in waste places (p. 372). The leaves are collected shortly after flowering from biennial plants of the second year's growth, and carefully dried and preserved. The commercial article comes chiefly from Germany.

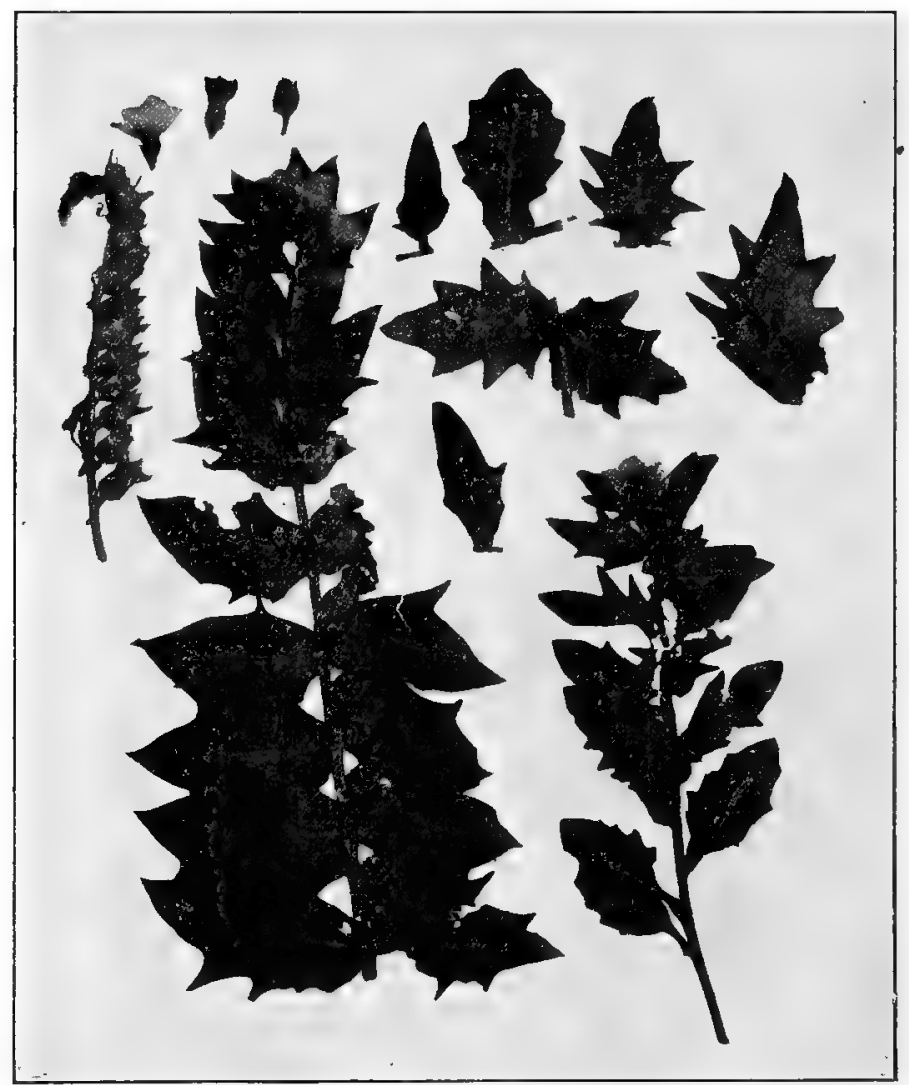

Fig. 267. Hyoscyamus niger. Flowering and fruiting branches showing the alternate, irregularly lobed, mostly sessile leaves, and the I-sided spike of fruits.

DESCRIPTION.-Usually in irregular, matted fragments. Stem hollow, cylindrical, flattened, longitudinally furrowed and wrinkled, 3 to $4 \mathrm{~mm}$. in diameter; internodes I to $3.5 \mathrm{~cm}$. long. Leaves ovate or ovate-lanceolate, 5 to $10 \mathrm{~cm}$. long, 2 to $7 \mathrm{~cm}$. broad, apex acuminate; base amplexicaul; margin acutely four-lobed; upper 
surface dark green and pubescent; under surface grayish-green and glandular-pubescent (Fig. 287, B) ; midrib yellowish-green, from which veins of the first order diverge at an angle of from $10^{\circ}$ to $35^{\circ}$ and pass into the lobes; texture fragile. Flowers solitary and with a pedicel about $4 \mathrm{~mm}$. long; calyx tubular, 5-toothed, about ro $\mathrm{mm}$. long, outer surface very pubescent; corolla 5-parted, the lobes more or less unequal, somewhat spreading, the tube purplish, the limb yellowish, reticulate from purplish veins; stamens five, declined, mostly exserted; stigma capitate. Fruit, a two-locular pyxis. Seeds numerous, campylotropous, somewhat reniform, flattened, I $\mathrm{mm}$. long, light brown, finely pitted, with a curved embryo embedded in the endosperm. Odor distinct. Taste bitter and somewhat acrid.

Inner Structure.-See Figs. $282, A ; 287, B ; 302, A$.

Constituents. - The alkaloids hyoscyamine and hyoscine (scopolamine) 0.08 to 0.15 per cent., of which three-fourths is hyoscyamine; an odorous principle in the nature of a butyric ether or butyrin; a glucosidal bitter principle, hyospicrin; potassium nitrate, about 2 per cent., and calcium oxalate.

Hyoscyanine (an isomer of atropine) occurs in colorless, silky needles with an acrid, disagreeable taste, partly soluble in water, soluble in alcohol, and is readily decomposed into atropine. It forms crystalline salts, of which the hydrobromide is official. Hxoscine forms prismatic crystals, which are soluble in water and alcohol, and on hydrolysis yields scopoline (oscine) and tropic acid. Hyoscine is even a more powerful mydriatic than hyoscyamine, and forms crystallizable salts, of which the hydrobromide is official.

Allied Plants.-Hyoscyamine is also found in Datura Stramonium, Atropa Belladonna, Anisodus luridus, Duboisia myoporoides, Lactuca sativa and L. virosa (p. 392), the two latter plants belonging to the Compositæ. Hyoscine (scopolamine) is also present in belladonna root, the seeds of Hyoscyamus niger (p. 372), the leaves of Datura Stranonium, Datura fastuosa of the East Indies, the leaves of Duboisia myoporoides and the roots of Scopolia japonica and S. atropoides.

Duborsin leaves are obtained from Duboisia myoporoides, a large shrub indigenous to Australia. They are short-petiolate, 7 
to Io $\mathrm{cm}$. long, I.5 to $2.5 \mathrm{~cm}$. broad, with acute or narrow apex and base, and entire or somewhat revolute margin. In the drug they usually occur in broken fragments, which are thin, greenishbrown, and have a slight narcotic odor and bitter taste. They contain in addition to hyoscyamine (duboisine) and hyoscine, the alkaloid PSEUDOHYOSCY.MINE, which occurs in small, needleshaped crystals that are difficultly soluble in water but readily soluble in alcohol. Duboisia Leichardtii also contains a large amount of alkaloids resembling those of Duboisia. Pituri or Australian tobacco is the leaf of Duboisia Hoprwoodii, and is used in Australia like tobacco. It contains 2.5 per cent. of a liquid alkaloid piturinè, which has a pungent odor and taste, and closely resembles nicotine.

BELLADONNÆ FOLIA.-BELLADONNA LEAVES.The leaves and flowering tops of Atropa Belladonna (Fam. Solanacex), a perennial herb (Fig. 268) native of Central and Southern Europe, Asia Minor and Persia, and cultivated in England and Germany, from which countries most of the commercial supply is obtained (p. 372). The leaves and tops are gathered when the plants are in flower, and used fresh or after being dried.

Description.-Ustally in irregular, matted fragments. Stem hollow, cylindrical, flattened, longitudinally furrowed and wrinkled, 1.5 to $2 \mathrm{~mm}$. in diameter, internodes from 2.5 to $6.5 \mathrm{~cm}$. long. Leaves single or in unequal pairs, broadly ovate or somewhat elliptical, 6 to $15 \mathrm{~cm}$. long, 2.5 to $7 \mathrm{~cm}$. broad; apex acuminate; base acute, somewhat unequal and tapering into the petiole; margin entire; upper surface dark green, glabrous, epidermis with distinct papillæ; under surface grayish-green, slightly pubescent (Fig. $287, C$ ) on the veins, epidermis distinctly sinuate, midrib dark brown, the veins of the first order diverging from it at angles of about $45^{\circ}$ and rumning nearly parallel to near the margin; petiole dark brown, 5 to $15 \mathrm{~mm}$. long and semi-circular in cross section; texture fragile. Flowers solitary, pedicel 1.5 to $2 \mathrm{~cm}$. long; calyx deeply 5-cleft, about I mm. long, outer surface slightly pubescent; corolla 5-parted, about $2 \mathrm{~mm}$. long, campanulate, yellowish-purple; stamens five, included; style somewhat exserted. Fruit, a superior berry, globular, dark green, 7 to. $10 \mathrm{~mm}$. in diameter, 2-locular, many-seeded." Seeds campylotropous, some- 
what reniform, flattened, light brown; testa finely pitted, with a curved embryo embedded in the endosperm. Orlor clistinct, heavy. Taste somewhat disagreeable.

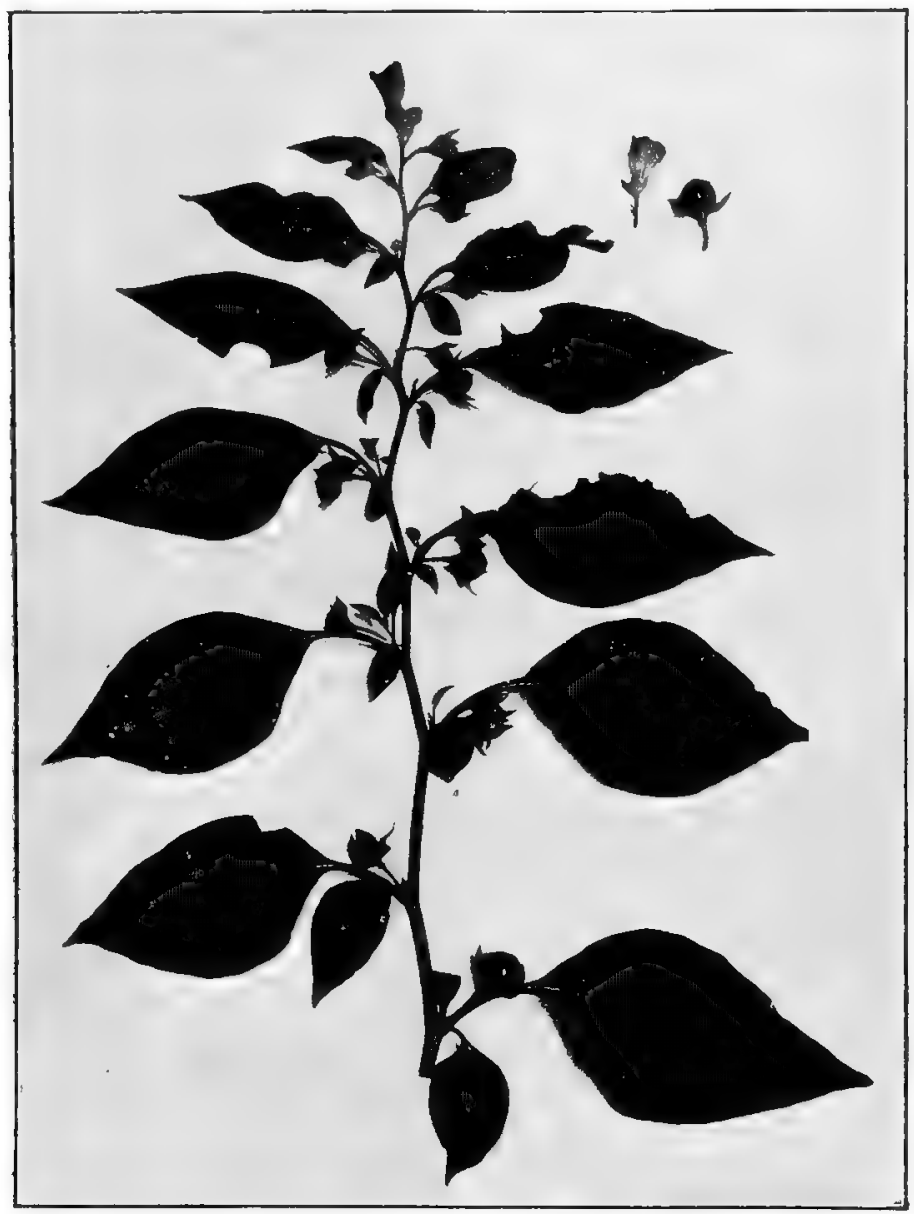

Fig. 268. Atropa Belladonna showing the alternate, petiolate, ovate, entire leaves, in the axils of which are the solitary fruits or flowers with large, leafly bracts.

Inner Structure.-See Figs. $285, K ; 287, C$.

Constituents.-Several alkaloids amounting to from 0.3 to 0.7 per cent., of which hyoscyamine (see Hyoscyamus) exists in largest proportion. The drug also contains hyoscine (scopola- 
mine), atropine, formed from hyoscyamine, and belladonnine, formed from atropine; a fluorescent principle $\beta$-methyl-æsculetin (atrosin or chrysatropic acid), which resembles a similar principle found in gelsemium; malic acid, and calcium oxalate in the form of cryptocrystalline crystals (Fig. 287, C).

Atropine is a powerful mydriatic alkaloid which occurs in colorless or white acicular crystals that are soluble in alcohol but sparingly soluble in water. It is optically inactive and may be sublimed without decomposition. The aqueous solutions are. however, easily decomposed, acquiring a yellow color and a disagreeable odor. On treating atropine with a few drops of nitric acid, evaporating to dryness and then adding a few drops of an alcoholic solution of potassium hydrate to the residue a violet color is produced, which rapidly changes to red. On hydrolysis atropine yields tropin and tropic acid. Upon heating atropine with nitric acid so as to cause the loss of a molecule of water the alkaloid APOATROPINE (atropamine or anhydro-atropine) is formed, which has been isolated from belladonna root and which does not possess any mydriatic properties. On heating apoatropine with hydrochloric acid or upon simply heating it for some time alone the base BELLADONNINE (oxyatropine) is formed.

The amount of alkaloids varies in different parts of the plant and has been given as follows: Roots, 0.06 per cent.; stems, 0.04 per cent. ; leaves, 0.2 per cent. ; unripe berries, o.I9 per cent.; ripe berries, $0.2 \mathrm{I}$ per cent., and seeds, 0.33 per cent.

STRAMONIUM.-STRAMONIUM LEAVES.-The leaves and flowering tops of Datura Stramonium (Fam. Solanaceæ), an annual herb (Fig. 269) probably indigenous to the region of the Caspian Sea, naturalized in waste places in Europe and North America, and cultivated in France, Germany and Hungary (p. 372). The leaves and tops are collected when the plant is in flower, and are carefully dried and preserved, the chief of the commercial supply being obtained from cultivated plants.

Description.-Usually in irregular, matted fragments. Stem cylindrical, flattened, longitudinally furrowed and wrinkled, 2 to $5 \mathrm{~mm}$. in diameter; internodes 1.5 to $2 \mathrm{~cm}$. long. Leaves ovate, 6 to $20 \mathrm{~cm}$. long, 2 to $12 \mathrm{~cm}$. broad; apex acuminate; base unequal, one side extending 3 to $12 \mathrm{~mm}$. below the other; margin 
irregularly sinuate-lobed, the lobes acute; upper surface dark green, nearly glabrous, under surface yellowish-green, glabrous, slightly pubescent (Fig. $287, D$ ) on the veins, midrib dark brown.

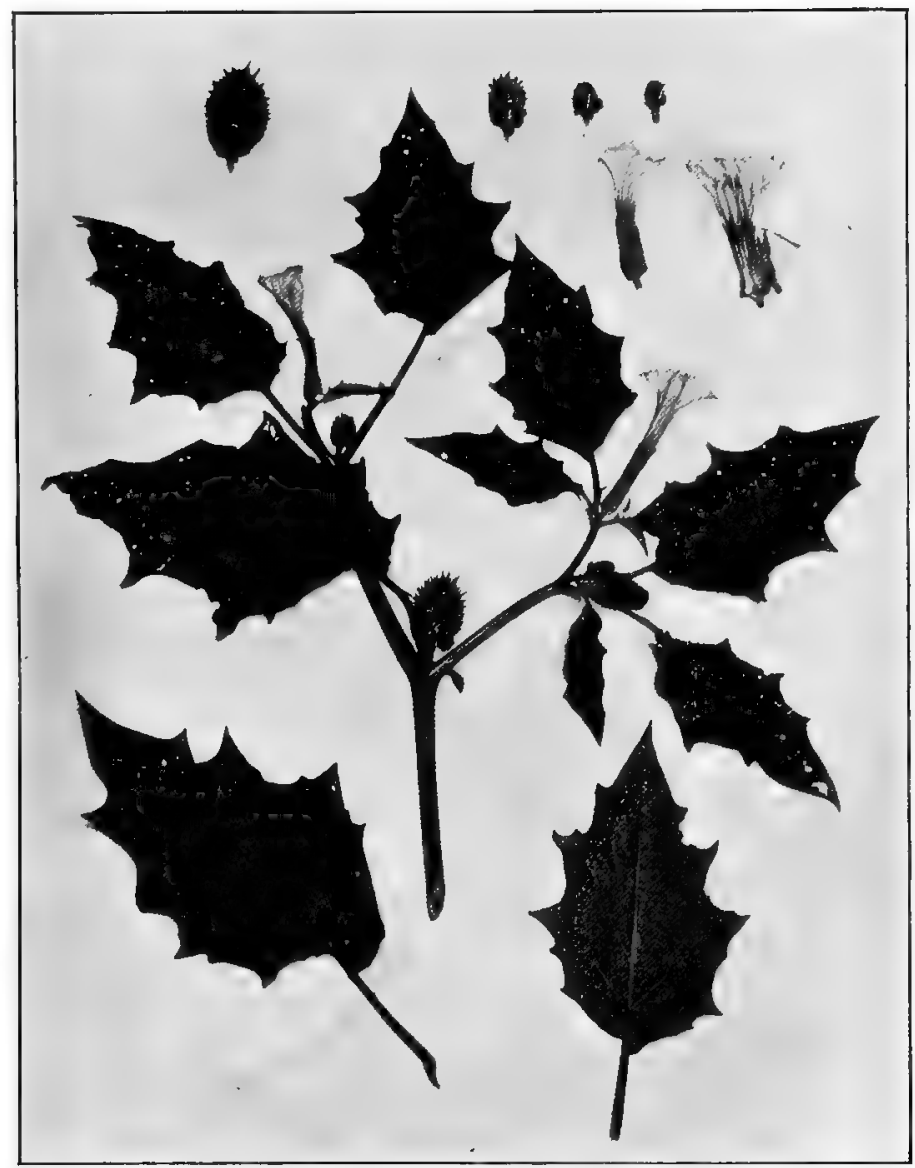

FIG. 269. Datura Stramonium showing the alternate, petiolate, sinuate-lobed leaves, which show perforations due to the bites of insects; the flowers with large funnelform corolla, and the prickly capstiles.

veins of the first order diverging from it at an angle of $45^{\circ}$ to $65^{\circ}$, dividing near the margin and the main branches passing into the lobes; petiole dark brown, 0.5 to $4.5 \mathrm{~cm}$. long, circular in crosssection; texture fragile. Flowers solitary, pedicel 2 to $10 \mathrm{~mm}$. 
long, calyx 5 -toothed, about $4 \mathrm{~cm}$. long, separating transversely near the base at maturity, the upper part falling away; corolla funnel-shaped, yellowish- or purplish-white, about $8 \mathrm{~cm}$. long, limb plaited, 5-lobed; stamens five, included, inserted near the middle of the corolla tube; stigma slightly 2 -lobed. The immature fruit somewhat conical, 4-valved. Seeds numerous. Odor disagreeable. Taste unpleasant, nauseous.

Inner, Structure.-See Figs. I I 7 ; 287, $D ; 285, C$.

-Constituents.-The important constituents of Stramonium leaves are similar to those of belladonna leaves, the amount of total alkaloids, however, being about one-half less ( 0.2 to 0.4 per cent). The substance known as DATURINE is a mixture of hyoscyamine and atropine, the former being in excess (see Belladonnæ Folia and Hyoscyamus). . Stramonium leaves also contain a volatile oil, resin, and yield about 17 per cent. of ash, containing considerable potassium nitrate.

The amount of total alkaloids varies in different parts of the same plant and has been reported as follows: Roots, 0.02 per cent.; stems, 0.02 per cent. ; leaves, 0.07 per cent., and seeds, 0.25 per cent.

Stramonil Semen (Stramonium Seed).-Campylotropous, reniform, flattened, about 3 to $4 \mathrm{~mm}$. long, 2 to $3 \mathrm{~mm}$. broad; externally bluish-black, minutely reticulate; hard but easily cut lengthwise along the edge; internally (Fig. I22, $B$ ) whitish, the reserve layer occupying about one-half the seed, the embryo crook-shaped; odor slight, disagreeable when the drug is bruised; taste bitter. They contain about 25 per cent. of fixed oil; proteids; about 0.4 per cent. of alkaloids, consisting principally of hyoscyamine, together with a small proportion of atropine and scopolamine (hyoscine); ash 2 to 3 per cent.

Allied Drugs.--See Hyoscyamus and Belladonnæ Folia.

The Purple Stramonium (Datura Tatula) which is naturalized in the United States from tropical America resembles D. Stramoninum, but the stems and flowers are purplish. The constituents in the two plants are similar. Several other species are also used in medicine, as Datura arborea indigenous to Chile and Peru, and cultivated for its handsome flowers. The leaves contain 0.44 per cent. of total alkaloids. 
EUPATORIUM.-BONESET.-The leaves and flowering tops of Eupatorium perfoliatum (Fam. Compositæ), a perennial herb (Fig. 270) indigenous to Eastern and Central North America (p. 392). Boneset is collected in July and August and dried:

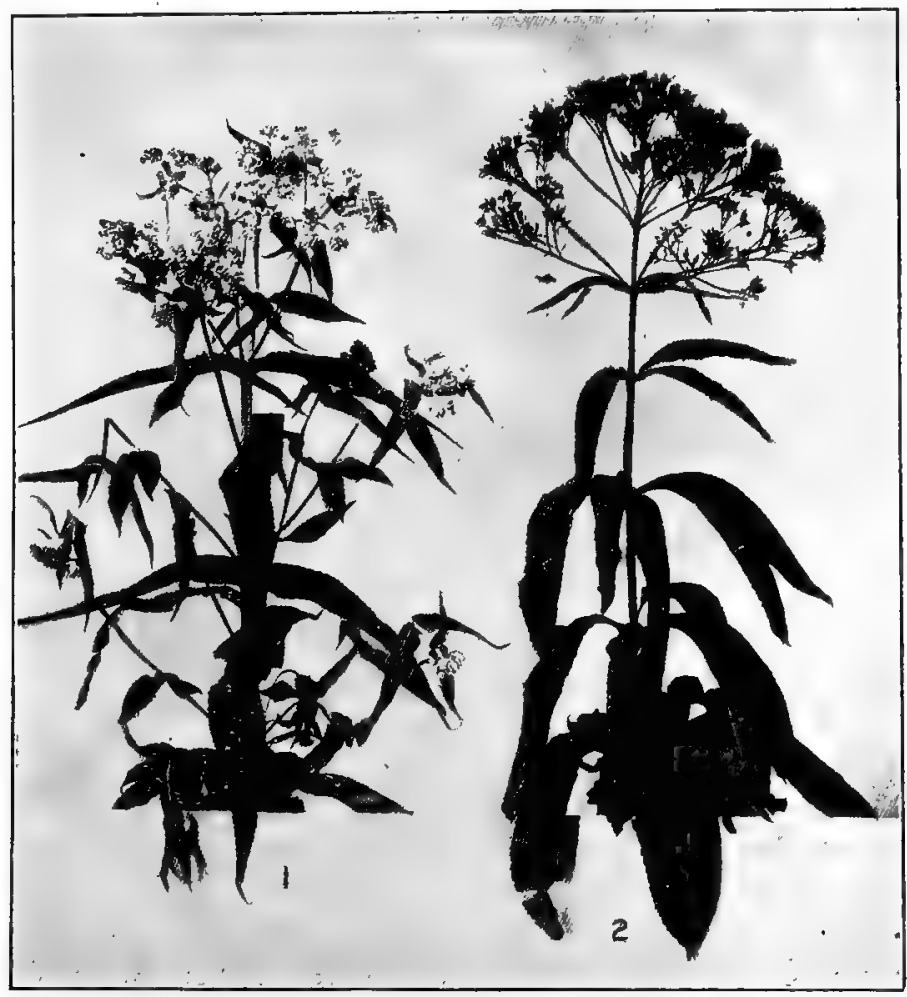

FIG. 270. I. Eupatorintm perfoliatum with opposite, connate-perfoliate leaves and cymose-paniculate inflorescence. 2. Eupalorium purpureum with verticillate, petiolate leaves, and a large terminal panicle of flowers.

DeSCRIPTION.-Usually in more or less broken fragments. Stem cylindrical, somewhat quadrangular, flattened, about $3 \mathrm{~mm}$. in diameter, longitudinally wrinkled, tomentose; internodes 5 to $8 \mathrm{~cm}$. long. Leaves lanceolate, opposite, Io to $20 \mathrm{~cm}$. long, 2 to 4 cm. broad; apex acuminate; base connate-perfoliate; margin crenate-serrate; upper surface dark green, midrib and veins depressed, reticulate, glabrous, except near the margin; under sur- 
face yellowish- or brownish-green, midrib prominent, reticulate, very tomentose, with glistening yellow resin masses. Flowers in large cymose panicles; heads $10-$ to 15 -flowered, about $5 \mathrm{~mm}$. long, torus flat; involucre light green, oblong, the scales imbricate, linear-lanceolate, hairy; corolla 5-toothed, whitish; anthers purplish, included; style deeply cleft, much exserted. Akenes 5-angled, pappus obrisisting of a single row of about twenty rough bristles. Odor aromatic. Taste bitter.

Constituents.-Volatile oil; a bitter, crystalline glucoside eupatorin; resin; a crystalline wax; a glucosidal coloring principle related to tannin but crystallizing in small yellow needles, and giving an orange-red precipitate with lead acetate solution; a glucosidal tannin, which is colored deep green with ferric chloride and gives a yellow precipitate with lead acetate solution; gallic acid; ash 7.5 to 9.9 per cent.

Allied Plants.-Purple boneset or Joe-pye weed (Eupatorium purpureum), a common herb (Fig. 270) in low grounds in Eastern and Central North America, is a tall stout herb, with oblong-lanceolate leaves, 3 to 6 in a whorl and lightpurplish-red flowers in dense corymbs. Purple boneset contains a volatile oil, 0.07 per cent.; a yellow crystalline principle euparin, which somewhat resembles quercitrin; resin, 0.25 per cent.; calcium oxalate, I.82 per cent.; and ash, I4 per cent. Dog-fennel (E. faniculaceum), a perennial herb, with alternate, I- to 2-pinnately parted leaves and white flowers, which is common in the Southern States, yields a volatile oil which contains considerable phellandrene.

The root of Eupatorium perfoliatum contains about 5 per cent. of inulin.

GRINDELIA.-The leaves and flowering tops of Grindelia robusta and Grindelia squarrosa (Fam. Compositæ), perennial herbs (p. 393) indigenous to Western North America, G. robusta, growing west of the Rocky Mountains, and G. squarrosa, eastward therefrom as far as the Mississippi. Grindelia is collected in early summer when the leaves and tops are covered with a resinous exudation, and dried.

Grindelia Robusta. - Stem cylindrical, lemon-yellow or rosecolored, 2 to $3 \mathrm{~mm}$. in diameter, longitudinally wrinkled, glandular-hairy, nearly glabrous, resinous; internodes 8 to $35 \mathrm{~mm}$. long. 
Leaf lanceolate or elliptical; apex acute; báse sessile or amplexicaul; margin entire or spinosely toothed; upper surface light green or yellowish-green, covered with resin and with occasional black disks of a species of Puccinia; under surface grayishgreen, somewhat resinous; texture somewhat coriaceous, brittle when dry. Heads many-flowered, globular or truncate-conical, about I to $2 \mathrm{~cm}$. in diameter, with numerous lanceolate-acuminate, imbricate and resinous involucral bracts; torus flat, deeply pitted; ray-flowers brownish-yellow and pistillate; tubular flowers yellowish-brown, perfect. Akenes slightly curved, somewhat compressed, about $3 \mathrm{~mm}$. long, and I- to 2 -dentate or auriculatebordered at the summit. Odor aromatic; taste aromatic and bitter.

Grindelia Souarrosa.-The leaves are linear, the akenes are 4-angled and more or less truncate at the apex.

Constituents.-Resinous substances amounting to about 2 I per cent., including a soft greenish resin soluble in petroleum ether, a dark colored resin soluble in ether and a dark colored, amorphous resin soluble in alcohol; a lævo-rotatory sugar 1-glucose; tannin I.5 per cent.; a volatile oil having the characteristic odor of the drug; and about 8 per cent. of ash. The drug has also been reported to contain two glucosides, 0.8 per cent. (G. squarrosa) to 2 per cent. (G. robusta), somewhat resembling the saponins in quillaja and senega; and a bitter crystalline alkaloid, grindeline.

Substitutes.-Most of the drug on the market at the present time appears to be derived from Grindelia camporum, the common Gum plant of California. The upper leaves are more or less oblong or spatulate and the akenes are usually bi-auriculate at the summit.

The commercial drug is alșo derived from Grindelia cuneifolia and its variety paludosa, growing in the marshes of upper California. The leaves are cuneate and less coriaceous than those of G. camporum, but the akenes are similar.

Allied Plants.-Other species of Grindelia growing in the Western United States and Mexico are similarly employed, as $G$. hirsutula, the stems of which are purplish-red and pubescent; and G. glutinosa, in which the leaves are glabrous, rounded at the apex and the pappus 5- to 8-toothed. 
MARRUBIUM.-WHITE HOREHOUND.-The leaves and flowering tops of Marrubium vulgare (Fam. Labiatæ), a perennial herb (p. 368) indigenous to Europe and Asia, and cultivated in various parts of Europe and the United States, being naturalized in waste places from Texas and Mexico to Maine and Ontario.

DesCRIPTION.-Stem guadrangular, yellowish- or grayishgreen, 3 to $5 \mathrm{~mm}$. in diameter, very pubescent; internodes 2 to 5 $\mathrm{cm}$. long. Leaves broadly ovate, opposite, $\mathrm{I} .5$ to $6 \mathrm{~cm}$. long, 8 to $25 \mathrm{~mm}$. broad; apex obtuse; base acute or rounded; margin coarsely crenate; upper surface dark green, pubescent, veins depressed, those of the first order diverging at an angle of about $65^{\circ}$ and branching near the margin; under surface grayish-green, very pubescent, veins prominent; petiole 0.5 to $3 \mathrm{~cm}$. long, very pubescent. Flowers sessile, in axillary clusters; calyx tubular, about $5 \mathrm{~mm}$. long, 5- to Io-nerved, very pubescent and with Io recurved, bristle-like lobes; corolla whitish or light brown, about 7 $\mathrm{mm}$. long, upper lip erect, entire or bifid, lower lip 3-lobed, the middle lobe the largest and emarginate; stamens four, included. Nutlets brownish-black, ellipsoidal, slightly compressed, about I.5 $\mathrm{mm}$. long, nearly smooth. Odor slight, aromatic. Taste aromatic and bitter.

Constituents.-A bitter, somewhat acrid principle marrubiin, 0.02 to 4 per cent., which forms prismatic crystals and is sparingly soluble in water; several other bitter principles; a volatile oil; a resin; and tannin.

Allied Plants.-Black horehound or Marrubium peregrinum, an herb of the old world, has ovate or lanceolate, dentate-serrate, grayish, hairy leaves and flowers with straight calyx-lobes. Ballota nigra (Fam. Labiatæ) has cordate, rough-hairy, dark green leaves, pale purple flowers and a disagreeable odor. Water horehound or Lycopus europaus has ovate-lanceolate, lobed or divided leaves, the calyx lobes being triangular.

HEDEOMA.-AMERICAN PENNYROYAL.-The leaves and flowering tops of Hedeoma pulegioides (Fam. Labiatæ), an annual herb (Fig. 27I) indigenous to the Eastern and Central United States and Canada (p. 369). Pennyroyal should be collected in July or August and dried. 
Description.-Stem quadrangular, I to $2 \mathrm{~mm}$. in diameter, light or reddish-brown, with numerous spreading hairs. Leaves

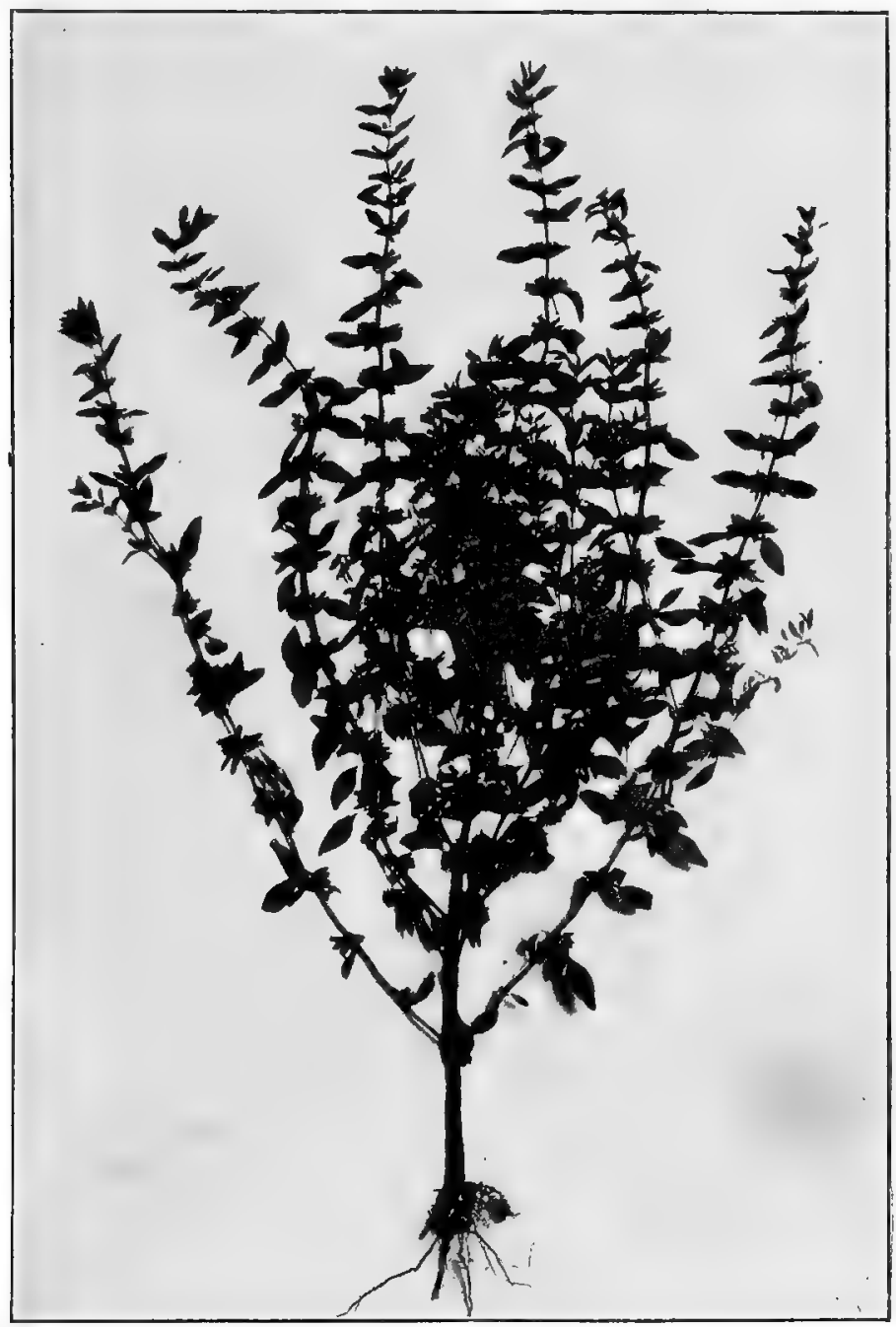

Frg. 27r. Hedeoma pulegioides. Entire plant showing the opposite leaves, the regular mode of branching, and the axillary clusters of bilabiate flowers.

elliptical or ovate, opposite, I5 to $35 \mathrm{~mm}$. long, 5 to $14 \mathrm{~mm}$. broad; apex obtuse; base tapering into the petiole; margin 
remotely serrate; upper surface dark green, pubescent on the nerves, slightly glandular-hairy; under surface light green, pubescent, glandular-hairy, veins of the first order diverging at an angle of $45^{\circ}$ to $65^{\circ}$, curving upwards and uniting near the margin; petiole 3 to $6 \mathrm{~mm}$. long, with numerous spreading hairs and slightly laminate in the upper portion. Inflorescence in sixflowered axillary whorls; calyx tubular, about $5 \mathrm{~mm}$. long, ovoid or slightty curved on the lower side near the base, bilabiate, upper lip 3-toothed, lower. lip with two linear-lanceolate divisions, I3nerved, longitudinally striate, pubescent; corolla about the size of the calyx, purplish, pubescent, upper lip erect, flat, emarginate, the lower spreading and 3-lobed; fertile stamens two, exserted, ascending, the sterile upper pair rarely with anthers. Nutlets nearly spherical or ovoid, about $0.5 \mathrm{~mm}$. in diameter. Odor strongly aromatic. Taste aromatic.

Constituents.-Volatile oil, a bitter principle and tannin. The dried leaves yield about 3 per cent. of volatile oil, while the dried stems and leaves yield only I.3 per cent. The volatile oil is official and consists chiefly of a ketone pulegone, which gives the oil its pectiliar properties. "The oil also probably contains two other ketones: (a) hedeomol and (b) another resembling menthone. Several acids have also been found in this oil: formic, acetic and isoheptylic.

Allied Plants.-Mentha Pulegium, of European pennyroyal, apparently contains principles similar to the American pennyroyal, and is distinguished from the latter by the more or less oval, serrate leaves, and the cymose inflorescence and four-lobed corolla. The oil of European pennyroyal closely resembles that of Hedeoma and is frequently substituted for it.

Wild Mint (Mentha canadensis), a perennial herb common in wet places in the United States, has ovate-oblong or lanceolate leaves, in the axils of which whorls or globular clusters of flowers arise. The plant has an odor of pennyroyal and yields I.25 per cent. of a volatile oil from which pulegone and thymol or carvacrol have been isolated.

WATER Mint (Mentha aquatica), a plant found in wet places from New England to Delaware, yields about 0.34 per cent. of a volatile oil having the odor of pennyroyal. 
Oil of Russian pennyroyal contains pulegone, but the botanical origin is not known.

MENTHA PIPERITA.-PEPPERMINT.-The leaves and flowering tops of Mentha piperita (Fam. Labiatæ), a perennial herb (Fig. I75) indigenous to Europe, naturalized in the Eastern and Central United States and Canada, and cultivated in Michigan and New York (p. 370). Peppermint should be collected during dry weather, in August and September, when the plant is in flower, and carefully dried and preserved. Peppermint is cultivated in Michigan chiefly for its volatile oil. This State produces annually over $6,800 \mathrm{~K}$ : of peppermint oil. Wayne County, in New York State, produces I,480 K. ; Indiana State, I,280 K., and other localities about $400 \mathrm{~K}$. annually. Japan produces about 70,000 K. annually ; England, 9,000 K. ; France, 3,000 K. ; Russia, I $200 \mathrm{~K}$. ; Germany, $800 \mathrm{~K}$., and Italy, $600 \mathrm{~K}$.

DESCRIPTION.-Stem quadrangular, I to $3 \mathrm{~mm}$. in diameter, yellowish-green, with scattered deflexed hairs, internodes I.5 to 5 $\mathrm{cm}$. long. Leaves ovate-lanceolate, opposite, 1.5 to $8 \mathrm{~cm}$. long, 0.5 to $2.5 \mathrm{~cm}$. broad; apex acute; base acute or rounded; margin sharply serrate; upper surface dark green, midrib and veins rosecolored, the latter diverging at an angle of about $60^{\circ}$, curving upward and uniting near the margin; under surface light green, slightly pubescent on the veins, glandular-pubescent; petiole 4 to Io $\mathrm{mm}$. long, slightly pubescent. Inflorescence in axillary whorls or in compact spikes; peduncle wanting or about $3 \mathrm{~mm}$. long, pedicel about I mm. long; calyx tubular, equally 5 -toothed, about $2 \mathrm{~mm}$. long, purplish, glandular-punctate; corolla tubular, nearly regular, 4-cleft, about $3 \mathrm{~mm}$. long, purplish; stamens four, erect, distant. Nutlets ellipsoidal, about $0.5 \mathrm{~mm}$. in diameter, blackishbrown. Odor aromatic. Taste aromatic, followed by a cooling sensation.

Constituents.-Volatile oil, containing 50 to 60 per cent. of menthol, about I per cent.; resin and tannin. American peppermint oil consists of about I7 different chemical constituents,- a larger number than is found in any other oil. The most important constituent is the stearoptene MENTHOL, of which 40 to 45 per cent. is free and 8 to. I4 per cent. is combined in various esters. Menthol occurs in colorless, acicular crystals, which are insoluble 
in water but soluble in alcohol, and on boiling with a sulphuric acid solution ( 50 per cent.) it becomes of a deep blue color, the acid solution becoming brown. American peppermint oil also contains: Acetaldehyde, isovaleraldehyde, acetic acid, valerianic acid, pinene, phellandrene, cineol, 1-limonene, menthone, menthyl acetate, menthyl iso-valerianate, menthyl ester, a lactone cadinene, amyl alcohol, and dimethyl sulphide.

ENGLISH peppermint oil is very highly prized on account of its fine aroma and pleasant taste. It consists of 50 to 60 per cent. of free menthol, 3 to I4 per cent. of menthol combined as esters, and 9 to 12 per cent. of menthone, a substance capable of being transformed into menthol. This oil also contains: Phellandrene, limonene, cadinene, acetic acid and iso-valerianic acid.

JAPANESE peppermint oil is obtained from Mentha arvensis piperascens. The oil has a bitter taste and consists of free menthol 65 to 85 per cent.; menthol combined as esters, 3 to 6 per cent.; and a body isomeric with borneol.

MENTHA VIRIDIS.-SPEARMINT.-The leaves and flowering tops of Mentha spicata (Syn. Mentha viridis) (Fam. Labiatæ), a perennial herb indigenous to Europe and cultivated and naturalized in various parts of North America. It should be collected in the same manner as peppermint (p. 370; Fig. 67).

Spearmint is extensively cultivated in Michigan and New York, these states producing annually about $500 \mathrm{~K}$. of volatile oil.

Description.-Closely resembling peppermint (see Mentha Piperita), but the stems are usually more purple, the leaves sessile or nearly so, inflorescence either in slender, interrupted cylindrical spikes or crowded lanceolate spikes; odor and taste aromatic, characteristic, the taste not being followed by a cooling sensation.

Construtuents.-Volatile oil about 0.3 per cent. in the fresh leaves; resin, and tannin. American oil of spearmint consists of about 56 per cent. of carvone, a considerable amount of 1-limonene and possibly also 1-pinene. The constituent giving the oil its characteristic odor is not known.

Allied Plants.-Russian spearmint oil is obtained from an undetermined plant and consists of 1-linalool, 50 to 60 per cent.; 20 per cent. of cineøl, 5 to ro per cent. of 1-carvone and possibly also 1 -limonene. 
GERMAN spearmint oil is obtained from Mcntha crispa, which is regarded as a cultural variety of $M$. arvensis. The plant is sparingly naturalized in the United States from Europe. It somewhat resembles $M$. piperita, but is distinguished by its cuspid, irregularly dentate leaves. It yields an oil containing carvone.

LOBELIA.-The leaves and flowering tops of Lobelia inflata (Fam. Campanulacex), an annual herb (Fig. 272) indigenous to the Eastern and Central United States and Canala, and cultivated in New York and Massachusetts (p. 388). Lobelia should be collected after a portion of the capsules have become inflated, carefully dried and preserved.

DESCRIPTION.-Stem cylindrical, somewhat angular, slightly winged, light brown, with numerous spreading hairs, internodes 2 to $3 \mathrm{~cm}$. long. Leaves elliptical or ovate-lanceolate, alternate, 4 to $9 \mathrm{~cm}$. long, 8 to $30 \mathrm{~mm}$. broad; apex acute or acuminate ; base obtuse or acute; margin irregularly denticulate, the divisions with a yellowish-brown, gland-like apex; upper surface yellowish-green or light brown and with scattered bristly hairs; under surface light brown, with numerous bristly hairs, the veins of the first order diverging at an angle of about $65^{\circ}$ and curving upward near the margin; petiole either wanting or about I mm. long. Inflorescence in leafy spikes; pedicel about $3 \mathrm{~mm}$. long; calyx 5-parted, about $5 \mathrm{~mm}$. long, the subulate lobes about as long as the tube; corolla 5-parted, tubular, about as long as the calyx, pale blue, upper portion cleft nearly to the base, the lobes on either side of the cleft erect or recurved, the other three united; stamens with anthers united above into a curved tube; stigma 2-lobed, ovary 2-locular. Fruit an ovoid, inflated capsule 5 to $8 \mathrm{~mm}$. long, opening at the summit, apex with the remains of the calyx. Seeds numerous, brownish, somewhat ellipsoidal or ovoid, about $0.7 \mathrm{~mm}$. long, coarsely reticulate. Odor slight; taste mild, becoming acrid.

Constituents.-An amorphous, acrid, emetic alkaloid LOBELINE, which decomposes readily on heating, and is contained in greatest amount in the seeds; a non-acrid but pungent volatile oil LOBELIANIN ; a colorless, tasteless, crystalline, neutral principle INFLATIN, which is intimately associated with the alkaloid; and lobelic acid, which is combined with the alkaloid lobeline. LoBELACRIN is regarded as the lobelate of lobeline. The seeds contain 
in addition a fixed oil which when pure is bland, non-acrid and somewhat resembles that of linseed. As it is usually seen on the

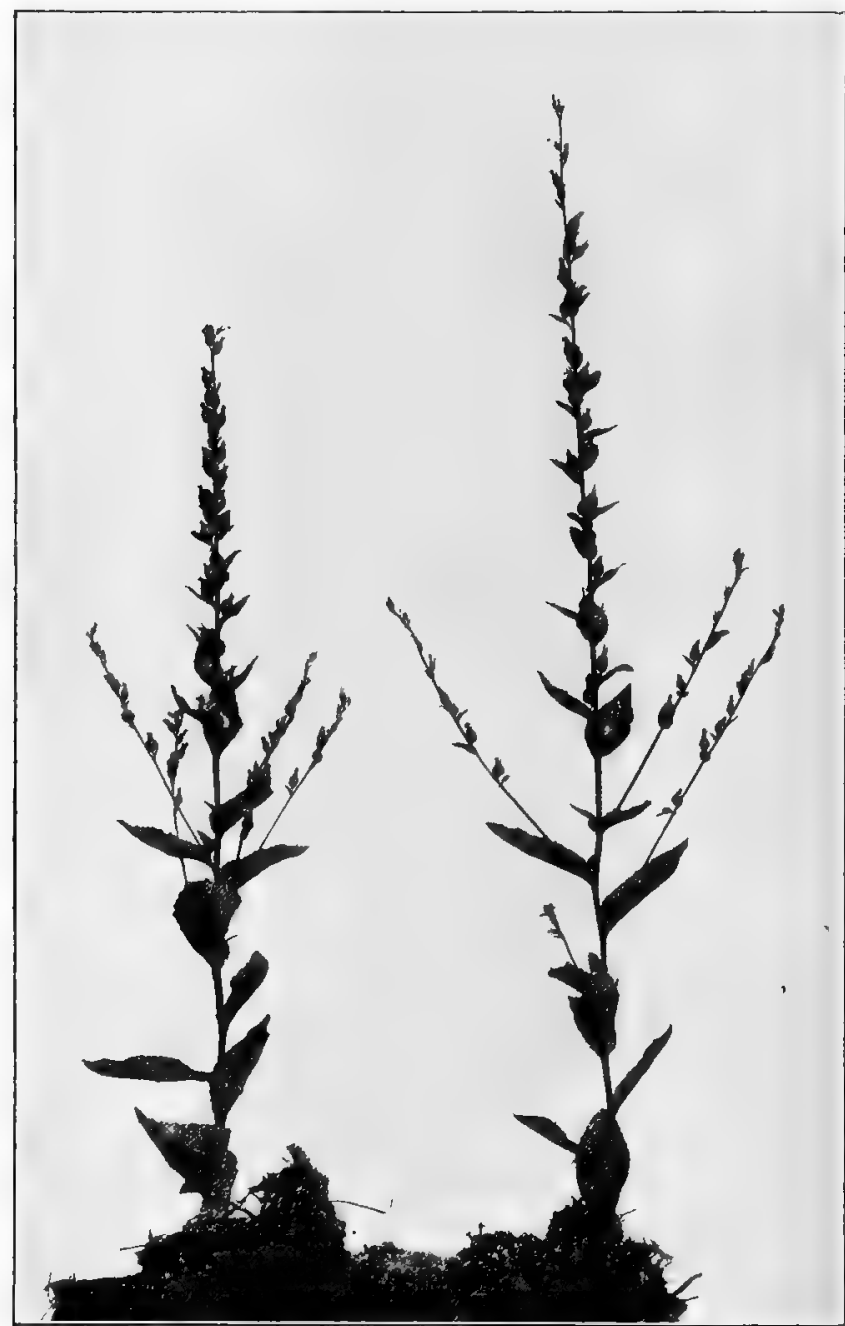

FIG. 272. Lobelia inflata showing the alternate leaves and the axillary flowers which are either solitary or in spike-like racemes, and which early develop into inflated capsules.

market it is of a greenish color and quite acrid and is said to contain all the active principles of the drug. 
Aldied Plints.-Red lobelia, Lobclia cardinalis (Fig. I80a), and blue lobelia, L. syphilitica (Fig. I80), as well as a large number of other species of Lobelia, are used to some extent in medicine. Lobclia nicotiancfolia of India and Delissca acuminata of the Hawaiian Islands have properties similar to Lobelia inflata.

Adulterants.-The seeds of mullein ( $V$ crbascum Thapsus) are commonly used as an adulterant of Lobelia seeds, but are distinguished from them by not being reticulate.

CANNABIS INDICA.-EAST INDIAN HEMP.-The flowering tops of the pistoltate plants of Camnabis sativa (Fam. Moraceæ), an annual herb ${ }^{b^{2}}$ (Fig. 273) indigenous to Central and Western Asia, and cultivated in India and other tropical countries and also in temperate regions for the fiber and seed (p. 255). The drug, however, is obtained from plants cultivated in tropical India. The flowering tops are made into more or less compressed masses, "forming what is known as "ganja" or "guaza." The best grade of ganja is obtained from unfertilized plants grown in Bengal. The leaves may be collected and dried separately and constitute what is known as "bhang." The resin which separates from ganja and bhang, or that which is collected from the growing plant, constitutes the product known as "charas" (p. 255). Cannabis sativa has become naturalized in the Central United States, and, while the American drug was at one time official, is now but little used in medicine. Fruiting spikes with mature seeds should be removed.

Description.-Usually in compressed masses 5 to $14 \mathrm{~cm}$. long. Stem cylindrical, about $3 \mathrm{~mm}$. in diameter, longitudinally furrowed and wrinkled, light green, pubescent, internodes 2 to 20 $\mathrm{mm}$. long. Leaf digitately compound, with three to seven linearlanceolate, nearly sessile leaflets, apex. of leaflets acuminate, base acute or cuneate, margin deeply serrate; upper and under surfaces dark green, pubescent, glandular, veins of the first order cliverging at an angle of $65^{\circ}$ and terminating in the teeth; petiole I to $5 \mathrm{~cm}$. long. Inflorescence in sessile spikes, each flower subtended by an ovate, pubescent bract; calyx entire, ovate or oblongacuminate, about $4 \mathrm{~mm}$. long, dark green, pubescent, split longitudinally on one side, somewhat enlarged at the base and folded around the ovary; styles two, about $8 \mathrm{~mm}$. long, filiform, pubes- 
cent, ovary oblong, about I $\mathrm{mm}$. long, with a single campylotropous ovule. Odor distinct. Taste slightly acrid.

Constituents.-From 15 to 20 per cent. of a resin (called CANNABIN), consisting of a number of substances, one of which,

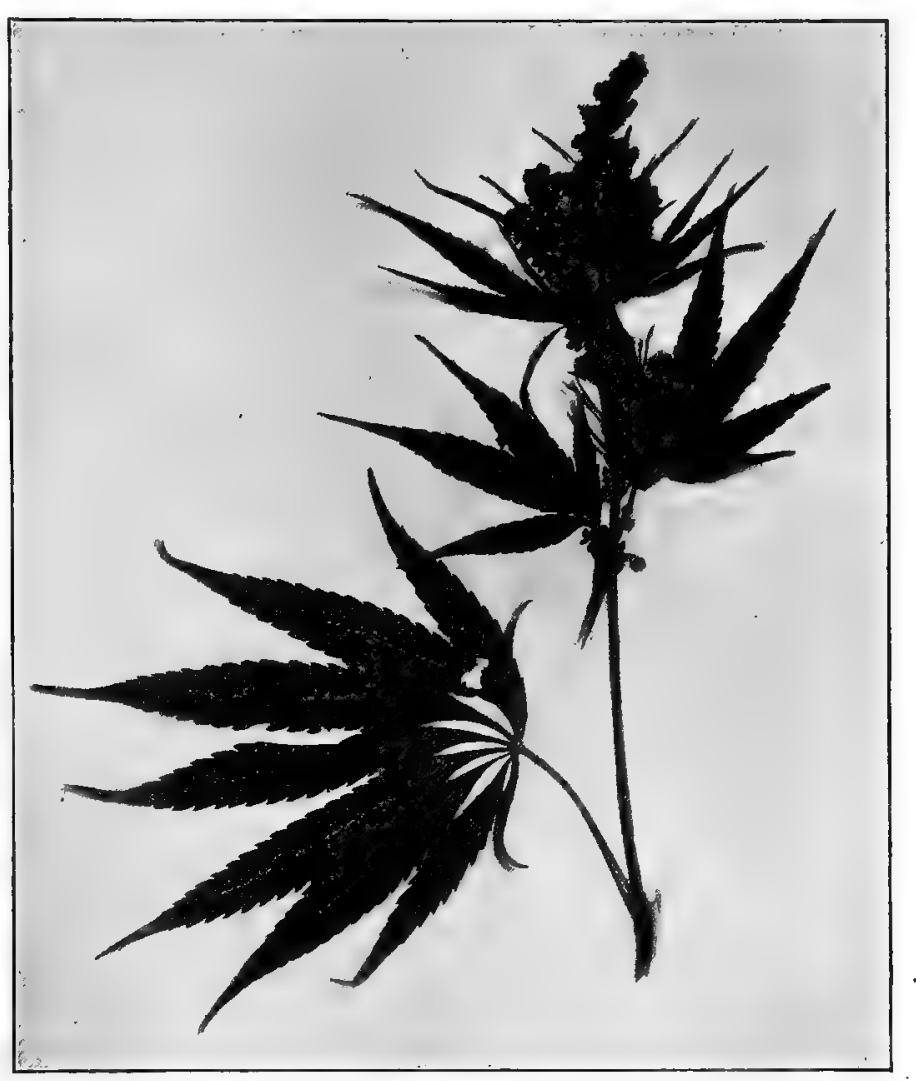

Fig. 273. Branch of a pistillate plant of Cannabis sativa showing the petiolate, 5- to 7 -digitately divided leaves and the axillary spikes of pistillate flowers with leaf-like bracts.

CANNABINOL (cannabindon) occurs as a red, oily substance and is said to possess the intoxicating properties of the drug. The drug also contains 0.3 per cent. of a yellowish Volatile OIL, which consists chiefly of a sesquiterpene, cannibene and a stearoptene. A similar sesquiterpene is present in the staminate plant of Canna- 
bis gigantea. The non-flowering herb yields about I per cent. of a narcotic volatile oil which has an odor that is not unpleasant. The volatile alkaloid cannabinene is supposed to be trimethylamine.

Allied Drugs.-The alkaloids harmine and harmaline are found in the seeds of Pegantum Harmala (Fam. Zygophyllaceæ) of India, and have narcotic properties similar to Cannabis indica.

SCOPARIUS.--BROOM.-The tops of Cytisus Scoparius (Fam. Leguminosæ), a shrub (p. 294) indigenous to the temperate parts of Europe, and naturalized in waste places from Virginia to Nova Scotia. The tops are gathered before flowering and are used in the fresh condition, or they are dried.

Description.-Usually cut into pieces; branches alternate, pentangular, 2 to $3 \mathrm{~mm}$. thick; externally dark green, with 5 yellowish-green wings and numerous reddish-brown cork patches, the younger branches somewhat pubescent; fracture short, fibrous, or of the larger pieces, tough, splintery; internally yellowish, bark thin, wood slightly porous, pith large, about I $\mathrm{mm}$. in diameter. Leaves elliptical, obovate, simple above, 5 to $10 \mathrm{~mm}$. long, 3 to 4 $\mathrm{mm}$. broad, digitately trifoliate below; apex of both leaves and leaflets acute; base acute; margin entire; upper surface dark green, nearly glabrous; under surface slightly pubescent; petiole wanting in the simple leaves and about $5 \mathrm{~mm}$. long in the compound leaves, pubescent. Odor peculiar. Taste bitter.

Constituents.-A volatile liquid alkaloid sparteine ( 0.03 per cent.), forming crystalline salts, the sulphate of which has physiological properties similar to digitalin; a yellow crystalline principle scoparin, which yields picric acid on treatment with nitric acid; volatile oil ; tannin; ash about 5 per cent.

Allied Plants.-Several plants of the Leguminosæ are used like Scoparius. Spanish broom is obtained from Spartium junceum, a shrub indigenous to the Mediterranean region. Coronilla scorpioides yields a yellow glucoside coronillin.

CHIRATA.-The entire plant of Sweertia Chirata (Fam. Gentianacex), an annual herb (p. $3^{62}$ ) indigenous to the mountains of Northern India. The plants are collected after the capsules are fully formed, dried and made into bundles.

Description.-Usually in flat bundles tied with a strip of bamboo and about I M. long, $15 \mathrm{~cm}$. wide and $7 \mathrm{~cm}$. thick. Root 
simple, tapering, about $7 \mathrm{~mm}$. thick near the crown; externally yellowish-brown, wrinkled, with few rootlets; internally, bark whitish, about $2 \mathrm{~mm}$. thick, wood yellow, porous, radiate. Stem cylindrical, flattened, quadrangular above, each angle with a decurrent wing, about I M. long, 4 to $6 \mathrm{~mm}$. thick, yellowish- or purplish-brown, longitudinally wrinkled, internodes 3 to $8 \mathrm{~cm}$. long; internally, bark yellowish-brown, very thin, easily separable, wood yellowish, slightly porous, radiate, 0.5 to $\mathbf{I m m}$. thick, pith lemonyellow, 2 to $3 \mathrm{~mm}$. in diameter, easily separable from the wood, sometimes wanting. Leaves opposite, ovate-lanceolate, about 6 $\mathrm{cm}$. long, $2.5 \mathrm{~cm}$. in diameter; apex acuminate; base somewhat amplexicaul; margin entire; upper and under surfaces brownishgreen, midrib prominent and with 3 to 7 parallel lateral veins. Inflorescence a large panicle; flowers numerous, regular; calyx about $4 \mathrm{~mm}$. long and with 4 lanceolate divisions; corolla yellow, rotate, about $10 \mathrm{~mm}$. long, with 4 lanceolate lobes, each with a pair of nectaries near the base; stamens 4 , inserted at the base of the corolla tube; style slender, with two recurved stigmas; ovary I-locular, with 2 parietal placentas. Fruit a superior, ovoid, pointed, yellowish-brown, bicarpellary, unilocular capsule. Seeds numerous, anatropous, somewhat oblong, flattened, about $0.5 \mathrm{~mm}$. long, testa reticulate; embryo small, straight, embedded in the endosperm. Odor slight. Taste extremely bitter.

Constituents.-A bitter glucoside chiratin, which is precipitated by tannin and yields on hydrolysis two bitter principles: ophelic acid and chiratogenin, the latter being insoluble in water. Ophelic acid is a brown hygroscopic substance which is readily soluble in water and alcohol and on heating with Trommer's reagent causes the deposition of yellowish cuprous oxide. The drug also contains resin, tannin and 4 to 8 per cent. of ash.

Allied Plants.-Other species of Sweertia, as well as other bitter plants known in India as "chiretta;" find there way into the market, but are, however, easily distinguished from the true drug.

SCUTELLARIA.-SKULLCAP.-The dried herb of $S c u$ tellaria lateriflora (Fam. Labiatæ), a perennial herbaceous plant growing in wet places in the United States and Canada. The plant blooms from July to September, when the herb should be collected (p. 368). 
Description.-Stem quadrangular, I to $4 \mathrm{~mm}$. in diameter, varying in color from yellowish-green to purplish-red; mostly glabrous below and hairy above. Leaves ovate, ovate-oblong, or ovate-lanceolate, opposite, $\mathrm{I} .5$ to $8 \mathrm{~cm}$. long, 0.5 to $2.5 \mathrm{~cm}$. broad; apex acute or acuminate; base acute, rounded or sub-cordate; margin coarsely serrate; upper surface dark green, glabrous; under surface light green, nearly smooth, veins of the first order diverging at an angle of $65^{\circ}$, curving upward and anastomosing near the margin; petiole 2 to Io $\mathrm{mm}$. long. Flowers axillary and solitary above or in I-sided racemes; calyx campanulate, toothed. about $2 \mathrm{~mm}$. long; corolla white or blue, about $6 \mathrm{~mm}$. long, the limb 2-lipped; stamens 4, didynamous, hairy, the anthers of the upper pair with 2 pollen sacs, the lower with one; style unequally 2-cleft and ovary deeply 4-parted. Fruit consisting of 4 ellipsoidal, distinctly tttberculate, light brown nutlets about I $\mathrm{mm}$. long, borne on an enlarged torus known as the gynobase, and enclosed by the persistent bilabiate calyx, the upper part of which becomes helmet-shaped after fertilization, whence the name "Skullcap." Odor slight. Taste bitter.

Constituents.-A bitter crystalline glucoside scutellarin; a small quantity of volatile oil, of which little is known.

Allied Plants.-Several species of Scutellaria growing in the United States are sometimes substituted for the official drug, nearly all of which have the flowers in terminal panicled racemes. Heart-leaved skullcap (Scutellaria cordifolia) is densely glandular pubescent, even the corolla being hairy; Hairy skullcap ( $S$. pilosa) is pubescent below, with numerous glandular hairs above, and the corolla is nearly glabrous; Hyssop skullcap ( $S$. integrifolia) has linear entire upper leaves; in Marsh skullcap ( $S$. galericulata) the flowers occur in the axils of the nearly sessile, narrow leaves. The European skullcap (S. altissima) has broad, ovate, glabrous leaves and terminal panicles of blute flowers.

Substitutes.-Scutellaria canescens, a plant growing. west of the Mississippi, furnishes much of the drug on the market. The plant is more robust than S. lateriflora; the leaves are oblong, petiolate, Io to $12 \mathrm{~cm}$. long, 3 to $5 \mathrm{~cm}$. broad, very hairy on the tnder surface, with prominent veins, and crenate-dentate margin; and the flowers are large, blue and in terminal racemes. 


\section{EXUDATIONS, JUICES AND OTHER PLANT PRODUCTS.}

A large number of substances are used in medicine which represent to a greater or less extent the constituents of the cells or alteration or decomposition products of them. These include exudations, inspissated juices, extracts, products of distillation, etc. The exudation products of milk-vessels or secretion reservoirs are eliminated either through natural or artificial wounds of the stem, and they are collected in special receptacles, as in the case of gamboge, scammony and turpentine; or they are allowed to dry and more or less harden on the stem, afterward being collected, as acacia and tragacanth; or the more or less plastic or partially dried exudation may be made into masses, as those of lactucarium and opium. These products may be grouped according to their origin, some of them being derived from the Coniferæ:

\section{Natural Exudations.}

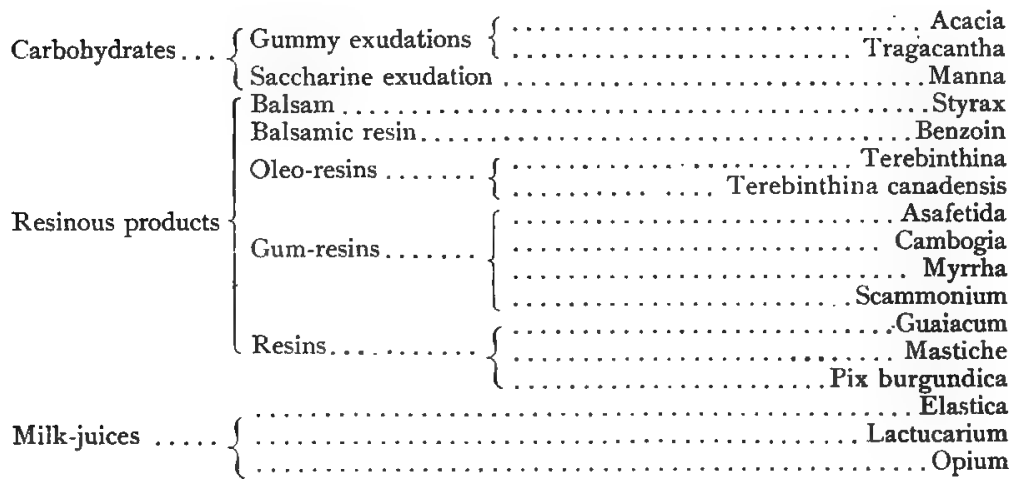

\section{An EXCRESCENCE.}

Formed as a result of the puncture of an insect Galla

\section{Artificially Prepared Products.}

Carbohydrates-Starch grains. Amylum

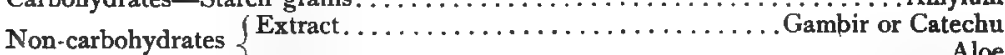

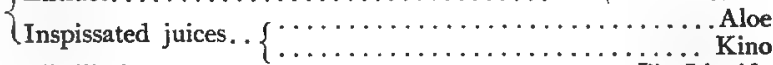

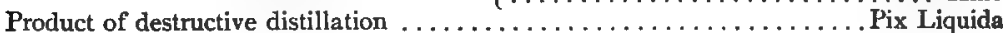
Residue from the distillation of turpentine. .Colophony 
For convenience in study, as well as identification, the drugs of this class may also be grouped as follows:

\section{Solid.}

I. In powder form.

White, inodorous, nearly tasteless................ Amylum

2. In tears and masses.

A. More or less spherical in form.

a. In tears.

Whitish or yellowish-white, mucilaginous.....Acacia Pale yellowish or greenish-yellow, resinous... Mastiche

b. Excrescence.

Somewhat spherical $\ldots \ldots \ldots \ldots \ldots \ldots \ldots$................

B. In cylindrical pieces.

Grayish orange-brown $\ldots \ldots \ldots \ldots \ldots \ldots \ldots$. Cambogia

Blackish-brown (see seeds)..$\ldots \ldots \ldots \ldots \ldots \ldots$. Guarana

C. In cubes.

Dull reddish-brown .............................

$D$. In quadrangular pieces, one side convex.

Dull reddish- or grayish-brown, odor opium-like ..........................Lactucarium

E. In three-sided elongated pieces.

Yellowish-white, odor of maple sugar.............Manna

F. In bands.

Whitish or pale-yellowish, mucilaginous...... Tragacantha

G. In angular fragments.

Whitish, inodorous and nearly tasteless...........Amylum

Amber-colored, odor terebinthinate.... Colophony (Resina)

Small, dark, reddish-brown, brittle, astringent pieces.. Kino Greenish-gray or brownish-black, odor peculiar ............................ Scammonium

$H$. In rounded masses.

Grayish-brown, odor distinct, heavy............ Opium

I. In irregular masses.

Orange-brown to blackish-brown, odor distinct, taste bitter ............................... Aloe

Dark reddish-brown, astringent.....................echu

Brownish-black, elastic ..................... Elastica

Greenish-brown, odor balsamic..............Guaiacum

Reddish-brown or yellowish-brown, odor terebinthinate..$\ldots \ldots \ldots \ldots \ldots \ldots \ldots$. Pix Burgundica 


\section{Solid.-Continucd.}

$J$. In irregular masses composed of matrix and tears.

Whitish tears, matrix yellowish-brown or brownish-gray, odor alliaceous..............Asafetida Yellowish-brown tears, matrix reddish-brown,

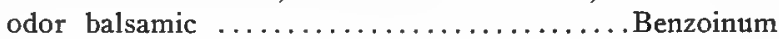

$K$. In masses composed of tears.

Brownish-red or yellowish-brown, balsamic........Myrrha Yellowish, terebinthinate..$\ldots \ldots \ldots \ldots$. Terebinthina

\section{Liquid or Semi-Liquid.}

Blackish-brown, empyreumatic and terebinthinate.......Pix Liquida

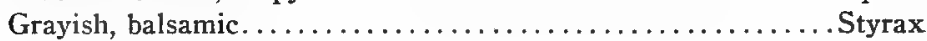
Pale yellowish, transparent, terebinthinate. .Terebinthina Canadensis

AMYLUM.-STARCH.-The starch grains obtained from the grains of wheat (Triticum sativum and its varieties), corn (Zea Mays, p. 228) and rice (Oryza sativa) (Fam. Graminex). The grains are separated from the cells, purified in various ways, and subsequently washed with large quantities of water. In the U. S. Pharmacopœia corn starch alone is recognized.

In the preparation of corn starch the corn grains are softened by being placed in running water and kept at a temperature of about $60^{\circ} \mathrm{C}$. for several days, care being taken to prevent any fermentation. The grains are then crushed between burr-stones and the paste carried by means of water to large sieves, the strained magma then being reground and carried to sieves made of bolting cloth. The milky-fluid containing the starch is then run into settling vats, the starch separating out. The starch is then freed from oil, albuminoids and other substances by treating it with a 15 per cent. solution of caustic soda. The supernatant liquid is removed and the starch washed with water to remove all traces of alkali. The starchy mixture is allowed to stand, when the starch separates out and is dried. Commercial starch is likely to contain some free alkali, which is readily detected by the addition of an aqueous solution of fuchsin, which becomes decolorized immediately in the presence of a starch containing free alkali. 
CoRn Starch.-In fine powder or irregular, angular, white, inodorous, tasteless masses; grains somewhat spherical, but usually polygonal, with a lenticular, circular or triangular point of origin of growth, about Io to $25 \mu$ in diameter (Fig. $3 \mathrm{I} 6, D$ ). Corn starch grains differ in structure in the different varieties (p. 229).

Wheat Starch.-Usually in a fine powder consisting of nearly spherical or ellipsoidal grains with point of origin of growth and lamellæ more or less indistinct, about ${ }_{5} 5$ to $40 \mu$ in diameter (Fig. 3I6, C).

Rice Starch.-Ustrally in a grayish-white powder consisting of minute angular grains about 5 to $8 \mu$ in diameter and with point of origin of growth and lamellæ indistinct.

Starch is insoluble in cold water or alcohol, but forms a white jelly when boiled with water, which, when cool, gives a deep-blue color with iodine and should give a neutral reaction to litmus paper (commercial cornstarch is usually alkaline); ash not more than $r$ per cent.

Structure of Starch Grains.-See Figs. 95, 96, 97, 316, 317. Composition of Starch Grains.-See p. I62.

ACACIA.-GUM ARABIC.-A dried, gummy exudation from the stem and branches of Acacia Senegal and probably other species of Acacia (Fam. Leguminosæ), trees (Fig. I53) growing in sandy soil and forming forests in tropical Africa (p. 294). The gum exudes spontaneously from the bark of the tree and is apparently formed by the action of a ferment on the cell-contents as it does not contain any remains of cell walls. The trees are also incised, which increases the production of gum. The more or less hardened pieces are collected and then sorted into different grades, the market supplies being obtained from Egypt by way of Alexandria (Kordofan gum), from the Soudan by way of Suakin ("Turkey sorts" and "Trieste picked"), and from Senegambia by way of the port of St. Louis. The Kordofan gum is. considered to be the best.

DESCRIPTION.-In roundish tears of variable size, or broken into angular fragments; externally whitish or yellowish-white, with numerous minute fissures; translucent; very brittle, with a glass-like, sometimes iridescent fracture; nearly inodorous; taste mucilaginous. 
Acacia is not soluble in alcohol, but is completely soluble in water; the solution is adhesive, gives an acid reaction with litmus paper, yields a gelatinous precipitate with basic lead acetate solution (Ghatti gum giving but a slight precipitate), ferric chloride or concentrated solution of sodium borate (Mesquite gum is not precipitated by any of these reagents), does not give a bluish or reddish color with iodine (absence of artificial gums containing starch or dextrin), or a brownish-black precipitate with ferric chloride (absence of gum of Australian species), and does not reduce Fehling's solution (absence of artificial gums containing sugars).

The powder contains few or no altered or unaltered starch grains or vegetable tissues.

Constituents.-A crystalline glucoside, which is apparently arabic acid (arabin or gummic acid) in combination with calcium, magnesium and potassium, and which constitutes the greater part of the gum; water, I 2 to I7 per cent.; ash 2.7 to 4 per cent.

Allied Plants. - The best grade of gum Arabic (gum Senegal) is obtained from Acacia Senegal and A. glaucophylla, both of tropical Africa. Gums with a brown or red color are obtained from $A$. arabica, $A$. Seyal, $A$. stenocarpa and $A$. Ehrenbergiana. There are a number of gums which have many of the properties of gum Arabic, as CAPE gum, from $A$. horrida and $A$. Giraffe; Australian or wattle gum, from the golden wattle ( $A$. pycnantha), $\tan$ wattle ( $A$. decurrens) and $A$. homalophylla; AmraD gum, from $A$. arabica; GEDDA gum, from $A$. gummifera; TALCA gum from $A$. modesta of India. Gums are also obtained from other genera of the Leguminosæ, as Mesouite gum, from Prosopis juliflora, of the Southern United States and Mexico; SASSA gum from Albizzia fastigiata, of Abyssinia ; BARrister gum, from Mezoneurum Scortichinii, of Australia. A gum resembling acacia is found in Flindersia maculosa, of Eastern Australia, and Chloroxylon Srietenia, of Farther India and Ceylon, both plants of the Fam. Rutaceæ. Other gums are obtained from the plants of the following families: Rosaceæ (p. 290); Burseraceæ (see Myrrha), Anacardiacex (p. 322); Guttiferæ (p. 336).

Adulterants.-Various species of Acacia indigenous to tropical Africa and Australia, as well as Anogeissus latifolia (Fam. 
Combretaceæ) (the latter being the source of the so-called Ghatti gum), yield gums which, while resembling true acacia, do not respond to the tests given above.

An artificial gum has been prepared by heating starch with sulphuric acid in an autoclave, the resulting product being neutralized, washed and then dried. It is said to resemble acacia in appearance and adhesiveness.

The powder, while sometimes adulterated with dextrin and rice starch, is more frequently mixed with inferior gums, especially the Mesquite gum. The tears of Mesquite gum are nearly smooth, light yellowish-brown to dark-brown, more or less opaque, but translucent and glassy when fractured. The powder is of a whitish or grayish-white color. The gum is further distinguished by not giving precipitates with lead sub-acetate, ferric chloride and sodium borate. Mesquite forms an adhesive mucilage and can be used as an emulsifying agent.

MASTICHE.-MASTIC.-The dried, resinous exudation from Pistacia Lentiscus (Fam. Anacardiaceæ), a large shrub (p. 32I) indigenous to the Mediterranean region. The resin exudes through incisions made in the bark, and when dry is collected. The chief source of supply is the island of Scio.

DesCription.-Somewhat globular or ovoid tears 3 to $7 \mathrm{~mm}$. long, pale yellow or greenish-yellow, translucent, having a glasslike luster, comparatively free from a whitish dust; brittle; fracture conchoidal, becoming plastic when chewed; odor slight, balsamic ; taste mild, terebinthinate.

Mastic is completely soluble in ether, acetone and volatile oils. It is almost completely soluble in alcohol, the solution giving an acid reaction with litmus paper.

Constituents.-About 90 per cent. of a resin, consisting of $a$-resin (mastichic acid), which is soluble in alcohol, and $\beta$-resin (masticin), which is insoluble in alcohol; a volatile oil, $I$ to 2.5 per cent., with the balsamic odor of the drug and consisting chiefly of d-pinene. A small quantity of a bitter principle is also present, which is soluble in hot water and is precipitated by tannin.

Allied Plants.-Various other species of Pistacia found in India and Northern Africa yield resins resembling mastic. American mastic is obtained from the Peruvian Peppertree (Schinus 
Molle). Similar resins are found in other genera of the Anacardiaceæ, as Astroniumi and Semecarpus.

Chios Turpentine is a product resembling mastic which is obtained from Pistachia terebinthinus (Fam. Anacardiaceæ) and consists of to to 12 per cent. of a volatile oil (consisting chiefly of pinene) and 80 to 90 per cent. of resin.

GALLA.-NUTGALL.-An abnormal development on the young twigs of Quercus infectoria (Fam. Cupuliferæ), due to the puncture and presence of the deposited ova of a Hymenopterous insect, Cymips tinctoria. The galls are collected before the maturing of the insect, and are obtained principally from Aleppo, in Asiatic Turkey (p. 252).

Aleppo Galls.-Somewhat spherical, I to $2 \mathrm{~cm}$. in diameter; externally grayish-brown or dark grayish-green, more or less tuberculate above, the basal portion nearly smooth, and contracted into a short stalk, sometimes with a perforation on one side; heavy; fracture horny; internally yellowish or dark brown, consisting of a central portion which contains starch, and occasionally the partly developed insect, and an outer zone which is porous, lustrous and occasionally traversed by a radial canal, these two zones being separated by a layer of nearly isodiametric stone cells or parenchyma cells with thick cellulose walls; odor slight; taste strongly astringent.

Constrtuents.-The principal constituent is tannic acid, which is found to the extent of 50 to 70 per cent.; the drug also contains gallic acid 2 to 4 per cent., starch and resin.

Tannic acid (gallotannic acid or digallic acid) is as a yellowish-white amorphous substance, with a characteristic odor and astringent taste. It is soluble in cold water and alcohol; forms amorphous salts; gives a blue color and precipitate with ferric chloride; forms a soluble compound with iodine and prevents the latter from giving the characteristic reaction with starch.

Two classes of tannic acid are recognized, depending on their behavior with iron salts and other reagents: (I) Tannic acid, giving a bluish color with ferric chloride, as that of Aleppo galls, and also found in chestnut (Castanea), pomegranate (Punica) and sumac (Rhus); (2) tannic acid, giving a greenish color with ferric chloride, as that contained in oak barks (Quercus), cate- 
chu (Acacia), kino (Pterocarpus), rhatany (Krancria), canaigre (Rumex), tormentilla (Potentilla) and mangrove (Rhizophora).

Gallic acid crystallizes in silky needles or prisms which are inodorous and possess a faintly astringent taste. It is sparingly soluble in cold water, but soluble in alcohol; forms crystalline compounds with the alkalies, alkaline earths, lead and copper salts; and gives a bluish-black precipitate with ferric chloride, which is soluble in acetic acid and loses its color on boiling.

There are three stages in the development of galls corresponding to the development of the insect and during which the composition varies: (I) When the galls are first formed and the larva is beginning to develop, the cells of the outer zone, as well as those of the central zone, contain numerous small starch grains. (2) When the insect reaches the chrysalis stage the starch in the cells near the middle of the galls is replaced in part by gallic acid, while the cells at the center and near the periphery contain masses of tannic acid. (3) When the winged insect is developed nearly all of the cells contain amorphous masses of tannic acid with some adhering crystals of gallic acid. After the insect has emerged from the gall the constituents again undergo change, depending largely on the presence of moisture, when the tannic acid is changd into an insoluble oxidation product and the gall becomes more porous, constituting the so-called white gall of commerce.

Allied Plants.-On a number of species of Rhus, galls due to the stings of certain plant lice (Aphis) are formed, as CHINESE Galls, formed on Rhus semialata; JAPANESE Galls, formed on $R$. japonica, and AmERICAN RHus Galls, formed on Rhus glabra (Fig. I64) and $R$. hirta. Chinese and Japanese galls are very rich in tannin, and as they contain less coloring matter than the oak galls are used in the manufacture of gallic acid. They are more or less irregular in shape, but somewhat ovoid, more or less tuberculate, grayish-brown, very hairy, light in weight, brittle. The wall is about I mm. thick, and the cavity contains the remains of numerous insects.

AmERICAN NUTGalls are formed on Quercus coccinea and $Q$. imbricaria by Cynips aciculata. When fresh they are globular, I.5 to $3 \mathrm{~cm}$. in diameter, and of a yellowish, somewhat mottled 
color. On drying they become yellowish or dark brown and much shrivelled externally. TEXAS NUTGALLS are formed on the live oak (Quercus virens) and yield 40 per cent. of tannic acid. CALIFORNIA OAK BALLS are excrescences on Quercus lobata and are about $5 \mathrm{~cm}$. in diameter, and said to contain considerable tannic acid.

Other tannin-yielding plants are found in the following families: Combretaceæ (p. 348), Leguminosæ (p. 292), Myrtaceæ (p. 346).

CAMBOGIA.-GAMBOGE.-A gum-resin obtained from Garcinia Hanburyi (Fam. Guttiferæ), a tree (Fig. I68) found growing on the Malabar coast and in Travancore (p. 335). Spiral incisions are made in the bark of the trees, and the gum-resin which exudes is collected in hollow bamboo stems; it is then allowed to dry slowly, after which the bamboo is removed. It is chiefly exported by way of Singapore and is known commercially as pipe gamboge.

DESCRIPTION.-In cylindrical pieces, frequently hollow in the center, of variable length, 2 to $5 \mathrm{~cm}$. in diameter; externally grayish orange-brown, longitudinally striate, due to the ridges on the inner surface of the bamboo canes in which they have been dried; hard; fracture short, the fractured surface being orange-red, waxy and somewhat porous; inodorous; taste very acrid.

The powder is bright yellow, sternutatory, and contains few or no starch grains; not more than 25 per cent. should be insoluble in alcohol. The resin is soluble in solutions of the alkalies, with the production of an orange-red color.

Constituents.-Gum allied to arabin, 15 to 20 per cent.; a resin known as cambogic acid, about 75 per cent.; a volatile oil; ash, I to 3 per cent.

Cake gamboge is collected in Saigon and Cochin from the same plant that yields pipe gamboge. The product is, however, collected in leaves and then allowed to dry. It occurs in irregular orange-red masses, weighing I to $2 \mathrm{~K}$, and is not so brittle as pipe gamboge, but is less uniform in composition and may contain impurities.

Allied Plants.-A drastic gum-resin is also obtained from Garcinia Morella and other members of the Guttiferæ, of India 
and Malaya, as G. collina, of New Caledonia ; Vismia laccifera, of Brazil ; Clusia rosea, of the West Indies and South America, and Chusia macrocarpa, of Guiana. Gamboge of a poor quality is obtained from Arasina Gurgi, of India.

Adulterants.-Gamboge is sometimes adulterated with vegetable fragments, inorganic substances, as sand, etc., and wheat or rice flour, which it may contain to the extent of nearly 50 per cent.

LACTUCARIUM.-The dried milk-juice of Lactuca virosa and other species of Lactuca (Fam. Compositæ), biennial herbs (p. 392) indigenous to Central and Southern Europe and cultivated in France, England and Germany, certain species being more or less naturalized in the United States. Lactucarium is obtained by cutting off the tops of the stems; and when the latex which exudes is partially hardened, it is collected and dried in hemispherical earthen cups until it can be cut into pieces, which are usually four in number, these being further dried.

DESCRIPTION.-In irregular, angular pieces or quadrangular sections, one surface of which is convex; externally dull reddishor grayish-brown; fracture tough, waxy; internally light brown or yellowish, somewhat porous; odor distinct, opium-like; taste bitter.

Lactucarium is partly soluble in alcohol and in ether, and about 50 per cent. is soluble in water, but the solution should not give a reaction for starch.

Constituents.-Three bitter principles: lactucin, which occurs in white rhombic prisms that are sparingly soluble in water; lactucopicrin, a brown, amorphous, very bitter principle which is readily soluble in water and alcohol; and lactucic acid, a yellow, very bitter substance crystallizing with difficulty and colored red by alkalies. The drug also contains about 50 per cent. of a colorless, odorless and tasteless crystalline principle, lactucerin (lactucon); $\alpha$ - and $\beta$-lactucerol in the form of acetates; volatile oil; mannitol; organic acids, as citric, malic and oxalic, and 7 to ro per cent. of ash.

A mydriatic alkaloid has been found in Lactuca virosa and in L. muralis.

MANNA.-The dried, saccharine exudation from the stems of Fraxinus Ornus (Fam. Oleacex), a small tree (p. 360) indigenous to Southern Europe, where it is also cultivated, particularly 
in Sicily. Manna is obtained by making transverse or oblique incisions in the bark, the exudation flowing down the side of the tree where it hardens, or it is collected in special receptacles. Scveral commercial varieties are recognized: LARGE FLAKE manna, consisting of light-colored pieces Io to $20 \mathrm{~cm}$. long; and SMILLL FLAIKE manna, which occurs in smaller light yellowish-brown pieces. The former is preferred.

DESCRIPTION.-In irregular, 3-sided, more or less elongated pieces, one side being smooth and concave; externally yellowishwhite; friable, somewhat waxy; internally whitish, porous and crystalline; odor suggestive of maple sugar; taste sweet, slightly bitter and acric.

Constituents.-The principal constituent is Mannitol (80 to 90 per cent.), which crystallizes in colorless needles that are soluble in water and sparingly soluble in alcohol; on sublimation it yields a sweet, syrupy liquid, MANNITAN; the solutions of mannitol do not ferment nor is it decomposed with dilute acids. Manna also contains a green, fltorescent glucosidal principle FRAXIN (resembling æesculin), which occurs in bitter, colorless prisms that are soluble in water and alcohol; dextrose, as high as I6 per cent. ; mucilage; resin, and I.3 to 4 per cent. of ash.

Allied Products.-A number of other species of Fraxinus indigenous to Europe also yield manna. The term "manna" is applied to a number of exudations obtained from different sources and of varying composition, none of which, however, appear to be supplied as a substitute for true manna, although they might be employed in a similar manner.

Manna of inferior quality, known as "sorts," is obtained from incisions lower down on the stem, and consists of brownishyellow, more or less agglutinated tears, which are sticky and but slightly crystalline.

The leaves of a number of species of Eucalyptus (Fam. Myrtaceæ) secrete a manna-like carbohydrate, as E. Gunnii and $E$. resinifera. (See in this connection Coniferæ, p. 8I; Leguminosæ, p. 292 ; Myrtaceæ, p. 346.)

TRAGACANTHA.-TRAGACANTH.-A gummy exudation from the stem of Astragalus gummifer and other species of Astragalus (Fam. Leguminosæ), shrubs (Fig. 152) indigenous 
to Southeastern Europe and Western Asia (p. 294). Some of the walls of the pith and medtllary rays are transformed into mucilage (Fig. 274), which exudes spontaneously, but is obtained in commercial quantities by making incisions in the bark, the gum

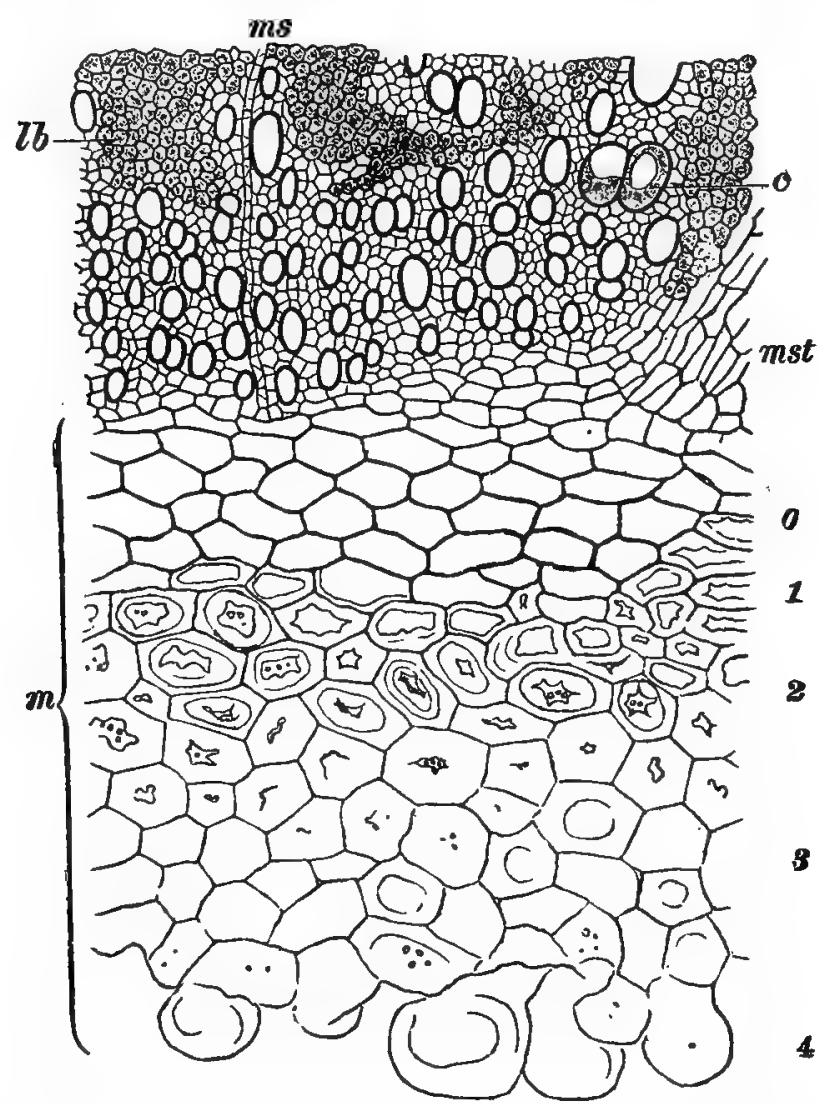

FIG. 274. Cross section through pith (m) and the inner portion of the wood (Ib) of Astragalus gummifer showing stages in the modification of the cell-walls in the formation of gum tragacanth $(0,1,4,3,4)$. Some of the tracheæ (c) contain globular masses of gum.After Tschirch.

being collected after it dries. The principal points of export are Smyrna and various ports along the Persian Gulf; that obtained from the latter is known as Persian or Syrian Tragacanth and is preferred. 
Persian or Syrian Tragacanth.-In flattened, lamellated, ribbon-like pieces, 0.5 to $2.5 \mathrm{~cm}$. long, about I $\mathrm{cm}$. wide and from I to $3 \mathrm{~mm}$. thick, irregularly oblong, more or less curved; externally nearly colorless or pale yellowish, with numerous concentric ridges or lamellæ; translucent; fracture short, tough, horny, rendered more easily pulverizable by a heat of $50^{\circ} \mathrm{C}$.; inodorous; taste insipid.

Constituents.-BAssorin (traganthin), 60 to 70 per cent., which gives the mucilage made from this gum its peculiar density, and which serves to distinguish it from acacia, which contains little or no bassorin; a carbohydrate apparently in the nature of an insoluble compound of arabic (gummic) acid, which swells in water but is insoluble in it; ARABIN, about Io per cent., soluble in water and probably formed from traganthin; starch; ash about 3 per cent., of which one-half is calcium carbonate.

Allied Products.-Smyrna tragacanth, which is collected in Asiatic Turkey and shipped from Smyrna, occurs in pieces that are less ribbon-like, more opaque, of a yellowish-brown color, with numerous prominent concentric ridges, and contains considerably more starch than the Syrian or Persian varieties.

Allied Plants.-Tragacanth is obtained from a number of other species of Astragalus. Gums containing a considerable amount of bassorin are also obtained from Piptadenia rigida, of Brazil, and Acacia micrantha (Caju gum), of Mexico, and also from a number of plants of the Cactacex (p. 342).

Sarcocold a is a gummy exudation of Pencea Sarcocolla and P. mucronata (Fam. Penæaceæ, one of the Myrtifloræ), small shrubs indigenous to Southern and Central Africa. The gum occurs in small, globular, yellowish-red or brownish-red friable grains, which are often agglutinated into masses and admixed with a few hairs. Sarcocolla has a licorice-like taste. It is soluble in water and alcohol, and contains an uncrystallizable principle sarcocollin, having a taste of glycyrrhizin; a resin; and a gum.

The gum yielded by Cochlospermum Gossypium (Fam. Bixaceæ) is sold in India as a substitute for tragacanth, which it resembles. It is free from starch, and has, like the gum of Sterculia urens, the property of slowly giving off acetic acid when exposed to moist air. 
COLOPHONY.-ROSIN OR RESIN.-The residue after the distillation of the crude oleo-resin (or turpentine) of Pinus palustris and other species of Pinus (Fam. Coniferæ), evergreen trees (Fig. 47, $B$ ) indigenous to the Southern United States (p. 8I). There are two commercial varieties of Colophony: ( $I$ ) one which is amber colored and derived from the oleo-resin of trees tapped for the first time; and (2) a yellowishred or reddish-brown variety derived from the oleo-resin of trees that have been tapped for a number of years. The former kind is preferred.

DESCRIPTION.-Usually in sharp, angular fragments; translucent, amber-colored, usually covered with a yellowish dust, hard, brittle, pulverizable, fracture shiny and shallow-conchoidal; odor and taste faintly terebinthinate.

Resin has a specific gravity of 1.070 to 1.080 , and it is soluble in alcohol, ether, benzol, carbon disulphide, acetic acid, fixed and volatile oils and in solutions of potassium or sodium hydrate.

Constituents.-From 80 to 90 per cent. of an anhydride of abietic acid, which on treatment with alcohol is changed into abietic acid, which latter is crystalline; sylvic acid, which is probably a decomposition product of abietic acid; ash, about I per cent.

WHITE Rosin, prepared by agitating melted rosin in water, occurs in whitish, opaque masses, due to inclusion of air.

Rosin is not infrequently used as an adulterant of other resinous products, as of Burgundy pitch and Venice turpentine. A mixture of rosin and oil of turpentine is sometimes substituted for the latter.

Substitute.-Claretta resin derived from Azorella compacta (Fam. Umbelliferæ) of Chile is a dark resin with an aromatic, acrid taste, which contains about 9 per cent. of vegetable tissues.

Resins are a class of substances which may be looked upon as final products in destructive metabolism. They result from the oxidation of oils and allied products and usually accompany them, as oleo-resins, gum-resins, etc. They are insoluble in water, soluble in alcohol, acetone, ether and similar solvents, and burn with a yellow flame, forming considerable soot. Several kinds of resins are recognized, depending upon the nature and constitution of their important constituents: 
(i) Resinolic Acid Resins include those that contain a large proportion of oxy-acids, which have been obtained in a crystalline condition, as abietic acid in colophony: copaivic and oxycopaivic acids, in copaiba; guaiaconic acid, in guaiac; pimaric acid, in Burgundy pitch and frankincense; and sandaracolic acid, in Sandarac.

(2) Resinol Resins are alcoholic or phenolic resins, a number of which have been crystallized, as benzoresinol, from benzoin; storesinol, from styrax; gurjuresinol, from gurjun balsam; and guaiacresinol, from guaiac resin.

(3) Resinotannol Resins are aromatic derivatives that behave towards iron salts and some other reagents like tannim and yield picric acid on oxidation with nitric acid. The following have been isolated: Aloeresinotannol, from aloes; ammoresinotannol and galbaresinotannol, from ammoniac; peruresinotannol, from balsam of Perı; siaresinotannol and sinnaresinotannol, from benzoin; and toluresinotannol, from balsam of tolu.

(4) Resene Resins form a group of resins which appear to be associated with bitter principles. They are insoluble in alkalies and with difficulty acted upon by reagents. They include alban and fluavil, from gutta percha; copalresene, from copal; dammaresene, from dammar; dracoresene, from dragon's blood; olibanoresene, from olibanum.

(5) Glucoresins or glucosidal resins, as the resins of jalap (p. 452) and scammony (p. 657).

Resins occur in 33 families of the Spermophytes.

KINO-MALABAR OR EAST INDIAN KINO.-The inspissated juice of Pterocarpus Marsupium, and probably other species of Pterocarpus (Fam. Leguminosæ), trees (p. 294) indigenous to Southern India and Ceylon. The juice exudes through incisions made in the bark, and is allowed to dry in the sun. The drug is exported from Madras and is known as Malabar or East Indian Kino.

Description.-Small, angular, opaque, black or reddishblack, translucent, glistening, brittle pieces, nearly free from dust; the thin laminæ appearing transparent and ruby-red at the edges; inodorous; sweetish, very astringent and adhering to the teeth when chewed, the saliva being colored red. 
Kino is entirely soluble in alcohol, only partly soluble in cold water, and not less than 80 per cent. should be soluble in boiling water, the solution having an acid reaction.

Constituents.-Tannin, 40 to 80 per cent., which resembles catechutannin and gives a blackish-green color and precipitate with ferric chloride, a violet color with ferrous salts, and the aqueous solutions of which deposit on exposure to air an insoluble, amorphous, reddish substance, kino red; 1.5 per cent. of kinoin, a colorless, crystalline substance, which is sparingly soluble in water and yields on hydrolysis, kino red. Kino also contains a small quantity of catechol (pyrocatechin), kino red, gallic acid, resin, gum, pectin, I 3 to 15 per cent. of moisture; and yields 2 to 6 per cent. of ash.

Ar.t.ied Products.-The term kino is applied to various astringent plant juices which, while they contain large amounts of tannin, do not appear to be as valuable as either the Malabar or Australian kino.

Allied Plants.-Australian kino (Red gum or Eucalyptus gum) is obtained from Eucalyptus rostrata and other species of Eucalyptus. It occurs in masses or small fragments, which are of a ruby or garnet-red color (not reddish-black), somewhat dusty, but not so brittle as Malabar kino. It contains 45 to 50 per cent. of tannic acid; kino red, and catechin. About 80 to 90 per cent. is soluble in cold water, the solution having a neutral reaction. Australian kino seems to be more unstable than Malabar kino and is converted into insoluble kino red, particularly if not thoroughly dried.

Eucalyptus Kino is also obtained from the following species: Iron-bark tree (E. Leucorylon), E. Gunnii, E. obliqua, E. piperata, E. ficifolia, E. stellutata, E. macrorhyncha, E. amygdalina radiata. Several species of Angophora yield a kino which is wholly soluble in alcohol and is entirely free from gum. So-called Botany Bay (Australian) kino was at one time supposed to be obtained from Eucalyptus resinifera.

Jamaica kino is obtained from Coccoloba uvifera (Fam. Polygonaceæ. A number of other India species of Pterocarpus also furnish kino. An African or Gambia kino is obtained from $P$. erinaceus, of Senegambia. 
Butea or Bengal kino is obtained from Butea monosperma, a tree growing in Western India and Farther India.

American DRAGON'S BLOOD, resembling black kino, is obtained from $P$. Draco, of the West Indies and Guiana. A false dragon's blood is obtained from Copaiba Mopane, of Southwestern Africa.

A tannin resembling kino is obtained from the Jambul tree (Syzygium Jambolana), of India. Tannin is also found in the root bark of Jambosa vulgaris, of the East Indies; the bark of Myrtus brabantica, of Mexico and Peru. A tannin and a coloring principle are found in the bark of Myrtus Arayan, of Mexico and Peru. A tannin and resin are found in the bark of Psidium Guajazia, of South America and the West Indies; Spermolepis gummifera, of New Caledonia, and the Myrtle tree (Myrtus communis), of Southern Asia and the Mediterranean region, the tannin in the latter plant occurring in larger proportion in the galls which are produced upon it.

SCAMMONIUM.-SCAMMONY.-A gum-resin obtained by incising the root of Convolvulus Scammonia (Fam. Convolvulacex), a perennial, twining herb (p. 366) indigenous to Syria, Asia Minor and Greece. The incisions are made in the upper part of the root in June, and the exuding gum-resin is collected in mussel shells, the product from a number of roots being mixed together, after which it is allowed to dry. The principal points of export are Smyrna and Aleppo. The natural exudation free from extraneous matter is known as native or vIRGIN scammony.

Smyrna Scammony.-In circular, flattened cakes, io to i2 $\mathrm{cm}$. in diameter and about $\mathbf{I ~ c m}$. in thickness, or irregular, angular pieces of variable size; greenish-gray or brownish-black, often covered with a grayish-white powder, formed by the rubbing of the pieces against one another in transportation; very brittle; fracture sharp; internally porous, lustrous and of a uniform brownishblack color, being more or less translucent in thin fragments; odor peculiar, somewhat cheese-like; taste slightly acrid.

Scammony is easily powdered and forms a milky emulsion with water. It does not effervesce on the addition of diluted hydrochloric acid (absence of calcium carbonate); an alcoholic solution is not colored blue on the addition of tincture of ferric chloride (absence of guaiac resin); ether dissolves not less than 
70 per cent. (distinction from jalap resin), and when the residue on evaporation of the ethereal solution is dissolved in a hot solution of potassium hydrate it is not reprecipitated on the addition of diluted sulphuric acid.

Constituents.-From 75 to 95 per cent. of a glucosidal resin (scammonin), which is completely soluble in ether; gum, 5 to 8 per cent.; ash, not more than 3 per cent. Scammonin is apparently identical with the resin in Ipomoca orizabensis and the ethersoluble resin in jalap. It occurs as a white powder, which on treatment with alkalies yields the glucoside SCAmmonIC ACID. The latter on hydrolysis decomposes into scammonolic acid and glucose. An anhydride of scammonolic acid, SCAMMONOL, some valerianic acid and sugar are formed on treating scammonin with mineral acids. The peculiar cheese-like odor of the resin is due to the formation of a volatile, fatty acid during the drying process.

AdULTERANTS.-Scammony is adulterated with inorganic substances, various starchy products, foreign resins, such as guaiac, and an extract of the juice of the root of Convolvulus althcoides, a plant indigenous to the countries bordering on the Mediterranean.

Allied Plants.-A resin resembling Scammony is also obtained from several other species of Convolvulus.

Montpellier Scammony is the natural exudation of Marsdenia erecta (Fam. Asclepiadaceæ), a plant indigenous to Southern Europe. It contains 50 to 60 per cent. of starch, Io to 2 I per cent. of resin, and yields I I to I8 per cent. of ash.

Scammony Root is official in the British Pharmacopoia. It is the dried root of C. Scammonia, and occurs in large, nearly cylindrical, spirally twisted pieces from 2.5 to $7.5 \mathrm{~cm}$. in diameter; externally it is yellowish-gray or brownish-gray and is longitudinally furrowed ; the fracture is coarsely fibrous from the presence of projecting wood fibers; internally it is whitish-gray, with the collateral fibrovascular bundles in radial rows forming concentric circles, the phloem of each containing numerous dark resin cells; the odor is like that of jalap, and the taste is first sweetish and then acrid. Scammony root contains about 5 per cent. of the glucoresin, scammonin; starch, and a sugar. It is used in the preparation of an alcoholic, resinous extract, known as 
Scammonia Resina, which occurs in brownish, translucent pieces that are brittle, shiny on the broken surfaces, fragrant and acrid. It does not form an emulsion with water (distinction from the natural resin), and is readily soluble in ether, consisting almost entirely of scammonin.

OPIUM.-The dried milk-juice of the capsules of Papaver somniferum (Fam. Papaveraceæ), an annual herb (Fig. 147), probably indigenous to Asia (p. 280), and now cultivated in Asia Minor, China, India, Persia and European Turkey. Experiments have been made both in this country and Europe to cultivate the opium poppy, but so far these experiments have been unprofitable. Opium is obtained by making transverse, oblique or longitudinal incisions in the unripe capsule (Fig. 9I) ; the latex which exudes is collected when partly dry and made into a mass. The latter is enclosed in a covering of rumex or poppy leaves and further dried, subsequently being packed in bags with rumex berries to prevent the masses from sticking together. While there are a number of varieties of opium, that used in this country is principally from Turkey and is exported chiefly from Smyrna and Constantinople. There are two principal kinds of Smyrna opium, namely, Karahissar, which occurs in spherical, somewhat flattened masses, and Balukissar, which is in the form of flattened, plano- convex masses, both kinds being wrapped in poppy leaves, packed with Rumex seeds, and yielding about I 3 per cent. of morphine.

Turkey Opium.- In irregular, flattened, more or less rounded masses of variable size and weighing from 250 to I,000 grammes; externally grayish-brown, covered with remnants of poppy leaves and with occasional fruits of a species of Rumex; internally dark brown, grantlar, somewhat lustrous, more or less plastic when fresh, but becoming hard and darker on keeping; odor distinct, heavy; taste peculiar, bitter (Fig. 3I4).

Constituents.-A large number of alkaloids have been obtained from opium and its extracts, some of which are, no doubt, alteration products of the alkaloids naturally occurring in the drug; the most important of these is morphine, which exists to the extent of 5 to 22 per cent., the largest amount being obtained from Turkey opium, the Persian ranking next, and the smallest amount being obtained from Indian opium. 
MORPHINE occurs in rhombic prisms or fine needles, which are nearly insoluble in water or oil of anise, and sparingly soluble in alcohol, and it forms crystallizable salts which are readily solttble in water, the solutions being lævorotatory. On the addition of morphine to concentrated sulphuric acid containing a little potassium dichromate, little or no change is produced at first, but the solution later becomes of a green color. On the addition first of some cane sugar to morphine and then of concentrated sulphuric acid and a little bromine water, the solution becomes purplish-red, changing to violet-blue, blue-green and finally a dingy yellow. Morphine gives a blue color with dilute solutions of ferric chloride, which is destroyed on heating, and it gives an orange or reddish color with nitric acid. On heating morphine in a sealed tube with hydrochloric acid a new salt is formed, known as APOMORPHINE hydrochloride. The latter occurs in minute, nearly colorless, monoclinic prisms, which become greenish on exposure to air and moisture; and the solutions are colored reddish on the addition of dilute solutions of ferric chloride. Pseudomorphine is a crystalline compound that is formed on heating alkaline solutions of morphine with oxidizing agents. It is insoluble in water, alcohol or even dilute sulphuric acid, but is readily soluble in a solution of potassitum hydrate.

CODEINE (or methyl morphine) occurs in opium to the extent of 0.5 to 2 per cent. It forms translucent, octahedral crystals or rhombic prisms, which are soluble in alcohol and oil of anise; somewhat soluble in water, and readily forms crystallizable salts. On heating codeine with concentrated sulphuric acid the solution is colored blue. On the addition of concentrated sulphuric acid containing traces of iron or nitric acid to codeine the solution becomes green, changing to blue, a blue precipitate finally separating. Dilute solutions of ferric chloride give a blue color with codeine, which is permanent if the solution be gently warmed. Codeine crystals are colored red with nitric acid, the solution remaining colorless or only becoming yellow on heating. On heating a solution of codeine hydrochloride in an autoclave with zinc chloride, an amorphous, yellowish-gray powder is formed, which is known as APOCODEINE hydrochloride, and which has the same physiological properties as apomorphine hydrochloride. 
Some opiun obtained from plants cultivated in France yielded 2.8I per cent. of codeine, while the morphine was but 2.4I per cent. and the narcotine o.Io per cent.

Narcotrine (opianine) occurs to the extent of 0.75 to 9 per cent. in opium, chiefly as a free base. It is found in greater amount in Persian and Indian opium than in Turkey opium. It forms colorless, shining, rhombic prisms or needles, that are tasteless, insoluble in water but soluble in alcohol. With concentrated sulphuric acid narcotine is colored greenish-yellow, the solution on heating changing to red and finally violet. It may be converted into a number of compounds, of which hydrocotarnine and vanillin are probably the most interesting.

Papaverine occurs to the extent of about I per cent. and forms colorless needles or prisms, which are partly soluble in water and alcohol, and colored deep purple or violet-blue on warming with sulphuric acid.

Thebaine (paramorphine) occurs to the extent of o.I5 per cent. in opium. It crystallizes in prisms which are insoluble in water or alkaline solutions, soluble in alcohol, and gives with sulphuric acid a deep red color.

NARCEINE ( 0.1 to 0.2 per cent.) occurs in silky needles or quadrangular prisms, which are nearly insoluble in cold water and alcohol, and are colored blue with iodine solutions and bloodred with chlorine water and ammonia.

Protorine occurs in monoclinic prisms, which are insoluble in water and sparingly soluble in alcohol, the solution having a bitter taste. Sulphuric acid dissolves protopine with a beautiful blue-violet color, which later becomes dull violet and finally greenish. Protopine is also found in a number of other plants of the Papaveraceæ, as the roots of Macleya cordata and Chelidonium majus; the rhizome of Sanguinaria, and other plants as well (p. 282).

Of the other alkaloids in opium the following may be mentioned: Codamine, cryptopine, gnoscopine, lanthopine, laudanine, laudanosine, meconine, meconidine and xanthaline.

Opium also contains from 3 to 5 per cent. of meconic acid, which exists in combination with morphine, codeine and other alkaloids. It forms rhombic prisms that are soluble in water and 
alcohol and give a deep red color to solutions of ferric chloride, which is not altered on the addition of dilute hydrochloric acid.

The yield of ash in Opium is from 4 to 8 per cent.

Persian Opium.-Usually in masses weighing about $35^{\circ}$ grammes, and internally more or less homogeneous. There are three commercial kinds of Persian opium: (I) Persian green, which is in plano-convex masses that are of a greenish color and with a closely adhering covering of leaf-tissue; (2) Persian white, which is in oblong, cubical masses, that are coated with a layer of closely adhering white paper; (3) Persian red, which is in either oblong, cubical, or truncate, cone-like masses, that are covered with a grayish-white layer and usually wrapped in red paper.

TURkey OpIum is produced in various parts of European and Asiatic Turkey, and there are three principal kinds on the market, namely: (I) Malatia opium, which is in the form of ellipsoidal or oblong, flattened cakes, with a closely adhering coating of leaftissue, and yields about to per cent. of morphine; (2) Salonica opium, which is in the form of long, broad, flattened cakes, coated with leaf-tissue, and yields about I5 per cent. of morphine; (3) Gheve opium, which is obtained from plants with red flowers, occurs in flat, oval masses; wrapped in poppy leaves, and yields I2.5 per cent. of morphine.

Egyptian OpIUM is in flat, nearly square masses, that are covered with poppy leaves, and yields from 3.5 to 7 per cent. of morphine.

INDIAN OPIUM is in flat cakes weighing about 200 grammes, or rounded masses weighing about 2 kilogrammes, wrapped in oiled paper. This variety is sent chiefly to China.

ADUlterints.-Opium sometimes contains fragments of the capsules, the pulp of figs and other fruits, tragacanth, starch, and varions inorganic substances, as clay, sand, stone, lead piping, lead bullets, etc. While starch is not usually admixed with Turkey opium it is nearly always present in the Persian variety.

ALOE.-ALOES.-The inspissated juice of the leaves of various species of Aloe (Fam. Liliacex), perennial succulents (Fig.I30) indigenous to Africa and India and naturalized in the West Indies (p. 237). There are three principal commercial varieties of aloes: (I) Socotrine (and Zanzibar) Aloes, derived 
from Aloe Perryi, and probably other species of Aloe, growing on the island of Socotra and in Eastern Africa, and exported by way of Bombay; (2) Curaçao (and Barbadoes) Aloes, obtained from Aloe chinensis and Aloe vera, growing in Curaçao and other

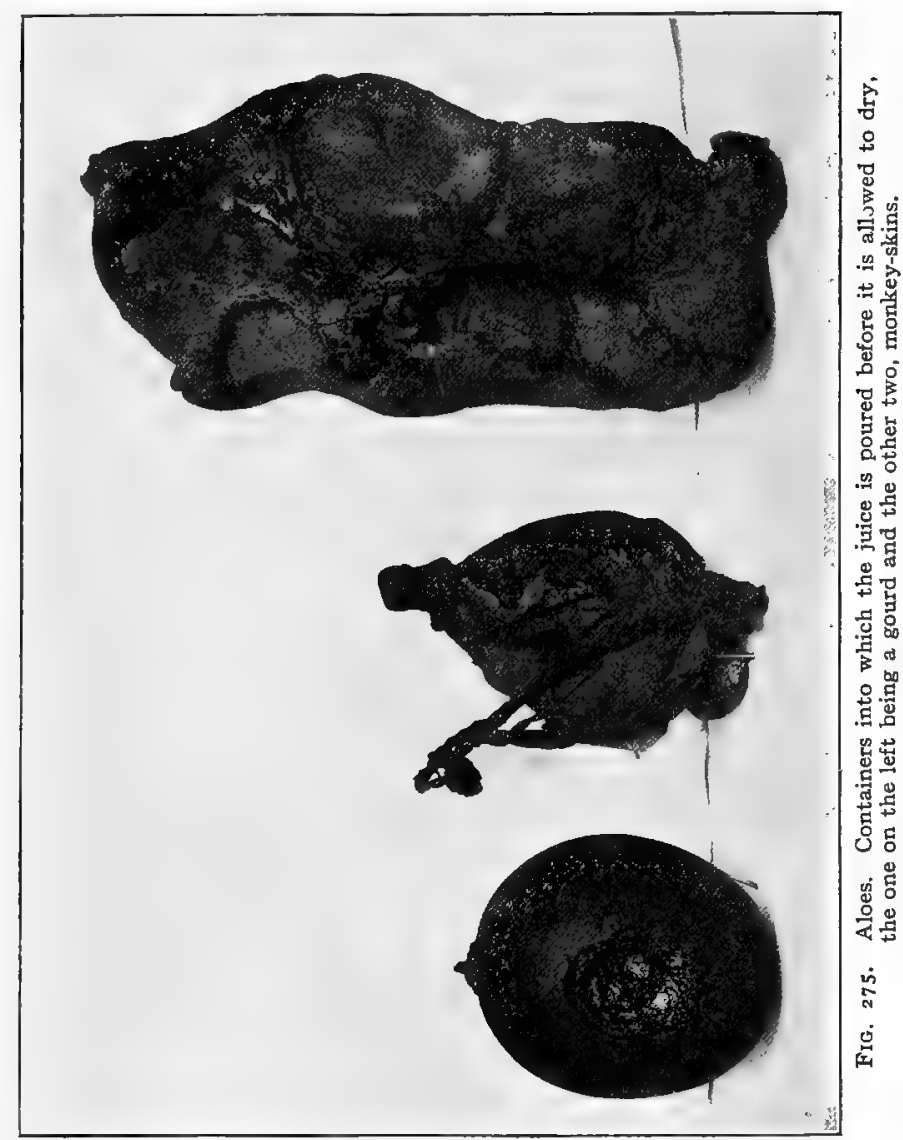

islands of the Dutch West Indies; and (3) Cape and Uganda Aloes, obtained from Aloe spicata and $A$. ferox, growing in Southern Africa, and exported from Cape Town and Mossel Bay. The leaves of the Aloe plant are cut transversely and the juice which exudes is allowed to evaporate spontaneously, it being 
usually, however, concentrated by boiling and then poured into boxes or gourds, and occasionally it is found in commerce enclosed in monkey-skins (Fig. 275). Socotrine aloes commands the highest price. The latter variety when fresh has an unpleasant odor, but on keeping develops an odor resembling myrrh and saffron.

I. Socotrine Aloes.-In yellowish-brown to dark-brown opaque masses, or smooth and glassy, fracture somewhat conchoidal; odor saffron-like; powder yellowish-brown or brownishyellow, giving a yellowish or reddish-brown color with nitric acid. About 50 per cent. of socotrine aloes is soluble in cold water. It is almost completely soluble in 60 per cent. alcohol or in water at $100^{\circ} \mathrm{C}$. On cooling the latter solution there separates from 40 to 60 per cent. of the so-called "resin of aloes," which is soluble in alkalies with a red color and is reprecipitated on the addition of acids. About 36.6 per cent. of aloes is soluble in chloroform, and from 4 to 5.5 per cent. in ether, the solution being of a yellow color. It should contain not more than 8 per cent. of moisture and yield not more than 4 per cent. of ash.

Zanzibar Aloes is a hepatic (or liver-colored) variety of Socotrine Aloes, produced by slowly evaporating the juice of the plant. It comes into market frequently in monkey-skins, has a. dark brown color, a dull, waxy fracture, and a nearly smooth. even surface. It forms a reddish-yellow powder that is colored dark yellow with nitric acid.

2. Curaçao Aloes.-Orange to blackish-brown opaque masses, translucent in thin pieces; fracture uneven, waxy, somewhat resinous, occasionally exhibiting microscopical crystals of aloin; odor distinct, tunpleasant; taste nauseous, bitter. The powder is dark brown and gives an immediate deep REDDISH COLOR WITH COLD NITRJC ACID or with solutions of the alkalies.

About 70 per cent. of Curaçao Aloes is soluble in cold water. It is almost completely soluble in 60 per cent. alcohol or boiling water; on cooling the solution made with boiling water there separates from 40 to 60 per cent. of "resin of aloes," which is similar to that of Socotrine aloes. About 66.6 per cent. is soluble in chloroform and not less than Io per cent. in ether. It contains less than 8 per cent. of moisture and yields from I.5 to 4 per cent. of ash. 
Barbadoes Aloes is a hepatic variety of Curaçao Aloes, which is not obtained at the present time from Barbadoes, but from the Dutch West Indies. It occurs in dark brown, dull, opaque masses, giving a yellow powder that is colored red with nitric acid. About 72.4 per cent. of fresh and 62.8 per cent. of old Barbadoes aloes is soluble in chloroform. It contains about 9 per cent. of moisture.

3. Cape Aloes.-O Of a reddish-brown or of an olive-black color, transparent in thin pieces; fracture smooth and glassy; powder greenish-yellow, becoming light brown and giving a greenish color with nitric acid.

About 65 per cent. of Cape aloes is soluble in cold water. It is almost completely soluble in alcohol or boiling water; and the latter solution gives a precipitate of 60 per cent. of "resin of aloes." From 8I to 86.8 per cent. is soluble in chloroform, and from $\mathrm{I} .5$ to 6.5 per cent. in ether. It contains about 9 per cent. of moisture, and yields but a small percentage of ash.

Uganda (or CROWN) Aloes is a hepatic variety of Cape Aloes prepared by allowing the juice to stand and undergo a partial fermentation, after which the clear liquor is decanted and evaporated by exposure to the sun. It occurs in reddish-brown masses, producing a powder, which is colored yellow to brown with nitric acid.

Constituents.-A crystalline, bitter principle, aloin, the percentage ( 4.5 to 30 per cent.) and composition of which vary in the different varieties, and which is supposed to occur in largest amount in old aloes; emodin (see Rhubarb); a pale yellow, volatile oil, which is apparently not identical in the different varieties, giving them their characteristic odors; 13 to 63 per cent. of resinous material, which consists chiefly of a resinotannol ester of cinnamic acid (Curaçao and Barbadoes Aloes) or of a resinotannol ester of paracumaric acid (Cape Aloes); and I to 4 per cent. of ash.

ALoIN is a neutral, bitter principle, which on distillation with zinc dust yields anthracene. It forms minute, lemon-yellow to yellowish-brown acicular crystals, which are sparingly soluble in water but more so in alcohol, the solutions becoming brown on standing. Alkaline solutions of aloin have a deep red color and exhibit a greenish-red fluorescence. Upon the addition of aloin 
to sulphuric acid a yellowish-red solution is formed, which upon the addition of a small quantity of potassium dichromate is changed to olive-green and finally to a blue color. Ferric chloride gives a brownish-green color to an alcoholic solution of aloin. Aloin occurs in the following amounts in the different aloes: Socaloin, from Socotrine Aloes, 4 to ro per cent. ; Barbaloin, from Curaçao or Barbadoes Aloes, Io to 25 per cent.; and Capaloin, from Cape and Uganda Aloes, $4.5^{\prime}$ to 9 per cent. The aloin obtained from Curaçao or Barbadoes aloes gives with nitric acid a cherry-red color or with Klunge's reagent a deep red color. These color reactions are due to the presence of about 0.5 per cent. of an isomeric body (isobarbaloin), which is not found in socaloin or capaloin. Alcoholic solutions of barbaloin and isobarbaloin lose their bitterness on standing, the aloin being replaced in part at least by a sugar aloinose, which forms yellow crystals that are colored red and then green with concentrated hydrochloric acid and orcin. Aloin is considered by some to be an emodin-glucoside which on oxidation splits off emodin, the latter on further oxidation forming rhein.

ADULTERANTS.-Aloes formerly contained various mechanical impurities, and this was the reason for the introduction of a purified aloes into the U. S. Pharmacopœia. As heat impairs the quality of aloes and as the requirements forbid adulteration the untreated aloes should be employed. The aloin is sometimes removed, as in the Curaçao aloes, when it has the appearance of Cape aloes and is sometimes sold for it. Recently aloes has been coming into market packed in thin layers separated by paper.

Allied Plants.-Natal Aloes is a hepatic variety of Aloes which was at one time exported from Natal, the botanical origin being unknown. It occurs in grayish-brown or greenishblack, dull, opaque masses, often covered with a brownish powder. The odor somewhat resembles that of Cape Aloes. The powder is grayish-green or pale yellowish-brown and microcrystalline, giving a permanent crimson color with nitric acid and a deep blue with sulphuric acid and vapor of nitric acid. The latter test serves to distinguish this aloes from all the other varieties. The drug contains aloin (nataloin), but not emodin. Both Natal Aloes and nataloin are physiologically inactive. 
JAFFARABAD Aloes is a vitreous variety obtained from the East Indies and is exported from Bombay. It occurs in circular, flattened cakes, of a deep black color externally, and with a black, glossy, slightly porous or somewhat laminated fracture. It yields about 20 per cent. of aloin, which is apparently chiefly isobarbaloin, and gives a deep crimson color with nitric acid.

CATECHU.-An extract prepared from the heartwood of Acacia Catechu (Fam. Leguminosæ), a tree (p. 294) indigenous to India and Burmah, and from the leaves and twigs of Uncaria (Ourouparia) Gambir (Fam. Rubiaceæ), a climbing shrub (p. $38 \mathrm{r}$ ) indigenous to Malacca, Java and Sumatra and mostly ctiltivated near Singapore, the former being known as "black catechu" or " cutch," and the latter as "pale catechu," "gambir," or " terra japonica." These extracts are prepared by boiling the parts of the trees and shrubs yielding them with water, evaporating the strained liquid to a syrupy consistence and allowing it to harden.

BLACK CATECHU.-In irregular masses, with fragments of leaves or mats upon the outside, dark brown, somewhat shiny; brittle, more or less porous internally; odor slight; taste astringent and sweetish.

Catechu is somewhat soluble in cold water, the undissolved portion containing acicular crystals; almost entirely soluble in boiling water, the solution giving an acid reaction; not less than 70 per cent. should be soluble in 90 per cent. alcohol. Few or no starch grains or vegetable tissues should be present, and the àsh should not be more than 5 per cent.

Gambir or Pale Catechu.-Usually in more or less porous irregular cubes, about $25 \mathrm{~mm}$. in diameter; externally dull reddish-brown; friable; internally paler, consisting chiefly of microscopic crystals when examined in a drop of oil; odor slight; taste bitter and very astringent.

Constituents.-Catechutannic acid, 25 (black catechu) or 22 to 50 per cent. (pale catechu), giving a green color and precipitate with ferric chloride and in other respects resembling the tannin in oak bark, kino and krameria; a substance somewhat resembling gallic acid, catechin, which crystallizes in silky needles; catechu-red; quercetin (p. 544), and ash about. 3 per cent. Pale catechu contains in addition a fluorescent principle. 
Allied Plants.-Black catechu is also extracted from the wood of Acacia Suma, of India. The barks of a number of species of Acacia growing in Australia, and known as WATrLE BARKS, are used in the preparation of an extract resembling black catechu. The tannin of Acacia arabica and of several species of Casalpinia yield on hydrolysis gallic and ellagic acids.

A tannin resembling catechu is obtained from the bark of Eugenia Smithii (Fam. Myrtaceæ), of Australia. A catechulike extract is obtained from the bark of the Mahogany Tree (Swietenia Mahagoni), one of the Meliaceæ, of the West Indies and Peru.

Adulterants.-On account of the inferior quality of black catechu in recent years the pale catechu has superseded it, and is the only kind recognized in the United States and British Pharmacopœias.

Catechu is sometimes adulterated with other plant extracts, various inorganic substances, and starch.

An extract (known as THAN), prepared from Terminalia Oliveri (Fam. Combretacex), a large tree growing in the dry regions of the Irrawaddy Valley, is used to adulterate Catechu. It contains a dark red coloring principle, but apparently no tannin, although the latter has been reported as occurring to the extent of between 14 and 68 per cent.

ELASTICA.-CAOUTCHOUC, INDIA-RUBBER.-The: latex or milk-juice of Hevea braziliensis, and probably other species of Hevea (Fam. Euphorbiacex), trees indigenous to Brazil (p. 316). The milk-juice is obtained by making incisions in the bark of the tree and is collected in small cups fastened to the trees. This is then poured into a larger vessel in which is placed a wooden paddle. The latter, with adhering latex, is dextrously revolved in an open fire until coagulated, new material being added from time to time until flask-shaped masses are formed, which are then removed, and constitute the commercial article known as "bolacho." The best grade, known as Para Rubber, is official.

DEscription.-In elastic flask-shaped masses or pieces of varying form and size; light, floating in water; externally brownish to brownish-black; internally brownish, consisting of a number of thin, alternate light and dark layers, due to the superimposed 
coats of latex formed during the drying process; odor slight, empyreumatic; nearly tasteless.

Caoutchouc is insoluble in water, dilute acids, or dilute solutions of the alkalies; more or less soluble in chloroform, carbon disulphide, oil of turpentine, benzin and benzol. It melts at about $125^{\circ} \mathrm{C}$., remaining soft and adhesive after cooling.

Constituents.-Caoutchouc consists chiefly of two hydrocarbons, one of which is ductile and readily soluble in chloroform, and the other elastic and less soluble in chloroform; it also contains I to 2 per cent. of resin, volatile oil, etc.

Allied Plants.-African rubber is obtained from several species of Landolphia and Kichsia africana (Fam. Apocynaceæ). BAHIA rubber is derived from Hancornia speciosa (Fam. Apocynaceæ). Central American or Panama rubber is obtained from Castilloa elastica (Fam. Moraceæ). CEará rubber is the product of Manihot Glaziovii (Fam. Euphorbiaceæ). EAST India rubber is the product of the commonly cultivated rubber plant, Ficus elastica (Fam. Moracea). Penang or Borneo rubber is the product of several species of Urceola (Fam. Apocynacex).

Vulcanization of RubBer.-Caoutchouc retains its elastic and other properties and is not affected by heat if it is first purified and then mixed with sulphur or sulphides. Ordinary rubber articles are prepared in this manner. Hard rubber articles are manufactured from Borneo rubber, to which colophony, gum balata and caoutchouc are added; a number of mineral substances. being added to cheapen as well as to color the final product.

GUAIACUM.-GUAIAC RESIN.-A resin obtained from the stem and branches of Guaiacum officinale, a small tree growing in Florida, the Antilles and Northern South America, and Guaiacum sanctum (Fam. Zygophyllaceæ), indigenous to the West Indies and the northern part of South America. The resin exudes spontaneously or is obtained from incisions in the bark or by heating the fallen trunks. The commercial article comes chiefly from $\mathrm{Cuba}$ and Hayti. The resin obtained from trees growing in the Bahama Islands is most highly esteemed (p. 303; Fig. 156).

DESCRIPTION.-Usually in irregular masses; externally greenish-brown, freqtiently covered with a greenish powder; brittle, the fracture having a glassy luster and being yellowish-green or 
reddish-brown and more or less transparent in thin pieces; fusible; odor balsamic; taste somewhat acrid.

The powder of guaiac is of a grayish color, but becomes green on exposure to the air, and on heating gives off an odor of benzoin. It is readily soluble in ether, alcohol, chloroform, solutions of the alkalies or chloral hydrate. It is sparingly soluble in benzol, fixed or volatile oils. The alcoholic solution has a brown color, which is changed to blute by the addition of ferric chloride, or oxidizing agents (as chromic acid or ozone) or through the action of chlorine, bromine or iodine. An alcoholic solution of guaiac is colored blue by enzymes. The blue color is destroyed on the addition of reducing substances:

Constituents.-Several acids are present, including guaiaconic, guaiaretic, guaiacresin, guaiacinic, and guaiacic. GUAIAconIC acid (alpha resin) occurs to the extent of 50 to 70 per cent., and forms a brown powder which is insoluble in water, soluble in alcohol and gives a blue color with nitric acid and other oxidizing agents; and on dry distillation yields guaiac oil and pyroguaiacin. Recent investigations show that guaiaconic acid consists of two crystalline substances: $a$-guaiaconic acid and $\beta$-guaiaconic acid. The latter crystallizes in rhombohedra and does not give a blue color with oxidizing agents. When a solution of a-gtaiaconic acid in chloroform is treated with lead peroxide GUAIAC BLUE is formed, which may be obtained as a blue mass with metallic luster on evaporating the chloroformic solution. On reduction with sulphurous acid it is changed to $a$-guaiaconic acid. Gualaretic acid (about ro per cent.) occurs in colorless needles and forms crystalline salts with the alkalies. GUAIACRESIN acid occurs in white, shining plates that are soluble in alcohol and give on dry distillation the same products as guaiaconic acid. Guaracinic acid (beta resin) occurs as a yellowishbrown powder and yields on dry distillation tiglic aldehyde (dimethyl acrolein). GuAJAcIC acid forms colorless needles which are soluble in water, but probably does not occur in the natural product, being in the nature of a decomposition product. Guaiac resin also contains a yellow coloring principle, GUAIAC yeLLOW (about 0.7 per cent.), which occurs in light yellow, hard octahedra that are sparingly soluble in hot water and give a blue color 
with concentrated sulphuric acid; and a light yellow, rather thick ethereal oil (guaiac oil), which cannot be obtained by distillation and possesses a characteristic aromatic odor. Among the other constituents are vanillin and a yellow gum. The yield of ash should not be more than 4 per cent. Guaiac wood yields from 20 to 25 per cent. of resin.

Of particular interest are the decomposition products obtained on heating guaiac resin. On dry distillation the following substances are obtained: Tiglic aldehyde; a colorless, aromatic liquid with the odor of benzaldehyde; guaiac oil; and a crystalline substance, pyroguaiacin, which on distillation with zinc yields guaiacene (an aldehyde of tiglic acid).

PIX BURGUNDICA.-BURGUNDY PITCH.-The resinous exudation of the stems of the Norway Spruce Fir, Picea excelsa (Fam. Coniferæ), an evergreen tree indigenous to Europe and Northern Asia (p. 8I). The resin is obtained by making incisions through the bark into the wood, the resin exuding and solidifying; it is then collected and purified by melting it in hot water and straining the mixture. The chief supplies of the drug come from Finland, the Black Forest (Germany) and the Jura Mountains. It is doubtful if the commercial supplies have ever been derived from the French province, Burgundy, from which it takes its name.

Description.-Irregular, hard, opaque or translucent pieces, more or less plastic and strongly adhesive, yellowish-brown or reddish-brown, brittle, the fracture shiny, conchoidal; odor agreeably terebinthinate; taste aromatic and sweetish.

Burgundy Pitch is partly soluble in cold alcohol ( $\mathrm{I}$ to 20 ), and almost entirely soluble in boiling alcohol or in glacial acetic acid.

Constituents.-Chiefly resin, consisting of two crystallizable resin acids: dextropimaric and lævopimaric acids; a volatile oil (isomeric with oil of turpentine), about 5 per cent., to which its peculiar fragrance is due; and about Io per cent. or less of water, which is included during the preparation.

Adulterants.-Burgundy pitch is sometimes substituted by various mixtures, as of other coniferous products and palm oil; these are distinguished by being more or less opaque and somewhat porous, and not having the characteristic odor of the gen- 
uine article, and also by the formation of a turbid mixture on the addition of two parts by weight of glacial acetic acid.

Allied Plants.-Canada (or Hemlock) Pitch is the oleoresin of the common Hemlock [Tsuga (Abie's) canadensis] which is obtained by making incisions in the trunk and collecting the exudate, or by boiling pieces of the wood and bark and skimming off the melted oleo-resin. It occurs in dark, reddishbrown, opaque or translucent pieces resembling Burgundy Pitch, and probably contains similar constituents.

ASAFETIDA.-A gum-resin obtained from the root of Ferula foctida and other species of Ferula (Fam. Umbelliferæ), perennial herbs ( $\mathrm{p} .352$ ) indigenous to Eastern Persia and Western Afghanistan. Asafetida is obtained by incising the crown of the root, when the gum-resin exudes, hardens and is then scraped from the root. It is exported by way of Bombay.

Description.-In irregular masses composed of tears, from I to $2.5 \mathrm{~cm}$. in diameter, which when fresh are tough, yellowish-white and translucent or milky white and opaque, changing gradually to pinkish and finally reddish-brown, and becoming, on drying, hard and brittle; internally yellowish and translucent or milky white and opaque; odor persistent, alliaceous; taste bitter, alliaceous and acrid.

Asafetida yields a milk-white emulsion when triturated with water. which becomes yellowish on the addition of solutions of the alkalies. Treated with strong hydrochloric acid, the filtrate gives a blue fluorescence on making it alkaline with ammonia water (distinguishing it from ammoniac). The freshly fractured surface gives a greenish color on the application of a few drops of 40 per cent. nitric acid solution (distinguishing it from galbanum). Not less than 40 to 50 per cent. should dissolve in alcohol.

Constituents.-About 60 per cent. of a reddish-brown amorphous RESIN (consisting of the fertulaic ester of asa-resinotannol), yielding on dry distillation umbelliferone; on treatment with sulphuric acid, resorcin, and on fusion with potassium hydrate, protocatechuic acid; from 3 to 6.7 per cent. of a volatile oIL, consisting in part of hexenyl sulphide, hexenyl disulphide, pinene and cadinere, and to which the odor of the drug is due; about 1.28 
per cent. of FERULAIC ACID (chemically related to vanillin, eugenol and cinnamic acid), which occurs in iridescent, tasteless, odorless needles and yields on fusion with potassium hydroxide, acetic, oxalic and protocatechuic acids. The drug also contains 0.06 per cent. of vanillin; 0.60 per cent. of free asa-resinotannol, and formic, acetic, valerianic and malic acids; and ash 5 to 10 per cent.

Adulterants.-Asafetida frequently contains fragments of vegetable tissues; red clay, sand and stones; it is sometimes adulterated with dirty white, gritty masses of gypsum, at other times with barley or wheat flour or translucent gums. Recently it has been adulterated with pieces of rose-colored marble.

BENZOINUM.-BENZOIN.-A balsamic resin obtained from Styra.r Bcnzoin, and probably other species of Styrax (Fam. Styraceæ), trees (p. 360) indigenous to Java, Sumatra and Siam. The resin flows from incisions made in the bark, hardens, and is then collected, the commercial varieties being known as Siam and Sumatra Benzoin, the former being preferred. The composition of the resin varies according to the age of the tree, the youngest trees yielding the best product. The constituents of the commercial resin are not found in the tissues of the tree, but appear to develop as a pathological product due to an injury of the trees resulting from the manner of incising the bark, although probably the exposure of the resin to the air has an influence on the constituents.

Sumatra Benzoin.--In irregular masses composed of yellowish or reddish-brown tears of variable size and a reddishbrown and translucent or grayish-brown and opaque matrix; brittle, the tears internally being milky white; becoming soft on warming, and yielding benzoic acid on sublimation; odor agreeable, balsamic, resembling that of styrax; taste slightly aromatic. About 80 per cent. is soluble in a solution of potassium hydroxide or in 95 per cent. alcohol.

Siam Benzorn occurs in concavo-convex tears; it has a vanilla-like odor and is almost completely soluble in solutions of the alkalies or in alcohol; it is further distinguished from the Sumatra variety in not containing cinnamic acid, and therefore does not yield benzaldehyde on boiling an acidulated solution with potassium permanganate. 
Constituents of Sumatra Benzoin.-About 75 per cent. of a resinous substance, BENZORESIN, which consists of two esters: (a) an ester of cinnamic acid and resinotannol (92.6 per cent), and (b) an ester of cinnamic acid and benzoresinol. Benzoresin on decomposition yields 30.3 per cent. of CINNAMIC ACID, 64.5 per cent. of RESINOTANNOL, which is soluble in a concentrated sodium salicylate solution, and 5.2 per cent. of BENZORESINOL.

Sumatra benzoin also contains traces of PENZALDEHYDE and BENZOL; O.I to I per cent. of vanillin; I per cent. of the phenylpropyl ester of cinnamic acid; 2 to 3 per cent. of styracin (cinnamic cinnamate); and I4 to I7 per cent. of insoluble matter consisting chiefly of woody tissues.

Constituents of Siam Benzoin.-It consists largely of a resinous substance, SIABENZORESIN, which is composed of about 90 per cent. of an ester of benzoic acid and siaresinotannol, and about to per cent. of an ester of benzoic acid and benzoresinol. SiABEnZORESIN on saponification yields 38.2 per cent. of BEnZOIC ACID, 56.7 per cent. of SIARESINOTANNOL, and 5.1 per cent. of BENZORESINOL.

Siam benzoin also contains 0.3 per cent. of a neutral ARomatic LIouid, which is probably an ester of benzoic acid, the nature of the alcohol not having been determined as yet; 0.I 5 to 1.5 per cent. of VANILLIN ; a small quantity of free BENZOIC ACID, and I.3 to 3.3 per cent. of impurities in the form of woody tissues. Pennng Benzorn has an odor of styrax, but resembles in its composition Siam benzoin. It sometimes, however, contains but little cinnamic acid and considerable benzoic acid, thus resembling the Sumatra variety.

MYRRHA.-MYRRH.-The dried gum-resin from the stem of Commiphora abyssinica and C. Schimperi (Fam. Burseraceæ), large shrubs (Fig. I60) indigenous to Northeastern Africa (chiefly Somali Land) and Southern Arabia (p. 310). The gumresin exudes spontaneously or from incisions made in the bark; it is first of a yellowish color but soon hardens, becoming darker, and is then collected. There are two principal commercial varieties of Myrrh, the one known as African or Somali Myrrh, and the other as Arabian or Yemen Myrrh, the former being considered the better. 
DESCRIPTION.-In irregular agglutinated tears or masses of variable size; externally rough and uneven, yellowish- or reddishbrown, covered with a yellowish powder; brittle, the fractured surface waxy, granular, oily, slightly mottled, somewhat translucent in thin pieces; odor balsamic; taste aromatic, bitter and acrid.

Myrrh forms a brownish-yellow emulsion when triturated with water (distinction from other gum-resins); an ethereal solution treated with bromine vapor becomes reddish (distinction from East Indian myrrh); when moistened with nitric acid it becomes purplish (distinction from false myrrh or bdellium); not more than 70 per cent. is insoluble in alcohol.

Constituents.-A yellowish or yellowish-green, rather thick volatile oil, 2.5 to 8 per cent., having the characteristic odor of myrrh; resin, 25 to 40 per cent., composed of several constituents, one of which yields protocatechuic acid and pyrocatechin; gum, about 60 per cent., consisting of a soluble and insoluble portion and forming a mucilage that does not readily ferment; a bitter principle, sparingly soluble in water but soluble in alcohol; ash, 5 to Io per cent.

The volatile oil of myrrh consists of cuminal (about I per cent.), eugenol, meta-cresol, pinene, limonene, dipentene and two sesquiterpenes. The acidity of old oil is due to free acetic and palmitic acids.

Adulterants.-Myrrh is frequently admixed with gums and other gum-resins, including several kinds of Bdellium which are obtained from various species of Commiphora, and which are characterized by not giving a purplish color with nitric acid. Of these the following may be mentioned: AFRICAN BDELLIUM, which occurs in yellowish-brown masses, that are reddish in transmitted light and have a pepper-like odor and bitter taste; INDIAN BDELLIUM, occurring in irregular, reddish-brown masses, covered with minute spicules of resin, and having a terebinthinate odor and an acrid taste; and OPAOUE BDELLIUM, which occurs in yellowish, hard, opaque masses, with a faint odor and bitter taste, and the alcoholic solution of which is colored black with ferric chloride. Thin pieces of a bark are frequently present in opaque bdellium. 
BisABol, or East Indian myrrh, is exported from Eastern Africa and Asia; it closely resembles true myrrh, but is distinguished from it by the ethereal solution not becoming reddish with bromine vapor. Furthermore, on mixing 6 drops of a petroleum ether solution (one part of myrrh to 5 of ether) with 3 c.c. of glacial acetic acid and then adding this liquid carefully to 3 c.c. of concentrated sulphuric acid, a rose-colored zone is at first developed, and finally the entire acetic acid solution assumes the same color. With genuine myrrh the solution is colored a very pale rose color.

Allied Plants.-Opopanax is a balsam-like product obtained from Commiphora Kataf, a plant indigenous to Arabia, and is supposed to be the Myrrh mentioned in the Bible. It yields from 6 to Io per cent. of a greenish-yellow volatile oil with a pleasant balsamic odor; and also contains opo-resinotannol (a compound not yielding umbelliferone on distillation) both free and combined with ferulaic acid; free ferulaic acid; vanillin, and a gum containing bassorin.

Mulu KiJanary is a gummy exudation obtained from Commiphora Berryi, a plant growing in India. It occurs in yellowishbrown or dark brown translucent fragments, having a conchoidal, oily fracture, and consists chiefly of gum, with a small quantity of a tasteless resin and a volatile oil.

TEREBINTHINA.-TURPENTINE.-An oleo-resin obtained from Pinus palustris and other species of Pinus (Fam. Coniferæ), evergreen trees (Fig. $47, B, C$ ) indigenous to the Southern United States (p. 8I). The oleo-resin is secreted in the sapwood and is obtained by making triangular incisions in the bark and wood in the spring; it flows into cavities (or boxes) made lower down on the trunk, from which it is dipped into barrels or other receptacles. The product of the first year's cutting is of superior quality and is known as "virgin" turpentine. It yields about I 5 per cent. of oil of turpentine, while the product of the second or third year yields Io per cent.

Description.-In yellowish, opaque masses, brittle in the cold; lighter internally, sticky and more or less shiny; odor and taste terebinthinate. One part dissolved in 5 parts of alcohol gives a clear solution having an acid reaction. 
Constituents.-Turpentine consists of 70 to 80 per cent. of resin and 15 to 30 per cent. of volatile oil; it also contians a bitter principle and various organic acids, as pinic, sylvic, etc.

Oil of Turpentine is obtained chiefly from the following pines growing in the Southern States: Pinus palustris, $P$. glabra. $P$. cubensis, $P$ cchinata and $P T_{\mathfrak{C}} d a$. The important constituent is the hydrocarbon pinene $\left(\mathrm{C}_{10} \mathrm{H}_{10}\right)$, which in the oil from some plants is dextro-rotatory, while in that from other plants it is

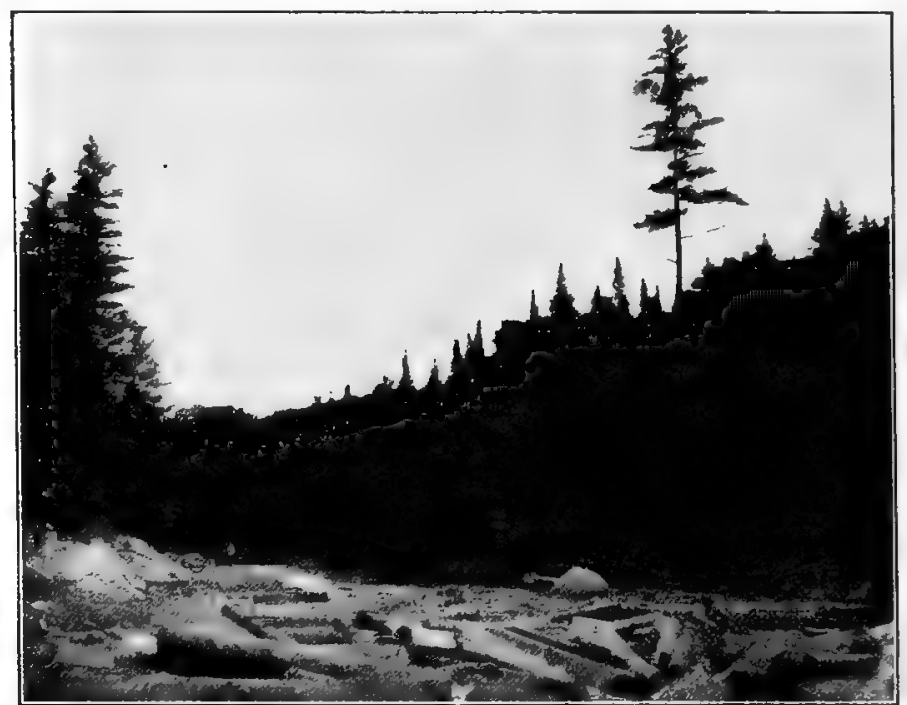

FIG. 276. Typical view in the Adirondacks showing the spire-like balsams (Abies balsamea) and a single white pine (Pinus Strobus).

lavo-rotatory. On allowing a moisture-containing oil to stand exposed to the light, crystals of pinol hydrate separate out in the course of time.

Allied Plants.-Various other species of Pinus yield an oleo-resin resembling turpentine, as Pinus Tada, a tree (Fig. 5I, $F$ ) growing in the regions where Pinus palustris is found; the rield of oleo-resin from this and other trees is considerably less. Pinuts sylvestris, or Scotch fir, which is indigenous to the mountains of Europe and Asia and extensively cultivated in this country, is the source of much of the turpentine used in Europe. 
Bordeaud turpentine is a product resembling American turpentine, and is obtained from Pinus maritima and other species of Pinus growing in Southern France, the resin consisting chiefly, however, of the anhydride of pimaric acid.

Austrian turpentine oIL is obtained from Pinus Laricio, and apparently consists of dextro-rotatory pinene.

The oil known as French tURPENTINE oIL is derived from Pinus pinaster, and, while it resembles the American variety, consists entirely of lævo-rotatory pinene.

PINE NEEDLE oIL is obtained by steam distillation from the leaves of Pinus pumilio, a tree of the Tyrolese Alps. It is a colorless oil with an aromatic odor and taste, and contains from 5 to 7 per cent. of bornyl acetate, cadinene, phellandrene, pinene and sylvestrine.

Pine needle oil is also obtained to a limited extent from the Scotch fir (Pinus sylvestris). The German product closely resembles the oil obtained from Pinus pumilio, as probably also does the Swedish oil, but the English oil is lavo-rotatory.

PIX LIQUIDA.-TAR.-A product obtained by the destructive distillation of the wood of Pinus palustris and other species of Pinus (Fam. Coniferæ), evergreen trees (Fig. 47, B, C) indigenous to the Southern United States, particularly near the Atlantic Coast and the Gulf of Mexico (p. 8I). Tar is obtained by distillation of the wood without access of air, the tarry liquid being separated from the aqueous mixture consisting of wood naphtha and pyroligneous (crude acetic) acid. The amount of tar obtained in the operation varies, depending on how rapidly the wood has been heated. If the wood is heated slowly the yield is about 5 per cent., if rapidly heated it is increased to nearly to per cent.

Descriptron.-Semi-fluid, viscid, blackish-brown, non-crystalline, transparent in thin layers, becoming granular or crystalline (due to the separation of pyrocatechin) and opaque with age: odor peculiar, aromatic, taste pungent. Tar is soluble in alcohol, fixed or volatile oils, and solutions of potassium or'sodium hydrate; it is heavier than water and slightly soluble in it; the solution is of a pale yellowish-brown color, has an acid reaction, yields with a dilute solution of ferric chloride, a reddish color, with the test-solution, an olive-green color, due to the presence of 
pyrocatechin (this distingtuishing it from Juniper Tar), and is colored brownish-red by an equal volume of calcium hydrate testsolution. The petroleum ether extract is colored greenish by a o. I per cent. solution of copper acetate.

Constituents.-Tar consists of a resinous substance, with which are admixed a small quantity of turpentine, acetic acid, methyl alcohol and various volatile empyreumatic substances. On distillation 4 distinct classes of products are obtained: ( $\mathrm{I}$ ) An AQUeOUS DisTILlate, from Io to 20 per cent., consisting chiefly of acetic acid, methyl alcohol and acetone. (2) A LIGHT OILY DisTILLATE, from to to 15 per cent., coming over under $150^{\circ} \mathrm{C}$., and consisting of mesit, toluene, xylene, cumene, methene and eupion, which products are used as solvents for varnishes and similar substances. (3) A HEAvy oILy distillate, about I5 per cent., distilling over between $150^{\circ}$ and $250^{\circ} \mathrm{C}$., and consisting of the CREOSOTE OILS, viz. : phenol, cresol, creosote, paraffin, naphthalene, pyrene, chrysene, retene and some other substances. (4) A black resinous mass, called PITCH ( 50 to 65 per cent.) which has the odor of tar and is still official in some pharmacopœias.

In the distillation of pine wood tar the distillate which is lighter than water contains a volatile oil known as oIL OF TAR (Oleum Picis Liquidæ). When recently prepared it is colorless, but it gradually darkens, becoming finally dark reddish-brown, there separating at the same time a blackish, resinous substance. Oil of tar consists chiefly of oil of turpentine, with some of the lighter hydrocarbons and phenol compounds, acetic and other acids, and a number of empyreumatic products.

Allied Products.-Beech wood tar is the product of the destructive distillation of the wood of Fagus sylzatica and $F$. ferruginea (Fam. Fagaceæ). It is distinguished from pine tar by the petroleum ether extract not giving a green color with copper acetate solution, and in the creosote oils containing a considerable amount of GUAIACOL. The official creosote is a mixture of guaiacol and creosol with some other phenol derivatives, as xylenol, methyl creosol and. methyl guaiacol, obtained from the heavy oily distillate of beach wood tar. Guaiacol is of interest because on treatment with chemicals it may be converted into vanillin. 
BIRCH TAR is the product of the destructive distillation of the wood and bark of the white birch (Betula alba). It is chiefly made in Russia, has a strong, penetrating odor and does not solidify. It is distinguished from beech wood tar and pine tar in not being completely soluble in 95 per cent. acetic acid, and is distinguished from juniper tar by not being entirely dissolved in anilin and in being colored greenish with ferric chloride.

An oily product is obtained in the destructive distillation of the wood of the Prickly cedar (Juniperus Oxycedrus), a tree indigenous to the countries bordering the Mediterranean, and is official as OIL OF CADE. It is a brown, viscid liquid with a tarry odor and a pungent, bitter taste. The oil varies in composition and the only constituent that has been isolated is the sesquiterpene cadinene. Of the phenols which it contains nothing is known.

An oil known as KIEN oIL is obtained by the destructive distillation of the wood of the root of Pinus sylvestris. The oil is prepared in Germany, Russia, Finland and Sweden, and consists of d-pinene, d-sylvestrine and in addition, in all except the Swedish oil, dipentene has been determined.

STYRAX.-STORAX.-A balsam obtained from the trunk of Liquidambar oricntalis (Fam. Hamamelidaceæ), a tree (p. 286) indigenous to Asia Minor and the Levant. The balsam is a pathological product and is produced by bruising the bark of the tree, removing it and then boiling the inner bark in sea-water, the balsam which rises to the surface being skimmed off.

Descriptron.-A viscid, grayish, more or less opaque semiliquid mass, depositing on standing a heavier, dark brown, oleoresinous stratum; translucent in thin layers; odor agreeable; taste balsamic.

Storax is insoluble in water; between 60 and 70 per cent. is soluble in warm alcohol, and the residue on evaporation of the alcoholic solution is almost completely soluble in ether, carbon disulphide, or benzol, but insoluble in benzin; the portion undissolved after thorough extraction with boiling alcohol should not be more than 4 per cent. When boiled with a solution of potassium dichromate and sulphuric acid it evolves an odor resembling that of bitter almonds (due to the presence of cinnamic acid); 
it forms little or no foam when mixed with an equal volume of alcohol and shaken with ammonia water, indicating the absence of turpentine and fixed oils.

Constituents.--Storax consists of about 50 per cent. of two resin alcohols, $\alpha$-storesin and $\beta$-storesin, which are partly free, partly in combination with cinnamic acid and partly with sodium. $a$-STORESIN ( $a$-storesinol) is an amorphous substance that is very sparingly soluble in water and forms a crystalline compound with potassium. $\beta$-STORESIN ( $\beta$-storesinol) occurs in white flakes which are somewhat soluble in water but do not form a crystalline compound with potassium. Storax also contains from to to 20 per cent. of an ester consisting of cinnamic acid and storesin; from 5 to io per cent. of cinnamyl or styryl cinnamate (STYRACIN) which occurs in colorless, odorless and tasteless needles and which on hydrolysis yields cinnamic alcohol (styrone) and a salt of cinnamic acid; about Io per cent. of an odorless, viscid substance, PHENYL PROPYL CINNAMATE; from 2 to 3 per cent. of PHENYL ETHYLENE (styrol or styrene), which occurs as a colorless liquid possessing the odor and pungent taste of storax; from 0.5 to I per cent. of a volatile oIL which is lævo-rotatory and consists of a hydrocarbon, styrene, about 0.4 per cent. of an oxygenated compound (styrocamphene), and cinnamates of ethyl, benzyl, phenyl-propyl and cinnamic alcohols; from 2 to 5 per cent. of free cinnamic acid; a small quantity of iso-cinnamic acid which occurs in colorless crystals; a crystallizable susbtance, styrogenin; about 0.I 5 per cent. of VANILLIN; a trace of benzoic acid; ethyl vanillin; resin, and caoutchouc. Storax sometimes yields more than 20 per cent. of free cinnamic acid and is the best available source of this substance.

Al.lien Plants. - Liquidambar Styraciflua, a tree indigenous to the Eastern and Southern United States and Mexico, yields the American storax, which occurs as a yellowish-brown, semi-liquid mass somewhat resembling Levant storax. It probably contains related storesins (storesinols), which appear to form similar combinations with cinnamic acid. On distillation of the fresh balsam about 7 per cent. of a volatile oil is obtained, which is dextrorotatory and contains styrol and a body with the odor of oil of turpentine, the cinnamyl-ethyl-ester and cinnamyl-benzyl-ester 
being wanting. It also contains phenyl propyl cinnamate, styracin, styrol, free cinnamic acid and vanillin.

Styrax is also obtained from Altingia excelsa, of the Indian Archipelago. It yields a soft, white, crystalline balsam developing the fragrant odor of styrol and contains about 50 per cent. of an ester of cinnamic acid. A brown solid balsam is also obtained from this tree. It has an odor of cinnamon and contains a trace of free cinnamic acid and 9.7 per cent. of cinnamic acid in the form of an ester. The oil from this plant is known as "Rasamala wood oil," and contains a ketone.

TEREBINTHINA CANADENSIS.CANADA TURPENTINE, CANADA BALSAM OR BALSAM OF FIR.-A liquid oleo-resin obtained from Abies balsamea (Fam. Coniferæ), a tall evergreen tree (Fig. 276) indigenous to the Northern United States and Canada (p. 79). The oleo-resin occurs normally in reservoirs in the bark and forms in vesicles or blisters on the surface, from which it is obtained by puncturing them with the spout of a can used by the balsam collectors. Canada Turpentine is collected chiefly in Quebec.

Description.-Viscid, pale yellow or greenish-yellow, occasionally with a greenish fluorescence; transparent; odor agreeable, terebinthinate; taste bitter, slightly acrid.

When exposed to the air Canada turpentine gradually dries, forming a transparent varnish; it solidifies on mixing 5 or 6 parts with I part of magnesia previously moistened with water (distinguishing it from other coniferous resins); it is completely soluble in ether, chloroform, benzol or oil of turpentine, and about 80 per cent. is soluble in alcohol (distinguishing it from other coniferous resins).

Constituents.-About 75 per cent. of a resinous substance, consisting chiefly of 4 acid resins: canadinic, canadolic, and $\boldsymbol{a}$ - and $\beta$-canadinolic resins, and I I to I 2 per cent. of an indifferent resin canadoresene; I6 to 25 per cent. of a volatile oil, consisting chiefly of 1-pinene; and pimaric acid.

Allied Plants.-Strasburg turpentine is the product of the European silver fir (Abies alba). It closely resembles the Canada turpentine, but has a lemon-like odor. It contains 24 to 30 per cent. of a greenish, fluorescent volatile oil, consisting 
chiefly of 1-pinene; 46 to 50 per cent. of $\alpha$ - and $\beta$-abietinolic acid; about 2 per cent. of a crystalline resin, abietolic acid; Io per cent. of an amorphous resin, abiennic acid; and small quantities of a bitter principle, succinic acid and a coloring principle.

Venice Turpentine is the product of the European larch (Larix decidua) and occurs as a yellowish or greenish-yellow, nearly transparent, slightly turbid, viscid liquid, with a terebinthinate odor and a bitter, aromatic taste. It consists of about 20 per cent. of a volatile oil, consisting chiefly of pinene; 60 to 64 per cent. of three acid resins, one of which is crystalline; and about 15 per cent. of an indifferent resin.

\section{DRUGS DERIVED FROM THE CONIFER}

In addition to the volatile oils, resins and allied products obtained from the Coniferæ (described under Exudations, pages 653-682), the tops and fruits of several of the plants are official in the various pharmacopœias. In the Coniferæ the tracheæ and wood fibers are replaced by tracheids (p. I9I). This structure is for the most part characteristic of the Gymnosperms, and there are very few Angiosperms in which tracheids alone are found, ipecac root being one of the exceptions (Figs. 203, 29I). The flowers of the Coniferæ have open carpels, and the fruits consist of dry cones or of berry-like cones, in which there is partial coalescence of the fleshy scales or carpels (p. 78).

SABINA.-SAVIN.-The young and tender, green branches of Juniperus Sabina (Fam. Coniferæ), an evergreen shrub indigenous to the mountainous regions of Southern and Central Europe and extending as far as Siberia. The young branches are collected in the spring, stripped from the older woody branches and dried. In the preparation of the volatile oil, which is official, they are used in the green state.

Description.-Branchlets I to $5 \mathrm{~cm}$. long, I to $2 \mathrm{~mm}$. in diameter; covered with closely appressed (except those at the base of the branches or branch-scars), grayish- or brownish-green, rhomboidal, scale-like leaves which are about I mm. long, alternate, closely imbricated, thus completely covering the branchlets, and show in cross-section a single large oil-gland directly beneath 
the epidermis of the dorsal surface. Some of the berry-like fruits are usually present. They are globular or ellipsoidal, brownish-yellow or purplish-black, 5 to $7 \mathrm{~mm}$. in diameter, with a whitish bloom, more or less tuberculate, due to the tips of the fleshy scales, and wrinkled; the pulp is brownish and contains from 2 to 6 ovoid, yellowish-brown seeds, 3 to $4 \mathrm{~mm}$. long, longitudinally grooved, particularly on the dorsal side, and enclosed by a resinous membrane. The odor is slightly terebinthinate, and the taste, bitterish and resinous.

Constituents.-From 4 to 6 per cent. of a volatile oil consisting of about Io per cent. of an alcohol sabinol, 40 to 44 per cent. of an ester of sabinol and acetic acid, a sesquiterpene, and a principle with an odor of cumin aldehyde; resin, and a small amount of tannin.

Allied Plants.-Red Cedar (Juniperus zirginiana) is a tree (Fig. 52) of wide distribution in North America. The fruits are purple, smaller, and contain fewer seeds than those of $J$. Sabina. The constituents are also similar. The volatile oil of the wood is known as red cedar wood oil and occurs to the extent of 2.5 to 4.5 per cent. The oil consists of so-called cedar camphor, or cedrol, and cedrene.

JUNIPER BerRiEs are obtained from Juniperus communis, a small evergreen tree with subulate, prickly-pointed, verticillate leaves, which is indigenous to North America, Europe and Asia. The berry-like fruits are nearly globular, from 5 to $10 \mathrm{~mm}$. in diameter, somewhat wrinkled, purplish-black or dark brown, frequently with a whitish bloom, with 3 to 6 minute bracts at the base, and a triangular scar at the apex marking the line of separation of the carpels. The pulp is brownish and usually contains three ovoid seeds, attached to which are 3 to 4 ellipsoidal oleoresinous masses. The odor is slight and the taste is sweet and resinous. Juniper berries contain 0.5 to I. 5 per cent. of a volatile oil containing pinene, cadinene, and a juniper camphor; Io per cent. of resin; 15 to 30 per cent. of dextrose; a yellow coloring principle; and yield 2 to 4 per cent. of ash. The oil and the fruits are chiefly used in the manufacture of gin.

The young twigs of ARBOR VITE (Thuja occidentalis), a conical tree indigenous from Canada to Virginia and extensively 
cultivated, are also used in medicine. The leaves are 4-ranked, of two kinds, those of the lateral pairs being more or less elongated, clasping, and triangular in section, those of the other pair being flattened, appressed and with a prominent oleo-resinous gland near the middle on the dorsal or outer surface, the arrangement of the leaves being such as to give the branches a flattish appearance. The fruits are small cones with six to ten carpels, each bearing a narrow-winged seed. Thuja contains I per cent. of a volatile oil with an odor resembling tansy and containing d-pinene, 1-fenchone, d-thujone, and an inactive oxime; two resins; a glucoside thujin, which resembles quercitrin; a bitter glucoside pinicrin, and pinitannic acid (which two latter principles are also found in Pintus sylvestris).

\section{DRUGS DERIVED FRON THALLOPHYTES AND ARCHEGONIATES.}

Not very many of the lower plants furnish important drugs, there being probably not more than five or six drugs from this source that are official in the different pharmacopœias. For purposes of identification they may be grouped as follows:

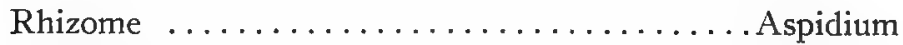

Entire, yellowish-white, cartilaginous thallus.... Chondrus

Entire, grayish-brown, papery thallts.......... Cetraria

Purplish-black cylindrical grains............. Ergota

Light yellow powder................. Lycopodium

ASPIDIUM.-MLLE FERN.-The rhizome and stipes of Aspidium (Dryopteris or Nephrodium) Fili. mas and Aspidium marginale (Fan. Polypodiaceæ), perennials, of which Aspidium Filix mas (Fig. 277) is more widely distributed, being indigenous to Europe, Asia, North America, west of the Rocky Mountains, and in the Andes of South America; while 4. marginale is found in the Eastern and Central United States and extends north to Prince Edward's Island (p. 6i ). The rhizome is collected in early autumn, the leaves cut off, leaving the lower portions or stipes attached to the rhizomes; the dead portions of 


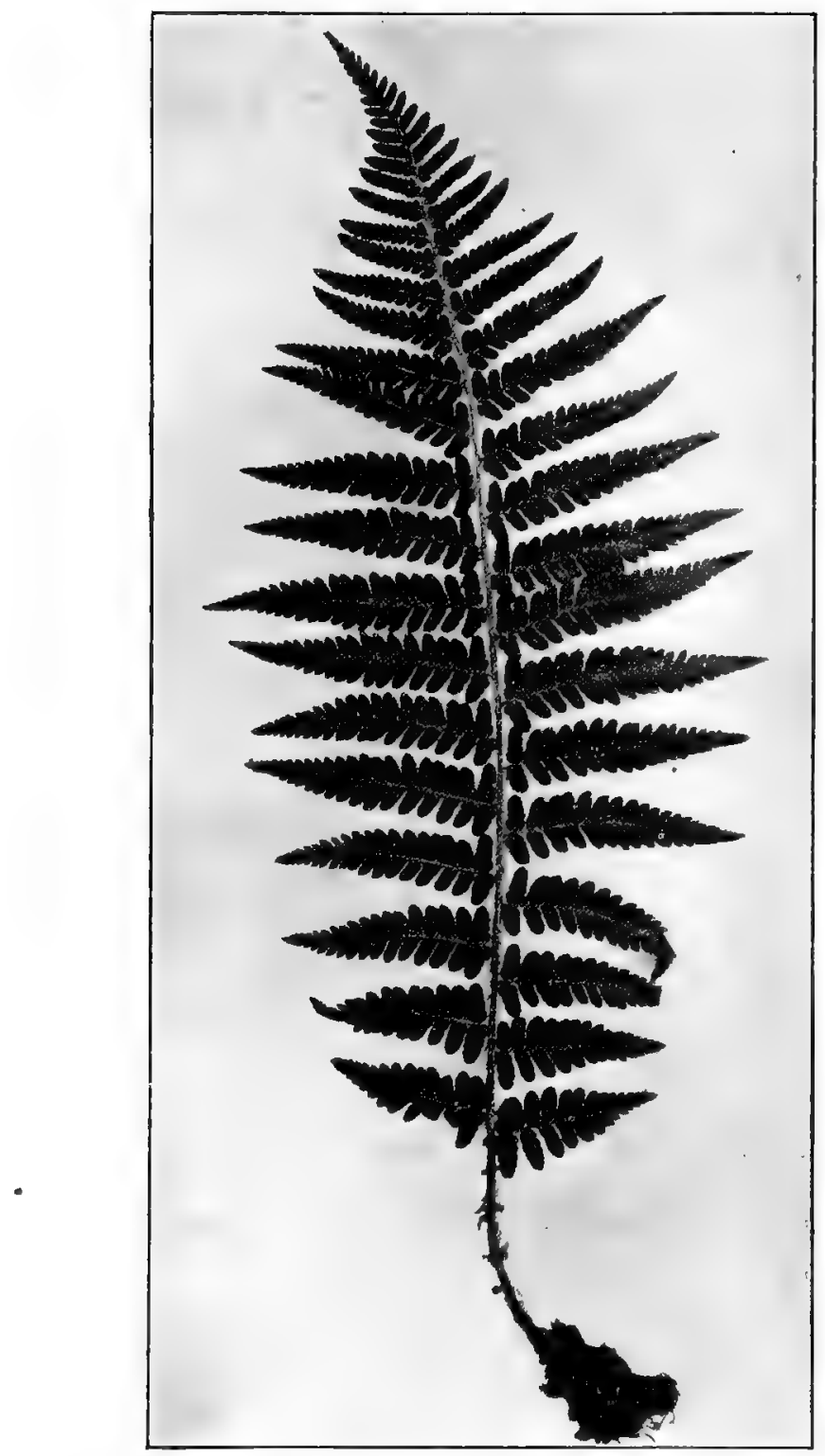

Fig. 277. Leaf and a portion of rhizome of male fern (Aspidium Filix mas), the upper pinnæ (divisions) showing faintly the sori near the middle veins. 
the rhizomes and the chaff are removed. Usually the drug consists of the stipes only, which are separated from the rhizome, the periderm being removed (Fig. 277a, $A$ ). The drug is carefully dried and preserved and should not be used after it loses its green color.

Description.-Of horizontal or oblique growth, 5 to $15 \mathrm{~cm}$. long and I to $2.5 \mathrm{~cm}$. thick, mostly covered with nearly cylindrical,

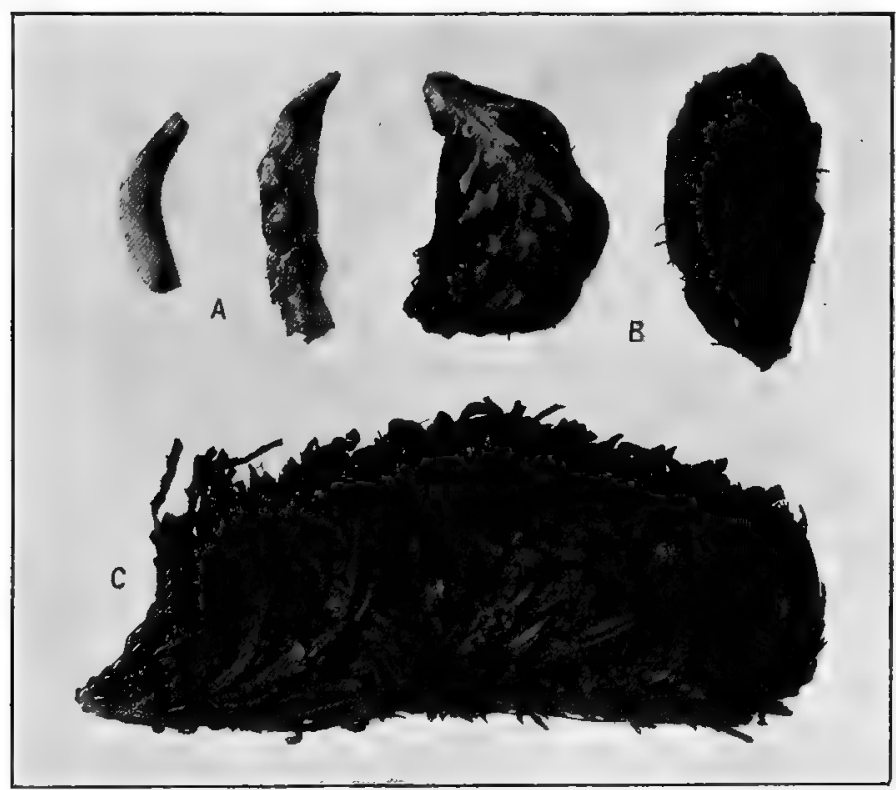

FIG. 277a. A, B, Aspidium Filix mas showing a decorticated stipe and piece of rhizome (A), and rhizomes with stipes attached (B); C, probably the rhizome of Osmunda Claytoniana, which is sometimes substituted for Aspidium.

slightly curved stipe-remnants (Fig. 277a), which are about $25 \mathrm{~mm}$. long and 5 to Io mm. thick, between which is a dense mass of dark-brown, glossy, transparent and soft-chaffy scales; internally spongy, pale green, becoming brownish with age; in transverse section showing an interrupted circle of about six ( $A$. marginale) or seven to nine ( $A$. Filix mas) groups of fibrovascular tissue, each of which is surrounded by an endodermislike layer; odor slight, taste acrid, somewhat bitter and nauseous. 
InNer Structure.-See Fig. 297.

Constituents.-An active, amorphous substance, FILICIC ACID, 2 to 8 per cent., being contained apparently in greatest abundance in rhizomes collected in autumn, and readily decomposing with the formation of an inactive but crystalline anhydride; and FILICIC ANHYDRIDE (filicin, or so-called crystalline filicic acid). The latter occurs from I9 to $3 \mathrm{I}$ per cent. in the drug, and may be converted into filicic acid by dissolving in alkalies and precipitating with acids. The drug also contains from 0.025 to 0.045 per cent. of a light yellow volatile oil with an intense odor of the drug and an aromatic, burning taste. It consists of free butyric and allied acids and hexyl and octyl esters of the fatty acid series, ranging from butyric acid to pelargonic. From 6 to 7 per cent. of a green fixed oil is present, which consists of the glycerides of filixolic and filosmylic acids, the latter being volatile. Among the other constituents are a small amount of a bitter principle; about Io per cent. of filixtannic acid; a soft black resin and a hard red resin; about I I per cent. of an uncrystallizable sugar; starch, and 2 to 3 per cent. of ash.

Allied Plants. - The rhizome of Aspidium spinulosum appears to possess properties similar to the official drug; it somewhat resembles that of $A$. Filix mas, but the chaffy scales possess marginal glandular hairs and the number of fibrovascular bundles in the rhizome is usually but 6 or 7 .

ADULTERANTS.-The rhizomes of other ferns are sometimes substituted for those of the true drug. The botanical origin of these substitutes is not clear. A very common substitute is shown in Fig. 277a, $C$, which is supposed to be derived from Osmunda Claytoniana or a related species. It occurs in large pieces with coarse, wiry roots, flattened stipes and is free from chaffy scales.

CHONDRUS.-IRISH MOSS OR CARRAGHEEN.The entire plant of Chondrus crispus (Fam. Gigartinaceæ), a red alga (Figs. 9; 278) found along the northwestern coast of Ireland and the coast of Massachusetts (p. I6). The plants are collected chiefly during June and July, spread out on the beach and bleached by the action of the sun and dew, then treated with salt water, finally dried and stored. The chief points of collection in this country are 15 to 25 miles south of Boston. 
DESCRIPTION.-Consisting of a number of dichotomously branching, somewhat enlarged segments, becoming emarginate or two-lobed, which arise from a slender, somewhat flattened base about one-half the length of the entire thallus; yellowish-white, translucent, sometimes with fruit-bodies or cystocarps embedded

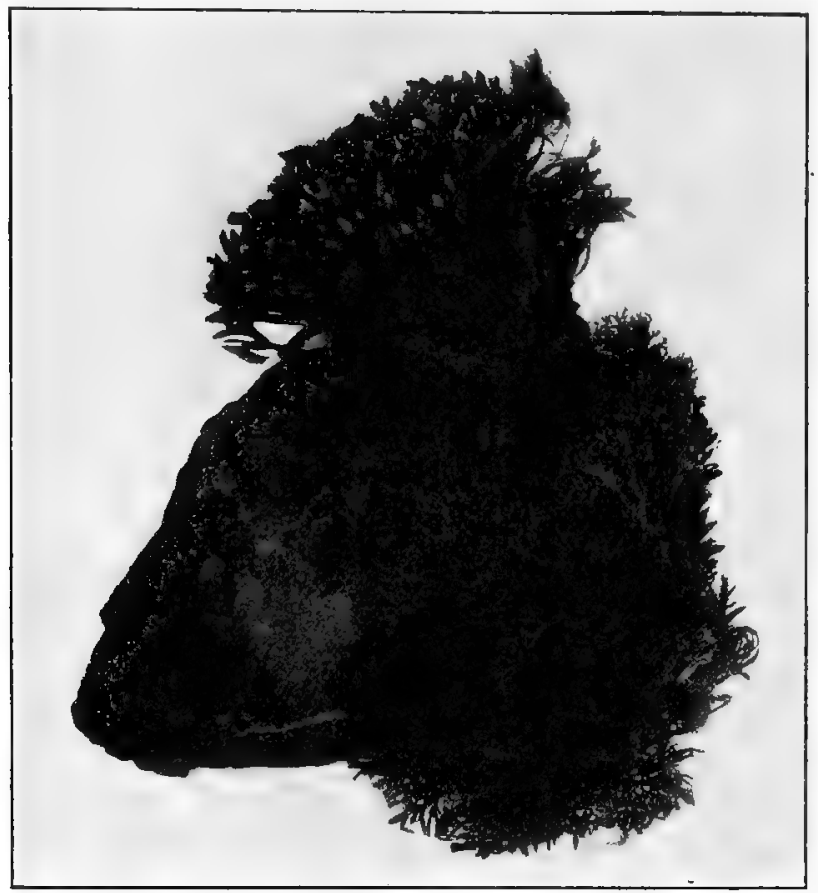

FIG. 278. Chondrus crispus attached to a rock and collected at Wood's Holl, Mass.

near the apex of the segments; somewhat cartilaginous; having a slight saline odor and a mucilaginous, somewhat saline taste.

One part of Chondrus boiled for ten minutes with 30 parts of water yields a solution which gelatinizes on cooling, and is not colored blue by iodine test-solution (absence of starch) ; nor precipitated by alcohol (distinction from true plant gums); nor precipitated by tannin (distinction from gelatin); nor precipitated by lead acetate (distinguishing it from pectin). 
Constituents.-From 55 to 90 per cent. of carrageenin, a mucilaginous principle which is but slightly adhesive; about Io per cent. of proteids, and Io to I 5 per cent. of ash, consisting of calcium oxalate and compounds of sodium, potassium, magnesium and calcium with chlorine, iodine, bromine and sulphur.

Allied Plants.-Gigartina mamillosa (Fig. 278a) somewhat resembles Chondrus, but it is most abundant north of the region where Chondrus is gathered and so rarely enters com-

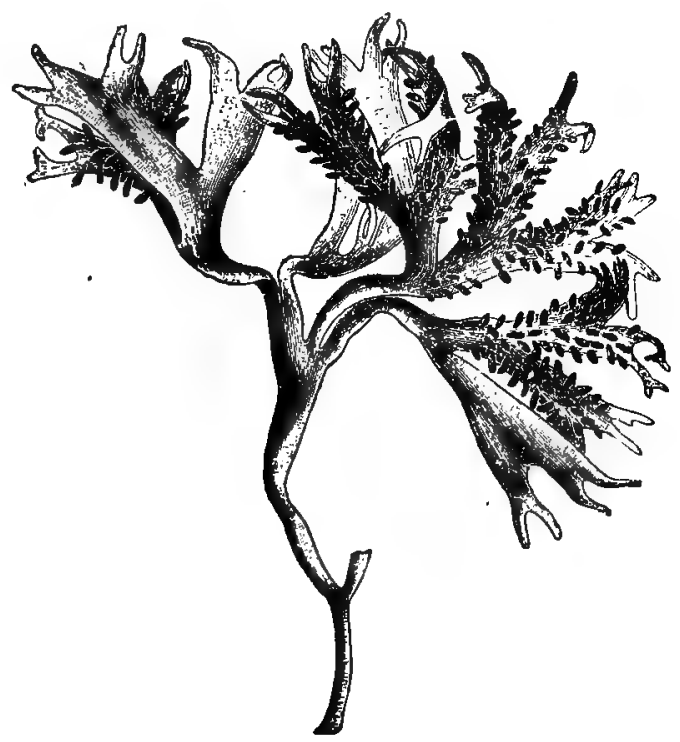

FIG. 278a. Gigartina mamillosa, a red seaweed closely related to Chondrus crispus, showing dichotomously branching thallus bearing at the upper part numerous cylindrical outgrowths in which the fruit bodies (cystocarps) are found.--After Kutzing.

merce. It is distinguished by having the cystocarps borne on short, tuberculated projections or stalks scattered over the upper portion of the segments.

For other Marine Algæ used in medicine, see p. 16.

An ARTIFICIAL GUM is prepared by adding starch to the mucilage of chondrus, and is said to be a good substitute for acacia and may be employed as a base for fixing colors in fabrics.

CETRARIA.-ICELAND MOSS.-The entire plant of Cetraria islandica, one of the Ascolichens (Fig. 26, illus. 5), 
which is widely distributed over the northern part of both continents (p. 4o). The chief commercial supplies are obtained from Scandinavia, Germany, Switzerland and parts of Austria.

DesCRIPTION.-Consisting of a number of somewhat dichotomously branching, more or less curled, papery, fringed segments, 5 to $10 \mathrm{~cm}$. long and about $5 \mathrm{~mm}$. wide; upper surface greenishbrown, with occasional dark reddish-brown cupular apothecia; under surface grayish, with numerous small, whitish, depressed spots; tough when damp, but brittle when dry; odor slight; taste mucilaginous and bitter.

Constituents.-The principal constituents are lichenin and isolichenin (about 70 per cent.), the former of which appears to be intermediate between starch and cellulose, and is soluble in hot water, the solution becoming gelatinous on cooling, but not colored blue with iodine; isolichenin (dextrolichenin) somewhat resembles soluble starch, being soluble in cold water and giving a blue reaction with iodine. The drug also contains 2 to 3 per cent. of a bitter crystalline principle, cetrarin, which is colored blue with concentrated hydrochloric acid and yields on hydrolysis cetraric acid, which is also intensely bitter; I per cent. of a tasteless, crystalline principle, lichenostearic acid; several organic acids, as oxalic, tartaric and fumaric (lichenic); about I5 per cent. of cellulose; about 3.6 per cent. of an uncrystallizable sugar; 3.7 per cent. of gum; a principle resembling chlorophyll thallochlor, which is unaffected by hydrochloric acid; and yields less than 2 per cent. of ash.

The bitter principle in Cetraria may be removed by treating the drug with a I per cent. solution of potassium carbonate at about $60^{\circ} \mathrm{C}$. for several hours.

Iceland moss jelly (Gelatina lichenis istandica) is official in the German Pharmacopœia, and is prepared by making a decoction of 3 parts of washed cetraria and Ioo parts of water, adding three parts of sugar and evaporating the whole to Io parts. Dried, saccharated iceland moss, which is official in the French Codex, is prepared somewhat similarly to the Iceland moss jelly, but the product is evaporated to dryness and then powdered.

Allied Plants.-Usnea barbata and Cornicularia aculeata contain a principle resembling lichenin, which on hydrolysis yields 
glucose. Evernia prunastri contains a carbohydrate evernin, which resembles lichenin but is dextrogyrate. The following lichens do not contain lichenin, but yield carbohydrates which on hydrolysis give little or no glucose: Cladonia rangiferina contains 30 per cent. of mannose; Stercocaulon pascale and Peltigeria aphthosa yield on hydrolysis dextromannose and dextrogalactose.

ERGOTA.-ERGOT OF RYE.-The sclerotium of Claviceps purpurea (Fam. Hypocreacex), a fungus having two distinct periods in its life history-an active and a resting stage (Fig. 19). During the latter it forms a compact mycelium, or sclerotium, which replaces the flowers and grains of rye. Ergot is picked by hand from the ears of rye, or it is separated after the thrashing of the rye; it is carefully dried, and preserved against the attacks of insects by the use of small quantities of chloroform. It deteriorates with age, particularly when powdered, and is not considered so valuable after one year. Various methods have been proposed for preparing the drug so as to preserve its medicinal properties for a longer period of time (p. 420). Russia, Spain and Germany furnish the chief part of the commercial supply, the Russian drug being considered the most active (p. 27).

Spanish ergot usually consists of large grains, having a fine appearance, but is not so active as that from the other countries mentioned, and contains considerable starch.

Description.-Sub-cylindrical, tapering toward but obtuse at both ends, somewhat curved, 2 to $4 \mathrm{~cm}$. long and about $3 \mathrm{~mm}$. thick: externally purplish-black, longitudinally furrowed, occasionally transversely fissured, one end with the whitish remains of mycelial threads, fracture short; internally whitish or pinkishwhite, sections somewhat triangular or two-lobed; odor peculiar, heavy, increased by trituration with potassium or sodium hydrate solution; taste oily and disagreeable.

Constituents.-The constituents of ergot have been the subject of considerable investigation, and the results have been more or less contradictory. Of the large number of substances which it contains the following may be mentioned:

The most important physiologically active substances are cornutine and sphacelinic acid. The crystallizable alkaloid CORNUTINE of Keller is insoluble in water and the dilute alcoholic solu- 
tions have a blue fluorescence. With concentrated sulphuric acid it produces a violet-blue color after standing several hours; with sulphuric acid and a drop of ferric chloride the solution of the alkaloid becomes orange-red, the margin being somewhat bluishgreen. SpHACELINIC ACID (sphacelotoxin) is a non-nitrogenous, resinous substance, which is insoluble in water but soluble in alcohol and is readily decomposed by chemicals.

An amorphous alkaloid ERGOTOXINE has recently been isolated. It forms crystallizable salts with oxalic, tartaric and phosphoric acids and possesses the physiological properties of the drug. The dose of the alkaloid is a few milligrams and for injection it is dissolved in a dilute solution of sodium hydrate.

The alkaloid EcBoline (Wenzell), which exists to the extent of 0.16 per cent., somewhat resembles cornutine in its physiological action in contracting the muscles. The alkaloid ERGOTINE (about 0.04 per cent.) described by Wenzell may be (like the alkaloid PICROSCLEROTINE of Dragendorff) similar to the ERGOTININE of Tanret, which, according to Keller, owes its activity to the presence of cornutine.

The substance known as SECALINTOXIN is a compourid of sphacelinic acid (sphacelotoxin) and a physiologically inactive crystalline substance, SECALINE. The drug also contains a crystallizable phenolic body, CHRYSOTOXIN ; an amorphous, nitrogenous, glucosidal acid, ERGOTINIC ACID (SCLEROTIC ACID), which is soluble in water and easily decomposed by the digestive secretions; choline; leucine (amido-caproic acid); a crystalline monatomic alcohol, phytosterin (cholesterin), also found in some animal fats; a crystalline substance, ergosterin; an amorphous red coloring principle, sclererythrin; about 2 per cent. of a crystalline sugar, mycose, occurring in rhombic octahedra; 13 to 35 per cent. of a yellowish, non-drying oil which is bland when pure but usually more or less acrid, due to the dissolved bitter principles; and starch.

Allited Plants.-Ergot is also found on other cereals, as wheat, barley and rice, but the drug from this source is apparently not much used.

Ustilago Maydis (Fam. Ustilaginaceæ), the fungus found upon the stem and flowers of Zea Mays, was formerly official as 
Ustilago (corn smut) ; it occurs in irregular, somewhat cylindrical or globose masses from to to I $5 \mathrm{~cm}$. in diameter (Fig. 22), consisting of a whitish membrane, becoming dark with age, and a brownish-black mass of spores, which are nearly spherical and about $7 \mu$ in diameter (Fig. 23). The drug has a heavy odor and a disagreeable taste. Ustilago should be carefully dried and not kept longer than one year. Corn Smut contains a crystallizable alkaloid, ustilagine, which is soluble in water and alcohol and forms crystalline salts; from 0.5 to 5.5 per cent. of a crystallizable acid substance, maizenic acid, which resembles sclerotic

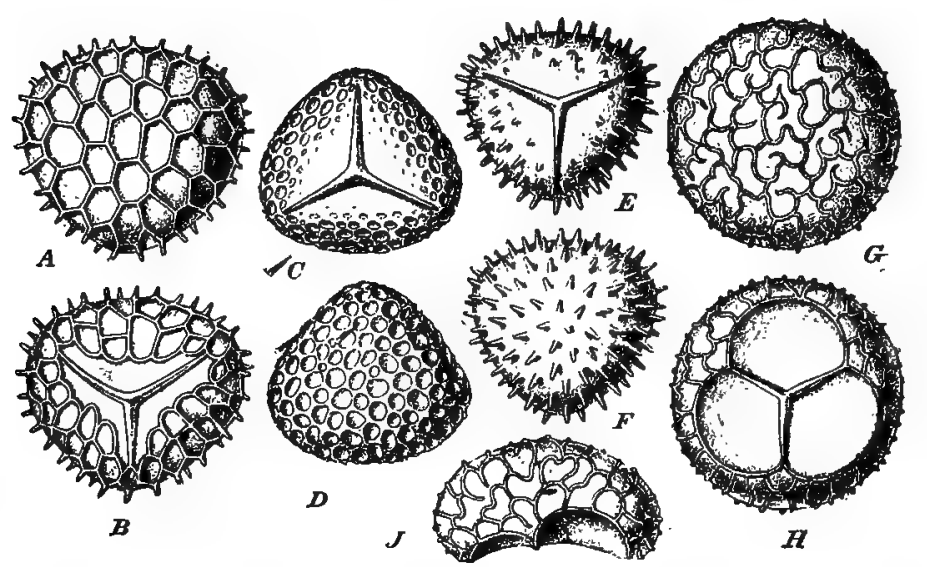

Fig. 278b. Spores of various species of Lycopodium. A, B, reticulated spores of Lycopodium rlavatum; C, D, spores of L. phyllanthum marked by pores; E, F, spinous spores of $L$. densum; G, H, J, spores of $L$. inundalum with wavy reticulations.-After Pritzel.

acid; about I. 5 per cent. of a volatile base resembling trimethylamine; 2.5 to 6.5 per cent. of a dark brown fixed oil, insoluble in alcohol and having the odor of the drug; about 8 per cent. of two resins, one being soluble in alcohol and the other in ether; 3.75 per cent. of a non-reducing sugar which crystallizes in needles; and yields 4.5 per cent. of ash.

LYCOPODIUM.-The spores of Ly'copodium clavatum, and of other species of Lycopodium (Fam. Lycopodiaceæ), perennial herbs (Fig. 46) indigenous to Europe, Asia, North America and Central America. The spores are obtained from the ripened cones by shaking the fruiting tops (sporogonia) and the extrane- 
ous matter is removed by sieving. The principal sources of supply of Lycopodium are Germany, Russia and Switzerland (p. 66).

Description.-A light-yellow, very mobile powder, nearly inodorous and tasteless, floating upon water and not wetted by it, but sinking on being boiled with it, and burning quickly when thrown into a flame.

Spores tetrahedral (Fig. 278b), from 25 to $40 \mu$ in diameter, with one convex side, and delicately reticulate on the surface.

Constituents.-About 50 per cent. of a greenish-yellow, odorless, non-drying oil with an acid reaction, which consists chiefly of oleic acid, together with some lycopodic, arabic, palmitic, stearic, myristic and decyliso-propyl acrylic acids; a small amount of phytosterin, and 3 to 8.2 per cent. of glycerin. The spores also contain 5.3 per cent. of a nitrogenous substance; about 3 per cent. of a sugar, and yield about I per cent. of ash. On heating with a solution of potassium hydrate monomethylamine is liberated, and on macerating the spores in alcohol a part of the alcohol is converted into an aldehyde.

Allied Plants. - The spores of other species of Lycopodium are sometimes collected with those of L. clavatum, as Fir club moss (L. Selago); stiff club moss (L. annotinum); bog club moss ( $L$. inundatum), and the ground pine ( $L$. complanatum) (Fig. 46, illus. 2). From the latter an alkaloid, lycopodine, has been isolated. A toxic alkaloid, piliganine, has been obtained from piligan (L. Saururus), growing in Brazil. L. polytrichoides, of the Hawaiian Islands; $L$. rubrum, of Venezuela; L. cernuum, of the Tropics, and L. Selago of Europe, are also employed in medicine.

Adulterants.-Lycopodium is sometimes admixed with pine pollen, starchy materials, and various inorganic substances, as sulphur, talc and gypsum. A recent adulterant of Lycopodium has been found to consist of corn starch which had been treated in a special manner and then colored with methyl orange. An artificial lycopodium is prepared by treating Bordeaux turpentine (galipot resin) at near the melting point with dry ammonia, the resulting product being then dried and powdered. The fragments are irregular, transparent and are readily detected by means of the microscope. 


\section{POWDERED VEGETABLE DRUGS AND FOODS.}

INASMUCH as a large proportion of vegetable drugs frequently occur in the market in a powdered or ground condition, it becomes of first importance to be able to identify them, as well as to determine their quality in this form. Without a microscopical examination or chemical analysis this would then depend on such factors as color, odor and taste. With some drugs an estimation of quality based on these properties would be of more or less value, particularly those containing aromatic and bitter principles; yet it would soon be found that a more detailed examination would be required to determine their degree of purity or even to identify them with certainty in all cases.

Classification.-It was not considered desirable to give a detailed description of the powder under each drug in the chapter on crude drugs, for the reason that the identity of the drug as a root, rhizome, bark, etc., is lost, and in the examination of a given powder it is usually found advantageous to compare it with those powders having a similar color. By a careful comparison of the powders of the vegetable drugs, it has been found that according to their colors they form five main groups, as follows: (I) Greenish powders, (2) yellowish powders, (3) brownish powders, (4) reddish powders, (5) whitish powders. These groups are then subdivided according to the kinds of cells and the nature of the cell-walls and cell-contents.

Adulterants.-Powdered drugs are frequently adulterated either by the use of wheat middlings or by the use of exhausted powders, i.e., those from which the active or important constituents have been extracted. The following examples serve to illustrate the methods in use: Powdered cloves are occasionally admixed with the exhausted powder, or the exhausted powder alone, to which a small quantity of oil of cloves and some coloring matter are added, is sold as powdered cloves. Exhausted gentian, to which has been added a small quantity of a bitter 
drug like aloes is sold in place of the genuine drug. In some cases, as in that of ground flaxseed, an attempt is made to supply the deficiency in oil of the exhausted product by adding a petroleum oil. In the case of a number of drugs, such as rhubarb, licorice and belladonna root, much of the commercial powder consists, in part at least, of the exhausted powder. In order to guard against the use of exhausted drugs there is a disposition to lay considerable stress upon the AMOUNT OF EXTRACTIVE (aqueous, alcoholic or ethereal) yielded by different drugs. In many instances drugs that are worm-eaten, or admixed with other drugs or plant parts, are used in the preparation of powdered drugs.

REAGENTS.-For the rapid differentiation and study of the characteristic tissues and cell-contents of the powder it is necessary to employ reagents which render the particles more or less transparent and at the same time do not destroy their characters. The most satisfactory reagent of this kind for general purposes is an aqueous solution of chloral or a solution of chloral and glycerin; about a milligram of the powder is mounted in a few drops of the solution, the preparation is gently heated, then allowed to cool, and examined; if it is not sufficiently transparent, it is heated again. The reagent causes a swelling of the cell-wall and is not applicable in the study of starch grains, but it is very useful in the study of mechanical tissues, hairs and calcium oxalate.

After having determined the presence of starch, a separate mount of the powder in water is made and the size and markings of the grains noted.

For the examination of more or less lignified cells, mounts are made, either in phloroglucin or aniline sulphate solution; in some cases it is advantageous to apply these solutions after the specimen has been previously treated with chloral. Sometimes it is desirable to study the mechanical cells more closely, and Schulze's macerating fluid (p. I88) may be used for isolating them.

ExAmination.-Before making a microscopical examination of coarsely comminuted on powdered drugs or foods it is desirable to mix a small quantity of the material with a little water contained in a watch crystal or small beaker and note such features 
as the following: (I) If the particles sink or float. In all genuine coffee, for instance, the particles rise to the surface, whereas in the substitutes and adulterants they sink. (2) If the particles disintegrate. All artificial products, as coffee and nutmeg, when made from exhausted powders or spurious substances, slowly disintegrate, leaving a fine sediment. (3) The color of the solution. A chelidonium powder, for instance, gives a golden-yellow solution, as also do many drugs containing berberine and allied principles. (4) Behavior of the solution and particles toward alkalies or dilute hydrochloric acid. Drugs containing oxymethyl-anthraquinone derivatives, as senna, rhubarb, aloes, frangula and cascara sagrada, are colored a deep red with alkalies. The particles of ruellia give a distinct effervescence with hydrochloric acid particularly if the mixture is slightly heated. The presence or absence of starch may be determined by heating the mixture, to which has been added a few drops of dilute hydrochloric acid, filtering, and adding iodine to the filtrate when cool. (5) The odor of the mixture, particularly on warming, is of considerable value, as in the detection of belladonna in inula or of conium in anise. The odor is also of value in recognizing the specimen, as very many drugs have a characteristic odor. The odor of a specimen is sometimes, however, misleading, as a number of substances not at all related may have a similar odor. The odor of elm bark, for instance, is possessed by other substances, as fenugreek and wheat middlings, particularly if these substances are kept in a closed vessel.

The fixed oil which occurs in considerable quantity in many seeds interferes with their microscopical examination, and it is necessary to remove this before making mounts of the material. This can be accomplished by treating the powder with chloroform, xylol, acetone, ether, or other similar solvents. Alcohol as a rule is not a good solvent for these oils. The solvent may be added directly to the mount and the solution absorbed by means of filter paper. The following drugs and foods contain fixed oil and should be treated in this way: Almond, anisum, cacao, cardamom, carum, conium, coriandrum, cubeba, ergota, linum, macis, myristica, pimenta, pepo, piper, sinapis alba, sinapis nigra, staphisagria, strophanthus, and the various cereal products. 
All powders contain a certain amount of fragments of cell walls and other materials which are more or less alike in the different powders, and it is important that this fact be borne in mind in order that attention may be especially directed to those elements of the powder which have a diagnostic value. The latter while relatively few in number, are easily identified and the distinguishing features readily determined in nearly all cases.

Inasmuch as the size and shape of starch grains and calcium oxalate crystals are characteristic for very many drugs, classifications of these based on the foregoing characters are given before taking up the study of the individual powders.

\section{A. DRLGS AND FOODS CONTAINING STARCH.}

The more important vegetable drugs, including some of the commercial starches, are here grouped according to the size and shape, or other characters, of the starch grains:

\section{SIMPLE SPHERICAL GRAINS.}

NOT MORE THAN $5 \mu$ in diameter: Cimicifuga, cypripedium, frangula (Fig. 228), hydrastis (Fig. 292), leptandra, piper (Fig. 3II), prunus virginiana, quassia (Fig. 239), quercus alba, rhamnus purshiana (Figs. 229a, 304), spigelia, viburnum opulus and viburnum prunifolium.

NOT MORE THAN IO $\mu$ in diameter: Calamus (Fig. IOI, $B$ ), euonymus, gelsemium (Fig. 208), granatum (Fig. 234), quillaja (Figs. 28I, $C$; 315), sanguinaria, serpentaria, tonka, ulmus, xanthoxylum.

NOT MORE THAN $15 \mu$ in diameter: Apocynum (Fig. 202), cinchona (Figs. 227, 307, 307a), colchici semen (in caruncle only), convallaria, sumbul, valeriana.

NOT MORE THAN $20 \mu$ in diameter: Glycyrrhiza (Figs. 104; 282, $B$; 204), phytolacca.

NOT MORE THAN $30 \mu$ in diameter: Rumex, stillingia.

\section{COMPOUND SPHERICAL OR POLYGONAL GRAINS.}

Two- to THRee-Compound: Belladonnæ radix, 5 to $5 \mu$ (Figs. 200 ; 28I, $D$; 303) ; sassafras, 7 to $20 \mu$ (Fig. 236); and veratrum viride, 7 to $20 \mu$ (Figs. 215,216 ).

Two- To Four-COMPOUND: Aconitum, 4 to $12 \mu$ (Figs. 206, 309); cinnamomum, 7 to $15 \mu$ (Figs. 224, 225, 305); colchici cormus, 7 to $20 \mu$; 
ipecacuanha, 4 to I4 $\mu$ (those of Carthagena ipecac being uniformly larger) (Figs. 203, 291) ; krameria, 20 to $30 \mu$ (Fig. 196) ; rheum, 5 to 20 $\mu$ (Figs. 28I, $A ; 289$ ), and sarsaparilla, 7 to $20 \mu$ (Figs. I93, I94).

Two- To sIX-Compound: Podophyllum, 5 to I2 $\mu$ (Fig. 223).

MoRe THAN SIX-COMPOUND: Capsicum, 3 to $7 \mu$ (Figs. $252 ; 301, C$ ); cardamomum, I to $4 \mu$ (Fig. 253); cubeba, I to $4 \mu$ (Fig. 250); gossypii cortex, 5 to $20 \mu$ (Figs. 23I, 23Ia) ; mezereum, Io to $15 \mu$; myristica, 5 to $7 \mu$; pimenta, 7 to Io $\mu$, and rubus, 3 to $7 \mu$.

\section{ELLIPSOIDAL OR OVOID GRAINS.}

Althæa, Io to $20 \mu$; geranium, Io to $15 \mu$; glycyrrhiza, 5 to Io $\mu$ (Figs. I04; $282, B$ ) ; pareira, 7 to I5 $\mu$; physostigma, 25 to $40 \mu$; rumex, to to $20 \mu$; stillingia, I5 to $30 \mu$; strophanthus, 2 to $4 \mu$ (Figs. I86, 306), and zingiber, 15 to $30 \mu$ (Figs. $212 ; 317, C$ ).

\section{GRAINS OF CHARACTERISTIC SHAPE.}

Calumba, 25 to $35 \mu$ (Fig. I98) ; iris florentina, 15 to $30 \mu$ (Figs. 317, 320), and potato and other starches (pp. 785-789).

\section{ALTERED GRAINS.}

Guarana, Io $\mu$; jalapa, I5 to $35 \mu$ (also two- to three-compound) (Fig. 288) ; tragacantha, 2 to Io $\mu$; turmeric in masses, 70 to I40 $\mu$ (Fig. 290).

\section{AMYLODEXTRIN GRAINS}

Mace (Fig. 190) contains starch grains, which give a reddish color with iodine.

\section{B. DRUGS AND FOODS WITHOUT STARCH.}

The following are some of the drugs which do not contain starch :

Amygdala amara and A. dulcis (Figs. I87; $188 ; 302, D ; 319$ ), anisum (Fig. 244), aurantii amari cortex, aurantii dulcis cortex, coffee, carum, caryophyllus (Fig. 3I2), cocculus, colocynthis, conium (Fig. 248), coriandrum (Fig. 245), cydonium, foniculum, gentiana (Fig. 300, $A$ ), hæmatoxylon, illicium (Fig. 302, $I$ ), lappa, limonis cortex, linum (Figs. 184, 293), nux vomica (except in pulp adhering to seed) (Fig. 318), pyrethrum, quassia (Figs. 239; 299, C), rhus glabra (Fig. 285, I), santalum rubrum, scilla (Fig. 28I, $B$ ), senega, sinapis alba (Fig. 302, $E, F$ ), sinapis nigra, 
staphisagria, stramonii semen, taraxacum (Fig. 10I, D); triticum and vanilla (Figs. 256; $285, G ; 313$ ).

Leaves, herbs and flowers do not, as a rule, contain reserve starch.

\section{A. DRUGS AND FOODS WITH CALCIUM OXALATE CRYSTALS.}

\section{CRYSTALS IN ROSETTE AGGREGATES.}

Not MORE THAN $7 \mu$ in diameter: Anisum (Fig. 244), calendula (Fig. 296), carum (Fig. 247), conium (Fig. 248), coriandrum (Fig. 245), fœniculum (Fig. 246).

NOT MORE THAN I5 $\mu$ in diameter: Caryophyllus (Fig. 3I2) and humulus (Fig. 298).

NOT MORE THAN $25 \mu$ in diameter: Althæa (Fig. 99, $B$ ), buchu, cannabis indica (Fig. 279), castanea, cusso, eriodictyon (Figs. 283, $A ; 285$, $F$ ), euonymus (Fig. 300, $E$ ), frangula (prisms and pyramids also occur) (Fig. 228), galla, gossypii cortex (Fig. 23I), granatum (Fig. 234), pimenta (Fig. 302, $B$ ), senna (Fig. 263), stramonii folia (Fig. II7).

Not MORE THAN $35 \mu$ in diameter: Jalapa (Fig. 288), pilocarpus (Fig. 257), rumex, stillingia, viburnum prunifolium and viburnum opulus (occasionally).

NOT MORE THAN IOO $\mu$ in diameter: Chimaphila, 40 to $60 \mu$; geranium, 45 to $70 \mu$, and rheum, 50 to Ioo $\mu$ (Figs. $28 \mathrm{I}, A$; 289).

\section{CRYSTALS IN MONOCLINIC PRISMS OR PYRAMIDS.}

NOT MORE THAN To $\mu$ in diameter: Coca (Fig. 286), hyoscyamus (Fig. 282, $A$ ), and uva ursi (Fig. 300, $D$ ).

NOT MORE THAN $20 \mu$ in diameter: Calumba (in stone cells, Fig. 302, H), frangula (Fig. 228), granatum (rosette aggregates also occur, Fig. 234), hamamelis, quercus alba (rosette aggregates also occur) (Figs. 300, $B, F$ ), rhamnus purshiana (Fig. 229a), and senna (Figs. 263).

Not MORE THAN $30 \mu$ in diameter: Cardamomum (Fig. 253), eucalyptus, gelsemium (Fig. 208), pimenta (occasional) (Fig. 302, B), prunus virginiana, quassia (cryptocrystalline crystals also occur) (Fig. 239), vanilla (Figs. 256, 3I3), viburnum opulus, viburnum prunifolium (occasional), and xanthoxylum.

NOT MORE THAN IOO Or $200 \mu$ in diameter: Krameria, about $100 \mu$ (Figs. I96; 300, $C$ ), and quillaja, 35 to $200 \mu$ (Figs. 3 I $5 ; 28 \mathrm{I}, C ; 300, G$ ).

\section{CRYSTAL FIBERS PRESENT.}

Crystal fibers occur in the following drugs, which are grouped according to the size of the individual crystals : 
NOT. MORE THAN IO $\mu$ in diameter: Uva ursi (Fig. 300, D).

NOT MORE THAN $20 \mu$ in diameter: Frangula (Fig. 228), glycyrrhiza (Figs. I04, 282, $B$ ), hamamelis, hæmatoxylon, quercus alba (Fig. 300, $B, F$ ) and rhamnus purshiana (Figs. 229a, 304).

NOT MORE THAN $30 \mu$ in diameter: Prunus virginiana.

About $35 \mu$ in diameter: Quillaja (Figs. $315 ; 28 \mathrm{I}, C$; 300, $G$ ).

\section{CRYSTALS IN RAPHIDES.}

Raphides are found in the following drugs, and of the length given with each:

Belladonnx folia (occasionally) (Figs. $285, K ; 287, C$ ) ; cinnamomum, about $5 \mu$ (Figs. 224, 225, 305) ; convallaria, about $45 \mu$; cypripedium, about $40 \mu$; ipecactuanha, 20 to $40 \mu$ (Figs. 203, 291) ; phytolacca, about $30 \mu$; sarsaparilla, 6 to $8 \mu$ (Figs. I93, I94); scilla, o.I to r.o mm. (Fig. 28I, $B$ ); vanilla, about $400 \mu$ (Figs. $256 ; 285, G ; 3 \mathrm{I} 3$ ); veratrum viride, about $45 \mu$ (Figs. 2I5, 216).

\section{CRYPTOCRYSTALLINE CRYSTÁLS.}

Cryptocrystalline crystals are found in the following drugs:

Belladonnæ folia (Fig. 287, C), belladonnæ radix (Fig. 28I, $D$ ), cinchona (Figs. 227, 307), dulcamara, phytolacca, quassia, solanum carolinense and tabacum.

\section{MEMBRANE CRYSTALS.}

Membrane crystals are found in the following drugs:

Aurantii amari cortex, I5 to $20 \mu$, and aurantii dulcis cortex, 20 to $30 \mu$.

\section{B. DRUGS WITHOUT CALCIUM OXALATE.}

In the following drugs, calcium oxalate crystals are either wanting entirely or so few as to be without any diagnostic value:

Aconitum, apocynum (Fig. 202), arnica (Fig. 24I), capsicum (Figs. 252; 301, C), chirata, cimicifuga, colchici cormus, colchici semen, colocynthis, cubeba (Fig. 250), digitalis (Figs. 266; 284, $E ; 285, D ; 287, A$ ), eupatorium, gentiana (Fig. 300, $A$ ), grindelia, hydrastis (Figs. 219, 292), lappa, leptandra, linum (Figs. 184, 293), lobelia, marrubium, mentha piperita, mentha viridis, mezereum, myristica, nux vomica (Figs. 283, $B$; 318), pareira, physostigma, piper (Fig. 3II), podophyllum (Fig. 223), rhus glabra (Fig. 285, I), rosa gallica, sabina, sanguinaria, santonica (Fig. 240), sassafras (Fig. 236), senega, serpentaria, sinapis alba (Figs. 294; 302, E, F), sinapis nigra (Fig. 295), spigelia, staphisagria, strophanthus (Figs. $186 ; 284, A ; 306$ ), sumbul, valeriana and zingiber (Fig. 212). 


\section{SUBSTANCES MISTAKEN FOR CALCIUM ÓXALATE.}

Calcium oxalate crystals have been mistaken for crystalline sugar, and it should also be pointed out that some of the soluble carbohydrates, as hesperidin and inulin, may be mistaken for sphere-crystals of calcium oxalate, which latter are of rare occurrence. Some of the soluble carbohydrates, including inulin (Fig. 105) occur in sphere-crystals or irregular spherical aggregates, which are more or less easily soluble in water. They are found in buchu, hedeoma, inula, lappa, pyrethrum, taraxacum and triticum.

\section{DRUGS CONTAINING CALCIUM CARBONATE.}

Cannabis indica (Fig. 284, C) and ruellia (Fig. 221).

\section{KEY FOR THE STUDY OF POWDERS.}

\section{POWDERS OF A GREENISH COLOR.}

\section{Crystals of Calcium Oxalate present.}

$A$. Crystals in rosette aggregates.

$a$. Glandular and non-glandular hairs present.

Cystoliths of calcium carbonate........ Cannabis Indica

Twisted non-glandular hairs.............. Eriodictyon

Starch grains I5 to $40 \mu$ in diameter......... Galia

Large multicellular glandular hairs.......... Humulus

Numerous pollen grains.............. Insect Powder

Glandular hairs few...............6. Stramonii Folia

$b$. Glandular hairs wanting.

Hairs with slight projections............. Pilocarpus

Characteristic stone cells.................... Tea

c. Glandular and non-glandular hairs wanting.

Sphere-crystals of a carbohydrate.............. Buchu

Crystals $I$ to $2 \mu$ in protein grains............. Conium

Crystals I5 $\mu \ldots \ldots \ldots \ldots \ldots \ldots \ldots \ldots \ldots \ldots \ldots \ldots \ldots . \ldots \ldots$. Castanea

Crystals 40 to $60 \mu \ldots \ldots \ldots \ldots \ldots \ldots \ldots$. 2 . Chimaphila

Outer wall of epidermal cells very thick.....r3. Eucalyptus

Crystal fibers........................ Granatum

B. IN MONOCLINIC PRISMS.

a. Glandular and non-glandular hairs present.

.Crystals about ro $\mu \ldots \ldots \ldots \ldots \ldots \ldots . . . . .$. 5. Hyoscyamus 
B. IN MONOCLINIC PRISMS.-Continued.

b. Only non-glandular hairs present.

Characteristic stone cells........ 6. Cardamomum (Ceylon) Crystal fibers................. H Hamamelidis Folia Fragments reddish with alkalies.............. Senna Non-glandular hairs few................. Uva Ursi

c. Glandular and non-glandular hairs wanting.

Epidermal cells with papillæ................20. Coca Few fragments of tissues............... Guaiacum Few crystal fibers and non-glandular hairs...22. Uva Ursi

C. IN CRYSTAL FIBERS.

Rosette-shaped crystals numerous........23. Granatum Crystal fibers few...................24. Uva Ursi

D. IN CRYPTOCRYSTALLINE CRYSTALS.

a. With hairs.

Hairs few...................25. Belladonnæ Folia Non-glandular hairs numerous............26. Tabacum Starch grains ro to $35 \mu \ldots \ldots \ldots 27$. Solanum Carolinense b. Hairs few or wanting.

Starch grains 5 to $7 \mu \ldots \ldots \ldots \ldots \ldots \ldots 28$. Dulcamara

\section{Calcium Oxalate Crystals wanting.}

$A$. Cystoliths of calcium Carbonate present.

Glandular and non-glandular hairs....29. Cannabis Indica Stone cells characteristic.................. Ruellia

B. Calcium carbonate wanting.

a. Glandular and non-glandular hairs present.

a Fragments of pappus present.

Pollen grains to to $20 \mu \ldots \ldots \ldots \ldots . \ldots 3$ I. Eupatorium

Pollen grains about $25 \mu \ldots \ldots \ldots \ldots \ldots 32$. Grindelia

$\boldsymbol{\beta}$ Fragments of pappus wanting.

I. Glandular hairs with I- and 2-celled heads.

Non-glandular hairs characteristic...33. Digitalis

2. Glandular hairs with I- to 8-celled head.

Odor characteristic..............34. Hedeoma

Non-glandular hairs twisted.....35. Marrubium

Non-glandular hairs I- to 8-celled.

36. Mentha Piperita

Non-glandular hairs I- to 3 -celled. .37. Scutellaria

Non-glandular hairs parallel with surface of leaf.

38. Salvia 
B. Calcium carbonate wanting.-Continucd.

b. Glandular hairs wanting.

a With non-glandular hairs.

r. Pollen grains present.

* Hairs numerous.

Non-glandular hairs I-celled......39. Lobelia

Non-glandular hairs I- to 6-celled..40. Matico

** Hairs very few.

Cells of non-glandular hairs very short, oblong.................4I. Tanacetum

2. Pollen grains wanting.

Hairs I-celled, with thick walls....42. Scoparius

$\beta$ Non-glandular hairs wanting.

Starch grains present..............43. Cardamomum

With tracheids......................43a. Sabina

Without starch grains..............44. Staphisagria

Aqueous solution of a golden-yellow color.

45. Chelidonium

\section{POWDERS OF A YELLOWISH COLOR.}

\section{Fragments of Vegetable Tissue present.}

$A$. Containing starch.

a. With calcium oxalate crystals.

u In rosette aggregates.

Crystal fibers.....................46. Frangula

Isodiametric stone cells.........47. Galla (Aleppo)

Starch grains swollen................ J8. Jalapa

Calcitum oxalate crystals 50 to Ioo $\mu \ldots \ldots .49$. Rheum

$\beta$ In monoclinic prisms.

Characteristic starch grains...........50. Calumba

Starch grains swollen...............5. Curcuma

Crystal fibers....................52. Frangula

Long sclerenchymatous fibers........53. Gelsemium

Tracheæ with bordered pores..........54. Quassia

$\gamma$ In crystal fibers.

W:ith cork fragments......55. Glycyrrhiza (Spanish)

Without cork fragments...56. Glycyrrhiza (Russian)

$\delta$ In raphides.

Tracheids with bordered pores.......57. Ipecacuanha

Long sclerenchymatous fibers.......58. Phytolacca

Endodermal cells with thick walls.59. VeratrumViride 
A. Containing starch.-Continued.

b. Calcium oxalate wanting.

a Stone cells present.

Characteristic starch grains............;60. Calumba $\boldsymbol{\beta}$ Stone cells wanting.

I. Starch grains I5 to $30 \mu$ in diameter.

With yellow oil-secretion cells.......6. Zingiber

2. Starch grains 5 to $15 \mu$ in diameter.

Long non-lignified bast fibers.....62. Mezereum

Ducts large..................63. Pareira

Lignified sclerenchymatous fibers..64. Serpentaria

Powder lemon-yellow............65. Berberis

3. Starch grains less than $5 \mu$ in diameter.

Crystals of alkaloids with sulphuric acid.

66. Hydrastis

4. Starch grains altered.

Large cells with swollen grains.....67. Curcuma

B. STARCH GraINS FEW OR NONE.

a. Calcium oxalate crystals present.

u In rosette aggregates.

Non-glandular hairs.................68. Anisum

Oil-like globules in epidermis.........69. Calendula

Non-glandular hairs wanting........7. Fœniculum

$\beta$ In monoclinic prisms.

Crystals I5 to $20 \mu \ldots \ldots \ldots 7$ I. Aurantii Amari Cortex

Crystals 20 to $30 \mu \ldots \ldots \ldots 72$. Aurantii Dulcis Cortex $\boldsymbol{\gamma}$ In raphides.

Crystals o.I to I mm. long...............73. Scilla

b. Calcium oxalate crystals wanting.

a Sclerenchymatous cells or fibers present.

I. Dark pigment cells wanting.

Stone cells with thickened inner walls.

74. Sinapis alba

Stone cells ellipsoidal, uniformly thickened.

Parenchyma cells large, thin-walled.

75. Pepo

76. Colocynthis

2. Pigment cells present.

Stone cells with thickened inner walls.

77. Sinapis Nigra

Characteristic sclerenchymatous cells and fibers.

78. Fenugreek 
2. Pigment cells present--Continued.

Short sclerenchymatous fibers........79. Linum

A colorless layer of cells with minute starch grains.................... Cydonium

$\beta$ Sclerenchymatous tissue wanting.

1. Pollen grains numerous.

Fragments of pappus........81. Arnica Flores

Pollen grains smooth............82. Sambucus

Pollen grains spinose...........83. Matricaria

2. Pollen grains few.

Pollen grains prickly...........84. Calendula

Pollen grains nearly smooth........85. Crocus

Corolla white...............86. Anthemis

Bitter, ducts scalariform..........87. Chirata

3. Pollen grains wanting.

* Fibrovascular tissue present.

Containing inulin masses........88. Lappa

Sclerenchymatous fibers numerous.89. Senega

Starch and scalariform tracheæ..90. Aspidium

** Fibrovascular tissue wanting.

Few fragments of tissues....99. Cambogia

Large glandular hairs..... 92. Lupulinum

Tetrahedral spores.........93. Lycopodium

II. Few or No Fragments of Vegetable Tissue.

A. Giving OFF OdOR OF SUlphuR dioxide on heAting.

Rounded masses in chains.............94. Sulphur Lotum

Rounded masses in irregular groups. 95. Sulphur Præcipitatum

B. No ODOR OF $\mathrm{SO}_{2}$ ON HeAting.

a. Nearly colorless in glycerin mount.

Transparent, irregular masses...........96. Mastiche

$b$. Yellowish in glycerin mount.

u Containing oil globules.

Irregular masses...............97. Scammonium

$\beta$ Transparent or translucent.

Soluble in cold alcohol............98. Colophony

Insoluble in cold alcohol.............99. Sandarac

Reddish with alkalies............ Ioo. Aloe (Cape)

$\gamma$ More opaque.

Light or grayish particles.......... ror. Ammoniac

Yellowish particles................. I02. Cambogia 


\section{POWDERS OF A BROWNISH COLOR.}

\section{Fibrovascular Tissue present.}

A. Containing starch.

a. Calcium oxalate crystals present.

a In rosette aggregates.

I. With sclerenchymatous fibers.

* Containing oil, resin or tannin masses.

Sclerenchymatous fibers few.

103. Belladonnæ Radix

Starch grains 4 to $20 \mu$.. I04. Gossypii Cortex

Starch grains 3 to $7 \mu$, compound. . I05. Rubus

Crystals ro to $35 \mu \ldots \ldots \ldots \ldots$. 106. Juglans

Crystals 35 to $70 \mu \ldots$... I07. Aralia Nudicaulis

Starch grains 5 to $30 \mu \ldots \ldots$ I08. Stillingia

Modified bast fibers.......... Iog. Euonymus

Red with alkalies.............. IIo. Rumex

Fibers few................. I

** No resin or tannin masses.

Crystals about $25 \mu \ldots \ldots \ldots \ldots$. III. Althæa

2. Sclerenchymatous fibers wanting.

* Containing tannin.

$\dagger$ With oil-secretion reservoirs.

Starch grains ellipsoidal. I I2. Fruit of Clove

Reddish brown tannin masses. I I3. Pimenta

计 Oil-secretion reservoirs wanting.

Light-brown tannin masses...... II4. Gall

Calcium oxalate 45 to $70 \mu$.II5. Geranium

Calcium oxalate 50 to $100 \mu$...iI6. Rheum

** Without tannin.

Cryptocrystalline crystals.

I17. Belladonnæ Radix

$\beta$ Crystals in monoclinic prisms and pyramids.

Crystal fibers....................... Fir. Frangula

Sclerenchymatous fibers characteristic...II9. Krameria

Crystal fibers and stone cells... I20. Rhamnus Purshiana

Crystals in stone cells.............. I2r. Juniperus

$\boldsymbol{\gamma}$ Crystal fibers present.

I. Sclerenchymatous fibers strongly lignified.

* Colored reddish with alkalies.

Without stone cells........... I22. Frangula

With stone cells.....I23. Rhamnus Purshiana 
I. Sclerenchymatous fibers strongly lignified.-Continued

** Not colored reddish with alkalies.

Stone cells characteristic... I24. Quercus Alba Stone cells characteristic.

125. Prunus Virginiana

Taste bitter, acrid........ 26. Myrica Cerifera Taste sweetish, slightly bitter.

127. Pulvis Glycyrrhizæ Compositus

2. Sclerenchymatous fibers not strongly lignified.

Fragments of ducts.............128. Calamus

No fragments of ducts.............. I29. Ulmus

$\delta$ Calciun oxalate in raphides.

I. Raphides not more than Io $\mu$ long.

No fragments of ducts.......r ro. Cinnamomum

Fragments of ducts present......I3I. Sarsaparilla

2. Raphides 40 to $45 \mu$ long.

Spherical starch grains 3 to I2 $\mu$.

I32. Convallaria

Thick-walled parenchyma with simple pores.

Ellipsoidal starch grains 7 to $20 \mu$.

I33. Cypripedium

3. Raphides $200 \mu$ long.

r34. Veratrum Viride

Starch grains 4 to I5 $\mu . . \ldots \ldots$. I35. Hydrangea

€ Calcium oxalate in cryptocrystalline crystals.

Sclerenchymatous fibers few....136. Belladonnæ Radix

Bast fibers characteristic...........137. Cinchona

$b$. Calcium oxalate crystals wanting.

a With non-glandular hairs.

Greenish fragments with sulphuric acid.

$\beta$ Non-glandular hairs wanting.

I38. Strophanthus

I. Sclerenchymatous fibers present.

* Tracheæ numerous.

† Starch grains 2 to $5 \mu$ in diameter.

Ducts large and with bordered pores.

139. Cimicifuga

Thick-walled parenchyma with simple pores............... I40. Cypripedium

Scalariform ducts......... I4I. Leptandra

Starch grains............. I42. Spigelia 
* Tracheæ numerous.-Continued.

计 Starch grains 5 to 15 or $20 \mu$ in diameter.

Characteristic starch grains. I43. Zingiber

Odor of coumarin............ I44. Tonka

Chocolate taste......... I45. Cocoa Shells

Fragments of milk vessels. 146. Apocynum

Raphides $45 \mu$ long...... I47. Convallaria

Raphides 6 to $8 \mu$ long... I48. Sarsaparilla

Ducts with bordered pores...149. Sumbul

Stone cells characteristic...I50. Valeriana

Stone cells........... I5I. Methysticum

** Tracheæ few or none.

Characteristic bast fibers....... I52. Cinchona

Raphides about $5 \mu$ long... I53. Cinnamomum

Short sclerenchymatous fibers..... I54. Coffee

Starch grains 7 to $20 \mu$, compound.

2. Sclerenchymatous fibers wanting.

I55. Sassafras

* Stone cells present.

$\dagger$ Giving tannin reaction with ferric salts.

Stone cells characteristic......I56. Cacao

Altered starch grains....... 557. Guarana

Stone cells characteristic....... 158. Piper

Thick-walled endosperm cells.

I59. Colchici Semen

if Not becoming blue or green with ferric salts.

Starch grains 4 to $12 \mu \ldots \ldots$ I60. Aconitum

Starch grains 25 to $40 \mu$.161. Physostigma

** Stone cells wanting.

Starch grains 7 to $20 \mu$...162. Colchici Cormus Altered starch grains...........163. Guarana Numerous oil globules..........164. Myristica Amylo-dextrin starch grains....... 65. Macis Few fragments of vegetable tissue. I66. Opium Starch grains 5 to $12 \mu \ldots \ldots$ I67. Podophyllum

Odor characteristic........ 68 . Chenopodium

B. Starch Grains FeW or None.

a. Containing calcium oxalate.

a In rosette-shaped crystals.

I. Small crystals in aleurone grains.

With non-glandular hairs.......... 69. Anisum

Calcium oxalate 0.5 to I $\mu \ldots \ldots \ldots \ldots$ izo. Carum

Calcium oxalate 3 to $7 \mu \ldots \ldots \ldots$ I I. Coriandrum

Calcium oxalate I to $2 \mu \ldots \ldots \ldots$ I 72 . Foniculum 
a In rosctie-shaped crystals.-Continued.

2. Crystals not less than Io $\mu$ in diameter.

* Pollen grains numerous.

Crystals numerous..........173. Caryophyllus

Crystals few............ I74. Insect Powder

** Pollen grains few.

$\dagger$ Ducts present.

Glandular and non-glandular hairs.

it Ducts wanting.

I75. Cusso

Stone cells few.... I76. Viburnum Opulus

Stone cells numerous.

177. Viburnum Prunifolium

$\beta$ Calcium oxalate in monoclinic prisms.

I. Numerous seeds.

Characteristic odor.

I78. Vanilla

2. Seeds wanting.

Stone cells few........... I79. Viburnum Opulus

Stone cells numerous, characteristic.

180. Viburnum Prunifolium

Numerous oil globules.......... I8I. Xanthoxylum

$\gamma$ Calcium oxalate in crystal fibers.

Stone cells characteristic............I82. Quercus Alba

$b$. Calcium oxalate wanting.

a Containing pollen grains.

Non-glandular hairs numerous......183. Arnicæ Flores

Spherical pollen grains................. Crocus

Non-glandular hairs few............. 85 . Santonica

$\beta$ Pollch grains wanting.

I. Stone cells numerous.

Fragments wine-colored with sulphuric acid.

186. Cubeba

Characteristic stone cells........ I87. Delphinium

Green fluorescence in chloral mount.

I88. Stramonii Semen

Ducts reticulate............... 89 . Pyrethrun

2. Stone cells wanting.

Non-lignified intermediate fibers.... Igo. Gentiana

Few fragments of tissues............19i. Opium

Tracheæ with elongated, narrow pores.

192. Taraxacum

Tracheæ with large, simple pores..... I93. Chicory

Ducts spiral, anuular or with simple pores.

194. Triticum 


\section{Without Fibrovascular Tissue.}

A. With cellular tissues.

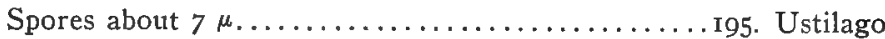

Numerous oil globules..................... 196. Ergota

Thick-walled cells of capsules............... Opium

Fragments of woody tissues.............. I98. Goa Powder

$B$. Without cellular tissues.

a. Possessing oil.

Grayish fragments.................. I99. Asafetida

Yellowish or yellowish-brown fragments......200. Myrrha

b. Without oil.

a Remaining opaque in glycerin.

Characteristic odor..........20r. Aloes (Socotrine)

Characteristic odor...............202. Benzoinum

Grayish opaque fragments.........203. Elaterinum

Brownish angular masses..........204. Lactucarium

$\beta$ More or less transluccnt in glycerin.

Dark brown..............205. Aloes (Curaçao)

Yellowish-brown...........206. Aloes (Socotrine)

With acicular crystals................... Gambir

Few fragments of tissues.............208. Catechu

Fragments translucent, deep red..........209. Kino

POWDERS OF A REDDISH COLOR.

\section{Containing Starch.}

Very light pink, crystals present................2 Qu. Quillaja

Reddish, crystals wanting................... II Sanguinaria

\section{Without Starch.}

A. Stone cells present.

Characteristic stone cells................2I2. Capsicum

Characteristic stone cells.................. Ily. Illicium

Mucilage cells and sclerenchymatous fibers......2I4. Cydonium

Characteristic glandular hairs...........215. Rhús Glabra

Non-glandular hairs 0.5 to $2 \mathrm{~mm}$. long......216. Rosa Canina

Woody tissues only................217. Willow Charcoal

$B$. Stone cells wanting.

a. With wood fibers.

Coloring principle soluble in water.....218. Hæmatoxylon

Coloring principle insoluble in water.219. Santalum Rubrum

b. Wood fibers wanting.

Blue with sulphuric acid................220. Crocus

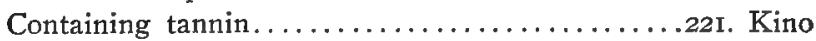

Large glandular hairs................222. Lupulinum 
b. Wood fibers wanting.-Continued.

Characteristic odor...................223. Opium Epidermal cells with papillæ..........224. Rosa Gallica Fragments of anthers.............225. Rosa Centifolia Long, slender styles...................226. Zea

\section{POWDERS OF A WHITISH APPEARANCE.}

\section{Plant Tissues or Cell-Contents recognizable.}

$A$. Containing starch.

a. Only unaltered starch grains present.

Excentral and fissured point of origin of growth.

227. Maranta Starch

Excentral and circular point of origin of growth.

228. Potato Starch

Polygonal grains.................229. Corn Starch

Small, polygonal, compound grains......230. Rice Starch Ellipsoidal, point of origin of growth indistinct.

23r. Wheat Starch

Characteristic grains.............232. Other Starches

b. Altered and unaltered starch grains present.

Becomes pasty on addition of cold water......233. Dextrin

Becomes pasty with hot water..............234. Sago

Disintegrates with water........235. Sago (Imitation)

c. Plant tissues in addition to starch.

a Do not readily dissolve or swell in cold water.

Polygonal starch grains.............236. Corn Meal

Free from hairs................237. Corn Bran

Starch grains 5 to $40 . \mu$ in diameter...238. Wheat Flour

Hairs with thick walls and narrow lumen.

239. Wheat Middlings

Starch grains 20 to $60 \mu$ in diameter...240. Rye Flour

Thin-walled hairs with large lumen. 24I. Rye Middlings

Starch grains 5 to $25 \mu$ in diameter...242. Barley Flour

Sclerenchyma fibers with brown contents.

243. Buckwheat Flour

Starch grains 2 to to $\mu$ in diameter...244. Rice Flour Hairs broader near the middle........245. Oat Meal

Lignified hairs, starch grains few....246. Nux Vomica Characteristic starch grains........247. Orris Root Very long prisms of calcium oxalate.....248. Quillaja Raphides of calcium oxalate...........249. Bryonia Aromatic odor..................249a. Calamus Thin-walled bast fibers..............249b. Ulmus 
c. Plant tissues in addition to starch-Continued.

$\beta$ Soluble or swelling in cold water to form a sticky mass.

Starch and fragments of ducts.....250. Tragacantha

B. Without starch.

a. Calcium oxalate present.

Raphides 0.1 to $\mathrm{I}$ mm....................... Scilla

$b$. Calcium oxalate wanting.

Characteristic lignified hairs...........252. Nux Vomica

Characteristic stone cells................253. Almond

\section{Absence of Plant Tissues.}

A. Soluble in water.

Forming a mucilage with water..............254. Acacia

Monoclinic prisms....................255. Saccharum

$B$. INSOLURLE IN WATER.

a. Soluble in alcohol.

Irregular fragments................256. Camphora

$b$. Insoluble in alcohol.

a Reddish color with sulphuric acid.

Gritty; monoclinic prisms of various sizes.

257. Saccharum Lactis

$\beta$ No color reaction with sulphuric acid.

I. Soapy feel.

Broken crystals................258. Talc

2. Soluble in acetic acid.

* With effervescence.

In prisms or irregular angular fragments.

259. Precipitated Calcium Carbonate

An amorphous powder...260. Prepared Chalk

Rhombic crystals or irregular fragments.

26r. Barium Carbonate

** Without effervescence.

Rounded masses......262. Heavy Magnesia

Very light...........263. Light Magnesia

3. Insoluble in acetic acid.

* Soluble in nitric acid.

Tetragonal or cubical crystals.

264.Precipitated Calcium Phosphate

Acicular crystals.....265. Calcium Sulphate

Rhombic prisms or crystals of various sizes.

266. Barium Sulphate

Irregular fragments........267. Terra Alba 


\section{POWDERS OF A GREENISH COLOR.}

In this group are included all those drugs which in a powdered condition are of a light-green, yellowish-green or darkgreen (sap-green) color. Most of the powders of the leaves and herbs belong to this class.

\section{CRYSTALS OF CALCIUM OXALATE PRESENT.}

\section{A. CRYSTALS IN ROSETTE AGGREGATES.}

\section{a. GLANDULAR AND NON-GLANDULAR HAIRS PRESENT.}

I. CANNABIS INDICA.-Dark green (Figs. 284, $C$; 279); non-glandular hairs, I-celled, more or less curved, with numerous slight projections, and sometimes with cystoliths of calciũm carbonate; glandular hairs two kinds-either with short unicellular or multicellular stalks-and 8- to I6-celled glandular heads; calcium oxalate, in rosette aggregates about $20 \mu$ in diameter; numerous oil globules and resin fragments; few nearly spherical pollen grains 25 to $35 \mu$ in diameter, with numerous centrifugal projections, among club-shaped unicellular hairs of style; ducts spiral or with simple or bordered pores; sclerenchymatous fibers long, thin-walled, non-lignified, and with few simple pores; laticiferous vessels with reddish-brown contents. When mature seeds are present, palisade-like stone cells occur, which are very thickwalled, and have a small lumen.

2. ERIODICTYON.-Dark green; calcium oxalate in rosette aggregates, 20 to $25 \mu$ in diameter; non-glandular hairs I-celled and thick-walled (Fig. 283, $A$ ); glandular hairs with I-celled stalk and 6- to 8-celled glandular head (Fig. $285, F$ ). In powder of the stems occur: ducts, spiral or with simple or bordered pores; sclerenchymatous fibers either non-lignified and thinwalled, or lignified and thick-walled, and with numerous simple pores; pith cells somewhat tabular, thick-walled, slightly lignified, and with numerous simple pores.

3. GALLA (Chinese or Japanese).-Grayish-green; calcium oxalate crystals about $20 \mu$ in diameter; starch grains 15 to $40 \mu$ 
in diameter; non-glandular hairs; milk vessels accompanying ducts. Mounts in glycerin may show acicular crystals.

4. HUMULUS.-Light green; calcium oxalate in rosette aggregates, ro to I $5 \mu$ in diameter; non-glandular hairs unicellular, more or less bent, thin-walled, 0.2 to $0.3 \mathrm{~mm}$. long; gland11lar hairs of two kinds (Fig. 298), either with a 3-celled stalk

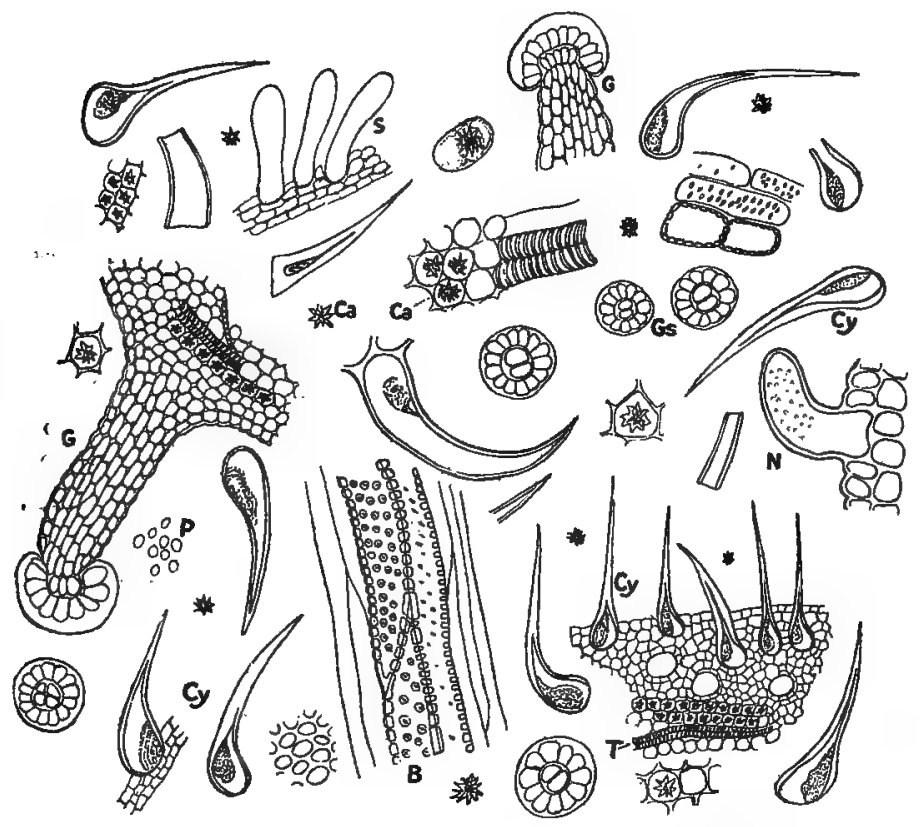

FIG. 279. Cannabis indica: $\mathrm{Cy}$, non-glandular hairs containing calcium carbonate in the form of cystoliths; G, multicellular glandular hairs of the bracts; Gs, multicellular heads of glandular hairs; S, papillæ of stigma; B, tracheæ with bordered pores, present in stem fragments; $T$, trachez with anrrular markings; $P$, pollen grains; $C a$, rosette aggregates of calcium oxalate; $N$, thick-walled non-glandular hair with numerous papillæ on the surface.

and a nearly colorless, multicellular, glandular head about $50 \mu$ in diameter, or with a short 4-celled stalk and a multicellular, bright yellow, glandular head 0.1 to $0.3 \mathrm{~mm}$. in diameter.

5. INSECT POWDER (Persian) (p. 395).-Grayish-green (Fig. 280); with numerous rounded and prickly pollen grains, $25 \mu$ in diameter; a few crystals 2 to $8 \mu$ in diameter, in stone cells or in parenchyma adjoining; sclerenchyma fibers about $20 \mu$ 
in diameter and 100 to $160 \mu$ long; fragments of T-shaped nonglandular hairs less numerous than in Dalmatian powder; characteristic, isolated, somewhat rounded or elliptical parenchyma cells, also occurring in papillæ-like fragments; fragments of

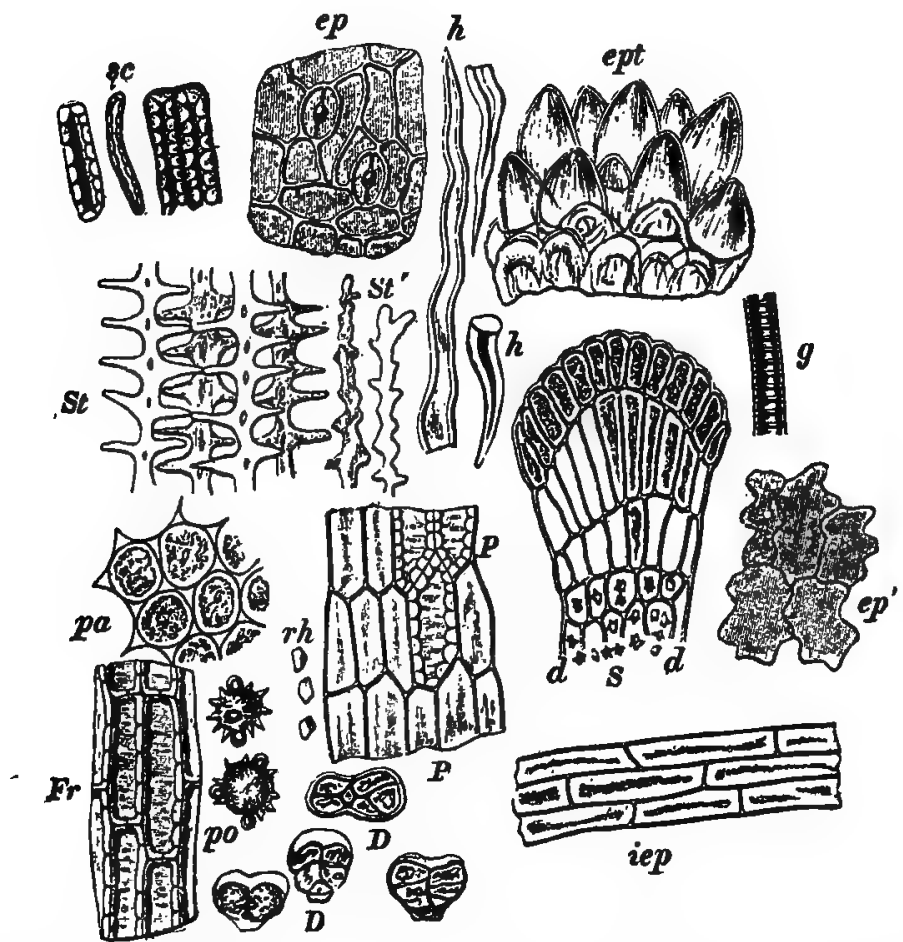

FIG. 280. Flores Pyrethri (Insect flowers): sc, stone cells; ep, upper epidermis of a bract; $h, h$, non-glandular hairs of bracts; ept, papiliæ on the upper surface of the ligulate corolla; St, St', loose parenchyma of the ligulate corolla; $\mathrm{g}$, a trachea of a bract with annular thickening; $S$, tooth of a tubular floret, some of the cells of which contain rosette aggregates of calcium oxalate; $\mathrm{ep}^{\prime}$, epidermis of the under surface of a ligulate corolla; P, section of pappus showing some of the lignified cells, some of which contain monoclinic prisms as shown at rh; pa, parenchyma of a bract; Fr, somewhat thickened, porous cells of the pericarp; D, glandular hairs found on the wall of the ovary; po, pollen grains; iep, cells of the involucre between the bracts.-After Hanausek.

acute papillæ (epidermis of corolla), which are more numerous than in Dalmation powder; glandular hairs about $50 \mu$ in diameter, being smaller than in Dalmatian powder; rose-colored fragments in chloral mounts possibly more numerous in the Persian powder. 
6. STRAMONII FOLIA.-Dark green (Fig. II7); calcium oxalate in rosette aggregates 10 to $20 \mu$ in diameter; non-glandular hairs few, 2- to 3-celled, with numerous slight centrifugal projections; glandular hairs few, stalk I- to 2-celled, glandular head 2- to 4-celled (Figs. I06, $A ; 285, C ; 287, D$ ).

\section{b. GLANDULAR hairS WANTING.}

7. PILOCARPUS.-Dark green (Fig. 257) ; epidermal cells on surface view $5^{-}$to 6 -sided, walls straight; calcium oxalate crystals in rosette aggregates, 20 to $30 \mu$ in diameter, frequently in palisade cells and also in cells in the air spaces of the stomata; mesophyll cells frequently with reddish-brown tannin masses, turning green with ammonio-ferric sulphate solution; non-glandular hairs I-celled, thick-walled, with numerous slight centrifugal projections, 0.4 to $0.6 \mathrm{~mm}$. long in P. Jaborandi and 40 to $60 \mu$ in $P$. pinnatifolius and $P$. microphyllus. In $P$. microphyllus the stomata are smaller than in the other two species.

8. TEA.-Large, elongated, irregular and colorless stone cells (idioblasts); numerous unicellular, long, thick-walled, nonglandular hairs Io $\mu$ wide; rosette aggregates of calcium oxalate Io $\mu$ in diameter; characteristic stomata 30 to $60 \mu$ in diameter, with 3 or 4 accompanying cells. Adulterants are distinguished by possessing chiefly other forms of calcium oxalate crystals and hairs.

Allied Plants.-Maté or Paraguay tea (p. 322) is distinguished by the stomata, which are much larger than the epidermal cells of the lower surface; the epidermal cells occurring near the veins are in nearly parallel rows and with a striated surface; sclerenchymatous fibers are associated with the tracheæ, and calcium oxalate occurs in rosette aggregates.

Adulterants.-Ash leaves (species of Fraxinus) have rather characteristic " horned" stomata, due to the extra development of the cutinous layers at the poles of the stomata ; the epidermal cells are very wavy in outline. CAmellia leaves contain idioblasts (similar to those in tea leaves) and calcium oxalate crystals, but the lower epidermis is thick-walled and with centripetal thickening. Cherry leaves (Prinus avium) have numerous small rosette 
aggregates of calcium oxalate in the lower epidermal cells. GromWELL leaves (Lithospermum officinale) have stiff, scythe-shaped hairs with centrifugal thickening of cuticle. MAPLE leaves (Acer
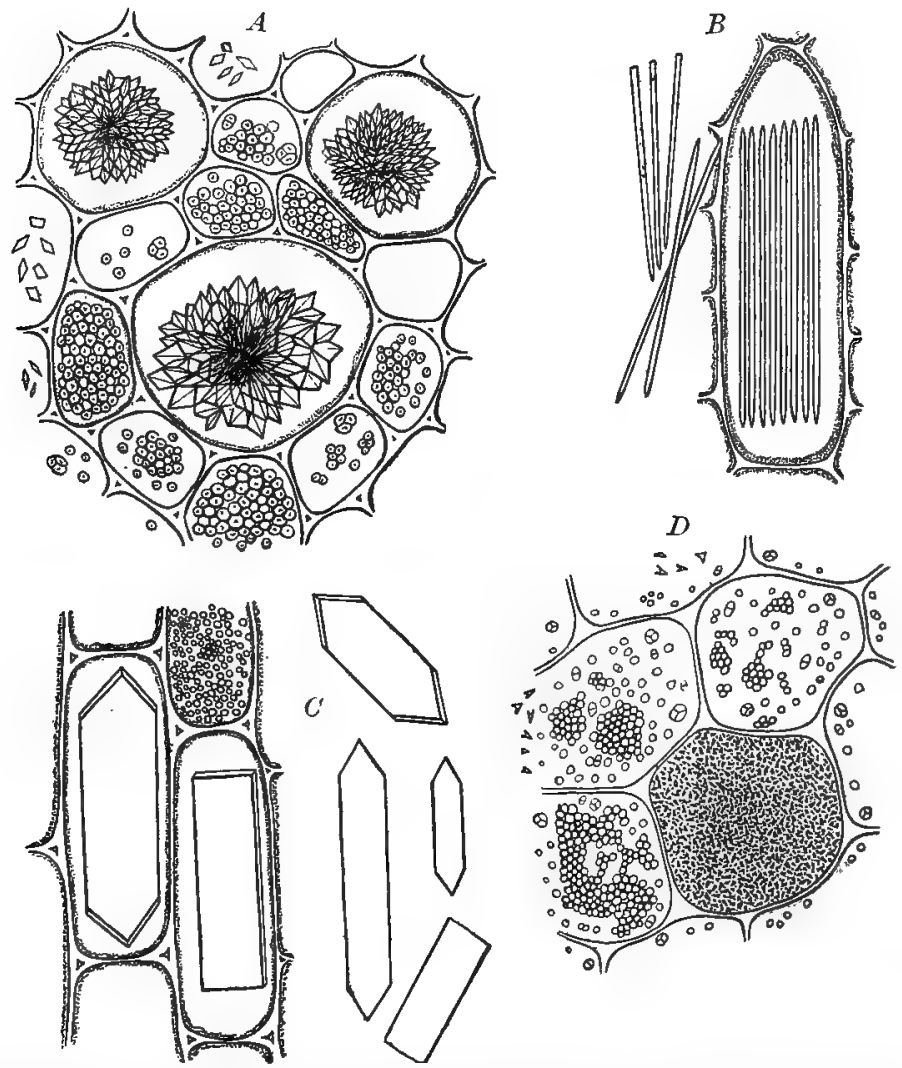

Ftg, 28r. Forms of calcium oxalate crystals: A, transverse section of rheum showing rosette aggregates of calcium oxalate in three of the cells and starch grains in some of the others; $B$, longitudinal section of scilla showing raphides; $C$, longitudinal section of quillaja showing large monoclinic prisms and pyramids of calcium oxalate and also some starch grains: D, transverse section of belladonna root showing one cell filled with cryptocrystalline crystals, the remaining cells containing starch.

Negunido) have non-glandular and glandular hairs, the latter with 2- to 3-celled stalk and large, unicellular head. MEADow-SWEET (Spircea Ulmaria) has unicellular, thin-walled, non-glandular hairs, the basal walls of which are truncate; the glandular hairs 
have either a 3-celled or multicellular stalk and a large, multicellular head. Mountain Ash or European Rowan (Sorbus Aucuparia) possesses long, thin-walled, non-glandular hairs with rounded base. MulberRy leaves (Morus alba and M. nigra) have cystoliths in epidermal cells, non-glandular and glandular hairs, the latter with unicellular stalk and 5- to 9-celled head. OAK leaves (Quercus pedunculata and Q. sessiliflora) have 2- to 3 -celled, non-glandular hairs and stomata only on epidermis of lower surface. SLOE leaves (Prumus spinosa) have rather characteristic crystal fibers. STRAw BerRy (Fragaria vesca) has long, unicellular, non-glandular hairs, the basal portion of which has a thick wall with simple pores, and glandular hairs consisting of a 3-celled stalk and large head, the cells swelling considerably in chloral solutions. The leaves of the WILLOw-HERB (Epilobium angustifolium) contain numerous raphides and the nonglandular hairs are slightly wavy, rather broad and with rounded ends. WILlow leaves (species of Salix) have small stomata (about $25 \mu$ in diameter) with two accompanying cells; the hairs are crooked and with thin walls; the calcium oxalate occurs in rosette aggregates and monoclinic prisms. WISTARIA (Kraunhia floribunda) has non-glandular hairs with 2 short basal cells and a long, thin-walled pointed cell; stomata only occur in the lower epidermis.

\section{c. GLANDULAR AND NON-GLANDULAR HAIRS WANTING.}

9. BUCHU.-Light green; calcium oxalate in rosette aggregates, I 5 to $25 \mu$ in diameter ; epidermal cells with irregular masses or sphere-crystals of a carbohydrate, 30 to $50 \mu$ in diameter, and with walls modified to mucilage; oil globules numerous.

Io. CONIUM.-Grayish-green or yellowish-brown (Fig. 248 ) ; calcium oxalate crystals in rosette aggregates, I to $2 \mu$ in diameter, those in aleurone grains about $5 \mu$ in diameter; parenchyma with chloroplastids and starch grains 2 to $4 \mu$ in diameter; sclerenchymatous fibers long, thin-walled, with numerous simple oblique pores; intermediate fibers with reticulated walls; cells of pericarp nearly isodiametric, yellowish, irregularly thickened, somewhat collenchymatous; oil globules numerous. 
II. CASTANEA.-The cells contain tannin masses, giving a blue color with ferric chloride. (See No. I8, under Senna.)

I2. CHIMAPHILA.-Dark green; calcium oxalate in rosette aggregates 40 to $60 \mu$ in diameter; mesophyll with irregular, reddish-brown tannin masses.

I3. EUCALYPTUS.-Light green; calcium oxalate in rosette aggregates or monoclinic prisms ${ }_{5} 5$ to $25 \mu$ in diameter; outer wall of epidermal cells about $20 \mu$ thick. In leaves from younger parts of the tree the outer wall of the epidermal cells is 5 to $8 \mu$ thick.

14. GRANATUM.-(See No. 23.)
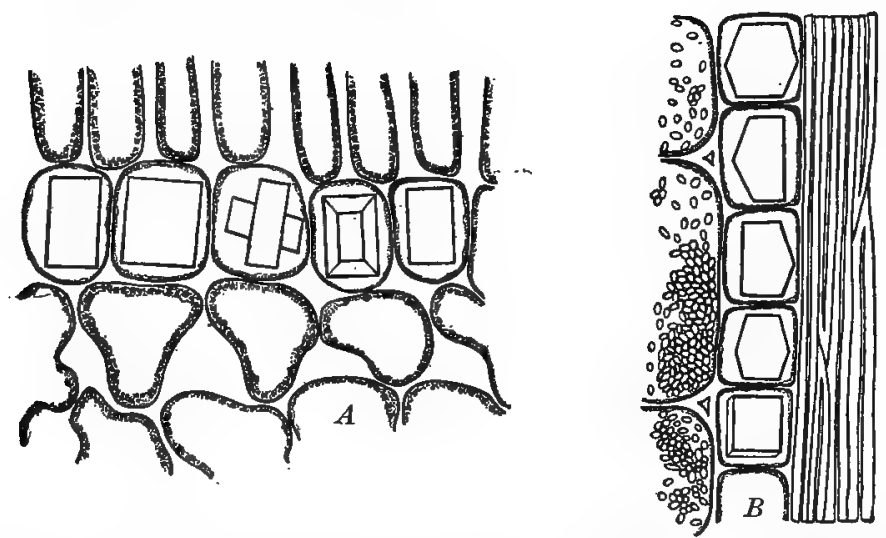

Fig. 282. A, transverse section of. hyoscyamus leaf showing monoclinic prisms of calcium oxalate, also a twin-crystal; $B$, longitudinal section of glycyrrhiza showing a crystal fiber, i.e., a row of superimposed cells, each containing a polygonal monoclinic prism of calcium oxalate, the crystal filling the cell. Adjoining the crystal fiber is a group of bast fibers on one side and some cells containing starch on the other.

\section{B. CALCIUM OXALATE IN MONOCLINIC PRISMS.}

\section{a. GLANDULAR AND NON-GLANDULAR HAIRS PRESENT.}

I5. HYOSCYAMUS.-Dark green (Fig. 282, $A$ ), calcium oxalate in single or twin monoclinic prisms about to $\mu$ in diameter, occasionally in rosette-shaped crystals; non-glandular hairs numerous, I- to 5-celled; glandular hairs numerous, of three different kinds, stalks $I$ - to 4 -celled, glandular heads one- to manycelled (see also Figs. 287, $B ; 302, A$ ). 
b. ONLY NON-GLANDULAR HAIRS PRESENT.

I6. CARDAMOMUM.-(See No. 43.)

I7. HAMAMELIDIS FOLIA.-Dark green; calcium oxalate in monoclinic prisms 7 to $20 \mu$ in diameter, frequently in crystal fibers; non-glandular hairs I-celled, about $0.5 \mathrm{~mm}$. long, more or less curved, thick-walled, with yellowish-brown contents, arranged in groups of about fifteen, and spreading from the base; mesophyll with irregular tannin masses; sclerenchymatous fibers thick-walled, lignified and with simple pores.

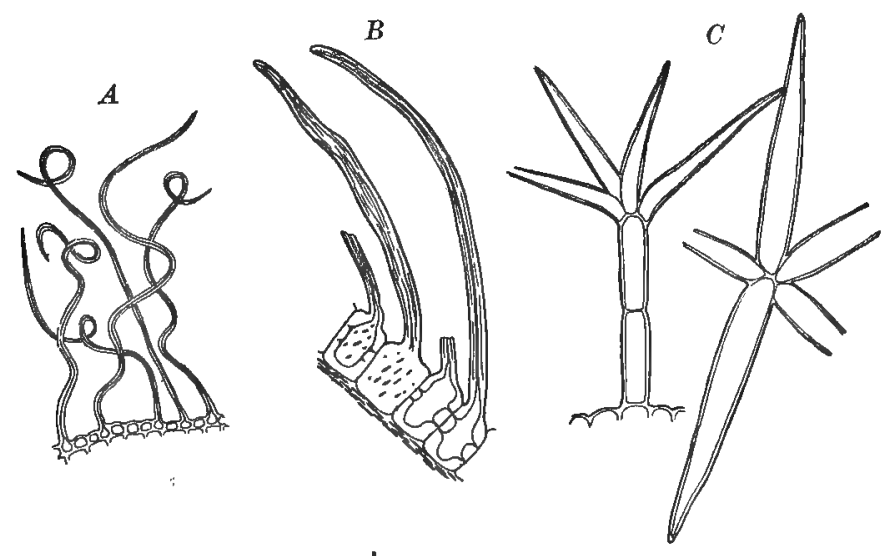

Frg. 283. Forms of non-glandular hairs: A, twisted hairs from under surface of leaf of eriodictyon; B, lignified hairs from the epidermis of nux vomica; C, branching hairs from the leaf of mullein (Verbascum thapsus).

I8. SENNA.-Light green (Figs. $263 ; 284, D$ ); non-glandular hairs 0.1 to $0.2 \mathrm{~mm}$. long, $\mathrm{r}$-celled, thick-walled, the wall of the upper part strongly cutinized, with numerous slight centrifugal projections; calcium oxalate in rosette aggregates, or occasionally in monoclinic prisms, Io to $20 \mu$ in diameter; fragments colored reddish with potassium hydrate solution.

The powder of Indian senna (Cassia angustifolia) is dark green and has relatively few non-glandular hairs. In the powder of Argel Leaves (Solenostemma Argel, Fam. Asclepiadaceæ) the non-glandular hairs are 3- to 4-celled. In the leaves of Castanea dentata (Fam. Fagacea) the non-glandular hairs are relatively few, 0.2 to $0.5 \mathrm{~mm}$. long, nearly smooth, thick-walled, occasionally 
in groups of three to eight and spreading from the base. The calcium oxalate crystals are numerous, in rosette aggregates or in monoclinic prisms, Io to $35 \mu$ in diameter, occasionally in crys-
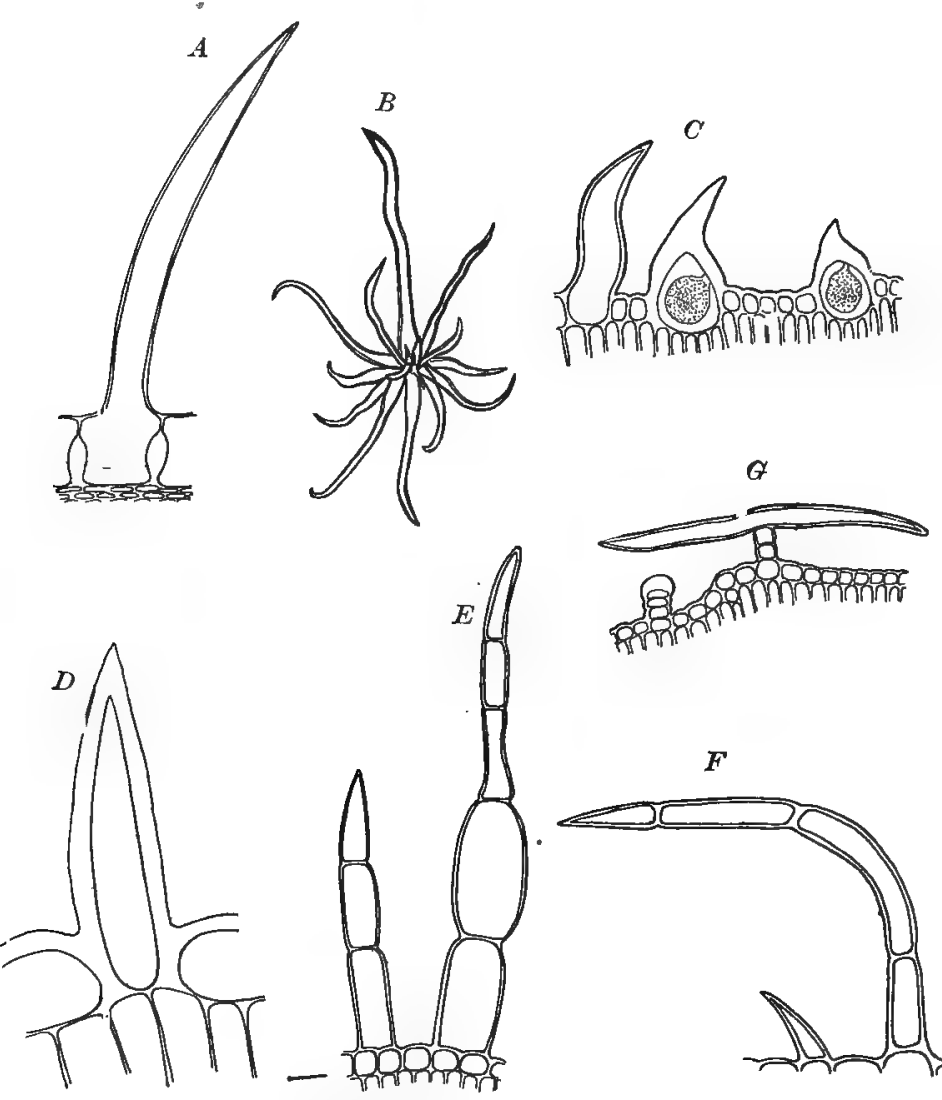

FIG. 284. Forms of non-glandular hairs: A, hair from the epidermis of strophanthus; B, a hair from the capsule of Mallotus philippinensis (found in the drug known as kamala); $C$, hairs from the leaves and bracts of cannabis indica, two of them containing cystoliths of calcium carbonate; D, a hair from the under surface of the leaf of senna; $E$, hairs from leaf of digitalis; F, two forms of hairs from sage leaf; $G$, two forms of hairs from the leaves of wormwood (Artemisia Absinthium): a T-shaped non-glandular hair and a short glandular hair.

tal fibers; the parenchymatous cells contain irregular yellowishbrown tannin masses which are colored blue with ammonio-ferric alum solution. 
19. UVA URSI.-(See No. 22.)
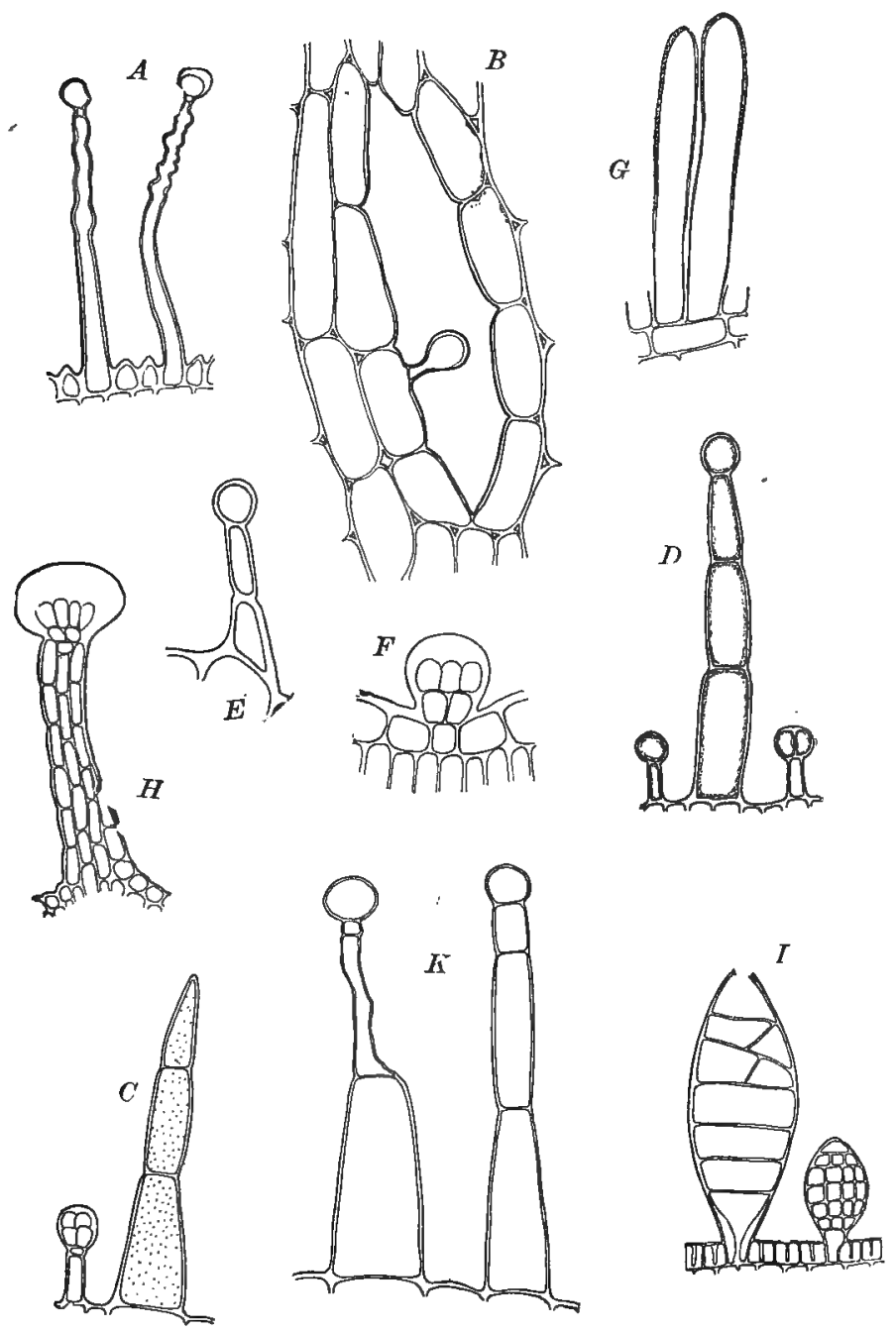

FIG. 285. Forms of glandular hairs: A, corkscrew-like hairs from the inner surface of the spurred corolla of lavender; $\mathrm{B}$, longitudinal section of rhizome of Aspidium marginalis showing large intercellular space and an internal oil-secretion hair; $C$, hairs from stramonium leaf; D, hairs from digitalis; $E$, hair from sage; $F$, hair from eriodictyon; $G$, hairs from inner walls of pericarp of vanilla; $H$, hair from cannabis indica; $I$, hairs from surface of fruit of Rhus glabra; ' $\mathrm{K}$, hairs from belladonna leaf. 


\section{c. GLANDULAR AND NON-GLANDULAR HAIRS WANTING.}

20. COCA.-Dark green (Fig. 286), calcium oxalate in monoclinic prisms 3 to Io $\mu$ in diameter; walls of under epidermal cells extended as minute papillæ (Fig. 26I).

2r. GUAIACUM.-Dark green (p. 669); numerous lemonyellow or dark brown resin masses, which when mounted in

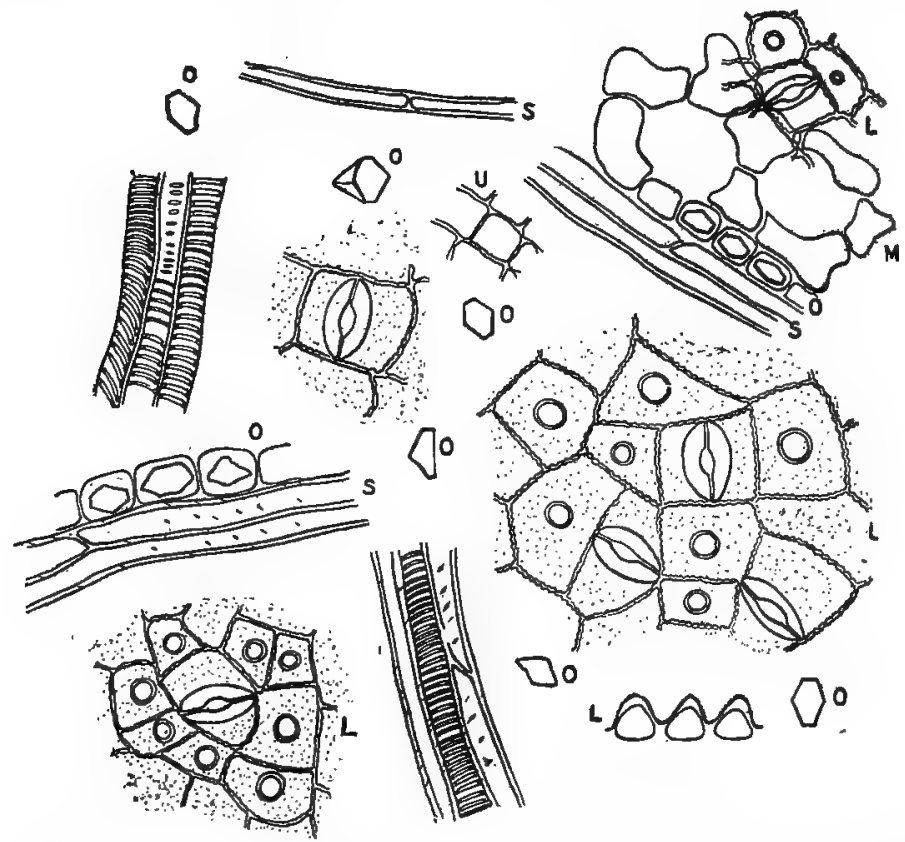

FIG. 286. Coca leaf: O, hexagonal prisms of calcium oxalate; $U$, surface view of a cell of the upper epidermis; I, view of fragments of lower epidermis in surface and cross sections, showing elliptical stomata, and cells with circles which represent papilla in surface view; $S$, sclerenchymatic fibers; $M$, loose parenchyma. Two fragments with annular trachea are also shown.

chloral are wine-colored at the margin; few fragments of tissues with characteristic sclerenchymatous cells and fibers; few crystals of calcium oxalate in monoclinic prisms.

22. UVA URSI.-Yellowish-green; calcium oxalate in monoclinic prisms 7 to $10 \mu$ in diameter, frequently in crystal fibers; non-glandular hairs few, somewhat curved, I-celled, thick-walled, 
longitudinally striate: mesophyll with irregular, yellowish-brown tannin masses; characteristic sclerenchymatous fibers (Fig. $300, D)$.

\section{CALCIUM OXALATE IN CRYSTAL FIBERS.}

23. GRANATUM.-Dark green (Fig. 234), crystal fibers containing calcium oxalate in rosette aggregates and monoclinic prisms, about $15 \mu$ in diameter; sclerenchymatous cells nonlignified, thick-walled, with distinct lamellæ, simple, more or less branching pores; starch grains spherical, 5 to $7 \mu$ in diameter; some parenchymatous cells with marked centripetal thickenings, others with irregular tannin masses. The powder of the root bark is free from chloroplastids; the cork cells are more numerous and the sclerenchymatots cells more irregular in shape.

24. UVA URSI.-(See No. 22.)

D. CALCIUM OXALATE IN CRYPTOCRYSTALLINE CRYSTALS.

a. WITH HAIRS.

25. BELLADONN E FOLIA.-Dark green (Fig. 287, C); calcium oxalate in cryptocrystalline crystals, occasionally in raphides or rosette aggregates; non-glandular hairs few, simple, 2- to 5-celled; glandular hairs few, of two kinds, stalks one- to threecelled, glandular heads one- to many-celled (Fig. 285, K).

26. TABACUMI.-Greenish-brown; non-glandular hairs, 3- to 6-celled, with a broad basal cell and not infrequently branching apical cells; glandular hairs of two kinds, either with a I-celled stalk or $3^{-}$to 5 -celled stalk, the head in each case being rather small and with 8 to 9 cells; stomata large and with 2 or 3 neighboring cells; epiclermal cells striated and somewhat granular on surface view; the cells of the mesophyll with a greenish-brown content, and some of them with cryptocrystalline crystals. The following leaves have been used as adulterants: Chestnut (see No. II), cherry (see No. 8), rose, melilot, cabbage, chicory, beet, and lappa. In the manufacture of plug tobacco various other substances are added: as, licorice (Figs. I04; 204; 282, B), 
cloves (Fig. 312), anise (Fig. 244), orris root (Figs. 317, 320), vanilla (Figs. 256, 313), tamarinds, prunes, besides other substances.

27. SOLANUM CAROLINENSE (Horse nettle).-Starch grains spherical, ellipsoidal, ovoid and 2- to 4-compound, varying in size from to to $35 \mu$ and with distinct lamellæ; non-glandular hairs, stellate, I- to 2-celled; abundance of parenchyma with cryptocrystalline crystals; ducts very broad, with oblique circular pores closely resembling those in glycyrrhiza; wood fibers long, the walls being I to $2 \mu$ thick.

\section{b. HAIRS FEW OR WANTING.}

28. DULCAMARA.-Calcium oxalate in cryptocrystalline crystals; starch grains 5 to $7 \mu$ in diameter; acicular crystals in parenchyma of bark; trachea with bordered pores, 35 to $45 \mu$ wide, and accompanied by sclerenchymatic fibers; an occasional single bast fiber; cork cells present. The following drugs have been substituted for Dulcamara: The stems of false bittersweet (Celastrus scandens) which are more woody and not hollow; hop stems which are rough hairy; and the rhizome of Saponaria which is terete and wrinkled.

\section{CALCIUM OXALATE CRYSTALS FEW OR WANTING.}

\section{A. CXSTOLITHS OF CALCIUM CARBONATE PRESENT.}

29. CANNABIS INDICA.-(See No. I.)

3o. RUELLIA.-This is a rather common adulterant of spigelia, and somewhat resembles it, but is readily distinguished from it by an effervescence on the addition of dilute hydrochloric acid. This effervescence is due to the presence of cystoliths in some of the cells of the cortex (Fig. 221). The cystolith-containing cells are spherical in transverse section and about $20 \mu$ wide, but in longitudinal view are about $80 \mu$ long. Numerous stone cells also occur; these are thick-walled and with numerous radiate simple pores. 


\section{B. CALCIUM CARBONATE WANTING.}

a. GLANDULAR AND NON-GLANDULAR HAIRS PRESENT.

a Fragments of Pappus Present.

3I. EUPATORIUM.-Dark green; non-glandular hairs of two kinds, 2- to 8-celled, thin-walled, finely striate, one kind with acute end-cell and the other with rounded end-cell; glandular hairs either 6- to 8-celled in a double row, and with 2-celled glandular head, or short-stalked and with $4^{-}$to I2-celled glandular head; pollen grains ellipsoidal, to to $20 \mu$ in diameter and with numerous centrifugal projections; pappus occurring as a multicellular axis about $30 \mu$ in diameter and with short unicellular alternate branches; ducts spiral, annular, or with bordered pores; sclerenchymatous fibers thin-walled, non-lignified, with few, simple, oblique pores.

32. GRINDELIA.-Light green; tracheæ spiral, annular, or with bordered pores, strongly lignified; sclerenchyma fibers thinwalled, non-lignified, with numerous simple more or less oblique pores; pollen grains spherical, about $25 \mu$ in diameter, with numerous centrifugal projections; glandular hairs depressed, globular, multicellular; numerous oil globules and resin masses; pappus consisting of a multicellular axis with minute teeth.

\section{$\beta$ Fragments of Pappus Wanting.}

33. DIGITALIS.-Dark green (Figs. $284, E$; 287, $A$ ) ; nonglandular hairs simple, consisting of 2 to 5 superimposed cells, straight or slightly curved; glandular hairs with I-celled stalk and I- to 2-celled glandular head; stone cells, star-shaped hairs and calcium oxalate crystals wanting (Figs. $266 ; 285, D$ ).

Adulterants.-The leaves of Matico (see No. 40) have numerous stomata and the non-glandular hairs are from 2- to 6celled. The leaves of Saliria Sclarea (Fam. Labiatæ) have nonglandular hairs somewhat resembling Digitalis, but the glandular hairs are of the labiate type with large, 8-celled, glandular heads. The leaves of Verbascum Phlomoides (Fam. Scrophulariaceæ) have multicellular, branching, non-glandular hairs resembling those of $V$. thapsus (Fig. 283,C), and small glandular 

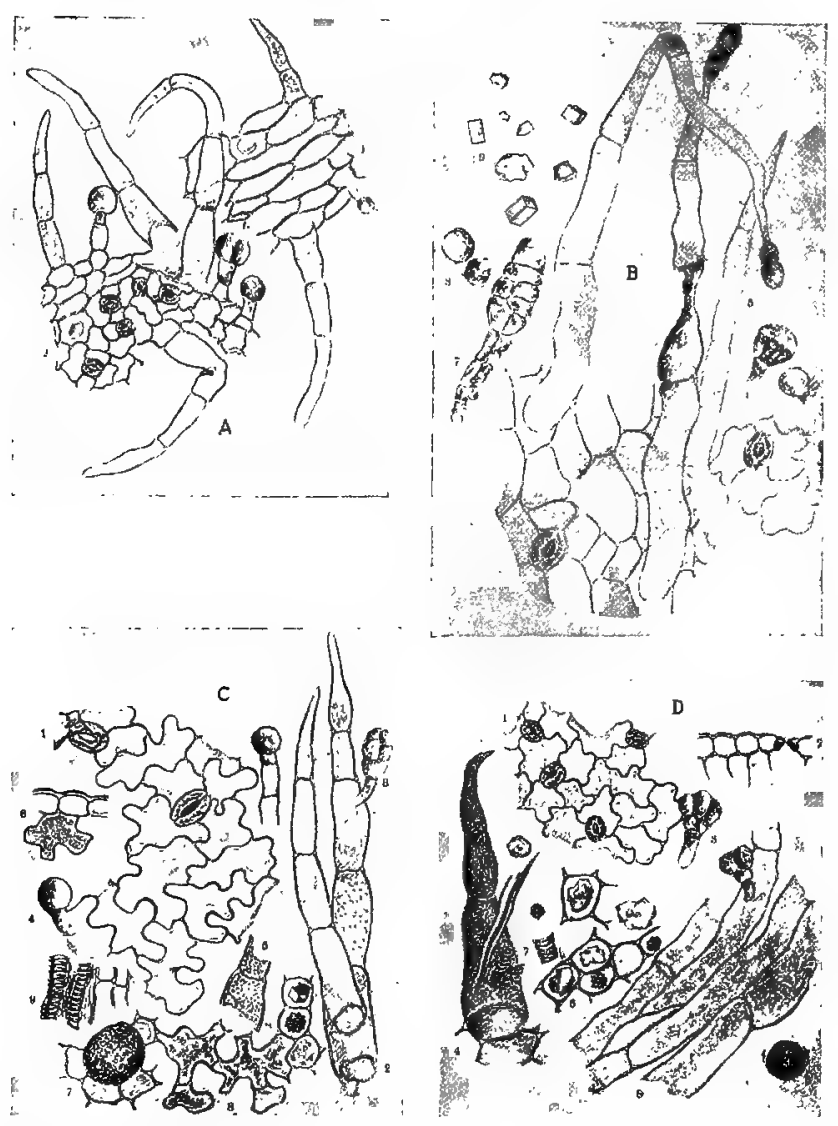

Frg. 287. A, Digitalis leaf: T, upper epidermis showing two non-glandular hairs and one glandular hair; 2 , lower epidermis showing stomata, four non-glandular hairs and three types of glandular hairs.

B, Hyoscyamus leaf: I, upper epidermis showing a stoma and hairs; 2, under epidermis showing a stoma; $3-7$, several forms of hairs; 8 , two pollen grains; 9 , prisms of calcium oxalate.

$C$, Belladonna leaf: $I$, under epidermis showing two stomita and a single glandular hair; 2, two non-glandular hairs; $3-5$, several types of hairs; 6 , a transverse section showing lower epidermal cells and a parenchyma cell containing plastids; 7 , fragment of parenchyma showing a cell containing cryptocrystalline crystals of calcium oxalate; 8 , loose parenchyma showing two adjoining cells respectively containing a monoclinic prism and a rosette aggregate of calcium oxalate; 9, fragment with two annular tracheæ.

D, Stramonium leaf: $x$, under epidermis showing four stomata; 2, transverse section showing a stoma; 3, glandular hairs; 4, prickly non-glandular hair; 5, a pollen grain; 6, parenchyma cells containing rosette aggregates of calcium oxalate; 7, fragments with tracheæ and sclerenchymatic fibers; 8, long collenchymatic cells.-After Moeller. 
hairs resembling those of digitalis. The non-glandular hairs of Inula Conyza (Fam. Compositæ) are $3^{-}$to 4-celled, with thick walls, the basal cell being broad and truncate.

34. HEDEOMA.-Dark green; non-glandular hairs slightly curved, 2- to 3 -celled, thick-walled, with numerous slight centrifugal projections; glandular hairs with I-celled stalk and 8-celled glandular head; pollen grains somewhat spherical, about $35 \mu$ in diameter, nearly smooth; tracheæ spiral or with simple and bordered pores; sclerenchymatous fibers long, thin-walled, lignified, with numerous simple pores; epidermal cells with sphere-crystals or irregular masses of a carbohydrate.

35. MARRUBIUM.-Dark green; non-glandular hairs much twisted, I- to 7-celled, thin-walled, smooth, frequently arranged in groups of about six or eight, and spreading from the base; glandular hairs with I-celled stalk and 8-celled glandular head; pollen grains spherical, about $25 \mu$ in diameter, and with numerous centrifugal projections; tracheæ spiral, annular, or reticulate, slightly lignified; sclerenchymatous fibers thin-walled, non-lignified, with few simple pores.

36. MENTHA PIPERITA.-Dark green; non-glandular hairs I- to 8-celled, thin-walled, with numerous slight projections; glandular hairs two kinds, I- or 3-celled stalk and I- or 8-celled glandular head; pollen grains somewhat spherical, smooth, about $35 \mu$ in diameter; tracheæ spiral, or with simple and bordered pores, and slightly lignified; sclerenchymatous fibers thinwalled, non-lignified, with numerous oblique pores. Contamination with M. spicata is said to be common.

37. SCUTELLARIA.-Dark green; non-glandular hairs, Ito 3 -celled, Ioo to $200 \mu$ long, the walls with numerous slight centrifugal projections, the basal cell being large, broadly cylindrical, and the apical cell narrow and with a sharp, frequently recurved apex; glandular hairs with a I- to 2-celled stalk and large, glandular head, composed of 6 or 8 cells placed side by side, indistinct; pollen grains nearly spherical or ellipsoidal, smooth and I 5 to $25 \mu$ in diameter; fragments of corolla colored light pink with chloral solution; narrow trachere with scalariform and reticulate thickenings, or bordered pores; sclerenchymatous fibers narrow, with walls 4 or $5 \mu$ thick and with simple pores; 
epidermal cells of stem and corolla with distinct striæ; the stomata broadly elliptical and with very small openings. In Scutellaria canescens the non-glandular hairs are 3- to 5-celled and vary in length from 0.3 to $\mathrm{I} \mathrm{mm}$; the glandular hairs have a 4 -celled stalk and 8-celled head, are larger and more prominent than in $S$. lateriflora; and the opening between the guard cells is on surface view long and narrow.

38. SALVIA.-Dark green; non-glandular hairs I- to 6celled, filled with air (Fig. 284, F) glandular hairs numerous, of two kinds, stalks I- to 3-celled, glandular heads unicellular or 8-celled (Fig. 285, E).

\section{$b$. GLANDULAR HAIRS WANTING.}

\section{a With Non-glandular Hairs.}

39. LOBELIA.-Dark green; non-glandular hairs, I-celled, 0.3 to $0.6 \mathrm{~mm}$. long, walls moderately thick, with numerous slight centrifugal projections; pollen grains ellipsoidal, smooth, I5 to $30 \mu$ in diameter; laticiferous vessels branched; trachea spiral, or with scalariform and bordered pores; sclerenchymatous fibers comparatively thin-walled, non-lignified, and with simple oblique pores. Seeds about $100 \mu$ long, reddish-brown, reticulate.

40. MATICO.-Grayish-green; non-glandular hairs numerous I- to 6-celled, varying from 0.2 to $\mathrm{I} \mathrm{mm}$. in length, with walls 2 to $4 \mu$ thick and striate, the apical cell being sharply pointed; numerous globular, yellowish or reddish resin masses in oil glands of leaf : fragments of perianth with fan-shaped upper portion, composed of numerous long, non-glandular hairs, which are much collapsed and deeply striate; seeds reddish-brown and distinctly reticulate, somewhat resembling those of Lobelia.

4I. TANACETUM.-Yellowish-green; non-glandular hairs few, 4- to 5-celled, about $150 \mu$ long, the individual cells being somewhat oblong and with yellowish-brown contents; glandular hairs on akenes with short stalk and large, ellipsoidal head; involucral bracts with a row of transparent marginal cells and central portion with narrow, thick-walled, libriform cells with numerous simple pores; pollen grains spherical or somewhat triangular, thick-walled and with numerous spinose, centrifugal projections; 
narrow tracheæ with scalariform and reticulate thickenings or bordered pores; sclerenchymatic fibers thin-walled and free from pores.

42. SCOPARIUS.-Dark green; non-glandular hairs I-celled, 0.5 to $0.7 \mathrm{~mm}$. long, thick-walled; trachea spiral or double spiral, slightly lignified; sclerenchymatous fibers narrow, thin-walled and with simple pores.

\section{$\beta$ Non-glandular Hairs Wanting.}

43. CARDAMOMUM.-Greenish-brown; stone cells dark brown, slightly elongated, I5 to $25 \mu$ in diameter, the inner wall thickened; outer epidermal cells 20 to $30 \mu$ in diameter, elongated on surface view, inner and outer walls thickened; oilsecretion cells with suberized walls; starch grains spherical or angular, single or compound, I to $4 \mu$ in diameter; monoclinic prisms of calcium oxalate few, Io to $25 \mu$ in diameter. The powder of the pericarp and seeds is pinkish and contains in addition, sclerenchyma fibers which are non-lignified, relatively thin-walled and with simple, slightly oblique pores; not more than ro per cent. of ash. The powder of Ceylon cardamom contains the unicellular hairs of the capsule; and the cells, as also the starch grains and calcium oxalate crystals, are larger (Fig. 253).

43a. SABINA.-Starch, $4 \mu$; characteristic hypodermis, consisting of long fibers I $_{5} \mu$ wide, associated with epidermis; narrow tracheids; numerous oleo-resin masses.

44. STAPHISAGRIA.-Dark green; sclerenchymatous cells somewhat ovate in cross-section, more or less thick-walled and non-lignified; parenchyma containing oil and aleurone.

45. CHELIDONIUM.-Light green; aqueous solution golden yellow; numerous small, somewhat plano-convex or reniform, slightly reticulate seeds, which are about I mm. long; fragments of leaves with spiral trachex, and latex tubes with light yellowish contents; elliptical or spherical stomata on lower surface only. walls rather indistinct; pollen grains spherical, nearly smooth, with 3 pores and 20 to $25 \mu$ in diameter; fragments of petals with distinctly yellowish fibrovascular bundles. Hairs, starch grains and calcium oxalate crystals are wanting. 
POWDERS OF A YELLOWISH COLOR.

In this group are inclucled all those powdered drugs which are of a light yellow (light yellow ochre), dark yellow (dark yellow ochre), lemon-yellow, bright yellow (luminous yellow) or yellowish-brown color. Representatives of all the different kinds of drugs are found in this group.

\section{FRAGMENTS OF VEGETABLE TISSUE PRESENT.}

\section{$A$. CONTAINING STARCH.}

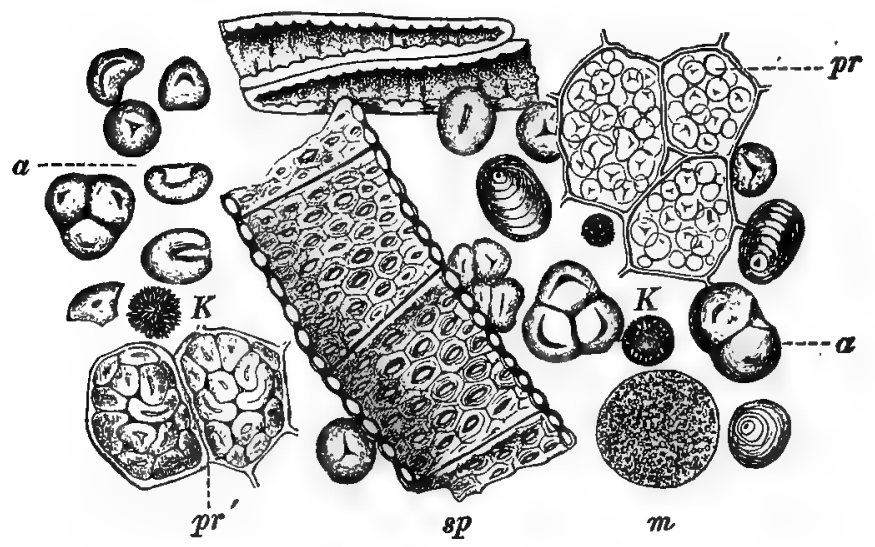

FIG. 288. Jalap: $\mathrm{pr}$, parenchyma containing unaltered starch grains; $\mathrm{pr}^{\prime}$, parenchyma containing swollen starch grains; a, starch grains; $\mathbf{K}$, rosette aggregates of calcium oxalate; $m$, globular mass of resin; sp, fragment of trachea with bordered pores.-After Vogl.

\section{a. C.ILIUM OXALATE PRESENT.}

a In Roscttc Aggregates.

46. FRANGUI_A.- (See No. 52.)

47. GALLA (ALEPPO).-Dark yellow crystals io $\mu$; starch grains Io $\mu$ in diameter, single or sometimes in groups; stone cells; tannin; crystals of gallic acid. Chinese or Japanese Galls.Grayish-green ; crystals few, about $20 \mu$ in diameter ; starch grains about $40 \mu$ in diameter; non-glandular hairs; milk vessels accompanying ducts. The mounts in glycerin show acicular crystals of gallic acid. 
48. JALAP A.-Dark yellow; crystals of calcium oxalate in rosette aggregates, 30 to $35 \mu$ in diameter; starch grains ellipsoidal and ovoid, with somewhat excentral lamellæ, I 5 to $35, \mu$ in diameter, I- to 3-compound and in some cases more or less swollen; resin cells yellowish-brown; sclerenchymatous fibers few, with simple pores (Fig. 195). Tubers deficient in resin are lighter in color, contain more starch and less calcium oxalate.

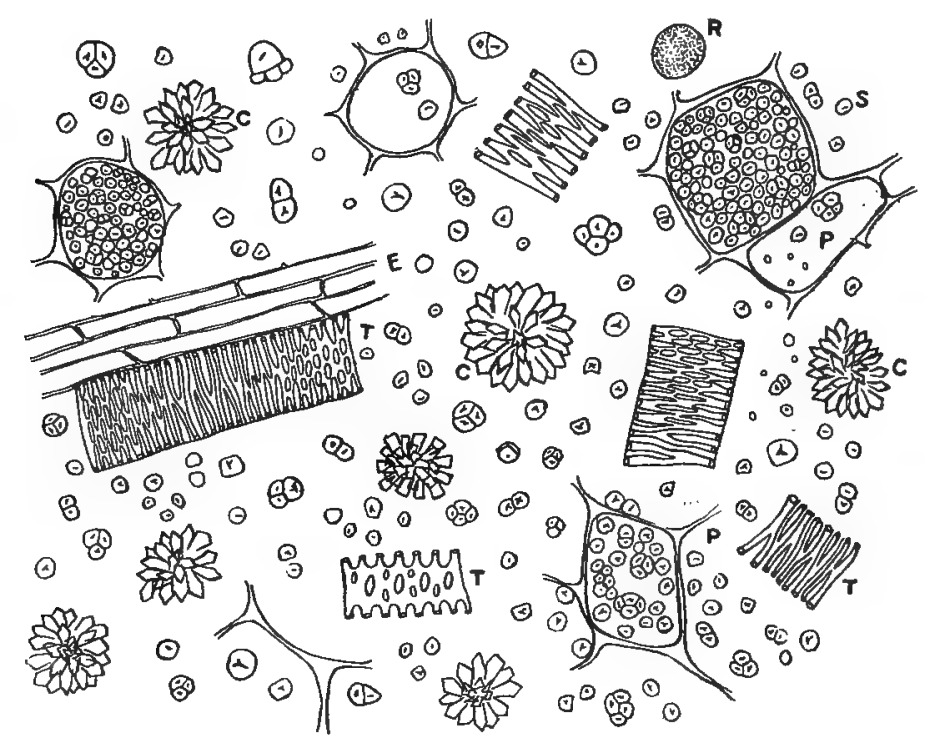

FIG. 289 . Rhubarb: $C$, rosette aggregates of calcium oxalate; $P$, parenchyma containing starch grains (S); $T$, trachex; $E$, sieve; $R$, reddish-brown masses.

49. RHEL'M.-Yellowish-brown (Figs. 28I, A; 289) ; crystals of calcium oxalate in rosette aggregates, 50 to $100 \mu$ in diameter; starch grains somewhat spherical, 5 to $20 \mu$ in diameter, either single or 2- to 4-compound; tracheæ few, scalariform. The powder is colored reddish with alkalies. A common adulterant is "wheat middlings." (See No. 239.) The exhausted drug is frequently added to the powder and may be detected by the somewhat altered starch grains and the decrease in the amount of the aqueous or dilute alcoholic extract, which in genuine rhubarb is about 35 per cent. 
RHAPONTIC RHUBARB contains a crystalline glucoside rhaponticin, which is colored purplish-red with sulphuric acid, changing to orange. It is insoluble in ether and readily separates from a dilute alcoholic fluid extract on the addition of ether.

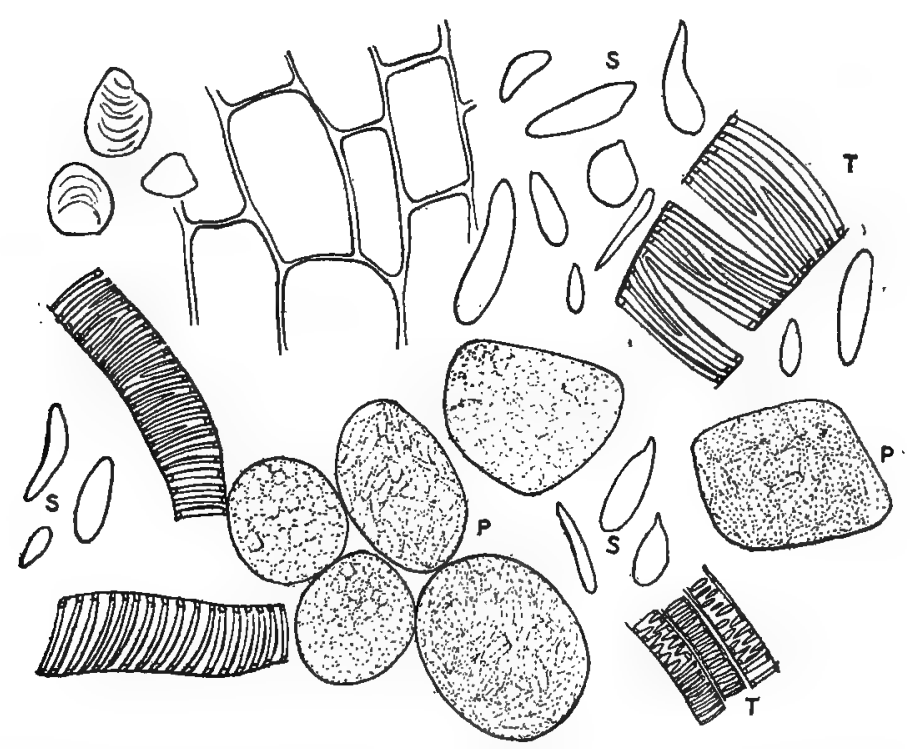

F1G. 290. Curcuma (Turmeric): P, fragments of parenchyma containing swollen and altered starch grains which form an indistinguishable mass within the cells and constitute the greater proportion of the powder; T, trachex; S, unaltered starch grains.

\section{$\beta$ In Monoclinic Prisms.}

50. CALUMBA.-(See No. 60.)

5. CURCUMA.-Bright yellow (Fig. 290); crystals few, 2 to $4 \mu$ in diameter; altered starch grains (test with iodine) in irregular masses from IoO to I $40 \mu$ in diameter, having the shape of the cell in which they occur; bright yellow oil-secretion cells; the pigment is soluble in solutions of chloral or chloral-glycerin, essential oils and alcohol. The latter solution becomes cherry-red with boric acid, changing to bluish-black with ammonia. CURry POWDER consists of allspice, caraway, cardamom, clove, coriander, fenugreek, ginger, pepper and turmeric. 
52. FRANGULA.-Yellowish-brown (Fig. 228) ; bast fibers lignified, much thickened, with numerous pores; crystal fibers containing small monoclinic prisms of calcium oxalate; calcium oxalate also in rosette aggregates or monoclinic prisms, 5 to $20 \mu$ in diameter; starch grains nearly spherical, about $4 \mu$ in diameter, not numerous; parenchymatous cells with yellowish contents colored red by alkalies.

53. GELSEMIUM.-Dark yellow (Fig. 208) ; tracheæ with simple pores; sclerenchymatous fibers long, narrow, lignified; starch grains spherical, from 4 to $8 \mu$ in diameter; calcium oxalate in monoclinic prisms 15 to $30 \mu$ in diameter. In the powder of the overground stem collenchymatous cells containing chloroplastids occur (Fig. 208, $A$ ).

54. QUASSIA.-Light yellow (Fig. 239); tracheæ large, with bordered pores; sclerenchymatous fibers long, thin-walled and with oblique pores; medullary rays with calcium oxalate in monoclinic prisms or in cryptocrystalline crystals, or with few spherical starch grains. When bark of the wood is present a few stone cells and cork cells are also present. In the bark of Surinam quassia stone cells are numerous. (See also Fig. 299, C.)

\section{$\gamma$ In Crystal Fibers.}

55. GLYCYRRHIZA (SPANISH),-Bright yellow (Figs. I04; $204 ; 282, B$ ) ; sclerenchymatous fibers numerous; crystal fibers containing monoclinic prisms of calcium oxalate; starch grains somewhat spherical, 2 to $20 \mu$ in diameter; fragments of cork. The aqueous extract amounts to about 30 per cent.

56. GLYCYRRHIZA (RUSSIAN).-Bright yellow; containing few or no fragments of cork; taste not so bitter as that of Spanish licorice.

\section{$\delta$ In Raphides.}

57. IPECACUANHA.—Dark yellow (Figs. 203; 29I; 299, $A)$; tracheids with simple oblique or bordered pores, sometimes containing starch grains; calcium oxalate in raphides 20 to $40 \mu$ long; starch grains ellipsoidal, 4 to I $_{4} \mu$ in diameter, single or 2- to 4-compound. In Carthagena ipecac the starch grains are uniformly larger, 4 to $15 \mu$ in diameter. 
Substitutes of IPECAC.-The root of Richardsonia scabra has simple and compound starch grains from 20 to $40 \mu$ in diameter; the root of Triosteum perfoliatum and the bark of Naregamia alata contain starch grains and rosette aggregates of calcium oxalate, the latter containing in addition orange-red secretion cells; the root of Heteropteris pauciflora (Fam. Malpighiaceæ) is free from starch but contains rosette aggregates of calcium oxalate, brown pigment cells and stone cells.

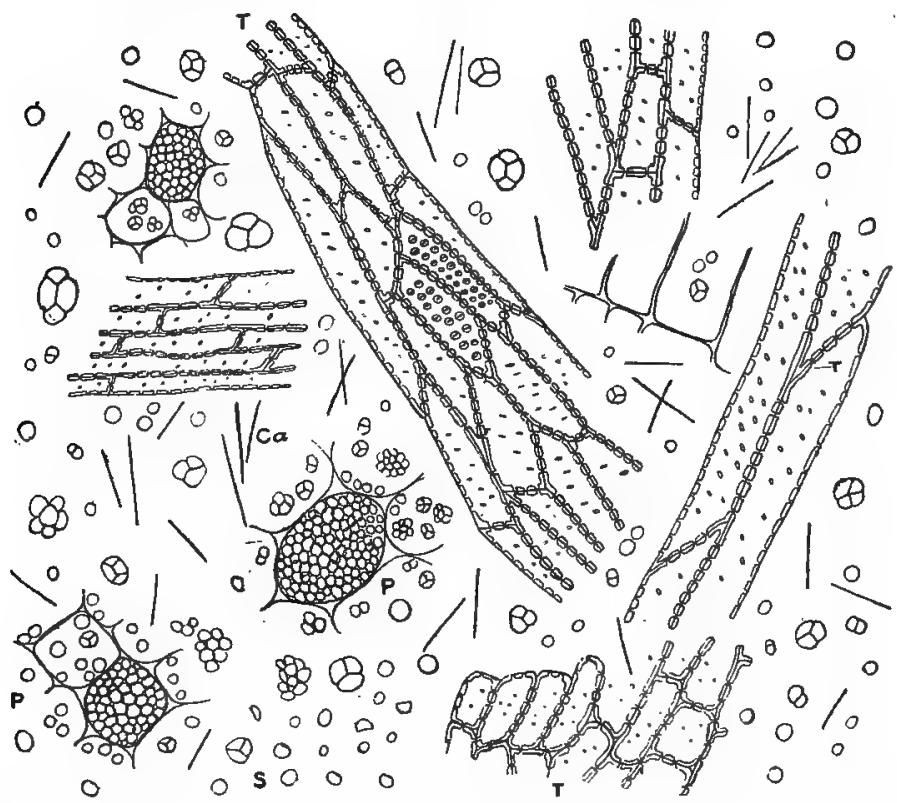

Frg. 291. Rio ipecac: T, tracheids; P, parenchyma contairing starch; S, starch grains; $\mathrm{Ca}$, raphides of calcium oxalate.

58. PHYTOLACCA.-Dark yellow; sternutatory; fragments with long sclerenchymatous fibers and large scalariform tracheæ; starch grains somewhat spherical, 7 to I8 $\mu$ in diameter; calcium oxalate in raphides $3^{\circ} \mu$ long, or in cryptocrystalline crystals.

59. VERATRL MI.-Yellowish-brown (Figs. 215, 216); sternutatory; trachex slightly lignified, scalariform or reticulate; sclerenchymatous fibers thin-walled, narrow, slightly lignified; calcium oxalate in raphides $45 \mu$ long; starch grains nearly ellip- 
soidal, 7 to $20 \mu$ in diameter, single or 2- to 3 -compound, point of origin of growth circular or slightly cleft; endodermal cells thickened on the inner.tangential wall. The powders of Veratrum album and Veratrum ziride cannot be distinguished one from the other by their microscopic characters, but appear to differ chemically, a mount of $V$. viride in concentrated sulphuric acid having a yellowish-red color and that of $V$. album a dull red color. The so-called powdered hellebore, used as an insecticide by gardeners consists of either $V$. album or $V$. viride, the former being mostly employed.

b. Calcium oxalate Wanting.

a Stone Cells Present.

6o. CALUMBA.-Bright yellow (Figs. $198 ; 302, H$ ) ; stone cells containing one or more monoclinic prismatic crystals of calcium oxalate; starch grains single, irregular, 25 to $35 \mu$ long, with excentral and distinct lamellæ.

\section{$\beta$ Stone Cells Wanting.}

I. Starch Grains 15 to $30 \mu$ in Diameter.

6I. ZINGIBER.-Light yellow (Figs. 212, 300, 317) ; starch grains ellipsoidal or somewhat ovoid, slightly beaked, 15 to $30 \mu$ in diameter; secretion cells with suberized walls and yellowish, oily contents; tracheæ large, thin-walled, annular or reticulate; sclerenchymatous fibers long, thin-walled, with oblique pores. The powder of African Ginger is dark yellow or dark brown, more aromatic and pungent, and has ntmerous fragments of cork.

In Japan Ginger (p. 488) the starch grains are as large as in the Jamaica variety, but are broadly ovoid and with distinct lamellæ; 2- to 3-compound starch grains also occur. Exhausted ginger is sometimes used to adulterate powdered ginger. If the exhaustion has been by means of water the starch grains are somewhat altered. If the extraction has been made with alcohol the yellowish-brown resinous cells are not so pronounced. Ginger, particularly the decorticated varieties, loses on keeping part of 
the pale yellowish oil, which is replaced in part by a reddish resin. Ginger is also sometimes adulterated with wheat middlings (No. 239), and flaxseed meal (Figs. 184, 293). Curcuma (Fig. 290) is sometimes added to an exhausted or adulterated ginger to bring up the color to that of the normal drug.

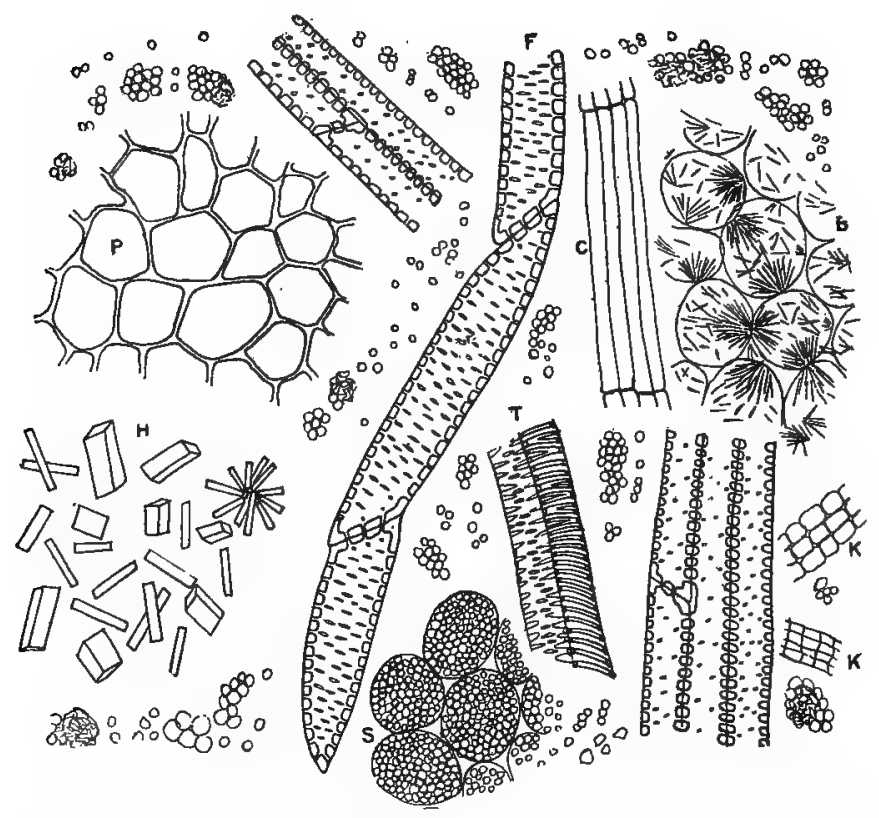

FIG. 292. Hydrastis: P, parenchyma; S, parenchyma containing starch; T, trachez with annular and reticulate thickenings of the walls; $F$, tracheids with simple pores; $C$, cambium; K, cork; $B$, parenchyma cells showing the separation of acicular crystals of one of the alkaloids on the addition of concentrated sulphuric acid; $H$, prisms of one of the alkaloids which separate on the addition of concentrated sulphuric acid to a powder previously moistened with water.

\section{Starch Grains 5 to $15 \mu$ in Diameter.}

62. MEZEREUM.-Dark yellow; sternutatory; bast fibers numerous, long, thin-walled, non-lignified; starch grains somewhat spherical, Io to I $5 \mu$ in diameter, single or compound.

63. PAREIRA.-Dark yellow; sclerenchymatous cells numerous, more or less thick-walled and slightly lignified; sclerenchy* 
matous fibers slightly lignified and with oblique, simple or bordered pores; tracheæ nearly $0.2 \mathrm{~mm}$. in diameter, short, nonlignified and with simple pores; starch grains nearly ellipsoidal, 7 to $I 5 \mu$ in diameter.

64. SERPENTARIA.-Dark yellow; tracheæ lignified, spiral or with simple pores; sclerenchymatous fibers lignified; parenchyma with yellowish or dark brown contents; starch grains nearly spherical, Io $\mu$ in diameter. The rhizome of yellow root (Jeffersonia diphylla) is sometimes substituted for serpentaria, from which it is distinguished by its lack of odor and by having a bitter, acrid taste.

65. BERBERIS.-Tracheæ $50 \mu$ wide, with bordered pores and scalariform and reticulate thickening of the wall; wood fibers $20 \mu$ wide and with walls $8 \mu$ thick; medullary rays yellow, about 9 rows wide, the cells containing starch grains which are about Io $\mu$ in diameter; bast fibers about I $5 \mu$ wide and with walls $4 \mu$ thick; cork cells distinct; parenchyma of cortex with brownishcolored substance.

3. Starch Grains Less Than $5 \mu$ in Diameter.

66. HYDRASTIS.-Bright yellow; tracheæ with simple pores; sclerenchymatous fibers short, thin-walled, with simple pores; starch grains spherical; about $4 \mu$ in diameter (Figs. 219, 292).

4. Starch Grains Altered.

67. CURCUMA.-(See No. 5I.)

\section{B. STARCH GRAINS FEW OR NONE.}

a. CAlCiUm oxalate CRYstals PRESEnT.

a In Rosette-Shaped Crystals.

68. ANISUM.-Yellowish-brown; non-glandular hairs 25 to $200 \mu$ long and Io to I $5 \mu$ wide, I-celled, straight or curved, with numerous slight centrifugal projections; calcium oxalate crystals rosette-shaped, 2 to $3 \mu$ in diameter, in aleurone grains about $6 \mu$ 
in diameter; vittæ (in fragments) from to to $150 \mu$ wide and showing a marked tendency to branch; long, narrow, brownish epidermal cells; sclerenchymatous cells of carpophore short, with simple pores and occasional scalariform thickenings (Fig. 244).

Italian Anise is occasionally ADMIXED WITH CONIUM, which is distinguished by the absence of hairs and vittæ and the presence of coniine, which is determined by the development of the characteristic odor on rubbing up the powder with alkalies or placing the powder in a solution of potassium or sodium hydrate. The following micro-chemical tests may be useful in determining the presence of coniine, which occurs in the parenchyma and epidermal cells of the fruit: Ammonium vanadinate and sulphuric acid produce a blue color; iodine solution gives a reddish-brown color; and picric acid gives a granular precipitate.

69. CALENDULA.-Bright yellow; epidermal cells long, narrow, with numerous oil-like globules, irregular chromoplastids and somewhat sinuate walls; pollen grains spherical, with numerous centrifugal projections, 3 -pored, about $40 \mu$ in diameter; non-glandular hairs consisting of a double row of cells and with a I- or 2-celled apex; calcium oxalate in rosette-shaped crystals about $4 \mu$ in diameter. On adding the powder to water the latter becomes a pale straw-color (Fig. 296, B).

7o. FENICULUM.-Yellowish-brown; calcium oxalate in rosette aggregates $I$ to $2 \mu$ in diameter, in aleurone grains 3 to 6 $\mu$ in diameter; fragments containing vittæ, which are 100 to $200 \mu$ wide; short, narrow, yellowish-brown epidermal cells of pericarp; sclerenchymatous fibers few, thick-walled, with oblique pores; parenchymatous cells slightly elongated or thick-walled, with numerous simple pores, and occasionally reticulately thickened; oil globules numerous (Fig. 246).

\section{B In Monoclinic Prisms.}

7I. AURANTII AMARI CORTEX.-Dark yellow; parenchymatous cells either somewhat collenchymatous or with simple pores, walls io to $15 \mu$ thick; calcium oxalate in monoclinic prisms I 5 to $20 \mu$ in diameter; tracheæ few, spiral, annular or with simple pores. 
72. AURANTII DULCIS CORTEX.-Light brown; calcium oxalate in monoclinic prisms 20 to $30 \mu$ in diameter; walls of parenchymatous cells about $4 \mu$ thick.

\section{$\gamma$ In Raphides.}

73. SCILLA.-Light yellow; calcium oxalate mostly in raphides from 0.1 to $I \mathrm{~mm}$. in length; few tracheæ and fragments of epidermis (Fig. 28I, $B$ ).

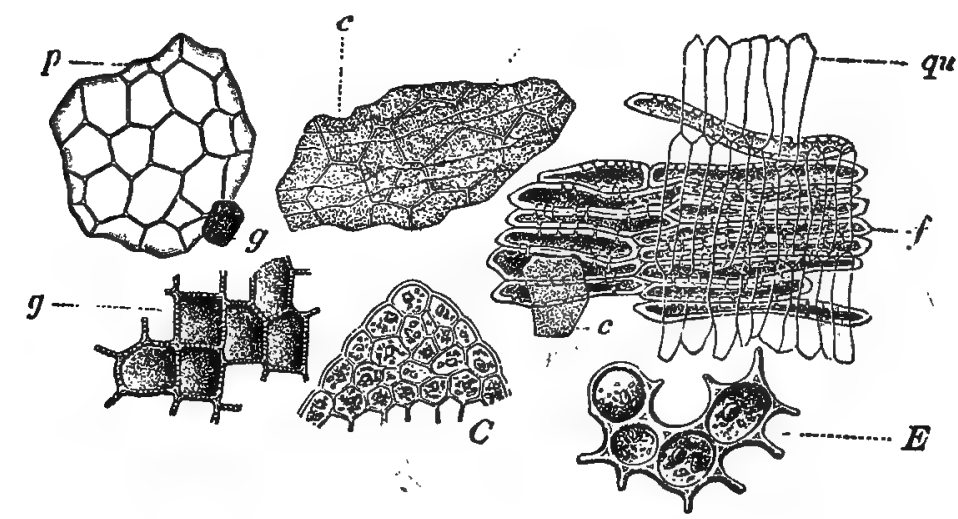

FIG, 293. Ground flaxseed: p, epidermis; c, epidermal cells with broken cutinized layer; $E$, parenchyma cells beneath the epidermis; $f$, short sclerenchymatic fibers; $q u$, colorless cells beneath the sclerenchymatic fibers; $g$, pigment cells with thick porous walls and yellowish-brown contents; $C$, cells of cotyledons containing aleurone grains.-After Moeller.

$b$. Calcium oxalate crystals wanting.

a Sclerenchymatic Cells or Fibers Present.

I. Dark Pigment Cells Wanting.

74. SINAPIS ALBA.—Light yellow (Figs. 294; 302, E, F) ; fragments of seed-coat with mucilaginous epidermal cells; a subepidermal collenchymatous layer of I or 2 rows of cells; a layer of radially elongated palisade or STONE CELLS (forming the socalled "beaker cells"), the walls of the lower part being slightly thickened and polygonal in surface view; two or more inner layers of thin-walled colorless cells; a single layer of cells containing aleurone grains and fixed oil, and some obliterated cells, 
which together constitute the endosperm. The embryo makes up the greater portion of the seed, and the cells contain aleurone grains with fixed oil.

Ground White Mustard or white mustard flour is prepared from the seed of Sinapis alba with or without the removal of a part of the seed-coat (hulls) and the fixed oil. In fact, not infrequently mustard seed-cake is employed.

Prepared Mustard (German Mustard, French Mustard or Mustard Paste) is a paste composed of a mixture of ground mustard (either Sinapis alba or Brassica nigra, or both), salt, spices and vinegar. It should contain not more than 24 per cent.

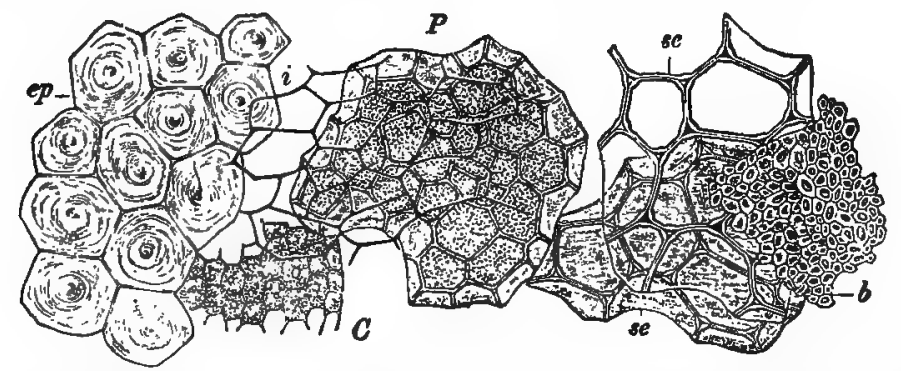

FIG. 294. White mustard. Surface view of the different tissues as seen in the powder: ep, polygonal cells of the outer epidermis showing mucilage lamellæ and the reduced lumen due to swelling of the lamellæ; se, collenchymatic cells beneath the epidermis; $b$, elongated stone cells (so-called beaker cells); $i$, parenchyma cells beneath the stone cells, which are distingtrished from the corresponding layer in a number of other seeds by not containing any pigment; $\mathrm{P}$, cells of endosperm containing aleurone; $\mathrm{C}$, tissue of cotyledon containing aleurone grains and oil.-After Moeller.

of oil; not less than 35 per cent. of protein substances, and not more than 12 per cent. of crude fiber. Prepared mustard is sometimes adulterated with white mustard hulls separated from the seed before expression of the fixed oil.

Allied Plant.-In Indian Colza (Brassica campestris Sarson) the epidermis forms a homogeneous layer, a sub-epidermal layer not being present.

75. PEPO.-Few ellipsoidal starch grains 2 to $4 \mu$ in diameter in cells of outer epidermis and endosperm; characteristic, ellipsoidal, lignified, thick-walled cells, from 45 to $100 \mu$ in diameter and with simple pores; yellow pigment cells of seedcoat; oil and protein grains in embryo. 
76. COLOCYNTHIS.-Light yellow; stone cells isodiametric, slightly thickened, non-lignified, with large simple pores; parenchymatous cells large, thin-walled, with large, simple pores. The powder in which seeds are present contains numerous oil globules, and the outer epidermal cells have reticulated thickenings; the stone cells are nearly isodiametric or irregular, with straight or undulate walls, which are more or less thickened, strongly lignified and with simple pores.

\section{Pigment Cells Present.}

77. SINAPIS NIGRA.-Yellowish-brown (Fig. 295); fragments of seed-coat with mucilaginous epidermal cells; a single layer of thin-walled, unequal sub-epidermal cells; a layer of palisade or stone cells (so-called "beaker cells"), thickened much the same as in Sinapis alba, but of unequal height, giving a section a somewhat reticulate appearance (Fig. 295, B) ; a pigment layer of one or two cells which may be tabular or considerably elongated tangentially and with a brown content which is colored blue with ferric chloride, as in flaxseed. The endosperm and embryo contain fixed oil and aleurone grains, these layers practically making up most of the drug. Starch grains are not present in mustard and the powder should not contain more than ten granules to a milligram.

Ground Black Mustard or Black Mustard Flour is usually prepared from the cake which has been deprived of the hulls and part of the oil. It is customary to mix some of the white mustard with the black mustard, it being supposed that the excess of the ferment in $S$. alba will change the unconverted glucoside into volatile oil of mustard. It is likely, however, that the enhanced quality of the product is due to the pungent and non-volatile character of the oil in white mustard.

Mustard Paste (see Sinapis alba, No. 74) is sometimes adulterated with starches. At one time this was considered to be necessary on account of the pungency of the drug.

Allied Plants.-In Russian or Sarepta Mustard (Brassica Besseriana) the sub-epidermal cells are scarcely apparent and the stone cells are somewhat triangular on surface view. In Charlock 
seeds (Brassica Sinapistrum) the stone cells contain a brown pigment which is colored deep red on treatment with chloral hydrate, particularly if the preparation is heated.

78. FCENUM GRÆCUM (FENUGREEK).-The dried, ripe seeds of Trigonella Fonum-gracum (Fam. Leguminosæ), an herb which is cultivated in Southern Europe and in tropical and sub-tropical Asia and Africa. The seeds are oblong, flattened, about $3 \mathrm{~mm}$. long and broad and $2 \mathrm{~mm}$. thick; brownish-yellow, with a diagonal groove, otherwise nearly smooth; they are hard, and have a peculiar odor and bitter, mucilaginous taste. Fenugreek contains 22 per cent. of proteids; 28 per cent. of mucilage
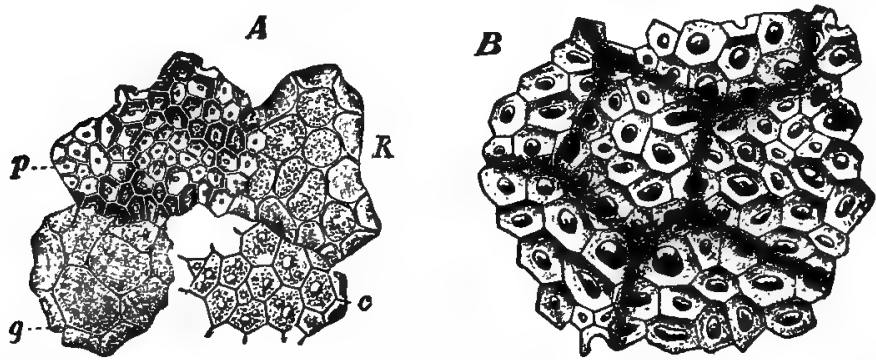

FIG, 295. Black mustard. A, surface view of some of the characteristic cells seen in the powder: p, elongated stone cells (beaker cells), beneath which is the pigment layer $(g) ; K$, endosperm cells containing aleurone; $c$, cells of cotyledon containing aleurone and oil. B, enlarged surface view of the stone cells, showing a shadow'-like reticulum composed of broad lines which appearance is due to the fact that some of the cells are higher than others.-After Moeller.

(in the cells of the endosperm); O.I3 per cent. of trigonelline (isomeric with pyridine-betaine); 0.05 per cent. of choline; and an odorous hydrocarbon.

POWDER.-Yellowish-brown; an outer epidermal layer of mucilage cells beneath which occur I to 3 layers of radially elongated stone cells with a triangular lumen and thick, porous walls. As seen in transverse section the stone cells are polygonal in outline and have simple, narrow, and distinct pores; beneath the latter is a layer of broad, thick-walled cells with large, radiate, simple pores; the endosperm consists chiefly of mucilage cells with wavy mucilaginous inner walls and a single layer of small aleurone cells; the embryo consists of yellowish cells containing aleurone grains. 
79. LINUM (Linseed or Flaxseed Meal).-Lemon-yellow (Figs. 99, $A$; I84; 293); fragments of seed-coat with mucilaginous epidermal cells; a sub-epidermal tissue composed of two rows of yellowish cells with rather large intercellular spaces; a layer of SCLERENCHYMATOUS FIBERS, which are IOO to $250 \mu$ long and about $10 \mu$ in diameter and with numerous simple pores; several layers of obliterated cells; and a layer of pigment cells which are more or less tabular or polygonal, tangentially elongated and with a reddish- or yellowish-brown pigment, which is colored dark blue with ferric chloride. The endosperm is made up of 2 to 6 layers of cells containing oil and difficultly distinguishable protein grains. The embryo contains considerable oil and large aleurone grains to to $20 \mu$ in diameter, the crystalloids of which can be more readily discerned on treating the material first with chloroform and then mounting it in iodine solution. Flaxseed does not contain starch and the commercial product should not show more than io starch grains to a milligram of powder; it should yield not less than 30 per cent. of a saponifiable oil, and not more than 3.5 per cent. of ash.

Ground flaxseed is sometimes infested by maggots. In order to obviate this it should be recently prepared and carefully preserved in tin cans with the addition of a few drops of chloroform.

Allied Plant.-In False Flax (Camclina sativa) of Europe, the sclerenchymatous fibers are replaced by broad, short stone cells, and the epidermal cells on the addition of water eject a central column of mucilage.

8o. CYDONIUM.-Yellowish-red or reddish-brown; fragments of seed-coat with polygonal, mucilaginous epidermal cells, the walls of which are readily stained with methylene blue; a number of rows of sclerenchymatous fibers with strongly thickened walls and brown contents; several layers of elongated, thinwalled cells resembling the "tube cells" in cereals; a colorless layer with minute starch grains; and an inner epidermis, the cells of which contain a brown pigment. The perisperm consists of several layers of more or less obliterated cells. The outer layers of the endosperm, as well as the cells of the embryo, contain aleurone grains and a fixed oil. The structure of quince seed resembles quite closely that of pear and apple seeds. 


\section{$\beta$ Sclerenchymatic Tissue Wanting.}

I. Pollen Grains Numerous.

8r. ARNICÆ FLORES.-Yellowish-brown; pollen grains spherical, with numerous centrifugal projections, 3-pored, 25 to 35 $\mu$ in diameter; non-glandular hairs of three kinds-either unicellular, 5- or 6-celled or consisting of a pair of united unicellular hairs with numerous pores on the dividing wall; glandular hairs of three kinds-either with a large unicellular stalk and unicellular glandular head, or with a stalk of a single row of 4 cells and a I-celled glandular head, or a stalk of a double row of 5 cells and a 2-celled glandular head; pappus consisting of a multicellular axis with unicellular branches (Figs. II9, $B ; 24 \mathrm{I}$ ).

82. SAMBUCUS.-Starch grains not present; pollen grains numerous, spherical or elliptical and nearly smooth, about $18 \mu$ in diameter; numerous fragments composed of broken or whole anthers; corolla with dentate papillæ; oil globules from secretion cells; in calyx some rosette aggregates of calcium oxalate; in flower stalk, large spiral duct $30 \mu$ wide, and parenchyma with brown contents.

83. MATRICARIA.-Pollen grains numerous, nearly spherical or triangular, very spinose, from $I 8$ to $25 \mu$ in diameter; fragments of corolla with glandular hairs; characteristic cells of anther; stigma with papillæ; peculiar ladder-like cells of wall of akene; sclerenchyma fibers of involucral scales.

\section{Pollen Grains Few.}

84. CALENDULA.-Bright yellow (Fig. 296, $B$ ) ; characteristic tissue of petals containing oily drops; few pollen grains; colored brownish with sulphuric acid.

85. CROCUS.-Orange-red (Fig. 296, $A$ ) ; glycerin mount of deep orange color; few, nearly smooth, nearly spherical pollen grains, 85 to $100 \mu$ in diameter; papillæ of stigma; coloring principle soluble in water but not in fatty oils, being the reverse in capsicum; with sulphuric acid fragments become blue immediately.

86. ANTHEMIS.-Non-glandular and glandular hairs; spherical, prickly pollen grains about $30 \mu$ in diameter, which are 
not usually very numerous; papillæ of corolla and stigma; sclerenchyma fibers Io $\mu$ wide, the walls of which are very much thickened; small rosette aggregates of calcium oxalate sometimes present; characteristic cells of anther.

A

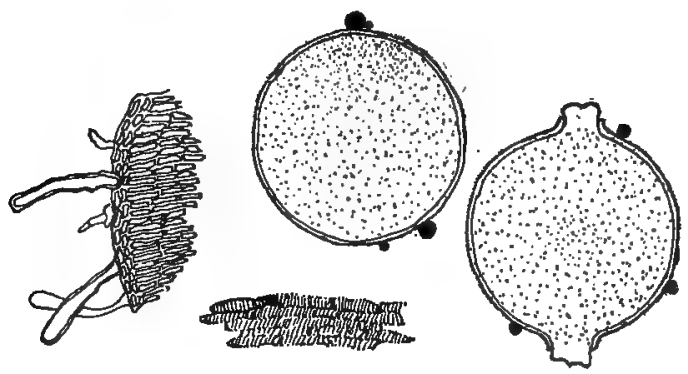

B.
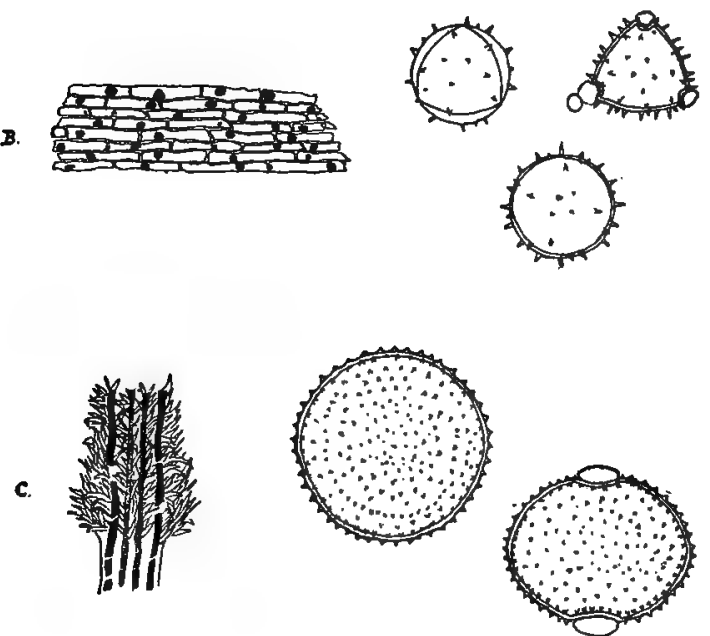

F1G. 296. A, Crocus (Spanish saffron) showing two spherical pollen grains, a fragment of stigma with papille, and fragment of an anther: B. Calendula showing 3 spinose pollen grains and fragment of corolla, the cells of which contain oil-like globules; C, Carthamus (so-called American saffron) showing 2 slightly spinose pollen grains and a fragment of the corolla with brown laticiferous vessels and numerous unicellular hairs.-After Weakley.

87. CHIRATA.-Dark yellow; tracheæ spiral, scalariform or with simple pores; sclerenchymatous fibers long, narrow, thickwalled, more or less lignified, and with oblique pores; parenchymatous cells of pith large, slightly lignified, and with numerous 
simple pores; pollen grains oblong or ellipsoidal, very prickly, about $35 \mu$ in diameter; collenchymatous cells with yellowishbrown resin and tannin masses.

\section{Pollen Grains Wanting. \\ * Fibrovascular Tissue Present.}

88. LAPPA.-Light yellow; parenchymatous cells with irregular crystalloidal masses of inulin; tracheæ few, reticulate, sometimes associated with few narrow sclerenchymatous fibers.

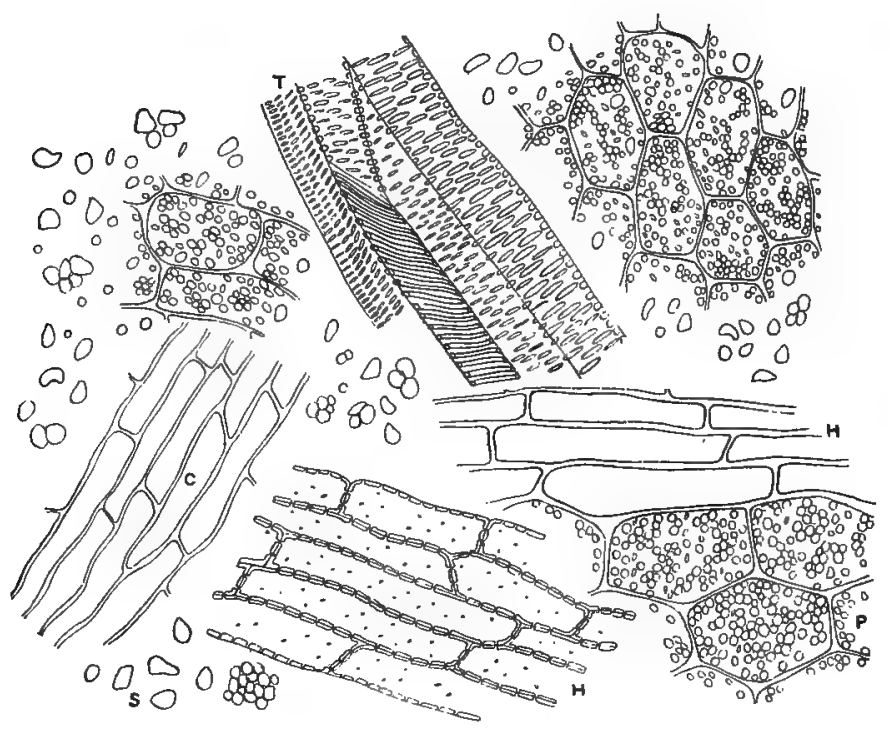

FIG. 297. Aspidium: P, parenchyma containing starch grains; S, starch grains; $T$, tracheæ; $H$, hypodermal cells with thickened walls and simple pores, $C$, yellow, thickwalled cells of chaff.

89. SENEGA.-Dark yellow; odor penetrating; slightly sternutatory; sclerenchymatous fibers thick-walled, non-lignified, with oblique simple pores; tracheæ short, lignified, with simple and bordered pores; medullary-ray cells somewhat lignified, with large simple pores. Quillaja (Figs. 281, $C$; 300, $G ; 315$ ) is distinguished from senega by having large monoclinic pyramids of calcium oxalate, starch and numerous lignified bast fibers and stone cells. 
90. ASPIDIUM.-Light brown or light greenish-brown (Figs. 277a ; 285, B; 297) ; starch grains numerous, ellipsoidal, ovoid, oblong and irregularly shaped, varying in length from 2 to I8 $\mu$; numerous small oil globules seen in chloral mounts; trachex long and with scalariform and reticulate thickenings, the cells being 25 to $75 \mu$ in width. The tracheæ are colored reddishviolet on the addition of concentrated sulphuric acid, the reaction resembling that of lignified cells with phloroglucin; few reddishbrown epidermal cells are present, and the strongly lignified cells
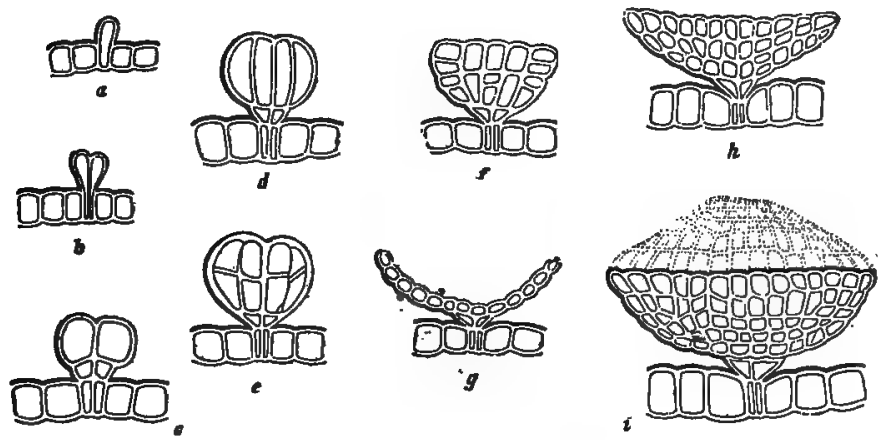

FIG. 298. Lupulin: $a-h$, successive stages in the development of the glandular hairs on the bracts and floral envelopes of Humulus; $g$, longitudinal section through a mature hair as seen at $h ; i$, glandular hair with the cuticle raised due to the accumulation and pressure of the oily secretion beneath it.-After Holzner.

of the hypodermis resemble the libriform cells in higher plants. Many of the cells of the parenchyma contain nuclei which may be differentiated by the use of iodine green or methyl green.

\section{** Fibrovascular Tissue Wanting.}

9r. CAMBOGIA.-Bright yellow; sternutatory; containing few or no starch grains. Not more than 25 per cent. should be insoluble in alcohol, and the ash should not be more than 3 per cent. (p. 648).

92. LUPULINUM.-(See No. 222.)

93. LYCOPODIUM.-Light yellow; spores tetrahedral, delicately reticulate, 25 to $40 \mu$ in diameter (Fig. $278 \mathrm{~b}$ ). 
II. FEW OR NO FRAGMENTS OF VEGETABLE TISSUE.

$A$. GIVING OFF ODOR OF SULPHUR

DIOXIDE ON HEATING.

94. SULPHUR LOTUM.-In small chain-like masses in glycerin mounts.

95. SULPHUR PRACIPITATUM.-Small rounded masses in irregular groups in glycerin mounts.

B. NO ODOR OF SULPHUR DIOXIDE WHEN HEATED.

a. NEARLY COLORLESS IN GLYCERIN MOUNT.

96. MASTICHE.-Transparent, irregular masses. (See p. 645.)

b. YELLOWISH IN GLYCERIN MOUNT.

a Containing Oil Globules.

97. SCAMMONIUM.-Irregular masses. (See p. 656.)

\section{$\beta$ Transparent or Translucent.}

98. COLOPHONY.-Irregular masses, soluble in cold alcohol (95 per cent.) forming a straw-colored liquid, which becomes milky-white on addition of water; on heating fragments of resin in water they melt, run together and form a sticky mass.

99. SANDARAC.-Almost insoluble in alcohol (95 per cent.), the solution remaining almost colorless; the fragments do not melt when heated with water. (See p. 8I.)

IOo. ALOE (CAPE).-In glycerin mount some fragments are conchoidal; the particles become clear and dissolve, leaving a few colorless lens-shaped or fine acicular crystals. The latter are more abundant in Barbadoes aloes. (See p. 664.)

\section{$\gamma$ More Opaque.}

ror. AMMONIAC--Irregular, faint yellow, opaque masses, made up of small, whitish or grayish particles. 
I02. CAMBOGIA.-Irregular, bright yellow masses, made up of small yellow particles (p. 648).

\section{POWDERS OF A BROWNISH COLOR.}

This group includes all those powdered drugs which have a light brown (raw sienna or raw umber), dark brown (Vandyke brown), blackish-brown (sepia), or grayisk-brown color. This is the largest group and includes most of the powdered roots, rhizomes and barks, together with a few flowers, fruits and seeds.

\section{FIBROVASCULAR TISSUE PRESENT.}

\section{$A$. CONTAINING STARCH.}

a. CALCIUM OXAlate CRYSTALS PRESENT.

a In Rosette Aggregates.

I. With Sclerenchymatous Fibers.

* Containing Oil, Resin or Tannin Masses.

I03. BELLADONN A RADIX.-(See No. II7.)

I04. GOSSYPII CORTEX.-Light brown (Figs. 23 I ; 23 Ia; $300, H)$; bast fibers long, narrow, thick-walled, lignified; starch grains somewhat spherical, 4 to $20 \mu$ in diameter, single or compound; parenchymatous cells with irregular yellowish and reddish tannin masses; calcium oxalate crystals rosette-shaped, about $20 \mu$ in diameter.

I05. RUBUS.-Light brown; bast fibers numerous, long, thick-walled, lignified; calcium oxalate in rosette aggregates 25 to $30 \mu$ in diameter; starch grains nearly spherical, 3 to $7 \mu$ in diameter, single or compound.

I06. JUGLANS.-Crystals usually in rosette aggregates I5 to $35 \mu$ or sometimes in monoclinic prisms Io to $15 \mu$, occurring in parenchyma or occasionally in crystal fibers; bast fibers, $30 \mu$ wide and very long; stone cells, 35 to $50 \mu$; oily drops and purplish-brown tannin masses in parenchyma. J. cinerea is distinguished from J. alba and J. nigra in that both of the latter possess numerous crystal fibers containing prismatic or rhombohedral 
crystals. J. nigra has also in the medullary rays rosette aggregates of calcium oxalate. J. regia appears more nearly to resemble $J$. cinerea.

I07. ARALIA NUDICAULIS (American Sarsaparilla).Light brown; rosette aggregates of calcium oxalate varying from 35 to $70 \mu$; spherical starch grains, from to to $I_{5} \mu$; tracheæ with scalariform and reticulate thickenings, also simple and bordered pores; wood fibers long, with slightly thickened walls and simple pores; large oil glands, and brown cork cells.

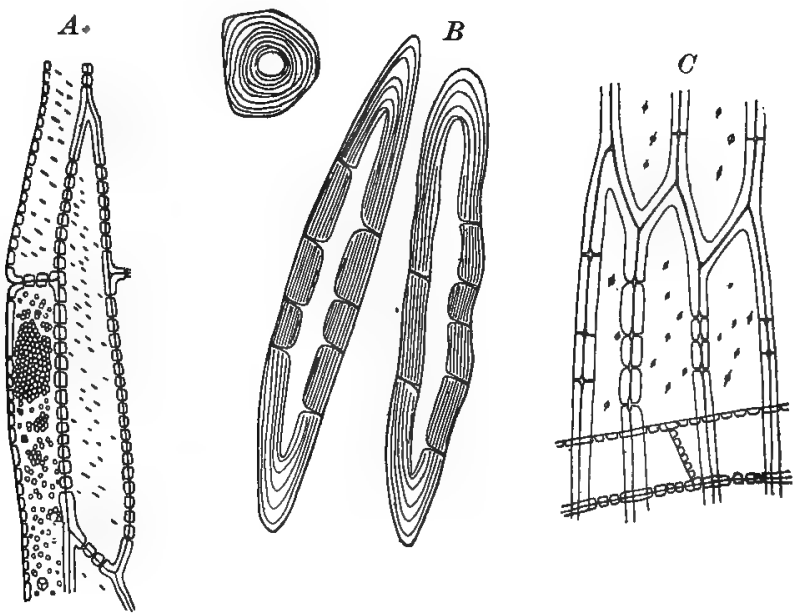

Fic. 299. Several forms of sclerenchymatic fibers: A, intermediate fibers from wood of ipecac showing lignified walls with oblique simple pores and one cell containing starch; B, bast fibers from cinchona showing in transverse section a stratification of the wall, and in longitudinal section a striation of the walls; $C$, longitudinal section of quassia showing tracheids with bordered pores and medullary-ray cells.

108. STILLINGIA.--Light brown; sclerenchymatous fibers very long, thick-walled and swelling perceptibly in potassium hydrate solution; starch grains spherical or ellipsoidal, I5 to $30 \mu$ in diameter; secretion cells containing oil, resin and a brown pigment; calcium oxalate crystals rosette-shaped, $35 \mu$ in diameter.

I09. EUONYMUS.-Light brown (Fig. 300, E) ; bast fibers long, thin-walled, non-lignified, the walls frequently modified to mucilage and possessing numerous small, more or less oblique pores, and irregular ends; starch grains spherical, 4 to Io $\mu$ in 
diameter; cork, thin-walled, white; secretion cells with yellowish or brownish masses; rosette aggregates of calcium oxalate, 15 to $20 \mu$ in diameter. The stem-bark as well as the whole twigs of E. atropurpureus are frequently admixed with or substituted for Euonymus.

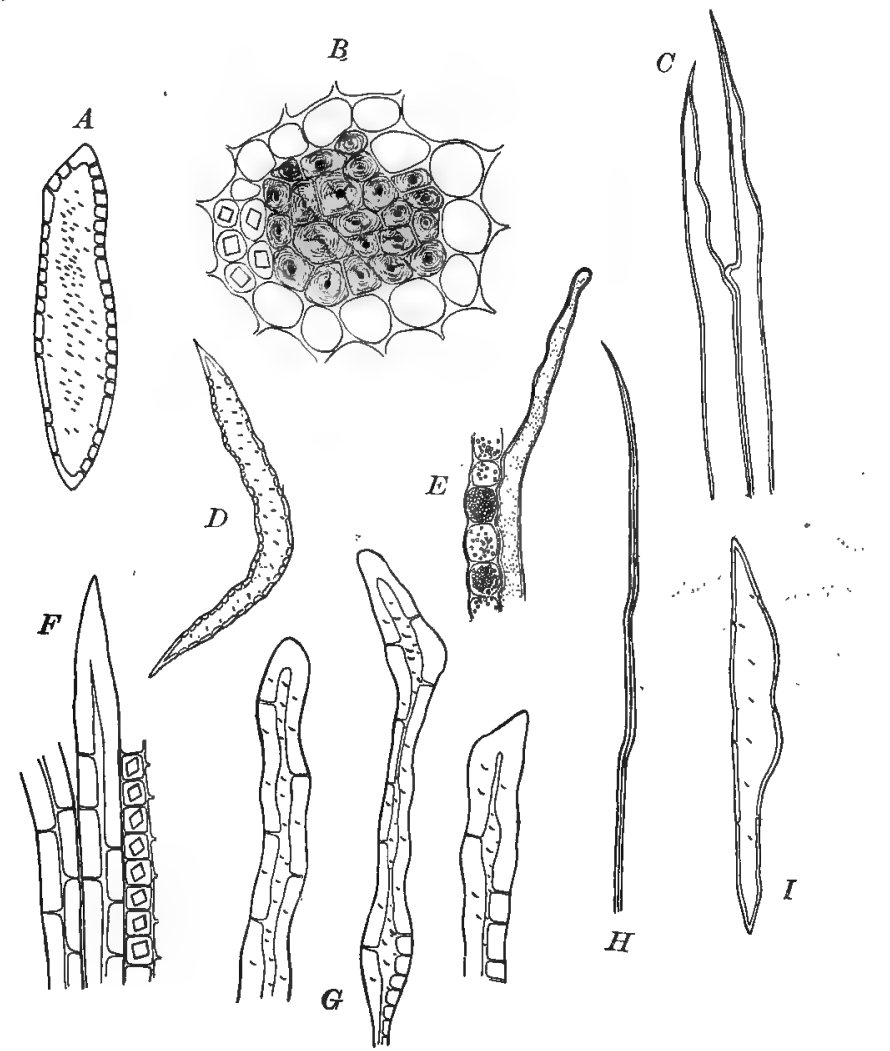

FIG. 300. Various forms of sclerenchymatic fibers: A, intermediate fiber of gentian the walls consisting of cellulose and having simple oblique pores; $B$, transverse section of a group of bast fibers in white oak bark, and a few crystal fibers; C, portions of two bast fibers from krameria; D, sclerenchymatous fiber from leaf of uva ursi; $E$, portion of modified bast fiber of euonymus; F, portions of bast fibers and a crystal fiber of white oak bark

- $G$, portions of sclerenchymatous fibers of quillaja showing unequal thickening; $H$, portion of bast fiber of cotton root bark; I, isolated sclerenchymatous fiber of ginger.

I IO. RUMEX.-Dark brown; calcium oxalate in rosette aggregates from 20 to $35 \mu$ in diameter; starch grains numerous, ellipsoidal or narrowly elongated, from Io to $18 \mu$ in length; stone 
cells occurring beneath the cork cells, 40 to $125 \mu$ in diameter, with walls that are somewhat lamellated, 15 to $20 \mu$ thick and with few simple pores; cork cells light brown; sclerenchymatic fibers wanting; trachex about $100 \mu$ wide, with scalariform and reticulate thickenings of the wall. On mixing the powder with water and adding a solution of one of the alkalies a red color is produced. In Rumex hymenosepalus the parenchyma cells are about $200 \mu$ in diameter, with reddish colored walls and contain numerous spherical or ellipsoidal starch grains from 8 to $15 \mu$ in diameter; calcium oxalate crystals are few or wanting.
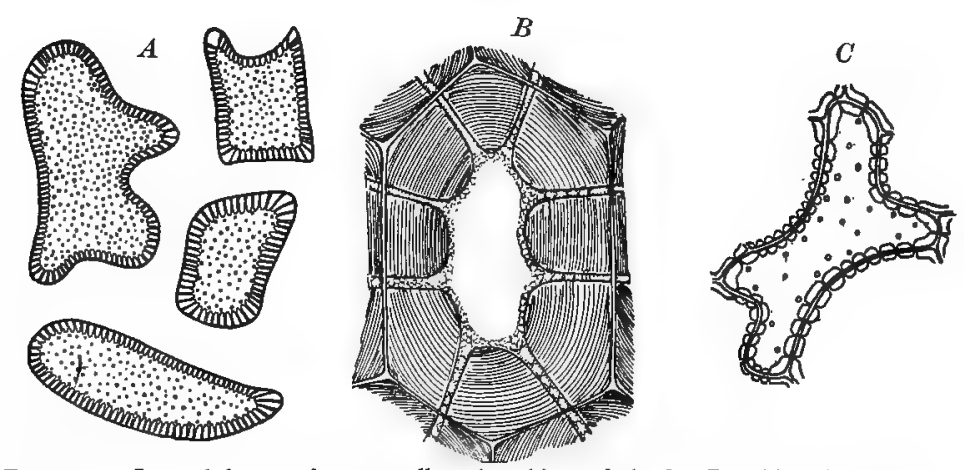

FIG. 30I. Several forms of stone cells: A, white oak bark; B, white cinnamon or canella bark (Canella alba); C, seed-coat of capsicum.

I Ioa. CANELLA (White Cinnamon)--Light brown or light reddish-brown; calcium oxalate in rosette aggregates, from 20 to $50 \mu$ in diameter; starch grains simple or 2 - to 3 -compound, 5 , to Io $\mu$ in diameter; numerous stone cells, about $75 \mu$ in diameter, the inner walls of which are considerably thickened, and with branching pores; sclerenchymatic fibers occasionally present; numerous large oil cells with suberized walls (Fig. 3OI, $B$ ).

** No Resin or Tannin Masses.

I I . ALTH压.-Light brown (Fig. 99, $B$ ) ; sclerenchyma fibers long and not strongly lignified; rosette aggregates of calcium oxalate, about $25 \mu$ in diameter; starch grains somewhat ellipsoidal, io to $20 \mu$ in diameter. 
2. Sclerenchymatous Fibers Wanting.

* Containing Tannin.

$\dagger$ With Oil-Secretion Reservoirs.
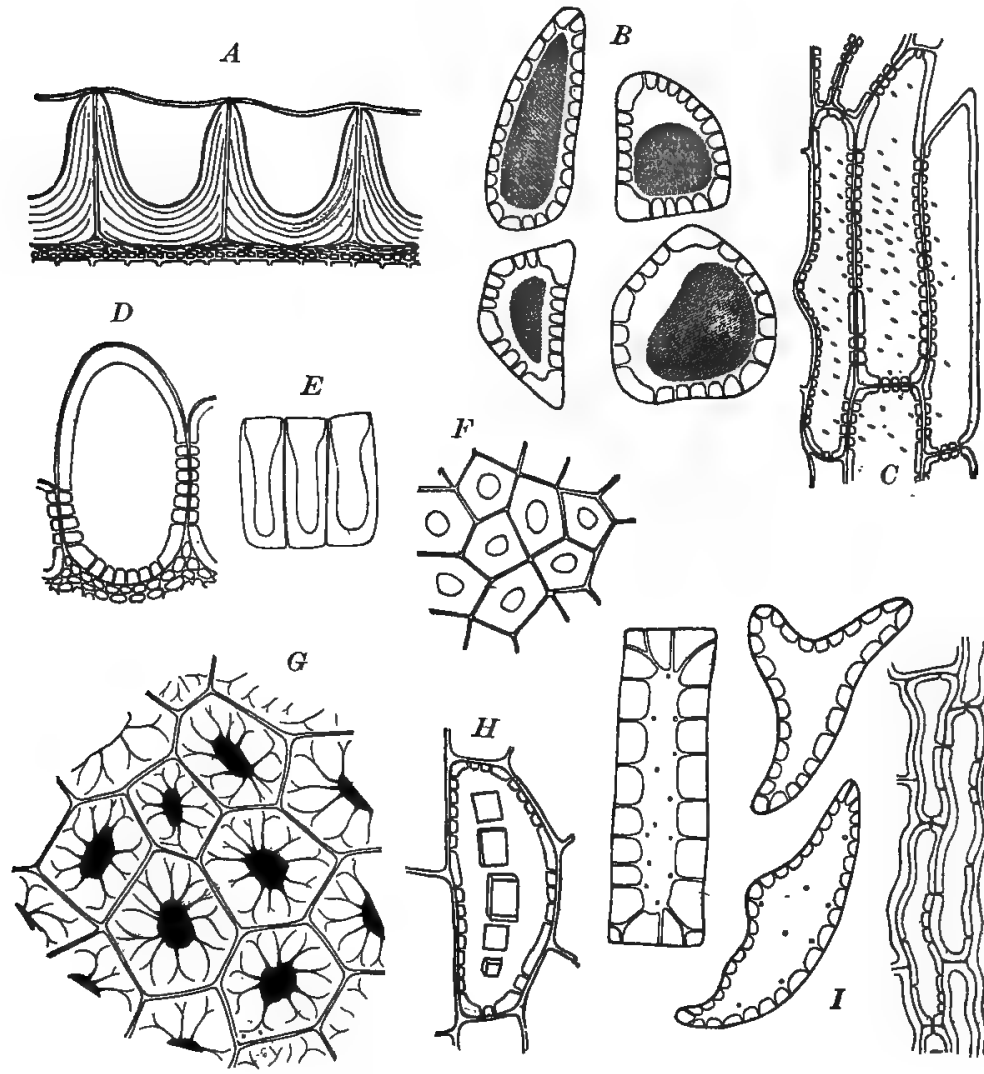

FIG, 302. Various forms of stone cells: A, epidermis of hyoscyamus seeds; B, pericarp of pimenta, containing brownish tannin masses; C, seed-coat of coffee; $D$, seed-coat of almond; $\mathrm{E}$, transverse section of seed-coat of white mustard showing beaker cells; $F$, surface view of beaker cells of seed-coat of white mustard; $G$, transverse section through stone cells of endocarp of olive, the lumen containing air; $H$, a stone cell from the periderm of calumba, containing numerous monoclinic prisms of calcium oxalate; I, various forms of stone cells isolated from pericarp of star anise.

II2. CLOVE FRUIT.-(See No. I73.)

I13. PIMENTA.-Dark brown (Fig. 302, $B$ ); rosette aggregates of calcium oxalate, occasionally in monoclinic prisms, 
about Io $\mu$ in diameter; starch grains somewhat spherical, about Io $\mu$ in diameter, single or 2 - to 3 -compound, each with a distinct cleft at the middle; stone cells nearly isodiametric, thin-walled, with numerous simple pores and branched canals and nearly colorless contents; oil-secretion reservoirs with wine-colored contents; oil globules numerous; parenchymatous cells occasionally lignified, and with irregular reddish-brown tannin masses, which are colored greenish with ammonio-ferric sulphate solution; nonglandular hairs from Ioo to $200 \mu$ long, with very thick walls and narrow lumen, particularly towards the apex.

Allspice stems, which are allways present to a greater or less extent in ground Pimenta have rather characteristic unicellular hairs that are somewhat swollen on one side.

Ground allspice has been adulterated with clove stems (Fig. 3I2), cocoa shells (No. I45), and the endocarp of the olive (Fig. $302, G)$. The presence of CoconNut SHELLS is determined by the yellow stone cells, which have thick yellow walls with branching pores and dark brown contents. The stone cells vary from polygonal and isodiametric cells to cylindrical and wedge-shaped forms that are quite characteristic; fragments of long, thickwalled, porous fibers with accompanying stegmatic cells, each containing a spherical, tuberculated silicious granule, are also present. The dark brown fragments in the powder are not affected by bleaching agents, such as Schulze's macerating solution.

The various spices have been adulterated with the following substances: The hulls of Sinapis alba (see No. 74); walnut shells (Juglans regia) which are distinguished by their colorless stone cells and brown parenchyma; and shells of the Brazil nut (Bertholletia excelsa, Fam. Myrtaceæ) which are identified by the isodiametric stone cells with colorless walls and dark brown contents, and the brown parenchyma.

†† Oil-Secretion Reservoirs Wanting.

II4. GALLA (ALEPPO).-Dark yellow; crystals of calcium oxalate to $\mu$ in diameter; starch grains to to $40 \mu$ in diameter, single or sometimes in groups; stone cells; tannin; crystals of gallic acid. 
II5. GERANIUM.-Dark brown; starch grains somewhat ellipsoidal or ovoid, Io to $15 \mu$ in diameter; rosette aggregates of calcium oxalate, 45 to $70 \mu$ in diameter ; tracheæ annular or scalariform; parenchyma with irregular tannin masses.

I 16. RHEUM.-(See No. 49.)

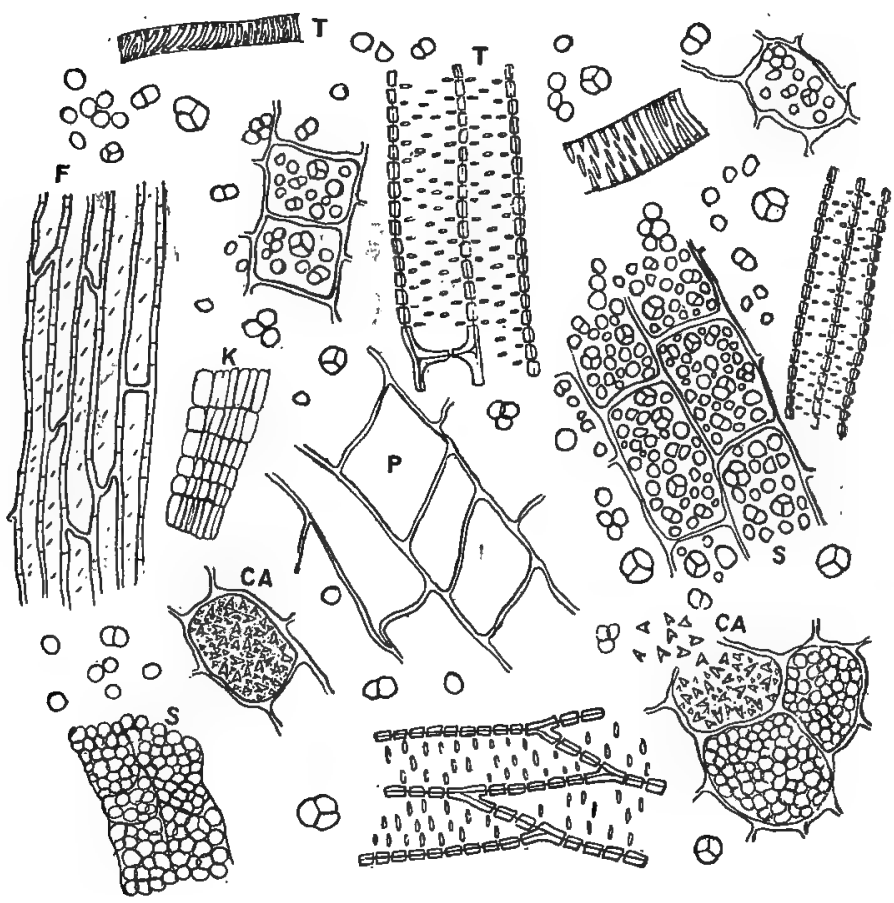

FIG. 303. Belladonna root: $S$, parenchyma cells containing starch: CA, cells containing cryptocrystalline crystals of calcium oxalate; $K$, cork; $T$, fragments of trachex with annular markings or simple pores; $P$, parenchyma; $F$, wood fibers with narrow oblique pores.

** Without Tannin.

I 17. BELLADONN E RADIX.-Light brown (Figs. 28I, $D$; 303) ; calcium oxalate in cryptocrystalline crystals; tracheæ few, scalariform or with simple pores; sclerenchymatous fibers relatively few; starch grains numerous, spherical, 5 to $15 \mu$ in diameter (Fig. 200). Scopola closely resembles belladonna root. 


\section{$\beta$ Crystals in Monoclinic Prisms and Pyramids.}

I18. FRANGULA.-(See No. 52.)

I I9. KRAMERIA. - Light brown (Figs. $196 ; 300, C$ ) ; sclerenchymatous fibers peculiarly bent, 0.3 to $0.5 \mathrm{~mm}$. long and I $5 \mu$ thick; calcium oxalate in monoclinic prisms and pyramids about o.I $\mathrm{mm}$. long; starch grains somewhat spherical, 20 to $30 \mu$ in

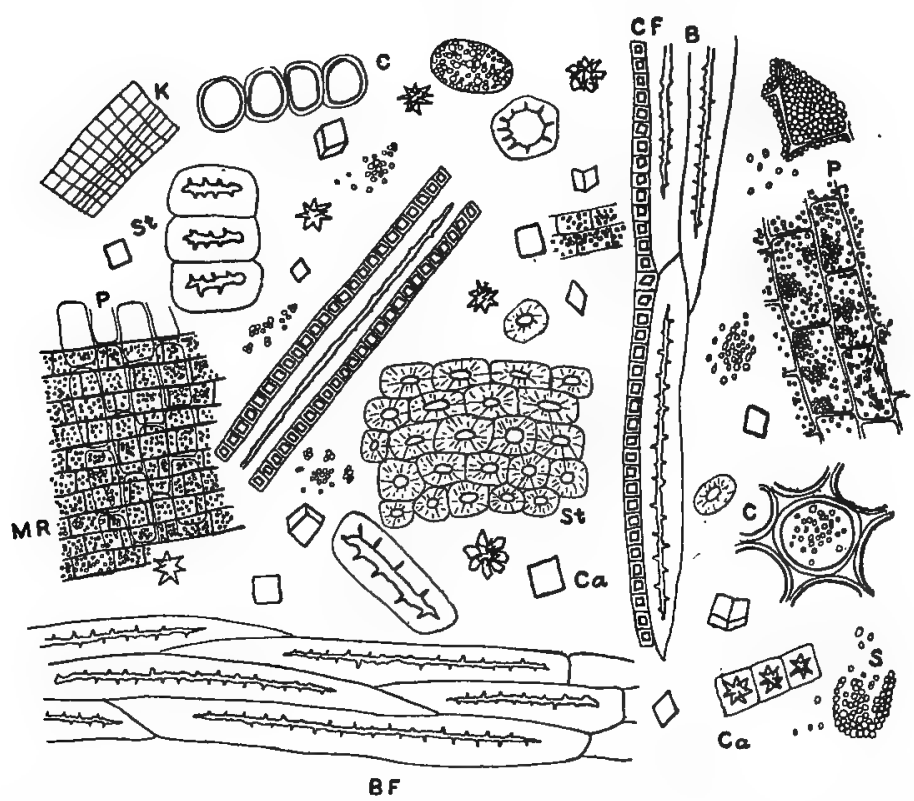

Fig. 304. Rhamnus Purshiana: B, BF, bast fibers; CF, crystal fibers; Ca, Calcium oxalate crystals; $S$, starch grains; $P$, parenchyma; MR, medullary rays; St, stone cells; C, thick-walled parenchyma of outer cortex; $\mathrm{K}$, cork.

diameter, single or 2- to 4-compound. In Savanilla rhatany the sclerenchymatous fibers are 0.5 to $0.8 \mathrm{~mm}$. long and ro to $40 \mu$ wide.

An alcoholic extract of Peruvian rhatany gives with alcoholic lead acetate a reddish-brown precipitate and a light-brown filtrate.

- The tincture of Savanilla rhatany gives a purplish precipitate and a colorless filtrate with this reagent.

I20. RHAMNUS PURSHIANA.-(See No. I23.) 
I21. JUNIPERUS.-Calcium oxalate in monoclinic prisms about $30 \mu$ in diameter, occurring in stone cells, which are about $60 \mu$ in diameter and with walls that are about I $5 \mu$ in thickness; a small number of nearly spherical starch grains from 5 to $7 \mu$ in diameter; fragments with oil glands and brown pigment cells.

\section{$\gamma$ Crystal Fibers Present}

I. Sclerenchymatous Fibers Strongly Lignified.

* Colored Reddish With Alkalies.

122. FRANGULA.-(See No. 52.)

123. RHAMNUS PURSHIANA.-Light brown (Figs. 229, $A$; 304); bast fibers long, much thickened, lignified; stone cells very thick-walled, about $50 \mu$ in diameter; crystal fibers containing monoclinic crystals of calcium oxalate; calcium oxalate also in rosette aggregates or monoclinic prisms 5 to $20 \mu$ in diameter; starch grains spherical, about $4 \mu$ in diameter; parenchymatous cells with yellowish contents colored red with alkalies.

** Not Colored Reddish With Alkalics.

124. QUERCUS ALBA.-(See No. I82.)

I25. PRUNUS VIRGINIANA.-Light brown; bast fibers and stone cells with much thickened and strongly lignified walls; crystal fibers containing monoclinic prisms and rosette aggregates of calcium oxalate 20 to $30 \mu$ in diameter; starch grains nearly spherical, 3 to $4 \mu$ in diameter.

126. MYRICA CERIFERA.-Greenish-brown (p. 250); crystals in rosette aggregates about $45 \mu$ in diameter, or in monoclinic prisms from $I_{5}$ to $20 \mu$ in diameter; crystal fibers, accompanying long bast fibers, the latter being Iоo $\mu$ in diameter and with walls about $25 \mu$ in thickness; starch grains about $7 \mu$ in diameter, also occurring in 2- to 4-compound grains.

I27. PULVIS GLYCYRRHIZÆ COMPOSITUS.-Tissues of glycyrrhiza (Figs. I04; 204; 282, B) and senna (Figs. 263; $284, D$ ) ; granules of sulphur (see No. 94); crystals of sugar, and masses of manna. 


\section{Sclerenchymatous Fibers Not Strongly Lignified.}

128. CALAMUS.-Light brown (Fig. IOI, $B$ ); tracheæ spiral, scalariform or reticulate; sclerenchymatous fibers slightly lignified, with oblique simple pores; starch grains nearly spherical, 4 to $8 \mu$ in diameter; crystal fibers containing monoclinic crystals of calcium oxalate; oil-secretion cells with suberized walls; contents of parenchymatous cells colored ruby-red by a strong alcoholic solution of vanillin and hydrochloric acid. The powder of the peeled rhizome is less aromatic, and cells of the epidermis and cork, and crystal fibers are wanting. The yield of aqueous extract should be between 18 and 20 per cent. Powdered calamus has been reported as being admixed with as much as 30 per cent. of diatomaceous earth.

I29. ULMUS.-Light brown (Fig. 99, C) ; bast fibers thinwalled, non-lignified; crystal fibers containing monoclinic prisms of calcitm oxalate to to $25 \mu$ in diameter; starch grains spherical, 5 to $10 \mu$ in diameter.

Ground elm bark has been reported to be adulterated with wheat starch or wheat middlings, but this does not seem to be the case. The small quantity of wheat starch which is sometimes detected is considered to be in the nature of an accidental contamination. The usual adulterant is a bark from which the mucilage has been extracted or at least barks poor in mucilage are sometimes found on the market. Good elm bark gives a rather thick mucilage on digesting one part of the ground bark in 40 to 45 parts of cold water.

\section{$\delta$ Calcium Oxalate in Raphides.}

I30. CINNAMOMUM (Saigon),-Dark brown; bast fibers much thickened; stone cells nearly isodiametric, more or less thickened, with numerous pores; calcium oxalate in raphides about $5 \mu$ long; starch grains somewhat spherical, 7 to I5 $\mu$ in diameter, single or 2- to 4-compound; parenchyma with irregular tannin masses; oil-secretion cells. Cassia Cinnamon has fewer cork cells and more sclerenchymatous cells and fibers. Ceylon Cinnamon has no cork cells and the stone cells are more elongated, irregular in outline and unevenly thickened (Figs. 224, 225, 305). 
The powder of Cassia buds (flowers of Cinnamomum Cassia) is characterized by numerous thick-walled, irregularly curved simple hairs; fragments of reticulate and scalariform tracheæ; and broad, blunt bast fibers.

I3I. SARSAPARILLA.—Dark brown (Figs. 193, I94); sclerenchymatous fibers very thick-walled, somewhat lignified; tracheæ large, strongly lignified, scalariform, reticulate, and with simple pores; the walls of endodermis and hypodermis variously thickened ; starch grains somewhat spherical, 7 to $20 \mu$ in diameter,

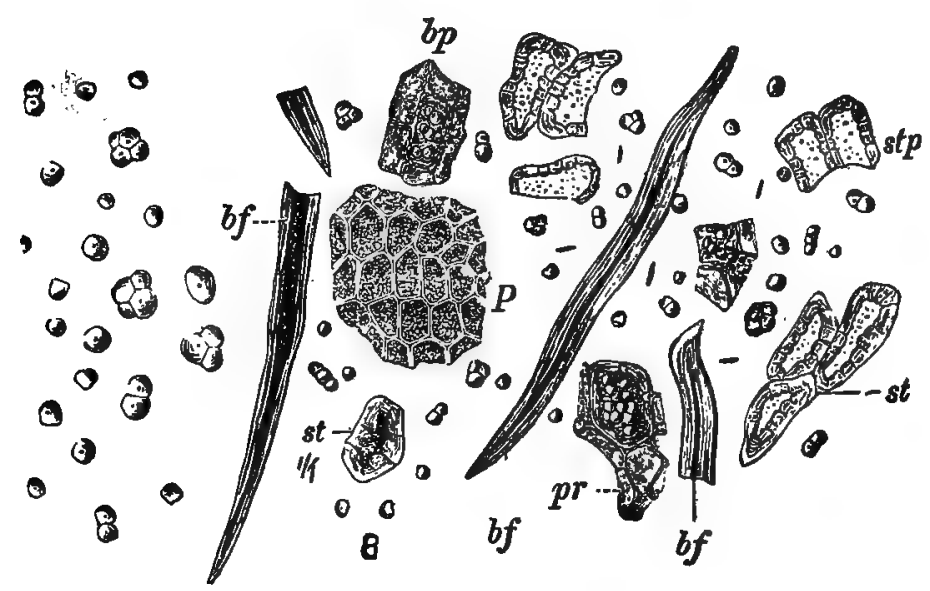

FIG. 305. Cassia cinnamon: st, stp, stone cells; pr, bp, parenchyma containing starch grains; bf, bast fibers; $P$, cork cells with lignified walls. Numerous simple and compound starch grains are shown at the left and among the fragments of tissues.-After Moeller.

single or 2- to 4-compound; calcium oxalate in raphides 6 to $8 \mu$ long. It is distinguished from American Sarsaparilla, yielded by Aralia nudicaulis, in that the latter has rosette aggregates of calcium oxalate 35 to $80 \mu$ in diameter.

I32. CONVALLARIA.-Dark brown (Fig. I I4); calcium oxalate in raphides about $45 \mu$ long; starch grains somewhat spherical, 3 to $\mathrm{I} 2 \mu$ in diameter, single or 2 - to 4 -compound; tracheæ spiral or scalariform; sclerenchymatous fibers long, thinwalled, with simple pores; endodermis with inner walls much thickened. 
I33. CYPRIPEDIUM.-Yellowish or brownish-black; calcium oxalate in raphides about $40 \mu$ long; starch grains somewhat spherical, 2 to $4 \mu$ in diameter, single or compound; tracheæ spiral, scalariform or with simple pores; sclerenchymatous fibers long, thin-walled; parenchyma thick-walled, with numerous simple pores.

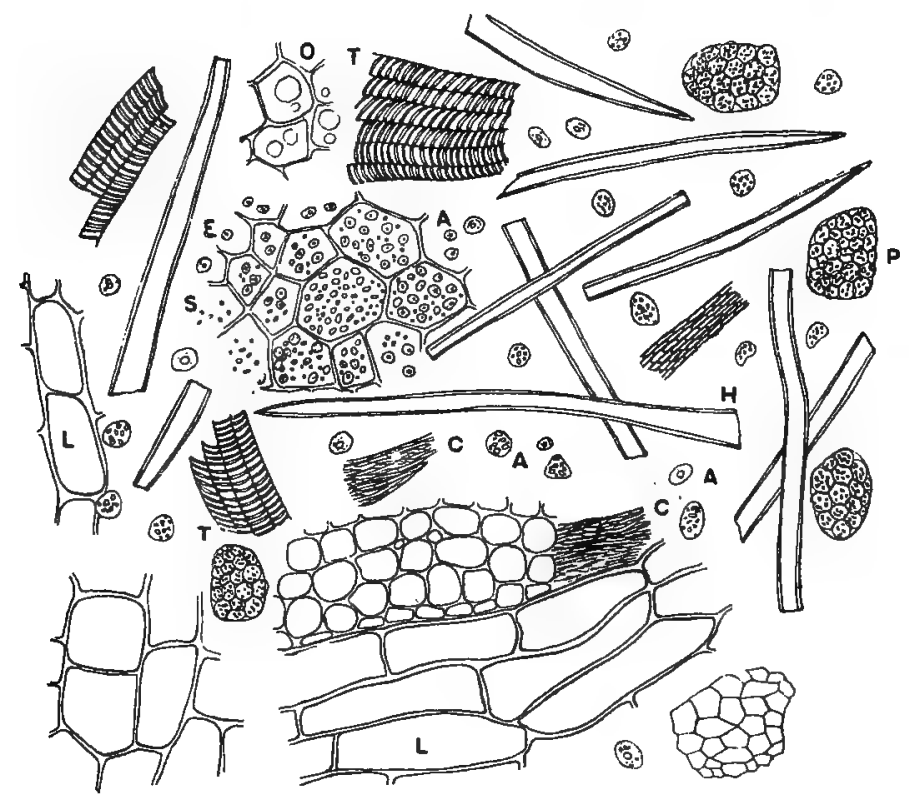

FIG. 306. Strophanthus: $H$, fragments of upper portion of non-glandular hairs; L, basal portion of non-glandular hairs; $E$, cells of endosperm with aleurone grains (A) and starch grains (S); $\mathrm{P}$, parenchyma of cotyledons with aleurone grains; $T$, trachex; C, collapsed cells of seed-coat; A, aleurone grains; O, parenchyma containing oil globules.

\section{I34. VERATRUM VIRIDE.-(See No. 59.)}

135. HYDRANGEA ARBORESCENS.-Raphides $200 \mu$ long; starch grains 4 to I $5 \mu$ in diameter; numerous sclerenchyma fibers with yery thick walls, narrow lumen and simple pores.

є Calcium Oxalate in Cryptocrystalline Crystals.

I36. BELLADONNÆ RADIX.-(See No. I17.)

I37. CINCHONA.-(See No. I52.) 


\section{b. Calcium ox.lLate CRystals Wanting.}

a With Non-glandular Hairs.

I38. STROPHANTHUS.-Dark brown (Figs. I86; 284, $A$; 306) ; epidermal cells modified to long, I-celled, non-lignified hairs, containing, in $S$. Kombe, colorless or yellowish-green granules and in S. hispidus, dark brown grantles; parenchyma with fixed oil and aleurone grains; starch grains ellipsoidal, $4 \mu$ in diameter.

\section{$\beta$. Non-glandular Hairs Wanting.}

I. Sclerenchymatous Fibers Present.

* Trachec Numerous.

$\uparrow$ Starch Grains 2 to $5 \mu$ in Diameter.

I39. CIMICIFUGA.-Brownish-black (Fig. 217); tracheæ large, scalariform or with bordered pores; sclerenchymatous fibers numerous; starch grains nearly spherical, 3 to $5 \mu$ in diameter; cells of periderm thick-walled and with reddish-brown contents.

I40. CYPRIPEDIUM.-(See No. 133.)

I4I. LEPTANDRA.-Dark brown; tracheæ scalariform or with simple pores; sclerenchymatous fibers narrow, thick-walled, with numerous simple pores; starch grains nearly spherical, 2 to 4 $\mu$ in diameter; parenchymatous cells nearly isodiametric or elongated, containing starch grains and a brownish-black pigment.

I42. SPIGELIA.-Brownish-black; tracheæ few, lignified, spiral or with simple pores; sclerenchymatous fibers long, narrow, lignified, with simple, oblique pores ; starch grains spherical, about $4 \mu$ in diameter. A not unusual substitute for spigelia is the rhizome and roots of Ruellia ciliosa (Fig. 22I) (No. 30).

If Starch Grains 5 to I5 or $20 \mu$ in Diameter.

r43. ZINGIBER.-African and Calcutta ginger (p. 488) are light brown in color, and the tissues resemble those in Jamaica ginger (No. 6I).

I44. TONKA. - The parenchyma cells of the cotyledons contain numerous spherical starch grains from 4 to $9 \mu$ in diameter; 
large, irregular aleurone grains 20 to $35 \mu$ long, and considerable fixed oil. The easily separable seed-coat contains rather characteristic stone cells, which on surface view are polygonal and possess rather porous, somewhat thickened walls and brownish-red or brownish-black contents. Beneath the stone cells is a layer of broad, irregularly-shaped cells with rather thick walls and numerous intercellular spaces.

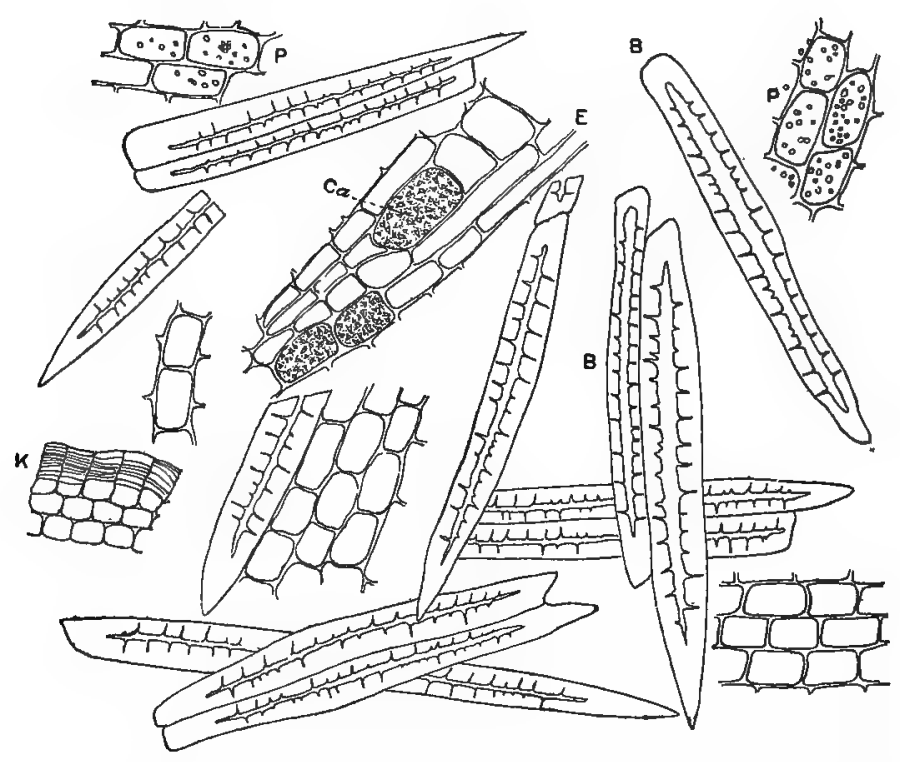

Fig, 307. Cinchona; B, bast fibers; Ca, cryptocrystalline crystals of calcium oxalate; $P$, parenchyma containing few small spherical starch grains; $E$, sieve; $K$, cork.

I45. COCOA SHELLS.-Little or no starch; oil globules; characteristic, brownish, adhesive fragnents, possessing more or less hexagonal epidermal cells; peculiar, small, tabular mucilage cells and a layer of nearly isodiametric stone cells ro by Io $\mu$, the walls of which are $4 \mu$ thick (Fig. 308).

I46. APOCYNUM.-Dark brown (Fig. 202); sclerenchymatous fibers numerous; fragments of laticiferous vessels yellowish; starch grains somewhat spherical, 7 to I $5 \mu$ in diameter. In Apocynum androsamifolium small groups of stone. cells occur. 
I47. CONVALLARIA.-(See No. $\left.{ }^{132 .}\right)$

148. SARSAPARILLA.-(See No. I31.)

I49. SUMBUL.-Dark brown; sclerenchymatous fibers numerous, narrow and lignified; trachere short, lignified, scalariform, or with simple or bordered pores; oil and resin-secretion reservoirs; starch grains nearly spherical, 4 to $15 \mu$ in diameter.

I 50. VALERIANA.-Brownish-black; tracheæ strongly lignified, scalariform or with simple pores; sclerenchyniatous fibers thin-walled, more or less lignified, with numerous simple pores; starch grains nearly spherical, 7 to I5 $\mu$ in diameter; stone cells nearly isodiametric, with very thick walls and numerous simple pores.

I51. METHYSTICUM (KAVA-KAVA),--Starch grains numerous, spherical, about $35 \mu$ in diameter, often with radial clefts or triangular fissures at the center; yellowish resin and oil cells; sclerenchyma fibers narrow, with thin, strongly lignified walls.

$$
\text { ** Trachece Few or None. }
$$

I52. CINCHONA.-Light brown (Figs. 227; 299, B; 307; $307 a)$; bast fibers spindle-shaped, thick-walled, strongly lignified. with numerous simple pores; starch grains nearly spherical, 4 to I $2 \mu$ in diameter; parenchymatous cells with reddish-brown tannin masses.

153. CINNAMOMUM.-(See No. I30.)

I 54. COFFEE.-Brownish; characteristic fragments of seedcoat made up of parenchyma and spindle-shaped stone cells 0.2 to I $\mathrm{mm}$. long and I 5 to $50 \mu$ wide, the latter occurring singly or in pairs with more or less thickened, porous walls. The cells of the endosperm have brownish-colored, porous walls, to $\mu$ thick, and contain oil, aleurone and starch. Ground coffee varies in the fineness of the particles, which are lighter than water and float on the surface. This is an important distinction between genuine coffee and the "substitutes" or "imitation" products which sink on being mixed with water (Fig. 302, C).

Coffee Hulls, also known as Sultan or Sacca coffee, are sometimes substituted for coffee. These consist of the outer layer of the pericarp and are characterized by a layer of some- 
what curved, elongated cells which lie close to one another (palisade cells), and the walls of which are mucilaginous and stained by safranin and methylene blue, the yellowish protoplasmic contents not being affected.

Carob Bean (Ceratonia Siliqua, Fam. Leguminosæ) in a ground condition is not only used as cattle food, but has been

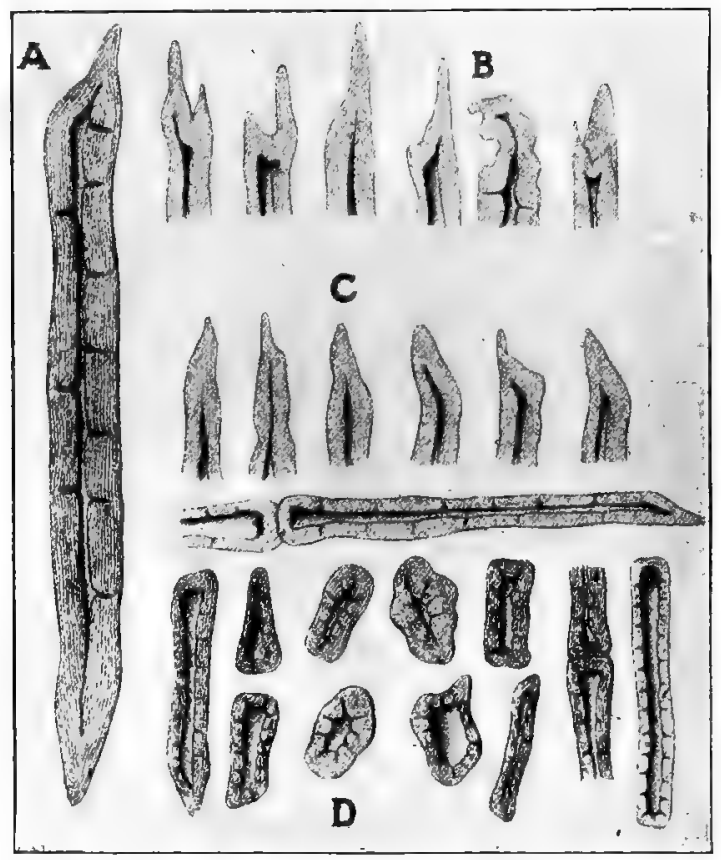

Fig. $307 \mathrm{a}$. A, C bast fibers of the bark of Cinchona succirubra; $\mathrm{B}$, bast fibers of the bark of Cinchona Ledgeriana; D, stone cells of Cuprea bark (Remijia peciunculata).-After Oesterle and Tschirch.

substituted for coffee. It is distinguished by the sclerenchymatic and crystal fibers, and the cells of the mesocarp, whi.h contain reddish-brown, spiral masses that are colored a deep violet or blue on heating with solutions of the alkalies.

Coffee Substitutes.-The following are commonly employed: Chicory (see No. 193); a number of the cereals and cereal products (see Nos. 236 to 245 ); and the seeds of soja beans; lupines, peas, beans and other leguminous seeds. Of the 
latter may be mentioned the Mogdad Coffee, the seeds of Cassia occidentalis which are used in various tropical countries. The seeds are free from starch and the cells of the endosperm are thick-walled and contain a brown proteid substance.

Of COFFEE ADULTERANTS the following may be mentioned: Ground ivory nut (Phytelephas macrocarpa, Fam. Palmæ), which is distinguished by the thick-walled cells of the endosperm; and the ground kernels of the acorns of several species of Quercus, which are readily identified by the elongated, more or less swollen, distorted starch grains that have a prominent elongated cleft in the middle.

I55. SASSAFRAS.-Light brown (Fig. 236); bast fibers thick-walled, lignified, usually single or not more than two or three together; starch grains 7 to $20 \mu$ in diameter, single or 2- to 3 -compound; parenchymatous cells with irregular masses of tannin; oil globules numerous. The stem bark contains groups of bast fibers and stone cells, and the parenchymatous cells contain chloroplastids.

2. Sclerenchymatous Fibers Wanting.

* Stone Cells Present.

$\dagger$ Giving Tannin Reaction with Ferric Salts.

156. CACAO.-Reddish-brown (Fig. 308); consisting chiefly of protein grains, oil and starch (grains 4 to $8 \mu$ in diameter); fragments with brownish or purplish-brown contents (cacao red); fat crystals in little prisms or needles; few fragments of seed-coat consisting of hexagonal epidermal cells, a peculiar mucilage layer of small tabular cells and a layer of nearly isodiametric stone cells Io by Io $\mu$, the walls of which are $4 \mu$ thick.

Cacao starch grains show a tendency to cohere and on "gently heating a section in water, after removal of part of the oil with ether or chloroform, the compound grains swell into angular, spherical or irregular masses which vary from I5 to several hundred microns in diameter (Fig. 308). The smaller masses thus produced bear a close resemblance to the starch grains of corn and wheat. The central triangular marking of the mass which resembles that of a corn starch grain is formed from the 
adjoining walls of three individual grains. Most of the aggregates, however, swell into rounded masses ( $35 \mu$ in diameter) resembling wheat starch grains, and have a clearly defined wall and nearly homogenous, hyaline contents. They may be distinguished from wheat starch by the use of dilute alkali or acid solutions, which cause an immediate breaking down of the masses without the successive changes in structure noticed on similar treatment of wheat starch grains (Fig. 97).

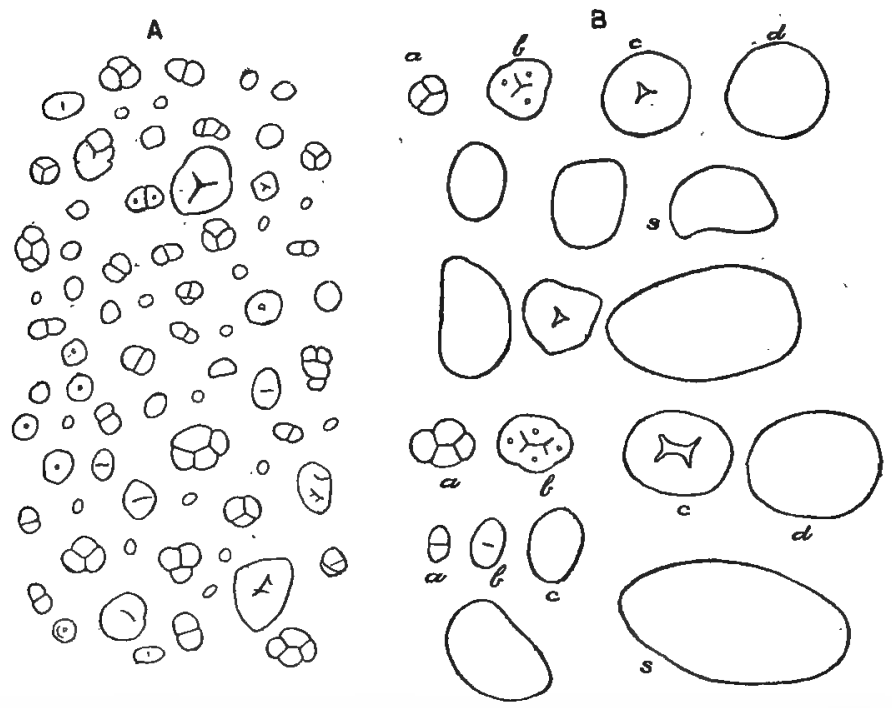

Fig. 308. Cacao starch: A, starch grains of commercial cacao powder, or chocolate, after removal of the oil by means of ether; B, altered starch grains of cacao produced by making sections or scrapings of the raw cacao bean, removing the oil with ether, mounting on a slide in water and heating at a temperature of $70^{\circ} \mathrm{C}$, for a few seconds; $a, b, c, d$, successive stages in the alteration of $2-, 3-$, and 4 -compound grains, the various masses showing resemblance in size and form to the single grains of corn, wheat and even potato starch as seen in some of the swollen masses (S).

Plain chocolate or cocoa mass is obtained by grinding the broken cotyledons (cocoa nibs) in a mill and separating the pasty mass, which is molded into forms that usually weigh a pound. COCOA is the plain chocolate from which a part of the fat (cocoa butter) has been removed, the resulting product being then powdered. Sweet chocolate is plain chocolate to which sugar and various flavoring substances are added. Milis chocolate is a sweet chocolate to which " milk powder" is added. 
AdrLTer.INTs.-All chocolate products may be adulterated with any of the cereal starches, those of corn, wheat and rice being usually employed.

I57. GUARANA.-Dark brown; parenchyma thin-walled, containing nearly spherical, more or less altered starch grains ro $\mu$ in diameter; sclerenchymatous cells nearly isodiametric, non-ligni-

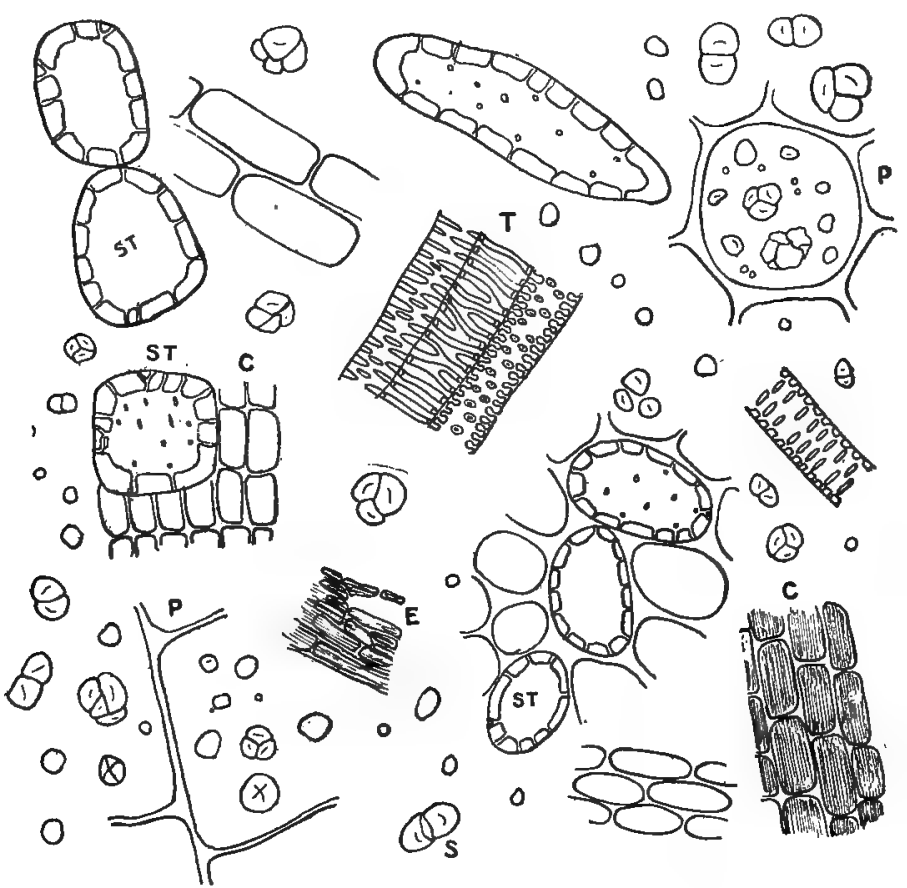

Fig. 309. Aconite: $T$, trachex with scalariform thickenings or bordered pores; ST, stone cells; P, parenchyma with starch grains; S, starch grains; C, E, cork.

fied; sclerenchymatous fibers few, narrow; tracheæ few, narrow, annular or scalariform.

I58. PIPER.-Dark brown (Fig. 3II) ; stone cells nearly isodiametric, uniformly thickened or with only three walls thickened, the contents consisting of yellowish-brown tannin masses, which give a blue reaction with ferric ammonium sulphate solution; starch grains spherical, I to $2 \mu$ in diameter; parenchyina with remains of chromoplastids and reddish-brown tannin masses; 
oil-secretion cells with suberized walls; oil globules numerous. (For chemical standard of purity see page 573.)

Adulter.ants.-Ground black pepper is sometimes adulterated with PEPPER HULLS or pepper shells, which are the outer layers of the ripe fruit and are obtained in the preparation of white pepper (p. 573). Pepper hulls consist chiefly of the stone

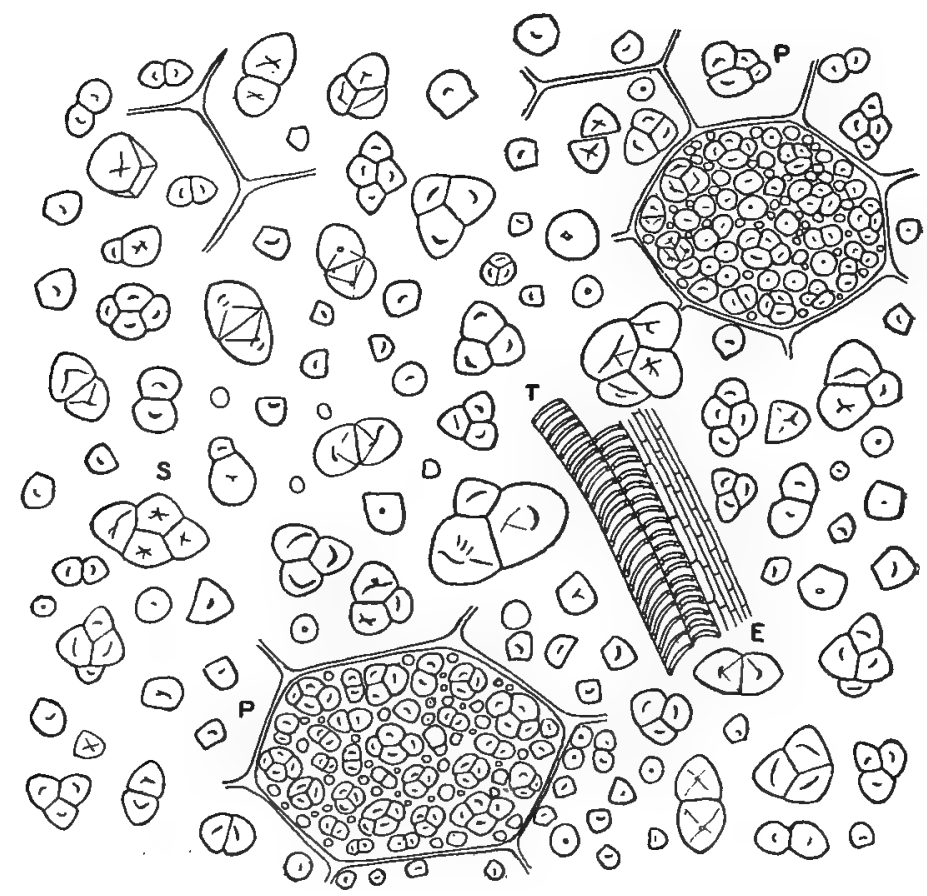

Fig. 3ro. Colchicum corm: S, 2- to 4-compound starch grains which make up the greater proportion of the powder; $P$, parenchyma with numerous starch grains; $T$, tracher; E, sieve.

cells described above. They increase the percentage of crude fiber and ash in the powder, the latter being due to adhering dirt. Ground black pepper sometimes consists of a mixture of pepper hulls, capsicum (Figs. $252 ; 301, C$ ) and the endocarp of the olive (Fig. 302, G). In the latter the lumen of the stone cells is filled with air. Black pepper has also been adulterated with flaxseed meal (see No. 79) and buckwheat hulls. The latter are dis- 
tinguished by the epidermal cells with peculiar diagonal thickening of the walls and the hypodermal fibers which have thick, porous walls and brown contents. (See also under Pimenta, No. II3.)

I59. COLCHICI SEMEN.-Light or dark brown; sclerenchymatous cells with.pigment soluble in potassium hydrate solution, and reacting with iron salts somewhat like tannin; cells of endosperm thick-walled, with simple pores and few oil globules; parenchymatous cells of strophiole thin-walled, and with numerous nearly spherical starch grains 7 to I $5 \mu$ in diameter.

t† Not Becoming Blue or Green with Ferric Salts.

I60. ACONITUM.-Dark brown (Figs. 206, 309); tracheæ few, spiral, scalariform, reticulate, or with simple pores; stone cells nearly isodiametric, variously thickened, associated with thickwalled parenchyma, the latter swelling in water; starch grains somewhat spherical, 4 to I2 $\mu$ in diameter, single or 2 - to $4^{-}$ compound.

I6r. PHYSOSTIGMA.-Brownish-black; taste starchy; stone cells nearly isodiametric or elongated, the contents reddened by alkalies; starch grains ellipsoidal, about 25 to $40 \mu$ in diameter; oil globules numerous.

\section{** Stone Cells Wanting.}

162. COLCHICI CORMUS.-Light or dark brown; starch grains irregularly spherical or ovoid, 7 to $20 \mu$ in diameter, single or 2- to 4-compound; trachea few, spiral or scalariform (Fig. $310)$.

I63. GUARANA.- (See No. I 57.)

164. MYRISTICA.-Light brown; perisperm cells with reddish contents; starch grains somewhat spherical, 5 to $7 \mu$ in diameter, generally in groups; globules of fixed oil numerous.

165. MACIS.-Amylodextrin starch grains (Fig. 190) which , are colored red with iodine. For other characteristics of genuine mace and the study of allied products and substitutes see p. 443 .

I66. OPIUM.-(See No. I97.) 
I67. PODOPHYLLUMI.-Light brown (Fig. 223); starch grains somewhat spherical, 5 to $12 \mu$ in diameter, single or 2 - to 6-compound; tracheæ few, scalariform, spiral, reticulate, or with simple pores.

I68. CHENOPODIUMI.-Yellowish-brown; seeds blackish, shiny, reniform, about I $50 \mu$ in diameter; seed-coat with polygonal, thin-walled pigment cells; numerous starch grains and small aleurone grains.

B. STARCH GRAINS FEW OR NONE.

a. Containing Calcium oxalate.

“ In Rosette Aggregatcs.

I. Small Crystals in Aleurone Grains.

I69. ANISUM.-(See No. 68.)

I70. CARUM.-Dark brown (Fig. 247); calcium oxalate crystals in rosette aggregates, 0.5 to I $\mu$ in diameter in aleurone grains; fragments of light yellow vittæ, together with nearly isodiametric or polygonal, yellowish-brown, inner epidermal cells of pericarp; sclerenchymatous fibers few, thick-walled, slightly lignified, with numerous simple pores; oil globules numerous.

17ı. CORIANDRUM.-Light brown (Fig. 245); calcium oxalate crystals in rosette aggregates and 3 to $7 \mu$ in diameter in aleurone grains; fragments of light yellow vittæ and long, narrow, yellowish, inner epidermal cells ; sclerenchymatous cells irregularly curved, yellowish, thick-walled, lignified and with numerous simple pores; oil globules numerous.

172. FENICULUN.-(See No. 7o.)

2. Crystals Not Less Than Io $\mu$ in Diameter.

* Pollen Grains Numerous.

I73. CARYOPHYLLLS.-Light brown (Fig. 312) ; pollen grains tetrahedral, somewhat spherical, with three pores, about I $5 \mu$ in diameter; calcium oxalate crystals in rosette aggregates Io to $15 \mu$ in diameter, occasionally in crystal fibers; sclerenchymatous fibers spindle-shaped, thick-walled, strongly lignified and with simple oblique pores; tracheæ spiral, thick-walled; oil glob- 
ules numerous. The powder of clove stems is less aromatic and contains numerous yellow, nearly isodiametric and irregular thickwalled stone cells with numerous canals and also scalariform and reticulate trachea. The powder of the fruit of cloves, or so-called MOTHER OF CLOVES, contains numerous single, oblong and irreg-

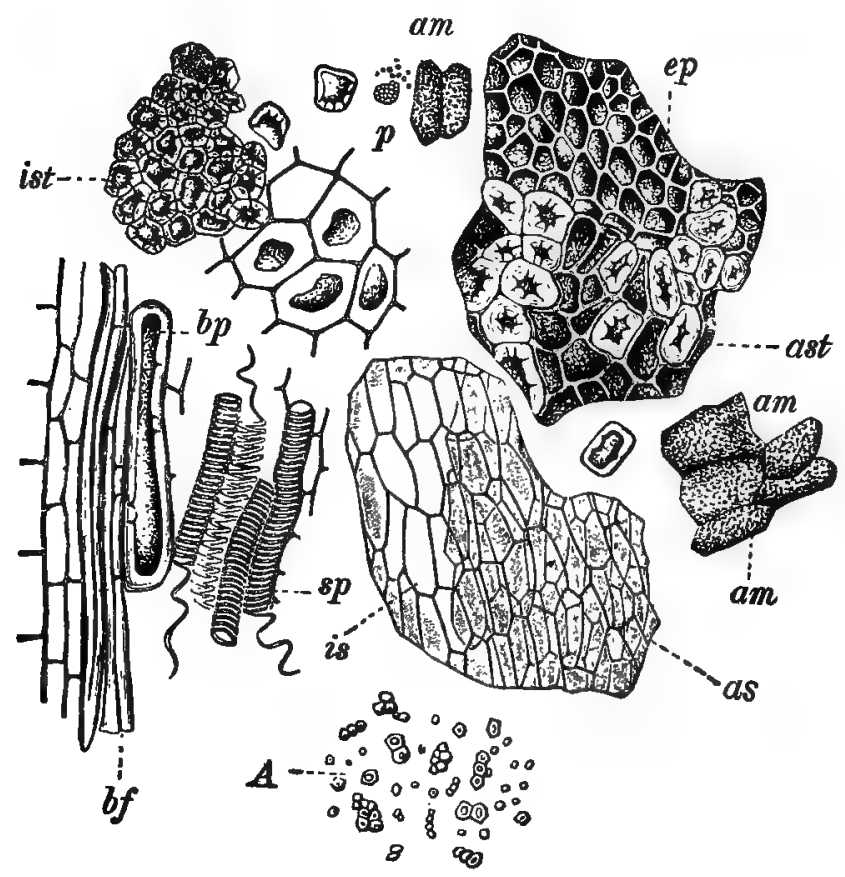

FIG. 3 II. Black pepper: ep, polygonal cells of the epicarp, beneath which are the hypodermal stone cells (ast); bf, elongated bast fibers; bp, short bast fibers; sp, trachea with spiral markings; ist, stone cells of the endocarp; is, as, fragments of tissues beneath the endocarp; am, parenchyma cells of perisperm containing starch grains; A, starch grains; p, oil cells.-After Moeller.

ular starch grains with excentral point of origin of growth, and varying in size from to to $35 \mu$. The pericarp of the fruit also contains numerous irregular stone cells and sclerenchyma fibers, the latter varying from short to $5 \mathrm{mmm}$. or more in length and being very irregular or knotty in outline. (For adlulterants see Pimenta No. II 3 and p. 549.)

I74. INSECT POWDER.-(See No. 5.) 


\author{
** Pollen Grains Few. \\ $\dagger$ Trachea Present.
}

I75. CUSSO.-Light brown (Figs. I 50, 243) ; calcium oxalate in rosette aggregates, about $20 \mu$ in diameter; non-glandular hairs I-celled, curved, thick-walled, 0.2 to $0.5 \mathrm{~mm}$. long; glandular hairs with 2 - or 3-celled stalk, glandular head unicellular or consisting of one or two pairs of cells; trachex spiral, scalariform, or with bordered pores; sclerenchymatous fibers long, thickwalled, strongly lignified, with numerous simple oblique pores; parenchyma of pith more or less lignified and with simple pores; pollen grains few, somewhat ellipsoidal, 25 to $40 \mu$ in diameter, with three pores.

部 Trachece Wanting.

I76. VIBURNUM OPULUS.-(See No. I79.)

I77. VIBURNUM PRUNIFOLIUM.-Dark brown; calcium oxalate in rosette aggregates and few monoclinic prisms I5 to $35 \mu$ in diameter; crystal fibers with rosette aggregates and occasional monoclinic prisms of calcium oxalate; stone cells large, numerous, irregular, thick-walled and with a few canals; bast fibers comparatively few, lignified. The barks of other species of Viburnum are frequently substituted for $V$. prunifolium.

\title{
B Calcium Oxalate in Monoclinic Prisms.
}

I. Numerous Seeds.

178. VANILLA.—Blackish-brown (Figs. 256; 285, G; 313); calcium oxalate in monoclinic prisms 7 to $35 \mu$ in diameter or in raphides about $0.4 \mathrm{~mm}$. long; occasional unicellular glandular papillæ with rounded apex and containing oil-like globules of a balsam; sclerenchymatous fibers more or less thick-walled, strongly lignified and with numerous oval pores; trachex with spiral or reticulate thickenings; minute, black, ovoid seeds about $0.5 \mathrm{~mm}$. in diameter, the structure being apparent only after boiling with chloral solution or solutions of the alkalies. The powder on treatment with a phloroglucin solution and sulphuric acid assumes a deep red color, due to the presence of vanillin. 
The powder is frequently admixed with tonka, which is easily determined by the presence of starch grains (see No. 144). Some of the so-called vanilla powders are mixtures containing vanillin or coumarin but none of the tissues of either vanilla or tonka.

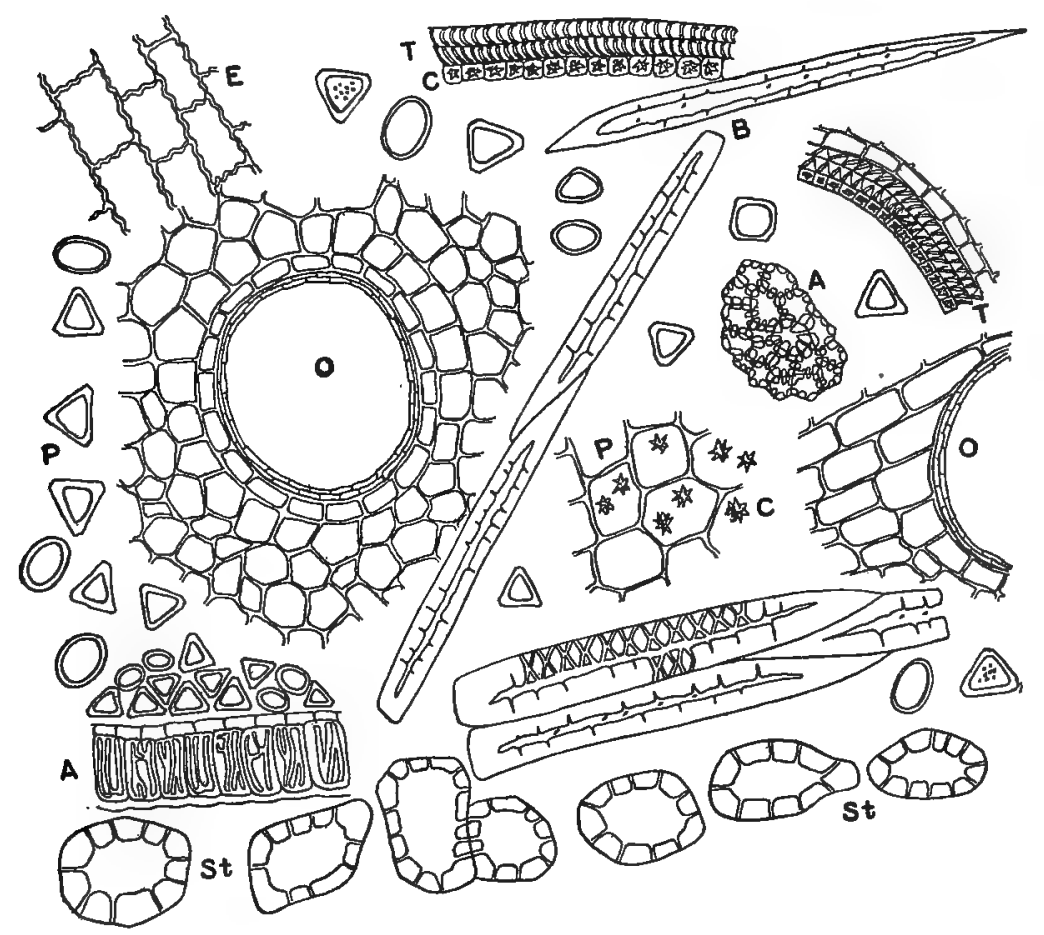

FIG. 3I2. Cloves: B, bast fibers; A, fragments of anther showing cells with characteristic marking or thickening of the walls; $P$, pollen grains which appear triangular in outline when mounted in water; $O$, oil glands, the large one to the left being from a petal; E surface view of epidermal cells of petal; $P$, parenchyma; $C$, calcium oxalate: $T$, tracheæ; St, seven stone cells from the young branches or twigs, the so-called "clove stems."

\section{Seeds Wanting.}

I79. VIBURNUM OPULUS.-Light brown; calcium oxalate in monoclinic prisms, or few rosette aggregates $I_{5}$ to $30 \mu$ in diameter; crystal fibers with monoclinic prisms of calcium oxalate ; stone cells few, relatively thick-walled; bast fibers numerous, lignified. 
I80. VIBURNUM PRUNIFOLIUM.-(See No. I77.)

I8I. XANTHOXYLUM.-Dark brown; calcium oxalate in monoclinic prisms Io to $25 \mu$ in diameter; starch grains nearly spherical, 4 to Io $\mu$ in diameter; oil-secretion cells colorless; cork cells strongly lignified; bast fibers few, thick-walled, slightly lignified, swelling perceptibly in chloral.

In Southern Prickly Ash (Fig. 233) occur groups of large, more or less lignified sclerenchymatous cells, and the lignified cork cells are more numerous.

\section{$\gamma$ Calcinm Oxalate in Crystal Fibers.}

I82. QUERCUS ALBA.-Light brown (Fig. 300, $B, F$ ); bast fibers long, thick-walled, lignified; crystal fibers containing rosette aggregates or monoclinic prisms of calcium oxalate about Io to $20 \mu$ in diameter; stone cells thick-walled, with numerous lamellæ and simple pores (Fig. 3or, $A$ ) ; parenchyma with irregular yellowish-brown tannin masses.

\section{b. Calcium oxalate wanting. a Containing Pollen Grains.}

I83. ARNIC $Æ$ FLORES.-(See No. 8I.)

184. CROCUS.-(See No. 85.)

I85. SANTONICA.—Light brown (Fig. 240); pollen grains nearly spherical, nearly smooth, 3-pored, 15 to $20 \mu$ in diameter; glandular hairs of two kinds, either with I or 2 short cells or with 2 to 3 pairs of cells. If a few c.c. of an alcoholic ( 95 per cent.) extract be heated with a few drops of potassium hydrate solution, a reddish color is produced.

\section{$\beta$ Pollen Grains Wanting.}

\section{Stone Cells Numerous.}

I86. CUBEBA.-Light brown (Fig. 250); stone cells single or in isolated groups, nearly isodiametric, thick-walled, with numerous simple pores, and colorless or light-yellow contents; sclerenchymatous fibers few, short, thick-walled, strongly lignified; parenchymatous cells with reddish-brown tannin masses; oil-secre- 
tion cells with suberized walls; oil globules numerous; fragments of powder becoming wine-colored with sulphuric acid.

I87. DELPHINIUM.-Grayish-brown or light brown; stone cells of outer epiclermis radially elongated, with thick walls and simple pores resembling those of staphisagria; a layer of pigment cells; fixed oil, and aleurone grains.

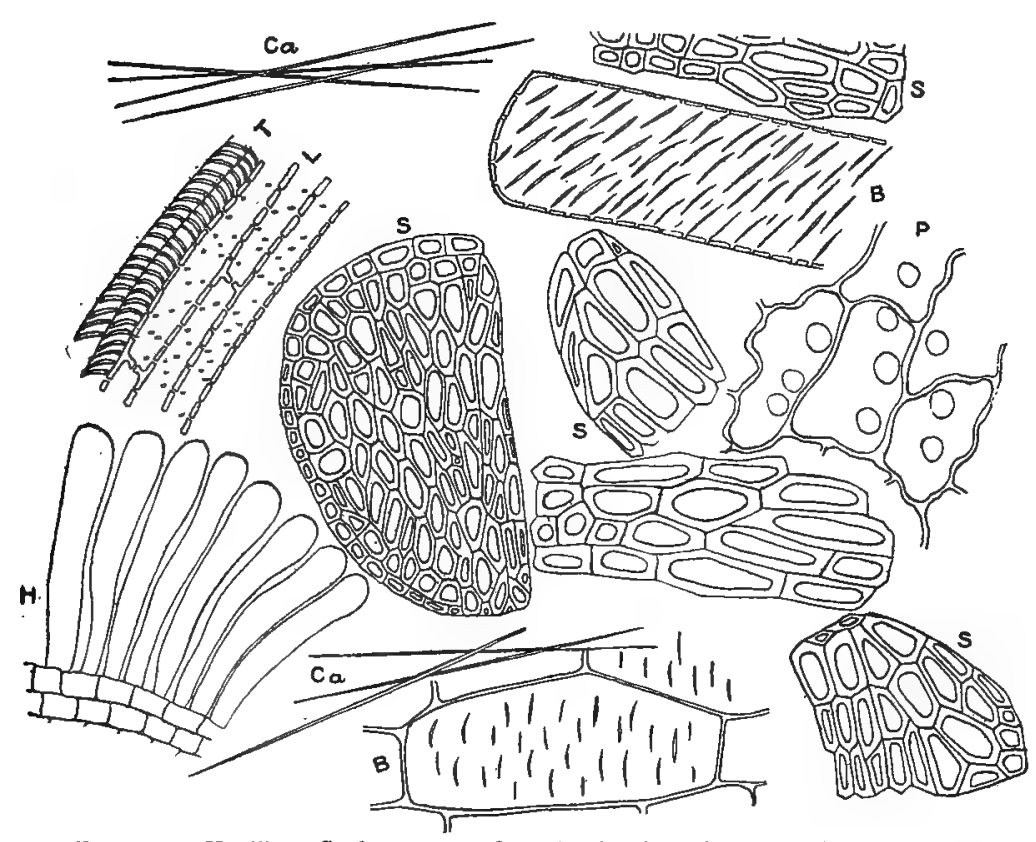

Fig. 3I3. Vanilla: S, fragments of seeds showing characteristic stone cells: $B$, parenchyma cells with narrow-elongated simple pores; $P$, parenchyma containing oil globules; T, tracheæ; L, lignified cells with simple pores; $\mathrm{Ca}$, raphides of calcium oxalate; $\mathrm{H}$, papillæ-like hairs from the inner surface of the pericarp which are occasionally seen massed together.

I88. STRAMONII SEMEN.-Brownish-black or grayishblack (Fig. I22, B) ; epidermal cells with thick mucilaginous outer walls, a small lumen and dark brown contents. Beneath the epidermis is a layer of thick-walled, nearly colorless cells with distinct, crescent-shaped lamellx in the radial walls and reticulate pores. The cells of the endosperm contain considerable oil and more or less numerous aleurone grains, the latter having I or 2 crystalloids and a number of globoids. 
I89. PYRETHRUM.-Dark brown; parenchymatous cells with irregular crystalloidal masses of inulin; periderm with nearly isodiametric stone cells, the contents of which are yellowish-brown; trachex reticulate, narrow; sclerenchymatous fibers few; secretion reservoirs with oil and resin (Fig. ror, $E$ ).

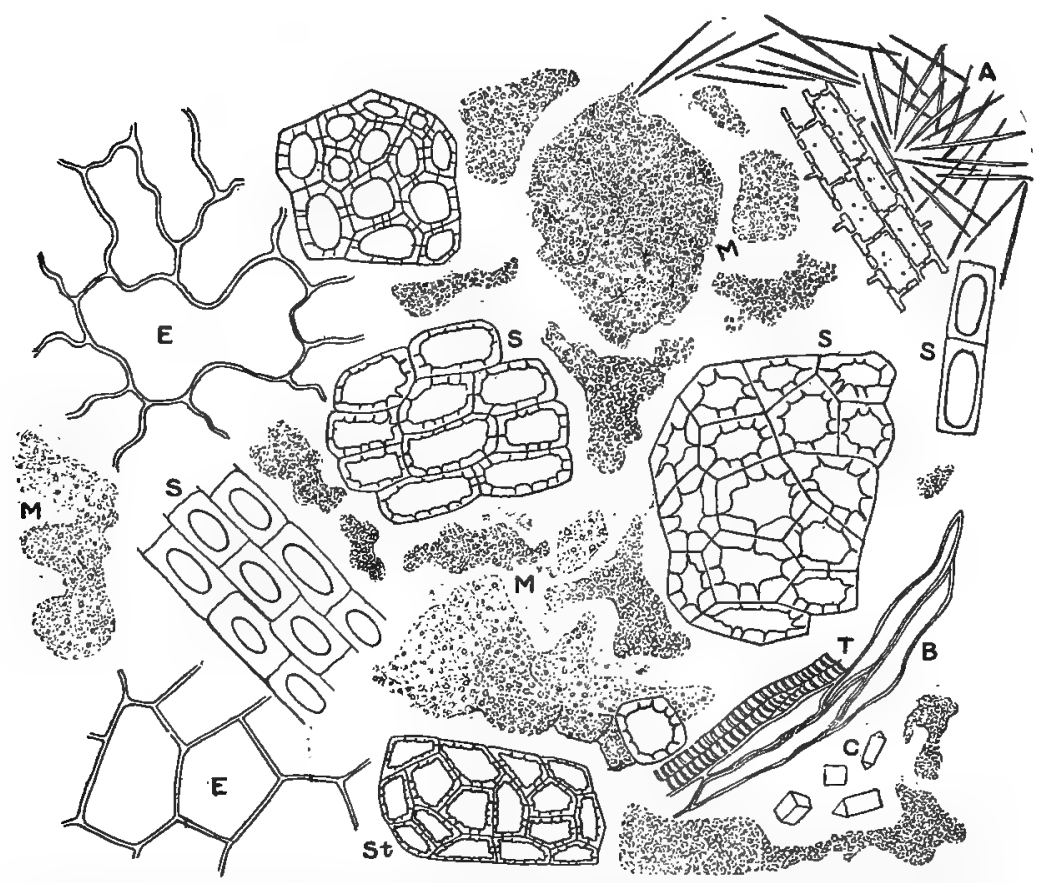

Fig. 314. Powdered opium: M, protoplasm-like latex, which constitutes the greater proportion of the powder; S, St, thick-walled cells of capsule; A, needle-shaped crystals which sometimes separate in a chloral-iodine mount. The following Rumex tissues are also generally present: E, epidermal cells of leaf; B, bast fibers and T, tracheæ from Rumex fruit; C, crystals (probably of calcium oxalate).

The root of Anacyclus officinarum contains tannin and an aqueous extract gives a precipitate with ammonio-ferric-alum solution.

\section{Stone Cells Wanting.}

190. GENTIANA.-Light brown (Fig. 210) ; ducts few, scalariform or reticulate; intermediate fibers non-lignified and with 
irregular, simple, oblique pores; few globules of fixed oil. (See also Fig. $300, A$.) The yield of aqueous extract should not be less than 33 per cent. A substitute has been offered consisting of the exhausted drug to which aloes had been added.

19I. OPIUM.-(See No. 197.)

192. TARAXACUM.-Light brown; parenchyma containing irregular crystalloidal masses of inulin; laticiferous vessels yellowish-brown (Fig. Ior, $D$ ); tracheæ reticulate; intermediate fibers non-lignified, with irregular simple and oblique pores.

I93. CICHORIUM (or Chicory).-Irregular masses of inulin in the parenchyma cells; branching latex vessels from 5 to Io $\mu$ wide; tracheæ short, more or less crlindrical, with pointed ends, from Ioo to $200 \mu$ long and 20 to $40 \mu$ wide, with large, elliptical, simple pores. Associated with the tracheæ are slightly thickened, elongated parenchyma cells with narrow, oblique pores.

194. TRITICUM.-Light brown; trachex lignified, with spiral or annular thickenings or simple pores; sclerenchymatous fibers long, thick-walled, strongly lignified; endodermal cells with inner walls thickened and slightly lignified; parenchyma with irregular masses of a soluble carbohydrate.

\section{WITHOL'T FIBROVASCLLAR TISSUE.}

\section{A. WITH CELLULAR TISSUES.}

I95. USTILAGO.-Grayish-brown (Figs. 22, 23); nearly spherical spores 7 by $7 \mu$; little or no foreign substances. Spores of Coprinus comatus, blackish and ellipsoidal, 5 by ro $\mu$. Spores of Agaricus campcstris more brownish than those of corn smut, ovoid and about 5 by $7 \mu$.

196. ERGOTA.-Oil globules; red or violet coloration in chloral or sulphuric acid; false parenchyma of compacted hyphæ.

I97. OPIUM.-Brownish (Fig. 3I4); in glycerin mounts showing grayish-brown, irregular granular masses 35 to $40 \mu$ in diameter; little or no starch; thick-walled polygonal cells of epidermis of capsule; epidermal cells of Rumex leaves (used in wrapping opium) somewhat polygonal on surface view, with elliptical stomata about $70 \mu$ long, having a narrow opening; fragments of wings of Rumex fruits (used to prevent cohesion of 
opium masses), with prominent, brown-colored fibrovascular tissue composed of spiral tracheæ and narrow sclerenchymatic fibers; parenchyma of seeds colorless, containing air; epidermal cells with large, elliptical, oblique pores; taste bitter; sparingly soluble in water or potassium hydrate solution. The Smyrna opium has the largest number of epidermal cells of capsule, the Indian few or none and the Persian very few. The Persian always has an appreciable amount of starch.

198. GOA POIVDER is formed as a result of pathological changes in the woody tissues of I'ouacapona Araroba (Fam. Leguminosæ), a forest tree of Brazil. It is obtained by cutting down the trees, splitting the trunk and removing the powder from the clefts or cavities. When fresh the powder is of a light yellow color, but on exposure to air it becomes dark brown or brownish-purple. It is composed of small, wine-colored, somewhat translucent, irregular, angular fragments, with a few fragments of trachex and libriform cells with bordered pores. It is sparingly soluble in water, soluble in alcohol, chloroform and solutions of the alkalies, the latter being colored deep red and showing a green fluorescence. It should contain between 50 and 75 per cent. of a netitral principle, chrysarobin, which is official. The latter is a crystalline yellow substance. Chrysarobin forms a red colored solution with solutions of the alkalies (due to the formation of chrysophanic acid) or sulphuric acid; on pouring the sulphuric acid solution into an excess of water the chrysarobin is re-deposited. Goa powder also contains about 2 per cent. of resin; 7 per cent. of bitter extractive; a small amount of chrysophanic acid, and yields about 3 per cent. of ash. Mounts of the powder sometimes show colorless prismatic crystals.

\section{B. WITHOUT CELLULAR TISSUES.}

a. POSSESSING OIL.

199. ASAFETIDA.-In a glycerin mount the powder shows irregular grayish (or gray streaked with brown) masses; these are opaque and become milky white on the edge from the presence of oil. The stony asafetida is pulverulent and contains less oil (p. 67r). 
200. MYRRHA.-In glycerin mount the powder appears in yellowish or yellowish-brown irregular fragments made up of a grayish matrix containing yellowish or yellowish-brown oil globules (p. 674).

\section{$b$. WITHOUT OIL.}

a Remaining Opaque (Not Affected) in Glycerin. 206.)

20I. ALOES (SOCOTRINE),-Slightly affected. (See No.

202. BENZOINUM.-Irregular, colorless and wine-colored fragments; some rosette-shaped groups and collections of small tetragonal crystals. Upon covering a fragment on a slide with a watch crystal and cautiously heating, crystals of benzoic acid are sublimed on the watch crystal (p. 672).

203. ELATERINUMI.-Grayish and grayish-brown, more or less opaque, irregular fragments; upon heating a fragment with phenol, and when cool, adding sulphuric acid, a deep-red coloration is produced. Potassium hydrate has no action on elaterin (p. 387).

204. LACTUCARIUM.-Grayish-brown and dark brown, irregular and rather angular masses; with alkalies they become reddish-brown and then a dirty brown; with sulphuric acid they are but slightly affected (p. 649).

\section{$\beta$ Becoming More or Less Translucent in Glycerin.}

205. ALOES (CURAÇAO).-In a glycerin mount the particles become clear and behave like Cape aloes, but generally numerous acicular, or large prismatic crystals remain, or separate in the clear yellow space where the fragment of aloes was originally. The fragments are colored red with solutions of the alkalies (p. 663).

206. ALOES (SOCOTRINE).--In a glycerin mount the fragments are not very perceptibly affected. At the most there is but a faint yellowish color around the grayish or grayish-brown masses. In old Socotrine aloes the gray masses look like rosette crystals. The fragments are colored red with alkalies (p. 663). 
207. GAMBIR.-Dark brown (p. 666); with numerous acicular crystals io to $60 \mu$ long; occasionally large cubical prisms; also fragments of vegetable tissue. In inferior grades of gambir spores of fungi are sometimes abundant.

208. CATECHU._Large, opaque, dark brownish-red masses which gradually become transparent on the edge and dissolve with a sherry-wine color; fragments of sclerenchyma (p. 666).

209. KINO.-The blackish-brown fragments become clearer and of a deeper red color as compared to catechu (p. 654).

\section{POWDERS OF A REDDISH COLOR.}

This group includes those powdered drugs which are of a pinkish, reddish, brownish-red (brown madder), or rose color.

\section{CONTAINING STARCH.}

210. QUILLAJA.-Pinkish (Figs. 28I, C; 300, G; 315); very sternutatory; calcium oxalate in monoclinic pyramids from 35 to $200 \mu$ long; bast fibers numerous, thick-walled, strongly lignified; crystal fibers containing monoclinic prisms of calcium oxalate; stone cells more or less thick-walled and with simple oblique pores ; starch grains nearly spherical, 3 to ro $\mu$ in diameter.

2I I. SANGUINARIA.-Reddish; starch grains spherical, 4 to $8 \mu$ in diameter; reddish secretion cells; tracheæ few, reticulate.

\section{WITHOUT STARCH.}

\section{A. STONE CELLS PRESENT.}

212. CAPSICLN.-Brownish-red (Figs. 252; 301, C); stone cells of two kinds, either nearly isodiametric, uniformly thickened and with middle lamella slightly lignified, or somewhat elongated on surface view, convolutely thickened on the inner and side walls and strongly lignified; starch grains somewhat spherical, about 3 to $7 \mu$ in diameter, single or compound; glandular hairs with $\mathrm{I}$ - to 3 -celled stalk and multicellular glandular head; collenchymatous cells with suberized walls; parenchymatous cells with yellowish-red oil globules and irregular masses of chromoplastids. 
Powdered capsicum is sometimes admixed with about I per cent. of a fixed oil to improve its appearance, and such powders are likely to contain in addition some of the commercial starches or by-products obtained in the manufacture of cereal prodtucts.

213. ILLICIUM (or Star Anise).-Dark reddish-brown (Fig. 302, I) ; stone (or palisade) cells 0.3 to $0.6 \mathrm{~mm}$. long and 20 to $50 \mu$ wide, with slightly thickened walls and

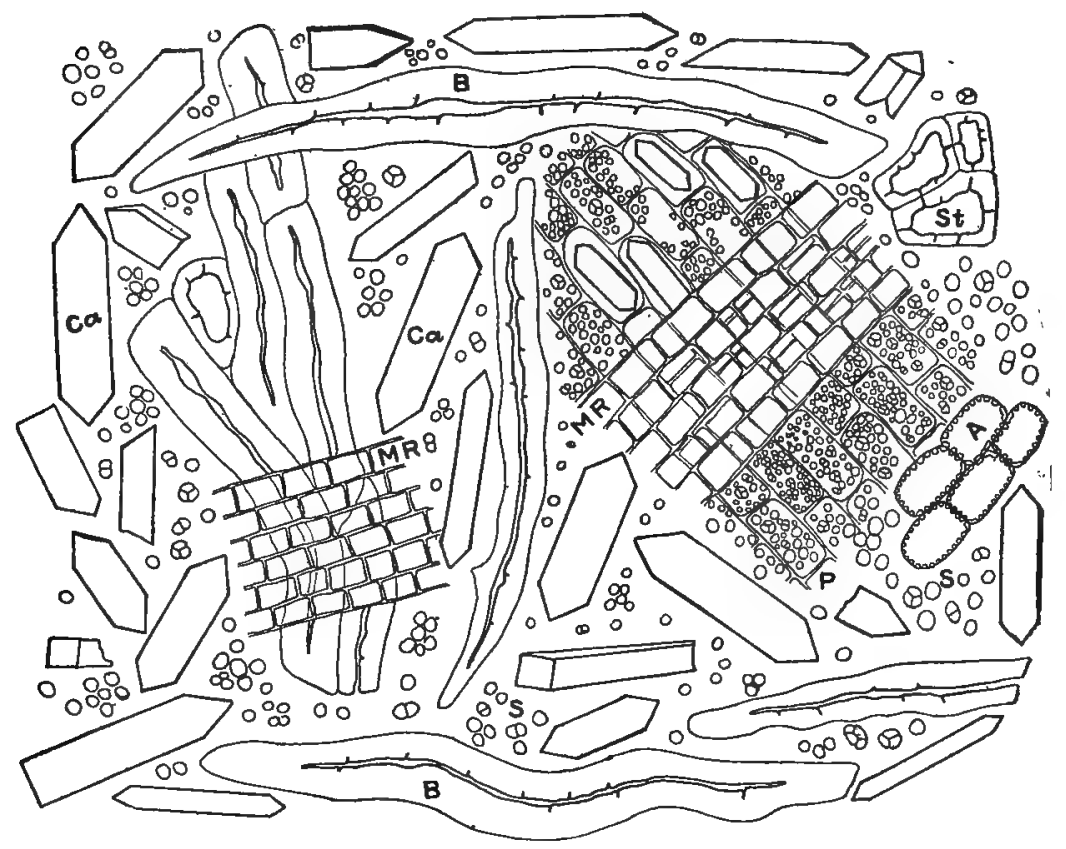

FIG. 3 15. Soap bark: Ca, pyramids of calcium oxalate; $B$, bast fibers; St, stone

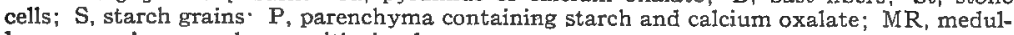
lary rays; A, parenchyma with simple pores.

simple pores; isodiametric stone cells with thickened walls and branching pores (astrosclereids); long sclerenchymatic fibers with more or less irregularly thickened walls and simple pores; outer epidermal cells with striated cuticle; aleurone grains from to to $20 \mu$ in diameter, usually containing globoids. The poisonous shikimi fruit is distinguished by somewhat shorter palisade cells; somewhat rounded stone cells; the aleurone grains contain crystalloids; alcoholic solutions yield an oil with a disagreeable odor. 


\section{I4. CYDONIUM.-(See No. 8o.)}

215. RHUS GLABRA.-Brownish-red (Fig. 285, I) ; nonglandular hairs unicellular, narrow, thick-walled, filled with air, or multicellular, cylindrical, ellipsoidal or spatulate and with a winecolored pigment; glandular hairs with I-celled stalk and multicellular globular or ellipsoidal head, with yellowish-brown contents; stone cells about $20 \mu$ in diameter, thick-walled, strongly lignified, with numerous pores; oil globules numerous.

216. ROSA CANINA (or Rose Hips).-Dark brownishred; non-glandular hairs of torus unicellular, from 0.5 to 2 $\mathrm{mm}$. long, about $35 \mu$ wide, gradually tapering toward the base as well as apex, with very thick walls and narrow lumen; parenchyma cells with brownish-red masses of plastids; calcium oxalate crystals in rosette aggregates from 35 to $50 \mu$ in diameter; sclerenchymatous cells and fibers of seed-coat with colorless, rather thick walls and numerous simple and branching pores; an inner epidermis of elongated cells containing a brown pigment; the cells of the embryo with small, nearly spherical aleurone grains and considerable oil.

2I7. WILLOW CHARCOAL.-Wine-colored or dark reddish, or blackish, irregular-shaped fragments, composed of woody tissues. Willow charcoal is frequently used to color cattle-foods, particularly those the basis of which is wheat-middlings.

\section{STONE CELLS WANTING.}

a. WITH WOOD FIBERS.

218. H压MATOXYLON.-Reddish; tracheæ with simple pores; sclerenchymatous fibers long, thin-walled; crystal fibers with monoclinic crystals of calcium oxalate.

2I9. SANTALUM RUBRUM.-Reddish; tracheæ with bordered pores; sclerenchymatous fibers long, thin-walled; crystal fibers with monoclinic crystals of calcium oxalate. The coloring principle is insoluble in water but soluble in alcohol and solutions of the alkalies.

\section{b. WOOD FIBERS WANTING.}

220. CROCUS.-(See No. 85.)

221. KINO.-(See No. 209.) 
222. LUPULINUM.-Reddish-brown (Fig. 298); large, characteristic glandular hairs about $20 \mu$ in diameter. In fresh Lupulin there are more light yellow glandular hairs than in old: In the latter there are browner or grayish-brown resinous masses replacing the light yellow oil. The amount of Humulus fragments should not be too large in Lupulin of good quality.

223. OPIUM.-(See No. 197.)

224. ROSA GALLICA.-Rose-colored; epidermis with acute papillæ; pollen grains few, broadly spherical, $30 \mu$ in diameter (p. 557).

225. ROSA CENTIFOLIA.-Pollen grains nearly smooth and elliptical, from 15 to $30 \mu$ long; fragments of corolla pinkish with chloral; papillæ of corolla somewhat rounded; cells of anther; long, I-celled, non-glandular hairs around ovary. A hydro-alcoholic solution becomes yellowish-red with acids.

226. ZEA.-Style with spiral and annular tracheæ; numerous non-glandular hairs consisting of 2 parallel rows of cells, and from 0.5 to $\mathrm{I} \mathrm{mm}$. tong (p. $55^{8}$ ).

\section{POWDERS OF A WHITISH APPEARANCE.}

This group includes all those powders which are light in color, and comprises chiefly the commercial starches, cereals, gums and some of the inorganic substances which are occasionally used as adulterants.

\section{PLANT TISSUES OR CELL-CONTENTS RECOG- NIZABLE.}

\section{$A$. CONTAINING STARCH.}

a. ONLY UNALTERED STARCH GRAINS PRESENT.

Grains characteristic for each; completely soluble in glycerin on heating, and precipitated on the addition of alcohol, the precipitate being soluble in water.

227. ARROWROOT STARCH.-There are a number of commercial kinds of this starch, depending upon the countries in which it is produced (p. 244). BERMUDA arrowroot is in the form of somewhat hard, irregular granules or masses, varying from 
I to $6 \mathrm{~mm}$. in diameter. When rubbed between the fingers it is reduced to a smooth powder, which is velvety to the touch. The starch grains (Fig. 3I6, B) vary in shape from ellipsoidal to ovoid
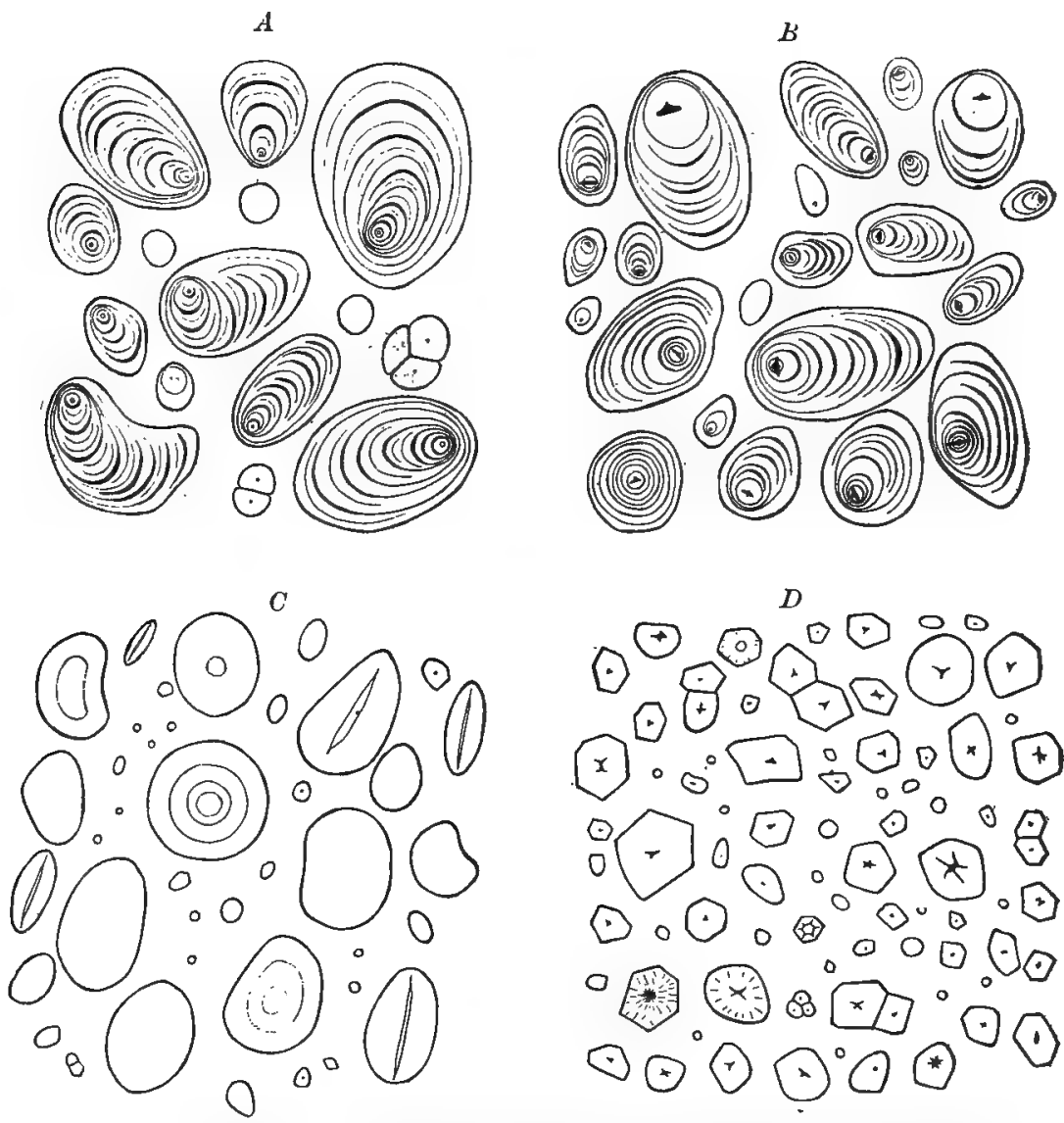

FIg. 3r6. A, potato starch grains showing the excentral and circular point of origin of growth, and lamellæ; B, maranta starch grains showing fissured point of origin of growth, and distinct lamellæ; $\mathrm{C}$, wheat starch grains showing indistinct point of origin of growth, and lamella; D, corn starch grains, which are more or less polygonal in outline and have a $3^{-}$to 5 -angled point of origin of growth.

or oblong, and from to to $65 \mu$ in diameter. The lamellæ are mostly indistinct and there is usually a transverse or crescentshaped cleft at the middle or near the broad end of the grain. 
MontserRat arrowroot closely resembles the Bermuda starch, but the grains are a little larger and more of them show the cleft. St. Vincent arrowroot is slightly darker in color and is in the form of masses or granules, which are sometimes 20 $\mathrm{mm}$. in diameter. The starch grains resemble those of the Bermuda arrowroot, but the grains having clefts are more numerous.

The arrowroot starches all show a distinct cross with the micropolariscope and a marked play of colors when a selenite plate is used. These starches usually contain about I 5 per cent. of water, the remainder being composed of the starch grains.

228. POTATO STARCH occurs as a more or less finely granular powder, and appears to have less tendency to form coherent masses than arrowroot starch. The grains (Figs. 95; $96 ; 316, A)$ are somewhat shell-shaped, having distinct lamellae and a circular point of origin of growth, which is at the smaller end of the grain. They vary in size from 50 to Ioo $\mu$, there being a large number of smaller, somewhat ellipsoidal or spherical grains, and a few 2- or 3-compound grains. Under the micropolariscope the grains show a distinct cross (Fig. 95), and a striking play of colors when a selenite plate is used. On heating the starch to a temperature of $65^{\circ} \mathrm{C}$. or treating it with very dilute alkali or acid solutions, the grains swell to four times their original size and finally burst, passing through the successive changes in structure illustrated in Fig. 96.

229. CORN STARCH.-This occurs as a fine, somewhat cream-colored, mobile powder, which is practically free from cohering particles. The starch grains (Fig. $316, D$ ) are more or less polygonal or somewhat rounded, usually with a distinct circular, or 2- to 5-rayed cleft in the center, and vary from Io to $35 \mu$ in diameter. When examined by means of the micropolariscope the grains show a distinct cross, but the display of colors when the selenite plate is used is less pronounced than in potato starch. This starch frequently contains traces of alkalies, which may be detected by adding $0.5 \mathrm{Gm}$. of the starch to 2 c.c. of an aqueous solution of fuchsin, when the latter is decolorized. Corn starch is official (p. 642). It should also be stated that the different kinds of corn produce starches that are somewhat different in character (p. 229). 
230. RICE STARCH.-This is prepared by the use of chemicals much the same as in the preparation of corn starch (p. 643). and is either in the form of a white or cream-colored powder or small, irregular masses. The individual grains like those of oat (Fig. $317, E$ ), are polygonal, from 2 to $10 \mu$ in diameter, with a central cleft, and usually united into small aggregates of two or more. The product sold for rice starch is frequently rice flour, and is characterized by the large, oval aggregates of numerous grains, as well as cellular tissue. (See No. 244.)
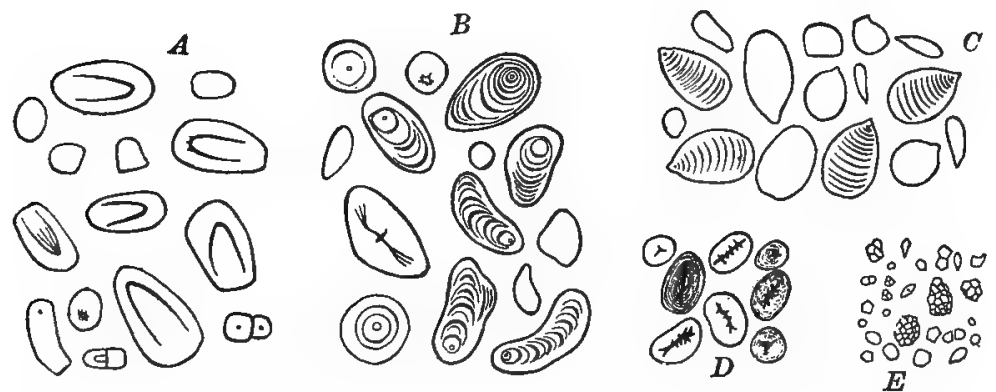

FIG. 317. A, starch grains of Iris florensina showing peculiar horseshoe-like fissure extending from point of origin of growth; B, irregular starch grains of calumba root; C, peculiar beaked starch grains of ginger rhizome; D, starch grains of bean showing irregular longitudinal fissures; $E$, compound starch grains of oat.

23I. WHEAT STARCH usually occurs in very hard, somewhat elongated and columnar or irregular masses, varying from $I$ to $3 \mathrm{~cm}$. in length. The starch grains are more or less rounded or flattened-circular, and depending upon the surface presented to view under the microscope, appear circular or elliptical in out. line; they vary from 15 to $35 \mu$ in diameter and are without distinct markings except when heated or treated, with dilute acid or alkaline solutions (Fig. 97). When viewed under the micropolariscope the grains do not show a distinct cross and the play of colors when the selenite plate is used is scarcely discernible. Wheat starch does not agglutinate on mixing with water as wheat flour does (Fig. 95).

232. OTHER STARCHES.-Among the other commercial starches the following may be mentioned: 
a. Consisting of Single Grains: Yam starch (from several species of Dioscorea) occurs in narrow, ellipsoidal grains, 30 to 50 $\boldsymbol{\mu}$ long, with distinct lamellæ and point of origin of growth at narrow end. CANNA starch (tous les mois arrowroot), derived from several species of Canna, occurs in broadly elliptical or ovate grains varying from 50 to $125 \mu$ in diameter and with distinct lamellæ and circular point of origin of growth. BEAN starch consists of ellipsoidal or reniform grains, which vary from 25 to $50 \mu$ in length and have a distinct, branching, elongated cleft in the middle. PEA-starch grains resemble those of bean starch, but the grains are smaller and more or less irregular on the surface (Figs. 95; 3I $7, D$ ).

b. Consisting of 2- To 3-COMpound grains: Cassava or tapioca starch is obtained from the Sweet and Bitter Cassava (p. 318 ), and occurs in somewhat plano-convex or bell-shaped, 2- to $3^{-}$, or even $4^{-}$to 8-compound grains, which vary from 6 to $30 \mu$ in diameter and have a distinct central, circular, or radiating cleft. Sweet potato starch resembles Cassava starch, but some of the grains are larger.

\section{b. ALTERED AND UNALTERED STARCH GRAINS PRESENT.}

233. DEXTRIN.-Sticky mass with water, consisting chiefly of altered starch grains, but ustally sufficient unaltered grains are present to determine the source of the dextrin.

234. SAGO starch is obtained from Cycas revoluta and other cycads as well as a number of palms (p. 233). It occurs in commerce in small, horny granules, which are slowly affected by cold water, when there separates the characteristic elliptical or truncate-elliptical starch grains. The latter vary from I5 to $50 \mu$ long and have a large central area surrounded by rather narrow, distinct, altered lamellæ.

235. SAGO (IMITATION).-Breaks down quickly in water and shows characteristic corn starch grains.

c. PLANT TISSUES IN ADDITION TO STARCH GRAINS.

The former remain upon treatment with hot glycerin. 


\section{a Do Not Readily Dissolve or Swell in Cold Water.}

236. CORN MEAL is whitish or yellowish, and in addition to the parenchyma which contains oil and characteristic starch grains there are also present fragments of the pericarp. The latter are free from hairs; the cells of the epicarp have thick walls with simple pores; beneath the latter occurs a layer of parenchyma cells which are thin-walled, more or less branching, between which are large intercellular spaces; running at right angles across the branching parenchyma cells are narrow, thin-walled tube cells, which are also found in the other cereals. Corn Meal contains more starch and oil and little hull, as compared to corn bran. In Broom Corn and Sugar Sorghum the tangential walls of the cells of the epicarp are undulate and distinctly porous; and the more or less polygonal cells of the perisperm are quite prominent. These two kinds of cells serve to distinguish these fruits from either corn or any of the other cereals.

237. CORN BRAN.-Less starch and oil and more hull, as compared to cornmeal. (See No. 236.)

238. WHEAT FLOUR.-Agglutinates with water (distinction from wheat starch); little tissue of wheat grain. (See No. 239.)

239. WHEAT MIDDLINGS are grayish-white and in addition to the characteristic starch grains (Figs. 95; 97;316,C) there are numerous fragments of tissues, as the thick-walled polygonal cells of the endosperm, which contain small aleurone grains and have a more or less distinct nucleus; the cells of the embryo containing aleurone grains and fixed oil; and the tissues of the pericarp. The latter include tunicellular hairs, which are 0.5 to I $\mathrm{mm}$. in length and $\mathrm{I} 5$ to $25 \mu$ in diameter, have a sharply pointed apex and rounded base, and a narrow lumen, which is but I or $2 \mu$ wide; a layer of tangentially elongated cells from 100 to $200 \mu$ long and 15 to $25 \mu$ in diameter, which are slightly thickened and with simple pores; and running across the latter are a number of more or less isolated vermiform cells with rounded ends.

WHEAT BRAN is said to be sometimes adulterated with " inner coffee hulls," which consist of the inner tissues of the pericarp of the coffee fruit (see No. ${ }_{54}$ ), and are readily detected by the 
fragments of palisade cells and the somewhat elongated, narrow, sclerenchymatic fibers which cross one another.

240. RYE FLOUR is faintly grayish-white, the starch grains closely resembling those of wheat, but sometimes larger ( 20 to $60 \mu)$; the lamella are distinct and the point of origin of growth is sometimes marked by a star-shaped cleft or fissure. Rye flour when mixed with water does not agglutinate like wheat flour. A few fragments of the pericarp are also present.

24I. RYE MIDDLINGS.-In addition to the starch grains in rye flour a considerable amount of the tissues of the pericarp are present. The latter closely resemble those of wheat, but hairs from the apex of the fruit have thinner walls, the lumen being 2 or 3 times the thickness of the walls; and the tangcntially elongated cells have simple pores only on the tangential walls, and do not lie closely together, so that there are intercellular spaces between them.

242. BARLEY FLOUR.-The starch grains closely resemble those of wheat, but are smaller, usually not more than $25 \mu$ in diameter, and in the case of malt the grains show distinct radial and circular clefts, due to the action of the diastase; the hairs from the apex of the grain resemble those of both wheat and rye but are shorter than either, being from 40 to $150 \mu$ long; the tangentially elongated cells are non-porous, the walls being I to $2 \mu$ thick.

243. BUCKWHEAT FLOUR.-Light grayish-brown; pericarp of elongated epidermal cells with latticed walls, due to the pores of the outer and inner walls running obliquely and at right angles to each other; short sclerenchymatic fibers with somewhat curved or oblique end walls, large simple pores and brown contents; parenchyma with brown contents. Seed-coat showing in surface section epidermal cells with undulate walls; branching parenchyma with greenish or brownish-yellow contents; and an inner epidermis of elongated cells. Endosperm having a layer of cells containing aleurone grains, resembling those found in the true cereals, and parenchyma with numerous angular or somewhat rounded or ellipsoidal starch grains (resembling those of rice or oat), with distinct central cleft and varying from 5 to $12 \mu$ in diameter. 
244. RICE FLOUR consists chiefly of the small, angular starch grains and aggregates like those of oat (Fig. 31.7, E). There are also present some of the polygonal cells containing aleurone grains and a few fragments of the pericarp. The latter is especially characterized by the radially elongated cells of the epicarp, which are 100 to $500 \mu$ long and 25 to I00 $\mu$ wide, and the end walls of which are deeply undulate, resembling the epidermal cells of some leaves.

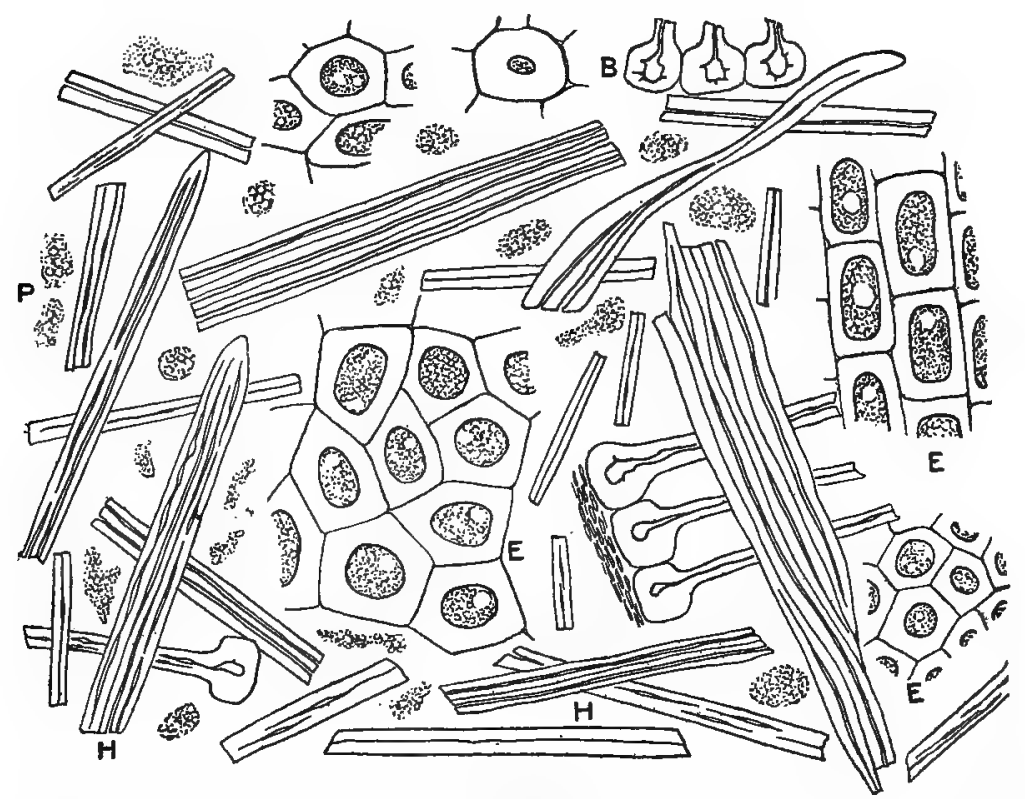

FIG. 318. Nux Vomica: H, fragments of lignified hairs of seed-coat; B, basal portion of hairs; $\mathbf{E}$, thick-walled parenchyma cells of endosperm containing one or more oil globules and protoplasm; $\mathrm{P}$, isolated protoplasmic substance from endosperm cells.

245. OATMEAL OR ROLLED OATS.-The starch grains are small and, like those in rice, in aggregate masses, which are more or less rounded, polygonal or pear-shaped. The endosperm consists of a single layer of cells containing aleurone grains, but the walls are 3 to $5 \mu$ thick. The cells of the epicarp are longitudinally elongated and possess very thin, porous walls, those situated at the upper end of the grain having long, unicellular hairs, which are about $20 \mu$ wide near the middle portion, and 
taper gradually towards the base as well as towards the apex. The other tissues of the pericarp are not so conspicuous as in the other cereals (Fig. I2O).

246. NUX VOMICA.-(See No. 252.)

247. ORRIS ROOT.-Characteristic starch grains 15 to $30 \mu$ in diameter; scalariform tracheæ $25 \mu$ in diameter; no cork; calcium oxalate in raphides or in long pyramids (Figs. 317, A, 320 ). Coarse angular fragments of orris root, which have been colored with yellow, green and red aniline dyes, are sometimes present in a so-named Japanese pot pourri which is used for filling rose jars.

248. QUILLAJA.-(See No. 210.)

249. BRYONIA.-Starch grains single or two or more compound, from to to $20 \mu$ in diameter; occasional acicular crystals $200 \mu$ in length ; tracheæ 35 to $60 \mu$ wide, associated with yellowish colored cells; cork cells yellow; powder colored purplish and reddish-brown with sulphuric acid.

249a. CALAMUS.-(See No. I 28.)

249b. ULMUS.-(See No. I29.)

$\beta$ Soluble in or Swelling in Cold Water to Form a Sticky Mass.

250. TRAGACANTHA.-Slowly affected by water; fragments of tracheæ and parenchyma; starch grains more or less spherical and from 2 to Io $\mu$ in diameter (p. 652).

\section{B. WITHOUT STARCH.}

a. CAlcium oXAlate PRESEnt.

25I. SCILLA.-Raphides very long, being sometimes I or 2 $\mathrm{mm}$. in length, and occurring either in mucilage cells or free in the powder or aggktutinated mass; also isolated fragments of fibrovascular tissue (Fig. 281, $B$ ).

\section{$b$. Calcium oxalate wanting.}

252. NUX VOMICA.-Grayish-white (Figs. $283, B ; 3 \mathrm{I} 8$ ); odor slight; taste intensely and persistently bitter; epidermal cells modified to strongly lignified hairs; endosperm cells containing 
a fixed oil and aleurone grains, thick-walled, finely porous and giving a blue or violet color., with potassium dichromate and sulphuric acid. Small, nearly spherical starch grains occur in the tissues of adhering fruit pulp.

253. ALMOND.-Both bitter almonds and sweet almonds .ave characteristic, rectangular, somewhat rounded stone cells in the outer epidermal layer of the seed-coat. These stone cells are from 70 to $I 75 \mu$ long and from 65 to IOO $\mu$ wide; the walls are from to to $15 \mu$ thick and have numerous simple pores. The seed-

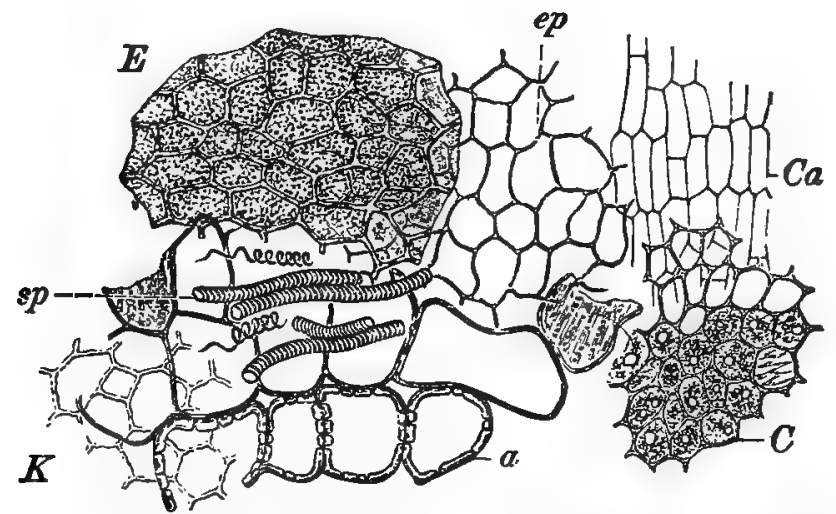

- FIg. 3 I9. Almond meal: a, stone cells of the outer epidermis; K, brown hypodermal cells; sp, spiral tracheæ of the seed-coat; ep, cells of inner epidermis with brown contents; $\mathbf{E}$, cells of the endosperm containing numerous small aleurone grains; $\mathrm{Ca}$, epidermal cells of cotyledons; C, parenchyma of the cotyledons containing aleurone grains and oil.-After Moeller.

coat also contains tracheæ with spiral thickenings, associated with which are cells containing rosette-shaped or prismatic crystals of calcium oxalate that are about $7 \mu$ in diameter. The endosperm consists of a single layer of nearly cubical cells about $15 \mu$ in diameter. The cells of the embryo contain numerous aleurone grains, which are from 5 to $\mathrm{I} 5 \mu$ in diameter and consist of crystalloids, globoids and calcium oxalate (Figs. $187 ; 188 ; 302, D$; 319).

Substitutes. - The seeds of other plants of the Rosaceæ are sometimes substituted for Almond seeds. These usually have a bitter and more or less disagreeable taste; the outer epidermal cells in apricot and plum being elongated tangentially, while those of peach are somewhat narrower and more or less conical. 
Almond menL consists chiefly of the tissues of the embryo. The so-called almond meal which is used as a cleansing agent consists of ALMOND CAKE, a by-product in the manufacture of almond oil, to which are added other substances to give it a pleasant odor, as orris root (see No. 247). A spurious almond meal consists of wheat middlings to which powdered soap and some volatile oil or triple extract are added.

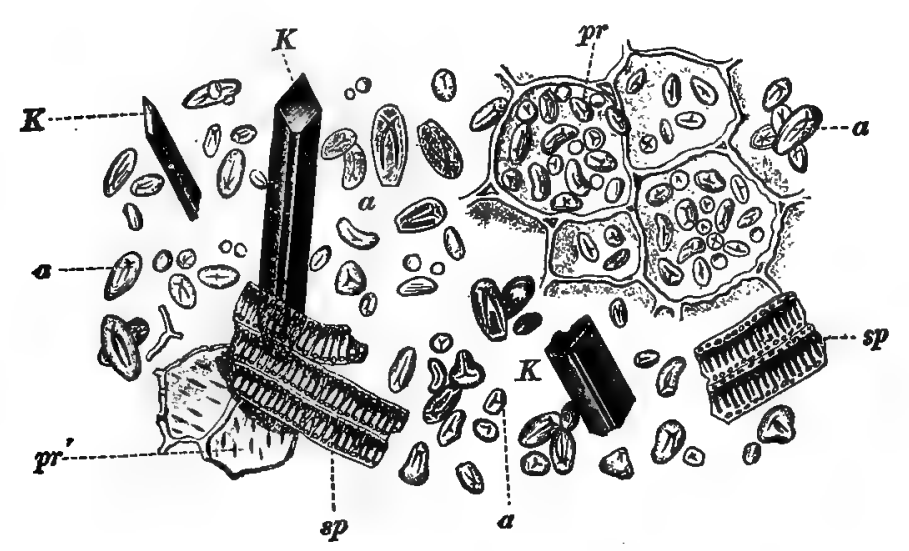

FIG. 320. Orris root: pr, parenchyma containing starch grains; a, starch grains with characteristic cleft; $\mathrm{pr}^{\prime}$, parenchyma with narrow oblique pores; $\mathrm{sp}$, fragments of tracheæ; K, prisms of calcium oxalate.-After Vogl.

\section{ABSENCE OF PLANT TISSUES.}

\section{$A$. SOLUBLE IN WATER.}

254. ACACIA (WHITE).-Soluble in cold water forming a sticky mass; few plant tissues present (p. 643).

255. SACCHARUM.-Crystals in rhombic prisms which are insoluble in fixed oils, chloroform or ether, but soluble in water, alcohol or glycerin.

\section{B. INSOLUBLE IN WATER.}

a. SOLUBLE IN ALCOHOL.

256. CAMPHORA.-Liquefies in mounts of glycerin and chloral; glycerin mounts show irregular masses, nearly insoluble in water but soluble in alcohol, and fixed and volatile oils. 
b. INSOLUBLE IN ALCOHOL.

a Reddish Color With Sulphuric Acid After Some Time.

257. SACCHARUM LACTIS.-Small and large irregularshaped crystals insoluble in mounts of glycerin, or alcohol.

B No Color Reaction With Sulphutric Acid.

I. Soapy Feel.

258. TALCUM (MAGNESIUM SILICATE).-Rather long, irregular, lustrous and broken crystals.

2. Soluble in Acetic Acid.

* With Effervescence.

259. CALCII CARBONAS PR.ÆCIPITATUS.-By adding hot solution of ammonium oxalate to an acetic acid solution of this salt on a slide, crystals of calcium oxalate are obtained. Mounts in glycerin show rosette aggregates or cubical crystals of a rather uniform size.

260. CRETA PRÆPARATA.-Same treatment as above. The resulting calcium oxalate crystals are triangular and cubical and not of uniform size.

261. BARIUM CARBONATE.-Add sulphuric acid, and in glycerin mount the barium sulphate precipitate occurs in very small particles.

\section{** Soluble in Acetic Acid Without Effervescence.}

262. MAGNESIA PONDEROSA.-In glycerin mount alone small, rounded masses are observed, frequently grouped together; if a few milligrams be dissolved in citric acid on a slide or watch crystal, then a few drops (excess) of ammonium hydrate and sodium phosphate solution be added, and stirred vigorously with a glass rod, triangular or tetragonal crystals are formed.

263. MAGNESIA. - In a glycerin mount the masses have the appearance of heavy magnesia, but are larger and more trans- 
parent. On treatment with citric acid, ammonium hydrate and sodium phosphate, the crystals of ammonium-magnesium phosphate in glycerin mount are large, star-shaped, and look like snow crystals.

3. Insoluble in Acetic Acid.

* Soluble in Nitric Acid.

If necessary, in deciding on any of the next four powders, they are to be fused with potassium carbonate or sodium carbonate, and a regular qualitative chemical separation effected.

264. CALCII PHOSPHAS PRÆCIPITATUS.-In glycerin mount alone small tetragonal and cubical crystals are observed. If to a few milligrams of the powder on a slide a few drops of nitric acid are added, and then a small quantity of ammonium molybdate solution, stirring well with a glass rod, small, yellow, diamond-shaped crystals are observed, which are permanent in glycerin mounts.

265. CALCII SULPHAS.-In glycerin mount alone needleshaped crystals, or long crystals in masses which look like a group of sclerenchyma fibers, are observed. The flame test with platinum wire gives bright reddish-yellow.

266. BARIUM SULPHATE.-In glycerin mount alone irregular-shaped crystals varying in size are observed. The flame test is green.

267. TERRA ALBA.-This powder is composed of aluminum silicate and magnesia and occurs in irregular masses. 


\section{PART III.-REAGENTS.}

THE reagents that have been recommended for microscopical work are quite numerous, and while nearly all of them may have more or less special merit, the number of reagents actually required in practice is fortunately quite small.

It is important that the student recognize the necessity for a 1 thorough understanding of the structure of the material under examination rather than place too much dependence upon the effects produced by reagents; in other words, the study of structure should precede the use of reagents, particularly stains, when it will often be found that the latter can be dispensed with entirely.

The chemicals that are employed in microscopical work, either as reagents or for other purposes, may be classified as follows: (I) Preservatives, (2) Fixing and Killing Agents, (3) Hardening and Dehydrating Agents, (4) Clearing Agents, (5) Stains and (6) Special Reagents.

PReservitives are substances used to preserve material which is to be examined. The most important of these are alcohol (from 40 to 95 per cent.) and formalin [ 2 to 6 per cent. aqueous or alcoholic (6o per cent, alcohol) solution], the latter of which is considered advantageous in the preservation of specimens containing coloring substances, as leaves, flowers, etc. Almost any antiseptic of the proper strength may be used as a preservative.

Fixing or Kileing Agents are more especially employed in the study of the protoplasmic cell-contents, where by their ise the life-processes of the cell are brought to a sudden termination, the object being to fix the contents in a condition approaching as nearly as possible the normal living state. In order to carry out this operation successfully, the living specimen must be placed in the fixing or killing agent as soon as collected, and if the specimen is large it should be cut into small pieces. The following are some of the common fixing agents: Chromic acid in 0.5 to I per cent. aqueous solution; osmic acid in $\mathrm{I}$ to 2 per cent. aqueous solution; 798 
Flemming's mixture, which is an aqueous solution of chromic acid (0.25 per cent.) containing o.I per cent. of osmic acid and o.I per cent. of acetic acid; picric acid in concentrated aqueous or alcoholic solution; picric-sulphuric acid, a concentrated aqueous solution of picric acid containing 2 per cent. by volume of sulphuric acid; and mercuric chloride (corrosive sublimate) used in O.I to I per cent. aqueous or alcoholic solution.

Hardening or Dehydrating Agents are those substances which are employed for the purpose of hardening the specimen so as to facilitate sectioning and for removing the water, which would interfere with its examination. Alcohol is to be regarded as the principal hardening or dehydrating agent, and considerable care is necessary in its use; the specimen is treated successively with alcoholic solutions of gradually increasing strength, beginning with a 35 per cent. solution, in which the specimen is kept for twenty-four hours; then it is placed in 50 per cent. alcohol for from six to twenty-four hours, and then in 70 per cent. alcohol, in which it may be kept until ready for use. In order to avoid shrinking of the material at this stage, it may be kept in a solt1tion of alcohol and glycerin, or oil of bergamot, or a mixture of xylol and paraffin. When the material is to be examined it should be removed to 85 per cent. alcohol for from six to twentyfour hours, then to 95 per cent. alcohol and absolute alcohol successively for the same length of time. Of the other dehydrating agents the most important are anhydrous glycerin, pure carbolic acid, and anhydrous sulphuric acid, the latter being used in a desiccator and not applied directly to the specimen.

Making of Sections.-Sections of roots, stems, barks and many fruits and seeds can be made directly without embedding the material, and while sections can be made holding the material in the hand, between the thumb and three fingers, the hand microtome for holding the material may be used by those who are less experienced. In the sectioning of leaves and other material that is not firm, and fruits and seeds which are too small to hold in the hand, the material should be embedded in some substance which will hold it and give it stability. When the tissues are not too hard the material may be placed between pieces of elder or sunflower pith. In some cases the making of sections is facili- 
tated by moistening both the pith and the razor. In the case of seeds and fruits which are very small and at the same time very hard, as colchicum and mustard, it is best to use a velvet or fine grade of cork for holding the material. The cork is indented by means of forceps and the seed or fruit forced into the cavity.

In the case of very delicate tissues, where the protoplasmic contents of the cells are to be studied, as in the ovaries of flowers, prothalli of ferns and other parts of the plant, where cell division is going on, the material should be embedded in paraffin or celloidin, subsequently hardened, and sectioned by means of a finely adjusted microtome.

Clearing Agents.-Most dehydrating agents are also clearing agents, because of the fact that the air and water in the specimen are replaced by a medium having greater refractive properties. Some clearing agents act chemically on the tissues and cellcontents. Among the clearing agents most frequently employed are: Chloral in saturated aqueous solution, and chloral-glycerin solution (a solution of equal parts of glycerin and water saturated with chloral). Essential oils, as clove, turpentine, cedar, marjoram, etc., are also useful for this purpose, particularly when the specimen is to be mounted in Canada balsam.

Staining Agents are those that produce more or less definitely colored compounds with the cell-contents or walls. They include: (I) the Aniline Dyes and (2) Non-aniline Stains:

The aniline stains may be used in aqueous solutions, weak alcoholic solutions or strong alcoholic solutions, containing from I to 3 per cent. of the dye. The following are the aniline stains most frequently employed: Aniline blue, Bismarck brown, fuchsin, gentian violet, methylene blue, methyl violet and safranin. In addition to these, aniline hydrochloride or sulphate is used in what is known as Wiesner's Reagent, which is a 25 per cent. solution of alcohol containing 5 per cent. of either of these salts, a drop of either hydrochloric or sulphuric acid being used with a drop of the solution, according as the hydrochloride or sulphate has been used.

LøFfler's Methylene Blue.-This reagent is prepared by adding 30 c.c. of a concentrated alcoholic solution of methylene blue to Ioo c.c. of water containing Io milligrams of potassium hydrate. 
Ziel's CARBol-Fuchsin.-This solution is prepared by adding I 5 c.c. of a concentrated alcoholic solution of fuchsin to Ioo c.c. of water containing 5 grams of carbolic acid.

Aniline Dyes are usually employed in concentrated aqueous solution, but owing to the difference in solubility of the dyes the solutions vary in strength. Saturated solutions of eosin or gentian violet may be prepared by dissolving I gram of the dye in Ioo c.c.

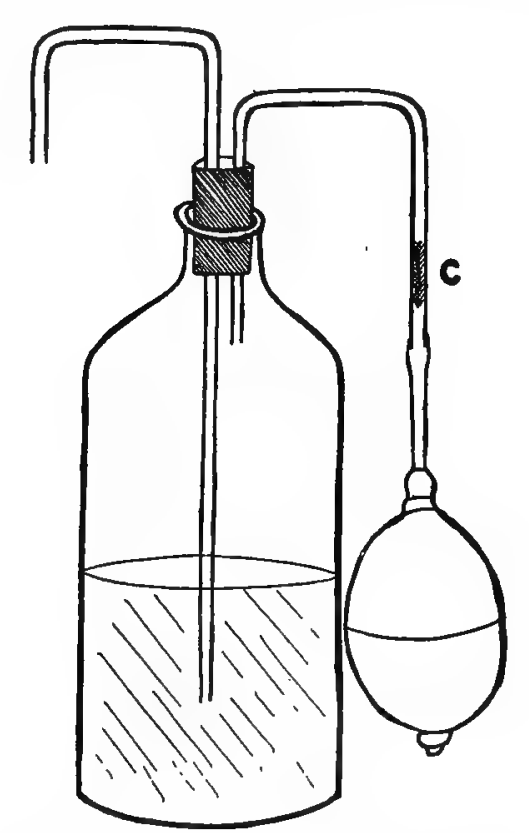

Frg. 321. Reagent bottle for sterile solutions.

of water, while to make a saturated solution of methylene blue requires $0.400 \mathrm{Gm}$. of the dye to Ioo c.c. of water. Some investigators prefer to replace the distilled water with aniline water, which is prepared by adding about 3 grams of anilin oil to Ioo c.c. of distilled water.

Reagent Bottle for Sterile Solutions.-The solutions of the aniline dyes as ordinarily prepared deteriorate more or less rapidly and are usually made up fresh each time they are required for use. These solutions, as well as other reagents that are prone 
to decomposition, may, however, be kept for months or even years by preparing them with care and keeping them in a special kind of bottle (Fig. 321). An ordinary bottle may be used, and is fitted with a rubber stopper perforated so as to allow the introduction of two glass tubes. These tubes are bent twice at right angles and the free ends directed downwards. One of the tubes is connected with an atomizer bulb and serves for forcing out the liquid. A small plug of absorbent cotton is placed in the tube at the point $C$, so as to filter the air. This may be improved by blowing a bulb in the tube for holding the cotton. The bottle should be sterilized before placing the solution in it, and the solution should be made by adding the dye to sterile water contained in the bottle. The solution may be afterwards further sterilized by means of steam if this should be found necessary, as in this way only a perfectly sterile solution could be produced.

The non-aniline stains give, as a rule, more reliable and constant results in the study of cell walls, as in the roots, stems and other parts of the plant, than the aniline stains. They include the following:

Beale's Carmine Solution, which is made as follows: Mix o.6 Gm. carmine with $3.75 \mathrm{Gm}$. ammonia water (ro per cent.) ; heat on a water-bath for several minutes; then add $60 \mathrm{Gm}$. of glycerin, $60 \mathrm{Gm}$. of water and $15 \mathrm{Gm}$. of alcohol, and filter.

Grenaciler's Borax-Carmine Solution.-Disolve 2 to 3 $\mathrm{Gm}$. of carmine and $4 \mathrm{Gm}$. of borax in 93 c.c. of water and then add Ioo c.c. of alcohol ( 70 per cent.); shake and filter. When this stain is employed the sections are freed from an excess by the use of alcoholic solutions of borax or oxalic acid.

Hoyer's Picro-Carmine Solution is made by dissolving carmine in a concentrated solution of neutral ammonium picrate. A solution of carmine and picric acid is known as Picro-Carmine Solution.

Chlor-Zinc-iodide Solution, or Schulze's Cellulose Reagent, consists of anhydrous zinc chloricle, $25 \mathrm{Gm}$.; potassium iodicle, 8 Gm., and water, 8.5 .Gm., to which as much iodine is added as the solution will dissolve.

Bohmer's Hamatoxylin Solution is prepared by mixing the two following solutions and filtering after allowing the mix- 
ture to stand for several days: $(a)$ one part of a 3.5 per cent. alcoholic (95 per cent.) solution of hæmatoxylin and $(b)$ three parts of a 0.4 per cent. aqueous solution of potassium alum.

Delafield's Hamatoxylin Solution, which is also incorrectly called "Grenacher's Hæmatoxylin Solution," is made by mixing the following solutions: (a) Hæmatoxylin $4 \mathrm{Gm}$., alcohol 25 c.c. and (b) 400 c.c. of a saturated aqueous solution of ammonia alum; this solution is exposed to the light for three or four. days, filtered, and then roo c.c. each of glycerin and methyl alcohol are added, the solution allowed to stand for several days and. finally filtered. An excess of the stain is removed from the sections by subsequent washing either with a 2 per cent. alum solution or an acidified alcoholic solution.

Iodine and Potassium-Iodide Solution consists of iodine, I3 Gm. ; potassium iodide, $20 \mathrm{Gm}$. ; water, roo c.c.

IODINe Water is prepared by adding as much iodine to dis-, tilled and sterilized water as it will dissolve (about I : 5,000 ).

Chloral-Iodine Solution consists of a saturated aqueous solution of chloral, to which as much iodine is added as it will take up.

Phloroglucin Solution, used as a test for lignin (p. i 82 ), is a 0.5 to 2 per cent. alcoholic solution of phloroglucin, which is used in conjunction with hydrochloric acid.

Iron Solutions are aqueous or alcoholic solutions containing 5 to 20 per cent. of ferric acetate or ferric chloride. These are mostly used as tests for tannin, giving either a bluish-black or greenish-black coloration or precipitate.

Copper-Acetate Solution is a 7 per cent. aqueous solution of cupric acetate (p. I8I).

Schulze's Macerating Solution is prepared by adding crystals of potassium chlorate from time to time to warm concentrated nitric acid. It is employed in the isolation of lignified cells.

Special Reagents comprise all those substances which are employed in the morphological study of the cells, and include solutions of the alkalies (o.I to 6 per cent.), solutions of the mineral acids, which may be weak or concentrated, and solutions of organic acids, as acetic and citric. 
Double Staining, or the use of two stains in the examination of a specimen, furnishes not only a means of beautifying the specimen, but also has a certain diagnostic value. The following are some of the combinations used: (a) aqueous solutions of carmine in connection with alcoholic solutions of iodine green; $(b)$ alcoholic solutions of hæmatoxylin and safranin; $(c)$ solutions of eosin and methylene blue; $(d)$ solutions of fuchsin and methylene blue; $(e)$ solutions of gentian violet and Bismarck brown.

MOUNTING OF SPECIMENS.-Microscopic preparations or mounts are of two kinds: they may serve a temporary" purpose only or they may be prepared so as to serve for future study, the latter being known as PERMANENT MOUNTS.

In taking up the study of a specimen it should first be mounted in water and examined; then the water may be replaced by a weak aqueous solution of glycerin ( 5 to Io per cent.) and the specimen examined again. After this preliminary examination other agents and reagents may be employed. Specimens mounted in glycerin will keep for several days and even months. Generally speaking, the only effect which the glycerin has on the tissues or contents is that of swelling them, which is obviated, to a greater or less extent, however, if the glycerin is washed out after an examination is made.

In addition to the methods involving the use of glycerin, there are two ways of making permanent mounts, depending upon the employment either of Canada balsam or glycerin jelly as the mounting medium. The method involving the use of the latter is the simpler, and leaves the specimen in such a condition that a re-examination with reagents can be made if desirable. GLyCERIN-JELLY MOUNTS are made as follows: Specimens which have been previously treated are transferred to glycerin and allowed to remain for several hours, the excess of glycerin removed, and the specimen transferred to a warm slide on which a drop of glycerin jelly ${ }^{1}$ has been placed. The preparation is warmed slightly to

${ }^{1}$ Kaiser's Glycerin Jelly.-Soak 7 Gm. of gelatin in $42 \mathrm{Gm}$. of water for two hours; dissolve I $\mathrm{Gm}$. of carbolic acid in $49 \mathrm{Gm}$. of glycerin; mix the two solutions; heat on a water-bath, with occasional stirring, for fifteen minutes, and finally filter through glass wool. The jelly is warmed slightly to liquefy it before using. 
remove air-bubbles, and a warm coverglass applied, care being taken to prevent the formation of air-bubbles. Evaporation of the glycerin jelly is prevented by the use of shellac cements, asphalt varnish or candlewax.

The following method may be used for the preparation of Canada balsam mounts: The specimen is cleared, dehydrated by the use of alcohol and then placed in chloroform or benzol. The clearing of the specimen is materially assisted by placing it in oil of cloves or turpentine prior to mounting it. A drop of Canada balsam solution ( $\mathrm{I}$ part of balsam to 3 parts of chloroform or benzol) is placed on a slide and the specimen mounted. When the preparation is nearly dry, scrape off the excess of balsam, clean the slide and coverglass with chloroform or benzol, and ring with cement.

Dried Material.-Most of the vegetable drugs and some of the vegetable foods occur in commerce in a more or less dried condition, a.ld in order to study them microscopically it is usually necessary to give them some preliminary treatment. With the majority of drugs, soaking in hot or cold water for from a few minutes to a few hours will render them sufficiently pliable or soft for sectioning. After this the material is hardened by placing it in alcohol (6o to 70 per cent.) for a few hours or over night. It may then be sectioned and treated with special reagents or stains as desired. 



\section{INDEX.}

Abelmoschus, 331

Abies, 187

Abies balsamea, 79

Abortive, I35

Abrin, 300

Abroma, 333

Abrus, 299, 474

Absinthe, 397

Absinthiin, 397

Absinthium, 396

oil of, 396

Absinthol, 397

Abuta, 274, 462

Abutilon, 33I

Acacia, 299, 643, 652, 667

artificial, 689

Catechu, 294

powder, 795

Senegal, 294

species, 644

Acajou gum, 322

Acanthaceæ, 377

Acanthus family, 377

Accumbent, I55

Acer species, 323

Aceraceæ, 323

Aceras, 590

Achillea, oil of, 399

Achillea species, 399

Achras, 359

Achyranthes, 265

Acid, abiennic, 682

abietinolic, 682

alantolic, 399

anisic, 565

anthemic, 555

arabic, 644, 652

artanthic, 6I7

aurantiamaric, 592

benzoic, 673

butyric, 300,319

caffeic, 521

caffeotannic, 52I

calumbic, 460

cambogic, 648

caryophyllinic, 549

catechutannic, 666

cathartic, 6ro

cetraric, 690
Acid, chrysophanic, $476,525,609$

cinchotannic, 52I

cinnamic, 673

citric, 594

cubebic, 57I

dextropimaric, 670

digallic, 646

elateric, 387

ellagic, 536

embelic, 574

ergotinic, 692

eriodictyonic, 6r 3

eucalyptic, 600

euonic, 532

ferulaic, 672,675

filicic, 687

filixtannic, 687

frangulic, 522

gallic, 647 .

gelsemic, 482

gentiotannic, 485

gentisic, 484

glycollic, 328

guaiacic, 669

guaiacinic, 669

guaiaconic, 669

guaiaretic, 669

gummic, 644, 652

hederic, 350

hydrocyanic, 537

ipecacuanhic, 469

isobutyric, 557

isovalerianic, 505

jervic, 494

kinic, 520

kombic, 431

krameric, 455

lactucic, 649

lævopimaric, 670

lichenostearic, 690

lupamaric, 583, 594

lupulic, 594

maizenic, 558, 693

meconic, 660

ophelic, 638

pectic, 288

pectosic, 288

phyllic, 539

phytolaccic, 466,467
Acid, pimaric, 68I pinitannic, 684 pipitzahoic, 400 podophyllic, 508 polygalic, 456 protocatechuic, 543

pyrethric, 456

quercitannic, 543

quillajice, $54 \mathrm{I}$

resinolic, 654

rheumic, 476

santalic, 547

scammonic, 657

sclerotic, 692, 693

sinapic, 428

sinapine sulphate, 428

sphacelinic, 692

syringic, 525

tannic, 646

tartaric, 594

valerianic, 527

viburnic, 527

Acid-resins, 654

Acids, fruit-, 288

Aconite, 477

Indian, 480

Japanese, 479

leaves, 480

Aconitine, 477

Aconitum, 477

Napellus, 268

powder, 771

species, 479,480

Acorin, 496

Acrinyl sulphocyanide, 428

Actæa, 272

Actinomorphic, 136

Acuminate, II 2

Acute, II2

Adansonia, 33I, 332

Adder's tongue family. 63

Adhatoda, 378

Adhesion, r34

Adiantum, 58, 63, 64

Adlumia, 282

Adnate, 128

Adnation, I34 
Adonidin, 496

Adonis, 272, 496

Ecidiospores, 38

Acidium, 38

Erobes, 222

Esculin, 324, 536

Esculus, 324

Afzelia, 299

Agar-Agar, I6

Agaric, deadly, 30

fly, 3I

Agaricus campestris, 29,30

trehalose in, 168

Agave, 240

Aggregatæ, 385

Agropyron repens, 227

Agrostemma, 218

Ailanthus, 310, 546

Ailanthus family, 309

Air-plants, 235

Aizoaceæ, 267

Akene, I47

Alæ, 248

Alantol, 399

Alantolactone, 399

Alaria, I6

Albizzia, 299, 644

Albumien of seed, 152

Alcohol, ceryl-, 3I7

melyl- 3I7

myricyl-, 319

Aleurites, 316-318

Aleurone grains, I73

in cereals, 226

Alfa, 230

Alizarin; 38I

Alga-like Fungi, I8

Algæ, 8

as foods, 16

Blue-green, 8

Brown, 8, I3

destruction of, 378

economic uses, I5

Green, 8

in medicine, 16

Red, 8, I3

Alkaloids, 168

Alkanet, 367

Alkanna, 367

Alkannin, 367

Allium, 239

Allspice, 574, 575

crown, 575

Mexican, 575

powder, 755

stems, 756
Allspice, Tobasco, 575

Almond, bitter, 433

cake, 795

meal, 795

meal, spurious, 795

' powder, 794

sweet, 434

Almonds, 287, 322

Jordan, 434

pistacio, 322

substitute for, 337,794

Aloe Perryi, 237

spicata, 238

vera, 238

Aloe wood, 312, 343

Aloes, 66r

adulterants, 665

Cape, powder, 750

Curaçao, powder, $78 \mathrm{I}$

Jafarabad, 666

Natal, 665

Socotrine, powder, 781 varieties, 663,664

Aloin, 664

Aloinose, 665

Alpinia, 242

Alsine, 268

Althæa,

$329,33 \mathrm{I}, 450,45 \mathrm{I}$

mucilage in, 176

officinalis, 329

powder, 754 substitutes, $45 \mathrm{I}$

Altingia $68 \mathrm{r}$

Alum root, 286

Alyssum, sweet, 284

Amanita muscaria, 3I phalloides, 30,32

Amarantaceæ, 265

Amaranthus, 265

Amaryllidaceæ, 239

Amaryllis, 240

Amaryllis family, 239

Amber, 8I

Amber seed, 33I

Ambrosiaceæ, 392

Amelanchier, 287

Aments, 250

Ámido-succinamide, $45 \mathrm{I}$

Ammanni, 344

Ammoniac, 354 powder, 750

Amomum, 242
Amorpha, 298

Amygdala amara, 433 powder, 794

Amygdala dulcis, 434 powder, 794

Amygdalin, $287,434,537$

Amylodextrin, if :5, 367

Amylose, I64

Amylum, 642 .

Amyris, 309

Anabolism, 222

Anacardiacea, 319

Anacardium, 319, 322

Anacyclus Pyrethrum, 394

species, 456

Anærobes, 222

Anagyris, 300

Angmirta paniculata, 274

Ananas, 235

Anatropous, 126

Anchieta, 472

Andrœcium, 129

Andromedotoxin, 357,602

Andropogon, 227, 230

Anemone, 27I

Anemone camphor, 271 species, 116

Anemonin, 27I

Anemonol, 271

Anemophilous, 142

Anethol, 562, 564

Anethum, 354

Angelica, 354 species, 354

Angiosperms, 82 economic importance, 90

outer morphology of, 9 I

Angustura bark, 308

Anhalonidine, 342

Anhalonine, 342

Anhydro-atropine, 622

Aniline dyes, 801

Aniline hydrochloride, 182

Anime, 310

Anise, 560

Italian, powder, 740

Japanese star, 274

powder, 739

powder, admixed, 740 
Anise, star, 149, 274, 562

Anisodus, 619

Anisomeria, 266

Anisum, 560 adulterants, 562 powder, 739

Annuals, 4Io

Annular ducts, I90

Annulus, 59

Anobium, 420

Anogeissus, 644

Anona, 277

Anonaceæ, 276

Anthemis, 554 nobilis, 393 powder, 746 species, 554

Anthemol, 555

Anther, I26 appendages of, 128

Antheridium, 7, 48

Antherozoid, 7

Anthoceros, 53

Anthophylli, 347

Anthotaxy, I37

Anthoxanthum, 230,590

Anthraglucosennin, 608

Anthraquinone compounds, 608

Anthraquinones, 476

Antiaris, 124, 256

Antidesma, 317, 318

Apeiba, 329

Apical cell, I99

Apiol, 354

Apium, 354

Apoatropine, 622

Apocarpous, I23

Apocodeine, 659

Apocynaceæ, 363

Apocynein, 467

Apocynin, 467

Apocynum, 467

powder, 764

species, 363

Apothecia, 40

Apple, 288

bitter, 583

May, 273

oxydase in, 436

star, 359

Apricot, 288

of St. Domingo, 337

seed, 794

Aquifoliaceæ, 322

Aquilaria, 343
Arabin, 644, 648, 652

Aracex, 233

Arachis, I44, 300

Arales, 233

Aralia, powder, 76I

nudicaulis, powder, 752 species, 450

Araliacex, 350

Araliin, 450

Arasina, 649

Arbor vita, 683

Arbutin, 60I

Arbutus stamen, I27

trailing, 356, $60 \mathrm{I}$

Archegoniates, 44

(drugs), 684

Ärchegonium, 44, 48

Archesporium, 48, 86

Archichlamydeæ, 247

Arctium Lappa, 394

species, I53, 394

Arctostaphylos Uva-

$$
\text { Ursi, } 356
$$

Arctuvin, 60I

Areca, 23I

nut, 23I

Arecaidine, 232

Arecaine, 232

Arecoline, 232

Argania, 359

Argel leaves, powder, $72 \mathrm{I}$

Argemone, 280,483

Argithamnia, 318

Arillode, I55

Arillus, 155

Arisæma, 234

Arisarum (stamen), I27

Aristolochia species, 260

Aristolochiaceæ, 260

Aristolochiales, 260

Aristotelia, 328

Arnica, 55I adulterants, 552

montana, 394

powder, 746

rhizome, 552

Arnicæ flores, powder, 746

Arnicin, 55a

Arnotta, 338

Arrow-poisons, 299

Arrowroot, Bermuda, 785
Arrowroot, Brazilian, $366^{\circ}$

Maranta, 244

Montserrat, 787

St. Vincent, 787

Arrow-wood, 383

Artemisia, 55I species 396,397

Arthrospore, 42

Artichokes, globe, 402 Jerusalem, 402

Artocarpus, 257

Arum family, 233

water, 234

Asafetida, 671, 780

Asagrza (see Schoenocaulon ), 495

Asarone, 260

Asarum, I 20

canadense, 260

europœum, 260

A sclepiadace 2,365

Asclepiadin, 365

Asclepias, 365

Ascomycetes, 23

Ascophyllum, I6

Ascospores in yeasts, 24

Ascus, 18

- Ash leaves, powder, 7I7

mountain, 287

prickly, 533

white, 360

Asimina, 277

Asparagin, 45I

Asparagus, 239

Aspergillus, 26

Aspidium, 57, 60, 684 powder, 749 species, 687

Asplenium, $61,62,63,64$

Aspidosamine, 363

Aspidosperma, 363

Aspidospermatine, 363

Aspidospermine, 363

Assinilation parenchyma, I84

Astragalus, 299 gummifer, 294

Astronium, 646

Atherosperma (stamen), I27

Atriplex, 264

Atropa Belladonna, 372 
Atropa Mandragora,465

Atropamin, $6 z 2$

Atropine, 622

Atropous, 126

Attar of rose, 289

Aurantiamarin. 308,592

Aurantii Amari Cortex, 592

powder, 740

Aurantii dulcis cortex, 59 I

powder, 74I

Aurantiin, 592

Auxospores, I5

Avena, 227

Azorella, 653

Azulene, 554

Baccaurea, 318

Baccharine, 40I

Baccharis, 400

Bacillus, 44

hav, 43

subtilis, 43

typhosus, 357

Bacteria, 42

classes, 44

occurrence, 43

spiral, 44

sulphur, 44

Bacterium, 44 soil, 99

Balanophora, 259

Balanophoraceæ, 259

Ballota, 628

Balm of Gilead, $25^{\circ}$

Balm, sweet, 37I

Balsam, garden, 326 of fir, 68I

Balsaminaceæ, 325

Balsams, I79

Bamboos, 226

Banana, 244

Banksia, 258

Banyan tree, (see Ficus benghalensis), 257 false, 591

Baobab, 332

Baphia, 547

Baptisia, 298, 300

Barberry, European, 483

family, 272

Barbiera, 299

Barium carbonate, 796 sulphate, 797
Bark, 203

alder buckthorn, 52I

blackberry, 530

black haw, 525

adulterants, 527

Calisaya, 519

cinchona, 517

cotton root, 527

cramp, 532

cuprea, 52I

hamamelis, 527

Honduras, 546

Huanco, 521

inner, 5 II

loxa, 521

mezereon, 536

outer, 5 I2

pomegranate, 534

prickly ash, 532

sassafras, 539

slippery-elm, 544

soap, 54I

Wahoo, 53I

white oak, 54I

wild black cherry, 537

Barks, drug, 512

Picrasma, 546

Quassia, 546

Barley, 227, 575

flour, 791

plant, 228

Barosma species, 306

Barringtonia, 345

Basidia, 3I

Basidiomycetes, 3I

Basidiospore, I8

Basidiospores, 3I

Basidium, 18, 35, 38

Basil, sweet, 37I

Bassorin, 652

Basswood, 328

Bauhinia, 299

Bayberry family, 250

Bay rum, 347

Bdellium, India, 3 I I varieties, 673

Beale's carmine solution, 802

Bean, garden, 300

Bearberry, red, 6or

Bebeerine, 279

Bebeeru bark, 46r

Beberine, 46I

Bedstraw, 378, 382 sweet scented, 590

Beeberu, 279
Beech American, 254

family, 252

red, 254

Beech-drops, 4I 3 false, 355

Beet, 265

Beggiatoa, 44

Begonia, I24, 190

species, 34I

Begoniacex, 34I

Beilschmiedia, 54I

Belladonna leaves, 6zo powder, 725

Belladonna root, 463 powder, 757

Belladonnæe folia, 620 powder, 725

Belladonnæ radix, 463 powder, 757

Belladonna Scopolia, 509

Belladonnine, 622

Bell-flower family, 388

Benne oil, 377

Benzaconine, 478

Benzaldehyde, $434,537,539,673$

Benzoin varieties, 672

Benzoinum, 672 powder, $78 \mathrm{I}$

Benzol, 673

Benzoresin, 673

Benzoresinol, 673

Benzoyl-pseudotropine, 605

Berbamine, 483

Berberidaceæ, 272

Berberine, 483, 500, 501 tetra-hydro, 500

Berberis, 482 Aquifolium, 272 powder, 739 species, 483 stamen, I27

Bergamot oil, 307 wild, $37 \mathrm{I}$

Berries, cubeb, 569 Juniper, $68_{3}$ orange, 593 prickly ash, 534

Berry, 147.

Bertholletia, 345, 756

Beta, 265

Betel, 249

leaves, 249

nut, 23 I

Betula, 252 
Betulaceæ, 252

Bhang, 255, 635

Bichy, 435

Bicuculla, 282

Bidens, 155

Bifacial leaves, 107

Bigaradia oil, 307

Bignoniaceæ, 377

Bilabiate, I 30

Bilateral leaves, 108

Bilberries, 357

Bind weed, great, 366

Birch, 252

family, 252

sweet, 252

white, 679

Bird food, 378

Bird-lime, 259, 322

Birthwort family, 260

Bisabol, 675

Bissy-bissy nut, 435

Bistorta, 264

Bitter principles, 258 , $312,326,340,360$

Bittersweet, climbing, 323

Bixa, 338

Bixaceæ, 338

Black cohosh, 268

haw, 382, 525

mustard, 429

flour, 743

ground, 743

snakeroot, 268

Blackberries, 53I

Blackberry, high bush, 288

low, 288

sand, 288

Bladders, I3

Blade, leaf, 106, I30

Blights, 20

Blinding tree, 317

Bloodroot, 280, 508

Blue flag, 240

Blueberries, 357

Bluets, 378

Bocconia, 282 .

Bæhmeria I88, 257, 258

Bœrhavia, 265

Bohmer's hæmatoxylin solution, 802

Bolacho, 667

Bombaceæ, 33I

Bombax, 284

species, 331
Boneset, 626

climbing, 390

purple, 626

Borage family, 367

Boraginacex, 367

Border, I30

Bork, $5 \mathrm{I} 2$

Borneol, 279, 505

Bornyl valerate, 505

Boswellia, 3i r

Botrychium, 62, 63, I 20

Bougainvillea, I32; 265

Bouncing bet, 267

Box tree, 319 family, 319

Box wood, 46I

Boxes, cigar, 313

Brabeium, 258

Bracts, 131 structure of, 2II

Brandy, 328

Brassica, 283, 284 nigra, 283,742

species, $429,742,743,744$

Brauneria, 400

Brayera, 556

Brayerin, 557

Brazil-nut, 345 shells, 756

Bread, bitter, 386 Indian, 34 St. Johns, 300

Bread-fruit, 257

Bread-stone, I5

Bridelia, 317

Brier, wild, 289

Bromeliaceæ, 235

Broom, 637

corn, 230, 790

green, 294

Scotch, 294

Spanish, 637

Brooms, 230

Brownish powders, key, 70 ?

Brucamarine, 310

Brucea, 3I0

Brucine, 437

Bruguiera, 346

Bryonia, 387

powder, 793

species, 387

tendrils, I02

Bryonidin, 387

Bryonin, 387

Bryony, 387
Bryophytes, 45 economic uses, $\mathbf{5 5}$

Buchania, 322

Buchu, 602 Karoo, 603 powder, 7 I9

Bucida, 348

Buckeye family, 324 red, 324

Buckthorn, alder, 326,521

berries, 525

family, 326

Buckwheat, 264

family, 262

flour, $79 \mathrm{I}$

flower, I4I

hulls, 770

Budding, yeast, 23

Buds, Ioo

Buffalo berry, 344

Bulbs, 106

Bundle, fibrovascular, $20 I$

Burdock, I 53, 394, 465

Bursera, 3II, 312

Burseraceæ, 3I0

Bursine, 284

Bush, burning, 323

Butea, 656

Butter, cacao, 332

Cay-Cay, 310

shea, 358

tree, 436

vegetable, $35^{8}$

Butter-and-eggs, 376

Buttercup, 27I

Buttercup flower, I33

Butternut, 257

powder, 75I

Button bush, 382

Buttons, 3I, 23I

Buxaceæ, 319

Buxine, 461

Buxus, 279, 319, 46I

Bytteria, 546

Cabbage, 284

Cacao butter, 332 substitute, 33I

powder, 767 substitutes, 332

Cacao-red, 332

Cactaceæ, 342

Cacti, 342, 410

Cactus family, 342

Cadinene, 679 
Caducous, I31

Cæsalpinia, 300

Cæsalpinia species, 547

Crsalpinioidex, 292

Caffeine, 435

Cake-meal, 427

Calabar bean, 438

Calabarine, 439

Calamites, 69

Calamus, I85, 232, 233, 496 powder, 760

Calcarate, I3I

Calcii carbonas præcipitatus, 796

phosphas præcipitatus, 797 sulphas, 797

Calcium, 4 carbonate, I74 drugs containing, 702

oxalate, I7I drugs containing, 700

drugs without, 70I substances mistaken for, 702

Calendula, 555 officinalis, 394 powder, 740

Calendulin, 555

Calisaya bark, 519

Calla, 234

lily, 233

stamen, I27

Calligonum, 477

Callisia, 235

Callitris, $8 \mathrm{I}$

Calluna, 601

Callus, I9I

Calophyllum species, 335,336

Caltha, 50I edulis, 323

Calthrop family, 303

Calumba, 459 adulterants, 460 powder, 737 substitutes, 460

Calyptra, 48

Calyptrogen, 198

Calyx, I29 duration, I3I structure, 2I I

Camas, death, 495

Cambium, I99, 201
Cambogia, 648 powder, 749

Camelina sativa, 745

Camellia leaves, 335 powder, 7I7

Campanulaceæ, 388

Campanulatæ, 386

Campanulate, I3I

Camphor, 279

Borneo, 337

Camphora, powder, 795

Camptosorus, 62

Campylotropous, 126

Canada balsam, 68I

Canadine, 500

Canadinic resin, 68I

Canadinolic resin, 68I

Canadolic resin, 68I

Canadoresene, 68I

Canaigre, 264, 647

Cananga, 277

Canarium, 3I0, 3II

Canary grass, 124

Canavalia, 439

Cancer root, $4 \mathrm{I} 3$

Candles, night, 349

Cane sugar, 227

Canella bark, 339 powder, 754

Canellaceæ, 339

Canna species, 244 starch, 789

Cannabin, 636

Cannabindon, 636

Cannabinene, 637

Cannabinol, 636

Cannabis indica, 635 powder, 714 sativa, 255

Cannibene, 636

Cantaloupe, 388

Cantharellus, 30

Cantharidin, 344

Caoutchouc, 316, 667

Caper, spurge, 315 wild, 3 I 5

Caprifoliaceæ, 382

Capsacutin, 580

Capsaicin, 580

Capsella, 88, 284

Capsicum, 578 powder, 782 species, 375 standard, 580

Capsule, I47

Caragana, 474

Caraipa, 335
Carapa, 3 I3

Caraway, 565

black, 567

powder, 772

Carbohydrates, I6I-I68 (drugs), 640

Carbon, 3

Carboniferous age, 68

Cardamom, 58I Ceylon, 582

Cardamoms, bastard, 582

Cardamomum, 58r powder, 73I

Cardinal flower, 388

Cardol, 319

Carex, 23I

Careya, 345

Carica, 277, 34I

Caricaceæ, 34I

Carina, 248

Carnation, 267

Carnauba-wax, 232

Carnivorous plants, II9

Carob bean, 766

Caroba, 377

Carobine, 377

Carpaine, 34r

Carpel, 7 I

Carpels, 122

Carpinus, 252

Carpophore, I49

Carposid, 34I

Carrageenin, 689

Carragheen, 687

Carrot, 354 family, 352

Carthamin, 397

Carthamus, 397

Carum, 565

Ajowan, 354

Carvi, 352 powder, 772

Caruncle, 155

Carvacrol, 370, 37 I

Carven, 567

Carvol, 567

Carvone, 567, 632

Caryophyllaceæ, 267

Caryophyllene, 549

Caryophyllin, 549

Caryophyllus, 549 powder, 772

Caryopsis, I49

Cascara amarga, 546 sagrada, 523 
Cascara sagrada, powder, 759

Cascarilla bark, 316

Cascarillin, 316

Cascarin, 525

Casearia, 840

Cashew nut, 319

Cassava, 789

bitter, 789

sweet, 789

Cassia, 300

Batavia, 516

buds, 517 powder, $76 \mathrm{I}$

Canton, 517

fagot, 516

fistula, 585

lignea, 517

purging, 585

species, $292,293,610,767$

Castanea, 254, 646 powder, 720, 721

Castilloa, 668

Castor-oil, I 24 plant, 314

Catabolism, 222

Catalpa, 377

Catalpin, 377

Catechin, 666

Catechol, 655

Catechu, 666 powder, 782

Catkins, 250

Catnep, II3, 372

Cattle poisons, 357

Caulophyllum thalictroides, 273

Cavanillesia, 332

Ceanothus species, 326

Cedar, bastard, 303 camphor, 683 prickly, 679 red, 79,683

Cedar-wood oil, $3^{\mathrm{I}} 3$

Cedrela, 313

Cedrene, $68_{3}$

Cedrol, 683

Cedronin, 310

Celandine, 28I

Celastraceæ, 323

Celastrus scandens, 323,726 species, 323

Celery, 354

Cell, apical, 199 cavity, 186
Cell-contents, I56 examination, 180 non-protoplasmic, I6I

protoplasmic, 156

division, 5, 9

fission, 5

mother, 6

wall, I8I

Cells, beaker, 573

canal, 58

conducting, 188

forms, 184

guard, I93

helping, 86

kinds, 196

mechanical, I86

palisade, 2II

protecting, I92

resting, I I

secretion, I97

tapetal, 84

Cellulose walls, 183

Celosia, 265

Centaury, 362

Central cylinder, 199

Centrifugal, I84

Centripetal, 184

Centrosperma, 264

Centrospheres, 158

Century plant, 240

Cephaëline, 469

Cephaëlis Ipecacuanha, 379

Cephalanthin, 382

Cephalanthus, 382

Cephalaria, 386

Ceramium, I6

Ceratonia, 300, 766

Ceratopteris, 63

Cereals, 227

Cereus, night-blooming, 342

species, 342

Cerin, 194

Cetraria, 40, 4I, 689

Cetrarin, 690

Cevadilline, 495

Cevadine, 494

Chaff, 226

Chaia resin, 338

Chakazzi-copal, 299

Chamomile, English, 554

German, 394, 553

Roman, 393, 554

wild, 553
Champagne, 328

Chanterelle, 30

Charas, 635

Charcoal, 250 willow, 784

Charlock, 284 seeds, 743

Chaulnugra oil, 339

Chavica, 574

Chavicin, 573

Chavicol, 565

methyl, $37 \mathrm{I}$

Cheken, 347

Chelerythrine, 28I, 508

Chelidonine, 508

Chelidonium, 28I

powder, 73I

Chelidoxanthin, 28I

Chelone, 376

Chenopodiacex, 264

Chenopodiales, 264

Chenopodium, 264

powder, $77^{2}$ species, 264, 265

Cherry, 288

choke, 287

flower, I33

laurel, 539

leaves, powder, 7I7

wild black, 287,537

Chestnut, horse, 324

leaves, powder, 720,721

water, 350

wild, 258

Chestnuts, 254 substitute, 328

Chicle, gum, $35^{8}$

Chicory, 401 powder, 779

Chillies, 579

Chimaphila, 603, 720 species, 355

Chimaphilin, 604

China tree, $3 \mathrm{I} 2$

Chinquapin, I Io, 254

Chionanthin, 360

Chionanthus, 360

Chirata, 637 powder, 747

Chiratogenin, 638

Chiretta, 638

Chitin, I7

Chives, 239

Chloral iodine solution, 803

Chlorococcum, 39 
Chlorophora, 257

ChTorophyceæ, 8

Chlorophyll, 160 parenchyma, I84

Chloroplastids, I59

Chlorosis, I 34

Chloroxylon, 644

Chlor-zinc-iodide solution, 802

Chocolate, 768

adulterants, 769

Dika, 310

Gabun, 310

milk, 768 sweet, 768

Choline, 496, 692, 744

Chondrodendron, 462 tomentosum, 274

Chondrus, 13, 687

Chordaria, I6

Choripetalous, I 30

Chorisepalous, 130

Chorisis, I34, 33I

Christmas green, 7o

Chromatin, 158

Chromophyll, ז6o

Chromoplastids, I 59, I60

Chromosomes, I58

Chrozophora, 317

Chrysanthemum species, 395, 397, 401

Chrysarobin, 525, 780

Chrysophan, 476

Chrysophyllum, 359

Chrysosplenium, 286

Chrysotoxin, 692

Cicely, sweet, 354

Cichoriacex, 39I

Cichorium, 4OI powder, 779

Cicutine, 569

Cicutoxin, 569

Cigar boxes, 3I 3

Cilia, 42 of sperms, 56

Cimicifuga, 497 powder, 763 racemosa, 268

Cimicifugin, 498

Cinchona, 517

bark, 5 I7

calisaya, 5 I 9

flat, 518

mossed, 518

pallida, $52 \mathrm{r}$

powder, 765
Cinchona, red, 519, 521

renewed, 518

root, 5 I 8

species, 378,379

stem, 517

Tambla, 518

Cinchonidine, 519

Cinchonine, 519

Cineol, 243, 55I

Cinnamanin, 5 I6

Cinnamodendron, 339

Cinnamomum, $5 \mathrm{I} 3,76 \mathrm{I}$ powder, 760 species, $278,279,5 \mathrm{I} 3,5 \mathrm{I} 7$

Cinnamon bark, 5I 3

Cassia, 5 I6 powder, 760

Ceylon, 516 powder, 760

Saigon, 515 powder, 760

varieties, $5 \mathrm{I} 3$

white, 754

wild, 517

Cinquefoil, I20

Circæa, 349

Circinate, I2I

Circumnutation, II7

Cirrhiferous-pinnate, I 44

Cissampeline, $46 \mathrm{~T}$

Cissampelos, $46 \mathrm{I}$

Citrullus species, 386,388

Citrus species, 306

Cladonia, 39, 40, 69I species, 4I, 42

Claret, 328

Classes, 224

Clavaria, 30

Claviceps purpurea, 27

Claw of petal, I30

Claytonia, 267

Clearing agents, 800

Cleft, II 4, I64

Cleistogamous flowers, I 35

Clematis, 27I

Cliff brake, 6I, 62

Climbers, I04

Climbing plants, 409

Clitoria, 299

Clotbur, spiny, 401

Cloth, fulling of, 386

Clove, 130

bark, 517
Clove, fruit, 773

powder, 772

stems, 773

Clover, 301

Dutch, 230

white, 230

Cloves, adulterants, 549

artificial, 550

mother of, 347,549

standard of, 549

substitute, 336

varieties, 549

Club moss, varieties, 694

Clusia, 335, 336, 649

Cnicin, 400

Cnicus, 400

Coach-whip cactus, 338

Coal age, 69

Coalescence, 134

Coca, 604

family, 303

powder, 724

Cocaine, 605, 606 cinnamyl-, 605, 607

Cocci, 44

Coccogonin, 536

Coccos oil, 339

Cocculus, 274

Cocculus villosus, 450

Coccus, 267, 327

insect, 343

species, 338

Cochineal insect, 343

Cochlearia, 283

Cochlospermum, 652 species, 338

Cocillana, 256, 472

Cock's-comb, 265

Cocoa, 768

butter, 768

shells, 764

Cocoanut, 23I, 233 palm, double, I55 shells, 756

Codamine, 660

Codeine, 659

Coenocytic, 12, 20

Coffea arabica, 380

Coffee adulterants, 767 aroma, 38I

fig, 59I

grain, 380

hulls, 765

"imitation," 765

Mogdad, 767 
Coffee powder, 765 roasting, $38 \mathrm{I}$ sacca-, 765 substitutes, 33I, 765 sultan, 765 wild, 347,385

Coffee-tree, Kentucky, 299

Coffeol, 38 I

Cohosh, black, 497 blue, 273

Cola, 435 acuminata, 333 family, 332 species, 436 staminate, 436

Colchiceine, 5 IO

Colchici cormus, 5 Io powder, 771

Colchici semen, 426 powder, 77 I

Colchicine, 426, 5 Io

Colchicoresin, 426

Colchicum autumnale, 236

corm, 510 powder, 77I

Colchicum seed, 426 powder, 771

Coleoptera, 420

Collection of drugs, 406

Collenchyma, I86

Colletia, 326

Colletin, 326

Colliguaya, 317

Colloid in starch, 164

Colloidal substances, I6I

Colocynth, 583,743

Colocynthein, 583

Colocynthin, 583

Colocynthis, 583

powder, 743

Colocynthitin, 585

Colophony, 653,750

Coloring principles, $25 \mathrm{I}, 349$

black, $318,348,349$

blue, 284, 298, 3I7, 328,33 I

green, I 59, 252

purplish-red, 350

violet, 3I7

red, $254,268,275$,

$280,285,3$ I0, 326 ,

$334,344,349,38 \mathrm{I}$,
Coloring principles, red $546,547,558$ yellow, I60, 252, $254,257,258,262$, 28I, 299, 317, 325, $328,335,338,34 \mathrm{I}$, $343,344,349,381$, $382,483,484,498$, $525,543,555,558$ (see also tannin)

Colors, cell-sap, I69 white, I7I

Coltsfoot, 400

Colubrina, 326

Columbamine, 460

Columbine stamen, I27

Columbo, 459

American, 460, 486

Columelia stamen, I27

Columella, 22, 49

Column (in orchids), 245

Colutea, 610

Combretaceæ, 348

Combretum, 348

Comfrey, 367

Commelina, 235

Commelinaceæ, 235

Commiphora, 3IO, 3II species, 675

Compass plant, 400

Complete flower, 136

Conpositx, 390, 392

Comptonia, 25I

Conducting cells, r88 parenchyma, I85

Conduplicate, I2I, 155

Condurango, 365

Cone, I50

Confluent, I28

Conhydrine, 567

Coniceine. 568

Conidia, I7, 34

Coniferæ (drugs), 682 economic uses, 78

Coniine, 567

Conium, 567

herb, 568

maculatum, 352

powder, 7 I9

test, 740

Conjugation, II

Connate-perfoliate, I 4

Connective, I27

forms, I 28

Connigellin, 567
Connivent, 392

Conquinamine, 520

Consolidin, 367

Contorte, 360

Convallamarin, 490

Convallaria, 488

majalis, 238

powder, $76 \mathrm{I}$

Convallarin, 490

Convolute, 12I

Convolvulaceæ, 365

Convolvulin, 452

Convolvulus species, 366

Copaiba, 296, 299, 3I7

Langsdorffii, 296

species, 297

substitute, 337,440

Copal, Inhambane, 299 resins, 299

Copalchi bark, $3 \mathbf{I} 6$

Copalchin, 3 I 6

Copal-like resins, 3I I

Copernicia, 232

Copper acetate solution, 803

Coptis, 483,501

Corchorus, 329

Coriaceous, II 2

Coriamyrtin, 318

Coriander, 562 powder, 772

Coriandrol, 563

Coriandrum, 562

powder, 772

sativum, 352

Coriaraceæ, 3 I 8

Coriaria, 318

Cork cells, 194

Corm, I06

Corn, 227

bran, 790

cockle seed, 2I 8

meal, 790

meal moth, 420

plant, 228

(root tip), 93

silk, 558 powder, 785

smut, 693

squirrel, 282

Cornaceæ, 355

Cornicularia, 600

Corns, kinds, 229

Corn-salad, European, 385

Cornus, 355 
Cornutine, 691

Corolla, I29 duration, I3I structure, 2II

Corona in passion flower, 34I

Coronilla, 300, 637

Coronillin, 637

Cortex, I99 secondary, 202

Corydaline, 282

Corylus, 252

Corymb, I38

Coscinum, 460

Cosin, 557

Cosotoxin, 557

Coto bark, 280

Cotoneaster, 287

Cotton, 329, 330 adulterants, 44I dead, 44I purified, 440 substitutes, 331 varieties, 440

Cotton-root bark, 527 powder, $75 \mathrm{I}$

Cotyledons, 88, I 54

Couch grass, 227, 490

Coumarin, $230,377,589$

in ferns, 64 occurrence, 590

Coumarouna species, 589

Couroupita, 345

Covillea, 304

Cowhage, 300

Cranberry, 357 small, 6oI tree, 382

Cranesbill, 505

Crassulaceæ, 285

Cratægus, 292

Crateriform, I3I

Cratoxylum, 335

Cream-of-tartar tree, 332

Creeper, Virginia, 328

Cremocarp, I 49

Crenate, II4

Creosote, 254, 678 bush, 304

Cresol, 678

Cress, Indian, 302

Para, 40I

water, 283

Creta præparata, 796
Crinum, 240

Crocin, 241 resembling, 382

Crocus, powder, 746 sativus, 24I

Crotalaria, 299, 300

Croton seeds, 314 species, 316, 317

Tiglium, 314

Croup, 285

Crowfoot family, 268

Cruciferæ, 283

Cryptocarya, 440

Cryptocrystalline, I72

Cryptopine, 660

Crystal fibers, 172

Crystalline substances, 167

Crystalloidal substances, I6I

Crystals, cryptocrystalline, $I 72$

membrane, I72

Cubeb, adulterants, $57 \mathrm{I}$ camphor, 57I

false, $57 \mathrm{I}$

substitutes, 57I

Cubeba, 569

powder, 776

Cubebin, 57I

Cucumber, squirting, 387

tree, 275 sour, 332

Cucumis species, 388

Cucurbita, 185 Pepo, 387 species, 430

Cucurbitaceæ, 386

Cudbear, 42

Cudrania, 257

Culms, 225

Cultivated medicinal plants, 407

Cultivation of medicinal plants, 403

Culver's root, 376

Cumin aldehyde, 683

Cuminum, 354

Cuneate, II 3

Cunila, 372

Cuphea, 344

Cups, quassia, 544

Cupule, I 50

Cupules, 52

Curanga, 377

Curare, 274, 362
Curarine, 362

Curatella, 334

Curcas, 315

Curcuma, 244, 738 powder, 734

Curcumin, 244

Curing of drugs, $406,421,422$

Currant, buffalo, 286 fetid, 286 fruit like, 344

Currants, 286

Cuscuta, 367

Cusparia, 308

Cuspidate, II 2

Cusso, 556 adulterants, 557

loose, 557

powder, 774

Custard apple, 277 family, 276

Cutin, I92

Cutting, 404, 405

Cyanophyceæ, 8

Cycas revoluta, 789

Cydonia flower, I4I vulgaris, 288

Cydonium, powder, 745

Cyme, 138 compound, I38

Cynara, 402

Cynoglossine, 367

Cynoglossum, 367

Cynomorium, 259

Cyperaceæ, 230

Cyperus, 23I

Cypripedium, 490 powder, 762 species, 245

Cystoliths, I74

Cytisine, 299

Cytisus, 6 ro Scoparius, 294

Cytoplasm, 2, I57

Daisy, 401

Damascenin, 567

Damiana, 340

Damianin, 340

Dammar, black, 3II

Dandelion, 392, 458

Daphne, 343

Daphnin, 536

Daphnopsis, 537

Dasya, I3

Date-palm, 231, 233

Datisca, 34I 
Datiscaceæ, 34I

Datiscin, 34I

Datura species, 619, 624

Stramonium, 372

Daturine, 624

Daucus, 354

Debregeasia, 258

Deciduous, I3I

Deer berry, 128

Dehiscence, I47

circumcissile, I48

loculicidal, I 48

marginicidal, I47

septicidal, 147

septifragal, I48

Dehydrating agents, 799

Delafield's hæmatoxylon solution, 803

Delphinine, 428

Delphinium consolida, 428.

powder, 777

Staphisagria, 270

Delphinoidine, 428

Delphisine, 428

Dentate, II4

Dent corns, 230

Dermatogen, 198

Derris, 299

Desmodium, II 7

Development, arrested, I 35

Devonian age, 68

Dextrin, 165, 789

Dextrin-starch, 367

Dextro-glucose, I67

Dextrolichenin, 690

Dextrose, 167

Dianthus, 267

Diastase, 576

Diastases, I79

Diatoms, I3

Dicotyledons, 84, 247 venation in, IIO

Dictyopteris, 16

Dicypellium, 279, 517

Didynamous, 129

Diervilla. 385

Digitalein, 6I6

Digitalin, 616

Digitalinum verum, 616

Digitalis, 6I 3

adulterants, 727

powder, 727
Digitalis purpurea, 376 species, 616 substitute, 342,344

Digitalosmin, 6I 5

Digitin, 6г6

Digitonin, 616

Digitoxin, 6I6

Dillenia, 334

Dilleniaceæ, 334

Dicecious, 48, 136

Dionce, 285

Dioscorea, 240, 789

Dioscoreacex, 240

Diosma, 603

Diospyros species, 359

Diphtheria, 285

Diplococci, 44

Dipsacaceæ, 385

Dipsacus, 386

Diptera, 420

Dipterocarpaceæ, 337

Dipterocarpus, 337

Dirca, 343, 344

Discaria, 326

Discoid, 391

Dissepiments, 124 false, 125

Dissotis, 349

Dittany, American, 372

Divergence, I I8

Divided, II 4

Doassansia, 36

Dock, curled, 263

Dodder, 367

Dogbane family, 363 spreading, 363

Dog's tongue, 590

Dogwood family, flowering, 355 Jamaica, 299

Doona, 338

Dorema, 354

Dorsiventral, 5I flowers, I 37 leaves, Io7

Dracæna, 238

Dracontomelum, 322

Dragon tree, 238

Dragon's blood, $232,238,317$

American, 656

Dried material, sectioning, 805

Drimys, 275

Drosera species, II

Droseracea, 284
Droseras, 285

Drug specimen case, 424

Drugs, collection of, $418,42 \mathrm{I}$

collections, 424

crude, 4I7

forms of, 420

moldy, 422

preservation, 419, 422

pressed, $42 \mathrm{I}$

quality, 42I

storing, 4I9

time of collecting, $418,42 \mathrm{I}$ valuation, 423 .

Drupe, I 49 dry, I 49

fleshy, I 49

Dryobalanops, 337

Dryopteris, 57

Duboisia, 6r9

Duboisia species, 620

Duckweed family, 233

Ducts, 186, I 90 forms of, 190

Dulcamara, 373 powder, 726 substitutes, 726

Dulce, I6

Dulcitol, I68, 532

Durvillæa, I6

Dutchman's breeches, 282

Dye, black, 318, 348 , 349

Dyer's broom, 299

Dyes, 34I

Dysoxylum, 313

Earth, edible, I5

Eau d'ange, 347 de creole, 337

Ebenaceæ, 359

Ebenales, 358

Ebony family, 359 kinds of, 359

Ecballin, 387

Ecballium Elaterium, 387

Ecboline, 692

Ecgonine, 605, 607

Echinacea, 400

Echinate, 210

Echinocarpus, 328

Ecology, I

Economic plants, 408 
Edible bulbs, 239

flowers, 239, 259, 402 fruits, $233,257,258$, $264,277,288,289$, 292, 300, 306, 318, $327,328,329,33$, $332,337,34 \mathrm{I}, 343$, $344,347,348,531$, $576,590,593$

grains, 226

nuts, $25 \mathrm{I}, 252$

rhizomes, 235, 244, 268

roots, 283,366

seeds, 24I, 254, 258, $265,267,268,300$, $322,332,337,349$, 434

tubers, 234, 375, 402

Eel-grass, I3, I6

Egg, 7, 45

Egg cell, 86

Egg plant, 376

Elæaginaceæ, 344

Elæis, 232

Elæocarpaceæ, 328

Elastica, 316,667

Elaterin, 387

Elaterinum, 78I

Elaterium, 387

Elaters, 52

Elder, American, 384 mountain, 384 poison, 319 powder, 746

Elecampane, 397

Elemi, Bengal, 3 Io Manila, 3 3 о

Occidentale, 3ro

West India, 3ro

Eleocharis, 23I

Elettaria Cardamomum, 242

Elm bark, mucilage in, 176 powder, 760

European, 544

family, 254

white, 254

Emarginate, II2

Embelia ribes, 574

Embryo, development of, 88

Embryo, pro-, 88 -sac, 86,87 structure of, 218

Emetic drugs, 472
Emetic root, 47I

Emetine, 469

Emodin, 476, 522, 525, 608,610

Empleurum, 603

Emulsin, 434

Emulsion of almonds, 434

Endocarp, 145

Endodermis, 199

Endosperm, 90, 152 structure of, 218

Endospores, I7, 42

Endothecium, 84

Entada, 299, 439

Enterolobium, 299

Entire, I30

Entomophilous, I42

Enzymes, I79

Enzymes in Sarraceniales, $284^{\circ}$

Eperna, 300

Ephemeral, I3I

Epicarp, I45

Epicotyl, I54

Epidermal cells, 192

Epidermis, 209

Epigæa, 356, 60I

Epigynous, I32

Epilobium, 349

Equisetales, 56, 64

Equisetum, 64, 65, 69

Ergosterin, 692

Ergot, 27, 69I

keeping of, 422

powder, 779

trehalose in, 168

varieties, 692

Ergotine, 692

Ergotinine, 692

Ergotoxine, 692

Ericaceæ, 356

Ericales, 355

Ericinol, 601

Ericolin, 60I

Erigeron species, 393

Eriobotyra, 287

Eriodendron, 33I, 45I

Eriodictyon, 367, 612 powder, 7 I 4

Erysimum, 283

Erythræa, 362

Erythroxylacex, 303

Erythroxylon Coca, 303 species, 303 stamens, I28

Eschscholtzia, 280
Eseramine, 439

Eseridine, 439

Eserine, 439

Esparto, 230

Esprit d'Iva, 399

Estivation, I32

Etærio, I 49

Euasci, 23

Eucalypten, 600

Eucalypto1, 6oo

Eucalyptus, 599, 650

kino, 655

powder, 720

species, $346,600,601$, 655

Euchlæna, I24

Eucitrus group, 305

Eugenia, 348, 667 Caryophyllata, 346 species, 347

Eugenol, 279, 549, 575

Eumycetes, 23

Euonymin, 532

Euonymus, 53I atropurpureus, 323 powder, 752 species, 323,532

Euparin, 626

Eupatorin, 626

Eupatorit1m, 626 species, 392,626 powder, 727

Euphorbia, 315, 316 species, 3I7, 318, 47 I

Euphorbiaceæ, 3I4

Euphorbium, 3I7

Euryale, 268

Evergreens, 72

Evernia, 4I, 69I

Evolution, 3

Excocaria, 3I6, 3I7

Exhausted powders, 695

Exine, 85, 2I4

Exocarp, 145

Exogonium, 365

Exospores, I7

Exothecium, 84

Extract of malt, 576

Extract of witchhazel, 527

Extractive, amount of, 696

Extrorse, 126

Exudations (drugs), 640

Eyes, potato, I05 
Fabiana, 373

Fagaceæ, 252

Fagales, 252

Fagopyrum, 264

Fagus species, 254, 678

False bitter sweet, 726 flax, 745

Families, 224

Farinales, 235

Fastigiaria, I6

Fenchone, 564

Fennel, 563 dog, 626

Macedonian, 565

Roman, 565

powder, 740

water, 354

wild bitter, 565

Fenugreek, powder, 744

Ferment, peptonizing, 591

Ferments, 179

Fermentation, alcoholic, 21, 24

Fern, cinnamon, I20 grape, 62 groups, 60 male, $57,60,684$ ostrich, 62 spores, 63 sweet, 25 I

Virginia grape, Izo walking, 62

Ferns, 56, 57 tree, 60 true, 6I used as foods, 63 in medicine, 63 water, 63,64

Fertilization, 48, I39 cross-, I4I in angiosperms, 88 self-, I4O

Ferula species, 352,354

Fibers, bast, I 88 crystal, I72 isolation of, 188 textile, 235, 257, 329, 343 wood, 188

Fibrovascular bundle, 201

Ficus, 590, 688

Carica, 255 species, 256, 590, 59 I

Fig, 590 Indian, 343
Fig-tree, mulberry, 590

Figwort family, 376

Filament, I 26 structure, $2 \mathrm{I} 3$

Filbert, 252

Filicales, 56, 57

Filicic anhydride, 687

Filicin, 687

Fir, California silver, 79

European silver, $18 \mathrm{I}$ Scotch, 78

Fishberries, 274

Fish-poisons, 257, $<74$, $299,327,329, \quad 345$

Fissure, I64

Fixing agents, 798

Flacourtiaceæ, 339

Flag, sweet, 496

Flagella, 42

Flax, common, 303 family, 303

Flaxseed, 426 meal, 427. 745

Fleabane, Canada, 393 daisy, 393

Philadelphia, 393

Flemming's mixture, 799

Flindersia, 644

Flint corns, 230

Floats, I3

Floral envelopes, I29

Flores Pyrethri, 395

Florets, 39I

Flowers, arnica, $55 \mathrm{I}$

classes of, 136

Compositæ, I38

cotton, 530

disk, 138

double, I34

drug, 548

inner morphology,2II

ligulate, I38, $39 \mathrm{I}$

moss, 54

ray, 138, 391

structure, I2I

tubular, I38, 39 I

Flueggea, 3r7

Fodder plants, 226, 301

Foniculum, 563

powder, 740 vulgare, 352

Fœnum græcum, 744

Fœtidia, 345

Folia malabathri, 294

Follicle, I49
Fontinalis, 55

Food of plants, 2I9

Foods, 226, 23I, 233, 234 (see also Edible)

Forage, 226

Forget-me-not, 367

Fouquieria, 338

Fourcroya, 124

Four-o'clock fanily, 265

Foxglove, 376

Fragaria species, 292

Fragilaria, I4

Frangula, 52I powder, 735

Frangulin, 522

Frankincense, 3 II pine, 79

Frasera, 460, 486

Fraxetin, 360

Fraxin, 360, 650

Fraxinus species, 360

Fremontia, 333

French berries, 525

Fringe tree, 360

Fructose, I68

Fruit, I45

Fruit-sugar, I68

Fruits, classification, I5I

Daphne, 536

drug, 559

geocarpic, 300

inner morphology, 216

pomegranate, 536

Prunus serotina, 539

prickly-ash, 534

types, $\mathrm{I}_{4} 6$

wild black cherry, 539

xanthoxylum, 534

Fuchsia, I34, 349, 350

Fucus, I3, 16

Fuel, 55

Fugaceous, I3I

Fumaria, 280, 282

Fumarine, 280, 282

Funaria, 46, 55

Fungi, I6

economic uses, 33

edible, 33

fission, 42

groups, I7

pore, $3 I$

rust, 34,36 
Fungi, smut, 34 teeth-bearing, 3 I true, 23

Fungus, fairy-ring, 30, 31

Funiculus, 87

Funifera, 343

Funnel-shaped, I3I

Furfurol, 549

Fusanus, 259

Galangal, 242, 244

Galbalus, I49

Galbanum, 354

Gale, sweet, 25 I

Galeate, I3I

Galium, 378, 382, 590

Gall fly, 646

Galla, 646 powder, 732

Galls, Aleppo, 646 American, 647

Chinese, 32I, 647 powder, 7 I 4

development, 647

European, 253

Japanese, 32I, 647 powder, $7 \mathrm{I}_{4}$

on oaks, 252

powder, 732

rhus, 647

Turkish, 253

white, 647

Gambir, 666 powder, 782

Gamboge, 648 adulterants, 649

family, 335 powder, 749

Gamete-bearer, 50

Gametes, 7, 45

Gametophyte, 45 in angiosperms, 85,86 in Coniferæ, 77

Gamosepalous, I30

Ganja, 635

Garbling, 422

Garcinia Hanburyi, 335 species, $335,336,337$, $436,648,649$

Gardenia, 382

Garlic, 239

Gaultherase, 355

Gaultheria, 357

Gaylussacia, 357

Gelidium species, I6

Gelsemine, $48 \mathrm{I}$
Gelseminine, 48I

Gelsemium, 480 powder, 735 sempervirens, 362

Gemmæ, 52

Generation, asexual, 45,50 sexual, 45,50

Genista, 299, 300

Gentiamarin, 486

Gentian, 483 allied plants, 486 family, 362 horse, 384 powder, 778

Gentiana, 483 lutea, 362 powder, 778 species, 486

Gentianaceæ, 362

Gentianales, 360

Gentianin, 484, 486

Gentianose, I68, 485

Gentienin, 486

Gentiopicrin, 484

Gentisin, 484

Genus, 224

Geotropic roots, 95 stems, 97, I00

Geraniaceæ, 30I

Geraniales, 301

Geranium, 301, 505 family, 30I maculatum, 301 powder, 757

German mustard, 742

Gigartina, I6, 689

Gilead balsam, 3I I

Gills, 3 I

Gin, 683

Ginger, 486

African, powder, 763

Calcutta, powder, 763

Japan, 488 powder, 737 preserved, 488 varieties, 487,488

Gingerol, 488

Ginseng, 98, 350 family, 350

Girardinia, 257

Girdle, I 5

Glabrous, 209

Glandular-punctate, 2 I 1

Glans, I 50

Glaucium, 282

Glaucous, 2Io
Glecoma, 372

Gleditchia, 299

Gloeocapsa, 39

Glomerule, I38

Gluco-alkaloids, 169

Glucogallin, 476

Glucoresins, 654

Glucosennin, 609

Glucosidal resins, 654

Glucosides, I69

Glumes, 225, 226

Glumifloræ, 225

Gluten cells, 226

Glycine, 300

Glycyrrhiza, 189, 472 allied plants, 474 glabra, 294 powder, 735

Glycyrrhizin, 474

Gnidia, 343

Gnoscopine, 660

Goa powder, 780

Golden-rod, 399 seal, 498

Gold-thread, 483, 501

Gonidium, 39

Gooseberries, 286

Gooseberry family, 286

Goosefoot family, 264

Gossypetin, 530

Gossypii cortex, 527 powder, 75I

Gossypium purificatum, 440

species, 329, 330

Gouania, 326

Gourd family, 386

Gracilaria, Io

Graft, 404

Grain, 149

Graminales, 225

Graminea, 225

Granatum, 534 powder, 725

Granulose, I64

Grape family, 327

fern, 62

-fruit, 307

-root, Oregon, 482

-sugar, I67

-vine, 327

wine, 327

Grapes, Catawba, 327

Concord, 327

Delaware, 327

dextrose in, 168

frost-, 327 
Grass of Parnassus, 286

sweet vernal, 590 vanilla, 590

Grasses, 225

Gratiola, 377

Gratiolin, 377

Gravity, influence of, 94

Greenish powders, key, 702

Grenacher's borax-carmine solution, 802

Grevillea, 258

Grewia, 329

Grias, 345

Griffithsia, 16

Grindelia, 626 powder, 727 species, 393,627

Grindeline, 627

Grinnellia, I3

Gromwell leaves, powder, 718

Grossulariaceæ, 286

Ground pine, 70

Growth, factors infuencing, 3

Guaiac blue, 669 resin, 668 powder, 724 yellow, 660

Guaiacol, 678

Guaiacresin, 669

Guaiacum, 668 powder, 724 species, 303, 304

Guarana, 44I powder, 769

Guard cells, I93

Guarea, 256, 472

Guava, 347

Guayava, 347

Guaza, 635

Guelder-rose, wild, 382,383

Gutevina, 258

Gulf weed, I3

Gum, Amrad, 644

arabic, 643

artificial, 689

Australian, 644

barrister, 644

Cape, 644

Gedda, 644

ghatti, 644,645

lac, $257,317,327$
Gum, mesquite, 644

Senegal, 644

Talca, 644

wattle, 644

Gumbo, 33I

Gum-resins, I79

Gums, I74

of Rosaceæ, 290

Gurjun balsam, 337

Gutta-percha, 358

Guttiferæ, 335

Guracine, 232

Gymnocladus, 299

Gymnosperms, 7I characters of, 72 groups of, 78

Gynæcium, 123

Gynandrous, I29

Gynocardia, 339

Gypsophila, 267

Gysbertsiana, 338

Habenaria, 590

Habitat, 4I7

Hæmatein, 547

Hæmatoxylin, 546

Hæmatoxylon, 546

campechianum, 295

powder, 784

Hagenia abyssinica, 290

Hair-restorer, 276

Hairs, glandular, I77, 192

mucilage-secreting, I77

non-glandular, I92 plant, I92

Half-compound, I64

Hamamelidaceæ, 286

Hamamelidis cortex, 527 folia, 6ro powder, 721

Hamamelis, 286

bark, 527

extract, $6 \mathrm{I} 2$

leaves, 6то powder, 72I

Hancornia, 668

Hardening agents, 799

Hardwickia, 297

Harebell, I3I

Harmaline, 637

Harmine, 637

Harpullia, 324

Hashish, 255

Haustoria, 34
Hawthorn, 292

Hay fever, 402

Hazelnut, 252

Chilean, 258

Head, I38

Heath family, 356

Heather, 60I

Hedeoma, 628 powder, 729 pulegioides, 369

Hedeomol, 630

Hedera, 350

Hedysarum, 474

Helenium, 401

Helianthenin, 167, 402

Helianthus, 40I, 402

Helicteres, 333

Heliotrope, garden, 367

Heliotropin, 589

Heliotropism, I07

Heliotropum species, 307

Helixin, 350

Hellebore, American, 4.92

black, 27I, 495

European, 493

false, 272, 496

green, 492,496

powder, 737

white, 493

Helleborein, 27I, 495

Helleborin, 495

Helleborus, 27I

niger, 495

viridis, 496

Hemiasci, 23

Hemlock, 67I

poison, 352,567

powder, 7 I 9

water, 569

Hemp, Canadian, 467

East Indian, 635

sisal, 240

yellow, 34I

Henbane, 372, 6і9

Henequen, 240

Henna plant, 344

Hepatic 2 , 5I

Herb, perennial, 94

Herba cochlearia, 283

Herbaceous perennials, 409

Herbs (drugs), 595

Hercules club, 450

Hermaphrodite, I 36 
Herniaria, 267

Hesperidin, 308, 592

Hesperidium, 149

Hesperis, 284

Heteropteris, powder, 736

Heterosporous, 56

Heuchera, 286

Hevea, 316, 318

Hibiscus, 33I, 45I

Hickory, I20, 25I

Hicoria, 25I

Hierochlœ, 230

Hilum, I54 of starch grain, 163

Hinna, 344

Hippocastanaceæ, 324

Hispid, 210

Histology, I

Holdfast, I3

Holigarna, 3 19

Holly, American, 322

Christmas, 322

Dahoon, 323

European, 322

family, 322

Hollyhock, 329, 33 I

Homalium, 340

Homocinchonidine, 520

Honesty, 283

Honey, 145

dew, 27 poisonous, 145,357

Honeysuckle, bush, 385 family, 382

Honeysuckles, 355

Hop, bitter, 594 tree, 308 stems, 726

Hopea, 338

Hops, 582 powder, 7I5 substitutes, 326,338

Hordeum, 227 plant, 228

Horehound, black, 628 water, 628 white, 628

Hornbeam, 252

Horse-nettle, 374 powder, 726

Horse poisons, 268

Horsemint, 37 I

Horseradish, 283

Horsetails, 64

Hound's tongue, 367

Houseleek, 285
Houstonia, 378

Hoyer's picro-carmine, 802

Huckleberries, 357

Huckleberry, European, 601

Humiri, stamen, I27

Humulene, 250, 583

Humulus, 582

Lupulus, 255

powder, 7I5

Hura crepitans, 316

Hybanthus, 472

Hybrid, 406

Hybridization, 406

Hydnocarpus, 339

Hydrangea, 286

arborescens, powder, 762

garden, 286

wild, 286

Hydrangin, 286

Hydrastine, 498

Hydrastis, 483, 498 canadensis, 268 powder, 739

Hydrocaryaceæ, 350

Hydrocinchonidine, 520

Hydro-elaterin, 387

Hydrogen, 3

Hydrophilous, I42

Hydrophyllaceæ, 367

Hydroquinidine, 5 I9

Hydroquinine, 5 19

Hydroquinone, 60I

Hydrothymoquinone, $37 \mathrm{I}, 552$

Hymenæa, 299

Hymenium, 3I

Hymenocallis, 240

Hyoscine, 509

Hyoscyamine, 6I9

Hyoscyamus, 619

niger, 372

powder, 720

Hypecoum, 280

Hypericaceæ, 337

Hypericum species, 337

Hypha, I7

Hypnum, 55

Hypocotyl, I54

Hypocrateriform, I3I

Hypodermis, I92, I99

Hypogynous, 132

Hyssop, 377

garden, $37 \mathrm{I}$

Hyssopus, 37I
Iceland moss, 689 saccharated, 690

Ice-plant, 267

Idioblasts, 717

Ilex species, 322, 323

Ilicaceæ, 322

Illicium, I49, 274, 562 powder, 783

Illipe, $35^{8}$

Imbricated, 132

Impari-pinnate, II4

Impatiens, 326

Imperfect flowers, I36

Incumbent, I55

Indian colza, powder, 742 pipe, 355

Indigo, 264, 284, 318 in Leguminosæ, 298 wild, 298

Indusium, 59

Inflatin, 633

Inflorescence, definite, I 38 determinate, ${ }^{13} 8$

indefinite, 137

indeterminate, I37

Infundibuliform, I3I

Inga flowers, 604

Inhambane copal, 299

Ink balls, 253

galls, 253

tree, 3 I9

Innate, I 28

Inosit, 328

Insect-catching plants, 284

Insect flowers, 395, 396 powder, 7I 5

Insects infecting drugs, 420

protection against. 382

Integuments, 87, 90

Intine, 85,213

Introrse, I 26

Inula, 397, 398

Conyza, powder, 729

leaves, 6I7

species, 552

Inulenin, I67, 402

Int1lin, 166, 390

in drugs, I67

in Helianthus, I90

sphere-crystals, 185

Invertases, I79

Involucre, I38 
Involute, I2I

Iodine from sea-weeds, I6 solution, 803 water, 803

Ionidium, 472

Ipecac, 467 allied plants, 47I

powder, 735

spurge, $47 \mathrm{I}$

substitutes, 47I, 736

varieties,

$467,469,47 \mathrm{I}$

wild, 384

Ipecacuanha, 467 powder, 735

Ipoh arrow-poison, 256

Ipomœa species, $366,453,657$

Iridacea, 240

Iris family, 240 florentina, I05, 24I species, 24I versicolor, 240

Irish moss, 687

Iron, 4 solutions, 803 woods, 359

Ironwood, 252

Irregular, 136

Irvingia, 310

Isaconitine, 479

Isatis, 284

Isoemodin, 525, 610

Isoetes, 67

Isohesperidin, 592

Isolichenin, 690

Isopelletierine, 534

Isophysostigmine, 439

Isopilocarpine, 598

Isoptera, $33^{8}$

Isorottlerin, 316

Isosporous, 56

Ivory nut, 767 vegetable, $23 \mathrm{I}$

Ivy, American, 328 English, 350 ground, 372

Jaborandi. 596 Aracati, 599 powder, 7 I7

Jaborine, 599

Jacaranda, 377

Jack-in-the-pulpit, 234

Jack-tree, 257

Jalap, 45I allied plants, 453
Jalap. male, 453 powder, 733

substitute, 265

Tampico, 453

wild, 453

Jalapa, 45I

Jalapin, 452

Jalapurgin, 452

Jambosa, 347,348

Caryophyllus, 346

Jambul tree, 656

Jambuse berries, 347

Japaconitine, 480

Jasmine, Cape, 382 yellow, 480

Jateorhiza palmata, 274

Jatropa, 3I5

Jeffersonia diphylla,

Jelly, Iceland-moss, 690

buffalo-berry, 344

Jequirity, 300

Jervine, 493, 494, 495

Jessamine, yellow, 362,480

Jewel-weed family, 325

Jimson weed, 372

Joannesia, 315

Joe-pye weed, 626

Juglandaceæ, 25I

Juglans, 25I

alba, $75 \mathrm{I}$

cinerea, $75^{\mathrm{I}}$

nigra, $75 \mathrm{I}$

powder, 75I

regia, 752,756

Jujube-paste, 327

Juncaceæ, 24I

Juncus, 24I

Jungermannia, 52, 55

Juniper berries, 78 camphor, 683 powder, 759

Juniperus, 79, 679

powder, 759

Sabina, 682 species, $8 \mathrm{I}, 683$ virginiana, 80

Jussiena, 349

Jute, 329

Kadsura, 275

Kaiser's glycerin jelly, 804

Kalmia, 357

Kamala, 3 I6
Kavaine, 249

Kava-kava, 249 powder, 765

Keel, 248

Kichsia, 668

Kien oil, 679

Kiggelaria, 339

Killing agents, 798

Kino, 654, 655 powder, 782 varieties, 655,656

Kinone, 520

Kinovin, 520

Ki-urushi, 320

Kleister, I65

Knight's experiments, 94

Kola, 435

Kolatine, 436

Kosteletzylia, 45I

Koussein, 557

Kousso, 556 powder, 774

Krameria, 453, 647 allied plants, 455 powder, 758 species, 295, 455

Kraunhia, 300

Labellum, I3 I

Labiatæe, 368

Laburnum, 299

Lac, 320 guim-, 317,327

Lace-tree, 343

Lacinaria, 400

Lacquer, Japanese, 3I9

Lactarius, 34

Lactuca species, 649

Lactuca virosa, 392

Lactucarium, 649, 78I

Lactucerin, 649

Lactucerol, 649

Lactucin, 649

Lactucon, 649

Lactucopicrin, 649

Lady's slipper, 490

Laetia, 339

Lafænsia, 344

Lagerstræmia, 344

Lagetta, 343

Lamella, middle, I8I primary, 182 secondary, I82

Lamellæ in starch grains, 163

Lamina, I06, I30 
Laminaria, I3, I6

Lamium, anther, 127

Lampwicks, 349

Landolphia, 668

Langsdorffia, 259

Lanthopine, 660

Laplacea, 335

Laportea, 257

Lappa, 465 powder, 748

Lappaconitine, 480

Lappin, 465

Lasioderma, 420

Lasiosiphon, 537

Lathyrus, 30I

Laticiferous tissue, I95

Laudanine, 660

Laudanosine, 660

Lauracex, 277

Laurel family, 277

Laurocerasin, 537, 539

Lavandula officinalis, 370

spica, 37 I

Lavender, garden, 370

Lawsonia, 344

Leaf, base, I I3

functions, 108

margin, 1 I 4

simple, Iо6

structure, 209

venation, 109

Leaflets, I I4

Leather wood, 343,344

Leaves, belladonna, 620

betel, 249

coca, 604

color in autumn, I7o

compound, II4

(drugs) , 595

duboisia, 619

floral, I 22

forms, 112

kinds, 107,108

light relation, 106

modified, I20

movement, II 4

perichætial, 53

scopolia, 509

senna, 607

stramonium, 622

surface, II 2

texture, II 2

witchhazel, 6ro

Lecanora, 42

Lecidea, 42
Lecythidaceæ, 345

Lecythis, 345

Ledum, 601, 602

Legume, I 49

Legumin, 300

Leguminosæ, 292

Lemnacex, 233

Lemon, 308

peel, 59I

substitutes, 334

Lemons, 322

Lens esculenta, 300

Lenticels, I95

Lentil, 300

Leonurus, 372

Lepargyræa, 344

Lepidium, 283,284

Lepidodendron, 69

Lepidoptera, 420

Leptandra, 50I powder, 763 virginica, 376

Leptandrin, 501

Leptilon, 393

Leptospermum, 347

Lessonia, I6

Lettuce, poison, 392

Leucadendron, 258

Leucæna, 299

Leucine, 692

Leucoplastids, 158, I59

Leucospermum, 258

Leucothœ, 357

Levistictum, 354

Levo-glucose, I68

Levulose, I68

Lianes, 104, 3I 3

Lice, plant, 647

Lichen groups, 40

Lichenin, 690

Lichens, 39 crustaceous, 40

foliose, 40

fruticose, 40

Licorice, I89

Anlerican, 474

Indian, 474

Jamaica, 474

powder, compound, 759

root, powder, 735

substitutes, 474

taste like, 652

varieties, 472

wild, 382, 474

Life, physical basis of, I60
Light, 4, 106

Lignified, 182

Lignin, I82

Lignocellulose walls, 182

Lignone, 182

Ligulate flowers, 391

Ligule, II4

Ligulifloræ, 39I

Ligustrum, $36 \mathrm{I}$

Lilac, garden, $36 \mathrm{I}$

Liliacea, 235

Liliales, 235

Liliifloræe, 235

Lilium, 225

Lily family, 235

pond, 268

water, 268

white, 225

Lily-of-the-valley, 488 flowers, 490

Limb, I 30

Lime, 308

Limonis cortex, 59I

Linaceæ, 303

Linaloe oil, Mexican, 312

Linalool, 517, 563, 632

Linaria, 376

Linden, 328, 329

family, 328

Lindera, 279

Linen, 303 mildewed, I7

Linseed, 426 crushed, 427 meal, 745

Linum, 426 mucilage, 176

powder, 745

seed, 219 species, 303

Lion's foot, 400

Lip (in orchids), 245

Lippia, 368

Lippiol, 368

Liquidambar, 680 orientalis, 286

Liriodendrin, 275

Liriodendron, 274, 344

Litmus, 42

Litsea, 280 , 57 I

Liverwort groups, 52

Liverworts, 51 leafy, 52

Lobe, I 4

Lobed, II4 
Lobelacrin, 633

Lobelia, 633

blue, 389,635

powder, 730

red, 388,635

species, 388,635

Lobelianin, 633

Lobeline, 633

Loco-weeds, 299

Locules, I23

Locust, 474

Lodicules, 226

Lodoicea, I 55

Loeffler's methy'lene blue, 800

Logania family, 362

Loganiaceæ, 362

Loganin, 437

Logwood, 546 powder, 784

Lomatia, 258

Lonchocarpus, 299

Lonicera, 385

Loosestrife family, 344 purple, I42, 344

Lopezia, 349

Lophophorine, 342

Loranthaceæ, 258

Loranthus, 259

Lotus, 268

Lovage, 354

Luffa species, 388 sponge, 388

Lumen, I86

Lunaria, 283

Lupinidine, 300

Lupinin, 300

Lupinine, 300

Lupinus, 300,587

Lupulin, 594

Lupuline, 583

Lupulinum, 594, 785

Lupuliretin, 594

Lizula, 24I

Lycaconitine, 480

Lychnis, 267

Lycoperdon species, 30, 34

Lycopodiales, 56, 66

Lycopodium, 693, 749

adulterants, 694

species, 70, 694

spores, 66

Lycopus, 628

Lyngbya, 39

Lysigenous, I78

Lythraceæ, 344
Lythrum, 344

flower, I4I, 142

Mabea, 316

Macaranga, 3I7

Mace, 442

Bombay, 443

Macassar, 443

Papua, 443

powder, 77I

Machilus, 279

Macis, 442 powder, 77I

Maclura, 257

Macrocystis, I6

Macrotin, 498

Macrotyn, 498

Madder, 38I family, 378

Magnesia, 796 ponderosa, 796

Magnesium, 4

Magnolia, 275, 276 family, 274

fruit. I40

Magnoliaceæ, 274

Magnolin, 275

Magonia, 324

Mahogany family, 3I2 tree, 667

Mahonia, trailing, 272

Mahurea, 335

Maiden hair spleenwort, 6I, 62

Malambo bark, 3 I6

Mallotus philippinensis, 3 I 6

Mallow, 33I family, 329 stamens, I28

Malpighiaceæ, 3I3

Malt, 575

Maltose, 168

Maltum, 575

Malva species, 33I

Malvaceæ, 329

Malvales, 328

Malvaviscus, $45 \mathrm{I}$

Mammei apple, 337

Mammey wine, 337

Mandragora, 465

Mandragorine, 465

Mandrake, European, 465

Mangifera, 322

Mango fruit, 337

Mangos, 322
Mangosteen, 335

Mangrove, 345 family, 345 swamps, 346

Manihot, 3I8, 668

Manna, 649, 650

Briançon, $8 \mathrm{I}$

Coniferæ, 8I

Israelites', 42

Luristan, 292

Manna-like sugar, 338

Mannitan, 650

Mannitol, I68, 288, 650

Maple family, 323

leaves, powder, 7 I8

sugar, 323

Maqui fruit, 328

Marasmius, 30

Marcescent, I3I

Marcgravia, 334

Marcgraviacæ, 334

Marchantia, 5I, 52, 55

Marigold, 394, 555 powder, 740 marsh, 50I

Marjoram, 37I

Marking tree, 319

Marrubiin, 628

Marrubium, 628 powder, 729 species, 628 vtlgare, 368

Marsdenia, 365

Marshmallow, 329, 450 substitutes, 45I

Marsilia, 63

Marvel-of-Peru, 265

Mastic, 645 American, 645

Mastiche, 645, 750

Masticin, 645

Maté, 322 powder, 7I7

Matico, 6I7 powder, 727, 730 substitutes, 333

Matisia, 332

Matricaria, 553 adulterants, 554 Chamomilla, 394 powder, 746

May-apple, I05, 506

Maytenus, 323

Meadow beatity, 349

Meadow-sweet leaves, powder, 718 
Meal, corn, 790 mountain, 16

Meconidine, 660

Meconine, 660

Medicinal plants, foreign, 4I4 indigenous, 4 Io naturalized, 4IO

Medinilla, 349

Medlar, Japanese, 287

Megasporangia, 56

Megaspore, 56, 86

Megasporophyll, 75

Melaleuca species, 347

Melanthin, 567

Melastoma, 349

Melastomaceæ, 348

Melia, 3I2, 3I3 stamens, I28

Meliacex, 3I2

Melilot, yellow, 590

Melilotus, 590

Melissa, $37 \mathrm{I}$

Melon tree, 341 water, 388

Membrane, primary, 182

Membranous, II 2

Menispermaceæ, 273

Menispermum, 208, 273

Menispine, 273

Mentha piperita, 63I powder, 729 species, 370, 630,633 spicata, 632

viridis, 632

Menthol, 63I

Mercurialis, 317. 318

Mericarp, I49

Meristem, I8I primary, 198

Meristems, secondary, I98

Mescal buttons, 342

Mescaline, 342

Mesembryanthemum, 267

Mesna, 335

Mesocarp, 145

Mesophyll, 21 I

Mespilodaphne, $54 \mathrm{I}$

Mestome, I88

Metabolism, 219, 222

Methyl-æesculetin, 482 -cephaëline, 469 -chavicol, 562 -granatonine, 536
Methyl-naphthoquinone, 285 -pelletierine, 534 salicylate, 225, 339 355,357

Methysticin, 249

Methysticum, 249 powder, 765

Mezcal, 240

Mezerein, 536

Mezereon, 343

Mezereum, 343, 536 powder, 738

Mezoneurum, 644

Michelia, 274, 275

Micrococci, 44

Micromeria, 4I3

Micron, I5

Micropyle, I 54

Microscopic life, I3

Microsomata, 158

Microsomes, 158

Microspermæ, 244

Microsporangia, $56,83,84$

Microspores, 56, 85

Microsporophyll, 65, 74

Mignonette, 284

Mikania, 390

Mildews, 20

downy, 20

green, 25

yellow, 25

Milk, blue color in, 264 juices (drugs), 640 tissue, I95

Milkweed family, 365

Milkwort family, 3I3 white, 3I 3

Millettia, 299

Mimosoideæ, 292

Mimt1sops species, 358,359

Mineral cellulose walls, 183

Mint family, 368

water, 630 wild, 630

Mio Mio, 400

Mirabilis, 265

Mistletoe, American, 259

European, 259

family, 258

Mitchella, 142, 382

Mitella, 285
Mitrewort, 285

false, 285

Mold, black, 20

Monarda, 37I

Monkey-bread tree, 332

-pot tree, 345

Monocarpia, 277

Monocotyledons, 83,225

venation in, 109

Moncecious, 48, 136

Monotropa, 355

Moonseed, Canada, 273 family, 273

Moraceæ, 254

Morchella, 30, 34

Morel, 30

Morinda, $38 \mathrm{I}$

Moringa, 284

Moringaceæ, 284

Morning-glory family, 365

Morphine, 659

methyl, 659

para, 660

Morphology, I inner, 156

Morus, 257

Moss, Florida, 235

flower, 54

groups, 55

Irish, I3

plant, 46

wolf's, 4 I

Mosses, 53

club, 56,66

scale, 52

true, 55

Mother of cloves, 773

Motherwort, 372

Mountain ash leaves, powder, 719

Mounts, 804 Canada balsam, 805 glycerin-jelly, 804 permanent, 804

Mourera, 285

Movement of leaves, I 4

Movements, sleep. II7

Mucilage, cell-content, 176

cell membrane, 177

cellulose walls, I83

hairs, I77

in Rosaceæ, 290

Mucilages, I74 
Nucor mucedo, 20

Mucronate, II2

Mucuna, 300

MIugwort, 397

Mulberry, 257 family, 254

leares, powder, 7I9

Mullein, 376 seeds, 635

Multinucleate, I2

Inlu kilavary, 675

Mundulea, 299

Muntingia, 329

Musa, 244

Musaceæ, 244

Musci, 53

Mushroom, common field, 30 poisonous, $30,3 \mathrm{I}$

Mushrooms, edible, 30, 3I, 33

Musk root, 462 odor, $33 \mathrm{I}$ seed, 33I

Minstard, black, 283,429 family, 283

field, 429

flour, 742

French, 742

garlic, 283

paste, 742,743

prepared, 742

(root hairs), 92

Russian, 743

-arepta, 429, 743

treacle, 283

yellow, 283

white, 283,428

wild, 284

Mutations, 3

Mycelium, I7

Mycose, 692

Myoctonine, 480

$M$ yosotis, 367

Myrceugenia, 347

Myrcia, 348

Myrica cerifera, 250 powder, 759

Myricales, 250

Myricaria, 338

Myricin, 319

Myristica, 439

fragrans, 277

powder, 771

species, 440

Myristicaceæ, 277
Myristicin, 440

Myrobalans, 348

Myrosin, 428

Myroxylon, 339

Myrth family, 310 varieties $673,674,675$

Myrrha, 673 powder, 78I

Myrtaceæ, 346

Myrtle family, 346 wax, 250

Myrtus species, 347, 656

Nabalus, 400

Naked flowers, 137

Napæa, 33I

Napelline, 478, 479

Narceine, 660

Narcissus, 240

Narcotine, 660

Naregamia, 472 powder, 736

Naregamine, 472

Naringin, 308, 592

Nasturtium family, 302

Nataloin, 665

Naturalized plants, 4I8

Navicula, I4

Nectandra, 279, 46I, 54I

Nectar, 215 poisonous, 357

Nectaries, I45

Nelumbo, 268

Nepenthaceæ, 285

Nepenthes, 285

Nepeta, 113, 372

Nephelium, 324, 594

Nephrodium, 57, 60

Nerium, 364

Nesæa, 344

Neslia, 284

Nettle, dead, I27

family, 257

horse, 374

Nicotiana species, 375

Nicotine, 375

Nigella species, 567

Nightshade, deadly, 372

enchanter's, 349

Nitrification, soil, 43

Nitrogen, 3 atmospheric, 99
Nitroglycerin, storing, 15

Nomenclature, 223

Nopalea, 343

Nostoc, 39

Nucellus, 7r, 86

Nucleoles, I 58

Nucleus, 2 starch grain, I63

Nuphar, 268

Nut, I 50

Nutation, II7

Nutgall, 646

Nutgalls, Texas, 648

Nutlet, I 50

Nutmeg, 439

American, 440

false, 440

family, 277

powder, $77 \mathrm{I}$

varieties, 440

Nux vomica, 436

endosperm, 219

powder, 793

Nyctaginaceæ, 265

Nyctinastic, II7

Nyctitropic, II7

Nymphra, 268 stamens, 127

Nymphæaceæ, 268

Nyssa, 259

Oak, 646

balls, California, 648

black, 253

leaves, powder, 719

poison, 319

red, 253

Spanish, 253

white, 253

Oaks, varieties, 543

Oat, 227

Oatmeal, 792

Oats, rolled, 792

Obcordate, II 2

Ochrocarpus, 335

Ocimum, 371

Ocotea, 280

Ocotilla, 338

Octomeles, 34I

Enanthe, 354

Enothera, 349, 350

Official, 223

Oil, A jowan, 354

allspice, 575

anise, 354,562

Apeiba, 329 
Oil, bay, 347

betula, 252

bitter almond, 434

cade, 679

Borneo camphor, 337

cajeput, 347

calamus, 496

Carapa, 3I3

caraway, 567

castor, 3I4

chamomile, 555

cinnamon, $5 \mathrm{I} 6$

clove, 549

coriander, 563

cotton seed, 331

croton, 3I 5

cubeb, $57 \mathrm{I}$

cumin, 354,569

cyperus, 23I

dill, 354

erigeron, 393

fennel, 564

geranium-grass, 230

gingergrass, 230

hedeoma, 630

hops, 583, 594

juniper, 8I

kapak, 33I

kesso root, 505

laurel-nut, 336

lavender, 370

lemon, 308

lemon-grass, 230

lupulin, 594

marcassa, 324

marjoram, $37 \mathrm{I}$

myrcia, 347

Neroli, 307

olive, 360

orange, 591

orange peel, 307

palm, 232, 333

pennyroyal,

Russian, 63I

pepper, 573

pepper, Japanese, 308

peppermint, 631, 632

pimenta, 575

pine needle, 677

red cedar wood, 683

rose, 289,558

rosemary, 370

sage, 6I2

santal, 259

sassafras, 539

savin, $8 \mathrm{I}, 683$

sesame, 377
Oil, spearmint, German, 633

Russian, 632

tar, 678

thyme, 370

turpentine, 676,677

wintergreen, 252, 357

Oil-cake, 427

Oils, I78

Okra, 33I

Oleaceæ, 360

Oleander, 364

Oleandrin, 364

Oleo-resins, 179

Oleum cedrelæ, 3I3

myristicæ, 440

picis Liquidæ, 678

rhodii, 309

theobromatis, 332

Olibanum, 3I r

Olive endocarp, 770 family, 360 tree, 360

Omphalocarpum, 358

Onion, 239

Onoclea, 62

Ononin, 300

Ononis, 300, 474

Oögonium, 7

Oömycetes, I8

Ö̈sphere, 7

Oöspore, 7, 45

Opegrapha, 42

Operculina, 453

Operculum, 49

Ophioglossum, 63 species, 69

Opium, 658, 66r adulterants, 66I

Opopanax, 675

Opuntia species, 342,343

Opuntiales, 34I

Orange, Bergamot, 307

bitter, 306

blood, 307

Curaçao, 306

flower, I 30

Malta, 306

mock, 286

navel, 308

osage, 257

Otaheite, 307

peel, bitter, 592

peel, sweet, 591

Portugal, 306

satsuma, 308
Orange, Seville, 306

trifoliate, 306

Oranges, moldy, I 7

Orcein, 42

Orchidales, 244

Orchid-like flowers, 349

Orchil, 42

Orchis, 590

Ordeal bean, 438

Orders, 224

Orellin, 338

Organs, inner structure, 197 nutritive, 5 plant, 5 propagative, 5

Orienting, II7

Origanum, Cretian, $37 \mathrm{I}$ species, $37 \mathrm{I}$

Origin, botanical, 4I7

commercial, 418

of growth, Point of, I53

natural, 4I7

Orizaba, 453

Orlean, 338

Ornamental plants, 23I, -3.. $240,244,2.57$. $260,264,265,267$. $302,314,326,334$, $340,341,349,408$

Orotava dragon tree, 238

Orpine family, 285

Orris-root, I05 powder, 793

Orthostichies, 118

Oryza, 227

Oscillaria, 44

Osmosis, $184,22 \mathrm{I}$

Osmunda, 687 species, 6I spores, 63

Ostrya, 252

Ourouparia Gambir. $38 \mathrm{I}$

Ovary, I23, 2 I 5

Ovule, development, 86 structure, 2I 5

Ovules, forms, I26

Oxalidaceæ, 301

Oxalis, 30I

Oxidation, 221

Oxyacanthine, 273, 483

Oxyatropine, 622

Oxycoccin, 358

Oxycoccus, 357,601 
Oxyconiine, 567

Oxydase enzymes, I80 in kola, 436

Oxygen, 3

Oxythymoquinone, 400

Oxytropis, 299

Pachira, 331, 45I

Pachyma cocos, 34

Palaquin species, 358

Pale, inner, 226 outer, 226

Palisade cells, 2I I

Palm oil, 233

Palmæ, 23I

Paimately-compound, I I4

Palmately-veined, II2

Palmi-nerved, I Io

Palms, 23I resembling, $35 \mathrm{I}$

Panax species, 98, $35^{\circ}$

Pangium, 340

Panicle, 137

Papain, I80, 277

Papaver capsules, 148 somnifertum, 280

Papaveraceæ, 280

Papaverales, 280

Papaverine, 660

Papaw, 34I family, 34I

North American, 277

Paper of ancients, 23I rice, $35^{\circ}$

Papilionaceous, I3O $_{3}$

Papilionatæ, 292

Pappus, 39I

Papyrus, 23I

Paracatechin, 328

Paradise grains, 242

Parallel-veined, 109

Paranine, 520

Para-nut, 345

Paraphyses, 53

Parasites, 16 half, 258

Pareira, 460 brava, 460 false, $46 \mathrm{r}$ powder, 738 substitutes, 46r, 462 white, 462 yellow, 462

Parenchyma, 184 kinds, 184, I85

Paricine, 520
Parietales, 334

Parillin, 450

Pari-pinnate, $1 \mathrm{I} 4$

Parnassia, 286

Paronychia, 267

Parrya, 283

Parsley, 354

Parsnip, 354 mistaken for, 569

Parthenocissus, 328

Partridge berry, I $42,378,382$

Passiflora species, 34I

Passifloraceæ, 341

Passion-flower family, $34 \mathrm{I}$

Pastinaca, 354

Patchouli, 37I

Paullinia Cupana, 324

Pavonia, 45I

Payena, 358, 359

Pea, garden, 92, 300 sweet, 301

Peach, 288, 539

seed, 794

Peaches, dextrose in, 167

Peanut, I44, 300

Pear, 288 prickly, 343

Peat, sphagnum, 55

Pecan, 25I

Pectin, 288

Pectose, 288

Pedaliaceæ, 377

Pedicel, I37

Peduncle, I 37

Peganum, 637 Harmala, 304

Peireskia, 342, 343

Pelargonium species, $30 \mathrm{I}$

Pellæa, 61, 62

Pelletierine, 534

Pellitory, 455

German, 456

Pellotine, 342

Pelosine, 46I

Peltigeria, 69I

Penæa species, 652

Pencil flower, 4I3

Penicillium, 25

Penny-cress, field, 283

Pennyroyal, American, 369. 628

European, 630

Pentadesma, 436
Pentalostigma, 317

Pentapetes, 333

Penthorum, 285

Peperomia, 124, 574

Pepo, I50, 429 powder, 742

Pepper, Acheen, 574

adulterants, 574,770

African, 578

black, 249, $57 \mathrm{I}$ powder, 769

Bombay, 580

Cayenne, 578, 782

garden, 580

-grass, 283

Guinea, 574

hulls, 574, 770

Japan, 580

long, 249,573

-moor, 308

Penang, 574

pod, 580

red, 376,579

standard, 573

substitutes, 573

wall-, 285

white, $249,573,574$

Peppercorns, 571

white, 573

Peppermint, 63I powder, 729

Peppertree, Peruvian, 645

Perennial, 94

Perezia species, 400

Perfoliate, II 4

Periandra, 474

Perianth, I29

Periblem, I98

Pericarp, 145

Perichætia, 53

Periderm, 5I2

Perigynous, I32

Perisperm, 90, I52, 218

Peristome, 49

Periwinkle, 364

Peronospora, I9

Persea, stamen, I27

Persian berries, 525

Persica, 539

Persimmon, 359

Persistent, I3I

Personate, I3I

Persoonia, 258

Pertusaria, 4I

Peru balsam, 298

Petaloid, I32 
Petals, I29

Petiole, 106

Petroselinum, 354

Peziza, 22, 23

Phaca (Astragalus) 299

Phæophyceæ, 8, I3

Pharmacognosy, 4I7

Pharmacopœial definition, 4 I 8

titles, 4 I8

Phaseolus, 300

Phellogen, I99, 202

Phenol, 678

Phenyl ethylene, 680 propyl cinnamate, 680

Philadelphus, 286

Phloem, 20I

Phlorizin, 292

Phloroglucin solution, I82, 803

Phloryl compounds, 552

Phœnix, 233

Phoradendron, 259

Phosphorous, 4

Photosynthesis, 4, I09

Phycomycetes, I8, 2I

Phyllanthus, 3I7, 3I8

Phyllophora, I6

Phyllotaxis, 1 I8

Phyllotaxy, I 8

Physcia, 4I

Physic, Indian, 47I

Physiology, I

Physostigma, 438

powder, $77 \mathrm{I}$

species, 439

venenosum, 298

Physostigmine, 439

Phytelephas, 231, 767

Phytolacca, 465

decandra, 265

fruit, 466

powder, 736

Phytolaccaceæ, 265

Phytolaccine, 466

Picea, 75

Pichi, 373

Picradonidin, 496

Picræna, 546

Picrasma excelsa, 309 species, 546

Picrasmin, 545

Picro-crocin, 241

Picropodophyllin, 508

Picrosclerotine, 692
Pieris, 357

Pileus, 3I

Piliganine, 694

Pilocarpene, 599

Pilocarpidine, 598

Pilocarpine, 598

Pilocarpus, 596

powder, 7I7

species, 305

Pilose, 2 Io

Pimelea, 343

Pimenta, 574

acris, 347

adulterants, 755

officinalis, 347

powder, 755

Pimpernel, 562

Pimpinella, 562

Anisum, 352

species, 562

Pimpinellin, 562

Pinanga, 338

Pine cones, 79

frankincense, 79

Georgia, 78

ground, 70, 694

loblolly, 79

long-leaved, 78

pitch, 78

prince's, 355

running, 70

stem, 209

torch, 79

Pineapple, 235

Pinene, 676

Piney resin, 338

Pinicrin, 684

Pinkroot, 503

Pinks, 267

Pinnately-compound, I I4

Pinni-nerved, I Io

Pinol hydrate, 676

Pinus, 4I species,

$73,78,79,8 \mathrm{I}, 676$

Piper, 57I

angustifolium, 249

Cubeba, 249

fruit, 218

longum, 573

methysticum, 249

nigrum, 247

powder, 769

species, 57I, 574

substitutes, 573

Piperaceæ, 247
Piperales, 247

Piperidine, 573

Piperine, 573

Pipitzahoac, 400

Pipsissewa, 355, 603

Piptadenia, 652

Pircunia, 266

Piscidia Erythrina, 299

Pistacia, 322, 646

Lentiscus, $32 \mathrm{I}$

Pistachio nuts, 322

Pistil, I23

Pistillate, I36

Pisum, 92, 300 stamens, 128

Pitch, 678

Burgundy, 8I, 670

Canada, 8I, 67 I

hemlock, 67I

Pitcher plants, I 9

Pitcher-plant family, 284

Pith, 203 sassafras, 547

Pituri, 620

Piturine, 620

Pix Burgundica, 670 liquida, 677

Placenta, I24, 2I5

Plaited, I32

Planchonia, 345

Plankton, I3

Plantaginaceæe, 378

Plantago species, 378

Plantain, I40, 378 family, 378

Plants, carnivorous, I I9

Plastid pigments, 160

Plastids, 2, I 58

Platonia, 337

Plerome, 198

Pleura, 15

Pleurisy root, 365

Pleurococcus, 9, 39

Pleurosigma, I4 angulatum, I5

Plicate, I2I, I32

Plum, French, 288 seed, 794

Plumule, I54

Poaya blanca, 472

Pod, I 50

Podophylloresin, 508

Podonhyllotoxin, 508

Podophyllum, 506 peltatum, 273 
Podophyllum, powder, Poppy, celandine, 282 772 rhizome, I04 species, 508

Podostemaceæ, 285

Podostemon, 285

Pogostemon, 37I

Poinsettia, I32

Point of growth, 93 vegetation, 93,197

Poisons, testing, 5

Poisonous plants to cattle, 299

horses, 268 sheep, 264

Poke, 265 berries, 267 root, 265

Polemoniales, 365

Pollantin, 402

Pollen grains, 85 structure, 2I3 sacs, 83 , I26

Pollination, I39

cross-, I4I self-, I40

Pollinia, 85

Pollinium, I28

Polyadenia, 574

Polygala species, 313,472

Polygalaceæ, 3I3

Polygamous, I36

Polygonaceæ, 262

Polygonales, 262

Polygonum flower, I4I species, 264, 477

Polymnia, 399

Polypodium, 62, 64, 474 spores, 63

Polyporus, 34

Polysiphonia, I3

Polytrichum, 46, 55

Pome, I50, 288

Pomegranate family, 345

bark, 534

powder, 725

Pomelos, 307

Pometia, 324

Pop corns, 229

Poplar, 250

balsam, 250

Popowia, 277 stamens, I27

Poppy, California, 280 capsules, 148 family, 280

Mexican, 280

opium, 280

yellow, 282

Populus, 250

Pore, bordered, 187 , I91

fungi, 31

simple, 184

stoma, 193

Pores in fibers, I88

kinds, I 84

water-, I93

Porteranthus, $47 \mathrm{I}$

Portulaca, 26

Portulacaceæ, 267

Potassium, 4

nitrate, 402

Potato, 375

Chinese, 240

family, 372

sweet, 366

white, I05

Potentilla, I20, 292, 647

Pouzolzia, 258

Powders, adulterants, 695 examination, 696 greenish, 7I4 key, 702 reagents, 696 reddish, 782 yellowish, 732 whitish, 785

Prefloration, I 32

Prefoliation, I2I

Preservatives, 798 powder, 776

Pride of China, 312

Primrose, evening, 349

Prince's feather, 264

Principes, 23I

Prisms, monoclinic, I 71

Privet, 361

Promycelium, 35, 38

Propagation, 404

Propenylanisol, 562

Prosopis, 644

Protea, 258

Proteacin, 258

Proteales, 258

Protecting cells, I92
Prickly ash bark, 533
Protective cellulose walls, I83

Proteids (proteins), I 58

Protein grains, I73

Proteolytic ferments, I79

Prothallus, 46

Protium, 3IO, 3II

Protocatechuic aldehyde, methyl, 587

Protonema, 46, 49

in Hepaticæ, 5I

Protopine, 28, 28I, $282,508,560$

Protoplasm, 2, I56

Protoplasmic cellcontents, 156

Protoplast, 2, 156

Protoveratridine, 404

Protoveratrine, 493

Prune, 576

Prunum, 576

Prunus, 288, 290, 590

Amygdalus, 287

domestica, 287

serotina, $28 z$

species, 537,539

virginiana, 287,537 powder, 759

Pseudaconitine, 480

Pseudo-ægle group, 306

Pseudo-coccus, 343

Pseudoconydrine, 567.

Pseudoemodin, 522

Pseudofrangulin, 522

Pseudohyoscyamine, 620

Pseudo-inulin, I67, 402

Pseudojervine, 494

Pseudomonas, 99

Pseudomorphine, 659

Pseudopelletierine, 536

Pseudopodium, 55

Pseudo-strophanthin, 432

Psidium, 347, 656

Psoralea, 298

Psychotrine, 469

Ptelea, 308

Pteridophytes, 55

Pteris, 58, 59, 64

Pterocarpus, 647 Marsupium, 294 santalinus, 295

species, 547 
Pterospermum, 333

Ptinedæ, 420

Ptinus, 420

Puberulent, 2 ro

Pubescent, 210

Puccinia, 37

Puffball, 30

Pulegone, 630

Pulsatilla, 27I

Pulse family, 292

Pulvinis, II 7

Pulvis glycytrhizæ compositus, 759

Pumpkin fruit, 387 seed, 429 powder, 742

vine, 387

Punica Granatum, 345 646

Punicaceæ, 345

Punicine, 534

Purging root, 47I

Purshia tridentata, 292

Purshianin, 525

Purslane, 267

Putamen, I45

Pycnidia, 40

Pycnoconidia, 40

Pyramids, I7I

Pyrenoids, I0, I5

Pyrethri Flores, 395

Pyrethrine, 456

Pyrethrum, 185, 455 powder, 778

Pyridine, hexa-hydropropyl, 567

Pyrocatechin, 543, 677

Pyrolacea, 355

Pyrus, 288

Pyxidium, 148

Pyxis, I48

Quaker button, 436

Quassia, 544

amara, 309

cups, 544

powder, 735

varieties, 544

Quassiin, 545, 546

Quebrachinamine, 363

Quebrachine, 363

Qutebracho, 322,363

Queen's-root, 314

Quercetin, 544

Quercitrin, $254,324,544$
Quercus, 541, 646, 647 Relationship, alba, 253 powder, 776 species, 253, 543

Quillaja, 54I

powder, 782

Saponaria, 290

spurious, 54I

Quillajasapotoxin, 54I

Quina blanca, 316

Quinamidine, 520

Quinamine, 519

Quince, 288

flower, I4I seed, powder, 745

Quinidine, 5I9

Quinine, 519

herb, 362 poor man's, 300

Quinone, 520

Quinovin, 520

Quisqualis, 348

Raceme, 137

Rachis, I37

Radial, I37 leaves, I08

Radiate, $39 \mathrm{I}$

Radicle, I 54

Radish, 283

Radix ononidis, 300

Rafflesiaceæ, 260

Raisins, 328

Rajania, 240

Ramie, 258

Ranales, 268

Ranunculaceæ, 268

Ranunculus, 27I

Raphanus, 283

Raphides, 172

Rasamala-wood oil, 68I

Raspberries, 53I

Raspberry, red, 289

Rattle-box, 299

Ravensara, 279. 280

Ray flowers, 39I

Reagent bottle, 801

Reagents, 696, 798 special, 803

Reaumuria, 338

Reclinate, I2I

Red gum, 655 saunders, 547

Reddish powders, key, $71 \mathrm{I}$

Red-wood, 78

Regular, I 36 tree of, 89

Repand, II4

Reseda, 284, 344

Resedaceæ, 284

Resene resins, 654

Reserve cellulose walls, ${ }_{1} 8_{3}$

in seeds, 152

layers, 152

parenchyma, I85

Resin, 653

claretta, 653

galipot, 694

guaiac, 668

podophyllum, 508

scammony, 658

soft, 3 I I

Resinol-resins, 654

Resinotannol, asa-, 671,672

Resinotannol, opo-, 675

Resinotannol resins, 654

Resins, I78

classes, 653,654

(drugs), 640

Respiration, 109

Reticulated ducts, 190

Reticulately-veined leaves, I I I

Retuse, II2

Revolute, I2I

Rhamnaceæ, 326

Rhamnales, 326

Rhamnochrysin, 525

Rhamnocitrin, 525

Rhamnol arachidate, 525

Rhamnolutin, 525

Rhamnonigrin, 525

Rhamnose, 522

Rhamnoxanthin, 522

Rhamnus cathartica, 525

Frangula, 326

powder, 735

Purshiana, 326, 523 powder, 759

species, 522, 525

Rhaponticin, 734

Rhatany, 453 powder, $75^{8}$

Rheedia, 335

Rhein, 476

Rheum, 474

powder, 733 
Rheum species, 262

Rhexia, 349

Rhipsalis, 342

Rhizoids, I I, 46, 5I

Rhizomes, I05

(drugs), 443

kinds, 444

Rhizophora, 345,647

Rhizophoracex, 345

Rhododendron, $357,601,602$

Rhodophyceæ, 8, I3

Rhodymenia, I6

Rhœadales, 280

Rhoesmin, 476

Rhubarb, 262, 474

Austrian, 476

English, 476

false, $50 \mathrm{I}$

fingers, $42 \mathrm{I}$

Rhaptonic, powder, 734

powder, 733

substitutes, 477

varieties, 476

Rhus, 646

glabra, 569 powder, 784

species, 319

Rhynchanthera, 349

Ribes, 286

Riccia, 52

Rice, 227

flour, 792

paper, Chinese, $35^{\circ}$

starch, 788

Richardsonia, powder, 736

Ricin, 3I4, 33I

Ricinus, 3 I 4 aleurone in, 2I9 seed, 2I8, 3I 4

Ringent, $\mathrm{I}_{3} \mathrm{I}$

River-weed, 285

family, 285

Rivinia, 267

Robinia, 298, 30I, 474

Roccella, 42

Root, 92

abnormal structure, 205

absorption, 220

aerial, 97

belladonna, 463

branches, 204

contraction, 204

Culver's, 50I
Root, drugs, 443

embryo, 154

fennel, 565

hairs, 92, 94

kinds, 94

licorice, 472

modified, 97

perennial, 94

poke, 465

pressure, 221

scammony, 657

-stocks, ro5

structure, 199

tubercles, 97

tuberous, 94

-tubers, 94

Roripa, 283

Rosa, 587

canina, powder, 784

centifolia, 558

powder, 785

gallica, 557

powder, 785

species, 289

Rosaceæ, 287

Rosales, 285

Rose apple, 347

family, 287

geranium, 30I

hips, powder, 784

powder, 785

red, 557

wood, 279

Roses, green, I34

Rosette aggregates, I7I

Rosin, 653

weed, 400

Rosmarinus officinalis, 370

Rotate, I3I

Rottlerin, 3I6

Rouge, 397

Rubber, India, 316 667

varieties, 668

vulcanization, 668

Rubia, 381

Rubiace 2,378

Rubiales, 378

Rubijervine, 494

Rubreserine, 439

Rthus, 530

powder, 75I

species, 288, 289, 53 I

Rudbeckia, 400

Rue family, 304

garden, 308
Ruellia, 504

ciliosa, 377

powder, 726

Rugose, 210

Rumex, 647

Acetosella, 264

crispus, 262

hymenosepalt1! 264,754

powder, 753, 779

species, 477

Rusbyine, 472

Rush, 24I

family, 241

scouring, 56, 64

wood, 24I

Rust, black, 36 wheat, 37

Ruta graveolens, 308

Rutaceæ, 304

Rye, 227

flour, $79 \mathrm{I}$

middlings, $79 \mathrm{I}$

Sabadilla seeds, 495

Sabadine, 495

Sabadinine, 495

Sabal, $57^{8}$ serrulata, 23I

Sabbatia, 362

Sabina, 682 powder, $73 \mathrm{I}$

Sabinol, 683

Saccate, I3I

Saccharomyces, 23

Saccharose, 168, 402

Saccharum, 227, 795 lactis, 796

Sacci, 240

Sacs, 23

Safflower, 397

Saffron, 24I powder, 746

Safrol, 5I7, 54 I

Sage, 6I2 Muscatel, 612

Sageretia, 326

Sago, imitation, 789 palms, 233 starch, 233, 789

Salep, 247

Salicales, 250

Salicin, $25^{\circ}$

Salix, 250

Saltations, 3

Salvia, 612

corolla, I33 
Saliva officinalis, 368 powder, 730 Sclarea; powder, 727 species, 612 stamens, I27

Salvinia, 63, 64

Samadera, 3ro, 546

Samara, I50 double, I50

Sambucus canadensis, 384 powder, 746 species, 384

Sandalwood family, 259 white, 259

Sandarac, 8I, 750 substitute, 339

Sand-box tree, 3 I 6

Sanguinaria, 508 canadensis, 280 powder, 782

Sanguinarine, 508

Santal substitute, 3I7

Santalaceæ, 259

Santalales, 258

Santalin, 547

Santalum, 259 rubrum, 547 powder, 784

Santonica, 550 powder, 776

Santonin, 55I

Sap, ascent, 22I

Sapindacex, 324

Sapindales, 3 I 8

Sapindus, 324

Sapodilla family, $35^{8}$

Saponaria, 267 rhizome, 726

Saponin, 299, 324, 331, $335,54 \mathrm{I}$

Sapotaceæ, 358

Sapotilla, 359

Saprolegnia, I8, 19

Saprophytes, I7

Sapucaya-nut, 345

Sarcocarp, I47

Sarcocollin, 652

Sarcolla, 652

Sarcophyte, 259

Sargassum, I3, I6

Sarracenia, I I9, 284

Sarraceniales, 284

Sarracenine, 284

Sarsaparilla, 446 American, $450,752,761$
Sarsaparilla, powder, 761 substitute, 450

varieties, 446

Virginia, 450

wild, 450

Sarsosaponin, 450

Sassafras, 539

bark, 195

leaves, II I

medulla, 547

officinale, 277

powder, 767

variifolium, 277

Sassafrid, 539

Satureja, 371

Saunders, red, 547

Savin, 682 powder; 73I

Savory, summer, 37I

Saw palmetto, 231,578

Saxifragaceæ, 285

Saxifrage family, 285 golden, 286

Scabiosa, 386

Scalariform ducts, I9o

Scales, 225

Scammonia Resina, 658

Scammonin, 657

Scammonium, 657,750

Scammonol, 657

Scammony, adulterants, 657 Montpellier, 657 varieties, 656

Schinopsis, 322

Schinus, 645

Schizandra, 275, 276

Schizogenous, 178

Schleichera, 324

Schoenocaulon, 495

Schulze's cellulose reagent, 802 macerating solution, 803

Scilla, 5Io powder, 741

Scillain, 5II

Scillin, 5II

Scillipicrin, 5II

Scillitoxin, 5I I

Scirpus, 23I

Scitaminales, 242

Scitaminex, 242

Scleranthus, 267
Sclereids (see Stone cells), 187

Sclerenchyma, I86 fibers, I 87

Sclererythrin, 692

Sclerotium, 29

Scoparin, 637

Scoparius, 637 powder, 73I

Scopola, 509

Scopolamine, 509

Scopolia carniolica, 372 species; 509, 619

Scrophularia, 376

Scrophulariaceæ, 376

Scurvy-grass, 283

Scutcllaria, 638 canescens, powder, 730

lateriflora, 368

powder, 729

species, 639

Scutellarin, 639

Scytonema, 39

Sea bean, 299

Secale, 227

Secaline, 692

Secalintoxin, 692

Secretion canals, I97 cells, 197

Sections, making, 799

Sedge family, 230

Sedum, 285

Seed, I5I

coat, 90, I52, 217

colchicum, 426

colza, 429

cucumber, 430

development, 90

digitalis, 6ı6

dispersal, I55

edible pine, 8I

germination, 405

lagenaria, 430

maw-, 280

muskmellon, 430

plants, 70, 7I

pumpkin, 42y

rape, 429

sabadilla, 495

stramonium, 624

structure, I5I

turnip, 429

watermelon, 430

Seeds, drug, 425

Selaginella, 56, 65-69

Selection, 405 
Selenipedium, 587

Semecarpus, 319, 646

Sempervivum, 285

Senega, 456

adulterants, 458

allied plants, 457

powder, 748

root, 456

Senegin, 456

Senna, 607

Aden, 6ro

American, 6Io

Arabian, 6ro

Mecca, 6ro

-nigrin, 609

pods, 6ro

powder, 721

-rhamnetin, 609

Sepals, I29

Sequoia, 78

Serenoa serrulata, 23I

Sericeous, 210

Serjania, 324

Serpentaria, 501 powder, 739

Serrate, I I4

Sesamum, 377

Sessile, тоб

Seven barks, 286

Sex cells, 45

Shaddock, 307

Shellac, 257, 324

Shepherd's purse, 88,284

Shoot, 92

assimilation, 92

hypogeous, IO4

kinds, IOI

Shorea, 338

Shrubs, 409

Siabenzoresin, 673

Siaresinotannol, 673

Sida, 45I species, 33I

Sideroxylon, 359

Siejas, 259

Sieve, I9I

plate, I9I tubes, I9I

Sigillaria, 69

Silica, I3, I72

in diatoms, I4

in Equisetales, 64

Silique, I 50

Silkworm, 257

Silphium, 400

Simaba, 3 IO
Simaruba, 310,546

Simarubaceæ, 309

Sinalbin, 428

Sinapine, 428

Sinapis alba, $283,428,742$ adulterants, 428 powder, 74I

nigra; $42 y$ allied products, 429 powder, 743 root-hairs, 92 species, 429

Sindor balsam; 337

Sinistrin, .5I I

Sinutate, II4

Sinus, I I 4

Sisymbrium, 283

Skullcap, 638, 639

Skunk cabbage, 234

Sleep movements, II7

Sloanea, 328

Sloe leaves, powder, 719

Smilax species, 238

Smut, corn, 35

Smuts, 36

Snake poison, antidote, 274,349

Snakeroot, black, 497

button-, 400

Canada, 260

Red River, 50I

Texas, 50I

Virginia, 5or

Sneeze-weed, 401

Snow crystals, I7I

Snow-ball, 382, 383

Snowberry, 385

Soap bark, powder, 782

Soapberry family, 324

Sodium chloride in ash, $276,285,338$

Soil-bacterium, 99

Solanaceæ, 372

Solanine, 373, 375

Solanum anther, I27 carolinense, 374 powder, 726

Dulcamara, 373

species, 376

tuberostum, 375

Solenostemma, $72 \mathrm{I}$

Solidago species, 399

Sorbitol, 288

Sorbus, 287
Soredia, 40

Sorghum, 227

Sori, 59

Sorosis, I5o

Sorrel, field, 264 sheep, 264

Spanish needles, 155 saffron, 241, 746

Sparteine, 637

Spartitum, 637

Spathifloræ, 233

Spathyema, 234

Spawn, 3I

Spearmint, 632 stolons, I03

Species, 244

Sperm, 7

Spermolepis, 656

Spermophytes, 70

Sperms in Bryophytes, 48

in Gymnosperms, I77

in Lycopodiales, 68

Sphacelotoxin, 692

Sphaerobacteria, 44

Sphagnum, 49, 55

Sphere-crystalloids, I67

Spice bush, 279

Spices, adulterants, 756

Spiderworts, 235

Spigelia, 503

adulterant, 504

marilandica, 362

powder, 763

Spigeline, 504

Spike, I38

Spikelets, 225

Spikenard, American, 450

Spilanthes, 401

Spilanthin, 40I

Spinach, 265

fruit, 218

Spinose, 210

Spiny clotbur, 40I

Spirza, 290, 587

Spiral ducts, Igo

Spirogyra, 9, ro

Spleenwort, 6I, 62

Spondias, I24

Sporangia in Angiosperms, 84

mega-, 56

micro-, 56

Sporangium, 6

Spore balls, 35 
Spores, asexual, 6, 45 fern, 59, 63 mega-, 56 micro-, 56 moss, 49 resting, II sexual, 6 summer, 38 swarm, 7 winter, 38

Sporidia, 35

Sporogonium, 48

Sporophyll, 59

Sporophyte, 45

Spring beauty, 267

Springs, sulphur, 44

Spruce, 75

black, 79

gum, 8I

hemlock, 8I

Norway, 81

Spurge, caper, 315

family, 3I4

laurel, 343

Squill, 5 IO powder, 74I

Staff-tree family, 323

Staining agents, 800 double, 804

Stamen, I26

Stamens, I22

Staminate, I 36

Staminodes, I35

Staminodia, I35

Staphisagria, 270, 427 powder, 73I

Staphisagroine, 428

Star-anise, 149 powder, 783

Starch, I6r, 642 acorn, 767 arrowroot, 785

barley, $79 \mathrm{I}$

bean, 789

cacao, 767

canna, 789

cassava, 789

commercial, I64, 785

composition, 162

corn, 643,787

drugs with, 698

drugs without, 699

maranta, 785

paste, I65

pea, 789

polarization of, 165 potato, 787
Starch, properties, 165 reserve, I62

rice, 788

sago, 789

soluble, I64

structure, 162

sweet-potato, 789

wheat, 643,788

yam, 789

Stavesacre, 427 powder, 73I

Stegmatic cells, 756

Stellera, 537

Stem branches, Ioo monocotyledonous, 206 structure, 205

Stems, size and form, 104

Stephania, 462

Sterculia, 333, 652

Sterculiacea, 332

Stereocaulon, 691

Stereome, 186

Sterile reagents, 80 I

Stichwort, 268

Sticta, 4I

Stigma, I23

forms, I25 structure, 214

Stillingia, 462 powder, 752 sylvatica, 314

Stilophora, I6

Stimuli, chemical, 4

Stink-wood, 280

Stipa, 230

Stipe, 3I

Stipules, 106 modified, I2I

St. John's-wort family, 337

Stoma, I93

Stomata, I93

Stone cells, 187 cork, $\cdot$ IO 4

Stonecrop, ditch, 285 mossy, 285 Virginia, 285

Storax, 679 American, family, 359

Storesin, 680

Storesinol, 680

Stramonii folia, 622 powder, 7I7

Stramonii semen, 624 powder, 777
Stramonium, 622

leaves, 622 powder, 7I7

purple, 624

seed, 2 I9

Strawberries, 53I

Strawberry, 292

leaves, powder, 7ig

Strigose, 2I0

Strobile, I50

Strophanthidin, 43I

Strophanthin, 4.3I

Strophanthus, 430 powder, 763 species, 363

Strophiole, 155

Structure, plant, 2 primary, 198 secondary, 199, 200

Struthiola, 537

Strychnine, 437

Strychnos Ignatii, 437

Nux-vomica, 362 species, 362

Style, I23

forms, I25

structure, 214

Stylophorine, 28I

Stylophorum, 282

Stylosanthes, 4I3

Styracex, 359

Styracin, 673, 680

Styrax, 679

Benzoin, 360

Styrene, 680

Styrocamphene, 680

Styrol, 680

Styrone, 680

Sub-classes, 224

Succisa, 386

Succulent, II2

Sucrose, I68

Sugar, 578,585

apple, 277

beet, 265

bush, $25^{8}$

boxes, 313

cane, 227

cane-, I68

corns, 230

fruit-, 288

grape, 590

sorghum, ground, 790

Sugars, I67

Sulphur, 4

lotum, 750

pracipitatum, 750 
Sumac berries, 569

family, 3I9

galls on, 569

leaves, 569

poison, 319

scarlet, $32 \mathrm{I}$

tanner's, 3 I8

Sumbul, 462

oil of, 554

powder, 765

Sundew family, 284

Sundew plants, 285

Sunflower, 40I

Suppressed, I35

Suringi, India, 336

Suspensor, 78, 88, 90

Suture, dorsal, I24 ventral, I24

Sweertia Chirata, 362

Sweet birch, 252

orange peel, 59I powder, $74 \mathrm{I}$

potato, 366

sap, 252

scabious, 393

William, 267

Swietenia, 667

Syconium, I50

Sylvacrol, 462

Symmetrical, 136

Symphonia, 336

Symphoricarpos, 385

Symphytum, 367

Synantherin, I67, 402

Syncarpous, 123

Synergids, 86

Syngenesious, 129

Syphon, I2

Syringa, 36I

Syringin, $36 \mathrm{I}$

Syringopicrin, $36 \mathrm{I}$

Syzygium, 656

Tabacum, 375 adulterants, 725 powder, 725

Tacamahac balsams, 335 poplar, 250

resins, 3I0, 3I I

Tagetes flower, 556

Talauma, 275,276

Talcum, 796

Tallow tree, 436

Tamaricaceæe, 3.38

Tamarind, 593, 594

Tamarindus, 593 indica, 294
Tamarix, 338

Tamonea, 349

Tamus, 240,388

Tanacetum, 397

powder, 730

Tangkawang, 338

Tannin, 174,646

Tannin-containing plants, I74, 232,

$250,25 \mathrm{I}, 252,264$,

$286,291,323,334$,

$339,344,345,346$,

$348,349,355,359$,

$455,476,5 \mathrm{I} 6,5 \mathrm{I} 9$,

$53 \mathrm{I}, 536,537,542$,

$549,557,569,575$, $646,655,666$

Tannoids, I74

Tansy, 397 powder, 730

Tapetal cells, 84

Tapetum, 84

Tapioca, 318,789

Tar, 677

beech-wood, 678

birch, 679

composition, 678

juniper, 678

Norway spruce, 670

Taraxacerin, 459

Taraxacin, 458

Taraxácum, 185,458

flower, 555

officinale, 392

powder, 779

Tea, 334

adulterants, 7I7

Appalachian, 323

black, 334

Brazilian, 322

Cassine, 323

-chests, 34I

family, 334

green, 334

Labrador, 602

marsh, 602

New Jersẹy, 326

Paraguay, 322

powder, 7I7

powder, 7I 7

substitutes, 33I

Teak tree, 368 wood, 368

Teasel family, 385

Fuller's, 386

Tectona. 368

Tegmen, I52
Telegraph plant, II7

Teleutospores, 36

Temperature, 4

Tentacles, I 18

Tephrosia, 299, 6ro

Terebinthina, 675 Canadensis, $68 \mathrm{I}$

Terminalia, 667 species, $34^{8}$

Terra alba, 797

Testa, I52

Tetradynamous, I29

Tetrameles, 34I

Tetrapanax, 350

Tetrarin, 476

Thalictrum, 501

Thalleioquin, 5 I9

Thallophytes, 8 drug, 684

Thallus, 8

Than, 667

Thea species, 334, 335

Theaceæ, 334

Thebaine, 660

Theca, I27 in diatoms, 14

Theine, 435

Thelesia, 4I 3

Theobroma Cacao, 332

Theobromine, 436

methyl, 435

Theophylline, 335

Thistle, 400

Thlaspi, 283

Thorns, I03

Thuja, 683

Thujin, 684

Thujone, 684

Thyme, garden, 370

Thymelæa, 343, 537

Thymelæaceæ, 343

Thymol, 354, $37 \mathrm{I}$

Thymoquinone, $37 \mathrm{I}$

Thymus vulgaris, 370

Tiarella, 286

Tibouchina, 349

Tilia, 328, 329

Tiliaceæ, 328

Tillandsia, 235

Timber-yielding plants, $233,250,25 \mathrm{I}, 252$, $254,258,274,277$. 287 , 3ก I, 3I 3, 3I9, $323,324,334,359$

Tincture of krameria, 455

Tinea, 420 
Tinospora, 460

Tissue, laticiferous, I95

Tobacco, $37 j$ adulterants, 725 Australian, 620 camphor, 375 curing, 375 Indian, 388 powder, 725 wild, 388

Tococa, 349

Toddalia, 50I, 57 I

Toddy, 337

Tolu balsam, 298

Toluifera, 587 Balsamum, 297 Pereiræ, 298

Tolu-resinotannol, 298

Tolyposporium, 36

Tomato, 376

Tomentose, 210

Tonka, 589 powder, 763

Tooth powder, I6

Tormentilla, 292

Torus, 122 forms, 132

Tous les mois,

$$
244,789
$$

Toxicodendrol, 3 I9, 328

Toxins, 44

Tracheæ, I86, I90 forms, I90

Tracheids, I87, I9I

Trachylobium, 299

Tradescantia, 185,235

Tragacanth, 310,650 powder, 793

Tragacanth-like gums,

Tragacantha, 650 powder, 793

Traganthin, 652

Tragapogon, 552

Transpiration, I09

Trapa, 350

Trapaceæ, 350

Tree of relationship, 89

Trees, deciduous, 408 evergreen, 408

Trehalose, I68

Triassic period, 72

Trichomes, I92

Trifolium, 30I

Trigonella Fœnumgræctum, 744
Trigonelline, 744

Trilisa, 590

Trimethylamine, $5^{8} 3$

Irimorphic, I42

Triosteum, 384,385 powder, 736

Triticin, 492

Triticum, 227, 490 powder, 779

Tropæolaceæ, 302

Tropæolum, 302

Tropic, II7

Truffles, 34

Trumpet creeper, 377 family, 377

Truncate, II2

Truxilline, 605, 607

Trypeta, 420, 55 I

Tsuga, 8I

Tube of corolla, I 30

Tuberaceæ, 34

Tubercles, 97

Tubers, 105

Tubular flowers, 39I

Tubulifloræ, 365, 39I

Tuckahoe, 34

Tulepo, 259

Tulip tree, 274

Turgescent, 194

Turmeric, 244 powder, 734

Turmerol, 244

Turnera, 340

Turneraceæ, 340

Turnip, 283 Indian, 234

Turpentine, 675

Bordeaux, 694

Canada, 8I, 68I

Chios, 646

Strasburg, 8I, 68I

varieties, 667

Venice, 8I, 682

Turpeth root, 453

Turpethin, 453

Turtle-head, 376

Tussilago, 400

flower, 555

Twiners, I03

Twining plants, 409

Ulex, 300

Ulmaceæ, 254

U1mus, 544

fulva, 254

mucilage, 176

powder, 760
Ulmus species, 254 , 544

substitute, 333

Ulothrix zonata, 6

Umbel, I38 compound, 138

Umbellales, 350

Umbelliferæ, 352

Umbellifloræ, 350

Umbrella tree, 275

Unguis, I 30

Uninucleate, I2

Unisexual, I36

Unona, 277

stamen, I27

Upas-tree, I24, 256

Uragoga Ipecacuanha, 379

Urari poison, 256

Urceola, 668

Urceolate, I3I

Uredineæ, 34

Uredospores, 38

Urena, 33I

Urginea Scilla, 238

Ursone, 6oI

Urtica, 257, 258

Urticaceæ, 257

Urticales, 254

Usnea, 40, 690

Ustilagineæ, 34

Ustilago, 692, 779

Maydis, 35

species, 36

Utricle, I50

Uva Ursi, 6or powder, 724

$\nabla$ accinium, 6or species, 357

Valerian, 504 adulterants, 505 family, $3^{8} 5$ garden, 385 oil, 554 powder, 765 substitutes, 505 varieties, 505 wild, 385

Valeriana, 504 officinalis, 385 species, 504, 505

Valerianaceæ, 385

Valerianella, 385

Valerianine, 505

Vallea, 328

Valvate, I32 
Valres of diatoms, I4

Vanilla, 585

Bourbon, 587

Carolina, 590

grass, 230

Iauritius, 588

Mexican, 587

planifolia, 245

pompona, 589

powder, 774

Tahiti, 588

Vanillin, $587,672,673,680$ plants yielding, 587

Vanillons, 589

Varicose, 2I0

Varnish tree, 319

Vascular system in Pteridophytes, 56

Vasicin, 378

Vateria, 338

Vatica, 338

Vaucheria, I I, I6

Vegetables, garden, 265 , $3.31,354,366,375$, 388

Vegetation, point of,197

Vegetative multiplication, 5

Venter in ferns, 58

Venus's flytrap, 285

Venus-hair fern, 58

Veratalbine, 495

Veratramarin, 494

Veratridine, 495

Veratrine, 495

Veratroidine, 495

Veratrum, 492 album, 236, 737 powder, 736 species, 495 viride, 235,737

Verbascum, 376,635 Phlomoides, powder, 727

Verbena species, 368

Verbenaceæ, 368

Vernation, 12I

Veronica, 376

Versatile, I27

Verticillaster, I.38

Vervain, 368

Vetiver, 230

Viburnin, 527

Viburnum, 774

opulus, 532

powder, 775
Viburnum prunifolium, 525 powder, 774 species, 382,383

Victoria, 268

Villosin, 53I

Vinca, 364

Viola odorata, 472 species, 339 tricolor, 2I2

Violacere, 339

Violet, English, 339 family, 339 leaf development, I07 sweet, 339

Viscin, 259, 285

Viscum, 259

Vismia, 335, 336, 649

Vitaceæ, 327

Vitellaria, $35^{8}$

Vitis, 590 species, 327,328

Viviania, 6ro

Volva, 3I

Voulacapoua Araroba, 780

Wahoo, 323

Wa-i-mas, 495

Wall, cell, I8I

kinds, 182

markings, 183 thickening, 183

Walnut, black, 25I English, 25I

shells, 756 white, 25I

Waltheria, 333

Wandering Jew, 235

Washingtonia, 354

Water ferns, 63 hamamelis, 527 hyacinth, I2I in plants, 407 lily stamens, I27 -pores, I93, I94 sulphur, 44

Waterleaf family, 367

Wattle barks, 667

Wax, Carnauba, 232

Weed, gulf, 13

Wheat, 227

bran, 790

flour, 790

middlings, 790

starch, 643,788
White mustard, ground, 742 powder, 74I oak, 253, 54I powder, 776

Whitish powders, key, 7r2

Whortleberries, 357

Wiesner's reagent, 800

Wild black cherry bark, 537 powder, 759 ginger, I 20

Willow herb, 349 leaves, powder, 719 leaves, powder, 7I9

Wine, blackberry, $53 \mathrm{I}$ wild cherry, 539

Wines, 327

Wings, 248

Winterana, 339

Winteranaceæ, 339

Wintergreen, 357

Winterin, 275

Winter's bark, 275 false, 339

Wistaria, 300 leaves, powder, 719

Wistarin, 300

Witchhazel bark, 527 family, 286 leaves, 6 ro

Wood, 203

bar-, 547

Brazil, 547

drugs, 5 I 3 false sandal, 547

fibers, 188

heart-, 512

oil, 337

quassia, 544

red, 303,547

sandal, 547

sap-. 5T2

Sappam, 547

Woodfordia species, 344

Wood-sorrel, 30I family, 30I

Wormseed, 264

Levant, 550

Spanish, 264

Wormwood, 390

Wormy drugs, 420

Xanthaline, 660

Xanthine, dimethyl, 436 trimethyl, 435 
Xanthium species, $40 \mathrm{I}$

Xanthor rhiza, 483 . 5or

Xanthosoma, 234

Xanthostrumarin, $40 \mathrm{I}$

Xanthoxylin, 534

Xanthoxylum, 532 powder, 776

species, 304, 305, 308

$X y l e m, 201$

Xylopia, 276, 277, 574

Xylose, 486

Xyridales, 235

Yam family, 240 root, 240

Yams, 240
Yarrow, 399

oil of, 554

Yeasts, 23

wild, 24

Yellowish powders, key, 704

Yellow-root, 483, 50I

Yerba buena, 413

Santa, 367, 612

Ylang-ylang, 277

Zea, 227, 558

Mays, 92, 228

powder, 785

species, 229, 230, 23 I

Ziel's carbol-fuchsin, $80 I$
Zeora, 42

Zingiber, 486

adulterants, 737

officinale, 242

powder, 737

adulterants, 737

Zingiberaceæ, $24^{2}$

Zizyphus species, 327

Zoöglœa, 42

Zoöspores, 7

Zygadenus, 495

Zygomorphic, I37

Zygomycetes, I8

Zygophyllacex, 303

Zygospore, 7

Zygote, 7

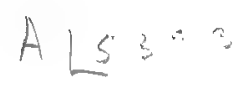







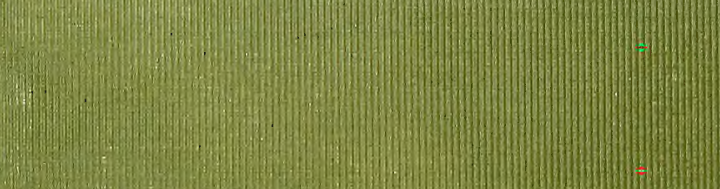

ting

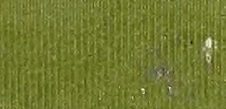

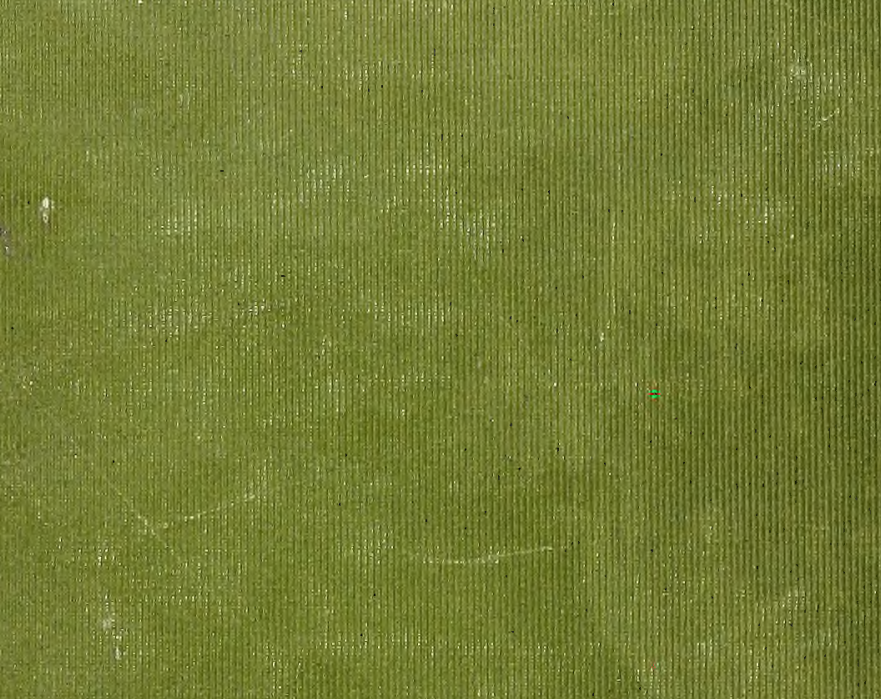

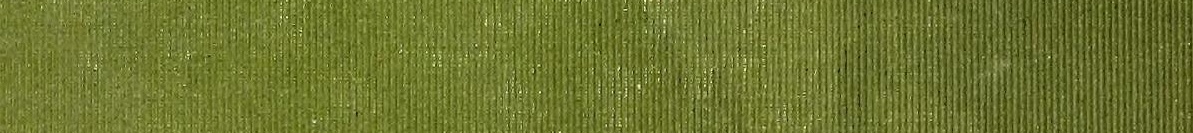
(1) 